NUREG/CR-6143

SAND93-2440

Vol. 2, Part 2

\title{
Evaluation of Potential Severe
} Accidents During Low Power and Shutdown Operations at Grand Gulf, Unit 1

\section{Analysis of Core Damage Frequency from Internal Events for Plant Operational State 5 During a Refueling Outage}

Internal Events Appendices $\mathrm{A}$ to $\mathrm{H}$

Manuscript Completed: April 1994

Date Published: June 1994

Prepared by

J. Darby*, D. Whitehead, B. Staple, V. Dandini

Sandia National Laboratories

Albuquerque, NM 87185

Prepared for

Division of Safety Issue Resolution

Office of Nuclear Regulatory Research

U.S. Nuclear Regulatory Commission

Washington, DC 20555-0001

NRC FIN L1923

*Science and Engincering Associates, Inc., 6100 Uptown Blvd. N.E.. Albuquerque, NM 87110 


\section{DISCLAIMER}

This report was prepared as an account of work sponsored by an agency of the United States Government. Neither the United States Government nor any agency thereof, nor any of their employees, make any warranty, express or implied, or assumes any legal liability or responsibility for the accuracy, completeness, or usefulness of any information, apparatus, product, or process disclosed, or represents that its use would not infringe privately owned rights. Reference herein to any specific commercial product, process, or service by trade name, trademark, manufacturer, or otherwise does not necessarily constitute or imply its endorsement, recommendation, or favoring by the United States Government or any agency thereof. The views and opinions of authors expressed herein do not necessarily state or reflect those of the United States Government or any agency thereof. 


\section{DISCLAIMER}

Portions of this document may be illegible in electronic image products. Images are produced from the best available original document. 


\begin{abstract}
This report provides supporting documentation for various tasks associated with the performance of the probabilistic risk assessment for Plant Operational State 5 (approximately Cold Shutdown as defined by Grand Gulf Technical Specifications) during a refueling outage at Grand Gulf, Unit 1 as documented in Volume 2, Part 1 of NUREG/CR-6143. The report contains the following appendices:

A - Definition and Characterization of Plant Operational States (POSs) and POS Change Initiators

B - Summary of the Detailed Review of Selected Grand Gulf Procedures

C - Overview of Grand Gulf Power Plant

D - Initiating Event Analysis from Screening Report

E - Updated Success Criteria

F - Supporting Calculations

G - Calculation of the Frequency and Recovery of LOSP Plus Recovery of LOSP/DG Failures

$\mathrm{H}$ - Event Trees
\end{abstract}




\section{Contents}

Acronyms . . . . . . . . . . . . . . . . . . . . . . . . . . . . . . . xv

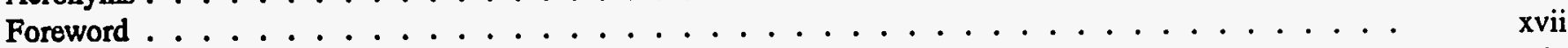

Acknowledgements ... . . . . . . . . . . . . . . . . . . . . . . . . . . . . xix

Appendix A. Definition and Characterization of Plant Operational States (POSs) and POS Change Initiators . A-1

A.1 Introduction . . . . . . . . . . . . . . . . . . . . . . . . . A-1

A.2 Definition and Characterization of POSs . . . . . . . . . . . . . . . . . . A-1

A.3 Definition and Characterization of POS Change Initiators . . . . . . . . . . . . . A-9

References for Appendix A . . . . . . . . . . . . . . . . . . . . . . . . . . A-13

Appendix B Summary of the Detailed Review of Selected Grand Gulf Procedures . . . . . . . . . . . . B-1

B.1 Power Operations - \#03-1-01-2 . . . . . . . . . . . . . . . . . . . . . B-1

B.1.1 Low Power to Full Power Increase . . . . . . . . . . . . . . . . . . . . . . . B-1

B.1.2 Full Power to Low Power Decrease . . . . . . . . . . . . . . . . . . . . B-1

B.1.3 Rapid Power Reduction . . . . . . . . . . . . . . . . . . . . . B-2

B.2 Plant Shutdown - \$03-1-01-3 . . . . . . . . . . . . . . . . . . . B-2

B.2.1 Cooldown with the MSIVs Open . . . . . . . . . . . . . . . . . . B B

B.2.2 Cooldown with the MSIVs Closed . . . . . . . . . . . . . . . . . B-2

B.3 Refueling - \$03-1-01-5 ........................... B-2

B.3.1 Plant Cooldown and Entry into OC 5 . . . . . . . . . . . . . . . . . . B-3

B.3.2 Reactor Pressure Vessel Reassembly and Entry into OC 4 . . . . . . . . . . . . . B-3

B.4 Cold Shutdown to Generator Carrying Minimum Load - \$03-1-01-1 . . . . . . . . . . . . . B-3

B.4.1 Reactor Startup . . . . . . . . . . . . . . . . . . . . . B-3

B.4.2 Unit Heatup . . . . . . . . . . . . . . . . . . . . . . B-4

B.4.3 Turbine Startup and Generator Synchronization . . . . . . . . . . . . . . B-4

B.5 Inadequate Decay Heat Removal - \#05-1-02-III-1 . . . . . . . . . . . . . . . B-5

B.5.1 Fuel in the Vessel and the Unit in OC 4 . . . . . . . . . . . . . . . . . . . B-5

B.5.2 Fuel in the Vessel and the RPV Head is Off . . . . . . . . . . . . . . . . B-5

Appendix C. Overview of Grand Gulf Power Plant . . . . . . . . . . . . . . . . . . . . . . . C-1

References for Appendix C . . . . . . . . . . . . . . . . . . . . . . . . . . C-6

Appendix D. Initiating Event Analysis from Screening Report . . . . . . . . . . . . . . . . . . . D-1

D.1 Approach and Summary . . . . . . . . . . . . . . . . . . . . . . . D-1

D.2 Transient Initiating Events . . . . . . . . . . . . . . . . . . . . . D-1

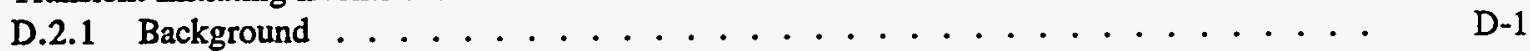

D.2.2 Introduction . . . . . . . . . . . . . . . . . . . . . . D-1

D.3 LOCA Initiating Events . . . . . . . . . . . . . . . . . . . . . D-6

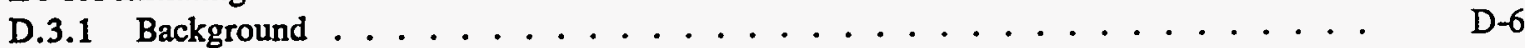

D.3.2 Introduction . . . . . . . . . . . . . . . . . . . . . . D -6

D.3.3 LOCA Events from NUREG 4550 . . . . . . . . . . . . . . . . . . . . D-6

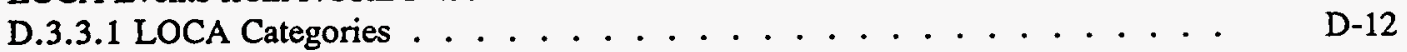

D.3.3.2 Interfacing System LOCA . . . . . . . . . . . . . . . . . . D-12

D.3.3.3 Vessel Rupture . . . . . . . . . . . . . . . . . . . . . . D-12

D.3.4 LOCA Events Unique to Low Power/Shutdown Operations . . . . . . . . . . . . D-12

D.3.4.1 Recoverable Diversion of Vessel Inventory (H) . . . . . . . . . . . . . D-12

D.3.4.1.1 Residual Heat Removal System . . . . . . . . . . . . D-13

D.3.4.1.2 Reactor Water Cleanup System . . . . . . . . . . . . D D-13

D.3.4.1.3 Reactor Core Isolation Cooling (RCIC) . . . . . . . . . . . D-13

D.3.4.1.4 High Pressure Core Spray (HPCS) . . . . . . . . . . . . D-13

D.3.4.1.5 Low Pressure Core Spray (LPCS) . . . . . . . . . . . . . D-13

D.3.4.2 LOCA in Operating Connected System . . . . . . . . . . . . . . . . D-13

D.3.4.3 Maintenance/Test-Induced LOCAs . . . . . . . . . . . . . . . . . D-14 


\section{Contents (Continued)}

D.4 Decay Heat Removal Challenge Initiators . . . . . . . . . . . . D-14

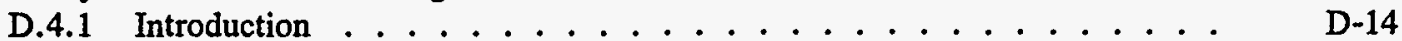

D.4.2 Identification and Estimation. . . . . . . . . . . . D-14

D.5 Special Events . . . . . . . . . . . . . . . . . D $\ldots$

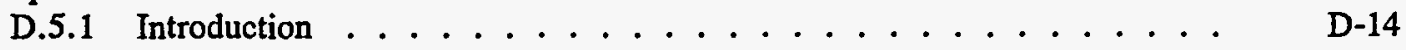

D.5.2 Criticality Events . . . . . . . . . . . . . . D-18

D.5.3 Support System Events . . . . . . . . . . . . . . . D-18

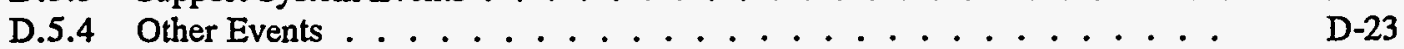

References for Appendix D . . . . . . . . . . . . . . . . . . . . D-24

Appendix E. Updated Success Criteria . . . . . . . . . . . . . . . . . E E-1

E.1 Summary Description of the Success Criteria for the Systems vs POSs: $\quad \ldots \ldots \ldots \ldots \ldots$. . . . . . . . . . . . . . . . . . . . .

E.2 Pressurization Concerns and Success Criteria at Rated Pressure . . . . . . . . . . E-7

E.3 Success Criteria . . . . . . . . . . . . . . . . . . E-8

References for Appendix E . . . . . . . . . . . . . . . . . . . . . E-27

Appendix F. Supporting Calculations . . . . . . . . . . . . . . . . . F-1

F.1 Calculation Files . . . . . . . . . . . . . . . . . . F F-1

F.2 Scoping Calculations ............................. F-1

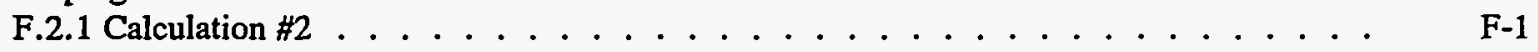

F.2.2 Calculation $\# 3 \ldots \ldots \ldots \ldots \ldots \ldots$ F-1 . . . . . . . . . . . . .

F.2.3 Calculation $\# 7 \ldots \ldots \ldots \ldots \ldots$ F-5

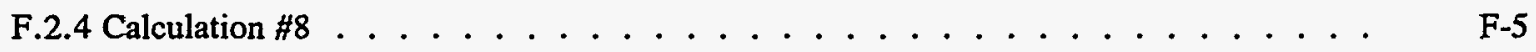

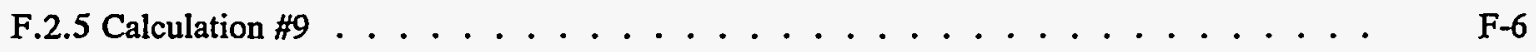

F.2.6 Calculation \#DRAFT . . . . . . . . . . . . F F

F.2.7 Calculation $\$ 22 \ldots \ldots \ldots \ldots$ F-6 . . . . . . . . . . . . . . .

F.3 Calculations for Multiple Initiators . . . . . . . . . . . . . . F F-6

F.4 Detailed Calculations . . . . . . . . . . . . . . . . . . . F F-21

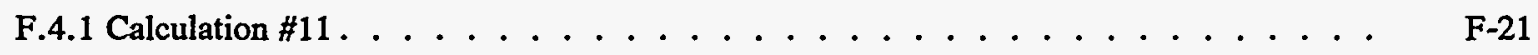

F.4.2 Calculation $\# 4.1 \ldots \ldots \ldots \ldots \ldots$ F-27

F.4.3 Calculation $\# 6 \ldots \ldots \ldots \ldots \ldots \ldots$ F-27

F.4.4 Calculation $\# 17 \ldots \ldots \ldots \ldots \ldots$ F-37

F.4.5 Calculation $\# 5 \ldots \ldots \ldots \ldots \ldots \ldots \ldots$ F-37

F.4.6 Calculation $\# 10 \ldots \ldots \ldots \ldots \ldots \ldots$ F-38

F.4.7 Calculation $\# 13 \ldots \ldots \ldots \ldots \ldots$ F-38

F.5 Operator Actions . . . . . . . . . . . . . . . . . . F F-38

References for Appendix F . . . . . . . . . . . . . . . . . . . . F F-42

Appendix G. Calculation of the Frequency and Recovery of LOSP Plus Recovery of LOSP/DG Failures . . . . G-1

G.1 Calculation of the Frequency of LOSP . . . . . . . . . . . . . . . G-1

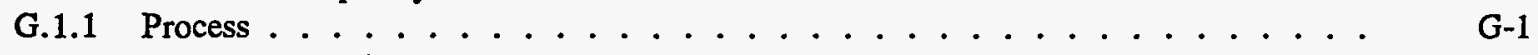

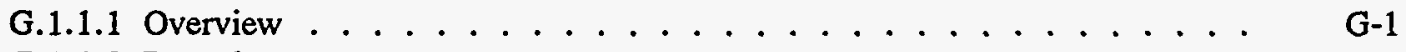

G.1.1.2 Procedure ................................ G-1

G.1.1.2.1 Phase 1.......................... G-1

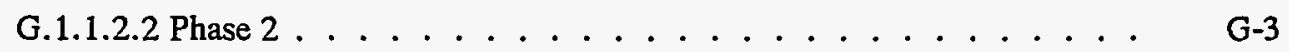

G.1.2 Results ................................. G-4

G.2 Determination of the Mean Probability of Recovery from LOSP at Different Times . . . . G-17

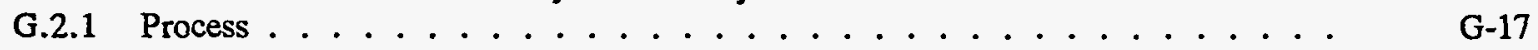

G.2.1.1 Overview ................................ G-17

G.2.1.2 Procedure ................................ G-17

G.2.2 Results ................................... G 


\section{Contents (Continued)}

G.3 Determination of Recovery Values for LOSP/DG-Failure Restorations: DG Fails to Start . . . . G-23

G.3.1 Process . . . . . . . . . . . . . . . . . .

G-23

G.3.1.1 Overview ................... G-23

G.3.1.2 Procedure .................... G-23

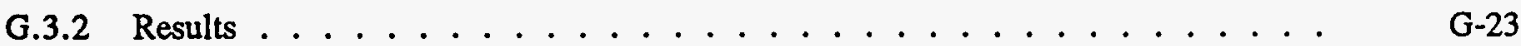

G.4 Determination of Recovery Values for LOSP/DG-Failure Restorations: DG Fails To Run . . . G-26

G.4.1 Process . . . . . . . . . . . . . . . . . . . . . G-26

G.4.1.1 Overview ............................... G-26

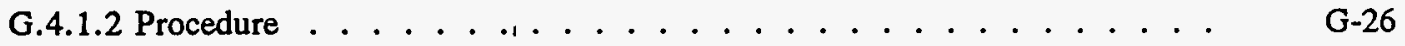

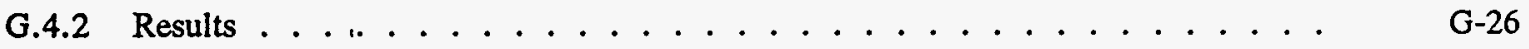

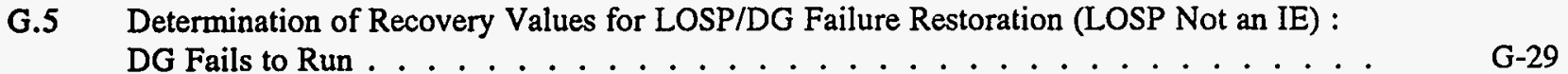

G.5.1 Overview . . . . . . . . . . . . . . . . . . . . . . . . . . . . . . . . . . .

G.5.2 Procedure . . . . . . . . . . . . . . . . . . . . . . . . . . . . . . . .

G.5.3 Results . . . . . . . . . . . . . . . . . . . . . . . . . . . . . . . . . . . .

G.6 Determination of Recovery Values for LOSP/DG Failure Restoration (LOSP not an IE):

DG Fails to Start . . . . . . . . . . . . . . . . . . . . G G-32

G.7 Recovery/Correction Factors for Uncertainty Analysis . . . . . . . . . . . . . . . G G-32

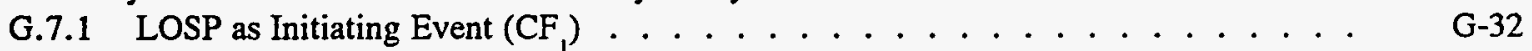

G.7.2 LOSP as Initiating Event: DG Fails to Run . . . . . . . . . . . . . . . . . G-32

G.7.3 LOSP as Initiating Event: DG Fails to Start . . . . . . . . . . . . . . . . . G-34

G.7.4 LOSP as Initiating Event: DG Fails to Start, Common Mode . . . . . . . . . . . G-34

G.8 IRRAS Histogram Development . . . . . . . . . . . . . . . . . . G G-36

References for Appendix G . . . . . . . . . . . . . . . . . . . . . . . . . . . . . . . . . . . . . . .

Attachments for Appendix $G$

Attachment G-1

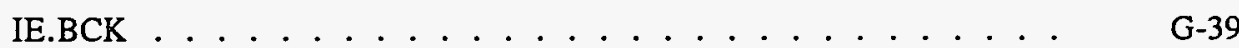

Attachment G-2

IE.BCK . . . . . . . . . . . . . . G G-42

Attachment G-3

Attachment G-4

Attachment G-5

Attachment G-6

Attachment G-7

Attachment G-7a

Attachment G-7b

LOSP IE PCGW.DAT . . . . . . . . . . . . . G G-45

LOSPIE IV.DAT. . . . . . . . . . . . . . . G-48

IE.DAT . . . . . . . . . . . . . . G-51

LOSP_IE_PCGW.INP ...................... G-57

IEBAT. COM . . . . . . . . . . . . . . . . G-59

IE.BAT.COM (SLOW BATCH MODE) . . . . . . . . . . G-61

Attachment G-8

Attachment G-9

IEBAT.COM LOG FILE . . . . . . . . . . . . . . . G-63

IE_PCGW.DAT (BEFORE UPDATE) . . . . . . . . . G-65

Attachment G-10

Attachment G-11

Attachment G-12

Attachment G-13

Attachment G-14

Attachment G-15

Attachment G-16

Attachment G-17

Attachment G-18

IE_PCGW.DAT (AFTER UPDATE) . . . . . . . . .

G-67

IE.DAT . . . . . . . . . . . . . . . . . . . . G-69

IEBAT.COM FOR CATEGORY IV . . . . . . . . . . G-73

LOSP_IE_IV.INP . . . . . . . . . . . . . G G-75

IE_IV.DAT. . . . . . . . . . . . . . . . G-77

IE_IV.DAT. . . . . . . . . . . . . . . . G G-79

IEBAT.LOG FOR CATEGORY IV . . . . . . . . . . . . G-81

IE IV.DAT. . . . . . . . . . . . . . . G-83

IE_IV.DAT. . . . . . . . . . . . . . . G G

LHS.COM . . . . . . . . . . . . . . . . G-87

Attachment G-19 LHS.INP. . . . . . . . . . . . . . . . . . . . . . . . . . . . . . . . . . G-89

Attachment G-20 USRDST.FOR (Subroutine) . . . . . . . . . . . . . . . . G-91

Attachment G-21 LHS.OUT . . . . . . . . . . . . . . . . . . . . . . . . . . . G-94

Attachment G-22 LHS.DAT . . . . . . . . . . . . . . . . . . . . . . . . . G- G9

Attachment G-23 REMOVECOL2.FOR . . . . . . . . . . . . . G G-110

Attachment G-24 LHSLOSP.INP . . . . . . . . . . . . . . . . . . . . . . . G G-112

Attachment G-25 LHSADDITION.FOR . . . . . . . . . . . . . . . . . G-120 


\section{Contents (Continued)}

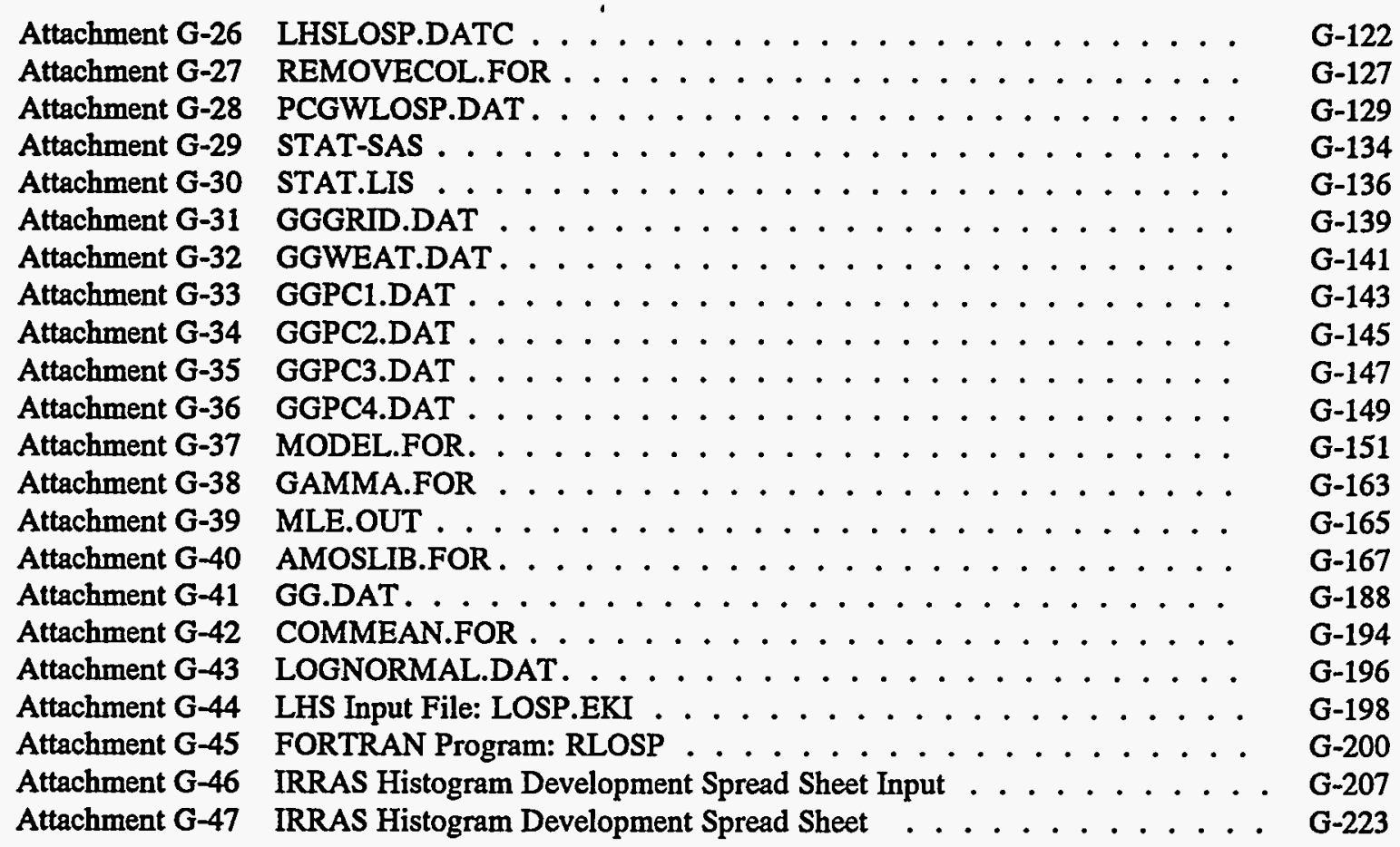

Appendix H. Event Trees ............................ H-1 


\section{List of Figures}

E.1-1 Functional Event Tree for Plant Operational States 4, 5, 6 and 7 . . . . . . . . . . . . . E-2

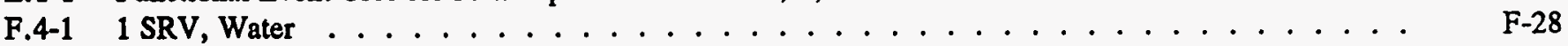

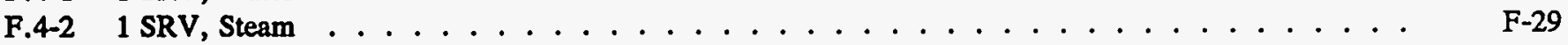

F.4-3 Vent Line, Water . . . . . . . . . . . . . . . . . . . . . . . . . . F-30

F.4-4 Vent Line, Steam . . . . . . . . . . . . . . . . . . . . . . . . . . F F-31

F.4-5 Steaming with Makeup . . . . . . . . . . . . . . . . . . . . F-32

F.4-6 Steaming with No Makeup . . . . . . . . . . . . . . . . . . . . F-33

F.4-7 Decay Heat. . . . . . . . . . . . . . . . . . . . . . . F-34

F.4-8 Pressure: Water Solid With 1 ECCS Pump . . . . . . . . . . . . . . . . . . F-35

F.4-9 Pressure: Water Solid With 2 ECCS Pump . . . . . . . . . . . . . . . . . . . . . . F-36

G.2-1 Probability of Recovery from LOSP vs. Time for the 5th, 50th, and 95 th Percentiles . . . . . . . G-20

G.2-2 Mean Probability of Recovery from LOSP vs. Time at Grand Gulf . . . . . . . . . . . . . . . . G-22

G.7-1 CF Distribution Calculation . . . . . . . . . . . . . . . . . . . . . . . G G-33

Attachment G-47-1 Example Plot of Cummulative Distribution Function . . . . . . . . . . . . . G-239

Attachment G-47-2 Example "Start Step" Plot of Cummulative Distribution Function . . . . . . . . . . G-240

H.1-1 A51SO Tree . . . . . . . . . . . . . . . . . . . . . . . . . . H-2

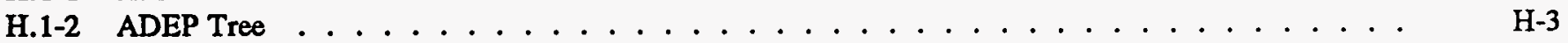

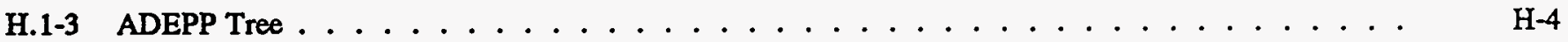

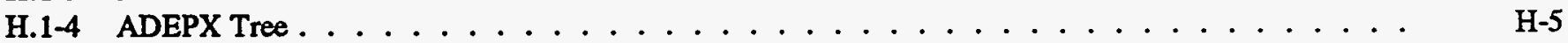

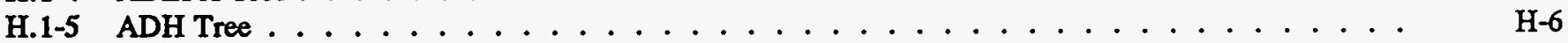

H.1-6 AIAD Tree. ......................... . . . . . . . . . . .

H.1-7 AIADP Tree ........................... . . . . . . . . . . . .

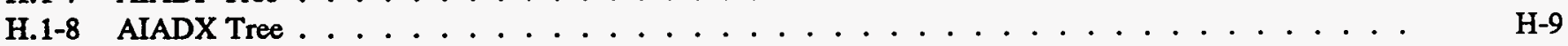

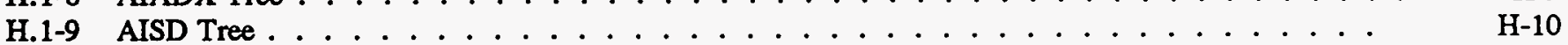

H.1-10 AISDP Tree . . . . . . . . . . . . . . . . . . . . . . H H

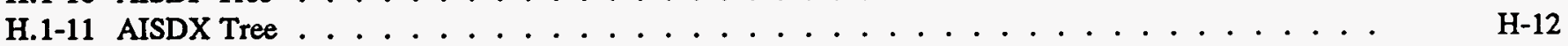

H.1-12 CAUX Tree . . . . . . . . . . . . . . . . . . . . . . . H H

H.1-13 CAUXN Tree. . . . . . . . . . . . . . . . . . . . . . . H-14

H.1-14 CAUXP Tree. . . . . . . . . . . . . . . . . . . . . . H-15

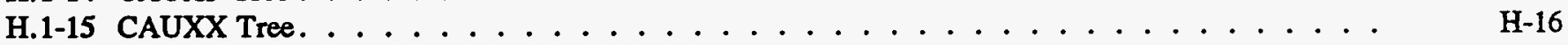

H.1-16 CB Tree ........................... . . . . . . . . . . . . . . .

H.1-17 CB1 Tree .......................... . . . . . . . . . . . . .

H.1-18 CB1P Tree . . . . . . . . . . . . . . . . . . . . . . . . H-19

H.1-19 CB1X Tree. ........................... H

H.1-20 CB2 Tree ............................ H H

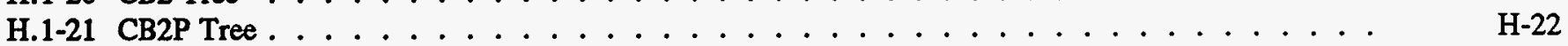

H.1-22 CB2X Tree. .......................... H H

H.1-23 CBN Tree ............................. H H

H.1-24 CBP Tree . . . . . . . . . . . . . . . . . . . . . . . . . . . . . . . . . . .

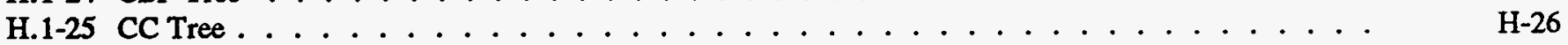

H.1-26 CC1 Tree . . . . . . . . . . . . . . . . . . . . . . . . H

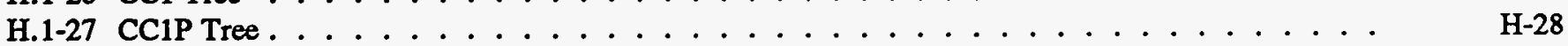

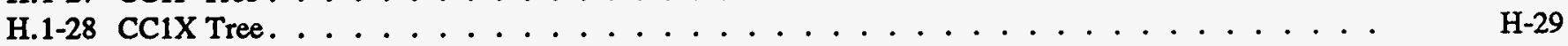

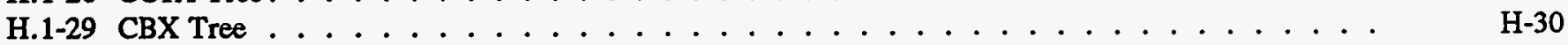

H.1-30 CSTMN Tree. . . . . . . . . . . . . . . . . . . . . . H

H.1-31 CSTMP Tree . . . . . . . . . . . . . . . . . . . . . H-32

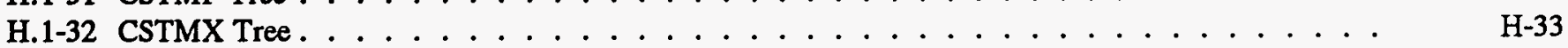

H.1-33 CC2 Tree ........................... . . . . . . . . . . . . . . . . . .

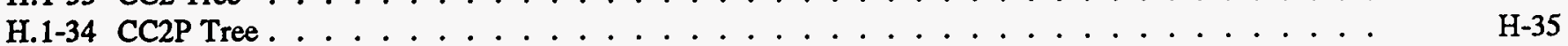

H.1-35 CC2X Tree. ......................... H-36

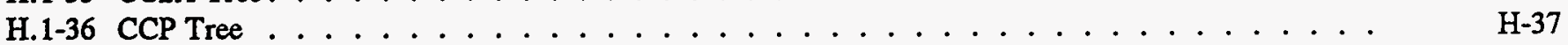

H.1-37 CCX Tree . . . . . . . . . . . . . . . . . . . . . H 


\section{List of Figures (Continued)}

H.1-38 CCN Tree . . . . . . . . . . . . . . . . . . . . . . . . . H H

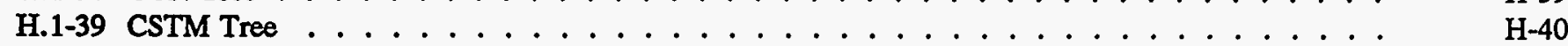

H.1-40 DEP Tree . . . . . . . . . . . . . . . . . . . . . . . . . . . . . H-41

H.1-41 E Tree. . . . . . . . . . . . . . . . . . . . . . . . . . . . . . . . . .

H.1-42 EA Tree ............................ . . . . . . . . . . . . . . .

H.1-43 EAP Tree ............................. . . . . . . . . . . . . . . . .

H.1-44 EAX Tree . . . . . . . . . . . . . . . . . . . . . . . H H

H.1-45 EC Tree . . . . . . . . . . . . . . . . . . . . . . . . H H

H.1-46 ECNP Tree. . . . . . . . . . . . . . . . . . . . . . . . . . H-47

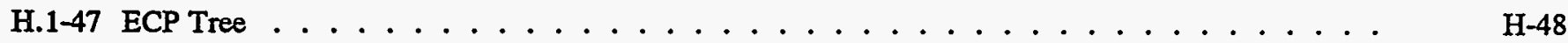

H.148 ECX Tree . . . . . . . . . . . . . . . . . . . . . . . . H H

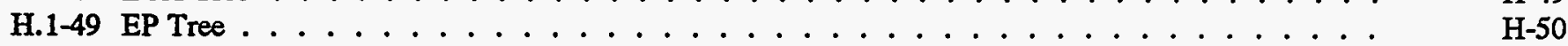

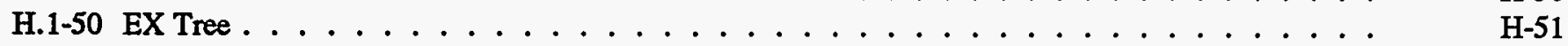

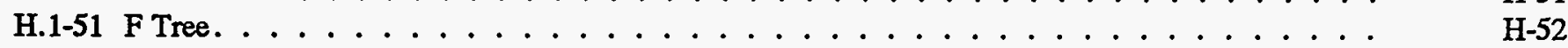

H.1-52 FC Tree . . . . . . . . . . . . . . . . . . . . . . . . H H

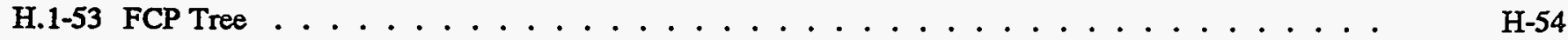

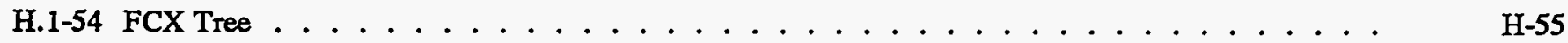

H.1-55 FNP Tree .......................... . . . . . . . . . . . . . .

H.1-56 FP Tree . . . . . . . . . . . . . . . . . . . . . . . . H H

H.1-57 FX Tree . . . . . . . . . . . . . . . . . . . . . . . . H

H.1-58 HPSWA Tree. . . . . . . . . . . . . . . . . . . . . . H

H.1-59 HPSWR Tree. . . . . . . . . . . . . . . . . . . . . . H

H.1-60 HYDRO Tree. . . . . . . . . . . . . . . . . . . . . . . . . . . . H-61

H.1-61 HPHA Tree . . . . . . . . . . . . . . . . . . . . . . . . H

H.1-62 IL Tree . . . . . . . . . . . . . . . . . . . . . . . . H

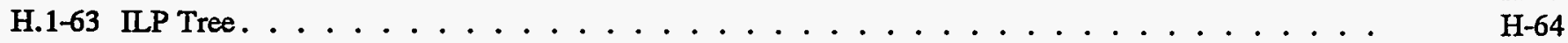

H.1-64 ILX Tree . . . . . . . . . . . . . . . . . . . . . . . H H

H.1-65 L Tree. . . . . . . . . . . . . . . . . . . . . . . . . H

H.1-66 LA Tree . . . . . . . . . . . . . . . . . . . . . . . . . . . . . . . . . . . . . . . .

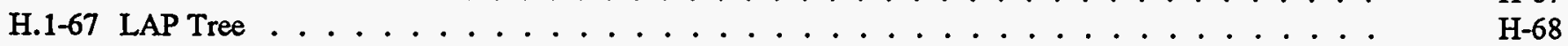

H.1-68 LAX Tree . . . . . . . . . . . . . . . . . . . . . . . . . H-69

H.1-69 LP Tree . . . . . . . . . . . . . . . . . . . . . . . . . . . H H

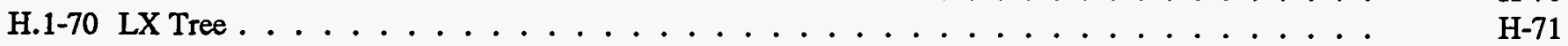

H.1-71 OF Tree ............................ H H

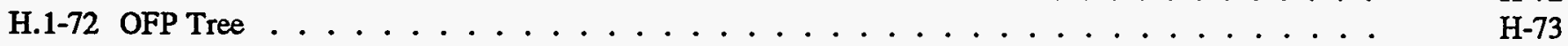

H.1-73 OFX Tree . . . . . . . . . . . . . . . . . . . . . . . H H

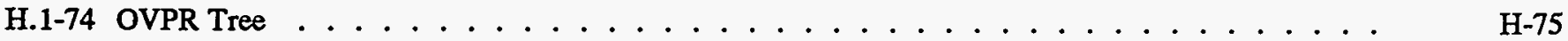

H.1-75 OVPRP Tree . . . . . . . . . . . . . . . . . . . . . . . . H-76

H.1-76 OVPRX Tree . . . . . . . . . . . . . . . . . . . . . . . H H

H.1-77 P Tree. . . . . . . . . . . . . . . . . . . . . . . H H

H.1-78 PISLP Tree. . . . . . . . . . . . . . . . . . . . . . H H

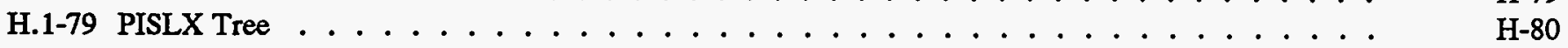

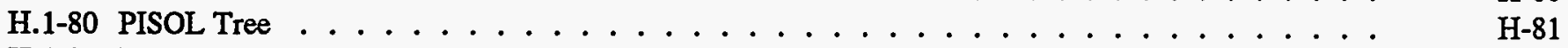

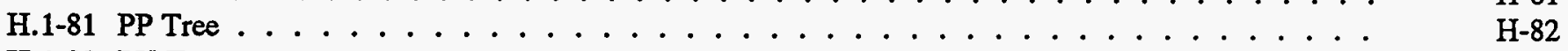

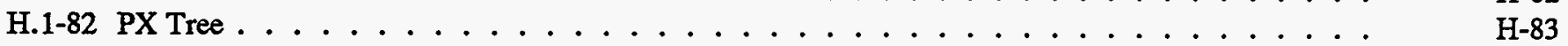

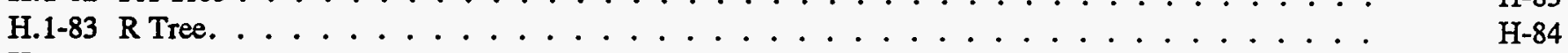

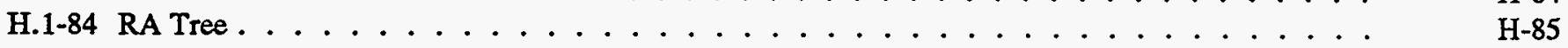

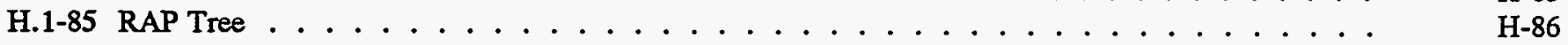

H.1-86 RAX Tree . . . . . . . . . . . . . . . . . . . . . . . . H H

H.1-87 RP Tree . . . . . . . . . . . . . . . . . . . . . . . . H H

H.1-88 RX Tree . . . . . . . . . . . . . . . . . . . . . . . . . . . H H

H.1-89 s Tree. . . . . . . . . . . . . . . . . . . . . . . . H H

$\begin{array}{lll}\text { NUREG/CR-6143 } & \mathrm{x} & \text { Vol. 2, Part } 2\end{array}$ 


\section{List of Figures (Continued)}

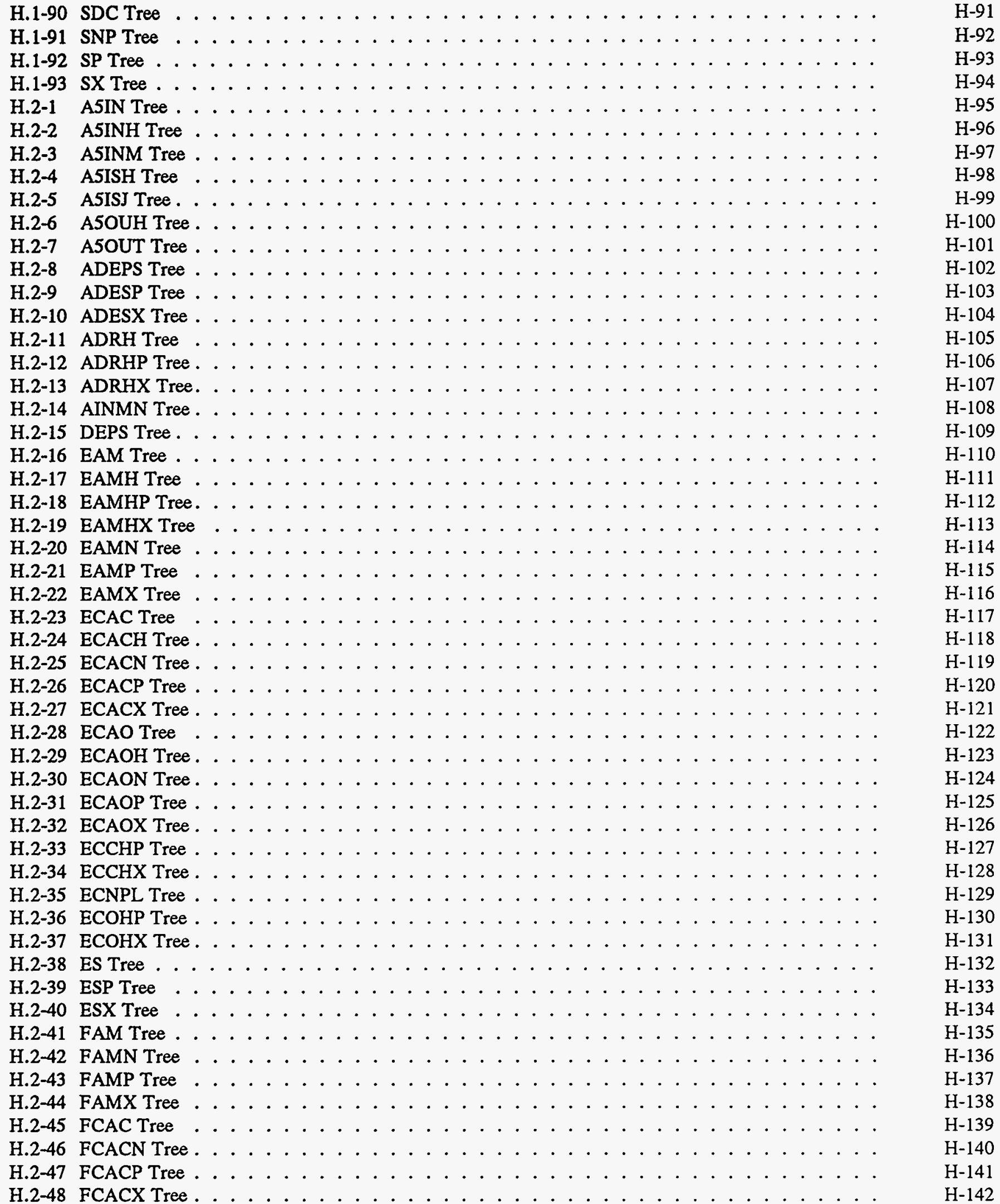




\section{List of Figures (Continued)}

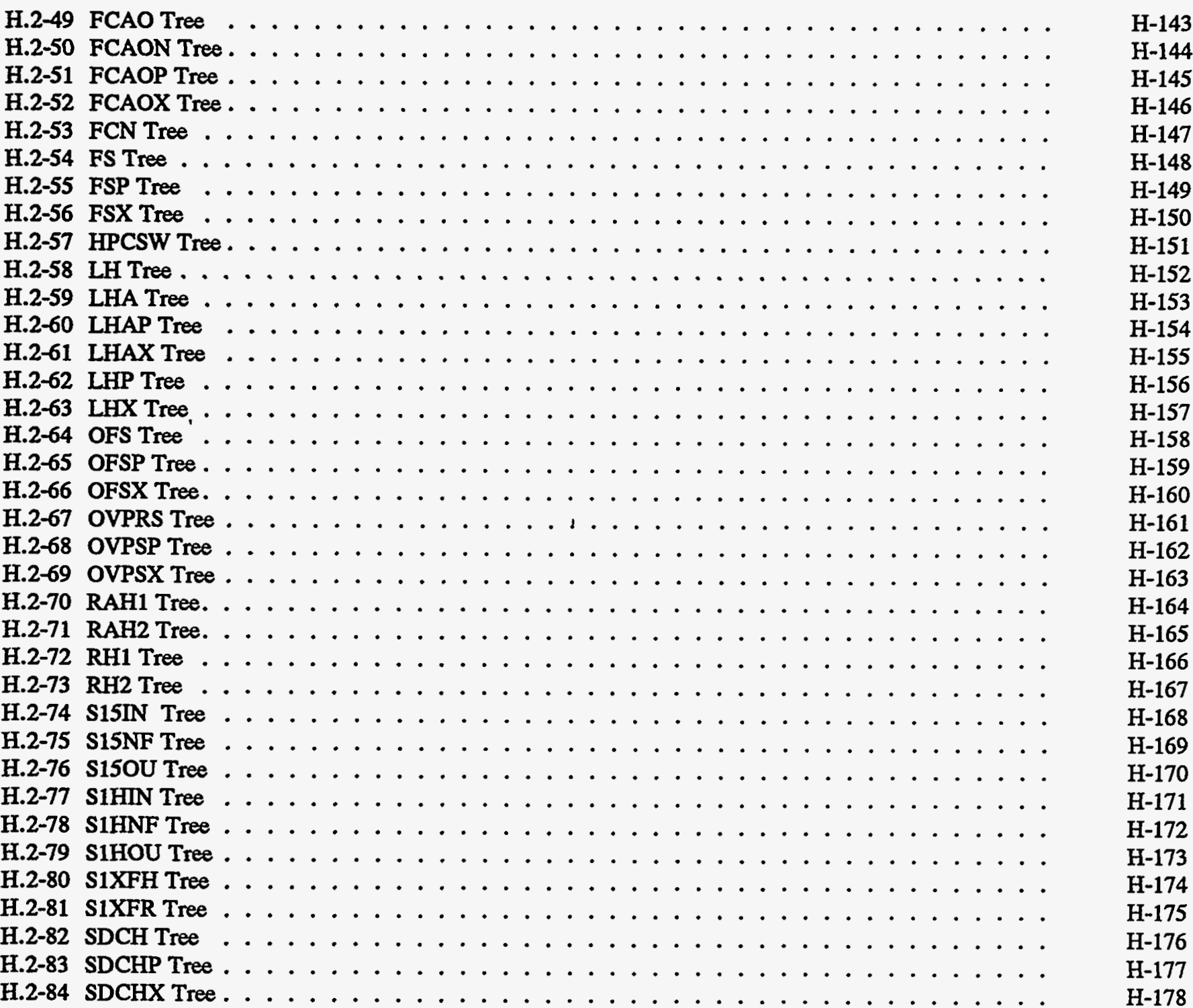




\section{List of Tables}

A.2-1 Plant Configuration in Various OC's Based on Procedures . . . . . . . . . . . . . . . . A-2

A.2-2 System Limitations . . . . . . . . . . . . . . . . . . . . . . . . . A-5

A.2.3 Summary of Major Systems Available for Each OC . . . . . . . . . . . . . . A-6

B.1.1 Precautions, Limitations, and Actions Associated with Procedure 03-1-01-2 . . . . . . . . . . . . B-6

B.1.2 Summarization of Procedure Steps Necessary for Low Power to Full Power Increase . . . . . . . . . . B-7

B.1.3 Summarization of Procedure Steps Necessary for Full Power to Low Power Decrease . . . . . . . . . B-10

B.1.4 Summarization of Procedure Steps Necessary for Rapid Power Reduction . . . . . . . . . . . . . . B-12

B.2.1 Precautions, Limitations, and Actions Associated with Procedure 03-1-01-3 . . . . . . . . . . . . . B-13

B.2.2 Summarization of Procedure Steps Necessary for Cool down with the MSIVs Open . . . . . . . . . B-14

B.2.3 Summarization of Procedure Steps Necessary for Cool down with the MSIVs Closed . . . . . . . . . . B-18

B.3.1 Precautions and Limitations Associated with Procedure 03-1-01-5 . . . . . . . . . . . . . . B-21

B.3.2 Summarization of Procedure Steps Necessary for Plant Cool down and Entry into OC 5 . . . . . . . . B-22

B.3.3 Summarization of Procedure Steps Necessary for Reactor Pressure Vessel Reassembly and Entry into OC 4 B-25

B.4.1 Precautions, Limitations, and Actions Associated with Procedure 03-1-01-1 . . . . . . . . . . . B-26

B.4.2 Summarization of the Procedure Steps Necessary for Reactor Startup . . . . . . . . . . . . . . . B-27

B.4.3 Summarization of the Procedure Steps Necessary for Unit Heatup . . . . . . . . . . . . . . . . . B-29

B.4.4 Summarization of the Procedure Steps Necessary for Turbine Startup and Generator Synchronization . . . B-32

B.5.1 Symptoms Which Require Use of Procedure 05-1-02-III-1 . . . . . . . . . . . . . . . B-34

B.5.2 Immediate Operator Actions . . . . . . . . . . . . . . . . . . . . . . . B-34

B.5.3 Summarization of Steps Necessary to Restore Decay Heat Removal When Fuel is in the Vessel and the Unit is in $\mathrm{OC} 4 \ldots \ldots \ldots \ldots \ldots$ B-35

B.5.4 Summarization of Steps Necessary to Restore Decay Heat Removal When Fuel is in the Vessel and the RPV Head is Off . . . . . . . . . . . . . . . . . . . . B-37

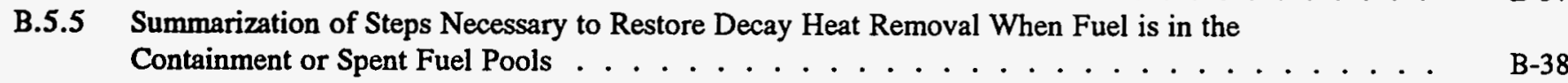

D.1.1 Grand Gulf Low Power and Shutdown Initiating Events and Frequencies . . . . . . . . . . . . . D-2

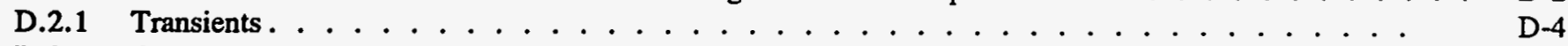

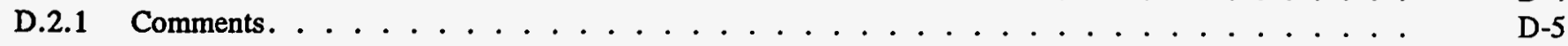

D.3.1 Loss of Coolant Accidents . . . . . . . . . . . . . . . . . . . . . D-7

D.3.1 Comments. . . . . . . . . . . . . . . . . . . . . . D

D.4.1 Decay Heat Removal (DHR) Challenge Initiators . . . . . . . . . . . . . . . D-15

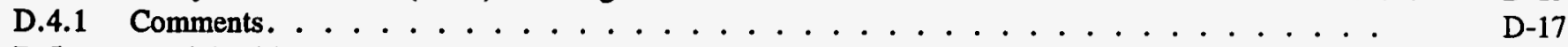

D.5.1 Special Initiating Events . . . . . . . . . . . . . . . . . . . D

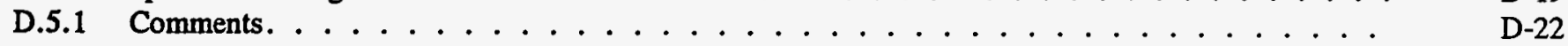

E.1.1 Success Criteria for Plant Operational State (POS ) $4 \ldots \ldots \ldots \ldots \ldots$ E-9

E.1.1 Notes. . . . . . . . . . . . . . . . . . . . . . . E E-11

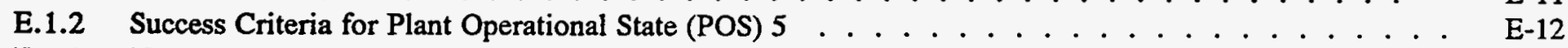

E.1.2 Notes. . . . . . . . . . . . . . . . . . . . . . . E-16

E.1.3 Success Criteria for Plant Operational State (POS) $6 \ldots \ldots \ldots \ldots \ldots$. . . . . . . . . . . . . . . . . . .

E.1.3 Notes. . . . . . . . . . . . . . . . . . . . . . . . E E-21

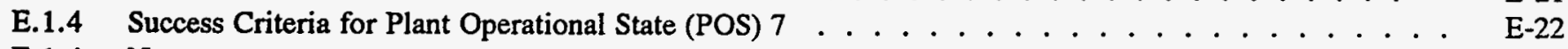

E.1.4 Notes. . . . . . . . . . . . . . . . . . . . . E-26

F.1.1 Calculations Performed ......................... . . F-2

F.2.1 Results of Initial Thermal Hydraulic Calculations for Screening Study . . . . . . . . . . . . . . . F-4

F.3.1 MULINIT.PAS Source Code . . . . . . . . . . . . . . . . . . . F F-8

F.3.2 Multiple Initiating Events for POS 5 . . . . . . . . . . . . . . . . . F F-12

F.4.1 GGENER.PAS Source Code . . . . . . . . . . . . . . . . . . . . F F-22

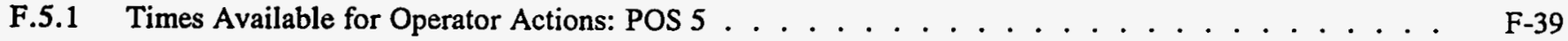




\section{List of Tables (Continued)}

G.1.1 Loss of Offsite Power Events Used to Estimate Frequency During POS $1 \ldots \ldots$. . . . . . . . . G-5

G.1.2 Additional Loss of Off-Site Power Events Used to Estimate Frequency During POS 2-7 . . . . . . . . G-8

G.1.3 Informational Worksheet for LOSP Calculation . . . . . . . . . . . . . . . . G-9

G.1.4 Non-category IV Event Data . . . . . . . . . . . . . . . . . . . . . G-15

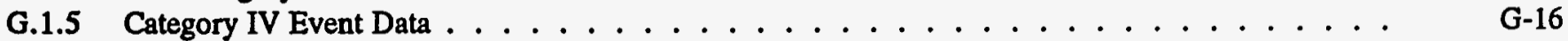

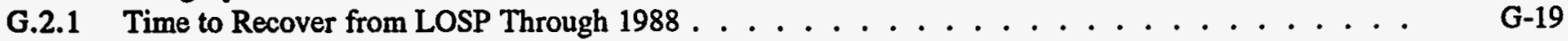

G.2.2 Mean Probability of Recovery from LOSP at Different Times . . . . . . . . . . . . . . . . . . G-21

G.3.1 Correction/Recovery Factors for DG Fails to Start (LOSP as Initiating Event) . . . . . . . . . . . . G-24

G.4.1 Correction/Recovery Factors for DG Fails to Run (LOSP as Initiating Event) . . . . . . . . . . . . G-27

G.5.1 Correction/Recovery Factors for LOSP (not an IE) with DG Fails to Run . . . . . . . . . . . . . G-30

G.7.1 DG Fail to Start Non Recovery Distributions . . . . . . . . . . . . . . . . . . . . G-35

G.7.2 DG Fail to Start Common Mode Non Recovery Distributions . . . . . . . . . . . . . . . G G5 


\section{Acronyms}

\begin{tabular}{ll} 
ADHR & Auxiliary Decay Heat Removal \\
ADS & Automatic Depressurization System \\
ATWS & Anticipated Transient Without Scram \\
BNL & Brookhaven National Laboratory \\
BWR & Boiling Water Reactor \\
CCW & Component Cooling Water \\
CDS & Condensate \\
CI & Containment Isolation \\
CRD & Control Rod Drive \\
CRWST & Condensate and Refueling Water Storage Transfer System \\
CS & Containment Spray \\
CST & Condensate Storage Tank \\
CV & Check Valves \\
CVS & Containment Venting System \\
DBA & Design Basis Accident \\
DG & Diesel Generator \\
ECCS & Emergency Core Cooling Systems \\
EHC & Electro-Hydraulic Controller \\
EHV & Emergency Ventilation System \\
ENSDC & Enhanced Shutdown Cooling \\
EPS & Emergency Power System \\
FCV & Flow Control Valve \\
FDW & Feed Water System \\
FW & Fire Water \\
HCU & Hydraulic Control Unit \\
HPCS & High Pressure Core Spray \\
IAS & Instrument Air System \\
IRRAS & Integrated Reliability and Risk Analysis System \\
LCO & Limiting Condition of Operation \\
LOCA & Loss of Coolant Accident \\
LPCI & Low Pressure Coolant Injection \\
LPCS & Low Pressure Core Spray \\
MSIV & Main Steam Isolation Valve \\
MSL & Mean Sea Level \\
MSR & Moisture Separator Reheater \\
NPSHA & Net Positive Suction Head Available \\
NPSHR & Net Positive Suction Head Required \\
NRC & Nuclear Regulatory Commission \\
OC & Operating Condition \\
POS & Plant Operating State \\
PRA & Probabilistic Risk Assessment \\
PSW & Plant Service Water \\
PWR & Pressurized Water Reactor \\
RCIC & Reactor Core Isolation Cooling \\
RES & Research (Office of NRC) \\
RFPT & Reactor Feedwater Pump Turbine \\
RHR & Residual Heat removal \\
RPV & Reactor Pressure Vessel \\
RRS & Reactor Recirculation System \\
RWCU & Reactor Water Cleanup System \\
SDC & Shutdown Cooling System(s) \\
SGTS & Standby Gas Treatment System \\
& \\
& \\
\hline
\end{tabular}




\section{Acronyms (Continued)}

$\begin{array}{ll}\text { SL } & \text { Safety Limit } \\ \text { SLC } & \text { Standby Liquid Control } \\ \text { SP } & \text { Suppression Pool } \\ \text { SPC } & \text { Suppression Pool Cooling } \\ \text { SPMU } & \text { Suppression Pool Makeup } \\ \text { SPMU } & \text { Suppression Pool Makeup } \\ \text { SR } & \text { Surveillance Requirement } \\ \text { SRV } & \text { Safety Relief Valve } \\ \text { SSWXT } & \text { Standby Service Water Crosstie } \\ \text { TBCW } & \text { Turbine Building Cooling Water } \\ \text { TBV } & \text { Turbine Bypass Valve(s) } \\ \text { UFSAR } & \text { Updated Final Safety Analysis Report }\end{array}$




\section{Foreword}

\section{(NUREG/CR-6143 and 6144) Low Power and Shutdown Probabilistic Risk Assessment Program}

Traditionally, probabilistic risk assessments (PRA) of severe accidents in nuclear power plants have considered initiating events potentially occurring only during full power operation. Some previous screening analyses that were performed for other modes of operation suggested that risks during those modes were small relative to full power operation. However, more recent studies and operational experience have implied that accidents during low power and shutdown could be significant contributors to risk.

During 1989, the Nuclear Regulatory Commission (NRC) initiated an extensive program to carefully examine the potential risks during low power and shutdown operations. The program includes two parallel projects performed by Brookhaven National Laboratory (BNL) and Sandia National Laboratories (SNL), with the seismic analysis performed by Future Resources Associates. Two plants, Surry (pressurized water reactor) and Grand Gulf (boiling water reactor), were selected as the plants to be studied.

The objectives of the program are to assess the risks of severe accidents due to internal events, internal fires, internal floods, and seismic events initiated during plant operational states other than full power operation and to compare the estimated core damage frequencies, important accident sequences and other qualitative and quantitative results with those accidents initiated during full power operation as assessed in NUREG-1150. The scope of the program includes that of a level-3 PRA.

The results of the program are documented in two reports, NUREG/CR-6143 and 6144. The reports are organized as follows:

For Grand Gulf:

NUREG/CR-6143 - Evaluation of Potential Severe Accidents During Low Power and Shutdown Operations at Grand Gulf, Unit 1

Volume 1: $\quad$ Summary of Results

Volume 2: $\quad$ Analysis of Core Damage Frequency from Internal Events for Plant Operational State 5 During a Refueling Outage

Part 1: Main Report

Part 1A: Sections 1 - 9

Part 1B: Section 10

Part 1C: Sections $11-14$

Part 2: Internal Events Appendices A to $\mathrm{H}$

Part 3: Internal Events Appendices I and J

Part 4: Internal Events Appendices $\mathrm{K}$ to $\mathrm{M}$

Volume 3: $\quad$ Analysis of Core Damage Frequency from Internal Fire Events for Plant Operational State 5 During a Refueling Outage

Volume 4: $\quad$ Analysis of Core Damage Frequency from Internal Flooding Events for Plant Operational State 5 During a Refueling Outage

Volume 5: Analysis of Core Damage Frequency from Seismic Events for Plant Operational State 5 During a Refueling Outage

Volume 6: Evaluation of Severe Accident Risks for Plant Operational State 5 During a Refueling Outage

Part 1: Main Report

Part 2: Supporting MELCOR Calculations 


\section{Foreword (Continued)}

\section{For Surry:}

NUREG/CR-6144 - Evaluation of Potential Severe Accidents During Low Power and Shutdown Operations at Surry Unit-1

Volume 1: Summary of Results

Volume 2: $\quad$ Analysis of Core Damage Frequency from Internal Events During Mid-loop Operations

Part 1: Main Report

Part 1A: Chapters 1 - 6

Part 1B: Chapters 7 - 12

Part 2: Internal Events Appendices A to D

Part 3: Internal Events Appendix E

Part 3A: Sections E.1 - E.8

Part 3B: Sections E.9 - E.16

Part 4: Internal Events Appendices $F$ to $H$

Part 5: Internal Events Appendix I

Volume 3: $\quad$ Analysis of Core Damage Frequency from Internal Fires During Mid-loop Operations

Part 1: Main Report

Part 2: Appendices

Volume 4: Analysis of Core Damage Frequency from Internal Floods During Mid-loop Operations

Volume 5: $\quad$ Analysis of Core Damage Frequency from Seismic Events During Mid-loop Operations

Volume 6: Evaluation of Severe Accident Risks During Mid-loop Operations

Part 1: Main Report

Part 2: Appendices 


\section{Acknowledgements}

The authors wish to acknowledge the following for their contributions to this study. The numerous individuals at the Grand Gulf site for their help in obtaining information that made this analysis possible. Richard C. Robinson, Jr. of the NRC for his support in obtaining timely support from the IRRAS computer code developers. Kenneth Russell of Idaho Nuclear Engineering Laboratory for his help in using IRRAS and for providing excellent code support during the use of IRRAS. Members of the Senior Consulting Group and the BWROG PRA Review Committee for their review and suggested improvements to the project. Finally, to Ellen Walroth and Emily Preston for their secretarial support during the project. 


\section{Appendix A. Definition and Characterization of Plant Operational States (POSs) and POS Change Initiators}

\section{A.1 Introduction}

This section of the report is taken from the earlier coarse screening study report [Whitehead et al, 1991]. It is included in this report so that the definition of Plant Operating State (POS) is clearly explained, and so that the concept of a known, pre-existing unavailability prior to an accident initiating event is clearly explained.

In order to analyze accidents initiated from conditions other than full power, a clear understanding of how the plant changes its operational status was needed. In addition, it was necessary to gain an understanding of why the plant changes its mode of operation. To evaluate how the plant transitions from full power to other conditions, a detailed review of several of the operational procedures for Grand Gulf was performed. To evaluate reasons for transitioning to conditions other than full power, the Technical Specifications were reviewed [USNRC, 1984], the Safety Analysis Report was reviewed [SERI, 1992], and discussions were held with Grand Gulf staff. Also, the experience of the authors of this report was brought to bear on evaluating the reasons for transitioning the plant.

This appendix uses information from various procedures at Grand Gulf. These procedures are discussed more completely in Appendix B. Appendix C is a summary of general information about BWRs with an emphasis on Grand Gulf, that is pertinent to understanding plant characteristics.

\section{A.2 Definition and Characterization of POSs}

As originally envisioned, the study would have identified and quantified potential accidents for the five modes of operation as defined by the Technical Specifications [USNRC 1984]. However, as the review of the plant's operating characteristics progressed, it became apparent that another means of classifying the status of the plant would be necessary. This new classification scheme needed to account for the various changes in system configurations, decay heat, pressure and temperature, and water level that occur during transitions from power operation to refueling and back to power operation, or some subset of these transitions. This need resulted in the development of Plant Operational States (POSs).

The technical specifications define Modes or Operating

\author{
Conditions (OCs) as follows [USNRC 1984]:
}

(1) OC 1, Power Operation: Mode Switch in Run, Any Temperature

(2) OC 2, Startup: Mode Switch in Startup/Hot Standby, Any Temperature

(3) OC 3, Hot Shutdown: Mode Switch in Shutdown, Temperature Greater than $200 \mathrm{~F}$

(4) OC 4, Cold Shutdown: Mode Switch in Shutdown, Temperature $200 \mathrm{~F}$ or Lower

(5) OC 5, Refueling: Fuel in Vessel with Head Detensioned or Removed, Mode Switch in Shutdown or Refuel, temperature $140 \mathrm{~F}$ or Lower.

The normal configuration of the plant in each of the five OCs is summarized in Table A.2-1 "Plant Configuration in Various OCs based on Procedures". (The entries in this table correspond to normal conditions as the plant is cooled down from full power. The situation for startup is subsequently discussed.) This table delineates when certain systems are placed into service, removed from service, or operated in a different mode as the plant transitions among OCs. (Note, this table was developed in the initial screening study, and does not consider the Hydro condition during cold shutdown. In the detailed analysis of POS 5 , the Hydro condition during cold shutdown was considered, as discussed in Section 3 of this report.) The systems aspects of Table A.2-1 are influenced by the design characteristics of the systems. For example, the Reactor Core Isolation Cooling (RCIC) system is auto isolated at $60 \mathrm{psig}$ since it requires adequate steam for the turbine driven pump. Also, the steam condensing mode of the RCIC system can only be used below 500 psig since this is the design rating of the RHR heat exchangers. (The steam condensing mode of RCIC is not currently used at Grand Gulf.) Design limitations are summarized in Table A.2-2 "System Limitations". To facilitate event tree development and review, Table A.2-3, "Summary of Major Systems Available for each OC" This table summarizes the availability of systems to provide the 
Table A.2-1 Plant Configuration in Various OC's Based on Procedures

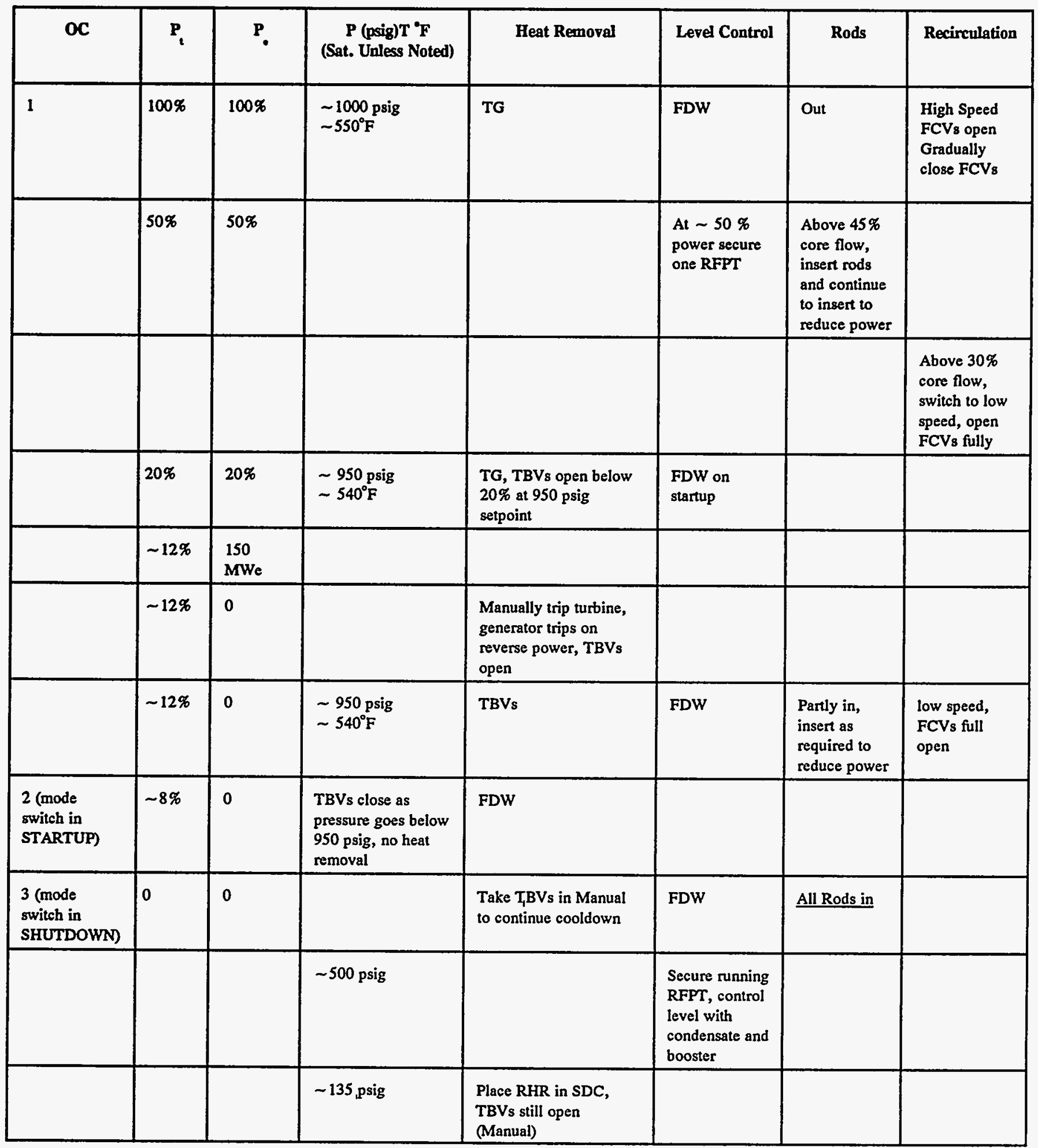


Table A.2-1 Plant Configuration in Various OC's Based on Procedures

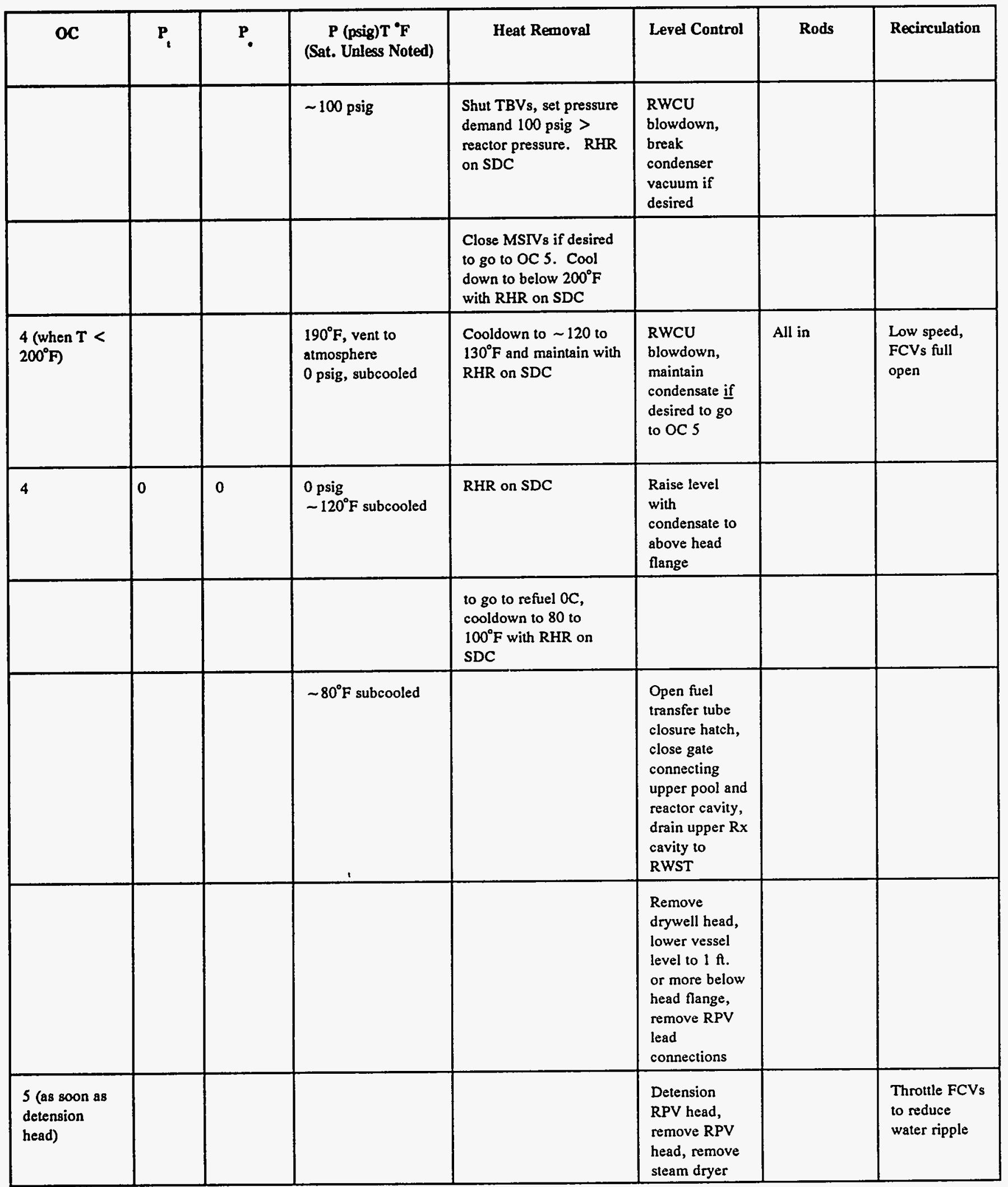




\section{Characterization of POSs}

Table A.2-1 Plant Configuration in Various OC's Based on Procedures

\begin{tabular}{|c|c|c|c|c|c|c|c|}
\hline OC & $P_{\text {. }}$ & P. & $\begin{array}{c}\text { P (psig) T }{ }^{\circ} \mathbf{F} \\
\text { (Sat. Unless Noted) }\end{array}$ & Heat Removal & Level Control & Rods & Recirculation \\
\hline & & & & & $\begin{array}{l}\text { Drain level to } \\
\text { below steam } \\
\text { lines (RWCU } \\
\text { blowdown), } \\
\text { install steam } \\
\text { line plugs }\end{array}$ & & \\
\hline & & & & & $\begin{array}{l}\text { Reflood upper } \\
\text { reactor cavity } \\
\text { from RWST, } \\
\text { lift steam } \\
\text { separator as } \\
\text { cavity fills }\end{array}$ & & \\
\hline & & & & & $\begin{array}{l}\text { Open gate } \\
\text { connecting } \\
\text { upper pool and } \\
\text { reactor cavity }\end{array}$ & & \\
\hline 5 & 0 & 0 & $\begin{array}{l}0 \text { psig } \\
-80^{\circ} \mathrm{F} \text { subcooled }\end{array}$ & RHR on SDC & $\begin{array}{l}\text { RWCU } \\
\text { blowdown, } \\
\text { condensate } \\
\text { available as } \\
\text { needed }\end{array}$ & & \\
\hline $\begin{array}{l}5 \text {, commence } \\
\text { required in- } \\
\text { vessel } \\
\text { activities }\end{array}$ & & & & & & & \\
\hline
\end{tabular}


RHR on SDC

\section{Table A.2-2 System Limitations}

- $\quad$ RPV pressure < 135 psig (pressure interlock FSAR 5.4.7.1.3.1)

- Requires manual alignment

\section{$\underline{\mathrm{RCIC}}$}

- HPCS can perform same function

- Auto isolates at $60 \mathrm{psig}$

- Once through mode can operate at rated pressure

- RHR steam condensing mode only if $<500$ psig (HX pressure rating)*

- Once through mode auto initiated on Level 2, low low water level $\left(-42^{\prime \prime}\right)$

- Steam condensing mode requires manual actuation*

\section{HPCS}

- Injects over all pressure, rated to $0 \mathrm{psig}$, evidentally no concern about runout (NPSH or power)

- Auto on at high drywell pressure (1.4 psig) or low low vessel water level (Level 2, $-42^{\text {") }}$

\section{ADS}

- 8 SRVs open auto if either:

- Low water (level 3, $+11^{\prime \prime}$ ) and Low low low water (level 1, $-150^{\prime \prime}$ ) and high drywell pressure (1.4 psig) and one low pressure pump running and $105 \mathrm{sec}$ timer times out

- Low water (level 3,+11") and Low low low water (level 1, $-150^{\prime \prime}$ ) and one low pressure pump running and $10 \mathrm{~min}$. timer times out

\section{$\underline{\text { LPCS }}$}

- Low pressure permissive $500 \mathrm{psig}$ and decreasing

- Given low pressure permissive, auto on if low low low level (Level $\left.1,-150^{\prime \prime}\right)$ or high drywell pressure (1.4 psig)

\section{LPCI Train A RHR}

- Low pressure permissive 500 psig and decreasing

- Given low pressure permissive, auto on if low low low level (Level 1, $-150^{\prime \prime}$ ) or high drywell pressure (1.4 psig)

\section{LPCI Train B RHR, or Train C}

- Low pressure permissive 500 psig and decreasing

- Given low pressure permissive, auto on if low low low level or high drywell pressure

\section{ADHRS}

- Section piping rated at $80 \mathrm{psig}$

- Only allowed in operation in $0 \mathrm{C} 4$ or $0 \mathrm{C} 5$

\section{*Not used at Grand Gulf}


Table A.2.3 Summary of Major Systems Available for Each OC

\begin{tabular}{|c|c|c|c|c|c|c|c|c|c|c|c|c|c|c|c|c|c|c|}
\hline \multirow[t]{3}{*}{$\underset{\text { psig }}{\mathbf{p}}$} & \multirow[t]{3}{*}{ oc } & \multicolumn{4}{|c|}{ Level Control } & \multirow{2}{*}{\multicolumn{2}{|c|}{$\begin{array}{l}\text { Reactivity } \\
\text { Control }\end{array}$}} & \multirow{2}{*}{\multicolumn{11}{|c|}{ Availability of Heat Removal Systems }} \\
\hline & & \multicolumn{2}{|c|}{ Injection } & \multicolumn{2}{|c|}{ Letdown } & & & & & & & & & & & & & \\
\hline & & CRD & $\begin{array}{l}\text { FDW' } \\
\text { CDS }\end{array}$ & Steam & RWCU & Rods & $S L C^{3}$ & Recirc & TBVs & SDC & ADHRS & RCIC & SRVs & HPCS & LPCS & LPCI & \begin{tabular}{|l|} 
Pool \\
Cooling
\end{tabular} & Other \\
\hline$\sim 1000$ & 1,2 , and 3 & $\mathbf{Y}$ & $\mathbf{Y}$ & $\mathbf{Y}$ & $N^{17}$ & $x$ & & $\begin{array}{l}\text { Not needed } \\
\text { if reactor } \\
\text { tripped } \\
\end{array}$ & $Y^{3}$ & $N^{4}$ & $N^{3}$ & $Y^{6}$ & $Y$ & $\mathrm{Y}$ & $\mathrm{Y}^{9}$ & $Y^{9}$ & $\mathbf{N}$ & $\begin{array}{l}\text { To be } \\
\text { developed' }\end{array}$ \\
\hline-500 & 3 & $\mathrm{Y}$ & $\mathrm{Y}^{*}$ & $\mathrm{Y}$ & $N^{17}$ & IN & & $\begin{array}{l}\text { Not } \\
\text { needed }\end{array}$ & $Y^{3}$ & $N^{4}$ & $N^{3}$ & $x^{8}$ & $y$ & $Y$ & $\mathrm{X}^{9}$ & $Y^{9}$ & $\mathbf{N}$ & Sce above \\
\hline-100 & 3 & $Y$ & $N^{10}$ & $\mathrm{~N}$ & $\mathrm{Y}$ & IN & & $\begin{array}{l}\text { Not } \\
\text { needed }\end{array}$ & $N^{11}$ & $Y^{12}$ & $N^{3}$ & $Y^{6}$ & $Y$ & $\mathbf{Y}$ & $\mathrm{Y}^{9}$ & $Y^{9.12}$ & $\mathbf{N}$ & See above \\
\hline $\begin{array}{l}-60 \text { to } \\
\sim 0\end{array}$ & 3 and 4 & $\mathbf{Y}$ & $N^{10}$ & $\mathrm{~N}$ & $Y$ & IN & & $\begin{array}{l}\text { Not } \\
\text { needed }{ }^{2,13}\end{array}$ & $N^{n}$ & $Y^{12}$ & $\mid \begin{array}{l}Y-\text { oc } 4 \\
\text { only }\end{array}$ & $N^{6}$ & $Y^{18}$ & $x$ & $\mathrm{Y}^{9}$ & $Y^{9,12}$ & $\mathbf{N}$ & See above \\
\hline 0 & \begin{tabular}{|l|}
5 \\
head \\
removed \\
upper cavity \\
filled pools \\
connected \\
\end{tabular} & $\mathbf{Y}$ & $x^{10}$ & $\mathbf{N}$ & $Y$ & IN & & $\begin{array}{l}\text { Not } \\
\text { needed }{ }^{13}\end{array}$ & $\mathrm{~N}^{11}$ & $Y^{12}$ & $Y^{14}$ & $N^{6}$ & $N^{19}$ & $N^{13,16}$ & $N^{13,16}$ & $\mathrm{~N}^{9,13,16}$ & $\mathbf{Y}$ & See above \\
\hline 0 & \begin{tabular}{|l|}
5 \\
head \\
removed \\
upper cavity \\
not filled \\
but level \\
raised
\end{tabular} & $\mathrm{Y}$ & $Y^{10}$ & $\mathrm{~N}$ & $Y$ & IN & & $\begin{array}{l}\text { Not } \\
\text { needed }\end{array}$ & $\mathrm{N}^{11}$ & $Y^{12}$ & $Y^{n 4}$ & $N^{6}$ & $N^{19}$ & $N^{15,16}$ & $N^{13,16}$ & $N^{9,15,16}$ & $\mathbf{N}$ & See above \\
\hline
\end{tabular}

$\mathrm{Y}$ is $\mathrm{Yes}$

$\mathrm{N}$ is No

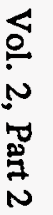


Table A.2-3 Summary of Major Systems Available for Each OC (Concluded)

Notes

1. SLC needed only if rods unavailable.

2. Natural circulation with raised level OK with reactor tripped.

3. TBVs auto control to $950 \mathrm{psig}$. Below $950 \mathrm{psig}$ use of TBVs requires manual operation.

4. RHR SDC auto isolated above 135 psig

5. ADHRS can only be used in $0 \mathrm{C} \mathrm{4}$; suction piping rated at 80 psig.

6. RCIC auto mode (once through) available from full pressure down to $60 \mathrm{psig}$ (auto isolate). RCIC manual mode (steam condensing) available below 500 psig (auto isolate) down to 60 psig (auto isolate). RHR HX limits steam condensing mode to below 500 psig.

7. Consider CRD, fire water, RWCU, condensate, etc. Some of these will only work at low decay heat levels (e.g., RWCU letdown, CRD/condensate makeup).

8. FDW secured but injection with condensate and booster pumps.

9. LPCI/LPCS requires $\mathrm{p}<500 \mathrm{psig}$ permissive for injection.

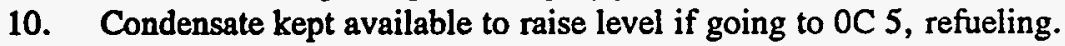

11. Below $135 \mathrm{psig}$, initiate RHR SDC, close TBVs. Assume condenser not available when TBVs are closed (stop circ. water, break vacuum, etc.).

12. When RHR on SDC, manual re-alignment of RHR A and B required for use as LPCI A and B.

13. Without recirc. on low, speed natural circulation can be established with level raised.

14. ADHRS can only be operated in $0 \mathrm{C} 4$ or $5\left(<200^{\circ} \mathrm{F}\right)$; suction piping rated at $80 \mathrm{psig}$.

15. In OC 5 with upper cavity filled and pools connected, TS 3.5.2 allows ECCS to be inoperable. In OC 4, or 5 without cavity filled and pools connected, 2 of 5 ECCS must be operable according to TS 3.5.2. In OC 1, 2, and 3 all ECCS must be operable according to TS 3.5.1

16. Inadequate Decay Heat Removal procedure does not discuss use of ECCS when head is off.

17. RWCU is not the primary means of letdown level control since steaming to the condenser is used.

18. 2 SRVs required per procedure.

19. Steam Line Plugs in place, vessel head removed. 
following functions: level control, reactivity control, and heat removal. All of these functions must be provided to cool fuel in the vessel.

During startup, the plant configuration in certain OCs is different than during shutdown. As indicated in the summary of the startup procedure (see Appendix B, Procedure \# 03-1-01-1), Grand Gulf uses nuclear heat, as opposed to pump heat, to heatup (decay heat is typically too low to be used for startup). For example, if the plant is in OC 4, and startup is requested, the following steps are taken:

(1) RHR/SDC is taken out of service and RHR is lined up for LPCI.

(2) Mode switch placed in Startup (this places unit in OC 2).

(3) Rods are pulled to critical.

(4) Turbine bypass is made operable.

(5) Rods are pulled and primary heats to temperature (pressure) where moderator feedback re-establishes criticality.

(6) Step 5 continues with heatup rate limited to $\leq$ 80 degrees $F$ per hour.

(7) At rated pressure (temperature), Turbine Bypass Valves (TBVs) control pressure. Rods pulled to position for $4 \%$ power, and power goes to $4 \%$ (fuel Doppler re-establishes criticality at $4 \%$ power).

(8) Mode switch placed in Run, and power increased. Recirc flow controlled, turbine rolled, and generator loaded per procedure. Full Power established.

In contrast to the situation during shutdown, during normal startup the unit goes from OC 4 directly to OC 2 without passing through OC 3 . This is because the mode switch is placed in Startup to allow rods to be pulled to heat up the unit. When the unit initially enters OC 2 during startup, it is at low pressure and temperature. However, the system lineups are basically the same as when the unit is in OC 2 during shutdown (i.e., RHR/SDC is isolated, ECCS is operable, and turbine bypass is operable). During the startup process, should it be required to initiate RHR/SDC, the rods will be fully inserted prior to establishing RHR/SDC, per the
RHR/SDC procedure (\# 04-1-01-E12-1, rev 44, step 3.6.1).

Since OCs are not one-to-one with system availabilities, the initial conditions of the plant prior to the occurrence of an accident initiating event cannot be easily specified based purely on OCs. For this reason, we developed a set of Plant Operational States (POSs), to segregate the various off power situations into a set of states for which the normal configuration of systems (prior to an accident initiating event) can be specified. Thus, a POS is defined as: a plant condition for which the status of plant systems (operating, standby, unavailable) can be specified with sufficient accuracy to model subsequent accident events. A POS is not identical to an OC, but POSs are defined based on OCs. In general, an OC cannot in itself meet the requirement for a POS. For example, in OC 3, above 135 psig RHR on SDC cannot be used and the Turbine Bypass Valves (TBV) or RCIC are used; while in OC 3, below 60 psig RCIC cannot be used.

There are some OCs that are essentially the same in terms of system availabilities and primary thermal hydraulic conditions, and these were treated as one POS. For example, OC 1 and OC 2 differ only in the power level, rods positions, and recirculation pumps speed - all of which are minor in terms of accident sequence progression, since reactor shutdown/trip with the rods is essentially the same regardless of power level, and recirc is not required post trip. The pressure/temperature of the primary is almost identical in OC 1 and 2 (during shutdown): about $1000 \mathrm{psig}$ and about 550 degrees F. In OC 3 from 1000 psig down to 500 psig, the systems configurations important to the accident analysis are identical to the configurations in $\mathrm{OC} 1$. The main differences are: in this upper pressure range of OC 3 the rods are all in, and the turbine/generator is tripped. Also, the pressure/temperature conditions that affect accident sequence progression are not drastically different at 500 psig from those at 1000 psig.

Using the OCs as a starting point, the following seven POSs were defined:

(1) POS 1 consisting of: OC 1 and OC 2 with pressure at rated conditions (about $1000 \mathrm{psig}$ ) and thermal power no greater than $15 \%$.

(2) POS 2 consisting of: OC 3 from rated pressure to $500 \mathrm{psig}$.

(3) POS 3 consisting of: OC 3 from 500 psig to where RHR/SDC is initiated (about 100 psig). 
(4) POS 4 consisting of: OC 3 with the unit on RHR/SDC.

(5) POS 5 consisting of: OC 4 (T $\leq 200$ degrees F) and OC 5 until the vessel head is off and level is raised to the steam lines.

(6) POS 6 consisting of: OC 5 with the head off and level raised to the steam lines.

(7) POS 7 consisting of: OC 5 with the head off, the upper pool filled, and the refueling transfer tube open.

Control rods are fully inserted in POSs $2,3,4,5,6$, and 7.

The reasons for this segregation of the five $O C$ into these seven POSs are indicated in Table A.2-3, and the most salient ones are as follows:

(1) $O C 1, O C 2$, and $O C 3$, down to 500 psig: steam dump to the condenser is used, feedwater is available, and other similar characteristics exist.

(2) OC 3, between 500 and 100 psig: have the potential to use RCIC in the steam condensing mode (not used currently at Grand Gulf), the pressure is below the LPCI/LPCS permissive setpoint, and feedwater is secured but condensate/booster makeup is still available.

(3) OC 3, between 100 and 0 psig: RHR on SDC, level control with RWCU, RCIC unavailable (conservative assumption since it is available above 60 psig), LPCI trains A and B require manual re-alignment of RHR from SDC.

(4) OC 4: vent can be opened, ADHRS can be used, RCIC cannot be used, RHR on SDC and LPCI trains A or B requires manual realignment, LPCI/LPCS flooding through two open SRV's to the SP can be used.

(5) OC 5 with head off, level raised but upper cavity not flooded: spent fuel pool cooling cannot be used for fuel in vessel, ECCS required operable per Tech Spec 3.5.2 (see Appendix $B$ for discussion of procedure for Inadequate Decay Heat Removal).

(6) OC 5 with head off, upper cavity flooded, and upper and spent fuel pools connected: spent fuel pool cooling can be used to cool fuel in vessel, ECCS allowed inoperable per Tech Spec 3.5.2.

This selection of POSs was based on the factors indicated in Table A.2-3. Because the information in this table is based on system configurations during shutdown, it must be shown that these POSs handle system configurations during startup as well. For POSs 6 and 7 , there is no distinction between system configurations for shutdown and startup. As discussed previously, during normal startup the unit passes from POS 5 directly to POS 1. However, should the heatup process be stopped (for example, to institute RHR/SDC), the rods are inserted and the mode switch placed in Shutdown. Therefore, should the unit enter POS 4, 3, or 2 during startup, it will do so with the same system configurations as during shutdown, and POS 4, 3, and 2 apply equally well to both situations. POS 1 is characterized as being at rated pressure, the situation during shutdown. During startup, the unit enters POS 1 at low pressure, but with the same lineups as for rated pressure since the idea is to heat up to rated pressure in this configuration. A rise to rated pressure is therefore of no concern in POS 1 during startup, and POS 1 , as defined for shutdown, applies equally well for startup.

It is interesting to note that for Grand Gulf, ECCS injection is not required to be manually blocked during cooldown as the unit depressurizes, because ECCS actuates on level, not purely on pressure, and water is maintained at normal level during cooldown. This is in contrast to PWR's where ECCS actuates on pressure and must be blocked during cooldown and reset during heatup.

\section{A.3 Definition and Characterization of POS Change Initiators}

After an understanding of how the plant operates and/or transitions among the identified POSs was obtained, it became necessary to identify the reasons why the plant would be required to change its POS and the implications of such a change (i.e., known pre-existing system and/or component unavailabilities). Since the major concern of this study was with accidents occurring in non full power POSs, its focus was on controlled shutdown initiating events. Also included are reactor trip events which allow orderly transition among POSs, hereafter called 'nuisance trips'. These 'nuisance' trips are included because they affect the amount of time that the plant is in POSs associated with conditions other than full power. 
Note, that by definition such nuisance trips do not prevent the plant from transitioning among POSs in an orderly manner.

For accident sequences initiated from full power as modeled in full power PRA's, this study addresses only those sequences defined in the top success path of the full power accident sequence event trees, for which the plant can transition among POSs in an orderly manner.

The coarse screening study did not address the long term issues following a non-nuisance reactor trip from full power. Consideration of such events is an extension of traditional full power PRA analyses of accident sequences. Full power PRAs model the response of the plant out to the time at which conditions are stabilized (e.g., hot shutdown for transient initiated accident sequences). However, the long term response of the plant is not considered.

The methodology employed in this study is not directly suitable for analyzing such concerns, since the methodology assumes that the plant is initially in a stable condition in a POS, and not initially transitioning into a POS from an accident at full power. The concept of POS is not always meaningful for accidents initiated at full power anyway, since the plant responds to the accident rather than transitioning among POS. For example, following a large LOCA the plant systems attempt to mitigate the LOCA rather than transition in a controlled manner to cold shutdown.

The fact that the screening study did address these nuisance trips and not the more stressful, but less likely, trips which progress along an event tree path (other than the top success path) should not be taken to imply that a transition to a POS following a nuisance trip is believed to be of higher risk than long term considerations following the more stressful trips. Rather it is a reflection of two facts: (1) nuisance trips occur relatively frequently (on the order of one to ten times a year depending on the particular plant), and (2) the methodology developed for quantifying accidents occurring following transitions among POSs can easily handle the nuisance trips as defined above. Also, the full power PRAs do analyze the accident sequences associated with non-nuisance trips, although long term accident management issues are not addressed.

A distinction must be made between what is meant by accident initiating events and initiating events which require a transition among POS. For example, initiating events requiring controlled shutdown but not a reactor trip are not accident initiating events, since they do not prevent controlled transitions among POS. However, they can impose known, pre-existing unavailabilities if a subsequent accident initiating event occurs. Reactor trip initiating events are, in general, accident initiating events since they require mitigative actions to handle the event without regard to orderly transitions among POSs. For example, following a LOCA at full power, the plant does not undergo an orderly transition to cold shutdown -ECCS systems respond as necessary to mitigate the break. Only certain types of events requiring reactor trip allow subsequent transitions among POSs. These include those that do not affect the ability to transition, or those that can be easily fixed to allow transition (e.g., the nuisance trips described above). Events requiring controlled shutdown, such as refueling or inoperable equipment, lead to orderly transitions "down" among POS. Transitions "up" among POS occur following outages or equipment repair .

In this study a POS Initiator has the following definition: An event which initiates controlled shutdown of the plant from full power, a nuisance trip from full power, or an event which requires the plant to transition up or down among POS in response to outage requirements or equipment conditions.

For the purposes of describing how the POS change initiators were identified and the implications of such initiators, the initial state of the plant is assumed to be full power; and before the first initiating event occurs it is assumed that no significant known system unavailabilities exist. The analysis starts when an event occurs that requires transitioning the plant through a set of POSs.

In general a given POS can be entered in one of four ways:

(1) coming down from full power for a scheduled refueling outage,

(2) coming down from full power not for a scheduled refueling outage,

(3) going up to full power following a refueling outage, or

(4) going up to full power not following a refueling outage. 
The following seven categories or classes of POS Initiators were identified:

Class Description

1. Refueling. The plant is scheduled for its next refueling outage.

2. Controlled shutdown required by Technical Specifications (Tech Specs) due to violation of a Safety Limit (SL) or Limiting Condition of Operation (LCO).

3. Controlled shutdown required by Tech Specs due to missed Surveillance Requirement (SR).

4. Controlled shutdown due to failures in non-Tech Spec equipment.

5. Preventive maintenance.

6. Change necessitated by a reactor trip from full power (nuisance trip only).

7. First time startup or final shutdown.

After these seven classes were developed, they were examined to determine if a change in the plant's POS necessitated by one of these events would impose known, pre-existing unavailabilities. For Class 1, the following assumption was made: the plant would not enter refueling (i.e., POSs 6 and 7) knowing that a system required during the refueling outage was unavailable. Class 2 events can impose pre-existing unavailabilities. If an inoperable system is required during shutdown, then entry into an action statement will impose known, pre-existing unavailabilites. If the system is not required, then no known, pre-existing unavailability exists. Events in Class 3 do not impose known, preexisting unavailabilities. Class 4 events may impose preexisting unavailabilities. If the equipment is taken credit for in a PRA (i.e., used to mitigate an accident initiating event), then its failure does impose a pre-existing unavailability. If not, then no pre-existing unavailability exists. Class 5 events do not impose pre-existing unavailabilities, because if the equipment were nonfunctional, then it would be in Class 2 or 4 . Class 6 events do not impose pre-existing unavailabilities, since only reactor trips associated with nuisance trips are analyzed. No exact determination of Class 7 events was made, as these events were outside the scope of this project.
Based on our understanding of the plant characteristics and operating practices, we developed seven rules of analysis for evaluating each POS.

Rule (1): When an accident initiating event occurs in a given POS, the event tree for that accident initiator in that POS totally describes the subsequent behavior of the plant. Once an accident occurs, the plant systems focus on mitigating that particular accident rather than on transitioning among the POS.

Rule (2): The structure of the accident event trees and constituent fault trees in a given POS for a given accident initiating event, are independent of how the plant transitioned to that POS; (except that consideration of additional methods of core cooling are considered at low decay heat levels that exist going up following a refueling outage). This rule follows from rule (1), in that any accident within a POS renders transitioning to a subsequent POS invalid. Thus, entry into a given POS is without an accident having previously occurred. Of course, the availability of systems and components is affected by known, pre-existing unavailabilities.

Rule (3): For any POS $6,5,4,3,2$, or 1 that is entered following a refueling outage, there are no known, preexisting unavailabilities. This rule is based on the assumption that the plant will not be restarted following a refueling outage if known, major equipment unavailabilities are present.

Rule (4): For POS 6, no known, pre-existing unavailabilities exist. This rule is based on the assumption that a refueling outage is a scheduled event and does not occur simultaneously with any other POS initiator. Conversely, if a POS initiator occurs which renders equipment inoperable, it is assumed that the problem will be fixed in POS 4 or 5. POS 6 or 7, which involve vessel head removal, are not entered.

Rule (5): For any POS entered in returning to power following a non-refueling outage, there are no known, pre-existing unavailabilities from any time prior to entry into the first POS. This rule is based on the assumption that the reason for coming down in power is fixed prior to going back up in power.

Rule (6): Failures occurring in a POS following the POS initiator which required entry into the POS, are accident initiating events, and by rule (1), do not affect subsequent POS. Failures in one POS can affect the availability of equipment in a subsequent POSs. Rules (3), (4), and (5) limit those earlier POS to which 
consideration should be given. We have made the additional assumption that any failure subsequent to the POS initiator initiates an accident. The rationale for this assumption is that in most cases in the POS, even if redundant trains exist, only one train is in operation (Shutdown Cooling with RHR, for example), and a failure in the running train and starting the backup train is modeled in the accident sequence event trees.

Rule (7): For any POS entered except as part of a planned refueling outage, the fault exposure time for standby components is $T / 2$, where $T$ is the average time between testing of component $i$. For any POS entered as part of a scheduled refueling outage, the fault exposure time is $T_{i r}+T_{p o s} / 2$, where $T_{j i}$ is the time interval from the last test of component $i$, and entry in to the POS, and $T$ is the duration of the POS. This rule is based on the fact that refueling is a scheduled (non-random) event.

These seven rules taken together, enable the accident sequences for a given POS to be evaluated without rigorously considering all the details of how the plant transitioned to that POS.

However, this methodology cannot in general handle time dependent changes in system configurations. For example, the methodology cannot easily model all the possible changes in system availabilies during a refueling outage as extensive maintenance is performed on different systems. For cold shutdown at Grand Gulf, (the subject of this report), this is not a serious limitation since train $A$ is frequently taken out for maintenance in cold shutdown. This was the conservative assumption used in our model. To assess risk during actual refueling operations involving extensive testing and maintenance, the methodology may have to be improved to consider 'rolling' unavailabilities of equipment.

Similarly, the methodology cannot easily consider accidents that occur as the plant transitions among modes during shutdown. For example, in hot shutdown the plant operators switch from cooling with turbine bypass to cooling with shutdown cooling at about 100 psig. Plant conditions are changing during this transition, and are different than those present while either on turbine bypass cooling or on shutdown cooling. We have assumed that accidents occurring during such transition operations are adequately considered by our models for the initial and final states of the transition, for the following reasons:

a) The time spent in transition is less than the time spent in the states transitioned from and transitioned to; thus, accidents due to random failures are less likely.

b) For Grand Gulf, and many other plants, this assumption is further supported by the practice to not disable one functional system (such as core cooling with turbine bypass) until the replacement system (such as shutdown cooling) is shown to be operable.

c) Finally, the historical record of events occurring at shutdown shows that they do not occur during transition states.

We believe that the most probable situations for which unique initiating events can occur during a transition state, are those associated with rod withdrawal during startup. Errors in rod movements during such situations can challenge the reactor trip system. Such situations do not occur in cold situation. 


\section{References for Appendix A}

[Whitehead et al, 1991]
D. W. Whitehead, J. L. Darby, B. D. Staple, B. Walsh, T. M. Hake, and T. D. Brown, "BWR Pow Power and Shutdown Accident Frequencies Project, Phase 1 - Coarse Screening Analysis", Vol. 1, Draft Letter Report, Sandia National

Laboratories and Science and Engineering Associates, Inc., November 23, 1991 update. (Available in USNRC Public Document Room)
[USNRC 1984] USNRC, "Technical Specifications, Grand Gulf Nuclear Station Unit No.

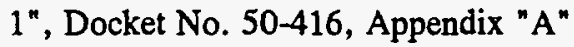
to License No. NPF-29, NUREG-0934, October, 1984.

[SERI, 1992] System Energy Resources, Inc., "Grand Gulf Updated Final Safety Analysis Report, " Revision 7, 1992 


\section{Appendix B Summary of the Detailed Review of Selected Grand Gulf Procedures}

This appendix summarizes the information obtained during detailed reviews of selected Grand Gulf Procedures. The reviewed procedures include:

(1) Power Operations - \#03-1-01-2,

(2) Plant Shutdown - \$03-1-01-3,

(3) Refueling - \#03-1-01-5,

(4) Cold Shutdown to Generator Carrying Minimum Load - \#03-1-01-1, and

(5) Inadequate Decay Heat Removal - \#05-1-02-III1.

For each procedure the most important steps (tasks) are identified and summarized both in text and tabular format. In addition, the important precautions, limitations, actions, and prerequisites are presented.

\section{B.1 Power Operations - \#03-1-01-2}

This procedure covers three situations: (A) low to full power increase, (B) full to low power decrease, and (C) rapid power reduction.

The prerequisites (initial conditions) for this procedure are as follows: For situation (A) recirculation is on low speed, the flow control valves are fully open, one reactor feed pump is maintaining vessel level, and the main generator is synchronized to the grid carrying about $15 \%$ $(196 \mathrm{MWe})$ load. Heat removal is through the loaded turbine with Turbine Bypass Valves (TBVs) open. For situations $(B)$ and $(C)$, the prerequisite conditions are those established in this procedure for a defined power level. See Table B.1.1 for a list of the most important precautions, limitations, and actions.

\section{B.1.1 Low Power to Full Power Increase}

Situation (A), low to full power increase, is accomplished as follows: The loading instructions are obtained from the system dispatcher. The load demand is increased in increments until the TBVs are fully closed. (As more steam flows to the turbine, the turbine header pressure drops, and once it is below the TBVs setpoint they close.) The TBVs are verified to be fully closed before raising power above $20 \%$ to satisfy Tech Spec 4.1.4.1; and the reactor feedwater pump turbine (RFPT) is verified to be on the master level controller (off startup). Power is increased by withdrawing rods. Power is held at $20 \%$ for about 1.5 hours to allow heat rate data to be gathered. As soon as the low power setpoint (20\%) is exceeded, the operability of the Rod Withdrawal Limiter (RWL) is verified per Tech Spec 4.1.4.2.b.1. Power is held at $40 \%$ for about 1.5 hours to allow heat rate data to be obtained. When the reactor is stable above $34 \%$ power and below the $80 \%$ rod line, the flow control valves are closed to minimum position, and the recirculation pumps are switched from low to high speed. At about $40 \%$ power, feedwater is placed in three element control where pump speed is a function of steam flow, vessel water level, and feedwater flow. At about $45 \%$ power, the second RFPT is placed in service on master level control, and the second circulating water pump is placed in service. Rods are positioned at the desired flow control line, and power is increased by opening the recirculation flow control valves and thereby increasing recirculation, with the rods fixed. Power is held at $60 \%$ for about 1.5 hours to allow for gathering of heat rate data. As soon as the high power setpoint is reached (70\%), RWL operability is demonstrated. At about $80 \%$ power and $90 \%$ core flow, all ECCS line break alarms should be cleared, but any applicable LCOs are entered for alarms not cleared. (Evidently the "ECCS line break alarms" are readouts from the "injection permissive" low pressure sensors of Tech Spec table 3.3.3-1 which, upon low pressure, permit LPCI and LPCS injection given either low vessel level or high drywell pressure.) Power is held steady at both $80 \%$ and $100 \%$ for about 1.5 hours to allow heat rate data to be gathered.

The above information is a summarization of the information presented in Table B.1.2.

\section{B.1.2 Full Power to Low Power Decrease}

Full power to low power decrease, situation (B), is accomplished essentially by reversing the steps just described for (A). If it is desired to trip the turbine, this is accomplished by manual action once power is 100 to $150 \mathrm{MWe}$. The generator then automatically trips on reverse power since with no driving torque it acts like a motor and draws power from the grid. The TBVs are verified to be maintaining vessel pressure. See Table B.1.3 for the appropriate steps for this portion of the procedure.

\section{B.1.3 Rapid Power Reduction}

Rapid power reduction, situation (C), is achieved by 
using the fast mode of recirculation flow reduction. If further reduction in power is required, the rods are inserted. The appropriate steps in (A) of this procedure are then followed. If reactor scram occurs, the Reactor Scram procedure \#05-1-02-1 is followed.

Table B.1.4 lists the steps necessary for performance of this section of the procedure.

\section{B.2 Plant Shutdown - \#03-1-01-3}

This procedure takes the plant from Operating Condition (OC) 1 at about 12\% power down to zero power in either OC 3 or 4 . The prerequisites (initial conditions) are as follows. Reactor power is about $12 \%$, and the turbine is offline. Recirculation pump(s) on low speed with flow control valves (FCVs) full open in loop manual control. Heat removal is via TBVs to the main condenser.

The procedure has two parts. One deals with cooldown keeping the main steam isolation valves MSIVs open, and the other deals with cooldown when the MSIVs are closed during the cooldown. See Table B.2.1 for a list of the most important precautions, limitations, and actions.

\section{B.2.1 Cooldown with the MSIVs Open}

Cooldown with the MSIVs open is accomplished as follows. If rapid and complete shutdown is desired, the reactor is manually tripped and the Reactor Scram procedure \#ONEP 05-1-02-I-1 is followed. Otherwise, the following steps are taken. Rods are inserted to reduce power to about $8 \%$. The IRMs are inserted. All surveillance requirements (SRs), per the Tech Specs, are completed before entry into OC 2 . The mode switch is placed in STARTUP, and hence the unit enters OC 2. Rods are inserted, the SRMs are inserted, and the TBVs are verified to close at the $950 \mathrm{psig}$ turbine header pressure control setpoint. All conditions for entry into OC 3 are met, and the unit enters OC 3 as the mode switch is placed in SHUTDOWN position when all rods are fully inserted. Reactor power is zero (except for decay heat). Cooldown is continued at less than 80 degrees $\mathrm{F}$ per hour by manually opening/closing the TBVs. (Operation of the TBVs reduces reactor pressure. Temperature also decreases along the saturation line due to controlled flashing as pressure decreases.) Level control is maintained with feedwater. The steam jet air ejectors (SJAEs) are secured and hoggers are placed in operation to maintain condenser vacuum. At about 500 psig, the running RFPT is secured, and it is verified that only one booster/condensate pump combination is running. Cooldown with the TBVs is continued as long as possible. When necessary, SDC with RHR is placed into operation. At $200 \mathrm{psig}$, one RWCU pump is secured if both pumps are running. At $100 \mathrm{psig}$, the running $R W C U$ pump is transferred to the pre-pump mode. The TBVs are closed (manual operation is stopped), and the pressure setpoint is set at 100 psig above reactor pressure. Heat removal is via RHR on SDC. If desired, the condenser vacuum is broken, and circ water is shutdown. When vessel temperature is below 190 degrees $F$ (unit enters OC 4 at 200 degrees $F$ ), the primary is vented to the atmosphere by opening F001 and F002 and closing F005. This establishes 0 psig and renders the primary subcooled. To prevent thermal stratification, recirculation on low speed is continued. If either recirculation or SDC is lost, procedure \#ONEP 05-1-02-III-1 "Inadequate Decay heat removal" is followed. Cooldown is continued to 120 to 130 degrees $F$. Level is controlled via RWCU blowdown to either the condenser or radwaste. To maintain cold shutdown conditions as desired, RHR is operated in the SDC mode per procedure \#SOI 04-1-01E12-1.

The above information is a summarization of the information presented in Table B.2.2.

\section{B.2.2 Cooldown with the MSIVs Closed}

Cooldown with the MSIVs closed during the cooldown process is similar to the case with the MSIVs open. The main difference is that just before the MSIVs are closed, RCIC is placed in operation in the open cycle mode (injection from the CST or SP) per procedure \#SOI 04-101-E51-1. Unless decay heat is so low that the steam discharged to the RCIC turbine provides adequate heat removal, the SRVs will cycle and relieve to the SP. SP cooling is instituted if necessary. RHR on SDC is placed in operation below $135 \mathrm{psig}$, and RCIC is isolated above $75 \mathrm{psig}$ (RCIC auto isolates at $60 \mathrm{psig}$ ). It is important to note that if RCIC is inoperable, then HPCS with SRVs (relief mode) can be used. See Table B.2.3 for the steps necessary for performing this portion of the procedure.

\section{B.3 Refueling - \#03-1-01-5}

This procedure takes the plant from OC 3 down to OC 5 , and from OC 5 up to $\mathrm{OC} 4$. The prerequisites going down are that the plant is in OC 3 per procedure \$03-101-3 "Plant Shutdown." The prerequisites going up are 
Review Procedures

that the plant is in OC 5 as specified in this procedure. See Table A.3.1 for a list of the most important precautions and limitations.

\section{B.3.1 Plant Cooldown and Entry into OC 5}

The steps for going from OC 3 down to OC 5 are as follows. Per procedure \#03-1-01-3 the unit is being cooled down with the TBVs. Once pressure is below $135 \mathrm{psig}$, SDC via RHR is instituted, and the TBVs are removed from service. The MSIVs are closed. RWCU is placed in the blowdown mode, but the condensate system is retained for vessel flooding. With condensate and using the startup level controller, the level is raised above the RPV head flange. Cooldown with SDC is continued (OC 4 is entered at 200 degrees $F$ ) to about 80 degrees F. (It is verified that RCIC auto isolated at 60 psig.) The fuel transfer tube closure hatch is opened, thus enabling fuel to be moved from the upper containment pool to the spent fuel storage transfer pool in the auxiliary building, once isolation valves in the transfer tube are opened. The gate and seal between the upper containment pool and the reactor upper cavity is installed, thus isolating the upper reactor cavity. The upper reactor cavity is drained to the Refueling Water Storage Tank (RWST). The drywell head is removed. Vessel level is lowered (with RWCU blowdown) to one foot or more below the flange. All external connections to the vessel head are removed. The head studs are detensioned. This places the unit in OC 5, Refueling. The vessel head is removed. Recirculation is throttled with the FCVs to reduce water ripple. The steam dryer is removed. The vessel is drained to below the main steam lines, and steam line plugs are installed. The upper reactor cavity is reflooded from the RWST and the steam separator is removed as the upper cavity fills. Once the upper cavity is filled, the gate/seal between the upper reactor cavity and the upper containment pool is removed. (Later, in preparation for fuel transfer, the transfer tube isolation valves will be opened. At this time, the vessel water, the water in the upper reactor cavity, the water in the upper containment pool, and the water in the spent fuel storage pool are interconnected since the vessel head is off, the upper reactor cavity is flooded, the gate between the upper cavity and the upper containment pool is open, and the refueling tube connecting the upper containment pool to the spent fuel storage pool is open.) Most of the required in-vessel work is performed with the unit in these conditions. (In service inspection of the vessel is performed with a lower water level.)

The above information is a summarization of the information presented in Table B.3.2.

\section{B.3.2 Reactor Pressure Vessel Reassembly and Entry into OC 4}

The steps for bringing the unit from OC 5 with the upper reactor cavity flooded, to OC 4 are essentially the reverse of the appropriate preceding steps. See Table B.3.3 for a list of the appropriate steps.

\section{B.4 Cold Shutdown to Generator Carrying Minimum Load - \#03-1- 01-1}

This procedure controls the activities necessary for reactor startup, unit heatup, and turbine startup and generator synchronization. The prerequisites (initial conditions) for this procedure are as follows: The reactor vessel head must be in place with the studs tensioned. The mode switch must be in the SHUTDOWN or REFUEL position. Recirculation is in operation on low speed, with the flow control valves full open and in loop manual control. The control rod hydraulic system is in operation, and the RWCU system is blowing down to the condenser or radwaste system to maintain level at normal level. RHR is in LPCI standby, or another mode as required, and ADHRS is in the isolate mode per procedure \#SOI-04-1-01-E12-1. (It should be noted that Section 3.1 of the procedure defines "standby" as able to respond upon automatic or manual initiation.) RCIC is ready for operation or on standby. The integrity of primary containment, secondary containment, and the drywell is verified per Tech Spec sections 3.6.1, 3.6.2, and 3.6.6. The turbine is on turning gear. Circulating water is in operation. Usually, the MSIVs are closed, atmospheric vents F001 and F002 are open, and temperature is below 190 degrees $\mathrm{F}$. The primary coolant is subcooled, and the unit is in OC 4. See Table B.4.1 for a list of the most important precautions, limitations, and actions associated with this procedure.

\section{B.4.1 Reactor Startup}

Reactor startup is completed as follows. RHR is aligned so that LPCI can be initiated with no manual realignment; thus, shutdown cooling is not provided since alignment of RHR for shutdown cooling is not allowed. The only active core cooling present is that due to injection from the control rod hydraulic system and blowdown with the RWCU system, and that is 
insufficient to prevent heatup. It is acceptable to have no active core cooling during heatup because:

(1) It is desired to heatup the unit anyway,

(2) The time to heat to saturation in this condition is long since the unit has been shutdown for an appreciable time and decay heat is low (procedure \#05-1-02-3-1 provides curves giving time to boil), and

(3) LPCI is available if needed.

The mode switch is placed in STARTUP and this places the unit in OC 2 (not that $O C 3$ is skipped during abnormal startup). The rods are withdrawn per the specified pattern until the unit is critical. This plant uses nuclear heat to heat up as opposed to pump heat as utilized in many PWRs. (The BWR can maintain shutdown margin with rods alone at near ambient temperatures while the PWR cannot. Thus, criticality on rods in the BWR at low temperatures is acceptable.)

The above information is a summarization of the information presented in Table B.4.2.

\section{B.4.2 Unit Heatup}

Unit heatup is accomplished as follows: The vent to atmosphere is isolated by closing F001 and F002. F005 is opened to provide controlled venting of noncondensibles to the main condenser. As the unit is heated up, the water will follow the saturation curve and temperature will be the saturated value at the existing pressure. The vacuum in the main condenser is established with hoggers (mechanical vacuum pumps). Heatup is initiated by withdrawing rods, and the rate is kept below 80 degrees $F$ per hour. The rods must be withdrawn to maintain criticality as the primary heats up to counter the negative temperature coefficient of the moderator. The turbine bypass stop valves are opened. The chemical conditions of the primary are verified to be acceptable. It is verified that one condensate pump is in operation. Feedwater level control is instituted using the startup level controller. At about $60 \mathrm{psig}, \mathrm{RCIC}$ is placed in standby. Letdown with RWCU is stopped when automatic control on level with feedwater is established. At about 100 psig, one RWCU pump/filter is placed in cleanup mode. At about 200 psig, the second RWCU pump/filter is placed in cleanup mode. At about 400 psig, the TBVs are verified to be about $10 \%$ open and one feed pump turbine is rolled into service; evidently, the second feed pump is placed in service per procedure \#SOI-04-1-01-N21-1. At about 500 to 800 psig, the steam jet air ejectors are placed in service to provide condenser vacuum. At about 950 psig, the TBVs operate at their setpoint, and open as thermal power increases. The mode switch is transferred to RUN and the unit is in OC 1, with thermal power at about $4 \%$, electrical power zero, pressure about 950 psig saturated, and steam being dumped to the condenser via the TBVs. As power increases, the rods are withdrawn to overcome the Doppler effect in the fuel and maintain criticality. See Table B.4.3 for the important steps associated with this portion of the procedure.

\section{B.4.3 Turbine Startup and Generator Synchronization}

Turbine startup and generator synchronization are accomplished as follows. The turbine stop valves are opened. The second stage moisture separator reheater is placed in service. The EHC is set for $400 \mathrm{rpm}$ and the turbine is rolled to $400 \mathrm{rpm}$ as the turbine control valves open in response to the EHC signal. The turbine speed is increased to $1800 \mathrm{rpm}$. The turbine bypass valves are verified to be at least $20 \%$ open to accommodate generator synchronization and loading. The generator is to be operated with constant output voltage using the voltage regulator in auto control (the emf of the generator is varied with load to maintain constant terminal voltage). The load dispatcher is notified that the generator is ready to come on the grid. The EHC is set to $1805 \mathrm{rpm}$, and at the $12 \mathrm{o}^{\prime}$ clock position on the synchroscope, the generator is connected to the grid. The $120^{\prime}$ 'clock position corresponds to the generator voltage being equal and opposite to the grid voltage and hence the generator is not loaded (no current to the grid). The grid provides synchronizing power to lock the speed in at $1800 \mathrm{rpm}$. (A speed setting of slightly greater than $1800 \mathrm{rpm}$ does not change the turbine speed once the generator is on the grid. It moves the TCVs to a position corresponding to the speed setting and thereby establishes the generator output power. Speed control can only be used up to about $175 \mathrm{MWe}$, thereafter load control is used.) Power output is increased with speed control to between 75 and $150 \mathrm{MWe}$. The first stage moisture separator reheater is placed in service. Power output is raised to about $175 \mathrm{MWe}$ by setting speed demand at about $1812 \mathrm{rpm}$. Control is transferred from speed to load demand. Electrical power is not to exceed $24 \%$ during use of this procedure. The second condensate and booster pumps are started. The high pressure feedwater heaters are placed in service. (The low pressure feedwater heaters were placed in service 
when steam was admitted to the low pressure turbines, since no valves need to be opened to extract steam to the low pressure heaters, as indicated on Figure 10.3-4 in the FSAR.) See Table B.4.4 for a list of the steps described above.

\section{B.5 Inadequate Decay Heat Removal - \#05-1-02-III-1}

The Inadequate Decay Heat Removal Procedure addresses two situations with respect to loss of decay heat removal. These are inadequate decay heat removal when fuel is in the vessel and the unit is in OC 4 and when fuel is in the vessel and the vessel head is off. Table B.5.1 lists the symptoms which indicate a loss of heat removal capability, and Table B.5.2 provides a list of the immediate operator actions which should be performed given entry into the procedure.

\section{B.5.1 Fuel in the Vessel and the Unit in OC 4}

If inadequate decay heat removal is encountered while the unit is in OC 4, the following steps are taken. Note that if decay heat removal is not restored prior to entering OC 3, the ADHRS must be isolated (its suction design pressure is only $80 \mathrm{psig}$ ). If the in-service loop of RHR on SDC is lost, the other RHR loop or the ADHRS is placed in operation for SDC. If forced recirculation (low speed) is lost, level is raised to about 82 inches to promote natural circulation and attempts are made to restore recirculation. If RHR SDC is also lost, the head spray is operated, if available. If SDC with RHR and cooling with ADHRS are completely lost, RWCU letdown and makeup (CRD hydraulic and condensate) are increased to the maximum to maximize their effect on cooling. (This alone will only work for low decay heat levels, but it does increase the time available to institute other measures. The maximum letdown rate with RWCU is about $360 \mathrm{gpm}$, which can match decay heat only if the unit has been shutdown for about 17 days or longer.) Also, Attachment $\# 1$ of the procedure is used to estimate the time to boil. If SDC or ADHRS cannot be restored within this time, the following steps are taken: SP cooling is initiated, all vents are closed (F001, F002, and F005), the MSIVs are closed, the RCIC steam line isolation valves are closed, SRVs are manually operated so that two of them are open, the vessel level is increased with any available means to 101 inches to 129 inches to allow water discharge to the SP, LPCS and/or LPCI are actuated to supply coolant to the vessel from the suppression pool, and the unit is taken to cold shutdown per procedure \#03-1-01-3. See Table B.5.3 for the important steps corresponding to this portion of the procedure.

\section{B.5.2 Fuel in the Vessel and the RPV Head is Off}

If inadequate decay heat removal is encountered with the vessel head removed, the mitigative actions depend on whether or not the upper reactor cavity pool is filled with water. If the upper cavity is filled with water, then fuel pool cooling is maximized if necessary until SDC with RHR or ADHRS can be re-established. (As discussed in Section B.3, the vessel water, the upper reactor cavity pool, the upper containment pool, and the spent fuel storage pool are interconnected when the head is off and the gates and valves isolating the pools are open. In this situation, the pool cooling system can cool vessel water as well as pool water.)

If inadequate heat removal is encountered with the vessel head off and the upper reactor cavity pool not filled, then the following steps are taken. Recovery of SDC with RHR or ADHRS is attempted as soon as possible, and vessel level is raised. If SDC with RHR and ADHRS are totally lost, letdown and makeup are increased to the maximum (RWCU and CRD/condensate). If increased letdown is not adequate, the fire water system is aligned to flood the vessel, and appropriate vessel drain lines are opened.

Tables B.5.4 and B.5.5 list the important steps associated with this section of the procedure.

With the vessel head off, if ECCS injection is used, the water injected into the vessel will exit the open top and fill the upper containment if the SRV's are unavailable due to installation of steam line plugs. In this situation, the operator will throttle ECCS injection to avoid overfilling upper containment. 
Table B.1.1

Precautions, Limitations, and Actions Associated with Procedure 03-1-01-2

$\underline{\text { Step }}$ Description

2.2 Adhere to power distribution limits specified in Tech Spec 3/4.2.

2.4 Generator loading must be within limits of the curves given in Figures 1 and 2.

2.5 Maintain thermal power less than or equal to that allowed as a function of core flow as specified by "Power to Flow Operating Map".

2.7 Balance recirculation loop flows per Tech Spec 3.4.1.3.

2.10 Decrease load as specified when feedwater heaters/reheaters are out of service.

2.16 Do not pull rods if thermal power $>20 \%$ unless TBVs are closed (Tech Spec 3.4.1).

2.21 At turbine loads $<50 \%$ condensor vacuum should be maintained $\geq 3.63$ psia as steam cooling on last stage blades is minimal. 


\begin{tabular}{|c|c|c|c|c|c|}
\hline & Step & $\begin{array}{c}\text { OC } \\
\text { Reactor Power, } \\
\mathbf{P} \\
\text { Electric Power, } \\
\mathbf{P} \\
\text { P (psig) } \\
\text { T (PF) }\end{array}$ & -. Reactivity & Heat Removal & Comments \\
\hline & Low power to full power increase & $\begin{array}{l}\text { OC } 1 \\
\mathrm{P}^{\mathrm{i}} \sim 15 \% \\
\mathrm{P}^{\mathrm{i}} \sim 15 \% \\
\mathrm{P}_{\text {rated }} \\
\mathrm{T}_{\mathrm{su}}(\mathrm{p})\end{array}$ & $\begin{array}{l}\text { Critical on rods with } \\
\text { recirculation low speed, } \\
\text { FCVs full open }\end{array}$ & $\begin{array}{l}\text { Loaded turbine and } \\
\text { turbine bypass }\end{array}$ & \\
\hline & $\begin{array}{l}\text { Obtain loading instructions from } \\
\text { system dispatcher }\end{array}$ & & & & \\
\hline & $\begin{array}{l}\text { Increase load demand in } \\
\text { increments until TBVs are closed }\end{array}$ & & $\begin{array}{l}\text { Reactor power fixed; } \\
\text { send more steam to } \\
\text { turbine and less via } \\
\text { TBVs }\end{array}$ & & $\begin{array}{l}\text { As flow to turbine increases, turbine } \\
\text { header pressure drops below TBVs set } \\
\text { point and bypass valves close. }\end{array}$ \\
\hline & $\begin{array}{l}\text { Before increasing thermal power } \\
>20 \% \text {, verify TBVs closed per } \\
\text { Tech Spec 4.1.4.1 }\end{array}$ & & $\begin{array}{l}\text { Change reactor power } \\
\text { with rods only until } \\
\text { switch recirculation to } \\
\text { high speed and establish } \\
\text { rod pattern (5.11 and } \\
5.16)\end{array}$ & Loaded turbine & $\begin{array}{l}\text { Load demand increase opens TCVs, } \\
\text { generator voltage automatically shifts } \\
\text { in phase to provide more electrical } \\
\text { power. Don't pull rods if }<20 \% \\
\text { power unless TBVs closed. }\end{array}$ \\
\hline 5.4 & $\begin{array}{l}\text { Check that RFPT is on FW } \\
\text { master level controller before } \\
\text { exceeding } 20 \% \text { power }\end{array}$ & & & & Off startup, on master level controller \\
\hline & $\begin{array}{l}\text { Hold for } 1.5 \mathrm{hrs} \text {. at } \sim 20 \% \\
\text { power }\end{array}$ & & & & Allow for gathering of heat rate data \\
\hline 5.7 & $\begin{array}{l}\text { As soon as low power setpoint } \\
\text { (LPSP) exceeded, verify RWL } \\
\text { operability per Tech Spec } \\
\text { 4.1.4.2.6.1 }\end{array}$ & & & & $\begin{array}{l}\text { LPSP }=20 \% \text { P } \\
\text { RWL is Rod Withdrawal } \\
\text { Limiter (for power peaking) }\end{array}$ \\
\hline
\end{tabular}


Table B.1.2 Summarization of Procedure Steps Necessary for Low Power to Full Power Increase

\begin{tabular}{|c|c|c|c|c|}
\hline Step & $\begin{array}{c}\text { OC } \\
\text { Reactor Power, } \\
\mathbf{P} \\
\text { Electric Power, } \\
\mathbf{P} \\
\text { P (psig) } \\
\text { T ( } \mathrm{F} \text { ) } \\
\end{array}$ & Reactivity $\cdot$ & Heat Removal & Comments \\
\hline $\begin{array}{l}5.10 \text { At } \sim 40 \% \text { power hold for } 1.5 \\
\text { hrs. }\end{array}$ & & & & Allow for gathering of heat rate data \\
\hline $\begin{array}{l}\text { While changing reactor power, } \\
\text { stay out of Region IV, Tech Spec } \\
\text { figure 3.4.1.1-1. If in Region } \\
\text { IV, reduce power to be in } \\
\text { Regions II or III within } 2 \text { hours }\end{array}$ & & & & \\
\hline $\begin{array}{l}5.11 \text { When reactor power stable }> \\
34 \% \text { and below } 80 \% \text { rod line, } \\
\text { shift-recirculation pumps to high } \\
\text { speed }\end{array}$ & & $\begin{array}{l}\text { Critical on rods, don't } \\
\text { increase recirculation } \\
\text { until Step } 5.16\end{array}$ & & $\begin{array}{l}\text { Switch to hi speed when clear low FW } \\
\text { flow limit }(\sim 30 \%) \text {, set FCVs on min. } \\
\text { open before speed change ( } 30 \% \mathrm{FW} \text { is } \\
\text { control valve cavitation interlock) }\end{array}$ \\
\hline $\begin{array}{l}5.13 \text { At } \sim 40 \text { to } 45 \% \text { reactor power, } \\
\text { verify level, steam, and feed flow } \\
\text { are stable. Place FW control in } \\
\text { 3-element mode }\end{array}$ & & & & $\begin{array}{l}3 \text { element mode is where RFP speed } \\
\text { is a function of vessel water level, } \\
\text { steam flow, and FW flow }\end{array}$ \\
\hline $\begin{array}{l}5.14 \text { At } \sim 45 \text { to } 55 \% \text { reactor power, } \\
\text { place } 2 \text { nd RFPT in service on } \\
\text { master level control, place } 2 \text { nd } \\
\text { circ. water pump in service }\end{array}$ & & & & \\
\hline $\begin{array}{l}\text { 5.16 When desired flow control line } \\
\text { reached, increase power by } \\
\text { increasing recirculation flow with } \\
\text { loop controllers in manual }\end{array}$ & & $\begin{array}{l}\text { Increase power with } \\
\text { recirculation after } \\
\text { desired rod pattern } \\
\text { reached }\end{array}$ & & $\begin{array}{l}\text { Rod pattern fixed, increase power by } \\
\text { opening FCVs }\end{array}$ \\
\hline 5.17 At $\sim 60 \%$ power, hold $\sim 1.5 \mathrm{hrs}$. & & & & Allow for gathering of heat rate data \\
\hline
\end{tabular}




\begin{tabular}{|c|c|c|c|c|}
\hline Step & $\begin{array}{c}\text { OC } \\
\text { Reactor Power, } \\
\mathbf{P} \\
\text { Electric Power, } \\
\mathbf{P} \\
\text { P (psig) } \\
\left.\text { T ( }{ }^{\circ} \mathrm{F}\right)\end{array}$ & Reactivity & Heat Removal & Comments \\
\hline $\begin{array}{l}5.20 \text { As soon as high power set point } \\
\text { (HPSP) reached }(\sim 70 \%) \\
\text { demonstrate RWL operability. } \\
\text { At } \sim 80 \% \text { power } 90 \% \text { core flow } \\
\text { all ECCS line break alarms } \\
\text { should be cleared; enter } \\
\text { applicable LCOs for any like } \\
\text { break alarms not cleared of these } \\
\text { conditions }\end{array}$ & & & & $\begin{array}{l}\text { Assumed: "ECCS line break alarm;" } \\
\text { is associated with the "low pressure" } \\
\text { sensors in the ECCS actuating I\&C, } \\
\text { per TS } 3 / 4.3 .3 \text {. Table 3.3.3-1. } \\
\text { These sensors provide "injection } \\
\text { permissive" signals to allow LPCI and } \\
\text { LPCS to actuate on either low vessel } \\
\text { level or on high drywell pressure if } \\
\text { pressure is also low. }\end{array}$ \\
\hline $\begin{array}{l}5.21 \text { At } \sim 80 \% \text { power maintain steady } \\
\text { state for } 1.5 \mathrm{hrs} \text {. }\end{array}$ & & & & Allow for gathering of heat rate data \\
\hline $\begin{array}{l}5.24 \text { At } \sim 100 \% \text { power hold for } \sim 1.5 \\
\text { hrs. }\end{array}$ & & & & Allow for gathering of heat rate data \\
\hline
\end{tabular}


Table B.1.3 Summarization of Procedure Steps Necessary for Full Power to Low Power Decrease

\begin{tabular}{|c|c|c|c|c|}
\hline Step & $\begin{array}{c}\text { OC } \\
\text { Reactor Power, } \mathbf{P} \\
\text { Electric Power, } \mathbf{P}^{\mathbf{t}} \\
\text { P (psig) } \\
\text { T (PF) }\end{array}$ & Reactivity & Heat Removal & Comments \\
\hline $\begin{array}{l}\text { 6.0 Full power to low power } \\
\text { decrease }\end{array}$ & $\begin{array}{l}\text { OC } 1 \\
P^{\prime} \sim 100 \% \\
P^{i} \sim 100 \% \\
p_{r^{200}} \\
T_{s i t}(p)\end{array}$ & $\begin{array}{l}\text { Rods positions and } \\
\text { recirculation flow }\end{array}$ & Loaded turbine & \\
\hline $\begin{array}{l}\text { 6.1 Notify system dispatcher before } \\
\text { decreasing generator load }\end{array}$ & & & & \\
\hline 6.3 Decrease power by closing FCVs & & $\begin{array}{l}\text { Decrease with } \\
\text { recirculation flow }\end{array}$ & & \\
\hline $\begin{array}{l}\text { 6.4 Below } \sim 14 \times 10^{6} \mathrm{lbm} / \mathrm{hr} \mathrm{FW} \\
\text { flow secure } 1 \text { condensate booster, } \\
\text { then } 1 \text { condensate pump }\end{array}$ & & & & \\
\hline $\begin{array}{l}\text { 6.7 Before reducing core flow }< \\
45 \% \text { begin inserting rods }\end{array}$ & & $\begin{array}{l}\text { Decrease with recirc. } \\
\text { flow; and rods when } \\
\sim 45 \%\end{array}$ & & Insert rods per SOI 04-1-01-C11-2 \\
\hline $\begin{array}{l}6.10 \text { At } \sim 45 \% \text { to } 55 \% \text { reactor power, } \\
\text { secure one RFPT }\end{array}$ & & & & \\
\hline $\begin{array}{l}6.12 \text { Before FW decreases to } 30 \% \text { and } \\
\text { after below } 80 \% \text { rod line, switch } \\
\text { recirculation to low speed and } \\
\text { open FCVs to maximum. }\end{array}$ & & $\begin{array}{l}\text { Decrease with rods } \\
\text { once switch to low } \\
\text { speed }\end{array}$ & & \\
\hline $\begin{array}{l}6.17 \text { At }-20 \text { to } 25 \% \text { rated FW flow, } \\
\text { verify stable level, transfer to } \\
\text { single element control }\end{array}$ & & & & \\
\hline
\end{tabular}

N 


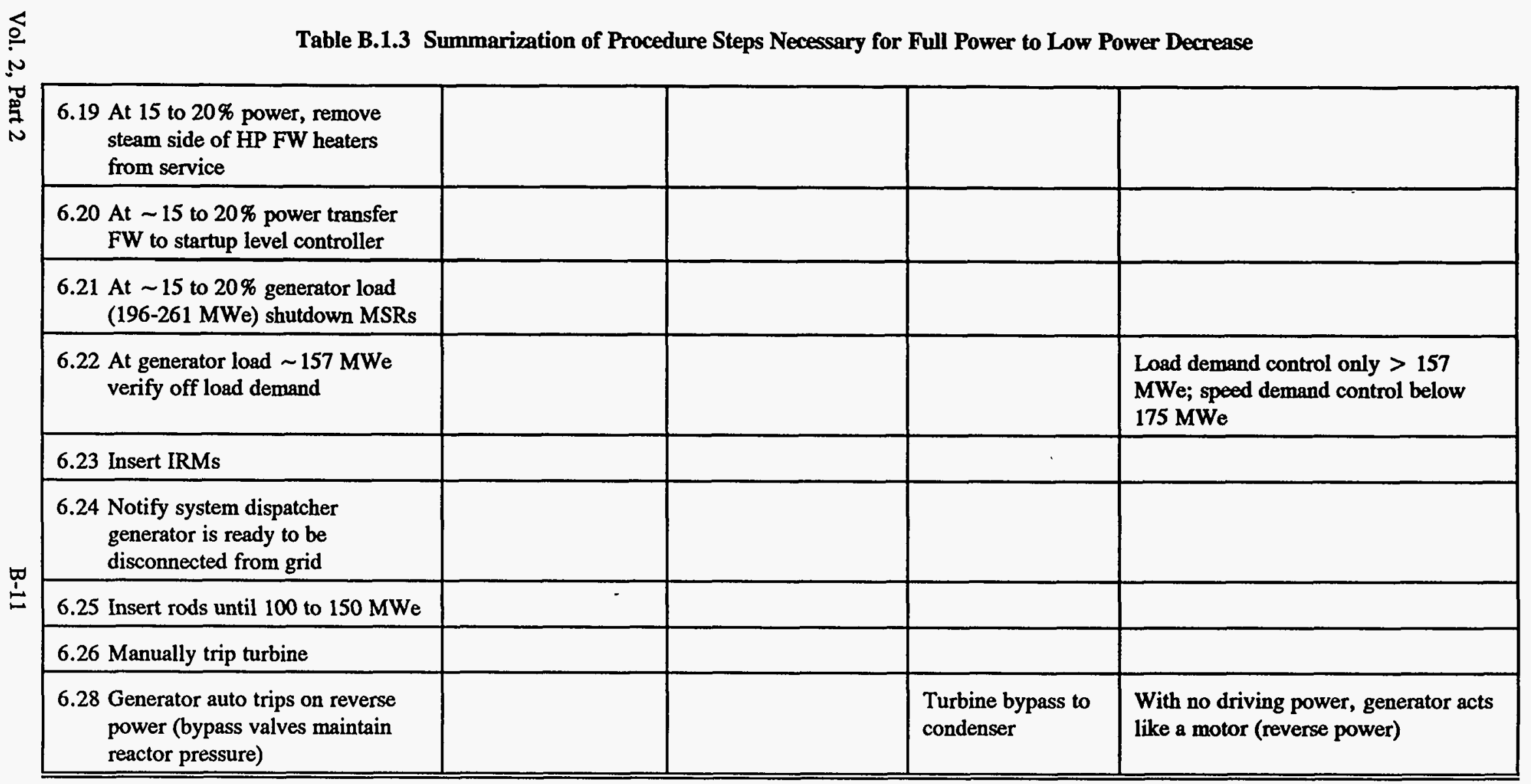


Table B.1.4 Summarization of Procedure Steps Necessary for Rapid Power Reduction

\begin{tabular}{|c|c|c|c|c|c|}
\hline & Step & $\begin{array}{c}\text { OC } \\
\text { Reactor Power, } \mathbf{P} \\
\text { Electric Power, } \mathbf{P}^{\prime} \\
\text { P (psig) } \\
\left.\text { T ( }^{\circ} \mathbf{F}\right)\end{array}$ & Reactivity & Heat Removal & Comments \\
\hline 7.0 & Rapid power reduction & 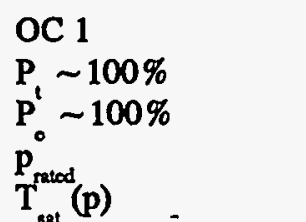 & & & \\
\hline 7.1 & $\begin{array}{l}\text { Reduce recirculation flow using } \\
\text { fast detent, then insert rods if } \\
\text { further power reduction necessary } \\
\text { or if scram occurred then follow } \\
6.0 \text {; enter ONEP-05-1-02-I-1 } \\
\text { "Reactor Scram" }\end{array}$ & & & & $\begin{array}{l}\text { Take appropriate action if in } \\
\text { unallowed power/flow regions }\end{array}$ \\
\hline
\end{tabular}


Table B.2.1 Precautions, Limitations, and Actions Associated with Procedure 03-1-01-3 Description

With mode switch in STARTUP, an APRM block occurs at $12 \%$ power, scram at $15 \%$ power.

2.2

With mode switch in RUN, APRM rod block if power $<5 \%$ (Procedure \#03-1-01-1 Step 2.1.10 says $4 \%$ ).

Maintain vessel level normal +32 to 40 inches.

2.5

Cooldown rate $\leq 80^{\circ} \mathrm{F} / \mathrm{hr}$.

2.6

Follow Tech Spec Figure 3.4.6-1-1 for vessel materials integrity.

2.8

If desired to remain in hot shutdown, reduce $\mathrm{Rx}$ pressure to approximately $400 \mathrm{psig}$ to minimize feedwater (feedwater temperature approximately $100^{\circ} \mathrm{F}$ with no feedwater heaters; $\mathrm{T}_{\text {zut }}(400 \mathrm{psig})$ is approximately $\left.450^{\circ} \mathrm{F}\right)$.

2.10

If cold shutdown is required, refer to SOI \#04-1-01-E12-1 and have shutdown cooling flushed $\&$ ready for service as soon as pressure permits.

2.12

Do not run two RWCU pumps in post pump mode at $<200$ psig RPV pressure as loss of NPSH may occur. 


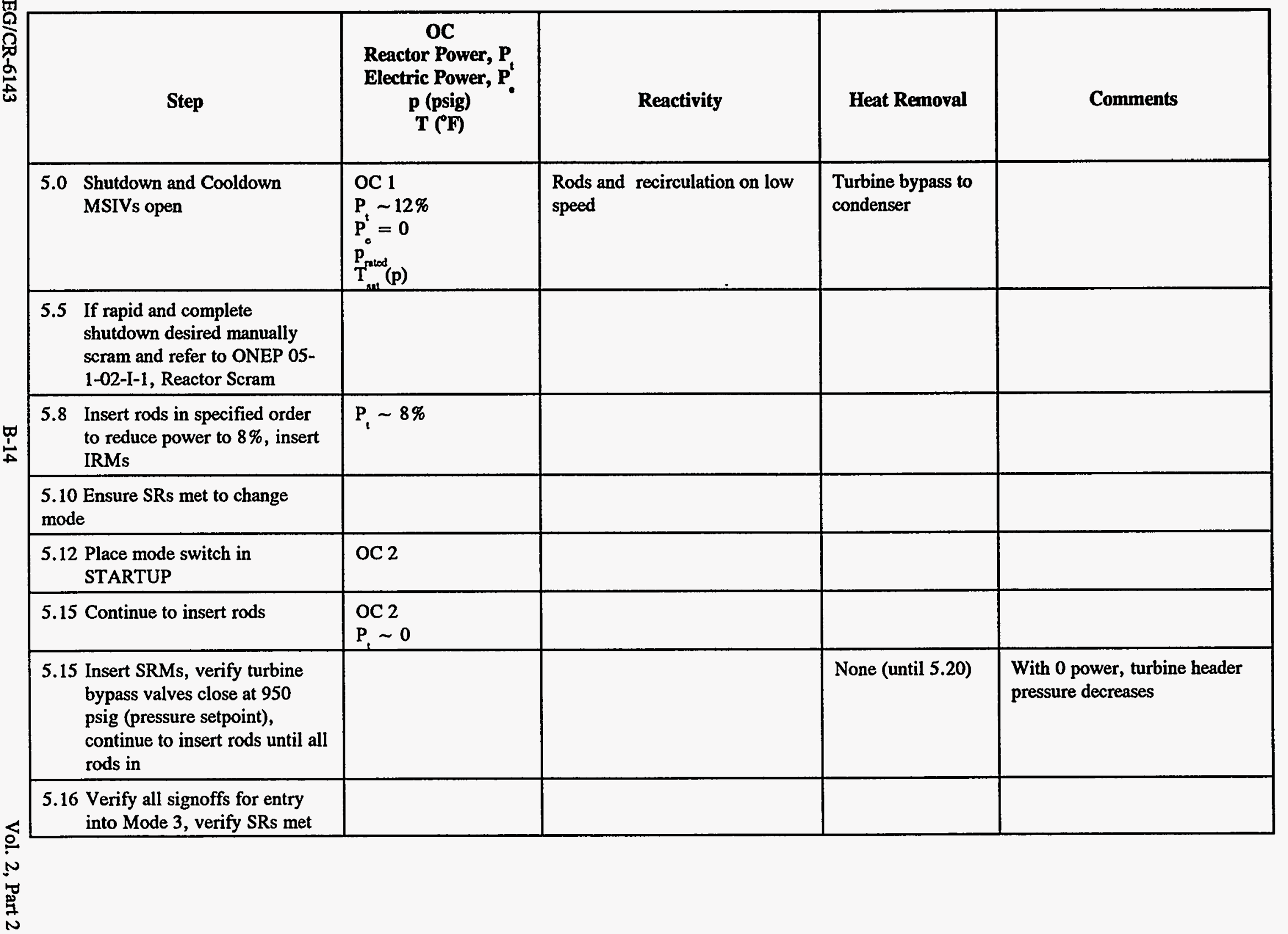




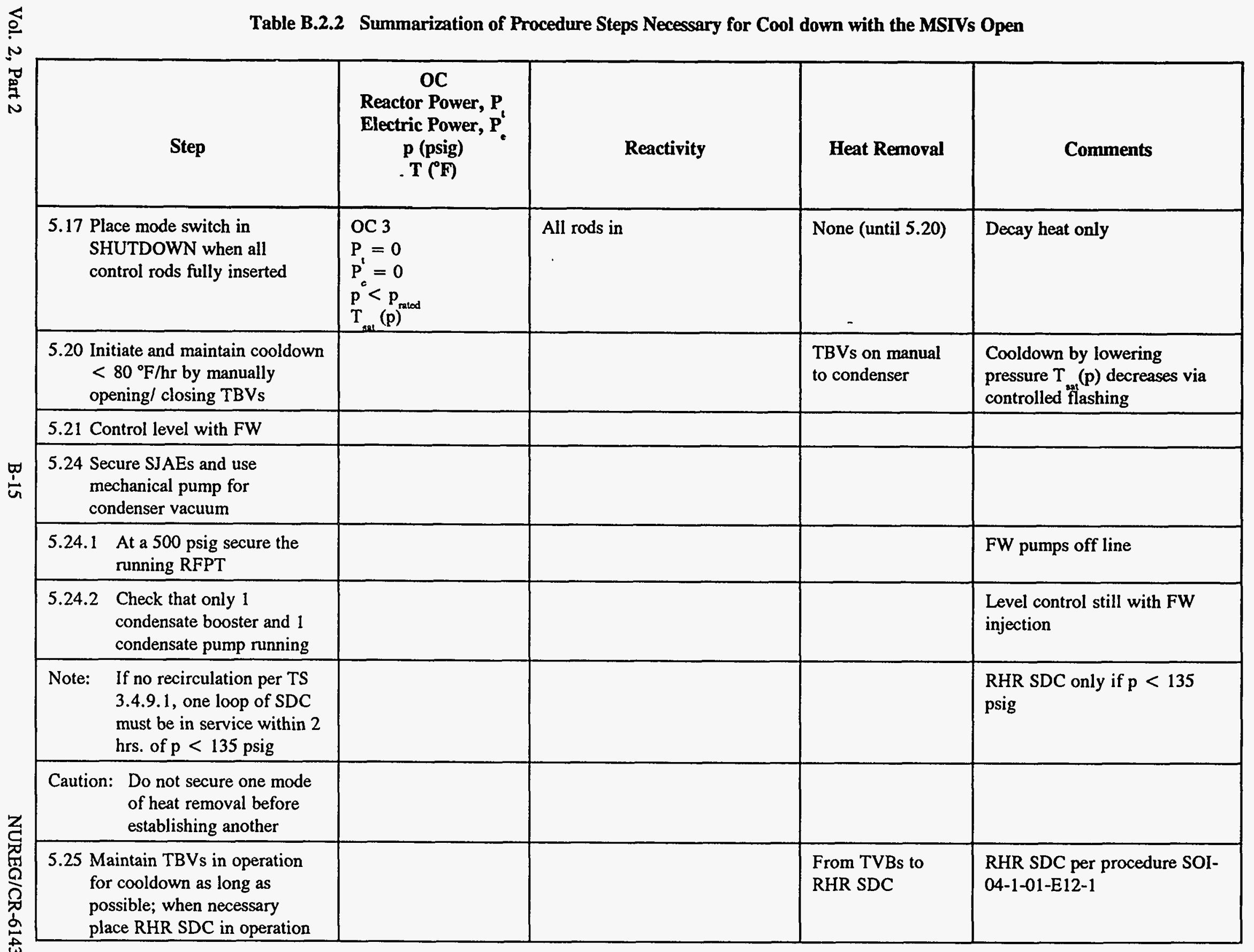


Table B.2.2 Summarization of Procedure Steps Necessary for Cool down with the MSIVs Open

\begin{tabular}{|c|c|c|c|c|}
\hline Step & $\begin{array}{c}\text { OC } \\
\text { Reactor Power, } \mathbf{P} \\
\text { Electric Power, } \mathbf{P}^{\mathrm{t}} \\
\mathbf{p} \text { (psig) } \\
\left.\mathbf{T} \text { ( }^{\circ} \mathbf{F}\right)\end{array}$ & Reactivity & Heat Removal & Comments \\
\hline \multicolumn{5}{|l|}{$\begin{array}{l}5.26 \text { At } 200 \text { psig secure } 1 \mathrm{RWCU} \\
\text { pump if both are running }\end{array}$} \\
\hline $\begin{array}{l}5.27 \text { At } 100 \text { psig transfer RWCU to } \\
\text { pre-pump mode }\end{array}$ & & & & $\begin{array}{l}\text { RWCU blowdown to } \\
\text { condenser or radwaste, can } \\
\text { take over level control from } \\
\text { FW }\end{array}$ \\
\hline $\begin{array}{l}5.29 \text { Shut the TBVs, set steam } \\
\text { demand setpoint } 100 \mathrm{psig}> \\
\text { reactor pressure }\end{array}$ & $\begin{array}{l}\text { OC } 3 \\
P_{1}=0 \\
P_{0}^{\prime}=0 \\
p_{0}<135 \text { psig } \\
T_{s i t}(p)\end{array}$ & & RHR SDC & $\cdots$ \\
\hline \multicolumn{5}{|l|}{$\begin{array}{l}\text { 5.30 Break condenser vacuum if } \\
\text { desired } \\
\text { - Shut down mech vacuum } \\
\text { pump } \\
\text { - Open condenser vacuum } \\
\text { breakers } \\
\text { - Shut down gland seal } \\
\text { steam } \\
\text { - Shut down circ. water, if } \\
\text { desired } \\
\end{array}$} \\
\hline $\begin{array}{l}5.31 \text { When } \mathrm{T}<190^{\circ} \mathrm{F} \text {, open } \\
\text { F001, open F002, and close } \\
\text { F006 }\end{array}$ & $\begin{array}{l}\text { OC } 4 \\
\mathrm{P}=0 \\
\mathrm{P}_{\mathrm{c}}^{\prime}=0 \\
\mathrm{p}^{\mathrm{c}}=0 \mathrm{psig} \\
\mathrm{T}<190^{\circ} \mathrm{F} \\
\text { subcooled }\end{array}$ & & & Vent primary to atmosphere \\
\hline $\begin{array}{l}\text { To prevent thermal stratification, } \\
\text { maintain recirculation on low speed }\end{array}$ & & & & \\
\hline
\end{tabular}




\begin{tabular}{|c|c|c|c|c|}
\hline Step & $\begin{array}{c}\text { OC } \\
\text { Reactor Power, } \mathbf{P} \\
\text { Electric Power, } \mathbf{P}^{\mathrm{t}} \text {. } \\
\text { p (psig) } \\
\text { T ( F) }\end{array}$ & Reactivity & Heat Removal & Comments \\
\hline $\begin{array}{l}\text { If recirculation or shutdown cooling } \\
\text { lost, go to procedure ONEP 05-1- } \\
02-\text { III-1 }\end{array}$ & & & & $\begin{array}{l}\text { Inadequate decay heat removal } \\
\text { procedure (ONEP 05-1-02-III- } \\
\text { 1) } \\
\text { (off normal event procedure) }\end{array}$ \\
\hline $\begin{array}{l}\text { 5.32 Cool down to and maintain } \\
120-130^{\circ} \mathrm{F}\end{array}$ & $\begin{array}{l}\text { OC } 4 \\
P^{\prime}=0 \\
P^{\prime}=0 \\
P^{c}=0 \text { psig }\end{array}$ & & & \\
\hline 5.33 Secure condensate/FW system & & & & Level control with RWCU \\
\hline $\begin{array}{l}5.34 \text { Reject water with RWCU to } \\
\text { maintain normal level }\end{array}$ & & & & $\begin{array}{l}\text { Reject to counter CRD } \\
\text { hydraulic injection }\end{array}$ \\
\hline $\begin{array}{l}\text { 5.35 While maintaining COLD } \\
\text { SHUTDOWN and as } \\
\text { necessary to maintain desired } \\
\text { reactor coolant temperature } \\
\text { operate RHR in SDC per SOI } \\
04-1-01-E 12-1\end{array}$ & & & & \\
\hline
\end{tabular}


Table B.2.3 Summarization of Procedure Steps Necessary for Cool down with the MSIVs Closed

\begin{tabular}{|c|c|c|c|c|}
\hline Step & $\begin{array}{c}\text { OC } \\
\text { Reactor Power, } \mathbf{P} \\
\text { Electric Power, } \mathbf{P}^{\prime} \\
\text { p (psig) } \\
\left.\text { T ( }{ }^{\circ} \mathbf{F}\right)\end{array}$ & Reactivity & Heat Removal & Comments \\
\hline $\begin{array}{l}\text { 6.0 Shutdown and Cooldown with } \\
\text { MSIVs closed }\end{array}$ & $\begin{array}{l}\text { OC } 1 \\
P^{\prime} \sim 12 \% \\
P_{0}^{i}=0 \\
p^{-}=p_{\text {ricod }} \\
T_{s u l}(p)\end{array}$ & $\begin{array}{l}\text { Rods and recirculation on low } \\
\text { speed }\end{array}$ & $\begin{array}{l}\text { Turbine bypass to } \\
\text { condenser (if } \\
\text { MSIVs open) }\end{array}$ & $\begin{array}{l}\text { This section assumes MSIVs } \\
\text { initially open. If MSIVs are } \\
\text { closed perform only applicable } \\
\text { steps }\end{array}$ \\
\hline $\begin{array}{l}\text { 6.5 Check for availability of } \\
\text { operation (with MSIVs closed) } \\
\text { of: } \\
\text { - RCIC } \\
\text { - RWCU (level control) } \\
\text { - SRVS } \\
\text { - SP } \\
\text { - SSW }\end{array}$ & & & & \\
\hline $\begin{array}{l}\text { 6.6 If rapid and complete } \\
\text { shutdown desired, scram } \\
\text { reactor and follow ONEP 05- } \\
\text { 1-02-I-1 "Reactor Scram" }\end{array}$ & & & & \\
\hline $\begin{array}{l}6.9 \text { Insert rods and reduce power } \\
\text { to } \sim 8 \% \text {, insert IRMs, mode } \\
\text { switch to STARTUP }\end{array}$ & $\begin{array}{l}\mathrm{OC} 2 \\
\mathrm{P}_{\imath} \sim 8 \%\end{array}$ & & & \\
\hline $\begin{array}{ll}6.15 .9 & \begin{array}{l}\text { Insert all rods, verify } \\
\text { signoffs for entry to OC } 3\end{array} \\
\end{array}$ & $\begin{array}{l}\text { OC } 2 \\
\text { P. } \sim 0 \%\end{array}$ & & & \\
\hline $\begin{array}{l}\text { 6.17 Place mode switch in } \\
\text { SHUTDOWN when all rods } \\
\text { inserted }\end{array}$ & $\begin{array}{l}\mathrm{OC} 3 \\
\mathrm{P}_{1} \sim 0 \%\end{array}$ & & & \\
\hline
\end{tabular}




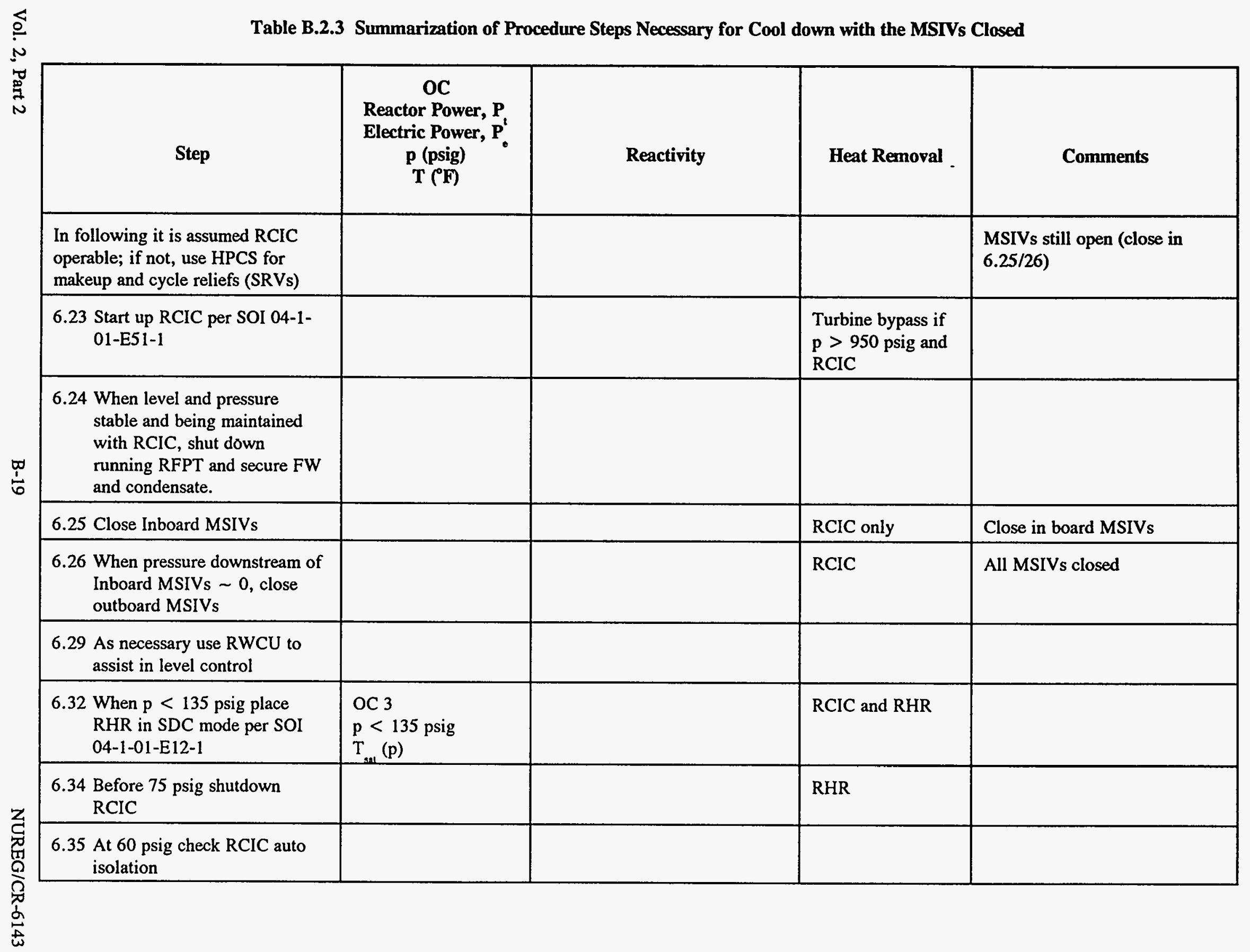




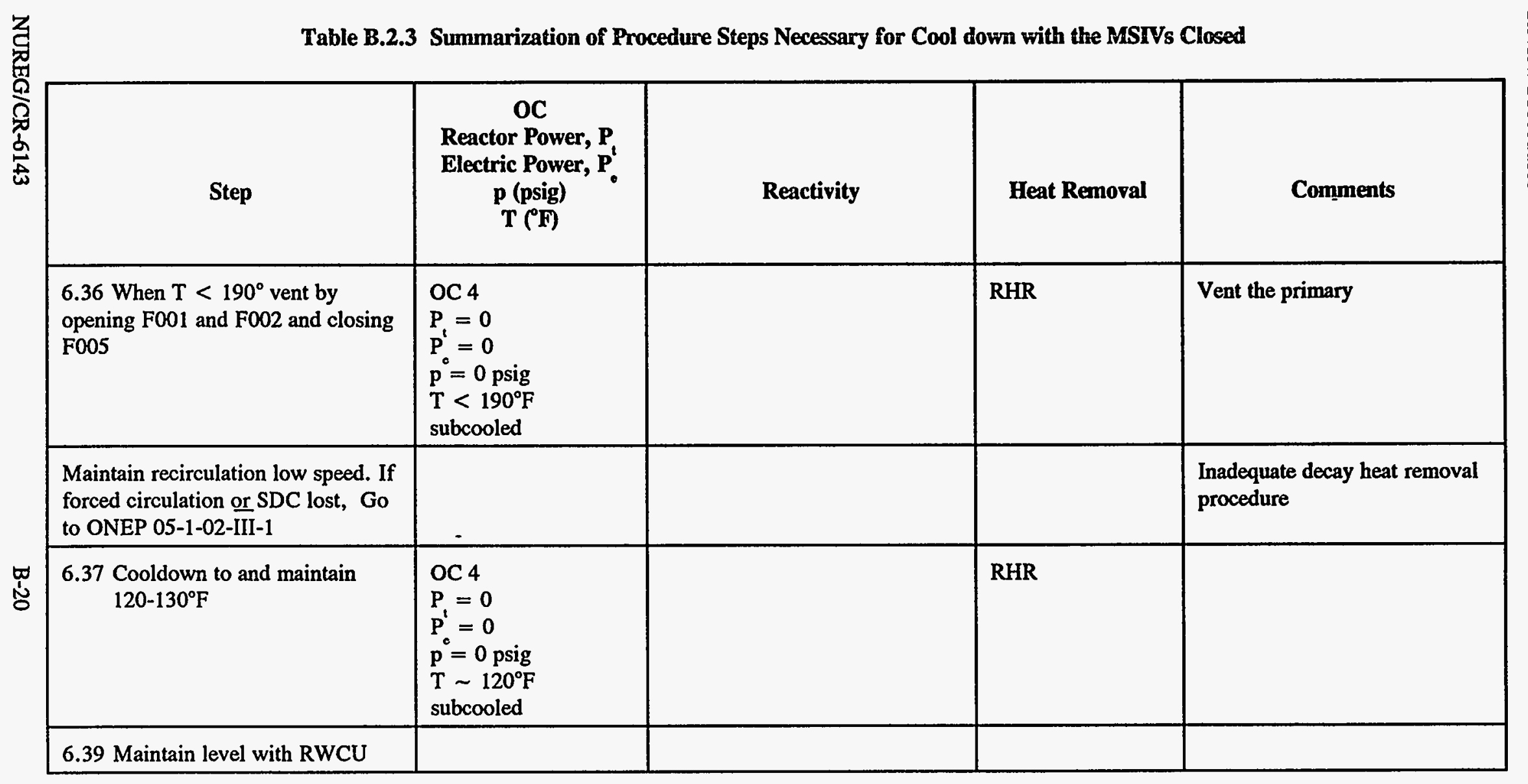


Table B.3.1

Precautions and Limitations Associated with Procedure 03-1-01-5

Step

2.19

2.20

2.21

2.22

\section{Description}

Recirculation on low speed. Go to ONEP 05-1-02-III-1 ("Inadequate Decay Heat Removal") if recirculation or SDC lost.

Limit cooldown $\leq 100^{\circ} \Delta \mathrm{F} / \mathrm{hr}$.

Adhere to pressure and temperature limits per Tech Spec Figure 3.4.6.1-1.

Vessel temperature $>70^{\circ} \mathrm{F}$ when studs tensioned. 


\begin{tabular}{|c|c|c|c|c|}
\hline Step & $\begin{array}{c}\text { OC } \\
\text { Reactor Power, } \mathbf{P} \\
\text { Electric Power, } \mathbf{P}^{\mathbf{t}} \\
\text { p (psig) } \\
\text { T ( } \text { ( }^{\circ} \text { ) }\end{array}$ & Reactivity & Heat Removal & Comments \\
\hline 5.0 Cooldown \& entry to mode 5 & $\begin{array}{l}O C 3 \\
P^{\prime}=0 \\
P^{\circ}=0 \\
T^{\circ}>200^{\circ} \mathrm{F} \\
p_{s i s}(T)\end{array}$ & & & \\
\hline $\begin{array}{l}5.1 \text { Cooldown with TBVs until pressure } \\
\text { interlock for SDC clears }\end{array}$ & & & $\begin{array}{l}\text { TBVs to } \\
\text { condenser }\end{array}$ & $\unlhd 135$ psig for SDC \\
\hline $\begin{array}{l}\text { 5.2 Place SDC A or B in operation (refer to } \\
\text { TS 3.5.1 and 3.6.3.2) }\end{array}$ & & & & \\
\hline 5.3 Remove TBVs from service & & & $\begin{array}{l}\text { RHR in SDC } \\
\text { mode }\end{array}$ & \\
\hline 5.4 Fast close inboard MSIVs & & & & $\begin{array}{l}\text { Fast closure required to support local } \\
\text { leak rate test (LLRT) }\end{array}$ \\
\hline $\begin{array}{l}\text { 5.5 Let pressure downstream of inboard } \\
\text { MSIVs drop to } 0 \text {, then fast close outboard } \\
\text { MSIVs, initiate head spray if desired but } \\
\text { don't exceed } 100^{\circ} \mathrm{F} / \mathrm{hr} \text { cooldown }\end{array}$ & & & & $\begin{array}{l}\text { Head spray to cooldown head for } \\
\text { detensioning }\end{array}$ \\
\hline $\begin{array}{l}5.7 \text { At } 200 \text { psig transfer RWCU to blowdown } \\
\text { mode }\end{array}$ & & & & \\
\hline $\begin{array}{l}\text { 5.8 With condensate and startup level } \\
\text { controller raise level }>\text { flange }\end{array}$ & & & & $\sim 230^{\prime \prime}$ on shutdown range \\
\hline 5.9 Continue cooldown to 80 to $100^{\circ} \mathrm{F}$ & & & RHR on SDC & \\
\hline 5.10 At 60 psig verify RCIC auto isolates & OC 4 & & & \\
\hline 5.12 Open HFTS transfer tube closure hatch & & & & $\begin{array}{l}\text { Connect spent fuel pool in aux } \\
\text { building to upper pool in containment }\end{array}$ \\
\hline
\end{tabular}


Table B.3.2 Summarization of Procedure Steps Necessary for Plant Cool down and Entry into OC 5

\begin{tabular}{|c|c|c|c|c|}
\hline Step & $\begin{array}{c}\text { OC } \\
\text { Reactor Power, } \mathbf{P} \\
\text { Electric Power, } \mathbf{P}^{\mathbf{t}} \\
\text { p (psig) } \\
\text { T ( } \mathbf{F} \text { ) }\end{array}$ & Reactivity & Heat Removal & Comments \\
\hline \multicolumn{5}{|l|}{ 5.14 Open containment air locks } \\
\hline \multicolumn{5}{|l|}{$\begin{array}{l}5.17 \text { Containment and drywell equipment } \\
\text { hatches removed }\end{array}$} \\
\hline $\begin{array}{l}5.20 \text { Install upper pool to reactor upper cavity } \\
\text { gate and inflate gate seal }\end{array}$ & & & & $\begin{array}{l}\text { Isolate upper cavity from upper pool } \\
\text { to allow draining upper cavity }\end{array}$ \\
\hline 5.21 Drain upper cavity to RWST & & & & Refueling water storage tank (RWST) \\
\hline \multicolumn{5}{|l|}{$\begin{array}{l}\text { 5.23 Drain RWST to Hotwell for cleanup in } \\
\text { prepration for reflooding upper pool if } \\
\text { required }\end{array}$} \\
\hline \multicolumn{5}{|l|}{ 5.24 Remove drywell head } \\
\hline \multicolumn{5}{|l|}{$\begin{array}{l}5.25 \text { Lower vessel level to } 1 \mathrm{ft} \text { or move below } \\
\text { flange and verify head spray not in service }\end{array}$} \\
\hline \multicolumn{5}{|l|}{ 5.26 Remove connections to RPV head } \\
\hline 5.29 Detension RPV head & OC 5 & & & \\
\hline \multicolumn{5}{|l|}{ 5.30 Remove RPV head } \\
\hline \multicolumn{5}{|l|}{$\begin{array}{l}5.31 \text { Throttle recirculation to reduce water } \\
\text { ripple }\end{array}$} \\
\hline \multicolumn{5}{|l|}{$\begin{array}{l}\text { 5.32 Establish containment cleanup mode } \\
\text { ventilation. May remove airlock doors and } \\
\text { equipment hatches }\end{array}$} \\
\hline \multicolumn{5}{|l|}{ 5.33 Remove RPV steam dryer } \\
\hline 5.34 Drain level to below steam lines & & & & $\sim 90^{\prime \prime}$ on shutdown range \\
\hline
\end{tabular}


Table B.3.2 Summarization of Procedure Steps Necessary for Plant Cool down and Entry into OC 5

\begin{tabular}{|c|c|c|c|c|}
\hline Step & $\begin{array}{c}\text { OC } \\
\text { Reactor Power, } \mathbf{P} \\
\text { Electric Power, } \mathbf{P}^{\mathbf{t}} \\
\text { p (psig) } \\
\text { T ( } \text {. }\end{array}$ & Reactivity & Heat Removal & Comments \\
\hline 5.35 Install steam line plugs & & & & Can't use SRVs with plugs installed \\
\hline $\begin{array}{l}\text { 5.37 Reflood reactor cavity from RWST. Lift } \\
\text { steam separator as reactor cavity fills }\end{array}$ & & & & 5.23 Drained RWST? \\
\hline $\begin{array}{l}\text { 5.39 Deflate gate seals and remove upper pool } \\
\text { to reactor upper cavity gate }\end{array}$ & & & & \\
\hline $\begin{array}{l}5.42 \text { Commence required in-vessel work (e.g., } \\
\text { fuel movement) }\end{array}$ & & & SDC with RHR & \\
\hline
\end{tabular}




\begin{tabular}{|c|c|c|c|c|}
\hline Step & $\begin{array}{c}\text { OC } \\
\text { Reactor Power, } \mathbf{P} \\
\text { Electric Power, } \mathbf{P} \\
\text { p (psig) } \\
\text { T ( F) }\end{array}$ & Reactivity & Heat Removal & Comments \\
\hline 6.0 Pressure vessel reassembly & OC 5 & & RHR or SDC & \\
\hline $\begin{array}{l}\text { 6.5 Upper pool to reactor cavity gate installed } \\
\text { and seal inflated }\end{array}$ & & & & \\
\hline $\begin{array}{l}\text { 6.7 Drain upper reactor cavity to RWST. } \\
\text { Lower level to } 1 \mathrm{ft} \text {. below flange }\end{array}$ & & & & \\
\hline 6.8 Install steam separator & & & & \\
\hline 6.9 Lower vessel level below main steam lines & & & & \\
\hline 6.10 Deflate and remove main steam line plugs & & & & - \\
\hline 6.12 Install steam dryer & & & & \\
\hline 6.13 Install RPV head & & & & \\
\hline 6.15 Tension RPV head studs & & & . & \\
\hline 6.17 Place mode switch in SHUTDOWN & OC 4 & & & \\
\hline $\begin{array}{l}\text { 6.21 Commence RPV heatup in preparation for } \\
03-1-01-6\end{array}$ & & & SDC & Throttle SDC to heat up \\
\hline 6.24 Install drywell head & & & & \\
\hline 6.26 Reflood upper reactor cavity & & & & \\
\hline $\begin{array}{l}\text { 6.27 Deflate gate seals and remove upper pool } \\
\text { to reactor upper cavity gate }\end{array}$ & & & & \\
\hline
\end{tabular}


Table B.4.1

Precautions, Limitations, and Actions Associated with Procedure 03-1-01-1

Step

2.1.4

2.1.9

2.1.10

2.1.11

2.2.3

2.10.1\&2

2.10 .11
Description

Period $\geq 50 \mathrm{Sec}$

In STARTUP an APRM Rod Block occurs at $12 \%$ Power and an APRM Scram at $15 \%$ Power.

In RUN RPRM Rod Block it $<4 \%$ Power.

No Rod Withdrawal unless TBVs fully closed and power > low setpoint of RCIIs (rod control and information system).

Maintain heatup to $\leq 80^{\circ} \mathrm{F}$ to prevent exceeding Tech Spec 3.4.6.1 limits

No gland seal steam to turbine if shaft not turning. Turbine on turning gear for 24 hour if performing a cold startup and $1.5 \mathrm{hrs}$ for a hot startup if turbine not off turning gear during shutdown.

At turbine loads $<50 \%$, condenser vacuum $\geq 3.63$ psia since little steam cooling occurs on the last stage of the turbine under $<50 \%$ load. 


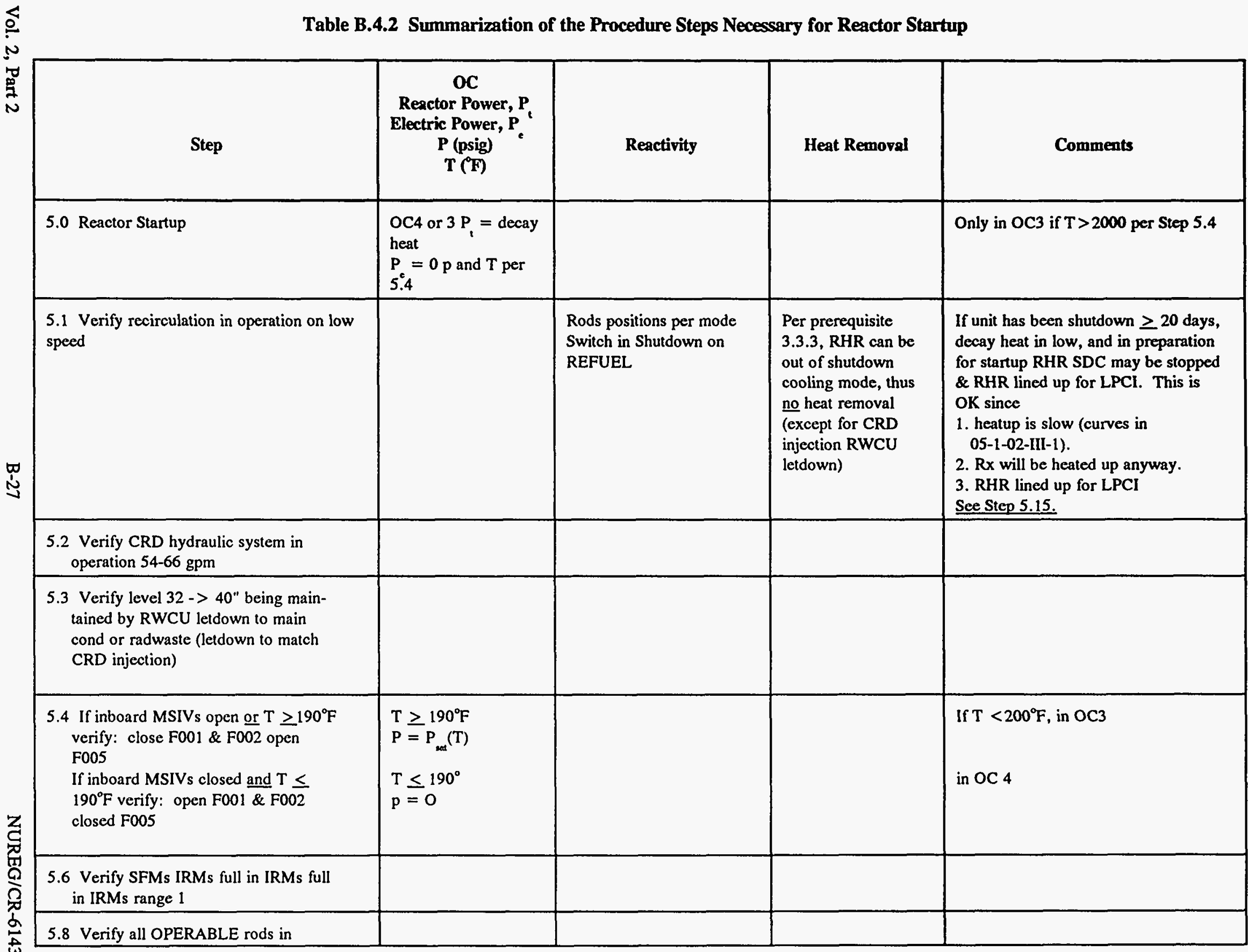


Table B.4.2 Summarization of the Procedure Steps Necessary for Reactor Startup

\begin{tabular}{|c|c|c|c|c|}
\hline Step & $\begin{array}{c}\text { OC } \\
\text { Reactor Power, } \mathbf{P} \\
\text { Electric Power, } \mathbf{P} \text {. } \\
\text { P (psig) } \\
\text { T ( (F) }\end{array}$ & Reactivity & Heat Removal & Comments \\
\hline $\begin{array}{l}\text { 5.15 Verify RHR A,B,C in Standby (or } \\
\text { in mode not requiring manual re- } \\
\text { alignment for LPCI) }\end{array}$ & & & & $\begin{array}{l}\text { No shutdown cooling; see comment } \\
\text { associated with Step 5.1. }\end{array}$ \\
\hline \multicolumn{5}{|l|}{5.20 Verify chemistry } \\
\hline 5.23 Place mode switch in STARTUP & $\begin{array}{l}\mathrm{OC} 2 \mathrm{P}^{\prime}=\text { decay } \\
\text { heat } \\
\mathrm{P}_{\mathrm{c}}=0 \mathrm{p} \text { and } \mathrm{T} \text { per } \\
5.4\end{array}$ & & & $\begin{array}{l}\text { TS Table } 1.2 \text { allows 'any temp' for } \\
\text { OC2. Normal cold startup posses } \\
\text { from OC4 to OC2 without any time in } \\
\text { OC3 } \\
\text { Heatup on nuclear heat; not pump heat } \\
\text { as for PWR }\end{array}$ \\
\hline \multicolumn{5}{|l|}{ 5.29 Pull 1 rod or 1 barg } \\
\hline \multicolumn{5}{|l|}{ 5.23 Withdraw rods until Rx critical } \\
\hline $\begin{array}{l}5.38 \text { Fully withdraw SRMs when IRMs on } \\
\geq \text { range } 3\end{array}$ & & & & \\
\hline
\end{tabular}




\begin{tabular}{|c|c|c|c|c|}
\hline Step & $\begin{array}{c}\text { OC } \\
\text { Reactor Power, } \mathbf{P} \\
\text { Electric Power, } \mathbf{P}^{\prime} \\
\text { P (psig) } \\
\text { T ( F) }\end{array}$ & Reactivity & Heat Removal & Comments \\
\hline \multicolumn{5}{|l|}{ 6.0 Unit Heatup } \\
\hline $\begin{array}{l}\text { 6.1 Establish Main Cond Vacuum } \\
\text { - If MSIVs closed, at 190 } \mathrm{F} \text { : } \\
\text { open F005, close F001 \& F002 } \\
\text { - verify main turbine \& RFPTs on } \\
\text { turning gear } \\
\text { - lineup seal steam condensate to } \\
\text { main turbine \& REPTs } \\
\text { - draw vacuum in main cond using } \\
\text { mech vacuum pumps to maintain } \\
20 \text { to } 26^{\prime \prime} \mathrm{Hg} \\
\text { - place cond demin's in service }\end{array}$ & $\begin{array}{l}P=P^{\text {sat }}(\mathrm{T}) \text { once } \\
\text { F001 \& F002 } \\
\text { closed }\end{array}$ & & & \\
\hline
\end{tabular}




\begin{tabular}{|c|c|c|c|c|}
\hline Step & $\begin{array}{c}\text { OC } \\
\text { Reactor Power, } \mathbf{P} \\
\text { Electric Power, P' } \\
\text { P (psig) } \\
\text { T ('F) }\end{array}$ & Reactivity & Heat Removal & Comments \\
\hline 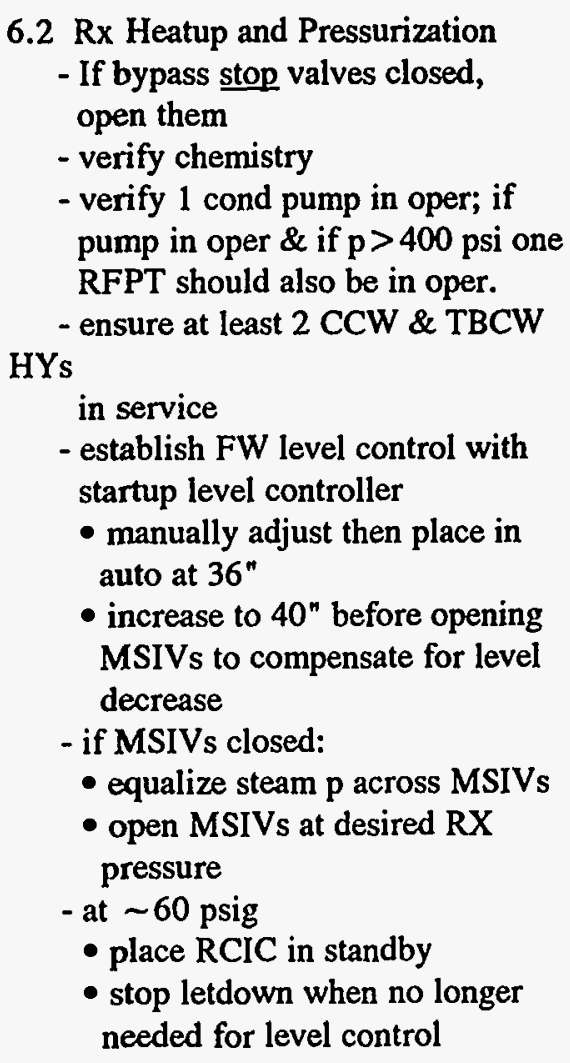 & & & & \\
\hline
\end{tabular}




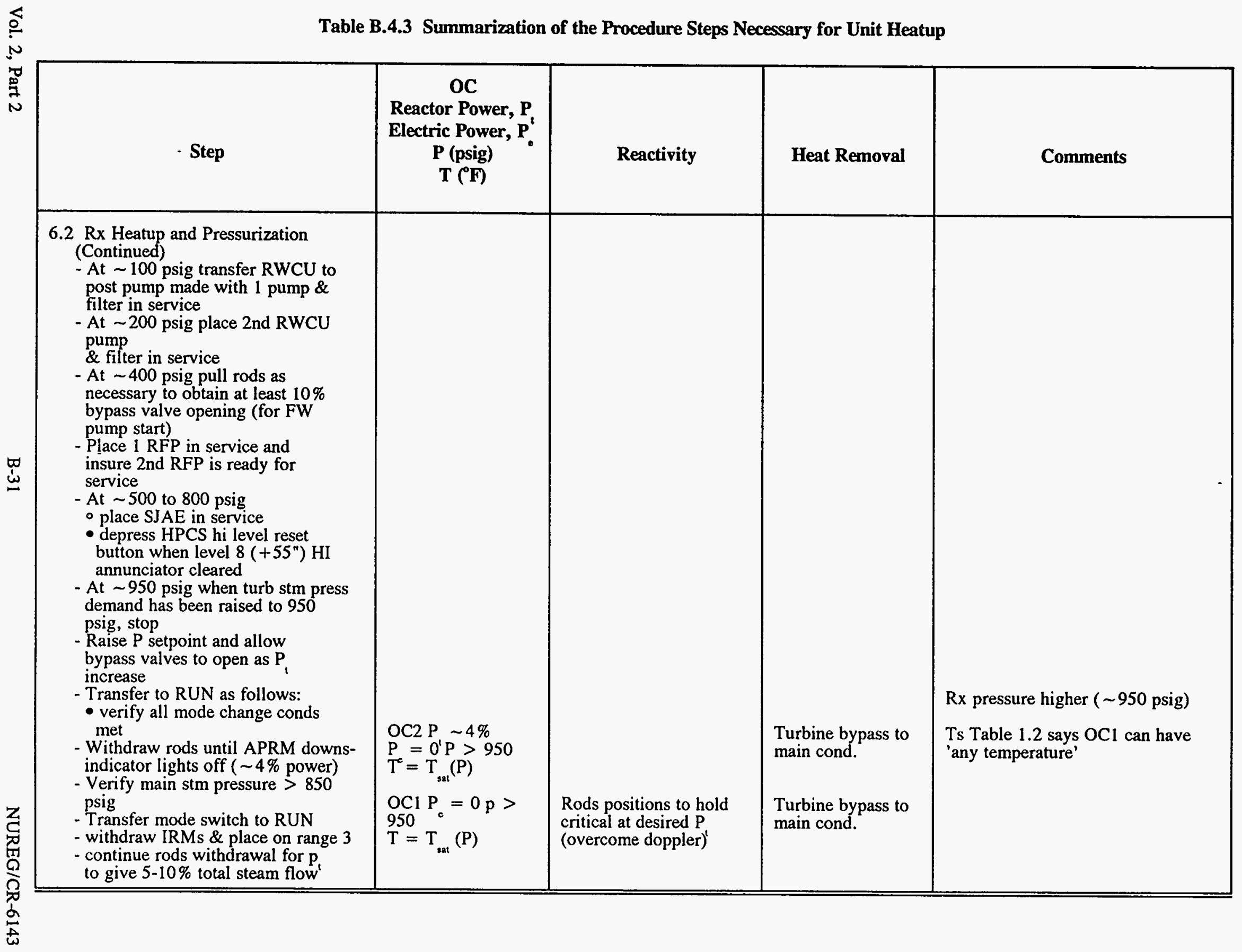




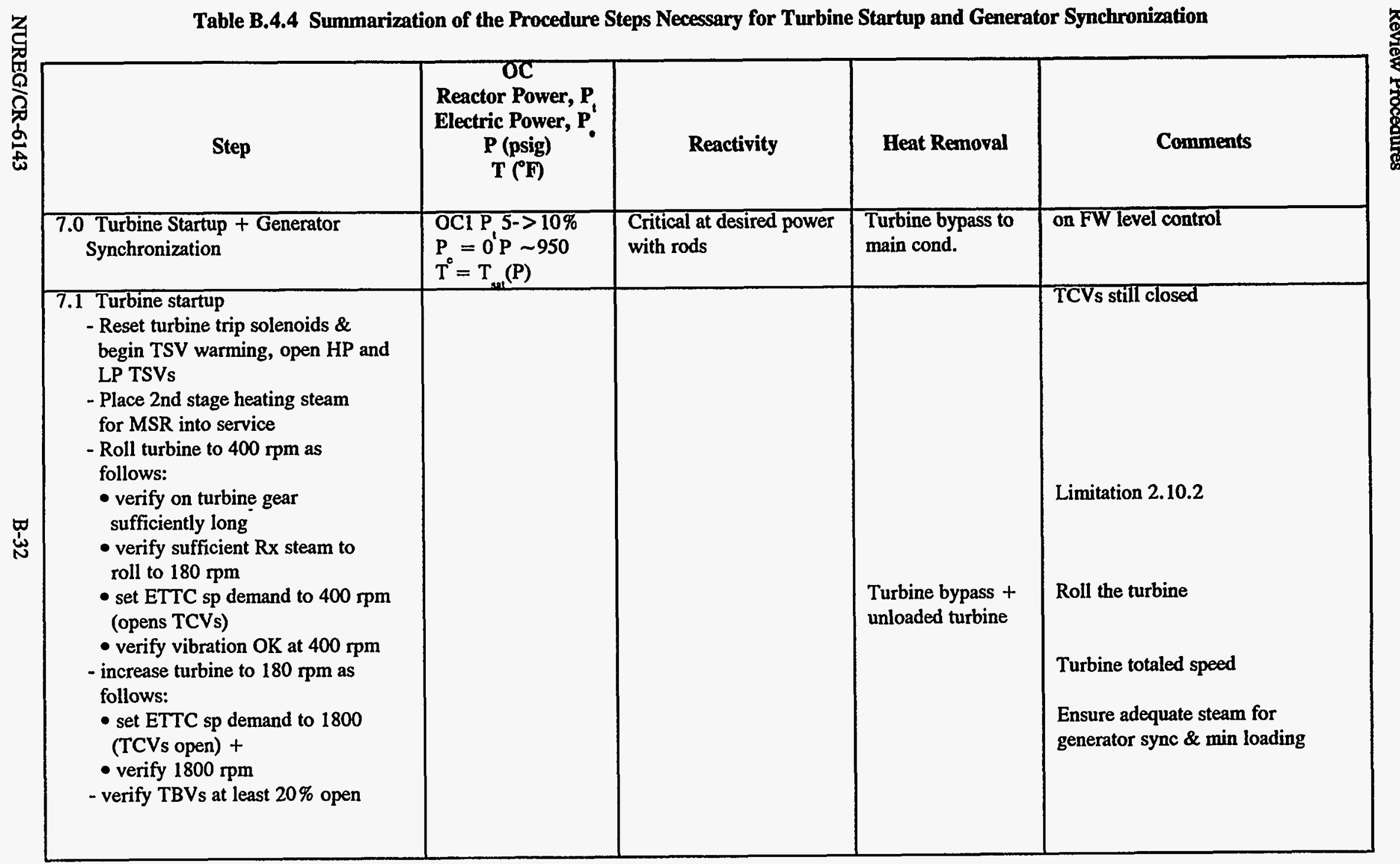




\begin{tabular}{|c|c|c|c|c|}
\hline Step & $\begin{array}{c}\text { OC } \\
\text { Reactor Power, } \mathbf{P} \\
\text { Electric Power, } \mathbf{P}^{\imath} \\
\text { P (psig) } \\
\text { T ( } \mathrm{F} \text { ) }\end{array}$ & Reactivity & Heat Removal & Comments \\
\hline $\begin{array}{l}7.2 \text { Generator Synchronization } \\
\text { - ensure motor disconnect J5230 } \\
\text { ready to be closed } \\
\text { - For breakers J5228 + J5231: } \\
\text { - verify switchyard lineup is } \\
\text { such that } 228+232 \text { can be } \\
\text { opened without losing loads; } \\
\text { open } 228+232 \\
\text { - close disconnect J5230 } \\
\text { - place isophase bus cooling in } \\
\text { oper. } \\
\text { - notify load dispatcher ready to } \\
\text { sync to grid } \\
\text { - verify generator }>1710 \mathrm{rpm}+ \\
\text { close generator field breaker } \\
\text { - adjust generator output to } 22 \mathrm{Kv} \\
\text { - close breaker J5228 or J5232 } \\
\text { - depress ETTC sp demand to } 1805 \\
\text { rpm } \\
\text { - watch synchroscope }+ \text { decrease } \\
\text { speed slowly until synchroscope } \\
\text { is slowly rotating in clockwise } \\
\text { ( fast) direction } \\
\text { - At } 12 \text { o'clock on synchroscope, } \\
\text { close J5232 (or J5228) } \\
\text { [depending on which closed } \\
\text { earlier] } \\
\text { - Increase gen load immediately } \\
\text { (by increasing speed demand of } \\
\text { EHC) to >75 Mw but } \leq 150 \mathrm{Mw} \\
\text { - Establish Ist stage MSR heating } \\
\text { steam } \\
\text { - Raise gen output to } 175 \mathrm{Mw} \text { with } \\
\text { EHC demand ( } 1812 \text { rpm } \\
\text { demand) } \\
\text { - Transfer from speed demand } \\
\text { control to load demand control } \\
\text { - Do not exceed } 34 \% \text { power in the } \\
\text { procedure } \\
\text { - Start } 2 \text { nd cond \& Booster pump } \\
\text { - Maintain } 1812 \text { rpm } 175 \mathrm{Mwe} \\
\text { - Place HP FW Ltrs in service }\end{array}$ & $\begin{array}{l}1 P_{1} \sim 10 \% \\
P \sim 75 \text { to } 150 \\
M w \\
P>950 \mathrm{~T}= \\
T_{\text {oxt }}(P) \\
P_{e} \leq 24 \% \text { rated }\end{array}$ & $\begin{array}{l}\text { Turbine bypass \& } \\
\text { unloaded turbine }\end{array}$ & & $\begin{array}{l} \\
\text { Generator freq slightly above grid; } \\
\text { ready to sync } \\
\text { Generator sync'd to grid; at any } \\
\text { fixed synchroscope position, gen. } \\
\& \text { grid frequency are equal; at } 12 \\
\text { o'clock position, in addition to } \\
\text { frequencies being equal, in each of } \\
3 \text { phases induced emf is equal and } \\
\text { opposite ( } 180^{\circ} \text { out of phase) with } \\
\text { line voltages and hence generator } \\
\text { is not loaded. } \\
\text { Ensure } ~ \\
\text { regardless of load demand } \\
\text { reast least } \\
\text { HP FW Htr steam extraction lines } \\
\text { have isolation valves that are } \\
\text { opened to place HPFW Htrs in } \\
\text { service } \\
\text { LP FW Htr steam extraction lines } \\
\text { probably have only check valves }\end{array}$ \\
\hline
\end{tabular}


Review Procedures

Table B.5.1

Symptoms Which Require Use of Procedure 05-1-02-III-1

Step

Description

2.2

Malfunction of RHR or SSW component associated with SDC mode of RHR.

2.3

Less than adequate RHR SDC flow.

2.4 Uncontrollable increase in reactor coolant temperature.

2.5 Steaming from head vents even though reactor coolant temperature indicates $<212^{\circ} \mathrm{F}$.

2.6 RPV pressurization in OC4, Cold shutdown.

2.7 Loss of ADHRS flow or loss of PSW to ADHRS.

\section{Table B.5.2}

Immediate Operator Actions

Step

\section{Description}

4.1

Check reactor pressure and temperature.

4.2

Check spent fuel pool temperature.

4.3 Ensure redundant loop available.

4.4 Increase frequency of monitoring temperature and reactor pressure. 


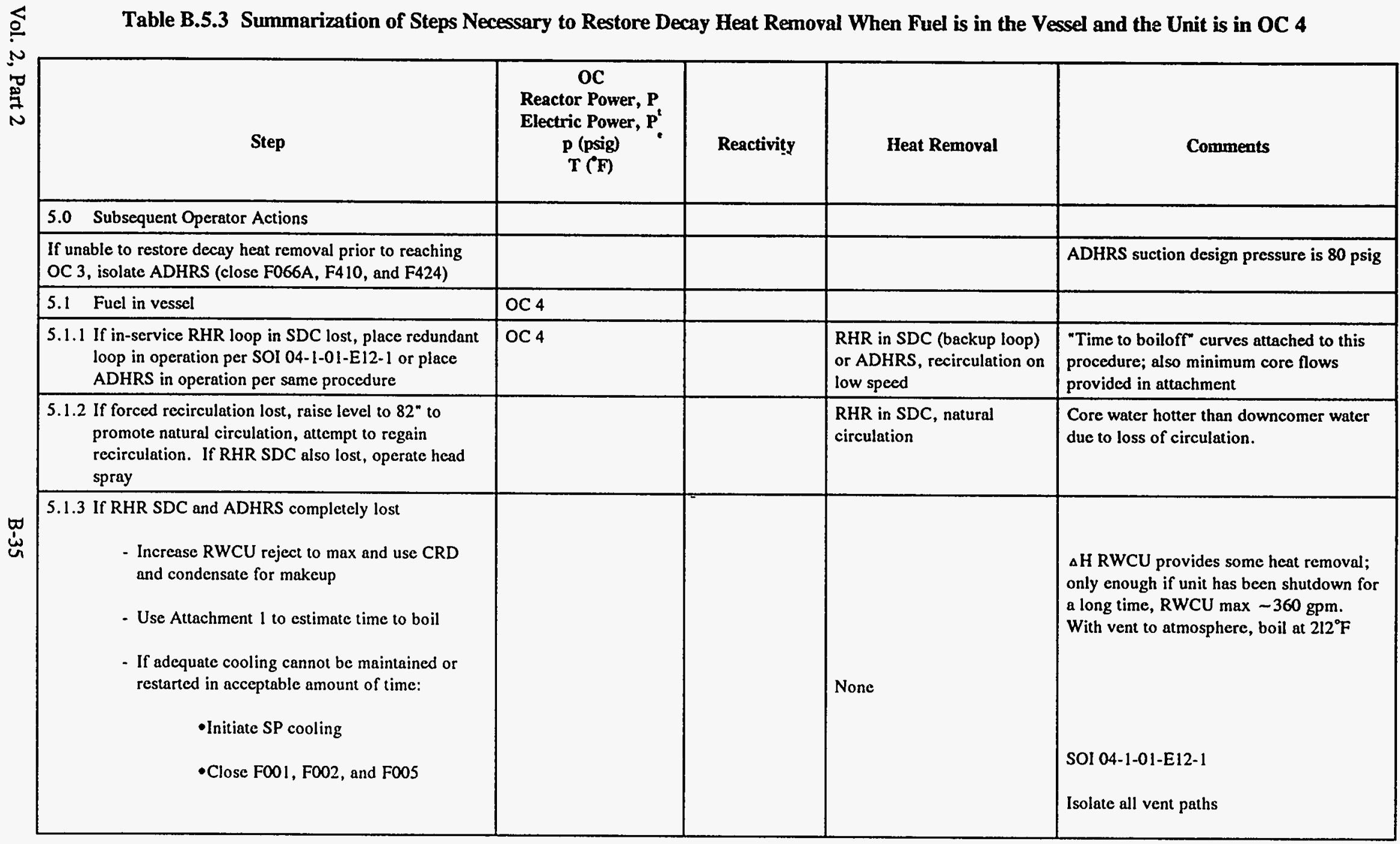




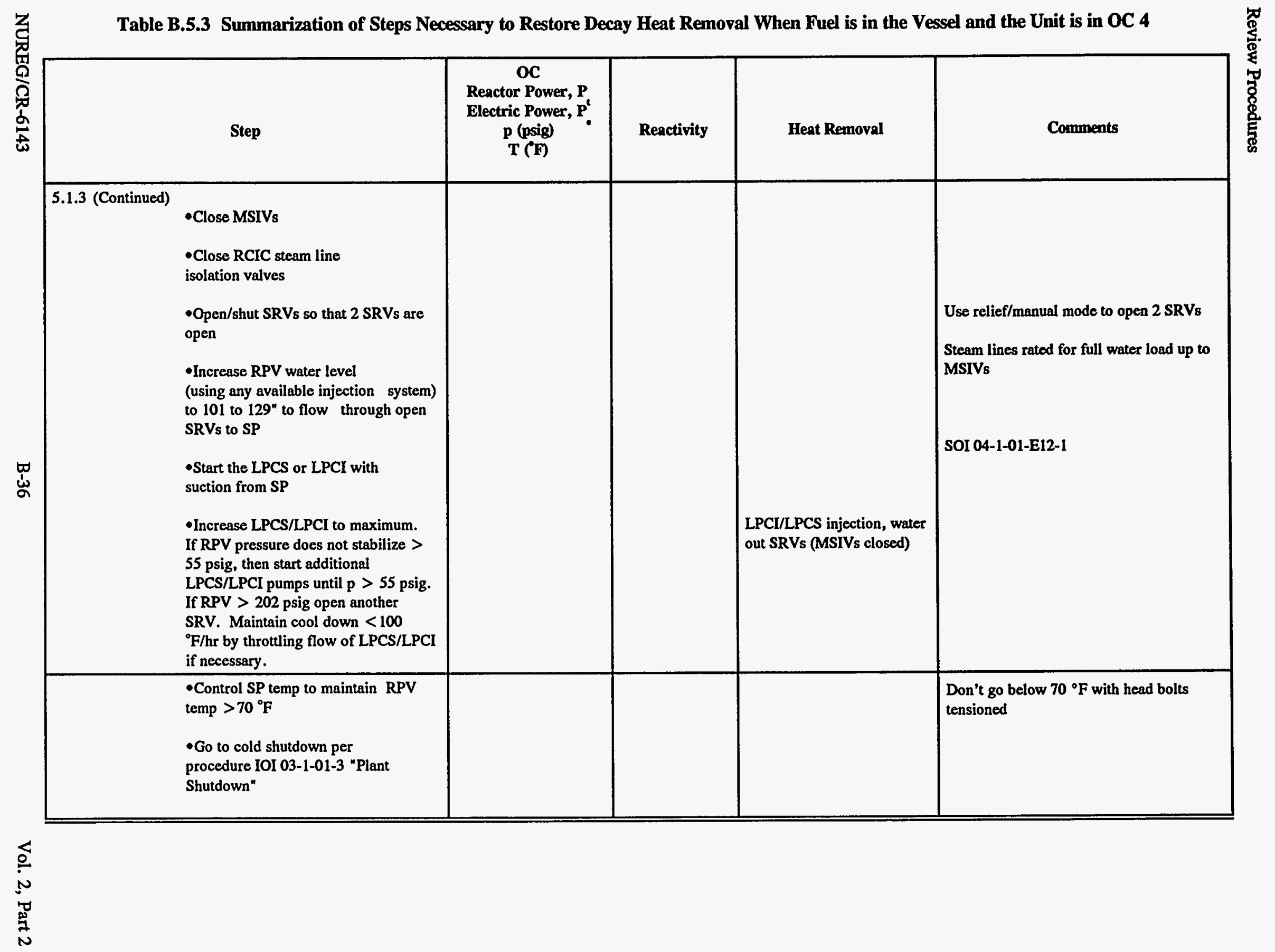




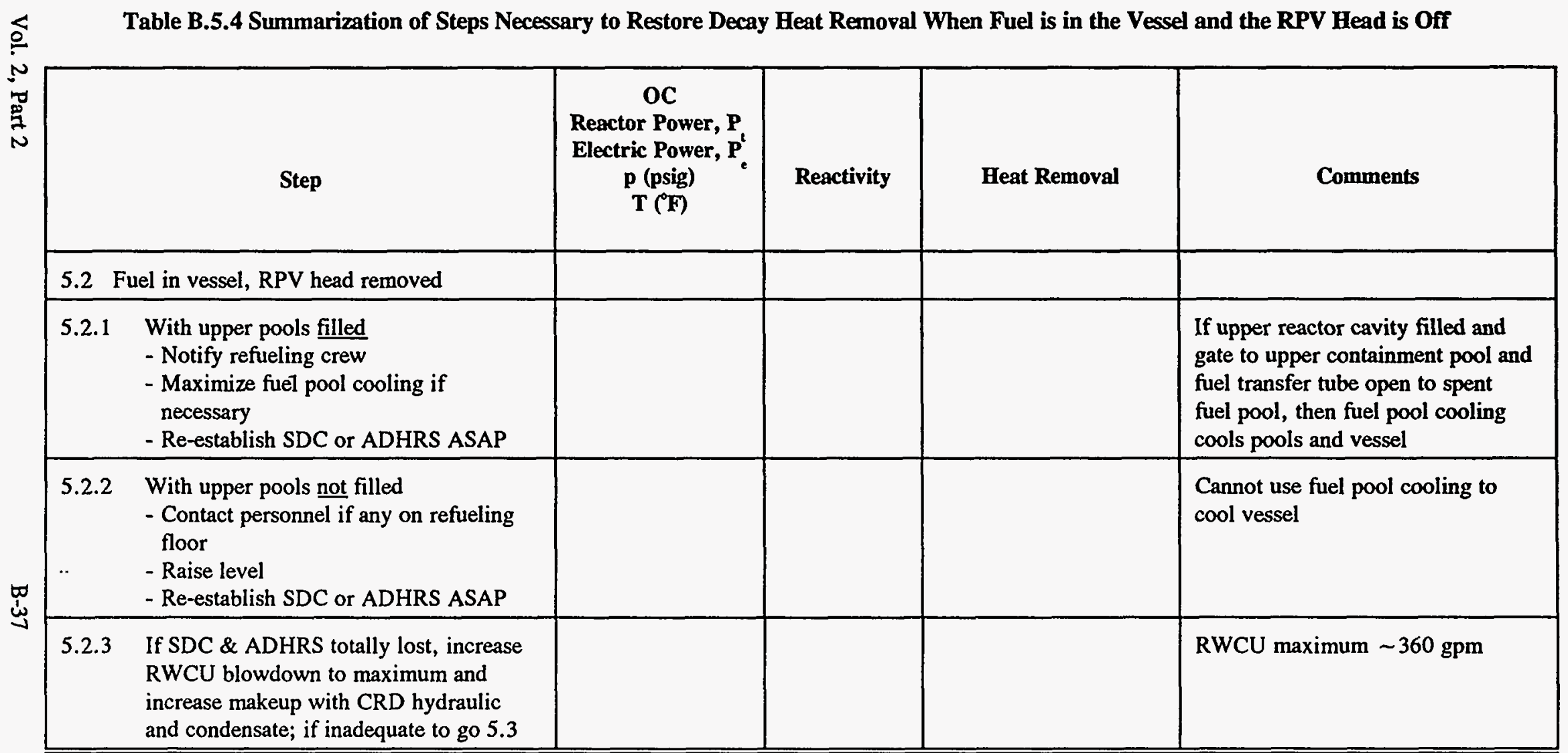




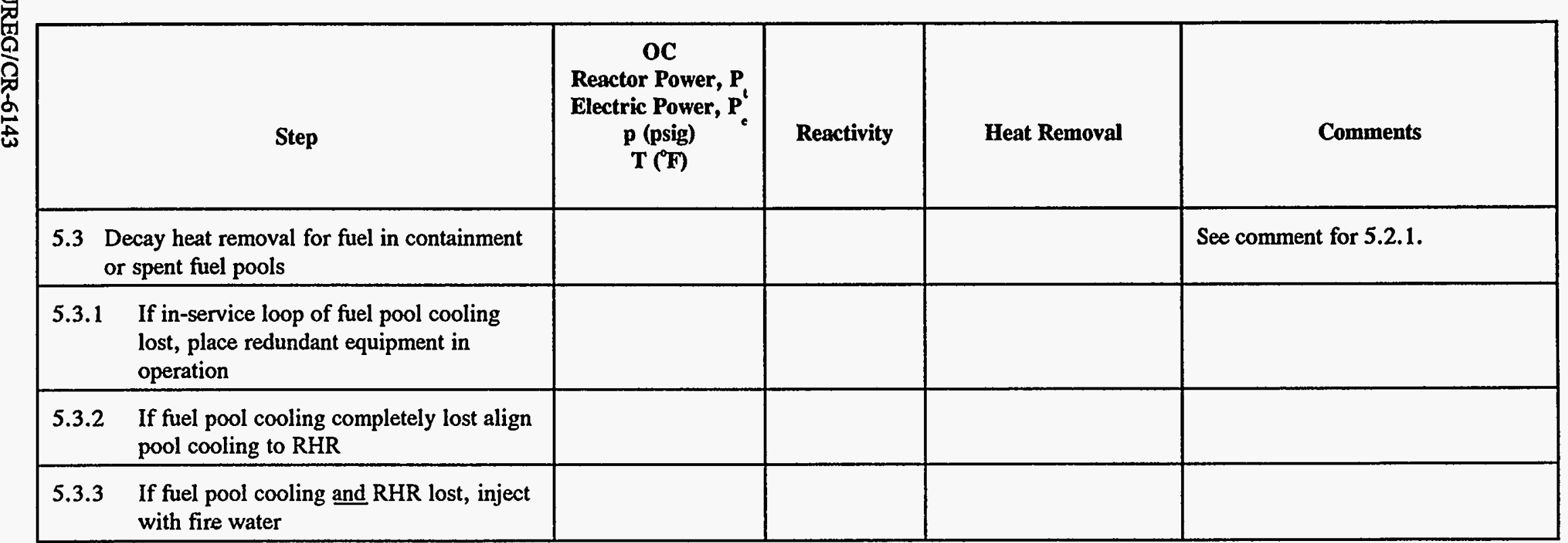




\section{Appendix C. Overview of Grand Gulf Power Plant}

This section is a brief summary of the technical aspects of the Grand Gulf power plant noted in our initial review of the referenced literature which are of special interest for the off-power risk study.

The following literature was reviewed:

(1) The NUREG 1150 PRA dealing with Grand Gulf at full power [USNRC, 1989]

(2) The Grand Gulf Updated Final Safety Analysis Report (FSAR) [SERI, 1992]

(3) The Grand Gulf Technical Specifications [USNRC 1984]

(4) Numerous Grand Gulf Procedures, as presented in Appendix B

(5) Class notebooks from the BWR/6 Fundamentals Course in Tulsa [General Electric, 1981]

(6) The textbook Nuclear Energy Conversion [ElWakil, 1971]

(7) The NRC's BWR Fundamentals Manual [USNRC, 1983]

(8) The GE General Description of the BWR/6 [General Electric, 1980]

(9) Various sources of information on nuclear power plant components.

The Operational Conditions (OCs) for Grand Gulf are defined in Table 1.2 of the Technical Specifications. At some plants, these are called operational modes. The OCs as defined in the technical specifications are as follows:

\section{Condition}

1. Power

2. Startup
Mode Switch Position and Average Reactor Coolant Temp.

Run

Any Temperature

Startup/Hot Standby

Any temperature
3. Hot Shutdown

Shutdown

$>200$ Degrees F

4. Cold Shutdown

Shutdown

$\leq 200$ Degrees F

5. Refueling

Shutdown or Refuel

$\leq 140$ degrees $F$

Five conditions are specified: Power Operation, Startup, Hot Shutdown, Cold Shutdown, and Refueling. No condition on $\mathrm{K}_{\text {eff }}$ is specified for these conditions in contrast to the case for typical PWR tech specs. This is because BWRs use rodded cores with no chemical shim, and the $1 \%$ shutdown margin can be maintained by rods alone with the highest single worth rod withdrawn [Section 4.3.2.4.1 of Grand gulf, UFSAR]. Below Hot Zero Power, PWRs must borate to maintain shutdown margin and their tech specs limit $\mathrm{K}_{\text {eff }}$ in each mode (operational condition). The table does specify the mode switch position which places limitations on rod positions in each condition as the mode switch activates various rod blocks in its various positions. Section 7 of the UFSAR discusses the limitations imposed by the Mode Switch Position. In the Refueling position, only one control rod can be withdrawn (without special bypass). In the Shutdown position, all rods are in. The control rod circuitry is in a scram state for ten seconds. In the Startup position, a rod block is set at $12 \%$ power, and a scram is set at $15 \%$ power. In the run position, power can be up to $100 \%$, but the full power protective scrams, and rod position/pattern limits, are present. The tech specs specify reactor coolant temperature limits in each OC, but do not specify pressure. The system is saturated (until it is vented at very low temperaturestypically 190 degrees $F$ ) and thus there is a unique pressure at each temperature. Other portions of the tech specs limit pressure to the ASME code allowable (design $+10 \%)$ and specify temperature/pressure limits for thermal stress and NDTT considerations in the vessel. The refueling $\mathrm{OC}$ does not cover refueling operations. The refueling condition applies for fuel in the vessel with the head studs less than fully tensioned. Refueling operations involving fuel transfer to and from the vessel are subject to tech spec section 3/4.9 "Refueling Operations".

Grand Gulf, like all latter-day BWR designs, is a recirculation controlled plant with turbine following (turbine leading is unstable). At steady state the turbine/generator rotor rotates at $1800 \mathrm{rpm}$. Load changes within the response capability of the plant are 
accommodated as follows. If it is desired to increase (decrease) the electrical load on the generator, the torque on the turbine shaft must be increased (decreased) to increase the instantaneous speed of the rotor and move it to a new position with respect to the stator windings where the torque from the magnetic field equals the driving torque. In a synchronous electromagnetic machine (alternator) such as an AC generator, with a change in driving torque the rotor changes its instantaneous speed and establishes a new position with respect to the stator so as to produce an equal opposing torque. Once this equality is established, the rotor regains its initial rotational speed. The stability of the speed control is enhanced by the grid 'flywheel' effect which provides synchronizing power to hold the generator output frequency at the grid value. Thus, a change in electrical load does not change shaft speed, so long as the control range of the generator (90 electrical degree shift between rotor position and stator field) is not exceeded. The turbine drives the rotor so as to change the phase angle between grid voltage and generator terminal voltage which changes the power delivered to the grid from the generator. The turbine demand is in response to the load desired on the grid, not in response to speed changes. Speed controllers on the turbine are used in startup (no load), for protection against overspeed if the control range of the generator is exceeded (e.g., loss of load), and for contributing to grid frequency stability by being set at $1800 \mathrm{rpm}$ for 60 cycle. [This discussion on speed stability is specific to a synchronous machine. For a DC generator or an induction motor, speed changes with load.] The change in driving torque is provided by a change in recirculation flow with the turbine following. The load demand signal is sensed by the turbine Electro-Hydraulic Controller (EHC) which interacts with recirculation flow control system to increase (decrease) recirculation flow. (Currently, at Grand Gulf, this automatic load following is not used and recirculation is manually controlled.) This increase (decrease) in recirc flow decreases (increases) the void fraction of the water exiting the core and via negative void fraction feedback the reactor thermal power increases (decreases). The steam header pressure increases (decreases) in response to the increased (decreased) steaming from the core and the turbine pressure controller opens (closes) the turbine control valves to restore header pressure as much as possible (the turbine follows the boiler). The increased (decreased) steam flow to the turbine increases (decreases) the driving torque on the rotor thereby 'instantaneously' (response time determined by rotational inertia of the shaft) shifting the rotor to provide the desired power output. Turbine header pressure is at its setpoint. The previous increase (decrease) in recirc results in lowering (raising) the vessel downcomer water level. The level is restored to its normal range by increasing (decreasing) feedwater flow, at the new steady state the feedwater flow equals the steam flow.

The following discussion focuses on those systems normally involved in changing operational conditions, such as: turbine and bypass, recirc, and shutdown cooling. These are the systems which the operations personnel will be manipulating during changes in operational condition, and they are those which will first drive the course of any accident scenario. The additional systems - such as LPCI, HPCS, SP Cooling - are already well understood as a result of the NUREG 4550 study. The primary effects on these systems are out-of-service conditions resulting from operational constraints (e.g., switching RHR trains A or B from LPCI to Shutdown Cooling) or resulting from down-for-maintenance as allowed by tech specs.

Since the BWR is operated at saturated conditions, special attention is paid to providing enough Net Positive Suction Head Available (NPSHA) to meet the Net Positive Suction Head Required (NPSHR) for the recirc and RHR pumps to prevent cavitation. When the recirc pumps are at rated speed $(1800 \mathrm{rpm})$ adequate NPSHA is provided by the amount of subcooling due to subcooled feedwater (420 degrees $F$ ) mixing with saturated recirculating water from the core exit (549 degrees $F$ ) with a recirc ratio -core exit recirc flow to feedwater (or steam) flow - of 7:1. The recirc suction water is 20 Btu/lbm subcooled (about 16 degrees F subcooled) at rated conditions. The recirc pumps are tripped to low speed if the subcooling margin ( $\left.\mathrm{T}_{\text {sceam }}-\mathrm{T}_{\text {suction }}\right)$ is less than 8 degrees F. On low speed, the recirc pumps are at $25 \%$ speed and adequate NPSHA is provided by the static head of water in the downcomer. This information on recirc NPSHA was taken from Section 5 of the UFSAR. Figure 5.4-4 of the FSAR indicates the NPSHR for the recirc pumps on high speed is about 100 $\mathrm{ft}$. Since head is proportional to pump speed squared, the.NPSHR on low speed should be about $1 / 16$ of 100 , or about $6 \mathrm{ft}$ (rough estimate neglecting actual system resistance and pump suction details). Since the vessel contains $\mathbf{5 7 0}$ in. of water in normal operation [Figure 5.3-2 of Grand Gulf, UFSAR], it is seen that the static head alone prevents cavitation.

The RHR pumps have a NPSHR of 2 feet, and they are located at an elevation of $96 \mathrm{ft}$ Mean Sea Level (MSL). With saturated water in the suppression pool at its minimum level of $107.5 \mathrm{ft}$, the NPSHA to the RHR 
pumps is $5.8 \mathrm{ft}$ under worst case flow loss conditions. This information is from Section 5 of the UFSAR. Since the vessel is at an elevation above the suppression pool, there is ample NPSHA to the RHR pumps in the shutdown cooling mode due to static head alone.

Certain options for energy removal which cool liquid in the downcomer region (such as RHR/SDC) require that the measured level, measured in the downcomer, be sufficiently high for adequate recirculation between the core and downcomer regions. This required measured level is significantly higher than the top of the core. The recirculation system is normally kept in operation in the off power conditions to reduce thermal stratification (from the Plant Shutdown Procedure. See Appendix B of this report). However, it is not required to be in operation at shutdown, as long as level in the core region is adequate, natural recirculation due to the difference in density between downcomer and core fluid is sufficient. The actual level of concern is the level in the core region which must be above the steam separator turnaround point to allow core water to flow back into the downcomer.

The actual core level is different from the measured level in the downcomer due to the following reasons: The core fluid is a two phase mixture (at power). If the recirculation pumps are on, they raise the core level with respect to the downcomer level. The level measurements are based on a standard delta $p$ sensor which measures the pressure difference between the head of water in the vessel and the head of water in a reference leg filled with condensate. In the safety grade level instrumentation (narrow and wide range), this pressure differential is converted to an equivalent level without compensating for changes in water density with temperature, which causes the measured level to be higher than the actual downcomer level at low temperature conditions.

A design basis accident at power is loss of both recirc pumps [Section 15 of Grand Gulf, UFSAR]. Tech Specs require operator action to scram the reactor via placing the mode switch in the Shutdown position [TS 3/4.4.1 of Grand Gulf, Tech Specs]. This is to reduce the time (prior to trip) during which the thermal margin (critical heat flux ratio) is below normal. The reactor will trip on high water level if the operator fails to manually trip. Note that a decrease in recirculation increases measured water level. The level is measured in the downcomer, and following a decrease in recirculation flow with feedwater flow constant, the level in the downcomer will increase. Without forced recirculation, cooldown is governed by the Inadequate Decay Heat Removal procedure which instructs operators to ensure natural recirculation by controlling the water level.

The following information is from the UFSAR and the BWR/6 Fundamentals Manual. The recirc system in BWR/5 and 6 designs is flow valve controlled rather than variable pump speed controlled as in earlier designs. The induction motors for the recirc pumps have two speeds: $1800 \mathrm{rpm}$ via a $60 \mathrm{hz}$ line source and $450 \mathrm{rpm}$ via a $15 \mathrm{hz}$ low frequency motor-generator source. The low speed is used during off-power conditions. The pumps are not canned, they use a dual mechanical shaft seal design with controlled leakage, and cooling with the Component Cooling Water (CCW) system. The CCW also cools the lube oil and the air to the motor stator windings. The pump/motors have sufficient inertia to provide slow coastdown to preserve thermal margin until the reactor can be tripped. A seized recirc pump accident is a design basis accident [Section 15 of Grand Gulf, UFSAR]. The high speed power circuit breakers incorporate an Anticipated Transient Without Scram (ATWS) trip coil to reduce power given an ATWS. The recirc flow control valves (FCV) are ball valves, hydraulically operated, with a linear flow control response $\left(C_{v}\right.$ versus position). The recirc pumps are always started on high speed with the FCVs at minimum position in order to lift the journals off the bearing faces. Evidently the bearing oil pump is gear driven off the recirc pump shaft and requires high speed to develop enough head to inject oil into the bearing and 'lift' the shaft. Once the pump has started and attained $95 \%$ high speed, the $60 \mathrm{hz}$ source is auto-tripped and the recirc pump coasts down to $25 \%$ speed where the $15 \mathrm{hz}$ power source is engaged. The major recirc pump trips are as follows:

(1) At any power, trip to low speed if inadequate subcooling for NPSH $\left(\mathrm{T}_{\text {stcam }}-\mathrm{T}_{\text {recirc }}\right.$ suction $<8$ degrees $\mathrm{F}$ )

(2) At feedwater flow $<23.3 \%$ and FCV $<24 \%$ open, trip to low speed to prevent FCV cavitation

(3) With either discharge or suction isolation valves $<90 \%$ open, pumps are tripped and cannot be started.

During startup, the plant follows the power flow operating map [Figure 4.4-5 of Grand Gulf, UFSAR]. The recirc pumps are started with the FCVs at minimum open position. Once the pumps trip to low speed, the FCVs are opened to maximum open position. When 
power is $>30 \%$ the low feedwater interlock is cleared, and the recirc pumps are switched to high speed after the FCVs are closed to minimum (to avoid reactivity insertion). The rod pattern is established and the FCVs are throttled open to achieve the desired operating power.

The RHR system has seven modes of operation, five of which are emphasized: LPCI, Containment Spray, SP Cooling, RCIC steam condensing (not used at Grand Gulf), and shutdown cooling [Section 5 of Grand Gulf, UFSAR] [USNRC, 1983]. The other two modes (containment flooding and spent fuel pool cooling) are less likely to be used. At power, RHR is lined up for LPCI and is subject to auto initiation in either that mode or the containment spray mode. Two of the RHR trains, $A$ and $B$, contain RHR heat exchangers and can be manually realigned for shutdown cooling when in $\mathrm{OC} 3$ if the vessel pressure is below the cut-in permissive [TS 3/4.4.9 of Grand Gulf, Tech Specs]. The cut-in permissive is 135 psig vessel pressure [Section 5 of Grand Gulf UFSAR].

The Reactor Core Isolation Cooling System (RCIC) serves the BWR as does the auxiliary feedwater system at a PWR. RCIC is used to remove decay heat if the main condenser/feedwater heat sink/makeup capability is unavailable [Section 15 of Grand Gulf, UFSAR] [USNRC, 1983]. RCIC has two modes of operation. The auto mode is one in which steam is relieved by the Safety Relief Valves to the SP, and makeup is from either the condensate storage tank or the SP via the steam-driven RCIC pump. This lineup can operate at rated pressure and temperature. The manual mode uses the RHR heat exchangers in a steam condensing mode with their condensate returned to the vessel by the RCIC pump. This mode is only allowed at less than 500 psig reactor pressure due to the limiting design pressure of the RHR heat exchangers. This steam condensing mode can match decay heat $1.5 \mathrm{hr}$ after shutdown. (Grand Gulf does not utilize the RCIC steam condensing lineup.) Since the HPCS is a fully diverse backup for RCIC, tech specs allow RCIC to be unavailable for up to 14 days if HPCS is operable [TS 3/4/7/3 of Grand Gulf, Tech Specs]. The RCIC pump turbine is driven off main steam line A.

The main steam system consists of four main steam lines: $A, B, C$, and $D$, details of which are provided in Sections 5 and 10 of the FSAR. Each line contains two Main Steam Isolation Valves (MSIV), one inboard and one outboard of containment, which fail closed and isolate the vessel given such accidents as a main steam line break. Downstream of the MSIVs, the steam lines provide steam to the high pressure turbine through the turbine stop and control valves. Between the outboard MSIV and the stop/control valves in each steam line, a branch feed is provided to the Reactor Feedwater Pump Turbine (RFPT) supply header. All four main steam lines feed this header. This header also is piped to the three parallel turbine bypass lines each of which contains a turbine bypass valve and discharges to one of the three parallel condensers.

Between the inboard MSIV and the vessel, each main steam line contains Safety Relief Valves (SRVs) which discharge to the SP. As in most BWRs, these valves serve both a safety function and a relief function and are different from the case at most PWRs which use separate safety and relief valves. The safety function is to prevent the primary system from exceeding the ACME code allowable pressure of 1375 psig (design $+10 \%$ ).

The system cannot be depressurized with the SRVs purely performing their safety function. The SRVs pop open at their safety pressure setting and require no power to do so. The SRVs automatically open at their lower relief setting, require air to do so, and fail closed on loss of air. Accumulators are provided. To operate an SRV in its relief mode, $\mathrm{DC}$ powered solenoid control valves in the air supply line must be energized. To depressurize the system, the SRVs can be manually opened, and of the 20 total SRVs eight can be actuated by the Automatic Depressurization System (ADS).

Main steam line A provides steam to the $\mathrm{RCIC}$ drive turbine. This steam is provided off the main line upstream of the inboard MSIV. Also, a continuous vent to vent noncondensibles is provided off main steam line A upstream of its inboard MSIV. This vent path is provided with an isolation valve (F005) and two pressure reducing orifices, and it discharges to the main condenser where deaeration occurs. At power F005 is open. This line also connects to the reactor head vent line which vents the vessel to atmospheric pressure when two isolation valves (F001 and F002) are opened. At power F001 and F002 are closed. The Plant Shutdown procedure specifies that when reactor temperature is less than 190 degrees F, F005 is closed and both F001 and F002 are opened. This establishes atmospheric pressure in the vessel and renders the fluid slightly subcooled.

The turbine system is described in Section 10 of the FSAR. The following discussion is based on that information supplemented with information on the design and operational characteristics of power plant 
components. The turbine pressure control setpoint is 950 psig. The turbine bypass capacity is $35 \%$ of rated steam. With bypass, the turbine generator system can accommodate a $100 \%$ to $40 \%$ load rejection at up to $1 \%$ per second, and it can accommodate a step load reduction of $35 \%$. A turbine trip with power greater than $35 \%$ causes a reactor trip. The high pressure turbine exhausts to two parallel Moisture Separator Reheaters (MSR) which reheat the exhaust to remove moisture before feeding the three parallel low pressure turbines. Gland seal steam is supplied by a seal steam generator. Gland seal steam is required to provide controlled bleeding of steam across the turbine seals to prevent air in leakage into the main condenser when it is at vacuum. The seal steam generator is heated by either main steam or turbine extraction, and it supplies nonradioactive steam. The turbine shaft is provided with a hydraulic-driven turning gear to rotate the drum whenever the turbine is heating up or cooling off to minimize thermal stresses which could kink the shaft. The turbine must be on turning gear rotation before any steam is admitted. The Cold Shutdown to Generator Carrying Minimum Load procedure requires that seal steam never be applied to the main turbine shaft seals if the turbine is not on turning gear. When gland seal steam is admitted, it rises to the top of the turbine casing and heats the top of the rotor, while the bottom of the rotor is kept cool due to condenser circulating water. Thus, if the rotor is not turning, it is stressed due to a thermal gradient and can bow and become unbalanced. To prevent thermal stresses, the turbine is kept on turning gear whenever it is heated up or cooled down. The major turbine trips are low condenser vacuum and overspeed. The turbine uses the EHC system for control. The condenser vacuum is maintained by steam jet air ejectors when steam is available and by mechanical vacuum pumps when it is not available.

The feedwater and condensate systems provide feedwater to the vessel. Three $50 \%$ capacity motor driven condensate pumps pull from the intermediate pressure condenser hotwell and supply three 50\% capacity motor driven condensate booster pumps. The flow from the booster pumps is heated by a series of low pressure feedwater heaters, then the water is supplied to two variable speed turbine driven feedwater pumps. The output of the feedwater pumps passes through a series of high pressure feedwater heaters then enters the vessel downcomer at 420 degrees $F$. Regenerative feedwater heating is used to increase the thermal efficiency of the rankine cycle. During startup, flow to the vessel is supplied by the condensate and booster pumps up to about $550 \mathrm{psig}$, with the first feedwater pump turbine rolled off turning gear at about 400 psig. Check valves isolate the vessel following a feedwater line break.

The Reactor Water Cleanup (RWCU) system is used to purify the reactor water. Also, during startup and shutdown when level is not controlled with feedwater, the RWCU system is used to blowdown to either the main condenser or the liquid radwaste system to control level which tends to increase due to fill from the control rod drive cooling system, and due to swell during heatup. This system is indirectly in the tech specs through chemistry control [TS $3 / 4.4 .4$, of Grand Gulf, Tech Specs]. 
Overview of Plant

\section{- References for Appendix C}

[USNRC, 1989]

[SERI, 1992]

[USNRC 1984]
USNRC, "Severe Accident Risks:

An Assessment for Five U.S.

Nuclear Power Plants, " NUREG-

1150, June, 1989.

System Energy Resources, Inc., "Grand Gulf Updated Final Safety Analysis Report", 1992.

USNRC, "Technical Specifications, Grand Gulf Nuclear Station Unit No. 1, " Docket No. 50-416, Appendix " $A$ " to License No. NPF-29, NUREG-0934, October, 1984.
[General Electirc, 1981]

[El-Wakil, 1971]

[USNRC, 1983]

[General Electric, 1980]
General Electric Co., BWR/6 Fundamentals, Operator Training Services, Tulsa, Oklahoma, 1981.

Nuclear Energy Conversion, Intext Educational Publishers, 1971.

USNRC, Course Material for R-104B, "Technology Manual for BWR/4 Design".

General Electric Co. "BWR/6 General Description of a Boiling Water Reactor", Revised September 1980. 


\section{Appendix D. Initiating Event Analysis from Screening Report}

This Appendix describes the initiating events that were identified and used for each POS during the coarse screening analysis [Whitehead et al., 1991]. This Appendix is from that earlier analysis. It correlates each initiating event to the appropriate plant operational state (POS). In addition, the information sources used to quantify the initiating event frequencies and the screening values assigned to each initiating event are presented.

\section{D.1 Approach and Summary}

The initiating event analysis task for this project was performed in much the same manner as for any full power PRA. First, a definition of what is meant by an initiating event was developed, and then a search for events which fit the definition was made. Finally, information was analyzed to produce estimates of the frequency for each initiating event.

For this study there are two definitions used for an initiating event depending upon the initial POS of the plant. For power operation, an initiating event is defined as an event which requires a rapid shutdown or trip of the plant, so as to challenge the safety systems to remove the decay heat still being generated in the reactor core. For non-power operations, an initiating event is defined as an event which would require an automatic or manual response to prevent core damage in the vessel.

Five major groups of initiating events were identified in this project: Transients, Loss of Coolant Accidents (LOCAs), Decay Heat Removal Challenges, Special Events, and Hazards Events. The Internal Fire and Flood Hazards Events will be considered in a subsequent stage of this project. The effects of seismic events will be analyzed by another organization, and all other externally initiated events are beyond the scope of this project. Table D.1-1 summarizes the initiators included in this study along with the screening values assigned to each initiator for each POS. The event nomenclature defines the shorthand notation used for each initiator in the subsequent tasks of this project.

The remainder of the section is divided into four subsections:

1. Transient Initiating Events,

2. LOCA Initiating Events,

3. Decay Heat Removal Challenge Initiators, and

\section{Special Events.}

In each of these subsections, the scope of events considered, as well as the methods employed to obtain the frequencies and distributions for each of the events, are described. A table summarizing the frequencies and distributions for the events is included in each subsection, along with comments that provide detailed descriptions of the methods for obtaining the frequencies.

\section{D.2 Transient Initiating Events}

\section{D.2.1 Background}

In order to obtain the transient categories considered in NUREG/CR-4550 volume 6 [ Drouin et al., 1989], EPRI transient events were grouped according to similar plant response. The reader is referred to Table 4.3-3 of Reference 1, which describes in detail the individual EPRI events and their grouping into the categories presented in Table 4.3-1 of Reference 1. From Table 4.3-1, the following transient categories are considered:

Transient Category Description

T1 Loss of Offsite Power

T2 Transients with Loss of the Power Conversion System (PCS)

T3A Transients with the PCS initially available

T3B Transients involving Loss of Feedwater but with the steamside of PCS initially available

T3C Transient caused by Inadvertent Open Relief Valve

\section{D.2.2 Introduction}

The individual EPRI events comprising the transient categories discussed in section D.2.1 were reviewed for their applicability to the various POSs. Each of these transient categories is listed in Table D.2-1, and the comments included with the table describe in detail the applicability of the various events in each POS. Loss of Offsite Power (T1) is applicable to all POSs. See 
IE Screening

Table D.1.1 Grand Gulf Low Power and Shutdown Initiating Events and Frequencies

\begin{tabular}{|c|c|c|c|c|c|c|c|c|}
\hline \multirow[t]{2}{*}{$\begin{array}{l}\text { Initiating Event } \\
\text { Nomenclature }\end{array}$} & \multirow[t]{2}{*}{ Description } & \multicolumn{7}{|c|}{$\begin{array}{c}\text { Mean Frequency } \\
\text { (per year) } \\
\text { for Each POS }\end{array}$} \\
\hline & & 1 & 2 & 3 & 4 & 5 & 6 & 7 \\
\hline $\mathbf{T 1}$ & $\begin{array}{l}\text { Loss of Offsite Power } \\
\text { (LOSP) transient }\end{array}$ & 0.07 & 0.13 & 0.13 & 0.13 & 0.13 & 0.13 & 0.13 \\
\hline $\mathbf{T}$ & $\begin{array}{l}\text { Transient with loss of the } \\
\text { Power Conversion System } \\
\text { (PCS) }\end{array}$ & 1.62 & 1.62 & 1.62 & - & - & - & - \\
\hline T3A & $\begin{array}{l}\text { Transient with PCS } \\
\text { initially available }\end{array}$ & 4.54 & 4.54 & 4.54 & - & - & - & - \\
\hline T3B & $\begin{array}{l}\text { Transients involving loss } \\
\text { of Feedwater }\end{array}$ & 0.88 & 0.88 & 0.88 & - & - & - & - \\
\hline T3C & $\begin{array}{l}\text { Transient caused by } \\
\text { Inadvertent Open Relief } \\
\text { Valve }\end{array}$ & 0.14 & 0.14 & 0.14 & - & - & - & - \\
\hline $\mathbf{A}$ & Large LOCA & $1 \mathrm{E}-4$ & $1 E-4$ & $1 \mathrm{E}-4$ & $1 E-4$ & $1 E-5$ & 1E-5 & 1E-5 \\
\hline s1 & Intermediate LOCA & $3 E-4$ & $3 E-4$ & $3 E-4$ & $3 \mathrm{E}-4$ & $3 E-5$ & $3 E-5$ & $3 E-5$ \\
\hline s2 & Small LOCA & 3E-3 & $3 \mathrm{E}-3$ & $3 \mathrm{E}-3$ & $3 E-3$ & $3 E-4$ & $3 E-4$ & $3 E-4$ \\
\hline s3 & Small-Small LOCA & $3 \mathrm{E}-2$ & $3 \mathrm{E}-2$ & $3 \mathrm{E}-2$ & $3 \mathrm{E}-2$ & $3 E-3$ & $3 E-3$ & 3E-3 \\
\hline $\mathbf{v}$ & Interfacing System LOCA & - & - & - & - & - & - & - \\
\hline $\mathbf{R}$ & Vessel Rupture & - & - & - & - & - & - & - \\
\hline H1 & $\begin{array}{l}\text { Diversion to Suppression } \\
\text { Pool via RHR }\end{array}$ & - & - & - & $8 \mathrm{E}-2$ & $8 \mathrm{E}-2$ & $8 \mathrm{E}-2$ & $8 \mathrm{E}-2$ \\
\hline $\mathbf{H 2}$ & $\begin{array}{l}\text { Diversion to Condenser } \\
\text { via RWCU }\end{array}$ & - & - & - & - & - & - & - \\
\hline J1 & $\begin{array}{l}\text { LOCA in Connected } \\
\text { System (RCIC) }\end{array}$ & $8 E-4$ & $8 E-4$ & $8 E-4$ & - & - & - & - \\
\hline J2 & $\begin{array}{l}\text { LOCA in Connected } \\
\text { System (RHR) }\end{array}$ & - & - & - & $5 E-2$ & $5 E-2$ & $5 \mathrm{E}-2$ & $5 E-2$ \\
\hline $\mathbf{K}$ & $\begin{array}{l}\text { Test/Maintenance-Induced } \\
\text { LOCA }\end{array}$ & - & + & - & - & - & - & - \\
\hline E1B & $\begin{array}{l}\text { Isolation of SDC Loop B } \\
\text { only }\end{array}$ & - & - & - & 0.1 & 0.1 & 0.1 & 0.1 \\
\hline E1C & $\begin{array}{l}\text { Isolation of RWCU as } \\
\text { DHR }\end{array}$ & - & - & - & - & - & - & 0.1 \\
\hline E1D & Isolation of ADHRS only & - & - & - & - & 0.1 & 0.1 & 0.1 \\
\hline E1T & $\begin{array}{l}\text { Isolation of SDC Common } \\
\text { Suction Line }\end{array}$ & - & - & - & 0.1 & 0.1 & 0.1 & 0.1 \\
\hline
\end{tabular}


Table D.1.1 Grand Gulf Low Power and Shutdown Initiating Events and Frequencies

\begin{tabular}{|c|c|c|c|c|c|c|c|c|}
\hline \multirow{2}{*}{$\begin{array}{l}\text { Initiating Event } \\
\text { Nomenclature }\end{array}$} & \multirow{2}{*}{\begin{tabular}{l}
\multicolumn{1}{c}{ Description } \\
Isolation of Common \\
Suction Line for ADHRS
\end{tabular}} & \multicolumn{7}{|c|}{$\begin{array}{c}\text { Mean Frequency } \\
\text { (per year) } \\
\text { for Each POS }\end{array}$} \\
\hline & & - & - & - & - & 0.1 & 0.1 & 0.1 \\
\hline E2B & Loss of SDC Loop B only & - & - & - & 0.37 & 0.37 & 0.37 & 0.37 \\
\hline E2C & Loss of RWCU as DHR & - & - & - & - & - & - & 0.1 \\
\hline E2D & Loss of ADHRS only & - & - & - & - & 0.37 & 0.37 & 0.37 \\
\hline E2T & $\begin{array}{l}\text { Loss of SDC Common } \\
\text { Suction Line }\end{array}$ & - & - & - & 0.37 & 0.37 & 0.37 & 0.37 \\
\hline E2V & $\begin{array}{l}\text { Loss of Common Suction } \\
\text { Line for ADHRS }\end{array}$ & - & - & - & - & 0.37 & 0.37 & 0.37 \\
\hline T4A & Rod Withdrawal Error & - & - & - & - & - & - & - \\
\hline $\mathrm{T} 4 \mathrm{~B}$ & $\begin{array}{l}\text { Refueling Accident (Rod } \\
\text { or Fuel Misposition) }\end{array}$ & - & - & - & - & - & - & - \\
\hline $\mathrm{T} 4 \mathrm{C}$ & Instability Event & - & - & - & - & - & - & - \\
\hline T5A & Loss of all SSW & - & - & - & $1.8 \mathrm{E}-2$ & $1.8 \mathrm{E}-2$ & $1.8 \mathrm{E}-2$ & $1.8 \mathrm{E}-2$ \\
\hline T5B & Loss of all TBCW & $1.8 \mathrm{E}-2$ & $1.8 \mathrm{E}-2$ & $1.8 \mathrm{E}-2$ & $1.8 \mathrm{E}-2$ & $1.8 \mathrm{E}-2$ & $1.8 \mathrm{E}-2$ & - \\
\hline T5C & $\begin{array}{l}\text { Loss of all PSW (includes } \\
\text { Radial Well) }\end{array}$ & $1.8 \mathrm{E}-2$ & $1.8 \mathrm{E}-2$ & $1.8 \mathrm{E}-2$ & $1.8 \mathrm{E}-2$ & $1.8 \mathrm{E}-2$ & $1.8 \mathrm{E}-2$ & - \\
\hline T5D & Loss of all CCW & - & - & - & $1.8 \mathrm{E}-2$ & $1.8 \mathrm{E}-2$ & $1.8 \mathrm{E}-2$ & - \\
\hline $\mathrm{TAB}$ & $\begin{array}{l}\text { Loss of } 1 \mathrm{E} 4160 \mathrm{~V} \mathrm{AC} \\
\text { Bus B }\end{array}$ & - & - & - & $9 E-4$ & $9 E-4$ & $9 E-4$ & $9 \mathrm{E}-4$ \\
\hline TDB & $\begin{array}{l}\text { Loss of } 1 E 125 V D C \text { Bus } \\
\text { B }\end{array}$ & - & - & - & $6 \mathrm{E}-3$ & $6 \mathrm{E}-3$ & $6 \mathrm{E}-3$ & $6 E-3$ \\
\hline TIA & Loss of Instrument Air & 0.5 & 0.5 & 0.5 & 0.5 & 0.5 & 0.5 & - \\
\hline TORV & $\begin{array}{l}\text { Inadvertent Open Relief } \\
\text { Valve at Shutdown }\end{array}$ & - & - & - & 0.1 & - & - & - \\
\hline TIOP & $\begin{array}{l}\text { Inadvertent } \\
\text { Overpressurization } \\
\text { (makeup greater than } \\
\text { letdown) }\end{array}$ & - & - & - & 0.16 & 0.16 & - & - \\
\hline TIHP & $\begin{array}{l}\text { Inadvertent } \\
\text { Overpressurization via } \\
\text { Spurious HPCS Actuation }\end{array}$ & - & - & - & $1 \mathrm{E}-2$ & $1 \mathrm{E}-2$ & - & - \\
\hline TIOF & $\begin{array}{l}\text { Inadvertent Overfill via } \\
\text { LPCS or LPCI }\end{array}$ & - & - & - & $4 \mathrm{E}-2$ & $4 \mathrm{E}-2$ & - & - \\
\hline TLM & Loss of Makeup & - & - & - & 0.49 & 0.49 & 0.49 & . - \\
\hline
\end{tabular}


Table D.2.1 Transients

Description

T1 LOSS OF OFFSITE POWER
Plant State: Mean Frequency [per Calendar Year] Distribution

FULL POWER: 0.078

1: 0.07

2: 0.13

3: 0.13

4: 0.13

5: 0.13

6: 0.13

7: 0.13
T2 TRANSIENTS WITH LOSS OF THE POWER CONVERSION SYSTEM (PCS)

FULL POWER: 1.62

1: 1.62

2: 1.62

3: 1.62

4: N/A

5: N/A

6: N/A

7: N/A

FULL POWER: 4.51

T3A TRANSIENTS WITH PCS INITIALLY AVAILABLE

1: 4.54 (4.50 to 4.54 )
2: 4.54 (4.50 to 4.54$)$

3: 4.54 (4.50 to 4.54$)$

4: N/A

5: N/A

6: N/A

7: N/A

FULL POWER: 0.76

$1: 0.88(0.76$ to 0.88$)$

2: 0.88 (0.76 to 0.88$)$

3: $0.88(0.76$ to 0.88$)$

4: N/A

5: N/A

6: N/A

7: N/A

T3C INADVERTENT OPEN RELIEF FULL POWER: 0.14

VALVE (IORV)
1: 0.14
2: 0.14
3: 0.14
4: N/A
5: N/A
6: N/A
7: N/A

\section{Comments}

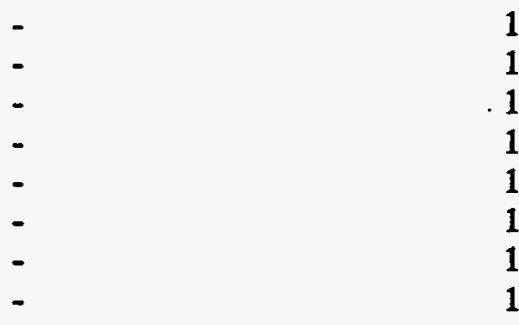

LOGNORMAL; $\mathrm{EF}=3 \quad 2$

"

" 2

" 2

N/A 3

n

LOGNORMAL; EF $=3$

$" 4$ and 5

" 4 and 5

$" 4$ and 5

N/A 6

n 6

" 6

" 6

LOGNORMAL; $\mathrm{EF}=3$

" 8

" 18

"

N/A 9

N/A 9

n 9

" 9

LOGNORMAL; $\mathrm{EF}=3 \quad 10$

$" \quad 10$

$n$

"

N/A 12

" 12

" 12

" 


\section{Table D.2.1 Comments}

(1) The calculation of LOSP frequency and distribution is described in Appendix G.

(2) The frequency and distribution for $T 2$ were taken from Table 4.9-26 of [Drouin et al., 1989]. Table 4.3-1 of [Drouin et al., 1989] describes the individual EPRI transient events comprising event T2. The values in Table 4.9-26 were calculated from the EPRI transient category frequency data in Table 33 of [Mackowiak et al., 1985]. The frequency used for full power is taken to apply to POS 1 , based on a review of the individual EPRI events included in T2. For POSs 2 and 3 where the turbine/generator is tripped, but the turbine bypass and condensate are still used, the frequency is conservatively taken to be that which was used for the full power analysis. This is conservative since not all events that make up T2 are valid during these POSs; however, it is expected that this conservatism will not be important because of the small amount of time spent in these two POSs.

\{3\} The events which make up T2 are not valid during these POSs.

44\} The frequency reported in Table 4.9-26 of [Drouin et al., 1989] includes the EPRI transient events listed in Table 4.3-1 of [Drouin et al., 1989] for the event T3A. For POS 1, all of these events are included in the T3A frequency. It should be noted that several of the events included in T3A may not be applicable for POS 1 when the mode switch is in RUN. EPRI events 14,18 , and 21 are all postulated to cause reactor SCRAM on high neutron flux. It is unclear whether, during POS 1 operations with the mode switch in the RUN position, the reactivity insertion from these events would be sufficient to cause SCRAM on high neutron flux. In this case, these events would have to be removed from T3A for POS 1 . For this analysis we conservatively assume that these events will cause a SCRAM and therefore are included in the initiating event frequency. For POS 1 with the mode switch in STARTUP, the EPRI event 26, "High Feedwater Flow During Startup or Shutdown", has been added to T3A. The frequency for this event in Table 33 of [Mackowiak et al., 1985] is 0.04/year.

(5) Note that the events 14,18 , and 21 as described above in $\{4\}$ are postulated to cause a reactor SCRAM on high neutron flux. With the mode switch in STARTUP a reactor trip will occur at a flux-indicated power level of 15\%, according to Grand Gulf Technical Specifications. It is assumed that these reactivity insertions are sufficient to cause an increase in power level which exceeds the $15 \%$ setpoint.

\{6\} None of the EPRI transient events under T3A apply in POSs 4 through 7, based on a review of the individual EPRI transient events comprising T3A. Although several might be postulated to cause an interruption in decay heat removal operations via the RHR, these are assumed to be included in the frequency determined for the DHR challenge initiators involving the RHR (see Table 4.2.3-1).

\{7\} The frequency and distribution for T3B are taken from Table 4.9-26 of [Drouin et al., 1989]; Table 4.3-1 of [Drouin et al., 1989] describes the individual EPRI transient events comprising event T3B. The values in Table 4.9-26 were calculated from the EPRI transient category frequency data in Table 33 of [Mackowiak et al., 1985].

(8\} The frequency used for full power is taken to apply to POS 1 when the mode switch is in RUN, based on a review of the individual EPRI events included in T3B. The frequency of T3B in POS 1 when the mode switch is in STARTUP is calculated by adding the frequency for EPRI event 25, Low Feedwater Flow During Startup or Shutdown, to the full power frequency described in \{7\}. Table 33 of [NRC, NUREG 3862] reports the event 25 frequency as 0.12 /year. The error factor is assumed to be the same as for full power. To be conservative the frequency for POS 1 is taken to be 0.88 with a lognormal distribution having an error factor of 3 . This same frequency was conservatively assumed to apply to POSs 2 and 3.

\{9\} Loss of feedwater events are not applicable in these POSs.

(10) The event T3C, Inadvertent Open Relief Valve, is considered in terms of its potential to cause a SCRAM (due to high suppression pool temperature) for POS 1, as it was for Full Power [1]. The same frequency reported in Table 4.9-26 of [Drouin et al., 1989] for this event was assigned to POS 1, as it is not expected to be any higher.

(11) Although not a concern in terms of causing a SCRAM, the potentially high pressure and temperature conditions existing in these plant states require that this event be considered for its loss of vessel inventory potential.

112\} For POSs 5, 6, and 7 this event is not of concern since the reactor is at atmospheric pressure (vented in POS 5; head off in POS 6 and 7). For POS 4 a special initiator was developed. See discussion in Section 4.2.4.3. 


\section{IE Screening}

Appendix $\mathbf{G}$ of this report for a listing of the data used to determine the frequency of $\mathrm{T} 1$.

It should be noted that the frequencies listed for the various transient initiators are given in terms of plant calendar years. A reference used for many of the frequency calculations [Mackowiak et al., 1985] states that "reactor years" (which usually denotes a time corrected by a plant's capacity factor) were used to determine event frequencies. However, the definition of "reactor year" in this report appears to be equivalent to a plant calendar year.

Because the frequencies are given on a per-calendar-year basis, it is intended that the transient frequencies reported in Table D.2-1 will be corrected by factors representing the fraction of the plant calendar year spent in a particular POS. In addition, events which depend on operation of a particular system, such as the condenser, should be multiplied by the fraction of time the given system operates in a particular POS. For the screening analysis this fraction was assumed to be 1.0.

\section{D.3 LOCA Initiating Events}

\section{D.3.1 Background}

The accident initiator termed Loss of Coolant Accident (LOCA) has traditionally referred to piping ruptures of various sizes causing a failure of the coolant pressure boundary. In NUREG-4550, Vol. 6 [Drouin et al., 1989], the possible LOCAs were categorized according to size of the break, based on similar safety system requirements within a category. The various LOCA categories used in the NUREG 4550 analysis are described below:

$\underline{\text { LOCA }}$

A

S1

S2

S3

\section{SIZE}

Steam $>0.4$ sq.ft. Liquid $>0.4$ sq.ft.

Steam $0.13-0.4$ sq.ft. Liquid $0.007-0.4$ sq.ft.

Steam $<0.13$ sq. ft. Liquid $<0.007$ sq.ft.

Recirculation pump seal break; categorized as S2 if operator does not isolate.
Another type of LOCA considered in the NUREG 4550 analysis is the Interfacing System LOCA, or V, which typically involves the failure of a high-to-low pressure interface such that reactor pressure causes failure within a low pressure system. Such failures were found to most likely involve failure of a testable check valve on ECCS injection lines. The V scenario was eliminated as an initiating event for Grand Gulf based on plant-specific arguments regarding testing practices and plant configuration [Drouin et al., 1989].

A final type of LOCA considered in NUREG 4550 is the Reactor Vessel Rupture event, R. The argument for excluding this initiating event in the Grand Gulf analysis draws upon previous studies involving PWRs, and concludes a lower vessel rupture frequency for BWRs. The argument also states that because Grand Gulf's vessel is newer, the rupture event is even less likely (presumably due to material considerations with regard to the pressurized thermal shock concern) [Drouin et al., 1989].

\section{D.3.2 Introduction}

The following sections describe the LOCA initiating events considered for this study. Applicability of events considered in NUREG 4550 are discussed first, followed by descriptions of LOCA events unique to this study. The scope of events considered is presented, as well as the justification for exclusion of certain events. Table D.3-1 summarizes the mean frequencies and distributions assigned to the various LOCA events, along with comments specifically describing the method for obtaining the frequencies.

It should be noted that the frequencies listed for the various LOCA initiators are given in terms of plant calendar years. It is intended that these frequencies will be corrected by factors representing the fraction of the plant calendar year spent in the POS being examined. In addition, events which involve operating systems are to be multiplied by the fraction of time the given system operates in a POS. This fraction was conservatively assumed to be 1.0 for this screening study.

\section{D.3.3 LOCA Events from NUREG 4550}

In determining the applicability of events considered in NUREG 4550 to POSs other than full power, consideration of the differing plant configurations and conditions for the various POSs is necessary. In most 
Table D.3.1 Loss of Coolant Accidents

\begin{tabular}{|c|c|c|c|}
\hline Description & $\begin{array}{l}\text { State: Mean Frequency } \\
\text { CALENDAR YEAR] }\end{array}$ & Distribution & Comments \\
\hline \multirow[t]{8}{*}{ A LARGE LOCA } & FULL POWER: 1E-4 & LOGNORMAL; EF =3 & 1 \\
\hline & 1: $1 \mathrm{E}-4$ & $"$ & 1 \\
\hline & 2: $1 \mathrm{E}-4$ & $n$ & 1 \\
\hline & 3: $1 \mathrm{E}-4$ & $n$ & 1 \\
\hline & 4: $1 \mathrm{E}-4$ & $n$ & 1 \\
\hline & 5: $1 E-5$ & $"$ & 2 \\
\hline & $6: 1 E-5$ & $n$ & 2 \\
\hline & $7: 1 E-5$ & $n$ & 2 \\
\hline \multirow{8}{*}{$\begin{array}{l}\text { S1 INTERMEDIATE } \\
\text { LOCA }\end{array}$} & FULL POWER: 3E-4 & LOGNORMAL; $E F=3$ & 1 \\
\hline & 1: $3 E-4$ & $n$ & 1 \\
\hline & 2: $3 E-4$ & $"$ & 1 \\
\hline & 3: $3 E-4$ & $n$ & 1 \\
\hline & 4: $3 \mathrm{E}-4$ & $"$ & 1 \\
\hline & 5: $3 \mathrm{E}-5$ & $"$ & 2 \\
\hline & $6: 3 E-5$ & $n$ & 2 \\
\hline & 7: $3 E-5$ & $"$ & 2 \\
\hline \multirow[t]{8}{*}{ S2 SMALL LOCA } & FULL POWER: 3E-3 & LOGNORMAL; $E F=3$ & 1 \\
\hline & $1: 3 E-3$ & $"$ & 1 \\
\hline & 2: $3 E-3$ & $n$ & 1 \\
\hline & 3: $3 E-3$ & $"$ & 1 \\
\hline & 4: $3 E-3$ & $n$ & 1 \\
\hline & 5: $3 E-4$ & $n$ & 2 \\
\hline & $6: 3 E-4$ & $"$ & 2 \\
\hline & $7: 3 E-4$ & $n$ & 2 \\
\hline \multirow{8}{*}{$\begin{array}{l}\text { S3 SMALL-SMALL } \\
\text { LOCA }\end{array}$} & FULL POWER: 3E-2 & LOGNORMAL; EF=3 & 1 \\
\hline & 1: 3E-2 & $n$ & 1 \\
\hline & 2: $3 \mathrm{E}-2$ & $n$ & 1 \\
\hline & 3: $3 \mathrm{E}-2$ & $n$ & 1 \\
\hline & 4: $3 \mathrm{E}-2$ & $n$ & 1 \\
\hline & 5: $3 \mathrm{E}-3$ & $n$ & 2 \\
\hline & $6: 3 E-3$ & $"$ & 2 \\
\hline & 7: $3 \mathrm{E}-3$ & $"$ & 2 \\
\hline \multirow{8}{*}{$\begin{array}{l}\text { V INTERFACING } \\
\text { SYSTEM LOCA } \\
\text { (failure of high to low } \\
\text { pressure interface) }\end{array}$} & FULL POWER: N/A & $\mathrm{N} / \mathrm{A}$ & 3 \\
\hline & 1: N/A & $"$ & 3 \\
\hline & 2: N/A & $"$ & 4 \\
\hline & 3: N/A & $"$ & 4 \\
\hline & 4: N/A & $"$ & 4 \\
\hline & 5: N/A & $n$ & 4 \\
\hline & 6: N/A & " & 4 \\
\hline & $7: \mathrm{N} / \mathrm{A}$ & $"$ & 4 \\
\hline
\end{tabular}


IE Screening

Table D.3.1 Loss of Coolant Accidents

\begin{tabular}{cccc} 
Description & $\begin{array}{c}\text { Plant State: Mean Frequency } \\
\text { [per CALENDAR YEAR] }\end{array}$ & Distribution & Comments \\
\hline R VESSEL: & FULL POWER: N/A & N/A & 5 \\
RUPTURE & 1: N/A & $n$ & 5 \\
& 2: N/A & $n$ & 5 \\
3: N/A & $n$ & 5 \\
4: N/A & $n$ & 5 \\
5: N/A & $n$ & 5 \\
6: N/A & $n$ & 5 \\
7: N/A & $n$ & 5
\end{tabular}

$\begin{array}{cl}\text { H1 DIVERSION OF } & \text { FULL POWER: N/A } \\ \text { VESSEL } & \text { 1: N/A } \\ \text { INVENTORY TO } & \text { 2: N/A } \\ \text { THE SUPPRESSION } & \text { 3 N/A } \\ \text { POOL via RHR } & \text { 4: } 8 \mathrm{E}-2 \\ & 5: 8 \mathrm{E}-2 \\ & 6: 8 \mathrm{E}-2 \\ & 7: 8 \mathrm{E}-2\end{array}$

$\begin{array}{cc}\text { N/A } & 6 \\ " & 6 \\ \text { LOGNORMAL; EF 5 } & 7 \\ " \text { " } & 7 \\ " & 8,9 \\ & 8,9 \\ & 8,9 \\ & 8,9\end{array}$

H2 DIVERSION OF FULL POWER: N/A

VESSEL

1: N/A

INVENTORY via

2: "

RWCU

3: "

4:"

5: "

6:"

7: "

$\begin{array}{cc}\text { N/A } & 10 \\ " \text { " } & 10 \\ " \text { " } & 10 \\ " & 10 \\ " & 10 \\ " & 10 \\ \text { " } & 10 \\ & 10\end{array}$

$\begin{array}{cl}\text { J1 LOCA IN } & \text { FULL POWER: N/A } \\ \text { OPERATING } & \text { 1: 8E-4 } \\ \text { CONNECTED } & \text { 2: 8E-4 } \\ \text { SYSTEM (RCIC) } & \text { 3: 8E-4 } \\ & 4: \text { N/A } \\ & 5: " \\ & 6: " \\ & 7: "\end{array}$

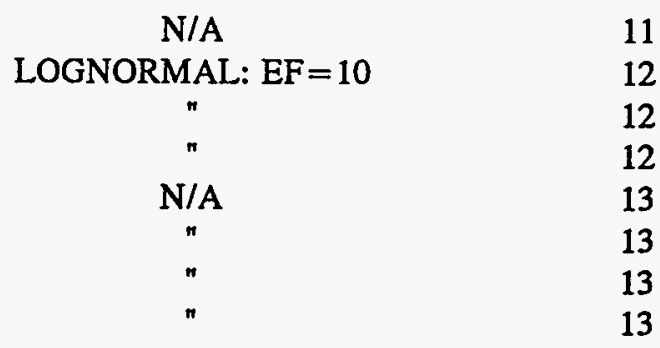

$\begin{array}{cl}\text { J2 LOCA IN } & \text { FULL POWER: N/A } \\ \text { OPERATING } & \text { 1: N/A } \\ \text { CONNECTED } & \text { 2: " } \\ \text { SYSTEM (RHR) } & \text { 3: " } \\ & \text { 4: } 5 \mathrm{E}-2 \\ & 5: 5 \mathrm{E}-2 \\ & 6: 5 \mathrm{E}-2 \\ & 7: 5 \mathrm{E}-2\end{array}$

$\begin{array}{cc}\text { N/A } & 11 \\ " \text { " } & 14 \\ \text { " } & 14 \\ \text { LOGNORMAL; EF }=10 & 14 \\ " \text { " } & 15 \\ \text { " } & 15 \\ \end{array}$


Table D.3.1 Loss of Coolant Accidents

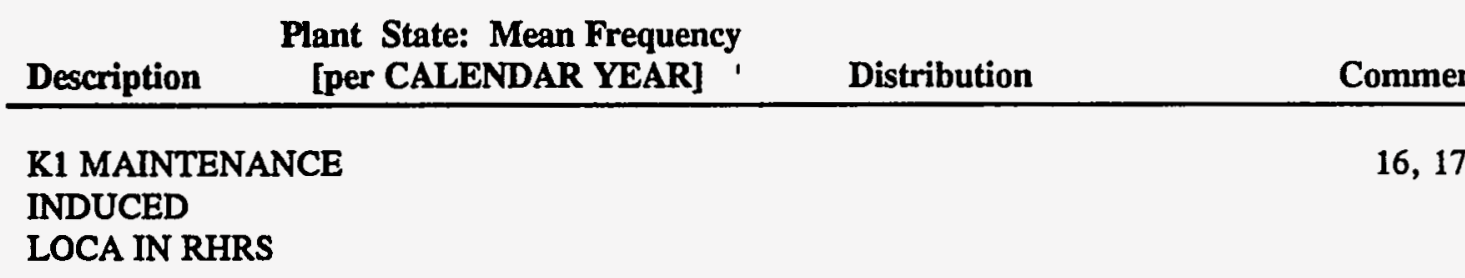

K2 MAINTENANCE

16,17

INDUCED

LOCA IN RWCU

SYSTEM

K3 MAINTENANCE

16,17

INDUCED

LOCA IN RCIC

SYSTEM

K4 MAINTENANCE

16,17

INDUCED

LOCA IN HPCS

SYSTEM

K5 MAINTENANCE

INDUCED

LOCA IN LPCS

SYSTEM

K6 MAINTENANCE

16,17

INDUCED

LOCA IN RECIRC

SYSTEM

Table D.3.1 Comments

(1) Frequency values for primary system LOCAs at Full Power are from Table 4.9-26 of [Drouin et al., 1989] and the distribution value from [Mackowiak et al., 1985]. Values for POSs 1 through 4 were taken to be the same as for Full Power (see $\{2\}$ ).

\{2\} The frequencies for POSs 5 through 7 are scaled down by 0.1 from the values listed in Table 4.9-26 of [Drouin et al., 1989], based on the information in Table A-5 of [Wright et al, 1987]. This table presents the expected effect on overall LOCA frequency for various factors such as pipe size or mode of operation. The multipliers in the table are meant to be applied to overall mean frequency. The factor 0.1 reported for "Shutdown" in this table seems to apply only to Cold Shutdown and Refueling. "Starting Up" and "Shutting Down" as defined in [Wright et al, 1987] encompass Hot Shutdown and Startup, whereas "Normal Operation" covers Low and Full Power. Although the results presented in Appendix A of the report have a large associated uncertainty (because expert elicitation was used to obtain the results), this multiplier is considered to be a valid qualitative adjustment for LOCA frequency during shutdown, versus the overall frequency used in the full power analysis. Factors greater than one are reported in the table for modes other than "Shutdown", but are not considered applicable to the Full Power values, because the overall mean frequency reported in the table is four orders of magnitude lower than 


\section{Table D.3.1 Comments (Continued)}

the smallest Full Power frequency. The distributions from [Mackowiak et al., 1985] have been applied to all plant states, as they are considered realistic for this analysis.

\{3\} Section 4.4.15 of [Drouin et al., 1989] justifies the exclusion of Interfacing LOCAs from consideration in the Grand Gulf Full Power study. These arguments are taken to apply to POS 1 since the plant configuration and conditions are nearly the same as for Full Power.

\{4\} For POSs 2 through 7, the plant conditions are such that a high-to-low pressure interface is not likely to exist. For these modes, new event identifiers have been created to describe LOCAs involving interfacing systems: H for recoverable diversion of vessel inventory through a system connected to the primary, $J$ for LOCAs in a connected system through which primary water is flowing, and $\mathrm{K}$ for maintenance-induced LOCAs in connected systems.

\{5\} Section 4.4.16 of [Drouin et al., 1989] describes the reason for exclusion of the Vessel Rupture event from the Full Power study. This same reasoning should apply to POS 1.

In POSs 2 through 7, the exi', : pressure or potential for overpressure in the vessel is considered to be significantly less than at Full rower. The arguments employed in [Drouin et al., 1989] regarding the probability of vessel rupture while at power are considered to bound the probability during POSs 2 through 7.

\{6\} Diversion of Vessel Inventory Through the RHRS is not considered applicable for Full Power for the reasons explained in the Interfacing LOCA section of [Drouin et al., 1989], and does not apply to POS 1 according to the same arguments.

\{7\} The "Diversion of Vessel Inventory Through RHRS" event is not applicable in POSs 2 and 3 since the RHR system is not normally used in these POSs.

\{8\} The "Diversion of Vessel Inventory Through RHRS" event frequency for POSs 4 through 7 has been calculated using the data collected in [Vine et al., 1989]. Thirteen events involving loss of vessel inventory through the RHR system were identified over the seven-year (1977-1983) time period covered by the study. Of the thirteen events, five events occurred during pre-commercial operation, and two events involved heat exchanger leakage, which is considered under event J2. One event, counted as a single event in [Vine et al., 1989], has been considered as two separate events in this frequency calculation. Six of the remaining seven commercial events involved loss of coolant inventory to the suppression pool. The seventh event involved significant coolant shrinkage upon cooldown initiation. Diversion of Vessel Inventory is defined to include events involving diversion to a sizable fluid sink, e.g. the suppression pool. The seven events mentioned above are the basis for the RHR Diversion of Vessel Inventory frequency. In each of these events the coolant was "recoverable", i.e. not lost to the system. This type of event appears to be the only credible diversion of inventory event involving the RHR (piping ruptures, component failures, or maintenance/test-induced LOCAs are considered in events J2 and $\mathrm{K})$. The events encompass two possible paths out of the vessel: through the RHR Recirculation Loop connection, and via the RHR/LPCI inlet line. The first path terminates at $2 / 3$ core height while the latter path naturally terminates at over $\mathbf{5 0}$ inches above the top of the active fuel, but is still included as part of the RHR inventory diversion frequency. It should be noted that the inventory diversion event is potentially significant during shutdown because of possible disabling of isolation signals on vessel level, as has been the case in one precommercial event. The seven years covered by the study represent approximately 152 BWR plant operating years.

A mean frequency for RHR Loss of Vessel Inventory is calculated using seven events over 152 years, by first calculating a median value using a binomial distribution computer [Binomial Computer] (5E-2). The error factor is estimated by finding the $5 \%$ and $95 \%$ confidence values on the binomial computer (1E-2 and $2.5 \mathrm{E}-1)$, and roughly doubling that value. The mean, assuming a lognormal distribution about the median value found above, is then $8 \mathrm{E}-2 / \mathrm{yr}$. 


\section{Table D.3.1 Comments (Continued)}

\{9\} Diversion of vessel inventory via the HPCS and LPCS systems is credible, based on the possible paths to the suppression pool involving failure on the testable check valve combined with two open isolation valves. However, according to [Vine et al., 1986], all previous diversion events have involved only RHR. In addition, the HPCS and LPCS events, would terminate with a water level above the top of the active fuel. The dominant contributors to this event are expected to be maintenance/test errors and as such will be included in the $K$ events.

\{10\} System normally in operation. Not considered as a diversion path.

\{11\} This initiator applies to systems through which primary water is flowing. The RCIC and RHR (SDC) systems are not normally operating in Full Power.

\{12\} The frequency was estimated by assuming a steam line break down stream of MOV 45. The pipe segment contains two valves with a failure rate of $4.5 \mathrm{E}-9 / \mathrm{hr}$. Multiplying by the number of hours in a year yields a value of 7.8894E-5. This value was increased by a factor of 10 , producing a final result of $8 \mathrm{E}-4 / \mathrm{yr}$. An EF of 10 was assumed for a lognormal distribution. This should be conservative since the value should be reduced by the fraction of time RCIC is operating in POS 1,2 , or 3.

\{13\} RCIC not operated in these POSs.

\{14\} RHR (SDC) does not normally operate during POS 1. It was operated one time in the Startup phase ("Training Startups"), but the utility decided not to operate SDC in this state again. Thus this initiator for POS1 was assumed to be not applicable. RHR (SDC) does not normally operate in POSs 2 and 3 and is assumed to be not applicable for these POSs.

\{15\} For POSs 4 through 7, the RHR LOCA frequency due to pipe or component ruptures is derived from the argument of Expert "B" on Component Cooling Water Pipe Rupture in [Wheeler et al., 1989], p. C-172. This expert used data from Appendix A, Figure A-2 of [Wright et al., 1987] which has a very high associated uncertainty. This expert's mean value estimate for $\mathrm{CCW}$ pipe rupture was one order of magnitude lower than the aggregate mean for the three experts involved. Because no better source of information was located, Figure A-3 of [Wright et al., 1987] was consulted to obtain a RHR pipe rupture frequency. The pipe rupture frequency for RHR at power was found to be about the same as that for the CCW system (2E-7/system year). Assuming the same distribution as expert "B" applied to the CCW frequency, the mean for RHR should be about the same as $\mathrm{CCW}: 1 \mathrm{E}-5 / \mathrm{yr}$. Increasing this value by one order of magnitude in order to more closely match the aggregate $\mathrm{CCW}$ frequency for the three experts yields $1 \mathrm{E}-4 /$ system year.

Although the operating conditions of the RHR system may be more harsh than for CCW, the CCW system contains over 2.5 times the length of piping as in RHR, so this frequency seems reasonable.

In considering piping system component failures, Expert " $\mathrm{C}$ " of [Wheeler et al., 1989] indicated that valves would probably not fail at low pressure. However, pump or heat exchanger failures must also be taken into account. [Vine et al., 1986] reports two RHR Heat Exchanger leak events causing about a 4000 gallon loss of vessel inventory to the RBCCW system. Assuming two events over 43.9 shutdown years, the frequency estimate is 0.05 /year. This value is much larger than the pipe rupture frequency estimated above, and is thus the value used for POSs 4 through 7.

Maintenance/Test-Induced LOCAs were not analyzed in the Full Power Study.

\{17\} Maintenance/Test-Induced LOCAs are of concern for POSs 2 through 7, where maintenance or test activities inadvertently open a path whereby coolant inventory is lost (e.g. removal of components for maintenance and improper valve alignments). All systems connected to the primary are considered for their $\mathrm{K}$ event potential. The analysis for these events will take place during the detailed phase of the project. 


\section{IE Scroening}

cases, the less stressful temperature and pressure conditions during shutdown should reduce the frequency of the various LOCA events considered at full power, or allow elimination of some events. Table D.3-1 lists the various LOCA events considered, their assigned screening frequencies and distributions, and comments describing in detail the method for obtaining the frequencies.

\section{D.3.3.1 LOCA Categories}

The various LOCA categories (A, S1, S2, and S3) assigned for full power are considered applicable for all POSs. Reclassification of the LOCA sizes for the various plant states is not considered necessary. The frequencies presented in NUREG 4550 are considered applicable to POSs 1, 2, 3, and 4. The error factors from NUREG/CR-4550 Vol. 1 are applied because they are considered more realistic. Although the transient conditions existing in the Startup Phase of POS 1 could be construed as more stressful to the plant than at full power, this is not considered to have a significant effect on the frequencies assigned for POS 1 . The frequencies for POSs 5, 6, and 7 have been scaled down from the full power values, as described in comment $\{2\}$ of Table D.3-1.

\section{D.3.3.2 Interfacing System LOCA}

As described in the Background section above, Interfacing System LOCAs (V) were screened out of the Reference 1 analysis by the use of arguments that apply to POS 1 as well. The high-to-low pressure interface conditions necessary for the $V$ scenario do not exist during Plant States 5, 6, and 7 except possibly as a result of an accident initiating event. This type of $V$ sequence is included in the appropriate event trees. Such conditions may exist during Plant States 2, 3, and 4, where maintenance/test conditions may increase the likelihood of a V event, but new LOCA categories have been created to take into account these situations (see Section D.3.4.3).

\section{D.3.3.3 Vessel Rupture}

As described in the previous section, Vessel Rupture (R) was excluded for Full Power. The less harsh conditions experienced in the POSs of this study allow exclusion of the $R$ event for these POSs as well. Although POS 1 (i.e., the Startup Phase) may involve increased stresses to the vessel due to the transient vessel conditions, the $R$ event is also excluded for POS 1 (see comment $\{3\}$ of Table D.3-1). A special event, Inadvertent
Overpressurization (see Table 4.5-1), may have a bearing on vessel rupture, as discussed in note $\{15\}$ of Table D.5-1.

\section{D.3.4 LOCA Events Unique to Low Power/Shutdown Operations}

Additional loss of coolant events have been postulated for the POSs defined in this study, due to the unusual plant configurations and maintenance practices occurring in these POSs. Three types of events, all involving systems connected to the primary, are identified for these POSs: 1) $\mathrm{H}$, involving recoverable diversion of vessel inventory through a connected system; 2) J, loss of coolant in an operating connected system involving piping or component failures; and 3) $\mathrm{K}$, maintenance/test-induced LOCAs on connected systems with potential for draining vessel inventory. These events, combined with the full-power events described in the previous section, are thought to encompass the credible loss of coolant events possible in all POSs.

In several of the events described in this section, the frequency has been estimated using a known number of events over a certain number of plant calendar years. A binomial distribution computer (see note $\{8\}$ of Table D.3-1) has been used to provide an estimate for the median frequency (using the $50 \%$ confidence value), and to give an indication of the error factor (using the $5 \%$ and $95 \%$ confidence values). The error factor indicated by the binomial computer was approximately doubled, and a mean frequency was calculated from the binomial median assuming a lognormal distribution. This method has been applied for $\mathrm{H}$ and $\mathrm{J}$ events.

\section{D.3.4.1 Recoverable Diversion of Vessel Inventory} (H)

The Recoverable Diversion of Vessel Inventory event involves the establishment of a path through a connected system whereby vessel inventory is reduced, but the inventory is recoverable. All of these events involve diversion to the suppression pool. These events are kept separate from the $J$ and $K$ events because the possibility of inventory recovery creates a potentially different response to this type of initiator.

In identifying the possible systems for the $\mathrm{H}$ event, connections from the vessel to a possible sink, such as the suppression pool are identified. The paths are brought about in most cases by misalignment or failure of valves. Only two connected systems have the 
potential to directly drain the vessel below the Top of the Active Fuel (TAF): 1) the Residual Heat Removal (RHR); and 2) Reactor Water Cleanup (RWCU) systems through the RHR connection on the $B$ recirculation loop. Other connections, such as the LPCI/RHR injection line, have the potential for draining coolant from the vessel but will naturally terminate above the top of the active fuel. These connections are also considered in this event because of the possibility of non-detection during shutdown and the need for makeup or cooling.

The following subsections describe the connections considered and justification for exclusion. It should be noted that instrumentation and leak-detection lines were not considered significant diversion paths and thus were not considered. The Alternate Decay Heat Removal System (ADHRS) is considered as part of the RHRS.

\section{D.3.4.1.1 Residual Heat Removal System}

The RHRS is an important system with regard to vessel diversion potential in the shutdown POSs. Several events have occurred in the past involving vessel inventory diversion to the suppression pool. These events formed the basis for the RHR inventory diversion (H1) frequency, as described in comment $\{8\}$ of Table D.3-1. Diversion is possible through either the recirculation loop Shutdown Cooling (SDC) suction connection, or through the LPCI/RHR injection line to the vessel. This event has been excluded for POSs 1,2 , and 3 since the plant configuration is so similar to Full Power.

\section{D.3.4.1.2 Reactor Water Cleanup System}

Section 4.4.15 (Interfacing LOCA) of NUREG 4550 considered the RWCU system. The contribution to core damage frequency from a RWCU pipe break was assessed to be less than for large LOCA, and was thus ruled out. The arguments for ruling out the RWCU included isolation potential, the high pressure design of the entire system, and the fact that the location of the RWCU precludes any adverse affect of a RWCU pipe break on coolant injection systems. These arguments apply to POS 1 .

Diversion of vessel inventory through the RWCU is not considered as an initiating event because no credible drain path with a sizable fluid sink other than the Condenser or Rad-Waste was identified. Since RWCU is normally rejecting to either Rad-Waste or the Condenser (or both), this diversion event was excluded as a potential initiating event. Furthermore, NSAC 88 notes that all known diversions have been through RHR. (For POSs 1, 2, and 3, RWCU is in normal alignment (i.e., cleanup mode). Beginning in POS 4, RWCU rejects water to the condenser or Rad-waste as a means of level control.)

\section{D.3.4.1.3 Reactor Core Isolation Cooling (RCIC)}

An interfacing LOCA at full power involving the RCIC was ruled out in NUREG 4550, and the same arguments apply to POSs 1 through 7 as well. Vessel inventory diversion through the RCIC system connection (to the feedwater line via the RHRS) is not considered credible because two check valves (one feedwater and one RCIC) must fail in addition to the testable check valve on the feedwater line. The event is thus ruled out for all plant states.

\section{D.3.4.1.4 High Pressure Core Spray (HPCS)}

As with other connected systems, NUREG 4550 screened out interfacing LOCAs involving the HPCS system. Again, this applies to POSs 1 through 7 as well. For all POSs, however, maintenance or testing activities involving the testable check valve or other valves make this event a concern and will be considered in the Maintenance/Test-Induced (M/T-I) LOCA initiating event. (This type of initiating event requires development by the detailed HRA methodology program and will be used if available. NOTE: Development not available.) where it can be used. A path to the suppression pool exists through one testable check valve and two isolation valves. Thus, from a hardware perspective, the M/T-I LOCA IEs are unlikely to occur. The event has been ruled out for all plant states.

\section{D.3.4.1.5 Low Pressure Core Spray (LPCS)}

The comments for HPCS above apply directly to LPCS.

\section{D.3.4.2 LOCA in Operating Connected System}

The LOCA in an Operating Connected System (J) event refers to pipe ruptures and component failures (e.g., heat exchangers) in operating systems connected to the primary. Three systems fit this definition: RHRS, RCIC, and RWCU. (Note that ADHRS is considered part of RHRS.) A J event involving the RWCU system has been ruled out of all POSs because it should be included in the full power LOCA initiators since RWCU operates at full power. The J event for the RCIC system (J1) and the RHR system (J2) are possible and the methods used to estimate their frequencies are described 
in Table D.3-1. These events apply to POSs 1,2 , and 3 for $\mathrm{J} 1$ and POSs 4, 5, 6, and 7 for J2. Note that the frequencies should be reduced by the fraction of time these systems are actually operating. For the screening analysis this factor was assumed to be 1.0 .

\section{D.3.4.3 Maintenance/Test-Induced LOCAs}

Maintenance/test-induced LOCAs (K) involve systems connected to the primary wherein maintenance or test activities result in a primary coolant loss through the connected system. Actions such as removal of system components for maintenance/test combined with inadvertent valve misalignment are considered in the $\mathrm{K}$ event. Maintenance/test-induced LOCAs are of concern for POSs 2 through 7, during which such maintenance or test activities are postulated to occur.

All systems connected to the primary will be considered for their $\mathrm{K}$ event potential. Other possible $\mathrm{K}$ events, such as maintenance/test involving the control rod drive system, have been identified. The analysis for these events did not occur because the detailed human reliability analysis methodology program was completed.

\section{D.4 Decay Heat Removal Challenge Initiators}

\section{D.4.1 Introduction}

A group of initiators that are unique to this project are the Decay Heat Removal (DHR) challenge initiators. These events involve an interruption or failure to establish decay heat removal during POSs 4 through 7 . They are broadly categorized into two types of events: isolation from an operating DHR system (E1); and failure of an operating DHR system (E2). All systems normally used for decay heat removal at various times in each POS are considered for these initiators (based on a review of Grand Gulf operating procedures). This includes the use of the condenser for decay heat removal after a shutdown evolution. However, this event has been included under the T2 event for POSs 2 and 3.

\section{D.4.2 Identification and Estimation}

The majority of the events involve the RHR system, with much of the data for RHRS failure taken from NSAC [Vine et al., 1986]. For several of the events described in this section, the frequency has been estimated using a known number of events found in NSAC 88 over a certain number of plant calendar years. A binomial distribution computer has been used to provide an estimate for the median frequency (using the 50\% confidence value), and to give an indication of the error factor (using the $5 \%$ and $95 \%$ confidence values) [Binomial Computer]. The error factor indicated by the binomial computer was approximately doubled, and a mean frequency was calculated from the binomial median assuming a lognormal distribution.

Table D.4-1 describes in detail the various events considered as well as the method for obtaining the event frequencies and distributions. It should be noted that the frequencies listed for the various DHR initiators are given in terms of plant calendar years. It is intended that these frequencies will be corrected by factors representing the fraction of the plant calendar year spent in the POS being analyzed. These events, which depend on operation of a particular system, should be multiplied by the fraction of time the given system operates in a particular POS. For this screening analysis, this factor was assumed to be 1.0 .

\section{D.5 Special Events}

\section{D.5.1 Introduction}

Events which did not fit into the previous three categories but which present a challenge to plant safety are included under the Special Initiating Events category. Events identified for inclusion in this category include some of the special events considered in full power, as well as events unique to POSs being examined by this study. Various sources were consulted to identify the events possible in the different plant states, including the NUREG/CR-4550 volumes, Nuclear Safety Analysis Center Reports, several years of BWR operating experience described in Nuclear Power Experience, and the information contained in the Precursor Reports.

The following sections describe the various events considered in this category. Table D.5-1 describes in detail the events considered as well as the method for obtaining the event frequencies and distributions. It should be noted that the frequencies listed for the various special initiators are given in terms of plant calendar years. It is intended that these frequencies will be corrected by factors representing the fraction of the plant calendar year spent in the POS. The events which depend on operation of a particular system, such as a service water system, should be multiplied by the fraction of time the given system operates in a particular POS. For this screening analysis the factor was assumed to be 1.0 . 
Table D.4.1 Decay Heat Removal (DHR) Challenge Initiators

Description

Plant State: Mean Frequency [per Calendar Year]

Distribution

Comments

E1B ISOLATION FROM OPERATING RHR-SHUTDOWN COOLING LOOP B
FULL POWER: N/A

1: N/A

2: "

3: "

4: 0.1

5: 0.1

6: 0.1

7: 0.1

E1C ISOLATION FROM OPERATING RWCU SYSTEM (DHR)

E1D ISOLATION FROM OPERATING ADHRS

EIT ISOLATION OF SDC COMMON SUCTION LINE

E1V ISOLATION OF COMMON SUCTION LINE FOR ADHRS
FULL POWER: N/A

1: N/A

2: "

3: "

4: "

5: "

6: "

7: 0.1

FULL POWER: N/A

1: N/A

2: N/A

3: N/A

4: N/A

5: 0.1

6: 0.1

7: 0.1

FULL POWER: N/A

1: N/A

3: N/A

4: 0.1

5: 0.1

6: 0.1

7: 0.1

FULL POWER: N/A

1: N/A

2: "

3: "

4: "

5: 0.1

6: 0.1

7: 0.1
2: N/A

$\begin{array}{cc}\text { N/A } & 1 \\ " & 2 \\ \text { LOGNORMAL; EF }=5 & 2 \\ " \text { " } & 2 \\ " & 3 \\ " & 3 \\ & 3\end{array}$

N/A 1

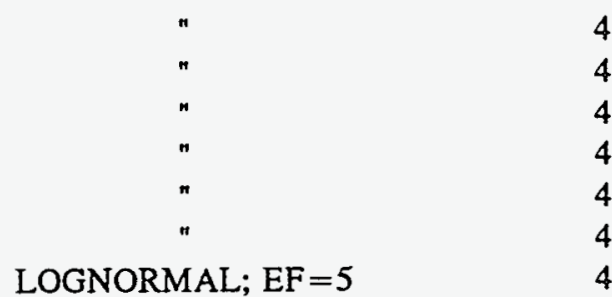

N/A

$$
1
$$

5

5

5

LOGNORMAL; $\mathrm{EF}=5$

5

5

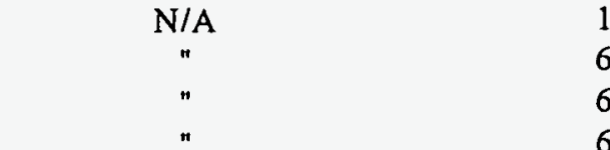

LOGNORMAL; $\mathrm{EF}=5$

7

7

7

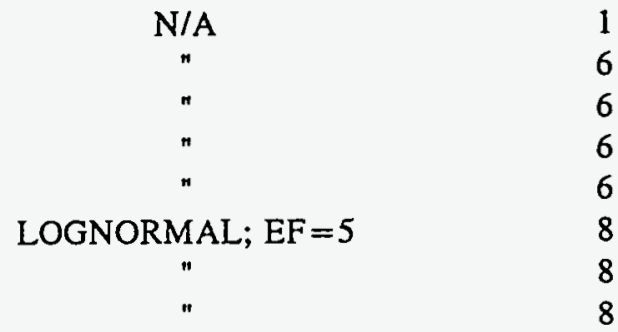


Table D.4.1 Decay Heat Removal (DHR) Challenge Initiators

Description

Plant State: Mean Frequency [per Calendar Year]

FULL POWER: N/A

1: N/A

2: "

3: "

4: 0.37

5: 0.37

6: 0.37

7: 0.37
E2C LOSS OF OPERATING RWCU SYSTEM (DHR)

FULL POWER: N/A

1: N/A

2: "

3: "

4: "

5:"

6:"

7: 0.1

E2D LOSS OF OPERATING ADHRS

FULL POWER: N/A

1: N/A
2: N/A

3: N/A

4: N/A

5: 0.37

6: 0.37

7: 0.37

E2T LOSS OF SDC COMMON SUCTION LINE
FULL POWER: N/A

1: N/A

2: "

3: "

4: 0.37

5: 0.37

6: 0.37

7: 0.37

FULL POWER: N/A

1: N/A

2: "

3: "

4: "

5: 0.37

6: 0.37

7: 0.37
Distribution

Comments
E2V LOSS OF COMMON SUCTION LINE FOR ADHRS
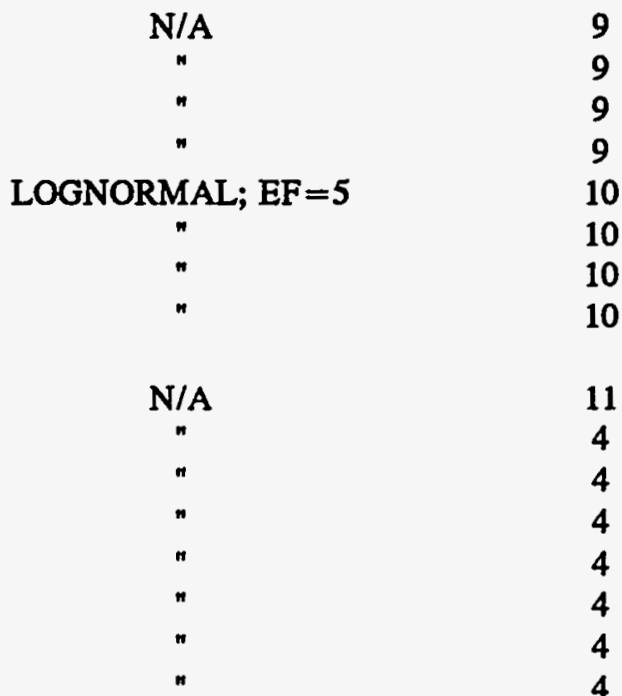

11

4

4

4

4

4

4

4

N/A

12

n 12

" 12

$" 12$

" 12

LOGNORMAL; $E F=5$

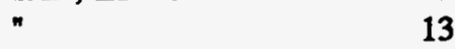

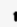

13
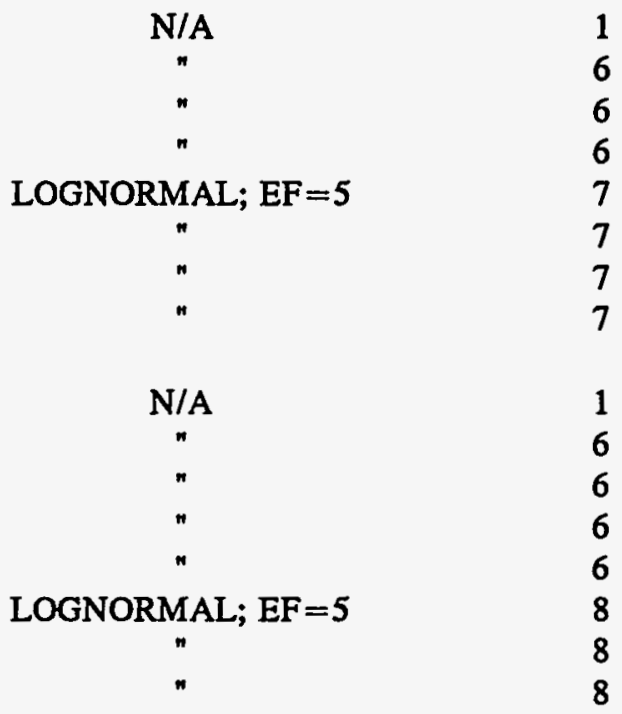


\section{Table D.4.1 Comments}

(1) A decay heat removal (DHR) system is not normally operating in Full Power, so that events E1B (RHRS), E1C (RWCU as DHR system), and E1D (ADHRS) do not apply.

\{2\} RHR Shutdown Cooling (SDC) is not normally operated in POSs 2 and 3. This event is assumed to be not applicable for these POSs.

(3) The frequency for E1B is found using nine events identified in [Vine et al., 1986]. NSAC-88 identifies 25 events involving isolation of the RHRS, but 16 of these were pre-commercial. The study covered approximately 152 years of BWR plant operating years (1977-83).

A mean frequency for E1B was calculated using nine events over 152 years, by first calculating a median value using a binomial distribution computer [Binomial Computer] (0.065). The error factor was estimated by finding the $5 \%$ and $95 \%$ confidence values on the binomial computer $(0.036$ and 0.099$)$, and roughly doubling that value. The mean, assuming a lognormal distribution about the median value found above, is then $0.1 / y r$.

44\} RWCU used only in POS 7. The same numerical value for E1B is used for E1C and E2C.

\{5\} ADHRS is only allowed to operate in POSs 5, 6, and 7 per Grand Gulf Technical Specifications [USNRC 1984]. The frequency calculated for event E1B, $\{3\}$, was applied to E1D, since the ADHRS operates through the RHRS, and isolation of RHR would also isolate ADHRS.

\{6\} Not normally operated in these POSs.

\{7\} Assume same numerical value for E1T (E2T) as for E1B (E2B).

\{8\} Assume same numerical value for E1V (E2V) as for E1B (E2B).

\{9\} SDC is not normally operated at Full Power or in these POSs.

\{10\} The calculational method for the E2B frequency is as described in [Wright et al., 1987], using 13 events for loss of RHR due to valve problems, four events for loss or degradation of RHR due to loss of a running RHR pump, five events involving RHR heat exchanger problems, three events for loss of RHR due to overfill or overpressurization of the RPV, (These events are considered here only for their potential to cause an interruption in decay heat removal operations. Overpressurization is considered as a special event, see Table 4.5-1.), and seven of the nine events for loss of RHR due to planned maintenance. The remaining two events were pre-commercial. All events are from [Vine et al., 1986].

\{11 $\quad$ RWCU used in a decay heat removal capacity does not apply to Full Power.

\{12\} Grand Gulf Technical Specifications mandate that ADHRS only be used in Modes 4 and 5 (i.e., POSs 5, 6, and 7).

\{13\} A screening frequency for loss of ADHRS has been estimated using the E2B events, since ADHRS operates through the RHRS and has similar components. 


\section{D.5.2 Criticality Events}

Three criticality events were identified for consideration. They are:

- T4A: Rod Withdrawal Error

- T4B: Refueling Accident (rod or fuel misposition)

- T4C: Instability Event.

All three of these were screened from the analysis, based on the following reasons.

T4A, the rod withdrawal accident at power (rod drop in a BWR), is a design basis accident. Thus, for significant fuel damage to occur, other failures (such as control rod pattern errors) must exist. (Rod drop during startup is precluded by design.) BNL concluded that the likelihood of significant fuel damage from a rod drop event at full power is < 1E-8/RY [Diamond et al., 1990]. The value for off-power conditions should not be higher. It is concluded that this event can be screened from the analysis.

T4B, the refueling accident, can be of two types. The first type involves incorrect placement of a fuel bundle in the core during refueling. This is a design basis accident and does not lead to unacceptable consequences. The second type is associated with local loading of fuel when more than one control blade is removed. This accident is discussed in reference [Drouin et al., 1989] which concludes that it can damage fuel and that its frequency may not be below 1E-7/RY (depending on the specific characteristics of a particular plant). BNL points out that improvements in technical specifications, such as suspending fuel loading when control blades are out, can reduce the frequency of this accident [Diamond et al., 1990]. The pertinent technical specification for Grand Gulf that allows for removal of more than one control blade during refueling is \# 3.9.10.2, and it requires that all fuel loading operations be suspended unless all control blades are inserted in the core [USNRC 1984]. Based on this control provided by the technical specifications, it is concluded that this event can be screened from the analysis.

$\mathrm{T} 4 \mathrm{C}$, the flow instability event refers to operation of the core with a local high power-to-mass-flow ratio. The concern is that with the instability, should a design basis event take place, the high power regions of the core can be damaged due to the occurrence of phenomena such as critical heat flux or excessive fuel enthalpy . BNL addressed early fuel damage from reactivity insertion events occurring given operation with instabilities, and concluded that early fuel damage due to excessive fuel enthalpy is not of concern [Diamond et al., 1990]. No detailed study of all design basis accidents occurring while core instabilities are present has been performed for the off power study. However, during off power conditions, instabilities are less likely than at full power, and therefore these events have been screened from the analysis.

BNL also concluded that a particular type of reactivity insertion can occur during an ATWS sequence, and it may not be sufficiently low to be screened from consideration [Diamond et al., 1990]. The reactivity insertion results from failure of the operator to inhibit (automatic) ADS following injection of borated water from the SLC. If the reactor depressurized, auto injection of non-borated water from LPCI or LPCS can displace borated water and result in a reactivity excursion which can damage fuel. This issue was not specifically addressed in the Grand Gulf full power PRA [Drouin et al., 1989]. This regulation does not address inhibiting ADS for those sequences involving successful shutdown with SLC. ADS can actuate if vessel level is low, and this can occur following an ATWS. (Table A-1 of NUREG 4550 indicates that the level will drop to the top of the active fuel following an ATWS even with injection from SLC, CRD, and HPCS.) Since ATWS sequences were contributors to core damage for accidents from full power at Grand Gulf, this issue should be addressed for full power. ATWS events are of concern for the off power study only in POS 1 , and in this POS, power is limited to $15 \%$ which reduces the severity of the ATWS. The success criteria for the ATWS in POS 1 are the same as those used in NUREG 4550 for full power, hence this particular reactivity excursion is not considered.

\section{D.5.3 Support System Events}

Several support system initiators were identified based on a review of the equipment required to function during the POSs. These include:

1. Loss of SSW (T5A),

2. Loss of TBCW (T5B),

3. Loss of PSW (T5C),

4. Loss of CCW (T5D), 
'Table D.5.1 Special Initiating Events

Description

Plant State: Mean Frequency

[per Calendar Year]

Distribution

Comments

NOTE: THE FOLLOWING "T4" EVENTS ARE "CRITICALITY EVENTS"

T4A ROD WITHDRAWAL ERROR

T4B REFUELING ACCIDENT

TAC INSTABILITY EVENT

OWER: N/A

2:

T5A LOSS OF SSW

T5B LOSS OF TBCW

T5C LOSS OF PSW

T5D LOSS OF CCW

Vol. 2, Part 2
1: N/A

3: "

4:"

5:"

6: "

7: "
1: N/A

2: N/A

3: N/A

4: $1.8 \mathrm{E}-2$

5: "

6: "

7: "
FULL POWER: N/A

N/A 1

" 2

" 2

" 2

" 2

" 2

$" \quad 2$

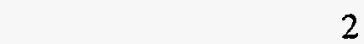

N/A 3

" 3

" 3

" 3

LOGNORMAL; $E F=54$

" 4

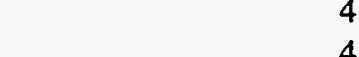

FULL POWER: N/A N/A $\quad 3$

1: $1.8 \mathrm{E}-2$

2: "

3: "

4: "

5:"

6: "

7:"

$\mathrm{AL} ; \mathrm{EF}=5$

FULL POWER: N/A N/A 3

1: $1.8 \mathrm{E}-2 \quad$ LOGNORMAL; $\mathrm{EF}=5$

2: "

3: "

4: " 50

5: " $5: " 5$

6: " $1 " 5$

$7: " \quad n$

FULL POWER: N/A N/A 3

1: N/A "

2: "

3: " $" ~ 3$

4: $1.8 \mathrm{E}-2 \quad$ LOGNORMAL; $\mathrm{EF}=55$

5: "

6: " $" 5$

7: " 5

2
2
2
2
2
2
3
3
3
3
4
4
4
4

(1)


IE Screening

Table D.5.1 Special Initiating Events

\begin{tabular}{|c|c|c|c|}
\hline Description & $\begin{array}{l}\text { thtate: Mean Frequency } \\
\text { [per Calendar Year] }\end{array}$ & Distribution & Comments \\
\hline$\overline{\text { TAB OR TDB }}$ & $\begin{array}{l}\text { FULL POWER: N/A } \\
\text { 1: N/A } \\
\text { 2: N/A } \\
\text { 3: N/A } \\
\text { 4: 9E-4 OR 6E-3 } \\
\text { 5: " } \\
\text { 6: " } \\
\text { 7: " }\end{array}$ & $\begin{array}{l}\text { N/A } \\
" \\
n \\
\text { LOGNORMAL; EF=5 } \\
" \\
"\end{array}$ & $\begin{array}{l}3 \\
3 \\
3 \\
3 \\
6 \\
6 \\
6 \\
6\end{array}$ \\
\hline $\begin{array}{l}\text { TIA LOSS OF INSTRUMENT } \\
\text { AIR SYSTEM }\end{array}$ & $\begin{array}{l}\text { FULL POWER: N/A } \\
\text { 1: } 0.5 \\
\text { 2: } 0.5 \\
\text { 3: } 0.5 \\
\text { 4: } 0.5 \\
\text { 5: } 0.5 \\
6: 0.5 \\
\text { 7: } 0.5\end{array}$ & $\begin{array}{l}\text { SEE "T2" } \\
\text { TBD } \\
" \\
" \\
" \\
" \\
"\end{array}$ & $\begin{array}{l}7 \\
8 \\
8 \\
8 \\
8 \\
8 \\
8 \\
8\end{array}$ \\
\hline $\begin{array}{l}\text { TORV INADVERTENT OPEN } \\
\text { RELIEF VALVE } \\
\text { (SHUTDOWN) }\end{array}$ & $\begin{array}{l}\text { FULL POWER: N/A } \\
\text { 1: N/A } \\
\text { 2: " } \\
\text { 3: } " \\
\text { 4: } 0.1 \\
5: \text { N/A } \\
\text { 6: N/A } \\
\text { 7: N/A }\end{array}$ & $\begin{array}{l}\text { SEE "T3C" } \\
" \\
" \\
\text { TBD } \\
\text { N/A } \\
" \\
n\end{array}$ & $\begin{array}{l}9 \\
9 \\
9 \\
9 \\
10 \\
11 \\
11 \\
11\end{array}$ \\
\hline $\begin{array}{l}\text { TIOP INADVERTENT } \\
\text { OVERPRESSURIZATION } \\
\text { EVENT }\end{array}$ & $\begin{array}{l}\text { FULL POWER: N/A } \\
\text { 1: N/A } \\
\text { 2: N/A } \\
\text { 3: N/A } \\
\text { 4: } 0.16 \\
\text { 5: } 0.16 \\
\text { 6: N/A } \\
\text { 7: N/A }\end{array}$ & $\begin{array}{l}\text { N/A } \\
n \\
n \\
\text { TBD } \\
n \\
\text { N/A }\end{array}$ & $\begin{array}{l}12 \\
12 \\
12 \\
12 \\
12 \\
13 \\
13 \\
14 \\
14\end{array}$ \\
\hline $\begin{array}{l}\text { TIHP INADVERTENT } \\
\text { OVERPRESSURIZATION } \\
\text { VIA SPURIOUS HPCS } \\
\text { ACTUATION }\end{array}$ & $\begin{array}{l}\text { FULL POWER: See T3A } \\
\text { 1: See T3A } \\
\text { 2: " } \\
\text { 3: " } \\
\text { 4: } 1 \mathrm{E}-2 \\
\text { 5: } 1 \mathrm{E}-2 \\
\text { 6: N/A } \\
\text { 7: N/A }\end{array}$ & $\begin{array}{l}\text { N/A } \\
" \\
" \\
\text { TBD } \\
\text { TBD } \\
\text { N/A } \\
\text { " }\end{array}$ & $\begin{array}{l}15 \\
15 \\
15 \\
15 \\
16 \\
16 \\
14 \\
14\end{array}$ \\
\hline
\end{tabular}


Table D.5.1 Special Initiating Events

\begin{tabular}{|c|c|c|c|}
\hline Description , & $\begin{array}{l}\text { State: Mean Frequency } \\
\text { [per Calendar Year] }\end{array}$ & Distribution & Comments \\
\hline $\begin{array}{l}\text { TIOF INADVERTENT } \\
\text { OVERFILL VIA LPCS OR } \\
\text { LPCI }\end{array}$ & $\begin{array}{l}\text { FULL POWER: N/A } \\
\text { 1: N/A } \\
\text { 2:" } \\
\text { 3: " } \\
\text { 4: } 4 \mathrm{E}-2 \\
\text { 5: } 4 \mathrm{E}-2 \\
\text { 6: N/A } \\
\text { 7: } "\end{array}$ & $\begin{array}{l}\text { N/A } \\
" \\
" \\
" \\
\text { TBD } \\
\text { TBD } \\
\text { N/A } \\
n\end{array}$ & $\begin{array}{l}17 \\
17 \\
17 \\
17 \\
18 \\
18 \\
14 \\
14\end{array}$ \\
\hline TLM LOSS OF MAKEUP & $\begin{array}{l}\text { FULL POWER: See T3B } \\
\text { 1: N/A } \\
\text { 2: " } \\
\text { 3: " } \\
\text { 4: } 0.49 \\
\text { 5: } 0.49 \\
\text { 6: } 0.49 \\
\text { 7: N/A }\end{array}$ & $\begin{array}{l}\text { N/A } \\
" \\
" \\
" \\
\text { TBD } \\
" \\
\text { N/A }\end{array}$ & $\begin{array}{l}19 \\
19 \\
19 \\
19 \\
20 \\
20 \\
20 \\
21\end{array}$ \\
\hline
\end{tabular}


IE Screening

\section{Table D.5.1 Comments}

(1) The Rod Withdrawal Error event for Full Power was included in the "T3A" frequency in Table 3.1-1. This is EPRI event number 27, Rod Withdraw at Power.

\{2\} See Section D.5.2 for justification for excluding these events.

(3) System not normally used during these POSs or was excluded from the Full Power analysis.

\{4\} NUREG-1275 Vol. 3 [Lam et al., 1988] gives a value of 1.8E-2 for the frequency of loss of service water. This value was assumed to be appropriate for this screening study.

\{5\} See note $\{4\}$.

\{6\} TAB estimated using hourly failure rate for an AC Bus. TDB used TDC value given in [Drouin et al., 1989].

\{7\} For Full Power [Drouin et al., 1989], Loss of Instrument Air (TIA) was considered to result in the same plant response as transient category T2, Loss of PCS, and was thus considered part of this transient category.

\{8\} Loss of Instrument Air applies to all POSs. The frequency is based on two events at Grand Gulf over a four year period.

\{9\} The Inadvertent Open Relief Valve (IORV) event, as it applies to causing a reactor SCRAM, is considered in event T3C (see Table D.2-1).

\{10\} Conservatively assumed same value as for transient from Inadvertent Open Relief Valve from [Drouin et al., 1989] Vol. 1, Rev. 1, page 8-20.

(11) Not applicable. Vessel is depressurized.

12\} Not applicable. System pressure can be as high as normal (approx. $1000 \mathrm{psi}$ ).

\{13\} Frequency estimated using value for EPRI category 20.

\{14\} Vessel head is off, cannot pressurize.

\{15\} Included in T3A.

\{16\} Frequency estimated using value for EPRI category 33.

\{17\} Low pressure systems cannot overpressurize the primary.

\{18\} Frequency estimated by multiplying the EPRI category 33 value by four.

\{19\} Included in T3B.

\{20\} Frequency estimated using value for EPRI category 24.

\{21\} Makeup can be off in POS 7. 
5. Loss of 1E AC Bus B (TAB),

6. Loss of 1E DC Bus B (TDB), and

7. Loss of IA (TIA).

The methods for quantifying these events are described in Table D.5-1

\section{D.5.4 Other Events}

In addition to the events identified above, several other events were identified that could lead to problems if unmitigated. These include:

1. Inadvertent Open Relief Valve at Shutdown (TORV),

2. Inadvertent Overpressurization (makeup greater than letdown) (TIOP),

3. Inadvertent Overpressurization via Suprious HPCS Actuation (TIHP),

4. Inadvertent Overfill via LPCI or LPCS (TIOF), and

5. Loss of Makeup (TLM).

The methods for quantifying these events are described in Table D.5-1. 
IE Screening

\section{References for Appendix D}

[Drouin et al., 1989]

[Diamond et al., 1990]

[Mackowiak et al., 1985]

\section{"Development of Transient Initiating Event Frequencies for Use in Probabilistic Risk Assessments, " NUREG/CR- 3862, EGG-2323, May 1985. \\ H. R. Booth, "Analysis of Refueling Incidents in Nuclear Power Plants, " NSAC-129, December 1988.}

D.P. Mackowiak et al.,

[Booth, 1988]

[Muench, 1964]

[Ericson, ed., 1990]

[Wright et al., 1987]

M.T. Drouin et al., "Analysis of Core Damage Frequency: Grand Gulf, Unit 1; Internal Events, ", NUREG/CR-4550, SAND86-2084, Vol. 6, Rev. 1, Part 1, September 1989.

D.J. Diamond et al., "Reactivity Accidents: A Reassessment of the DesignBasis Events," NUREG/CR-5368, BNLNUREG- 52198, September 1989.

J.O. Muench, "Cumulative Binomial Distribution Computer, "Sandia Corporation, October 1964.

D. M. Ericson, ed., "Analysis of Core Damage Frequency: Internal Events Methodology," NUREG/CR-4550, SAND86-2084, Vol. 1, Rev. 1, January 1990.

R.E. Wright et al., "Pipe
[Lam et al., 1988]

[Vine et al., 1986]

[Wheeler et al, 1989]

[Whitehead et al., 1991]

[USNRC 1984] Break Frequency Estimation for Nuclear Power Plants," NUREG/CR-4407, EGG-2421, May 1987.
G. Vine et al., "Residual Heat Removal Experience Review and Safety Analysis: Boiling Water Reactors, " NSAC-88, March 1986.

T. A. Wheeler et al., "Analysis of Core Damage Frequency From Internal Events: Expert Judgment Elicitation," NUREG/CR-4550, SAND86-2084, Vol. 2, April 1989.

D. W. Whitehead, J. L. Darby, B. D. Staple, B. Walsh, T. M. Hake, and T. D. Brown, "BWR Low Power and Shutdown Accident Frequencie Project, Phase 1 Coarse Screening Analysis", Vol. 1, Draft Letter Report, Sandia National Laboratories and Science and Engineering Associates, Inc., November 23, 1991 update, (Available at the USNRC Public Document Room).

USNRC, "Technical Specifications, Grand Gulf Nuclear Station Unit No. 1," Docket No. 50-416, Appendix "A" to License No. NPF-29, NUREG 0934, October, 1984.

P. Lam et al., "Operating Experience Feedback Report Service Water System Failures and Degradation," NUREG-1275, Vol. 3, November 1988. 


\section{Appendix E. Updated Success Criteria}

This Appendix is the Success Criteria used in the screening study [Whitehead et al., 1991], updated for the detailed study of POS 5. The update was performed for POS 5, but if the update affected other POSs, then the success criteria for these POSs were also updated.

This appendix provides the success criteria for POS 4, 5 , 6 , and 7. (The success criteria for POS 1,2, and 3 are the NUREG 4550 success criteria for full power and are not reproduced here.)

\section{E.1 Summary Description of the Success Criteria for the Systems vs POSs: Low Pressure Conditions}

There are two basic methods of cooling the core:

(1) Injecting subcooled or saturated water so that the fluid exiting the vessel after being heated by decay heat is subcooled or is a two phase mixture of low quality.

(2) Injecting subcooled or saturated water in small quantities and steaming out the vessel.

Method (1) is the normal way of cooling the core. Method (2) must be verified to work in the limiting case of natural convection of boiling saturated water at 15 psia. It must be verified that dryout due to flooding does not occur with $1 \%$ decay heat at 15 psia. NUREG 4550 assumed that method (2) works after trip. from full power. However, in this case, the dryout heat flux will be higher (even though the decay heat is also higher) due to a higher density for saturated vapor at the higher pressure (dryout heat flux is proportional to the square root of the vapor density according to the Wallis flooding criteria). Using Lahey and Moody, it is conservatively estimated that the dryout heat flux for flooding is $8.5 \mathrm{E}+3 \mathrm{Btu} / \mathrm{hr} / \mathrm{ft} / \mathrm{ft}$ at $15 \mathrm{psia}$ [Lahey and Moody, 1984]. The UFSAR, table 4.4-1, specifies a maximum full power heat flux of $3.62 \mathrm{E}+5 \mathrm{Btu} / \mathrm{hr} / \mathrm{ft} / \mathrm{ft}$ and $1 \%$ of this value is less than the estimated dryout heat flux [SERI, 1992]. Thus, method (2) should prevent core damage. The success criteria used in this study assume that steaming the core at low pressure does not lead to flooding induced dryout.

The functional event tree for POS 4, 5, 6 and 7 is shown in Figure E.1.1.

Vol. 2, Part 2
In terms of functions, the tree is very simple. Three functions must be successfully provided to prevent core damage: (1) reactivity control to ensure that the core is not producing heat in excess of decay heat, (2) level control to ensure that the core is maintained "covered" with water, and (3) energy removal to remove energy from the water covering the core. (The situation following a large LOCA in a recirculation line, for which only two thirds of the core is covered with water, is a special case.) The specific combinations of systems which can fulfill these three functions depend on the POS and the specific accident initiating event. A discussion of each function follows, addressing success criteria which maintain system pressure low enough so that isolation of RHR/SDC is not required. Options for cooling the core considering isolation of RHR/SDC and pressurization of the system are subsequently discussed.

\section{Function 1: Reactivity Control}

Shutdown margin at Grand Gulf can be maintained with the rods alone all the way down to refueling conditions without the need for boron injection. The SLC is a backup for the rods. Since in POS 4, 5, 6, and 7 the rods are fully inserted, it is considered extremely improbable that loss of reactivity control can occur.

\section{Function 2: Level Control}

The core can be cooled as long as the top of the core is "covered" with water, assuming that natural convection of boiling saturated water does not lead to dryout (as discussed earlier). "Covered" means that the collapsed level of the water is above the top of the core. A design basis large LOCA in a recirculation suction line leads to uncovery of about one third of the core. Licensing analyses verify that for LOCAs from full power, the top third can be cooled by steam. The situation for off power is different, as discussed in the following description of function 3, Energy Removal.

Certain options for energy removal which cool liquid in the downcomer region (such as RHR/DHR) require that the measured level, measured in the downcomer, be sufficiently high for adequate recirculation between the core and downcomer regions. This required measured level is significantly higher than the top of the core. The actual level of concern is the level in the core region which must be above the minimum steam separator turnaround point to allow core water to flow back into 


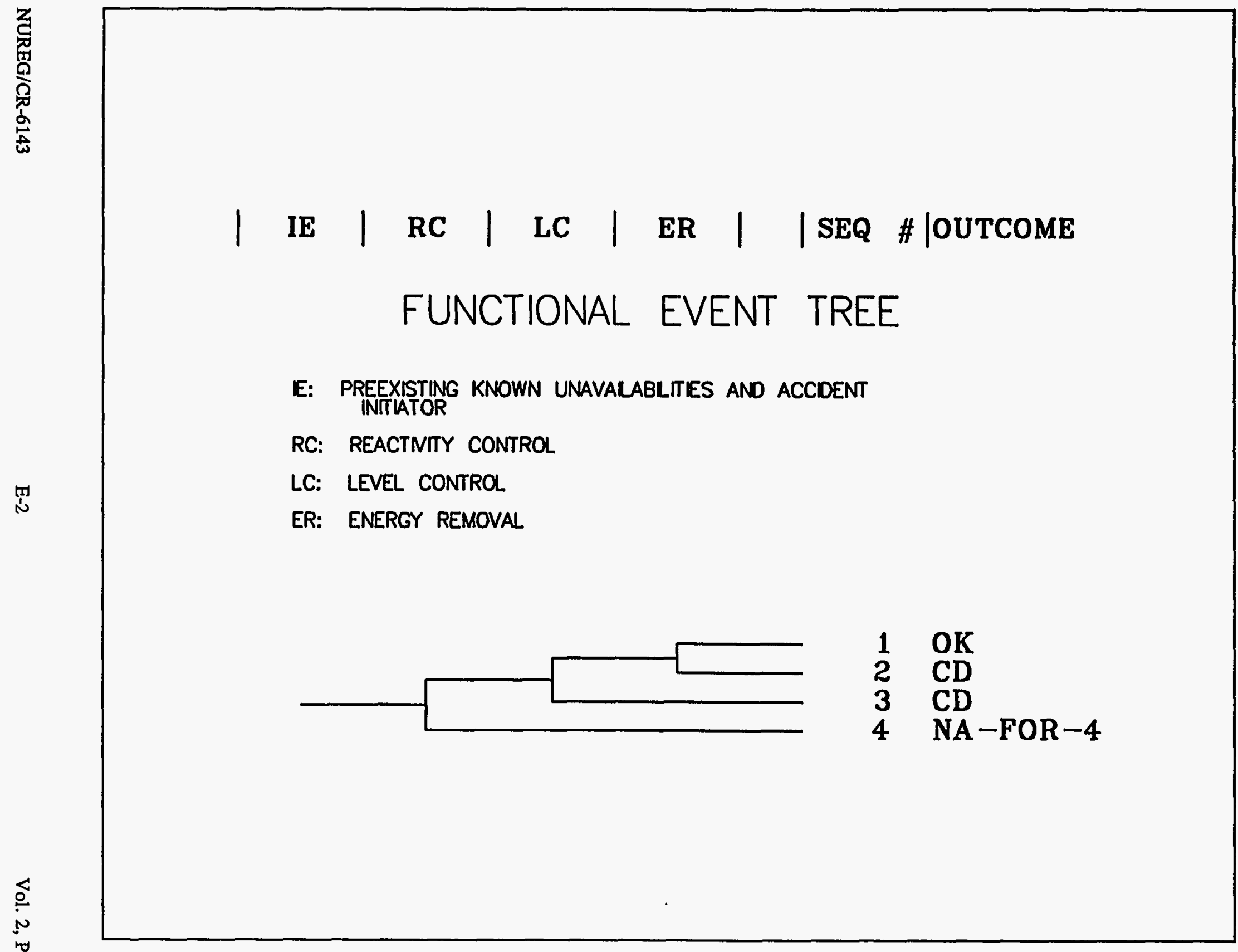

Figure E.1-1. Functional Event Tree for Plant Operational States 4, 5, 6, and 7 
the downcomer. The actual core level is different from the measured level in the downcomer due to the following reasons:

- The core fluid is a two phase mixture (at power);

- If the recirculation pumps are on, they raise the core level with respect to the downcomer level; and

- The safety-related level measurements are based on converting a differential pressure measurement made using a reference leg into an equivalent level without compensating for changes in water density with temperature which causes the measured level to be different than the actual downcomer level at low temperature conditions. (If actual level is above instrument zero, then actual level is less than measured level at cold conditions. If actual level is below instrument zero, then actual level is greater than measured level at cold conditions.)

At shutdown, operation of the recirculation pumps is not required if level is sufficient, since natural circulation due to the difference in density between downcomer and core fluid can remove decay heat. If the recirculation pumps are not available and the measured level is too low for natural recirculation, it is possible to establish core cooling by operating both loops of RHR/SDC at high flow rates [Vine et al., 1986]. This 'Enhanced Shutdown Cooling' method can provide mixing of downcomer and core water with the measured level as low as a few feet below normal. The required (measured downcomer) levels at shutdown used for our success criteria are:

- +11.4 inches with forced recirculation;

- +82 inches for natural recirculation; and

- +36 inches minus 2 feet for enhanced shutdown cooling.

(Normal measured downcomer level, when forced recirculation is on, is between +36 and +40 inches. RHR/SDC isolates on measured low level $3,+11.4$ inches. Forced recirculation with at least one recirc pump provides enough head to maintain core-todowncomer recirculation down to this level.)

For Non-LOCA situations, level control is accomplished by matching letdown, with RWCU, to makeup, with CDS or CRD. During refueling, after the cavity is flooded, letdown and makeup can isolated.

For LOCA situations, level control is accomplished with ECCS, SSW cross-tie, or FW (given sufficient makeup until alignment of FW can be achieved). The ECCS sources ultimately recirculate from the SP. The SSW cross-tie and FW systems provide once through cooling. When level control is provided with ECCS using the SP, fluid exiting the vessel must not bypass containment, or even with SPMU, eventual loss of SP inventory with subsequent loss of ECCS cannot be prevented.

\section{Function 3: Energy Removal}

Energy Removal from the core is accomplished by maintaining level control. Adequate level control depends on the method of energy removal.

Energy Removal from fluid in the vessel must match decay heat. The methods which can be used to remove energy depend on the accident situation and the availability of systems in that accident as well as the decay heat level. Five options are available to remove the energy, but not every option can be used in every situation. The five options are:

(1) Closed loop cooling of subcooled vessel water using the RHR on SDC, the ADHRS (not available in POS 4), or the fuel pool cooling system (only available in POS 7). Downcomer level must be sufficient for recirculation from the core to the downcomer region when RHR/SDC or ADHRS is used; with forced recirculation the minimum allowed measured level is +11.4 inches, and with natural circulation the minimum allowed measured level is +82 inches. (Enhanced shutdown cooling can be used if the measured level is no lower than two feet below the average normal measured level of +36 inches.)

(2) Recirculation of water from the SP using the ECCS (HPCS, LPCS, or LPCI) with water flow out a break and/or the SRVs, or the vessel when the head is removed. For sufficiently small breaks, normal makeup with CDS or CRD can match the break flow if let down is isolated, and method (1) can be used. The acceptable upper limit on this break size depends on the driving pressure. To prevent loss of SP inventory, fluid exiting the vessel must not bypass containment. Thus, the MSIVs must be closed except when 
steam line plugs are in place.

(3) Injection of water from the SSW cross-tie or the FW system with water flow out a break and/or the SRVs, or the vessel when the head is removed. (If SPMU or SRVs are available, then lower containment can be flooded up to the maximum level specified in the EP. If SPMU and the SRVs are not available, then vessel level is controlled. Upper containment is not flooded and, if necessary, the core can be steamed.)

(4) Steaming out a break and/or the SRVs, or the vessel when the head is removed, with makeup from low capacity systems such as the CRD. If necessary, other sources of makeup can be used (such as SSW cross-tie) and the core steamed.

(5) At sufficiently low decay heat levels (e.g., after refueling), letdown of hot water through the RWCU with makeup from the CDS and/or the CRD.

Options (1) and (5) require a high enough water level for adequate forced or natural recirculation between the core and downcomer regions, or for enhanced shutdown cooling. Options (2) and (3) fill the vessel to a level determined by the size and location of the exit path (break and/or SRVs). Option (4) requires the core to be covered with water.

Of these five options, three are once through: (3), (4), and (5). Option (5) requires no heat removal from containment. Option (3) requires heat removal from containment in the short term only if the core is steamed. If lower containment is flooded, containment heat removal is required only after the entire inventory of water is heated to saturation.

Options (2), (4), and sometimes (3) require containment cooling to prevent containment overpressurization. Containment cooling can be provided by either the SPC or CS. If containment cooling is not provided, the containment can be vented and the heat sink for these two options is boiling to the atmosphere at 15 psia. If containment cooling is lost and the containment is not vented, for these options in which energy is being added to containment, the containment pressure will rise to maintain saturation conditions as the SP temperature increases. NUREG 4550 concluded that containment would overpressurize and fail before equipment temperature limits are reached (pumps, relays, and so on), and that structural failure of the containment would not render the SP unavailable [Drouin et al., 1989]. This important conclusion means that option (2) can be used to cool the core with the containment failed. That is, containment overpressurization is an effective way to vent containment. The success criteria use this conclusion.

The SPMU system has two functions: (1) maintain SP inventory by compensating for all water entrapment volumes (e.g., drywell volume below the top of the weir wall) [Section 6.2.7.1 of SERI, 1992], and (2) lower the long term containment pressure since the heat removal capacity of one RHR train is less than the decay heat at 30 minutes, the time when containment cooling is assumed to be actuated in a DBA [Section 6.2.7.3.4 of SERI, 1992]. The second function of the SPMU is not required for POS $4,5,6$, and 7 , since the maximum decay heat is $38 \mathrm{Mw}$ and the heat removal capacity of one RHR train is $54 \mathrm{Mw}$ [185 E+6 Btu/hr from Table 6.2-2 of SERI, 1992].

The first function ensures that the SP level is not decreased below the minimum level required for pumps NPSH while the SP is supplying water to the core and water out the break is filling up the drywell. This function of SPMU is required for LOCAs in POS 4, 5 , 6 , and 7 , since, as is the case at full power, the fluid is discharged to the drywell and not to the SP. (For a small LOCA at full power, SPMU is not required until 30 minutes due to the relatively low amount of water drawn from the SP by HPCS/RCIC to feed the pressurized vessel [Section 6.2.7.3.1 of SERI, 1992].)

SPMU is not required to maintain SP inventory for transients in POS 4 and 5, since any use of the SP in these cases is associated with the use of the SRVs which discharge directly to the SP. (To prevent bypass flow outside of containment, one of two MSIVs in each steam line must be closed.) In POS 6 and 7, the head is off the vesel and steam line plugs are installed. Thus, the SRVs are not available, and if the SP is used for core cooling in plant states 6 or 7, the SPMU system must be made available to refill the SP with water pumped from the SP out the vessel head into the upper cavity/upper containment pool.

Long term makeup to the suppression pool is required if the containment is vented, to prevent boiloff of water to where adequate inventory for ECCS is lost.

The three functions of the functional event tree have been discussed. From this discussion success criteria can be developed. The success criteria need to be specified for 
the following situations:

- POS 4 at $38 \mathrm{Mw}$

- POS 4 at $6 \mathrm{Mw}$

- POS 5 at $34 \mathrm{Mw}$

- POS 5 at $6 \mathrm{Mw}$

- POS 6 at $15 \mathrm{Mw}$

- POS 6 at $6 \mathrm{Mw}$

- POS 7 at $12 \mathrm{Mw}$.

Both LOCAs and Transients need to be considered for these situations.

A basic distinction between POS 4 and the other three POSs should be discussed. In POS 4 the primary pressure is 100 psig (about one tenth the full power value) and the temperature is 328 degrees $F$ (full power is 550 degrees F). For a LOCA in POS 4, the primary will flash as in the full power case, but the blowdown rate will be less due to the lower pressure. The internal energy of the primary water in POS 4 is about half that at full power since it is determined mainly by the temperature (32 degree $\mathrm{F}$ reference for zero internal energy). Thus about half of the full power energy is deposited into containment following a large LOCA in POS 4. LOCAs in POS 4 are similar to LOCAs from full power. Instead of calculating detailed thermal hydraulic behavior for POS 4 LOCAs (a lengthy process), we chose to use the full power LOCA success criteria with three modifications: (1) there is no need for SPMU for long term containment pressure control as discussed previously for event \#3 of the functional event tree; (2) ADS is not required to allow low pressure ECCS systems to be used since the initial pressure is already low; (3) the SRVs are required to be manually operated in a relief mode for small LOCAs, and for small size medium LOCAs, to prevent pressure from rising to where the integrity of RHR/SDC components are threatened during the time from when adequate level for core cooling is lost and the time at which level has dropped to the minimum ECCS auto-actuation setpoint. (If one SRV is opened allowing discharge of steam following a small or medium LOCA, pressure will not threaten RHR/SDC components during the time required for auto-actuation of ECCS. Following refill with ECCS and a water solid vessel, SRVs are required to be open to control pressure below the shutoff heads of the ECCS pumps, and to allow for discharge of enthalpy. If RHR/SDC fails to auto-isolate on high pressure or low level, one SRV is sufficient to prevent overpressurizing RHR/SDC piping, rated at 220 psig. However, two SRVs must be open to prevent possible overpressurizing of $A D H R$ piping, rated at 80 psig.)

LOCAs in POS 5,6 , and 7 , with the primary subcooled at $15 \mathrm{psia}$, are very different from LOCAs at higher pressure during the initial time period following the LOCA. No primary inventory is lost due to flashing, thus LOCAs in steam lines are not of concern unless they interrupt level control or energy removal. The only vessel penetrations which are located below the top of the core are the recirculation connections, and the control rod and instrumentation penetrations. A recirculation line break will not completely drain the core since the jet pump riser separates the downcomer (the source for recirculation) from the lower plenum. Instead about one third of the core would be uncovered. Similarly, a break in an RHR line during SDC, or diversion of inventory to the SP, cannot completely drain the core since the RHR connects to a recirculation suction line. Licensing analyses demonstrate that for LOCAs from full power, the top one third of the core can be adequately cooled by steam. However, in POS 4, 5, 6, and 7 the core fluid can be initially subcooled leading to no steam cooling of the top one third of the core immediately following a LOCA. (Vine et al., 1986 also points out the need to verify the coolability of the top $1 / 3$ of the core with ECCS in off-power modes.) HPCS or LPCS should adequately cool the top $1 / 3$, since they spray down over the top of the fuel. LPCI fills the volume outside of each fuel channel and flows over the top and down into the fuel assemblies. Based on MELCOR analyses, 2 of 3 LPCI trains are needed to cool the top $1 / 3$ of the core at low temperature conditions. Since SSWXT and FW inject into LPCI lines, for a large LOCA, the flow from either of these two systems should be at least equal to that from 2 LPCI pumps. SSWXT can provide sufficient flow, but FW cannot.

Vessel rupture, and failures in the control rod and instrumentation penetrations in the bottom of the vessel can drain the core. Vessel rupture can be screened out on low frequency. Failures of bottom penetrations were screened from analysis in NUREG 4550. We discussed the potential for failure of lower vessel penetrations with Grand Gulf, and asked if any maintenance is performed during refueling which could contribute to an increased potential for such failure. Based on the results of this 
discussion, we deferred examination of this event until the detailed human action phase of the study, which is beyond the scope of this report. It is not possible to syphon or pump out water below the top of the core through any of the penetrations above the top of the core since the steam separators ensure that the pressure at the top of the downcomer is that at the top of the core region (i.e., the steam separators act as a syphon break). We verified with Grand Gulf that during refueling, no temporary lineups are used which could completely drain the core (e.g., hoses dropped to the lower plenum of the vessel).

The same LOCA sizes as used in NUREG 4450 can be used for POSs 4 through 7. A large LOCA is greater than or equal to $0.4 \mathrm{sq} \mathrm{ft}$. An intermediate LOCA is $0.007 \mathrm{sq} \mathrm{ft}$ to $0.4 \mathrm{sq} \mathrm{ft}$. A small LOCA is less than $0.007 \mathrm{sq} \mathrm{ft}$. As previously discussed, for small and medium LOCAs SRVs must be opened to: (1) prevent potential overpressurization of SDC piping (2) prevent system pressurization to pump shutoff heads, and (3) to allow for discharge of enthalpy sufficient to match decay heat. At full power, this requirement is provided by the safety function of the SRVs. In POS 4, 5, 6, and 7, the pressure is low (below 135 psig, except for the special Hydro condition which is discussed later) and the safety function of the SRVs (high pressure control) cannot be used. The SRVs must be manually opened (relief mode). In POS 6 and 7, the SRVs are unavailable due to the installation of steam line plugs, but the head is off the vessel, thus providing a relief path.

Option (2) considers the possibility that small breaks can be within the capability of the normal makeup systems. First, consider a large or medium size LOCA in the worst location, a recirc suction line. In the steady state, following blowdown and refill, the top $1 / 3$ of the core is not covered with water since the break is so large. (This is a conservative assumption for medium LOCAs.) Core cooling is accomplished with injection of ECCS water from above the core. In steady state it is possible that injection from only the CRD, to match steaming, can cool the core. The CRD can supply about $240 \mathrm{gpm}$. 240 gpm can match decay heat if steaming is allowed. The situation with CRD makeup differs from the case of ECCS addition in two important respects:

(a) CRD injection into the vessel is via the control rod drive cooling water header through the rod drive seals (i.e., the water enters from the bottom of the vessel). ECCS water is injected from above the core and provides for some cooling of the top $1 / 3$ of the core as it is injected.

(b) The CRD flow rate is substantially less than the ECCS flow rate. This may not be too significant because the ECCS water that is not boiled merely flows out the break. However, mixing considerations may be important. Without examining in detail the case for $1 / 3$ core uncovery, with steaming, and with bottom makeup sufficient only for inventory replacement, we do not know if this option will work Also, the option of using CRD is only possible if the transient aspects of the LOCA are not of concern. By transient aspects, we mean the flashing, blowdown, and rewetting aspects immediately following a LOCA in a pressurized primary. The CRD has insufficient capacity to prevent cladding damage under these conditions. Therefore, we cannot take credit for this option in POS 4 (100 psig) even if the steady state situation is acceptable. We could take credit for this option in POSs 5, 6, and 7 (0 psig) if the steady state situation is acceptable since no flashing/blowdown occurs. We decided to take no credit for this option in POSs 5, 6, and 7 until detailed thermal hydraulic analyses justify doing so. The only situation under which this option is needed is if all the ECCS injection options fail, and even if CRD makeup is available throughout the accident it cannot prevent level falling to the actuation setpoint of ECCS due to the size of the break, and thus CRD makeup is not an option for preventing the use of ECCS.

[Note that using condensate makeup (as a backup for CRD makeup) for steaming in the steady state following a large or medium LOCA, should not even be considered, since condensate is supplied to the downcomer, not the core, and thus the injected water would run out the break and never reach the core.]

The situation for small break LOCAs is different from the case just discussed for the larger breaks. We defined small break LOCAs as less than or equal to $0.007 \mathrm{sq} \mathrm{ft}$ in area, to be consistent with the NUREG 4550 fullpower PRA. In general, a loss of inventory is not considered to be a LOCA if it is within the capability of the normal makeup systems. In POS 4 (100 psig), a $0.007 \mathrm{sq} \mathrm{ft}$ hole discharges about $160 \mathrm{gpm}$ (water flashing, Moody model). In POS 5, 6, and 7 (0 psig), a $0.007 \mathrm{sq} f \mathrm{fthole}$ with a 100 foot head discharges about $200 \mathrm{gpm}$ (water draining through the hole). As 
discussed previously, the CRD can supply about 240 gpm (CDS can supply even more), and normal letdown via the RWCU can be isolated. Therefore, the small break LOCA is not really a LOCA for the POS of concern. We continue to call it a small break LOCA since it is treated so at full power, and we use success criteria for a small break LOCA tree which accounts for the possibility of isolation of letdown/increased makeup.

Steaming through one open SRV is adequate to prevent overpressurization of RHR/SDC and ADHR piping and components.

An interfacing systems LOCA, $V$ sequence due to overpressurization of low pressure piping, can only occur in POSs 4 and 5 (non hydro condition) if a prior failure pressurizes the primary, because the typical pressure in POS 4 is 100 psig (unless a pressurization transient occurs) which is below the 135 psig permissive pressure for RHR SDC initiation. Overpressurization of low pressure piping is not an initiating event in POSs 4 and 5 (excluding the Hydro condition). Overpressurization of low pressure piping cannot occur in POS 6 and 7 since the vessel head is off which prevents pressurization of the primary.

The likelihood of a pipe break LOCA in POSs 4, 5, 6 and 7 is lower than at full power due to the lower driving pressure (135 psig at most - excluding the Hydro condition -- as compared to 1000 psig at full power). For a LOCA to occur, a critical crack must exist which can propagate under the driving pressure. The lower the pressure, the greater the required size of the critical crack.

\section{E.2 Pressurization Concerns and Success Criteria at Rated Pressure}

Pressure control could be lost in POS 4 and 5. For example, if cooling is lost and SRVs cannot be opened to relieve pressure, the system pressurizes along the saturation line. Pressurization is not of concern in POS 6 and 7 , since the vessel head is off.

If pressure rises too high, and the shutdown cooling system is not isolated, the piping/components in the RHR/SDC or ADHR systems could rupture, leading to a LOCA outside containment. The pressure rating of the RHR/SDC is $220 \mathrm{psig}$, and the pressure rating of the $\mathrm{ADHR}$ is $80 \mathrm{psig}$. Failure is not expected unless system pressure is about a factor of two greater than rated pressure. However, if the system pressurizes all the way to the SRV safety setpoints, about $1000 \mathrm{psig}$, the shutdown cooling systems will fail if they are not isolated.

In POS 4, the high pressure auto-isolation for RHR/SDC (135 psig) is active, and the low level 3 auto-isolation for RHR/SDC is active. In POS 5, the high pressure autoisolation for RHR/SDC (135 psig) is active, and the low level 3 auto-isolation for RHR/SDC is active. (In the screening study [Whitehead et al., 1991], it was assumed that in POS 5 auto-isolation of RHR/SDC on high pressure was inactive, based on information received during the plant visit in January 1991. During a subsequent visit to the site in June, 1992, we were informed that auto-isolation of RHR/SDC is active in cold shutdown, POS 5.)

If the primary pressurizes and shutdown cooling is not isolated on high pressure (either automatically or manually), we assume that an interfacing systems LOCA outside containment occurs. This LOCA can be isolated by the auto-isolation of shutdown cooling on low level 3, in which case the isolated LOCA becomes a transient. If the interfacing LOCA is not isolated, ECCS is lost since SP inventory cannot be maintained even with SPMU. In this case, we assume core melt since the LOCA drains the top third of the core and, without ECCS, a partially drained core cannot be cooled. (It is possible to flood with SSWXT, but this leads to flooding of equipment in the auxiliary building. We have conservatively assumed that flooding with SSWXT cannot mitigate the RHR/SDC LOCA outside containment.)

If shutdown cooling is isolated either on high pressure or low level, the system can pressurize up to the SRV safety setpoints and the core can be cooled by steaming on the SRVs. (For operation in the safety mode, the SRVs do not require any support systems and do not require operator action. As discussed previously, for operation of the SRVs in the relief mode at low pressure, operator action, dc power, and control air are required.) Steaming can be accomplished with one SRV cycling at its safety setpoint, and with makeup water from HPCS or CRD. (LPCS, LPCI, and CDS -- without feedpumps -cannot inject at 1000 psig.)

During hydro testing in POS 5 coming up from a refueling outage, the 200 degrees $F$ subcooled water is presurized to about 1000 psig. The low pressure SDC system is isolated, and pressure protection is provided by the SRVs in the safety mode. 


\section{E.3 Success Criteria}

Table E.1-1 through E.5-4 presents the detailed success criteria for POS 4, 5, 6 and 7. These success criteria are based on the previous discussions. Three considerations affect the application of these success criteria: (1) Systems unavailabilities as allowed by tech specs. (2) Whether or not procedures are in place for every proposed option. (3) The time available for instituting systems operations which can be substantial considering the low decay heat levels present.

An example of consideration (1) is as follows. Given a large LOCA in POS 5, portions of ECCS are required to be operable per tech spec 3.5.2, but the SPMU can be inoperable per tech spec 3.6.3.4. The success criteria require SPMU when ECCS pulls from the SP to prevent depleting the SP inventory (see earlier discussion on SPMU). Thus, if SPMU is unavailable, ECCS injection from the SP following a large LOCA cannot be maintained and this option for core cooling is not valid. Similarly, tech spec 3.4.2.1 allows the SRVs to be inoperable in POS 5, and without opening the SRVs, transients cannot be mitigated by injection of water from any source since no relief path exists. In applying the success criteria, we modeled the availability of systems allowed unavailable by the Tech Specs based on discussions with Grand Gulf staff. For example, SPMU is taken out of service in POS 5, but two SRVs remain operable in POS 5.

An example of consideration (2) is as follows. The success criteria allow for enhanced shutdown cooling if forced recirculation is not available and the level is below that required for natural circulation. This option is not specified in the Grand Gulf procedures.
An example of consideration (3) is as follows. Given a transient in POS 5 to be mitigated by pumping water from the SP to the vessel and returning the heated water to the SP via opening SRVs, SP cooling with the SPC or CS systems is not needed until the SP water increases in temperature by at least 80 degrees $F$ (100 to 180 degrees F). At low decay heat levels, this requires a long time. The FSAR Table 1.3-4 specifies the SP inventory as 136,000 cubic feet. At an initial decay heat level of 38 Mw it would take about 6 hours to heat the SP by 80 degrees F. At an initial decay heat level of $6 \mathrm{Mw}$, it would take about 32 hours to heat the SP by 80 degrees F. Such long times available for operator action are considered in the detailed analysis. 
Table E.1.1 Success Criteria for Plant Operational State (POS) 4

\begin{tabular}{|c|c|c|c|}
\hline Plant State & Event & Level Control & Energy Removal \\
\hline \multirow{3}{*}{$\begin{array}{l}4 \\
\text { (338 F, Saturated at } 100 \\
\text { psig) }\end{array}$} & $\begin{array}{l}\text { Large } \\
\text { LOCA } \\
\left(\geq 0.4 \mathrm{ft}^{2}\right)^{:}\end{array}$ & $\begin{array}{l}{\left[\mathrm{HPCS} \text { or } 2 / 3 \mathrm{LPCI}^{\mathrm{b}} \text { or LPCS }\right]^{\natural} \text { and } 1 / 2 \mathrm{SPMU}^{\mathrm{a}, \mathrm{p}}} \\
\text { and } 4,1 / 2 \mathrm{MSIVs}^{v} \text { and } 1 / 2 \mathrm{CVs}^{v} \text { and } 1 \mathrm{SRV}^{\mathrm{v}} \\
\qquad \text { or } \\
\text { SSW Crosstie } \\
\end{array}$ & $\begin{array}{l}\left\{[1 / 2 \text { SPC or } 1 / 2 C S]^{d} \text { or [Vent Containment and }\right. \\
1 / 2 \text { SPMUU }]\}^{p} \\
\text { (Once through) }\end{array}$ \\
\hline & $\begin{array}{l}\text { Medium } \\
\text { LOCA } \\
(0.007 \text { to } \\
\left.0.4 \mathrm{ft}^{2}\right)^{8}\end{array}$ & $\begin{array}{l}\text { [HPCS or } 1 / 3 \mathrm{LPCl}^{\mathrm{b}} \text { or } \mathrm{LPCS}^{q} \text { and } 1 / 2 \mathrm{SPMU}^{\mathrm{c}, \mathrm{p}} \\
\text { and } 1 \mathrm{SRV}^{\mathrm{f,j}} \text { and } 4,1 / 2 \mathrm{MSIVs}^{\mathrm{w}} \text { and } 1 / 2 \mathrm{CVs}^{\mathrm{v}} \\
\text { or } \\
\text { SSW crosstie } \\
\end{array}$ & $\begin{array}{l}\left\{[1 / 2 \text { SPC or } 1 / 2 C S]^{d} \text { or [Vent Containment and }\right. \\
1 / 2 \text { SPMU }]\}^{\mathrm{P}} \\
\text { (Once through) }\end{array}$ \\
\hline & $\begin{array}{l}\text { Small } \\
\text { LOCA } \\
\left(<0.007 \mathrm{ft}^{2}\right)\end{array}$ & 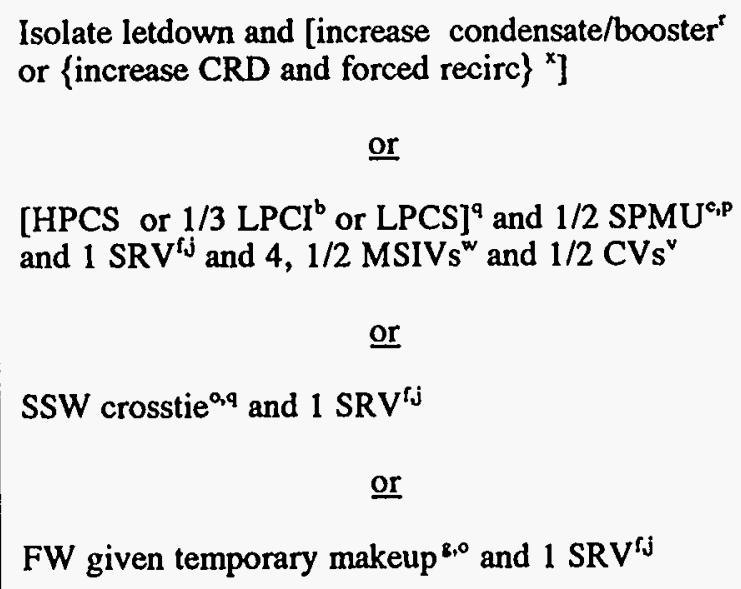 & $\begin{array}{l}\text { Transfer to transient success criteria } \\
\left\{[1 / 2 \text { SPC or } 1 / 2 \mathrm{CS}]^{\mathrm{d}} \text { or [Vent Containment and }\right. \\
1 / 2 \mathrm{SPMU}]\}^{\mathrm{p}} \\
\text { (Once through) } \\
\text { (Once through) }\end{array}$ \\
\hline
\end{tabular}


Table E.1.1 Success Criteria for Plant Operational State (POS ) $4^{2}$

\begin{tabular}{|c|c|c|c|}
\hline Plant State & Event & Level Control & Energy Removal \\
\hline & Transients $^{b}$ & $\begin{array}{l}\text { [Letdown (RWCU) and Makeup (CRD }{ }^{k} \text { or } \\
\text { Condensate/Booster })] \text { or alternate source of } \\
\text { makeup }{ }^{u}\end{array}$ & 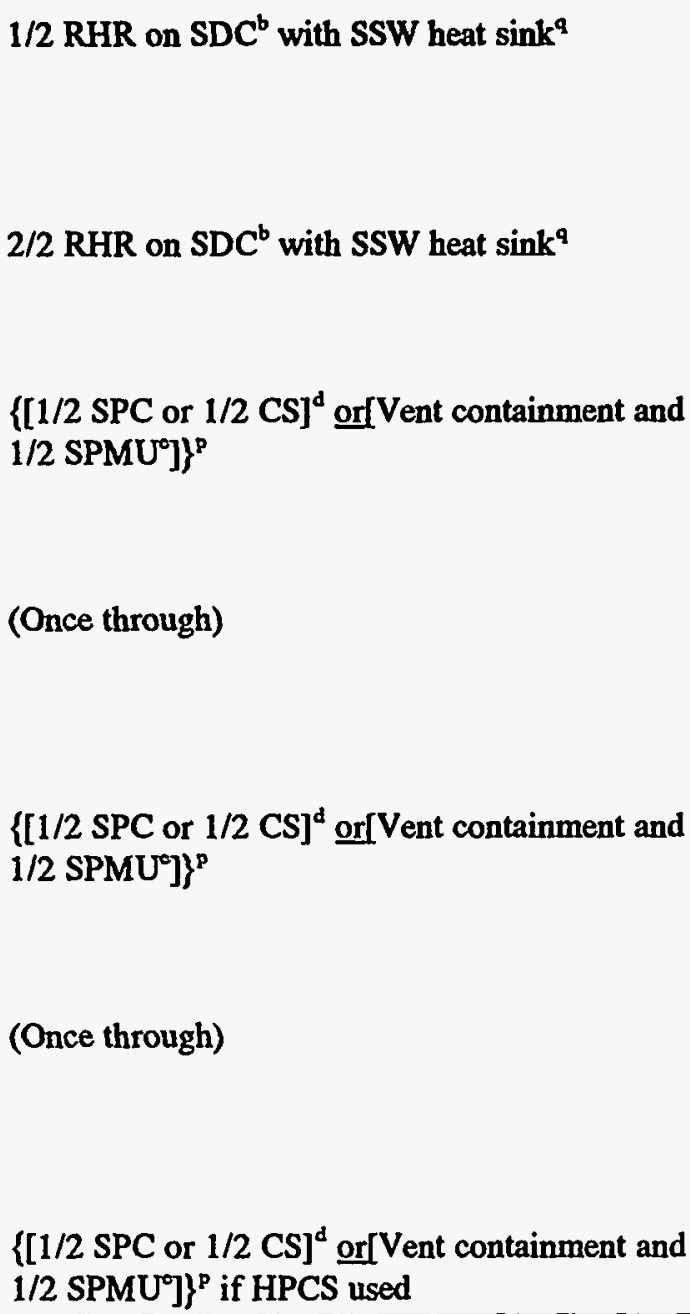 \\
\hline
\end{tabular}


Table E.1.1 Notes

- Reactivity control by fully inserted rods

- LPCI Trains A and B require manual re-alignment from SDC. RHR SDC operability per Tech Spec 3.4.9.2. 2/3 LPCI per MELCOR calc.

- SPMU required to prevent loss of SP inventory

- SPMU not required since maximum decay heat less than one RHR train heat removal capability

- SPMU required to makeup for boiloff from SP when containment vented

1 SRV required to augment flow out break and prevent pressurization for break $\leq 0.3 \mathrm{ft}^{2}$

- Use NUREG/CR-4550 model for FW; thus, assume for small LOCAs and Transients FW can be aligned in time. Need to quantify makeup required until FW available

bCS not available, and Feedwater not available. SPMU to compensate for loss of inventory not required since SRVs discharge to SP.

- Condensate/Booster injection may either be on standby or be unavailable.

1 SRV provides for flow of hot water or steam out of vessel to SP and prevents pressurization of primary

- CRD flow rate at low vessel pressure is $240 \mathrm{gpm}$ max. If forced recirc lost, CRD cannot raise level for natural recirc before auto isolation of RHR/SDC occurs on high pressure in POS 4 at $38 \mathrm{MW}$.

$1240 \mathrm{gpm}$ injection required.

${ }^{m}$ Maximum RWCU letdown of $\mathbf{3 6 0}$ gpm per Inadequate Decay Heat Removal Procedure Step 5.1.3.

n This method can match decay heat only after refueling when decay heat is low.

- NUREG/CR-4550 modeled SSW crosstie and FW.

P SPC, CS, SPMU required to be operable in POS 4 per Tech Specs 3.6.3.3, 3.6.3.2, and 3.6.3.4, respectively. SRVs required to be operable in PS 4 per Tech Spec 3.4.2.1

T ECCS and SP operability per Tech Spec 3.5.2 and 3.5.3. SSW operability per Tech Spec 3.7.1.1

- Small LOCA is within makeup capability, but CRD cannot both match break flow and raise level.

- Adequate cooling with $1 / 3$ core uncovered evaluated with MELCOR

- With normal level and with no recirc, increased SDC provides mixing between downcomer and core. Not enough time to establish enhanced SDC in POS 4 at $38 \mathrm{MW}$ before auto isolation of RHR/SDC occurs on high pressure

- To provide adequate natural circulation, raise level with alternate sources including ECCS

v If LOCA is Main Steam Line Break outside containment, one of two MSIVs in line with break must close to prevent eventual loss of SP inventory and subsequent loss of ECCS from SP. Following closure of MSIV to isolate break, one SRV must open to provide relief path for ECCS fluid injection, and at least one MSIV in each steam line without the break must close to prevent bypass flow outside containment which would result in loss of SP inventory. For Feedwater Line Break outside containment, one of two check valves in the broken line must close to prevent injection from the SP from draining the SP.

" If the LOCA is a feedwater line break that is isolated, I SRV is required for egress of injected water.

"Whenever SRVs are used in conjunction with ECCS from SP, one of two MSIVs in all four steam lines must close to prevent bypass flow outside containment, and subsequent loss of SP inventory and loss of ECCS.

x Only with forced recirculation, can level be sufficient following small break LOCA for core-to-downcomer recirculation if CRD is the only source of makeup.

y Cooling option for pressurization to rated pressure and temperature (1000 psig, $545 \mathrm{~F}$ ). In POS 4, RHR/SDC is auto-isolated on high pressure or low level. One SRV steaming at its safety setpoint can remove energy, makeup is from either the HPCS or CRD pumps which can supply sufficient water at rated pressure.

FW not sufficient for large LOCA since flow not equal to 2 LPCI; SSWXT provides sufficient flow. 
Table E.1.2 Success Criteria for Plant Operational State (POS) $5^{2}$

\begin{tabular}{|c|c|c|c|}
\hline Plant State & Event & Level Control & Energy Removal \\
\hline $\begin{array}{l}5 \\
\text { (200 F, 0 psig, except for } \\
\text { HYDRO; 200 F, 1000 psig } \\
\quad \text { during HYDRO) } \\
\\
\text { Maximum decay heat is } \\
0.9 \% \text { (34MW), } 7 \text { hours } \\
\text { after shutdown. } \\
\text { After refueling decay heat } \\
\text { is } 0.16 \% \text { (6MW), } 30 \text { days } \\
\text { after shutdown }\end{array}$ & $\begin{array}{l}\text { Large } \\
\text { LOCA } \\
\left(\geq 0.4 \mathrm{ft}^{2}\right)^{\mathrm{b}, v} \\
\text { which } \\
\text { affects level } \\
\text { control } \\
\text { and/or heat } \\
\text { removal }^{c}\end{array}$ & $\begin{array}{l}\text { [HPCS or } 2 / 3 \mathrm{LPCI}^{\mathrm{d}} \text { or } \mathrm{LPCS}^{\mathrm{y}} \text { and } 1 / 2 \mathrm{SPMU}^{\mathrm{o}, \mathrm{r}} \\
\text { and } 4,1 / 2 \mathrm{MSIVs}^{\mathrm{y}} \text { and } 1 \mathrm{SRV}^{\mathrm{y}} \text { and } 1 / 2 \mathrm{CVs}^{\mathrm{y}} \\
\text { or } \\
\text { oRD and/or condensate booster steaming }{ }^{y} \text { (for } \\
\text { unisolated feedwater line break only) } \\
\text { or } \\
\text { Transient Success Criteria }{ }^{y} \text { (for isolated feedwater } \\
\text { line breaks only) } \\
\text { SSW Crosstie } \\
\text { or } \\
\text { CRD makeup (steam out break) }\end{array}$ & $\begin{array}{l}\left\{[1 / 2 \text { SPC or } 1 / 2 \mathrm{CS}]^{t} \text { or [Vent Containment and }\right. \\
1 / 2 \text { SPMU' }]\}^{z} \\
\text { (Once through) } \\
\text { Transient Success Criteria } \\
\text { (Once through) } \\
\left\{[1 / 2 \text { SPC or } 1 / 2 \mathrm{CS}]^{f} \text { or [Vent Containment and }\right. \\
1 / 2 \text { SPMU }]\}^{r}\end{array}$ \\
\hline
\end{tabular}




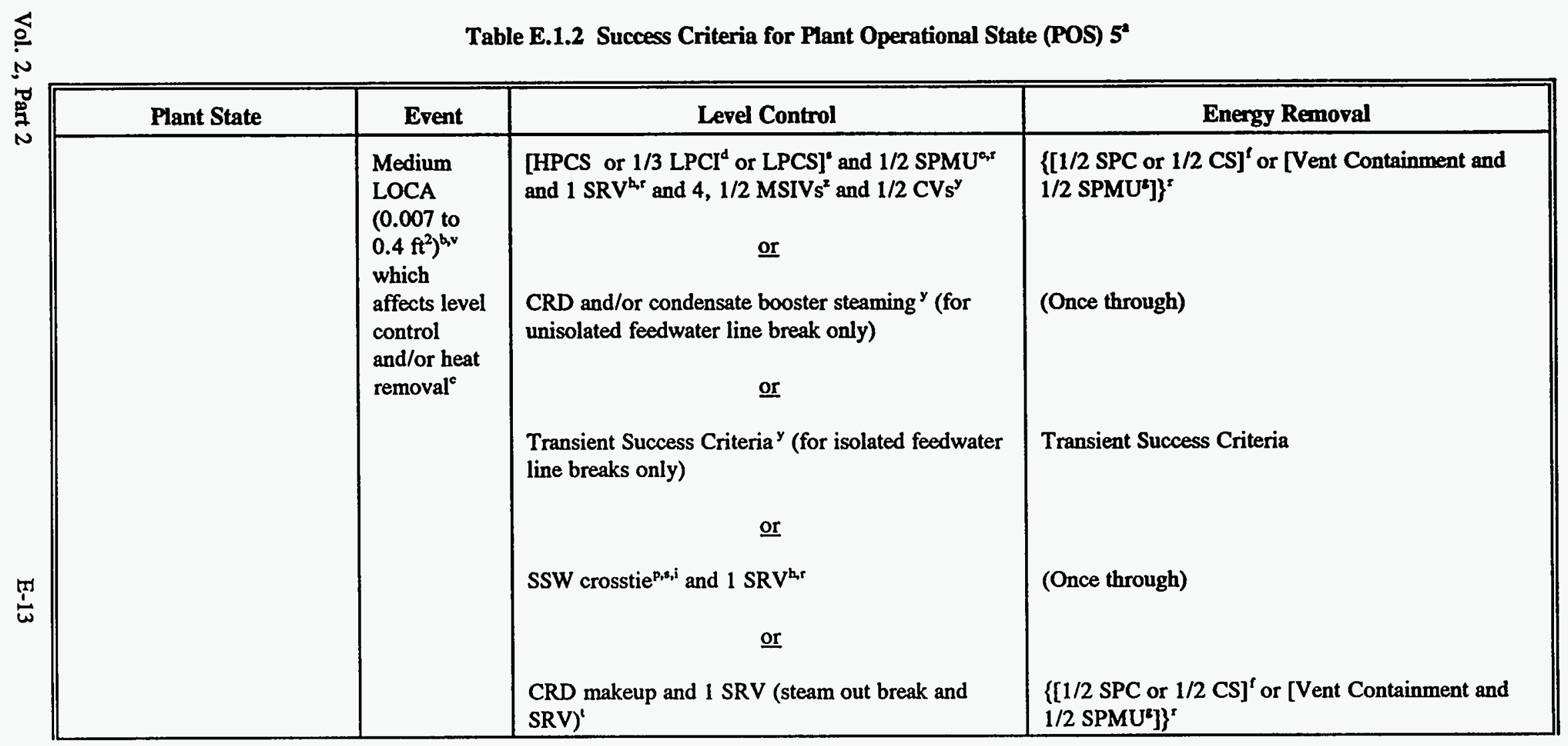




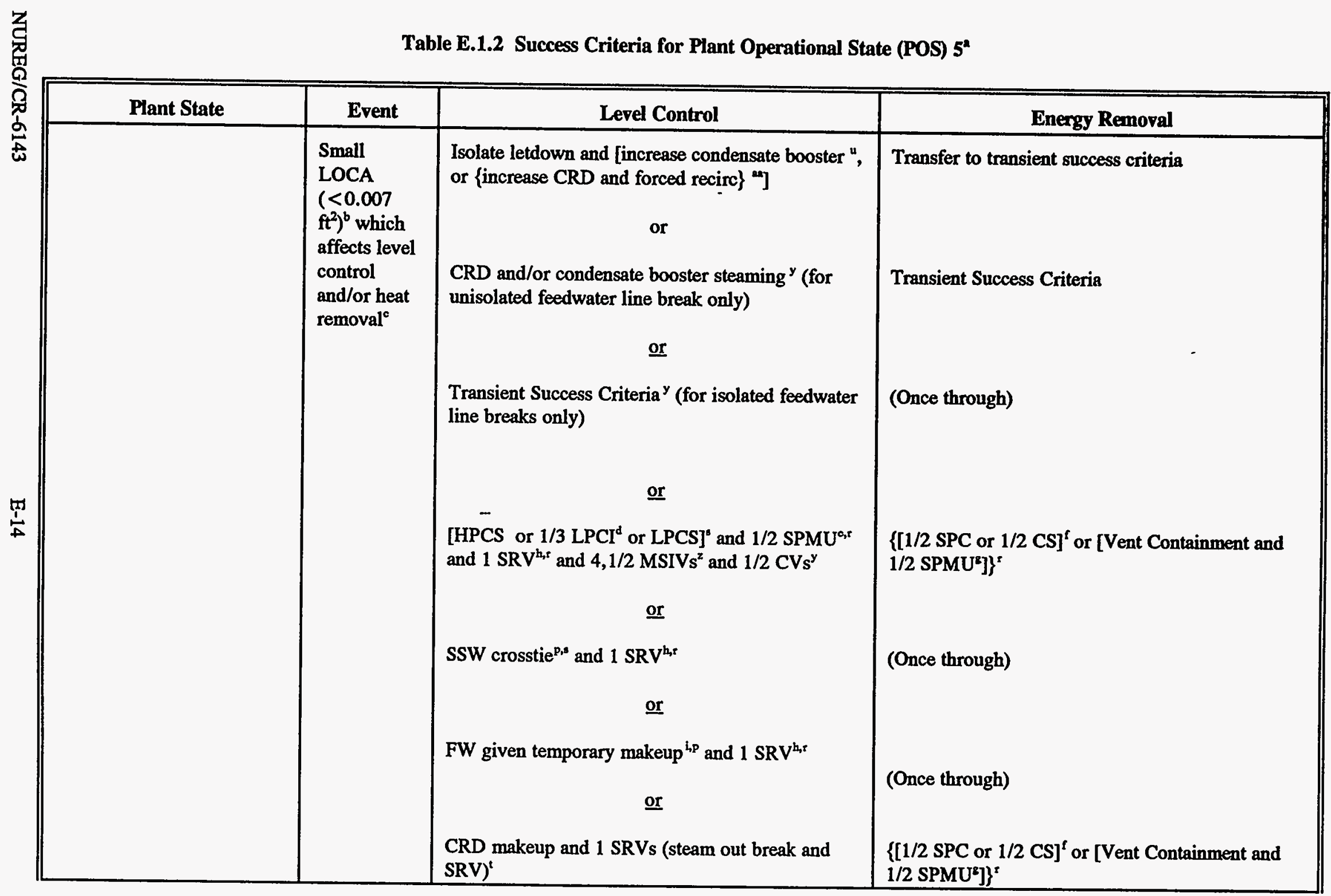




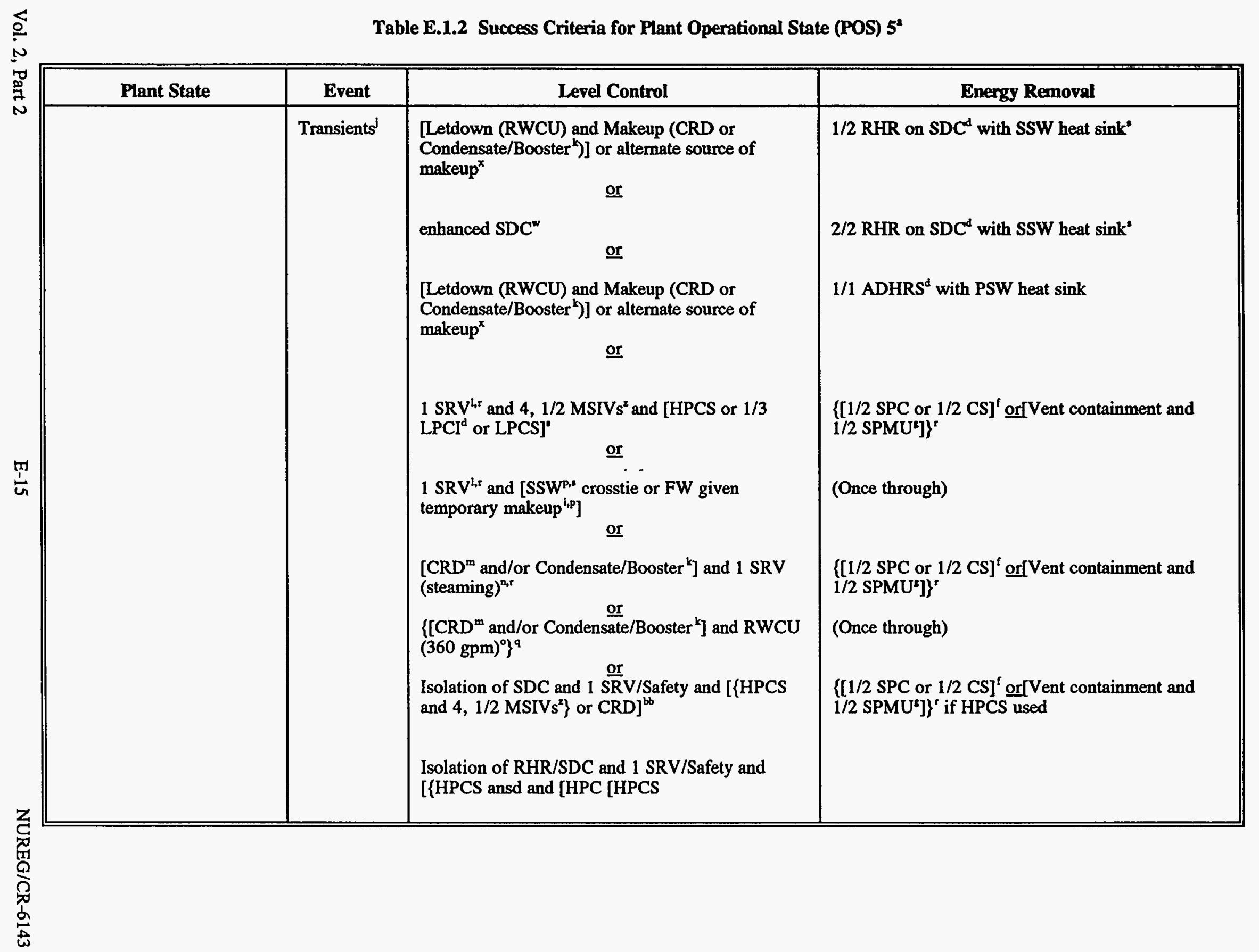


- Reactivity Control by Fully Inserted Rods

berify that in POS 5 lineups do not allow LOCA to drain the vessel (this cannot be mitigated); concern is loss of level control and/or loss of heat removal due to LOCA

- LOCA in "steam" lines not of concern since 0 psig primary will not flash

d LPCI Trains A and B require manual re-alignment from SDC. If ADHRS is operable, only one train of RHR on SDC required to be operable per Tech Spec 3.4.9.2. 2/3 LPCI per MELCOR calc. ADHR cannot handle decay heat load until 24 hrs after shutdown.

- SPMU required to prevent loss of SP inventory

f SPMU not required since maximum decay heat less than one RHR train heat removal capability

- SPMU required to makeup for boiloff from SP when containment vented

b 1 SRV required to augment flow out break and prevent pressurization for break $\leq 0.3 \mathrm{ft}^{2}$

1 FW not sufficient for large LOCA since flow not equal to 2 LPCI; SSWXT provides sufficient flow.

J PCS not available, and Feedwater not available. SPMU to compensate for loss of inventory not required since SRVs discharge to SP.

- Condensate/Booster injection may either be on standby or be unavailable

1 SRV provide for flow of hot water out of vessel to SP and prevents pressurization

m CRD flow rate at low vessel pressure is $240 \mathrm{gpm}$ max.

- $146 \mathrm{gpm}$ injection required

- Maximum RWCU letdown of $360 \mathrm{gpm}$ per Inadequate Decay Heat Removal Procedure step 5.1.3

P NUREG/CR-4550 modeled SSW crosstie and FW.

This method can match decay heat only after refueling when decay heat is low. Either of two modes can be used. The RWCU can be used in a closed loop transferring heat to its heat exchangers, or RWCU letdown can be increased to a level such that the change in enthalpy between letdown and makeup matches decay heat.

- SPC, CS, SPMU not required to be operable in POS 5 per Tech Specs 3.6.3.3, 3.6.3.2, and 3.6.3.4, respectively. SRVs not required to be operable in POS 5 per Tech Spec 3.4.2.1

- ECCS and SP operability per Tech Specs 3.5.2 and 3.5.3. SSW operability per Tech Spec 3.7.1.1.

' Not modeled in the ET's; requires detailed thermal-hydraulic evaluation

"Small LOCA is within makeup capability, but CRD cannot both match break flow and raise level.

- Adequate cooling with $1 / 3$ core uncovered evaluated with MELCOR.

With normal level and with no recirc, increased SDC provides mixing between downcomer and core

To provide adequate natural circulation, raise level with alternate sources including ECCS

${ }^{y}$ Main Steam Line Break not a LOCA in POS 5 (even in Hydro, it just drains full vessel down to steam lines, no flashing), but Feedwater Line Break outside containment requires one of two check valves in the broken line to close, and an MSIV on each main steam line to close to prevent loss of SP inventory with ECCS injection. Given closure of check valve and MSIVs, one SRV must open to provide for egress of injected water (see footnote $v$ for POS 4 success criteria). In POS 5, following feedwater line break, 200 degrees F fluid does not flash, and level drops no lower than elevation of feedwater injection nozzle; no syphon concern since in a BWR the core region is 'open' to the downcomer region. Thus, in POS 5, if feedwater line break is not isolated, which renders ECCS from SP unavailable after SP level drops below ECCS suction, core is still covered and can be steamed.

${ }^{2}$ Whenever SRVs are used in conjunction with ECCS from SP, one of two MSIVs in all four steam lines must close to prevent bypass flow outside containment, and subsequent loss of SP inventory and loss of ECCS.

w Only with forced recirculation, can level be sufficient following small break LOCA for core-to-downcomer recirculation if CRD is only source of makeup.

bo Cooling option if heat and pressurize to rated conditions (545 F, 1000psig). RHR/SDC must be isolated; autoisolation either on high pressure or low level. SRV steams at safety setpoint. HPCS or CRD can provide makeup for steaming at high pressure. 


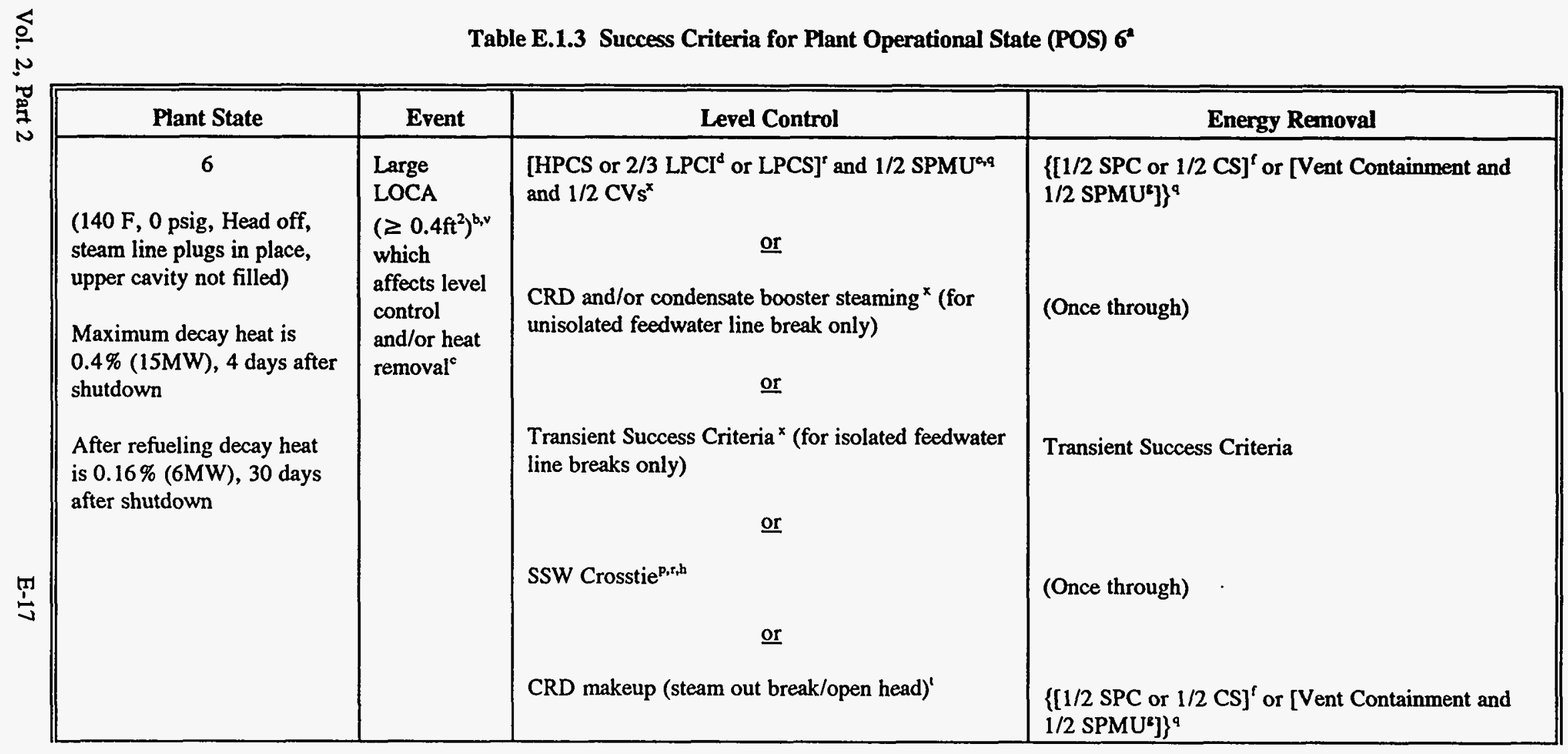




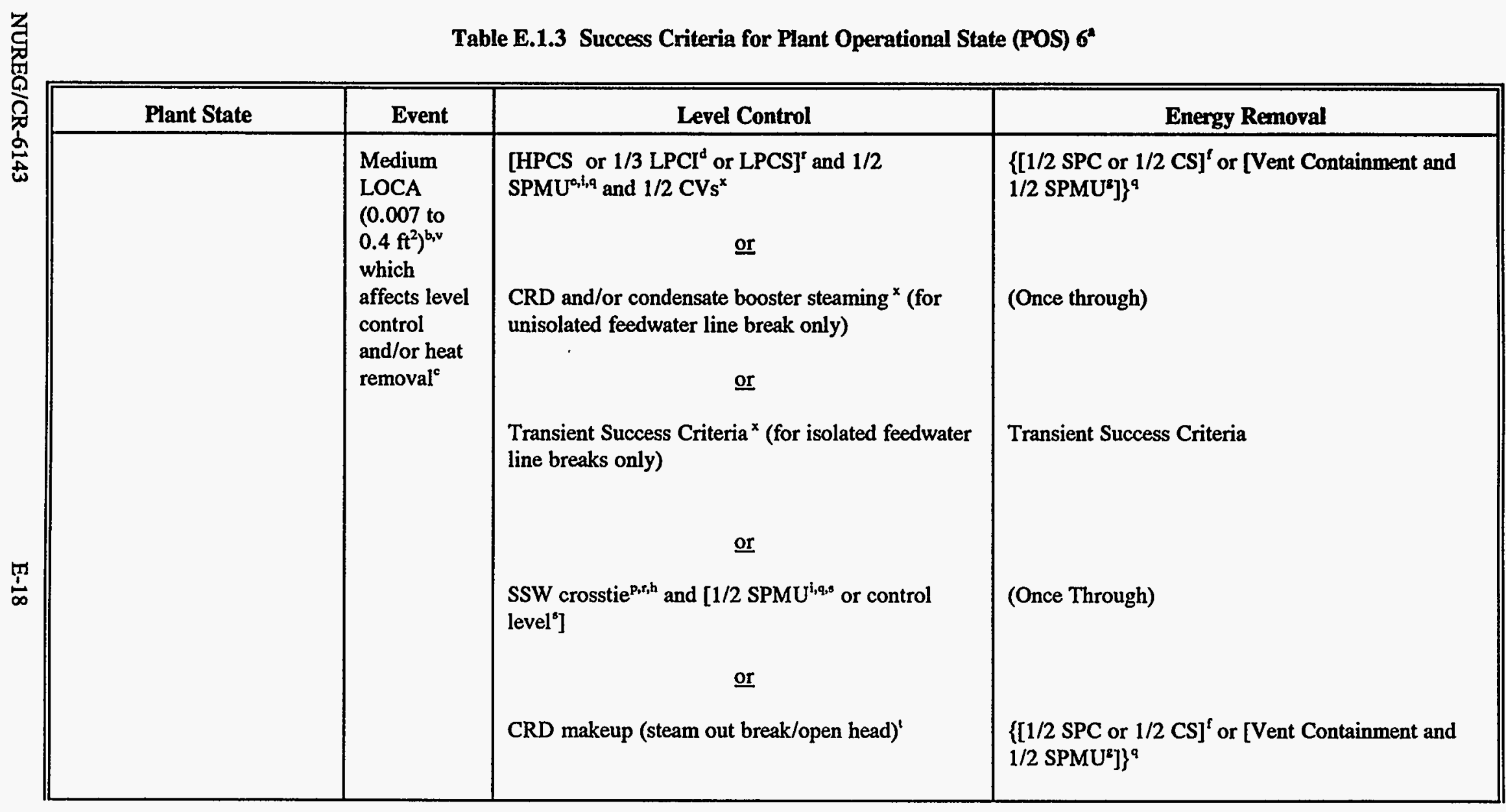




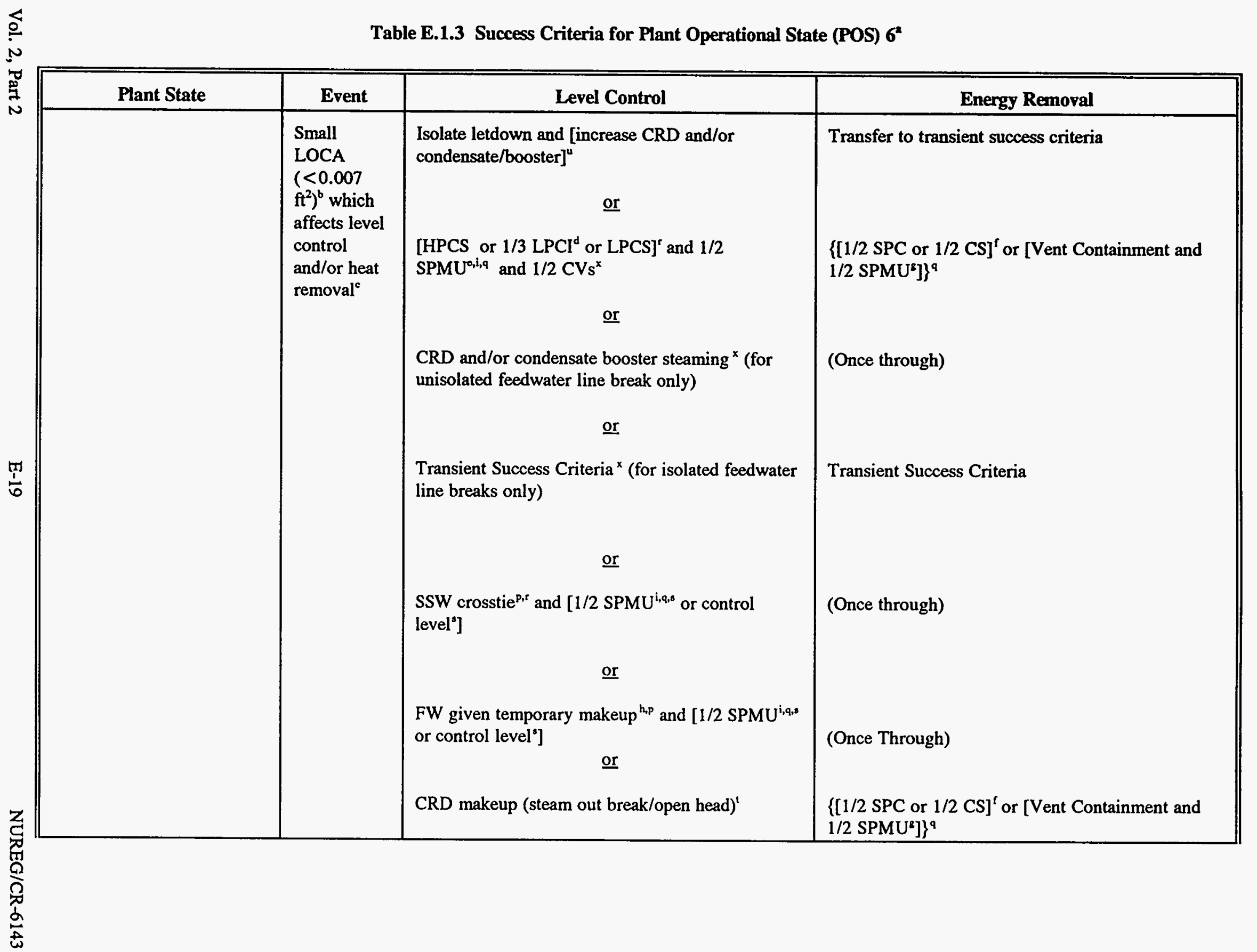


Table E.1.3 Success Criteria for Plant Operational State (POS) $6^{n}$

\begin{tabular}{|c|c|c|c|}
\hline Plant State & Event & Level Control & Energy Removal \\
\hline & Transients & 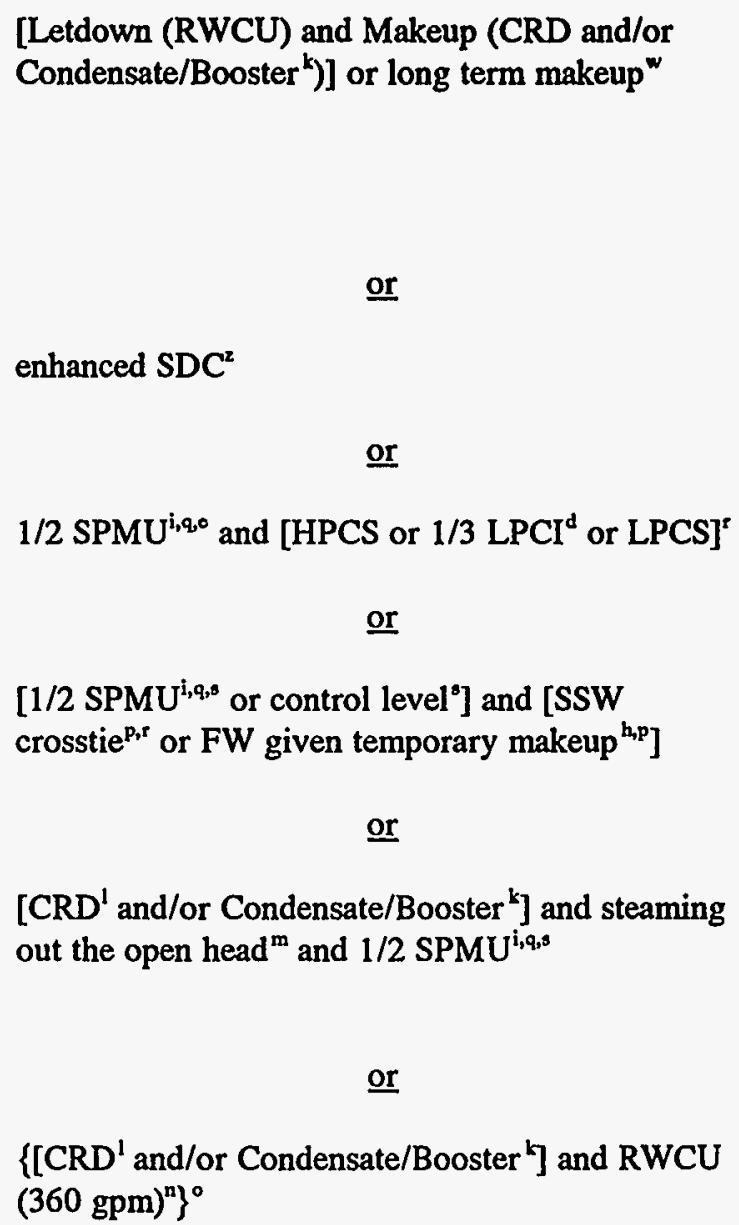 & 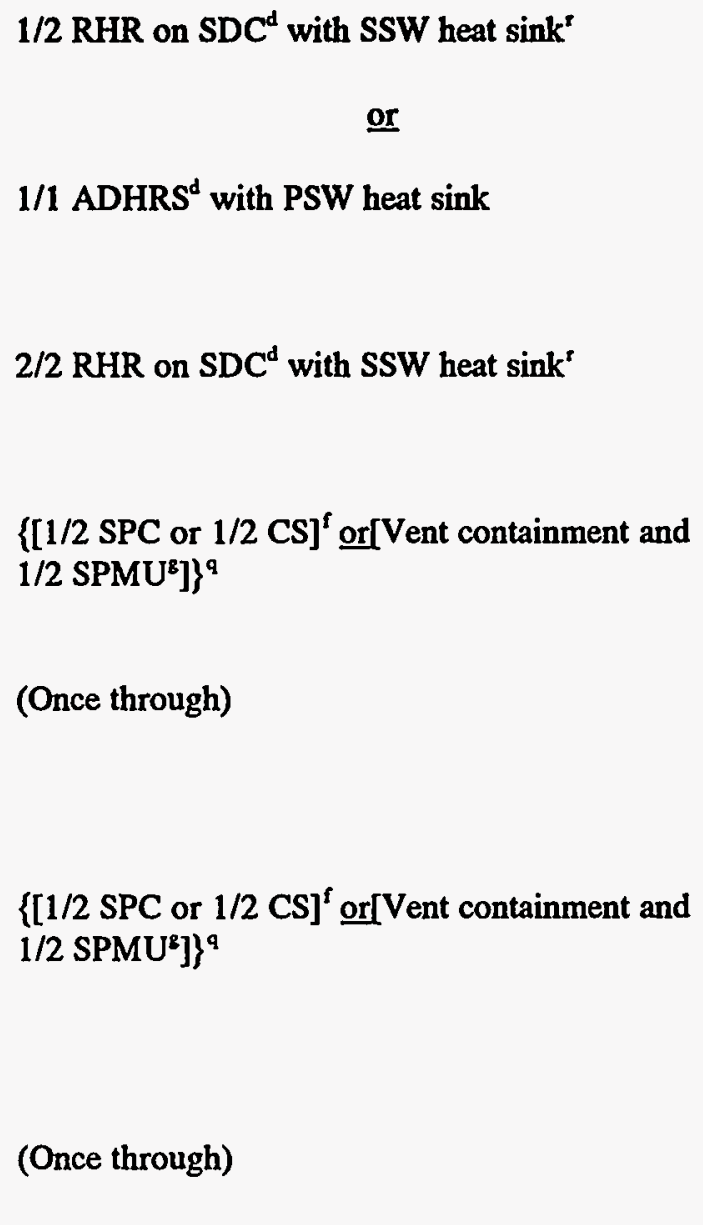 \\
\hline
\end{tabular}

萬 
- Reactivity Control by Fully Inserted Rods

b Verify that in POS 6 lineups do not allow LOCA to drain the vessel (this cannot be mitigated); concern is loss of level control and/or loss of heat removal due to LOCA

- LOCA in "steam" lines not of concern since 0 psig primary will not flash. Assume steam line plugs are installed

d LPCI Trains A and B require manual re-alignment from SDC. If ADHRS is operable, only one train of RHR on SDC required to be operable per Tech Spec 3.9.11.2. 2/3 LPCI per MELCOR calc. ADHR can handle decay heat load in POS 6, since entry into POS 6 is longer than 24 hours after shutdown.

- SPMU required to prevent loss of SP inventory

\& SPMU not required since maximum decay heat less than one RHR train heat removal capability

- SPMU required to makeup for boiloff from SP when containment vented

h FW not sufficient for large LOCA since flow not equal to 2 LPCI; SSWXT provides sufficient flow.

1 SRVs unavailable for water discharge due to presence of steam line plugs; water or condensed steam out top of open vessel returned to SP by SPMU.

1 PCS not available, and Feedwater not available. SPMU required when SP used for injection since SRVs unavailable due to presence of steam line plugs and injected water flows out open vessel top to upper pool

k Condensate/Booster injection may either be on standby or be unavailable

1 CRD flow rate at low vessel pressure is $240 \mathrm{gpm}$ max.

- $146 \mathrm{gpm}$ injection required. SRVs unavailable due to presence of steam line plugs.

- Maximum RWCU letdown of 360 gpm per Inadequate Decay Heat Removal Procedure step 5.1.3

- This method can match decay heat only after refueling when decay heat is low

$p$ NUREG/CR-4550 modeled SSW crosstie and FW.

q SPC, CS, SPMU not required to be operable in POS 6 per Tech Specs 3.6.3.3, 3.6.3.2, and 3.6.3.4, respectively. SRVs not required to be operable in POS 6 per Tech Spec 3.4.2.1

- ECCS and SP operability per Tech Specs 3.5.2 and 3.5.3. SSW operability per Tech Spec 3.7.1.1.

- Assume overfill of upper containment is a problem; SPMU drains upper pool to SP.

' Not modeled in the ET's; requires detailed thermal-hydraulic evaluation

"Small LOCA is within makeup capability, but CRD cannot both match break flow and raise level. In POS 6, level high enough for natural recirc if letdown isolated early, and CRD can maintain level.

- Adequate cooling with $1 / 3$ core uncovered evaluated with MELCOR

" Level sufficient for natural circulation, long term makeup to compensate for leakage.

$\times$ Main Steam Line Break not a LOCA in POS 6, since main steam line plugs in place. Feedwater Line Break LOCA outside containment requires check valve(s) to close for ECCS injection to not drain SP (as discussed for POS 5); MSIVs closure not required since steam line plugs in place; SRV not required since head is off. For Feedwater line break, core is not uncovered and can be steamed (as discused for POS 5).

y MSIV closure required whenever ECCS from SP used to not drain SP.

$=$ With normal level and with no recirc, increased SDC provides mixing between downcomer and core 


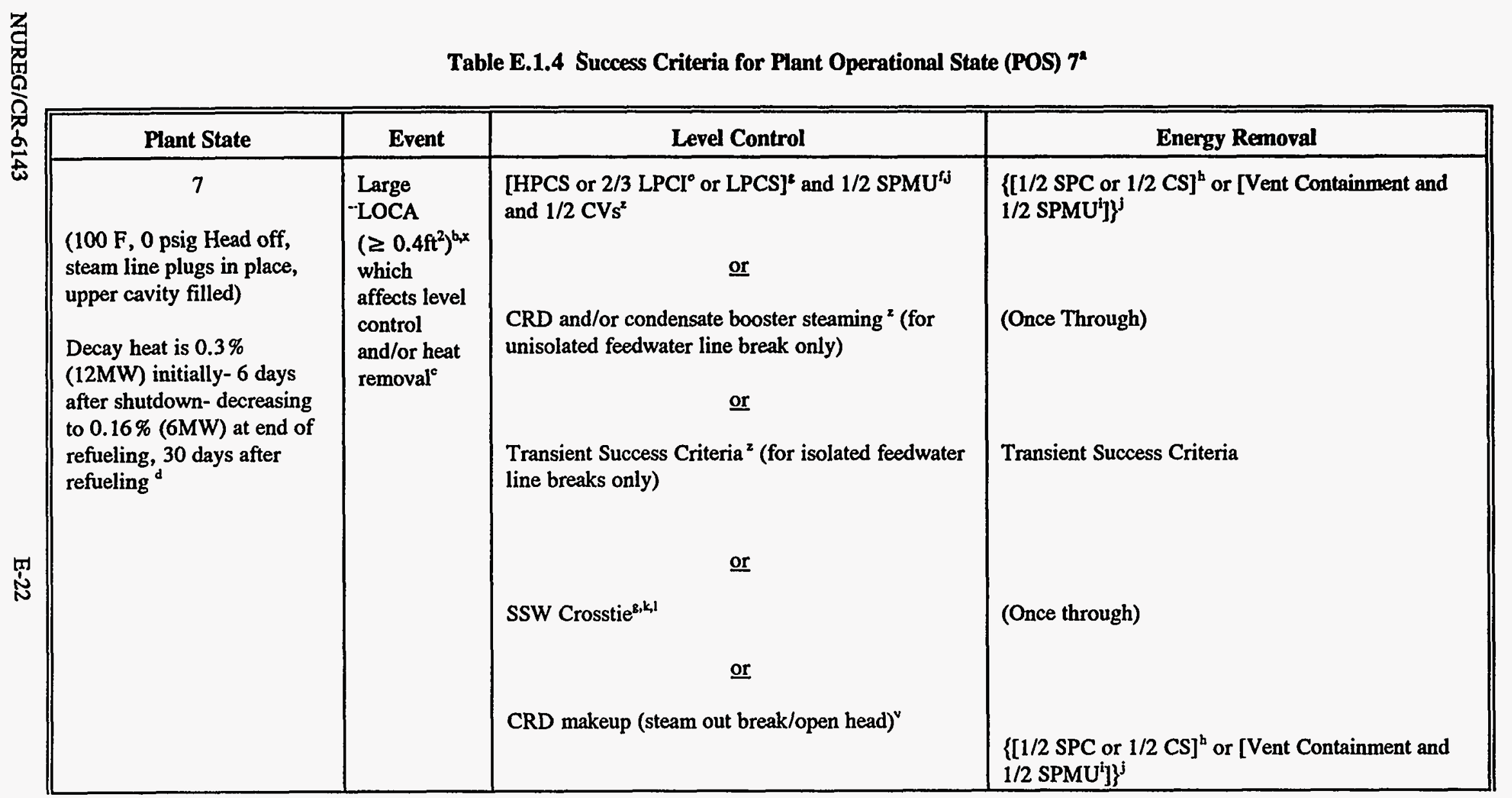




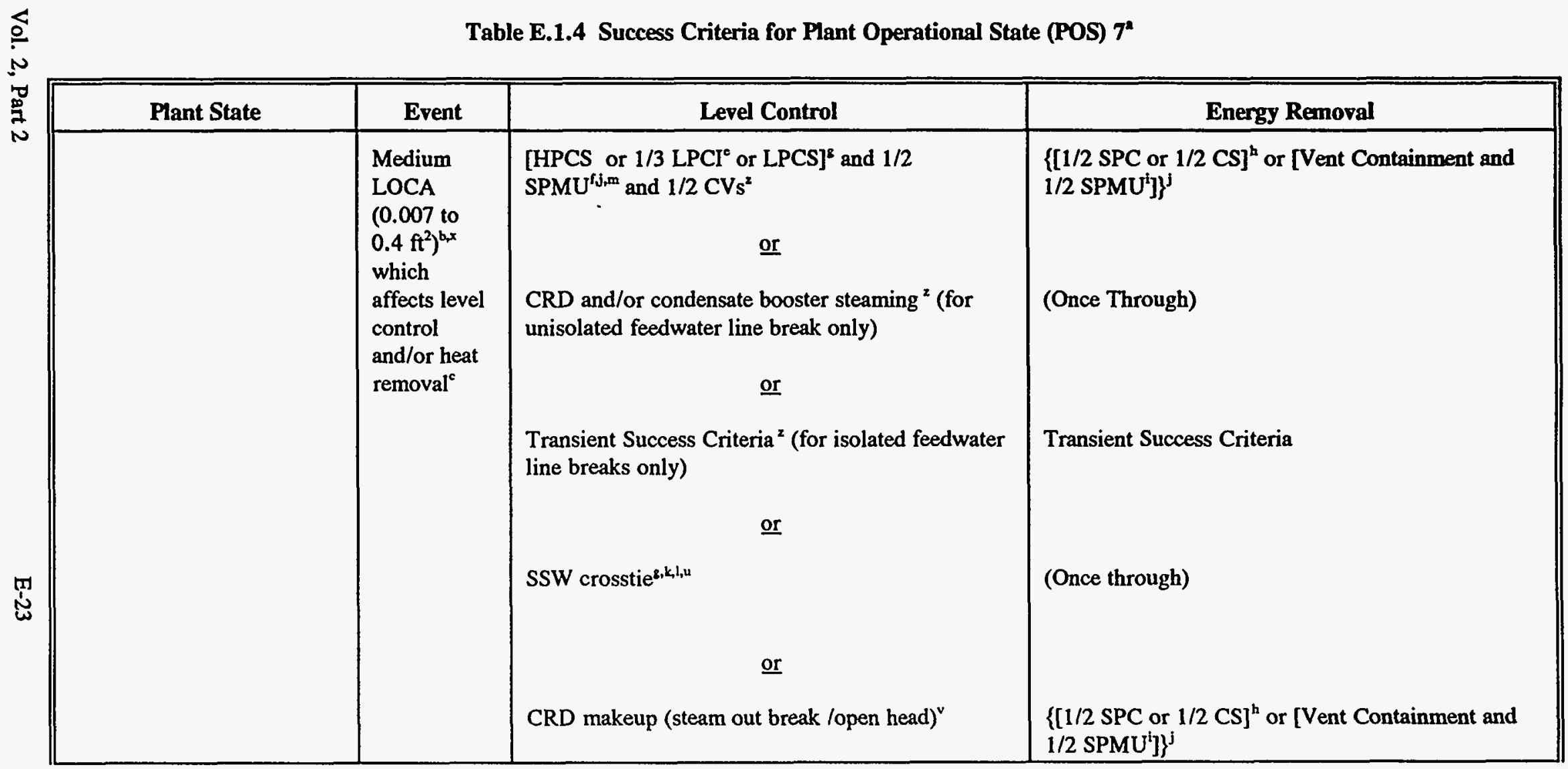




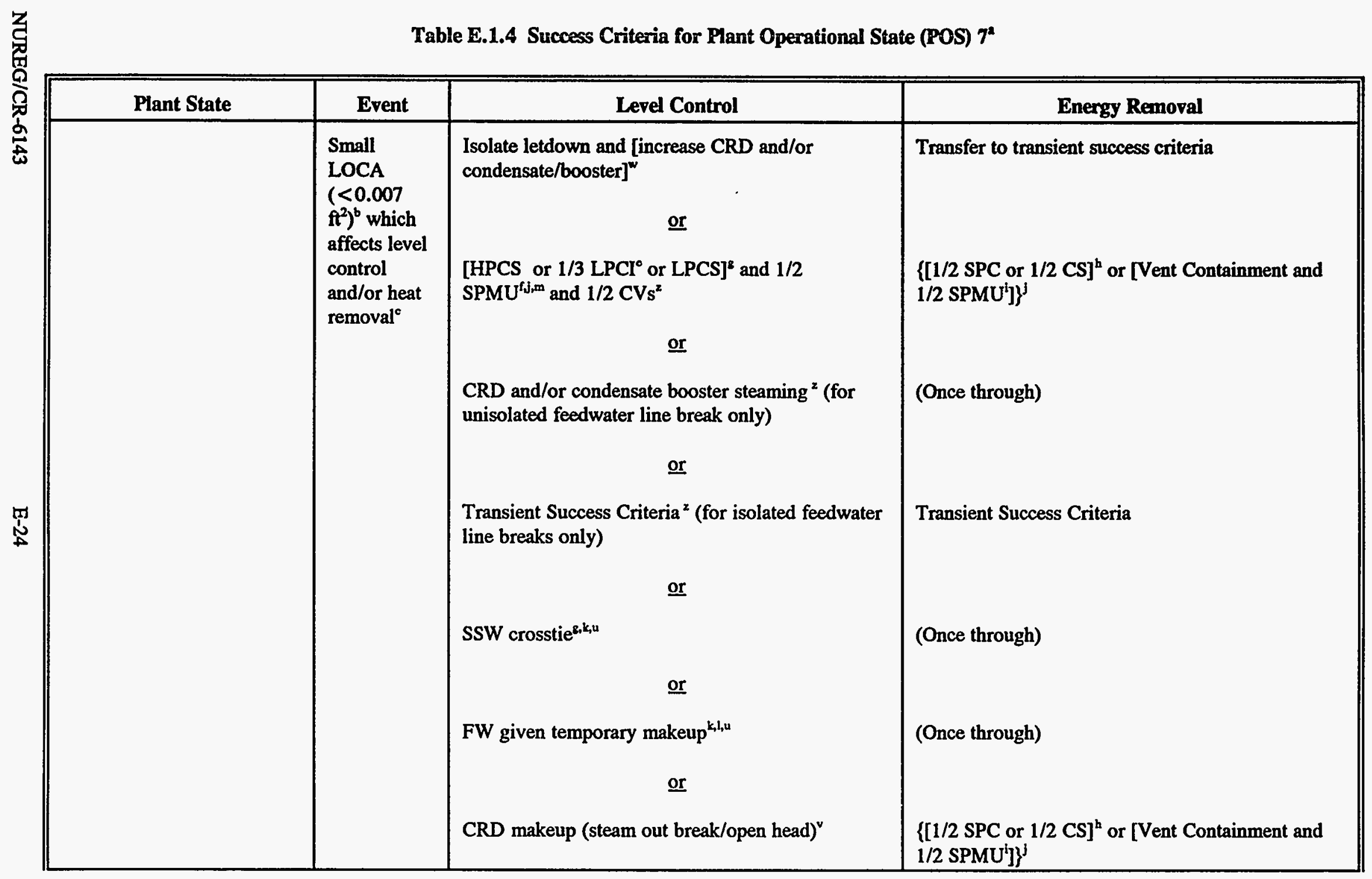




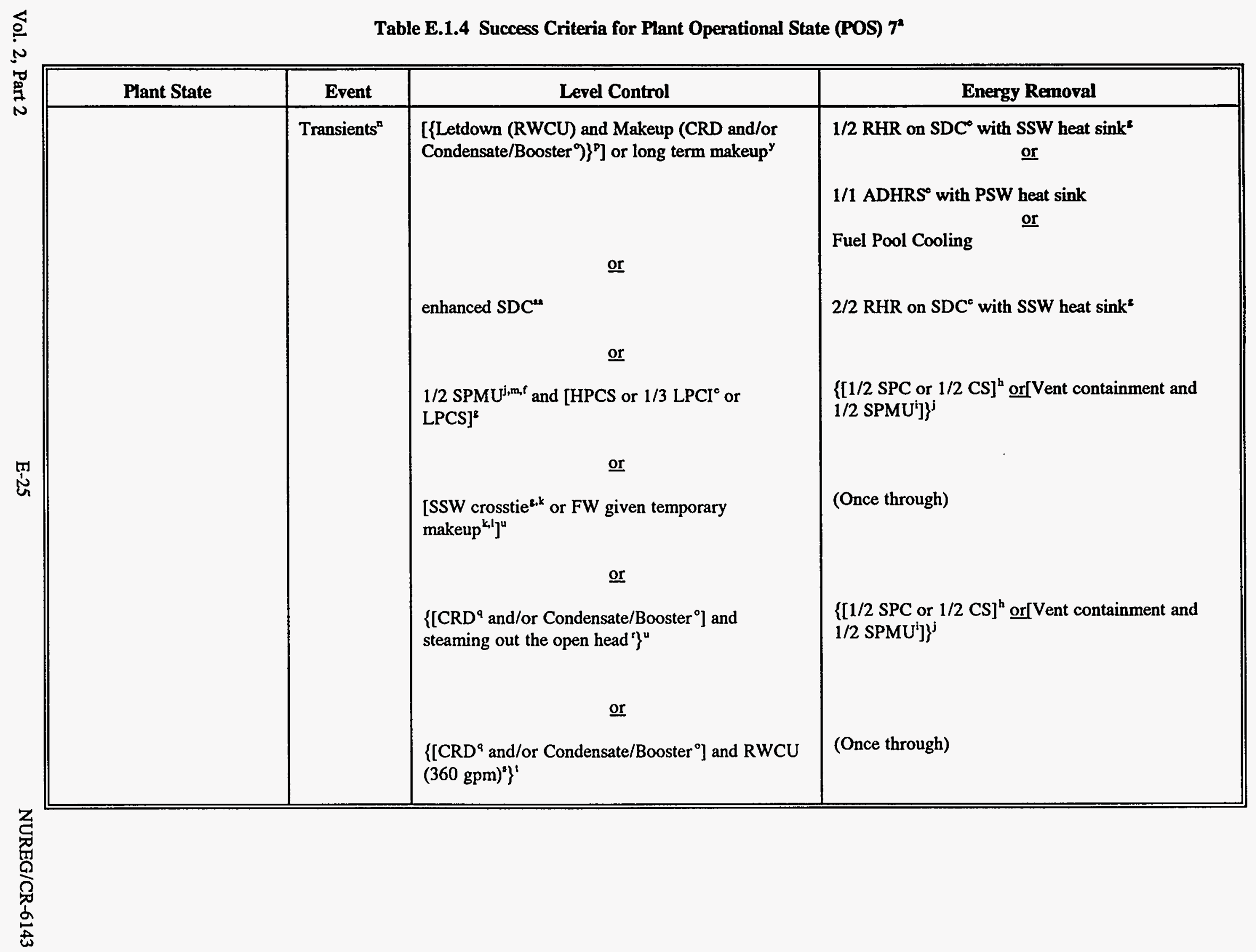


- Reactivity Control by Fully Inserted Rods

berify in POS 7 lineups do not allow LOCA to drain the vessel (this cannot be mitigated); concem is loss of level control and/or loss of heat removal due to LOCA

- LOCA in "steam" lines not of concern since 0 psig primary will not flash. Steam line plugs are installed in PS 7

- Conservatively take decay heat as $0.3 \%$ throughout POS 7

- LPCI Trains A and B require manual re-alignment from SDC. If ADHRS is operable, neither train of RHR on SDC is required to be operable per Tech Spec 3.9.11.1. 2/3 LPCI per MELCOR calc. ADHR can remove decay heat in POS 7 snice entry into POS 7 not within 24 hours from shutdown.

$f$ SPMU required to prevent loss of SP inventory

- ECCS not required to be operable, per Tech Spec 3.5.2, in POS 7. SSW required to be operable, per Tech Spec 3.7.1.1, in POS 7 (required operable only when RHR on SDC required operable).

b SPMU not required since maximum decay heat less than one RHR train heat removal capability

i SPMU required to makeup for boiloff from SP when containment vented

3 SPC, CS, SPMU not required to be operable in POS 7 per Tech Specs 3.6.3.3, 3.6.3.2, and 3.6.3.1 respectively. SRVs not required to be operable in POS 7 per Tech Spec 3.4.2.1.

1 NUREG/CR-4550 modeled SSW crosstie and FW.

1 FW not sufficient for large LOCA since flow not equal to 2 LPCI; SSWXT provides sufficient flow.

m SRVs unavailable for water discharge due to presence of steam line plugs; water out top of open vessel returned to SP by SPMU.

- PCS not available and Feedwater not available. SPMU required when SP used for injection since SRVs unavailable due to presence of steam line plugs and injected water flows out open vessel top to upper pool

- Condensate/Booster injection may be either on standby or unavailable

Petdown/makeup is normally isolated in POS 7

a CRD flow rate at low vessel pressure is $240 \mathrm{gpm}$ max.

- SRVs unavailable for steaming due to presence of steam line plugs. $146 \mathrm{gpm}$ injection required (see footnote d)

- Maximum RWCU letdown of 360 gpm per Inadequate Decay Heat Removal Procedure Step 5.1.3

t This method can match decay heat only toward the end of refueling. Based on the assumption in footnote d, it is not to be considered

"Assume overfill of upper containment is a problem, but water flows out transfer canal to spent fuel pool

$\checkmark$ Not modeled in the ET's; requires detailed thermal-hydraulic evaluation

" Small LOCA is within makeup capability, but CRD cannot both match break flow and raise level. In POS 7 , level high enough for natural recirc if letdown isolated early, and CRD can maintain level.

× Adequate cooling with $1 / 3$ core uncovered evaluated with MELCOR.

$y$ Level sufficient for natural circulation, long term makeup to compensate for leakage

$=$ Main Steam Line Break not a LOCA in POS 7, since main steam line plugs in place. Feedwater Line Break LOCA outside containment requires check valve(s) to close for ECCS injection to not drain SP (as discussed for POS 5); MSIVs closure not required since steam line plugs in place; SRV not required since head is off. For Feedwater line break, core is not uncovered and can be steamed (as discused for POS 5).

2* With normal level and with no recirc, increased SDC provides mixing between downcomer and core 


\section{References for Appendix E}

[Whitehead et al., 1991] D. W. Whitehead, J. L.

Darby, B. D. Staple, B.

Walsh, T. M. Hake, and T.

D. Brown, "BWR Low Power and Shutdown Accident

Frequencies Project, Phase 1 Coarse Screening Analysis,"

Vol. 1, Draft Letter Report, Sandia National Laboratories and Science and Engineering Associates, Inc., November 23, 1991 update, (Available at the USNRC Public Document Room).

[Lahey and Moody, 1984] R. T. Lahey, Jr, and F. J. Moody, "The ThermalHydraulics of a Boiling Water Nuclear Reactor." American Nuclear Society, 1984.

[SERI, 1992]

System Energy Resources, Inc., "Grand Gulf Updated Final Safety Analysis Report," 1992

[Vine et al., 1986] G. Vine, et al., "Residual Heat Removal Experience Review and Safety Analysis: Boiling Water Reactors," Nuclear Safety Analysis Center, NSAC-88, March, 1986.

[Drouin et al., 1989] M. T. Drouin et al., "Analysis of Core Damage Frequency: Grand Gulf, Unit 1 Internal Events." NUREG/CR-4550, SAND862084, Vol. 6, Rev. 1, Part 1, September 1989. 


\section{Appendix F. Supporting Calculations}

This Appendix summarizes calculations performed to support the success criteria and event tree development for the detailed analysis of POS 5.

Some of the calculations summarized were performed to support the earlier screening study [Whitehead et al., 1991], and they are also described in this Appendix.

The actual calculations which are described in this Appendix are maintained in project files. To facilitate cross referencing of the information in this Appendix to the actual calculations, the information in this Appendix is referenced by calculation number.

\section{F.1 Calculation Files}

Table F.1-1 summarizes the calculations performed. A brief summary of each calculation that is active is provided in the following discussions.

\section{F.2 Scoping Calculations}

To understand the basic characteristics of POSs $4,5,6$, and 7, various scoping calculations were performed.

Based on the results of these scoping calculations, and the development of the event trees, more detailed calculations were subsequently performed, as necessary.

\section{F.2.1 Calculation \#2}

Calculation 90-492-01-A:2, "Thermodynamics Calcs for Grand Gulf", documents scoping calculations performed for POS 4, 5, 6, and 7. The following topics were addressed:

(1) Decay Heat

(2) Injection to Remove Decay Heat without Steaming

(3) Injection to Remove Decay Heat with Steaming

(4) Heat Vessel Water to Saturation

(5) Boil Off Vessel Water to Top of Fuel

(6) Overheat Suppression Pool

(7) Drain Vessel to Top of Core

(8) Pressurize to 200 psig after Loss of
Recirculation

(9) Heat Removal Capability of ADHR at $200 \mathrm{~F}$

(10) Heat Removal Capability of FPCCU at 200 F.

The results of these calculations are given in Table F.21. The decay heat was determined by a curve fit to that given in the NRC Standard Review Plan [USNRC, 1987]. For times of interest for POSs 4, 5, 6, and 7 [5 to 720 hours] the fit is:

$$
\ln \left(\mathrm{DH}_{\mathrm{x}}\right)=-0.368 \ln \left(\mathrm{t}_{\mathrm{hr}}\right)+0.593
$$

where $\mathrm{DH}_{\infty}$ is decay heat in per cent of full power and $t_{h r}$ is time after shutdown in hours.

Based on information received during a visit to Grand Gulf [Plant Visit, 1991], appropriate conservative times, after reactor shutdown, for entry into the POSs are as follows:

$$
\begin{aligned}
& \text { POS 4, } 5 \text { hours } \\
& \text { POS 5, } 7 \text { hours } \\
& \text { POS 6, } 4 \text { days } \\
& \text { POS } 7,6 \text { days }
\end{aligned}
$$

Heatup After Refueling Outage, 30 days.

\section{F.2.2 Calculation \#3}

Calculation 90-492-01-A:3, "Miscellaneous Thermodynamics Calcs for Grand Gulf", documents additional scoping analyses. the topics addressed were:

(1) Capacity of 1 SRV in Safety Mode at Rated Pressure

(2) Capacity of 1 SRV in Relief Mode at 100 psig (Steam)

(3) Capacity of 1 SRV in Relief Mode at 200 psig (Steam)

(4) Capacity of 1 SRV Passing Water at 100 psig and 200 psig

(5) Loss through Small LOCA in POS 4 
Table F.1.1 Calculations Performed

\begin{tabular}{|c|c|c|}
\hline Calculation Name and Number & Purpose of Calculation & Status of Calculation \\
\hline $\begin{array}{l}\text { "Grand Gulf Shutdown } 24 \text { Hour Success } \\
\text { Criteria", 90-492-01-A:1 }\end{array}$ & $\begin{array}{l}\text { Perform Scoping Thermalhydraulic Calculations } \\
\text { for POSs } 4,5,6 \text {, and } 7\end{array}$ & $\begin{array}{l}\text { Superseded by Calculation 90-492-01-A:2 based } \\
\text { on more accurate information received during } \\
\text { 1/91 Site Visit (Plant Visit, 1/91) }\end{array}$ \\
\hline $\begin{array}{l}\text { "Thermodynamics Calcs for Grand Gulf", 90- } \\
\text { 492-01-A:2 }\end{array}$ & $\begin{array}{l}\text { Perform Scoping Thermalhydraulic Calculations } \\
\text { for POSs } 4,5,6 \text {, and } 7\end{array}$ & Active \\
\hline $\begin{array}{l}\text { "Miscellaneous Thermodynamics Calculations } \\
\text { for Grand Gulf", 90-492-01-A:3 }\end{array}$ & Expand Calc 90-492-01-A:2 & Active \\
\hline $\begin{array}{l}\text { "Multiple Initiators for GG Shutdown", 90-492- } \\
01-A: 4\end{array}$ & $\begin{array}{l}\text { Perform Screening Search for Multiple Initiating } \\
\text { Events of Potential Importance for POSs } 4,5 \text {, } \\
6 \text {, and } 7\end{array}$ & $\begin{array}{l}\text { Active, but Updated for POS } 5 \text { by Calc } 90-492- \\
01-A ; 14\end{array}$ \\
\hline $\begin{array}{l}\text { "Relief Capabilities at Grand Gulf", 90-492-01- } \\
\text { A:4.1 }\end{array}$ & $\begin{array}{l}\text { Calculate Relief Capabilities for SRV and Vent } \\
\text { Line, Calculate Pressures for ECCS Water Solid } \\
\text { Cases (ECCS pumps and } 1 \text { or } 2 \text { SRVs) }\end{array}$ & Active \\
\hline "Levels for Grand Gulf", 90-492-01-A:5 & $\begin{array}{l}\text { Determine Actual vs. Measured Level, Levels } \\
\text { required for Shutdown Cooling }\end{array}$ & Active \\
\hline $\begin{array}{l}\text { "SRVs for Small/Medium LOCAs", 90-492- } \\
01-A: 6\end{array}$ & $\begin{array}{l}\text { Determine Need for SRV for Small LOCA in } \\
\text { POS } 4\end{array}$ & $\begin{array}{l}\text { Active, Levels Recalculated with Calc 90-492- } \\
\text { 01-A:19 }\end{array}$ \\
\hline $\begin{array}{l}\text { "Loss of ECCS due to Loss of SP", 90-492-01- } \\
\text { A:7 }\end{array}$ & $\begin{array}{l}\text { Calculate Conditions under which SP Inventory } \\
\text { is Insufficient for ECCS }\end{array}$ & Active \\
\hline $\begin{array}{l}\text { "Containment Flooded or Vented", 90-492-01- } \\
\text { A:8 }\end{array}$ & $\begin{array}{l}\text { Estimate Time to Boil Off SP Inventory to lose } \\
\text { ECCS if no Heat Removal, Estimate Time for } \\
\text { Containment Overpressure if Flooded with no } \\
\text { Heat Removal }\end{array}$ & Active \\
\hline $\begin{array}{l}\text { "Restore Makeup for Recirculation", 90-492-01- } \\
\text { A:9 }\end{array}$ & $\begin{array}{l}\text { Estimate Time Available to Restore Makeup } \\
\text { given No Makeup, Letdown Isolated, Nominal } \\
\text { Leakage }\end{array}$ & Active \\
\hline "1 CRD Pump for POS 5", 90-492-01-A:10 & $\begin{array}{l}\text { Calculate Effectiveness of } 1 \text { CRD Pump for } \\
\text { Restoring Level, and for Matching Steaming in } \\
\text { POS } 5\end{array}$ & $\begin{array}{l}\text { Active, Levels Recalculated with Calc 90-492- } \\
01-A: 19\end{array}$ \\
\hline $\begin{array}{l}\text { SDC Relief Valves for POS } 4 \text { and 5", 90-492- } \\
\text { 01-A: } 11\end{array}$ & $\begin{array}{l}\text { Calculate Ability of Relief Valves in RHR/SDC } \\
\text { to Prevent Overpressurizing RHR and ADHR } \\
\text { Components }\end{array}$ & $\begin{array}{l}\text { Active, Levels Recalculated with Calc 90-492- } \\
\text { 01-A:19 }\end{array}$ \\
\hline
\end{tabular}




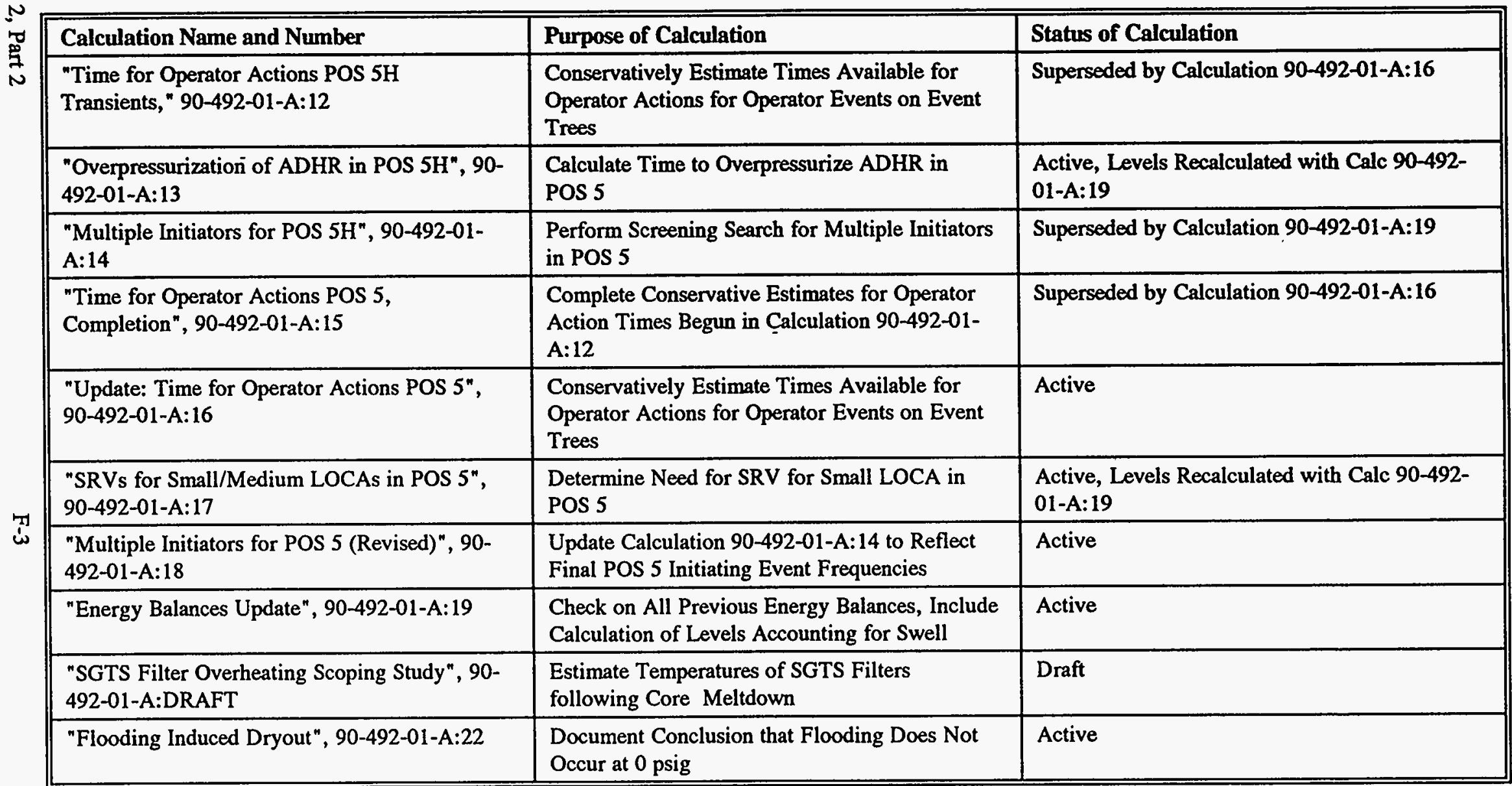


Table F.2.1.

Results of Initial Thermal Hydraulic Calculations for Screening Study

\begin{tabular}{|c|c|c|c|c|c|c|c|c|c|c|}
\hline $\begin{array}{l}\text { Ptant } \\
\text { State }\end{array}$ & $\begin{array}{l}\text { Decay } \\
\text { Heat }\end{array}$ & $\begin{array}{l}\text { Remove } \\
\text { Decay Heat } \\
\text { without } \\
\text { Steaming } \\
\end{array}$ & $\begin{array}{l}\text { Remove } \\
\text { Decay Heat } \\
\text { with } \\
\text { Steaming }\end{array}$ & $\begin{array}{l}\text { Heat Vessel } \\
\text { Water to } \\
\text { Saturation }\end{array}$ & $\begin{array}{l}\text { Boil off to } \\
\text { Top of Core }\end{array}$ & $\begin{array}{l}\text { Overheat } \\
\text { Suppression } \\
\text { Pool }\end{array}$ & $\begin{array}{l}\text { Drain to Top } \\
\text { of Core }\end{array}$ & $\begin{array}{l}\text { Pressurize to } \\
200 \text { psig }^{4 j}\end{array}$ & $\begin{array}{l}\text { Ability of } \\
\text { ADHRS to } \\
\text { Remove Decay } \\
\text { Heat }\end{array}$ & $\begin{array}{l}\text { Ability of } \\
\text { FPCCU to } \\
\text { Remore } \\
\text { Decay Heat }\end{array}$ \\
\hline $4^{2}$ & $38 \mathrm{MW}$ & $1333 \mathrm{gpm}$ & $278 \mathrm{gpm}^{\mathrm{c}}$ & $0 \min ^{d}$ & $2.0 \mathrm{hr}$ & $15.5 \mathrm{hr}$ & $1.7 \mathrm{hr}$ & $12 \mathrm{~min}$ & $f$ & $\mathbf{f}$ \\
\hline $5^{2}$ & $34 \mathrm{MW}$ & $2087 \mathrm{gpm}$ & $249 \mathrm{gpm}^{\mathrm{c}}$ & $5.4 \mathrm{~min}$ & $2.6 \mathrm{hr}$ & $16.8 \mathrm{hr}$ & $1.7 \mathrm{hr}$ & $0.8 \mathrm{hr}^{i}$ & h & f \\
\hline $6^{2}$ & $15 \mathrm{MW}$ & $921 \mathrm{gpm}$ & $110 \mathrm{gpm}$ & $1.8 \mathrm{hr}$ & $12.0 \mathrm{hr}$ & $35.9 \mathrm{hr}$ & $3.1 \mathrm{hr}$ & e & $2 \mathrm{HX}$ & f \\
\hline 7 & $12 \mathrm{MW}$ & $737 \mathrm{gpm}$ & $88 \mathrm{gpm}$ & $19.4 \mathrm{hr}$ & $100.1 \mathrm{hr}$ & $41.2 \mathrm{hr}$ & $20.7 \mathrm{hr}$ & e & $2 \mathrm{HX}^{*}$ & $2 \mathrm{HX}$ \\
\hline $6^{b}$ & $6 \mathrm{MW}$ & $368 \mathrm{gpm}$ & $44 \mathrm{gpm}$ & $3.8 \mathrm{hr}$ & $24.8 \mathrm{hr}$ & $72.2 \mathrm{hr}$ & $3.1 \mathrm{hF}$ & e & $1 \mathrm{HX}$ & $\mathbf{f}$ \\
\hline $5^{b}$ & $6 \mathrm{MW}$ & $368 \mathrm{gpm}$ & $44 \mathrm{gpm}$ & $30 \mathrm{~min}$ & $13.8 \mathrm{hr}$ & $72.2 \mathrm{hr}$ & $1.7 \mathrm{hr}$ & $4.5 \mathrm{hr}^{\mathrm{i}}$ & $1 \mathrm{HXX}$ & f \\
\hline $4^{b}$ & $6 \mathrm{MW}$ & $368 \mathrm{gpm}$ & $44 \mathrm{gpm}$ & $0 \min ^{d}$ & $11.7 \mathrm{hr}$ & $72.2 \mathrm{hr}$ & $1.7 \mathrm{hr}$ & $1.1 \mathrm{hr}$ & $\mathbf{f}$ & $\mathbf{f}$ \\
\hline
\end{tabular}

NOTES:

7 "Coming down from full power

$\downarrow$ "Going up after 30 days

'240 gpm makeup adequate to prevent core uncovery

SSaturated initially

Head off, cannot pressurize

Not available in this POS

'Results indicates IADHRS HX can just match decay heat; $2 \mathrm{HX}$ to be sure

ADHRS cannot remove $34 \mathrm{Mw}$; ADHRS can match decay heat at 24 hours after shutdown

Neglecting relief through vent line

${ }^{j}$ Assume water in downcomer has no effect (Conservative) 
(6) Loss through Small LOCA at 0 psig (POSs 5, 6, and 7)

(7) Drop in Level when SRV Opens in POS 4 at 100 psig.

The conclusions of this calculation are as follows:

(1) 1 SRV steaming at its safety setpoint can match $4 \%$ decay heat without makeup, and $8 \%$ decay heat with makeup at 100 degrees $F$ to maintain constant level,

(2) At 100 psig, 1 SRV steaming in relief can match $0.5 \%$ decay heat without makeup, and $0.6 \%$ decay heat with makeup at 100 degrees $F$ to maintain constant level,

(3) At $230 \mathrm{psig}, 1 \mathrm{SRV}$ steaming in relief can match $1 \%$ decay heat without makeup. At 200 psig, 1 SRV steaming in relief can match $1.2 \%$ decay heat with makeup at 100 degrees $F$ to maintain constant level,

(4) When injecting with one ECCS pump at 8000 gpm:

(a) at $100 \mathrm{psig}, 2 \mathrm{SRVs}$ can provide relief (2 SRVs pass water at $9600 \mathrm{gpm}$ ),

(b) at $200 \mathrm{psig}, 1 \mathrm{SRV}$ cannot provide relief (1 SRV passes water at $6700 \mathrm{gpm}$ ),

(5) Makeup with $2 \mathrm{CRD}$ pumps at $240 \mathrm{gpm}$ can equal mass loss from small LOCA (0.007 sq ft) in POSs 4, 5, 6, and 7. Loss is about $160 \mathrm{gpm}$ in POS 4200 psig (flashing water), loss is about $200 \mathrm{gpm}$ in POSs 5, 6, and 7 (subcooled water, $100 \mathrm{ft}$ gravity head), and

(6) If 1 SRV spuriously opens in POS 4 at $100 \mathrm{psig}$, with no operator action, and assuming instant flashing to $0 \mathrm{psig}$, level drops below low level 3, SDC isolation setpoint, but not below level 2 setpoint for ECCS actuation (a later calculation, \# 6, performed a time dependent analysis including heat addition).

\section{F.2.3 Calculation \#7}

Calculation 90-492-01-A:7, "Loss of ECCS due to Loss of SP", evaluated under what conditions the SP inventory is inadequate for ECCS. According to the Tech Specs, in POS 4 the SP is required to be at Low Water Level, 18 feet $41 / 12$ inches. However, in POSs 5, 6, and 7, the SP can be at 12 feet 8 inches, or empty if 170,000 gal are available to HPCS from the CST. This calculation concluded that:

(1) In POS 4 or 5 with SP at Low Water Level:

(a) For a LOCA inside containment, SPMU is required,

(b) For water solid operation with SRVs returning water to the SP, no SPMU is required except if long term boiloff occurs, and

(c) For a LOCA outside containment that is not isolated, adequate SP inventory can be lost between 6 and 25 minutes, depending on the number of ECCS pumps operating.

(2) In POS 5 with SP at 12 feet 8 inches:

(a) For a LOCA inside containment, adequate SP inventory is lost even with SPMU, and

(b) For water solid operation with SRVs returning water to the SP, no SPMU is required except if long term boiloff occurs.

(3) In POS 5 with SP Empty and 170,000 for HPCS:

(a) For a LOCA inside containment, adequate SP inventory is lost even with SPMU, and

(b) For water solid operation with SRVs returning water to the SP, adequate SP inventory cannot be maintained even with SPMU.

\section{F.2.4 Calculation \#8}

Calculation 90-492-01-A:8, "Containment Flooded or Vented", addressed two issues:

(1) Time for heating flooded containment to failure pressure (taken as 70 psia) with no heat removal, and

(2) Time to boil off SP inventory to where ECCS is lost. 
The calculation concluded:

(1) Time to heat flooded containment to 70 psia is 54 to 80 hours, depending on volume flooded.

(2) Time to boil off SP inventory at 15 psia to where ECCS is lost, assuming initially saturated water, is as follows:

(a) SP at Low Water Level:

12 hours for LOCA, 18 hours for Transients

(b) SP at 12 Feet 8 Inches:

LOCA cannot be mitigated (see calc \#7) 3 hours for Transients.

\section{F.2.5 Calculation \#9}

Calculation 90-492-01-A:9, "Restore Makeup for Recirculation", estimates the time available to restore makeup if makeup is lost and letdown is isolated, before recirculation from the core to the downcomer is lost. Two cases are of interest, forced recirculation and enhanced shutdown cooling. In either case, the time available is that for leakage to lower level from the initial level $(+36$ inches measured or +27.5 inches actual) to the low level 3 SDC isolation setpoint $(+11.4$ inches measured or +8.7 inches actual).

The Tech Specs allow a total leakage of $\mathbf{3 0} \mathrm{gpm}$ at rated pressure. We assumed a nominal full power leakage of $10 \mathrm{gpm}$. At full power the leaking water flashes, and converting $10 \mathrm{gpm}$ flashing at full pressure to subcooled water draining from a 100 foot head of water, the estimated leak rate at shutdown is about $6 \mathrm{gpm}$. This allows 10 hours before level drains to low level 3 .

\section{F.2.6 Calculation \#DRAFT}

Calculation 90-492-01-A:DRAFT, "SGTS Filter Overheating Scoping Study", was performed to assist Sandia personnel examining the source term for core melt in POS 6. This calculation showed that for the radionuclides released into the auxiliary building, it is possible that the SGTS can maintain aux building integrity and its filters possibly not overheat. The calculation was a scoping study using a filter heatup model developed for the Savannah River K Reactor Confinement [Darby et al., 1991]. The results indicate that ignition of the charcoal filters may or may not occur depending on the fraction of iodine released in vapor form, the number of SGTS trains running (1 or 2), and the filter peaking factors. HEPA filter ignition is unlikely.

\section{F.2.7 Calculation $\# 22$}

Calculation 90-492-01-A:22, "Flooding Induced Dryout", documents a conservative calculation showing that at zero psig the core can be steamed. The Wallis flooding criterion (in combination with an energy balance and a mass balance) is used to calculate the maximum heat flux allowed: $8.5 \mathrm{E}+3 \mathrm{Btu} / \mathrm{ht} / \mathrm{ft}^{2}$.

\section{F.3 Calculations for Multiple Initiators}

Three calculations addressing multiple initiating events were performed. Calculation 90-492-01-A:4, "Multiple Initiators for GG Shutdown", addressed multiple initiators for the earlier screening study. Two calculations, 90-492-01-A:14 "Multiple Initiators for POS 5H" and 90-492-01-A: 18 "Multiple Initiators for POS 5: Revised", addressed multiple initiators for the detailed study of POS 5. The latter of these two calculations updated the analysis of the former, by using revised initiating event frequencies.

This section provides results of the search for multiple initiating events of potential importance at Grand Gulf in Pos 5.

If every possible event subsequent to the first event is in the PRA model, then the concept of a multiple initiating event is merely one of semantics. No "multiple" initiator is possible, since every event subsequent to the first one is included in the mitigation model. In practice, PRAs do not include every possible event subsequent to the first event in the mitigation model. For example, randomly occurring LOCAs following a transient initiating event are not considered. Thus, the concept of a multiple initiating event is one for which the events subsequent to the initial event are not in the model. Many such multiple initiating events are of low frequency and can be screened out. The set of initiating events can be analyzed to quantitatively identify those combinations of events that are numerically significant, and that are not present in the original model. Once these multiple initiating events are identified, they can be analyzed for importance. 
The frequency of a multiple initiating event containing " $n$ " events is the product of:

(a) the frequency of the first initiating event

(b) the probability the second initiating event occurring within the fault exposure time following the first initiating event

(n) the probability the $\mathrm{n}^{\text {th }}$ initiating event occurs within the fault exposure time following the first initiating event.

Let $T$ denote the fault exposure time. Let $f_{i}$ denote the frequency of initiating event $i$. Let $P_{j \mid 1}$ denote the probability that event $j$ occurs, given 1 , within time $T$. If event $j$ is independent of event $i$, then $P_{j l i}$ equals $P_{j}$, where $P_{j}$ is: $1-\exp \left(-f_{j} T\right)$.

In shorthand notation, a double event multiple initiator can be expressed as "ij", a triple event multiple initiator can be expressed as 'ijk', and so on, where the first index refers to the frequency of the first event, and the succeeding indices refer to the probability of the indicated initiating event over time T. Note that numerically, assuming no dependence among events:
(1) $\mathrm{ij} \neq \mathrm{ji}$
(2) $\mathbf{i j k} \neq \mathrm{jik} \neq \mathrm{kij}$
(3) $\mathrm{ijk}=\mathrm{ikj}$.

When dependent effects are considered, it may be that:

(4) $\mathrm{ijk} \neq \mathrm{ikj}$.

A code was written to identify and quantify all double and triple multiple initiating events. The code is MULINIT.PAS, written in TurboPascal 6.0; source code is provided in Table F.3-1. This code eliminates userdefined illogical dependencies, and it eliminates userdefined combinations of multiple initiating events for which events subsequent to the first event are already considered in the fault trees. An example of an illogical dependency is loss of offsite power followed by loss of main feedwater, because the event trees for loss of offsite power already account for the fact that main feedwater is unavailable given loss of offsite power. An example of a dependency already "hard-wired" into the fault trees is any initial initiating event followed by loss of shutdown cooling, if loss of shutdown cooling is included as a failure during the fault exposure time everywhere in the fault trees.

A listing of all multiple initiating events with a frequency of greater than $10^{-8}$ per year is provided in Table F.3.2. There are about $\mathbf{4 5 0}$ double initiating event sequences, and no triple initiating event sequences. Those multiple initiating events with a frequency greater than or equal to $10^{-6}$ per year which are not already addressed by the existing models are as follows (NOTE: Not all sequences of table F.3-2 greater than $10^{-6}$ per year are listed. Upon detailed examination of the model, many of these sequences were determined to already be considered):

$$
\begin{aligned}
& \text { E1T*H1, 1.8E-6 per year, } \\
& \text { E1V*H1, 1.8E-6 per year, } \\
& \text { T1*TORV, 1.5e-6 per year, } \\
& \text { E1T*TORV, 4.2E-6 per year, } \\
& \text { E1V*TORV, 4.2E-6 per year, and } \\
& \text { TIA*TORV, 2.1E-6 per year. }
\end{aligned}
$$

The calculated frequencies consider the fraction of time that the plant is in POS 5, 0.031, but do not factor in the fractions of time that POS 5 is in HYDRO, on SDC/RHR, or on ADHR. These fractions are 0.11 , 0.81 , and 0.08 , respectively. When these six sequences are corrected for these effects, only the first one is above $10^{-6}$, and its frequency is $1.5 \mathrm{E}-6$ per year. Furthermore, E1T is isolation of the SDC common suction line when using RHR, and H1 (diversion of water through the SDC system(s) to the suppression pool) cannot occur if the common suction line is isolated. Therefore, E1T*H1 is a valid sequence only if the operators restore the common suction line, which requires success of event RESCS, and then the remainder of the sequence is essentially the same as the $\mathrm{H} 1$ sequence. Therefore, the impact of the multiple initiating event, E1T*H1, is to increase the frequency of the $\mathrm{H} 1$ initiating event by a factor:

\section{$(1+\mathrm{E} 1 \mathrm{~T} * \underline{\mathrm{RESCS}})$}

where RESCS is success of RESCS. Numerically, this factor is equal to $1+(0.356)^{*}(0.9)=1.32$. 
Table F.3.1 MULINIT.PAS Source Code

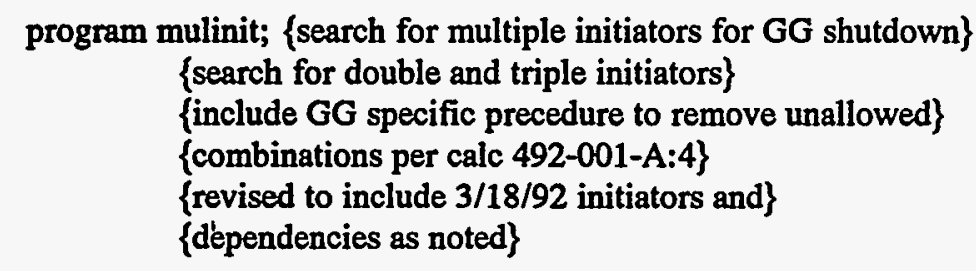

\{Turbo Pascal 6.0. J. Darby, SEA, Inc., Oct 15, 1991 Version\}

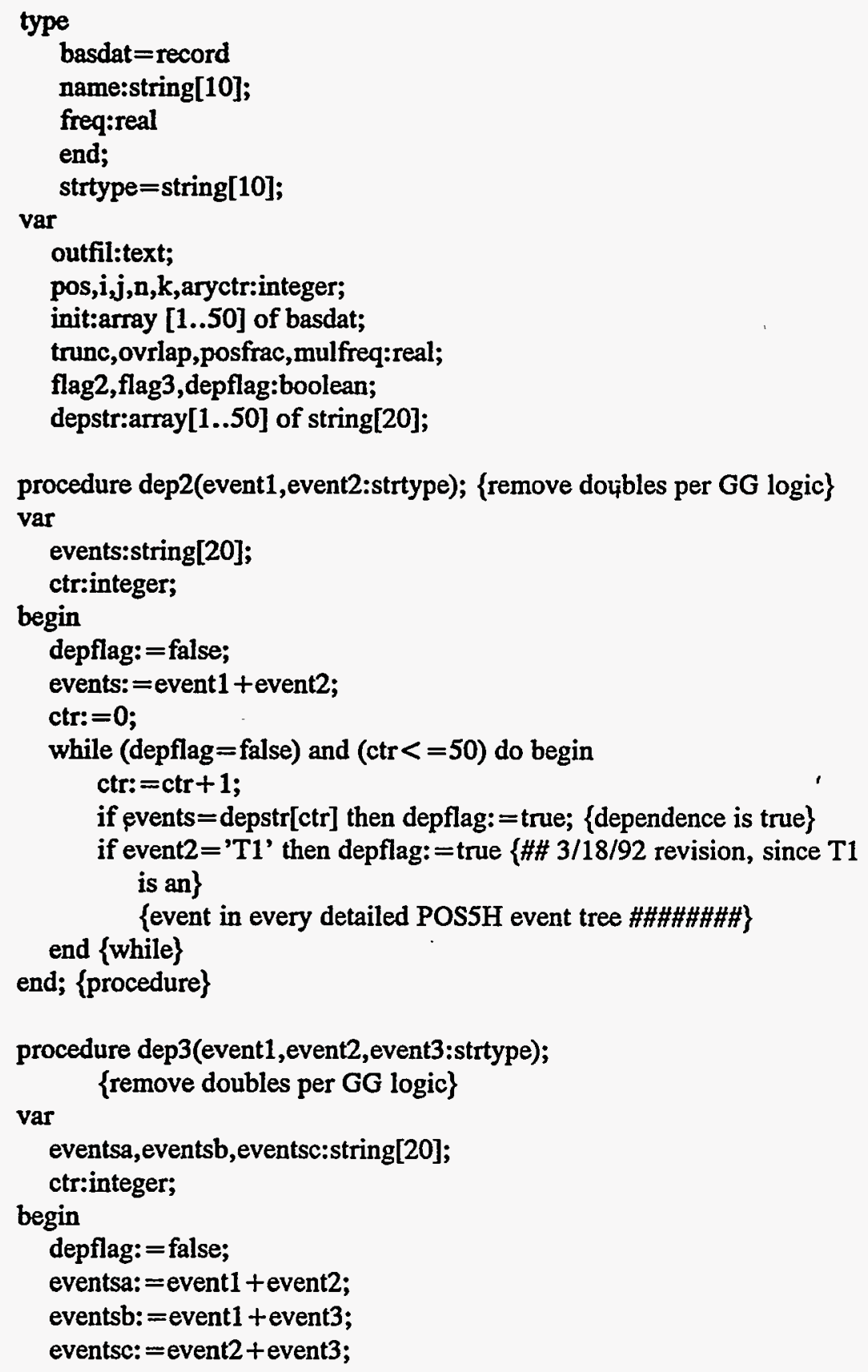


Table F.3.1 MULINIT.PAS Source Code (Continued)

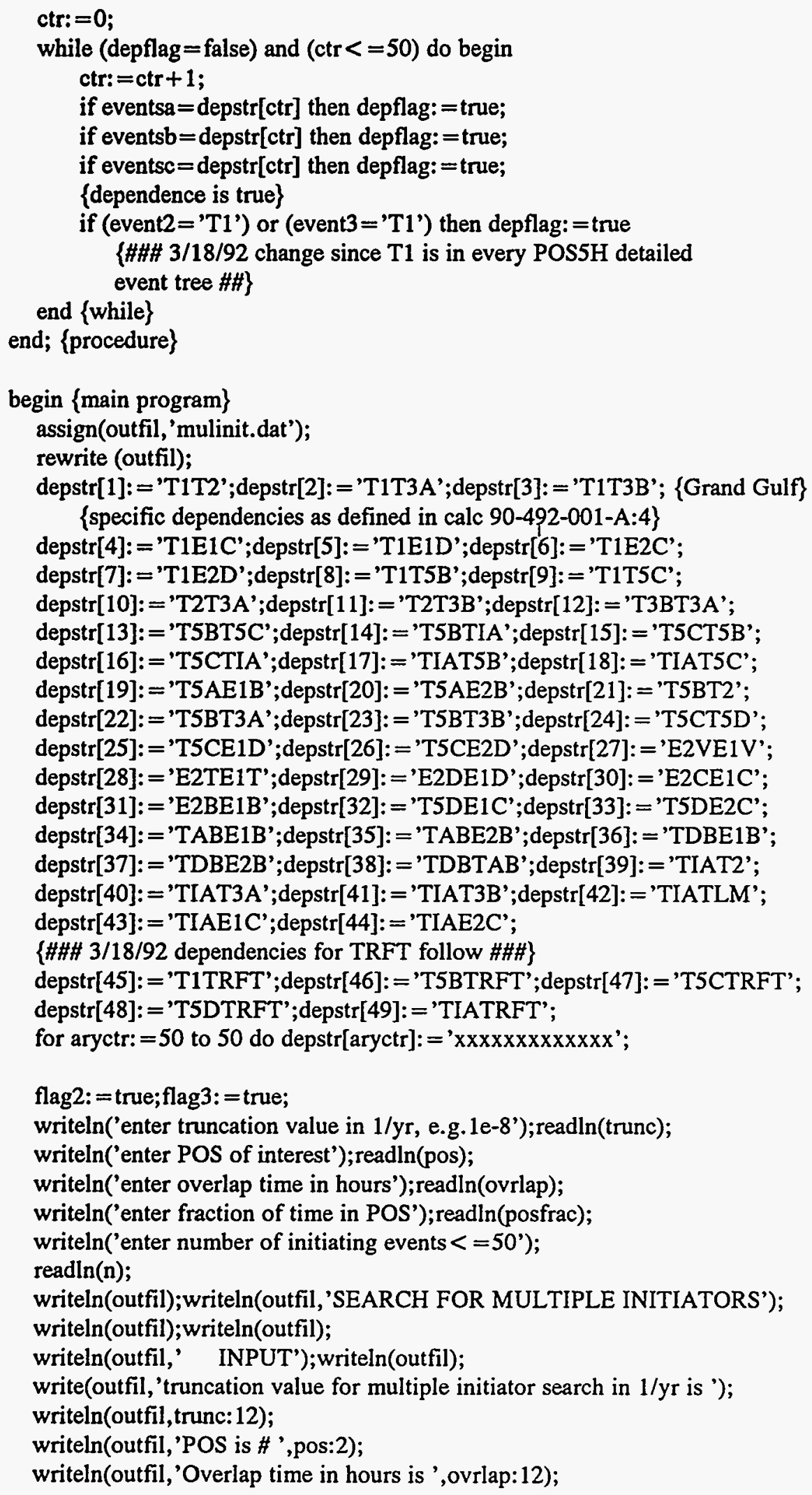


Table F.3.1 MULINIT.PAS Source Code (Continued)

writeln(outfil, 'Fraction of time spent in POS is ',posfrac: 12);

writeln(outfil,' Number of initiating events examined is ', $n: 3$ );

writeln(outfil);

for $\mathrm{i}:=1$ to $\mathrm{n}$ do begin \{input\}

with init[i] do begin

writeln('for initiator no. ',i:2,' enter name up to 10 characters');

readln(name);

writeln(' enter its freq in 1/yr');readln(freq); writeln;

writeln(outfil, name,' has freq $1 / \mathrm{yr}$ of ',freq:12);

end; \{with\}

end; $\{i$ loop\} \{end input

writeln(outfil); writeln(outfil);

writeln(outfil,' OUTPUT'); writeln(outfil);

write(outfil,'List of double and triple multiple initiators ');

writeln(outfil, 'with freq $>=$ ',trunc:12,' per yr,');

writeln(outfil,' using ',ovrlap:12,' hours as overlap time ,and weighted by');

writeln(outfil,posfrac:12, ,the fraction of time in the selected POS.');

writeln(outfil);

writeln(outfil,'DOUBLE INITIATORS'); writeln(outfil);

for $i:=1$ to $n$ do begin

for $j:=1$ to $n$ do begin

if $i<>j$ then begin

dep2(init[i].name, init[j].name); \{search for GG specific

dependencies\}

mulfreq: =init[i].freq*(1-exp(-init[j].freq*ovrlap/(24*365.25)));

$\{1 /(24 * 365.25) \mathrm{yr} / \mathrm{hr}\}$

mulfreq: =mulfreq*posfrac; \{weight by fraction of time in POS

if (mulfreq $>=$ trunc) and (depflag $=$ false) then begin

flag2: = false;

writeln(outfil,'freq in 1/yr of ',init[i].name,' and ',init[j].name,'

is');

writeln(outfil,mulfreq:12);writeln(outfil);

end \{if mulfreq\}

end $\{\mathrm{j}\}$

end $\{$ if $i<>j\}$

end; $\{i\}$

if flag2 $=$ true then

writeln(outfil,'NO DOUBLE INITIATORS ABOVE TRUNCATION VALUE');

writeln(outfil,'TRIPLE INITIATORS'); writeln(outfil);

for $\mathrm{i}:=1$ to $\mathrm{n}$ do begin

for $\mathrm{j}:=1$ to $\mathrm{n}$ do begin

for $k:=1$ to $n$ do begin

if $(i<>j)$ and $(i<>k)$ and $(j<>k)$ then begin

dep3(init[i].name, init[j].name, init[k].name); \{search for GG sepc. dep's\}

mulfreq: =init[i].freq*

(1-exp(-init[j].freq*ovrlap/(24*365.25)))*

(1-exp(-init[k].freq*ovrlap/(24*365.25)));

$\{1 /(24 * 365.25) \mathrm{yr} / \mathrm{hr}\}$

mulfreq: = mulfreq*posfrac; \{weight by fraction of time in POS 
Table F.3.1 MULINIT.PAS Source Code (Continued)

if (mulfreq $>=$ trunc) and (depflag $=$ false) then begin

flag3: = false;

write(outfil, 'freq in $1 / \mathrm{yr}$ of ',init[i].name,' and ',init[j].name);

writeln(outfil,' and ',init[k].name,' is');

writeln(outfil,mulfreq:12); writeln(outfil);

end \{if mulfreq\}

end $\{$ if $i<>j\}$

end $\{k\}$

end $\{j\}$

end; $\{i\}$

if flag3 $=$ true then

writeln(outfil,'NO TRIPLE INITIATORS ABOVE TRUNCATION

VALUE');

close(outfil);

end. 
Supporting Calculations

Table F.3.2 Multiple Initiating Events for POS 5

\section{SEARCH FOR MULTIPLE INITIATORS}

\section{INPUT}

truncation value for multiple initiator search in $1 / \mathrm{yr}$ is 1.00000E-08

POS is \# 5

Overlap time in hours is $2.40000 \mathrm{E}+01$

Fraction of time spent in POS is $3.10000 \mathrm{E}-02$

Number of initiating events examined is 34

T1 has freq $1 / \mathrm{yr}$ of $1.30000 \mathrm{E}-01$

A has freq $1 / \mathrm{yr}$ of $3.62000 \mathrm{E}-05$

A5HY has freq $1 / y r$ of $1.25000 \mathrm{E}-04$

S1 has freq $1 / \mathrm{yr}$ of $3.62000 \mathrm{E}-05$

$\mathrm{S} 1 \mathrm{H}$ has freq $1 / \mathrm{yr}$ of $1.25000 \mathrm{E}-04$

$\mathrm{S} 2$ has freq $1 / \mathrm{yr}$ of $3.62000 \mathrm{E}-05$

S2H has freq $1 / \mathrm{yr}$ of $1.25000 \mathrm{E}-04$

S3 has freq $1 /$ yr of $3.62000 \mathrm{E}-05$

S3H has freq $1 / \mathrm{yr}$ of $1.25000 \mathrm{E}-04$

$\mathrm{H} 1$ has freq $1 / \mathrm{yr}$ of $6.10000 \mathrm{E}-02$

$\mathrm{J} 2$ has freq $1 / \mathrm{yr}$ of $1.56000 \mathrm{E}-02$

E1B has freq $1 / y r$ of $5.70000 \mathrm{E}-02$

$\mathrm{E} 1 \mathrm{C}$ has freq $1 / \mathrm{yr}$ of $1.57000 \mathrm{E}-03$

E1D has freq $1 / \mathrm{yr}$ of $5.70000 \mathrm{E}-02$

E1T has freq $1 / \mathrm{yr}$ of $3.56000 \mathrm{E}-01$

E1V has freq $1 / \mathrm{yr}$ of $3.56000 \mathrm{E}-01$

E2B has freq $1 / \mathrm{yr}$ of $6.50000 \mathrm{E}-02$

$\mathrm{E} 2 \mathrm{C}$ has freq $1 / \mathrm{yr}$ of $1.57000 \mathrm{E}-03$

E2D has freq $1 / \mathrm{yr}$ of $6.50000 \mathrm{E}-02$

E2T has freq $1 / \mathrm{yr}$ of $3.80000 \mathrm{E}-02$

E2V has freq $1 /$ yr of $3.80000 \mathrm{E}-02$

T5A has freq $1 / \mathrm{yr}$ of $2.40000 \mathrm{E}-02$

T5B has freq $1 / \mathrm{yr}$ of $2.40000 \mathrm{E}-02$

T5C has freq $1 / \mathrm{yr}$ of $2.40000 \mathrm{E}-02$

T5D has freq $1 / \mathrm{yr}$ of $2.40000 \mathrm{E}-02$

TAB has freq $1 / \mathrm{yr}$ of $1.66000 \mathrm{E}-03$

TDB has freq $1 /$ yr of $6.00000 \mathrm{E}-03$

TIA has freq $1 / \mathrm{yr}$ of $1.80000 \mathrm{E}-01$

TORV has freq $1 / \mathrm{yr}$ of $1.40000 \mathrm{E}-01$

TIOP has freq $1 / \mathrm{yr}$ of $1.57000 \mathrm{E}-03$

TIHP has freq $1 / \mathrm{yr}$ of $1.40000 \mathrm{E}-02$

TIOF has freq $1 / \mathrm{yr}$ of $2.20000 \mathrm{E}-02$

TRPT has freq $1 / \mathrm{yr}$ of $7.20000 \mathrm{E}-02$

TLM has freq $1 / \mathrm{yr}$ of $8.00000 \mathrm{E}-03$

OUTPUT
List of double and triple multiple initiators with freq $\checkmark 1.00000 \mathrm{E}-08$ per yr, using $2.40000 \mathrm{E}+01$ hours as overlap time, and weighted by $3.10000 \mathrm{E}-02$,the fraction of time in the selected POS.

\section{DOUBLE INITIATORS}

freq in $1 / \mathrm{yr}$ of $\mathrm{T} 1$ and $\mathrm{H} 1$ is $6.72990 \mathrm{E}-07$

freq in $1 / \mathrm{yr}$ of $\mathrm{T} 1$ and $\mathrm{J} 2$ is $1.72120 \mathrm{E}-07$

freq in $1 / y r$ of $\mathrm{T} 1$ and $\mathrm{E} 1 \mathrm{~B}$ is $6.28863 \mathrm{E}-07$

freq in $1 / y r$ of T1 and E1T is 3.92603E-06

freq in $1 / \mathrm{yr}$ of $\mathrm{T} 1$ and $\mathrm{E} 1 \mathrm{~V}$ is $3.92603 \mathrm{E}-06$

freq in $1 / y r$ of $\mathrm{T} 1$ and E2B is $7.17116 \mathrm{E}-07$

freq in $1 / \mathrm{yr}$ of $\mathrm{T} 1$ and E2T is 4.19253E-07

freq in $1 / \mathrm{yr}$ of $\mathrm{T} 1$ and $\mathrm{E} 2 \mathrm{~V}$ is $4.19253 \mathrm{E}-07$

freq in $1 / \mathrm{yr}$ of $\mathrm{T} 1$ and $\mathrm{T} 5 \mathrm{~A}$ is $2.64796 \mathrm{E}-07$

freq in $1 / \mathrm{yr}$ of T1 and T5D is $2.64796 \mathrm{E}-07$

freq in $1 / \mathrm{yr}$ of $\mathrm{T} 1$ and $\mathrm{TAB}$ is $1.83156 \mathrm{E}-08$

freq in $1 / \mathrm{yr}$ of $\mathrm{T} 1$ and TDB is $6.62007 \mathrm{E}-08$

freq in $1 / \mathrm{yr}$ of T1 and TIA is $1.98555 \mathrm{E}-06$

freq in $1 / \mathrm{yr}$ of $\mathrm{T} 1$ and TORV is $1.54440 \mathrm{E}-06$

freq in $1 / \mathrm{yr}$ of $\mathrm{T} 1$ and TIOP is $1.73226 \mathrm{E}-08$

freq in $1 / \mathrm{yr}$ of $\mathrm{T} 1$ and TIHP is $1.54467 \mathrm{E}-07$

freq in $1 / \mathrm{yr}$ of T1 and TIOF is 2.42731E-07

freq in $1 / y r$ of T1 and TRPT is 7.94336E-07

freq in $1 / y r$ of $T 1$ and TLM is $8.82673 \mathrm{E}-08$

freq in $1 / \mathrm{yr}$ of $\mathrm{H} 1$ and $\mathrm{J} 2$ is $8.07638 \mathrm{E}-08$

freq in $1 / \mathrm{yr}$ of $\mathrm{HI}$ and $\mathrm{E} 1 \mathrm{~B}$ is $2.95082 \mathrm{E}-07$ 
Table F.3.2 Multiple Initiating Events for POS 5 (Continued)

freq in 1/yr of $\mathrm{H} 1$ and E1D is $2.95082 \mathrm{E}-07$

freq in $1 /$ yr of $\mathrm{H} 1$ and $\mathrm{E} 1 \mathrm{~T}$ is $1.84221 \mathrm{E}-06$

freq in $1 / \mathrm{yr}$ of $\mathrm{H} 1$ and $\mathrm{E} 1 \mathrm{~V}$ is $1.84221 \mathrm{E}-06$

freq in $1 / y r$ of $\mathrm{H} 1$ and E2B is 3.36493E-07

freq in 1/yr of H1 and E2D is 3.36493E-07

freq in 1/yr of H1 and E2T is $1.96726 \mathrm{E}-07$

freq in $1 / \mathrm{yr}$ of $\mathrm{H} 1$ and $\mathrm{E} 2 \mathrm{~V}$ is $1.96726 \mathrm{E}-07$

freq in $1 / \mathrm{yr}$ of $\mathrm{H} 1$ and T5A is $1.24251 \mathrm{E}-07$

freq in $1 / \mathrm{yr}$ of $\mathrm{H} 1$ and T5B is $1.24251 \mathrm{E}-07$

freq in 1/yr of H1 and T5C is $1.24251 \mathrm{E}-07$

freq in $1 / \mathrm{yr}$ of $\mathrm{H1}$ and TSD is $1.24251 \mathrm{E}-07$

freq in 1/yr of H1 and TDB is 3.10634E-08

freq in $1 / \mathrm{yr}$ of $\mathrm{H} 1$ and TIA is $9.31680 \mathrm{E}-07$

freq in $1 / \mathrm{yr}$ of $\mathrm{H} 1$ and TORV is $7.24680 \mathrm{E}-07$

freq in $1 / \mathrm{yr}$ of $\mathrm{H} 1$ and TIHP is $7.24805 \mathrm{E}-08$

freq in $1 / \mathrm{yr}$ of $\mathrm{H} 1$ and TIOF is 1.13897E-07

freq in $1 / \mathrm{yr}$ of $\mathrm{H} 1$ and TRPT is 3.72727E-07

freq in $1 / \mathrm{yr}$ of $\mathrm{H1}$ and TLM is $4.14178 \mathrm{E}-08$

freq in $1 / \mathrm{yr}$ of $\mathrm{J} 2$ and $\mathrm{H} 1$ is $8.07588 \mathrm{E}-08$

freq in $1 / \mathrm{yr}$ of $\mathrm{J} 2$ and E1B is $7.54635 \mathrm{E}-08$

freq in $1 / \mathrm{yr}$ of $\mathrm{J} 2$ and E1D is 7.54635E-08

freq in $1 / \mathrm{yr}$ of $\mathrm{J} 2$ and $\mathrm{E} 1 \mathrm{~T}$ is $4.71123 \mathrm{E}-07$

freq in $1 / \mathrm{yr}$ of $\mathrm{J} 2$ and $\mathrm{E} 1 \mathrm{~V}$ is 4.71123E-07

freq in $1 / \mathrm{yr}$ of $\mathrm{J} 2$ and E2B is $8.60539 \mathrm{E}-08$

freq in $1 / \mathrm{yr}$ of $\mathrm{J} 2$ and $\mathrm{E} 2 \mathrm{D}$ is $8.60539 \mathrm{E}-08$

freq in 1/yr of $\mathrm{J} 2$ and E2T is 5.03103E-08

freq in $1 / \mathrm{yr}$ of $\mathrm{J} 2$ and $\mathrm{E} 2 \mathrm{~V}$ is $5.03103 \mathrm{E}-08$

Vol. 2, Part 2 freq in $1 / \mathrm{yr}$ of $\mathrm{J} 2$ and T5A is 3.17755E-08

freq in $1 / \mathrm{yr}$ of $\mathrm{J} 2$ and $\mathrm{T} 5 \mathrm{~B}$ is $3.17755 \mathrm{E}-08$

freq in $1 / \mathrm{yr}$ of $\mathrm{J} 2$ and $\mathrm{T} 5 \mathrm{C}$ is $3.17755 \mathrm{E}-08$

freq in $1 / \mathrm{yr}$ of $\mathrm{J} 2$ and T5D is $3.17755 \mathrm{E}-08$

freq in $1 / \mathrm{yr}$ of $\mathrm{J} 2$ and TIA is $2.38266 \mathrm{E}-07$

freq in $1 / \mathrm{yr}$ of $\mathrm{J} 2$ and TORV is $1.85328 \mathrm{E}-07$

freq in $1 / \mathrm{yr}$ of $\mathrm{J} 2$ and TIHP is $1.85360 \mathrm{E}-08$

freq in $1 / \mathrm{yr}$ of $\mathrm{J} 2$ and TIOF is $2.91277 \mathrm{E}-08$

freq in $1 / \mathrm{yr}$ of $\mathrm{J} 2$ and TRPT is $9.53204 \mathrm{E}-08$

freq in $1 / \mathrm{yr}$ of $\mathrm{J} 2$ and TLM is $1.05921 \mathrm{E}-08$

freq in $1 / \mathrm{yr}$ of E1B and $\mathrm{H} 1$ is $2.95080 \mathrm{E}-07$

freq in $1 / \mathrm{yr}$ of $\mathrm{E} 1 \mathrm{~B}$ and $\mathrm{J} 2$ is $7.54678 \mathrm{E}-08$

freq in $1 / y r$ of E1B and E1D is 2.75732E-07

freq in $1 / y r$ of E1B and E1T is 1.72141E-06

freq in $1 / y r$ of E1B and E1V is 1.72141E-06

freq in $1 / \mathrm{yr}$ of E1B and E2B is 3.14428E-07

freq in $1 / \mathrm{yr}$ of E1B and E2D is 3.14428E-07

freq in $1 / y r$ of E1B and E2T is $1.83826 \mathrm{E}-07$

freq in $1 / \mathrm{yr}$ of E1B and E2V is $1.83826 \mathrm{E}-07$

freq in $1 / y r$ of E1B and T5A is 1.16103E-07

freq in 1/yr of E1B and T5B is 1.16103E-07

freq in $1 / y r$ of E1B and T5C is $1.16103 E-07$

freq in 1/yr of E1B and T5D is 1.16103E-07

freq in $1 / y r$ of E1B and TDB is $2.90265 \mathrm{E}-08$

freq in $1 / y r$ of E1B and TIA is $8.70586 \mathrm{E}-07$

freq in $1 / \mathrm{yr}$ of E1B and TORV is $6.77160 \mathrm{E}-07$

freq in $1 / \mathrm{yr}$ of E1B and TIHP is 6.77277E-08 
Supporting Calculations

Table F.3.2 Multiple Initiating Events for POS 5 (Continued)

freq in $1 / y$ r of E1B and TIOF is $1.06428 \mathrm{E}-07$

freq in $1 / \mathrm{yr}$ of E1B and TRPT is $3.48286 \mathrm{E}-07$

freq in 1/yr of E1B and TLM is $3.87018 \mathrm{E}-08$

freq in $1 / y r$ of E1C and E1T is 4.74143E-08

freq in $1 / y r$ of E1C and E1V is 4.74143E-08

freq in 1/yr of E1C and TIA is 2.39793E-08

freq in $1 / y r$ of E1C and TORV is $1.86516 \mathrm{E}-08$

freq in $1 / y r$ of E1D and $H 1$ is $2.95080 E-07$

freq in $1 / \mathrm{yr}$ of E1D and $\mathrm{J} 2$ is $7.54678 \mathrm{E}-08$

freq in 1/yr of E1D and E1B is 2.75732E-07

freq in 1/yr of E1D and E1T is 1.72141E-06

freq in 1/yr of E1D and E1V is 1.72141E-06

frog in $1 / y r$ of E1D and E2B is 3.14428E-07

freq in 1/yr of E1D and E2D is 3.14428E-07

freq in 1/yr of E1D and E2T is $1.83826 \mathrm{E}-07$

freq in 1/yr of E1D and E2V is $1.83826 \mathrm{E}-07$

freq in 1/yr of E1D and T5A is 1.16103E-07

freq in 1/yr of E1D and T5B is 1.16103E-07

freq in 1/yr of E1D and T5C is 1.16103E-07

freq in $1 / \mathrm{yr}$ of E1D and TSD is $1.16103 \mathrm{E}-07$

freq in 1/yr of E1D and TDB is $2.90265 \mathrm{E}-08$

freq in $1 / \mathrm{yr}$ of E1D and TIA is $8.70586 \mathrm{E}-07$

freq in $1 / \mathrm{yr}$ of E1D and TORV is $6.77160 \mathrm{E}-07$

freq in $1 / \mathrm{yr}$ of E1D and TIHP is 6.77277E-08

freq in 1/yr of E1D and TIOF is $1.06428 \mathrm{E}-07$

freq in 1/yr of E1D and TRPT is 3.48286E-07

freq in 1/yr of E1D and TLM is 3.87018E-08 freq in $1 / \mathrm{yr}$ of E1T and $\mathrm{H} 1$ is $1.84296 \mathrm{E}-06$ freq in 1/yr of E1T and J2 is 4.71343E-07

freq in $1 / y r$ of E1T and E1B is $1.72212 \mathrm{E}-06$ freq in $1 / y r$ of E1T and E1C is $4.74373 \mathrm{E}-08$ freq in $1 / y r$ of E1T and E1D is 1.72212E-06 freq in 1/yr of E1T and E1V is 1.07513E-05 freq in $1 / y r$ of E1T and E2B is $1.96380 \mathrm{E}-06$ freq in $1 / y r$ of E1T and E2C is 4.74373E-08 freq in $1 / \mathrm{yr}$ of E1T and E2D is $1.96380 \mathrm{E}-06$ freq in $1 / y r$ of E1T and E2T is 1.14811E-06 freq in $1 / y r$ of E1T and E2V is 1.14811E-06 freq in $1 / \mathrm{yr}$ of $\mathrm{E} 1 \mathrm{~T}$ and T5A is $7.25134 \mathrm{E}-07$ freq in $1 / \mathrm{yr}$ of E1T and T5B is 7.25134E-07 freq in $1 / \mathrm{yr}$ of E1T and T5C is 7.25134E-07 freq in $1 / \mathrm{yr}$ of E1T and T5D is 7.25134E-07 freq in $1 / y r$ of E1T and TAB is $5.01567 \mathrm{E}-08$ freq in $1 / \mathrm{yr}$ of E1T and TDB is $1.81288 \mathrm{E}-07$ freq in $1 / \mathrm{yr}$ of E1T and TIA is $5.43735 \mathrm{E}-06$ freq in $1 / \mathrm{yr}$ of E1T and TORV is 4.22928E-06 freq in $1 / \mathrm{yr}$ of E1T and TIOP is 4.74373E-08 freq in $1 / \mathrm{yr}$ of E1T and TIHP is 4.23001E-07 freq in $1 / \mathrm{yr}$ of E1T and TIOF is $6.64708 \mathrm{E}-07$ freq in $1 / \mathrm{yr}$ of E1T and TRPT is $2.17526 \mathrm{E}-06$ freq in $1 / y r$ of E1T and TLM is 2.41717E-07 freq in $1 / \mathrm{yr}$ of $\mathrm{E} 1 \mathrm{~V}$ and $\mathrm{H} 1$ is $1.84296 \mathrm{E}-06$ freq in $1 / \mathrm{yr}$ of E1V and $\mathrm{J} 2$ is $4.71343 \mathrm{E}-07$ freq in $1 / y r$ of E1V and E1B is 1.72212E-06 
Table F.3.2 Multiple Initiating Events for POS 5 (Continued)

freq in $1 / y r$ of E1V and E1C is 4.74373E-08

freq in 1/yr of E1V and E1D is 1.72212E-06

freq in 1/yr of E1V and E1T is 1.07513E-05

freq in $1 / y r$ of E1V and E2B is $1.96380 E-06$

freq in $1 / y r$ of E1V and E2C is $4.74373 E-08$

freq in $1 / y r$ of E1V and E2D is $1.96380 \mathrm{E}-06$

freq in $1 / \mathrm{yr}$ of E1V and E2T is 1.14811 E-06

freq in $1 / y r$ of E1V and E2V is 1.14811E-06

freq in $1 / \mathrm{yr}$ of E1V and T5A is 7.25134E-07

freq in $1 / \mathrm{yr}$ of E1V and T5B is 7.25134E-07

freq in 1/yr of E1V and TSC is 7.25134E-07

freq in $1 / \mathrm{yr}$ of E1V and T5D is 7.25134E-07

freq in $1 / y r$ of $E 1 V$ and $T A B$ is 5.01567E-08

freq in $1 / \mathrm{yr}$ of $\mathrm{E} 1 \mathrm{~V}$ and TDB is $1.81288 \mathrm{E}-07$

freq in $1 / y r$ of EIV and TIA is 5.43735E-06

freq in $1 / \mathrm{yr}$ of EIV and TORV is 4.22928E-06

freq in $1 / \mathrm{yr}$ of E1V and TIOP is 4.74373E-08

freq in $1 / \mathrm{yr}$ of E1V and TIHP is 4.23001E-07

freq in $1 / y r$ of E1V and TIOF is $6.64708 \mathrm{E}-07$

freq in $1 / \mathrm{yr}$ of E1V and TRPT is $2.17526 \mathrm{E}-06$

freq in $1 / y r$ of E1V and TLM is 2.41717E-07

freq in $1 / \mathrm{yr}$ of E2B and $\mathrm{H} 1$ is 3.36495E-07

freq in $1 / y r$ of E2B and $J 2$ is $8.60598 \mathrm{E}-08$

freq in 1/yr of E2B and E1D is 3.14431E-07

freq in 1/yr of E2B and E1T is 1.96301E-06

freq in 1/yr of E2B and E1V is 1.96301E-06

freq in 1/yr of E2B and E2D is 3.58558E-07

Vol. 2, Part 2 freq in $1 / y r$ of E2B and E2T is $2.09626 \mathrm{E}-07$

freq in $1 / y r$ of E2B and E2V is 2.09626E-07

freq in $1 / y r$ of E2B and T5A is $1.32398 \mathrm{E}-07$

freq in $1 / \mathrm{yr}$ of E2B and T5B is $1.32398 \mathrm{E}-07$

freq in $1 / \mathrm{yr}$ of E2B and T5C is $1.32398 \mathrm{E}-07$

freq in $1 / \mathrm{yr}$ of E2B and T5D is $1.32398 \mathrm{E}-07$

freq in $1 / \mathrm{yr}$ of E2B and TDB is 3.31003E-08

freq in $1 / \mathrm{yr}$ of E2B and TIA is $9.92774 \mathrm{E}-07$

freq in $1 / \mathrm{yr}$ of E2B and TORV is $7.72200 \mathrm{E}-07$

freq in 1/yr of E2B and TIHP is 7.72333E-08

freq in $1 / \mathrm{yr}$ of E2B and TIOF is $1.21365 \mathrm{E}-07$

freq in $1 / y r$ of E2B and TRPT is 3.97168E-07

freq in $1 / \mathrm{yr}$ of E2B and TLM is 4.41337E-08

freq in $1 / \mathrm{yr}$ of E2C and E1T is $4.74143 \mathrm{E}-08$

freq in $1 / y r$ of E2C and E1V is 4.74143E-08

freq in 1/yr of E2C and TIA is 2.39793E-08

freq in $1 / \mathrm{yr}$ of E2C and TORV is $1.86516 \mathrm{E}-08$

freq in $1 / \mathrm{yr}$ of E2D and $\mathrm{H} 1$ is $3.36495 \mathrm{E}-07$

freq in $1 / \mathrm{yr}$ of E2D and J2 is 8.60598E-08

freq in $1 / y r$ of E2D and E1B is 3.14431E-07

freq in $1 / y r$ of E2D and E1T is $1.96301 \mathrm{E}-06$

freq in $1 / y r$ of E2D and E1V is 1.96301E-06

freq in $1 / y r$ of E2D and E2B is 3.58558E-07

freq in $1 / y r$ of E2D and E2T is 2.09626E-07

freq in $1 / \mathrm{yr}$ of E2D and E2V is 2.09626E-07

freq in $1 / \mathrm{yr}$ of E2D and T5A is $1.32398 \mathrm{E}-07$

freq in 1/yr of E2D and T5B is $1.32398 \mathrm{E}-07$ 
Supporting Calculations

Table F.3.2 Multiple Initiating Events for POS 5 (Continued)

freq in 1/yr of E2D and T5C is 1.32398E-07

freq in 1/yr of E2D and T5D is 1.32398E-07

freq in 1/yr of E2D and TDB is 3.31003E-08

freq in 1/yr of E2D and TIA is $9.92774 \mathrm{E}-07$

freq in $1 / y r$ of E2D and TORV is 7.72200E-07

freq in $1 / y r$ of E2D and TIHP is 7.72333E-08

freq in $1 / \mathrm{yr}$ of E2D and TIOF is $1.21365 \mathrm{E}-07$

freq in $1 / \mathrm{yr}$ of E2D and TRPT is $3.97168 \mathrm{E}-07$

freq in $1 / \mathrm{yr}$ of E2D and TLM is 4.41337E-08

freq in 1/yr of E2T and H1 is $1.96720 \mathrm{E}-07$

freq in $1 / \mathrm{yr}$ of E2T and J2 is $5.03119 \mathrm{E}-08$

freq in 1/yr of E2T and E1B is 1.83821E-07

freq in 1/yr of E2T and E1D is 1.83821E-07

freq in 1/yr of E2T and E1V is 1.14761E-06

freq in $1 / \mathrm{yr}$ of E2T and E2B is 2.09619E-07

freq in 1/yr of E2T and E2D is 2.09619E-07

freq in 1/yr of E2T and E2V is 1.22551E-07

freq in $1 / \mathrm{yr}$ of E2T and T5A is 7.74020E-08

freq in $1 / \mathrm{yr}$ of E2T and T5B is 7.74020E-08

freq in $1 / \mathrm{yr}$ of E2T and T5C is $7.74020 \mathrm{E}-08$

freq in $1 / \mathrm{yr}$ of E2T and T5D is 7.74020E-08

freq in $1 / \mathrm{yr}$ of E2T and TDB is $1.93510 \mathrm{E}-08$

freq in 1/yr of E2T and TIA is 5.80391E-07

freq in $1 / \mathrm{yr}$ of E2T and TORV is $4.51440 \mathrm{E}-07$

freq in $1 / \mathrm{yr}$ of E2T and TIHP is 4.51518E-08

freq in $1 / y r$ of E2T and TIOF is 7.09520E-08

freq in 1/yr of E2T and TRPT is 2.32191E-07 freq in $1 / \mathrm{yr}$ of E2T and TLM is $2.58012 \mathrm{E}-08$

freq in $1 / \mathrm{yr}$ of E2V and $\mathrm{H} 1$ is $1.96720 \mathrm{E}-07$

freq in $1 / \mathrm{yr}$ of E2V and J2 is $5.03119 \mathrm{E}-08$

freq in $1 / \mathrm{yr}$ of E2V and E1B is $1.83821 \mathrm{E}-07$

freq in $1 / \mathrm{yr}$ of E2V and E1D is 1.83821E-07

freq in $1 / y r$ of E2V and E1T is 1.14761E-06

freq in $1 / y r$ of E2V and E2B is 2.09619E-07

freq in 1/yr of E2V and E2D is 2.09619E-07

freq in $1 / y r$ of E2V and E2T is 1.22551E-07

freq in $1 / \mathrm{yr}$ of E2V and T5A is $7.74020 \mathrm{E}-08$

freq in $1 / y r$ of E2V and T5B is 7.74020E-08

freq in $1 / \mathrm{yr}$ of E2V and T5C is 7.74020E-08

freq in $1 / y r$ of E2V and T5D is 7.74020E-08

freq in $1 / \mathrm{yr}$ of E2V and TDB is $1.93510 \mathrm{E}-08$

freq in 1/yr of E2V and TIA is 5.80391E-07

freq in $1 / y r$ of E2V and TORV is 4.51440E-07

freq in $1 / \mathrm{yr}$ of E2V and TIHP is $4.51518 \mathrm{E}-08$

freq in $1 / \mathrm{yr}$ of E2V and TIOF is $7.09520 \mathrm{E}-08$

freq in 1/yr of E2V and TRPT is 2.32191E-07

freq in $1 / y r$ of E2V and TLM is $2.58012 \mathrm{E}-08$

freq in $1 / \mathrm{yr}$ of T5A and $\mathrm{H} 1$ is $1.24244 \mathrm{E}-07$

freq in $1 / \mathrm{yr}$ of T5A and J2 is 3.17759E-08

freq in 1/yr of T5A and E1D is 1.16098E-07

freq in $1 / \mathrm{yr}$ of T5A and E1T is 7.24805E-07

freq in $1 / \mathrm{yr}$ of T5A and E1V is 7.24805E-07

freq in 1/yr of T5A and E2D is 1.32391E-07

freq in $1 / \mathrm{yr}$ of T5A and E2T is 7.74005E-08 
Table F.3.2 Multiple Initiating Events for POS 5 (Continued)

freq in $1 / y r$ of T5A and E2V is 7.74005E-08

freq in $1 / y r$ of T5A and T5B is $4.88855 \mathrm{E}-08$

freq in $1 / y r$ of T5A and T5C is $4.88855 \mathrm{E}-08$

freq in $1 / \mathrm{yr}$ of T5A and T5D is $4.88855 \mathrm{E}-08$

freq in $1 / \mathrm{yr}$ of T5A and TDB is $1.22217 \mathrm{E}-08$

freq in $1 / y r$ of T5A and TIA is $3.66563 \mathrm{E}-07$

freq in $1 / y r$ of T5A and TORV is $2.85120 \mathrm{E}-07$

freq in $1 / \mathrm{yr}$ of T5A and TIHP is $2.85169 \mathrm{E}-08$

freq in $1 / \mathrm{yr}$ of T5A and TIOF is $4.48118 \mathrm{E}-08$

freq in $1 / \mathrm{yr}$ of T5A and TRPT is $1.46647 \mathrm{E}-07$

freq in $1 / y r$ of T5A and TLM is $1.62955 \mathrm{E}-08$

freq in $1 / \mathrm{yr}$ of T5B and $\mathrm{H} 1$ is $1.24244 \mathrm{E}-07$

freq in $1 / \mathrm{yr}$ of T5B and $\mathrm{J} 2$ is $3.17759 \mathrm{E}-08$

freq in $1 / \mathrm{yr}$ of T5B and E1B is $1.16098 \mathrm{E}-07$

freq in 1/yr of T5B and E1D is 1.16098E-07

freq in 1/yr of T5B and E1T is 7.24805E-07

freq in $1 / \mathrm{yr}$ of T5B and E1V is 7.24805E-07

freq in 1/yr of T5B and E2B is 1.32391E-07

freq in 1/yr of T5B and E2D is 1.32391E-07

freq in 1/yr of T5B and E2T is 7.74005E-08

freq in 1/yr of T5B and E2V is 7.74005E-08

freq in $1 / \mathrm{yr}$ of T5B and T5A is $4.88855 \mathrm{E}-08$

freq in $1 / \mathrm{yr}$ of T5B and T5D is $4.88855 \mathrm{E}-08$

freq in $1 / y r$ of T5B and TDB is $1.22217 \mathrm{E}-08$

freq in $1 / y r$ of T5B and TORV is $2.85120 \mathrm{E}-07$

freq in $1 / \mathrm{yr}$ of T5B and TIHP is $2.85169 \mathrm{E}-08$

freq in $1 / \mathrm{yr}$ of T5B and TIOF is $4.48118 \mathrm{E}-08$

Vol. 2, Part 2 freq in $1 / \mathrm{yr}$ of T5B and TRPT is $1.46647 \mathrm{E}-07$

freq in $1 / \mathrm{yr}$ of T5B and TLM is $1.62955 \mathrm{E}-08$

freq in $1 / \mathrm{yr}$ of T5C and H1 is $1.24244 \mathrm{E}-07$

freq in $1 / \mathrm{yr}$ of T5C and $\mathrm{J} 2$ is $3.17759 \mathrm{E}-08$

freq in $1 / \mathrm{yr}$ of T5C and E1B is $1.16098 \mathrm{E}-07$

freq in $1 / \mathrm{yr}$ of T5C and E1T is 7.24805E-07

freq in $1 / \mathrm{yr}$ of T5C and E1V is $7.24805 \mathrm{E}-07$

freq in $1 / \mathrm{yr}$ of T5C and E2B is 1.32391E-07

freq in $1 / \mathrm{yr}$ of T5C and E2T is 7.74005E-08

freq in $1 / \mathrm{yr}$ of T5C and E2V is $7.74005 \mathrm{E}-08$

freq in $1 / \mathrm{yr}$ of T5C and T5A is $4.88855 \mathrm{E}-08$

freq in $1 / \mathrm{yr}$ of T5C and TDB is 1.22217E-08

freq in $1 / \mathrm{yr}$ of T5C and TORV is $2.85120 \mathrm{E}-07$

freq in $1 / y r$ of T5C and TIHP is $2.85169 \mathrm{E}-08$

freq in $1 / y r$ of T5C and TIOF is $4.48118 \mathrm{E}-08$

freq in $1 / \mathrm{yr}$ of T5C and TRPT is $1.46647 \mathrm{E}-07$

freq in $1 / \mathrm{yr}$ of T5C and TLM is $1.62955 \mathrm{E}-08$

freq in $1 / \mathrm{yr}$ of T5D and $\mathrm{H} 1$ is $1.24244 \mathrm{E}-07$

freq in $1 / \mathrm{yr}$ of T5D and $\mathrm{J} 2$ is $3.17759 \mathrm{E}-08$

freq in $1 / \mathrm{yr}$ of T5D and E1B is $1.16098 \mathrm{E}-07$

freq in $1 / y r$ of T5D and E1D is 1.16098E-07

freq in $1 / y r$ of T5D and E1T is $7.24805 E-07$

freq in $1 / \mathrm{yr}$ of T5D and E1V is 7.24805E-07

freq in $1 / \mathrm{yr}$ of T5D and E2B is 1.32391E-07

freq in $1 / y r$ of T5D and E2D is 1.32391E-07

freq in $1 / \mathrm{yr}$ of T5D and E2T is $7.74005 \mathrm{E}-08$

freq in $1 / \mathrm{yr}$ of T5D and E2V is 7.74005E-08 
Supporting Calculations

Table F.3.2 Multiple Initiating Events for POS 5 (Continued)

freq in $1 / y r$ of T5D and T5A is $4.88855 \mathrm{E}-08$

freq in 1/yr of T5D and T5B is 4.88855E-08

freq in $1 / \mathrm{yr}$ of T5D and T5C is $4.88855 \mathrm{E}-08$

freq in $1 / y r$ of T5D and TDB is $1.22217 \mathrm{E}-08$

freq in $1 / \mathrm{yr}$ of T5D and TIA is $3.66563 \mathrm{E}-07$

freq in $1 / \mathrm{yr}$ of T5D and TORV is $2.85120 \mathrm{E}-07$

freq in $1 / y r$ of T5D and TIHP is $2.85169 \mathrm{E}-08$

freq in $1 / y r$ of T5D and TIOF is $4.48118 \mathrm{E}-08$

freq in $1 / y r$ of T5D and TRPT is $1.46647 \mathrm{E}-07$

freq in $1 / y r$ of TSD and TLM is $1.62955 \mathrm{E}-08$

freq in $1 / y r$ of TAB and E1T is 5.01323E-08

freq in $1 / \mathrm{yr}$ of TAB and E1V is $5.01323 \mathrm{E}-08$

freq in $1 / \mathrm{yr}$ of TAB and TIA is $2.53539 \mathrm{E}-08$

freq in $1 / \mathrm{yr}$ of TAB and TORV is $1.97208 \mathrm{E}-08$

freq in $1 / \mathrm{yr}$ of TAB and TRPT is $1.01431 \mathrm{E}-08$

freq in $1 / \mathrm{yr}$ of TDB and $\mathrm{H} 1$ is $3.10611 \mathrm{E}-08$

freq in $1 / \mathrm{yr}$ of TDB and E1D is 2.90244E-08

freq in $1 / y r$ of TDB and E1T is 1.81201E-07

freq in $1 / \mathrm{yr}$ of TDB and E1V is $1.81201 \mathrm{E}-07$

freq in 1/yr of TDB and E2D is 3.30977E-08

freq in $1 / \mathrm{yr}$ of TDB and E2T is $1.93501 \mathrm{E}-08$

freq in 1/yr of TDB and E2V is 1.93501E-08

freq in $1 / \mathrm{yr}$ of TDB and T5A is $1.22214 \mathrm{E}-08$

freq in $1 / \mathrm{yr}$ of TDB and T5B is $1.22214 \mathrm{E}-08$

freq in $1 / \mathrm{yr}$ of TDB and T5C is $1.22214 \mathrm{E}-08$

freq in $1 / y r$ of TDB and T5D is $1.22214 \mathrm{E}-08$

freq in $1 / \mathrm{yr}$ of TDB and TIA is $9.16407 \mathrm{E}-08$ freq in $1 / \mathrm{yr}$ of TDB and TORV is 7.12800E-08

freq in $1 / \mathrm{yr}$ of TDB and TIOF is $1.12029 \mathrm{E}-08$

freq in $1 / y r$ of TDB and TRPT is 3.66617E-08

freq in $1 / \mathrm{yr}$ of TIA and H1 is 9.31832E-07

freq in $1 / \mathrm{yr}$ of TIA and $\mathrm{J} 2$ is $2.38319 \mathrm{E}-07$

freq in 1/yr of TIA and E1B is $8.70733 \mathrm{E}-07$

freq in $1 / y r$ of TIA and E1D is 8.70733E-07

freq in 1/yr of TIA and E1T is 5.43604E-06

freq in $1 / \mathrm{yr}$ of TIA and E1V is 5.43604E-06

freq in 1/yr of TIA and E2B is 9.92930E-07

freq in 1/yr of TIA and E2D is $9.92930 \mathrm{E}-07$

freq in $1 / \mathrm{yr}$ of TIA and E2T is 5.80504E-07

freq in 1/yr of TIA and E2V is 5.80504E-07

freq in $1 / \mathrm{yr}$ of TIA and T5A is $3.66641 \mathrm{E}-07$

freq in $1 / y r$ of TIA and TSD is 3.66641E-07

freq in $1 / y r$ of TIA and TAB is 2.53601E-08

freq in $1 / \mathrm{yr}$ of TIA and TDB is $9.16625 \mathrm{E}-08$

freq in $1 / \mathrm{yr}$ of TIA and TORV is $2.13840 \mathrm{E}-06$

freq in $1 / \mathrm{yr}$ of TIA and TIOP is $2.39852 \mathrm{E}-08$

freq in $1 / \mathrm{yr}$ of TIA and TIHP is $2.13877 \mathrm{E}-07$

freq in $1 / \mathrm{yr}$ of TIA and TIOF is $3.36088 \mathrm{E}-07$

freq in $1 / \mathrm{yr}$ of TIA and TRPT is $1.09985 \mathrm{E}-06$

freq in $1 / \mathrm{yr}$ of TORV and $\mathrm{H} 1$ is $7.24758 \mathrm{E}-07$

freq in $1 / \mathrm{yr}$ of TORV and $\mathrm{J} 2$ is $1.85359 \mathrm{E}-07$

freq in $1 / y r$ of TORV and E1B is 6.77237E-07

freq in $1 / y r$ of TORV and E1C is $1.86551 \mathrm{E}-08$

freq in $1 / \mathrm{yr}$ of TORV and E1D is $6.77237 \mathrm{E}-07$ 
Table F.3.2 Multiple Initiating Events for POS 5 (Continued)

freq in $1 / y r$ of TORV and E1T is 4.22803E-06

freq in $1 / y r$ of TORV and E1V is 4.22803E-06

freq in $1 / y r$ of TORV and E2B is $7.72279 \mathrm{E}-07$

freq in $1 / y r$ of TORV and E2C is $1.86551 \mathrm{E}-08$

freq in $1 / y r$ of TORV and E2D is 7.72279E-07

freq in $1 / y r$ of TORV and E2T is 4.51503E-07

freq in $1 / \mathrm{yr}$ of TORV and E2V is 4.51503E-07

freq in $1 / \mathrm{yr}$ of TORV and T5A is $2.85165 \mathrm{E}-07$

freq in $1 / \mathrm{yr}$ of TORV and T5B is $2.85165 \mathrm{E}-07$

freq in $1 / \mathrm{yr}$ of TORV and T5C is $2.85165 \mathrm{E}-07$

freq in $1 / y r$ of TORV and T5D is $2.85165 \mathrm{E}-07$

freq in $1 / y r$ of TORV and TAB is $1.97245 \mathrm{E}-08$

freq in $1 / y r$ of TORV and TDB is 7.12931E-08

freq in $1 / \mathrm{yr}$ of TORV and TIA is $2.13828 \mathrm{E}-06$

freq in $1 / y r$ of TORV and TIOP is $1.86551 \mathrm{E}-08$

freq in $1 / \mathrm{yr}$ of TORV and TIHP is $1.66349 \mathrm{E}-07$

freq in $1 / \mathrm{yr}$ of TORV and TIOF is 2.61402E-07

freq in $1 / y r$ of TORV and TRPT is $8.55439 \mathrm{E}-07$

freq in $1 / \mathrm{yr}$ of TORV and TLM is $9.50571 \mathrm{E}-08$

freq in 1/yr of TIOP and EIT is 4.74143E-08

freq in $1 / \mathrm{yr}$ of TIOP and EIV is 4.74143E-08

freq in $1 / \mathrm{yr}$ of TIOP and TIA is $2.39793 \mathrm{E}-08$

freq in $1 / \mathrm{yr}$ of TIOP and TORV is $1.86516 \mathrm{E}-08$

freq in $1 / \mathrm{yr}$ of TIHP and $\mathrm{H} 1$ is $7.24758 \mathrm{E}-08$

freq in $1 / \mathrm{yr}$ of TIHP and $\mathrm{J} 2$ is $1.85359 \mathrm{E}-08$

freq in $1 / y r$ of TIHP and E1B is $6.77237 \mathrm{E}-08$

freq in $1 / \mathrm{yr}$ of TIHP and E1D is 6.77237E-08

Vol. 2, Part 2 freq in $1 / \mathrm{yr}$ of TIHP and E1T is $4.22803 \mathrm{E}-07$

freq in $1 / \mathrm{yr}$ of TIHP and EIV is 4.22803E-07

freq in 1/yr of TIHP and E2B is 7.72279E-08

freq in $1 / \mathrm{yr}$ of TIHP and E2D is 7.72279E-08

freq in 1/yr of TIHP and E2T is 4.51503E-08

freq in $1 / \mathrm{yr}$ of TIHP and E2V is 4.51503E-08

freq in $1 / \mathrm{yr}$ of TIHP and T5A is $2.85165 \mathrm{E}-08$

freq in $1 / \mathrm{yr}$ of TIHP and T5B is $2.85165 \mathrm{E}-08$

freq in $1 / \mathrm{yr}$ of TIHP and T5C is $2.85165 \mathrm{E}-08$

freq in $1 / \mathrm{yr}$ of TIHP and T5D is $2.85165 \mathrm{E}-08$

freq in $1 / \mathrm{yr}$ of TIHP and TIA is $2.13828 \mathrm{E}-07$

freq in $1 / \mathrm{yr}$ of TIHP and TORV is $1.66320 \mathrm{E}-07$

freq in $1 / \mathrm{yr}$ of TIHP and TIOF is $2.61402 \mathrm{E}-08$

freq in $1 / \mathrm{yr}$ of TIHP and TRPT is $8.55439 \mathrm{E}-08$

freq in $1 / \mathrm{yr}$ of TIOF and $\mathrm{H} 1$ is $1.13891 \mathrm{E}-07$

freq in $1 / \mathrm{yr}$ of TIOF and J2 is $2.91279 \mathrm{E}-08$

freq in $1 / \mathrm{yr}$ of TIOF and E1B is $1.06423 \mathrm{E}-07$

freq in 1/yr of TIOF and E1D is 1.06423E-07

freq in $1 / \mathrm{yr}$ of TIOF and E1T is $6.64404 \mathrm{E}-07$

freq in 1/yr of TIOF and EIV is 6.64404E-07

freq in $1 / \mathrm{yr}$ of TIOF and E2B is $1.21358 \mathrm{E}-07$

freq in $1 / \mathrm{yr}$ of TIOF and E2D is $1.21358 \mathrm{E}-07$

freq in $1 / \mathrm{yr}$ of TIOF and E2T is $7.09505 \mathrm{E}-08$

freq in $1 / \mathrm{yr}$ of TIOF and E2V is $7.09505 \mathrm{E}-08$

freq in $1 / y r$ of TIOF and T5A is $4.48117 \mathrm{E}-08$

freq in $1 / y r$ of TIOF and T5B is $4.48117 \mathrm{E}-08$

freq in $1 / \mathrm{yr}$ of TIOF and T5C is $4.48117 \mathrm{E}-08$

F-19

NUREG/CR-6143 
Supporting Calculations

Table F.3.2 Multiple Initiating Events for POS 5 (Continued)

freq in $1 / y r$ of TIOF and T5D is 4.48117E-08

freq in $1 / \mathrm{yr}$ of TIOF and TDB is $1.12032 \mathrm{E}-08$

freq in $1 / \mathrm{yr}$ of TIOF and TIA is $3.36016 \mathrm{E}-07$

freq in $1 / y r$ of TIOF and TORV is $2.61360 \mathrm{E}-07$

freq in 1/yr of TIOF and TIHP is 2.61405E-08

freq in $1 / \mathrm{yr}$ of TIOF and TRPT is $1.34426 \mathrm{E}-07$

freq in $1 / \mathrm{yr}$ of TIOF and TLM is $1.49376 \mathrm{E}-08$

freq in 1/yr of TRPT and H1 is 3.72733E-07

freq in $1 / \mathrm{yr}$ of TRPT and J2 is $9.53277 \mathrm{E}-08$

freq in $1 / \mathrm{yr}$ of TRPT and E1B is 3.48293E-07

freq in 1/yr of TRPT and E1D is 3.48293E-07

freq in $1 / \mathrm{yr}$ of TRPT and E1T is 2.17441E-06

freq in $1 / \mathrm{yr}$ of TRPT and E1V is 2.17441E-06

freq in 1/yr of TRPT and E2B is 3.97172E-07

freq in 1/yr of TRPT and E2D is 3.97172E-07

freq in $1 / \mathrm{yr}$ of TRPT and E2T is $2.32201 \mathrm{E}-07$

freq in 1/yr of TRPT and E2V is 2.32201E-07

freq in $1 / \mathrm{yr}$ of TRPT and T5A is $1.46656 \mathrm{E}-07$

freq in $1 / \mathrm{yr}$ of TRPT and T5B is $1.46656 \mathrm{E}-07$

freq in $1 / \mathrm{yr}$ of TRPT and T5C is $1.46656 \mathrm{E}-07$

freq in $1 / \mathrm{yr}$ of TRPT and T5D is $1.46656 \mathrm{E}-07$

freq in $1 / \mathrm{yr}$ of TRPT and TAB is $1.01440 \mathrm{E}-08$

freq in $1 / y r$ of TRPT and TDB is $3.66650 \mathrm{E}-08$

freq in $1 / \mathrm{yr}$ of TRPT and TIA is $1.09969 \mathrm{E}-06$

freq in $1 / y r$ of TRPT and TORV is $8.55360 \mathrm{E}-07$

freq in $1 / \mathrm{yr}$ of TRPT and TIHP is $8.55507 \mathrm{E}-08$

freq in $1 / \mathrm{yr}$ of TRPT and TIOF is $1.34435 \mathrm{E}-07$ freq in $1 / \mathrm{yr}$ of TRPT and TLM is $4.88865 \mathrm{E}-08$

freq in 1/yr of TLM and H1 is 4.14147E-08

freq in $1 / \mathrm{yr}$ of TLM and J2 is $1.05920 \mathrm{E}-08$

freq in 1/yr of TLM and E1B is 3.86992E-08

freq in 1/yr of TLM and E1D is 3.86992E-08

freq in $1 / \mathrm{yr}$ of TLM and E1T is $2.41602 \mathrm{E}-07$

freq in $1 / \mathrm{yr}$ of TLM and E1V is $2.41602 \mathrm{E}-07$

freq in $1 / \mathrm{yr}$ of TLM and E2B is 4.41302E-08

freq in 1/yr of TLM and E2D is 4.41302E-08

freq in $1 / \mathrm{yr}$ of TLM and E2T is $2.58002 \mathrm{E}-08$

freq in $1 / y r$ of TLM and E2V is $2.58002 \mathrm{E}-08$

freq in $1 / \mathrm{yr}$ of TLM and T5A is $1.62952 \mathrm{E}-08$

freq in $1 / \mathrm{yr}$ of TLM and T5B is $1.62952 \mathrm{E}-08$

freq in $1 / y r$ of TLM and T5C is $1.62952 \mathrm{E}-08$

freq in $1 / \mathrm{yr}$ of TLM and T5D is $1.62952 \mathrm{E}-08$

freq in $1 / \mathrm{yr}$ of TLM and TIA is $1.22188 \mathrm{E}-07$

freq in $1 / y r$ of TLM and TORV is $9.50400 \mathrm{E}-08$

freq in $1 / y r$ of TLM and TIOF is 1.49373E-08

freq in $1 / y r$ of TLM and TRPT is $4.88822 \mathrm{E}-08$

TRIPLE INITIATORS

NO TRIPLE INITIATORS ABOVE TRUNCATION VALUE 


\section{F.4 Detailed Calculations}

Based on results of the scoping calculations as described in Section F.2 of this report, more detailed calculations were performed.

At shutdown, the normal methods for core cooling use the shutdown cooling system, either with RHR or with ADHR. The minimum design pressure for these systems is $220 \mathrm{psig}$ for RHR and 80 psig for ADHR. In POSs 4 and 5 the vessel head is on and pressurization transients can overpressurize these systems. We have taken the failure pressure of these systems as twice the design rating - namely, 440 psig for RHR and 160 psig for ADHR. Overpressurization of these systems leads to an interfacing systems LOCA outside containment. In POSs 4 and 5 these systems are auto-isolated at 135 psig, and they are auto-isolated at low level 3 . If the systems are isolated, shutdown cooling is lost, but the overpressurization is prevented.

To perform these calculations, a computer code was written. This code, GGENER.PAS, performs an energy balance on a system of saturated steam/water accounting for time dependent decay heat, addition of water, and blowdown of steam or flashing water. The code uses the following special case of the first law of thermodynamics for the energy balance:

$$
\int P(t) d t=\Delta U+\Delta H
$$

where $P(t)$ is the power (decay heat), $\Delta U$ is the change in internal energy of the water/steam in the vessel, and $\Delta \mathrm{H}$ is the net enthalpy lost from the vessel.

$$
\begin{gathered}
P(t)=\exp \left(-0.368 * \ln \left(t_{h x}\right)+0.593\right) \\
\Delta U=U_{f i n}-U_{i n i} \\
\Delta H=H_{\text {outof }}-H_{\text {into }}
\end{gathered}
$$

where $P(t)$ is the power in $\%$ of full power as a function of time in hours since shutdown $\left(t_{h r}\right), U_{f i n}^{\prime}$ is final internal energy, $U_{\text {int }}$ is initial internal energy, $\mathrm{H}_{\text {out or }}^{\text {fin }}$ is enthalpy out of the vessel, and $\mathrm{H}_{\text {into }}$ is enthalpy into the vessel.

$$
\begin{aligned}
& U_{f i n}=\left(1-x_{f i n}\right) * M_{f i n} * u_{w a t f i n}+x_{f i n} * M_{f i n} * u_{\text {stmfin }} \\
& U_{i n i}=\left(1-x_{i n i}\right) * M_{i n i} * u_{w a t i n i}+x_{i n i} * M_{i n i} * u_{s t m i n i} \\
& H_{\text {outof }}=\int \text { massout }(t) * h_{\text {outof }} d t \\
& H_{\text {into }}=\int \operatorname{massin}(t) * h_{\text {into }} d t
\end{aligned}
$$

$M$ denotes total fluid mass, $x$ denotes quality, $u$ denotes specific internal energy, subscript fin denotes final state, subscript ini denotes initial state, subscript wat denotes water, and subscript stm denotes vapor (steam). Massout and massin are time dependent mass flow rates out of and into the vessel, respectively. " $h$ " denotes specific enthalpy, subscript outof denotes mass out, and subscript into denotes mass in.

The source code is given as Table F.4-1. The code was modified and improved throughout the project. For example, the capability to handle time dependent decay heat was added, and the numerical fit to Moody's blowdown model was improved. Also, in the latest version, the code calculates actual and measured water levels, relative to instrument zero, accounting for changes in actual density of water at the calculated thermodynamic state. Calculation 90-492-01-A:19 contains the latest version of the code (that listed in Table F.4-1). Also, this calculation contains detailed results for the re-analysis of all earlier energy balances. The re-analysis results agreed with the original analysis results. However, levels were more accurately calculated in the re-analyzed results. The re-analysis was performed for the following calculations in the 90-492-01 series: $A: 6, A: 10, A: 11, A: 13$, and $A: 17$.

\section{F.4.1 Calculation \#11}

Calculation 90-492-01-A:11,: SDC Relief Valves POS 4 and $5^{\prime \prime}$, addressed whether or not relief valves in the RHR/SDC system could prevent overpressurization given heatup of the system due to loss of heat removal. The calculation concludes the following (including the effects of the re-analysis of calculation 19):

(1) For POS 4, $440 \mathrm{psig}$ is reached at $49 \mathrm{~min}$ even 


\title{
Table F.4.1 GGENER.PAS Source Code
}

\author{
\{J. Darby, SEA 7/22/92 Version\}
}

program ggblfil; \{modification of blowfil.pas code to include\}

$\{\$ N+\} \quad$ \{Grand Gulf time dependent decay heat\}

\{initial saturated state, blowdown sat water or sat steam via Moody\}

\{rom tank out to 15 psia sink; MAKEUP AT CONSTANT RATE and no work\}

\{case of two phase IN tank NOT modeled here\}

\{calculates final sat state, fixed volume,both initial and final\}

\{states must be sat >212 F, 15 psia\}

\{stops if tank has no water\}

\{limit polynomial fit of Moody's data to 5 points in dataset to \}

\{better fit high pressure data\}

\{change Moody steam mass flux from 500 to 600 for steam at 300 psia\}

\{7/15/92 add option for static head into driving pressure for $\}$

\{FLASHING water out the hole; no effect if steam out hole\}

\{7/22/92 use simple linear fit to Moody, add level indication\}

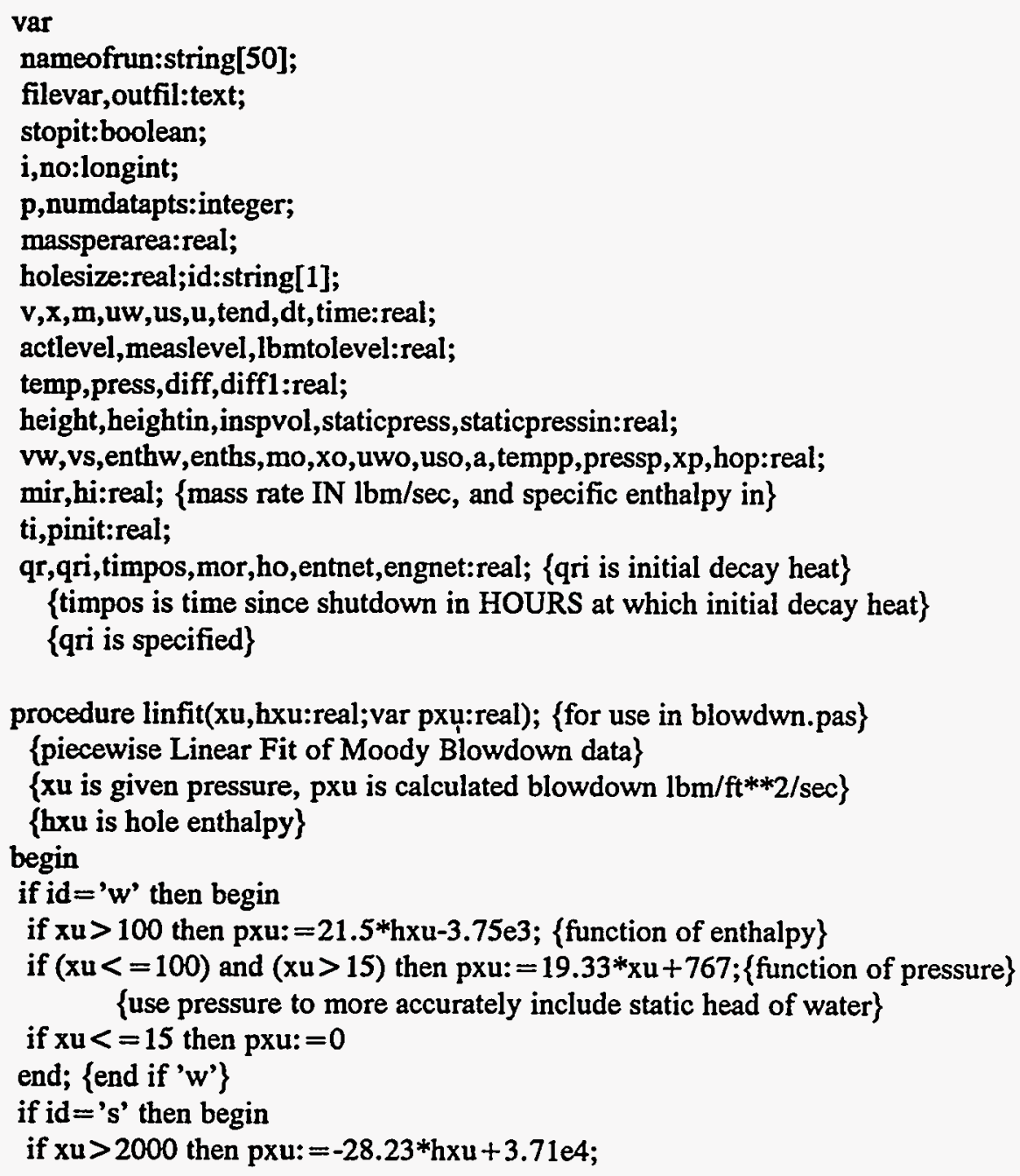


Table F.4.1 GGENER.PAS Source Code (Continued)

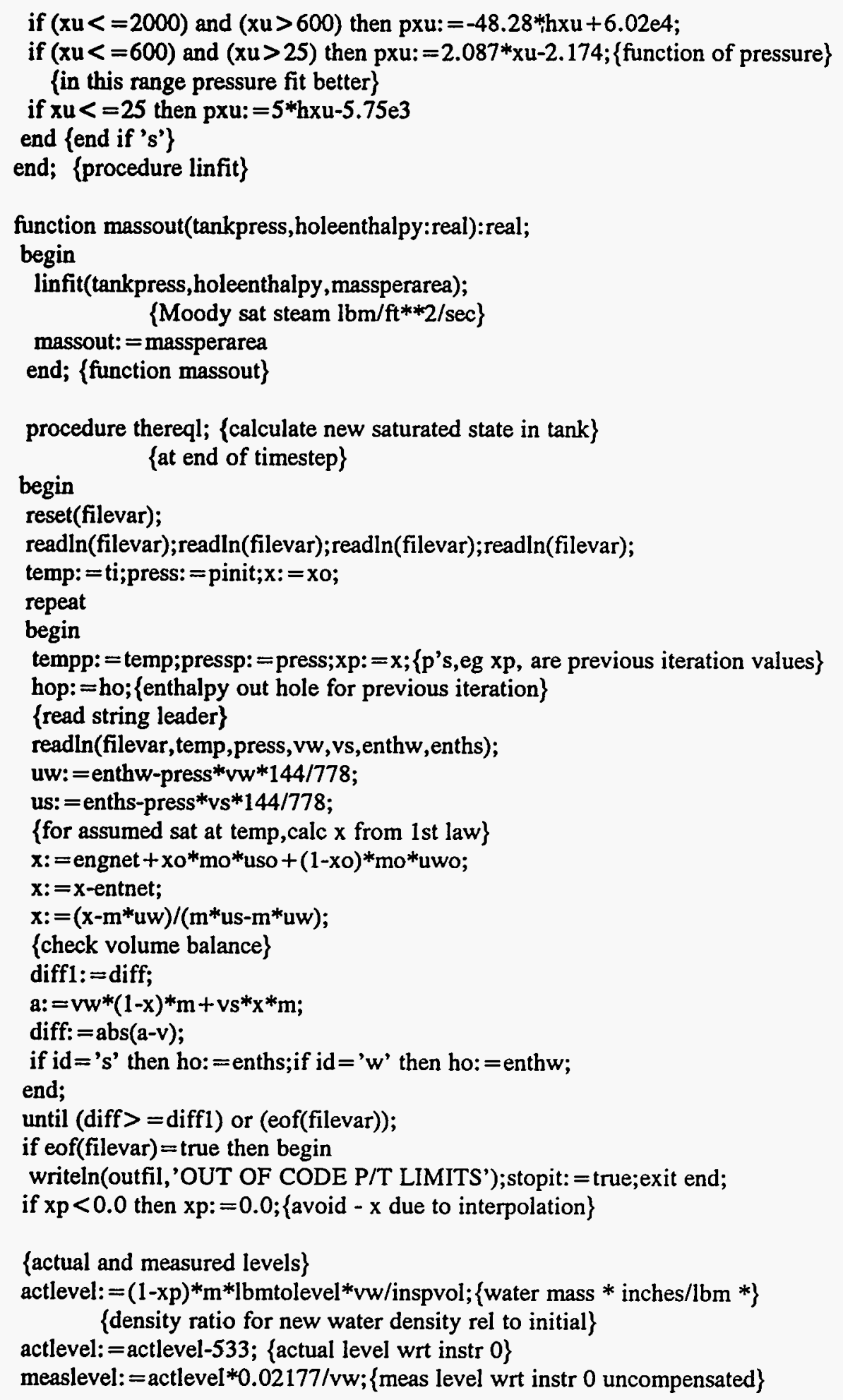

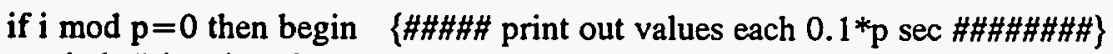
writeln('time is ',time: 12,' sec'); 
Table F.4.1 GGENER.PAS Source Code (Continued)

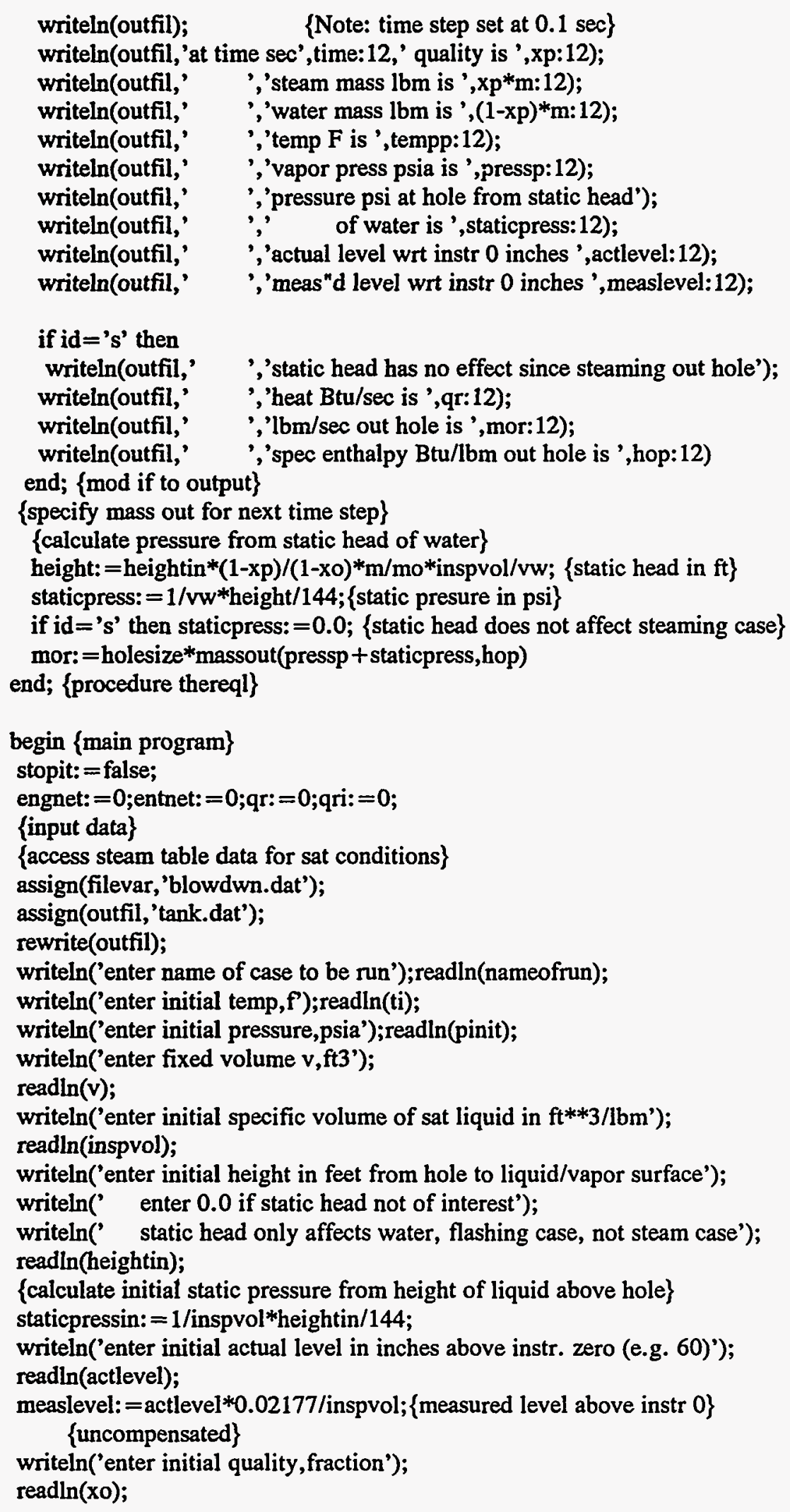


Table F.4.1 GGENER.PAS Source Code (Continued)

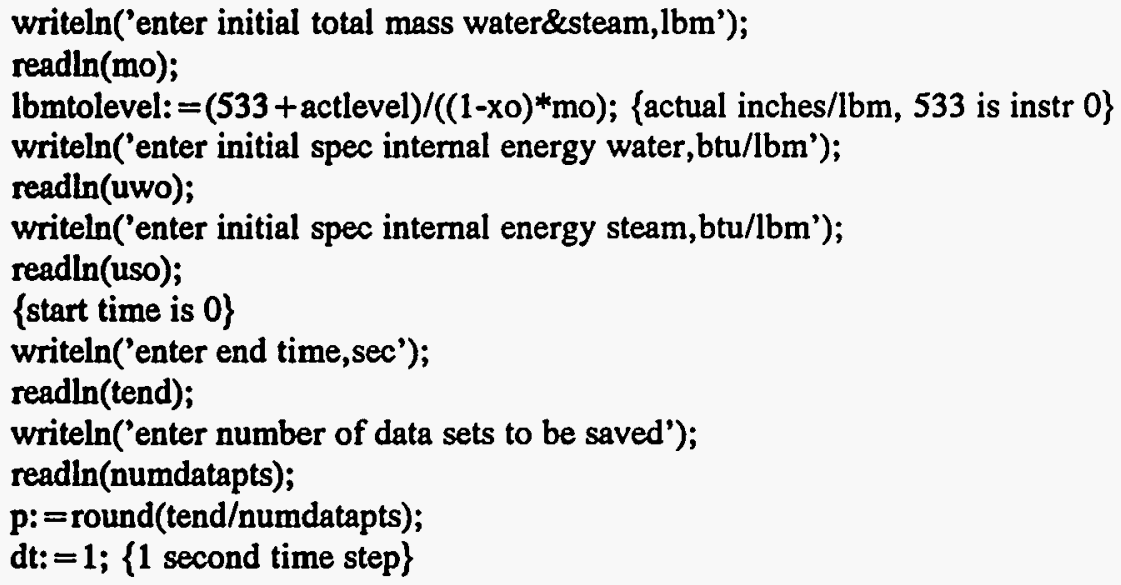


Table F.4.1 GGENER.PAS Source Code (Continued)

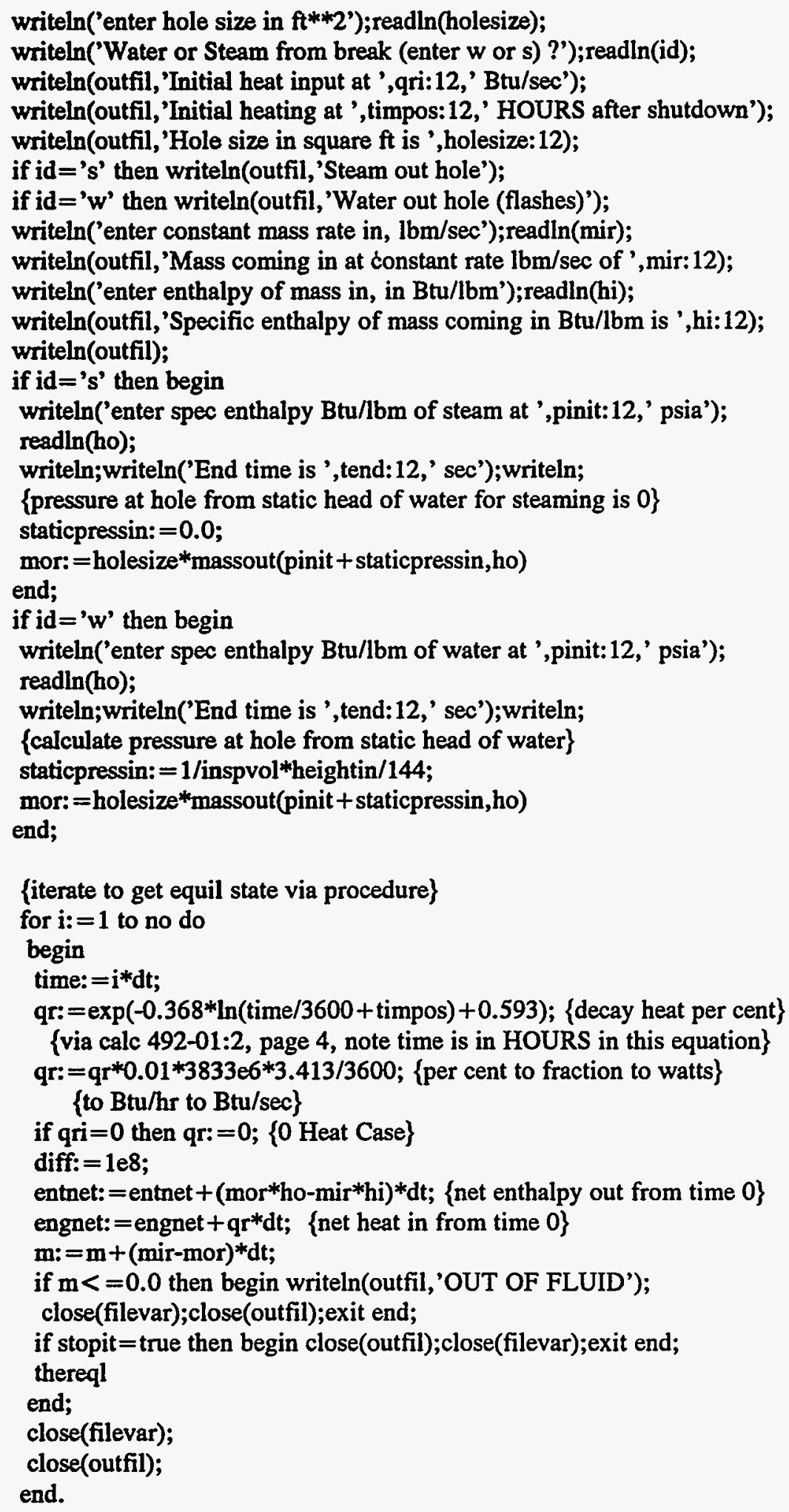


with relief from both RHR trains available,

(2) For POS 5, 440 psig is reached at $120 \mathrm{~min}$ even with relief from both RHR trains available,

(3) For ADHR with decay heat at 24 hours, 160 psig is reached at 113 min even with relief from both RHR trains available.

The relief capability is inadequate to prevent overpressurizing the components.

\section{F.4.2 Calculation \#4.1}

Calculation 90-492-01-A:4.1, "Relief Capabilities at Grand Gulf", was a more detailed evaluation of the ability of the SRVs to relieve pressure than performed in the earlier scoping calculation \# 3. This calculation addressed the following topics:

(1) Friction Factors for SRV Relief and the 2 Inch vent line

(2) Relief of Saturated Steam and 200 degree F Water from One SRV between 100 and 1400 psig

(3) Relief of Saturated Steam and 200 degree F Water from the Vent Line between 100 and 1400 psig

(4) Grand Gulf Steaming Rate:

(a) No Makeup

(b) Makeup with 100 degree $F$ Water to Maintain Level

(5) Vessel Pressure for Water through SRVs from: HPCS, LPCS, LPCI, and Combinations

(6) Steam Relief through 1 SRV to match $1 \%$ Decay Heat for the two cases of Item (4)

(7) Ability of the Vent Line to Match Decay Heat.

The calculated relief capacities for one SRV and for the vent line, for steam and water, are provided in Figures F.4-1 through F.4-4.

The steaming rate for Grand Gulf, with and without makeup, is given in Figure F.4-5 and F.4-6. The decay heat curve used to calculate these steaming rates is given in Figure F.4-7.
The vessel pressure for various combinations of ECCS injection and either 1 or 2 SRVs open is provided in Figure F.4-8 and F.4-9.

Steaming through 1 SRV will match $1 \%$ decay heat, without makeup, at 220 psig. With makeup, steaming can match $1 \%$ decay heat at 180 psig.

Steaming through the vent line is inadequate to prevent pressurization to SRV safety setpoints in POSs 4 and 5 with decay heat at $1 \%$ and $0.9 \%$, respectively. After a 30 day refueling outage, with decay heat at $0.16 \%$, steaming through the vent line can match decay heat only if pressure is $600 \mathrm{psig}$ (without makeup), or $400 \mathrm{psig}$ (with makeup).

\section{F.4.3 Calculation \#6}

Calculation 90-492-01-A:6, "SRVs for Small/Medium LOCAs in POS 4" evaluated the ability of breaks and SRVs to control pressure in POS 4. The re-analyses of calculation 19 agreed with the results of the original calculation, except that level was calculated to be higher due to swell.

The updated results are as follows. The calculation evaluated the need for opening an SRV in relief on POS 4 following a small LOCA ( $0.007 \mathrm{sq} \mathrm{ft})$ to prevent pressurization before ECCS is auto-actuated. Assuming a steam line break of $0.007 \mathrm{sq} \mathrm{ft}$, complete phase separation in the vessel, and complete mixing of core and downcomer water, the system pressure /measured water level history is as follows:

(a) 135 psig and +88 inches at 420 seconds

(b) 440 psig and +128 inches at 3220 seconds.

The high measured levels at these pressures are due to swell of the actual level with temperature. ECCS does not actuate until level 2, -41.6 inches measured, or level $1,-150.3$ inches measured. Thus, a small (or small, medium LOCA) will pressurize the system before ECCS injection is auto-initiated. A $0.007 \mathrm{sq} \mathrm{ft}$ water break was also analyzed, and the conclusions are the same as for the steam break as expected, since water breaks do not depressurize as effectively as steam breaks. This same calculation showed that if one SRV is opened for steam relief, even with a zero size LOCA, pressure never exceeds 135 psia before the level 1 ECCS actuation setpoint is reached. Thus, opening an SRV prevents significant pressurization of the system. [The difference 


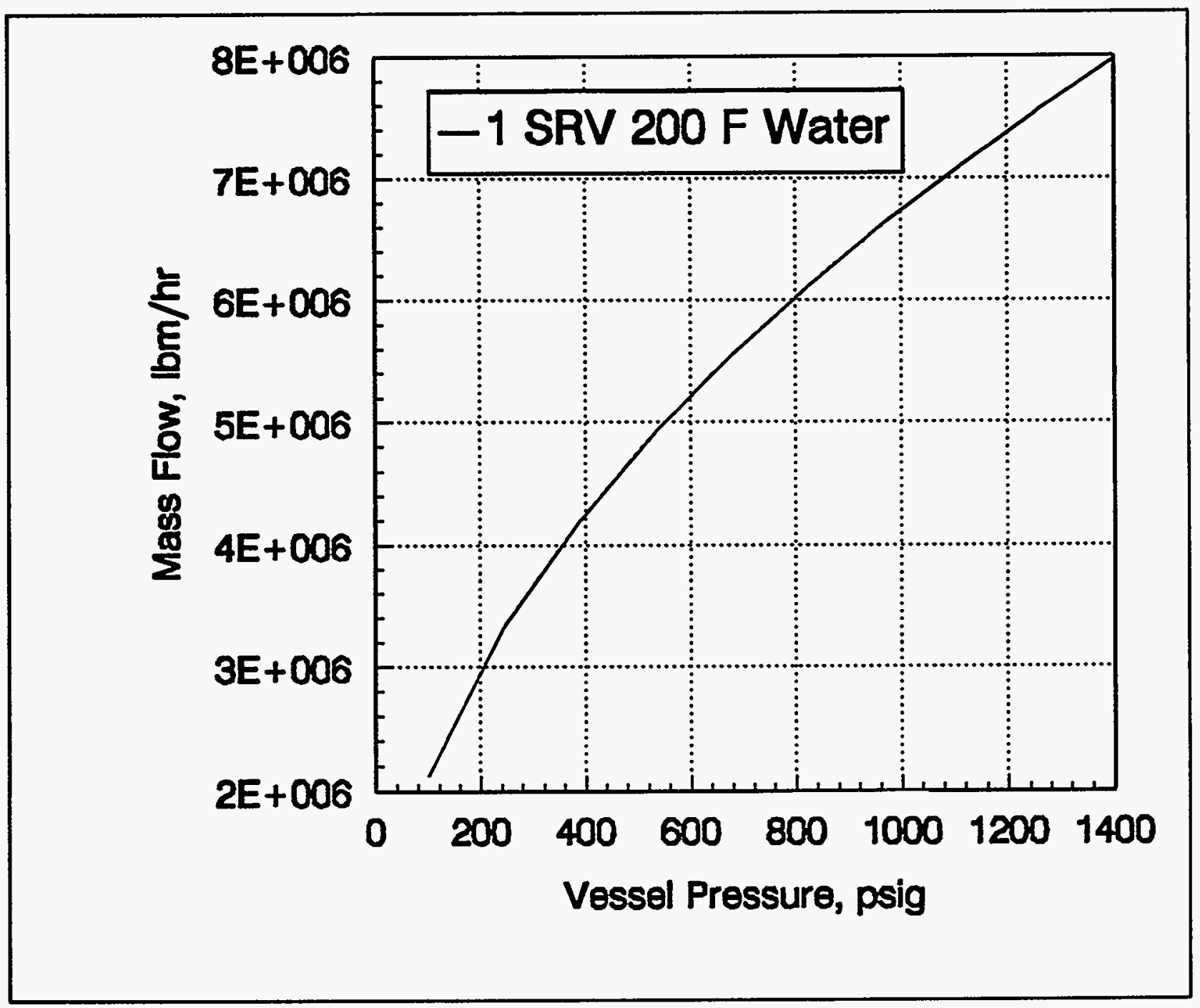

Figure F.4-1 1 SRV, Water 


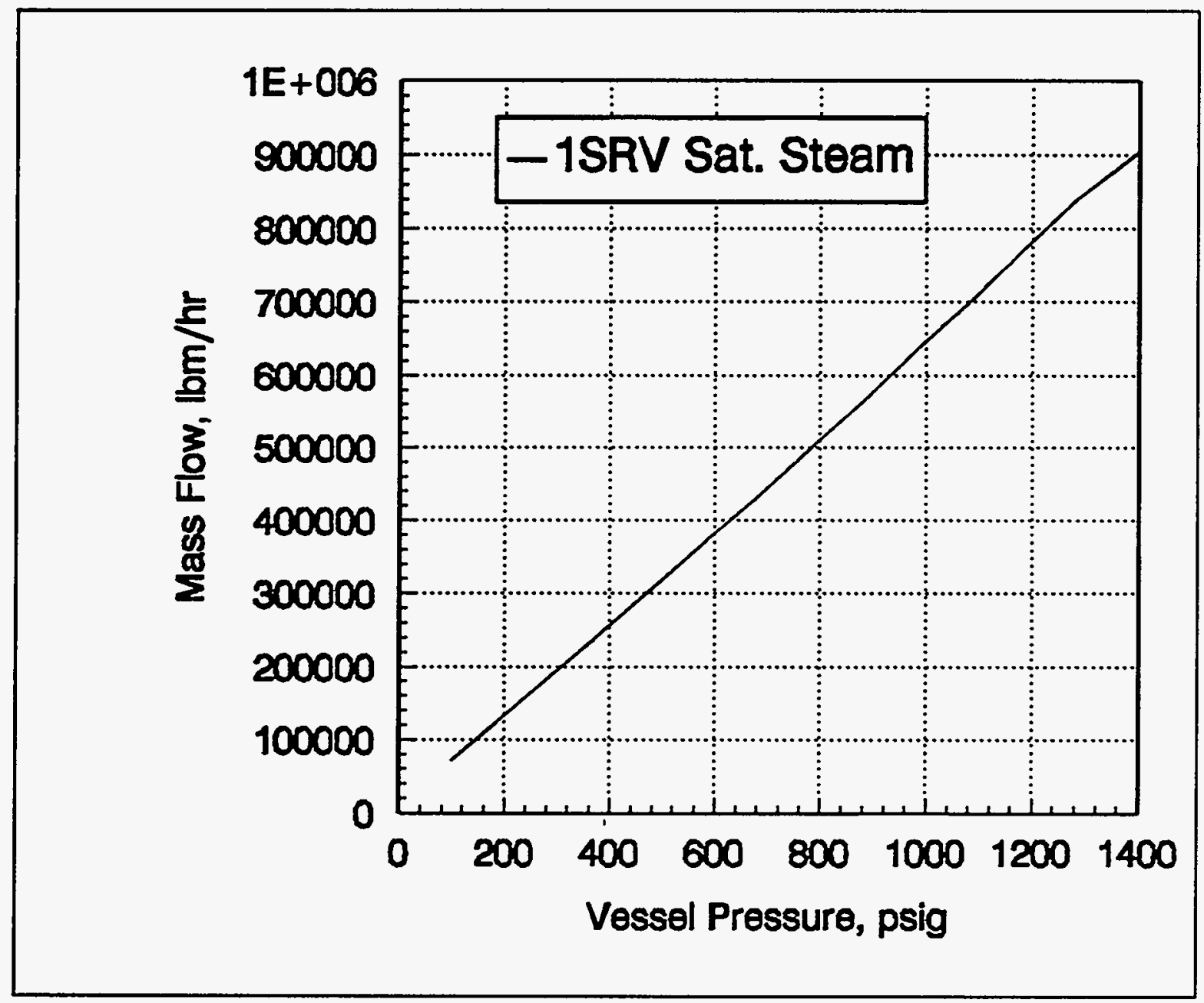

Figure F.4.2 1 SRV, Steam 


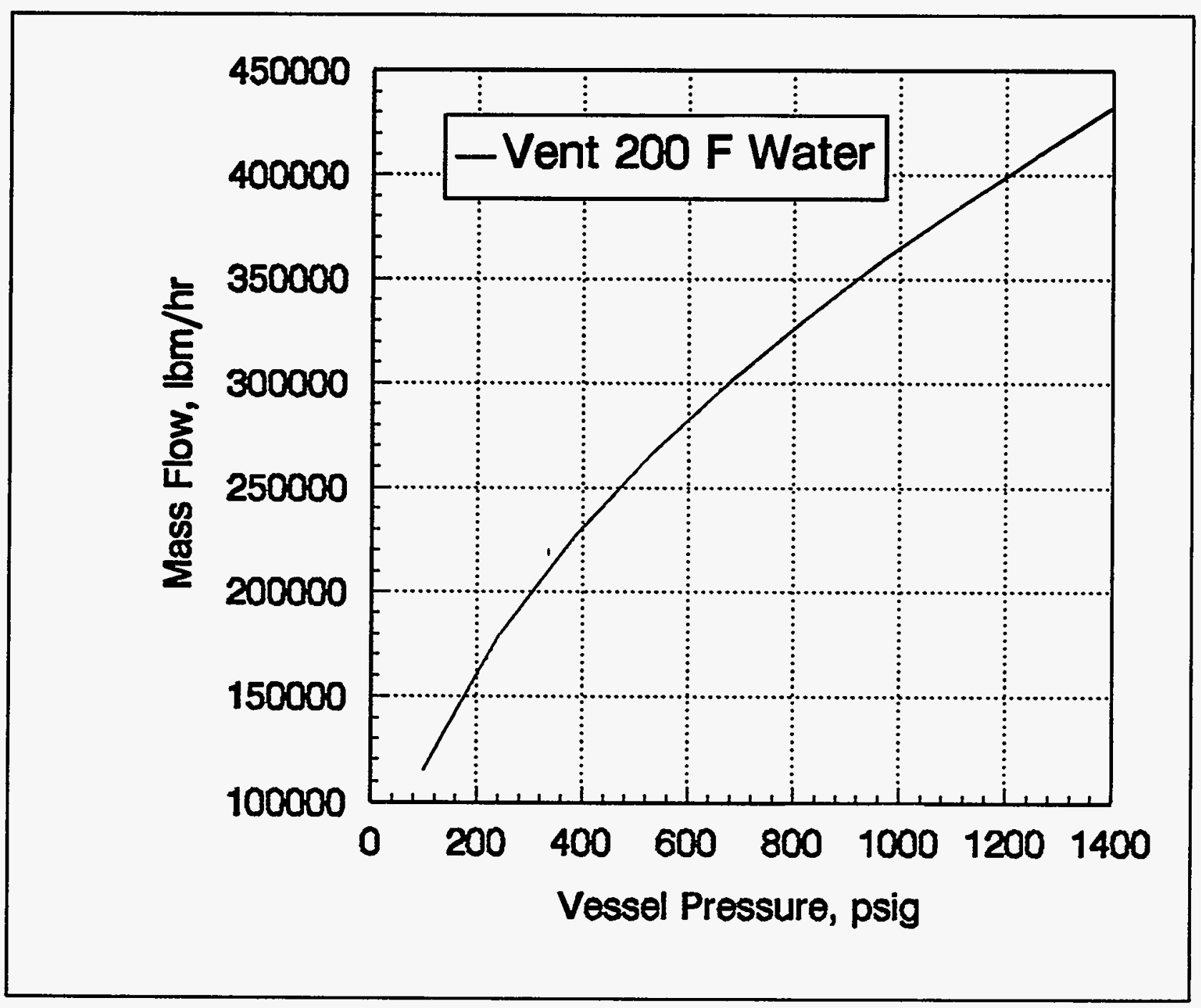

Figure F.4.3 Vent Line, Water 


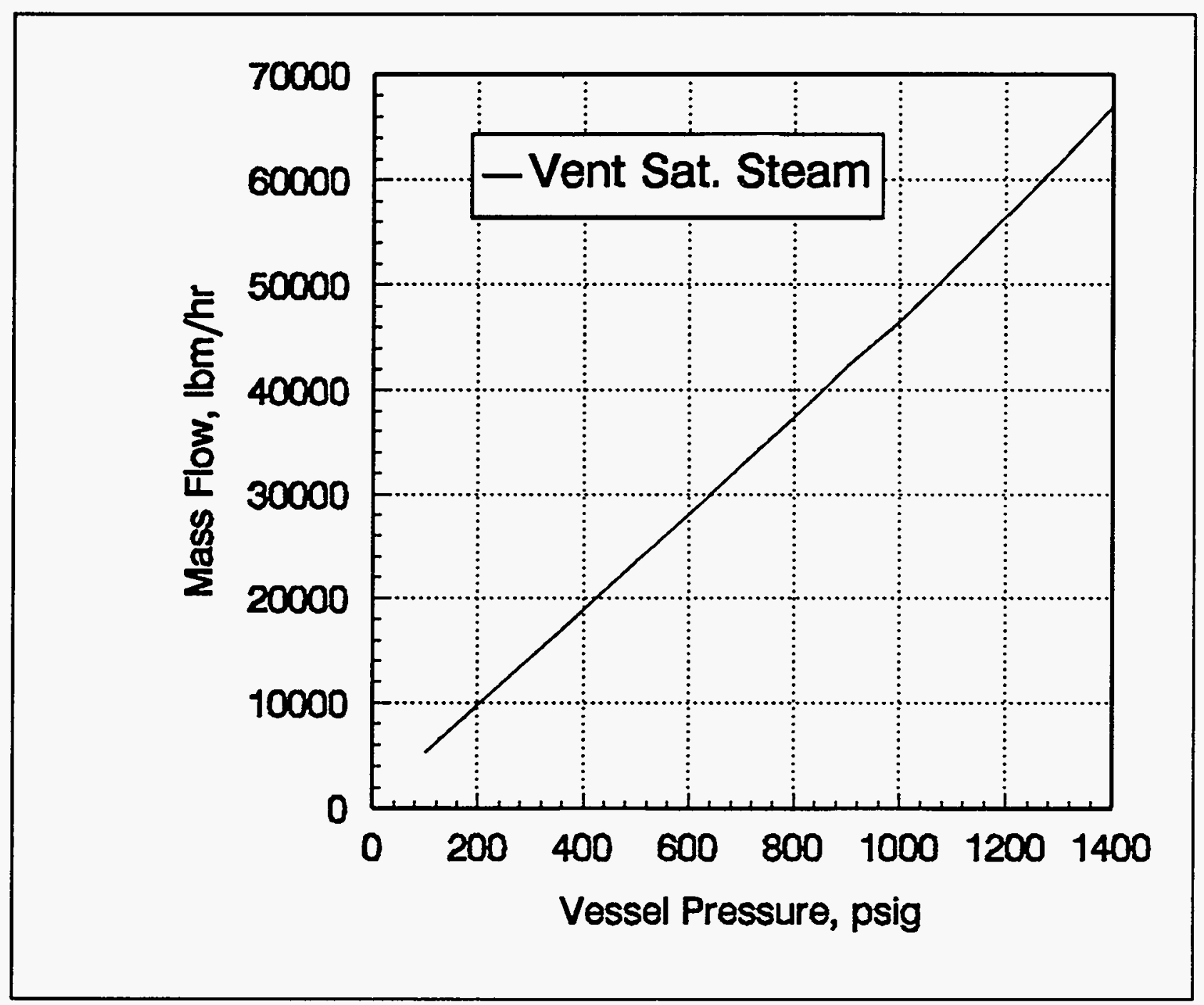

Figure F.4.4 Vent Line, Steam 


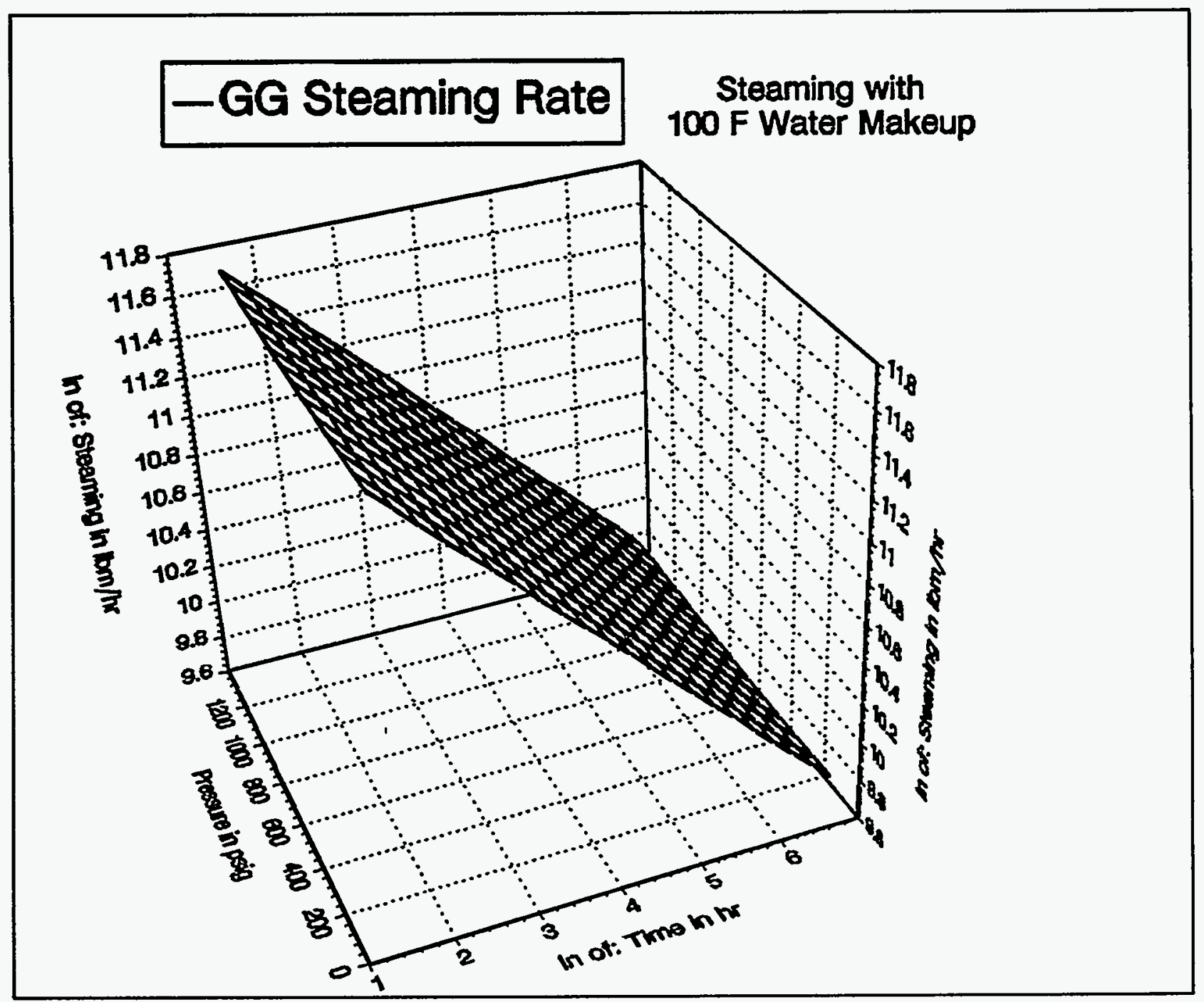

Figure F.4.5 Steaming with Makeup 


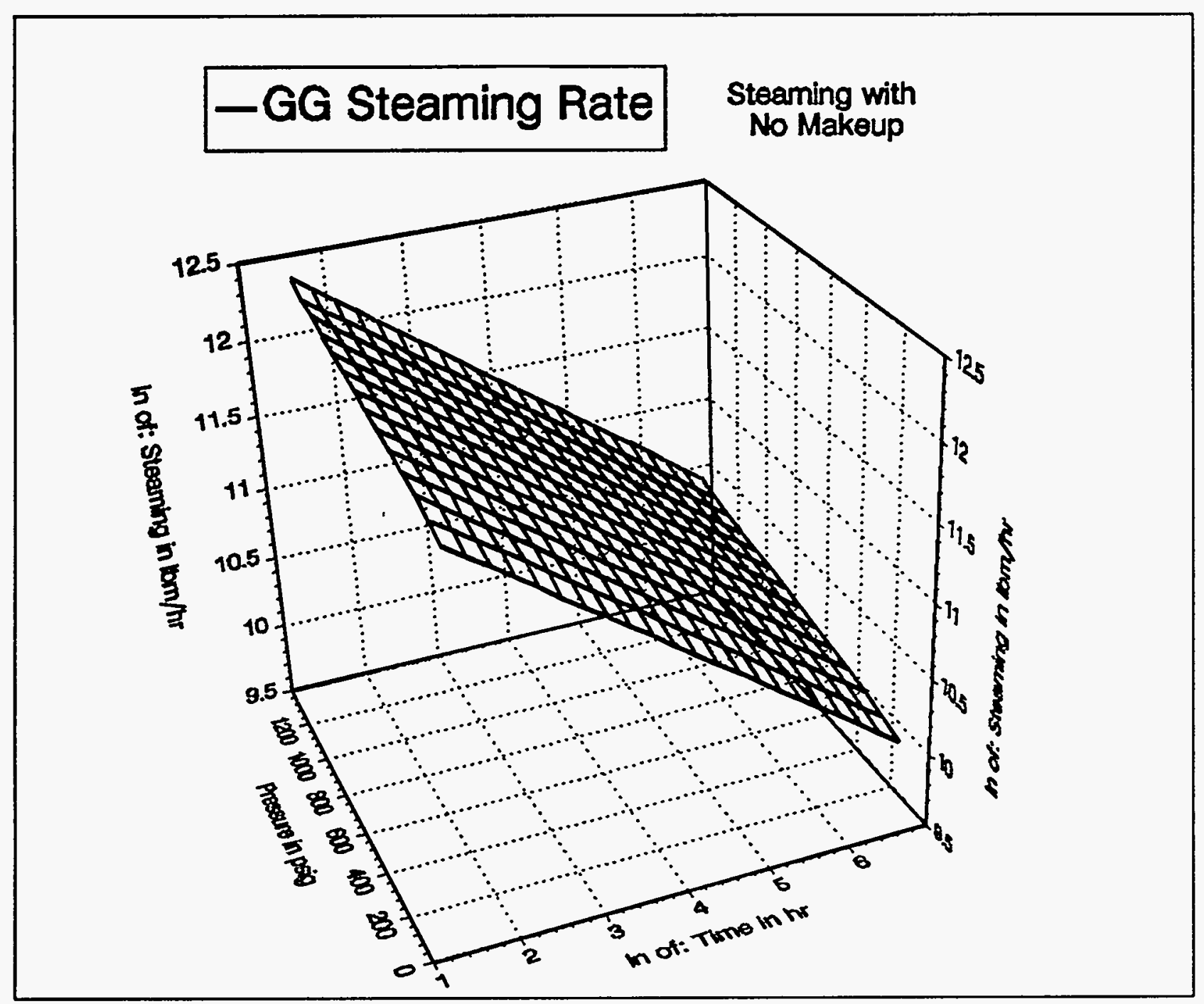

Figure F.4.6 Steaming with No Makeup 


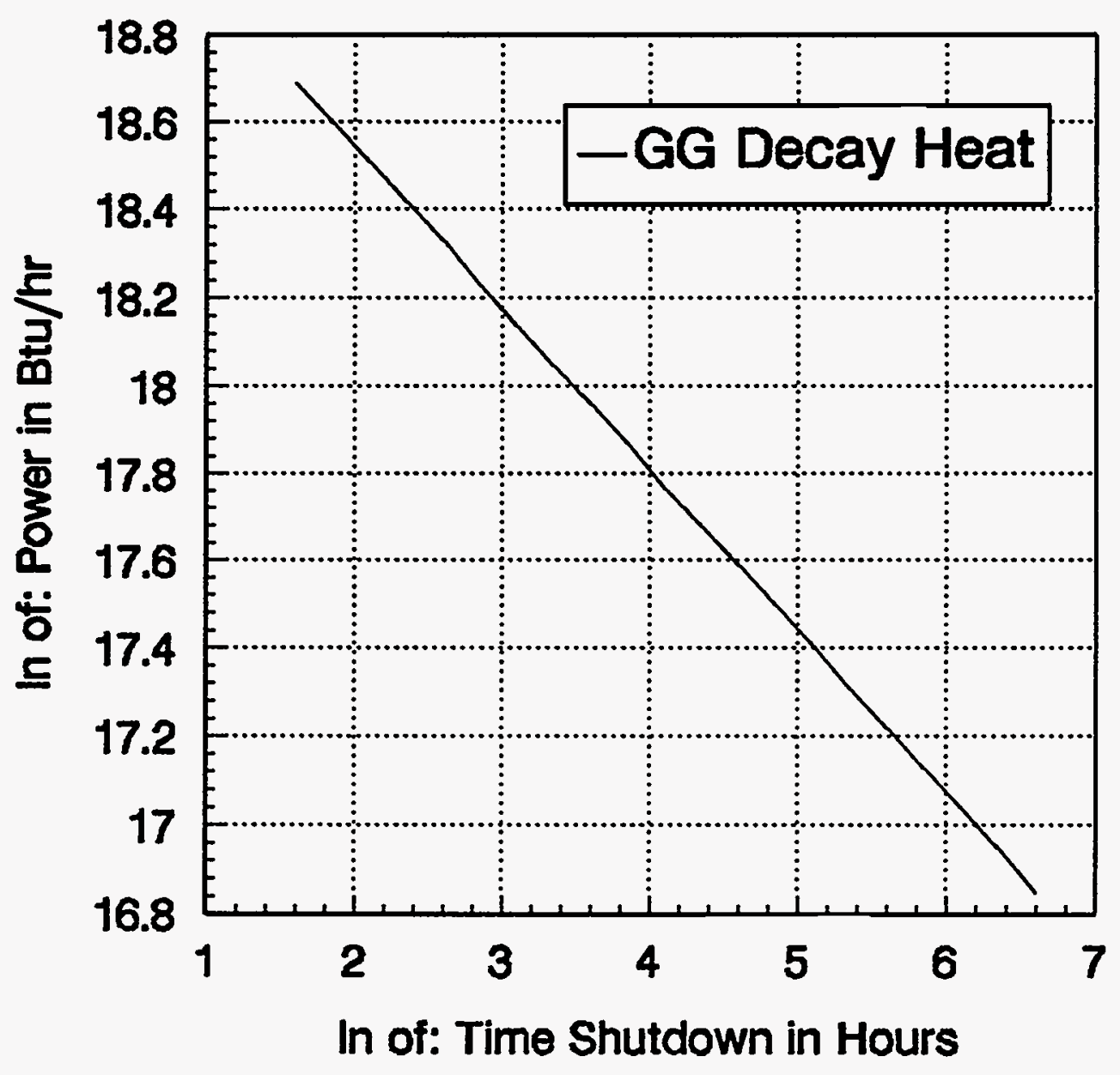

Figure F.4.7 Decay Heat 


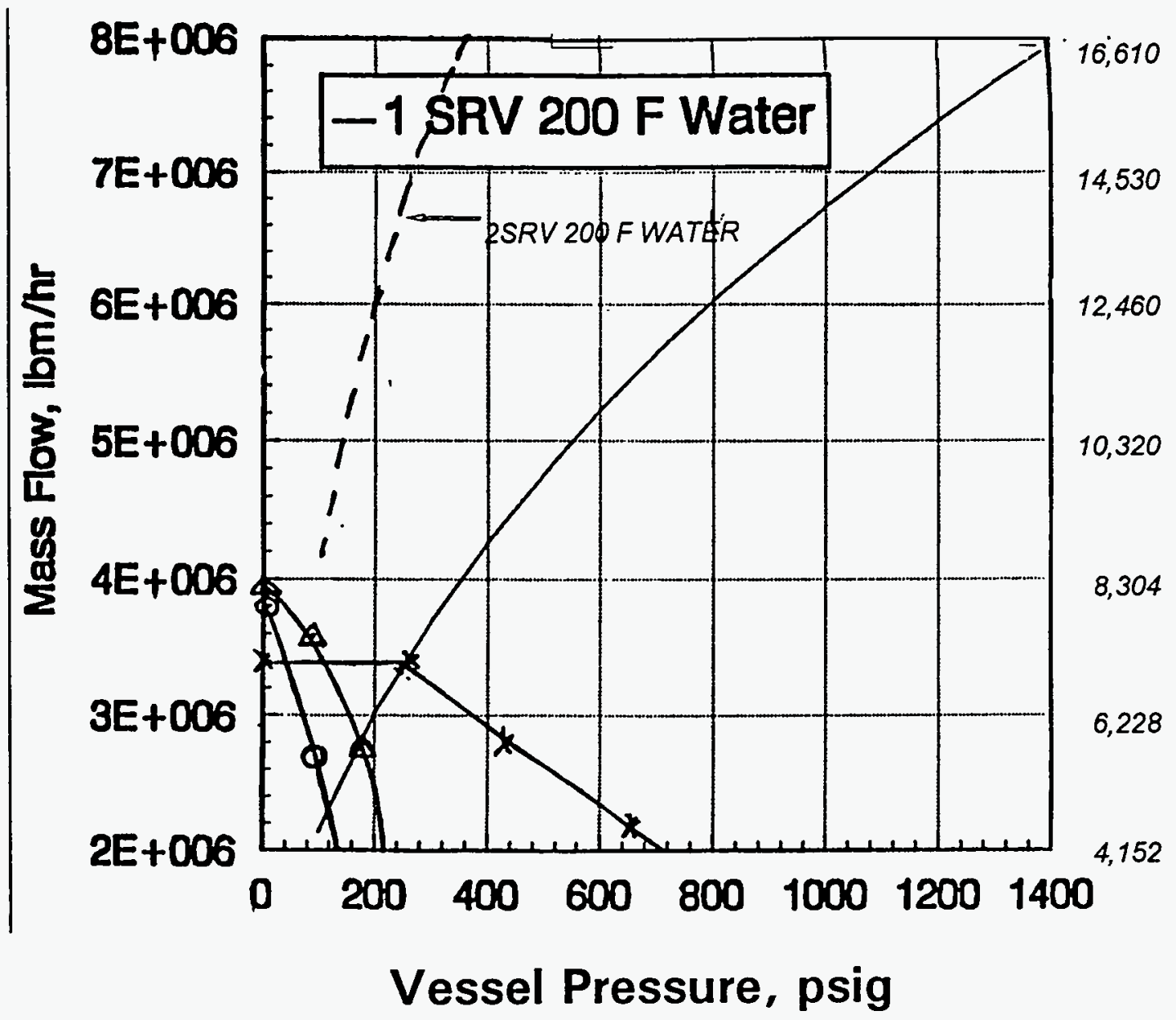

$X$ HPCS HPCS intersects 1 SRV curve at $260 \mathrm{psig}, 7000 \mathrm{gpm}$

$\triangle$ LPCS LPCS intersects $1 S R V$ curve at $170 \mathrm{psig}, 5700 \mathrm{gpm}$

o LPCI LPCI intersects 1 SRV curve at $120 \mathrm{psig}, 4700 \mathrm{gpm}$ (1 pump)

Figure F.4-8 Pressure: Water Solid With 1 ECCS Pump 


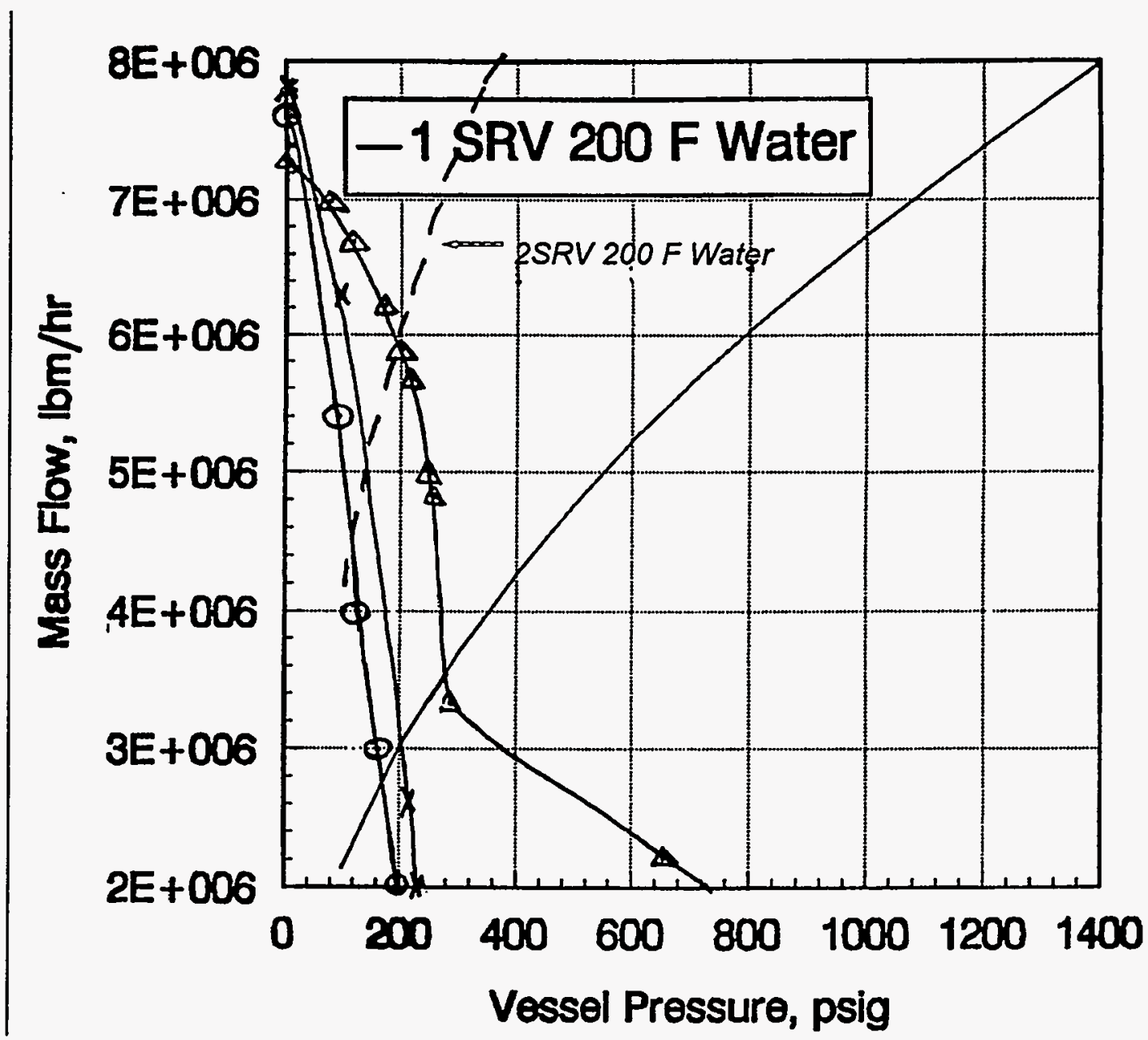

$X$ LPCI and LPCS

$\triangle$ HPCS and LPCS

o 2 LPCI Pumps (Separate lines)

Figure F.4-9 Pressure: Water Solid With 2 ECCS Pump 
between the 135 psia calculated here and the 220 psig calculated in \# 4.1, is that a more conservative friction factor was used in 4.1 , while this calculation used Moody data.] This calculation also showed that for a $0.04 \mathrm{sq} f t$ water LOCA, level 1 is reached before the system pressurizes above about $118 \mathrm{psia}$. Therefore, for a large LOCA (or large, medium LOCA) opening of an $\mathrm{SRV}$ is not required to prevent pressurization before ECCS auto-actuation is reached.

\section{F.4.4 Calculation \#17}

Calculation 90-492-01:17, "SRVs for Small/Medium LOCAs in POS 5", performed the same analyses for POS 5 that calculation \#6 performed for POS 4 . The reanalyses of calculation 19 agreed with the results of the original calculation, except that level was calculated to be higher due to swell. Assuming a water line break of $0.007 \mathrm{sq} \mathrm{ft}$ (a steam line break is of no concern in POS 5), and complete phase separation in the vessel, and complete mixing of core and downcomer water, the system pressure /measured water level history is as follows:

(a) 135 psig and +78 inches at 4000 seconds, and

(b) 440 psig and +39 inches at 7200 seconds.

The high measured levels at these pressures are due to swell of the actual level with temperature. ECCS does not actuate until level $2,-41.6$ inches measured, or level $1,-150.3$ inches measured; thus, a small (or small, medium LOCA) will pressurize the system before ECCS injection is completely auto-initiated. This same calculation showed that if one SRV is opened for steam relief, even with a zero size LOCA, pressure never exceeds 118 psia before the level 1 ECCS actuation setpoint is reached; thus, opening an SRV prevents significant pressurization of the system. This calculation also showed that for a $0.4 \mathrm{sq} \mathrm{ft}$ water LOCA, level 1 is reached before the system pressurizes above 50 psia; thus, for a large LOCA (or large, medium LOCA) opening of an SRV is not required to prevent pressurization before ECCS auto-actuation is reached.

\section{F.4.5 Calculation \#5}

Calculation 90-492-01-A:5, "Levels for Grand Gulf", derived factors for converting from actual to measured levels.

For $200^{\circ} \mathrm{F}$ water, measured level is 1.31 times actual level, in agreement with NSAC-88 (NSAC 88). Because levels can be negative with respect to instrument zero, actual level is less than measured level for actual level above instrument zero, and actual level is greater than measured level for actual level below instrument zero. For example, if actual level is +10 inches, measured level is +13 inches. If actual level is -10 inches, measured level is -13 inches. This calculation also concludes that with one recirculation pump in operation, the height of water in the core region is above the minimum steam separator turnaround point so long as measured (downcomer) level is above level $3(+11.4$ inches measured). At low level 3, shutdown cooling is isolated.

Calculation 90-492-01-A:19, "Energy Balances Checked", included calculations of actual and measured levels at each thermodynamic state during an energy balance calculation. Based on the derivations on Calculation \#5,

$$
\text { MeasLv }=v_{w_{\text {reted }}} / v_{w} *\left(h_{\text {water }}-533\right)
$$

where MeasLv is the measured level in inches, with respect to instrument zero. $\nu_{w \text { rated }}$ is the uncompensated water specific volume, $0.02177 \mathrm{cu} \mathrm{ft}$ per lbm, $\nu_{w}$ is the actual specific volume, $h_{\text {water }}$ is the actual height of water relative to vessel bottom, and 533 inches is the distance from vessel bottom to instrument zero. $h_{\text {water }}$ is calculated from water mass as follows:

$$
\begin{aligned}
& h_{\text {water }}=T e r m 1 * T e r m 2 \\
& \text { TermI }=\text { MassWtr } / \text { InMassWtr } *(533+\operatorname{InActLv)}
\end{aligned}
$$$$
\text { Term2 }=v_{w} / v_{w n}
$$

where Term1 is the actual water level relative to vessel bottom, not corrected for density changes. MassWtr is water mass, InMassWtr is initial water mass, and InActLv is initial actual level with respect to instrument zero. Term2 corrects for density changes (due to swell) where $\nu_{w}$ is water specific volume, and $\nu_{\text {win }}$ is initial water specific volume. Actual level with respect to instrument zero is: 
Supporting Calculations

$$
A c t L v=h_{\text {water }}-533
$$

and measured level with respect to instrument zero is:

$$
\text { MeasLv }=0.02177 / v_{w} * \text { Actlv }
$$

Note that $0.02177 / \nu_{w}$ is equal to 1.31 only for 200 degree F water.

\section{F.4.6 Calculation \#10}

Calculation 90-492-01-A:10, "1 CRD pump for POS 5H", evaluated the ability of $1 \mathrm{CRD}$ pump to restore level or match steaming in POS $5 \mathrm{H}$. The re-analyses of calculation 19 agreed with the results of the original calculation, except that level was calculated to be higher due to swell. This calculation was performed, because, as discussed in Section 3 of the main report, the detailed model for POS 5 assumes train $A$ is out for maintenance. Thus, only one CRD pump is available. The calculation concluded that if forced recirculation is lost, one CRD pump can raise level to allow natural circulation in $\mathbf{3 3}$ minutes, and pressure is only 103 psia, below the autoisolation setpoint of 135 psig for auto-isolation of shutdown cooling. The calculation also concluded that if the core is steamed and only one CRD pump is available for makeup, the makeup rate is insufficient to prevent core uncovery. The core uncovers by about four feet.

\section{F.4.7 Calculation \#13}

Calculation 90-492-01-A:13, "Over Pressurization of ADHR in POS 5", evaluated overpressurization concerns for ADHR. In comparison with RHR, ADHR has a lower failure pressure, but the maximum decay heat when on ADHR is less than when on RHR, since ADHR' cannot be used until at least 24 hours after shutdown. The re-analyses of calculation 19 agreed with the results of the original calculation, except that level was calculated to be higher due to swell. The calculation concluded that the time to overpressurize ADHR piping is similar to times calculated for overpressurizing RHR piping. The calculation concluded that the effect of having 1 CRD pump when on ADHR is similar to that when on RHR - namely, 1 CRD pump can restore level for natural circulation shutdown cooling before autoisolation or overpressurization occur. The calculation pointed out that when on water solid ECCS operation, if auto-isolation of shutdown cooling at $135 \mathrm{psig}$ does not occur, and if only 1 SRV is available for relief, ADHR can overpressurize (assuming a failure pressure of 160 psig, twice design rated pressure). Figure F.1-8 of this Appendix illustrates this concern. The calculation also showed that if one SRV is opened in response to a small LOCA (or no LOCA), pressure does not exceed 78 psia, and ADHR will not overpressurize.

\section{F.5 Operator Actions}

Calculation 90-492-01-A:16, "Update: Time for Operator Actions POS 5", provided estimates of times available for operator actions in the event trees.

Table F.5-1 summarizes the times available for operator actions from this calculation. 
Table F.5.1 Times Available for Operator Actions: POS 5

\begin{tabular}{|c|c|}
\hline Operator Action in Event Trees & Times Available for Action \\
\hline RM-LT & $10 \mathrm{hr}$, All Trees \\
\hline LCMK & $2.5 \mathrm{hr}$, All Trees \\
\hline OPDHR & $10 \mathrm{~min}$, All Trees \\
\hline OPLEC & Action Simultaneous with OPDHR \\
\hline OPSDC & $37 \mathrm{~min}$, All Trees \\
\hline OPECS, OPFLD, OPSTM & $23 \mathrm{~min}$ each, All Trees \\
\hline OPIS & Action Simultaneous with OPSTM, All Trees \\
\hline OPISA & Action Simultaneous with OPECS, All Trees \\
\hline RESCS, RESAD, RESB & Action Simultaneous with OPSDC, All Trees \\
\hline RESRW & No Time, All Trees \\
\hline OPSTH & $4.0 \mathrm{hr}$, All Trees \\
\hline OPMSV & $\begin{array}{l}4.4 \text { min for Trees: E, EA, ES, EP, EX, EAP, } \\
\text { EAX, ESP, ESX } \\
35 \text { min for Trees: S15OU, S1HOU, S, SP, SX, FS, } \\
\text { FSP, FSX } \\
\text { Action Simultaneous with OPOSF for Trees: F, FP, } \\
\text { FX, FNP, HWSPR }\end{array}$ \\
\hline OPOMS & Operators will not do this event (open MSIVs) \\
\hline LCHPC, LC-LP & 7.7 min each, All Trees \\
\hline OP1SV & Action Simultaneous with OPECS, All Trees \\
\hline OPHIS & Action Simultaneous with OPECS, All Trees \\
\hline OPICT & $\begin{array}{l}6.4 \mathrm{hr} \text { but Simultaneous with OPSTM (11 hr time) } \\
\text { for Trees: ECAOH, ECACH, ECOHP, ECOHX, } \\
\text { ECCHP, ECCHX, EC, ECP, ECX, ECNP, } \\
\text { ECNPL, ECACN, ECAON, CAUXN, CAUXP, } \\
\text { CAUXX, CAUX } \\
6.4 \mathrm{hr} \text { for Trees: ECAC, ECAOP, ECACP, } \\
\text { ECACX, ECAOX, ECAO } \\
\text { For Trees FC, FCACP, FCACX, FCAO, FCAOP, } \\
\text { FCAOX, FCP, FCX, FCAON, FCACN, FCN: } 20 \\
\text { min if event 'CTGOP' is 'No'; } 6.4 \mathrm{hr} \text { if event } \\
\text { 'CTGOP' is 'Yes' }\end{array}$ \\
\hline
\end{tabular}


Table F.5.1 Times Available for Operator Actions: POS 5

\begin{tabular}{|c|c|}
\hline Operator Action in Event Trees & Times Available for Action \\
\hline OPCMT & $54 \mathrm{hr}$, All Trees \\
\hline OPSPM, SPMUN & $\begin{array}{l}13 \mathrm{~min} \text { for Trees: A5IN, A5INH, S15IN, S1HIN } \\
11 \mathrm{hr} \text { for All Other Trees }\end{array}$ \\
\hline OPVNT & $\begin{array}{l}\text { Action Simultaneous with SPMKP }(11 \mathrm{hr}) \text { for } \\
\text { Trees: ECAC, ECACH, ECACP, ECACX, } \\
\text { ECCHP, ECCHX, EC, ECP, ECX, ECACN } \\
\text { Action Simultaneous with OPCMT for Trees: } \\
\text { FCAC, FC, FCACP, FCACX, FCP, FCX, } \\
\text { FCACN, FCN }\end{array}$ \\
\hline SPMKP & $\begin{array}{l}\text { Action Simultaneous with OPSPM }(11 \mathrm{hr}) \text { for } \\
\text { Trees: ECAOH, ECACH, ECOHP, ECOHX, } \\
\text { ECCHP, ECCHX, EC, ECP, ECX } \\
11 \mathrm{hr} \text { for Trees: ECAC, ECAO, ECAOP, ECAOX, } \\
\text { ECACP, ECACX }\end{array}$ \\
\hline OPSOF & $20 \mathrm{~min}$, All Trees \\
\hline $\mathrm{CS}, \mathrm{CSA}$ & Action Simultaneous with SPMKP, All Trees \\
\hline HPCAO & $7.7 \mathrm{~min}$, All Trees \\
\hline ISSSL & $15 \mathrm{~min}$, All Trees \\
\hline OPDSV & No Time, All Trees \\
\hline OPDEP & $8.7 \mathrm{hr}$, All Trees \\
\hline OPFLL & $0.64 \mathrm{hr}$, All Trees \\
\hline OPHPC & $7.7 \mathrm{~min}$, All Trees \\
\hline OPNCF & $8.7 \mathrm{hr}$, All Trees \\
\hline OPLDM & $\begin{array}{l}15 \mathrm{~min} \text { for Trees: } \mathrm{S} 2-5 \text { and S2H-5 } \\
\text { Action Simultaneous with ISSSL for Trees: S3-5 } \\
\text { and S3H-5 }\end{array}$ \\
\hline OPLMS & $6.4 \mathrm{hr}$, All Trees \\
\hline OPLST & $1.7 \mathrm{hr}$, All Trees \\
\hline OPL1L & $23 \mathrm{sec}$, All Trees \\
\hline OPL1S & $3.8 \mathrm{~min}$, All Trees \\
\hline OPL2L & $3.5 \mathrm{~min}$, All Trees \\
\hline
\end{tabular}


Table F.5.1 Times Available for Operator Actions: POS 5

\begin{tabular}{||l|l||}
\hline Operator Action in Event Trees & Times Available for Action \\
\hline OPSLP & $7.7 \mathrm{~min}$, All Trees \\
\hline OPSRV & $1.9 \mathrm{hr}$, All Trees \\
\hline OPSTL & $33 \mathrm{hr}$, All Trees \\
\hline SDCUI & $\begin{array}{l}8.7 \mathrm{hr} \text { if event 'OPDEP' not in sequence } \\
\text { Action Simultaneous with OPDEP if event } \\
\text { OPDEP' in sequence }\end{array}$ \\
\hline ISO89 SPCA & Action Simultaneous with SPMKP, All Trees \\
\hline SPMKN & $\begin{array}{l}\text { Action Simultaneous with OPECS for Tree } \\
\text { HPSWA } \\
\text { Action Not Required for Tree HPSWR }\end{array}$ \\
\hline FWMAN & $\begin{array}{l}\text { Action Simultaneous with OPSPM (1l hr) for } \\
\text { Trees: ECNP, ECNPL, ECACN, ECAON } \\
35 \text { min for Tree SNP }\end{array}$ \\
\hline
\end{tabular}


Supporting Calculations

\section{References for Appendix F}

[Whitehead et al., 1991] D. W. Whitehead, J. L.

Darby, B. D. Staple, B.

Walsh, T. M. Hake, and T.

D. Brown, "BWR Low

Power and Shutdown

Accident Frequencies

Project, Phase 1 - Coarse

Screening Analysis," Vol. 1,

Draft Letter Report, Sandia

National Laboratories and

Science and Engineering

Associates, Inc., November

23, 1991 update, (Available

in the NRC Public Document

Room).
[USNRC, 1987]

[Darby et al., 1991]
USNRC, "Standard Review Plan for the Review of Nuclear Power Plants, " NUREG 0800, June, 1987.

J. L. Darby, et al., "Savannah River Site K Reactor Filter Heatup Model, " SEA 90-500007-A: 1, July 31, 1991. 


\section{Appendix G. Calculation of the Frequency and Recovery of LOSP Plus Recovery of LOSP/DG Failures}

The process used to estimate the frequency of loss of offsite power (LOSP) for the Low Power and Shutdown Program (LP\&S) is similar to the one used in NUREG1150 [1]. The only significant difference is that for the LP\&S Program the events occuring during shutdown conditions (i.e., the Category IV events) were used in determining the frequency of LOSP for those plant operational states (POSs) wherein the plant was shutdown (i.e., POSs 2 through 7). In addition, the data base used in Reference 1 was updated to the end of 1988 using the information in NSAC-144 [2].

\section{G.1 Calculation of the Frequency of LOSP}

\section{G.1.1 Process}

\section{G.1.1.1 Overview}

The information contained in Reference 2 was examined to determine which events should be used in estimating the frequency of LOSP for either power operation or for shutdown conditions. Table G.1.1 lists the events used in determining the initiating event frequency for LOSP for low power and startup conditions, and Table G.1.2 provides additional events which must be considered when calculating the LOSP frequency for shutdown conditions.

After the shutdown events were identified, a data base of all LOSP events was created. The data base includes information on how long each plant has been in operation, how much time the plant has been in shutdown conditions, and the number of LOSP events that have occurred at the plant. Table G.1.3 presents the information contained in this data base.

In order to calculate the LOSP initiating event frequency for each plant operational state (POS), certain information in Table G.1.3 was extracted and combined into two data bases. First, information for each multiunit site was combined to produce an aggregate data set for each plant. This process involved combining the plant centered and grid/weather LOSP events into a single number, combining the Category IV events into a single number, estimating the total amount of time multiunit sites are operated in the low power and shutdown conditions of interest, determining the total site calendar years of commercial operation, and replacing the plant name (site name) with a number identifier. Next, for each single unit site, the plant centered and grid/weather LOSP events were combined, the amount of time the unit is operated in low power and shutdown conditions was determined, the total calendar years of commercial operation were calculated, and the plant name was replaced by a unique number identifier. Using this interim information, the two data bases needed to start the LOSP frequency calculation were constructed by parsing the above interim data base into one containing plant information for non-Category IV events and another containing Category IV events. The information in these two data bases is presented in Tables G.1.4 and G.1.5 respectively.

These two data bases were then processed using the same procedures used in the NUREG-1150 analysis of LOSP for Grand Gulf [1].

\section{G.1.1.2 Procedure}

The processing of the data which led to the LOSP frequency was done on a VAX computer. While the description given here describes the operations for a VAX, the detail should be sufficient to allow the reader to translate it to a PC or any other appropriate machine. The process is described in steps with additional detail given in sub-steps as appropriate. The determination of LOSP frequency was done in two phases. The first phase, which had nine steps, resulted in 32 point frequency/probability distributions for initiating events for PCGW (Plant Centered, Grid and Weather) and Category IV scenarios. The second phase, which had six steps, used these distributions to determine the point estimate LOSP frequency.

\section{G.1.1.2.1 Phase 1}

The processing started with a file titled IE.BCK. This file contained the following information for 67 plants: plant name, plant name abbreviation, number of PC (plant centered) LOSP events at the plant, number of years the plant had been on line, number of $G / W$ (grid or weather caused) LOSP events at the plant, and the number of years that the plant had been operational.

Step 1. The IE.BCK file was edited to:

a. Add a line number for each plant entry.

b. Update the number of LOSP events for each plant since the data were originally entered. 
c. Add Category IV events and shutdown times.

This file was saved under a different version number of IE.BCK in order to preserve the original data. It is given in Attachment G-1.

Step 2. The new IE.BCK was further edited to:

a. Delete plant names and abbreviations (the line numbers served as plant identifiers in subsequent steps).

b. Combine PC and G/W events (the occurrences were added).

c. Delete the on-line time.

This file was saved under still another IE.BCK version number. It is given in Attachment G-2.

Step 3. The latest IE.BCK file was then edited to:

a. Delete Category IV events.

b. Delete shutdown times.

This file contains the data for the non-Category IV LOSP events. It was saved as LOSP_IE_PCGW.DAT and is given in Attachment G-3.

Step 4. The latest IE.BCK file was again edited to:

a. Delete the operating time.

b. Delete the PC and G/W events.

This file was saved as LOSP_IE_IV.DAT. It contained the Category IV initiating events. It is given in Attachment G-4.

Step 5. The program IEFREQ1.EXE was run for $\mathrm{PC} / \mathrm{GW}$ data. This is an interactive program that calculates the cumulative probability for LOSP for a user specified failure frequency at a user specified plant. The plant is identified by the line number in the input file.

a. The code requires a data base from which to draw basic plant data for the initiating event. For the PC/GW events the LOSP_IE_PCGW.DAT file was copied to IE.DAT (Attachment G-5) and IE.DAT was used as input. The file title IE.DAT is the input file title hard-wired into the code. b. At the command to run the code it is only necessary to respond to a few simple prompts on the screen.

(1) At the plant ID input (GGNS=23) the code summarizes the input file data for the plant and the total number of plant years for the whole file.

(2) At the prompt "If you know the value of the constant..." input 2 to let the code determine it.

(3) At the prompt "Input the failure frequency..." input the best estimate (a guess based on engineering judgement) for LOSP. The code will return the cumulative probability for LOSP for the input failure frequency.

(4) Iterate on the failure frequency of step (3) until a cumulative probability of .99900 is obtained.

(5) When .99900 is obtained

(a) Record the input failure frequency.

(b) Enter "Y" at the prompt "Is this satisfactory?"

(c) The .99900 value for PC/GW for GGNS was found to be .416 .

A copy of the screen and prompts is included in Attachment G-5.

Step 6. In preparation for running the IEBAT1 code, and input file for the code , LOSP_IE_PGCW.INP, was prepared. This input file consisted of a single line which contained:

a. The file containing the PC/GW data for the listed plants enclosed in single ticks.

b. Plant ID number.

c. The failure frequency for the .999 LOSP

probability obtained in Step 5.b.(4) above.

d. The number of points to output.

The single line was:

'LOSP_IE_PCGW.DAT' 23.41630

The IEBAT1 code produces an initiating event probability distribution for a range of failure frequencies from near zero to the frequency .999 frequency determined in Step 5.b.(4) above. The number of output points is specified by the last entry of the single line input file. The input file is given in Attachment G-6. 
Step 7. The IEBAT.COM file (Attachments G-7, G-7A \& G-7B) was created to run IEBAT1. This file:

a. Renames LOSP_IE_PCGW.INP to IEFREQ.INP, the name of the input file hard-wired into IEBAT1.

b. Runs IEBAT1.

c. Renames IEFREQ.INP back to LOSP_IE_PCGW.INP.

d. Renames the plot file of frequency and IE probability produced by IEBAT1, PLOT.DAT, to IE_PCGW.DAT (Attachment G-8).

Once the COM file for IEBAT1 was completed, the file was executed producing the above mentioned .DAT file.

Step 8. IE PCGW.DAT was updated to include probabilities of 0.0 and 1.0. This was done by plotting the 30 output points of IEBAT1 and, using engineering judgement, extrapolating the resulting curve to 0.0 and 1.0. See Attachment G-9.

Step 9. Steps 6-9 were repeated for Category IV data. File titles had IV instead of PCGW in them. Otherwise, the process was exactly the same. The input and output files for the Category IV analysis are given in Attachments G-10 through G-17.

\section{G.1.1.2.2 Phase 2}

The second phase of the process produced 1000 point distributions for the PCGW and Category IV scenarios from the 30 point distributions determined in Phase 1. The files IE_PCGW.DAT and IE_IV.DAT produced in the first phase were used as input to the LHS code to produce 1000 point distributions.

Step 1. Preparation for the LHS run.

a. Prepared LHS.COM (Attachment G-18):

$\begin{array}{ll}\text { ASSIGN LHS.DAT } & \text { FOR001 } \\ \text { ASSIGN LHS.INP } & \text { FOR005 } \\ \text { ASSIGN LHS.OUT } & \text { FOR006 } \\ \text { RUN LHS } & \\ \text { DELETE FOR*.DAT;* } & \end{array}$

(1) LHS.DAT is the 1000 point output from LHS.

(2) LHS.OUT is a histogram output file that (a) Lists IE_XXX.DAT data. (b) Puts the 1000 output points from LHS into a 20 bin histogram.

This file is used as a diagnostic tool to assure the analyst that the 1000 points fit a distribution that makes sense.

b. Prepare LHS.INP (Attachment G-19), the input file to LHS:

TITLE - (Specify Title of Analysis)

RANDOM SEED (Specify a 10 digit integer)

NOBS 1000 (no. of observations desired)

RANDOM SAMPLE (LHS Option)

USER DISTRIBUTION

IE_PGCW.DAT (1 line w/above)

USER DISTRIBUTION IE_IV_.DAT

OUTPUT HIST

c. Edited SUBROUTINE USRDST (Attachment G20):

Four lines were edited to specify input files and titles in FORMAT statements.

(1) Nested IF:

IF(IFLAG.EQ. 1)OPEN(UNIT $=60$,FILE

='IE_PCGW.DAT',...)

(2) 12 FORMAT (' $1 ', l, l, 6 \mathrm{X}$, 'INPUT DATA FOR IE_PCGW',/...)

(3) ELSEIF(J.EQ.2)THEN

IF(IFLAG.EQ.2)OPEN(UNIT =61, FILE $=$ 'IE_IV', $/ \ldots$ )

(4) 16 FORMAT(' $1 ', l, l, 6 \mathrm{X}$, 'INPUT DATA FOR IE_IV', I...)

Step 2. Run LHS with the above files:

a. Compile USRDST

b. Link USRDST to LHS

c. Run LHS.COM (i.e. @ LHS)

Step 3. LHS Outputs

a. LHS.OUT-Described above

b. LHS.DAT - 4 columns, 1000 lines

(1) Line Number

(2) No. of data points in the line

(3) PCGW value

(4) Category IV value. 
LHS.OUT and LHS.DAT are given in Attachments G-21 and G-22.

Step 4. The analysis requires the combined values of the PC/GW and Category IV data. Thus, the two data sets were added.

a. LHS.DAT was edited to remove the first and second columns. This required the use of the program REMOVECOL2.FOR (Attachments G-23).

(1) The program input is LHS.DAT. This file name is hard wired into the program.

(2) The output file is LHSLOSP.INP (Attachment G-24). This is also hard wired into the program. The output is two columns of data, PC/GW and CAT IV.

b. Using LHSLOSP.INP as input, the program LHSADDITION (Attachment G-25) was run to add the PGCW and Cat IV columns. The output was contained in LHSLOSP.DAT (Attachment G-26). The two file names are hard wired into LHSADDITION.
Step 5. Prepare TEMAC input file. The Cat IV data was removed from LHSLOSP.INP by a second REMOVECOL program (Attachment G-27). This left just the PC/GW data. This file was stored as PCGWLOSP.DAT (Attachment G-28).

Step 6. The STAT.SAS program (Attachment G-29) was run on LHSLOSP.DAT and PCGWLOSP.DAT. PROC UNIVARIATE was specified for the two files to determine the statistical characteristics of the data in each. Among the outputs was the mean value of the data which was used as the point estimate for the LOSP frequency in the ensuing PRA analyses. The outputs are given in STAT.LIS, Attachment G-30.

Step 6 completed the LOSP frequency point estimate calculation.

\section{G.1.2 Results}

Using the above process, the mean frequency for LOSP in POS 1 was calculated to be 0.0649 . For POSs $2-7$ it was 0.1235 . 
Table G.1.1 Loss of Offsite Power Events Used to Estimate Frequency During POS 1

\begin{tabular}{|c|c|c|c|c|c|c|c|}
\hline$\#$ & PLANT & SY & CAT & DATE & DURATION & FREQ? & RECOV? \\
\hline 1 & ANO & 2 & PC & $09 / 16 / 78$ & 1.480 & $\mathrm{~F}$ & $\mathbf{R}$ \\
\hline 2 & Beaver Valley & 2 & PC & $07 / 28 / 78$ & 0.280 & $\mathrm{~F}$ & $\mathbf{R}$ \\
\hline 3 & Big Rock Point & 3 & G & $01 / 25 / 75$ & 0.333 & $\mathrm{~F}$ & $\mathbf{R}$ \\
\hline 4 & Brunswick & 2 & $\mathrm{PC}$ & $03 / 26 / 75$ & 0.070 & $\mathrm{~F}$ & $\mathbf{R}$ \\
\hline 5 & Calvert Cliffs & 3 & PC & $07 / 23 / 87$ & 1.970 & $\mathrm{~F}$ & $\mathbf{R}$ \\
\hline 6 & Davis Besse & 1 & PC & $11 / 29 / 77$ & 0.002 & $\mathrm{~F}$ & $\mathbf{R}$ \\
\hline 7 & Davis Besse & 1 & $\mathrm{PC}$ & $10 / 15 / 79$ & 0.430 & $\mathrm{~F}$ & $\mathbf{R}$ \\
\hline 8 & Diablo Canyon & 1 & $\mathrm{PC}$ & $07 / 17 / 88$ & 0.633 & $\mathrm{~F}$ & $\mathbf{R}$ \\
\hline 9 & Dresden & 2 & W & $11 / 12 / 65$ & 4.000 & $\mathrm{~F}$ & $\mathrm{R}$ \\
\hline 10 & Dresden & 2 & PC & $08 / 16 / 85$ & 0.083 & $\mathrm{~F}$ & $\mathbf{R}$ \\
\hline 11 & Farley & 3 & $\mathrm{PC}$ & $09 / 16 / 77$ & 0.900 & F & $\mathrm{R}$ \\
\hline 12 & Farley & 3 & $\mathrm{PC}$ & $10 / 08 / 83$ & 2.750 & $\mathrm{~F}$ & $\mathbf{R}$ \\
\hline 13 & Fort Calhoun & 3 & $\mathrm{PC}$ & $02 / 21 / 76$ & 0.900 & $\mathrm{~F}$ & $\mathrm{R}$ \\
\hline 14 & Fort Calhoun & 3 & $\mathrm{PC}$ & $08 / 22 / 77$ & 0.015 & $\mathrm{~F}$ & $\mathbf{R}$ \\
\hline 15 & Fort St. Vrain & 3 & $\mathrm{~W}$ & $05 / 17 / 83$ & 1.750 & $\mathrm{~F}$ & $\mathbf{R}$ \\
\hline 16 & Ginna & 2 & PC & $03 / 04 / 71$ & 0.500 & $\mathbf{F}$ & $\mathbf{R}$ \\
\hline 17 & Ginna & 2 & $\mathrm{PC}$ & $10 / 21 / 73$ & 0.670 & $\mathrm{~F}$ & $\mathbf{R}$ \\
\hline 18 & Haddam Neck & 1 & PC & $04 / 27 / 68$ & 0.480 & $F$ & $\mathrm{R}$ \\
\hline 19 & Haddam Neck & 1 & PC & $07 / 15 / 69$ & 0.150 & $F$ & $\mathrm{R}$ \\
\hline 20 & Haddam Neck & 1 & PC & 07/19'/72 & 0.017 & $\mathrm{~F}$ & $\mathrm{R}$ \\
\hline 21 & Haddam Neck & 1 & $\mathrm{PC}$ & $01 / 19 / 74$ & 0.330 & $\mathrm{~F}$ & $\mathrm{R}$ \\
\hline 22 & Haddam Neck & 1 & $\mathrm{PC}$ & $06 / 26 / 76$ & 0.270 & $\mathrm{~F}$ & $\mathrm{R}$ \\
\hline 23 & Haddam Neck & 1 & $\mathrm{PC}$ & $08 / 01 / 84$ & 0.167 & $\mathrm{~F}$ & $\mathbf{R}$ \\
\hline 24 & Indian Point & 3 & G & $11 / 09 / 65$ & - & $\mathrm{F}$ & \\
\hline 25 & Indian Point & 3 & G & $07 / 20 / 72$ & 0.920 & $\mathrm{~F}$ & $\mathbf{R}$ \\
\hline 26 & Indian Point & 3 & G & $07 / 13 / 77$ & 6.470 & $\mathrm{~F}$ & $\mathbf{R}$ \\
\hline
\end{tabular}

Vol. 2, Part 2 
LOSP Frequency

Table G.1.1 Loss of Offsite Power Events Used to Estimate Frequency During POS 1 (Continued)

\begin{tabular}{|c|c|c|c|c|c|c|c|}
\hline$\#$ & PLANT & SY & CAT & DATE & DURATION & FREQ? & RECOV? \\
\hline 27 & Indian Point & 3 & PC & $06 / 03 / 80$ & 1.750 & F & $\mathbf{R}$ \\
\hline 28 & Indian Point & 3 & PC & $06 / 03 / 80$ & 0.500 & F & $\mathbf{R}$ \\
\hline 29 & McGuire & 2 & PC & $08 / 21 / 84$ & 0.334 & F & $\mathbf{R}$ \\
\hline 30 & Millstone' & 1 & PC & $07 / 21 / 76$ & 0.080 & $\mathrm{~F}$ & $\mathbf{R}$ \\
\hline 31 & Millstone & 1 & w & $08 / 10 / 76$ & 5.000 & $\mathrm{~F}$ & $\mathbf{R}$ \\
\hline 32 & Millstone & 1 & w & $09 / 27 / 85$ & 5.500 & F & $\mathbf{R}$ \\
\hline 33 & Monticello & 1 & PC & $04 / 27 / 81$ & 0.250 & $\mathrm{~F}$ & $\mathbf{R}$ \\
\hline 34 & Nine Mile Point & 1 & $\mathrm{PC}$ & $11 / 17 / 73$ & 0.003 & $\mathrm{~F}$ & $\mathbf{R}$ \\
\hline 35 & Nine Mile Point & 1 & PC & $12 / 26 / 88$ & 0.150 & $\mathrm{~F}$ & $\mathbf{R}$ \\
\hline 36 & Oconee & 1 & $\mathrm{PC}$ & $01 / 04 / 74$ & 0.013 & $\mathbf{F}$ & $\mathbf{R}$ \\
\hline 37 & Oyster Creek & 2 & PC & $09 / 08 / 73$ & 0.003 & $\mathbf{F}$ & $\mathbf{R}$ \\
\hline 38 & Palisades & 3 & PC & $09 / 02 / 71$ & 0.930 & $\mathrm{~F}$ & $\mathbf{R}$ \\
\hline 39 & Palisades & 3 & PC & $09 / 24 / 77$ & 0.500 & $\mathrm{~F}$ & $\mathbf{R}$ \\
\hline 40 & Palisades & 3 & PC & $07 / 14 / 87$ & 7.430 & F & $\mathbf{R}$ \\
\hline 41 & Palo Verde & 3 & PC & $10 / 03 / 85$ & 0.400 & $\mathrm{~F}$ & $\mathbf{R}$ \\
\hline 42 & Palo Verde & 3 & PC & $10 / 07 / 85$ & 0.200 & $\mathrm{~F}$ & $\mathbf{R}$ \\
\hline 43 & Pilgrim & 1 & W & $05 / 10 / 77$ & 2.670 & F & $\mathbf{R}$ \\
\hline 44 & Pilgrim & 1 & W & $02 / 06 / 78$ & 8.900 & $\mathrm{~F}$ & $\mathbf{R}$ \\
\hline 45 & Pilgrim & 1 & w & $11 / 19 / 86$ & 4.317 & F & $\mathbf{R}$ \\
\hline 46 & Pilgrim & 1 & W & $11 / 12 / 87$ & 11.000 & $\mathrm{~F}$ & $\mathbf{R}$ \\
\hline 47 & Point Beach & 2 & $\mathrm{PC}$ & $02 / 05 / 71$ & 0.130 & $\mathrm{~F}$ & $\mathbf{R}$ \\
\hline 48 & Point Beach & 2 & $\mathrm{PC}$ & $04^{\prime} / 27 / 74$ & 0.020 & $\mathrm{~F}$ & $\mathbf{R}$ \\
\hline 49 & Prairie Island & 2 & $\mathrm{PC}$ & $07 / 15 / 80$ & 1.030 & $\mathrm{~F}$ & $\mathbf{R}$ \\
\hline 50 & Quad Cities & 3 & $\mathrm{PC}$ & $11 / 06 / 77$ & 1.150 & F & $\mathbf{R}$ \\
\hline 51 & Quad Cities & 3 & $\mathrm{PC}$ & $06 / 22 / 82$ & 0.570 & $\mathrm{~F}$ & $\mathbf{R}$ \\
\hline 52 & River Bend & 3 & $\mathrm{PC}$ & $01 / 01 / 86$ & 0.767 & $\mathrm{~F}$ & $\mathbf{R}$ \\
\hline
\end{tabular}


Table G.1.1 Loss of Offsite Power Events Used to Estimate Frequency During POS 1 (Continued)

\begin{tabular}{|r|l|c|c|c|c|c|c||}
\hline$\#$ & PLANT I & SY & CAT & DATE & DURATION & FREQ? & RECOV? \\
\hline 53 & Robinson & 3 & PC & $01 / 28 / 86$ & 1.667 & F & R \\
\hline 54 & San Onofre & 3 & PC & $11 / 22 / 80$ & 0.004 & F & R \\
\hline 55 & San Onofre & 3 & PC & $11 / 21 / 85$ & 0.067 & F & R \\
\hline 56 & St. Lucie & 2 & G & $05 / 16 / 77$ & 0.330 & F & R \\
\hline 57 & St. Lucie & 2 & G & $05 / 16 / 77$ & 1.500 & & R \\
\hline 58 & St. Lucie & 2 & G & $05 / 14 / 78$ & 0.130 & F & R \\
\hline 59 & Susquehanna & 1 & PC & $07 / 26 / 84$ & 0.183 & F & R \\
\hline 60 & Turkey Point & 2 & G & $04 / 03 / 73$ & 0.300 & F & R \\
\hline 61 & Turkey Point & 2 & G & $04 / 04 / 73$ & 0.250 & F & R \\
\hline 62 & Turkey Point & 2 & G & $04 / 25 / 74$ & 0.330 & F & R \\
\hline 63 & Turkey Point & 2 & G & $06 / 28 / 74$ & 0.180 & F & R \\
\hline 64 & Turkey Point & 2 & G & $05 / 16 / 77$ & 1.030 & F & R \\
\hline 65 & Turkey Point & 2 & G & $05 / 16 / 77$ & 2.000 & F & R \\
\hline 66 & Turkey Point & 2 & PC & $02 / 12 / 84$ & 0.250 & F* & R* \\
\hline 67 & Turkey Point & 2 & PC & $02 / 16 / 84$ & 0.250 & F & R \\
\hline 68 & Turkey Point & 2 & G & $05 / 17 / 85$ & 2.083 & F & R \\
\hline 69 & Yankee Rowe & 3 & G & $11 / 09 / 65$ & 0.550 & F & R \\
\hline
\end{tabular}

*This event is used in the LOSP calculation for power operation and startup only, not for the shutdown states. 


\section{LOSP Frequency}

Table G.1.2 Additional Loss of Off-Site Power Events Used to Estimate Frequency During POS 2 - 7

\begin{tabular}{|c|c|c|c|c|c|c|c|}
\hline$\#$ & PLANT & SY & CAT & DATE & DURATION & FREQ? & $\begin{array}{c}\text { RECOV } \\
\text { ? }\end{array}$ \\
\hline 1 & Brunswick & 2 & PC & $04 / 26 / 83$ & 0.283 & F & $\mathbf{R}$ \\
\hline 2 & Fitzpatrick & 1 & PC & $04 / 10 / 78$ & 0.004 & F & $\mathbf{R}$ \\
\hline 3 & Fitzpatrick & 1 & $\mathrm{PC}$ & $03 / 27 / 79$ & 0.050 & $\mathrm{~F}$ & $\mathbf{R}$ \\
\hline 4 & Fitzpatrick & 1 & PC & $10 / 31 / 88$ & 1.000 & $\mathrm{~F}$ & $\mathbf{R}$ \\
\hline 5 & Ft. Calhoun & 3 & $\mathrm{PC}$ & $03 / 13 / 75$ & 11.083 & $\mathrm{~F}$ & $\mathbf{R}$ \\
\hline 6 & Indian Point & 3 & PC & $11 / 16 / 84$ & 0.233 & F & $\mathbf{R}$ \\
\hline 7 & Haddam Neck & 1 & $\mathrm{PC}$ & $.08 / 24 / 84$ & 0.367 & $\mathrm{~F}$ & $\mathrm{R}$ \\
\hline 8 & McGuire & 2 & PC & $09 / 16 / 87$ & 0.417 & $\mathrm{~F}$ & $\mathbf{R}$ \\
\hline 9 & Monticello & 1 & $\mathrm{PC}$ & $06 / 04 / 84$ & 0.033 & $\mathrm{~F}$ & $\mathbf{R}$ \\
\hline 10 & Oyster Creek & 2 & $\mathrm{PC}$ & $11 / 14 / 83$ & 4.000 & $\mathrm{~F}$ & $\mathbf{R}$ \\
\hline 11 & Palisades & 3 & PC & $01 / 08 / 84$ & 2.683 & $\mathrm{~F}$ & $\mathbf{R}$ \\
\hline 12 & Point Beach & 2 & PC & $10 / 13 / 73$ & - & $F$ & \\
\hline 13 & Point Beach & 2 & PC & $10 / 22 / 84$ & 0.050 & $\mathrm{~F}$ & $\mathbf{R}$ \\
\hline 14 & Quad Cities & 3 & $\mathrm{PC}$ & $05 / 07 / 85$ & 0.717 & $\mathrm{~F}$ & $\mathbf{R}$ \\
\hline 15 & Salem & 2 & $\mathrm{PC}$ & $06 / 05 / 84$ & 2.000 & $\mathrm{~F}$ & $\mathbf{R}$ \\
\hline 16 & San Onofre & 3 & $\mathrm{PC}$ & $06 / 07 / 73$ & 4.983 & $\mathrm{~F}$ & $\mathbf{R}$ \\
\hline 17 & San Onofre & 3 & $\mathrm{PC}$ & $04 / 22 / 80$ & & $\mathrm{~F}$ & \\
\hline 18 & Turkey Point & 2 & $\mathrm{PC}$ & $04 / 29 / 85$ & & $\mathrm{~F}$ & \\
\hline 19 & Yankee Rowe & 3 & PC & $05 / 03 / 84$ & 0.117 & F & $\mathbf{R}$ \\
\hline
\end{tabular}


Table G.1.3 Informational Worksheet for LOSP Calculation

\begin{tabular}{|c|c|c|c|c|c|c|c|c|c|c|c|c|c|c|c|}
\hline plant & $\begin{array}{l}\text { Start } \\
\text { Date }\end{array}$ & $\begin{array}{c}\% \\
\text { Cap. }\end{array}$ & $\begin{array}{c}\% \\
\text { Aveil. }\end{array}$ & $\begin{array}{l}\text { End } \\
\text { Date }\end{array}$ & Optime & Online & Modonline & Comment & $\begin{array}{c}\text { fpc } \\
\text { LOSP }\end{array}$ & $\begin{array}{l}f_{\mathrm{B}} \boldsymbol{} \\
\text { LOSP }\end{array}$ & $\begin{array}{c}\text { Cet. } \\
\text { IV }\end{array}$ & $\begin{array}{c}\text { FP } \\
\text { Time }\end{array}$ & $\begin{array}{c}\text { ModFP } \\
\text { Time }\end{array}$ & $\begin{array}{c}\text { SD } \\
\text { Time }\end{array}$ & $\begin{array}{c}\text { ModsD } \\
\text { Time }\end{array}$ \\
\hline arkansas1 & Dec-74 & 0.59 & 0.69 & Doc-88 & 14.09 & 8.31 & 10.78 & & 1 & 0 & 0 & 9.65 & 11.64 & 4.44 & 6.18 \\
\hline arkansas 2 & Mar-80 & 0.68 & 0.71 & Doc-88 & na & 6.01 & $\mathbf{n a}$ & & & & & 6.29 & na & 2.55 & $\mathrm{na}$ \\
\hline beavervally 1 & Oct-76 & 0.54 & 0.61 & Dec-88 & 12.26 & 6.62 & 7.07 & & 1 & 0 & 0 & 7.48 & 7.88 & 4.78 & 4.83 \\
\hline beavervally2 & Nov-87 & 0.88 & 0.93 & Dec-88 & na & 0.99 & na & & & & & 1.04 & $\mathrm{na}$ & 0.08 & na \\
\hline bigrockpoint & Mar-63 & 0.6 & 0.71 & Dec-88 & 25.85 & 15.51 & 15.51 & & 0 & 1 & 0 & 18.25 & 18.25 & 7.6 & 7.6 \\
\hline braidwood1 & na & na & $\mathrm{na}$ & Dec-88 & na & na & $\mathrm{na}$ & notupyet & & & & $\mathrm{na}$ & na & na & $\mathrm{na}$ \\
\hline brownsferryl & Aug-74 & 0.4 & 0.46 & Dec-88 & 14.43 & 5.77 & 10.6 & & 0 & 0 & 0 & 6.64 & 11.51 & 7.79 & 12.69 \\
\hline brownsferry2 & Mar-75 & 0.38 & 0.45 & Dec-88 & na & 5.26 & na & & & & & 6.23 & na & 7.62 & na \\
\hline brownsferry3 & Mar-77 & 0.38 & 0.43 & Dec-88 & $\mathrm{na}$ & 4.5 & na & & & & & 5.09 & na & 6.75 & na \\
\hline brunswick1 & Mar-77 & 0.53 & 0.62 & Dec-88 & na & 6.28 & $\mathrm{na}$ & & & & & 7.34 & na & 4.5 & na \\
\hline brunswick2 & Nov-75 & 0.48 & 0.6 & Dec-88 & 13.18 & 6.32 & 9.59 & & 1 & 0 & 1 & 7.91 & 10.84 & 5.27 & 7.97 \\
\hline byron1 & Sep-85 & 0.63 & 0.74 & Dec-88 & 3.33 & 2.1 & 2.42 & & 0 & 0 & 0 & 2.47 & 2.78 & 0.87 & 0.98 \\
\hline byron2 & Aug-87 & 0.63 & 0.89 & Dec-88 & na & 0.86 & na & & & & & 1.21 & na & 0.15 & $\mathrm{na}$ \\
\hline callaway1 & Dec-84 & 0.78 & 0.84 & Dec-88 & 4.08 & 3.19 & 3.19 & & 0 & 0 & 0 & 3.43 & 3.43 & 0.65 & 0.65 \\
\hline calvertcliffs 1 & May-75 & 0.73 & 0.76 & Dec-88 & 13.68 & 9.96 & 12.52 & & 1 & 0 & 0 & 10.42 & 12.72 & 3.26 & 4.87 \\
\hline calvertcliffs 2 & Apr-77 & 0.8 & 0.82 & Dec.88 & na & 9.41 & na & & & & & 9.64 & na & 2.12 & na \\
\hline catawbal & Jun-85 & 0.65 & 0.7 & Dec-88 & 3.59 & 2.33 & 3.07 & & 0 & 0 & 0 & 2.51 & 3.24 & 1.08 & 1.77 \\
\hline calawba2 & Aug- 85 & 0.62 & 0.71 & Dec-88 & na & 2.12 & na & & & & & 2.43 & na & 0.99 & $\mathrm{na}$ \\
\hline clinton 1 & Nov-87 & 0.73 & 0.84 & Dec. 88 & 1.1 & 0.81 & 0.81 & & 0 & 0 & 0 & 0.93 & 0.93 & 0.18 & 0.18 \\
\hline cook1 & Aug-75 & 0.66 & 0.73 & Dec.88 & 13.43 & 8.86 & 11.01 & & 0 & 0 & 0 & 9.8 & 11.67 & 3.63 & 6.23 \\
\hline $\operatorname{cook} 2$ & Jul. 78 & 0.6 & 0.66 & Dec. 88 & na & 6.31 & na & & & & & 6.94 & na & 3.57 & $\mathrm{na}$ \\
\hline cooper & Jul-74 & 0.6 & 0.74 & Dec-88 & 14.51 & 8.71 & 8.71 & & 0 & 0 & 0 & 10.74 & 10.74 & 3.77 & 3.77 \\
\hline crystalriver 3 & Mar-77 & 0.56 & 0.63 & Dec-88 & 11.84 & 6.63 & 6.63 & & 0 & 0 & 0 & 7.46 & 7.46 & 4.38 & 4.38 \\
\hline
\end{tabular}




\begin{tabular}{|c|c|c|c|c|c|c|c|c|c|c|c|c|c|c|c|c|c|c|c|c|c|c|c|}
\hline 寒员 & $\begin{array}{l}\overrightarrow{0} \\
\dot{v}\end{array}$ & $\vec{m}$ & : & g & $\bar{a}$ & a & $\stackrel{m}{+}$ & $\begin{array}{l}0 \\
? \\
i\end{array}$ & g & $g$ & 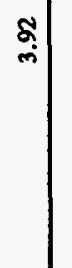 & $\stackrel{\square}{\dot{m}}$ & $\begin{array}{l}8 \\
6 \\
6\end{array}$ & $\vec{m}$ & $\stackrel{0}{=}$ & $\underset{+}{\mathbb{t}}$ & $\begin{array}{l}\vec{i} \\
\dot{0}\end{array}$ & $g$ & क. & $\pi$ & 足 & $\Xi$ & స్ల్య \\
\hline 成息 & $\begin{array}{l}\overrightarrow{0} \\
\dot{0}\end{array}$ & S & : & : & శึ & i & $\stackrel{m}{*}$ & \$ & 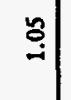 & 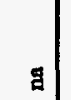 & స్ & $\overrightarrow{\dot{m}}$ & 8 & $\overrightarrow{7}$ & $\stackrel{0}{=}$ & $\underset{+}{+}$ & $\underset{+}{+\infty}$ & $\underset{\Phi}{\infty}$ & $\begin{array}{c}5 \\
0 \\
0\end{array}$ & & $\stackrel{0}{\circ}$ & $\begin{array}{l}5 \\
\vdots \\
\text { in }\end{array}$ & స్ \\
\hline 案首 & 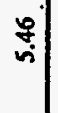 & $\stackrel{\tilde{m}}{m}$ & g & $\Xi$ & $\begin{array}{l}0 \\
\stackrel{0}{0} \\
0 \\
0\end{array}$ & a & ลั. & 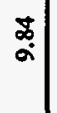 & : & a & ลे & $\stackrel{9}{\Xi}$ & $\begin{array}{l}\infty \\
\sim \\
\sim\end{array}$ & 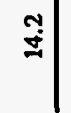 & 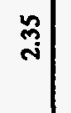 & $\stackrel{9}{9}$ & $\begin{array}{l}\stackrel{0}{2} \\
\stackrel{\theta}{\circ}\end{array}$ & $\mathrm{g}$ & $\stackrel{5}{-1}$ & $g$ & 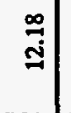 & \pm & 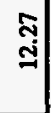 \\
\hline 置 & $\begin{array}{l}\text { fo } \\
\text { जे }\end{array}$ & $\vec{i}$ & $\stackrel{0}{\sim}$ & I & $\stackrel{-}{m}$ & $\stackrel{\circ}{\underset{\Xi}{=}}$ & 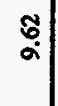 & $\vec{\infty}$ & 章 & ' & ڤ్ & $\stackrel{9}{=}$ & $\begin{array}{l}\infty \\
\sim \\
\sim\end{array}$ & $\stackrel{\text { Tे }}{\dot{\Xi}}$ & స్ & $\stackrel{9}{5}$ & $\mid \begin{array}{l}\overrightarrow{0} \\
\infty \\
\infty\end{array}$ & 勇 & $\stackrel{5}{-1}$ & & $\begin{array}{l}5 \\
\vdots \\
0\end{array}$ & : & 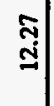 \\
\hline छㄹ & 0 & 0 & & & 0 & & 0 & 0 & & & $m$ & $r$ & 0 & 0 & 0 & -1 & 0 & & 0 & & - & & 0 \\
\hline 致容 & 0 & 0 & & & -1 & & 0 & 0 & & & 0 & 0 & -1 & 0 & 0 & 0 & 0 & & 0 & & m & & 0 \\
\hline 总 & $N$ & $r$ & & & -1 & & 0 & $N$ & & & 0 & $N$ & 0 & $N$ & 0 & 0 & 0 & & 0 & & $N$ & & 0 \\
\hline 鄫 & & & & 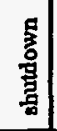 & & & & & & 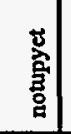 & & & & & & & & & - & 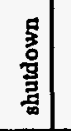 & & & \\
\hline 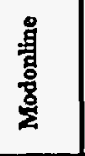 & พִ & $\stackrel{\circ}{\circ}$ & a & 政 & 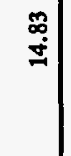 & a & $\begin{array}{l}8 \\
\end{array}$ & $\begin{array}{l}0 \\
0 \\
0\end{array}$ & a & $\Xi$ & $\underset{\infty}{\stackrel{\infty}{\infty}}$ & ส & $\stackrel{m}{\rightarrow}$ & $\stackrel{\leftrightarrow}{\sim}$ & $\underset{i}{7}$ & \begin{tabular}{l}
\multirow{2}{*}{} \\
$\vdots$ \\
0
\end{tabular} & | & $\Xi$ & వִ & $\Xi$ & $\stackrel{E}{\Xi}$ & $g$ & 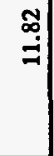 \\
\hline 奇 & $\underset{f}{*}$ & $\tilde{n}$ & $\stackrel{-1}{-1}$ & $\Xi$ & $\begin{array}{l}0 \\
\vdots \\
0\end{array}$ & ర్ & $\stackrel{8}{8}$ & $\stackrel{2}{2}$ & สุ่ & g & $\underset{\infty}{\infty}$ & ๙ิ & $\stackrel{m}{-}$ & $\vec{m}$ & ثै & 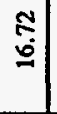 & $\stackrel{乛}{\sim}$ & i & $\vec{b}$ & a & $\begin{array}{c}\infty \\
\infty \\
\infty\end{array}$ & $\overrightarrow{\overrightarrow{0}}$ & $\stackrel{\Omega}{=}$ \\
\hline 基 & $\begin{array}{c}\vec{n} \\
\dot{2}\end{array}$ & $\hat{b}$ & ב & $\Xi$ & 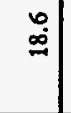 & q & $\begin{array}{l}\tilde{\omega} \\
\dot{m}\end{array}$ & $\stackrel{8}{9}$ & : & a & $\begin{array}{l}\overrightarrow{\tilde{n}} \\
\stackrel{m}{m}\end{array}$ & †े & $\bar{\vdots}$ & $\underset{\substack{\infty \\
\infty}}{|c|}$ & $\stackrel{n}{n}$ & $\stackrel{7}{\stackrel{7}{*}}$ & $\begin{array}{l}\stackrel{g}{0} \\
\dot{q}\end{array}$ & $\Xi$ & $\stackrel{8}{\circ}$ & I & 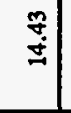 & $\Xi$ & ज़ \\
\hline 袁总 & 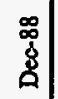 & $\begin{array}{l}\infty \\
\vdots \\
\dot{\delta} \\
\not\end{array}$ & $\begin{array}{l}\infty \\
\stackrel{\leftrightarrow}{8} \\
\stackrel{\leftrightarrow}{a}\end{array}$ & 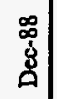 & 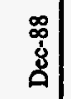 & $\begin{array}{l}\infty \\
\dot{\leftrightarrow} \\
\stackrel{\leftrightarrow}{a}\end{array}$ & 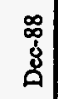 & 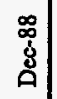 & $\begin{array}{l}\infty \\
\vdots \\
\dot{\bigsqcup} \\
a\end{array}$ & $\begin{array}{l}\infty \\
\vdots \\
\dot{8} \\
\square\end{array}$ & $\begin{array}{l}\infty \\
\vdots \\
\grave{\Delta} \\
ٌ\end{array}$ & $\begin{array}{l}\infty \\
\vdots \\
\dot{\leftrightarrow} \\
a\end{array}$ & $\begin{array}{c}\infty \\
\dot{\vdots} \\
\dot{\Delta}\end{array}$ & $\begin{array}{l}\infty \\
\vdots \\
\dot{8} \\
\square\end{array}$ & 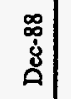 & $\begin{array}{l}\infty \\
\dot{8} \\
\stackrel{8}{a}\end{array}$ & 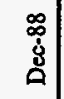 & $\begin{array}{c}\infty \\
0 \\
8 \\
\&\end{array}$ & $\begin{array}{c}\infty \\
\vdots \\
\dot{\xi} \\
\xi\end{array}$ & $\begin{array}{l}\infty \\
0 \\
\dot{\leftrightarrow} \\
\ddot{g}\end{array}$ & 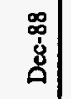 & 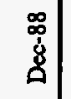 & $\begin{array}{l}\infty \\
0 \\
\dot{\leftrightarrow} \\
\not\end{array}$ \\
\hline ง & స్ & $\frac{9}{5}$ & $\begin{array}{l}\circ \\
\vdots \\
0\end{array}$ & a & $\stackrel{1}{\circ}$ & $\begin{array}{l}0 \\
0 \\
0 \\
0\end{array}$ & : & $\stackrel{?}{0}$ & $\begin{array}{c}0 \\
0 \\
0 \\
0\end{array}$ & $\Xi$ & $\begin{array}{l}\overrightarrow{5} \\
0\end{array}$ & 잉 & $\stackrel{m}{\delta}$ & : & ర్ర & 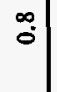 & 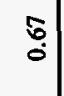 & : & $\begin{array}{l}0 \\
0 \\
0\end{array}$ & a & 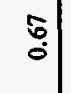 & $\stackrel{0}{\circ}$ & 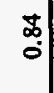 \\
\hline * 형 & $\ddot{0}$ & s. & : & $g$ & ڤ్ర & $\begin{array}{l}0 \\
0 \\
0 \\
0\end{array}$ & $\tilde{\vdots}$ & $\grave{0}$ & $\begin{array}{l}\infty \\
0 \\
0\end{array}$ & $g$ & $\begin{array}{l}n \\
0 \\
0\end{array}$ & $\stackrel{\circ}{0}$ & $\frac{\pi}{0}$ & : & : & $\stackrel{\infty}{0}$ & oे & : & ڤ̊ & $\mathfrak{g}$ & $\begin{array}{l}\overline{5} \\
\vdots\end{array}$ & $\begin{array}{l}0 \\
0 \\
0\end{array}$ & \begin{tabular}{r|}
$\overrightarrow{0}$ \\
0 \\
0
\end{tabular} \\
\hline 点 & $\stackrel{\infty}{\frac{1}{3}}$ & 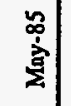 & 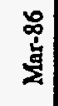 & $\begin{array}{l}8 \\
8 \\
0 \\
8 \\
2\end{array}$ & 尽 & $\begin{array}{l}\vec{z} \\
\dot{\vec{z}} \\
\dot{z}\end{array}$ & 奋 & 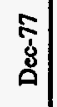 & $\begin{array}{l}\vec{\Phi} \\
\vec{\Xi}\end{array}$ & \& & $\begin{array}{c}\stackrel{n}{5} \\
\stackrel{3}{\xi}\end{array}$ & 葡 & 㥉 & 尽 & 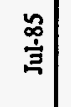 & 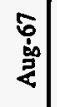 & 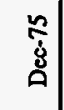 & 究 & 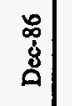 & 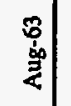 & 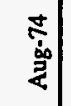 & 章 & 盇 \\
\hline 壱 & 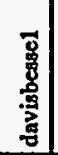 & 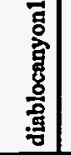 & 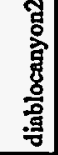 & $\begin{array}{l}\overrightarrow{3} \\
\overrightarrow{3} \\
\frac{3}{5}\end{array}$ & $\begin{array}{l}\frac{\pi}{8} \\
\frac{8}{4}\end{array}$ & 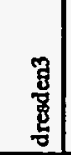 & 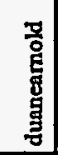 & 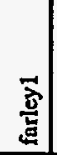 & 离 & 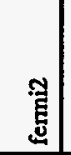 & 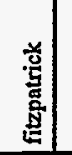 & 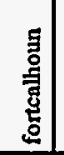 & 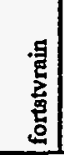 & 䭴 & 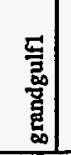 & 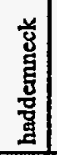 & $\begin{array}{l}\overrightarrow{3} \\
\underline{5} \\
\end{array}$ & $\begin{array}{l}3 \\
3 \\
5\end{array}$ & 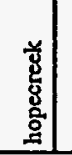 & 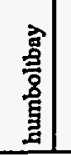 & 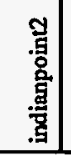 & 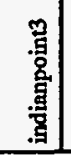 & $\begin{array}{l}\mathbf{8} \\
\mathbf{z} \\
\mathbf{z} \\
\end{array}$ \\
\hline
\end{tabular}


Table G.1.3 Informational Worksheet for LOSP Calculation (Continued)

\begin{tabular}{|c|c|c|c|c|c|c|c|c|c|c|c|c|c|c|c|}
\hline plent & $\begin{array}{l}\text { Start } \\
\text { Date }\end{array}$ & $\begin{array}{c}\% \\
\text { Cap. }\end{array}$ & $\begin{array}{c}\% \\
\text { Aveil. }\end{array}$ & $\begin{array}{l}\text { End } \\
\text { Dete }\end{array}$ & Optime & Online & Modonline & Comment & $\begin{array}{c}\text { pe } \\
\text { LOSP }\end{array}$ & $\begin{array}{l}\text { LOSP } \\
\text { LOSP }\end{array}$ & Cel. & $\begin{array}{c}\text { FP } \\
\text { Time }\end{array}$ & $\begin{array}{c}\text { ModFP } \\
\text { Time }\end{array}$ & $\begin{array}{c}\text { SD } \\
\text { Time }\end{array}$ & $\begin{array}{c}\text { ModSD } \\
\text { Time }\end{array}$ \\
\hline lacrosse & Nov-69 & na & $\mathrm{ng}$ & Dec-88 & na & na & $\mathrm{na}$ & shutdown & & & & na & $\mathrm{ma}$ & $\mathrm{na}$ & $\mathrm{ma}$ \\
\hline lasallel & $\operatorname{Jan}-84$ & 0.47 & 0.58 & Dec-88 & $s$ & 2.35 & 3.57 & & 0 & 0 & 0 & 2.9 & 3.95 & 2.1 & 3.12 \\
\hline lasalle2 & Oct-84 & 0.54 & 0.59 & Dec-88 & na & 2.3 & na & & & & & 2.5 & $\mathrm{na}$ & 1.76 & $\mathrm{ma}$ \\
\hline limerick1 & Feb-86 & 0.7 & 0.82 & Doc-88 & 2.92 & 2.04 & 2.04 & & 0 & 0 & 0 & 2.39 & 2.39 & 0.52 & 0.52 \\
\hline maineyan & Dec-72 & 0.7 & 0.77 & Dec-88 & 16.09 & 11.27 & 11.27 & & 0 & 0 & 0 & 12.44 & 12.44 & 3.65 & 3.65 \\
\hline meguirel & Dec-81 & 0.6 & 0.68 & Dec-88 & 7.09 & 4.25 & 5.63 & & 1 & 0 & 1 & 4.83 & 5.96 & 2.25 & 3.14 \\
\hline meguire2 & Mar-84 & 0.71 & 0.73 & Dec-88 & na & 3.44 & $\mathrm{na}$ & & & & & 3.53 & na & 1.31 & na \\
\hline millstoneI & Mar-71 & 0.7 & 0.77 & Dec-88 & 17.85 & 12.49 & 15.3 & & 1 & 2 & 0 & 13.74 & 16.03 & 4.11 & 7.35 \\
\hline millstone2 & Dec-75 & 0.66 & 0.71 & Dec-88 & na & 8.64 & na & & & & & 9.3 & na & 3.8 & $n \mathfrak{n}$ \\
\hline millstone3 & Apr -86 & 0.75 & 0.79 & Dec-88 & na & 2.07 & $\mathfrak{n a}$ & & & & & 2.18 & $n a$ & 0.58 & $n a^{-}$ \\
\hline monticello & Jun-71 & 0.72 & 0.77 & Dec-88 & 17.6 & 12.67 & 12.67 & & 1 & 0 & 1 & 13.55 & 13.55 & 4.05 & 4.05 \\
\hline ninemileptI & Dec-69 & 0.59 & 0.67 & Dec-88 & 19.1 & 11.27 & 11.27 & & 2 & 0 & 0 & 12.79 & 12.79 & 6.3 & 6.3 \\
\hline ninernilept2 & $\mathrm{na}$ & na & $\mathrm{na}$ & Dec-88 & na & na & $\mathrm{na}$ & notupyet & & & & na & na & $\mathrm{na}$ & na \\
\hline northannal & Jun-78 & 0.62 & 0.69 & Dec-88 & 10.59 & 6.57 & 8.81 & & 0 & 0 & 0 & 7.31 & 9.31 & 3.28 & 4.4 \\
\hline northanna2 & Dec-80 & 0.73 & 0.8 & Dec-88 & $\mathbf{n a}$ & 5.9 & na & & & & & 6.47 & $n a$ & 1.62 & na \\
\hline oconeel & Jul-73 & 0.67 & 0.73 & Dec-88 & 15.51 & 10.39 & 14.61 & & 1 & 0 & 0 & 11.32 & 14.91 & 4.19 & s \\
\hline oconee2 & Sep-74 & 0.67 & 0.75 & Dec-88 & $\mathrm{na}$ & 9.61 & na & & & & & 10.73 & $n a$ & 3.61 & na \\
\hline oconee3 & Dec-74 & 0.68 & 0.72 & Dec-88 & $\mathrm{na}$ & 9.58 & na & & & & & 10.1 & na & 3.99 & $\mathrm{na}$ \\
\hline oystercreek & Dec-69 & 0.54 & 0.63 & Dec-88 & 19.1 & 10.29 & 10.29 & & 1 & 0 & 1 & 12.03 & 12.03 & 7.07 & 7.07 \\
\hline palissdes & Dec-71 & 0.43 & 0.5 & Dec-88 & 17.1 & 7.35 & 7.35 & & 3 & 0 & 1 & 8.55 & 8.55 & 8.55 & 8.5 \\
\hline paloverde1 & Feb-86 & 0.58 & 0.6 & Dec-88 & 2.92 & 1.69 & 2.4 & & 2 & 0 & 0 & 1.75 & 2.44 & 1.17 & 1.53 \\
\hline paloverde2 & Sep-86 & 0.72 & 0.74 & Dec-88 & $\mathbf{n a}$ & 1.68 & na & & & & & 1.73 & $\mathrm{na}$ & 0.61 & $\mathrm{na}$ \\
\hline paloverde3 & na & $\mathrm{na}$ & na & Dec-88 & na & na & na & notupyet & & & & na & na & na & $\mathrm{ng}$ \\
\hline
\end{tabular}




\begin{tabular}{|c|c|c|c|c|c|c|c|c|c|c|c|c|c|c|c|c|c|c|c|c|c|c|c|}
\hline 害首 & $\frac{n}{a}$ & I & స్త & 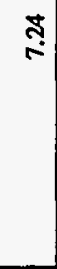 & ฉ్ & g & 7 & g & 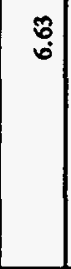 & g & 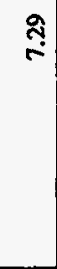 & 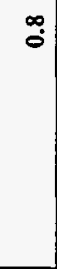 & & $\underset{6}{0}$ & 政 & 志 & g & g & ণั) & g & $\begin{array}{l}\ddagger \\
\\
0\end{array}$ & I & $\underset{m}{\stackrel{\infty}{m}}$ \\
\hline 菑量 & ఫ్ & $\underset{⿱ 亠 ⿱ 口 小}{n}$ & స్ & 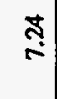 & $\underset{m}{J}$ & $\overline{\text { N }}$ & $\overline{5}$ & $\stackrel{\infty}{-}$ & $\stackrel{n}{n}$ & ڤ్ & $\stackrel{\text { ș }}{\text { - }}$ & $\stackrel{\infty}{0}$ & in & + & స్ & สุ & 5 & $\stackrel{n}{-3}$ & న్ల & $\stackrel{\leftrightarrow}{m}$ & 李 & & นั่ \\
\hline 害息 & $\stackrel{\bar{a}}{=}$ & I & $\stackrel{\infty}{\infty}$ & $\begin{array}{l}\infty \\
0 \\
\infty\end{array}$ & $\stackrel{m}{\Xi}$ & $\exists$ & $\begin{array}{l}\vec{b} \\
\dot{\Xi}\end{array}$ & $g$ & $\begin{array}{c}\tilde{8} \\
\dot{\mathbf{g}}\end{array}$ & g & 急 & $\stackrel{\infty}{\leftrightarrows}$ & 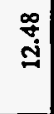 & $\mid$ & $g$ & $\stackrel{9}{\stackrel{g}{m}}$ & $\Xi$ & $\Xi$ & 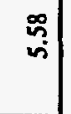 & $g$ & $\underset{-1}{-1}$ & a & $\stackrel{0}{0}$ \\
\hline 苗总 & స్ & $\underset{\infty}{+}$ & $\stackrel{\infty}{\infty}$ & $\begin{array}{l}\infty \\
0 \\
\infty\end{array}$ & $\begin{array}{l}8 \\
+1 \\
1\end{array}$ & $\begin{array}{l}\check{L} \\
\dot{ \pm} \\
\end{array}$ & 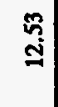 & $\stackrel{\nexists}{\Xi}$ & $\stackrel{\circ}{\stackrel{్}{\mathrm{j}}}$ & $\stackrel{9}{=}$ & 急 & $\stackrel{\infty}{\leftrightarrows}$ & 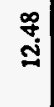 & $\stackrel{9}{\div}$ & $\stackrel{\infty}{\Im}$ & $\begin{array}{l}= \\
=\end{array}$ & 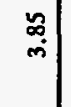 & $\stackrel{q}{n}$ & $\stackrel{\infty}{\leftarrow}$ & $\begin{array}{l}0 \\
\dot{m} \\
\dot{m}\end{array}$ & $\stackrel{\text { A }}{-1}$ & $\Xi$ & $\underset{\infty}{\infty}$ \\
\hline dुㄹ & 0 & & 0 & 0 & $N$ & & 0 & & - & & 0 & 0 & 0 & - & & $N$ & & & 0 & & 0 & & 0 \\
\hline 暂 & 0 & & 0 & $\nabla$ & 0 & & 0 & & 0 & & 0 & 0 & 0 & 0 & & 0 & & & 0 & & 0 & & $N$ \\
\hline 告要 & 0 & & 0 & 0 & $N$ & & - & & $\sim$ & & 0 & - & - & 0 & & $N$ & & & 0 & & 0 & & 0 \\
\hline 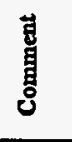 & & & & & & & & & & & & & & & & & & & & & & 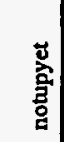 & \\
\hline $\begin{array}{l}\text { : } \\
\text { 总 } \\
\text { 일 }\end{array}$ & $\begin{array}{l}\text { s. } \\
\dot{0}\end{array}$ & ฐ & $\stackrel{2}{2}$ & $\stackrel{+}{*}$ & $\stackrel{\Sigma}{\circ}$ & g & $\begin{array}{l}\vec{\nabla} \\
\dot{\Xi}\end{array}$ & $g$ & $\begin{array}{l}\infty \\
\stackrel{0}{m} \\
\stackrel{m}{\sim}\end{array}$ & $\mathbf{a}$ & 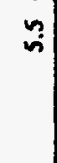 & $\tilde{n}$ & $\stackrel{9}{\Xi}$ & $\begin{array}{l}\overleftarrow{c} \\
\infty\end{array}$ & $g$ & $\frac{a}{9}$ & ฐ & gี & $\underset{f}{\mathbb{t}}$ & $a$ & $\cong$ & a & $\stackrel{\infty}{\alpha}$ \\
\hline 咠 & ঙ̊: & $\underset{\leftarrow}{\stackrel{5}{*}}$ & $\stackrel{0}{5}$ & $\stackrel{+}{\leftarrow}$ & స్త్ & $\overrightarrow{⿱ 亠 䒑}$ & $\stackrel{\alpha}{=}$ & $\stackrel{\Xi}{=}$ & $\begin{array}{l}\vec{n} \\
0\end{array}$ & 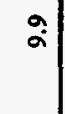 & $\tilde{\omega}$ & $\stackrel{\curvearrowleft}{-}$ & $\stackrel{\Im}{\sharp}$ & 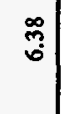 & $\vec{i}$ & 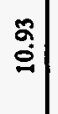 & 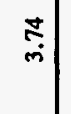 & $\stackrel{2}{m}$ & $\stackrel{\infty}{i}$ & $\underset{\sim}{\mathbf{d}}$ & $\cong$ & a & $\underset{\infty}{\widetilde{6}}$ \\
\hline 悬 & $\begin{array}{l}\bar{n} \\
\dot{z}\end{array}$ & $\Xi$ & 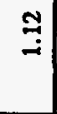 & 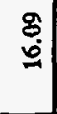 & $\overrightarrow{\mathbf{0}}$ & $z$ & $\begin{array}{l}8 \\
\vdots \\
\vdots\end{array}$ & $\mathrm{g}$ & \begin{tabular}{l}
\multirow{2}{*}{} \\
$\vdots$
\end{tabular} & 政 & $\begin{array}{l}\stackrel{2}{9} \\
\dot{m}\end{array}$ & $\hat{\grave{n}}$ & 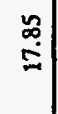 & $\stackrel{\mathfrak{n}}{=}$ & $g$ & : & $\Xi$ & g & కุ & $\pi$ & 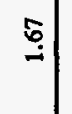 & $g$ & 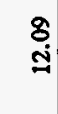 \\
\hline 青咅 & 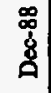 & 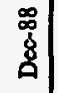 & $\begin{array}{l}\infty \\
\vdots \\
\vdots \\
8\end{array}$ & $\begin{array}{l}\mathscr{0} \\
\stackrel{8}{8} \\
\stackrel{8}{a}\end{array}$ & $\begin{array}{l}\infty \\
\vdots \\
\vdots \\
\stackrel{\S}{0}\end{array}$ & 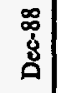 & 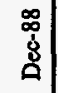 & 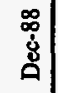 & $\begin{array}{l}\infty \\
\vdots \\
\dot{\delta} \\
\curvearrowleft\end{array}$ & 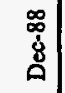 & $\begin{array}{l}\infty \\
\vdots \\
\dot{\delta} \\
\not\end{array}$ & $\begin{array}{l}\infty \\
\mathbf{0} \\
\dot{8} \\
\emptyset\end{array}$ & $\begin{array}{c}\infty \\
\dot{\leftrightarrow} \\
\dot{\Xi} \\
\not\end{array}$ & 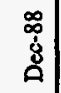 & $\begin{array}{c}\infty \\
\stackrel{\leftrightarrow}{8} \\
\not ̊\end{array}$ & 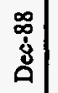 & $\begin{array}{c}\infty \\
\vdots \\
\dot{8} \\
0\end{array}$ & $\begin{array}{c}\boldsymbol{\infty} \\
\dot{\mathbf{u}} \\
\ddot{a}\end{array}$ & $\begin{array}{c}\infty \\
0 \\
\vdots \\
0\end{array}$ & $\begin{array}{c}0 \\
\vdots \\
\vdots \\
\vdots\end{array} \mid$ & $\begin{array}{c}\infty \\
\vdots \\
\grave{\Xi} \\
\not\end{array}$ & $\begin{array}{l}\infty \\
\grave{\dot{\zeta}} \\
\stackrel{a}{a}\end{array}$ & $\begin{array}{c}\infty \\
\vdots \\
8 \\
a\end{array}$ \\
\hline ง สี่ & ஸุ & $\stackrel{0}{\circ}$ & $\begin{array}{l}0 \\
0 \\
0\end{array}$ & $\stackrel{n}{n}$ & $\begin{array}{c}\overrightarrow{0} \\
0\end{array}$ & $\begin{array}{l}\stackrel{0}{0} \\
0 \\
0\end{array}$ & $\begin{array}{l}\stackrel{\infty}{0} \\
0\end{array}$ & $\begin{array}{c}\infty \\
0 \\
0\end{array}$ & $\stackrel{\infty}{0}$ & 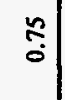 & f & $\begin{array}{l}0 \\
0 \\
0\end{array}$ & $\tilde{0}$ & $\stackrel{0}{0}$ & âे & 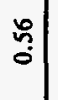 & $\overrightarrow{\hat{0}}$ & 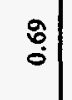 & 5 & $\begin{array}{l}0 \\
0 \\
0\end{array}$ & $\underset{0}{\mathbb{S}}$ & 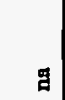 & ț \\
\hline 8 & $\tilde{0}$ & 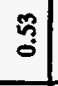 & $\begin{array}{l}0 \\
0 \\
0\end{array}$ & 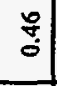 & $\begin{array}{l}0 \\
0 \\
0\end{array}$ & $\begin{array}{c}-0 \\
0 \\
0\end{array}$ & $\begin{array}{l}2 \\
0 \\
0\end{array}$ & $\begin{array}{c}\mathbf{D} \\
\vdots \\
\end{array}$ & 足 & 8 & $\stackrel{+}{0}$ & $\stackrel{0}{0}$ & 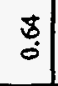 & $\stackrel{\varpi}{\vdots}$ & $\vec{n}$ & స్. & o: & $\stackrel{:}{\circ}$ & ڤ్లి & $\stackrel{\overrightarrow{0}}{0}$ & o: & a & $\stackrel{2}{0}$ \\
\hline 苛题 & 方 & \begin{tabular}{l} 
\pm \\
\multirow{3}{3}{} \\
$\stackrel{1}{1}$
\end{tabular} & $\begin{array}{l}\hat{\mathbf{p}} \\
\hat{\vdots} \\
\dot{z}\end{array}$ & $\begin{array}{c}\tilde{\dot{\delta}} \\
\stackrel{\tilde{g}}{2}\end{array}$ & $\begin{array}{c}\stackrel{8}{\grave{s}} \\
\stackrel{8}{8}\end{array}$ & $\frac{\pi}{\frac{3}{8}}$ & 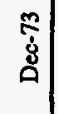 & 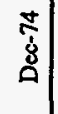 & 蛋 & 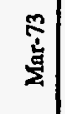 & 号 & 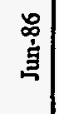 & 案 & $\underset{\mathbf{i}}{\mathbf{i}}$ & $\begin{array}{l}\overrightarrow{\mathbf{a}} \\
\stackrel{\Delta}{\Delta} \\
0\end{array}$ & 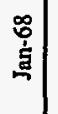 & 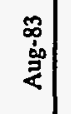 & 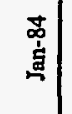 & 离 & $\begin{array}{l}\approx \\
\vdots \\
\vdots \\
\end{array}$ & $\begin{array}{l}\hat{\infty} \\
\stackrel{\mathbf{a}}{\mathbf{z}}\end{array}$ & $g$ & 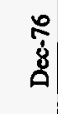 \\
\hline 鄫 & 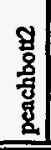 & 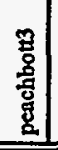 & $\begin{array}{l}\overrightarrow{\mathbf{g}} \\
\mathrm{g}\end{array}$ & 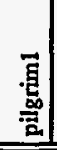 & 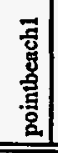 & 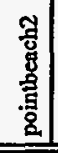 & 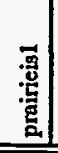 & 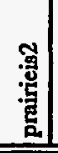 & 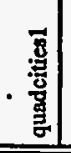 & 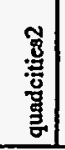 & 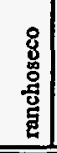 & 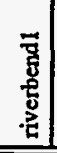 & 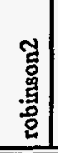 & 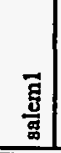 & 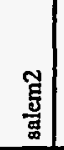 & 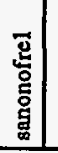 & 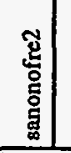 & 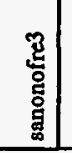 & $\begin{array}{l}\overrightarrow{\mathbf{z}} \\
\mathbf{0} \\
\overrightarrow{0} \\
\overrightarrow{\mathbf{D}} \\
\end{array}$ & 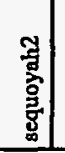 & $\begin{array}{l}\vec{z} \\
\vec{z} \\
\vec{z} \\
\vec{z} \\
\end{array}$ & 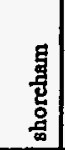 & 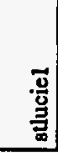 \\
\hline
\end{tabular}




\begin{tabular}{|c|c|c|c|c|c|c|c|c|c|c|c|c|c|c|c|}
\hline plant & $\begin{array}{l}\text { Start } \\
\text { Date }\end{array}$ & $\begin{array}{c}\% \\
\text { Cap. }\end{array}$ & $\begin{array}{c}\% \\
\text { Avail. }\end{array}$ & $\begin{array}{l}\text { End } \\
\text { Date }\end{array}$ & Optime & Online & Modonline & Comment & $\begin{array}{c}\text { tpe } \\
\text { LOSP }\end{array}$ & $\begin{array}{l}\text { Ig\&W } \\
\text { LOSP }\end{array}$ & $\begin{array}{l}\text { Cat. } \\
\text { IV }\end{array}$ & $\begin{array}{c}\text { FP } \\
\text { Time }\end{array}$ & $\begin{array}{l}\text { Modrs } \\
\text { Time }\end{array}$ & $\begin{array}{c}\text { SD } \\
\text { Time }\end{array}$ & $\begin{array}{c}\text { ModsD } \\
\text { Time }\end{array}$ \\
\hline stlucie2 & Jun-83 & 0.85 & 0.86 & Dec-88 & nn & 4.75 & na & & & & & 4.81 & $\mathrm{mn}$ & 0.78 & na \\
\hline summer1 & $\operatorname{Jan}-84$ & 0.69 & 0.73 & Dec-88 & 5 & 3.45 & 3.45 & & 0 & 0 & 0 & 3.65 & 3.65 & 1.35 & 1.35 \\
\hline surryl & Dec-72 & 0.56 & 0.64 & Dec-88 & 16.09 & 9.01 & 13.07 & & 0 & 0 & 0 & 10.3 & 13.91 & 5.79 & 9.41 \\
\hline surry 2 & May-73 & 0.59 & 0.64 & Dec-88 & na & 9.22 & na & & & & & 10.03 & $\mathrm{na}$ & 5.64 & na \\
\hline susquehannal & Jun-83 & 0.7 & 0.74 & Dec-88 & 5.59 & 3.91 & 4.8 & & 1 & 0 & 0 & 4.14 & 4.95 & 1.45 & 2.03 \\
\hline susquehanna2 & Feb-85 & 0.76 & 0.8 & Dec-88 & na & 2.98 & $\mathrm{na}$ & & & - & & 3.13 & $\mathrm{na}$ & 0.78 & na \\
\hline threemileisland1 & Sep-74 & 0.41 & 0.42 & Dec-88 & 14.34 & 5.88 & 5.88 & & 0 & 0 & 0 & 6.02 & 6.02 & 8.32 & 8.32 \\
\hline threemileisland 2 & Dec-78 & na & na & Dec-88 & na & na & na & shutdown & & & & na & $\mathbf{n a}$ & na & na \\
\hline trojan & May-76 & 0.56 & 0.65 & Dec-88 & 12.68 & 7.1 & 7.1 & & 0 & $\mathbf{0}$ & 0 & 8.24 & 8.24 & 4.44 & 4.44 \\
\hline turkeypoint3 & Dec-72 & 0.63 & 0.66 & Dec-88 & 16.09 & 10.14 & 13.72 & & 2 & 7 & 1 & 10.59 & 14.02 & 5.5 & 9.01 \\
\hline turkcypoint4 & Sep.73 & 0.63 & 0.65 & Dec-88 & na & 9.67 & na & & & & & 10.02 & na & 5.32 & na \\
\hline vermontyankee & Nov-72 & 0.72 & 0.78 & Dec-88 & 16.18 & 11.65 & 11.65 & & 0 & 0 & 0 & 12.62 & 12.62 & 3.56 & 3.56 \\
\hline vogtlel & Jun-87 & 0.72 & 0.75 & Dec-88 & 1.59 & 1.14 & 1.14 & & 0 & 0 & 0 & 1.19 & 1.19 & 0.4 & 0.4 \\
\hline washingtonnp2 & Dec-84 & 0.59 & 0.72 & Dec-88 & 4.08 & 2.41 & 2.41 & & 0 & 0 & 0 & 2.94 & 2.94 & 1.14 & 1.14 \\
\hline waterford3 & Sep-85 & 0.75 & 0.78 & Dec-88 & 3.33 & 2.5 & 2.5 & & 0 & 0 & 0 & 2.6 & 2.6 & 0.73 & 0.73 \\
\hline wolfcreek1 & Sep-85 & 0.7 & 0.73 & Dec-88 & 3.33 & 2.33 & 2.33 & & 0 & 0 & 0 & 2.43 & 2.43 & 0.9 & 0.9 \\
\hline yankeerowe & Nov- 60 & 0.74 & 0.79 & Dec-88 & 28.18 & 20.86 & 20.86 & & 0 & 1 & 1 & 22.27 & 22.27 & 5.92 & 5.92 \\
\hline zionl & Dec-73 & 0.58 & 0.69 & Dec-88 & 15.09 & 8.75 & 12.49 & & 0 & 0 & 0 & 10.41 & 13.56 & 4.68 & 7.58 \\
\hline zion2 & Sep-74 & 0.62 & 0.71 & Dec-88 & na & 8.89 & na & & & & & 10.14 & na & 4.2 & na \\
\hline
\end{tabular}

ż 
\% Cap $=$ Cumulative Plant Capacity Factor [Nuclear Safety, Vol. 30, No. 2]

+ End Date = End Date of Analysis, December 31, 1988

+ Optime $=$ Site Calendar Years of Commercial Operation (End Date - StartDate)

Online $=$ Optime times the Capacity Factor

ModOnline = Effective Online Time for Multiple Unit Sites

+ PC LOSP $=$ Number of Plant-Centered LOSP Occurring at Site During Optime

+ G\&W LOSP $=$ Number of Grid and Weather Events Occurring at Site During Optime

+ Cat IV = Number of Category IV Events (Unique to Shutdown) Occurring at Site During Optime FP time $=$ Optime times the Availability Factor modFPtime $=$ Effective FP time for Multiple Unit Sites

+ SDtime $=$ Optime times $(1-$ Avail Factor $)$

+ modSDtime $=$ Effective SD time for Multiple Unit Sites

+ Parameter Used in Shutdown Study LOSP Calculation 
Table G.1.4 Non-Category IV Event Data

\begin{tabular}{|c|c|c|}
\hline Plant & No. Events & Site Years \\
\hline 1 & 1 & 14.09 \\
\hline 2 & 1 & 12.25 \\
\hline 3 & 1 & 25.85 \\
\hline 4 & 0 & 14.42 \\
\hline 5 & 1 & 13.17 \\
\hline 6 & 0 & 3.33 \\
\hline 7 & 0 & 4.08 \\
\hline 8 & 1 & 13.68 \\
\hline 9 & 0 & 3.58 \\
\hline 10 & 0 & 1.10 \\
\hline 11 & 0 & 13.42 \\
\hline 12 & 0 & 14.51 \\
\hline 13 & 0 & 11.84 \\
\hline 14 & 0 & 10.51 \\
\hline 15 & 1 & 3.67 \\
\hline 16 & 2 & 18.59 \\
\hline 17 & 0 & 13.92 \\
\hline 18 & 0 & 11.09 \\
\hline 19 & 0 & 13.51 \\
\hline 20 & 2 & 14.59 \\
\hline 21 & 1 & 9.51 \\
\hline 22 & 2 & 18.51 \\
\hline 23 & 0 & 3.50 \\
\hline 24 & 6 & 21.43 \\
\hline 25 & 0 & 13.09 \\
\hline 26 & 0 & 2.03 \\
\hline 27 & 5 & 14.42 \\
\hline 28 & 0 & 14.59 \\
\hline 29 & 0 & 5.00 \\
\hline 30 & 0 & 2.92 \\
\hline 31 & 0 & 16.09 \\
\hline 32 & 1 & 7.08 \\
\hline 33 & 3 & 17.85 \\
\hline 34 & 1 & 17.59 \\
\hline 35 & 2 & 19.09 \\
\hline 36 & 0 & 10.59 \\
\hline 37 & 1 & 15.51 \\
\hline 38 & 1 & 19.09 \\
\hline 39 & 3 & 17.09 \\
\hline 40 & 2 & 2.91 \\
\hline 41 & 0 & 14.51 \\
\hline 42 & 0 & 1.12 \\
\hline 43 & 4 & 16.09 \\
\hline 44 & 2 & 18.09 \\
\hline 45 & 1 & 15.09 \\
\hline 46 & 2 & 15.92 \\
\hline 47 & 0 & 13.76 \\
\hline 48 & 1 & 2.58 \\
\hline 49 & 1 & 17.85 \\
\hline 50 & 0 & 11.59 \\
\hline
\end{tabular}

$\begin{array}{rcr}\text { Plant } & \text { No. Events } & \text { Site Years } \\ \mathbf{5 1} & 2 & \\ 52 & 0 & 21.01 \\ 53 & 2 & 7.50 \\ 54 & 0 & 12.09 \\ 55 & 0 & 1.69 \\ 56 & 0 & 5.00 \\ 57 & 1 & 16.09 \\ 58 & 0 & 5.59 \\ 59 & 0 & 14.34 \\ 60 & 9 & 12.67 \\ 61 & 0 & 16.09 \\ 62 & 0 & 16.17 \\ 63 & 0 & 1.58 \\ 64 & 0 & 4.08 \\ 65 & 0 & 3.33 \\ 66 & 1 & 3.33 \\ 67 & 0 & 28.18 \\ & & 15.09\end{array}$




\section{LOSP Frequency}

Table G.1.5 Category IV Event Data

\begin{tabular}{|c|c|c|c|c|c|}
\hline Plant & No. Events & Site Years & Plant & No. Events & Site Years \\
\hline 1 & 0 & 6.18 & 51 & 2 & 10.74 \\
\hline 2 & 0 & 4.83 & 52 & 0 & 5.26 \\
\hline 3 & 0 & 7.60 & 53 & 0 & 3.78 \\
\hline 4 & 0 & 12.69 & 54 & 0 & 0.44 \\
\hline 5 & 1 & 7.97 & 55 & 0 & 1.35 \\
\hline 6 & 0 & 0.98 & 56 & 0 & 9.41 \\
\hline 7 & 0 & 0.65 & 57 & 0 & 2.03 \\
\hline 8 & 0 & 4.87 & 58 & 0 & 8.32 \\
\hline 9 & 0 & 1.77 & 59 & 0 & 4.44 \\
\hline 10 & 0 & 0.18 & 60 & 1 & 9.01 \\
\hline 11 & 0 & 6.23 & 61 & 0 & 3.56 \\
\hline 12 & 0 & 3.77 & 62 & 0 & 0.40 \\
\hline 13 & 0 & 4.38 & 63 & 0 & 1.14 \\
\hline 14 & 0 & 5.04 & 64 & 0 & 0.73 \\
\hline 15 & 0 & 1.31 & 65 & 0 & 0.90 \\
\hline 16 & 0 & 9.10 & 66 & 1 & 5.92 \\
\hline 17 & 0 & 4.30 & 67 & 0 & 7.58 \\
\hline 18 & 0 & 3.76 & & & \\
\hline 19 & 3 & 3.92 & & & \\
\hline 20 & 1 & 3.40 & & & \\
\hline 21 & 0 & 6.66 & & & \\
\hline 22 & 0 & 4.31 & & & \\
\hline 23 & 0 & 1.16 & & & \\
\hline 24 & 1 & 4.24 & & & \\
\hline 25 & 0 & 6.21 & & & \\
\hline 26 & 0 & 0.37 & & & \\
\hline 27 & 1 & 8.16 & & & \\
\hline 28 & 0 & 2.32 & & & \\
\hline 29 & 0 & 3.12 & & & \\
\hline 30 & 0 & 0.52 & & & \\
\hline 31 & 0 & 3.65 & & & \\
\hline 32 & 1 & 3.14 & & & \\
\hline 33 & 0 & 7.35 & & & \\
\hline 34 & 1 & 4.05 & & & \\
\hline 35 & 0 & 6.30 & & & \\
\hline 36 & 0 & 4.40 & & & \\
\hline 37 & 0 & 9.00 & & & \\
\hline 38 & 1 & 7.07 & & & \\
\hline 39 & 1 & 8.55 & & & \\
\hline 40 & 0 & 1.53 & & & \\
\hline 41 & 0 & 9.45 & & & \\
\hline 42 & 0 & 0.27 & & & \\
\hline 43 & 0 & 7.24 & & & \\
\hline 44 & 1 & 5.23 & & & \\
\hline 45 & 0 & 4.11 & & & \\
\hline 46 & 1 & 6.63 & & & \\
\hline 47 & 0 & 7.29 & & & \\
\hline 48 & 0 & 0.80 & & & \\
\hline 49 & 0 & 5.37 & & & \\
\hline 50 & 1 & 6.25 & & & \\
\hline
\end{tabular}




\section{G.2 Determination of the Mean Probability of Recovery from LOSP at Different Times}

\section{G.2.1 Process}

\section{G.2.1.1 Overview .}

This section contains a summary of the methodology used to determine the times to recover from a LOSP event at the Grand Gulf Nuclear Station (GGNS) and the mean probabilities of recovery at the different times. The report covers all LOSP events up to 1988 and includes Category IV (Shutdown) events summarized in Reference 2. The steps used to determine these recovery times and probabilities are given below.

\section{G.2.1.2 Procedure}

Step 1. The LOSP events listed in Reference 2 were categorized by type: Plant Centered (PC), Grid (G), and Weather caused (W). Plant centered events are those in which the design and operational characteristics of the plant played a role in the LOSP and its duration [3]. Grid caused events are those in which the design and operational characteristics of the power grid from which the plant draws its off-site power are a factor.

Six data files (Attachments G-31 - G-36) were constructed for the LOSP recovery times. One contained the recovery times for grid events (GGGRID.DAT) and another contained the recovery times for weather events (GGWEAT.DAT). The plant centered events were subdivided into three subsets based on switchyard configuration classifications defined in NUREG-1032 [4]. The three data files for these three subsets were GGPC1.DAT, GGPC2.DAT, and GGPC3.DAT. A fourth PC file containing all of the recovery times of the first three was also established. This file was GGPC4.DAT. The recovery times are also summarized in Table G.2.1.

Step 2. The program MODEL was run to calculate the probabilities of recovery from LOSP at different times from each of the three categories. MODEL is an interactive program that implements the mixture model for the distribution of the recovery from LOSP as developed in Reference 3. The program has a number of values hardwired into it. These values were updated to reflect the most recent data on the occurrence of and recovery from LOSP events (including Category IV events) in the United States as of 1988 . The values updated were $P(1)$, a weighting function for each $P C$ LOSP category; S(1), a sample mean term for each PC LOSP category; and N(1), the number of events in each PC LOSP category. The values are different for each of the three PC LOSP types and, in the MODEL code, reside in different branches of an IF-THEN-ELSE statement (Statement 13). The variable NPC (just below Statement 12) was changed to 62 , the updated number of PC LOSP events. A copy of the MODEL.FOR code is given in the Attachment G-37.

The $P(N)$ and $S(N)$ terms are statistical characteristics of the PC LOSP recovery time populations. They were determined using the program GAMMA. GAMMA is an interactive program that prompts the user for an input file which contains data for which the user requires the Maximum Likelihood Estimates of the Geometric and Sample Means. The input files for the LOSP recovery analyses were the GGXXX.DAT files containing the recovery times for the six types of LOSP events. The output of the code is written to the file MLE.OUT. In the case of the PC LOSP events, the output "Geometric Mean $^{n}$ is the $P(1)$ value for the corresponding GGPCN.DAT data. The output "Sample Mean" is the $S(1)$ value, and $N(1)$ is the Sample Size. Copies of GAMMA.FOR and MLE.OUT are given in Attachments G-38 and G-39.

After the changes were incorporated into MODEL.FOR, it was compiled and linked to two libraries, AMOSLIB (see Attachment G-40) and IMSLIBS/LIB [5] and run. The MODEL output was written to the file GG.DAT (Attachment G-41). This file contained the probabilities of recovery from LOSP at different times for the three categories of LOSP events.

Step 3. The results of the MODEL calculations were plotted using the program MAPPER, a graphics routine. The GG.DAT file was copied to a file for MAPPER input called MAP.DAT. The plot contained curves for the fifth, 50th and 95 th percentiles of the recovery times. The plot is shown in Figure G.2-1.

Step 4. The program COMMEAN was run using the MAP.DAT file a input. The program uses a lognormal distribution routine to calculate the error factor $(E F)$ and the mean probability for recovery from LOSP at the different time steps in the MODEL output. The results of the calculation are stored in LOGNORMAL.DAT. COMMEAN also creates a file called MEAN.DAT which is essentially LOGNORMAL.DAT without the column headings. Listings of COMMEAN.FOR and LOGNORMAL.DAT are included in the Attachments G- 


\section{LOSP Frequency}

42 and G-43.

Step 5. Finally, the probability of recovery was plotted against the mean time to recover. This plot is given in Figure G.2.2.

\section{G.2.2 Results}

Using the process outlined above, the mean probability of rocovery of LOSP versus time was determined and recorded in Table G.2.2 and plotted as shown in Figure G.2.2. 
Table G.2.1 Time to Recover from LOSP through 1988

\begin{tabular}{|c|c|c|c|c|}
\hline $\begin{array}{c}\text { Plant Centered } \\
\text { Switchyard Group } 1 \\
\text { Recovery Times(hrs) }\end{array}$ & $\begin{array}{c}\text { Plant Centered } \\
\text { Switchyard Group } 2 \\
\text { Recovery } \\
\text { Times(hrs) }\end{array}$ & $\begin{array}{c}\text { Plant Centered } \\
\text { Switchyard Group } 3 \\
\text { Recovery Times(hrs) }\end{array}$ & $\begin{array}{c}\text { Grid } \\
\text { Recovery } \\
\text { Times(hrs) }\end{array}$ & $\begin{array}{c}\text { Severe } \\
\text { Weather } \\
\text { Recovery } \\
\text { Times(hrs) }\end{array}$ \\
\hline .002 & .070 & 1.970 & .130 & 1.750 \\
\hline .003 & 1.480 & .900 & .180 & 2.670 \\
\hline .004 & .280 & 2.740 & .250 & 4.000 \\
\hline .033 & .083 & .900 & .300 & 4.317 \\
\hline .050 & .500 & .015 & .330 & 5.000 \\
\hline .330 & .670 & 1.750 & .330 & 5.500 \\
\hline .367 & .334 & .500 & $.333^{*}$ & 8.900 \\
\hline 1.000 & .003 & .930 & .550 & $11.000^{*}$ \\
\hline .430 & .130 & .500 & .920 & \\
\hline .663 & .020 & 7.430 & 1.030 & \\
\hline .270 & 1.030 & .400 & 1.500 & \\
\hline .167 & .250 & .200 & 2.000 & \\
\hline .080 & .250 & 1.150 & 2.083 & \\
\hline .250 & .283 & .570 & 6.470 & \\
\hline .150 & .417 & .767 & & \\
\hline .013 & 4.000 & 1.667 & & \\
\hline .183 & .050 & .004 & & \\
\hline .480 & 2.000 & .067 & & \\
\hline .150 & & 11.083 & & \\
\hline \multirow[t]{5}{*}{.017} & & .233 & & \\
\hline & & 2.683 & & \\
\hline & & 4.983 & & \\
\hline & & .117 & & \\
\hline & & .717 & & \\
\hline
\end{tabular}



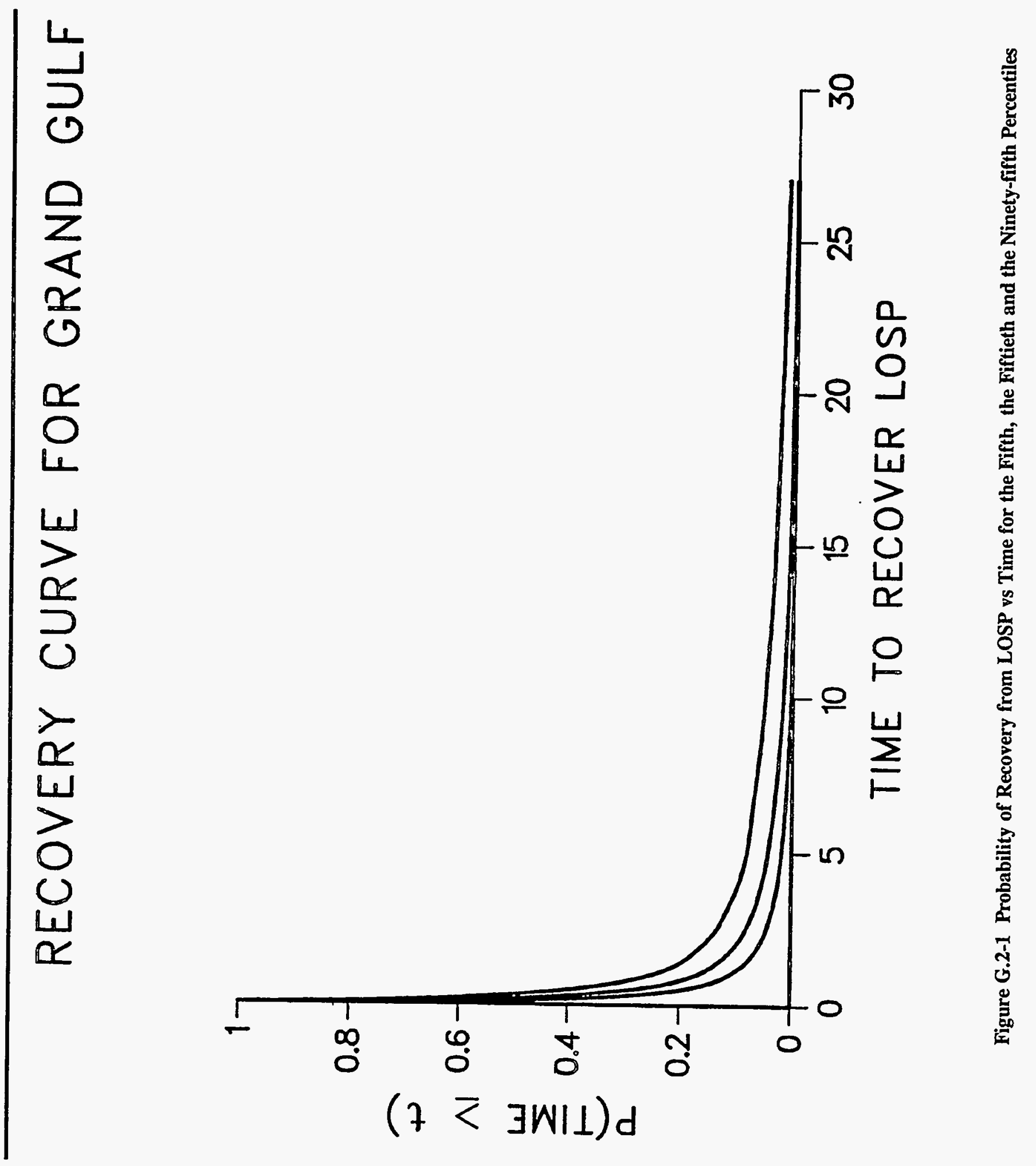
Table G.2.2 Mean Probability of Recovery from LOSP at Different Times

\begin{tabular}{|c|c|c|c|c|c|}
\hline Time & EF & Mean & Time & EF & Mean \\
\hline 0.00 & 1.0 & $1.000 \mathrm{E}+00$ & 2.50 & 1.8 & $8.706 \mathrm{E}-02$ \\
\hline 0.05 & 1.2 & $7.501 \mathrm{E}-01$ & 2.75 & 1.9 & $8.010 \mathrm{E}-02$ \\
\hline 0.10 & 1.2 & $6.370 \mathrm{E}-01$ & 3.00 & 1.9 & $7.453 \mathrm{E}-02$ \\
\hline 0.15 & 1.2 & $5.564 \mathrm{E}-01$ & 3.17 & 1.9 & $7.066 \mathrm{E}-02$ \\
\hline 0.20 & 1.3 & $4.958 \mathrm{E}-01$ & 3.50 & 2.0 & $6.528 \mathrm{E}-02$ \\
\hline 0.25 & 1.3 & 4.472E-01 & 3.75 & 2.1 & $6.247 \mathrm{E}-02$ \\
\hline 0.30 & 1.4 & 4.069E-01 & 4.00 & 2.1 & $5.898 \mathrm{E}-02$ \\
\hline 0.35 & 1.4 & 3.697E-01 & 4.25 & 2.2 & $5.575 E-02$ \\
\hline 0.40 & 1.4 & $3.404 E-01$ & 4.50 & 2.2 & $5.284 \mathrm{E}-02$ \\
\hline 0.45 & 1.4 & $3.146 \mathrm{E}-01$ & 4.75 & 2.3 & $5.054 \mathrm{E}-02$ \\
\hline 0.50 & 1.4 & $2.921 E-01$ & 5.00 & 2.3 & $4.828 \mathrm{E}-02$ \\
\hline 0.55 & 1.4 & $2.720 \mathrm{E}-01$ & 5.25 & 2.4 & $4.652 \mathrm{E}-02$ \\
\hline 060 & 1.5 & $2.548 \mathrm{E}-01$ & 5.50 & 2.5 & $4.526 \mathrm{E}-02$ \\
\hline 065 & 1.5 & $2.396 \mathrm{E}-01$ & 5.75 & 2.5 & $4.336 \mathrm{E}-02$ \\
\hline 0.70 & 1.5 & $2.266 \mathrm{E}-01$ & 6.00 & 2.6 & 4.141E-02 \\
\hline 0.75 & 1.5 & 2.160E-01 & 6.25 & 2.6 & 3.970E-02 \\
\hline 0.80 & 1.5 & $2.053 \mathrm{E}-01$ & 6.50 & 2.7 & $3.840 \mathrm{E}-02$ \\
\hline 0.85 & 1.5 & $1.962 \mathrm{E}-01$ & 6.75 & 2.8 & $3.725 E-02$ \\
\hline 0.90 & 1.5 & $1.885 \mathrm{E}-01$ & 7.00 & 2.8 & $3.603 E-02$ \\
\hline 0.95 & 1.5 & $1.801 \mathrm{E}-01$ & 7.25 & 2.9 & $3.474 \mathrm{E}-02$ \\
\hline 1.00 & 1.5 & $1.730 \mathrm{E}-01$ & 7.50 & 3.0 & $3.346 \mathrm{E}-02$ \\
\hline 1.05 & 1.5 & $1.671 E-01$ & 7.75 & 3.1 & $3.242 E-02$ \\
\hline 1.10 & 1.5 & $1.614 \mathrm{E}-01$ & 8.00 & 3.2 & $3.151 E-02$ \\
\hline 1.13 & 1.5 & $1.575 E-01$ & 8.25 & 3.2 & $3.022 \mathrm{E}-02$ \\
\hline 1.20 & 1.6 & $1.523 \mathrm{E}-01$ & 8.50 & 3.3 & $2.910 \mathrm{E}-02$ \\
\hline 1.25 & 1.6 & $1.483 \mathrm{E}-01$ & 8.75 & 3.4 & $2.798 \mathrm{E}-02$ \\
\hline 1.28 & 1.6 & $1.451 \mathrm{E}-01$ & 9.00 & 3.5 & $2.708 \mathrm{E}-02$ \\
\hline 1.33 & 1.6 & $1.416 \mathrm{E}-01$ & 9.25 & 3.6 & $2.640 \mathrm{E}-02$ \\
\hline 1.40 & 1.6 & $1.365 \mathrm{E}-01$ & 9.50 & 3.7 & $2.559 E-02$ \\
\hline 1.45 & 1.6 & $1.329 E-01$ & 9.75 & 3.8 & $2.503 E-02$ \\
\hline 1.50 & 1.6 & $1.290 \mathrm{E}-01$ & 10.00 & 3.9 & $2.430 \mathrm{E}-02$ \\
\hline 1.55 & 1.6 & $1.257 \mathrm{E}-01$ & $13-30$ & 6.2 & $1.970 \mathrm{E}-02$ \\
\hline 1.60 & 1.7 & $1.230 \mathrm{E}-01$ & 15.00 & 7.7 & $1.780 \mathrm{E}-02$ \\
\hline 1.65 & 1.7 & $1.203 \mathrm{E}-01$ & 16.00 & 8.8 & $1.682 \mathrm{E}-02$ \\
\hline 1.70 & 1.7 & $1.173 E-01$ & 18.00 & 11.5 & $1.597 \mathrm{E}-02$ \\
\hline 1.75 & 1.7 & $1.147 \mathrm{E}-01$ & 23.00 & 22.1 & $1.476 \mathrm{E}-02$ \\
\hline 1.80 & 1.7 & $1.124 \mathrm{E}-01$ & 27.00 & 32.8 & $1.328 \mathrm{E}-02$ \\
\hline 1.85 & 1.7 & $1.098 \mathrm{E}-01$ & & & \\
\hline 1.90 & 1.7 & $1.077 \mathrm{E}-01$ & & & \\
\hline 1.95 & 1.7 & $1.051 \mathrm{E}-01$ & & & \\
\hline 2.00 & 1.7 & $1.032 \mathrm{E}-01$ & & & \\
\hline 2.05 & 1.7 & $1.011 \mathrm{E}-01$ & & & \\
\hline 2.10 & 1.8 & $9.923 \mathrm{E}-02$ & & & \\
\hline 2.15 & 1.8 & $9.724 \mathrm{E}-02$ & & & \\
\hline 2.20 & 1.8 & $9.540 \mathrm{E}-02$ & & & \\
\hline 2.25 & 1.8 & $9.410 \mathrm{E}-02$ & & & \\
\hline 2.30 & 1.8 & $9.273 E-02$ & & & \\
\hline 2.35 & 1.8 & $9.120 \mathrm{E}-02$ & & & \\
\hline 2.40 & 1.8 & $8.973 E-02$ & & & \\
\hline 2.45 & 1.8 & $8.832 E-02$ & & & \\
\hline
\end{tabular}




\section{RECOVERY CURVE FOR GRAND GULF}

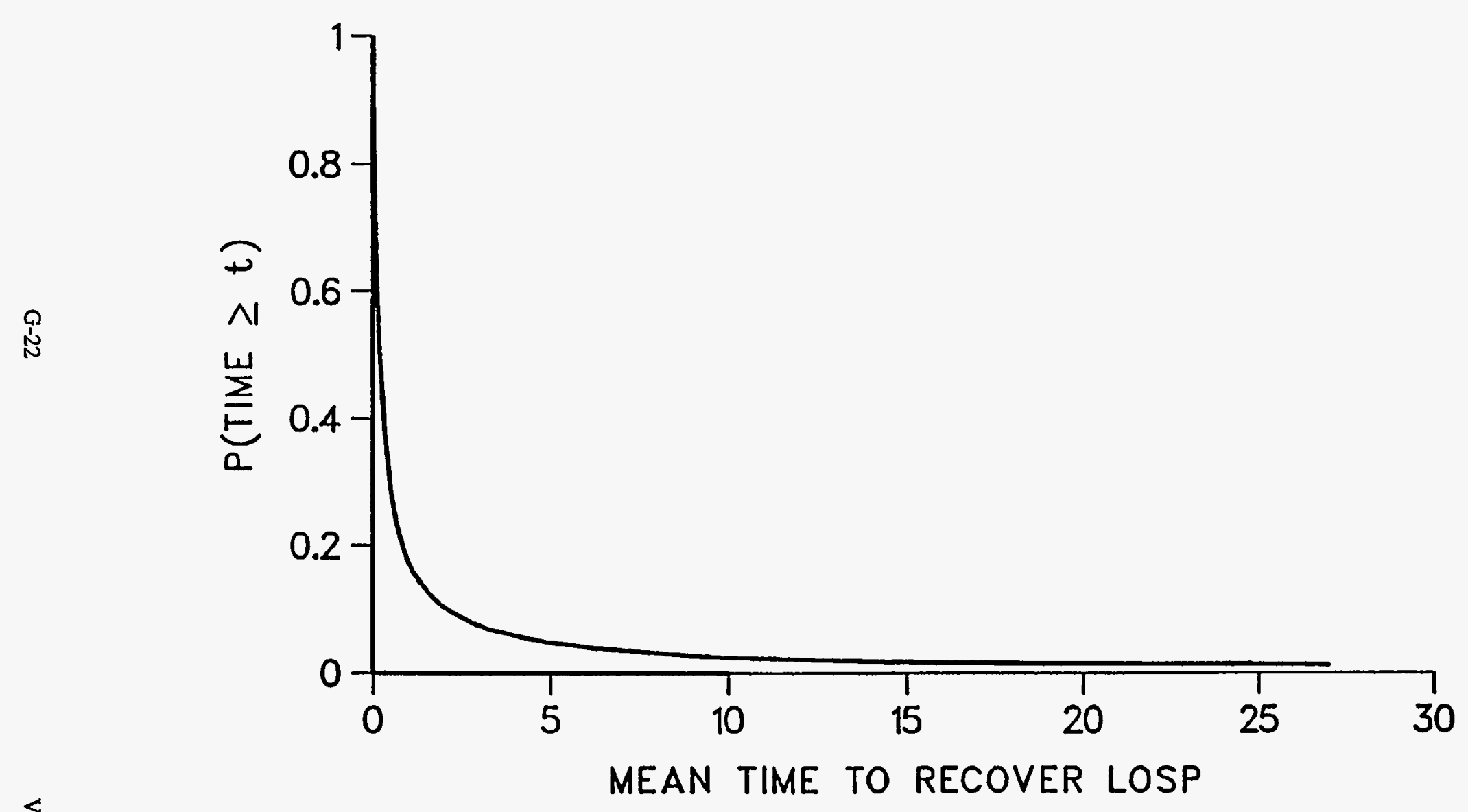

Figure G.2-2 Mean Probability of Recovery from LOSP vs Time at Grand Gulf 


\section{G.3 Determination of Recovery Values for LOSP/DG-Failure Restorations: DG Fails to Start}

\section{G.3.1 Process}

\section{G.3.1.1 Overview}

The following process describes the steps carried out in the calculation of the non-recovery probabilities for LOSP accompanied by the failure of the diesel generators to start. The process assumes that the DGs were called for at the onset of LOSP.

The calculations consider failure to start due to hardware failures and due to common mode failures. The results of the calculations are tables of nonrecovery probabilities vs. time after the $D G(s)$ fail to start.

The correction factor (or recovery factor) for the recovery from LOSP and failure of diesel generators to start at time $\mathrm{T}\left(\mathrm{CF}_{\mathrm{DGS}}\right)$ is given by

$$
C F_{D G S}(T)=P_{n r}(T) * P_{n D G}(T)
$$

where:

$$
\begin{gathered}
P_{n s}(T)=\begin{array}{l}
\text { probability of non-recovery of off- } \\
\text { site power at time } T \text { after LOSP. }
\end{array} \\
P_{n D G}(T)=\begin{array}{l}
\text { probability of non-recovery of DG } \\
\text { at time } T \text { after LOSP. }
\end{array}
\end{gathered}
$$

\section{G.3.1.2 Procedure}

Step 1. Data for the probability of non-recovery of offsite power versus time were plotted.

The plot was in the form

$$
\ln \left(P_{n r}\right) \text { vs. } T
$$

where:

$P_{a s}=$ probability of non-recovery of off-site power.

$\mathrm{T}=$ time required for recovery after which core damage is to be expected.

A second treatment of the data involved the determination of an interpolating polynomial using Newton's Interpolatory Algorithm [7]. This polynomial was of the form:

$$
y(x)=\Sigma_{i=1}^{3} Q_{i i} \Pi_{j=0}^{i=1}\left(x-x_{j}\right)
$$

where:

$$
\begin{aligned}
& y=\ln \left(P_{n r}\right) \\
& x=\ln (1+t) \\
& t=\text { time at which LOSP occurs. }
\end{aligned}
$$

The expression for $x$ has a 1 in the $\ln$ argument because $t$ may be set to zero.

Step 2. Data for the probability of non-recovery of diesel generators after their failure to start were plotted [8]. Two cases were considered: a) failure to start due to a hardware failure; and b) failure to start due to a common mode failure. In both cases a linear fit was made of $\ln \left(\mathrm{P}_{\mathrm{DGS}}\right)$, the $\log$ of the probability of nonrecovery of the DG after failure to start vs. time from the failure to start. Thus:

$$
P_{n G S}(T)=\exp (m \cdot T)
$$

where: $m=$ slope of the $\ln \left[P_{n G S}(T)\right]$ graph

$\mathrm{T}=$ time since failure to start.

Step 3. A table of values for $\mathrm{CF}_{\mathrm{DGS}}$ was formed from the product:

$$
\left.C F_{D G S}=\exp \left\{\ln r P_{n r}(T)\right]\right\} *\left\{\ln \left[P_{N D G}(T)\right]\right\}
$$

for values of $\mathrm{T}$ from 0 to 24 hours in half-hour time steps.

Analyses requiring a value between the half-hour increments was either interpolated from the table or calculated directly from the equations (curve fits) for $P_{n t}$ and $P_{N D G}$.

\section{G.3.2 Results}

The table of results is given in Table G.3.1. 
Table G.3.1 Correction/Recovery Factors for DG Fails to Start (LOSP as Initiating Event)

\begin{tabular}{|c|c|c|}
\hline Time (hr.) & Hardware & Common Mode \\
\hline 0 & 1 & 1 \\
\hline .5 & $2.988 \mathrm{E}-1$ & $2.945 \mathrm{E}-1$ \\
\hline 1.0 & $1.5298 \mathrm{E}-1$ & $1.4861 \mathrm{E}-1$ \\
\hline 1.5 & $9.9556 \mathrm{E}-2$ & $9.5127 \mathrm{E}-2$ \\
\hline 2.0 & $7.3188 \mathrm{E}-2$ & $6.9064 \mathrm{E}-2$ \\
\hline 2.5 & $5.8076 \mathrm{E}-2$ & $5.4015 \mathrm{E}-2$ \\
\hline 3.0 & $4.8821 \mathrm{E}-2$ & $4.4294 \mathrm{E}-2$ \\
\hline 3.5 & $4.1504 E-2$ & $3.7498 \mathrm{E}-2$ \\
\hline 4.0 & $3.6452 \mathrm{E}-2$ & $3.2460 \mathrm{E}-2$ \\
\hline 4.5 & $3.2535 \mathrm{E}-2$ & $2.8555 \mathrm{E}-2$ \\
\hline 5.0 & $2.9389 \mathrm{E}-2$ & $2.5422 \mathrm{E}-2$ \\
\hline 5.5 & $2.6788 \mathrm{E}-2$ & $2.2839 \mathrm{E}-2$ \\
\hline 6.0 & $2.4589 \mathrm{E}-2$ & $2.0662 \mathrm{E}-2$ \\
\hline 6.5 & $2.2695 \mathrm{E}-2$ & $1.8796 \mathrm{E}-2$ \\
\hline 7.0 & $2.1038 \mathrm{E}-2$ & $1.7173 \mathrm{E}-2$ \\
\hline 7.5 & $1.9570 \mathrm{E}-2$ & $1.5745 \mathrm{E}-2$ \\
\hline 8.0 & $1.8257 \mathrm{E}-2$ & $1.4477 \mathrm{E}-2$ \\
\hline 8.5 & $1.7072 \mathrm{E}-2$ & $1.3342 \mathrm{E}-2$ \\
\hline 9.0 & $1.5994 \mathrm{E}-2$ & $1.2320 \mathrm{E}-2$ \\
\hline 9.5 & $1.5008 \mathrm{E}-2$ & $1.1394 \mathrm{E}-2$ \\
\hline 10.0 & $1.4102 \mathrm{E}-2$ & $1.0552 \mathrm{E}-2$ \\
\hline 10.5 & $1.3265 \mathrm{E}-2$ & $9.7828 \mathrm{E}-3$ \\
\hline 11.0 & $1.2490 \mathrm{E}-2$ & $9.0786 \mathrm{E}-3$ \\
\hline 11.5 & $1.1770 \mathrm{E}-2$ & $8.4319 \mathrm{E}-3$ \\
\hline 12.0 & $1.1099 \mathrm{E}-2$ & $7.8867 \mathrm{E}-3$ \\
\hline 12.5 & $1.0472 \mathrm{E}-2$ & $7.2879 E-3$ \\
\hline
\end{tabular}


Table G.3.1 Correction/Recovery Factors for DG Fails to Start (LOSP as Initiating Event) (Continued)

\begin{tabular}{|c|c|c|}
\hline Time (hr.) & Hardware & Common Mode \\
\hline 13.0 & $9.8859 \mathrm{E}-3$ & $6.7809 \mathrm{E}-3$ \\
\hline 13.5 & $9.3367 \mathrm{E}-3$ & $6.3120 \mathrm{E}-3$ \\
\hline 14.0 & $8.8215 \mathrm{E}-3$ & $5.8778 \mathrm{E}-3$ \\
\hline 14.5 & $8.3374 \mathrm{E}-3$ & $5.4754 \mathrm{E}-3$ \\
\hline 15.0 & $7.8823 \mathrm{E}-3$ & $5.1019 \mathrm{E}-3$ \\
\hline 15.5 & $7.4539 \mathrm{E}-3$ & 4.7552E-3 \\
\hline 16.0 & $7.0504 \mathrm{E}-3$ & $4.4330 \mathrm{E}-3$ \\
\hline 16.5 & $6.6701 \mathrm{E}-7$ & $4.1335 \mathrm{E}-3$ \\
\hline 17.0 & $6.3114 \mathrm{E}-3$ & $3.8550 \mathrm{E}-3$ \\
\hline 17.5 & $5.9730 \mathrm{E}-3$ & $3.5957 \mathrm{E}-3$ \\
\hline 18.0 & $5.6535 \mathrm{E}-3$ & $3.3544 \mathrm{E}-3$ \\
\hline 18.5 & 5.3517E-3 & $3.1297 \mathrm{E}-3$ \\
\hline 19.0 & $5.0667 \mathrm{E}-3$ & $2.9203 \mathrm{E}-3$ \\
\hline 19.5 & 4.7973E-3 & $2.7253 \mathrm{E}-3$ \\
\hline 20.0 & $4.5427 \mathrm{E}-3$ & $2.5435 \mathrm{E}-3$ \\
\hline 20.5 & $4.3020 \mathrm{E}-3$ & $2.3740 \mathrm{E}-3$ \\
\hline 21.0 & $4.0743 \mathrm{E}-3$ & $2.2160 \mathrm{E}-3$ \\
\hline 21.5 & $3.8590 \mathrm{E}-3$ & $2.0687 \mathrm{E}-3$ \\
\hline 22.0 & $3.6552 \mathrm{E}-3$ & $1.9312 \mathrm{E}-3$ \\
\hline 22.5 & 3.4625E-3 & $1.8031 \mathrm{E}-3$ \\
\hline 23.0 & $3.2801 \mathrm{E}-3$ & $1.6835 \mathrm{E}-3$ \\
\hline 23.5 & $3.1075 \mathrm{E}-3$ & $1.5719 \mathrm{E}-3$ \\
\hline 24.0 & $2.9441 \mathrm{E}-3$ & $1.4678 \mathrm{E}-3$ \\
\hline
\end{tabular}




\section{G.4 Determination of Recovery Values for LOSP/DG-Failure Restorations: DG Fails To Run}

\section{G.4.1 Process}

\section{G.4.1.1 Orerview}

This section describes the steps carried out in the calculation of the non-recovery probabilities for LOSP accompanied by the failure of diesel generators to run at some time after LOSP.

The correction factor (or recovery factor) for the recovery from LOSP given that the DGs fail to run is given by

$$
C F_{O P}(T)=\frac{P_{D G R t}(T)}{P_{D G R}}
$$

where

$$
\begin{aligned}
P_{D G R}(T)= & \begin{array}{l}
\text { probability that the DG fails to run during } \\
\text { the mission time }(t) \text { before offsite power is } \\
\text { recovered. }
\end{array} \\
P_{D G R}= & \begin{array}{l}
\text { probability that DG will fail to run in any } \\
\text { given } 24 \text { hour period (the mission time). }
\end{array}
\end{aligned}
$$

The result of the calculations was a table of probabilities of non-recovery of off-site power for times up to 24 hours after the DG failed to run.

\section{G.4.1.2 Procedure}

Step 1. Determine $P_{D G R}$. The probability that the DG will fail to run in any given 24 hour period is given by

$$
\begin{aligned}
P_{D G R} & =\int_{0}^{24 h r} \lambda \exp (-\lambda t) d t \\
& =1-\exp \left(-\lambda t_{\text {mission }}\right)
\end{aligned}
$$

$$
\begin{gathered}
\lambda=\text { the failure rate for } D G \text { to run. } \\
\qquad t_{\text {mission }}=24 \mathrm{hrs} .
\end{gathered}
$$

For GGNS, $P_{D G R}=.047$ and $\lambda=2 E-3 / h r$.

Step 2. Determine $P_{D G R}$. The probability that the DG fails to run during the mission time before offsite power is recovered is

$$
P_{D G R t}=\int_{0}^{24} \lambda \exp (-\lambda t) P_{n r}(t+T) d t
$$

$$
\text { where } \begin{aligned}
P_{n s}= & \text { non-recovery of offsite power in time } t+ \\
& T \text { after LOSP: } \\
t= & \text { time DG ran before failure: } \\
T= & \text { time available to restore off-site power } \\
& \text { before core damage occurs. }
\end{aligned}
$$

The integration of Equation (2) was performed using the MathCAD integration function[9]. In order to perform the integration it was necessary to express $P_{n r}(t+T)$ in a form compatible with the integration scheme. This form was the polynomial described in the DG Fails to Start case. (Section G.3.2)

The integration provided a table of values of $P_{D G R t}(T)$ for values of $T$ from 0 to 12 hours.

Step 3. Form the quotient

$$
C F_{o p}(T)=\frac{P_{D G R T}(T)}{P_{D G R}}
$$

\section{G.4.2 Results}

The resulting values are given in Table G.4.1.

where 
Table G.4.1 Correction/Recovery Factors for DG Fails to Run (LOSP as Initiating Event)

\begin{tabular}{|c|c|}
\hline Time (hr.) & $\mathrm{CF}_{\mathrm{op}}(\mathrm{T})$ \\
\hline 0 & $4.8211 \mathrm{E}-2$ \\
\hline 0.5 & $3.5676 \mathrm{E}-2$ \\
\hline 1.0 & $3.117 \mathrm{E}-2$ \\
\hline 1.5 & $2.8631 \mathrm{E}-2$ \\
\hline 2.0 & $2.6899 \mathrm{E}-2$ \\
\hline 2.5 & $2.5585 \mathrm{E}-2$ \\
\hline 3.0 & $2.4521 \mathrm{E}-2$ \\
\hline 3.5 & $2.3621 \mathrm{E}-2$ \\
\hline 4.0 & $2.2835 \mathrm{E}-2$ \\
\hline 4.5 & $2.2133 \mathrm{E}-2$ \\
\hline 5.0 & $2.1495 \mathrm{E}-2$ \\
\hline 5.5 & $2.0907 \mathrm{E}-2$ \\
\hline 6.0 & $2.0360 \mathrm{E}-2$ \\
\hline 6.5 & $1.9846 \mathrm{E}-2$ \\
\hline 7.0 & $1.9360 \mathrm{E}-2$ \\
\hline 7.5 & $1.8899 \mathrm{E}-2$ \\
\hline 8.0 & $1.8458 \mathrm{E}-2$ \\
\hline 8.5 & $1.8036 \mathrm{E}-2$ \\
\hline 9.0 & $1.7630 \mathrm{E}-2$ \\
\hline 9.5 & $1.7239 \mathrm{E}-2$ \\
\hline 10.0 & $1.6862 \mathrm{E}-2$ \\
\hline 10.5 & $1.6497 \mathrm{E}-2$ \\
\hline 11.0 & $1.6143 \mathrm{E}-2$ \\
\hline 11.5 & $1.5799 \mathrm{E}-2$ \\
\hline 12.0 & $1.5465 \mathrm{E}-2$ \\
\hline 12.5 & $1.5141 \mathrm{E}-2$ \\
\hline
\end{tabular}




\section{LOSP Frequency}

Table G.4.1 Correction/Recovery Factors for DG Fails to Run (LOSP as Initiating Event) (Continued)

\begin{tabular}{|c|c|}
\hline Time (hr.) & $\mathrm{CF}_{\mathrm{op}}(\mathrm{T})$ \\
\hline 13.0 & $1.4825 \mathrm{E}-2$ \\
\hline 13.5 & $1.4517 \mathrm{E}-2$ \\
\hline 14.0 & $1.4218 \mathrm{E}-2$ \\
\hline 14.5 & $1.3925 \mathrm{E}-2$ \\
\hline 15.0 & $1.3640 \mathrm{E}-2$ \\
\hline 15.5 & $1.3362 \mathrm{E}-2$ \\
\hline 16.0 & $1.3090 \mathrm{E}-2$ \\
\hline 16.5 & $1.2925 \mathrm{E}-2$ \\
\hline 17.0 & $1.2566 \mathrm{E}-2$ \\
\hline 17.5 & $1.2312 \mathrm{E}-2$ \\
\hline 18.0 & $1.2065 \mathrm{E}-2$ \\
\hline 18.5 & $1.1823 \mathrm{E}-2$ \\
\hline 19.0 & $1.1586 \mathrm{E}-2$ \\
\hline 19.5 & $1.1355 \mathrm{E}-2$ \\
\hline 20.0 & $1.1128 \mathrm{E}-2$ \\
\hline 20.5 & $1.0907 \mathrm{E}-2$ \\
\hline 21.0 & $1.0690 \mathrm{E}-2$ \\
\hline 21.5 & $1.0479 \mathrm{E}-2$ \\
\hline 22.0 & $1.0271 \mathrm{E}-2$ \\
\hline 22.5 & $1.0068 \mathrm{E}-2$ \\
\hline 23.0 & $9.8698 \mathrm{E}-3$ \\
\hline 23.5 & $9.6755 \mathrm{E}-3$ \\
\hline 24.0 & $9.4953 \mathrm{E}-3$ \\
\hline
\end{tabular}




\section{G.5 Determination of Recovery Values for LOSP/DG Failure Restoration (LOSP Not an IE) : DG Fails to Run}

\section{G.5.1 Overview}

This section describes the calculation of the non-recovery probabilities for LOSP (LOSP not an IE) accompanied by failure of the diesel generators to run sometime after LOSP.

The correction factor for recovery from LOSP, with the failure of the DG to run at some time after LOSP, is given by:

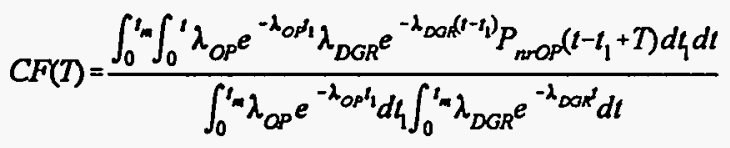

where:

$$
\begin{aligned}
\lambda_{O P} & =\text { frequency of the loss of off-site power } \\
\lambda_{\text {DGR }} & =\text { frequency of DG failure to run } \\
t^{m} & =\text { mission time (24 hrs.) } \\
P_{\text {aroP }} & =\text { probability of non-recovery of off-site power } \\
t & =\text { in time } t-t+T . \\
t_{1} & =\text { time at which DG fails to run }
\end{aligned}
$$

The double integral in the numerator of $\mathrm{CF}(\mathrm{T})$ is the probability that (during the mission time $t_{m}$ ) offsite power will be lost, the diesel generator will fail to run and offsite power cannot be recovered in time to prevent core damage at time $t-t_{1}-T$. The denominator is the probability that offsite power will be lost and the diesel generator will fail to run during the mission time.

\section{G.5.2 Procedure}

Step 1. $P_{\text {nrop }}$ was put into integrable form. Data for $\mathbf{P}_{\text {prop }}$ versus time was formed into a polynomial using Newton's interpolating algorithm. The form of the polynomial is given in the earlier discussion of DG fails to start with LOSP as an initiating event.

Step 2. The double integral of the numerator was performed using MathCAD [9]. The polynomial fit of $P_{\text {nrop }}$ was placed in the integrand in the form $\exp \left\{\ln \left[P_{\text {nrop }}\left(t t_{1}\right)\right\}\right.$ to account for the logarithm fit of the

Vol. 2, Part 2 polynomial fit. This double integral resulted in a set of numerator values from $T=0$ to $T=24$ hours in halfhour increments.

Step 3. The product of the integrals in the denominator gives a point value. With $\lambda_{\text {OP }}=1.484 \mathrm{E}-5, \lambda_{\mathrm{DGR}}=$ $2.0 \mathrm{E}-3$ and $\mathrm{T}_{\mathrm{m}}=24$ hours, the denominator was found to be $1.6689 \mathrm{E}-5$.

Step 4. $C F(T)$ was determined by dividing each value of the numerator by the value determined in Step 3. In the MathCAD calculation, these values were given the symbol $\mathrm{CF}_{\text {ofpur }}(\mathrm{T})$.

\section{G.5.3 Results}

The values for $\mathrm{CF}(\mathrm{T})$ determined in Step 4 above are given in Table G.5.1 which follows. 
Table G.5.1 Correction/Recovery Factors for LOSP (not an IE) with DG Fails to Run

\begin{tabular}{|c|c|}
\hline Time (hr.) & $\mathrm{CF}(\mathrm{T})$ \\
\hline 0 & $3.5746 \mathrm{E}-2$ \\
\hline 0.5 & $2.4606 \mathrm{E}-2$ \\
\hline 1.0 & $2.0556 \mathrm{E}-2$ \\
\hline 1.5 & $1.8354 \mathrm{E}-2$ \\
\hline 2.0 & $1.6912 \mathrm{E}-2$ \\
\hline 2.5 & $1.5862 \mathrm{E}-2$ \\
\hline 3.0 & $1.5043 \mathrm{E}-2$ \\
\hline 3.5 & $1.4373 \mathrm{E}-2$ \\
\hline 4.0 & $1.3805 \mathrm{E}-2$ \\
\hline 4.5 & $1.3311 \mathrm{E}-2$ \\
\hline 5.0 & $1.2872 \mathrm{E}-2$ \\
\hline 5.5 & $1.2476 \mathrm{E}-2$ \\
\hline 6.0 & $1.2113 \mathrm{E}-2$ \\
\hline 6.5 & $1.1778 \mathrm{E}-2$ \\
\hline 7.0 & $1.1465 \mathrm{E}-2$ \\
\hline 7.5 & $1.1171 \mathrm{E}-2$ \\
\hline 8.0 & $1.0893 \mathrm{E}-2$ \\
\hline 8.5 & $1.0630 \mathrm{E}-2$ \\
\hline 9.0 & $1.0378 \mathrm{E}-2$ \\
\hline 9.5 & $1.0137 \mathrm{E}-2$ \\
\hline 10.0 & $9.9060 \mathrm{E}-3$ \\
\hline 10.5 & $9.6833 E-3$ \\
\hline 11.0 & $9.4685 \mathrm{E}-3$ \\
\hline 11.5 & $9.2608 \mathrm{E}-3$ \\
\hline 12.0 & $9.0598 \mathrm{E}-3$ \\
\hline 12.5 & $8.8649 \mathrm{E}-3$ \\
\hline
\end{tabular}


Table G.5.1 Correction/Recovery Factors for LOSP (not an IE) with DG Fails to Run (Continued)

\begin{tabular}{|c|c|}
\hline Time (hr.) & $\mathrm{CF}(\mathrm{T})$ \\
\hline 13.0 & 8.6757E-3 \\
\hline 13.5 & $8.4918 \mathrm{E}-3$ \\
\hline 14.0 & $8.3130 \mathrm{E}-3$ \\
\hline 14.5 & $8.1390 \mathrm{E}-3$ \\
\hline 15.0 & $7.9694 \mathrm{E}-3$ \\
\hline 15.5 & $7.8042 \mathrm{E}-3$ \\
\hline 16.0 & $7.6431 \mathrm{E}-3$ \\
\hline 16.5 & $7.4859 \mathrm{E}-3$ \\
\hline 17.0 & $7.3325 \mathrm{E}-3$ \\
\hline 17.5 & $7.1828 \mathrm{E}-3$ \\
\hline 18.0 & $7.0365 \mathrm{E}-3$ \\
\hline 18.5 & $6.8937 \mathrm{E}-3$ \\
\hline 19.0 & $6.7541 \mathrm{E}-3$ \\
\hline 19.5 & $6.6177 \mathrm{E}-3$ \\
\hline 20.0 & $6.4843 E-3$ \\
\hline 20.5 & $6.3539 \mathrm{E}-3$ \\
\hline 21.0 & $6.2264 \mathrm{E}-3$ \\
\hline 21.5 & $6.1017 \mathrm{E}-3$ \\
\hline 22.0 & $5.9798 \mathrm{E}-3$ \\
\hline 22.5 & $5.8605 \mathrm{E}-3$ \\
\hline 23.0 & $5.7438 \mathrm{E}-3$ \\
\hline 23.5 & $5.6296 \mathrm{E}-3$ \\
\hline 24.0 & $5.5179 \mathrm{E}-3$ \\
\hline
\end{tabular}




\section{G.6 Determination of Recovery Values for LOSP/DG Failure Restoration (LOSP not an IE): DG Fails to Start}

The diesel generator would be called for at the time offsite power is lost. This is the case whether the LOSP is random after an initiating event or it is itself an initiating event. Thus, the time available for recovery is the same as for DG fails to start for LOSP as an initiating event and the results are the same. The probabilities of nonrecovery from DG failure to start for either as a hardware or common mode failure are given in Table G.3.1.

\section{G.7 Recovery/Correction Factors for Uncertainty Analysis}

This section describes the calculation of the offsite power recovery correction factors. The equations which form the basis for the calculation are given in Reference 10.

For uncertainty analysis, the calculations must consider the uncertainty in the inputs to these equations. To do this, distributions characterizing the uncertainty in the equations were developed. Once the distributions for the input parameters were obtained, these distributions were incorporated into the appropriate correction factor (CF) expressions. The output from this operation was a distribution of correction factors which reflected the uncertainties in the inputs.

Distributions of correction factors for recovery from four LOSP events were calculated:

- LOSP as an initiating event $\left(\mathrm{CF}_{1}\right)$

- LOSP as an initiating event, diesel generator (DG) fails to run ( $\left.\mathrm{CF}_{2}\right)$

- LOSP as an initiating event, DG fails to start (Hardware failure) $\left(\mathrm{CF}_{3}\right)$

- LOSP as an initiating event, DG fails to start (Common Mode failure) $\left(\mathrm{CF}_{4}\right)$

The process for the CF distribution calculations is given in Figure G.7-1.

The ouput of the process was a distribution of 500 values for CF (T) at 7 values of $T(2,3,3.5,5,6,11$ and 14 hours). "Each distribution reflects the uncertainty in $\mathrm{CF}_{\mathrm{n}}(\mathrm{T})$ at its particular value of $\mathrm{T}$.

\section{G.7.1 LOSP as Initiating Event (CF)}

The expression for this correction factor is

$$
C F_{1}(T)=P_{n \text { roP }} T
$$

where $P_{n=0}=$ probability of not recovering off-site power in time $T$.

The calculation of this CF distribution used only the left branch of Figure G.7-1. A data base of plant data for $P_{\text {rop }}(T)$ versus $T$ was used as input to MODEL.FOR. The MODEL code applies the mixture model of Reference 3 to the plant input data. The result is a set of $500 \mathrm{P}_{\text {nrop }}(\mathrm{T})$ vs. $T$ curves which reflect the uncertainty in the probability of recovery of off-site power. Each curve is identified by a number (called a pointer). For the Grand Gulf analysis, T varied from .05 to 100 hours and each curve was constructed of 85 points. The time range and number of points are user specified inputs to MODEL. The curves are written to a curve file.

The 500 point distribution for $P_{\text {nrop }}(T)$ at each of the seven time steps consists of the set of values from each of the 500 curves for the specified $T$.

\section{G.7.2 LOSP as Initiating Event: DG Fails to Run}

The correction factor for this case is given by

$$
C F_{2}(T)=\frac{\int_{0}^{t_{m}} \lambda_{D G R} e^{-\lambda_{D O R} t} P_{n O P P}(T+t) d t}{1-e^{-\lambda_{D O R} t_{m}}}
$$

where:

$$
\begin{array}{ll}
\lambda_{D G R} & =\text { DG run failure frequency of the DG } \\
t_{\mathrm{m}} & =\text { mission time ( } 24 \text { hours) } \\
\mathrm{P}_{\text {nrop }} & =\text { value from non-recovery curve for off- } \\
& \text { site power } \\
\mathrm{T} & =\text { time after which core damage occurs } \\
\mathrm{t} & =\text { time at which DG fails to run }
\end{array}
$$




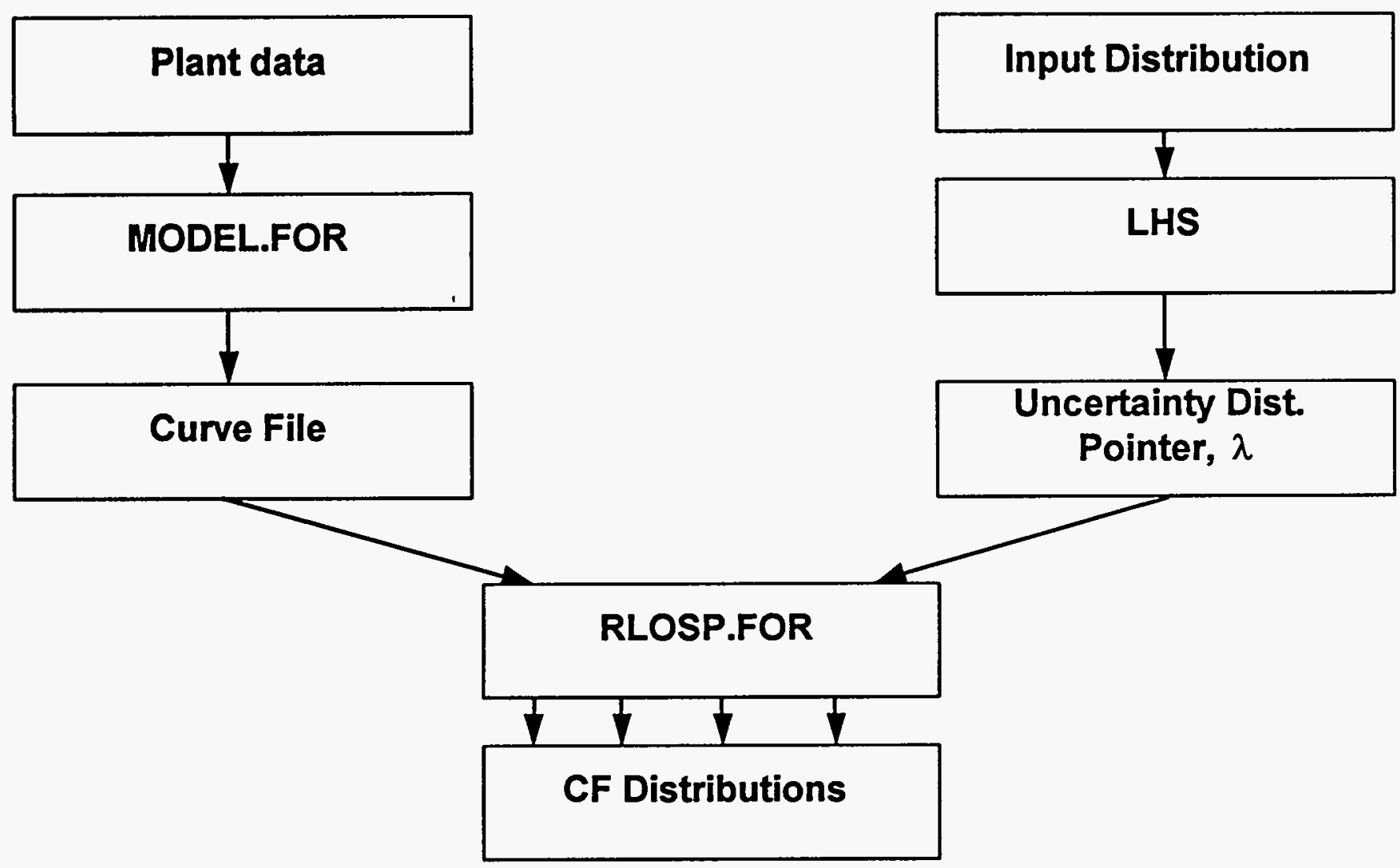

Figure G.7-1 CF Distribution Calculation 
The determination of $\mathrm{CF}_{2}$ required both branches of Figure G.7-1. The curves for $P_{\text {nrop }}$ were taken from the $\mathrm{CF}_{1}$ case. Using an input distribution of DG failure to run frequencies based on plant data, the LHS code developed a 500 point distribution for $X_{\mathrm{PGR}}$. This distribution is lognormal with a mean of 2.0E-3 and an error factor of 10 . The LHS step also writes a uniform distribution of the 500 points for the $P_{\text {nrop }}$ curves. The input for LHS used to determine these and subsequent distributions is given as Attachment G-44 to this Appendix.

The denominator of the $\mathrm{CF}_{2}(\mathrm{~T})$ expression is a point value evaluated at the mean value for $\lambda_{\mathrm{DGR}}$. This term cancels out the existing event in the cut set which was quantified using the same $\lambda_{D G R}$ value. The numerator of $\mathrm{CF}_{2}$ is calculated by the RLOSP code which samples $\lambda_{D G R}$ and $P_{\text {nrop }}$ and performs the integral. First, RLOSP selectes (at random) a value for $\lambda_{D G R}$ from the 500 calculated by LHS and a pointer corresponding to one of the $500 \mathrm{P}_{\text {moP }}$ curves. RLOSP then integrates the numerator over the mission time using a Runge-Kutta solution technique. The sampling and integration are repeated a total of 500 times until the 500 values of $P_{\text {nrop }}$ and $500 \lambda_{\text {DGR }}$ curves have been used, yielding 500 numerators. Each numerator is divided by the point value denominator yielding a distribution of 500 values of $\mathrm{CF}_{2}(\mathrm{~T})$.

A listing of the RLOSP code is given in Attachment G-45 to this Appendix.

\section{G.7.3 LOSP as Initiating Event: DG Fails to Start}

The correction factor for this event is given by

$$
C F_{3}(T)=P_{n r O P}(T) P_{n r D G}(T)
$$

where $P_{\text {nIDG }}$ is the non-recovery probability for the diesel generator at time $T$. Both offsite power and the $D G$ are taken to fail at time 0 . Both $P_{\text {nroP }}$ and $P_{\text {nrDG }}$ are sampled. Values for $P_{\text {nrop }}$ are obtained from the 500 curves calculated for $\mathrm{CF}_{1}(T)$. A maximum entropy distribution was used to characterize $P_{\text {prpg }}$. Each $P_{n s p G}(T) 500$ point distribution was calculated by LHS. This required an input of the lower value, mean, and upper value for the desired distribution. These inputs for each of the seven recovery times are given in Table G.7.1.
For each specified $T$, the mean value was selected from the mean non-recovery curve of Reference 10 . The upper value was set to 1.0 and the lower value was set an order of magnitude below the mean.

Having the $500 \mathrm{P}_{\text {nrop }}$ curves and pointers and the 500 point maximum entropy distribution for $P_{n x G}$ for a given time $T$, the RLOSP code samples both and forms their product as $\mathrm{CF}_{3}(\mathrm{~T})$. The sampling and multiplication are performed $500^{3}$ times to form a 500 point distribution for $\mathrm{CF}_{3}(\mathrm{~T})$ at each desired $\mathrm{T}$.

\section{G.7.4 LOSP as Initiating Event: DG Fails to Start, Common Mode}

The correction factor for this event is given by

$$
C F_{4}=P_{n r O P}(T) P_{n r D G C M}(T)
$$

where $\mathrm{P}_{\text {nDGCM }}(T)$ is the probability of non-recovery at time $T$ of a DG that failed to start due to a common mode failure. $P_{\text {niop }}$ has the usual definition. A maximum entropy distribution for $P_{n r D G C M}$ at each desired $T$ was determined in the same manner as for $P_{\text {nog }}$. The distribution inputs are given in Table G.7-2. Sampling and the calculation of $\mathrm{CF}_{4}(\mathrm{~T})$ was performed in the same manner as for $\mathrm{CF}_{3}(\mathrm{~T})$. 
Table G.7.1 DG Fail to Start non-Recovery Distributions

\begin{tabular}{||l|l|l|l|l|l|l|l||}
\hline \multirow{2}{*}{$\begin{array}{l}\text { Distribution } \\
\text { Parameters }\end{array}$} & \multicolumn{7}{|c|}{ Time Available for Recovery } \\
\cline { 2 - 9 } & \multicolumn{1}{|c|}{2.0} & 3.0 & 3.5 & 5.0 & 6.0 & 11.0 & 14.0 \\
\hline Distribution Type & $\begin{array}{l}\text { Max. } \\
\text { Entropy }\end{array}$ & $\begin{array}{l}\text { Max. } \\
\text { Entropy }\end{array}$ & $\begin{array}{l}\text { Max. } \\
\text { Entropy }\end{array}$ & $\begin{array}{l}\text { Max. } \\
\text { Entropy }\end{array}$ & $\begin{array}{l}\text { Max. } \\
\text { Entropy }\end{array}$ & $\begin{array}{l}\text { Max. } \\
\text { Entropy }\end{array}$ & $\begin{array}{l}\text { Max. } \\
\text { Entropy }\end{array}$ \\
\hline Upper Value & 1.0 & 1.0 & 1.0 & 1.0 & 1.0 & 1.0 & 1.0 \\
\hline Mean & 0.87 & 0.8 & 0.775 & 0.7 & 0.65 & 0.48 & 0.41 \\
\hline Lower Value & 0.087 & 0.08 & 0.0775 & 0.07 & 0.065 & 0.048 & 0.041 \\
\hline
\end{tabular}

Table G.7.2 DG Fail to Start Common Mode non-Recovery Distributions

\begin{tabular}{||l|l|l|l|l|l|l|l||}
\hline \hline \multirow{2}{*}{$\begin{array}{l}\text { Distribution } \\
\text { Parameters }\end{array}$} & \multicolumn{7}{|c||}{ Time Available for Recovery } \\
\cline { 2 - 9 } & \multicolumn{1}{|c|}{0.8} & 3.0 & 3.5 & 5.0 & 6.0 & 11.0 & \multicolumn{1}{|c||}{14.0} \\
\hline Distribution Type & $\begin{array}{l}\text { Max. } \\
\text { Entropy }\end{array}$ & $\begin{array}{l}\text { Max. } \\
\text { Entropy }\end{array}$ & $\begin{array}{l}\text { Max. } \\
\text { Entropy }\end{array}$ & $\begin{array}{l}\text { Max. } \\
\text { Entropy }\end{array}$ & $\begin{array}{l}\text { Max. } \\
\text { Entropy }\end{array}$ & $\begin{array}{l}\text { Max. } \\
\text { Entropy }\end{array}$ & $\begin{array}{l}\text { Max. } \\
\text { Entropy }\end{array}$ \\
\hline Upper Value & 1.0 & 1.0 & 1.0 & 1.0 & 1.0 & 1.0 & 1.0 \\
\hline Mean & 0.77 & 0.7 & 0.675 & 0.6 & 0.55 & 0.29 & 0.24 \\
\hline Lower Value & 0.077 & 0.07 & 0.0675 & 0.06 & 0.055 & 0.029 & 0.024 \\
\hline
\end{tabular}




\section{G.8 IRRAS Histogram Development}

The uncertainty analysis was performed using the IRRAS code. The histograms are limited to 20 points. Thus, the 500 point $C F$ distributions whose development was described in Section G.7 had to be reduced to 20 bin histograms for entry into IRRAS. This binning was performed with the QUATRO PRO spread sheet software [11]. It was done using the following steps for each $\mathrm{CF}_{n}$.

Step 1. The seven columns corresponding to each recovery time (T) were read into a QUATTRO PRO spread sheet and parsed into seven spread sheet columns. Time headings for each $T$ were assigned to row 1 of each column. This first page in the spread sheet served as the repository for the $\mathrm{CF}_{\mathrm{n}} \mathrm{s}$ as calculated by RLOSP in section G.7. The binning for each time $T$ was done on a separate page in the spread sheet.

Step 2. On a separate spread sheet page, headings Step,

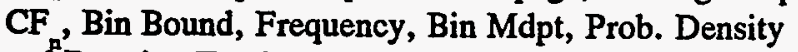
and Running Total were assigned to row 1 of columns $A$, $B, D, E, G, H$, and I respectively.

Step 3. Rows 2 through 502 of column A were filled with quantile values from 0.0 to 1.0 in .002 increments.

Step 4. The column of CFs to be binned for the time $T$ of interest was copied from the first spread sheet page into rows 3 through 502 of column B. The value 0.0E0 was assigned to row 2 of column B. Exponential format was used.

Step 5. Using the spread sheet sorting utility, the CFs in column B were sorted in ascending order. The sorted values remained in column $B$.

Step 6. The values in column B and quantiles in column A were plotted in a Cummulative Distribution Function (CDF). See Figure Attachment G-47-1 for an example.

Step 7. Bin bounds were estimated and filled into rows 2 through 22 of column D. The bounds were estimated so as to:

a. Preserve the high frequencies in the tail of the $\mathrm{CDF}$ at a high bin midpoint value.

b. Match the frequency population of each bin as closely as possible to the CDF.
Step 8. Several equations were copied into columns to track and fine-tune the calculation.

a. Column $\mathrm{G}$, the bin midpoint column, had 0.0 assigned to row 2 . In row 3 , the expression

$$
(D 2+D 3) / 2
$$

was inserted and copied into rows 4 through 22 . As the expression is copied down the column, the indices on $\mathrm{D}$ are changed to reflect the new row position so that the appropriate bin midpoint is calculated.

b. Row 3 of column $\mathrm{H}$ was assigned the expression

$$
\text { E3 } / 500 * 100
$$

to calculate the bin probability density in percent. This expression was copied down to row 22 . Row 24 was assigned the sum of rows 3 through 22 . After each calculation, row 24 was checked for the value 100 to be sure all points were counted.

c. A running total of the cummulative probability density was kept in column I. The expression

$$
I 2+H 3 / 100
$$

was assigned to row 3 of column I and copied into rows 4 through 22 .

Step 9. Using the frequency function from the Data menu in QUATTRO PRO, the CFs in column B were sorted according to the bin bounds of column $D$. The frequency of CFs in each bin was entered into column $E$ by the software. The software also filled in columns $G$, $\mathrm{H}$, and $\mathrm{I}$ using the mathematical expressions defined in Step 8.

Step 10. Results of the calculation were compared to the $\mathrm{CDF}$ for the 500 points in Column $\mathrm{B}$ in the following manner.

a. The frequency (COLUMN E) of the highest value bin was checked to ensure the high frequencies in the tail of the CDF were represented at a sufficiently high bin midpoint value.

b. Using the spread sheet plotting package, the running total (column I) was plotted twice against the bin midpoint column on the same 
graph. One plot was of spread sheet elements I2 to $I 20$ vs. G3 to G21. The second was of I3 to I21 v8. G3 to G21. This results in a "stair-step" representation of the Cummulative Distribution Function plotted in Step 6. Figure Attachment G-47-2 is an example of this type of plot. This is discussed in greater detail in Step 12 and Step 13.

Step 11. The plot of $10 \mathrm{~b}$ was overlaid on the CDF plot of Step 6. The degree to which the CDF plot passed through the middle of the vertical part of each step of the Step 10 graph was assessed by engineering judgement. The closer the CDF is to the middle of the vertical step, the better the 20 bin approximation is to the CDF.

Step 12. Depending on the CDF-step fit of Step 11, the bin bounds were adjusted and the process was repeated beginning at Step 9 until a satisfactory fit was obtained. An example of the spread sheet and graphs are given in Attachments G-46 and G-47.

Step 13. The results were entered into the appropriate IRRAS data base as a percentage histogram: Bin Midpoint (COLUMN G) and Probability Density in percent (COLUMN H).
Statistically speaking, the step representation of the CDF in Step 11 results from the histogram representation of the $C F$ frequency distribution. The histogram (which is our approximation of the CF probability density function) is a series of delta functions at discrete points (the bin midpoints).

One obtains the CDF for a continuous distribution by integrating over the population density. The result is the smooth CDF of Step 6 . When integrating over a density function represented by delta functions, the probability density (integrated) is equal to zero where the delta functions do not exist. The resulting CDF is then a series of steps (one step for each data function) located at the bin midpoints.

In order to assess the adequacy of the 20 bin histogram, the bottom as well as the top of each step must be defined. That is the purpose of the two plots of Step $10 \mathrm{~b}$. One plot represents the top of each step, while the other represents the bottom. Since the top of one step is the bottom of the next, the step bottoms in the histogram $\mathrm{CDF}$ are given by the I2 to I20 curve. The step tops are given by the $\mathrm{I} 3$ to $\mathrm{I} 21$ curve. 


\section{LOSP Frequency}

\section{References for Appendix G}

[1] USNRC, "Severe Accident Risks: An Assessment for Five U.S. Nuclear Power Plants, " NUREG1150, June, 1989.

[2] H. Wyckoff, "Losses of Offsite Power at U.S. Nuclear Power Plants: All Years through 1988," NSAC-144, April 1989.

[3] R. Iman, "Modelling Time to Recover and Initiating Event Frequency for Losses of Offsite Power Incidents at Nuclear Power Plants," NUREG/CR-5032, January 1988.

[4] P.W.Baranowsky, "Evaluation of Station Blackout Accidents at Nuclear Power Plants: Technical Findings Related to Unresolved Safety Issue A-44, " NUREG/CR-1032, May 1985.

[5] IMSL, Inc. "IMSL MATH/LIBRARY Users Manual, " Version 2.0, IMSL, Houston, TX 1991.

[7] J.Darby, "SEACALC: Code Verification for the SEA Set of Numerical Analysis Algorithms for the IBM.PC," SEA C 90-662-04-A:1, February 1, 1990.

[8] D.M.Erickson et al., "Analysis of Core Damage Frequency: Internal Events Methodology," NUREG CR/4550, SAND-86-2084, Vol. 1, Rev. 1, January 1990.

[9] MathSoft, Inc. MathCAD Version 2.5 Users Guide, 1989

[11] Borland International, Inc., "QUATTRO PRO for Windows Users Guide," 1992. 
Attachment G-1

\section{IE.BCK}


LOSP Frequency

\begin{tabular}{|c|c|c|c|c|c|c|c|}
\hline 1 ARKANSAS NUCLEAR ONE & ANO & 1 & 9.81 & 0 & 14.09 & 0 & 6.18 \\
\hline 2 BEAVER VALLEY & BV & 1 & 5.80 & 0 & 12.25 & 0 & 4.83 \\
\hline 3 BIG ROCK POINT & BRP & 0 & 14.64 & 0 & 25.85 & 0 & 760 \\
\hline 4 BROWNS FERRY & $\mathrm{BF}$ & 0 & 10.52 & 0 & 14.42 & 0 & 12.69 \\
\hline 5 BRUNSWICH & BRU & 1 & 8.5 & 0 & 13.17 & 1 & 7.97 \\
\hline 6 BYRON & BYR & 0 & 1.31 & 0 & 3.33 & 0 & 0.98 \\
\hline 7 CALLAWAY & CAL & 0 & 2.37 & 0 & 4.08 & 0 & 0.65 \\
\hline 8 CALVERT CLIFFS & $\mathrm{CC}$ & 1 & 11.50 & 0 & 13.68 & 0 & 4.87 \\
\hline 9 CATAWABA & CAT & 0 & 2.17 & 0 & 3.58 & 0 & 1.77 \\
\hline 10 CLINTON & CLN & 0 & 0.08 & 0 & 1.10 & 0 & 0.18 \\
\hline $11 \mathrm{COOK}$ & $\mathrm{COK}$ & 0 & 10.23 & 0 & 13.42 & 0 & 6.23 \\
\hline 12 COOPER & $\mathrm{COP}$ & 0 & 7.92 & 0 & 14.51 & 0 & 3.77 \\
\hline 13 CRYSTAL RIVER & CR & 0 & 6.21 & 0 & 11.48 & 0 & 4.38 \\
\hline 14 DAVIS-BESSE & DB & 2 & 3.85 & 0 & 10.51 & 0 & 5.04 \\
\hline 15 DIABLO CANYON & DC & 0 & 2.27 & 0 & 3.67 & 0 & 1.31 \\
\hline 16 DRESDEN & $\mathrm{DR}$ & 1 & 13.89 & 1 & 18.59 & 0 & 9.10 \\
\hline 17 DUANE ARNOLD & $\mathrm{DA}$ & 0 & 6.83 & 0 & 13.92 & 0 & 4.30 \\
\hline 18 FARLEY & FAR & 2 & 8.60 & 0 & 11.09 & 0 & 3.76 \\
\hline 19 FITZPATRICK & FIT & 0 & 8.01 & 0 & 13.51 & 3 & 3.92 \\
\hline 20 FORT CLAHOUN & FC & 2 & 9.01 & 0 & 14.59 & 1 & 3.40 \\
\hline 21 FORT ST. VRAIN & FSV & 0 & 1.11 & 1 & 9.51 & 0 & 6.66 \\
\hline 22 GINNA & GIN & 2 & 12.61 & 0 & 18.51 & 0 & 4.31 \\
\hline 23 GRAND GULF & GG & 0 & 1.45 & 0 & 3.50 & 0 & 1.16 \\
\hline 24 HADDAM NECK & HN & 6 & 16.49 & 0 & 21.43 & 1 & 4.24 \\
\hline 25 HATCH & HAT & 0 & 9.10 & 0 & 13.09 & 0 & 6.21 \\
\hline 26 HOPE CREEK & $\mathrm{HC}$ & 0 & 0.81 & 0 & 2.03 & 0 & 0.37 \\
\hline 27 INDIAN POINT & IP & 2 & 10.40 & 3 & 14.42 & 1 & 8.16 \\
\hline 28 KEWAUNEE & KEW & 0 & 10.89 & 0 & 14.59 & 0 & 2.32 \\
\hline 29 LASALLE & LAS & 0 & 2.27 & 0 & 5.00 & 0 & 3.12 \\
\hline 30 LIMERICK & LIM & 0 & 1.43 & 0 & 2.01 & 0 & 0.52 \\
\hline 31 MAIN YANKEE & MY & 0 & 10.56 & 0 & 16.09 & 0 & 3.65 \\
\hline 32 MCGUIRE & MCG & 1 & 4.47 & 0 & 7.08 & 1 & 3.14 \\
\hline 33 MILLSTONE & MIL & 1 & 14.17 & 2 & 17.85 & 0 & 7.35 \\
\hline 34 MONTICELLO & MON & 1 & 11.70 & 0 & 17.59 & 1 & 4.05 \\
\hline 35 NINE MILE POINT & NMP & 1 & 11.11 & 0 & 19.09 & 0 & 6.30 \\
\hline 36 NORTH ANNA & NA & 0 & 7.91 & 0 & 10.59 & 0 & 4.40 \\
\hline 37 OCONEE & $\mathrm{OCO}$ & 1 & 13.56 & 0 & 15.51 & 0 & 9.00 \\
\hline 38 OYSTER CREEK & OYC & 1 & 9.75 & 0 & 19.09 & 1 & 7.07 \\
\hline 39 PALISADES & PAL & 3 & 7.69 & 0 & 17.09 & 1 & 8.55 \\
\hline 40 PALO VERDE & PV & 2 & 1.54 & 0 & 2.91 & 0 & 1.53 \\
\hline 41 PEACH BOTTOM & $\mathrm{PB}$ & 0 & 11.00 & 0 & 14.51 & 0 & 9.45 \\
\hline 42 PERRY & PER & 0 & 0.08 & 0 & 1.12 & 0 & 0.27 \\
\hline 43 PILGRIM & PIL & 0 & 7.71 & 4 & 16.09 & 0 & 7.24 \\
\hline 44 POINT BEACH & $\mathrm{PB}$ & 2 & 15.73 & 0 & 18.09 & 1 & 5.23 \\
\hline 45 PRAIRIE ISLAND & PI & 1 & 13.38 & 0 & 15.09 & 0 & 4.11 \\
\hline 46 QUAD CITIES & QC & 2 & 12.95 & 0 & 15.92 & 1 & 6.63 \\
\hline 47 RANCHO SECO & RS & 0 & 5.230 & 1 & 3.76 & 0 & 7.29 \\
\hline 48 RIVER BEND & $\mathrm{RB}$ & 1 & 1.04 & 0 & 2.58 & 0 & 0.80 \\
\hline 49 ROBINSON & ROB & 1 & 10.78 & 0 & 17.85 & 0 & 5.37 \\
\hline 50 SALEM & SAL & 0 & 7.15 & 0 & 11.59 & 1 & 6.25 \\
\hline 51 SAN ONOFRE & so & 2 & 12.13 & 0 & 21.01 & 2 & 10.74 \\
\hline 52 SEQUOYAH & SEQ & 0 & 4.30 & 0 & 7.50 & 0 & 5.26 \\
\hline 53 ST LUCIE & STL & 0 & 9.03 & 2 & 12.09 & 0 & 3.78 \\
\hline
\end{tabular}

NUREG/CR-6143 


$\begin{array}{llllllll}\text { 54 SHEARON HARRISON } & \text { SH } & 0 & 0.49 & 0 & 1.69 & 0 & 0.44 \\ \text { 55 SUMMER } & \text { SUM } & 0 & 2.69 & 0 & 5.00 & 0 & 1.35 \\ \text { 56 SURRY } & \text { SUR } & 0 & 12.28 & 0 & 16.09 & 0 & 9.41 \\ \text { 57 SUSQUEHANNA } & \text { SUS } & 1 & 3.81 & 0 & 5.59 & 0 & 2.03 \\ \text { 58 THREE MILE ISLAND } & \text { TMI } & 0 & 4.70 & 1 & 4.34 & 0 & 8.32 \\ \text { 59 TROJAN } & \text { TRO } & 0 & 6.63 & 0 & 12.67 & 0 & 4.44 \\ \text { 60 TURKEY POINT } & \text { TP } & 2 & 13.05 & 7 & 16.09 & 1 & 9.01 \\ \text { 61 VERMONT YANKEE } & \text { VY } & 0 & 10.68 & 0 & 16.17 & 0 & 3.56 \\ \text { 62 VOGTLE } & \text { VOG } & 0 & 0.15 & 0 & 1.58 & 0 & 0.40 \\ \text { 63 WASHINGTON NUCLEAR } & \text { WN } & 0 & 1.57 & 0 & 4.08 & 0 & 1.14 \\ \text { 64 WATERFORD } & \text { WAT } & 0 & 1.75 & 0 & 2.33 & 0 & 0.73 \\ \text { 65 WOLF CREEK } & \text { WC } & 0 & 184 & 0 & 3.33 & 0 & 0.90 \\ \text { 66 YANKEE ROWE } & \text { YR } & 0 & 20.11 & 1 & 28.18 & 1 & 5.92 \\ \text { 67 ZION } & \text { ZIO } & 0 & 11.59 & 0 & 15.09 & 0 & 7.58\end{array}$




\section{LOSP Frequency}

Attachment G-2

IE.BCK 


\begin{tabular}{|c|c|c|c|c|}
\hline 1 & 1 & 14.09 & 0 & 6.18 \\
\hline 2 & 1 & 12.25 & 0 & 4.83 \\
\hline 3 & 1 & 25.85 & 0 & 7.60 \\
\hline 4 & 0 & 14.42 & 0 & 12.69 \\
\hline 5 & 1 & 13.17 & 1 & 7.97 \\
\hline 6 & 0 & 3.33 & 0 & 0.98 \\
\hline 7 & 0 & 4.08 & 0 & 0.65 \\
\hline 8 & 1 & 13.68 & 0 & 4.87 \\
\hline 9 & 0 & 3.58 & 0 & 1.77 \\
\hline 10 & 0 & 1.10 & 0 & 0.18 \\
\hline 11 & 0 & 13.42 & 0 & 6.23 \\
\hline 12 & 0 & 14.51 & 0 & 3.77 \\
\hline 13 & 0 & 11.84 & 0 & 4.38 \\
\hline 14 & 0 & 10.51 & 0 & 5.04 \\
\hline 15 & 1 & 3.67 & 0 & 1.31 \\
\hline 16 & 2 & 18.59 & 0 & 9.10 \\
\hline 17 & 0 & 13.92 & 0 & 4.30 \\
\hline 18 & 0 & 11.09 & 0 & 3.76 \\
\hline 19 & 0 & 13.51 & 3 & 3.92 \\
\hline 20 & 2 & 14.59 & 1 & 3.40 \\
\hline 21 & 1 & 9.51 & 0 & 6.66 \\
\hline 22 & 2 & 18.51 & 0 & 4.31 \\
\hline 23 & 0 & 3.50 & 0 & 1.16 \\
\hline 24 & 6 & 21.43 & 1 & 4.24 \\
\hline 25 & 0 & 13.09 & 0 & 6.21 \\
\hline 26 & 0 & 2.03 & 0 & 0.37 \\
\hline 27 & 5 & 14.42 & 1 & 8.16 \\
\hline 28 & 0 & 14.59 & 0 & 2.32 \\
\hline 29 & 0 & 5.00 & 0 & 3.12 \\
\hline 30 & 0 & 2.92 & 0 & 0.52 \\
\hline 31 & 0 & 16.09 & 0 & 3.65 \\
\hline 32 & 1 & 7.08 & 1 & 3.14 \\
\hline 33 & 3 & 17.85 & 0 & 7.35 \\
\hline 34 & 1 & 17.59 & 1 & 4.05 \\
\hline
\end{tabular}




\begin{tabular}{|c|c|c|c|c|}
\hline 35 & 2 & 19.09 & 0 & 6.30 \\
\hline 36 & 0 & 10.59 & 0 & 4.40 \\
\hline 37 & 1 & 15.51 & 0 & 9.00 \\
\hline 38 & 1 & 19.09 & 1 & 7.07 \\
\hline 39 & 3 & 17.09 & 1 & 8.55 \\
\hline 40 & 2 & 2.91 & 0 & 1.53 \\
\hline 41 & 0 & 14.51 & 0 & 9.45 \\
\hline 42 & 0 & 1.12 & 0 & 0.27 \\
\hline 43 & 4 & 16.09 & 0 & 7.24 \\
\hline 44 & 2 & 18.09 & 2 & 5.23 \\
\hline 45 & 1 & 15.09 & 0 & 4.11 \\
\hline 46 & 2 & 15.92 & 1 & 6.63 \\
\hline 47 & 0 & 13.76 & 0 & 7.29 \\
\hline 48 & 1 & 2.58 & 0 & 0.80 \\
\hline 49 & 1 & 17.85 & 0 & 5.37 \\
\hline 50 & 0 & 11.59 & 1 & 6.25 \\
\hline 51 & 2 & 21.01 & 2 & 10.74 \\
\hline 52 & 0 & 7.50 & 0 & 5.26 \\
\hline 53 & 2 & 12.09 & 0 & 3.78 \\
\hline 54 & 0 & 169 & 0 & 0.44 \\
\hline 55 & 0 & 5.00 & 0 & 1.35 \\
\hline 56 & 0 & 16.09 & 0 & 9.41 \\
\hline 57 & 1 & 5.59 & 0 & 2.03 \\
\hline 58 & 0 & 14.34 & 0 & 8.32 \\
\hline 59 & 0 & 12.67 & 0 & 4.44 \\
\hline 60 & 9 & 16.09 & 1 & 9.01 \\
\hline 61 & 0 & 16.17 & 0 & 3.56 \\
\hline 62 & 0 & 1.58 & 0 & 0.40 \\
\hline 63 & 0 & 4.08 & 0 & 1.14 \\
\hline 64 & 0 & 3.33 & 0 & 0.73 \\
\hline 65 & 0 & 3.33 & 0 & 0.90 \\
\hline 66 & 1 & 28.18 & 1 & 5.92 \\
\hline 67 & 0 & 15.09 & 0 & \\
\hline
\end{tabular}


Attachment G-3

LOSP_IE_PCGW.DAT 
LOSP Frequency

\begin{tabular}{|c|c|c|}
\hline 1 & 1 & 14.09 \\
\hline 2 & 1 & 12.25 \\
\hline 3 & 1 & 25.85 \\
\hline 4 & 0 & 14.42 \\
\hline 5 & 1 & 13.17 \\
\hline 6 & 0 & 3.33 \\
\hline 7 & 0 & 4.08 \\
\hline 8 & 1 & 13.68 \\
\hline 9 & 0 & 3.58 \\
\hline 10 & 0 & 1.10 \\
\hline 11 & 0 & 13.42 \\
\hline 12 & 0 & 14.51 \\
\hline 13 & 0 & 11.84 \\
\hline 14 & 0 & 10.51 \\
\hline 15 & 1 & 3.67 \\
\hline 16 & 2 & 18.59 \\
\hline 17 & 0 & 13.92 \\
\hline 18 & 0 & 11.09 \\
\hline 19 & 0 & 13.51 \\
\hline 20 & 2 & 14.59 \\
\hline 21 & 1 & 9.51 \\
\hline 22 & 2 & 18.51 \\
\hline 23 & 0 & 3.50 \\
\hline 24 & 6 & 21.43 \\
\hline 25 & 0 & 13.09 \\
\hline 26 & 0 & 2.03 \\
\hline 27 & 5 & 14.42 \\
\hline 28 & 0 & 14.59 \\
\hline 29 & 0 & 5.00 \\
\hline 30 & 0 & 2.92 \\
\hline 31 & 0 & 16.09 \\
\hline 32 & 1 & 7.08 \\
\hline 33 & 3 & 17.85 \\
\hline 34 & 1 & 17.59 \\
\hline
\end{tabular}




\begin{tabular}{|c|c|c|}
\hline 35 & 2 & 19.09 \\
\hline 36 & 0 & 10.59 \\
\hline 37 & 1 & 15.51 \\
\hline 38 & 1 & 19.09 \\
\hline 39 & 3 & 17.09 \\
\hline 40 & 2 & 2.91 \\
\hline 41 & 0 & 14.51 \\
\hline 42 & 0 & 1.12 \\
\hline 43 & 4 & 16.09 \\
\hline 44 & 2 & 18.09 \\
\hline 45 & 1 & 15.09 \\
\hline 46 & 2 & 15.92 \\
\hline 47 & 0 & 13.76 \\
\hline 48 & 1 & 2.58 \\
\hline 49 & 1 & 17.85 \\
\hline 50 & 0 & 11.59 \\
\hline 51 & 2 & 21.01 \\
\hline 52 & 0 & 7.50 \\
\hline 53 & 2 & 12.09 \\
\hline 54 & 0 & 1.69 \\
\hline 55 & 0 & 5.00 \\
\hline 56 & 0 & 16.09 \\
\hline 57 & 1 & 5.59 \\
\hline 58 & 0 & 14.34 \\
\hline 59 & 0 & 12.67 \\
\hline 60 & 9 & 16.09 \\
\hline 61 & 0 & 16.17 \\
\hline 62 & 0 & 1.58 \\
\hline 63 & 0 & 4.08 \\
\hline 64 & 0 & 3.33 \\
\hline 65 & 0 & 3.33 \\
\hline 66 & 1 & 28.18 \\
\hline 67 & 0 & 15.09 \\
\hline
\end{tabular}


LOSP Frequency

Attachment G-4

LOSP_IE_IV.DAT 


\begin{tabular}{|c|c|c|}
\hline 1 & 0 & 6.18 \\
\hline 2 & 0 & 4.83 \\
\hline 3 & 0 & 7.60 \\
\hline 4 & 0 & 12.69 \\
\hline 5 & 1 & 7.97 \\
\hline 6 & 0 & 0.98 \\
\hline 7 & 0 & 0.65 \\
\hline 8 & 0 & 4.87 \\
\hline 9 & 0 & 1.77 \\
\hline 10 & 0 & 0.18 \\
\hline 11 & 0 & 6.23 \\
\hline 12 & 0 & 3.77 \\
\hline 13 & 0 & 4.38 \\
\hline 14 & 0 & 5.04 \\
\hline 15 & 0 & 1.31 \\
\hline 16 & 0 & 9.10 \\
\hline 17 & 0 & 4.30 \\
\hline 18 & 0 & 3.76 \\
\hline 19 & 3 & 3.92 \\
\hline 20 & 1 & 3.40 \\
\hline 21 & 0 & 6.66 \\
\hline 22 & 0 & 4.31 \\
\hline 23 & 0 & 1.16 \\
\hline 24 & 1 & 4.24 \\
\hline 25 & 0 & 6.21 \\
\hline 26 & 0 & 0.37 \\
\hline 27 & 1 & 8.16 \\
\hline 28 & 0 & 2.32 \\
\hline 29 & 0 & 3.12 \\
\hline 30 & 0 & 0.52 \\
\hline 31 & 0 & 3.65 \\
\hline 32 & 1 & 3.14 \\
\hline 33 & 0 & 7.35 \\
\hline 34 & 1 & 4.05 \\
\hline
\end{tabular}




\begin{tabular}{|c|c|c|}
\hline 35 & 0 & 6.30 \\
\hline 36 & 0 & 4.40 \\
\hline 37 & 0 & 9.00 \\
\hline 38 & 1 & 7.07 \\
\hline 39 & 1 & 8.55 \\
\hline 40 & 0 & 1.53 \\
\hline 41 & 0 & 9.45 \\
\hline 42 & 0 & 0.27 \\
\hline 43 & 0 & 7.24 \\
\hline 44 & 1 & 5.23 \\
\hline 45 & 0 & 4.11 \\
\hline 46 & 1 & 6.63 \\
\hline 47 & 0 & 7.29 \\
\hline 48 & 0 & 0.80 \\
\hline 49 & 0 & 5.37 \\
\hline 50 & 1 & 6.25 \\
\hline 51 & 2 & 10.74 \\
\hline 52 & 0 & 5.26 \\
\hline 53 & 0 & 3.78 \\
\hline 54 & 0 & 0.44 \\
\hline 55 & 0 & 1.35 \\
\hline 56 & 0 & 9.41 \\
\hline 57 & 0 & 2.03 \\
\hline 58 & 0 & 8.32 \\
\hline 59 & 0 & 4.44 \\
\hline 60 & 1 & 9.01 \\
\hline 61 & 0 & 3.56 \\
\hline 62 & 0 & 0.40 \\
\hline 63 & 0 & 1.14 \\
\hline 64 & 0 & 0.73 \\
\hline 65 & 0 & 0.90 \\
\hline 66 & 1 & 5.92 \\
\hline 67 & 0 & 7.58 \\
\hline
\end{tabular}


Attachment G-5

IE.DAT 


\section{LOSP Frequency}

$\begin{array}{lll}1 & 1 & 14.09 \\ 2 & 1 & 12.25 \\ 3 & 1 & 25.85 \\ 4 & 0 & 14.42 \\ 5 & 1 & 13.17 \\ 6 & 0 & 3.33 \\ 7 & 0 & 4.08\end{array}$

81

13.68

3.58

1.10

13.42

14.51

11.84

10.51

3.67

18.59

13.92

11.09

13.51

14.59

9.51

18.51

3.50

21.43

13.09

2.03

14.42

14.59

5.00

2.92

16.09

7.08

17.85

17.59 


\begin{tabular}{|c|c|c|}
\hline 35 & 2 & 19.09 \\
\hline 36 & 0 & 10.59 \\
\hline 37 & 1 & 15.51 \\
\hline 38 & 1 & 19.09 \\
\hline 39 & 3 & 17.09 \\
\hline 40 & 2 & 2.91 \\
\hline 41 & 0 & 14.51 \\
\hline 42 & 0 & 1.12 \\
\hline 43 & 4 & 16.09 \\
\hline 44 & 2 & 18.09 \\
\hline 45 & 1 & 15.09 \\
\hline 46 & 2 & 15.92 \\
\hline 47 & 0 & 13.76 \\
\hline 48 & 1 & 2.58 \\
\hline 49 & 1 & 17.85 \\
\hline 50 & 0 & 11.59 \\
\hline 51 & 2 & 21.01 \\
\hline 52 & 0 & 7.50 \\
\hline 53 & 2 & 12.09 \\
\hline 54 & 0 & 1.69 \\
\hline 55 & 0 & 5.00 \\
\hline 56 & 0 & 16.09 \\
\hline 57 & 1 & 5.59 \\
\hline 58 & 0 & 14.34 \\
\hline 59 & 0 & 12.67 \\
\hline 60 & 9 & 16.09 \\
\hline 61 & 0 & 16.17 \\
\hline 62 & 0 & 1.58 \\
\hline 63 & 0 & 4.08 \\
\hline 64 & 0 & 3.33 \\
\hline 65 & 0 & 3.33 \\
\hline 66 & 1 & 28.18 \\
\hline 67 & 0 & 15.09 \\
\hline
\end{tabular}




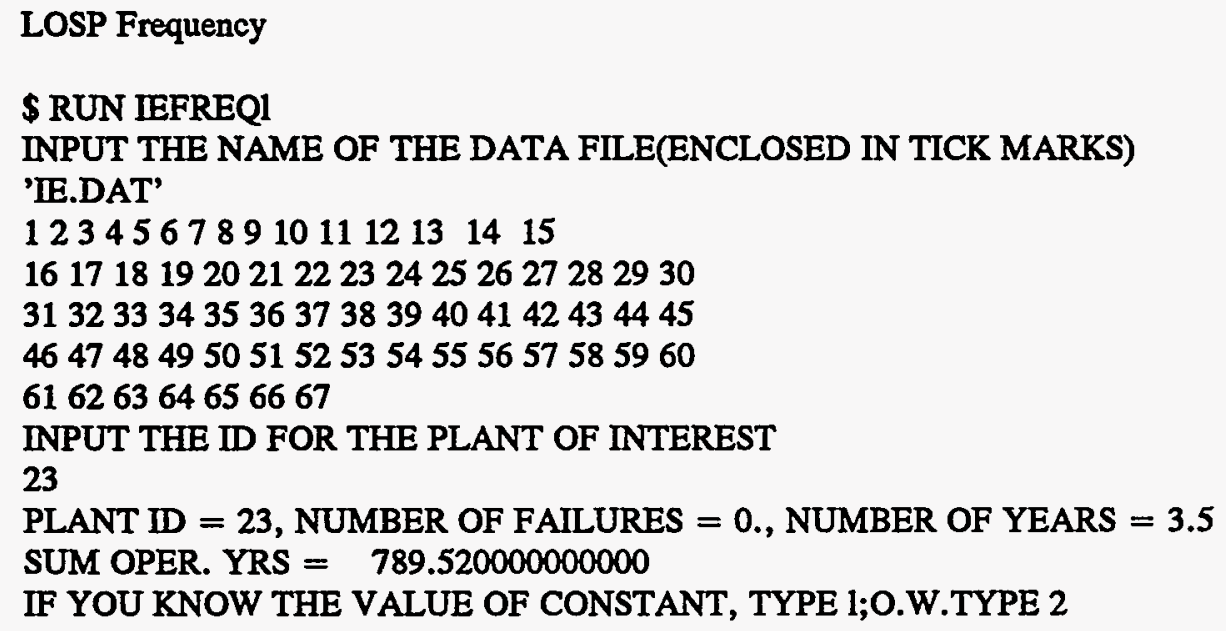


INPUT THE FAILURE FREQUENCY FOR PLANT LOSP

FOR 23

.43

PLEASE WAIT WHILE THE INTEGRATION IS PERFORMED CONSTK $=1.580239660651922 \mathrm{E}-095$

THE CUMULATIVE PROBABILITY FOR PLANT LOSP FOR A FAILURE FREQUENCY OF 0.430000

AT 23

0.999191

THIS VALUE SATISFACTORY? Y OR N

$\mathbf{N}$

INPUT THE FAILURE FREQUENCY FOR PLANT LOSP

FOR 23

.42

PLEASE WAIT WHILE THE INTEGRATION IS PERFORMED CONSTK $=1.580239660651922 \mathrm{E}-095$

THE CUMULATIVE PROBABILITY FOR PLANT LOSP FOR

FAILURE FREQUENCY OF 0.420000

AT 23

IS 0.999062

IS THIS VALUE SATISFACTORY? Y OR N

$\mathbf{N}$

INPUT THE FAILURE FREQUENCY FOR PLANT LOSP

FOR 23

.418

PLEASE WAIT WHILE THE INTEGRATION IS PERFORMED CONSTK $=1.580239660651922 \mathrm{E}-095$

THE CUMULATIVE PROBABILITY FOR PLANT LOSP FOR A FAILURE FREQUENCY OF 0.418000

AT 23

is 0.999030

IS THIS VALUE SATISFACTORY? Y OR N

$\mathrm{N}$

INPUT THE FAILURE FREQUENCY FOR PLANT LOSP

FOR 23

.417

PLEASE WAIT WHILE THE INTEGRATION IS PERFORMED CONSTK $=1.580239660651922 \mathrm{E}-095$

THE CUMULATIVE PROBABILITY FOR PLANT LOSP FOR

A FAILURE FREQUENCY OF 0.417000

AT 23

IS 0.999019

IS THIS VALUE SATISFACTORY? Y OR N 


\section{LOSP Frequency}

INPUT THE FAILURE FREQUENCY FOR PLANT LOSP

FOR 23

.416

PLEASE WAIT WHILE THE INTEGRATION IS PERFORMED CONSTK $=1.580239660651922 \mathrm{E}-095$

THE CUMULATIVE PROBABILITY FOR PLANT LOSP FOR A FAILURE FREQUENCY OF 0.416000

AT 23

IS 0.999006

IS THIS VALUE SATISFACTORY? Y OR N

$\mathbf{Y}$

FORTRAN STOP 
LOSP Frequency

Attachment G-6

LOSP_IE_PCGW.INP 
LOSP Frequency

'LOSP IE PCGW.DAT'23.416 30 


\section{LOSP Frequency}

Attachment G-7

IEBAT.COM 
LOSP Frequency

\section{\$ SET VERIFY}

$\$$ SET DEFAULT UD4:[BDSTAPL]

\$ RENAME LOSP_IE_PCGW.INP IEFREQ.INP

$\$$ RUN IEBAT1

\$ RENAME IEFREQ.INP LOSP_IE PCGW.INP

\$ RENAME PLOT.DAT IE PCGW.DAT 
LOSP Frequency

Attachment G-7a

IEBAT.COM

(Slow Batch Mode)

Vol. 2, Part 2 
LOSP Frequency

\$ SUBMIT/Q=SLOW\$BATCH/LOG_FILE=IEBAT/NOPRINT/CPU = 1:30:00 IEBAT.COM

$\$$ EXIT - 
LOSP Frequency

Attachment G-7b

IEBAT.COM LOG FILE 
LOSP Frequency

\$Set NoControl $=\mathbf{Y}$

$\$$ SSet NoVerify

$\$$ SET DEFAULT UD4:[BDSTAPL]

$\$$ RENAME LOSP_IE PCGW.INP IEFREQ.INP

$\$$ RUN IEBAT1

FORTRAN STOP

\$ RENAME IEFREQ.INP LOSP IE_PCGW.INP

$\$$ RENAME PLOT.DAT IE PCGW.DAT

BDSTAPL job terminated at 3-JUN-1991 18:43:33.13

Accounting information:

Buffered I/O count: $\quad 129$

Direct I/O count: $\quad 100$

Page faults: $\quad 4276$

Charged CPU time: $\quad 000: 05: 32.22$

Peak working set size: $\quad 1239$

Peak page file size: $\quad 4311$

Mounted volumes: $\quad 0$

Elapsed time: $\quad 001: 15: 1851$ 
LOSP Frequency

Attachment G-8

IE_PCGW.DAT

(BEFORE UPDATE)

Vol. 2, Part 2

G-65

NUREG/CR-6143 


\begin{tabular}{|c|c|}
\hline $0.154074 \mathrm{E}-04$ & 0.000978 \\
\hline $0.123259 E-03$ & 0.003558 \\
\hline $0.416000 \mathrm{E}-03$ & 0.008215 \\
\hline $0.986074 \mathrm{E}-03$ & 0.015590 \\
\hline $0.192593 \mathrm{E}-02$ & 0.026452 \\
\hline $0.332800 \mathrm{E}-02$ & 0.041697 \\
\hline $0.528474 \mathrm{E}-02$ & 0.062328 \\
\hline $0.788859 \mathrm{E}-02$ & 0.089409 \\
\hline $0.112320 \mathrm{E}-01$ & 0.124002 \\
\hline $0.154074 \mathrm{E}-01$ & 0.167035 \\
\hline $0.205073 E-01$ & 0.219149 \\
\hline $0.266240 \mathrm{E}-01$ & 0.280514 \\
\hline $0.338501 \mathrm{E}-01$ & 0.350585 \\
\hline $0.422779 \mathrm{E}-01$ & 0.427906 \\
\hline $0.520000 \mathrm{E}-01$ & 0.510082 \\
\hline $0.631087 E-01$ & 0.593832 \\
\hline $0.756966 \mathrm{E}-01$ & 0.675337 \\
\hline $0.898560 \mathrm{E}-01$ & 0.750074 \\
\hline $0.105679 E+00$ & 0.814062 \\
\hline $0.123259 \mathrm{E}+00$ & 0.865966 \\
\hline $0.142688 \mathrm{E}+00$ & 0.906261 \\
\hline $0.164058 \mathrm{E}+00$ & 0.936288 \\
\hline $0.187462 E+00$ & 0.957847 \\
\hline $0.212992 \mathrm{E}+00$ & 0.972826 \\
\hline $0.240741 \mathrm{E}+00$ & 0.982946 \\
\hline $0.270801 E+00$ & 0.989592 \\
\hline $0.303264 \mathrm{E}+00$ & 0.993861 \\
\hline $0.338223 E+00$ & 0.996512 \\
\hline $0.375771 E+00$ & 0.998145 \\
\hline $0.416000 \mathrm{E}+00$ & 0.999006 \\
\hline
\end{tabular}




\section{Attachment G-9}

IE_PCGW.DAT

(After Update) 


$\begin{array}{ll}0.100000 \mathrm{E}-07 & 0.000000 \\ 0.154074 \mathrm{E}-04 & 0.000978 \\ 0.123259 \mathrm{E}-03 & 0.003558 \\ 0.416000 \mathrm{E}-03 & 0.008215 \\ 0.986074 \mathrm{E}-03 & 0.015590 \\ 0.192593 \mathrm{E}-02 & 0.026452 \\ 0.332800 \mathrm{E}-02 & 0.041697 \\ 0.528474 \mathrm{E}-02 & 0.062328 \\ 0.788859 \mathrm{E}-02 & 0.089409 \\ 0.112320 \mathrm{E}-01 & 0.124002 \\ 0.154074 \mathrm{E}-01 & 0.167035 \\ 0.205073 \mathrm{E}-01 & 0.219149 \\ 0.266240 \mathrm{E}-01 & 0.280514 \\ 0.338501 \mathrm{E}-01 & 0.350585 \\ 0.422779 \mathrm{E}-01 & 0.427906 \\ 0.520000 \mathrm{E}-01 & 0.510082 \\ 0.631087 \mathrm{E}-01 & 0.593832 \\ 0.756966 \mathrm{E}-01 & 0.675337 \\ 0.898560 \mathrm{E}-01 & 0.750074 \\ 0.105679 \mathrm{E}+00 & 0.814062 \\ 0.123259 \mathrm{E}+00 & 0.865966 \\ 0.142688 \mathrm{E}+00 & 0.906261 \\ 0.164058 \mathrm{E}+00 & 0.936288 \\ 0.187462 \mathrm{E}+00 & 0.957847 \\ 0.212992 \mathrm{E}+00 & 0.972826 \\ 0.240741 \mathrm{E}+00 & 0.982946 \\ 0.270801 \mathrm{E}+00 & 0.989592 \\ 0.303264 \mathrm{E}+00 & 0.993861 \\ 0.338223 \mathrm{E}+00 & 0.996512 \\ 0.375771 \mathrm{E}+00 & 0.998145 \\ 0.416000 \mathrm{E}+00 & 0.999006 \\ 0.900000 \mathrm{E}+00 & 1.000000\end{array}$


Attachment G-10

\section{IE.DAT for CATEGORY IV}


LOSP Frequency

\begin{tabular}{|c|c|c|}
\hline 1 & 0 & 6.18 \\
\hline 2 & 0 & 4.83 \\
\hline 3 & 0 & 7.60 \\
\hline 4 & 0 & 12.69 \\
\hline 5 & 1 & 7.97 \\
\hline 6 & 0 & 0.98 \\
\hline 7 & 0 & 0.65 \\
\hline 8 & 0 & 4.87 \\
\hline 9 & 0 & 1.77 \\
\hline 10 & 0 & 0.18 \\
\hline 11 & 0 & 6.23 \\
\hline 12 & 0 & 3.77 \\
\hline 13 & 0 & 4.38 \\
\hline 14 & 0 & 5.04 \\
\hline 15 & 0 & 1.31 \\
\hline 16 & 0 & 9.10 \\
\hline 17 & 0 & 4.30 \\
\hline 18 & 0 & 3.76 \\
\hline 19 & 3 & 3.92 \\
\hline 20 & 1 & 3.40 \\
\hline 21 & 0 & 6.66 \\
\hline 22 & 0 & 4.31 \\
\hline 23 & 0 & 1.16 \\
\hline 24 & 1 & 4.24 \\
\hline 25 & 0 & 6.21 \\
\hline 26 & 0 & 0.37 \\
\hline 27 & 1 & 8.16 \\
\hline 28 & 0 & 2.32 \\
\hline 29 & 0 & 3.12 \\
\hline 30 & 0 & 0.52 \\
\hline 31 & 0 & 3.65 \\
\hline 32 & 1 & 3.14 \\
\hline 33 & 0 & 7.35 \\
\hline 34 & 1 & 4.05 \\
\hline
\end{tabular}




\begin{tabular}{|c|c|c|}
\hline 35 & 0 & 6.30 \\
\hline 36 & 0 & 4.40 \\
\hline 37 & 0 & 9.00 \\
\hline 38 & 1 & 7.07 \\
\hline 39 & 1 & 8.55 \\
\hline 40 & 0 & 1.53 \\
\hline 41 & 0 & 9.45 \\
\hline 42 & 0 & 0.27 \\
\hline 43 & 0 & 7.24 \\
\hline 44 & 1 & 5.23 \\
\hline 45 & 0 & 4.11 \\
\hline 46 & 1 & 6.63 \\
\hline 47 & 0 & 7.29 \\
\hline 48 & 0 & 0.80 \\
\hline 49 & 0 & 5.37 \\
\hline 50 & 1 & 6.25 \\
\hline 51 & 2 & 10.74 \\
\hline 52 & 0 & 5.26 \\
\hline 53 & 0 & 3.78 \\
\hline 54 & 0 & 0.44 \\
\hline 55 & 0 & 1.35 \\
\hline 56 & 0 & 9.41 \\
\hline 57 & 0 & 2.03 \\
\hline 58 & 0 & 8.32 \\
\hline 59 & 0 & 4.44 \\
\hline 60 & 1 & 9.01 \\
\hline 61 & 0 & 3.56 \\
\hline 62 & 0 & 0.40 \\
\hline 63 & 0 & 1.14 \\
\hline 64 & 0 & 0.73 \\
\hline 65 & 0 & 0.90 \\
\hline 66 & 1 & 5.92 \\
\hline 67 & 0 & \\
\hline
\end{tabular}


LOSP Frequency

\$ RUN IEFREQ1

INPUT THE NAME OF THE DATA FILE (ENCLOSED IN TICK MARKS)

'IE.DAT'

$\begin{array}{lllllllllllllll}123456 & 6 & 8 & 10 & 11 & 13 & 14 & 15\end{array}$

161718192021222324252627282930

$313233343536373839404142 \quad 4344 \quad 45$

464748495051525354555657585960

61626364656667

INPUT THE ID FOR THE PLANT OF INTEREST

23

PLANT ID $=23$, NUMBER OF FAILURES $=0 .$, NUMBER OF YEARS $=1.2$

SUM OPER. YRS $=312.69000000000$

IF YOU KNOW THE VALUE OF CONSTANT, TYPE 1;0.W.TYPE 2

2

INPUT THE FAILURE FREQUENCY FOR PLANT LOSP

FOR 23

'91

PLEASE WAIT WHILE THE INTEGRATION IS PERFORMED

CONSTK $=5.158047635733690 \mathrm{E}-030$

THE CUMULATIVE PROBABILITY FOR PLANT LOSP FOR

A FAILURE FREQUENCY OF 0.291000

AT 23

IS 0.999005

IS THIS VALUE SATISFACTORY? Y OR N

y

FORTRAN STOP 
Attachment G-11

IEBAT.COM for CATEGORY IV 
LOSP Frequency

\section{\$ SET VERIFY}

$\$$ SET DEFAULT UD4:[BDSTAPL]

$\$$ RENAME LOSP_JE_IV.INP IEFREQ.INP

$\$$ RUN IEBATI

$\$$ RENAME IEFREQ.INP LOSP_IE IV.INP

\$ RENAME PLOT.DAT IE IV.DAT 
Attachment G-12

LOSP_IE_IV.INP 


\section{LOSP Frequency}

\section{'LOSP IE IV.DAT' 23.29130}


Attachment G-13

IE_IV.DAT 


$\begin{array}{ll}0.107778 \mathrm{E}-04 & 0.000552 \\ 0.862222 \mathrm{E}-04 & 0.001262 \\ 0.291000 \mathrm{E}-03 & 0.002208 \\ 0.689778 \mathrm{E}-03 & 0003445 \\ 0.134722 \mathrm{E}-02 & 0.005048 \\ 0.232800 \mathrm{E}-02 & 0.007116 \\ 0.369678 \mathrm{E}-02 & 0.009782 \\ 0.551822 \mathrm{E}-02 & 0.013229 \\ 0.785700 \mathrm{E}-02 & 0.017711 \\ 0.107778 \mathrm{E}-01 & 0.023589 \\ 0.143452 \mathrm{E}-01 & 0.031407 \\ 0186240 \mathrm{E}-01 & 0.042058 \\ 0.236788 \mathrm{E}-01 & 0.057274 \\ 0.295742 \mathrm{E}-01 & 0.085147 \\ 0.363750 \mathrm{E}-01 & 0.136164 \\ 0.441458 \mathrm{E}-01 & 0.238943 \\ 0.529512 \mathrm{E}-01 & 0.443061 \\ 062856 \mathrm{E}-01 & 0.695064 \\ 0.739248 \mathrm{E}-01 & 0.840654 \\ 0.862222 \mathrm{E}-01 & 0.925578 \\ 0.998130 \mathrm{E}-01 & 0.960696 \\ 0.114762 \mathrm{E}+00 & 0.977024 \\ 0.131133 \mathrm{E}+00 & 0.985120 \\ 0.148992 \mathrm{E}+00 & 0.990093 \\ 0.168403 \mathrm{E}+00 & 0.993320 \\ 0.189430 \mathrm{E}+00 & 0.995462 \\ 0.212139 \mathrm{E}+00 & 0.996903 \\ 0236594 \mathrm{E}+00 & 0.997882 \\ 0.262859 \mathrm{E}+00 & 0.998550 \\ 0291000 \mathrm{E}+00 & 0.999005\end{array}$


Attachment G-14

IE_IV.DAT 


\begin{tabular}{ll}
$0.100000 \mathrm{E}-07$ & 0.000000 \\
$0.107778 \mathrm{E}-04$ & 0.000552 \\
$0.862222 \mathrm{E}-04$ & 0.001262 \\
$0.291000 \mathrm{E}-03$ & 0.002208 \\
$0.689778 \mathrm{E}-03$ & 0.003445 \\
$0.134722 \mathrm{E}-02$ & 0.005048 \\
$0.232800 \mathrm{E}-02$ & 0.007116 \\
$0.369678 \mathrm{E}-02$ & 0.009782 \\
$0.551822 \mathrm{E}-02$ & 0.013229 \\
$0.785700 \mathrm{E}-02$ & 0.017711 \\
$0.107778 \mathrm{E}-01$ & 0.023589 \\
$0.143452 \mathrm{E}-01$ & 0.031407 \\
$0.186240 \mathrm{E}-01$ & 0.042058 \\
\hline $0.236788 \mathrm{E}-01$ & 0.057274 \\
\hline $0.295742 \mathrm{E}-01$ & 0.085147 \\
$0.363750 \mathrm{E}-01$ & 0.136164 \\
$0.441458 \mathrm{E}-01$ & 0.238943 \\
\hline $0.529512 \mathrm{E}-01$ & 0.443061 \\
\hline $0.628560 \mathrm{E}-01$ & 0.695064 \\
$0.739248 \mathrm{E}-01$ & 0.840654 \\
$0.862222 \mathrm{E}-01$ & 0.925578 \\
$0.998130 \mathrm{E}-01$ & 0.960696 \\
$0.114762 \mathrm{E}+00$ & 0.977024 \\
$0.131133 \mathrm{E}+00$ & 0.985120 \\
$0.148992 \mathrm{E}+00$ & 0.990093 \\
$0.168403 \mathrm{E}+00$ & 0.993320 \\
$0.189430 \mathrm{E}+00$ & 0.995462 \\
$0.212139 \mathrm{E}+00$ & 0.996903 \\
$0.236594 \mathrm{E}+00$ & 0.997882 \\
$0.262859 \mathrm{E}+00$ & 0.998550 \\
\hline $0.291000 \mathrm{E}+00$ & 0.999005 \\
\hline & 1.000000
\end{tabular}


Attachment G-15

IEBAT.LOG for CATEGORY IV 


\section{LOSP Frequency}

$\$ S 0$ NoControl $=Y$

$\$ S$ Set NoVerify

$\$$ SET DEFAULT UD4:[BDSTAPL]

$\$$ RENAME LOSP_IE_IV.INP IEFREQ.INP

$\$$ RUN IEBAT1

FORTRAN STOP

$\$$ RENAME IEFREQ.INP LOSP_IE_IV.INP

$\$$ RENAME PLOT.DAT IE_IV.DAT

BDSTAPL job terminated at 31-MAY-1991 13:57:27.78

Accounting information:

Buffered I/O count: 132

Direct I/O count: 102

Page faults:4115

Charged CPU time:0 00:33:21.77

Peak working set size: 1199

Peak page file size:4274

Mounted volumes:0

Elapsed time:0 00:36:17.30 


\section{Attachment G-16}

IE_IV.DAT 


$\begin{array}{ll}0.107778 \mathrm{E}-04 & 0.000552 \\ 0.862222 \mathrm{E}-04 & 0.001262 \\ 0.29100 \mathrm{E}-03 & 0.002208 \\ 0.689778 \mathrm{E}-03 & 0.003445 \\ 0.134722 \mathrm{E}-02 & 0.005048 \\ 0232800 \mathrm{E}-02 & 0.007116 \\ 0.369678 \mathrm{E}-02 & 0.009782 \\ 0.551822 \mathrm{E}-02 & 0.013229 \\ 0.785700 \mathrm{E}-02 & 0.017711 \\ 0107778 \mathrm{E}-01 & 0.023589 \\ 0.143452 \mathrm{E}-01 & 0.031407 \\ 0.186240 \mathrm{E}-01 & 0.042058 \\ 0.236788 \mathrm{E}-01 & 0.057274 \\ 0.295742 \mathrm{E}-01 & 0.085147 \\ 0.363750 \mathrm{E}-01 & 0.136164 \\ 0.441458 \mathrm{E}-01 & 0.238943 \\ 0.529512 \mathrm{E}-01 & 0.443061 \\ 0.628560 \mathrm{E}-01 & 0.695064 \\ 0.739248 \mathrm{E}-01 & 0.840654 \\ 0.86222 \mathrm{E}-01 & 0.925578 \\ 0.998130 \mathrm{E}-01 & 0.960696 \\ 0.114762 \mathrm{E}+00 & 0.977024 \\ 0.131133 \mathrm{E}+00 & 0.985120 \\ 0148992 \mathrm{E}+00 & 0.990093 \\ 0.168403 \mathrm{E}+00 & 0.993320 \\ 0189430 \mathrm{E}+00 & 0.995462 \\ 0.212139 \mathrm{E}+00 & 0.996903 \\ 0.236594 \mathrm{E}+00 & 0.997882 \\ 0.262859 \mathrm{E}+00 & 0.998550 \\ 0.291000 \mathrm{E}+00 & 0.999005\end{array}$


Attachment G-17

IE_IV.DAT

(Updated) 


$\begin{array}{ll}0.10000 \mathrm{E}-07 & 0.000000 \\ 0.107778 \mathrm{E}-04 & 0.000552 \\ 0.862222 \mathrm{E}-04 & 0.001262 \\ 0.291000 \mathrm{E}-03 & 0.002208 \\ 0.689778 \mathrm{E}-03 & 0.003445 \\ 0.134722 \mathrm{E}-02 & 0.005048 \\ 0.232800 \mathrm{E}-02 & 0.007116 \\ 0.369678 \mathrm{E}-02 & 0.009782 \\ 0.551822 \mathrm{E}-02 & 0.013229 \\ 0.785700 \mathrm{E}-02 & 0.017711 \\ 0.107778 \mathrm{E}-01 & 0.023589 \\ 0.143452 \mathrm{E}-01 & 0.031407 \\ 0.186240 \mathrm{E}-01 & 0.042058 \\ 0.236788 \mathrm{E}-01 & 0.057274 \\ 0.295742 \mathrm{E}-01 & 0.085147 \\ 0.363750 \mathrm{E}-01 & 0.136164 \\ 0.441458 \mathrm{E}-01 & 0.238943 \\ 0.529512 \mathrm{E}-01 & 0.443061 \\ 0.628560 \mathrm{E}-01 & 0.695064 \\ 0.739248 \mathrm{E}-01 & 0.840654 \\ 0.862222 \mathrm{E}-01 & 0.925578 \\ 0.998130 \mathrm{E}-01 & 0.960696 \\ 0.114762 \mathrm{E}+00 & 0.977024 \\ 0.131133 \mathrm{E}+00 & 0.985120 \\ 0.148992 \mathrm{E}+00 & 0.990093 \\ 0.168403 \mathrm{E}+00 & 0.993320 \\ 0.189430 \mathrm{E}+00 & 0.995462 \\ 0.212139 \mathrm{E}+00 & 0.996903 \\ 0.236594 \mathrm{E}+00 & 0.997882 \\ 0.262859 \mathrm{E}+00 & 0.998550 \\ 0.291000 \mathrm{E}+00 & 0.999005 \\ 0.850000 \mathrm{E}+00 & 1.000000 \\ & \end{array}$


LOSP Frequency

Attachment G-18

LHS.COM 
LOSP Frequency

$\$$ ASSIGN LHS.DAT FOR001

$\$$ ASSIGN LHS.INP FOR005

$\$$ ASSIGN LHS.OUT FOR006

$\$$ RUN LHS

$\$$ DELETE FOR*.DAT;* 
Attachment G-19

LHS.INP 
LOSP Frequency

TITLE - LHS SAMPLE FOR LOSP INITIATING EVENT

RANDOM SEED 1787673089

NOBS 1000

RANDOM SAMPLE

USER DISTRIBUTION IE PCGW.DAT

USER DISTRIBUTION IE_IV.DAT

OUTPUT HIST 
Attachment G-20

Subroutine USRDST.FOR 


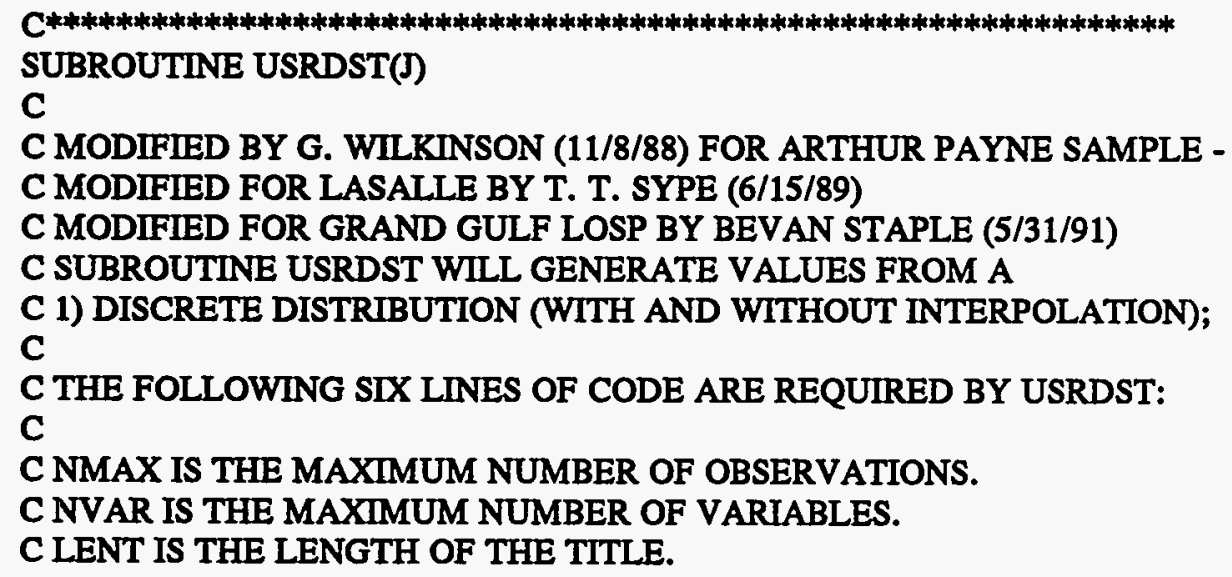


C

ELSEIF (J.EQ.2) THEN
IF(IFLAG EQ.2)OPEN(UNIT=61,FILE='IE_IV.DAT',STATUS='OLD')

$\mathrm{NP}=32$

IF (IFLAG.EQ 2)WRITE $(6,16)$

16 FORMAT('l',l,I,6X,'INPUT DATA FOR IE_IV',/,11X,'XVAL',14X,'CP')

DO $1 \mathrm{~K}=1, \mathrm{NP}$

$\operatorname{READ}(61, *)$ XVAL(K), CP(K)

IF(IFLAG.EQ 2) WRITE(6,18) XVAL(K), CP(K)

18 FORMAT(6X,EI3.7,3X,E13.7)

1 CONTINUE

REWIND 61

C

ENDIF

C

C SET THE STARTING POINT (STRTPT) EQUAL TO ZERO AND THE PROBABILITY

C INCREMENT (PROBINC) EQUAL TO 1/N FOR A LHS WHERE N IS THE SAMPLE SIZE

C

STRTPT $=0.0$

PROBINC $=1.0 /$ FLOAT(N)

IF(IRS EQ.1)PROBINC $=1.0$

C THIS LOOP WILL OBTAIN THE N SAMPLES

C

ITEMP $=1$

DO $4 \mathrm{I}=1, \mathrm{~N}$

C

$\mathrm{R}=$ STRTPT + PROBINC*RAN(ISEED)

DO $3 \mathrm{~K}=$ ITEMP,NP-1

IF(R.GE.CP(K).AND.R.LT.CP(K+l)) THEN

C IF(XVAL(K).EQ.XVAL(K+1)) THEN

C DISCRETE PROBABILITY

C

$\mathrm{X}(\mathrm{LOC}(\mathrm{I}, \mathrm{J}))=\mathrm{XVAL}(\mathrm{K})$

C

ELSE

C INTERPOLATION

C

$\mathrm{X}(\mathrm{LOC}(\mathrm{I}, \mathrm{J}))=((\mathrm{R}-\mathrm{CP}(\mathrm{K})) /(\mathrm{CP}(\mathrm{K}+1)-\mathrm{CP}(\mathrm{K})))^{*}$

$1 \quad(X V A L(K+1)-X V A L(K))+\operatorname{XVAL}(K)$

ENDIF

IF(IRS.NE.1) ITEMP $=K$

GO TO 25

ENDIF

3 CONTINUE

25 CONTINUE

IF(IRS.NE.I)STRTPT $=$ STRTPT + PROBINC

4 CONTINUE

GO TO 99

C

99 RETURN

END

Vol. 2, Part 2

G-93

NUREG/CR-6143 
LOSP Frequency

Attachment G-21

LHS.OUT 
TITLE - LHS SAMPLE FOR LOSP INITIATING EVENT ***RANDOM SAMPLE***

RANDOM SEED $=1787673089$

NUMBER OF VARIABLES $=2$

NUMBER OF OBSERVATIONS $=1000$

HISTOGRAMS OF THE ACTUAL SAMPLE WILL BE PLOTTED FOR EACH INPUT VARIABLE

TITLE - LHS SAMPLE FOR LOSP INITIATING EVENT

VARIABLE DISTRIBUTION

1 USER SUPPLIED DISTRIBUTION

2 USER SUPPLIED DISTRIBUTION
RANGE LABEL

IE_PCGW.DAT

IE IV.DAT

INPUT DATA FOR IE_PCGW

$\begin{array}{ll}\text { XVAL } & \text { CP } \\ 0.1000000 \mathrm{E}-07 & 0.0000000 \mathrm{E}+00 \\ 0.1540740 \mathrm{E}-04 & 0.9780000 \mathrm{E}-03 \\ 0.1232590 \mathrm{E}-03 & 0.3558000 \mathrm{E}-02 \\ 0.4160000 \mathrm{E}-03 & 0.8215000 \mathrm{E}-02 \\ 0.9860740 \mathrm{E}-03 & 0.1559000 \mathrm{E}-01 \\ 0.1925930 \mathrm{E} 02 & 0.2645200 \mathrm{E}-01 \\ 0.3328000 \mathrm{E}-02 & 0.4169700 \mathrm{E}-01 \\ 0.5284740 \mathrm{E}-02 & 0.6232800 \mathrm{E}-01 \\ 0.7888590 \mathrm{E}-02 & 0.8940900 \mathrm{E} 01 \\ 0.1123200 \mathrm{E}-01 & 0.1240020 \mathrm{E}+00 \\ 0.1540740 \mathrm{E}-01 & 0.1670350 \mathrm{E}+00 \\ 0.2050730 \mathrm{E} 01 & 0.2191490 \mathrm{E}+00 \\ 0.2662400 \mathrm{E}-01 & 0.2805140 \mathrm{E}+00 \\ 0.3385010 \mathrm{E}-01 & 0.3505850 \mathrm{E}+00 \\ 0.4227790 \mathrm{E}-01 & 0.4279060 \mathrm{E}+00 \\ 0.5200000 \mathrm{E}-01 & 0.5100820 \mathrm{E}+00 \\ 0.6310870 \mathrm{E}-01 & 0.5938320 \mathrm{E}+00 \\ 0.7569660 \mathrm{E} 01 & 0.6753370 \mathrm{E}+00 \\ 0.8985600 \mathrm{E}-01 & 0.7500740 \mathrm{E}+00 \\ 0.1056790 \mathrm{E}+00 & 0.8140620 \mathrm{E}+00 \\ 0.1232590 \mathrm{E}+00 & 0.8659660 \mathrm{E}+00 \\ 0.1426880 \mathrm{E}+00 & 0.9062610 \mathrm{E}+00 \\ 0.1640580 \mathrm{E}+00 & 0.9362880 \mathrm{E}+00 \\ 0.1874620 \mathrm{E}+00 & 0.9578470 \mathrm{E}+00 \\ 0.2129920 \mathrm{E}+00 & 0.9728260 \mathrm{E}+00 \\ 0.2407410 \mathrm{E}+00 & 0.9829460 \mathrm{E}+00 \\ 0.2708010 \mathrm{E}+00 & 0.9895920 \mathrm{E}+00 \\ 0.3032640 \mathrm{E}+00 & 0.9938610 \mathrm{E}+00 \\ 0.3382230 \mathrm{E}+00, & 0.9965120 \mathrm{E}+00 \\ 0.3757710 \mathrm{E}+00 & 0.9981450 \mathrm{E}+00 \\ 0.4160000 \mathrm{E}+00 & 0.9990060 \mathrm{E}+\infty 0 \\ 0.9000000 \mathrm{E}+00 & 0.1000000 \mathrm{E}+01\end{array}$




\section{LOSP Frequency}

INPUT DATA FOR IE_IV

XVAL

$0.1000000 \mathrm{E}-07$

$0.1077780 \mathrm{E}-04$

$0.8622220 \mathrm{E}-04$

$0.2910000 \mathrm{E}-03$

$0.6897780 E-03$

$0.1347220 \mathrm{E}-02$

$0.2328000 \mathrm{E}-02$

$0.3696780 \mathrm{E}-02$

$0.5518220 \mathrm{E}-02$

$0.7857000 \mathrm{E}-02$

$0.1077780 \mathrm{E}-01$

$0.1434520 \mathrm{E}-01$

$0.1862400 \mathrm{E}-01$

$0.2367880 E-01$

$0.2957420 \mathrm{E}-01$

$0.3637500 \mathrm{E}-01$

$0.4414580 \mathrm{E}-01$

$0.5295120 \mathrm{E}-01$

$0.6285600 \mathrm{E}-01$

$0.7392480 \mathrm{E}-01$

$0.8622220 \mathrm{E} 01$

$0.9981300 \mathrm{E}-01$

$0.1147620 E+00$

$0.1311330 \mathrm{E}+00$

$0.1489920 \mathrm{E}+00$

$0.1684030 \mathrm{E}+00$

$0.1894300 \mathrm{E}+00$

$0.2121390 \mathrm{E}+00$

$0.2365940 \mathrm{E}+00$

$0.2628590 \mathrm{E}+00$

$0.2910000 \mathrm{E}+00$

$0.8500000 \mathrm{E}+\infty 0$
CP

$0.0000000 E+00$

$0.5520000 \mathrm{E}-03$

$0.1262000 \mathrm{E}-02$

$0.2208000 \mathrm{E}-02$

$0.3445000 \mathrm{E}-02$

0.5048000 E 02

$0.7116000 \mathrm{E}-02$

$0.9782000 \mathrm{E}-02$

$0.1322900 \mathrm{E}-01$

$0.1771100 E-01$

$0.2358900 \mathrm{E} 01$

$0.3140700 \mathrm{E}-01$

$0.4205800 E-01$

$0.5727400 \mathrm{E}-01$

$0.8514700 E-01$

$0.1361640 \mathrm{E}+00$

$0.2389430 \mathrm{E}+00$

$0.4430610 \mathrm{E}+00$

$0.6950640 \mathrm{E}+00$

$0.8406540 \mathrm{E}+00$

$0.9255780 \mathrm{E}+00$

$0.9606960 \mathrm{E}+00$

$0.9770240 \mathrm{E}+00$

$0.9851200 \mathrm{E}+00$

$0.9900930 \mathrm{E}+00$

$0.9933200 \mathrm{E}+00$

$0.9954620 \mathrm{E}+00$

$0.9969030 \mathrm{E}+00$

$0.9978820 \mathrm{E}+00$

$0.9985500 \mathrm{E}+00$

$0.9990050 \mathrm{E}+00$

$0.1000000 \mathrm{E}+01$

TITLE - LHS SAMPLE FOR LOSP INITIATING EVENT ***RANDOM SAMPLE***

HISTOGRAM FOR VARIABLE NO. 1 USER SUPPLIED DISTRIBUTION

\section{MIDPOINT FREQ.}

$0.1050000 \mathrm{E}-01$

\section{7}

$0.3150000 \mathrm{E} 01$

199

$0.5250001 E-01$

154

$0.7350001 \mathrm{E}-01$

116

$0.9450002 \mathrm{E}-01$

98

0.1155000

67

0.1365000

38

0.1575000

34

0.1785000

19 
0.1995000

$0.2205000 \quad 10$

$0.2415000 \quad 5$

$0.2625000 \quad 1$

$0.2835000 \quad 2$

$0.3045000 \quad 3$

$0.3255000 \quad 1$

$0.3465000 \quad 0$

$0.3675000 \quad 0$

0.3885000

$0.4095000 \quad 1$

1000

MIN

$0.1252443 E-05$

14
10
5
1
3
1
0
1

0.4126163

RANGE

MEAN MEDIAN VARIANCE

0.4126150

$0.6490128 \mathrm{E}-01$

$0.5088609 \mathrm{E}-01 \quad 0.3193550 \mathrm{E}-02$ 
HISTOGRAM FOR VARIABLE NO. 2 USER SUPPLIED DISTRIBUTION

员

ث $0.2100000 \mathrm{E} 01229$

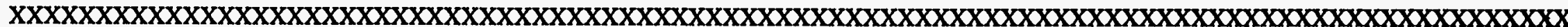
$0.6299999 E 01676$

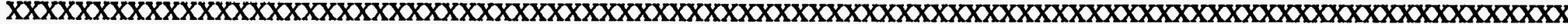

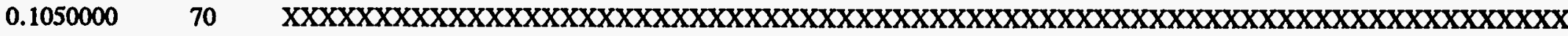

$0.1470000 \quad 18 \quad \mathrm{XXXXXXXXXXXXXXXXXX}$

$0.1890000 \quad 3 \quad \mathrm{XXX}$

0.2310000

0.2729999

0.3149999

0.3569999

0.3989999

0.4409999

0.4829999

0.5249999

bे 0.5669999

$\infty 0.6089999$

0.6509999

0.6929999

0.7349999

0.7769999

0.8189999

$\begin{array}{lll}0.8609999 & 1 & X \\ & 1000 & \end{array}$

$\begin{array}{ll}0 & \mathrm{XX}\end{array}$

0

$\mathrm{xX}$

MIN MAX

RANGE

MEAN

MEDIAN

VARIANCE

$0.1395887 E-03 \quad 0.8440393$

0.8438997

$0.5864298 \mathrm{E}-01$

$0.5470004 E-01$

$0.1796476 E-02$

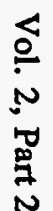


Attachment G-22

LHS.DAT 


\begin{tabular}{|c|c|c|c|c|c|c|c|}
\hline 1 & 2 & $9.5802836 \mathrm{E}-02$ & $5.7157081 \mathrm{E}-02$ & 54 & 2 & $6.3890698 \mathrm{E}-03$ & 6.1642252E-02 \\
\hline 2 & 2 & $5.0940670 \mathrm{E}-02$ & $6.0416732 \mathrm{E}-02$ & 55 & 2 & $1.1955368 E-02$ & $5.3150438 \mathrm{E}-02$ \\
\hline 3 & 2 & 3.7110481E-02 & $5.8251712 \mathrm{E}-02$ & 56 & 2 & $20493850 \mathrm{E}-02$ & 0.1857526 \\
\hline 4 & 2 & 0.3011881 & $5.3329077 \mathrm{E}-02$ & 57 & 2 & $3.9378010 \mathrm{E}-02$ & $3.7598554 \mathrm{E}-02$ \\
\hline 5 & 2 & $6.8660229 \mathrm{E}-02$ & $5.5287939 \mathrm{E}-02$ & 58 & 2 & $3.5381936 \mathrm{E}-02$ & $4.7152728 \mathrm{E}-02$ \\
\hline 6 & 2 & 4.1418765E-02 & $5.6494150 \mathrm{E}-02$ & 59 & 2 & 6 2365174E-02 & $7.5856574 \mathrm{E}-02$ \\
\hline 7 & 2 & $3.8164826 \mathrm{E}-03$ & 6.1932772E-02 & 60 & 2 & $6.9060028 E-02$ & $8.9874759 E-02$ \\
\hline 8 & 2 & $7.3756211 \mathrm{E}-02$ & 9.4944753E-02 & 61 & 2 & 4.4734307E-02 & $5.6779027 \mathrm{E}-02$ \\
\hline 9 & 2 & 0.1116926 & $5.5104259 \mathrm{E}-02$ & 62 & 2 & 4 3982375E-02 & $6.2561035 \mathrm{E}-02$ \\
\hline 10 & 2 & $8.3901752 E-03$ & $5.9206437 \mathrm{E}-02$ & 63 & 2 & 6 0694963E-02 & $3.8645752 \mathrm{E}-02$ \\
\hline 11 & 2 & 2.1001803E-04 & 0.1903778 & 64 & 2 & 9 1746241E-02 & 0.1081921 \\
\hline 12 & 2 & 0.19843083 .84 & $71486 \mathrm{E}-02$ & 65 & 2 & $12195393 E-02$ & 0.1378729 \\
\hline 13 & 2 & $6.1446220 \mathrm{E}-02$ & $5.7531755 \mathrm{E}-02$ & 66 & 2 & $9.7427778 E-03$ & $4.6029627 \mathrm{E}-02$ \\
\hline 14 & 2 & $1.3037866 \mathrm{E}-02$ & $7.0953816 \mathrm{E}-02$ & 67 & 2 & $1.9653393 \mathrm{E}-02$ & $4.2656578 \mathrm{E}-02$ \\
\hline 15 & 2 & $8.6331956 \mathrm{E}-02$ & $6.8710037 \mathrm{E}-02$ & 68 & 2 & $3.1145809 \mathrm{E}-02$ & $4.1980006 \mathrm{E}-02$ \\
\hline 16 & 2 & $.3 .7155967 \mathrm{E}-02$ & $3.2672279 \mathrm{E}-02$ & 69 & 2 & $7.1229465 \mathrm{E}-02$ & $6.0362123 E-02$ \\
\hline 17 & 2 & $\cdot 3.2555930 \mathrm{E}-02$ & $4.4575006 \mathrm{E}-02$ & 70 & 2 & $5.5966739 \mathrm{E}-02$ & 0.1215986 \\
\hline 18 & 2 & $4.5071386 \mathrm{E}-02$ & $3.1056585 \mathrm{E}-02$ & 71 & 2 & $2.9009812 E-02$ & $6.5682463 \mathrm{E}-02$ \\
\hline 19 & 2 & 6.3797474E-02 & $4.6071306 \mathrm{E}-02$ & 72 & 2 & 7.5244442E-02 & $5.8911454 \mathrm{E}-02$ \\
\hline 20 & 2 & $4.3774538 \mathrm{E}-02$ & $3.0516183 E-02$ & 73 & 2 & $7.8743502 \mathrm{E}-02$ & $5.4237224 \mathrm{E}-02$ \\
\hline 21 & 2 & 0.1065058 & $7.9281092 \mathrm{E}-02$ & 74 & 2 & $5.0527163 E-02$ & $6.1270196 \mathrm{E}-02$ \\
\hline 22 & 2 & $5.5102311 \mathrm{E}-02$ & $3.2996830 \mathrm{E}-02$ & 75 & 2 & 3.1681322E-02 & $8.5060455 \mathrm{E}-02$ \\
\hline 23 & 2 & $3.5599325 \mathrm{E}-02$ & $4.8942689 \mathrm{E}-02$ & 76 & 2 & $5.1817849 \mathrm{E}-02$ & $5.0090570 \mathrm{E}-02$ \\
\hline 24 & 2 & $2.0490789 \mathrm{E}-03$ & $4.5054294 \mathrm{E}-02$ & 77 & 2 & $5.0831504 \mathrm{E}-02$ & $2.4951266 \mathrm{E}-02$ \\
\hline 25 & 2 & $2.5542006 \mathrm{E}-02$ & $2.5336470 \mathrm{E}-02$ & 78 & 2 & 0.1170508 & $6.8073846 \mathrm{E}-02$ \\
\hline 26 & 2 & $4.6561282 \mathrm{E}-02$ & $7.3678486 \mathrm{E}-02$ & 79 & 2 & $3.0360568 \mathrm{E}-02$ & $4.9490560 \mathrm{E}-02$ \\
\hline 27 & 2 & 9.7525999E-02 & $7.1654484 \mathrm{E}-02$ & 80 & 2 & 3.7065927E-02 & $5.0325025 \mathrm{E}-02$ \\
\hline 28 & 2 & $3.6980748 \mathrm{E}-02$ & $6.9754799 \mathrm{E}-03$ & 81 & 2 & 8.4724374E-02 & $3.4361262 \mathrm{E}-02$ \\
\hline 29 & 2 & $3.8461756 \mathrm{E}-02$ & $2.1312614 \mathrm{E}-03$ & 82 & 2 & 0.2172877 & $7.2943039 \mathrm{E}-02$ \\
\hline 30 & 2 & 0.1308402 & $4.2214524 \mathrm{E}-02$ & 83 & 2 & 0.1707056 & $6.1654635 \mathrm{E}-02$ \\
\hline 31 & 2 & $1.5121906 \mathrm{E}-02$ & $6.1416168 \mathrm{E}-02$ & 84 & 2 & 4.1157823E-02 & $6.0433898 \mathrm{E}-02$ \\
\hline 32 & 2 & 0.1576969 & $4.6902116 \mathrm{E}-02$ & 85 & 2 & $4.6242714 \mathrm{E}-02$ & $5.8522064 \mathrm{E}-02$ \\
\hline 33 & 2 & $1.1520608 \mathrm{E}-02$ & $6.0953710 \mathrm{E}-02$ & 86 & 2 & 7.8710178E-03 & $6.0102671 E-02$ \\
\hline 34 & 2 & 0.1065259 & $9.9590011 \mathrm{E}-02$ & 87 & 2 & 8.4139876E-02 & $7.9868220 E-02$ \\
\hline 35 & 2 & 0.1838354 & $9.7384945 \mathrm{E}-02$ & 88 & 2 & $9.9810176 \mathrm{E}-02$ & 6.6642977E-02 \\
\hline 36 & 2 & $2.3105722 \mathrm{E}-02$ & $5.1488169 \mathrm{E}-02$ & 89 & 2 & $5.6254819 \mathrm{E}-02$ & $7.4072085 \mathrm{E}-02$ \\
\hline 37 & 2 & $7.8000881 E-02$ & 8.7991364E-02 & 90 & 2 & 4.5131359E-02 & 3.6564417E-02 \\
\hline 38 & 2 & $8.4191918 E-02$ & 4.7253303E-02 & 91 & 2 & 0.1175776 & $6.0518596 \mathrm{E}-02$ \\
\hline 39 & 2 & $3.0882679 E-02$ & 3.7661687E-02 & 92 & 2 & $2.3901181 E-02$ & $5.5216696 \mathrm{E}-02$ \\
\hline 40 & 2 & 0.1168672 & 9.2032492E-02 & 93 & 2 & 6.8641901E-02 & 4.5617305E-02 \\
\hline 41 & 2 & $6.9784876 E-03$ & $2.3598088 \mathrm{E}-02$ & 94 & 2 & 8.4755734E-02 & $3.5917133 \mathrm{E}-02$ \\
\hline 42 & 2 & $2.8681975 E-02$ & $3.9681610 \mathrm{E}-02$ & 95 & 2 & 4.7624674E-02 & $5.0922580 \mathrm{E}-02$ \\
\hline 43 & 2 & 2.7508037E-02 & $8.6506894 \mathrm{E}-03$ & 96 & 2 & $7.6687358 \mathrm{E}-02$ & 4.7751363E-02 \\
\hline 44 & 2 & 5.7893977E-02 & $3.1828873 \mathrm{E}-02$ & 97 & 2 & $6.1508259 \mathrm{E}-03$ & $6.2739216 \mathrm{E}-02$ \\
\hline 45 & 2 & 8.7122709E-02 & $3.0945832 E-02$ & 98 & 2 & $6.9542497 \mathrm{E}-02$ & $6.6954583 \mathrm{E}-02$ \\
\hline 46 & 2 & $4.0420175 \mathrm{E}-02$ & 0.1134561 & 99 & 2 & $5.0025929 \mathrm{E}-02$ & $7.1312711 \mathrm{E}-02$ \\
\hline 47 & 2 & $6.7433029 E-02$ & 4.9484331E-02 & 100 & 2 & $7.6181762 \mathrm{E}-02$ & 0.1293133 \\
\hline 48 & 2 & 3.1565614E-02 & $5.5348329 \mathrm{E}-02$ & 101 & 2 & $4.7242548 \mathrm{E}-02$ & $2.8041681 \mathrm{E}-02$ \\
\hline 49 & 2 & $6.2981918 \mathrm{E}-02$ & $4.5933411 \mathrm{E}-02$ & 102 & 2 & 5 1474594E-02 & 4.7649670E-02 \\
\hline 50 & 2 & $3.6439944 \mathrm{E}-02$ & $6.5376133 \mathrm{E}-02$ & 103 & 2 & $1.6576273 E-02$ & $8.9545082 \mathrm{E}-03$ \\
\hline 51 & 2 & $23256298 \mathrm{E}-03$ & 6.1091572E-02 & 104 & 2 & 3.3260591E-02 & 4.7793541E-02 \\
\hline 52 & 2 & $37388284 \mathrm{E}-02$ & $6.3234374 \mathrm{E}-02$ & 105 & 2 & 5 7211630E-02 & 4.9049694E-02 \\
\hline 53 & 2 & 4.9667925E-02 & 8.1571952E-02 & 106 & 2 & $9.6157566 \mathrm{E}-02$ & $5.0513197 \mathrm{E}-02$ \\
\hline
\end{tabular}




\begin{tabular}{|c|c|c|c|c|c|c|c|}
\hline 107 & 2 & 0.1619431 & $3.6086690 \mathrm{E}-02$ & 160 & 2 & 0.1213369 & $6.8935312 \mathrm{E}-02$ \\
\hline 108 & 2 & $6.5522656 \mathrm{E}-02$ & $5.0114769 \mathrm{E}-02$ & 161 & 2 & 4.5888089E-03 & $8.6619906 \mathrm{E}-02$ \\
\hline 109 & 2 & 9.9551871E-02 & 5.3492881E-02 & 162 & 2 & $7.6253237 \mathrm{E}-03$ & $7.2223626 \mathrm{E}-02$ \\
\hline 110 & 2 & $3.2978956 \mathrm{E}-02$ & $8.2634754 \mathrm{E}-02$ & 163 & 2 & 0.1213599 & $5.0378244 \mathrm{E}-02$ \\
\hline 111 & 2 & $5.2812852 E-02$ & $6.2103730 \mathrm{E}-02$ & 164 & 2 & $5.0322939 \mathrm{E}-02$ & 5.5347841E-02 \\
\hline 112 & 2 & $4.1240700 \mathrm{E}-02$ & $5.0557747 \mathrm{E}-02$ & 165 & 2 & $5.3692952 \mathrm{E}-02$ & $1.6964931 \mathrm{E}-02$ \\
\hline 113 & 2 & $7.0628084 \mathrm{E}-02$ & $3.3015352 \mathrm{E}-02$ & 166 & 2 & $6.8447582 \mathrm{E}-02$ & $5.8529630 \mathrm{E}-02$ \\
\hline 114 & 2 & $3.2155325 \mathrm{E}-03$ & $5.7052251 \mathrm{E}-02$ & 167 & 2 & 0.3917790 & $4.3206576 \mathrm{E}-02$ \\
\hline 115 & 2 & 0.2955990 & 0.1668376 & 168 & 2 & $5.7127774 \mathrm{E}-02$ & $1.4987160 \mathrm{E}-02$ \\
\hline 116 & 2 & 0.1707724 & $1.8475348 \mathrm{E}-02$ & 169 & 2 & $8.3935164 \mathrm{E}-02$ & $8.4336311 \mathrm{E}-02$ \\
\hline 117 & 2 & $5.5750683 \mathrm{E}-02$ & $5.8639225 \mathrm{E}-02$ & 170 & 2 & $5.8236878 \mathrm{E}-02$ & $5.1324982 E-02$ \\
\hline 118 & 2 & $3.3989530 \mathrm{E}-02$ & 5.5715863E-02 & 171 & 2 & $2.7824761 \mathrm{E}-02$ & $5.8796186 \mathrm{E}-02$ \\
\hline 119 & 2 & $9.6589506 \mathrm{E}-02$ & $6.0960405 \mathrm{E}-02$ & 172 & 2 & $1.0342170 \mathrm{E}-02$ & $6.6040970 \mathrm{E}-02$ \\
\hline 120 & 2 & $4.4756867 \mathrm{E}-02$ & $2.0783002 E-02$ & 173 & 2 & 0.1130472 & $4.6403021 \mathrm{E}-02$ \\
\hline 121 & 2 & 7 3829912E-02 & $3.9646626 \mathrm{E}-02$ & 174 & 2 & $1.9324374 \mathrm{E}-03$ & $2.1041799 \mathrm{E}-02$ \\
\hline 122 & 2 & 0.12158771 .57 & $97980 \mathrm{E}-02$ & 175 & 2 & $2.1123756 \mathrm{E}-02$ & 5.4619823E-02 \\
\hline 123 & 2 & $8.4925257 \mathrm{E}-02$ & $2.0765597 \mathrm{E}-02$ & 176 & 2 & $7.3582875 \mathrm{E}-03$ & $3.7066460 \mathrm{E}-02$ \\
\hline 124 & 2 & $5.1617451 \mathrm{E}-02$ & 5.5218507E-02 & 177 & 2 & $8.1938533 E-03$ & $5.8557700 \mathrm{E}-02$ \\
\hline 125 & 2 & $1.6678156 \mathrm{E}-02$ & $5.4130182 \mathrm{E}-02$ & 178 & 2 & $3.8392141 \mathrm{E}-03$ & $5.4025233 \mathrm{E}-02$ \\
\hline 126 & 2 & $1.7280921 \mathrm{E}-02$ & $47160003 E-02$ & 179 & 2 & 0.1114586 & $4.5126867 \mathrm{E}-02$ \\
\hline 127 & 2 & $6.1498184 \mathrm{E}-02$ & 5 8692340E-02 & 180 & 2 & 3.7242990E-02 & $6.1717805 \mathrm{E}-02$ \\
\hline 128 & 2 & 0.1538038 & $2.3057584 E-02$ & 181 & 2 & $1.9190241 \mathrm{E}-02$ & $4.8077114 \mathrm{E}-02$ \\
\hline 129 & 2 & $7.0079938 E-02$ & $5.9342016 \mathrm{E}-02$ & 182 & 2 & $2.3559626 \mathrm{E}-02$ & $4.2224646 \mathrm{E}-02$ \\
\hline 130 & 2 & 4 6549104E-02 & $1.9712312 \mathrm{E}-02$ & 183 & 2 & $6.7579068 \mathrm{E}-02$ & $5.4060549 \mathrm{E}-02$ \\
\hline 131 & 2 & $8.5495159 \mathrm{E}-02$ & $1.8631760 \mathrm{E}-02$ & 184 & 2 & 0.1495474 & 0.1292609 \\
\hline 132 & 2 & $2.9121149 \mathrm{E}-02$ & $6.0043842 \mathrm{E}-02$ & 185 & 2 & 8.7243997E-02 & $5.6941222 E-02$ \\
\hline 133 & 2 & $5.2379847 \mathrm{E}-02$ & 6.7772292E-02 & 186 & 2 & $3.9188843 \mathrm{E}-03$ & $4.8121687 \mathrm{E}-02$ \\
\hline 134 & 2 & $2.2424161 \mathrm{E}-02$ & $5.7133570 \mathrm{E}-02$ & 187 & 2 & $2.0487398 \mathrm{E}-02$ & $6.9975689 \mathrm{E}-02$ \\
\hline 135 & 2 & $1.4448942 \mathrm{E}-02$ & $7.5433329 E-02$ & 188 & 2 & 0.1687348 & $5.1983319 E-02$ \\
\hline 136 & 2 & 0.12594440 & $4.9683046 \mathrm{E}-02$ & 189 & 2 & $1.9494988 \mathrm{E}-02$ & $3.7827380 \mathrm{E}-02$ \\
\hline 137 & 2 & $2.1840738 \mathrm{E}-02$ & $3.7463218 E-02$ & 190 & 2 & $3.1080063 E-02$ & $2.2208920 \mathrm{E}-02$ \\
\hline 138 & 2 & 4.6944050E-03 & $6.5001808 E-02$ & 191 & 2 & $3.3260230 \mathrm{E}-02$ & $3.4254942 E-02$ \\
\hline 139 & 2 & $6.5334700 \mathrm{E}-02$ & $3.5716325 \mathrm{E}-02$ & 192 & 2 & 0.1394177 & $6.1570350 \mathrm{E}-02$ \\
\hline 140 & 2 & 0.1371943 & $1.9875966 \mathrm{E}-02$ & 193 & 2 & $4.6089880 \mathrm{E}-02$ & 8.3428882E-02 \\
\hline 141 & 2 & $1.6964525 \mathrm{E}-02$ & 8.1631653E-02 & 194 & 2 & 0.1716556 & $5.5070791 E-02$ \\
\hline 142 & 2 & 0.1015151 & $2.9490849 \mathrm{E}-02$ & 195 & 2 & $5.3486563 \mathrm{E}-02$ & $7.9588860 \mathrm{E}-02$ \\
\hline 143 & 2 & $1.8315334 \mathrm{E}-02$ & $4.2935792 \mathrm{E}-02$ & 196 & 2 & $4.7258500 \mathrm{E}-02$ & 0.1550756 \\
\hline 144 & 2 & $3.3113606 \mathrm{E}-02$ & $3.9712951 \mathrm{E}-02$ & 197 & 2 & $3.3940416 \mathrm{E}-02$ & $8.4298290 \mathrm{E}-02$ \\
\hline 145 & 2 & 0.1321511 & $6.5156333 E-02$ & 198 & 2 & $2.1830970 \mathrm{E}-02$ & $5.5529773 \mathrm{E}-02$ \\
\hline 146 & 2 & $4.2373762 \mathrm{E}-02$ & $6.5489277 \mathrm{E}-02$ & 199 & 2 & $4.0602647 \mathrm{E}-03$ & $5.6944489 \mathrm{E}-02$ \\
\hline 147 & 2 & 7.2913952E-03 & $5.9004165 \mathrm{E}-02$ & 200 & 2 & $1.0020436 \mathrm{E}-02$ & $5.4907784 \mathrm{E}-02$ \\
\hline 148 & 2 & $6.3795552 \mathrm{E}-02$ & $4.7587328 \mathrm{E}-02$ & 201 & 2 & 3.7182402E-02 & $4.9482226 \mathrm{E}-02$ \\
\hline 149 & 2 & 0.2103213 & $8.3966292 \mathrm{E}-02$ & 202 & 2 & $4.2706481 \mathrm{E}-03$ & 0.1606795 \\
\hline 150 & 2 & 0.1109417 & $4.0622294 \mathrm{E}-02$ & 203 & 2 & 3.1993993E-02 & $5.3374309 \mathrm{E}-02$ \\
\hline 151 & 2 & 0.1395433 & $5.4257885 \mathrm{E}-02$ & 204 & 2 & $7.7867016 \mathrm{E}-02$ & $2.8862229 \mathrm{E}-02$ \\
\hline 152 & 2 & 4.7899157E-02 & 0.1202568 & 205 & 2 & $4.5282654 \mathrm{E}-02$ & 4.6392612E-02 \\
\hline 153 & 2 & $6.8555456 \mathrm{E}-02$ & 6.0329355E-02 & 206 & 2 & 2.3415735E-02 & $6.4310737 \mathrm{E}-02$ \\
\hline 154 & 2 & $4.7816616 \mathrm{E}-03$ & $3.7393130 \mathrm{E}-02$ & 207 & 2 & 0.2160491 & 5.5371974E-02 \\
\hline 155 & 2 & $1.3575777 \mathrm{E}-02$ & $2.2464391 \mathrm{E}-02$ & 208 & 2 & $6.4673787 \mathrm{E}-03$ & 0.7566715 \\
\hline 156 & 2 & $3.7566062 \mathrm{E}-02$ & $1.2979862 \mathrm{E}-02$ & 209 & 2 & $1.7433336 \mathrm{E}-02$ & $5.5316355 \mathrm{E}-02$ \\
\hline 157 & 2 & $9.9475965 \mathrm{E}-02$ & $3.7282106 \mathrm{E}-02$ & 210 & 2 & $2.2904482 \mathrm{E}-05$ & 4.6597488E-02 \\
\hline 158 & 2 & 0.1179500 & 4.4079732E-02 & 211 & 2 & 0.1147942 & $5.9636269 \mathrm{E}-02$ \\
\hline 159 & 2 & 0.1407464 & $8.6003169 \mathrm{E}-02$ & 212 & 2 & $7.6124631 \mathrm{E}-02$ & 7.3863171E-02 \\
\hline
\end{tabular}


LOSP Frequency

\begin{tabular}{|c|c|c|c|c|c|c|c|}
\hline 213 & 2 & $5.3303089 \mathrm{E}-02$ & $6.8604030 \mathrm{E}-02$ & 266 & 2 & 0.1101487 & $5.3302426 \mathrm{E}-02$ \\
\hline 214 & 2 & 5.0968453E-02 & $3.0148089 \mathrm{E}-02$ & 267 & 2 & $1.0786332 \mathrm{E}-02$ & $6.1759170 \mathrm{E}-02$ \\
\hline 215 & 2 & 0.1519960 & $5.0956085 \mathrm{E}-02$ & 268 & 2 & 0.1050531 & $6.6191122 E-02$ \\
\hline 216 & 2 & $.9 .9529408 \mathrm{E}-02$ & 5.1027179E-02 & 269 & 2 & $8.6179286 \mathrm{E}-02$ & $3.9748408 \mathrm{E}-02$ \\
\hline 217 & 2 & ' 1.2661025E-02 & $3.2987788 \mathrm{E}-02$ & 270 & 2 & $7.1867579 E-03$ & $4.2479008 \mathrm{E}-02$ \\
\hline 218 & 2 & $1.1452804 \mathrm{E}-02$ & $1.9742427 \mathrm{E}-02$ & 271 & 2 & $9.5057264 \mathrm{E}-02$ & $5.1139485 \mathrm{E}-02$ \\
\hline 219 & 2 & $5.9550323 \mathrm{E}-02$ & $8.1923068 E-02$ & 272 & 2 & 0.1684978 & $2.7940258 \mathrm{E}-02$ \\
\hline 220 & 2 & 8.4897578E-02 & $3.2943714 \mathrm{E}-02$ & 273 & 2 & $1.2539796 \mathrm{E}-02$ & $7.8760505 \mathrm{E}-02$ \\
\hline 221 & 2 & 0.1265632 & 4.4650719E-02 & 274 & 2 & $6.4291013 \mathrm{E}-03$ & $4.0083379 \mathrm{E}-02$ \\
\hline 222 & 2 & 0.1636941 & $6.5610617 \mathrm{E}-02$ & 275 & 2 & $7.7832922 \mathrm{E}-02$ & $5.9734005 \mathrm{E}-02$ \\
\hline 223 & 2 & 7.2806217E-02 & $7.1486212 E-02$ & 276 & 2 & 0.1206533 & $4.1501082 \mathrm{E}-02$ \\
\hline 224 & 2 & $9.7682148 \mathrm{E}-02$ & 0.1179187 & 277 & 2 & $5.6917291 \mathrm{E}-02$ & $4.7410175 \mathrm{E}-02$ \\
\hline 225 & 2 & $4.3897450 \mathrm{E}-02$ & $5.7352368 \mathrm{E}-02$ & 278 & 2 & $3.6365487 \mathrm{E}-02$ & $5.2262317 \mathrm{E}-02$ \\
\hline 226 & 2 & $5.3755235 \mathrm{E}-02$ & 0.1008180 & 279 & 2 & $7.0993602 \mathrm{E}-02$ & $4.4433460 \mathrm{E}-02$ \\
\hline 227 & 2 & 7.2366193E-02 & 0.1015658 & 280 & 2 & $4.3315183 E-02$ & $6.5824345 \mathrm{E}-02$ \\
\hline 228 & 2 & 0.2446719 & $3.0301256 \mathrm{E}-02$ & 281 & 2 & 7.4349679E-02 & 0.1840891 \\
\hline 229 & 2 & 8.7504514E-02 & 7.1135163E-02 & 282 & 2 & $9.5265292 \mathrm{E}-02$ & $8.2059130 \mathrm{E}-02$ \\
\hline 230 & 2 & $6.1651595 E-02$ & 7.9552941E-02 & 283 & 2 & 0.1238719 & $3.2222025 \mathrm{E}-02$ \\
\hline 231 & 2 & 0.1204444 & $5.2140828 \mathrm{E}-02$ & 284 & 2 & $9.5689654 \mathrm{E}-02$ & $8.1871301 E-02$ \\
\hline 232 & 2 & $1.0141240 \mathrm{E}-02$ & $4.9205273 E-02$ & 285 & 2 & 0.2603333 & 0.1265700 \\
\hline 233 & 2 & $2.9848058 E-02$ & $5.8265250 \mathrm{E}-02$ & 286 & 2 & 0.1145876 & $5.6587834 \mathrm{E}-02$ \\
\hline 234 & 2 & 9.4402153E-03 & $5.9602566 \mathrm{E}-02$ & 287 & 2 & $6.2036499 \mathrm{E}-02$ & $5.0692923 \mathrm{E}-02$ \\
\hline 235 & 2 & 4.3066703E-03 & $7.0935003 \mathrm{E}-02$ & 288 & 2 & 0.1287113 & $5.4666784 \mathrm{E}-02$ \\
\hline 236 & 2 & $8.8652149 E-03$ & $8.9759074 \mathrm{E}-02$ & 289 & 2 & 7.6434948E-02 & 0.2836348 \\
\hline 237 & 2 & $8.2147315 \mathrm{E}-02$ & $3.4737453 \mathrm{E}-02$ & 290 & 2 & 3.7384395E-02 & $5.1759280 \mathrm{E}-02$ \\
\hline 238 & 2 & $8.9766808 \mathrm{E}-02$ & 2.2139974E-02 & 291 & 2 & $5.5710252 \mathrm{E}-02$ & $7.9793416 \mathrm{E}-02$ \\
\hline 239 & 2 & 5.7522781E-02 & $8.4488504 \mathrm{E}-02$ & 292 & 2 & $3.0785400 \mathrm{E}-02$ & $6.5113649 \mathrm{E}-02$ \\
\hline 240 & 2 & $1.9196231 \mathrm{E}-02$ & $7.9581648 \mathrm{E}-02$ & 293 & 2 & 0.1471515 & $6.0857952 E-02$ \\
\hline 241 & 2 & $3.2749761 \mathrm{E}-02$ & $6.2474120 \mathrm{E}-02$ & 294 & 2 & $1.6241783 \mathrm{E}-02$ & $5.7650033 \mathrm{E}-02$ \\
\hline 242 & 2 & $7.4022703 \mathrm{E}-02$ & 4.1953418E-02 & 295 & 2 & $5.5924322 \mathrm{E}-02$ & $3.0042961 \mathrm{E}-02$ \\
\hline 243 & 2 & 2.8199911E-02 & $5.1889852 E-02$ & 296 & 2 & $3.6231801 \mathrm{E}-02$ & $4.6817876 \mathrm{E}-02$ \\
\hline 244 & 2 & 0.1044558 & $6.7030467 \mathrm{E}-02$ & 297 & 2 & $5.1834852 \mathrm{E}-02$ & $7.3877349 E-02$ \\
\hline 245 & 2 & 3.6798760E-02 & 8.6043261E-02 & 298 & 2 & $1.36161041 \mathrm{E}-02$ & $4.0530287 \mathrm{E}-02$ \\
\hline 246 & 2 & 2.8888844E-02 & $3.2008789 \mathrm{E}-02$ & 299 & 2 & 0.1356705 & $3.7863705 E-02$ \\
\hline 247 & 2 & 0.1416059 & $4.2976875 \mathrm{E}-02$ & 300 & 2 & $6.1036717 \mathrm{E}-02$ & $5.6248203 E-02$ \\
\hline 248 & 2 & $1.1433396 \mathrm{E}-02$ & $4.2970411 \mathrm{E}-02$ & 301 & 2 & $3.2080885 \mathrm{E}-02$ & 8.4085375E-02 \\
\hline 249 & 2 & $8.4602527 \mathrm{E}-02$ & 4.8343554E-02 & 302 & 2 & $6.3935861 \mathrm{E}-02$ & 5.3747039E-02 \\
\hline 250 & 2 & 0.1223382 & $4.7623150 \mathrm{E}-02$ & 303 & 2 & 8.4782112E-03 & $5.2066682 \mathrm{E}-02$ \\
\hline 251 & 2 & 5.3186379E-02 & 7.3586397E-02 & 304 & 2 & 0.1483902 & 3.3199754E-02 \\
\hline 252 & 2 & $9.5278546 \mathrm{E}-03$ & $7.3705859 \mathrm{E}-02$ & 305 & 2 & $1.6334236 \mathrm{E}-02$ & $4.4072583 E-02$ \\
\hline 253 & 2 & $3.6003832 E-02$ & $6.3980505 E-02$ & 306 & 2 & $2.6464649 E-02$ & $6.5281264 \mathrm{E}-02$ \\
\hline 254 & 2 & 0.2368298 & $6.8291128 \mathrm{E}-02$ & 307 & 2 & 3.3093113E-02 & $6.1957162 \mathrm{E}-02$ \\
\hline 255 & 2 & 9.8380804E-02 & $5.4853976 \mathrm{E}-02$ & 308 & 2 & 0.1980580 & $6.3871555 \mathrm{E}-02$ \\
\hline 256 & 2 & 0.1627849 & $6.9135174 \mathrm{E}-02$ & 309 & 2 & $3.2279663 \mathrm{E}-02$ & $3.2386724 \mathrm{E}-02$ \\
\hline 257 & 2 & $4.3205872 \mathrm{E}-02$ & 5.5737238E-02 & 310 & 2 & $7.2981618 \mathrm{E}-02$ & $2.3961281 E-02$ \\
\hline 258 & 2 & 7.7809721E-02 & $5.7787050 \mathrm{E}-02$ & 311 & 2 & $1.0505857 \mathrm{E}-02$ & $6.9583394 \mathrm{E}-02$ \\
\hline 259 & 2 & $9.2956319 \mathrm{E}-02$ & 6.5993495E-02 & 312 & 2 & $2.7589556 \mathrm{E}-02$ & 4.9572527E-02 \\
\hline 260 & 2 & 0.1799912 & 5.1761754E-02 & 313 & 2 & $9.8100808 \mathrm{E}-03$ & 4.5669530E-02 \\
\hline 261 & 2 & $5.3744238 E-02$ & 0.1043923 & 314 & 2 & 0.1137452 & $6.7695037 \mathrm{E}-02$ \\
\hline 262 & 2 & $2.3056671 \mathrm{E}-02$ & $5.9782274 \mathrm{E}-02$ & 315 & 2 & $7.2744422 \mathrm{E}-02$ & $8.2279146 \mathrm{E}-02$ \\
\hline 263 & 2 & $6.4727686 \mathrm{E}-02$ & $7.6576352 \mathrm{E}-02$ & 316 & 2 & $9.1899738 \mathrm{E}-02$ & $5.7338905 \mathrm{E}-02$ \\
\hline 264 & 2 & 0.1216711 & 5.7241727E-02 & 317 & 2 & 3.0302284E-02 & 7.9181217E-02 \\
\hline 265 & 2 & 0.3209038 & 7.3334612E-02 & 318 & 2 & $4.4912171 \mathrm{E}-02$ & $5.0130807 \mathrm{E}-02$ \\
\hline
\end{tabular}




\begin{tabular}{|c|c|c|}
\hline 319 & 2 & $1.7556440 \mathrm{E}-02$ \\
\hline 320 & 2 & 7.8613654E-02 \\
\hline 321 & 2 & $7.6832488 \mathrm{E}-02$ \\
\hline 322 & 2 & $5.3756524 \mathrm{E}-02$ \\
\hline 323 & 2 & 0.1039997 \\
\hline 324 & 2 & $5.1588386 \mathrm{E}-02$ \\
\hline 325 & 2 & $4.1753639 \mathrm{E}-02$ \\
\hline 326 & 2 & $9.4200537 \mathrm{E}-02$ \\
\hline 327 & 2 & 0.2072446 \\
\hline 328 & 2 & $1.9067375 \mathrm{E}-02$ \\
\hline 329 & 2 & $5.2268062 \mathrm{E}-02$ \\
\hline 330 & 2 & $9.3951240 \mathrm{E}-02$ \\
\hline 331 & 2 & $2.5747674 \mathrm{E}-02$ \\
\hline 332 & 2 & $9.1002814 \mathrm{E}-02$ \\
\hline 333 & 2 & $5.2193556 \mathrm{E}-02$ \\
\hline 334 & 2 & $1.3168592 \mathrm{E}-02$ \\
\hline 335 & 2 & $7.8425752 \mathrm{E}-03$ \\
\hline 336 & 2 & $2.4083138 \mathrm{E}-02$ \\
\hline 337 & 2 & $2.9606896 \mathrm{E}-02$ \\
\hline 338 & 2 & $3.2791542 E-03$ \\
\hline 339 & 2 & $5.5754423 E-02$ \\
\hline 340 & 2 & $1.9297315 \mathrm{E}-02$ \\
\hline 341 & 2 & 0.1221153 \\
\hline 342 & 2 & 0.1836627 \\
\hline 343 & 2 & $2.6211066 \mathrm{E}-02$ \\
\hline 344 & 2 & 0.1165744 \\
\hline 345 & 2 & $7.7690028 \mathrm{E}-02$ \\
\hline 346 & 2 & $8.6576715 E-03$ \\
\hline 347 & 2 & $3.0842939 \mathrm{E}-02$ \\
\hline 348 & 2 & $3.4306709 \mathrm{E}-02$ \\
\hline 349 & 2 & $8.0743775 E-02$ \\
\hline 350 & 2 & $1.8435411 \mathrm{E}-02$ \\
\hline 351 & 2 & $3.2321534 \mathrm{E}-03$ \\
\hline 352 & 2 & $4.0109031 \mathrm{E}-02$ \\
\hline 353 & 2 & $7.1211591 \mathrm{E}-02$ \\
\hline 354 & 2 & 4.9363904E-02 \\
\hline 355 & 2 & $3.8666770 \mathrm{E}-02$ \\
\hline 356 & 2 & $5.1464181 \mathrm{E}-02$ \\
\hline 357 & 2 & $2.9909359 \mathrm{E}-02$ \\
\hline 358 & 2 & 8.5642956E-02 \\
\hline 359 & 2 & 0.1428766 \\
\hline 360 & 2 & $6.8073608 \mathrm{E}-02$ \\
\hline 361 & 2 & $3.6340430 \mathrm{E}-03$ \\
\hline 362 & 2 & $9.6433230 \mathrm{E}-02$ \\
\hline 363 & 2 & 0.1015370 \\
\hline 364 & 2 & $4.2306870 \mathrm{E}-02$ \\
\hline 365 & 2 & 8.6678125E-02 \\
\hline 366 & 2 & 8.0561943E-02 \\
\hline 367 & 2 & $3.5065666 \mathrm{E}-02$ \\
\hline 368 & 2 & $5.6423653 \mathrm{E}-02$ \\
\hline 369 & 2 & $9.1383748 \mathrm{E}-02$ \\
\hline 370 & 2 & $90465531 \mathrm{E}-02$ \\
\hline 371 & 2 & $8.2488284 \mathrm{E}-02$ \\
\hline
\end{tabular}

4.8635080E-02

$7.7345565 \mathrm{E}-02$

6.1814152E-02

3.1926371E-02

5.9751723E-02

6.9555439E-02

4.2831965E-02

5.0937343E-02

5.0402451E-02

0.1326806

4.6196971E-02

$5.7576288 \mathrm{E}-02$

4.7689557E-02

$5.8826875 \mathrm{E}-02$

7.2790295E-02

6.9407247E-02

5.0967094E-02

0.1204861

$6.9861956 \mathrm{E}-02$

8.4400952E-02

$7.2532296 \mathrm{E}-02$

0.1260565

0.1444877

$7.1748078 \mathrm{E}-02$

1.8517802E-02

4.8370954E-02

5.5468269E-02

4.8304219E-02

5.0762452E-02

7.1425423E-02

3.7325677E-02

5.4139994E-02

$6.7153610 \mathrm{E}-02$

0.2683479

$9.8831236 \mathrm{E}-02$

4.6027701E-02

$6.8053164 \mathrm{E}-02$

$5.0975636 \mathrm{E}-02$

8.1957847E-02

6.1596613E-02

3.1131679E-02

4.3255195E-02

2.4262222E-02

$6.5032646 \mathrm{E}-02$

$5.0547209 \mathrm{E}-02$

3.0492617E-02

2.2774333E- 02

4.8459731E-02

0.1246275

$5.6726296 \mathrm{E}-02$

0.1002052

$6.9393113 \mathrm{E}-02$

$6.2411986 \mathrm{E}-02$

\begin{tabular}{ll}
372 & 2 \\
373 & 2 \\
374 & 2 \\
375 & 2 \\
376 & 2 \\
377 & 2 \\
378 & 2 \\
379 & 2 \\
380 & 2 \\
381 & 2 \\
382 & 2 \\
383 & 2 \\
384 & 2 \\
385 & 2 \\
386 & 2 \\
387 & 2 \\
388 & 2 \\
389 & 2 \\
390 & 2 \\
391 & 2 \\
392 & 2 \\
393 & 2 \\
394 & 2 \\
395 & 2 \\
396 & 2 \\
397 & 2 \\
398 & 2 \\
399 & 2 \\
400 & 2 \\
401 & 2 \\
402 & 2 \\
403 & 2 \\
404 & 2 \\
405 & 2 \\
406 & 2 \\
407 & 2 \\
408 & 2 \\
409 & 2 \\
410 & 2 \\
411 & 2 \\
412 & 2 \\
413 & 2 \\
414 & 2 \\
415 & 2 \\
416 & 2 \\
417 & 2 \\
418 & 2 \\
419 & 2 \\
420 & 2 \\
421 & 2 \\
422 & 2 \\
423 & 2 \\
424 & 2 \\
& \\
\hline
\end{tabular}

5.7035097E-04

4.2432569E-02

$1.4777359 \mathrm{E}-02$

3.2787994E-02

$5.1232055 \mathrm{E}-02$

5 4714889E-03

2 0741522E-02

8.3291810E-04

9 0837017E-02

2 3047213E-02

$4.1621886 \mathrm{E}-02$

$3.9833665 \mathrm{E}-02$

9.0728611E-02

0.1397989

4.4620942E-02

0.1943297

3.5363667E-02

$6.8349316 \mathrm{E}-04$

0.1459142

8.0266237E-02

$19203138 \mathrm{E}-02$

7.1140945E-02

$5.2328020 \mathrm{E}-02$

$7.3376082 \mathrm{E}-02$

$6.3577600 \mathrm{E}-02$

$1.2584946 \mathrm{E}-03$

$1.5184088 \mathrm{E}-02$

$2.0581085 \mathrm{E}-02$

2.4160979E-02

0.1186002

6.6469684E-02

$3.7167817 \mathrm{E}-02$

$0.1164 \mathrm{t} 28$

$5.5276338 \mathrm{E}-02$

0.1067105

$6.9141306 \mathrm{E}-02$

8.5148111E-02

$1.0854620 \mathrm{E}-02$

7.3132701E-03

$3.9495885 \mathrm{E}-02$

0.1621865

2.7274314E-02

9.4924212E-02

$7.8715859 \mathrm{E}-03$

$7.6369330 \mathrm{E}-02$

1.1159037E-02

$1.6781913 \mathrm{E}-02$

9.4187953E-02

1.5712211E-02

0.1357202

9.6314792E-03

3.5887018E-02

6.3044518E-02
5.1698089E-02

$7.5730167 \mathrm{E}-02$

4.6410918E-02

$6.7062199 \mathrm{E}-02$

5.1038437E-02

4.4249024E-02

8.2121037E-02

4.7168367E-02

3.1095194E-02

7.5219192E-02

$7.2013229 \mathrm{E}-02$

$5.4039750 \mathrm{E}-02$

5.1099844E-02

8.3080105E-02

4.7020800E-02

$4.5590665 \mathrm{E}-02$

3.1711053E-02

4.6826027E-02

1.5171967E-02

$6.2088851 \mathrm{E}-02$

$5.7292338 \mathrm{E}-02$

4.8464339E-02

$6.8254374 \mathrm{E}-02$

5.7114784E-02

4.6294525E-02

4.2093381E-02

4.1216429E-02

4.8308022E-02

6.1195992E-02

6.8436407E-02

3.3913091E-02

4.7778640E-02

$4.5537926 \mathrm{E}-02$

8.6885706E-02

6.1804399E-02

5.4143526E-02

$5.0867260 \mathrm{E}-02$

3.4957122E-02

4.1457672E-02

$6.5525882 \mathrm{E}-02$

4.4940747E-03

9.0562209E-02

6.5175451E-02

7.2900273E-02

0.1102054

4.9953319E-02

5.9157480E-02

3.6562186E-02

$7.7645145 \mathrm{E}-02$

4.8308227E-02

5.2776337E-02

4.6999138E-02

2.9852998E-02 
LOSP Frequency

\begin{tabular}{|c|c|c|c|c|c|c|c|}
\hline 425 & 2 & $6.0450430 \mathrm{E}-03$ & 5.4368593E-02 & 478 & 2 & 5.8667913E-02 & $1.1793434 \mathrm{E}-02$ \\
\hline 426 & 2 & $1.9245146 \mathrm{E}-02$ & 0.8440393 & 479 & 2 & $8.5019536 \mathrm{E}-02$ & $5.3816400 \mathrm{E}-02$ \\
\hline 427 & 2 & 7.1171016E-02 & 7.2131597E-02 & 480 & 2 & $3.2430448 \mathrm{E}-02$ & $4.2968925 \mathrm{E}-02$ \\
\hline 428 & 2 & $6.7888290 \mathrm{E}-02$ & 7.7404454E-02 & 481 & 2 & $2.9151317 \mathrm{E}-02$ & $7.0211180 \mathrm{E}-02$ \\
\hline 429 & 2 & $5.5506688 \mathrm{E}-02$ & 7.5137384E-02 & 482 & 2 & $2.0972826 \mathrm{E}-02$ & $3.0125555 \mathrm{E}-02$ \\
\hline 430 & 2 & 0.2476660 & $1.9120978 \mathrm{E}-02$ & 483 & 2 & $9.0942435 \mathrm{E}-02$ & $6.9475524 \mathrm{E}-02$ \\
\hline 431 & 2 & 2.9247994E-02 & $6.0947556 \mathrm{E}-02$ & 484 & 2 & 0.1594650 & $8.8435039 \mathrm{E}-02$ \\
\hline 432 & 2 & $6.4376746 \mathrm{E}-03$ & $5.6334939 \mathrm{E}-02$ & 485 & 2 & 0.1471007 & 3.7287861E-02 \\
\hline 433 & 2 & $1.3259222 \mathrm{E}-02$ & $3.8407531 \mathrm{E}-02$ & 486 & 2 & 6.9947779E-02 & 6.6194192E-02 \\
\hline 434 & 2 & $9.5137425 \mathrm{E}-02$ & $5.0707649 \mathrm{E}-02$ & 487 & 2 & $2.9659139 \mathrm{E}-03$ & $3.6363807 E-02$ \\
\hline 435 & 2 & $1.6477322 \mathrm{E}-02$ & $2.4710726 \mathrm{E}-02$ & 488 & 2 & 0.1435275 & $6.4530842 \mathrm{E}-02$ \\
\hline 436 & 2 & 4.0688049E-02 & $4.2610008 \mathrm{E}-02$ & 489 & 2 & 0.1113859 & $7.8945436 \mathrm{E}-02$ \\
\hline 437 & 2 & $2.2278026 \mathrm{E}-02$ & $5.1053967 \mathrm{E}-02$ & 490 & 2 & 3.9282557E-02 & 4.3159917E-02 \\
\hline 438 & 2 & $2.4768834 \mathrm{E}-03$ & $6.1949339 E-02$ & 491 & 2 & $6.1981261 \mathrm{E}-02$ & $3.8630560 \mathrm{E}-02$ \\
\hline 439 & 2 & $1.9059179 \mathrm{E}-02$ & 7.1737774E-02 & 492 & 2 & $1.9839078 \mathrm{E}-02$ & $7.6724023 \mathrm{E}-02$ \\
\hline 440 & 2 & 4.2819299E-02 & $5.2731704 \mathrm{E}-02$ & 493 & 2 & $5.7827588 \mathrm{E}-02$ & $5.1710501 \mathrm{E}-02$ \\
\hline 441 & 2 & $9.5047787 \mathrm{E}-02$ & 8.5911974E-02 & 494 & 2 & $2.5132930 \mathrm{E}-02$ & $3.8794026 \mathrm{E}-02$ \\
\hline 442 & 2 & $2.2842348 E-02$ & $6.0070943 E-02$ & 495 & 2 & $4.0411420 \mathrm{E}-02$ & $5.6560256 E-02$ \\
\hline 443 & 2 & 8.9984555E-03 & 0.1145708 & 496 & 2 & 0.1284811 & $8.2200252 \mathrm{E}-02$ \\
\hline 444 & 2 & $4.0717803 \mathrm{E}-02$ & $4.3459535 \mathrm{E}-02$ & 497 & 2 & 8.3482713E-03 & $6.4073250 \mathrm{E}-02$ \\
\hline 445 & 2 & $1.8620146 \mathrm{E}-02$ & 7.6692447E-02 & 498 & 2 & 0.1010389 & $7.6155193 \mathrm{E}-02$ \\
\hline 446 & 2 & $5.5759195 \mathrm{E}-03$ & $1.6390927 \mathrm{E}-02$ & 499 & 2 & $1.0805682 \mathrm{E}-02$ & $6.2696621 \mathrm{E}-02$ \\
\hline 447 & 2 & $5.9370346 \mathrm{E}-02$ & 7576E-02 & 500 & 2 & $6.1287235 E-02$ & $5.4863572 \mathrm{E}-02$ \\
\hline 448 & 2 & $1.4559478 \mathrm{E}-02$ & $562 \mathrm{E}-02$ & 501 & 2 & $4.9389787 \mathrm{E}-03$ & $6.3365564 \mathrm{E}-02$ \\
\hline 449 & 2 & 2.1993279E-02 & 401E-02 & 502 & 2 & $5.8028206 \mathrm{E}-02$ & $6.8783589 E-02$ \\
\hline 450 & 2 & 3.4803309E-02 & 0.1 & 503 & 2 & $1.0797053 \mathrm{E}-02$ & 4.3770362E-02 \\
\hline 451 & 2 & 0.1713544 & $5.8508251 \mathrm{E}-02$ & 504 & 2 & $6.0769171 \mathrm{E}-02$ & $5.1254261 \mathrm{E}-02$ \\
\hline 452 & 2 & 4.7787406E-02 & 5.6298438E-02 & 505 & 2 & 817E-02 & 34E-02 \\
\hline 453 & 2 & 0.1166827 & $9.4757400 \mathrm{E}-02$ & 506 & 2 & $38 \mathrm{E}-02$ & $43 \mathrm{E}-02$ \\
\hline 454 & 2 & 0.1062214 & 4.4456623E-02 & 507 & 2 & 522E-02 & $64 \mathrm{E}-02$ \\
\hline 455 & 2 & $1.4152073 \mathrm{E}-02$ & 3.3927958E-02 & 508 & 2 & $2.2795934 \mathrm{E}-02$ & 7E-02 \\
\hline 456 & 2 & $7.3292643 \mathrm{E}-02$ & $2.9449234 \mathrm{E}-02$ & 509 & 2 & $6.2227350 \mathrm{E}-02$ & $360 \mathrm{E}-02$ \\
\hline 457 & 2 & $3.0571070 \mathrm{E}-02$ & $6.2851891 \mathrm{E}-02$ & 510 & 2 & 0.1672506 & $1.6204851 \mathrm{E}-02$ \\
\hline 458 & 2 & 0.1430519 & $1.2923073 \mathrm{E}-02$ & 511 & 2 & $1.8789757 \mathrm{E}-02$ & $5.9325770 \mathrm{E}-02$ \\
\hline 459 & 2 & $5.7888649 \mathrm{E}-02$ & 4.0874809E-02 & 512 & 2 & $2.6002435 \mathrm{E}-02$ & 4.6509504E-02 \\
\hline 460 & 2 & 0.1176199 & $5.1488835 \mathrm{E}-02$ & 513 & 2 & $8.3665326 E-02$ & $5.5244900 \mathrm{E}-02$ \\
\hline 461 & 2 & 8.8838212E-02 & 3.5273183E-02 & 514 & 2 & 3.0448386E-02 & $7.2145104 \mathrm{E}-02$ \\
\hline 462 & 2 & $83055459 \mathrm{E}-02$ & 5.2958019E-02 & 515 & 2 & 0.2885319 & $6.7223296 \mathrm{E}-02$ \\
\hline 463 & 2 & 7.8486003E-02 & $4.2060331 \mathrm{E}-02$ & 516 & 2 & $7.5610541 \mathrm{E}-02$ & 5.3584695E-02 \\
\hline 464 & 2 & $3.7651348 \mathrm{E}-03$ & $4.5594558 \mathrm{E}-02$ & 517 & 2 & 0.1016252 & 5.0296757E-02 \\
\hline 465 & 2 & 8.9207999E-02 & 4.9712803E-02 & 518 & 2 & 4.5112247E-04 & $3.4339830 \mathrm{E}-02$ \\
\hline 466 & 2 & 0.1019203 & $5.3399816 \mathrm{E}-02$ & 519 & 2 & 3.3670895E-02 & 5.3941634E-02 \\
\hline 467 & 2 & 3.8159367E-02 & $6.1574344 E-02$ & 520 & 2 & $5.0228938 \mathrm{E}-02$ & $2.8962769 \mathrm{E}-02$ \\
\hline 468 & 2 & 7.2341422E-03 & 3.9367147E-02 & 521 & 2 & $6.2303629 E-02$ & $5.5208676 \mathrm{E}-02$ \\
\hline 469 & 2 & 2.1741793E-02 & 4.9255345E-02 & 522 & 2 & $1.5903739 E-03$ & $6.3049272 \mathrm{E}-02$ \\
\hline 470 & 2 & 1.7596968E-02 & $6.9260821 \mathrm{E}-02$ & 523 & 2 & $2.3061221 E-02$ & $3.7146755 \mathrm{E}-02$ \\
\hline 471 & 2 & 4.9762029E-02 & $5.0212156 \mathrm{E}-02$ & 524 & 2 & $1.7828470 \mathrm{E}-02$ & $2.2134250 \mathrm{E}-02$ \\
\hline 472 & 2 & $6.2078778 \mathrm{E}-02$ & 4.3626074E-02 & 525 & 2 & 0.1489135 & $4.6703458 E-02$ \\
\hline 473 & 2 & 0.1199143 & $6.5188862 E-02$ & 526 & 2 & $2.9991554 \mathrm{E}-02$ & $5.4632392 \mathrm{E}-02$ \\
\hline 474 & 2 & $7.7847488 \mathrm{E}-02$ & $4.6927504 \mathrm{E}-02$ & 527 & 2 & 3.8592044E-02 & 6.0892493E-02 \\
\hline 475 & 2 & $1.0528071 \mathrm{E}-02$ & 3.3243977E-02 & 528 & 2 & $2.6665970 \mathrm{E}-03$ & $4.0781397 \mathrm{E}-02$ \\
\hline 476 & 2 & $8.3635688 \mathrm{E}-02$ & 6.8293311E-02 & 529 & 2 & 0.1594036 & $5.7811223 E-02$ \\
\hline 477 & 2 & 0.2009909 & $5.2799009 \mathrm{E}-02$ & 530 & 2 & $4.8654587 \mathrm{E}-03$ & $6.7245990 \mathrm{E}-02$ \\
\hline
\end{tabular}




\begin{tabular}{|c|c|c|c|}
\hline 531 & 2 & 4.1176889E-02 & 2.3709267E \\
\hline 532 & 2 & 0.1111817 & $5.4197088 \mathrm{E}-$ \\
\hline 533 & 2 & $3.2693163 \mathrm{E}-02$ & $6.3513294 \mathrm{E}-$ \\
\hline 534 & 2 & 2.7328093E-02 & 4.5014217E- \\
\hline 535 & 2 & $5.4314032 E-02$ & $6.1339408 \mathrm{E}-$ \\
\hline 536 & 2 & 0.1534035 & $1.9215468 \mathrm{E}-$ \\
\hline 537 & 2 & 0.1076253 & 2.8773729E- \\
\hline 538 & 2 & $1.1158386 \mathrm{E}-02$ & $5.3947240 \mathrm{E}-$ \\
\hline 539 & 2 & $7.5296283 E-02$ & $5.1808033 \mathrm{E}$ \\
\hline 540 & 2 & $9.0385396 \mathrm{E}-03$ & 4.2649522E- \\
\hline 541 & 2 & $1.8177083 \mathrm{E}-02$ & $2.3263156 \mathrm{E}-$ \\
\hline 542 & 2 & $3.4835618 \mathrm{E}-02$ & 3.4496263E- \\
\hline 543 & 2 & 0.2126295 & $7.1400881 \mathrm{E}-\mathrm{C}$ \\
\hline 544 & 2 & 0.1055460 & 3.7581399E- \\
\hline 545 & 2 & $1.6926570 \mathrm{E}-02$ & $8.2580023 E-$ \\
\hline 546 & 2 & 9.7805411E-02 & 6.6657782E- \\
\hline 547 & 2 & $2.4215424 \mathrm{E}-02$ & $5.5337630 \mathrm{E}-$ \\
\hline 548 & 2 & $4.6272218 E-02$ & $7.3172510 \mathrm{E}-$ \\
\hline 549 & 2 & 0.1436211 & $2.3976738 \mathrm{E}-$ \\
\hline 550 & 2 & $9.6115790 \mathrm{E}-02$ & $5.8919404 \mathrm{E}-$ \\
\hline 551 & 2 & $1.8233091 \mathrm{E}-02$ & $5.0471243 E-$ \\
\hline 552 & 2 & $7.0725784 \mathrm{E}-02$ & $4.9269639 \mathrm{E}-$ \\
\hline 553 & 2 & $8.6573020 \mathrm{E}-02$ & $3.0284656 \mathrm{E}-$ \\
\hline 554 & 2 & $5.2638784 E-02$ & $7.0753917 \mathrm{E}-$ \\
\hline 555 & 2 & $1.2816365 \mathrm{E}-02$ & $5.8832102 \mathrm{E}-$ \\
\hline 556 & 2 & $9.5106354 \mathrm{E}-03$ & $9.2986114 \mathrm{E}-$ \\
\hline 557 & 2 & $2.0517757 \mathrm{E}-02$ & $9.1534806 \mathrm{E}-$ \\
\hline 558 & 2 & $8.8717468 \mathrm{E}-02$ & $5.4625418 \mathrm{E}$ \\
\hline 559 & 2 & 0.1110684 & $6.2296972 \mathrm{E}-$ \\
\hline 560 & 2 & 0.1252603 & $3.7447959 \mathrm{E}-$ \\
\hline 561 & 2 & $1.4984865 \mathrm{E}-02$ & $4.1524138 \mathrm{E}-$ \\
\hline 562 & 2 & $4.1367975 \mathrm{E}-03$ & $7.9745278 \mathrm{E}-$ \\
\hline 563 & 2 & 0.1044355 & $4.4853296 \mathrm{E}-$ \\
\hline 564 & 2 & 0.1163967 & $6627 \mathrm{E}-$ \\
\hline 565 & 2 & $6.4864228 \mathrm{E}-03$ & $066 \mathrm{E}-$ \\
\hline 566 & 2 & $95 \mathrm{E}-02$ & $385 \mathrm{E}-$ \\
\hline 567 & 2 & $21 E-03$ & $60 \mathrm{E}-$ \\
\hline 568 & 2 & 0.1216575 & $5.9582046 \mathrm{E}-$ \\
\hline 569 & 2 & $7.5110182 E-02$ & $8.3018109 \mathrm{E}-$ \\
\hline 570 & 2 & $9.4210796 \mathrm{E}-02$ & $3.5506029 \mathrm{E}-$ \\
\hline 571 & 2 & 0.1249922 & $2.4129305 \mathrm{E}-$ \\
\hline 572 & 2 & 0.1011262 & $8.6357377 \mathrm{E}-$ \\
\hline 573 & 2 & $2.4293195 \mathrm{E}-02$ & $1.3958868 \mathrm{E}-$ \\
\hline 574 & 2 & $6.6678897 \mathrm{E}-03$ & $6.0641464 E-$ \\
\hline 575 & 2 & 0.1111950 & $3.6001086 \mathrm{E}-$ \\
\hline 576 & 2 & $1.9772781 \mathrm{E}-02$ & $3.8195383 E$ \\
\hline 577 & 2 & 0.1155881 & $3.9210908 \mathrm{E}-$ \\
\hline 578 & 2 & 0.1582730 & $6.9811329 \mathrm{E}-$ \\
\hline 579 & 2 & 0.1393309 & $4.6100881 E-$ \\
\hline 580 & 2 & $1.4094720 \mathrm{E}-02$ & $3.6581177 \mathrm{E}-$ \\
\hline 581 & 2 & 0.1499535 & 0.1384112 \\
\hline 582 & 2 & $7.1544766 \mathrm{E}-02$ & $3.3210576 \mathrm{E}-\mathrm{C}$ \\
\hline 583 & 2 & $3.0904636 \mathrm{E}-02$ & $5.6052897 \mathrm{E}-$ \\
\hline
\end{tabular}

\begin{tabular}{ll}
$\mathbf{5 8 4}$ & 2 \\
$\mathbf{5 8 5}$ & 2 \\
$\mathbf{5 8 6}$ & 2 \\
$\mathbf{5 8 7}$ & 2 \\
$\mathbf{5 8 8}$ & 2 \\
$\mathbf{5 8 9}$ & 2 \\
$\mathbf{5 9 0}$ & 2 \\
591 & 2 \\
$\mathbf{5 9 2}$ & 2 \\
$\mathbf{5 9 3}$ & 2 \\
594 & 2 \\
$\mathbf{5 9 5}$ & 2 \\
$\mathbf{5 9 6}$ & 2 \\
$\mathbf{5 9 7}$ & 2 \\
598 & 2 \\
599 & 2 \\
600 & 2 \\
601 & 2 \\
602 & 2 \\
603 & 2 \\
604 & 2 \\
605 & 2 \\
606 & 2 \\
607 & 2 \\
608 & 2 \\
609 & 2 \\
610 & 2 \\
611 & 2 \\
612 & 2 \\
613 & 2 \\
614 & 2 \\
615 & 2 \\
616 & 2 \\
617 & 2 \\
618 & 2 \\
619 & 2 \\
620 & 2 \\
621 & 2 \\
622 & 2 \\
623 & 2 \\
624 & 2 \\
625 & 2 \\
626 & 2 \\
627 & 2 \\
628 & 2 \\
629 & 2 \\
630 & 2 \\
631 & 2 \\
632 & 2 \\
633 & 2 \\
634 & 2 \\
635 & 2 \\
636 & 2 \\
& \\
\hline
\end{tabular}

9.8734237E-02

$1.3600629 \mathrm{E}-02$

$5.8635902 \mathrm{E}-02$

0.1916036

4.9487189E-03

1.2524434E-06

3.2651860E-02

0.1841026

0.1599361

$5.8705285 \mathrm{E}-02$

$6.6332571 \mathrm{E}-02$

2.1626830E-02

$2.8318062 \mathrm{E}-02$

$1.5888639 \mathrm{E}-02$

3.4715347E-02

4.7073562E-02

5.9949227E-02

4.5089148E-02

$7.4199475 \mathrm{E}-02$

4.3561067E-02

$7.8390967 \mathrm{E}-03$

8.5252132E-03

9.4841480E-02

$9.8654538 \mathrm{E}-02$

8.2921065E-02

0.1212057

4.1389301E-02

3.9176088E-02

$3.6713161 \mathrm{E}-02$

2.6123142E-02

7.1415707E-02

0.1111227

3.3226274E-02

4.3823916E-02

$2.3118341 \mathrm{E}-02$

$1.5971426 \mathrm{E}-02$

$1.8822059 \mathrm{E}-02$

$5.8292266 \mathrm{E}-02$

$5.7775807 \mathrm{E}-02$

$3.5423137 \mathrm{E}-02$

$2.9857086 \mathrm{E}-02$

0.1548729

4.3557987E-02

1.5834160E-02

3.0191801E-02

4.0227517E-02

$6.4106800 \mathrm{E}-02$

0.1264381

$5.0514825 \mathrm{E}-03$

$7.4786786 \mathrm{E}-03$

5.6379151E-02

6.5043934E-02

2.3314461E-02
$5.2587286 \mathrm{E}-02$

$5.6890666 \mathrm{E}-02$

$5.5508066 \mathrm{E}-02$

$6.0558066 \mathrm{E}-02$

$3.9720256 \mathrm{E}-02$

$6.1670996 \mathrm{E}-02$

$6.2497389 \mathrm{E}-02$

2.5924018E-02

7.9104915E-02

3.7483837E-02

$6.2288031 \mathrm{E}-02$

$5.4086905 \mathrm{E}-02$

$5.9075210 \mathrm{E}-02$

$5.6085356 \mathrm{E}-02$

$5.3803716 \mathrm{E}-02$

8.2605429E-02

4.7632530E-02

8.4848598E-02

$6.5386884 \mathrm{E}-02$

5.8682919E-02

4.0172376E-02

$5.8117419 \mathrm{E}-02$

$5.9852250 \mathrm{E}-02$

3.0269235E-02

$6.1462905 \mathrm{E}-02$

4.6906881E-02

7.1643874E-02

5.8735572E-02

5.9419930E-02

$4.9866855 \mathrm{E}-02$

9.7280517E-02

4.7417659E-02

0.1087197

5.3581931E-02

$2.6443675 \mathrm{E}-02$

5.5992521E-02

$6.8028539 \mathrm{E}-02$

$7.5867422 \mathrm{E}-02$

$6.8557747 \mathrm{E}-02$

$5.8446933 \mathrm{E}-02$

$3.0045392 \mathrm{E}-02$

$7.3036246 \mathrm{E}-02$

5.5324331E-02

3.4643687E-02

0.1435142

4.2338185E-02

5.5072434E-02

6.1384298E-02

8.6178847E-02

4.3397933E-02

$3.2816466 \mathrm{E}-02$

$2.6079575 \mathrm{E}-02$

3.8492594E-02

Vol. 2, Part 2

G-105

NUREG/CR-6143 
LOSP Frequency

\begin{tabular}{|c|c|c|c|c|c|c|c|}
\hline 637 & 2 & $7.4765138 \mathrm{E}-02$ & $3.5316885 \mathrm{E}-02$ & 690 & 2 & $1.2667705 \mathrm{E}-02$ & 3.7954487E-02 \\
\hline 638 & 2 & 1.7438317E-02 & $6.0133357 \mathrm{E}-02$ & 691 & 2 & $9.5690675 E-03$ & $4.6867296 \mathrm{E}-02$ \\
\hline 639 & 2 & $1.9293664 E-02$ & 4.6111993E-02 & 692 & 2 & 8.5062332E-02 & $6.7823358 \mathrm{E}-02$ \\
\hline 640 & 2 & $1.2643554 \mathrm{E}-02$ & $2.4007510 \mathrm{E}-02$ & 693 & 2 & $8.1150882 E-02$ & $5.9913274 \mathrm{E}-02$ \\
\hline 641 & 2 & $6.2489253 \mathrm{E}-04$ & 7.0830792E-02 & 694 & 2 & $1.4643470 \mathrm{E}-02$ & $5.0341334 \mathrm{E}-02$ \\
\hline 642 & 2 & $7.2150782 \mathrm{E}-02$ & $4.0100031 \mathrm{E}-02$ & 695 & 2 & 8.3918739E-03 & 8.7849453E-02 \\
\hline 643 & 2 & $8.0911592 \mathrm{E}-02$ & 0.1194109 & 696 & 2 & 5.2297127E-02 & 3.3744439E-02 \\
\hline 644 & 2 & $4.5478538 \mathrm{E}-02$ & $7.1966670 \mathrm{E}-02$ & 697 & 2 & 0.1712909 & $6.2485963 \mathrm{E}-02$ \\
\hline 645 & 2 & 0.1769705 & $6.1874941 E-02$ & 698 & 2 & $3.9250352 \mathrm{E}-03$ & $6.0935359 \mathrm{E}-02$ \\
\hline 646 & 2 & $1.2616337 \mathrm{E}-02$ & $2.7611544 \mathrm{E}-03$ & 699 & 2 & 0.1462693 & 3.8154949E-02 \\
\hline 647 & 2 & $72607398 \mathrm{E}-03$ & $1.8355193 E-02$ & 700 & 2 & $6.3159265 E-02$ & $6.9870718 \mathrm{E}-02$ \\
\hline 648 & 2 & $4.3000471 \mathrm{E}-02$ & $7.4872628 \mathrm{E}-02$ & 701 & 2 & $6.3968100 \mathrm{E}-02$ & $5.8013394 \mathrm{E}-02$ \\
\hline 649 & 2 & 0.2969601 & $1.4178558 \mathrm{E}-02$ & 702 & 2 & $6.1579641 \mathrm{E}-02$ & $4.4959161 \mathrm{E}-02$ \\
\hline 650 & 2 & 0.1011943 & $6.3337684 E-02$ & 703 & 2 & $3.1537369 E-02$ & $5.3400274 \mathrm{E}-02$ \\
\hline 651 & 2 & $4.0632688 \mathrm{E}-02$ & 6.2715657E-02 & 704 & 2 & 0.1300344 & $3.3928584 \mathrm{E}-02$ \\
\hline 652 & 2 & 1.1991364E-02 & $5.5741306 \mathrm{E}-02$ & 705 & 2 & $4.2458829 \mathrm{E}-02$ & $5.9283480 \mathrm{E}-02$ \\
\hline 653 & 2 & 0.1659063 & $2.9904557 \mathrm{E}-02$ & 706 & 2 & $6.8499178 \mathrm{E}-02$ & $6.9322161 \mathrm{E}-02$ \\
\hline 654 & 2 & $6.7917205 \mathrm{E}-02$ & $4.2753242 \mathrm{E}-02$ & 707 & 2 & $5.0882958 \mathrm{E}-03$ & $5.6380130 \mathrm{E}-02$ \\
\hline 655 & 2 & $2.9479271 \mathrm{E}-02$ & $5.0045524 \mathrm{E}-02$ & 708 & 2 & 0.1220675 & 7.6671772E-02 \\
\hline 656 & 2 & $2.7579788 \mathrm{E}-02$ & $4.5462053 \mathrm{E}-02$ & 709 & 2 & $6.1601184 \mathrm{E}-02$ & 5.8840957E-02 \\
\hline 657 & 2 & $1.8036981 \mathrm{E}-04$ & $8.4291220 \mathrm{E}-02$ & 710 & 2 & $6.6456713 \mathrm{E}-02$ & $5.7752959 \mathrm{E}-02$ \\
\hline 658 & 2 & $3.4363531 \mathrm{E}-02$ & 5.3680379E-02 & 711 & 2 & 0.1217265 & $8.9464970 \mathrm{E}-02$ \\
\hline 659 & 2 & $7.1762465 \mathrm{E}-02$ & $4.8111111 E-02$ & 712 & 2 & $4.7997069 \mathrm{E}-03$ & $9.1979116 \mathrm{E}-02$ \\
\hline 660 & 2 & 0.1614968 & $8.2661159 \mathrm{E}-02$ & 713 & 2 & $29600626 \mathrm{E}-02$ & $4.9833305 \mathrm{E}-02$ \\
\hline 661 & 2 & $2.5125390 \mathrm{E}-02$ & $5.7087846 \mathrm{E}-02$ & 714 & 2 & 0.1141646 & $3.4966715 E-02$ \\
\hline 662 & 2 & $3.1458316 \mathrm{E}-05$ & $5.2861001 \mathrm{E}-02$ & 715 & 2 & $7.1259312 E-02$ & $5.4746557 \mathrm{E}-02$ \\
\hline 663 & 2 & 0.1076581 & $6.9154672 E-02$ & 716 & 2 & $8.6525485 E-02$ & $5.2404400 \mathrm{E}-02$ \\
\hline 664 & 2 & $2.6002066 \mathrm{E}-02$ & $8.3394058 \mathrm{E}-02$ & 717 & 2 & $7.5258906 \mathrm{E}-03$ & 0.1074915 \\
\hline 665 & 2 & 0.1655387 & $5.6196619 \mathrm{E}-02$ & 718 & 2 & $7.5813979 \mathrm{E}-02$ & $7.3007323 \mathrm{E}-02$ \\
\hline 666 & 2 & $2.6791573 \mathrm{E}-02$ & $6.6164300 \mathrm{E}-02$ & 719 & 2 & $1.0426432 E-04$ & 3.1289287E-02 \\
\hline 667 & 2 & 0.1573987 & 0.1171114 & 720 & 2 & $9.9009417 \mathrm{E}-02$ & 8.5363977E-02 \\
\hline 668 & 2 & $37749022 E-02$ & $5.5093467 \mathrm{E}-02$ & 721 & 2 & $8.5491806 \mathrm{E}-02$ & $6.5238811 E-02$ \\
\hline 669 & 2 & $3.2987423 \mathrm{E}-02$ & $8.3813868 \mathrm{E}-02$ & 722 & 2 & $6.9037460 \mathrm{E}-02$ & $5.1741201 E-02$ \\
\hline 670 & 2 & $7.6349050 \mathrm{E}-02$ & $4.0644743 \mathrm{E}-02$ & 723 & 2 & 4.4828497E-02 & 5.3312019E-02 \\
\hline 671 & 2 & 0.1368688 & $6.2713839 \mathrm{E}-02$ & 724 & 2 & 7.9834806E-03 & $4.3321740 \mathrm{E}-02$ \\
\hline 672 & 2 & $1.0591272 \mathrm{E}-02$ & $3.0946087 \mathrm{E}-02$ & 725 & 2 & $4.4560567 \mathrm{E}-02$ & $5.8733013 E-02$ \\
\hline 673 & 2 & $5.0359242 \mathrm{E}-02$ & $1.6257817 \mathrm{E}-02$ & 726 & 2 & $6.5790229 \mathrm{E}-02$ & 0.1134825 \\
\hline 674 & 2 & $8.6674066 \mathrm{E}-03$ & $6.6296309 E-02$ & 727 & 2 & 2.3019051E-02 & $5.6591086 \mathrm{E}-02$ \\
\hline 675 & 2 & 2.7813993E-02 & $8.4544651 E-02$ & 728 & 2 & $4.8554119 E-02$ & $5.5661380 \mathrm{E}-02$ \\
\hline 676 & 2 & $9.2147784 \mathrm{E}-06$ & $4.8570462 \mathrm{E}-02$ & 729 & 2 & 2.3537399E-02 & $4.0238518 \mathrm{E}-02$ \\
\hline 677 & 2 & $9.7445004 \mathrm{E}-02$ & $6.9969364 \mathrm{E}-02$ & 730 & 2 & 3.9333194E-02 & $5.5914365 \mathrm{E}-02$ \\
\hline 678 & 2 & 0.1148768 & $5.1222965 \mathrm{E}-02$ & 731 & 2 & $6.6698194 \mathrm{E}-02$ & 0.1130819 \\
\hline 679 & 2 & $1.2202328 \mathrm{E}-02$ & $9.6307933 \mathrm{E}-02$ & 732 & 2 & $1.9953102 \mathrm{E}-02$ & $8.5162811 E-02$ \\
\hline 680 & 2 & $1.8492657 \mathrm{E}-03$ & $6.1574437 E-02$ & 733 & 2 & $6.7289076 \mathrm{E}-03$ & $4.5264572 \mathrm{E}-02$ \\
\hline 681 & 2 & 4.1577820E-02 & $5.2975034 \mathrm{E}-03$ & 734 & 2 & 0.2049074 & $9.3866616 \mathrm{E}-02$ \\
\hline 682 & 2 & 0.1904121 & $6.1209939 \mathrm{E}-02$ & 735 & 2 & $2.6612628 \mathrm{E}-02$ & $6.4750165 \mathrm{E}-02$ \\
\hline 683 & 2 & $1.9257167 \mathrm{E}-02$ & $5.7236783 \mathrm{E}-02$ & 736 & 2 & $6.2301848 \mathrm{E}-02$ & $6.2756054 \mathrm{E}-02$ \\
\hline 684 & 2 & $6.0050576 \mathrm{E}-03$ & 4.2949833E-02 & 737 & 2 & $4.7661878 \mathrm{E}-02$ & $8.2719140 \mathrm{E}-02$ \\
\hline 685 & 2 & $1.5237578 \mathrm{E}-02$ & $6.6271603 \mathrm{E}-02$ & 738 & 2 & 0.1032232 & $3.4457006 \mathrm{E}-02$ \\
\hline 686 & 2 & 0.1926419 & $6.1559569 \mathrm{E}-02$ & 739 & 2 & $2.2303181 E-02$ & $4.6219658 \mathrm{E}-02$ \\
\hline 687 & 2 & 0.2087683 & $3.2510523 \mathrm{E}-02$ & 740 & 2 & $2.3918238 \mathrm{E} \div 02$ & $5.8558207 \mathrm{E}-02$ \\
\hline 688 & 2 & 0.1375539 & $7.4545696 \mathrm{E}-02$ & 741 & 2 & $8.8102572 \mathrm{E}=02$ & $4.6565115 \mathrm{E}-02$ \\
\hline 689 & 2 & 0.1049394 & $7.7320695 \mathrm{E}-02$ & 742 & 2 & $1.0482088 \mathrm{E}-02$ & $3.9032046 \mathrm{E}-02$ \\
\hline
\end{tabular}




\begin{tabular}{|c|c|c|c|}
\hline 743 & 2 & 0.1262614 & $5.7312895 \mathrm{E}-02$ \\
\hline 744 & 2 & $5.1675425 E-03$ & 8.5691601E-02 \\
\hline 745 & 2 & 0.2224558 & $6.0074564 \mathrm{E}-02$ \\
\hline 746 & 2 & $4.9047388 \mathrm{E}-02$ & 8.3372809E-02 \\
\hline 747 & 2 & $4.1865766 E-02$ & 5.8311015E-02 \\
\hline 748 & 2 & $3.0313108 \mathrm{E}-02$ & $5.0959568 \mathrm{E}-02$ \\
\hline 749 & 2 & $6.0838363 E-03$ & $5.0049245 E-02$ \\
\hline 750 & 2 & 0.1005661 & $5.2472834 \mathrm{E}-02$ \\
\hline 751 & 2 & 4.4937138E-02 & $5.8725663 \mathrm{E}-02$ \\
\hline 752 & 2 & 0.1633220 & $2.5648102 E-02$ \\
\hline 753 & 2 & $4.3697253 E-02$ & $3.0470233 \mathrm{E}-02$ \\
\hline 754 & 2 & $3.1902997 \mathrm{E}-03$ & $6.9020033 \mathrm{E}-02$ \\
\hline 755 & 2 & 0.2287423 & $3.2850880 \mathrm{E}-02$ \\
\hline 756 & 2 & 3.0959342E-02 & $4.8091192 \mathrm{E}-02$ \\
\hline 757 & 2 & $9.4964199 E-02$ & $5.4733302 E-02$ \\
\hline 758 & 2 & 0.4126163 & 6.5297917E-02 \\
\hline 759 & 2 & $6.2819786 \mathrm{E}-02$ & $3.2475919 \mathrm{E}-02$ \\
\hline 760 & 2 & $4.5202851 E-02$ & $4.1657679 \mathrm{E}-02$ \\
\hline 761 & 2 & $1.2994861 \mathrm{E}-02$ & $6.9093086 \mathrm{E}-02$ \\
\hline 762 & 2 & $5.1764749 \mathrm{E}-02$ & 3.1948324E-02 \\
\hline 763 & 2 & 0.1174101 & $3.8581774 \mathrm{E}-02$ \\
\hline 764 & 2 & 0.1159837 & $7.1235195 \mathrm{E}-02$ \\
\hline 765 & 2 & 0.1918874 & 3.1310797E-02 \\
\hline 766 & 2 & $9.2250086 \mathrm{E}-02$ & $2.7791988 \mathrm{E}-02$ \\
\hline 767 & 2 & 0.1249470 & $6.7267433 E-02$ \\
\hline 768 & 2 & $9.5545508 \mathrm{E}-02$ & $5.5780765 E-02$ \\
\hline 769 & 2 & $1.9758463 \mathrm{E}-02$ & $6.1134670 \mathrm{E}-02$ \\
\hline 770 & 2 & $6.9996879 E-02$ & $5.1670320 \mathrm{E}-02$ \\
\hline 771 & 2 & $8.2011253 E-02$ & 3.5231430E-02 \\
\hline 772 & 2 & $9.7375177 \mathrm{E}-02$ & 0.1671166 \\
\hline 773 & 2 & $9.4023019 E-02$ & 3.9594948E-02 \\
\hline 774 & 2 & 0.1476692 & 5.1349733E-02 \\
\hline 775 & 2 & 4.5043502E-02 & $5.9255589 \mathrm{E}-02$ \\
\hline 776 & 2 & $7.7810525 \mathrm{E}-03$ & $3.5913724 \mathrm{E}-02$ \\
\hline 777 & 2 & 4.3228015E-02 & $5.2891221 \mathrm{E}-02$ \\
\hline 778 & 2 & 4.5226362E-02 & $6.0764175 \mathrm{E}-02$ \\
\hline 779 & 2 & $1.1131806 \mathrm{E}-02$ & $4.4246893 \mathrm{E}-02$ \\
\hline 780 & 2 & $7.1365029 E-02$ & 4.6598349E-02 \\
\hline 781 & 2 & 0.1534233 & 3.6120445E-02 \\
\hline 782 & 2 & $4.5220446 E-02$ & 8.1419945E-02 \\
\hline 783 & 2 & $4.0321246 \mathrm{E}-02$ & $4.4738114 \mathrm{E}-02$ \\
\hline 784 & 2 & $9.2383265 \mathrm{E}-02$ & $6.0023449 \mathrm{E}-02$ \\
\hline 785 & 2 & 0.1957802 & $3.8790107 \mathrm{E}-02$ \\
\hline 786 & 2 & $6.2168173 E-02$ & 4.6073996E-02 \\
\hline 787 & 2 & 0.1421046 & $4.9145039 \mathrm{E}-02$ \\
\hline 788 & 2 & 4.6885949E-02 & $2.6521334 \mathrm{E}-02$ \\
\hline 789 & 2 & $2.9114503 E-02$ & $5.4491013 \mathrm{E}-02$ \\
\hline 790 & 2 & $9.4231784 \mathrm{E}-02$ & $2.7507348 \mathrm{E}-02$ \\
\hline 791 & 2 & $3.5982575 \mathrm{E} 02$ & $1.0827117 \mathrm{E}-02$ \\
\hline 792 & 2 & 0.2368337 & $6.6368714 \mathrm{E}-02$ \\
\hline 793 & 2 & $8.9359716 \mathrm{E}-02$ & $4.3520104 \mathrm{E}-02$ \\
\hline 794 & 2 & $1.8088779 \mathrm{E}-03$ & $4.3661300 \mathrm{E}-02$ \\
\hline 795 & 2 & 0.1065253 & $6.1910994 \mathrm{E}-02$ \\
\hline
\end{tabular}

$\begin{array}{ll}796 & 2 \\ 797 & 2 \\ 798 & 2 \\ 799 & 2 \\ 800 & 2 \\ 801 & 2 \\ 802 & 2 \\ 803 & 2 \\ 804 & 2 \\ 805 & 2 \\ 806 & 2 \\ 807 & 2 \\ 808 & 2 \\ 809 & 2 \\ 810 & 2 \\ 811 & 2 \\ 812 & 2 \\ 813 & 2 \\ 814 & 2 \\ 815 & 2 \\ 816 & 2 \\ 817 & 2 \\ 818 & 2 \\ 819 & 2 \\ 820 & 2 \\ 821 & 2 \\ 822 & 2 \\ 823 & 2 \\ 824 & 2 \\ 825 & 2 \\ 826 & 2 \\ 827 & 2 \\ 828 & 2 \\ 829 & 2 \\ 830 & 2 \\ 831 & 2 \\ 832 & 2 \\ 833 & 2 \\ 834 & 2 \\ 835 & 2 \\ 836 & 2 \\ 837 & 2 \\ 838 & 2 \\ 839 & 2 \\ 840 & 2 \\ 841 & 2 \\ 842 & 2 \\ 843 & 2 \\ 844 & 2 \\ 845 & 2 \\ 846 & 2 \\ 847 & 2 \\ 848 & 2 \\ & 2\end{array}$

7.3502332E-02

1.9874904E-02

4.0966433E-02

0.1398786

0.1679944

3.6314774E-02

3.9298572E-02

0.1538339

7.3337995E-02

$3.2945636 \mathrm{E}-03$

7.4707083E-02

3.7277136E-02

2.3415873E-03

0.1363300

2.7190035E-02

6.1469404E-03

4.8396634E-03

$6.1320782 \mathrm{E}-02$

5.1850434E-02

$2.9650316 \mathrm{E}-02$

5.2909732E-02

7.2582185E-02

2.7631711E-02

0.1479920

6.8155609E-02

4.8517105E-03

$1.0592137 \mathrm{E}-02$

8.4417984E-02

1.3834529E-02

3.1368252E-02

0.1733319

0.1083883

3.4713827E-02

$6.9029287 \mathrm{E}-02$

8.6368740E-02

1.0906375E-02

2.3066474E-02

0.1874645

2.9084072E-02

3.2290604E-02

0.1759330

1.4150621E-02

0.1159350

4.2492867E-02

0.2267004

0.1055374

0.1955333

2.6470978E-02

6.8814188E-02

$5.3744357 \mathrm{E}-02$

0.2325092

$6.0120583 \mathrm{E}-02$

0.1314537
3.0958410E-02

6.5839842E-02

$6.1447807 \mathrm{E}-02$

$1.0918747 \mathrm{E}-02$

6.4998902E-02

$6.1941538 \mathrm{E}-02$

2.6657805E-02

5.7514656E-02

4.7599960E-02

4.7168393E-02

2.7054267E-02

0.1055952

6.3766249E-02

$5.8460943 \mathrm{E}-02$

4.6317127E-02

5.7112314E-02

$1.8904120 \mathrm{E}-02$

$1.3836190 \mathrm{E}-02$

4.4858344E-02

4.5002442E-02

5.2177414E-02

7.4897297E-02

$6.0897086 \mathrm{E}-02$

3.7642244E-02

0.1125266

3.7218831E-02

5.7463851E-02

4.8830070E-02

$5.6467827 \mathrm{E}-02$

5.5263419E-02

2.1836525E-02

$7.8432508 \mathrm{E}-02$

5.4580510E-02

4.9784124E-02

0.1490737

4.3313839E-02

6.1758589E-02

0.1090954

5.4830268E-02

0.1488167

4.1155804E-02

6.6617176E-02

3.4868266E-02

5.3134032E-02

6.1173547E-02

4.8246101E-02

$6.4037368 \mathrm{E}-02$

4.3714132E-02

3.6620829E-02

5.1303342E-02

6.4085588E-02

8.2462795E-02

$6.8409018 \mathrm{E}-02$

Vol. 2, Part 2

G-107

NUREG/CR-6143 


\begin{tabular}{|c|c|c|c|c|c|c|c|}
\hline 849 & 2 & 0.1753536 & 7.1260124E-02 & 902 & 2 & $9.5153023 E-03$ & 0.1135739 \\
\hline 850 & 2 & $7.0344500 \mathrm{E}-02$ & 3.3605255E-02 & 903 & 2 & 1.3199417E-02 & $7.3137805 \mathrm{E}-02$ \\
\hline 851 & 2 & $1.9798214 \mathrm{E}-02$ & $5.2160297 \mathrm{E}-02$ & 904 & 2 & 0.1678364 & $1.6668446 \mathrm{E}-02$ \\
\hline 852 & 2 & 4.2904954E-02 & 8.3821729E-02 & 905 & 2 & $3.6986031 E-02$ & $6.3447930 \mathrm{E}-02$ \\
\hline 853 & 2 & $8.9058951 \mathrm{E}-02$ & $4.7565345 \mathrm{E}-02$ & 906 & 2 & 0.1057777 & $4.8246510 \mathrm{E}-02$ \\
\hline 854 & 2 & 0.1282351 & $5.6744356 \mathrm{E}-02$ & 907 & 2 & $4.0126458 \mathrm{E}-04$ & $5.1750962 E-02$ \\
\hline 855 & 2 & $6.3481316 \mathrm{E}-02$ & $9.3530454 E-03$ & 908 & 2 & 0.1166051 & $8.0631763 E-02$ \\
\hline 856 & 2 & $5.8032546 \mathrm{E}-02$ & $5.0135382 E-02$ & 909 & 2 & $9.2176422 \mathrm{E}-03$ & 5.7477903E-02 \\
\hline 857 & 2 & $4.0085889 \mathrm{E}-02$ & 3.6050949E-02 & 910 & 2 & 0.1591447 & $4.3792546 \mathrm{E}-02$ \\
\hline 858 & 2 & $6.8856232 \mathrm{E}-02$ & $5.4024547 \mathrm{E}-02$ & 911 & 2 & 7.9803653E-02 & 4.5938723E-02 \\
\hline 859 & 2 & 0.1148059 & $5.0873883 E-02$ & 912 & 2 & $6.8583310 \mathrm{E}-02$ & 4.3378543E-02 \\
\hline 860 & 2 & $3.3868130 \mathrm{E}-02$ & $6.0785957 \mathrm{E}-02$ & 913 & 2 & $3.3945039 \mathrm{E}-02$ & $3.2092944 \mathrm{E}-02$ \\
\hline 861 & 2 & $1.5916673 \mathrm{E}-02$ & $6.5029919 \mathrm{E}-02$ & 914 & 2 & $1.5667401 \mathrm{E}-02$ & $7.0161469 \mathrm{E}-02$ \\
\hline 862 & 2 & $2.4237448 \mathrm{E}-02$ & $5.5624705 E-02$ & 915 & 2 & $1.2216034 E-02$ & $3.7499879 \mathrm{E}-02$ \\
\hline 863 & 2 & $3.8375910 \mathrm{E}-02$ & $5.2462641 \mathrm{E}-02$ & 916 & 2 & $2.6205523 E-02$ & 0.1016790 \\
\hline 864 & 2 & $7.1393445 E-02$ & $1.5578598 E-02$ & 917 & 2 & 0.1345783 & $5.8055867 \mathrm{E}-02$ \\
\hline 865 & 2 & 6.6492967E-02 & $1.9284455 \mathrm{E}-02$ & 918 & 2 & $2.7402056 \mathrm{E}-02$ & $2.1080213 E-02$ \\
\hline 866 & 2 & $1.2682325 \mathrm{E}-02$ & $5.7558499 \mathrm{E}-02$ & 919 & 2 & $5.2395917 \mathrm{E}-02$ & 0.1310989 \\
\hline 867 & 2 & 2.5767982E-02 & $4.4060186 \mathrm{E}-02$ & 920 & 2 & 9.7891323E-02 & $5.1882077 \mathrm{E}-02$ \\
\hline 868 & 2 & $1.9472765 E-02$ & $6.1348185 E-02$ & 921 & 2 & $8.9353189 E-02$ & $8.4825300 \mathrm{E}-02$ \\
\hline 869 & 2 & $1.3780744 \mathrm{E}-02$ & $5.5703067 \mathrm{E}-04$ & 922 & 2 & $2.7940512 \mathrm{E}-02$ & $7.4167669 \mathrm{E}-02$ \\
\hline 870 & 2 & 7.0846647E-02 & $2.5572006 \mathrm{E}-02$ & 923 & 2 & $5.0494056 \mathrm{E}-02$ & $7.5886257 \mathrm{E}-02$ \\
\hline 871 & 2 & $3.2919362 \mathrm{E}-02$ & $1.4207551 \mathrm{E}-02$ & 924 & 2 & $9.0468293 \mathrm{E}-03$ & $3.9250501 \mathrm{E}-02$ \\
\hline 872 & 2 & 0.1041866 & $7.3884562 \mathrm{E}-02$ & 925 & 2 & 0.2264951 & 0.1131693 \\
\hline 873 & 2 & $6.4161711 \mathrm{E}-04$ & $3.8655475 E-02$ & 926 & 2 & $5.8889549 \mathrm{E}-02$ & $6.8122149 \mathrm{E}-02$ \\
\hline 874 & 2 & $2.7210578 \mathrm{E}-02$ & $5.3686421 \mathrm{E}-02$ & 927 & 2 & $1.8761925 \mathrm{E}-03$ & $5.3185504 E-02$ \\
\hline 875 & 2 & $5.0297618 \mathrm{E}-02$ & $3.0133445 \mathrm{E}-02$ & 928 & 2 & 8.0460243E-02 & $6.2511340 \mathrm{E}-02$ \\
\hline 876 & 2 & 3.9070893E-02 & $3.9580315 E-02$ & 929 & 2 & $5.6212086 \mathrm{E}-02$ & 4.4533499E-02 \\
\hline 877 & 2 & 0.2120718 & $7.1436375 \mathrm{E}-02$ & 930 & 2 & 0.1232555 & $4.9721505 \mathrm{E}-02$ \\
\hline 878 & 2 & 0.1207141 & $8.4866486 \mathrm{E}-02$ & 931 & 2 & $1.7296594 \mathrm{E}-02$ & $4.0684052 E-02$ \\
\hline 879 & 2 & $7.0493244 \mathrm{E}-02$ & 0.1654756 & 932 & 2 & $2.5122650 \mathrm{E}-02$ & $5.3252496 \mathrm{E}-02$ \\
\hline 880 & 2 & 0.2736189 & $5.8602590 \mathrm{E}-02$ & 933 & 2 & $2.4814460 \mathrm{E}-02$ & $5.1550169 \mathrm{E}-02$ \\
\hline 881 & 2 & 0.1644907 & $3.9456370 \mathrm{E}-03$ & 934 & 2 & 0.1282181 & $6.1518714 \mathrm{E}-02$ \\
\hline 882 & 2 & 0.1962140 & $5.2651335 \mathrm{E}-02$ & 935 & 2 & $2.2284815 E-02$ & $7.6629288 \mathrm{E}-02$ \\
\hline 883 & 2 & $1.2658233 \mathrm{E}-03$ & $5.1541779 \mathrm{E}-02$ & 936 & 2 & $5.1063392 \mathrm{E}-02$ & $9.5875099 E-02$ \\
\hline 884 & 2 & $9.3008801 E-03$ & $5.8484331 \mathrm{E}-02$ & 937 & 2 & $2.3033345 E-02$ & $7.2320491 \mathrm{E}-02$ \\
\hline 885 & 2 & $9.6362727 \mathrm{E}-03$ & $1.4103325 \mathrm{E}-03$ & 938 & 2 & 0.1255693 & $5.7018407 \mathrm{E}-02$ \\
\hline 886 & 2 & 0.1297920 & $5.3637575 E-02$ & 939 & 2 & $4.9152099 \mathrm{E}-02$ & $4.2099785 \mathrm{E}-02$ \\
\hline 887 & 2 & $7.4851378 \mathrm{E}-03$ & $5.6227304 \mathrm{E}-02$ & 940 & 2 & 0.1012888 & $9.5059328 E-02$ \\
\hline 888 & 2 & 7.1975842E-02 & $6.0246613 \mathrm{E}-02$ & 941 & 2 & $3.2810923 \mathrm{E}-02$ & $6.8614222 \mathrm{E}-02$ \\
\hline 889 & 2 & $3.9767893 \mathrm{E}-04$ & $7.8546464 \mathrm{E}-02$ & 942 & 2 & $5.5024467 \mathrm{E}-02$ & $5.5538766 \mathrm{E}-02$ \\
\hline 890 & 2 & 0.1267434 & $4.3185066 \mathrm{E}-02$ & 943 & 2 & 0.1023091 & 0.1114717 \\
\hline 891 & 2 & $1.7169040 \mathrm{E}-02$ & $3.8028657 \mathrm{E}-02$ & 944 & 2 & $4.7409418 \mathrm{E}-03$ & $6.2105045 \mathrm{E}-02$ \\
\hline 892 & 2 & $1.1717744 \mathrm{E}-02$ & $6.0267188 \mathrm{E}-02$ & 945 & 2 & $3.1449161 E-02$ & $7.2473414 E-02$ \\
\hline 893 & 2 & $2.5022475 \mathrm{E}-03$ & $7.1386263 \mathrm{E}-02$ & 946 & 2 & $3.5321389 \mathrm{E}-03$ & 0.1433671 \\
\hline 894 & 2 & $2.8072709 \mathrm{E}-02$ & $3.6606077 \mathrm{E}-02$ & 947 & 2 & $2.1979650 \mathrm{E}-02$ & $3.7572309 E-02$ \\
\hline 895 & 2 & 8.4042564E-02 & $2.4940511 \mathrm{E}-02$ & 948 & 2 & $3.2869723 \mathrm{E}-02$ & $6.4480387 E-02$ \\
\hline 896 & 2 & $3.6001012 E-02$ & $1.9995760 \mathrm{E}-02$ & 949 & 2 & $1.6251069 \mathrm{E}-02$ & $3.8868442 \mathrm{E}-02$ \\
\hline 897 & 2 & $4.6982206 \mathrm{E}-03$ & $4.1722868 \mathrm{E}-02$ & 950 & 2 & $9.9207006 \mathrm{E}-02$ & $5.0651442 E-02$ \\
\hline 898 & 2 & $1.1233456 \mathrm{E}-02$ & 7.1409829E-02 & 951 & 2 & 0.1344099 & $4.9624890 \mathrm{E}-02$ \\
\hline 899 & 2 & $4.3577466 \mathrm{E}-02$ & $3.5525009 \mathrm{E}-02$ & 952 & 2 & $1.4781847 \mathrm{E}-02$ & $5.6478623 E-02$ \\
\hline 900 & 2 & $7.6863907 \mathrm{E}-02$ & $6.3962050 \mathrm{E}-02$ & 953 & 2 & $7.0901610 \mathrm{E}-02$ & $1.3658642 E-02$ \\
\hline 901 & 2 & $4.2035021 \mathrm{E}-02$ & $6.0748342 \mathrm{E}-02$ & 954 & 2 & $1.0775675 \mathrm{E}-03$ & $4.9721941 E-02$ \\
\hline
\end{tabular}




$\begin{array}{llll}955 & 2 & 2.9384814 \mathrm{E}-02 & 7.2166272 \mathrm{E}-02 \\ 956 & 2 & 9.1045044 \mathrm{E}-02 & 5.0976101 \mathrm{E}-02 \\ 957 & 2 & 2.7149079 \mathrm{E}-02 & 6.9073819 \mathrm{E}-02 \\ 958 & 2 & 0.1487750 & 4.9753133 \mathrm{E}-02 \\ 959 & 2 & 0.1281379 & 3.3494946 \mathrm{E}-02 \\ 960 & 2 & 0.2261254 & 4.8859332 \mathrm{E}-02 \\ 961 & 2 & 7.0052288 \mathrm{E}-02 & 4.7748096 \mathrm{E}-02 \\ 962 & 2 & 5.5682145 \mathrm{E}-02 & 5.8132105 \mathrm{E}-02 \\ 963 & 2 & 0.1027336 & 4.9926355 \mathrm{E}-02 \\ 964 & 2 & 1.4832543 \mathrm{E}-02 & 5.5490620 \mathrm{E}-02 \\ 965 & 2 & 5.5337563 \mathrm{E}-02 & 8.2520597 \mathrm{E}-02 \\ 966 & 2 & 6.2655270 \mathrm{E}-02 & 3.8574792 \mathrm{E}-02 \\ 967 & 2 & 4.0548373 \mathrm{E}-02 & 6.3032411 \mathrm{E}-02 \\ 968 & 2 & 6.2372845 \mathrm{E}-02 & 7.3105752 \mathrm{E}-02 \\ 969 & 2 & 6.0694687 \mathrm{E}-02 & 6.0532637 \mathrm{E}-02 \\ 970 & 2 & 0.1315373 & 5.8275152 \mathrm{E}-02 \\ 971 & 2 & 5.6101017 \mathrm{E}-02 & 5.1635120 \mathrm{E}-02 \\ 972 & 2 & 0.1784956 & 4.4583969 \mathrm{E}-02 \\ 973 & 2 & 1.0766561 \mathrm{E}-02 & 6.2380012 \mathrm{E}-02 \\ 974 & 2 & 4.4256584 \mathrm{E}-03 & 3.2339543 \mathrm{E}-02 \\ 975 & 2 & 0.1317025 & 0.1138625 \\ 976 & 2 & 0.1184175 & 7.8903660 \mathrm{E}-02 \\ 977 & 2 & 8.3891869 \mathrm{E}-02 & 7.8740507 \mathrm{E}-02 \\ 978 & 2 & 1.3691519 \mathrm{E}-02 & 3.7798133 \mathrm{E}-02 \\ 979 & 2 & 0.1829110 & 4.5573011 \mathrm{E}-02 \\ 980 & 2 & 1.2218891 \mathrm{E}-02 & 3.7880022 \mathrm{E}-02 \\ 981 & 2 & 3.5861585 \mathrm{E}-02 & 5.3079080 \mathrm{E}-02 \\ 982 & 2 & 3.0800391 \mathrm{E}-03 & 5.3664945 \mathrm{E}-02 \\ 983 & 2 & 3.8509235 \mathrm{E}-02 & 4.5091420 \mathrm{E}-02 \\ 984 & 2 & 8.6480059 \mathrm{E}-02 & 3.8442094 \mathrm{E}-02 \\ 985 & 2 & 3.8517248 \mathrm{E}-02 & 6.3969307 \mathrm{E}-02 \\ 986 & 2 & 2.0938128 \mathrm{E}-02 & 6.4974770 \mathrm{E}-02 \\ 987 & 2 & 6.3549548 \mathrm{E}-02 & 8.5598998 \mathrm{E}-02 \\ 988 & 2 & 7.8335539 \mathrm{E}-02 & 3.6386952 \mathrm{E}-02 \\ 989 & 2 & 6.9398761 \mathrm{E}-02 & 5.0369952 \mathrm{E}-02 \\ 990 & 2 & 3.5620485 \mathrm{E}-02 & 5.3879078 \mathrm{E}-02 \\ 991 & 2 & 5.7140426 \mathrm{E}-03 & 7.6112233 \mathrm{E}-02 \\ 992 & 2 & 4.2732999 \mathrm{E}-02 & 4.7157414 \mathrm{E}-02 \\ 993 & 2 & 1.0141055 \mathrm{E}-02 & 5.9863053 \mathrm{E}-02 \\ 994 & 2 & 5.2287020 \mathrm{E}-02 & 5.2066594 \mathrm{E}-02 \\ 995 & 2 & 0.1110769 & 6.1749782 \mathrm{E}-02 \\ 996 & 2 & 2.7594246 \mathrm{E}-02 & 5.7561927 \mathrm{E}-02 \\ 997 & 2 & 0.1713138 & 4.4933297 \mathrm{E}-02 \\ 998 & 2 & 2.2145273 \mathrm{E}-02 & 7.4739300 \mathrm{E}-02 \\ 999 & 2 & 0.1135392 & 3.7415762 \mathrm{E}-02 \\ 1000 & 2 & 4.1683346 \mathrm{E}-02 & 5.8121778 \mathrm{E}-02 \\ & & & \end{array}$


LOSP Frequency

Attachment G-23

REMOVECOL2.FOR 
Character $* 25$ remo

Character $* 0$ infile, outfile

character*55 inse

infile = 'ud4:[bdstapl] lhs.dat'

outfile = 'ud4:[bdstapl]lhslosp.inp'

open(unit $=10$, name $=$ infile,status $=$ 'old')

open (unit $=15$, name $=$ outfile, status $=$ 'new')

$25 \operatorname{read}(10,20$,end $=50)$ remo, inse

20 format $(a, a)$

write $(15,30)$ inse

30 format(a)

goto 25

50 close (10)

close(15)

end 


\section{LOSP Frequency}

Attachment G-24

LHSLOSP.1NP 
9.5802836E-02 $5.7157081 \mathrm{E}-02$

5.0940670E-02 6.0416732E-02

3.7110481E-02 5.8251712E-02

$0.3011881 \quad 5.3329077 \mathrm{E}-02$

6.8660229E-02 5.5287939E-02

4.1418765E-02 5.6494150E-02

3.8164826E-03 6.1932772E-02

7.3756211E-02 9.4944753E-02

$0.1116926 \quad 5.5104259 \mathrm{E}-02$

8.3901752E-03 5.9206437E-02

$2.1001803 E-04 \quad 0.1903778$

$0.1984308 \quad 3.8471486 \mathrm{E}-02$

6.1446220E-02 5.7531755E-02

$1.3037866 \mathrm{E}-02 \quad 7.0953816 \mathrm{E}-02$

8.6331956E-02 6.8710037E-02

3.7155967E-02 3.2672279E-02

3.2555930E-02 4.4575006E-02

4.5071386E-02 3.1056585E-02

6.3797474E-02 4.6071306E-02

4.3774538E-02 3.0516183E-02

$0.1065058 \quad 7.9281092 \mathrm{E}-02$

5.5102311E-02 3.2996830E-02

3.5599325E-02 4.8942689E-02

2.0490789E-03,4.5054294E-02

$2.5542006 \mathrm{E}-02 \quad 2.5336470 \mathrm{E}-02$

4.6561282E-02 7.3678486E-02

9.7525999E-02 7.1654484E-02

3.6980748E-02 6.9754799E-03

$3.8461756 \mathrm{E}-02 \quad 2.1312614 \mathrm{E}-03$

$0.1308402 \quad 4.2214524 \mathrm{E}-02$

$1.5121906 \mathrm{E}-02 \quad 6.1416168 \mathrm{E}-02$

$0.1576969 \quad 4.6902116 \mathrm{E}-02$

$1.1520608 \mathrm{E}-02 \quad 6.0953710 \mathrm{E}-02$

$0.1065259 \quad 9.9590011 \mathrm{E}-02$

$0.1838354 \quad 9.7384945 \mathrm{E}-02$

2.3105722E-02 5.1488169E-02

7.8000881E-02 8.7991364E-02

8.4191918E-02 4.7253303E-02

3.0882679E-02 3.7661687E-02

$0.1168672 \quad 9.2032492 \mathrm{E}-02$

$6.9784876 \mathrm{E}-03 \quad 2.3598088 \mathrm{E}-02$

$2.8681975 \mathrm{E}-02 \quad 3.9681610 \mathrm{E}-02$

$2.7508037 \mathrm{E}-02 \quad 8.6506894 \mathrm{E}-03$

5.7893977E-02 3.1828873E-02

8.7122709E-02 3.0945832E-02

$4.0420175 \mathrm{E}-02 \quad 0.1134561$

6.7433029E-02 4.9484331E-02

3.1565614E-02 5.5348329E-02

6.2981918E-02 4.5933411E-02

3.6439944E-02 6.5376133E-02

$2.3256298 \mathrm{E}-03 \quad 6.1091572 \mathrm{E}-02$

3.7388284E-02 6.32343744E-02

$4.9667925 \mathrm{E}-02 \quad 8.1571952 \mathrm{E}-02$
$6.3890698 \mathrm{E}-03 \quad 6.1642252 \mathrm{E}-02$

$1.1955368 \mathrm{E}-02 \quad 5.3150438 \mathrm{E}-02$

$2.0493850 \mathrm{E}-02 \quad 0.1857526$

3.9378010E-02 3.75985544E-02

$3.5381936 \mathrm{E}-02 \quad 4.7152728 \mathrm{E}-02$

6.2365174E-02 7.5856574E-02

6.9060028E-02 8.9874759E-02

4.4734307E-02 5.6779027E-02

4.3982375E $02 \quad 6.2561035 \mathrm{E}-02$

6.0694963E-02 3.8645752E-02

$9.1746241 \mathrm{E}-02 \quad 0.1081921$

$\begin{array}{ll}1.2195393 E-02 & 0.1378729\end{array}$

9.7427778E-03 4.6029627E-02

$1.9653393 \mathrm{E}-02 \quad 4.2656578 \mathrm{E}-02$

$3.1145809 \mathrm{E}-02 \quad 4.1980006 \mathrm{E}-02$

$7.1229465 \mathrm{E}-02 \quad 6.0362123 \mathrm{E}-02$

$5.5966739 \mathrm{E}-02 \quad 0.1215986$

$2.9009812 \mathrm{E}-02 \quad 6.5682463 \mathrm{E}-02$

$7.5244442 \mathrm{E}-02 \quad 5.8911454 \mathrm{E}-02$

$7.8743502 \mathrm{E}-02 \quad 5.4237224 \mathrm{E}-02$

5.0527163E-02 6.1270196E-02

3.1681322E-02 8.5060455E-02

$5.1817849 \mathrm{E}-02 \quad 5.0090570 \mathrm{E}-02$

5.0831504E-02 2.4951266E-02

$0.1170508 \quad 6.8073846 \mathrm{E}-02$

3.0360568E-02 4.9490560E-02

3.7065927E-02 5.0325025E-02

8.4724374E-02 3.4361262E-02

$0.2172877 \quad 7.2943039 \mathrm{E}-02$

$0.1707056 \quad 6.1654635 \mathrm{E}-02$

4.1157823E-02 6.0433898E-02

4.6242714E-02 5.8522064E-02

$7.8710178 \mathrm{E}-03 \quad 6.0102671 \mathrm{E}-02$

$8.4139876 \mathrm{E}-02 \quad 7.9868220 \mathrm{E}-02$

$9.9810176 \mathrm{E}-02 \quad 6.6642977 \mathrm{E}-02$

5.6254819E-02 7.4072085E-02

4.5131359E-02 3.6564417E-02

$0.1175776 \quad 6.0518596 \mathrm{E}-02$

$2.3901181 \mathrm{E}-02 \quad 5.5216696 \mathrm{E}-02$

6.8641901E-02 4.5617305E-02

8.4755734E-02 3.5917133E-02

4.7624674E-02 5.0922580E-02

$7.6687358 \mathrm{E}-02 \quad 4.7751363 \mathrm{E}-02$

$6.1508259 \mathrm{E}-03 \quad 6.2739216 \mathrm{E}-02$

$6.9542497 \mathrm{E}-02 \quad 6.6954583 \mathrm{E}-02$

$5.0025929 \mathrm{E}-02 \quad 7.1312711 \mathrm{E}-02$

$7.6181762 \mathrm{E}-02 \quad 0.1293133$

4.7242548E-02 2.8041681E-02

5.1474594E-02 4.7649670E-02

1.6576273E-02 8.9545082E-03

3.3260591E-02 4.7793541E-02

5.7211630E-02 4.9049694E-02

9.6157566E-02 5.0513197E-02
$0.1619431 \quad 3.6086690 \mathrm{E}-02$

$6.5522656 \mathrm{E}-02 \quad 5.0114769 \mathrm{E}-02$

9.9551871E-02 5.3492881E-02

$3.2978956 \mathrm{E}-02 \quad 8.2634754 \mathrm{E}-02$

$5.2812852 \mathrm{E}-02 \quad 6.2103730 \mathrm{E}-02$

$4.1240700 \mathrm{E}-02 \quad 5.0557747 \mathrm{E}-02$

$7.0628084 \mathrm{E}-02 \quad 3.3015352 \mathrm{E}-02$

3.2155325E-03 5.7052251E-02

$0.2955990 \quad 0.1668376$

$0.1707724 \quad 1.8475348 \mathrm{E}-02$

5.5750683E-02 5.8639225E-02

$3.3989530 \mathrm{E}-02 \quad 5.5715863 \mathrm{E}-02$

9.6589506E-02 $6.0960405 \mathrm{E}-02$

4.4756867E-02 2.0783002E-02

$7.3829912 \mathrm{E}-02 \quad 3.9646626 \mathrm{E}-02$

$0.1215877 \quad 1.5797980 \mathrm{E}-02$

8.4925257E-02 2.0765597E-02

5.1617451E-02 5.5218507E-02

$1.6678156 \mathrm{E}-02 \quad 5.4130182 \mathrm{E}-02$

$1.7280921 \mathrm{E}-02 \quad 4.7160003 \mathrm{E}-02$

$6.1498184 \mathrm{E}-02 \quad 5.8692340 \mathrm{E}-02$

$0.1538038 \quad 2.3057584 \mathrm{E}-02$

$7.0079938 \mathrm{E}-02 \quad 5.9342016 \mathrm{E}-02$

4.6549104E-02 1.9712312E-02

$8.5495159 \mathrm{E}-02 \quad 1.8631760 \mathrm{E}-02$

$2.9121149 \mathrm{E}-02 \quad 6.0043842 \mathrm{E}-02$

5.2379847E-02 6.7772292E-02

2.2424161E-02 5.7133570E-02

$1.4448942 \mathrm{E}-02 \quad 7.5433329 \mathrm{E}-02$

$0.1259440 \quad 4.9683046 \mathrm{E}-02$

$2.1840738 \mathrm{E}-02 \quad 3.7463218 \mathrm{E}-02$

$4.6944050 \mathrm{E}-03 \quad 6.5001808 \mathrm{E}-02$

$6.5334700 \mathrm{E}-02 \quad 3.5716325 \mathrm{E}-02$

$0.1371943 \quad 1.9875966 \mathrm{E}-02$

$1.6964525 \mathrm{E}-02 \quad 8.1631653 \mathrm{E}-02$

$0.1015151 \quad 2.9490849 \mathrm{E}-02$

$1.8315334 \mathrm{E}-02 \quad 4.2935792 \mathrm{E}-02$

$3.3113606 \mathrm{E}-02 \quad 3.9712951 \mathrm{E}-02$

$0.1321511 \quad 6.5156333 E-02$

4.2373762E-02 6.5489277E-02

$7.2913952 \mathrm{E}-03 \quad 5.9004165 \mathrm{E}-02$

$6.3795552 \mathrm{E}-02 \quad 4.7587328 \mathrm{E}-02$

$0.2103213 \quad 8.3966292 \mathrm{E}-02$

$0.1109417 \quad 4.0622294 \mathrm{E}-02$

$0.1395433 \quad 5.4257885 \mathrm{E}-02$

$\begin{array}{lll}4.7899157 \mathrm{E}-02 & 0.1202568\end{array}$

$6.8555456 \mathrm{E}-03 \quad 6.0329355 \mathrm{E}-02$

4.7816616E-03 3.7393130E-02

$1.3575777 \mathrm{E}-02 \quad 2.2464391 \mathrm{E}-02$

$3.7566062 \mathrm{E}-02 \quad 1.2979862 \mathrm{E}-02$

$9.9475965 \mathrm{E}-02 \quad 3.7282106 \mathrm{E}-02$

$0.1179500 \quad 4.4079732 \mathrm{E}-02$

$0.1407464 \quad 8.6003169 \mathrm{E}-02$ 


\begin{tabular}{|c|c|}
\hline & \\
\hline 4.5888089E-03 & 8.6619906E-02 \\
\hline $7.6253237 \mathrm{E}-03$ & $7.2223626 \mathrm{E}-02$ \\
\hline 0.1213599 & 5.0378244E-02 \\
\hline $5.0322939 \mathrm{E}-02$ & 5.5347841E-02 \\
\hline 5.3692952E-02 & $1.6964931 \mathrm{E}-02$ \\
\hline $6.8447582 E-02$ & $5.8529630 \mathrm{E}-02$ \\
\hline 0.3917790 & $4.3206576 \mathrm{E}-02$ \\
\hline $5.7127774 \mathrm{E}-02$ & $1.4987160 \mathrm{E}-02$ \\
\hline 8.3935164E-02 & $8.4336311 \mathrm{E}-02$ \\
\hline $5.8236878 \mathrm{E}-02$ & $5.1324982 \mathrm{E}-02$ \\
\hline 2.7824761E-02 & $5.8796186 \mathrm{E}-02$ \\
\hline $1.0342170 \mathrm{E}-02$ & $6.6040970 \mathrm{E}-02$ \\
\hline 0.1130472 & 4.6403021E-02 \\
\hline $1.9324374 \mathrm{E}-03$ & 2.1041799E-02 \\
\hline $2.1123756 \mathrm{E}-02$ & 5.4619823E-02 \\
\hline 7.3582875E-03 & $3.7066460 \mathrm{E}-02$ \\
\hline 8.1938533E-03 & $5.8557700 \mathrm{E}-02$ \\
\hline 3.8392141E-03 & $5.4025233 \mathrm{E}-02$ \\
\hline 0.1114586 & $4.5126867 \mathrm{E}-02$ \\
\hline 3.7242990E-02 & $6.1717805 E-02$ \\
\hline $1.9190241 E-02$ & $4.8077114 \mathrm{E}-02$ \\
\hline 2.3559626E-02 & $4.2224646 \mathrm{E}-02$ \\
\hline $6.7579068 \mathrm{E}-02$ & $5.4060549 E-02$ \\
\hline 0.1495474 & 0.1292609 \\
\hline 8.7243997E-02 & 5.6941222E-02 \\
\hline 3.9188843E-03 & $4.8121687 E-02$ \\
\hline 2.0487398E-02 & $6.9975689 \mathrm{E}-02$ \\
\hline 0.1687348 & $5.1983319 \mathrm{E}-02$ \\
\hline $1.9494988 \mathrm{E}-02$ & $3.7827380 \mathrm{E}-02$ \\
\hline 3.1080063E-02 & 2.2208920E-02 \\
\hline $3.3260230 \mathrm{E}-02$ & $3.4254942 \mathrm{E}-02$ \\
\hline 0.1394177 & $6.1570350 \mathrm{E}-02$ \\
\hline $4.6089880 \mathrm{E}-02$ & 8.3428882E-02 \\
\hline 0.1716556 & $5.5070791 E-02$ \\
\hline 5.3486563E-02 & $7.9588860 \mathrm{E}-02$ \\
\hline $4.7258500 \mathrm{E}-02$ & 0.1550756 \\
\hline $3.3940416 \mathrm{E}-02$ & 8.4298290E-02 \\
\hline $2.1830970 \mathrm{E}-02$ & 5.5529773E-02 \\
\hline $4.0602647 \mathrm{E}-03$ & $5.6944489 \mathrm{E}-02$ \\
\hline $1.0020436 \mathrm{E}-02$ & $5.4907784 \mathrm{E}-02$ \\
\hline 3.7182402E-02 & $4.9482226 \mathrm{E}-02$ \\
\hline $4.2706481 \mathrm{E}-03$ & 0.1606795 \\
\hline 3.1993993E-02 & $5.3374309 \mathrm{E}-02$ \\
\hline $7.7867016 \mathrm{E}-02$ & $2.8862229 \mathrm{E}-02$ \\
\hline 4.5282654E-02 & $4.6392612 \mathrm{E}-02$ \\
\hline 2.3415735E-02 & $6.4310737 \mathrm{E}-02$ \\
\hline 0.2160491 & $5.5371974 \mathrm{E}-02$ \\
\hline $6.4673787 \mathrm{E}-03$ & 0.7566715 \\
\hline $1.7433336 \mathrm{E}-02$ & $5.5316355 \mathrm{E}-02$ \\
\hline 2.2904482E-05 & 4.6597488E-0? \\
\hline 0.1147942 & $5.9636269 \mathrm{E}-0$ \\
\hline 7. & $1.08031 / 1 \mathrm{E}$ \\
\hline
\end{tabular}

5.3303089E-02 $6.8604030 \mathrm{E}-02$ 5.0968453E-02 3.0148089E-02 $0.1519960 \quad 5.0956085 \mathrm{E}-02$ 9.9529408E-02 $5.1027179 \mathrm{E}-02$ $1.2661025 \mathrm{E}-02 \quad 3.2987788 \mathrm{E}-02$ $1.1452804 \mathrm{E}-02 \quad 1.9742427 \mathrm{E}-02$ 5.9550323E-02 8.1923068E-02 8.4897578E-02 3.2943714E-02 $0.1265632 \quad 4.4650719 \mathrm{E}-02$ $0.1636941 \quad 6.5610617 \mathrm{E}-02$

7.2806217E-02 7.1486212E-02 $\begin{array}{lll}9.7682148 \mathrm{E}-02 & 0.1179187\end{array}$ 4.3897450E-02 5.7352368E-02 $5.3755235 \mathrm{E}-02 \quad 0.1008180$ $7.2366193 \mathrm{E}-02 \quad 0.1015658$ $0.2446719 \quad 3.0301256 \mathrm{E}-02$ 8.7504514E-02 7.1135163E-02 6.1651595E-02 7.9552941E-02 $0.1204444 \quad 5.2140828 \mathrm{E}-02$ $1.0141240 \mathrm{E}-02 \quad 4.9205273 \mathrm{E}-02$ $2.9848058 \mathrm{E}-02 \quad 5.8265250 \mathrm{E}-02$ 9.4402153E-03 5.9602566E-02 4.3066703E-03 7.0935003E-02 8.8652149E-03 8.9759074E-02 8.2147315E-02 3.4737453E-02 8.9766808E-02 2.2139974E-02 5.7522781E-02 8.4488504E-02 $1.9196231 \mathrm{E}-02 \quad 7.9581648 \mathrm{E}-02$ 3.2749761E-02 6.2474120E-02 7.4022703E-02 4.1953418E-02 $2.8199911 \mathrm{E}-02 \quad 5.1889852 \mathrm{E}-02$ $0.1044558 \quad 6.7030467 \mathrm{E}-02$ 3.6798760E-02 8.6043261E-02 $2.8888844 \mathrm{E}-02 \quad 3.2008789 \mathrm{E}-02$ $0.1416059 \quad 4.2976875 \mathrm{E}-02$ $1.1433396 \mathrm{E}-02 \quad 4.2970411 \mathrm{E}-02$ 8.4602527E-02 4.8343554E-02 $0.1223382 \quad 4.7623150 \mathrm{E}-02$ 5.3186379E-02 7.3586397E-02 9.5278546E-03 7.3705859E-02 3.6003832E-02 6.3980505E-02 $0.2368298 \quad 6.8291128 \mathrm{E}-02$ 9.8380804E-02 $5.4853976 \mathrm{E}-02$ $0.1627849 \quad 6.9135174 \mathrm{E}-02$ 4.3205872E-02 5.5737238E-02 7.7809721E-02 5.7787050E-02 9.2956319E-02 6.5993495E-02 $0.1799912 \quad 5.1761754 \mathrm{E}-02$ $5.3744238 \mathrm{E}-02 \quad 0.1043923$ 2.3056671E-02 5.9782274E-02 $6.4727686 \mathrm{E}-02 \quad 7.6576352 \mathrm{E}-02$ $0.1216711 \quad 5.7241727 \mathrm{E}-02$ $0.3209038 \quad 7.3334612 \mathrm{E}-02$

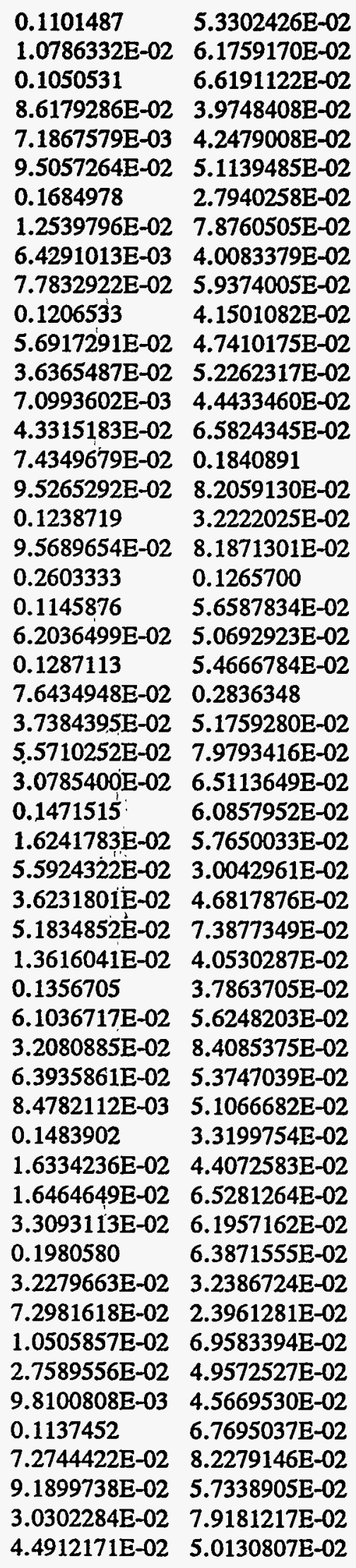


1.7556440E-02 4.8635080E-02

7.8613654E-02 7.7345565E-02

$7.6832488 \mathrm{E}-02 \quad 6.1814152 \mathrm{E}-02$

$5.3756524 \mathrm{E}-02 \quad 3.1926371 \mathrm{E}-02$

$0.1039997 \quad 5.9751723 E-02$

5.1588386E-02 6.9555439E-02

4.1753639E-02 4.2831965E-02

9.4200537E-02 5.0937343E-02

$0.2072446 \quad 5.0402451 \mathrm{E}-02$

$1.9067375 \mathrm{E}-02 \quad 0.1326806$

5.2268062E-02 4.6196971E-02

9.3951240E-02 $5.7576288 \mathrm{E}-02$

2.5747674E-02 :4.7689557E-02

9.1002814E-02 5.8826875E-02

$5.2193556 \mathrm{E}-02 \quad 7.2790295 \mathrm{E}-02$

1.3168592E-02 6.9407247E-02

7.8425752E-03 5.0967094E-02

$2.4083138 \mathrm{E}-02 \quad 0.1204861$

$2.9606896 \mathrm{E}-02 \quad 6.9861956 \mathrm{E}-02$

3.2791542E-03 8.4400952E-02

5.5754423E-02 7.2532296E-02

$\begin{array}{ll}1.9297315 \mathrm{E}-02 & 0.1260565\end{array}$

$0.1221153 \quad 0.1444877$

$0.1836627 \quad 7.1748078 \mathrm{E}-02$

$2.6211066 \mathrm{E}-02 \quad 1.8517802 \mathrm{E}-02$

$0.1165744 \quad 4.8370954 \mathrm{E}-02$

$7.7690028 \mathrm{E}-02 \quad 5.5468269 \mathrm{E}-02$

8.6576715E-03 4.8304219E-02

3.0842939E-02 5.0762452E-02

3.4306709E-02 7.1425423E-02

3.0743775E-02 3.7325677E-02

$1.8435411 \mathrm{E}-02 \quad 5.4139994 \mathrm{E}-02$

3.2321534E-03 6.7153610E-02

4.0109031E-02 0.2683479

$7.1211591 \mathrm{E}-02 \quad 9.8831236 \mathrm{E}-02$

4.9363904E-02 4.6027701E-02

3.8666770E-02 6.8053164E-02

5.1464181E-02 5.0975636E-02

$2.9909359 \mathrm{E}-02 \quad 8.1957847 \mathrm{E}-02$

8.5642956E-02 6.1596613E-02

$0.1428766 \quad 3.1131679 \mathrm{E}-02$

$6.8073608 \mathrm{E}-02 \quad 4.3255195 \mathrm{E}-02$

3.6340430E-03 2.4262222E-02

9.6433230E-02 $6.5032646 \mathrm{E}-02$

$0.1015370 \quad 5.0547209 \mathrm{E}-02$

4.2306870E-02 3.0492617E-02

8.6678125E-02 2.2774333E-02

8.0561943E-02 4.8459731E-02

$3.5065666 \mathrm{E}-02 \quad 0.1246275$

5.6423653E-02 5.6726296E-02

$9.1383748 \mathrm{E}-02 \quad 0.1002052$

$9.0465531 \mathrm{E}-02 \quad 6.9393113 \mathrm{E}-02$

8.2488284E-02 $6.2411986 \mathrm{E}-02$
5.7035097E-04 5.1698089E-02

4.2432569E-02 7.5730167E-02

1.4777359E-02 4.6410918E-02

3.2787994E-02 6.7062199E-02

5.1232055E-02 5.1038437E-02

5.4714889E-03 4.4249024E-02

2.0741522E-02 8.2121037E-02

8.3291810E-04 4.7168367E-02

9.0837017E-02 3.1095194E-02

2.3047213E-02 7.5219192E-02

4.1621886E-02 7.2013229E-02

$3.9833665 \mathrm{E}-02 \quad 5.4039750 \mathrm{E}-02$

9.0728611E-02 5.1099844E-02

$0.1397989 \quad 8.3080105 \mathrm{E}-02$

4.4620942E-02 4.7020800E-02

$0.1943297 \quad 4.5590665 \mathrm{E}-02$

3.5363667E-02 3.1711053E-02

6.8349316E-04 4.6826027E-02

$9.1459142 \quad 1.5171967 \mathrm{E}-02$

8.0266237E-02 6.208885IE-02

$1.9203138 \mathrm{E}-02 \quad 5.7292338 \mathrm{E}-02$

$7.1140945 \mathrm{E}-02 \quad 4.8464339 \mathrm{E}-02$

5.2328020E-02 6.8254374E-02

7.3376082E-02 5.7114784E-02

6.3577600E-02 4.6294525E-02

$1.2584946 \mathrm{E}-03 \quad 4.2093381 \mathrm{E}-02$

$1.5184088 \mathrm{E}-02 \quad 4.1216429 \mathrm{E}-02$

2.0581085E-02 4.8308022E-02

$2.4160979 \mathrm{E}-02 \quad 6.1195992 \mathrm{E}-02$

$0.1186002 \quad 6.8436407 \mathrm{E}-02$

6.6469684E-02 3.3913091E-02

?.7167817E-02 4.7778640E-02

$0.1164728 \quad 4.5537926 \mathrm{E}-02$

$5.5276338 \mathrm{E}-02 \quad 8.6885706 \mathrm{E}-02$

$0.1067105 \quad 6.1804399 E-02$

$6.9141306 \mathrm{E}-02 \quad 5.4143526 \mathrm{E}-02$

8.5148111E-02 5.0867260E-02

$1.0854620 \mathrm{E}-02 \quad 3.4957122 \mathrm{E}-02$

$7.3132701 \mathrm{E}-03 \quad 4.1457672 \mathrm{E}-02$

$3.9495885 \mathrm{E}-02 \quad 6.5525882 \mathrm{E}-02$

$0.1621865 \quad 4.4940747 E-03$

2.7274314E-02 9.0562209E-02

9.4924212E-02 6.5175451E-02

?.8715859E-03 7.2900273E-02

$7.6369330 \mathrm{E}-02 \quad 0.1102054$

$1.1159037 \mathrm{E}-02 \quad 4.9953319 \mathrm{E}-02$

$1.6781913 \mathrm{E}-02 \quad 5.9157480 \mathrm{E}-02$

9.4187953E-02 3.6562186E-02

$1.5712211 \mathrm{E}-02 \quad 7.7645145 \mathrm{E}-02$

$0.1357202 \quad 4.8308227 \mathrm{E}-02$

9.6314792E-03 5.2776337E-02

$3.5887018 \mathrm{E}-02$ ' $4.6999138 \mathrm{E}-02$

$6.3044518 \mathrm{E}-02 \quad 2.9852998 \mathrm{E}-02$
6.0450430E-03 5.4368593E-02

$1.9245146 \mathrm{E}-02 \quad 0.8440393$

$7.1171016 \mathrm{E}-02 \quad 7.2131597 \mathrm{E}-02$

6.7888290E-02 7.7404454E-02

$5.5506688 \mathrm{E}-02 \quad 7.5137384 \mathrm{E}-02$

$0.2476660 \quad 1.9120978 \mathrm{E}-02$

$2.9247994 \mathrm{E}-02 \quad 6.0947556 \mathrm{E}-02$

$6.4376746 \mathrm{E}-03 \quad 5.6334939 \mathrm{E}-02$

1.3259222E-02 3.8407531E-02

9.5137425E-02 5.0707649E-02

$1.6477322 \mathrm{E}-02 \quad 2.4710726 \mathrm{E}-02$

4.0688049E-02 4.2610008E-02

$2.2278026 \mathrm{E}-02 \quad 5.1053967 \mathrm{E}-02$

2.4768834E-03 6.1949339E-02

$1.9059179 \mathrm{E}-02 \quad 7.1737774 \mathrm{E}-02$

4.2819299E-02 5.2731704E-02

$9.5047787 \mathrm{E}-02 \quad 8.5911974 \mathrm{E}-02$

$2.2842348 \mathrm{E}-02 \quad 6.0070943 \mathrm{E}-02$

$8.9984555 \mathrm{E}-03 \quad 0.1145708$

4.0717803E-02 4.3459535E-02

$1.8620146 \mathrm{E}-02 \quad 7.6692447 \mathrm{E}-02$

$5.5759195 \mathrm{E}-03 \quad 1.6390927 \mathrm{E}-02$

$5.9370346 \mathrm{E}-02 \quad 4.4554576 \mathrm{E}-02$

$1.4559478 \mathrm{E}-02 \quad 4.8129562 \mathrm{E}-02$

2.1993279E-02 4.8157401E-02

$3.4803309 \mathrm{E}-02 \quad 0.1230489$

$0.1713544 \quad 5.8508251 \mathrm{E}-02$

4.7787406E-02 5.6298438E-02

$0.1166827 \quad 9.4757400 \mathrm{E}-02$

$0.1062214 \quad 4.4456623 \mathrm{E}-02$

$1.4152073 \mathrm{E}-02 \quad 3.3927958 \mathrm{E}-02$

7.3292643E-02 2.9449234E-02

3.0571070E-02 6.2851891E-02

$0.1430519 \quad 1.2923073 E-02$

$5.7888649 \mathrm{E}-02 \quad 4.0874809 \mathrm{E}-02$

$0.1176199 \quad 5.1488835 E-02$

8.8838212E-02 3.5273183E-02

8.3055459E-02 5.2958019E-02

$7.8486003 \mathrm{E}-02 \quad 4.2060331 \mathrm{E}-02$

$3.7651348 \mathrm{E}-03 \quad 4.5594558 \mathrm{E}-02$

8.9207999E-02 4.9712803E-02

$0.1019203 \quad 5.3399816 \mathrm{E}-02$

3.8159367E-02 6.1574344E-02

7.2341422E-03 3.9367147E-02

?.1741793E-02 4.9255345E-02

$1.7596968 \mathrm{E}-02 \quad 6.9260821 \mathrm{E}-02$

$4.9762029 \mathrm{E}-02 \quad 5.0212156 \mathrm{E}-02$

6.2078778E-02 4.3626074E-02

$0.1199143 \quad 6.5188862 \mathrm{E}-02$

$7.7847488 \mathrm{E}-02 \quad 4.6927504 \mathrm{E}-02$

$1.0528071 \mathrm{E}-02 \quad 3.3243977 \mathrm{E}-02$

$8.3635688 \mathrm{E}-02 \quad 6.8293311 \mathrm{E}-02$

$0.2009909 \quad 5.2799009 \mathrm{E}-02$ 
LOSP Frequency

5.8667913E-02 1.1793434E-02

8.5019536E-02 5.3816400E-02

3.2430448E-02 4.2968925E-02

$\sim .9151317 \mathrm{E}-02$ 7.0211180E-02

$2.0972826 \mathrm{E}-02 \quad 3.0125555 \mathrm{E}-02$

9.0942435E-02 6.9475524E-02

$0.1594650 \quad 8.8435039 \mathrm{E}-02$

$0.1471007 \quad 3.7287861 \mathrm{E}-02$

6.9947779E-02 6.6194192E-02

$2.9659139 \mathrm{E}-03 \quad 3.6363807 \mathrm{E}-02$

$0.1435275 \quad 6.4530842 E-02$

$0.1113859 \quad 7.8945436 \mathrm{E}-02$

3.9282557E-02 4.3159917E-02

6.1981261E-02 3.8630560E-02

$1.9839078 \mathrm{E}-02 \quad 7.6724023 \mathrm{E}-02$

$5.7827588 \mathrm{E}-02 \quad 5.1710501 \mathrm{E}-02$

2.5132930E-02 3.8794026E-02

$\sim .0411420 \mathrm{E}-025.6560256 \mathrm{E}-02$

$0.1284811 \quad 8.2200252 \mathrm{E}-02$

8.3482713E-03 6.4073250E-02

$0.1010389 \quad 7.6155193 \mathrm{E}-02$

$1.0805682 \mathrm{E}-02 \quad 6.2696621 \mathrm{E}-02$

6.1287235E-02 5.4863572E-02

4.9389787E-03 6.3365564E-02

$5.8028206 \mathrm{E}-02 \quad 6.8783589 \mathrm{E}-02$

1.0797053E-02 4.3770362E-02

6.0769171E-02 5.1254261E-02

2.5214817E-02 4.5434184E-02

1.1230638E-02 6.0345143E-02

2.5707522E-02 4.3819964E-02

2.2795934E-02 4.3428607E-02

$6.2227350 \mathrm{E}-02 \quad 5.0626360 \mathrm{E}-02$

$0.1672506 \quad 1.6204851 \mathrm{E}-02$

$1.8789757 \mathrm{E}-02 \quad 5.9325770 \mathrm{E}-02$

2.6002435E-02 4.6509504E-02

8.3665326E-02 5.5244900E-02

3.0448386E-02 7.2145104E-02

$0.2885319 \quad 6.7223296 \mathrm{E}-02$

7.5610541E-02 5.3584695E-02

$0.1016252 \quad 5.0296757 \mathrm{E}-02$

4.5112247E-04 3.4339830E-02

3.3670895E-02 5.3941634E-02

5.0228938E-02 2.8962769E-02

$6.2303629 \mathrm{E}-02 \quad 5.5208676 \mathrm{E}-02$

$1.5903739 \mathrm{E}-03 \quad 6.3049272 \mathrm{E}-02$

$2.3061221 \mathrm{E}-02 \quad 3.7146755 \mathrm{E}-02$

$1.7828470 \mathrm{E}-02 \quad 2.2134250 \mathrm{E}-02$

$0.1489135 \quad 4.6703458 \mathrm{E}-02$

2.9991554E-02 5.4632392E-02

3.8592044E-02 6.0892493E-02

$2.6665970 \mathrm{E}-03 \quad 4.0781397 \mathrm{E}-02$

$0.1594036 \quad 5.7811223 E-02$

4.8654587E-03 6.7245990E-02
4.1176889E-02 2.3709267E-02

$0.1111817 \quad 5.4197088 \mathrm{E}-02$

3.2693163E-02 6.3513294E-02

2.7328093E-02 4.5014217E-02

?.4314032E-02 6.1339408E-02

$0.1534035 \quad 1.9215468 \mathrm{E}-02$

$0.1076253 \quad 2.8773729 \mathrm{E}-02$

$1.1158386 \mathrm{E}-02 \quad 5.3947240 \mathrm{E}-02$

7.5296283E-02 5.1808033E-02

$9.0385396 \mathrm{E}-03 \quad 4.2649522 \mathrm{E}-02$

$1.8177083 \mathrm{E}_{-} 02 \quad 2.3263156 \mathrm{E}-02$

$3.4835618 \mathrm{E}-02 \quad 3.4496263 \mathrm{E}-02$

$0.2126295 \quad 7.1400881 \mathrm{E}-02$

$0.1055460 \quad 3.7581399 \mathrm{E}-02$

$1.6926570 \mathrm{E}-02 \quad 8.2580023 \mathrm{E}-02$

9.7805411E-02 $6.6657782 \mathrm{E}-02$

$2.4215424 \mathrm{E}-02 \quad 5.5337630 \mathrm{E}-02$

4.6272218E-02 7.3172510E-02

$0.1436211 \quad 2.3976738 \mathrm{E}-02$

9.6115790E-02 5.8919404E-02

1.8233091E-02 5.0471243E-02

$7.0725784 \mathrm{E}-02 \quad 4.9269639 \mathrm{E}-02$

8.6573020E-02 3.0284656E-02

$5.2638784 \mathrm{E}-02 \quad 7.0753917 \mathrm{E}-02$

$1.2816365 \mathrm{E}-02 \quad 5.8832102 \mathrm{E}-02$

9.5106354E-03 9.2986114E-02

$2.0517757 \mathrm{E}-02 \quad 9.1534806 \mathrm{E}-03$

$8.8717468 \mathrm{E}-02 \quad 5.4625418 \mathrm{E}-02$

$0.1110684 \quad 6.2296972 \mathrm{E}-02$

$0.1252603 \quad 3.7447959 \mathrm{E}-02$

$1.4984865 \mathrm{E}-02 \quad 4.1524138 \mathrm{E}-02$

4.1367975E-03 7.9745278E-02

$0.1044355 \quad 4.4853296 \mathrm{E}-02$

$0.1163967 \quad 4.7956627 \mathrm{E}-02$

$6.4864228 \mathrm{E}-03 \quad 5.0529066 \mathrm{E}-02$

8.6171895E-02 5.2243385E-02

9.6399421E-03 3.5095360E-02

$0.1216575 \quad 5.9582046 \mathrm{E}-03$

7.5110182E-02 8.3018109E-02

9.4210796E-02 3.5506029E-02

$0.1249922 \quad 2.4129305 \mathrm{E}-02$

$0.1011262 \quad 8.6357377 \mathrm{E}-02$

$2.4293195 \mathrm{E}-02 \quad 1.3958868 \mathrm{E}-04$

$6.6678897 \mathrm{E}-03 \quad 6.0641464 \mathrm{E}-02$

$0.1111950 \quad 3.6001086 \mathrm{E}-02$

1.9772781E-02 $3.8195383 \mathrm{E}-02$

$0.1155881 \quad 3.9210908 \mathrm{E}-02$

$0.1582730 \quad 6.9811329 \mathrm{E}-02$

$0.1393309 \quad 4.6100881 \mathrm{E}-02$

$1.4094720 \mathrm{E}-02 \quad 3.6581177 \mathrm{E}-02$

$0.1499535 \quad 0.1384112$

$7.1544766 \mathrm{E}-02 \quad 3.3210576 \mathrm{E}-02$

3.0904636E-02 5.6052897E-02
9.8734237E-02 $5.2587286 \mathrm{E}-02$

$1.3600629 \mathrm{E}-02 \quad 5.6890666 \mathrm{E}-02$

5.8635902E-02 5.5508066E-02

$0.1916036 \quad 6.0558066 \mathrm{E}-02$

$4.9487189 \mathrm{E}-03 \quad 3.9720256 \mathrm{E}-02$

$1.2524434 \mathrm{E}-06 \quad 6.1670996 \mathrm{E}-02$

$3.2651860 \mathrm{E}-02 \quad 6.2497389 \mathrm{E}-02$

0.1841026

0.1599361

2.5924018E-02

$5.8705285 \mathrm{E}-02$.

$6.6332571 \mathrm{E}-02 \quad 6.2288031 \mathrm{E}-02$

2.1626830E-02 5.4086905E-02

$2.8318062 \mathrm{E}-02 \quad 5.9075210 \mathrm{E}-02$

$1.5888639 \mathrm{E}-02 \quad 5.6085356 \mathrm{E}-02$

3.4715347E-02 5.3803716E-02

4.7073562E-02 8.2605429E-02

5.9949227E-02 4.7632530E-02

?.5089148E-02 8.4848598E-02

7.4199475E-02 6.5386884E-02

4.3561067E-02 $\quad 5.8682919 \mathrm{E}-02$

$7.8390967 \mathrm{E}-03 \quad 4.0172376 \mathrm{E}-02$

8.5252132E-03 5.8117419E-02

$9.4841480 \mathrm{E}-02 \quad 5.9852250 \mathrm{E}-02$

$9.8654538 \mathrm{E}-02 \quad 3.0269235 \mathrm{E}-02$

8.2921065E-02 6.1462905E-02

$0.1212057 \quad 4.6906881 \mathrm{E}-02$

4.1389301E-02 7.1643874E-02

$3.9176088 \mathrm{E}-02 \quad 5.8735572 \mathrm{E}-02$

3.6713161E-02 5.9419930E-02

2.6123142E-02 4.9866855E-02

7.1415707E-02 9.7280517E-02

0.1111227

$4.7417659 \mathrm{E}-02$

3.3226274E-02 0.1087197

4.3823916E-02 5.3581931E-02

$2.3118341 \mathrm{E}-02 \quad 2.6443675 \mathrm{E}-02$

$1.5971426 \mathrm{E}-02 \quad 5.5992521 \mathrm{E}-02$

$1.8822059 \mathrm{E}-02 \quad 6.8028539 \mathrm{E}-02$

$5.8292266 \mathrm{E}-02 \quad 7.5867422 \mathrm{E}-02$

$5.7775807 \mathrm{E}-02 \quad 6.8557747 \mathrm{E}-02$

3.5423137E-02 5.8446933E-02

$2.9857086 \mathrm{E}-02 \quad 3.0045392 \mathrm{E}-02$

$0.1548729 \quad 7.3036246 \mathrm{E}-02$

4.3557987E-02 5.5324331E-02

$1.5834160 \mathrm{E}-02 \quad 3.4643687 \mathrm{E}-02$

$3.0191801 \mathrm{E}-02 \quad 0.1435142$

4.0227517E-02 4.2338185E-02

$6.4106800 \mathrm{E}-02 \quad 5.5072434 \mathrm{E}-02$

$0.1264381 \quad 6.1384298 \mathrm{E}-02$

$5.0514825 \mathrm{E}-03 \quad 8.6178847 \mathrm{E}-02$

$7.4786786 \mathrm{E}-03 \quad 4.3397933 \mathrm{E}-02$

5.6379151E-02 3.2816466E-02

6.5043934E-02 2.6079575E-02

2.3314461E-02 3.8492594E-02 
7.4765138E-02 3.5316885E-02

$1.7438317 \mathrm{E}-02 \quad 6.0133357 \mathrm{E}-02$

$1.9293664 \mathrm{E}-02 \quad 4.6111993 \mathrm{E}-02$

$1.2643554 \mathrm{E}-02 \quad 2.4007510 \mathrm{E}-02$

6.2489253E-04 7.0830792E-02

$7.2150782 \mathrm{E}-02 \quad 4.0100031 \mathrm{E}-02$

8.0911592E-02 0.1194109

4.5478538E-02 7.1966670E-02

$0.1769705 \quad 6.1874941 \mathrm{E}-02$

$1.2616337 \mathrm{E}-02 \quad 2.7611544 \mathrm{E}-03$

$7.2607398 \mathrm{E}-03 \quad 1.8355193 \mathrm{E}-02$

4.3000471E-02 7.4872628E-02

$0.2969601 \quad 1.4178558 \mathrm{E}-02$

$0.1011943 \quad 6.3337684 \mathrm{E}-02$

4.0632688E-02 6.2715657E-02

$1.1991364 \mathrm{E}-02 \quad 5.5741306 \mathrm{E}-02$

0.1659063

2.9904557E-02

6.7917205E-02 4.2753242E-02

2.9479271E-02 5.0045524E-02

2.7579788E-02 4.5462053E-02

1.8036981E-04 8.4291220E-02

3.4363531E-02 5.3680379E-02

7.1762465E-02 4.8111111E-02

$0.1614968 \quad 8.2661159 \mathrm{E}-02$

$2.5125390 \mathrm{E}-02 \quad 5.7087846 \mathrm{E}-02$

3.1458316E-05 5.2861001E-02

$0.1076581 \quad 6.9154672 \mathrm{E}-02$

$2.6002066 \mathrm{E}-02 \quad 8.3394058 \mathrm{E}-02$

$0.1655387 \quad 5.6196619 \mathrm{E}-02$

2.6791573E-02 6.6164300E-02

?.1573987 0.1171114

3.7749022E-02 5.5093467E-02

3.2987423E-02 8.3813868E-02

$7.6349050 \mathrm{E}-02 \quad 4.0644743 \mathrm{E}-02$

$0.1368688 \quad 6.2713839 \mathrm{E}-02$

1.0591272E-02 3.0946087E-02

5.0359242E-02 1.6257817E-02

8.6674066E-03 6.6296309E-02

$2.7813993 \mathrm{E}-02 \quad 8.4544651 \mathrm{E}-02$

9.2147784E-06 4.8570462E-02

9.7445004E-02 6.9969364E-02

$0.1148768 \quad 5.1222965 E-02$

1.2202328E-02 9.6307933E-02

$1.8492657 \mathrm{E}-03 \quad 6.1574437 \mathrm{E}-02$

4.1577820E-02 5.2975034E-03

$0.1904121 \quad 6.1209939 \mathrm{E}-02$

$1.9257167 \mathrm{E}-02 \quad 5.7236783 \mathrm{E}-02$

6.0050576E-03 4.2949833E-02

$1.5237578 \mathrm{E}-02 \quad 6.6271603 \mathrm{E}-02$

$0.1926419 \quad 6.1559569 E-02$

$0.2087683 \quad 3.2510523 E-02$

$0.1375539 \quad 7.4545696 E-02$

$0.1049394 \quad 7.7320695 E-02$
1.2667705E-02 3.7954487E-02

9.5690675E-03 4.6867296E-02

8.5062332E-02 6.7823358E-02

8.1150882E-02 5.9913274E-02

$1.4643470 \mathrm{E}-02 \quad 5.0341334 \mathrm{E}-02$

8.3918739E-03 8.7849453E-02

5.2297127E-02 3.3744439E-02

$0.1712909 \quad 6.2485963 \mathrm{E}-02$

$3.9250352 \mathrm{E}-03 \quad 6.0935359 \mathrm{E}-02$

$0.1462693 \quad 3.8154949 \mathrm{E}-02$

$6.3159265 \mathrm{E}-02 \quad 6.9870718 \mathrm{E}-02$

$6.3968100 \mathrm{E}-02 \quad 5.8013394 \mathrm{E}-02$

6.1579641E-02 4.4959161E-02

3.1537369E-02 5.3400274E-02

$0.1300344 \quad 3.3928584 \mathrm{E}-02$

4.2458829E-02 5.9283480E-02

$6.8499178 \mathrm{E}-02 \quad 6.9322161 \mathrm{E}-02$

$5.0882958 \mathrm{E}-03 \quad 5.6380130 \mathrm{E}-02$

$0.1220675 \quad 7.6671772 \mathrm{E}-02$

6.1601184E-02 5.8840957E-02

6.6456713E-02 5.7752959E-02

$0.1217265 \quad 8.9464970 \mathrm{E}-02$

4.7997069E-03 9.1979116E-02

$2.9600626 \mathrm{E}-02 \quad 4.9833305 \mathrm{E}-02$

$0.1141646 \quad 3.4966715 \mathrm{E}-02$

7.1259312E-02 5.4746557E-02

8.6525485E-02 5.2404400E-02

$7.5258906 \mathrm{E}-03 \quad 0.1074915$

$7.5813979 \mathrm{E}-02 \quad 7.3007323 \mathrm{E}-02$

1.0426432E-04 3.1289287E-02

9.9009417E-02 8.5363977E-02

8.5491806E-02 6.5238811E-02

$6.9037460 \mathrm{E}-02 \quad 5.1741201 \mathrm{E}-02$

4.4828497E-02: 5.3312019E-02

$7.9834806 \mathrm{E}-03 \quad 4.3321740 \mathrm{E}-02$

4.4560567E-02 5.8733013E-02

$6.5790229 E-02 \quad 0.1134825$

2.3019051E-02 5.6591086E-02

4.8554119E-02 5.5661380E-02

2.3537399E-02 4.0238518E-02

3.9333194E-02 5.5914365E-02

$\begin{array}{ll}6.6698194 \mathrm{E}-02 & 0.1130819\end{array}$

$1.9953102 \mathrm{E}-02 \quad 8.5162811 \mathrm{E}-02$

?.7289076E-03 4.5264572E-02

$0.2049074 \quad 9.3866616 \mathrm{E}-02$

$2.6612628 \mathrm{E}-02 \quad 6.4750165 \mathrm{E}-02$

$6.2301848 \mathrm{E}-02 \quad 6.2756054 \mathrm{E}-02$

4.7661878E-02 8.2719140E-02

$0.1032232 \quad 3.4457006 \mathrm{E}-02$

$2.2303181 \mathrm{E}-02 \quad 4.6219658 \mathrm{E}-02$

$2.3918238 \mathrm{E}-02 \quad 5.8558207 \mathrm{E}-02$

8.8102572E-02 4.6565115E-02

$1.0482088 \mathrm{E}-02 \quad 3.9032046 \mathrm{E}-02$
$0.1262614 \quad 5.7312895 E-02$

5.1675425E-03 8.5691601E-02

$1.2224558 \quad 6.0074564 \mathrm{E}-02$

?.9047388E-02 8.3372809E-02

4.1865766E-02 5.8311015E-02

$3.0313108 \mathrm{E}-02 \quad 5.0959568 \mathrm{E}-02$

6.0838363E-03 5.0049245E-02

$0.1005661 \quad 5.2472834 \mathrm{E}-02$

4.4937138E-02 5.8725663E-02

$0.1633220 \quad 2.5648102 \mathrm{E}-02$

4.3697253E-02 3.0470233E-02

3.1902997E-03 6.9020033E-02

$0.2287423 \quad 3.2850880 \mathrm{E}-02$

3.0959342E-02 4.8091192E-02

9.4964199E-02 5.4733302E-02

0.4126163

$6.5297917 \mathrm{E}-02$

$6.2819786 \mathrm{E}-02 \quad 3.2475919 \mathrm{E}-02$

4.5202851E-02 4.1657679E-02

$1.2994861 \mathrm{E}-02 \quad 6.9093086 \mathrm{E}-02$

$5.1764749 \mathrm{E}-02 \quad 3.1948324 \mathrm{E}-02$

0.1174101

3.8581774E-02

0.1159837

$7.1235195 \mathrm{E}-02$

0.1918874

$3.1310797 \mathrm{E}-02$

$9.2250086 \mathrm{E}-02 \quad 2.7791988 \mathrm{E}-02$

$0.1249470 \quad 6.7267433 \mathrm{E}-02$

9.5545508E-02 5.5780765E-02

$1.9758463 \mathrm{E}-02 \quad 6.1134670 \mathrm{E}-02$

6.9996879E-02 5.1670320E-02

8.2011253E-02 3.5231430E-02

$9.7375177 \mathrm{E}-02 \quad 0.1671166$

9.4023019E-02 3.9594948E-02

0.1476692

$5.1349733 \mathrm{E}-02$

$4.5043502 \mathrm{E}-02 \quad 5.9255589 \mathrm{E}-02$

7.7810525E-03 3.5913724E-02

4.3228015E-02 5.2891221E-02

$4.5226362 \mathrm{E}-02 \quad 6.0764175 \mathrm{E}-02$

$1.1131806 \mathrm{E}-02 \quad 4.4246893 \mathrm{E}-02$

7.1365029E-02 4.6598349E-02

$0.1534233 \quad 3.6120445 \mathrm{E}-02$

4.5220446E-02 8.1419945E-02

4.0321246E-02 4.4738114E-02

$9.2383265 \mathrm{E}-02 \quad 6.0023449 \mathrm{E}-02$

$0.1957802 \quad 3.8790107 E-02$

8.2168173E-02 4.6073996E-02

$0.1421046 \quad 4.9145039 E-02$

4.6885949E-02 2.6521334E-02

$2.9114503 \mathrm{E}-02 \quad 5.4491013 \mathrm{E}-02$

9.4231784E-02 2.7507348E-02

$3.5982575 \mathrm{E}-02 \quad 1.0827117 \mathrm{E}-02$

$0.2368337 \quad 6.6368714 \mathrm{E}-02$

8.9359716E-02 4.3520104E-02

1.8088779 E-03 4.3661300E-02

$0.1065253 \quad 6.1910994 \mathrm{E}-02$ 
LOSP Frequency

7.3502332E-02 3.0958410E-02

$1.9874904 \mathrm{E}-02 \quad 6.5839842 \mathrm{E}-02$

4.0966433E-02 6.1447807E-02

?.1398786 $1.0918747 E-02$

$0.1679944 \quad 6.4998902 \mathrm{E}-02$

3.6314774E-02 6.1941538E-02

3.9298572E-02 2.6657805E-02

$0.1538339 \quad 5.7514656 \mathrm{E}-02$

7.3337995E-02 4.7599960E-02

3.2945636E-03 4.7168393E-02

7.4707083E-02 2.7054267E-02

$3.7277136 \mathrm{E}-02 \quad 0.1055952$

$2.3415873 \mathrm{E}-03 \quad 6.3766249 \mathrm{E}-02$

$0.1363300 \quad 5.8460943 E-02$

2.7190035E-02 4.6317127E-02

?.1469404E-03 5.7112314E-02

4.8396634E-03 1.8904120E-02

6.1320782E-02 1.3836190E-02

5.1850434E-02 4.4858344E-02

$2.9650316 \mathrm{E}-02 \quad 4.5002442 \mathrm{E}-02$

5.2909732E-02 5.2177414E-02

$7.2582185 \mathrm{E}-02 \quad 7.4897297 \mathrm{E}-02$

2.7631711E-02 6.0897086E-02

$0.1479920 \quad 3.7642244 \mathrm{E}-02$

6.8155609E-02 0.1125266

4.8517105E-03 3.7218831E-02

$1.0592137 \mathrm{E}-02 \quad 5.7463851 \mathrm{E}-02$

8.4417984E-02 4.8830070E-02

$1.3834529 \mathrm{E}-02 \quad 5.6467827 \mathrm{E}-02$

3.1368252E-02 5.5263419E-02

$0.1733319 \quad 2.1836525 \mathrm{E}-02$

$0.1083883 \quad 7.8432508 \mathrm{E}-02$

3.4713827E-02 5.4580510E-02

6.9029287E-02 4.9784124E-02

8.6368740E-02 0.1490737

$1.0906375 \mathrm{E}-02 \quad 4.3313839 \mathrm{E}-02$

$2.3066474 \mathrm{E}-02 \quad 6.1758589 \mathrm{E}-02$

$0.1874645 \quad 0.1090954$

2.9084072E-02 5.4830268E-02

3.2290604E-02 0.1488167

$0.1759330 \quad 4.1155804 \mathrm{E}-02$

1.4150621E-02 6.6617176E-02

$0.1159350 \quad 3.4868266 \mathrm{E}-02$

4.2492867E-02 5.3134032E-02

$0.2267004 \quad 6.1173547 \mathrm{E}-02$

$0.1055374 \quad 4.8246101 \mathrm{E}-02$

$0.1955333 \quad 6.4037368 \mathrm{E}-02$

2.6470978E-02 4.3714132E-02

$6.8814188 \mathrm{E}-02 \quad 3.6620829 \mathrm{E}-02$

$5.3744357 \mathrm{E}-02 \quad 5.1303342 \mathrm{E}-02$

$0.2325092 \quad 6.4085588 \mathrm{E}-02$

$6.0120583 \mathrm{E}-02 \quad 8.2462795 \mathrm{E}-02$

$0.1314537 \quad 6.8409018 \mathrm{E}-02$
$0.1753536 \quad 7.1260124 \mathrm{E}-02$

7.0344500E-02 3.3605255E-02

$1.9798214 \mathrm{E}-02 \quad 5.2160297 \mathrm{E}-02$

4.2904954E-02 8.3821729E-02

8.9058951E-02 4.7565345E-02

$0.1282351 \quad 5.6744356 \mathrm{E}-02$

6.3481316E-02 9.3530454E-03

$5.8032546 \mathrm{E}-02 \quad 5.0135382 \mathrm{E}-02$

$4.0085889 \mathrm{E}-02 \quad 3.6050949 \mathrm{E}-02$

$6.8856232 \mathrm{E}-02 \quad 5.4024547 \mathrm{E}-02$

$0.1148059 \quad 5.0873883 \mathrm{E}-02$

3.3868130E-02 6.0785957E-02

1.5916673E-02 6.5029919E-02

2.4237448E-02 5.5624705E-02

3.8375910E-02 5.2462641E-02

?.1393445E-02 1.5578598E-02

?.6492967E-02 1.9284455E-02

$1.2682325 \mathrm{E}-02 \quad 5.7558499 \mathrm{E}-02$

$2.5767982 \mathrm{E}-02 \quad 4.4060186 \mathrm{E}-02$

$1.9472765 \mathrm{E}-02 \quad 6.1348185 \mathrm{E}-02$

$1.3780744 \mathrm{E}-02 \quad 5.5703067 \mathrm{E}-04$

7.0846647E-02 2.5572006E-02

3.2919362E-02 1.4207551E-02

$0.1041866 \quad 7.3884562 \mathrm{E}-02$

6.4161711E-04 3.8655475E-02

2.7210578E-02 5.3686421E-02

$5.0297618 \mathrm{E}-02 \quad 3.0133445 \mathrm{E}-02$

3.9070893E-02 3.9580315E-02

$? .2120718 \quad 7.1436375 \mathrm{E}-02$

$0.1207141 \quad 8.4866486 \mathrm{E}-02$

$7.0493244 \mathrm{E}-02 \quad 0.1654756$

$0.2736189 \quad 5.8602590 \mathrm{E}-02$

$0.1644907 \quad 3.9456370 \mathrm{E}-03$

$0.1962140 \quad 5.2651335 \mathrm{E}-02$

$1.2658233 \mathrm{E}-03 \quad 5.1541779 \mathrm{E}-02$

9.3008801E-03 5.8484331E-02

9.6362727E-03 1.4103325E-03

$0.1297920 \quad 5.3637575 E-02$

7.4851378E-03 5.6227304E-02

7.1975842E-02 6.0246613E-02

3.9767893E-04 7.8546464E-02

$0.1267434 \quad 4.3185066 \mathrm{E}-02$

1.7169040E-02 3.8028657E-02

$1.1717744 \mathrm{E}-02 \quad 6.0267188 \mathrm{E}-02$

$2.5022475 \mathrm{E}-03 \quad 7.1386263 \mathrm{E}-02$

$2.8072709 \mathrm{E}-02 \quad 3.6606077 \mathrm{E}-02$

8.4042564E-02 2.4940511E-02

$3.6001012 \mathrm{E}-02 \quad 1.9995760 \mathrm{E}-02$

4.6982206E-03 4.1722868E-02

$1.1233456 \mathrm{E}-02 \quad 7.1409829 \mathrm{E}-02$

4.3577466E-02 3.5525009E-02

7.6863907E-02 6.3962050E-02

4.2035021E-02 6.0748342E-02
9.5153023E-03 0.1135739

$1.3199417 \mathrm{E}-02 \quad 7.3137805 \mathrm{E}-02$

$0.1678364 \quad 1.6668446 \mathrm{E}-02$

3.6986031E-02 6.3447930E-02

$0.1057777 \quad 4.8246510 \mathrm{E}-02$

4.0126458E-04 5.1750962E-02

$0.1166051 \quad 8.0631763 \mathrm{E}-02$

9.2176422E-03 5.7477903E-02

$0.1591447 \quad 4.3792546 \mathrm{E}-02$

7.9803653E-02 4.5938723E-02

6.8583310E-02 4.3378543E-02

3.3945039E-02 3.2092944E-02

$1.5667401 \mathrm{E}-02 \quad 7.0161469 \mathrm{E}-02$

1.2216034E-02 3.7499879E-02

$2.6205523 E-02 \quad 0.1016790$

0.1345783

5.8055867E-02

$2.7402056 \mathrm{E}-02 \quad 2.1080213 \mathrm{E}-02$

$5.2395917 \mathrm{E}-02 \quad 0.1310989$

9.7891323E-02 5.1882077E-02

8.9353189E-02 8.482530OE-02

$2.7940512 \mathrm{E}-02 \quad 7.4167669 \mathrm{E} 02$

$5.0494056 \mathrm{E}-02 \quad 7.5886257 \mathrm{E} 02$

9.0468293E-03 3.9250501E-02

0.2264951

0.1131693

5.8889549E-02 6.8122149E-02

$1.8761925 \mathrm{E}-03 \quad 5.3185504 \mathrm{E}-02$

8.0460243E-02 6.2511340E-02

$5.6212086 \mathrm{E}-02 \quad 4.4533499 \mathrm{E}-02$

$0.1232555 \quad 4.9721505 \mathrm{E}-02$

L.7296594E-02 4.0684052E-02

2.5122650E-02 5.3252496E-02

$2.4814460 \mathrm{E}-02 \quad 5.1550169 \mathrm{E}-02$

$0.1282181 \quad 6.1518714 \mathrm{E}-02$

$2.2284815 \mathrm{E}-02 \quad 7.6629288 \mathrm{E}-02$

5.1063392E-02 9.5875099E-02

2.3033345E-02 7.2320491E-02

0.1255693

$5.7018407 \mathrm{E}-02$

4.9152099E-02 4.2099785E-02

0.1012888

9.5059328E-02

3.2810923E-02 6.8614222E-02

$5.5024467 \mathrm{E}-02 \quad 5.5538766 \mathrm{E}-02$

$0.1023091 \quad 0.1114717$

4.7409418E-03 6.2105045E-02

3.1449161E-02 7.2473414E-02

$3.5321389 \mathrm{E}-03 \quad 0.1433671$

2.1979650E-02 3.7572309E-02

3.2869723E-02 6.4480387E-02

$1.6251069 \mathrm{E}-02 \quad 3.8868442 \mathrm{E}-02$

$9.9207006 \mathrm{E}-02 \quad 5.0651442 \mathrm{E}-02$

0.1344099

4.9624890E-02

$1.4781847 \mathrm{E}-02 \quad 5.6478623 \mathrm{E}-02$

$7.0901610 \mathrm{E}-02 \quad 1.3658642 \mathrm{E}-02$

$1.0775675 \mathrm{E}-03 \quad 4.9721941 \mathrm{E}-02$ 


$\begin{array}{ll}2.9384814 \mathrm{E}-02 & 7.2166272 \mathrm{E}-02 \\ 9.1045044 \mathrm{E}-02 & 5.0976101 \mathrm{E}-02 \\ 2.7149079 \mathrm{E}-02 & 6.9073819 \mathrm{E}-02 \\ 0.1487750 & 4.9753133 \mathrm{E}-02 \\ 0.1281379 & 3.3494946 \mathrm{E}-02 \\ 0.2261254 & 4.8859332 \mathrm{E}-02 \\ 7.0052288 \mathrm{E}-02 & 4.7748096 \mathrm{E}-02 \\ 5.5682145 \mathrm{E}-02 & 5.8132105 \mathrm{E}-02 \\ 0.1027336 & 4.9926355 \mathrm{E}-02 \\ 1.4832543 \mathrm{E}-02 & 5.5490620 \mathrm{E}-02 \\ 5.5337563 \mathrm{E}-02 & 8.2520597 \mathrm{E}-02 \\ 6.2655270 \mathrm{E}-02 & 3.8574792 \mathrm{E}-02 \\ 4.0548373 \mathrm{E}-02 & 6.3032411 \mathrm{E}-02 \\ 6.2372845 \mathrm{E}-02 & 7.3105752 \mathrm{E}-02 \\ 6.0694687 \mathrm{E}-02 & 6.0532637 \mathrm{E}-02 \\ 0.1315373 & 5.8275152 \mathrm{E}-02 \\ 5.6101017 \mathrm{E}-02 & 5.1635120 \mathrm{E}-02 \\ 0.1784956 & 4.4583969 \mathrm{E}-02 \\ 1.0766561 \mathrm{E}-02 & 6.2380012 \mathrm{E}-02 \\ 4.4256584 \mathrm{E}-03 & 3.2339543 \mathrm{E}-02 \\ 0.1317025 & 0.1138625 \\ 0.1184175 & 7.8903660 \mathrm{E}-02 \\ 8.3891869 \mathrm{E}-02 & 7.8740507 \mathrm{E}-02 \\ 1.3691519 \mathrm{E}-02 & 3.7798133 \mathrm{E}-02 \\ 0.1829110 & 4.5573011 \mathrm{E}-02 \\ 1.2218891 \mathrm{E}-02 & 3.7880022 \mathrm{E}-02 \\ 3.5861585 \mathrm{E}-02 & 5.3079080 \mathrm{E}-02 \\ 3.0800391 \mathrm{E}-03 & 5.3664945 \mathrm{E}-02 \\ 3.8509235 \mathrm{E}-02 & 4.5091420 \mathrm{E}-02 \\ 8.6480059 \mathrm{E}-02 & 3.8442094 \mathrm{E}-02 \\ 3.8517248 \mathrm{E}-02 & 6.3969307 \mathrm{E}-02 \\ 2.0938128 \mathrm{E}-02 & 6.4974770 \mathrm{E}-02 \\ 6.3549548 \mathrm{E}-02 & 8.5598998 \mathrm{E} 02 \\ 7.8335539 \mathrm{E} 02 & 3.6386952 \mathrm{E}-02 \\ 6.9398761 \mathrm{E}-02 & 5.0369952 \mathrm{E}-02 \\ 3.5620485 \mathrm{E}-02 & 5.3879078 \mathrm{E} 02 \\ 5.7140426 \mathrm{E}-03 & 7.6112233 \mathrm{E}-02 \\ 4.2732999 \mathrm{E}-02 & 4.7157414 \mathrm{E}-02 \\ 1.0141055 \mathrm{E}-02 & 5.9863053 \mathrm{E}-02 \\ 5.2287020 \mathrm{E}-02 & 5.2066594 \mathrm{E}-02 \\ 0.1110769 & 6.1749782 \mathrm{E}-02 \\ 2.7594246 \mathrm{E}-02 & 5.7561927 \mathrm{E}-02 \\ 0.1713138 & 4.4933297 \mathrm{E}-02 \\ 2.2145273 \mathrm{E}-02 & 7.4739300 \mathrm{E}-02 \\ 0.1135392 & 3.7415762 \mathrm{E}-02 \\ 4.1683346 \mathrm{E}-02 & 5.8121778 \mathrm{E}-02 \\ & \end{array}$


LOSP Frequency

Attachment G-25

LHSADDITION.FOR 
C

C THIS PROGRAM READS IN TWO VALUES FROM LHSLOSP.INP, ADDS

C THEM AND OUTPUTS TO LHSLOSP.DAT.

C

PROGRAM ADDITION

DIMENSION X1(1000), X2(1000), Y(1000)

OPEN(UNIT =62,FILE = 'LHSLOSP.INP',STATUS ='OLD')

OPEN(UNIT =63,FILE = 'LHSLOSP.DAT',STATUS = 'NEW')

$\mathrm{NP}=1000$

DO $5 \mathrm{~K}=1, \mathrm{NP}$

$\operatorname{READ}(62, *) \mathrm{X} 1(\mathrm{~K}), \mathrm{X} 2(\mathrm{~K})$

5 CONTINUE

$\mathrm{Y}(\mathrm{K}) \mathrm{X}(\mathrm{K})+\mathrm{X} 2(\mathrm{~K})$

DO $15 \mathrm{~K}=1, \mathrm{NP}$

WRITE $(63,10) Y(K)$

10 FORMAT(4X,F13.7)

15 CONTINUE

END 
LOSP Frequency

Attachment G-26

LHSLOSP.DATC 


$\begin{array}{ll}0.1529599 & 0.0680313 \\ 0.1113574 & 0.0651058 \\ 0.0953622 & 0.2062465 \\ 0.3545172 & 0.0769766 \\ 0.1239482 & 0.0825347 \\ 0.0979129 & 0.1382218 \\ 0.0657493 & 0.1589348 \\ 0.1687010 & 0.1015133 \\ 0.1667969 & 0.1065434 \\ 0.0675966 & 0.0993407 \\ 0.1905878 & 0.1999383 \\ 0.2369023 & 0.1500683 \\ 0.1189780 & 0.0557724 \\ 0.0839917 & 0.0623100 \\ 0.1550420 & 0.0731258 \\ 0.0698282 & 0.1315916 \\ 0.0771309 & 0.1775653 \\ 0.0761280 & 0.0946923 \\ 0.1098688 & 0.1341559 \\ 0.0742907 & 0.1329807 \\ 0.1857869 & 0.1117974 \\ 0.0880991 & 0.1167418 \\ 0.0845420 & 0.1019084 \\ 0.0471034 & 0.0757828 \\ 0.0508785 & 0.1851247 \\ 0.1202398 & 0.0798511 \\ 0.1691805 & 0.0873910 \\ 0.0439562 & 0.1190856 \\ 0.0405930 & 0.2902308 \\ 0.1730547 & 0.2323602 \\ 0.0765381 & 0.1015917 \\ 0.2045990 & 0.1047648 \\ 0.0724743 & 0.0679737 \\ 0.2061159 & 0.1640081 \\ 0.2812203 & 0.1664532 \\ 0.0745939 & 0.1303269 \\ 0.1659922 & 0.0816958 \\ 0.1314452 & 0.1780962 \\ 0.06854444 & 0.0791179 \\ 0.2088997 & 0.1142592 \\ 0.0305766 & 0.1206729 \\ 0.0683636 & 0.0985473 \\ 0.0361587 & 0.1244387 \\ 0.0897228 & 0.0688900 \\ 0.1180685 & 0.1364971 \\ 0.1538763 & 0.1213386 \\ 0.1169174 & 0.2054951 \\ 0.0869139 & 0.0752842 \\ 0.1089153 & 0.0991243 \\ 0.1018161 & 0.0255308 \\ 0.0634172 & 0.1462613 \\ 0.1006227 & \\ 0.1312399 & \end{array}$

0.1980298

0.1156374

0.1530448

0.1156137

0.1149166

0.0917984

0.1036434

0.0602678

0.4624366

0.1892478

0.1143899

0.0897054

0.1575499

0.0655399

0.1134765

0.1373857

0.1056909

0.1068360

0.0708083

0.0644409

0.1201905

0.1768614

0.1294219

0.0662614

0.1041269

0.0891650

0.1201521

0.0795577

0.0898823

0.1756271

0.0593040

0.0696962

0.1010510

0.1570703

0.0985962

0.1310059

0.0612511

0.0728266

0.1973074

0.1078630

0.0662956

0.1113829

0.2942876

0.1515640

0.1938012

0.1681560

0.0671849

0.0421748

0.0360402

0.0505459

0.1367581

0.1620297

0.2267496
0.1902722

0.0912087

0.0798490

0.1717381

0.1056708

0.0706579

0.1269772

0.4349856

0.0721149

0.1682715

0.1095619

0.0866209

0.0763831

0.1594502

0.0229742

0.0757436

0.0444247

0.0667516

0.0578644

0.1565855

0.0989608

0.0672674

0.0657843

0.1216396

0.2788083

0.1441852

0.0520406

0.0904631

0.2207181

0.0573224

0.0532890

0.0675152

0.2009880

0.1295188

0.2267264

0.1330754

0.2023341

0.1182387

0.0773607

0.0610048

0.0649282

0.0866646

0.1649501

0.0853683

0.1067292

0.0916753

0.0877265

0.2714211

0.7631389

0.0727497

0.0466204

0.1744305

0.1499878
0.1219071

0.0811165

0.2029521

0.1505566

0.0456488

0.0311952

0.1414734

0.1178413

0.1712139

0.2293047

0.1442924

0.2156008

0.1012498

0.1545732

0.1739320

0.2749732

0.1586397

0.1412045

0.1725852

0.0593465

0.0881133

0.0690428

0.0752417

0.0986243

0.1168848

0.1119068

0.1420113

0.0987779

0.0952239

0.1159761

0.0800898

0.1714863

0.1228420

0.0608976

0.1845828

0.0544038

0.1329461

0.1699613

0.1267728

0.0832337

0.0999843

0.3051209

0.1532348

0.2319201

0.0989431

0.1355968

0.1589498

0.2317530

0.1581365

0.0828389

0.1413040

0.1789128

0.3942384 
LOSP Frequency

\begin{tabular}{|c|c|c|c|c|}
\hline 0.1634511 & 0.0661915 & 0.0522684 & 0.0604136 & 0.0704613 \\
\hline 0.0725455 & 0.1559592 & 0.1181627 & 0.8632845 & 0.1388359 \\
\hline 0.1712442 & 0.1386466 & 0.0611883 & 0.1433026 & 0.0753994 \\
\hline 0.1259277 & 0.0856829 & 0.0998502 & 0.1452927 & 0.0993625 \\
\hline 0.0496658 & 0.1637514 & 0.1022705 & 0.1306441 & 0.0510984 \\
\hline 0.1461968 & 0.1211438 & 0.0497205 & 0.2667870 & 0.1604180 \\
\hline 0.1964381 & 0.0845856 & 0.1028626 & 0.0901956 & 0.2479000 \\
\hline 0.0913003 & 0.1451379 & 0.0480013 & 0.0627726 & 0.1843886 \\
\hline 0.0465125 & 0.2576471 & 0.1219322 & 0.0516668 & 0.1361420 \\
\hline 0.1372069 & 0.1517480 & 0.0982664 & 0.1458451 & 0.0393297 \\
\hline 0.1621544 & 0.0984650 & 0.1136351 & 0.0411881 & 0.2080583 \\
\hline 0.1043275 & 0.1515275 & 0.0938734 & 0.0832981 & 0.1903313 \\
\hline 0.0886278 & 0.0734372 & 0.1418285 & 0.0733320 & 0.0824425 \\
\hline 0.0515328 & 0.1498297 & 0.2228790 & 0.0644262 & 0.1006118 \\
\hline 0.1091395 & 0.1249839 & 0.0916417 & 0.0907970 & 0.0965631 \\
\hline 0.2584388 & 0.0825758 & 0.2399204 & 0.0955510 & 0.1095381 \\
\hline 0.1773244 & 0.0588097 & 0.0670747 & 0.1809598 & 0.0639270 \\
\hline 0.1560939 & 0.1445692 & 0.0475095 & 0.0829133 & 0.0969717 \\
\hline 0.1775610 & 0.0994688 & 0.1610862 & 0.1235693 & 0.2106814 \\
\hline 0.3869033 & 0.0876801 & 0.1423551 & 0.0841773 & 0.0724215 \\
\hline 0.1711754 & 0.1282867 & 0.0764955 & 0.0953126 & 0.1771941 \\
\hline 0.1127294 & 0.1453538 & 0.1196053 & 0.0219668 & 0.0735023 \\
\hline 0.1833781 & 0.2666030 & 0.1205824 & 0.1039249 & 0.1161508 \\
\hline 0.3600698 & 0.2554108 & 0.1304909 & 0.0626890 & 0.0683045 \\
\hline 0.0891437 & 0.0447289 & 0.1098721 & 0.0701507 & 0.1268118 \\
\hline 0.1355037 & 0.1649453 & 0.0433519 & 0.1578522 & 0.0545674 \\
\hline 0.0958991 & 0.1331583 & 0.0564005 & 0.2298626 & 0.1120234 \\
\hline 0.2080095 & 0.0569619 & 0.0688891 & 0.1040858 & 0.0706490 \\
\hline 0.0738918 & 0.0816054 & 0.0853570 & 0.2114401 & 0.0715758 \\
\hline 0.0859673 & 0.1057321 & 0.1870366 & 0.1506780 & 0.0695275 \\
\hline 0.0830497 & 0.1180695 & 0.1003828 & 0.0480800 & 0.0662245 \\
\hline 0.1257122 & 0.0725754 & 0.0849465 & 0.1027419 & 0.1128537 \\
\hline 0.0541463 & 0.0703858 & 0.1620107 & 0.0934230 & 0.1834555 \\
\hline 0.1735342 & 0.3084569 & 0.1421620 & 0.1559750 & 0.0781155 \\
\hline 0.1172849 & 0.1700428 & 0.1685149 & 0.0987635 & 0.0725119 \\
\hline 0.1161663 & 0.0953916 & 0.1232848 & 0.1691087 & 0.1389102 \\
\hline 0.1176829 & 0.1067199 & 0.1360154 & 0.1241114 & 0.1025935 \\
\hline 0.0595449 & 0.1024398 & 0.0458117 & 0.1360135 & 0.3557552 \\
\hline 0.1815900 & 0.1118672 & 0.0487709 & 0.1205463 & 0.1291952 \\
\hline 0.0604068 & 0.1472396 & 0.1050218 & 0.0493597 & 0.1519220 \\
\hline 0.0817459 & 0.1740083 & 0.1666806 & 0.1389208 & 0.0347910 \\
\hline 0.0950503 & 0.1113288 & 0.1178365 & 0.1553201 & 0.0876125 \\
\hline 0.2619295 & 0.0278963 & 0.1600997 & 0.0997337 & 0.0791917 \\
\hline 0.0646664 & 0.1614659 & 0.0807719 & 0.0466013 & 0.1175123 \\
\hline 0.0969429 & 0.1520842 & 0.1865747 & 0.0709971 & 0.0646396 \\
\hline 0.0800892 & 0.0727995 & 0.0611124 & 0.0868578 & 0.0602080 \\
\hline 0.0771621 & 0.1094525 & 0.0759394 & 0.0999742 & 0.0399627 \\
\hline 0.0554796 & 0.1290217 & 0.1307501 & 0.1057049 & 0.1956170 \\
\hline 0.1814402 & 0.1596932 & 0.0933574 & 0.1851032 & 0.0846239 \\
\hline 0.1550236 & 0.1131499 & 0.1840284 & 0.1247750 & 0.0994845 \\
\hline 0.1492386 & 0.1915890 & 0.0624078 & 0.0437720 & 0.0434480 \\
\hline 0.1094835 & 0.1598586 & 0.0828862 & 0.1519290 & 0.2172148 \\
\hline 0.0950430 & 0.1449003 & 0.0928975 & 0.2537899 & 0.0721115 \\
\hline
\end{tabular}




\begin{tabular}{|c|c|c|c|c|}
\hline 0.0648862 & 0.1513215 & 0.1100820 & 0.0506222 & 0.1835743 \\
\hline 0.1653788 & 0.0704913 & 0.0775717 & 0.0564364 & 0.0908591 \\
\hline 0.0962065 & 0.1141440 & 0.0654057 & 0.1528857 & 0.2825304 \\
\hline 0.0723423 & 0.2521617 & 0.0366511 & 0.1410642 & 0.1324202 \\
\hline 0.1156534 & 0.0446690 & 0.0714557 & 0.0649848 & 0.1001768 \\
\hline 0.1726190 & 0.0616722 & 0.1122508 & 0.0962413 & 0.0812727 \\
\hline 0.1363990 & 0.0951492 & 0.2003225 & 0.0860416 & 0.0561331 \\
\hline 0.0651056 & 0.2100266 & 0.1174452 & 0.2337769 & 0.1530389 \\
\hline 0.1271043 & 0.2390410 & 0.2388454 & 0.0648604 & 0.1036628 \\
\hline 0.0516881 & 0.0961891 & 0.0153775 & 0.1844243 & 0.1889701 \\
\hline 0.0414402 & 0.1286206 & 0.0256159 & 0.1330300 & 0.0741675 \\
\hline 0.0693319 & 0.0757137 & 0.1178731 & 0.1219815 & 0.0722103 \\
\hline 0.2840304 & 0.0873933 & 0.3111386 & 0.1065388 & 0.2615932 \\
\hline 0.1431274 & 0.0719740 & 0.1645320 & 0.0849376 & 0.0790505 \\
\hline 0.0995066 & 0.0885191 & 0.1033483 & 0.1639630 & 0.1496975 \\
\hline 0.1644632 & 0.1296790 & 0.0677327 & 0.1017423 & 0.4779142 \\
\hline 0.0795531 & 0.1075818 & 0.1958109 & 0.1378213 & 0.0952957 \\
\hline 0.1194447 & 0.1299378 & 0.1106704 & 0.0614684 & 0.0868605 \\
\hline 0.1675978 & 0.1395864 & 0.0795248 & 0.1987393 & 0.0820879 \\
\hline 0.1550352 & 0.1022440 & 0.0730418 & 0.1204421 & 0.0837131 \\
\hline 0.0687043 & 0.0480115 & 0.0844716 & 0.1242097 & 0.1559919 \\
\hline 0.1199954 & 0.0666426 & 0.0880439 & 0.2111915 & 0.1872189 \\
\hline 0.1168577 & 0.1546937 & 0.1198736 & 0.0967788 & 0.2231982 \\
\hline 0.1233927 & 0.1289238 & 0.2441580 & 0.0794339 & 0.1200421 \\
\hline 0.0716485 & 0.1443840 & 0.0822132 & 0.1491313 & 0.1922144 \\
\hline 0.1024968 & 0.1681126 & 0.0528925 & 0.1260059 & 0.1513263 \\
\hline 0.0296712 & 0.1130332 & 0.1768128 & 0.1389299 & 0.0808931 \\
\hline 0.1433429 & 0.0979117 & 0.1093961 & 0.1150174 & 0.1216672 \\
\hline 0.1733654 & 0.0961331 & 0.2217353 & 0.1488213 & 0.1172427 \\
\hline 0.1627083 & 0.0759900 & 0.0929559 & 0.0313936 & 0.2644918 \\
\hline 0.0565090 & 0.1686962 & 0.2745101 & 0.1843734 & 0.1336180 \\
\hline 0.0838821 & 0.1585404 & 0.0928425 & 0.1507306 & 0.1990189 \\
\hline 0.1492888 & 0.1419460 & 0.1168013 & 0.1207787 & 0.1042991 \\
\hline 0.1643533 & 0.0974059 & 0.1169938 & 0.0981405 & 0.0436948 \\
\hline 0.0570155 & 0.0495620 & 0.1995827 & 0.0513052 & 0.0961192 \\
\hline 0.1384153 & 0.0719640 & 0.0415374 & 0.1032936 & 0.1059905 \\
\hline 0.0447353 & 0.0868506 & 0.0666171 & 0.1792727 & 0.0553787 \\
\hline 0.1276157 & 0.1341597 & 0.0749637 & 0.0796101 & 0.1179634 \\
\hline 0.1581283 & 0.1263335 & 0.1123586 & 0.1042155 & 0.1895437 \\
\hline 0.1297168 & 0.0938701 & 0.0485797 & 0.0637759 & 0.1266404 \\
\hline 0.1491215 & 0.0599025 & 0.1674144 & 0.0952476 & 0.0850594 \\
\hline 0.1874836 & 0.2279091 & 0.1660998 & 0.1797801 & 0.1524067 \\
\hline 0.0244328 & 0.0988823 & 0.1085103 & 0.1051159 & 0.2345703 \\
\hline 0.0673094 & 0.0504778 & 0.0634237 & 0.0519935 & 0.1082422 \\
\hline 0.1471961 & 0.1737060 & 0.0468753 & 0.2987740 & 0.1912496 \\
\hline 0.0579682 & 0.0825657 & 0.2516221 & 0.0913628 & 0.0734073 \\
\hline 0.1547990 & 0.1191792 & 0.0764939 & 0.1250579 & 0.0836055 \\
\hline 0.2280843 & 0.1878224 & 0.0489549 & 0.1303810 & 0.1217391 \\
\hline 0.1854318 & 0.0912303 & 0.0815092 & 0.1376802 & 0.0468097 \\
\hline 0.0506759 & 0.0508766 & 0.2542015 & 0.0685228 & 0.3032024 \\
\hline 0.2883647 & 0.0891956 & 0.2412788 & 0.0824764 & 0.1328798 \\
\hline 0.1047553 & 0.0911235 & 0.2120996 & 0.1346677 & 0.0454702 \\
\hline 0.0869575 & 0.0618071 & 0.1822601 & 0.0495141 & 0.1684363 \\
\hline
\end{tabular}


LOSP Frequency

\begin{tabular}{|c|c|c|c|}
\hline 0.1044607 & 0.2466137 & 0.1230892 & 0.1015511 \\
\hline 0.0857147 & 0.1039498 & 0.0863372 & 0.1420211 \\
\hline 0.1024142 & 0.0719585 & 0.1845049 & 0.0962229 \\
\hline 0.1507974 & 0.1267267 & 0.1004340 & 0.1985281 \\
\hline 0.2329933 & 0.1366243 & 0.1540242 & 0.1616329 \\
\hline 0.0982563 & 0.1849795 & 0.0521522 & 0.2749847 \\
\hline 0.0659564 & 0.0728344 & 0.1972369 & 0.1178004 \\
\hline 0.2113485 & 0.1081679 & 0.0666955 & 0.1138142 \\
\hline 0.1209380 & 0.0761368 & 0.2029372 & 0.1526600 \\
\hline 0.0504630 & 0.1228808 & 0.1257424 & 0.0703232 \\
\hline 0.1017613 & 0.1656798 & 0.1119619 & 0.1378582 \\
\hline 0.1428723 & 0.0946541 & 0.0660380 & 0.1012301 \\
\hline 0.0661078 & 0.0809466 & 0.0858289 & 0.1035808 \\
\hline 0.1947909 & 0.0798622 & 0.0497159 & 0.1354786 \\
\hline 0.0735072 & 0.0908386 & 0.1278845 & 0.1212273 \\
\hline 0.0632593 & 0.0869720 & 0.1926342 & 0.1898125 \\
\hline 0.0237438 & 0.0857774 & 0.0484823 & 0.1077361 \\
\hline 0.0751570 & 0.0702408 & 0.1834948 & 0.2230796 \\
\hline 0.0967088 & 0.0698282 & 0.1497734 & 0.0731466 \\
\hline 0.0746528 & 0.0808209 & 0.1741785 & 0.0367652 \\
\hline 0.1050871 & 0.0143378 & 0.1021082 & 0.2455650 \\
\hline 0.1474795 & 0.0964187 & 0.1263803 & 0.1973212 \\
\hline 0.0885288 & 0.0471269 & 0.0482973 & 0.1626324 \\
\hline 0.1856342 & 0.1780712 & 0.3396644 & 0.0514897 \\
\hline 0.1806822 & 0.0392971 & 0.1270117 & 0.2284840 \\
\hline 0.0420705 & 0.0808970 & 0.0550617 & 0.0500989 \\
\hline 0.0680560 & 0.0804311 & 0.1429716 & 0.0889407 \\
\hline 0.1332481 & 0.0786512 & 0.1007456 & 0.0567450 \\
\hline 0.0703024 & 0.2835082 & 0.1729770 & 0.0836007 \\
\hline 0.0866317 & 0.2055806 & 0.0579806 & 0.1249222 \\
\hline 0.1951684 & 0.2359689 & 0.0783751 & 0.1024866 \\
\hline 0.1868208 & 0.3322215 & 0.0763646 & 0.0859129 \\
\hline 0.0892943 & 0.1684363 & 0.1897368 & 0.1491486 \\
\hline 0.1188134 & 0.2488653 & 0.0989141 & 0.1147225 \\
\hline 0.2354424 & 0.0528076 & 0.1469385 & 0.1197687 \\
\hline 0.0542202 & 0.0677852 & 0.0953538 & 0.0894996 \\
\hline 0.0848251 & 0.0110466 & 0.1825877 & 0.0818263 \\
\hline 0.2965599 & 0.1834296 & 0.0912519 & 0.0898904 \\
\hline 0.0839143 & 0.0637124 & 0.1963481 & 0.0700041 \\
\hline 0.1811073 & 0.1322225 & 0.1014251 & 0.1043536 \\
\hline 0.2170888 & 0.0789441 & 0.1105632 & 0.1728267 \\
\hline 0.0807678 & 0.1699285 & 0.2137808 & 0.0851562 \\
\hline 0.1508033 & 0.0551977 & 0.0668460 & 0.2162471 \\
\hline 0.0956269 & 0.0719849 & 0.1039226 & 0.0968846 \\
\hline 0.2878740 & 0.0738885 & 0.1468992 & 0.1509550 \\
\hline 0.1537835 & 0.0646788 & 0.0595520 & 0.0998051 \\
\hline 0.2595707 & 0.1089831 & 0.0973501 & \\
\hline 0.0701851 & 0.0559968 & 0.0551195 & \\
\hline 0.1054350 & 0.0464211 & 0.1498584 & \\
\hline 0.1050477 & 0.0826433 & 0.1840348 & \\
\hline 0.2965948 & 0.0791025 & 0.0712605 & \\
\hline 0.1425834 & 0.1408260 & 0.0845603 & \\
\hline 0.1998627 & 0.1027834 & 0.0507995 & \\
\hline
\end{tabular}


LOSP Frequency

Attachment G27

REMOVECOL.FOR

Vol. 2, Part 2

G-127

NUREG/CR-6143 


\section{LOSP Frequency}

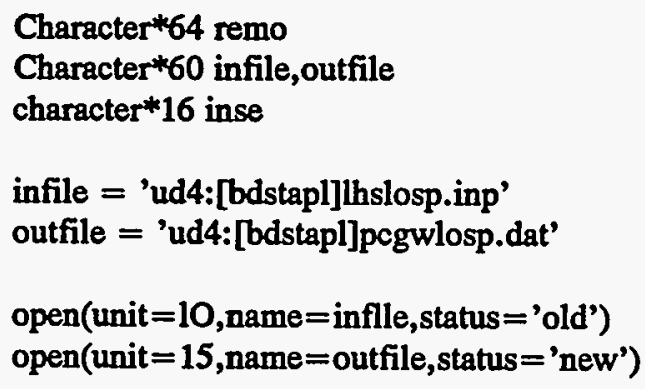

$25 \operatorname{read}(10,20$, end $=50)$ inse, remo

20 format(a,a) write(15,30)inse

30 format(a)

goto 25

$50 \quad \operatorname{close}(10$

close(15

end 
Attachment G-28

PCGWLOSP.DAT 
LOSP Frequency

\begin{tabular}{|c|c|c|}
\hline 9.5802836E-02 & $6.3890698 \mathrm{E}-03$ & 0.1619431 \\
\hline $5.0940670 \mathrm{E}-02$ & $1.1955368 \mathrm{E}-02$ & $6.5522656 \mathrm{E}-02$ \\
\hline 3.7110481E-02 & $2.0493850 \mathrm{E}-02$ & $9.9551871 \mathrm{E}-02$ \\
\hline 0.3011881 & $3.9378010 \mathrm{E}-02$ & $3.2978956 \mathrm{E}-02$ \\
\hline $6.8660229 \mathrm{E}-02$ & $3.5381936 \mathrm{E}-02$ & $5.2812852 \mathrm{E}-02$ \\
\hline 4.1418765E-02 & $6.2365174 \mathrm{E}-02$ & 4.1240700E-02 \\
\hline $3.8164826 \mathrm{E}-03$ & $6.9060028 \mathrm{E}-02$ & $7.0628084 \mathrm{E}-02$ \\
\hline 7.3756211E-02 & 4.4734307E-02 & $3.2155325 \mathrm{E}-03$ \\
\hline 0.1116926 & $4.3982375 E-02$ & 0.2955990 \\
\hline 8.3901752E-03 & $6.0694963 \mathrm{E}-02$ & 0.1707724 \\
\hline 2.1001803E-04 & $9.1746241 E-02$ & 5.5750683E-02 \\
\hline 0.1984308 & 1.2195393E-02 & $3.3989530 \mathrm{E}-02$ \\
\hline $6.1446220 \mathrm{E}-02$ & $9.7427778 \mathrm{E}-03$ & $9.6589506 \mathrm{E}-02$ \\
\hline $1.3037866 \mathrm{E}-02$ & $1.9653393 \mathrm{E}-02$ & $4.4756867 \mathrm{E}-02$ \\
\hline $8.6331956 \mathrm{E}-02$ & 3.1145809E-02 & 7.3829912E-02 \\
\hline 3.7155967E-02 & $7.1229465 \mathrm{E}-02$ & 0.1215877 \\
\hline 3.2555930E-02 & $5.5966739 \mathrm{E}-02$ & 8.4925257E-02 \\
\hline $4.5071386 \mathrm{E}-02$ & $2.9009812 E-02$ & $5.1617451 \mathrm{E}-02$ \\
\hline $6.3797474 \mathrm{E}-02$ & 7.5244442E-02 & $1.6678156 \mathrm{E}-02$ \\
\hline $4.3774538 \mathrm{E}-02$ & $7.8743502 E-02$ & $1.7280921 \mathrm{E}-02$ \\
\hline 0.1065058 & $5.0527163 \mathrm{E}-02$ & $6.1498184 \mathrm{E}-02$ \\
\hline $5.5102311 \mathrm{E}-02$ & $3.1681322 E-02$ & 0.1538038 \\
\hline 3.5599325E-02 & $5.1817849 E-02$ & $7.0079938 \mathrm{E}-02$ \\
\hline 2.0490789E-03 & $5.0831504 \mathrm{E}-02$ & $4.6549104 \mathrm{E}-02$ \\
\hline $2.5542006 \mathrm{E}-02$ & 0.1170508 & 8.5495159E-02 \\
\hline 4.6561282E-02 & $3.0360568 E-02$ & $2.9121149 \mathrm{E}-02$ \\
\hline 9.7525999E-02 & 3.7065927E-02 & $5.2379847 \mathrm{E}-02$ \\
\hline 3.6980748E-02 & $8.4724374 E-02$ & $2.2424161 \mathrm{E}-02$ \\
\hline $3.8461756 \mathrm{E}-02$ & 0.2172877 & $1.4448942 \mathrm{E}-02$ \\
\hline 0.1308402 & 0.1707056 & 0.1259440 \\
\hline $1.5121906 \mathrm{E}-02$ & $4.1157823 \mathrm{E}-02$ & $2.1840738 E-02$ \\
\hline 0.1576969 & $4.6242714 \mathrm{E}-02$ & $4.6944050 \mathrm{E}-03$ \\
\hline 1.1520608E-02 & $7.8710178 \mathrm{E}-03$ & $6.5334700 \mathrm{E}-02$ \\
\hline 0.1065259 & 8.4139876E-02 & 0.1371043 \\
\hline 0.1838354 & $9.9810176 \mathrm{E}-02$ & $1.6964525 \mathrm{E}-02$ \\
\hline 2.3105722E-02 & $5.6254819 \mathrm{E}-02$ & 0.1015151 \\
\hline $7.8000881 \mathrm{E}-02$ & $4.5131359 \mathrm{E}-02$ & $1.8315334 \mathrm{E}-02$ \\
\hline $8.4191918 \mathrm{E}-02$ & 0.1175776 & $3.3113606 \mathrm{E}-02$ \\
\hline 3.0882679E-02 & $2.3901181 E-02$ & 0.1321511 \\
\hline 0.1168672 & $6.8641901 \mathrm{E}-02$ & $4.2373762 E-02$ \\
\hline $6.9784876 \mathrm{E}-03$ & $8.4755734 \mathrm{E}-02$ & $7.2913952 \mathrm{E}-03$ \\
\hline 2.8681975E-02 & 4.7624674E-02 & $6.3795552 \mathrm{E}-02$ \\
\hline 2.7508037E-02 & $7.6687358 \mathrm{E}-02$ & 0.2103213 \\
\hline 5.7893977E-02 & $6.1508259 E-03$ & 0.1109417 \\
\hline 8.7122709E-02 & 6.9542497E-02 & 0.1395433 \\
\hline 4.0420175E-02 & $5.0025929 \mathrm{E}-02$ & 4.7899157E-02 \\
\hline $6.7433029 \mathrm{E}-02$ & 7.6181762E-02 & $6.8555456 \mathrm{E}-03$ \\
\hline $3.1565614 \mathrm{E}-02$ & 4.7242548E-02 & 4.7816616E-03 \\
\hline $6.2981918 \mathrm{E}-02$ & 5.1474594E-02 & 1.3575777E-02 \\
\hline 3.6439944E-02 & 1.6576273E-02 & $3.7566062 \mathrm{E}-02$ \\
\hline $2.3256298 \mathrm{E}-03$ & 3.3260591E-02 & $9.9475965 \mathrm{E}-02$ \\
\hline $3.7388284 \mathrm{E}-02$ & $5.7211630 \mathrm{E}-02$ & 0.1179500 \\
\hline $4.9667925 \mathrm{E}-02$ & $9.6157566 \mathrm{E}-02$ & 0.1407464 \\
\hline
\end{tabular}

0.1213369

4.5888089E-03

7.6253237E-03

0.1213599

5.0322939E-02

5.3692952E-02

$6.8447582 \mathrm{E}-02$

0.3917790

5.7127774E-02

8.3935164E-02

$5.8236878 \mathrm{E}-02$

2.7824761E-02

1.0342170E-02

0.1130472

1.9324374E-03

$2.1123756 \mathrm{E}-02$

$7.3582875 \mathrm{E}-03$

8.1938533E-03

3.8392141E-03

0.1114586

3.7242990E-02

1.9190241E-02

$2.3559626 \mathrm{E}-02$

$6.7579068 \mathrm{E}-02$

0.1495474

8.7243997E-02

3.9188843E-03

2.0487398E-02

0.1687348

$1.9494988 \mathrm{E}-02$

3.1080063E-02

3.3260230E-02

0.1394177

4.6089880E-02

0.1716556

5.3486563E-02

4.7258500E-02

3.3940416E-02

2.1830970E-02

4.0602647E-03

$1.0020436 \mathrm{E}-02$

3.7182402E-02

4.2706481E-03

3.1993993E-02

$7.7867016 \mathrm{E}-02$

4.5282654E-02

2.3415735E-02

0.2160491

$6.4673787 \mathrm{E}-03$

$1.7433336 \mathrm{E}-02$

2.2904482E-05

0.1147942

7.6124631E-02
5.3303089E-02

5.0968453E-02

0.1519960

9.9529408E-02

$1.2661025 \mathrm{E}-02$

1.1452804E-02

5.9550323E-02

8.4897578E-02

0.1265632

0.1636941

7.2806217E-02

9.7682148E-02

4.3897450E-02

5.3755235E-02

7.2366193E-02

0.2446719

8.7504514E-02

6.1651595E-02

0.1204444

1.0141240E-02

$2.9848058 \mathrm{E}-02$

9.4402153E-03

4.3066703E-03

8.8652149E-03

8.2147315E-02

8.9766808E-02

5.7522781E-02

1.9196231E-02

$3.2749761 \mathrm{E}-02$

7.4022703E-02

2.8199911E-02

0.1044558

$3.6798760 \mathrm{E}-02$

$2.8888844 \mathrm{E}-02$

0.1416059

1.1433396E-02

8.4602527E-02

0.1223382

5.3186379E-02

$9.5278546 \mathrm{E}-03$

3.6003832E-02

0.2368298

9.8380804E-02

0.1627849

4.3205872E-02

7.780972IE-02

9.2956319E-02

0.1799912

5.3744238E-02

2.3056671E-02

$6.4727686 \mathrm{E}-02$

0.1216711

0.3209038 


\begin{tabular}{ll}
0.1101487 & $1.7556440 \mathrm{E}-02$ \\
$1.0786332 \mathrm{E}-02$ & $7.8613654 \mathrm{E}-02$ \\
0.1050531 & $7.6832488 \mathrm{E}-02$ \\
$8.6179286 \mathrm{E}-02$ & $5.3756524 \mathrm{E}-02$ \\
$7.1867579 \mathrm{E}-03$ & 0.1039997 \\
$9.5057264 \mathrm{E}-02$ & $5.1588386 \mathrm{E}-02$ \\
0.1684978 & $4.1753639 \mathrm{E}-02$ \\
$1.2539796 \mathrm{E}-02$ & $9.4200537 \mathrm{E}-02$ \\
$6.4291013 \mathrm{E}-03$ & 0.2072446 \\
$7.7832922 \mathrm{E}-02$ & $1.9067375 \mathrm{E}-02$ \\
0.1206533 & $5.2268062 \mathrm{E}-02$ \\
$5.6917291 \mathrm{E}-02$ & $9.3951240 \mathrm{E}-02$ \\
$3.6365487 \mathrm{E}-02$ & $2.5747674 \mathrm{E}-02$ \\
$7.0993602 \mathrm{E}-03$ & $9.1002814 \mathrm{E}-02$ \\
$4.3315183 \mathrm{E}-02$ & $5.2193556 \mathrm{E}-02$ \\
$7.4349679 \mathrm{E}-02$ & $1.3168592 \mathrm{E}-02$ \\
$9.5265292 \mathrm{E}-02$ & $7.8425752 \mathrm{E}-03$ \\
0.1238719 & $2.4083138 \mathrm{E}-02$ \\
$9.5689654 \mathrm{E}-02$ & $2.9606896 \mathrm{E}-02$ \\
0.2603333 & $3.2791542 \mathrm{E}-03$ \\
0.1145876 & $5.5754423 \mathrm{E}-02$ \\
$6.2036499 \mathrm{E}-02$ & $1.9297315 \mathrm{E}-02$ \\
0.1287113 & 0.1221153 \\
$7.6434948 \mathrm{E}-02$ & 0.1836627 \\
$3.7384395 \mathrm{E}-02$ & $2.6211066 \mathrm{E}-02$ \\
$5.5710252 \mathrm{E}-02$ & 0.1165744 \\
$3.0785400 \mathrm{E}-02$ & $7.7690028 \mathrm{E}-02$ \\
0.1471515 & $8.6576715 \mathrm{E}-03$ \\
$1.6241783 \mathrm{E}-02$ & $3.0842939 \mathrm{E}-02$ \\
$5.5924322 \mathrm{E}-02$ & $3.4306709 \mathrm{E}-02$ \\
$3.6231801 \mathrm{E}-02$ & $8.0743775 \mathrm{E}-02$ \\
$5.1834852 \mathrm{E}-02$ & $1.8435411 \mathrm{E}-02$ \\
$1.3616041 \mathrm{E}-02$ & $3.2321534 \mathrm{E}-03$ \\
0.1356705 & $4.0109031 \mathrm{E}-02$ \\
$6.1036717 \mathrm{E}-02$ & $7.1211591 \mathrm{E}-02$ \\
$3.2080885 \mathrm{E}-02$ & $4.9363904 \mathrm{E}-02$ \\
$6.3935861 \mathrm{E}-02$ & $3.8666770 \mathrm{E}-02$ \\
$8.4782112 \mathrm{E}-03$ & $5.1464181 \mathrm{E}-02$ \\
0.1483902 & $2.9909359 \mathrm{E}-02$ \\
$1.6334236 \mathrm{E}-02$ & $8.5642956 \mathrm{E}-02$ \\
$1.6464649 \mathrm{E}-02$ & 0.1428766 \\
$3.3093113 \mathrm{E}-02$ & $6.8073608 \mathrm{E}-02$ \\
0.1980580 & $3.6340430 \mathrm{E}-03$ \\
$3.2279663 \mathrm{E}-02$ & $9.6433230 \mathrm{E}-02$ \\
$7.2981618 \mathrm{E}-02$ & 0.1015370 \\
$1.0505857 \mathrm{E}-02$ & $4.2306870 \mathrm{E}-02$ \\
$2.7589556 \mathrm{E}-02$ & $8.6678125 \mathrm{E}-02$ \\
$9.8100808 \mathrm{E}-03$ & $8.0561943 \mathrm{E}-02$ \\
7.1137452 & $3.5065666 \mathrm{E}-02$ \\
$4.49149722 \mathrm{E}-02$ & $5.6423653 \mathrm{E}-02$ \\
& $9.1383748 \mathrm{E}-02$ \\
\hline $.028 \mathrm{E}-02$ & $9.0465531 \mathrm{E}-02$ \\
\hline & $8.2488284 \mathrm{E}-02$ \\
&
\end{tabular}

0.1101487

0.1050531

8.6179286E-02

$1.2539796 \mathrm{E}-02$

6.4291013E-03

7.7832922E-02

0.1206533

5.6917291E-02

$3.6365487 \mathrm{E}-02$

7.0993602E-03

4.3315183E-02

$7.4349679 \mathrm{E}-02$

-

9.5689654E-02

0.2603333

0.1145876

6.2036499E-02

0.1287113

$3.0785400 \mathrm{E}-02$

0.1471515

$1.6241783 \mathrm{E}-02$

$5.5924322 \mathrm{E}-02$

3.6231801E-02

$5.1834852 \mathrm{E}-02$

$1.3616041 \mathrm{E}-02$

0.1356705

$8.4782112 \mathrm{E}-03$

0.1483902

$1.6334236 \mathrm{E}-02$

$1.6464649 \mathrm{E}-02$

3.3093113E-02

0.1980580

3. $2279663 \mathrm{E}-02$

$2.7589556 \mathrm{E}-02$

9.8100808E-03

0.1137452

7.2744422E-02

4.4912171E-02

Vol. 2, Part 2
5.7035097E-04

4.2432569E-02

1.4777359E-02

3.2787994E-02

$5.1232055 \mathrm{E}-02$

$5.4714889 \mathrm{E}-03$

2.0广41522E-02

8.3291810E-04

9.0837017E-02

2.3047213E- 02

4.1621886E-02

$3.9833665 \mathrm{E}-02$

9.0728611E-02

0.1397989

4.4620942E-02

0.1943297

3.5363667E-02

$6.8349316 \mathrm{E}-04$

0.1459142

8.0266237E-02

$1.9203138 \mathrm{E}-02$

7.1140945E-02

5.2328020E-02

7.3376082E-02

$6.3577600 \mathrm{E}-02$

$1.2584946 \mathrm{E}-03$

$1.5184088 \mathrm{E}-02$

$2.0581085 \mathrm{E}-02$

2.4160979E-02

0.1186002

6.6469684E-02

3.7167817E-02

0.1164728

$5.5276338 \mathrm{E}-02$

0.1067105

$6.9141306 \mathrm{E}-02$

8.5148111E-02

$1.0854620 \mathrm{E}-02$

$7.3132701 \mathrm{E}-03$

$3.9495885 \mathrm{E}-02$

0.1621865

2.7274314E-02

9.4924212E-02

$7.8715859 \mathrm{E}-03$

7.6369330E-02

1.1159037E-02

1.6781913E-02

$9.4187953 \mathrm{E}-02$

$1.5712211 \mathrm{E}-02$

0.1357202

9.6314792E-03

$3.5887018 \mathrm{E}-02$

$6.3044518 \mathrm{E}-02$
$6.0450430 \mathrm{E}-03$

$1.9245146 \mathrm{E}-02$

$7.1171016 \mathrm{E}-02$

$6.7888290 \mathrm{E}-02$

$5.5506688 \mathrm{E}-02$

0.2476660

2.9247994E-02

$6.4376746 \mathrm{E}-03$

1.3259222E-02

9.5137425E-02

1.6477322E-02

4.0688049E-02

$2.2278026 \mathrm{E}-02$

$2.4768834 \mathrm{E}-03$

$1.9059179 \mathrm{E}-02$

4.2819299E-02

$9.5047787 \mathrm{E}-02$

2.2842348E-02

8.9984555E-03

4.0717803E-02

$1.8620146 \mathrm{E}-02$

$5.5759195 \mathrm{E}-03$

$5.9370346 \mathrm{E}-02$

$1.4559478 \mathrm{E}-02$

2.1993279E-02

3.4803309E-02

0.1713544

4.7787406E-02

0.1166827

0.1062214

1.4152073E-02

$7.3292643 \mathrm{E}-02$

3.05 1070E-02

0.1430519

$5.7888649 \mathrm{E}-02$

0.1176199

8.8838212E-02

8.3055459E-02

$7.8486003 \mathrm{E}-02$

3.7651348E-03

8.9207999E-02

0.1019203

3.8159367E-02

7.2341422E-03

2.1741793E-02

$1.7596968 \mathrm{E}-02$

4.9762029E-02

$6.2078778 \mathrm{E}-02$

0.1199143

$7.7847488 \mathrm{E}-02$

$1.0528071 \mathrm{E}-02$

$8.3635688 \mathrm{E}-02$

0.2009909
5.8667913E-02

8.5019536E-02

$3.2430448 \mathrm{E}-02$

2.9151317E-02

$2.0972826 \mathrm{E}-02$

$9.0942435 \mathrm{E}-02$

0.1594650

0.1471007

6.9947779E-02

2.9659139E-03

0.1435275

0.1113859

3.9282557E-02

6.1981261E-02

$1.9839078 \mathrm{E}-02$

$5.7827588 \mathrm{E}-02$

2.5132930E-02

4.0411420E-02

0.1284811

8.3482713E-03

0.1010389

$1.0805682 \mathrm{E}-02$

$6.1287235 \mathrm{E}-02$

4.9389787E-03

$5.8028206 \mathrm{E}-02$

$1.0797053 \mathrm{E}-02$

6.0769171E-02

2.5214817E-02

$1.1230638 \mathrm{E}-02$

2.5707522E-02

2.2795934E-02

$6.2227350 \mathrm{E}-02$

0.1672506

1.8789757E-02

2.6002435E-02

8.3665326E-02

$3.0448386 \mathrm{E}-02$

0.2885319

7.5610541E-02

0.1016252

4.5112247E-04

3.3670895E-02

$5.0228938 \mathrm{E}-02$

$6.2303629 \mathrm{E}-02$

$1.5903739 \mathrm{E}-03$

2.3061221E-02

1.7828470E-02

0.1489135

2.9991554E-02

3.8592044E-02

2.6665970E-03

0.1594036

4.8654587E-03 
LOSP Frequency

\subsection{E-02 \\ 0.1111817}

3.2693163E-02

2.7328093E-02

5.4314032E-02

0.1534035

0.1076253

$1.1158386 \mathrm{E}-02$

7.5296283E-02

$9.0385396 \mathrm{E}-03$

$1.8177083 \mathrm{E}-02$

3.4835618E-02

0.2126295

0.1055460

1.6926570E-02

9.7805411E-02

2.4215424E-02

4.6272218E-02

0.1436211

9.6115790E-02

1.8233091E-02

7.0725784E-02

8.6573020E-02

5.2638784E-02

1.2816365E-02

9.5106354E-03

2.0517757E-02

8.8717468E-02

0.1110684

0.1252603

$1.4984865 \mathrm{E}-02$

4.1367975E-03

0.1044355

0.1163967

6.4864228E-03

8.6171895E-02

9.6399421E-03

0.1216575

7.5110182E-02

9.4210796E-02

0.1249922

0.1011262

2.4293195E-02

6.6678897E-03

0.1111950

1.9772781E-02

0.1155881

0.1582730

0.1393309

1.4094720E-02

0.1499535

$7.1544766 \mathrm{E}-02$

3.0904636E-02
9.8734237E-02

$1.3600629 \mathrm{E}-02$

5.8635902E-02

0.1916036

4.9487189E-03

1.2524434E-06

3.2651860E-02

0.1841026

0.1599361

5.8705285E-02

6.6332571E-02

2.1626830E-02

$2.8318062 \mathrm{E}-02$

$1.5888639 \mathrm{E}-02$

3.4715347E-02

4.7073562E-02

$5.9949227 \mathrm{E}-02$

4.5089148E-02

7.4199475E-02

4.3561067E-02

7.8390967E-03

8.5252132E-03

$9.4841480 \mathrm{E}-02$

9.8654538E-02

8.2921065E-02

0.1212057

4.1389301E-02

$3.9176088 \mathrm{E}-02$

3.6713161E-02

2.6123142E-02

7.1415707E-02

0.1111227

3.3226274E-02

4.3823916E-02

2.3118341E-02

$1.5971426 \mathrm{E}-02$

1.8822059E-02

5.8292266E-02

$5.7775807 \mathrm{E}-02$

3.5423137E-02

2.9857086E-02

0.1548729

4.3557987E-02

$1.5834160 \mathrm{E}-02$

3.0191801E-02

4.0227517E-02

$6.4106800 \mathrm{E}-02$

0.1264381

5.0514825E-03

7.4786786E-03

5.6379151E-02

6.5043934E-02

2.3314461E-02
7.4765138E-02

1.7438317E-02

1.9293664E-02

1.2643554E-02

6.2489253E-04

7.2150782E-02

8.0911592E-02

4.5478538E-02

0.1769705

1.2616337E-02

7.2607398E-03

4.3000471E-02

0.2969601

0.1011943

4.0632688E-02

1.1991364E-02

0.1659063

6.7917205E-02

2.9479271E-02

2.7579788E-02

1.8036981E-04

3.4363531E-02

$7.1762465 \mathrm{E}-02$

0.1614968

2.5125390E-02

3.1458316E-05

0.1076581

2.6002066E-02

0.1655387

2.6791573E-02

0.1573987

3.7749022E-02

3.2987423E-02

7.6349050 E- 02

0.1368688

1.0591272E-02

5.0359242E-02

8.6674066E-03

2.7813993E-02

9.2147784E-06

9.7445004E-02

0.1148768

$1.2202328 \mathrm{E}-02$

1.8492657E-03

4.1577820E-02

0.1904121

$1.9257167 \mathrm{E}-02$

$6.0050576 \mathrm{E}-03$

$1.5237578 \mathrm{E}-02$

0.1926419

0.2087683

0.1375539

0.1049394
1.2667705E-02

9.5690675E-03

8.5062332E-02

8.1150882E-02

$1.4643470 \mathrm{E}-02$

8.3918739E-03

5.2297127E-02

0.1712909

3.9250352E-03

0.1462693

6.3159265E-02

$6.3968100 \mathrm{E}-02$

6.1579641E-02

3.1537369E-02

0.1300344

4.2458829E-02

$6.8499178 \mathrm{E}-02$

5.0882958E-03

0.1220675

6.1601184E-02

6.6456713E-02

0.1217265

4.7997069E-03

2.9600626E-02

0.1141646

$7.1259312 \mathrm{E}-02$

8.6525485E-02

$7.5258906 \mathrm{E}-03$

$7.5813979 \mathrm{E}-02$

1.0426432E-04

9.9009417E-02

$8.5491806 \mathrm{E}-02$

$6.9037460 \mathrm{E}-02$

4.4828497E-02

$7.9834806 \mathrm{E}-03$

4.4560567E-02

$6.5790229 \mathrm{E}-02$

2.3019051E-02

4.8554119E-02

2.3537399E-02

3.9333194E-02

6.6698194E-02

1.9953102E-02

$6.7289076 \mathrm{E}-03$

0.2049074

2.6612628E-02

$6.2301848 \mathrm{E}-02$

4.7661878E-02

0.1032232

2.2303181E-02

2.3918238E-02

8.8102572E-02

$1.0482088 \mathrm{E}-02$
0.1262614

5.1675425E-03

0.2224558

4.9047388E-02

4.1865766E-02

3.0313108E-02

$6.0838363 \mathrm{E}-03$

0.1005661

4.4937138E-02

0.1633220

4.3697253E-02

3.1902997E-03

0.2287423

3.0959342E-02

9.4964199E-02

0.4126163

$6.2819786 \mathrm{E}-02$

4.5202851E-02

1.2994861E-02

5.1764749E-02

0.1174101

0.1159837

0.1918874

9.2250086E-02

0.1249470

9.5545508E-02

1.9758463E-02

6.9996879E-02

8.2011253E-02

9.7375177E-02

9.4023019E-02

0.1476692

4.5043502E-02

$7.7810525 \mathrm{E}-03$

4.3228015E-02

4.5226362E-02

$1.1131806 \mathrm{E}-02$

7.1365029E-02

0.1534233

4.5220446E-02

4.0321246E-02

$9.2383265 \mathrm{E}-02$

0.1957802

6.2168173E-02

0.1421046

4.6885949E-02

$2.9114503 \mathrm{E}-02$

9.4231784E-02

$3.5982575 \mathrm{E}-02$

0.2368337

8.9359716E-02

$1.8088779 \mathrm{E}-03$

0.1065253 


\begin{tabular}{|c|c|c|c|}
\hline 7.3502332E-02 & 0.1753536 & $9.5153023 E-03$ & $2.9384814 \mathrm{E}-02$ \\
\hline $1.9874904 \mathrm{E}-02$ & $7.0344500 \mathrm{E}-02$ & $1.3199417 \mathrm{E}-02$ & $9.1045044 \mathrm{E}-02$ \\
\hline $4.0966433 \mathrm{E}-02$ & $1.9798214 \mathrm{E}-02$ & 0.1678364 & $2.7149079 \mathrm{E}-02$ \\
\hline 0.1398786 & 4.2904954E-02 & $3.6986031 \mathrm{E}-02$ & 0.1487750 \\
\hline 0.1679944 & 8.9058951E-02 & 0.1057777 & 0.1281379 \\
\hline $3.6314774 \mathrm{E}-02$ & 0.1282351 & $4.0126458 E-04$ & 0.2261254 \\
\hline 3.9298572E-02 & $6.3481316 \mathrm{E}-02$ & 0.1166051 & $7.0052288 \mathrm{E}-02$ \\
\hline 0.1538339 & $5.8032546 \mathrm{E}-02$ & 9.2176422E-03 & $5.5682145 \mathrm{E}-02$ \\
\hline $7.3337995 \mathrm{E}-02$ & $4.0085889 \mathrm{E}-02$ & 0.1591447 & 0.1027336 \\
\hline $3.2945636 E-03$ & $6.8856232 \mathrm{E}-02$ & $7.9803653 E-02$ & $1.4832543 \mathrm{E}-02$ \\
\hline 7.4707083E-02 & 0.1148059 & $6.8583310 E-02$ & $5.5337563 \mathrm{E}-02$ \\
\hline $3.7277136 \mathrm{E}-02$ & $3.3868130 \mathrm{E}-02$ & 3.3945039E-02 & $6.2655270 E-02$ \\
\hline 2.3415873E-03 & $1.5916673 E-02$ & $1.5667401 \mathrm{E}-02$ & 4.0548373E-02 \\
\hline 0.1363300 & $2.4237448 \mathrm{E}-02$ & $1.2216034 \mathrm{E}-02$ & $6.2372845 \mathrm{E}-02$ \\
\hline 2.7190035E-02 & $3.8375910 \mathrm{E}-02$ & $2.6205523 E-02$ & $6.0694687 \mathrm{E}-02$ \\
\hline $6.1469404 \mathrm{E}-03$ & 7.1393445E-02 & 0.1345783 & 0.1315373 \\
\hline $4.8396634 \mathrm{E}-03$ & 6.6492967E-02 & $2.7402056 \mathrm{E}-02$ & $5.6101017 \mathrm{E}-02$ \\
\hline $6.1320782 \mathrm{E}-02$ & $1.2682325 E-02$ & $5.2395917 \mathrm{E}-02$ & 0.1784956 \\
\hline $5.1850434 E-02$ & 2.5767982E-02 & $9.7891323 E-02$ & $1.0766561 \mathrm{E}-02$ \\
\hline $2.9650316 \mathrm{E}-02$ & $1.9472765 \mathrm{E}-02$ & 8.9353189E-02 & 4.4256584E-03 \\
\hline 5.2909732E-02 & $1.3780744 \mathrm{E}-02$ & $2.7940512 \mathrm{E}-02$ & 0.1317025 \\
\hline $7.2582185 E-02$ & $7.0846647 \mathrm{E}-02$ & $5.0494056 \mathrm{E}-02$ & 0.1184175 \\
\hline $2.7631711 \mathrm{E}-02$ & $3.2919362 E-02$ & $9.0468293 \mathrm{E}-03$ & $8.3891869 E-02$ \\
\hline 0.1479920 & 0.1041866 & 0.2264951 & $1.3691519 E-02$ \\
\hline $6.8155609 \mathrm{E}-02$ & $6.4161711 E-04$ & 5.8889549E-02 & 0.1829110 \\
\hline $4.8517105 \mathrm{E}-03$ & $2.7210578 \mathrm{E}-02$ & $1.8761925 \mathrm{E}-03$ & $1.2218891 \mathrm{E}-02$ \\
\hline $1.0592137 \mathrm{E}-02$ & $5.0297618 \mathrm{E}-02$ & $8.0460243 E-02$ & $3.5861585 \mathrm{E}-02$ \\
\hline 8.4417984E-02 & $3.9070893 E-02$ & $5.6212086 E-02$ & $3.0800391 E-03$ \\
\hline $1.3834529 \mathrm{E}-02$ & 0.2120718 & 0.1232555 & $3.8509235 \mathrm{E}-02$ \\
\hline 3.1368252E-02 & 0.1207141 & $1.7296594 \mathrm{E}-02$ & 8.6480059E-02 \\
\hline 0.1733319 & $7.0493244 \mathrm{E}-02$ & $2.5122650 \mathrm{E}-02$ & $3.8517248 \mathrm{E}-02$ \\
\hline 0.1083883 & 0.2736189 & $2.4814460 \mathrm{E}-02$ & $2.0938128 \mathrm{E}-02$ \\
\hline $3.4713827 \mathrm{E}-02$ & 0.1644907 & 0.1282181 & $6.3549548 \mathrm{E}-02$ \\
\hline 6.9029287E-02 & 0.1962140 & 2.2284815E-02 & $7.8335539 \mathrm{E}-02$ \\
\hline $8.6368740 \mathrm{E}-02$ & $1.2658233 E-03$ & 5.1063392E-02 & $6.9398761 E-02$ \\
\hline $1.0906375 \mathrm{E}-02$ & $9.3008801 E-03$ & $2.3033345 E-02$ & $3.5620485 E-02$ \\
\hline $2.3066474 \mathrm{E}-02$ & $9.6362727 \mathrm{E}-03$ & 0.1255693 & $5.7140426 \mathrm{E}-03$ \\
\hline 0.1874645 & 0.1297920 & 4.9152099E-02 & 4.2732999E-02 \\
\hline $2.9084072 \mathrm{E}-02$ & $7.4851378 \mathrm{E}-03$ & 0.1012888 & $1.0141055 \mathrm{E}-02$ \\
\hline $3.2290604 \mathrm{E}-02$ & $7.1975842 \mathrm{E}-02$ & 3.2810923E-02 & $5.2287020 \mathrm{E}-02$ \\
\hline 0.1759330 & 3.9767893E-04 & $5.5024467 \mathrm{E}-02$ & 0.1110769 \\
\hline $1.4150621 \mathrm{E}-02$ & 0.1267434 & 0.1023091 & $2.7594246 \mathrm{E}-02$ \\
\hline o. 1159350 & $1.7169040 \mathrm{E}-02$ & 4.7409418E-03 & 0.1713138 \\
\hline 4.2492867E-02 & $1.1717744 \mathrm{E}-02$ & $3.1449161 \mathrm{E}-02$ & $2.2145273 E-02$ \\
\hline 0.2267004 & $2.5022475 \mathrm{E}-03$ & 3.5321389E-03 & 0.1135392 \\
\hline 0.1055374 & 2.8072709E-02 & $2.1979650 \mathrm{E}-02$ & $4.1683346 \mathrm{E}-02$ \\
\hline 0.1955333 & $8.4042564 \mathrm{E}-02$ & 3.2869723E-02 & \\
\hline $2.6470978 \mathrm{E}-02$ & $3.6001012 \mathrm{E}-02$ & $1.6251069 \mathrm{E}-02$ & \\
\hline $6.8814188 \mathrm{E}-02$ & $4.6982206 \mathrm{E}-03$ & $9.9207006 \mathrm{E}-02$ & \\
\hline $5.3744357 \mathrm{E}-02$ & $1.1233456 \mathrm{E}-02$ & 0.1344099 & \\
\hline 0.2325092 & $4.3577466 \mathrm{E}-02$ & $1.4781847 \mathrm{E}-02$ & \\
\hline $6.0120583 \mathrm{E}-02$ & $7.6863907 \mathrm{E}-02$ & 7.0901610E-02 & \\
\hline 0.1314537 & $4.2035021 \mathrm{E}-02$ & $1.0775675 \mathrm{E}-03$ & \\
\hline
\end{tabular}

Vol. 2, Part 2 
LOSP Frequency

Attachment G-29

STAT-SAS 
OPTIONS LINESIZE=79;

DATA DATAl;

INFILE PCGWLOSP

INPUT X;

PROC UNIVARIATE;

TITLE 'PC/GW DATA';

VAR X;

DATA DATA2;

INFILE LHSLOSP;

INPUT X;

PROC UNIVARIATE;

TITLE 'CAT IV DATA';

VAR X; 
LOSP Frequency

Attachment G-30

STAT.LIS 
PC/GW DATA14:17 TUESDAY, JUNE 4, 1991

UNIVARIATE

VARIABLE $=\mathbf{X}$

MOMENTS

$\begin{array}{llll}\text { N } & 1000 & \text { SUM WGTS } & 1000 \\ \text { MEAN } & 0.0649013 & \text { SUM } & 64.9013 \\ \text { STD DEV } & 0.0565115 & \text { VARIANCE } & 0.00319355 \\ \text { SKEWNESS } & 1.59296 & \text { KURTOSIS } & 3.86073 \\ \text { USS } & 7.40253 & \text { CSS } & 3.19036 \\ \text { CV } & 87.073 & \text { STD MEAN } & 0.00178705 \\ \text { T:MEAN =0 } & 36.3175 & \text { PROB > | T | } & 0.0001 \\ \text { SGN RANK } & 250250 & \text { PROB > | | | } & 0.0001 \\ \text { NUM }=0 & 1000 & & \end{array}$

QUANTILES(DEF =4)

EXTREMES

$\begin{array}{llllll}\text { 100\% MAX } & 0.412616 & 99 \% & 0.247636 & \text { LOWEST } & \text { HIGHEST } \\ \text { 75\% Q3 } & 0.09235 & 95 \% & 0.171641 & 1.252 \mathrm{E}-06 & 0.29696 \\ \text { 50\% MED } & 0.0508861 & 90 \% & 0.14066 & 9.215 \mathrm{E}-06 & 0.301188 \\ \text { 25\% Q1 } & 0.0228075 & 10 \% & 0.00840051 & .000022904 & 0.320904 \\ \text { 0\% MIN } & 1.252 \mathrm{E}-06 & 5 \% & 0.0046946 & .000031458 & 0.391779 \\ & & 1 \% & .000452315 & .000104264 & 0.412616 \\ \text { RANGE } & 0.412615 & & & & \\ \text { Q3-Q1 } & 0.0695424 & & & & \\ \text { MODE } & 1.252 \mathrm{E}-06 & & & & \end{array}$


LOSP Frequency

CAT IV DATA $\quad$ 14:17 TUESDAY, JUNE 4, 19912

UNIVARIATE

\section{VARIABLE $=\mathbf{X}$}

MOMENTS

\begin{tabular}{|c|c|c|c|}
\hline $\mathbf{N}$ & 1000 & SUM WGTS & 1000 \\
\hline MEAN & 0.123544 & SUM & 123.544 \\
\hline STD DEV & 0.0698132 & VARIANCE & 0.00487388 \\
\hline SKEWNESS & 2.93389 & KURTOSIS & 20.8052 \\
\hline USS & 20.1322 & CSS & 4.86901 \\
\hline CV & 56.5087 & STD MEAN & 0.00220769 \\
\hline T:MEAN $=0$ & 55.9609 & PROB $>|\mathrm{T}|$ & 0.0001 \\
\hline $\begin{array}{l}\text { SGN RANK } \\
\text { NUM }{ }^{\wedge}=0\end{array}$ & $\begin{array}{l}250250 \\
1000\end{array}$ & PROB $>|S|$ & 00001 \\
\hline
\end{tabular}

\section{QUANTILES(DEF =4) EXTREMES}

$\begin{array}{llllll}\text { 100\% MAX } & 0.863285 & 99 \% & 0.354369 & \text { LOWEST } & \text { HIGHEST } \\ \text { 75\% Q3 } & 0.154967 & 95 \% & 0.244014 & 0.0110466 & 0.434986 \\ \text { 50\% MED } & 0.1078 & 90 \% & 0.199931 & 0.0143378 & 0.462437 \\ \text { 25\% Q1 } & 0.0765061 & 10 \% & 0.0565326 & 0.0153775 & 0.477914 \\ \text { 0\% MIN } & 0.0110466 & 5 \% & 0.0480018 & 0.0219668 & 0763139 \\ & & 1 \% & 0.02919 & 0.0229742 & 0.863285\end{array}$

RANGE $\quad 0.852238$

Q3-Q1 $\quad 0.0784613$

MODE $\quad 0.0698282$ 
Attachment G-31

GGGRID.DAT

Vol. 2, Part 2

G-139

NUREG/CR-6143 
LOSP Frequency

.13

.18

.25

.3

.33

.33

.333

.55

.92

1.03

1.5

2.0

2.083

6.470 
Attachment G-32

GGW'EAT.DAT 


\section{LOSP Frequency}

1.75

2.67

4.0

4.317

5.0

5.5

8.9

11. 
Attachment G-33

GGPC1.DAT 


\section{LOSP Frequency}

.002

.003

.004

.033

.05

.33

.367

1.

.43

.633

.27

.167

.08

.25

.15

.013

.183

.48

.15

.017 
Attachment G-34

GGPC2.DAT 


\section{LOSP Frequency}

.07

1.48

.28

.083

.5

.67

.334

.003

.13

.02

1.03

.25

.25

.283

.417

4.0

.050

2. 


\section{LOSP Frequency}

Attachment G-35

GGPC3.DAT 


\section{LOSP Frequency}
1.97
.9
2.75
.9
.015
1.75
.5
.93
.5
7.43
.4
.2
1.15
.57
.767
1.667
.004
.067
11.083
.233
2.683
4.983
.117
.717 
Attachment G-36

GGPC4.DAT 


\section{LOSP Frequency}

$$
\begin{aligned}
& .002 \\
& .003 \\
& .004 \\
& .033 \\
& .05 \\
& .33 \\
& .367
\end{aligned}
$$

1.

.43

.633 .

.27

.167

.08

.25

.15

.013

.183

.48

.15

.017

.07

1.48

.28

.083

.5

.67

.334

.003

.13

.02

1.03

.25

.25

.283

.417

4.0

.050

2.

1.97

.9

2.75

.9

.015

1.75

.5

93

.5

7.43

.4

.2

1.15

.57

.767

1.667

.004

.067

11.083

.233

2.683

4.983

.117

.717 
MODEL.FOR 
C AN INTERACTIVE PROGRAM TO IMPLEMENT THE MIXTURE MODEL FOR THE DISTRIBUTION C OF TIME TO RECOVERY OF LOSP AS DEVELOPED IN NUREG/CR-5032, SAND87-2428, C JANUARY 1988:

C

C "MODELING TIME TO RECOVERY AND INITIATING EVENT FREQUENCY FOR LOSS OF

C OFF-SITE POWER INCIDENTS AT NUCLEAR POWER PLANTS"

C BY RONALD L. IMAN AND STEPHEN C. HORA

C THE MIXTURE MODEL MODEL AS GIVEN IN EQUATION (23) OF THAT REPORT IS C OF THE FORM:

C

C $\quad G(x)=P 1 * G 1(x)+P 2 * G 2(x)+P 3 * G 3(x)$

C WHERE THE $G(x)$ 's REPRESENT THE FITTED GAMMA DISTRIBUTIONS

C AND THE P's ARE WEIGHTS THAT ARE TREATED WITH A DIRICHLET DISTRIBUTION

C

C ADDITIONAL INFORMATION CAN BE FOUND IN THE FOLLOWING REFERENCE:

C

C RONALD L. IMAN AND STEPHEN C. HORA (1989). "BAYESIAN METHODS FOR

C MODELING RECOVERY TIMES WITH AN APPLICATION TO THE LOSS OF OFF-SITE

C POWER AT NUCLEAR POWER PLANTS," RISK ANALYSIS, VOL. 9, NO. 1, 25-36.

C NOTE THAT ERRATA FOR THIS ARTICLE APPEARS IN VOL. 9, NO. 3.

C

C TO RUN USE LINK RECOVERY,AMOSLIB,IMSLIBS/LIB

C

C NREP = NUMBER OF REPLICATIONS TO BE USED IN THE MONTE CARLO

C NPLANT = NUMBER OF PLANTS IN THE DATA BASE CONTAINED IN FILE "REC.DAT"

C

C "NX" TIME STEPS ARE USED TO GENERATE A GRAPH OF THE RECOVERY CURVE.

C THE "NX" TIME STEPS CORRESPOND TO TIMES IN HOURS OF .05, .10, .15,

C $\quad 1.30,1.33,1.40,1.45, \ldots, 2.50,2.75,3.00,3.167,3.25,3.50$,

C $\quad 10.00,13.3,15,16,18,23,27$

C

C

C

C

C

C

C

C

THE VECTOR IDT IS USED TO SPECIFY "NTIME" TIMES AT WHICH THE UNCERTAINTY DISTRIBUTION WILL BE SAVED IN AN OUTPUT FILE NAMED "XX.DAT," WHERE XX IS ABBREVIATION OF THE PLANT NAME THAT APPEARS IN FILE REC.DAT. THE EXACT TIMES SPECIFIED WILI VARY FROM ONE PLANT ANALYSIS TO THE NEXT. THE DIMENSIONS OF THE MATRIX "XX.DAT" ARE "NREP" $x$ "NTIME."

FOR EXAMPLE, IF THE DISTRIBUTION OF TIME TO RECOVERY OF LOSP FOR A PARTICULAR PLANT IS DESIRED FOR THE FOLLOWING "NTIME=20" TIMES (IN HOURS): $.5, .8,1,1.133,1.283,1.33,2.5,3,3.167,5,7,8,9,10,13.3$, $15,16,18,23,27$

THEN THE VECTOR IDT MUST SPECIFY TO SAVE "NTIME" RESULTS. IN PARTICULAR, SAVE THE RESULTS OF THE 10th, 16th, 20th, OUT OF THE "NX' TIMES FOR WHICH THE DISTRIBUTION OF RECOVERY TIMES IS GENERATED AS SPECIFIED ABOVE. FOR THIS EXAMPLE THE VALUES STORED IN THE VECTOR IDX ARE : 10, 16, 20, 23, $26,27,50,52,53,60,68,72,76,80,81,82,83,84,85,86$.

C

PROGRAM MODEL PARAMETER(NREP $=500$, NPLANT $=70, \mathrm{~K}=3, \mathrm{NX}=86, \mathrm{NTIME}=20$ )

DIMENSION RESULTS(NREP,NX),X(NX),OUTPUT(K,NX),FMAX(K),IDT(NTIME)

1 ,ISWITCH(NPLANT),P(K),S(K),CUMPROB(K),PD(K),B(K),ICOMP(K) CHARACTER*1 CANS 


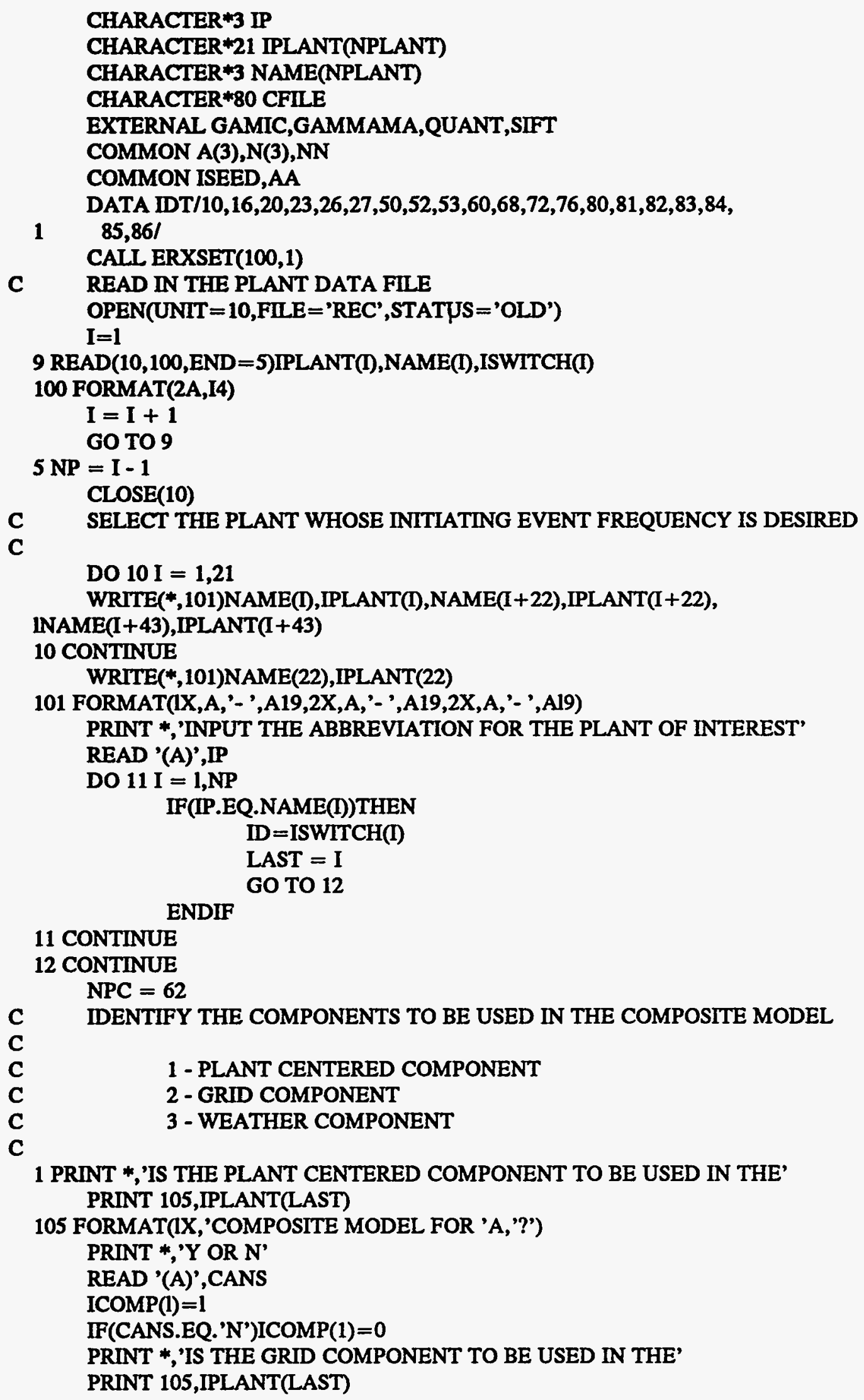




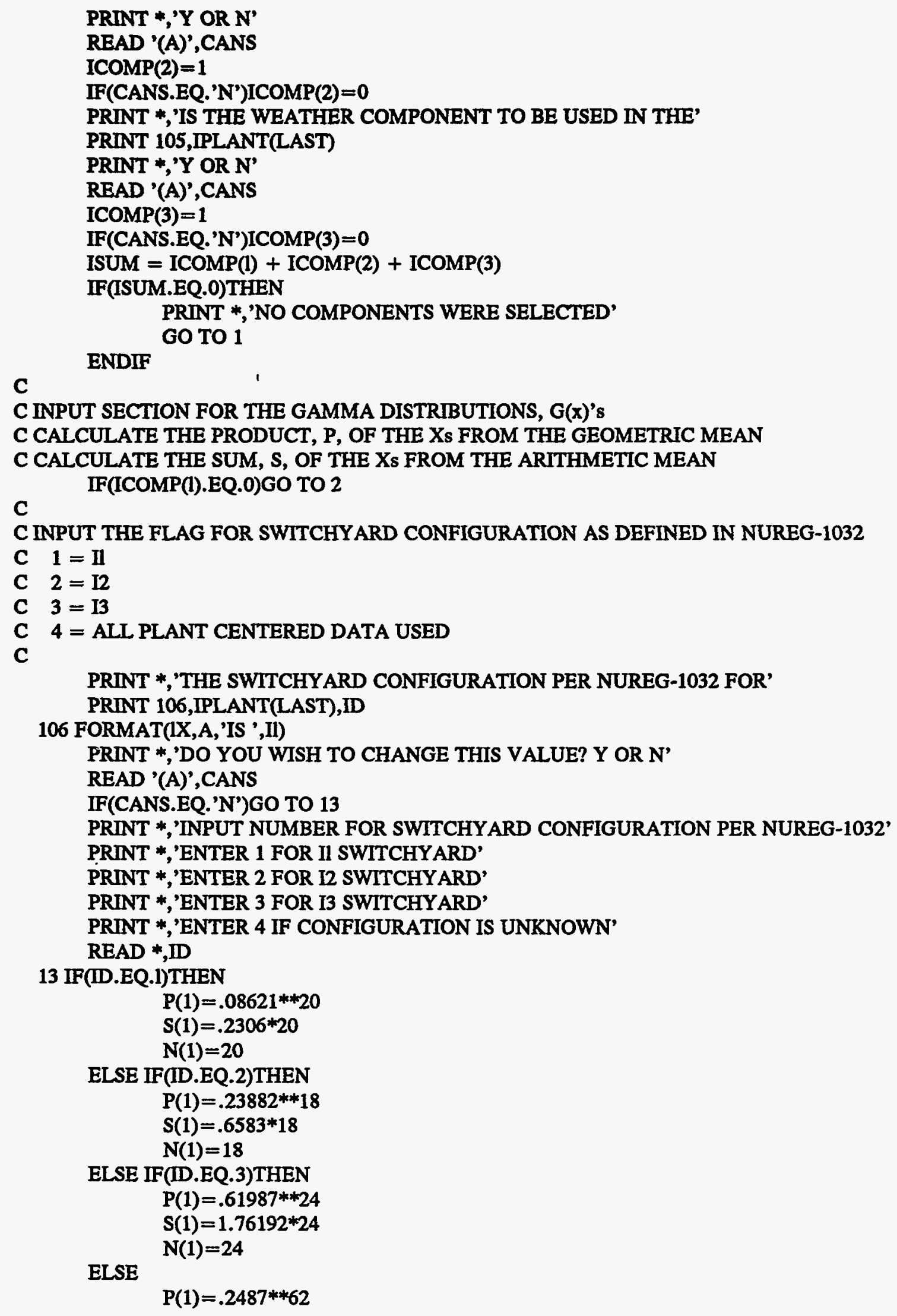




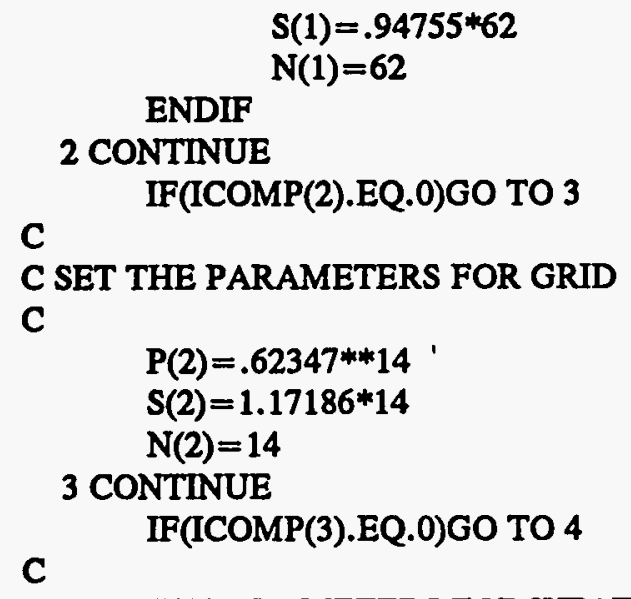

C

C GENERATE THE TIME IN STEPS OF .05 FROM .05 TO 2.5 FOR THE RECOVERY CURVE

C WITH EXCEPTIONS FOR 1.133, 1.283 AND 1.33

C

DO $15 \mathrm{I}=1,50$

$\mathrm{X}(\mathrm{I})=.05 * \mathrm{I}$

C PATCH TO GENERATE A TIME OF 1.133, 1.283 AND 1.33 HOURS

IF (I .EQ. 23) X(I) $=1.133$

IF (I .EQ. 26) X(I) $=1.283$

IF (I .EQ. 27) X(I) $=1.333$

15 CONTINUE

C GENERATE THE TIME IN STEPS OF .25 FROM 2.75 TO 10 FOR THE RECOVERY CURVE

C WITH ONE EXCEPTION AT 3.167 
LOSP Frequency

C

DO $16 \mathrm{I}=51,80$ '

$X(I)=0.25 * I-10.0$

IF (I .EQ. 53) X(I) $=3.167$

16 CONTINUE

C SET THE LAST SIX TIME STEPS

$\mathrm{X}(81)=13.3$

$X(82)=15$.

$X(83)=16$.

$X(84)=18$.

$X(85)=23$.

$\mathbf{X}(86)=27$.

C

ISEED $=327251$

C SETUP

c

DO $50 \mathrm{I}=1, \mathrm{~K}$

C

IF(ICOMP(I).EQ.0)GO TO 50

C FIND THE MAXIMUM VALUE OF THE VARIABLE THAT MAXIMIZES THE MARGINAL

C DENSITY OF ALPHA (EQUATION 18 OF THE LOSP REPORT)

CALL RMAX(XMAX,S(I),P(I),N(I))

C FIND THE MAXIMUM VALUE OF THE MARGINAL DENSITY OF ALPHA

FMAX(I) $=$ F(XMAX,N(I),P(I),S(I))

50 CONTINUE

DO $6 \mathrm{I}=1, \mathrm{~K} 6 \mathrm{PD}(\mathrm{I})=1$.

PRINT *,',

PRINT *,'PLEASE WAIT WHILE THE MONTE CARLO IS BEING PERFORMED'

PRINT *

$\mathrm{IPC}=0$

DO $500 \mathrm{~J}=1$, NREP

$300 \mathrm{DO} 70 \mathrm{I}=1, \mathrm{~K}$

IF(ICOMP(I).EQ.0)GO TO 70

C

$\mathbf{N N}=\mathbf{N}(\mathrm{I})$

C OBTAIN A VALUE OF BETA FROM THE CONDITIONAL DENSITY GIVEN BY

C EQUATION 17 OF THE LOSP REPORT

C

C

CALL GAMPARAM(A(I),B(I),S(I),P(I),FMAX(I))

70 CONTINUE

C

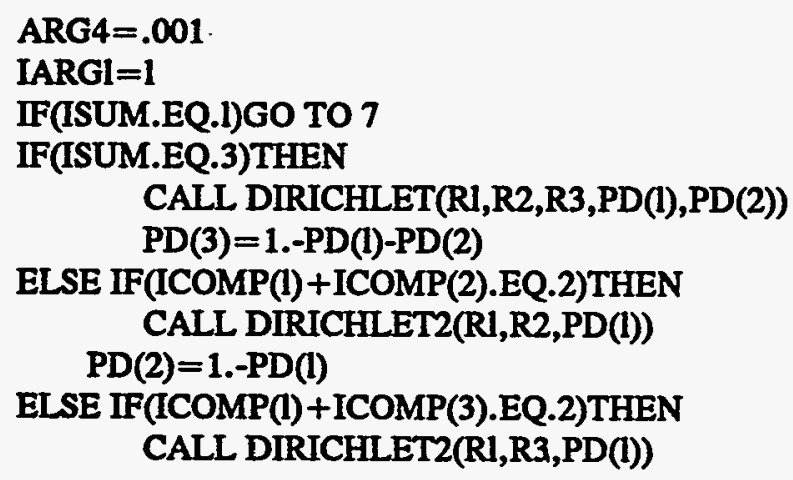




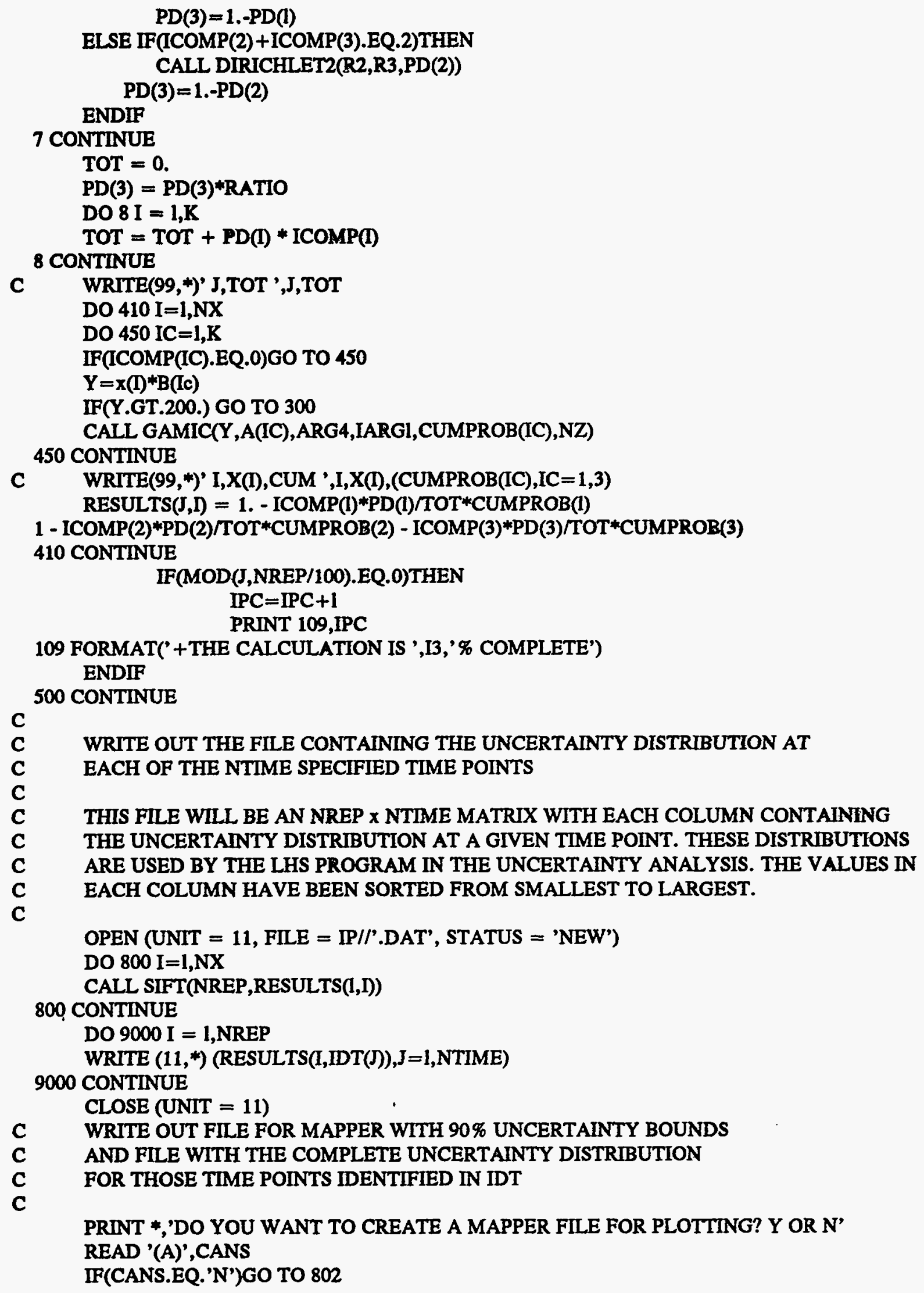


LOSP Frequency

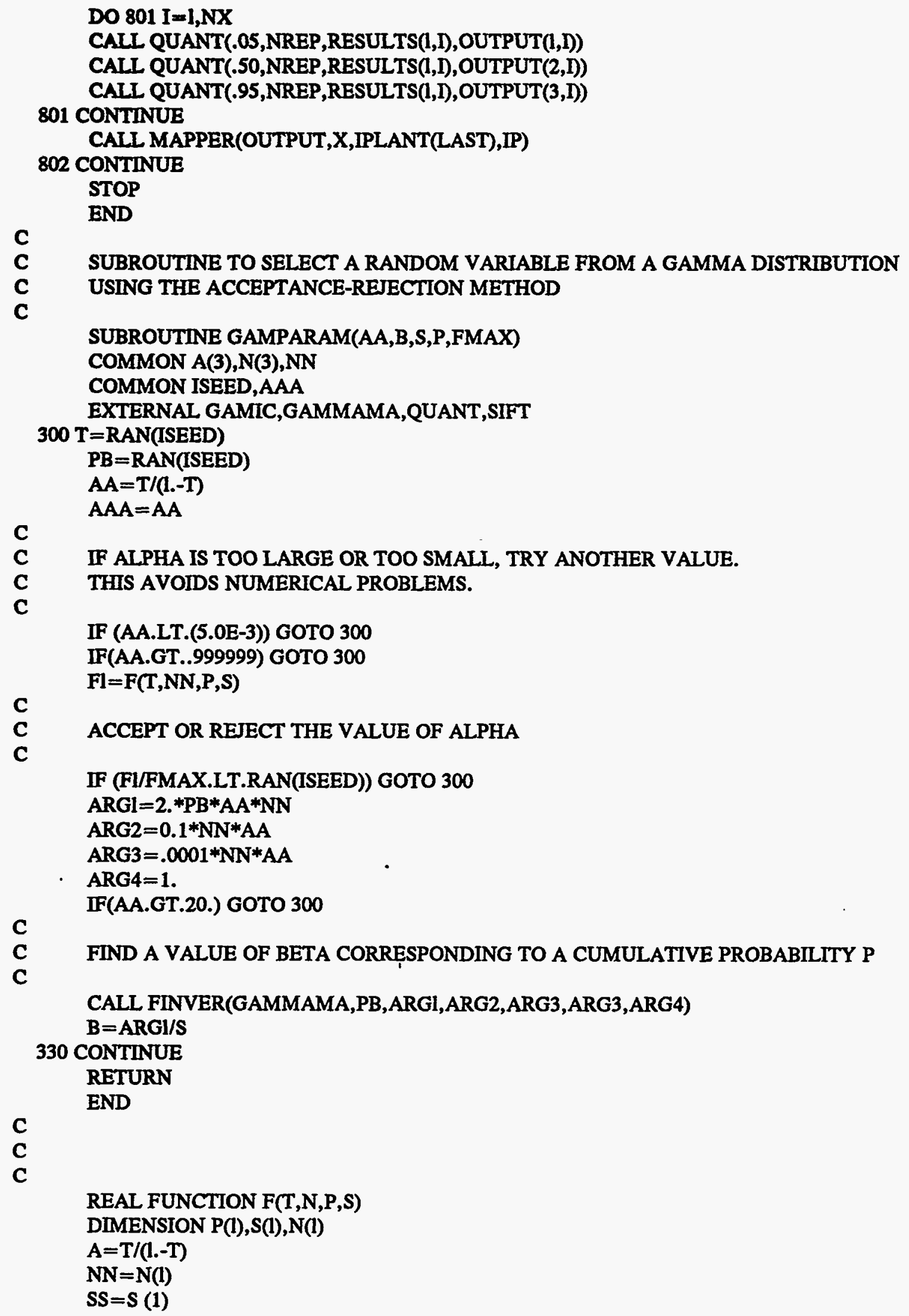




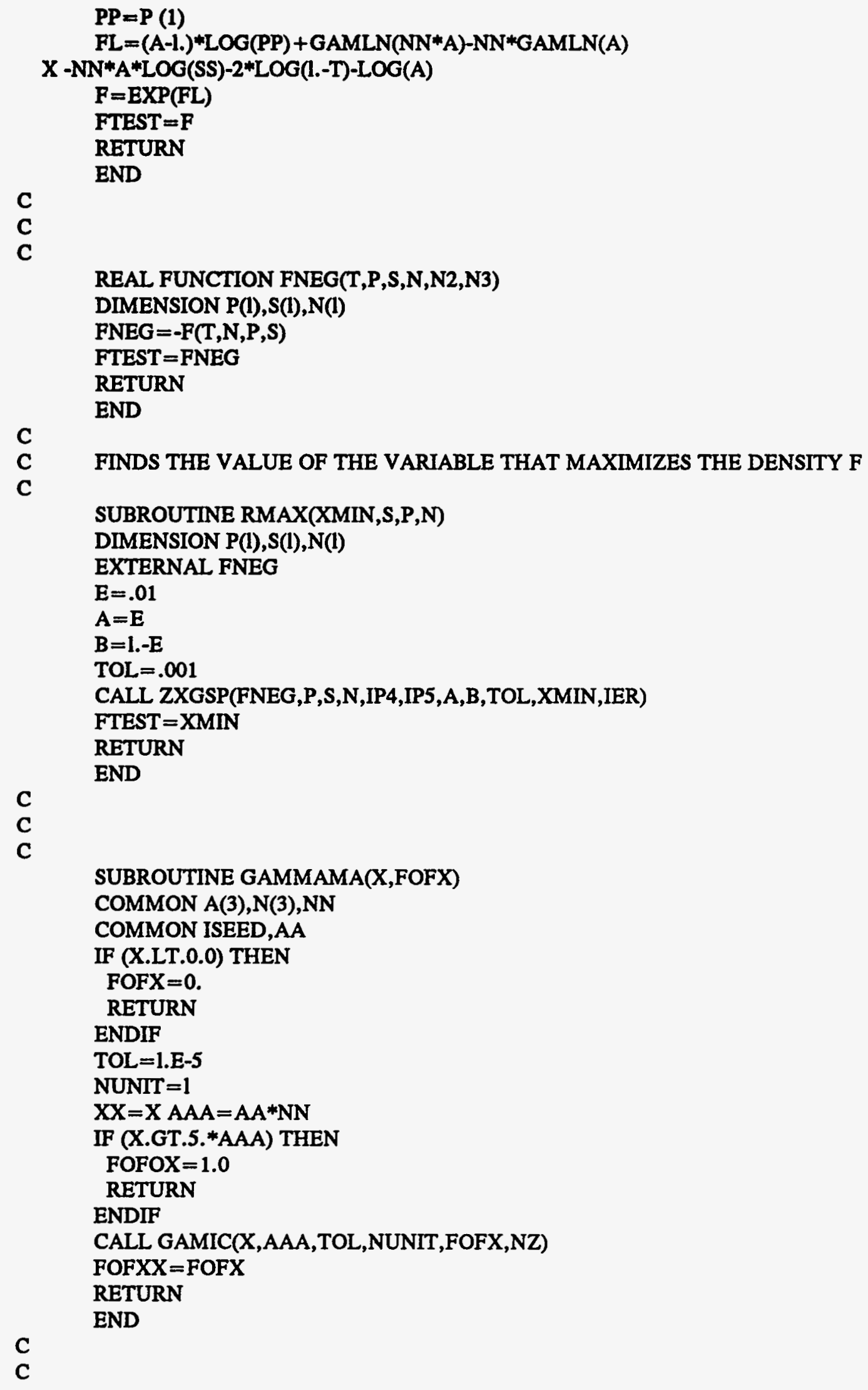




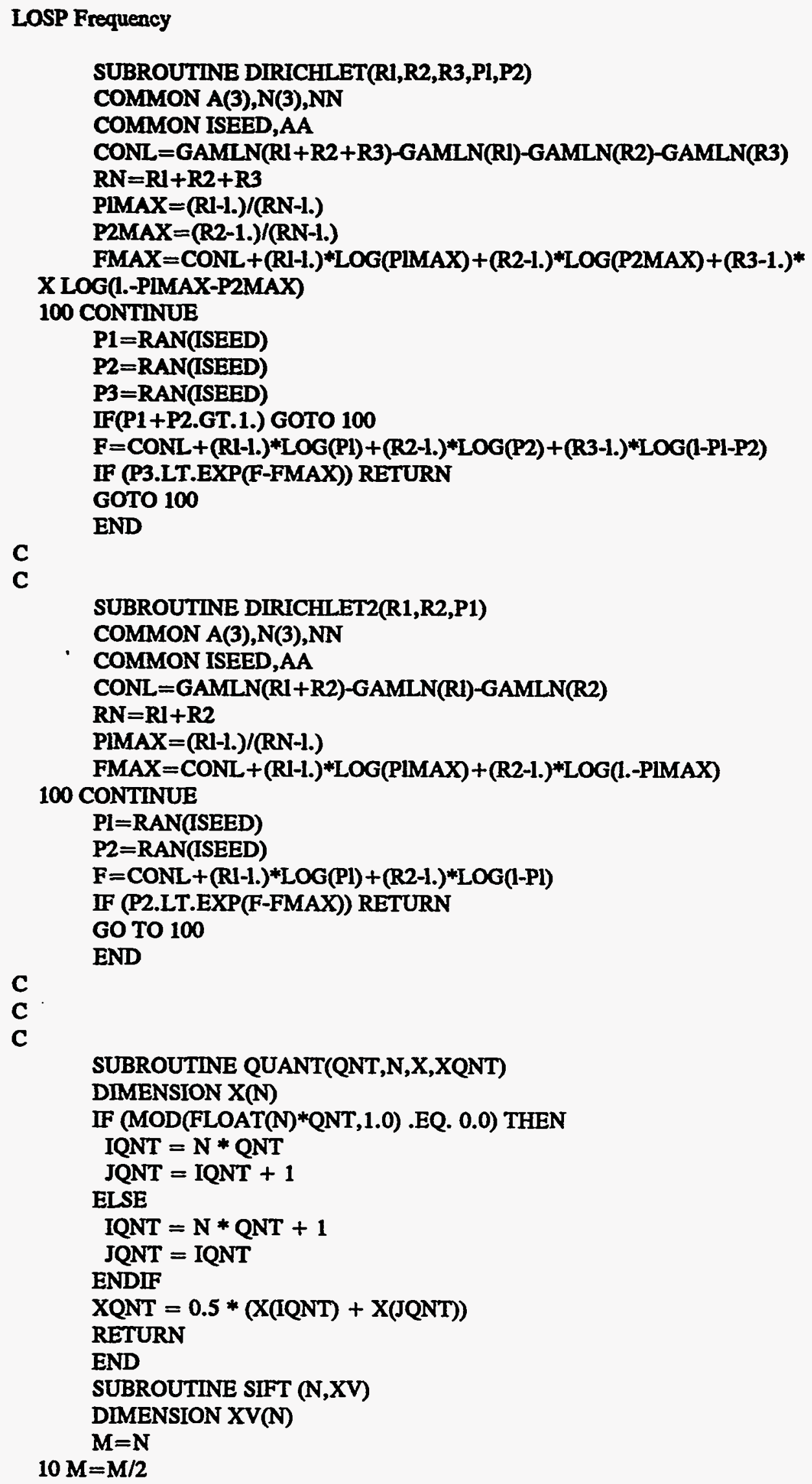




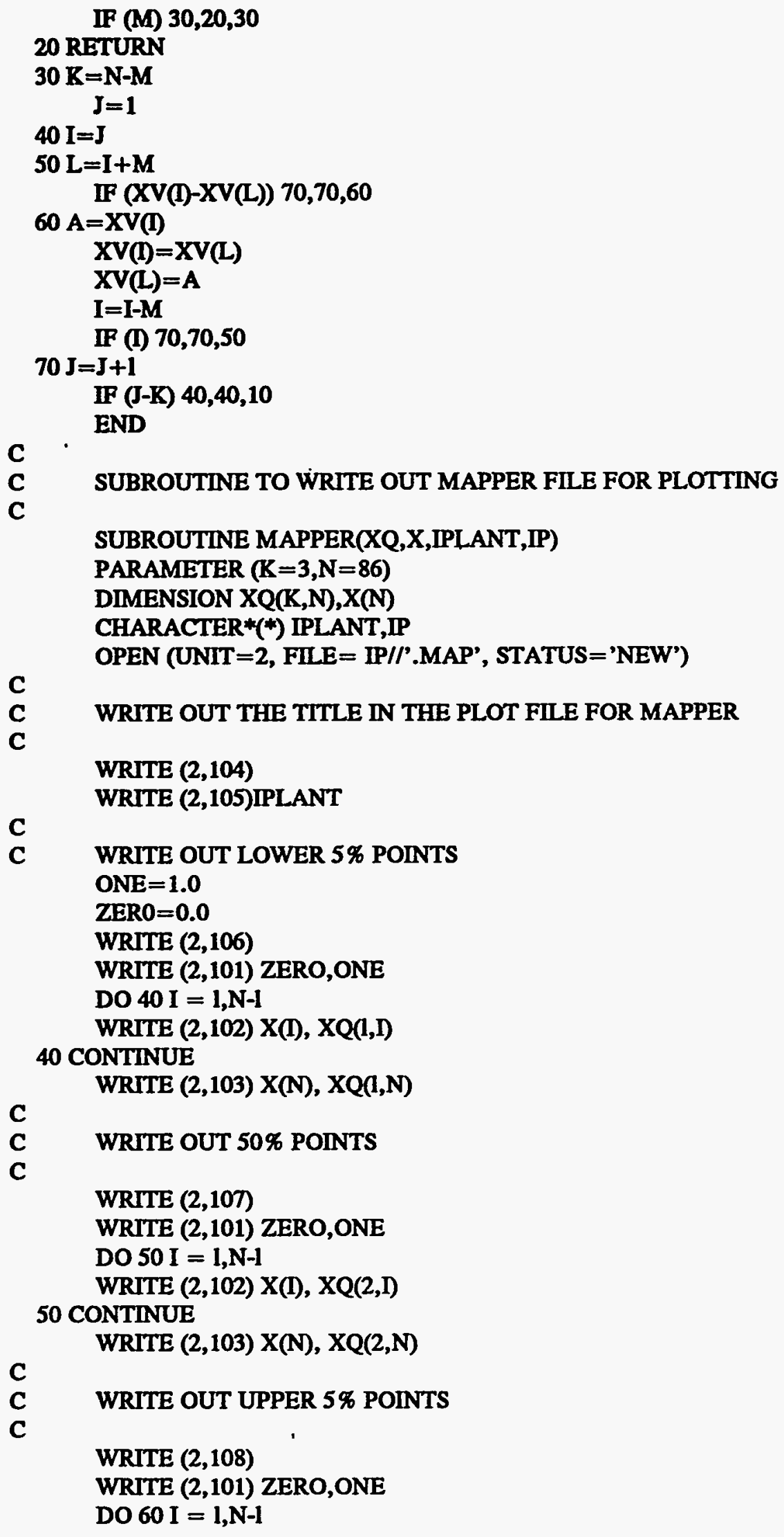




\section{LOSP Frequency}

WRITE $(2,102) \mathrm{X}(\mathrm{I}), \mathrm{XQ}(3, \mathrm{I})$

60 CONTINUE

WRITE $(2,103) X(N), X Q(3, N)$

CLOSE (2)

101 FORMAT ('SLINE(',E14.7,','E14.7,',1')

102 FORMAT (E14.7,','E14.7)

103 FORMAT (E14.7, ',',E14.7,',2',l,'RETURN')

104 FORMAT ('*TITLE*', /'LABEL(1,,8.5,9.5,11,2,0')

105 FORMAT ('\&I.35 > RECOVERY CURVE FOR ',A,/,'RETURN')

106 FORMAT ('*LOWER*')

107 FORMAT ("*MEDIAN*)

108 FORMAT ('*UPPER*')

RETURN 
Attachment G-38

GAMMA.FOR 


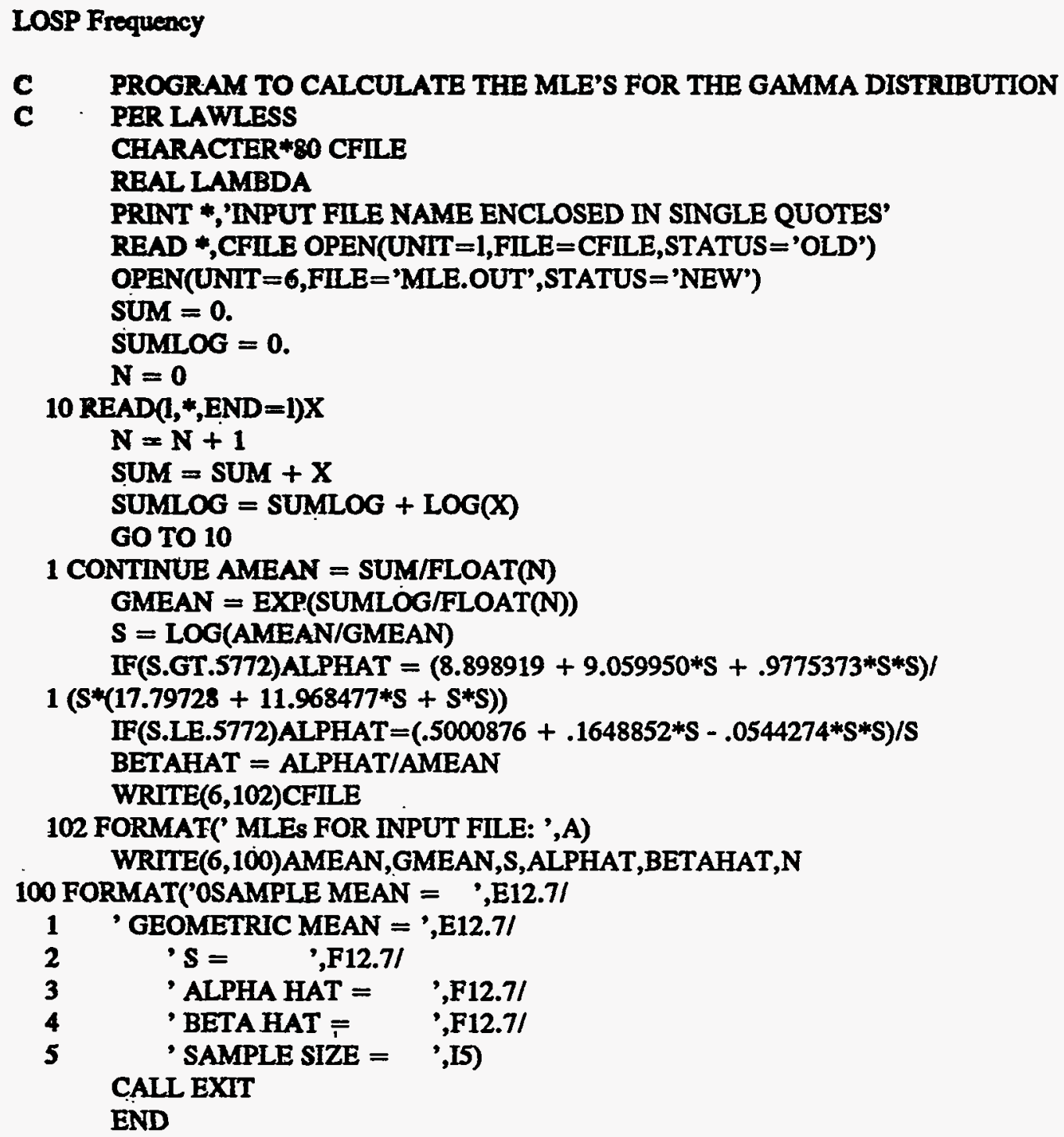


Attachment G-39

MLE.OUT 


\section{LOSP Frequency}

MLES FOR INPUT FILE: ggpc4.dat

$\begin{array}{lll}\text { SAMPLE MEAN } & = & .9475484 \mathrm{E}+00 \\ \text { GEOMETRIC MEAN } & = & .2486961 \mathrm{E}+00 \\ \text { S } & = & 1.3376462 \\ \text { ALPHA HAT } & = & 0.4659370 \\ \text { BETA HA } & = & 0.4917290 \\ \text { SAMPLE SIZE } & = & 62\end{array}$


Attachment G-40

AMOSLIB.FOR 


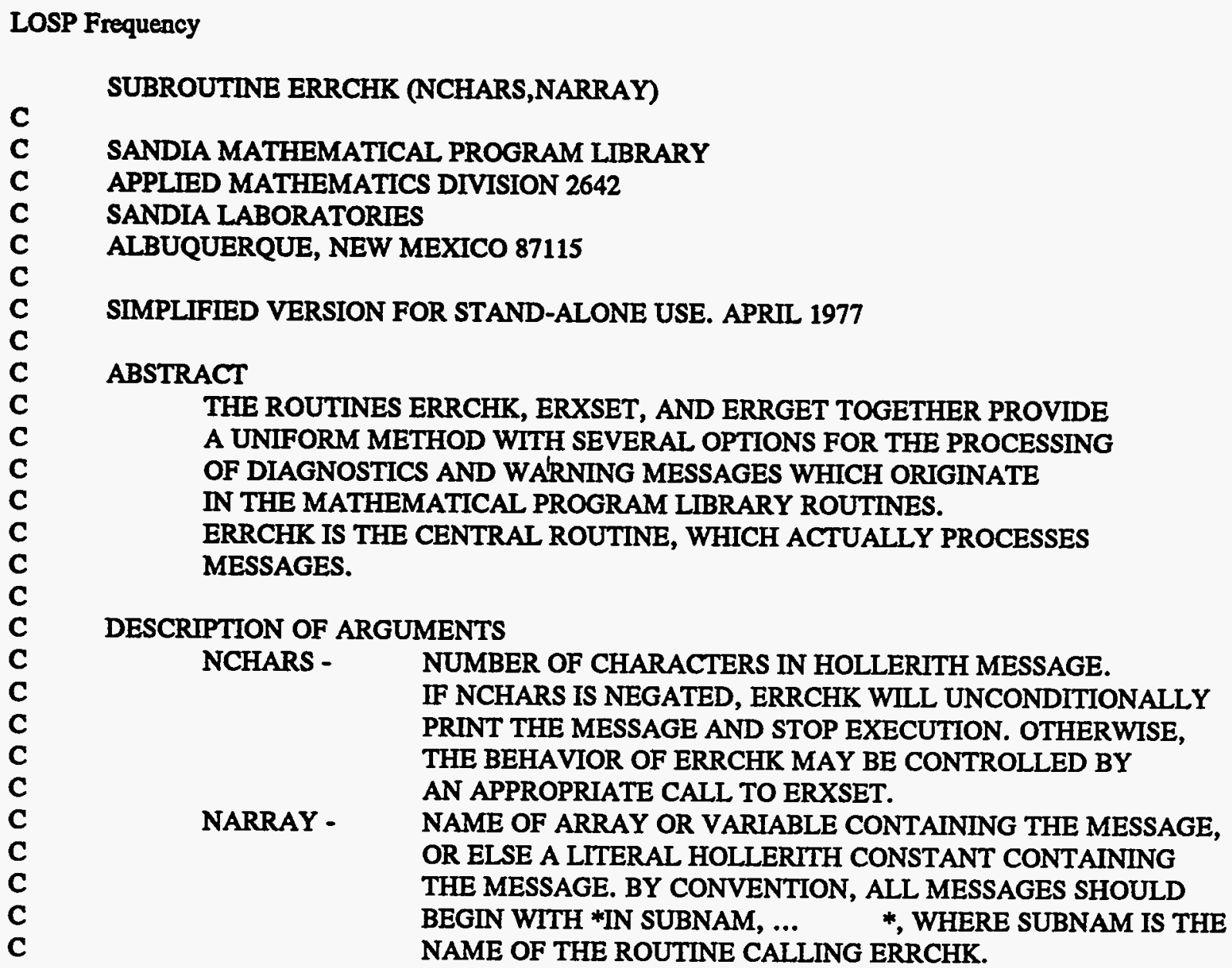

1. TO ALLOW CONTROL BY CALLING ERXSET, USE CALL ERRCHK(30,30HIN QUAD, INVALID VALUE OF ERR.)

2. TO UNCONDITIONALLY PRINT A MESSAGE AND STOP EXECUTION,USE CALL ERRCHK(-30,30HIN QUAD, INVALID VALUE OF ERR.)

C ERRCHK USES SUBROUTINES ERRGET, ERRPRT, ERXSET, ERSTGT

C COMPILE DECKS ERRCHK

DIMENSION NARRAY(14)

C

CALL ERRGET(NF,NT)

C IF ERRCHK WAS CALLED WITH NEGATIVE CHARACTER COUNT, SET FATAL FLAG

IF (NCHARS.LT.0) NF $=-1$

C IF MESSAGES ARE TO BE SUPPRESSED, RETURN

IF (NF.EQ.0) RETURN

C IF CHARACTER COUNT IS INVALID, STOP

IF (NCHARS.EQ.0) PRINT 5

5 FORMAT(/31H ERRCHK WAS CALLED INCORRECTLY.)

IF (NCHARS.EQ.0) STOP

C PRINT MESSAGE

CALL ERRPRT(IABS(NCHARS),NARRAY)

C IF LAST MESSAGE, SAY SO 
IF (NF.EQ.1) PRINT 10

10 FORMAT (3OH ERRCHK MESSAGE LIMIT REACHED.)

C PRINT TRACE-BACK IF ASKED TO

C IF ((NT.GT.0).OR.(NF.LT.0)) CALL SYSTEM ROUTINE FOR TRACEBACK

C DECREMENT MESSAGE COUNT

IF (NF.GT.0) NF = NF-1

CALL ERXSET(NF,NT)

C IF ALL IS WELL, RETURN

IF (NF.GE.0) RETURN

C IF THIS MESSAGE IS SUPPRESSABLE BY AN ERXSET CALL,

C THEN EXPLAIN ERXSET USAGE.

IF (NCHARS.GT.0) PRINT 15

15 FORMAT $(/ 13 H * * *$ NOTE ***

1/53H TO MAKE THE ERROR MESSAGE PRINTED ABOVE BE NONFATAL,

2/39H OR TO SUPPRESS THE MESSAGE COMPLETELY,

3/37H INSERT AN APPROPRIATE CALL TO ERXSET

$430 H$ AT THE START OF YOUR PROGRAM.

5/62H FOR EXAMPLE, TO PRINT UP TO 10 NONFATAL WARNING MESSAGES, USE

6/27H CALL ERXSET(10,0)

PRINT 20

20 FORMAT (/28H PROGRAM ABORT DUE TO ERROR.)

STOP

END

c

SUBROUTINE ONECHK(NCHARS,NARRAY)

$\begin{array}{ll}\text { C } & \text { ABSTRACT } \\ \text { C } & \text { ONECHK IS A COMPANION ROUTINE OF ERRCHK. IT IS CALLED }\end{array}$

C

C

C

C

C

C

C

C

C

C

C

C

C

C

C

C

C ERRCHK

JUST LIKE ERRCHK, AND MESSAGES FROM IT MAY BE SUPPRESSED

BY AN APPROPRIATE CALL TO ERXSET. IT DIFFERS FROM ERRCHK

IN THAT EACH CALL TO ONECHK WILL PRODUCE NO MORE THAN ONE

PRINTED MESSAGE, REGARDLESS OF HOW MANY TIMES THAT CALL IS

EXECUTED, AND ONECHK NEVER TERMINATES EXECUTION.

ITS PURPOSE IS TO PROVIDE ONE-TIME-ONLY INFORMATIVE

DIAGNOSTICS.

\section{DESCRIPTION OF ARGUMENTS}

NCHARS - $\quad$ NUMBER OF CHARACTERS IN THE MESSAGE.

IF NEGATED, THE MESSAGE WILL BE PRINTED (ONCE) EVEN

IF NFATAL HAS BEEN SET TO 0 (SEE ERXSET).

NARRAY - $\quad$ SAME AS IN ERRCHK

C

DIMENSION NARRAY(14)

DATA NFLAG/4H.\$, $* I$

IF (NARRAY(1).EQ.NFLAG) RETURN

CALL ERRGET(NF,NT)

IF ((NF.EQ.0).AND.(NCHARS.GT.0)) RETURN

CALL ERRPRT (59,59HTHE FOLLOWING INFORMATIVE DIAGNOSTIC WILL APPEA

IR ONLY ONCE.)

CALL ERRPRT(IABS(NCHARS),NARRAY) 
LOSP Frequency

IF (NF.GT.0) NF = NF-1

CALL ERXSET(NF,NT)

NARRAY(l) = NFLAG

END

SUBROUTINE ERRPRT(NCHARS,NARRAY)

C

C UTILITY ROUTINE TO SIMPLY PRINT THE HOLLERITH MESSAGE IN NARRAY,

C WHOSE LENGTH IS NCHARS CHARACTERS.

C

DIMENSION NARRAY(14)

C

C NOTE - NCH MUST BE THE NUMBER OF HOLLERITH CHARACTERS STORED

C PER WORD. IF NCH IS CHANGED, FORMAT 1 MUST ALSO BE

C CHANGED CORRESPONDINGLY.

C

$\mathrm{NCH}=10$

C FOR LINE PRINTERS, USE

1 FORMAT (IX,13A10)

C FOR DATA TERMINALS, USE

C 1 FORMAT (IX,7A10)

NWORDS $=($ NCHARS $+\mathrm{NCH}-\mathrm{l}) / \mathrm{NCH}$

PRINT 1,(NARRAY(I),I=1,NWORDS)

RETURN

END

C

SUBROUTINE ERXSET(NFATAL,NTRACE)

C ABSTRACT

C

c

C

C

C

C

C

C

C

C

C

C

C

C

C

C

C

C

C

C

C

C

C

C EXAMPLES

C 1. TO PRINT UP TO 100 MESSAGES AS NONFATAL WARNINGS USE

C CALL ERXSET $(100,0)$ 


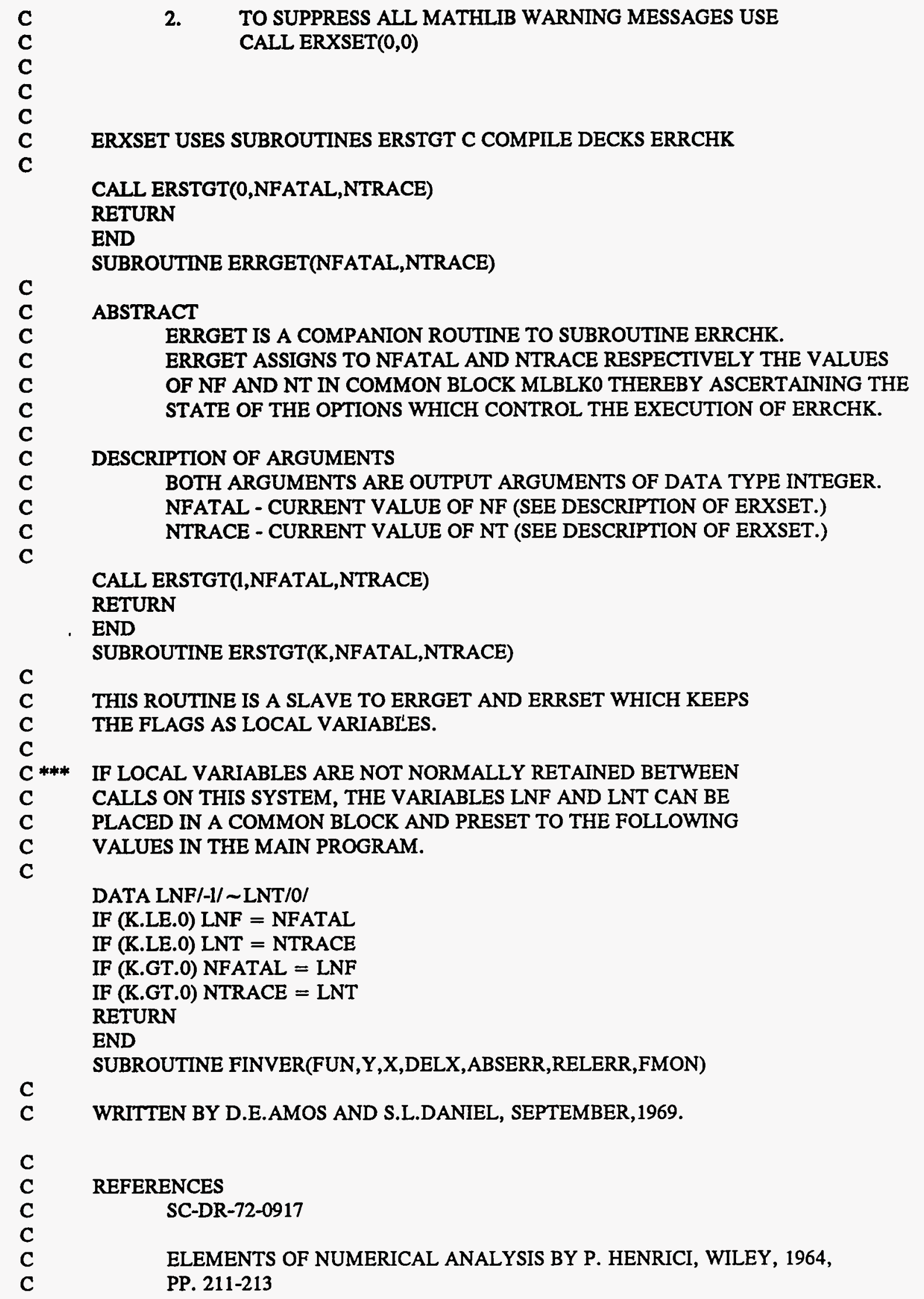




\section{LOSP Frequency}

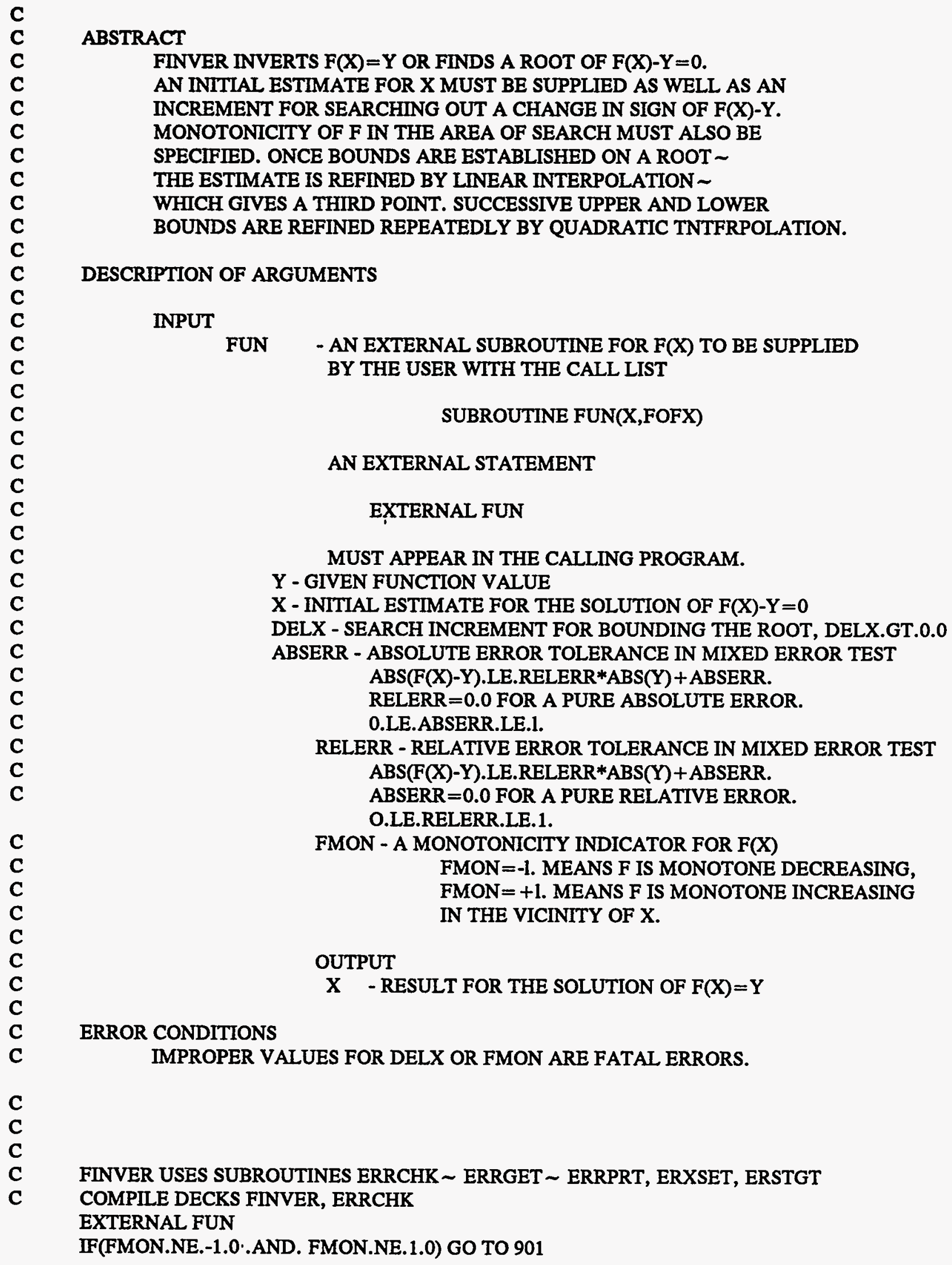




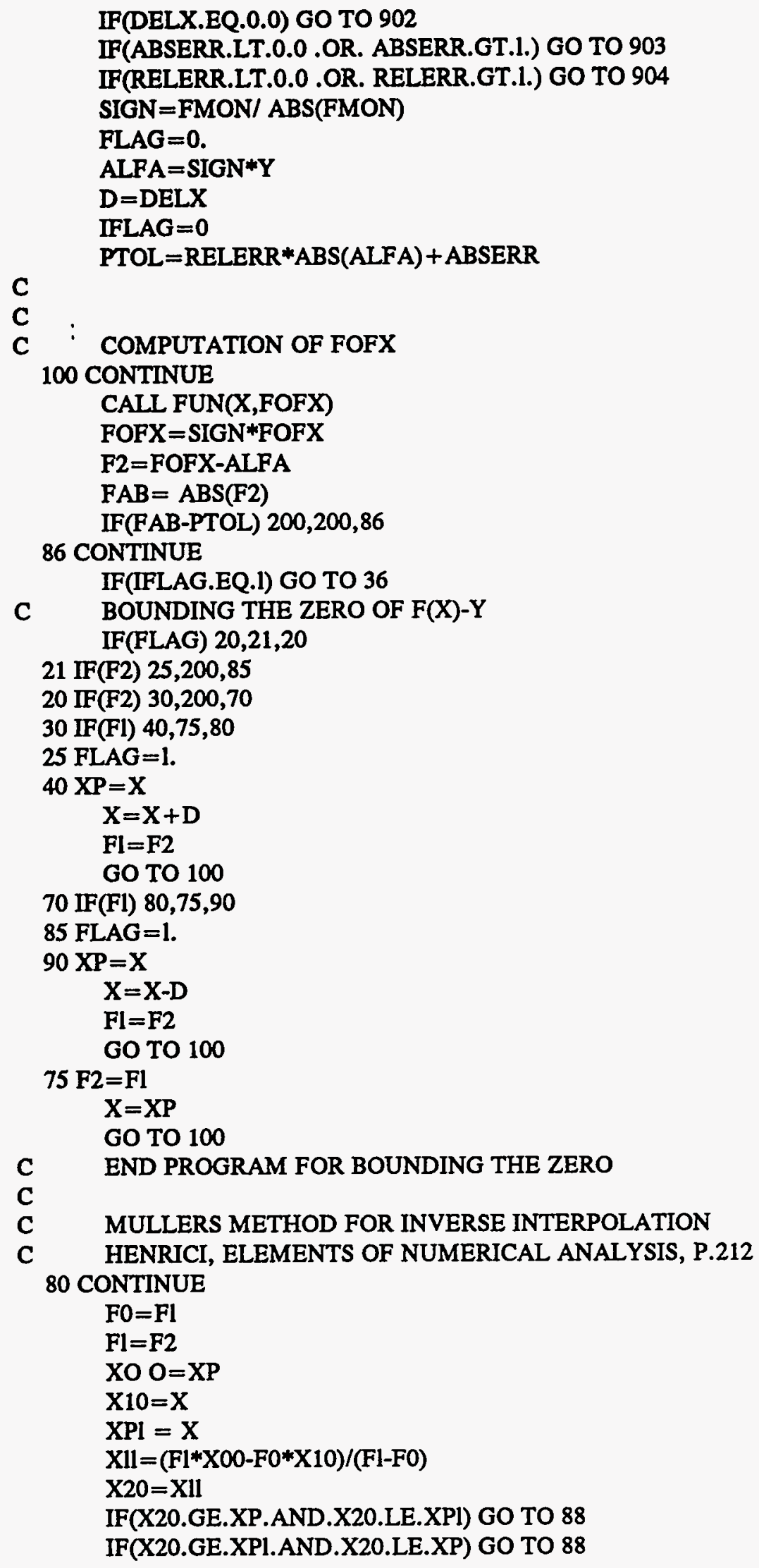


LOSP Frequency

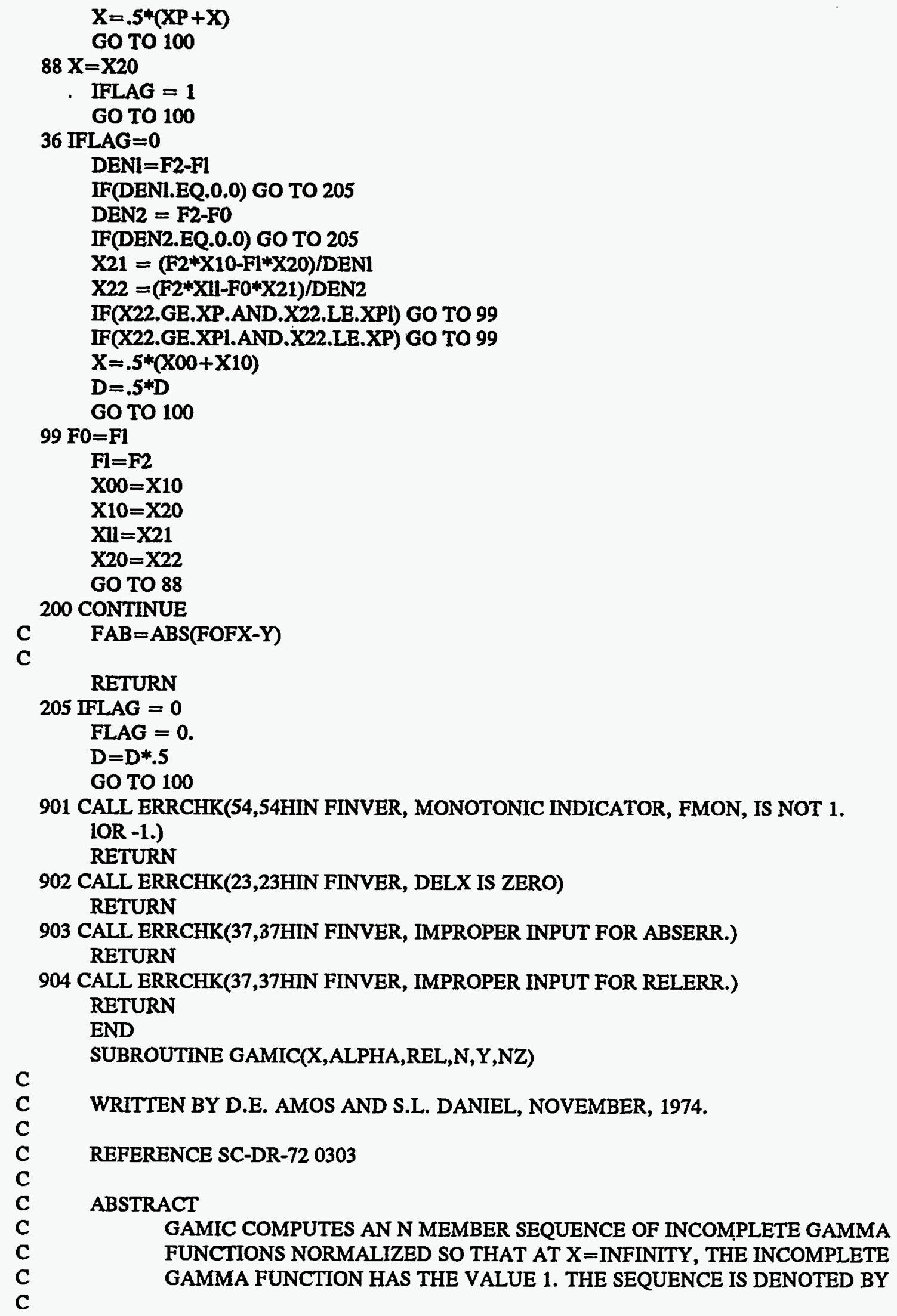


C

C

C

C

C

C

C

C

C

C

C

C

C

C

C

C

C

C

C

C

C

C

C

C

C

C

C

C

C

C

C

C

C

GAMIC USES SUBROUTINES GAMLN, ERRCHK, ERRGET, ERRPRT, ERXSET, ERSTGT

COMPILE DECKS GAMIC, GAMLN, ERRCHK

DIMENSION Y(l)

DIMENSION AA(6) BB(6), CC(5)
- ARGUMENT, X.GE.0.0

- PARAMETER, ALPHA.GT.0.0

- RELATIVE ERROR TOLERANCE, REL=1.E-S FOR $S$ SIGNIFICANT DIGITS

- NUMBER OF GAMMA FUNCTIONS IN THE SEQUENCE BEGINNING AT PARAMETER ALPHA, N.GE.1

- A VECTOR CONTAINING AN N MEMBER SEQUENCE $\mathrm{Y}(\mathrm{K})=$ INCGAMMA(ALPHA +K-1,X)/GAMMA(ALPHA + K-1), $\mathrm{K}=1, \ldots$,N TO A RELATIVE ERROR REL.

- UNDERFLOW FLAG NZ.EQ.0, A NORMAL RETURN

NZ.NE.0, UNDERFLOW, $\mathrm{Y}(\mathrm{K})=0.0, \mathrm{~K}=\mathrm{N}-\mathrm{NZ}+1, \mathrm{~N}$ RETURNED
ERROR CONDITIONS

IMPROPER INPUT PARAMETERS - A FATAL ERROR

UNDERFLOW - A NON-FATAL ERROR.

DATA AA / 1.18399941922176E +00, 3.30888136276861E + 02, $11.04930832947926 \mathrm{E}+04,3.78420325596908 \mathrm{E}+04,1.57586618187374 \mathrm{E}+02$, $21.30569632410551 \mathrm{E}+03 /$

DATA BB / 1.02652821626751E +00, 9.29753107520368E+03, $16.53848923630220 \mathrm{E}+06,2.89543295992889 \mathrm{E}+08,8.16836456953161 \mathrm{E}+03$, $24.12237656364399 \mathrm{E}+06 /$

DATA CC / 4.30952856710482E + 05, 8.27988256743362E +09, $12.41944468684445 \mathrm{E}+12,4.21722873236008 \mathrm{E}+05,7.56593802747116 \mathrm{E}+09 /$ 


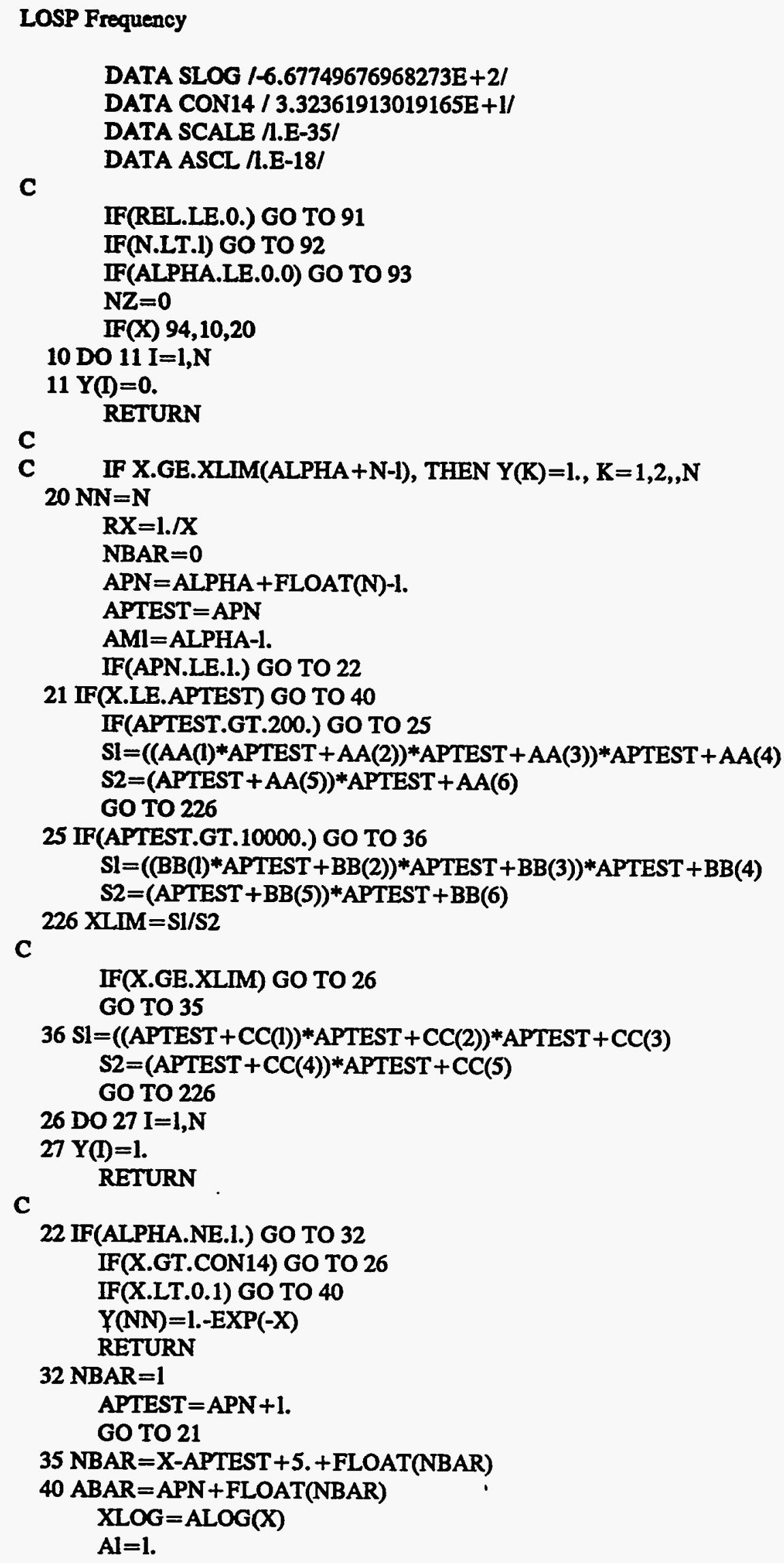




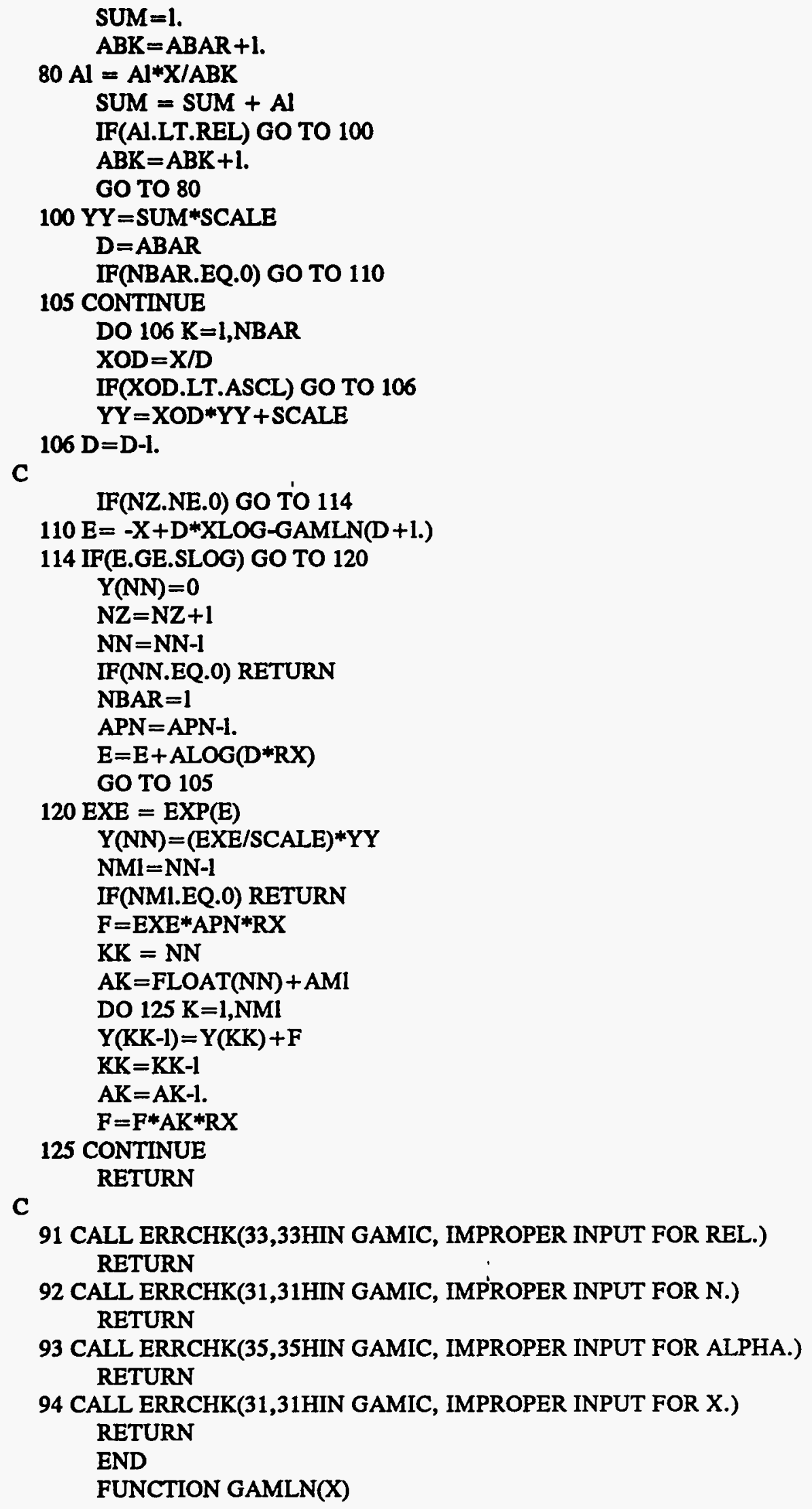




\section{LOSP Frequency}

C

C WRITEN BY D. E. AMOS, SEPTEMBER, 1977.

C

C

REFERENCES

SAND-77-1518

COMPUTER APPROXIMATIONS BY J.F.HART, ET.AL., SIAM SERIES IN APPLIED MATHEMATICS, WILEY, 1968, P.135-136.

NBS HANDBOOK OF MATHEMATICAL FUNCTIONS, AMS 55, BY M. ABRAMOWITZ AND I.A. STEGUN, DECEMBER. 1955, P.257.

ABSTRACT

GAMLN COMPUTES THE NATURAL LOG OF THE GAMMA FUNCTION FOR X.GT.O. A RATIONAL CHEBYSHEV APPROXIMATION IS USED ON 8.LT.X.LT.1000., THE ASYMPTOTIC EXPANSION FOR X.GE.1000. AND A RATIONAL CHEBYSHEV APPROXIMATION ON 2.LT.X.LT.3. FOR 0.LT.X.LT.8. AND X NON-INTEGRAL, FORWARD OR BACKWARD RECURSION FILLS IN THE INTERVALS O.LT.X.LT.2 AND 3.LT.X.LT.8. FOR $X=1 ., 2 ., \ldots, 100$., GAMLN IS SET TO NATURAL LOGS OF FACTORIALS.

DESCRIPTION OF ARGUMENTS

INPUT

X $\quad$ X.GT.0

OUTPUT

GAMLN - NATURAL LOG OF THE GAMMA FUNCTION AT X

ÉRROR CONDITIONS

IMPROPER INPUT ARGUMENT - A FATAL ERROR

C

C

C

C

C

C

GAMLN USES SUBROUTINES ERRCHK, ERRGET, ERRPRT, ERXSET, ERSTGT

COMPILE DECKS GAMLN, ERRCHK

DIMENSION GLN(100),P(5),Q(2),PCOE(9),QCOE(4)

DATA XIIMI,XLIM2,RTWPIL/ 8. | 1000. , 9.18938533204673E-01/

DATA P / 7.66345188000000E-04,-5.94095610520000E-04,

$17.93643110484500 \mathrm{E}-04,-2.77777775657725 \mathrm{E}-03,8.33333333333169 \mathrm{E}-02 /$

C

$\mathbf{C}$

DATA Q I-2.777777777777778E-03, 8.33333333333333E-02/

DATA PCOE / 2.97378664481017E-03, 9.23819455902760E-03,

1 1.09311595671044E-01, 3.98067131020357E-01, 2.15994312846059E + 00 ,

2 6.33806799938727E+00, 2.07824725317921E +01, 3.60367725300248E+01, $36.20038380071273 \mathrm{E}+01 /$

C

DATA QCOE $/ 1.00000000000000 \mathrm{E}+\infty 0,-8.90601665949746 \mathrm{E}+\infty$, $19.82252110471399 \mathrm{E}+00,6.20038380071270 \mathrm{E}+01 /$

C 
DATA(GLN(I),I=1,60) I $2 * 0.0,6.93147180559945 E-01$, $11.79175946922806 \mathrm{E}+00,3.17805383034795 \mathrm{E}+00,4.78749174278205 \mathrm{E}+\infty$, $26.57925121201010 \mathrm{E}+00,8.52516136106541 \mathrm{E}+00,1.06046029027453 \mathrm{E}+01$, $31.28018274800815 \mathrm{E}+01,1.51044125730755 \mathrm{E}+01,1.75023078458739 \mathrm{E}+01$, $41.99872144956619 \mathrm{E}+01,2.25521638531234 \mathrm{E}+01,2.51912211827387 \mathrm{E}+01$, $52.78992713838409 \mathrm{E}+01,3.06718601060807 \mathrm{E}+01,3.35050734501369 \mathrm{E}+01$, $63.63954452080331 \mathrm{E}+01,3.93398841871995 \mathrm{E}+01,4.23356164607535 \mathrm{E}+01$, $74.53801388984769 \mathrm{E}+01,4.84711813518352 \mathrm{E}+01,5.16066755677644 \mathrm{E}+01$, $85.47847293981123 \mathrm{E}+01,5.80036052229805 \mathrm{E}+01,6.12617017610020 \mathrm{E}+01$, $96.45575386270063 \mathrm{E}+01,6.78897431371815 \mathrm{E}+01,7.12570389671680 \mathrm{E}+01$, A 7.46582363488302E + 01, 7.80922235533153E +01, 8.15579594561150E +01, B 8.50544670175815E + 01, 8.85808275421977E+01, 9.21361756036871E+01, C 9.57196945421432E +01, 9.93306124547874E + 01, 1.02968198614514E+02, D 1.06631760260643E +02, 1.10320639714757E +02, 1.14034211781462E + 02, E 1.17771881399745E + 02, 1.21533081515439E + 02, 1.25317271149357E +02, F 1.29123933639127E + 02, 1.32952575035616E +02, 1.36802722637326E + 02, G 1.40673923648234E +02, 1.44565743946345E + 02, 1.48477766951773E +02, H 1.52409592584497E + 02, 1.56360836303079E + 02, 1.60331128216631E + 02, I $1.64320112263195 \mathrm{E}+02,1.68327445448428 \mathrm{E}+02,1.72352797139163 \mathrm{E}+02$, J 1.76395848406997E + 02, 1.80456291417544E + 02, 1.84533828861449E + 02/

DATA(GLN(I), $I=61,100) / 1.88628173423672 \mathrm{E}+02,1.92739047287845 \mathrm{E}+02$, $11.96866181672890 \mathrm{E}+02,2.01009316399282 \mathrm{E}+02,2.05168199482641 \mathrm{E}+02$, $22.09342586752537 \mathrm{E}+02,2.13532241494563 \mathrm{E}+02,2.17736934113954 \mathrm{E}+02$, $32.21956441819130 \mathrm{E}+02,2.26190548323728 \mathrm{E}+02,2.30439043565777 \mathrm{E}+02$, $42.34701723442818 \mathrm{E}+02,2.38978389561834 \mathrm{E}+02,2.43268849002983 \mathrm{E}+02$, $52.47572914096187 \mathrm{E}+02,2.51890402209723 \mathrm{E}+02,2.56221135550010 \mathrm{E}+02$, $62.60564940971863 \mathrm{E}+02,2.64921649798553 \mathrm{E}+02,2.69291097651020 \mathrm{E}+02$, $72.73673124285694 \mathrm{E}+02,2.78067573440366 \mathrm{E}+02,2.82474292687630 \mathrm{E}+02$, $82.86893133295427 \mathrm{E}+02,2.91323950094270 \mathrm{E}+02,2.95766601350761 \mathrm{E}+02$, $93.00220948647014 \mathrm{E}+02,3.04686856765669 \mathrm{E}+02,3.09164193580147 \mathrm{E}+02$, A 3.13652829949879E +02, 3.18152639620209E+02, 3.22663499126726E +02, B 3.27185287703775E +02, 3.31717887196928E +02, 3.36261181979198E +02, C 3.40815058870799E + 02, 3.45379407062267E + 02, 3.49954118040770E + 02, D 3.54539085519441E +02, 3.59134205369575E +02/

C

$5 \mathrm{NDX}=\mathrm{X}$

IF(X) $90,90,5$

$\mathrm{T}=\mathrm{X}-\mathrm{FLOAT}(\mathrm{NDX})$

IF(T.EQ.0.0) GO TO 51

$\mathrm{DX}=\mathrm{XLIMI}-\mathrm{X}$

IF(DX.LT.0.0) GO TO 40

c

C RATIONAL CHEBYSHEV APPROXIMATION ON 2.LT.X.LT.3 FOR GAMMA(X)

C

$\mathrm{NXM}=\mathrm{NDX}-2$

$\mathrm{PX}=\mathrm{PCOE}(\mathrm{l})$

DO $10 \mathrm{I}=2,9$

$10 \mathrm{PX}=\mathrm{T} * \mathrm{PX}+\mathrm{PCOE}(\mathrm{I})$

$\mathrm{QX}=\mathrm{QCOE}(\mathrm{l})$

DO $15 \mathrm{I}=2,4$

$15 \mathrm{QX}=\mathrm{T}^{*} \mathrm{QX}+\mathrm{QCOE}(\mathrm{I})$

$\mathrm{DGAM}=\mathrm{PX} / \mathrm{QX}$

IF(NXM.GT.0) GO TO 22 


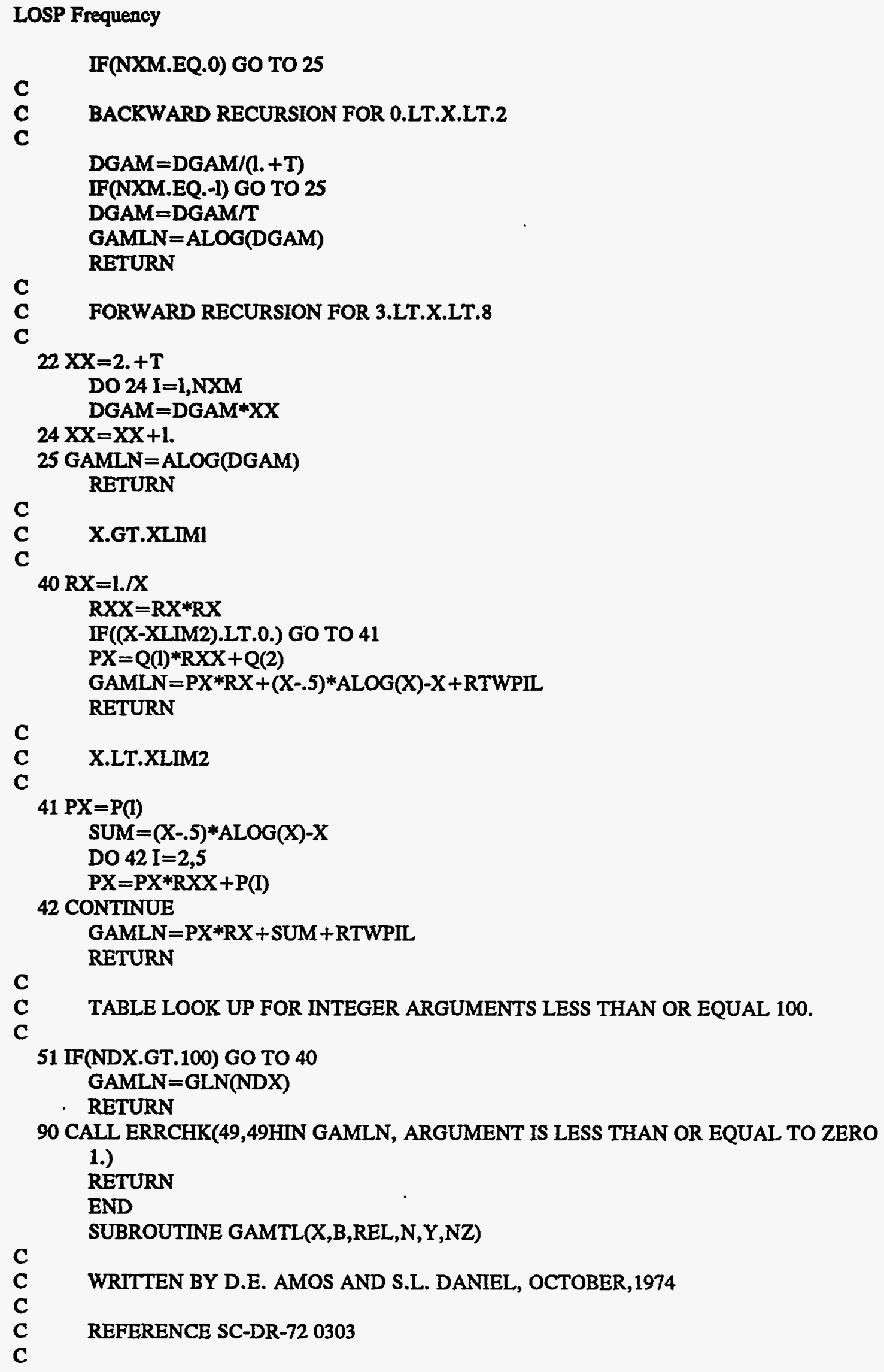




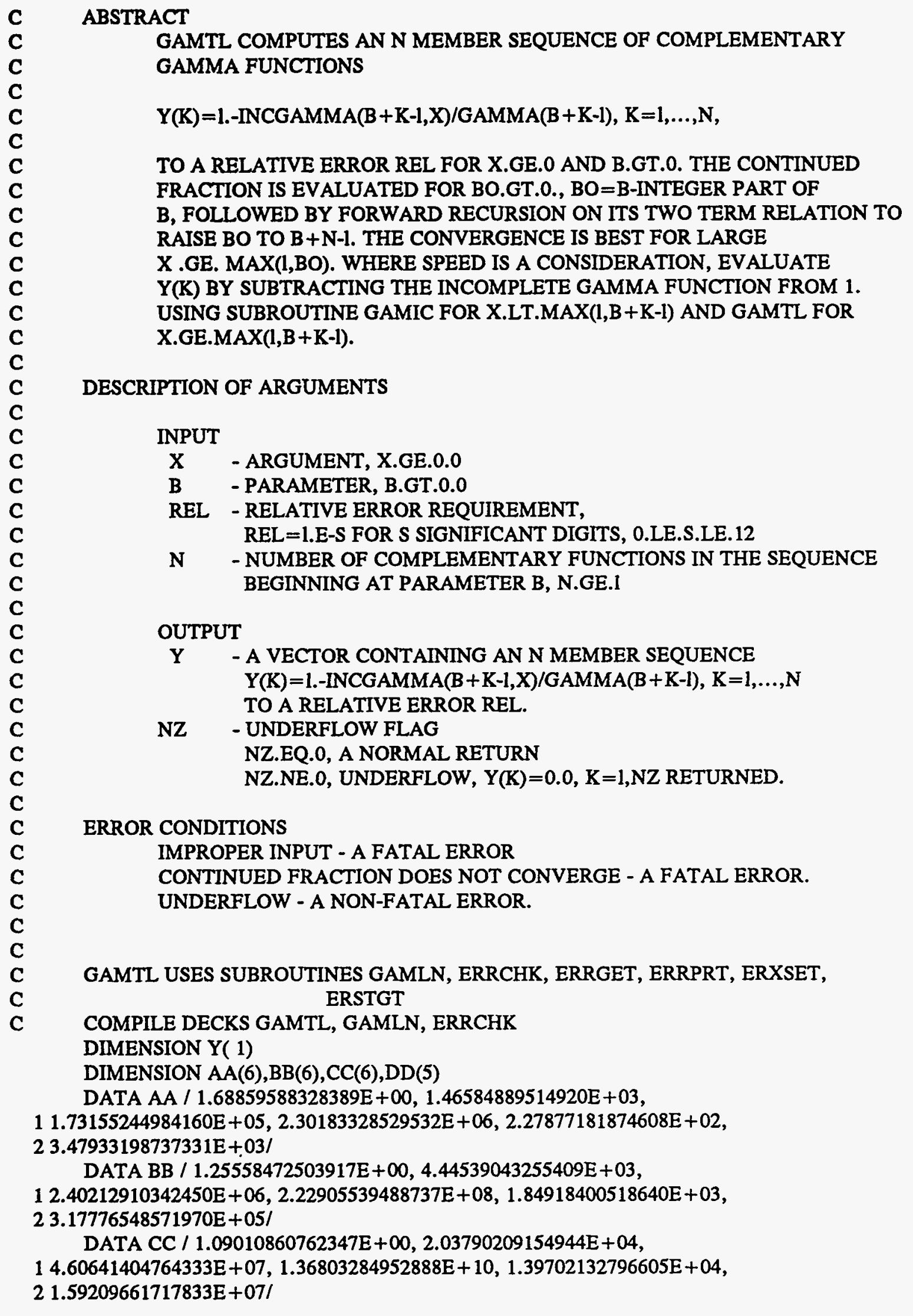


DATA DD / 4.68251145610753E + 05, 1.11348212926478E + 10,

$11.38713354995651 \mathrm{E}+13,4.29493174834810 \mathrm{E}+05,7.88439389479852 \mathrm{E}+09 /$

DATA MAXR,W,SP250,SM250,A250/1280,632.5,1.E+35,1.E-35,

$\$ 5.75646273248511 \mathrm{E}+2 /$

DATA ELIM , RLIM/ 667. , l.E-12/

IF(N.LE.0) GO TO 91

IF(B.LE.0.0) GO TO 92

$\mathrm{NZ}=0$

IF (X) $93,6,8$

6 DO $7 \mathrm{~J}=1, \mathrm{~N}$

$7 \quad \mathrm{Y}(\mathrm{J})=1$.

RETURN

8 CONTINUE

IF(REL.LT.RLIM) GO TO 94

C IF X.GE.XLIM(B $+N-1), Y(K)=0 ., K=1,2,, N$ DUE TO UNDERFLOW

C

$\mathrm{BPN}=\mathrm{B}+\mathrm{FLOAT}(\mathrm{N})-1$.

BPIEST $=$ BPN

$\mathrm{BMI}=\mathrm{B}-1$.

i IF(BPN.LE.1.) GO TO 11

IF(X.LE.BPTEST) GO TO 9

IF(BPTEST.GT.200.) GO TO 12

$\mathrm{Sl}=((\mathrm{AA}(\mathrm{l}) * \mathrm{BPTEST}+\mathrm{AA}(2)) * \mathrm{BPTEST}+\mathrm{AA}(3)) * \mathrm{BPTEST}+\mathrm{AA}(4)$

$S 2=(B P T E S T+A A(5)) * B P T E S T+A A(6)$

GO TO 15

12 IF(BPTEST.GT.1000.) GO TO 14

$\mathrm{Sl}=((\mathrm{BB}(\mathrm{l}) * \mathrm{BPTEST}+\mathrm{BB}(2)) * \mathrm{BPTEST}+\mathrm{BB}(3)) * \mathrm{BPTEST}+\mathrm{BB}(4)$

$\mathrm{S} 2=(\mathrm{BPTEST}+\mathrm{BB}(5)) * \mathrm{BPTEST}+\mathrm{BB}(6)$

GO TO 15

14 IF(BPTEST.GT.10000.) GO TO 16

$\mathrm{Sl}=((\mathrm{CC}(\mathrm{l}) * \mathrm{BPTEST}+\mathrm{CC}(2)) * \mathrm{BPTEST}+\mathrm{CC}(3)) * \mathrm{BPTEST}+\mathrm{CC}(4)$

$\mathrm{S} 2=(\mathrm{BPTEST}+\mathrm{CC}(5)) * \mathrm{BPTEST}+\mathrm{CC}(6)$

GO TO 15

$16 \mathrm{Sl}=((\mathrm{BPTEST}+\mathrm{DD}(\mathrm{l})) * \mathrm{BPTEST}+\mathrm{DD}(2)) * \mathrm{BPTEST}+\mathrm{DD}(3)$

S2 $=(B P T E S T+D D(4)) * B P T E S T+D D(5)$

$15 \mathrm{XLIM}=\mathrm{S} 1 / \mathrm{S} 2$

IF(X.GE.XLIM) GO TO 17

GO TO 9

17 DO $18 \mathrm{I}=1, \mathrm{~N}$

$18 \mathrm{Y}(\mathrm{I})=0$ -

$\mathrm{NZ}=\mathrm{N}$

RETURN

11 IF(X.LT.ELIM) GO TO 9

GO TO 17

9 CONTINUE

$\mathrm{NB}=\mathrm{B}$

$\mathrm{BO}=\mathrm{B}-\mathrm{FLOAT}(\mathrm{NB})$

IF(BO) $10,10,20$

$10 \mathrm{BO}=1$.

$\mathrm{NB}=\mathrm{NB}-1$

GBOPLX $=0$.

SCALE $=0$.

$\mathrm{Rl}=\mathbf{X}$ 


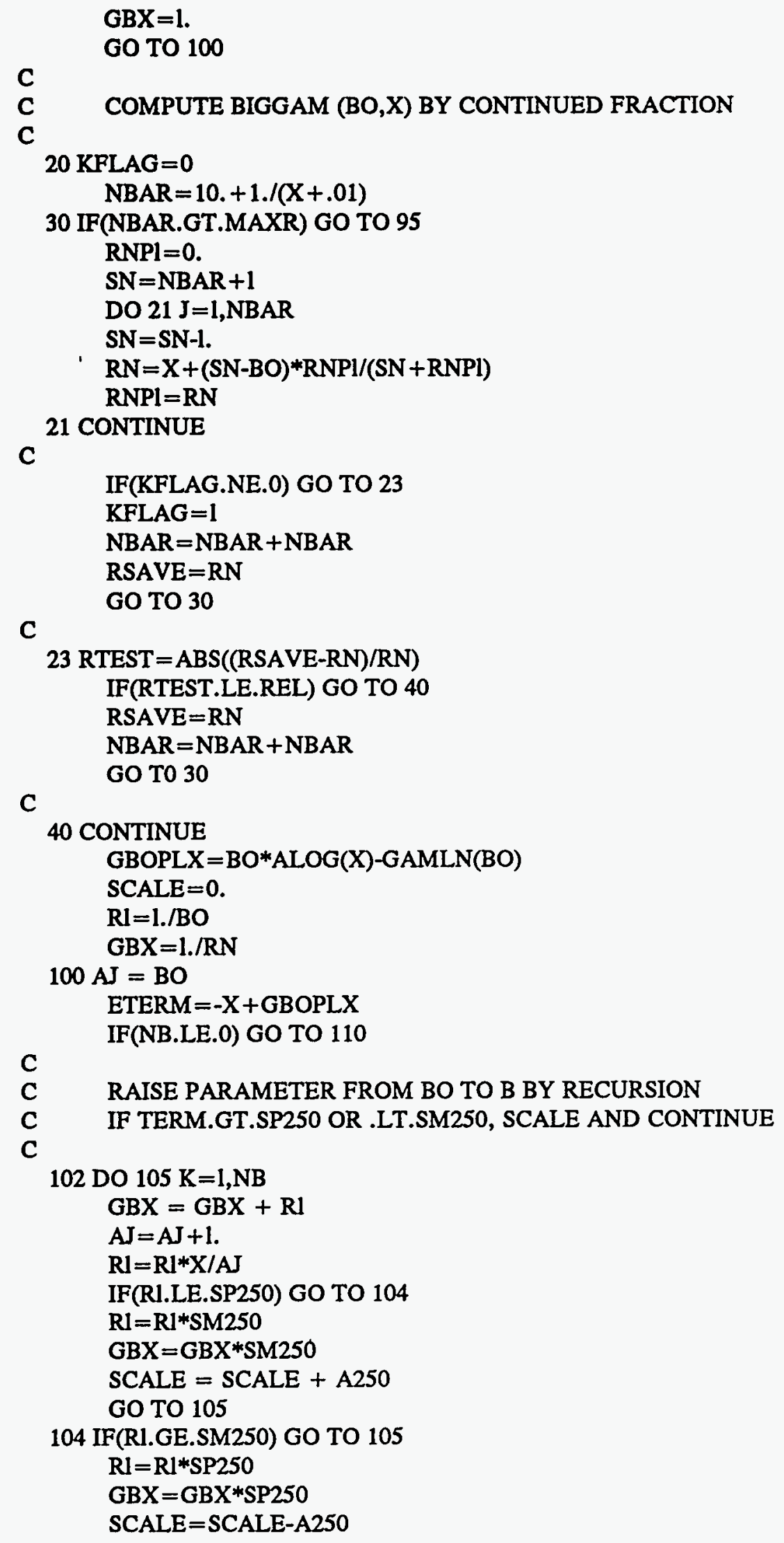




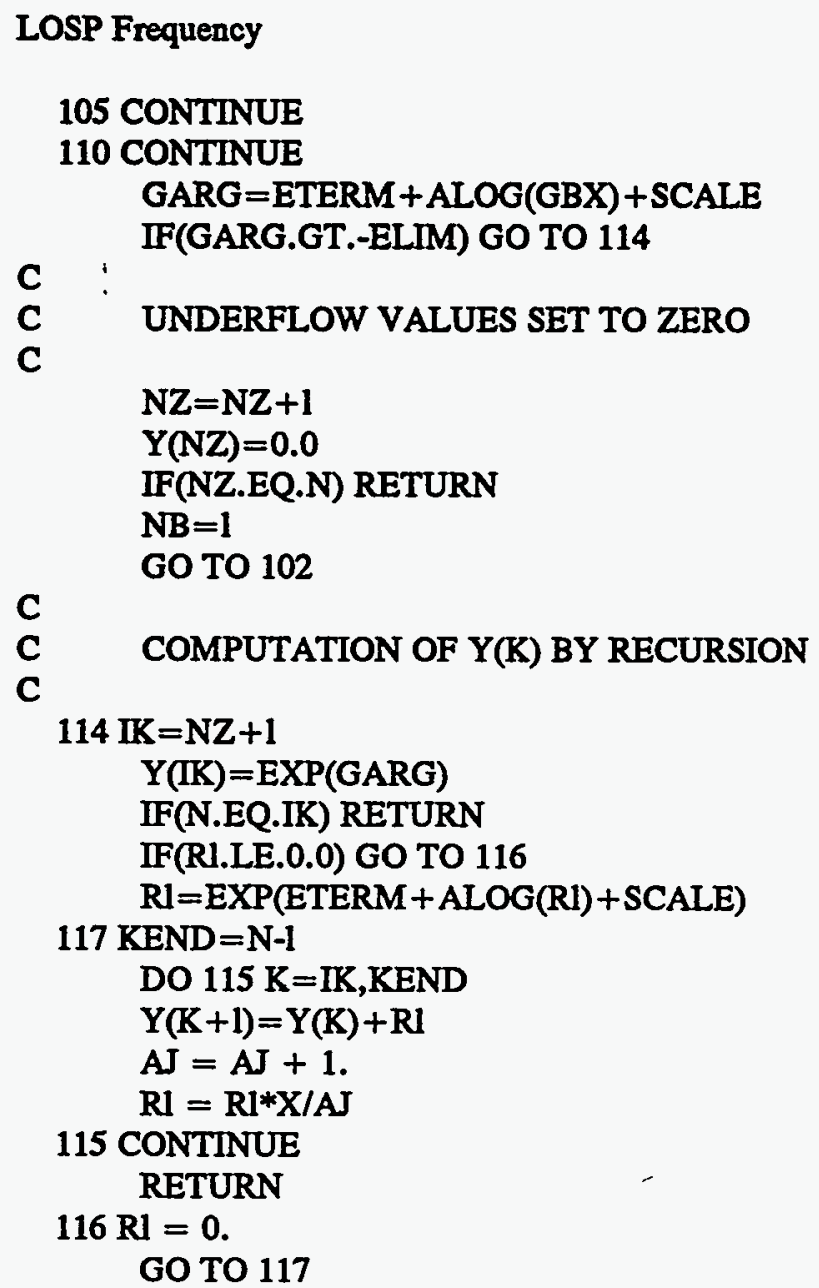




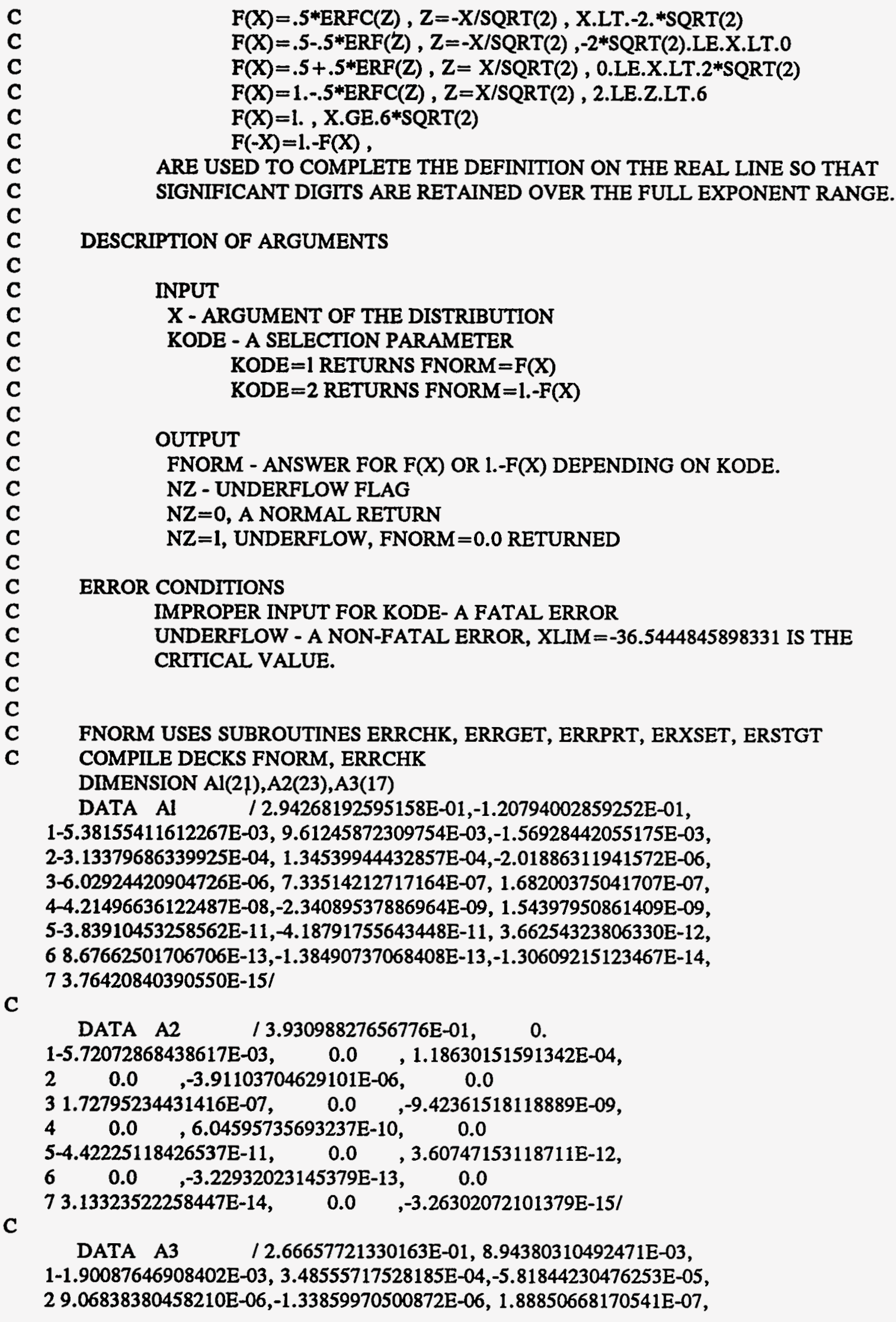


3-2.56245596590501E-08, 3.35935312400552E-09,-4.27010392442662E-10, 4 5.27726756655456E-11,-6.35545872359585E-12, 7.47249710210314E-13, 5-8.59121451944801E-14, 9.67175305486972E-15,-1.06741339515971E-15/

C

DATA RTWO,TRTWO,FRTWO,SRTWO,XLIM/

$11.41421356237310 \mathrm{E}+\infty 0,2.82842712474619 \mathrm{E}+00,5.65685424949238 \mathrm{E}+\infty$,

$28.48528137423857 \mathrm{E}+00,-3.65444845898331 \mathrm{E}+01 /$

C

C

DATA N1,N2,N3,M1,M2,M3/21,23,17,19,21,15/

IF(KODE.LT.1.OR.KODE.GT.2) GO TO 900

$\mathrm{NZ}=0$

GO TO $(100,200)$, KODE

100 CONTINUE

$\mathrm{XX}=\mathrm{X}$

150 IF(XX.GE.XLIM) GO TO 102

FNORM $=0.0$

$\mathrm{NZ}=1$

RETURN

102 IF(XX.LT.SRTWO) GO TO 104

FNORM $=10$

RETURN

104 IF(XX.LE.FRTWO) GO TO 106

ASSIGN 110 TO ISET

107 CONTINUE

$\mathrm{Z}=\mathrm{FRTWO} / \mathrm{XX}$

$\mathrm{TZ}=\mathrm{Z}+\mathrm{Z}$

$\mathrm{J}=\mathrm{N} 2 \mathrm{Bl}=\mathrm{A} 2(\mathrm{~J})$

$\mathrm{B} 2=0$.

DO $25 \mathrm{I}=1, \mathrm{M} 2$

$\mathrm{J}=\mathrm{J}-\mathrm{I}$

TEMP $=\mathrm{BI}$

$\mathrm{Bl}=\mathrm{TZ} * \mathrm{Bl}-\mathrm{B} 2+\mathrm{A} 2(\mathrm{~J})$

$\mathrm{B} 2=$ TEMP

25 CONTINUE

$\mathrm{ANS}=\mathrm{Z} * \mathrm{~B} 1-\mathrm{B} 2+\mathrm{A} 2$ (1)

FNORM $=(\operatorname{EXP}(-X X * X X * .5) / X X) * A N S$

GO TO ISET, $(110,115)$

110 FNORM $=1$.-FNORM

115 RETURN

106 IF(XX.GT.TRTWO) GO TO 112

IF(XX.LT.-TRTWO) GO TO 108

$\mathrm{Z}=\mathrm{ABS}(\mathrm{XX}) / \mathrm{RTWO}-1$.

$\mathrm{TZ}=\mathrm{Z}+\mathrm{Z}$

$\mathrm{J}=\mathrm{NI}$

$\mathrm{Bl}=\mathrm{Al}(\mathrm{J})$

$\mathrm{B} 2=0$.

DO $45 \mathrm{I}=1, \mathrm{Ml}$

$\mathrm{J}=\mathrm{J}-\mathrm{I}$

$\mathrm{TEMP}=\mathrm{Bl}$

$\mathrm{Bl}=\mathrm{TZ} * \mathrm{Bl}-\mathrm{B} 2+\mathrm{Al}(\mathrm{J})$

$\mathrm{B} 2=$ TEMP

45 CONTINUE

NUREG/CR-6143

G-186

Vol. 2, Part 2 
$\mathrm{FNORM}=\mathrm{XX} *(\mathrm{Z} * \mathrm{Bl}-\mathrm{B} 2+\mathrm{Al}(1))+0.5$

RETURN

108 IF(XX.GT.-FRTWO) GO TO 109

ASSIGN 115 TO ISET

$\mathrm{XX}=-\mathrm{XX}$ GO TO 107

109 CONTINUE XS $=-X X /$ RTWO

$113 \mathrm{Z}=\mathrm{XS}-3$.

$\mathrm{TZ}=\mathrm{Z}+\mathrm{Z}$

$\mathrm{J}=\mathrm{N} 3$

$\mathrm{Bl}=\mathrm{A} 3(\mathrm{~J})$

$\mathrm{B} 2=0$.

DO $36 \mathrm{I}=1, \mathrm{M} 3$

$\mathrm{J}=\mathrm{J}-\mathrm{I}$

TEMP $=\mathrm{Bl}$

$\mathrm{Bl}=\mathrm{TZ} * \mathrm{Bl}-\mathrm{B} 2+\mathrm{A} 3(\mathrm{~J})$

B2 $=$ TEMP

36 CONTINUE

$\mathrm{ANS}=\mathrm{Z} * \mathrm{~B} 1-\mathrm{B} 2+\mathrm{A} 3(1)$

FNORM $=$ EXP $(-X S * X S) * A N S / X S$

IF(XX.GT.0.0) FNORM=1.-FNORM

RETURN

$200 \mathrm{XX}=-\mathrm{X}$

GO TO 150

$112 \mathrm{XS}=\mathrm{XX} / \mathrm{RTWO}$

GO TO 113

900 CALL ERRCHK(34,34HIN FNORM, IMPROPER INPUT FOR KODE.)

RETURN

END 
LOSP Frequency

Attachnent G-41

GG.DAT

NUREG/CR-6143 


\section{TITLE*}

TABEL $(1,8.5,9.5,11,2,0$

I.35 > RECOVERY CURVE FOR GRAND GULF

RETURN

LOWER*

$\operatorname{LINE}(0.0000000 \mathrm{E}+00,0.1000000 \mathrm{E}+01,1$

$0.5000000 \mathrm{E}-01,0.6332765 \mathrm{E}+00$

$0.1000000 \mathrm{E}+00,0.5221666 \mathrm{E}+\infty 0$

$0.1500000 \mathrm{E}+00,0.4418805 \mathrm{E}+00$

$0.2000000 \mathrm{E}+00,0.3805399 \mathrm{E}+\infty 0$

$0.2500000 \mathrm{E}+00,0.3321897 \mathrm{E}+00$

$0.3000000 \mathrm{E}+00,0.2959414 \mathrm{E}+\infty 0$

$0.3500000 \mathrm{E}+00,0.2639019 \mathrm{E}+\infty 0$

$0.4000000 \mathrm{E}+00,0.2377258 \mathrm{E}+00$

$0.4500000 \mathrm{E}+00,0.2159356 \mathrm{E}+00$

$0.5000000 \mathrm{E}+00,0.1979217 \mathrm{E}+00$

$0.5500000 \mathrm{E}+00,0.1835196 \mathrm{E}+00$

$0.6000000 \mathrm{E}+00,0.1708331 \mathrm{E}+00$

$0.6500000 E+00,0.1598593 E+00$

$0.7000000 \mathrm{E}+00,0.1493906 \mathrm{E}+00$

$0.7500000 \mathrm{E}+00,0.1405793 \mathrm{E}+00$

$0.8000000 \mathrm{E}+00,0.1333128 \mathrm{E}+00$

$0.8500000 \mathrm{E}+00,0.1262909 \mathrm{E}+00$

$0.9000000 \mathrm{E}+00,0.1205451 \mathrm{E}+\infty$

$0.9500000 \mathrm{E}+00,0.1149577 \mathrm{E}+00$

$0.1000000 \mathrm{E}+01,0.1102719 \mathrm{E}+00$

$0.1050000 \mathrm{E}+01,0.1056353 \mathrm{E}+\infty 0$

$0.1100000 \mathrm{E}+01,0.1014440 \mathrm{E}+00$

$0.1133000 \mathrm{E}+01,0.9869112 \mathrm{E}-01$

$0.1200000 \mathrm{E}+01,0.9392024 \mathrm{E}-01$

$0.1250000 \mathrm{E}+01,0.8945530 \mathrm{E}-01$

$0.1283000 \mathrm{E}+01,0.8722764 \mathrm{E}-01$

$0.1333000 \mathrm{E}+01,0.8405942 \mathrm{E}-01$

$0.1400000 \mathrm{E}+01,0.8031324 \mathrm{E}-01$

$0.1450000 \mathrm{E}+01,0.7762612 \mathrm{E}-01$

$0.1500000 \mathrm{E}+01,0.7501823 \mathrm{E}-01$

$0.1550000 \mathrm{E}+01,0.7281739 \mathrm{E}-01$

$0.1600000 \mathrm{E}+01,0.7047690 \mathrm{E}-01$

$0.1650000 \mathrm{E}+01,0.6827596 \mathrm{E}-01$

$0.1700000 \mathrm{E}+01,0.6635383 \mathrm{E}-01$

$0.1750000 \mathrm{E}+01,0.6447174 \mathrm{E}-01$

$0.1800000 \mathrm{E}+01,0.6267905 \mathrm{E}-01$

$0.1850000 \mathrm{E}+01,0.6098870 \mathrm{E}-01$

$0.1900000 \mathrm{E}+01,0.5930665 \mathrm{E}-01$

$0.1950000 \mathrm{E}+01,0.5773523 \mathrm{E}-01$

$0.2000000 \mathrm{E}+01,0.5629625 \mathrm{E}-01$

$0.2050000 \mathrm{E}+01,0.5508481 \mathrm{E}-01$

$0.2100000 \mathrm{E}+01,0.5343305 \mathrm{E}-01$

$0.2150000 \mathrm{E}+01,0.5228697 \mathrm{E}-01$

$0.2200000 \mathrm{E}+01,0.5091853 \mathrm{E}-01$

$0.2250000 \mathrm{E}+01,0.4930571 \mathrm{E}-01$

$0.2300000 \mathrm{E}+01,0.4812152 \mathrm{E}-01$

$0.2350000 \mathrm{E}+01,0.4712099 \mathrm{E}-01$

$0.2400000 \mathrm{E}+01,0.4609329 \mathrm{E}-01$

$0.2450000 \mathrm{E}+01,0.4509338 \mathrm{E}-01$

Vol. 2, Part 2

G-189

NUREG/CR-6143 


\section{LOSP Frequency}

$0.2500000 \mathrm{E}+01,0.4413055 \mathrm{E}-01$ $0.2750000 \mathrm{E}+01,0.3985612 \mathrm{E}-01$ $0.3000000 E+01,0.3599319 E-01$ $0.3167000 \mathrm{E}+01,0.3364090 \mathrm{E}-01$ $0.3500000 \mathrm{E}+01,0.2977570 \mathrm{E}-01$ $0.3750000 \mathrm{E}+01,0.2700900 \mathrm{E}-01$ $0.4000000 \mathrm{E}+01,0.2464051 \mathrm{E}-01$ $0.4250000 \mathrm{E}+01,0.2305845 \mathrm{E}-01$ $0.4500000 \mathrm{E}+01,0.2131568 \mathrm{E}-01$ $0.4750000 \mathrm{E}+01,0.1970513 \mathrm{E}-01$ $0.5000000 \mathrm{E}+01,0.1842000 \mathrm{E}-01$ $0.5250000 \mathrm{E}+01,0.1704338 \mathrm{E}-01$ $0.5500000 \mathrm{E}+01,0.1558531 \mathrm{E}-01$ $0.5750000 E+01,0.1451475 E-01$ $0.6000000 \mathrm{E}+01,0.1370299 \mathrm{E}-01$ $0.6250000 \mathrm{E}+01,0.1289671 \mathrm{E}-01$ $0.6500000 \mathrm{E}+01,0.1204479 \mathrm{E}-01$ $0.6750000 \mathrm{E}+01,0.1111974 \mathrm{E}-01$ $0.7000000 \mathrm{E}+01,0.1035678 \mathrm{E}-01$ $0.7250000 \mathrm{E}+01,0.9655474 \mathrm{E}-02$ $0.7500000 \mathrm{E}+01,0.8968785 \mathrm{E}-02$ $0.7750000 \mathrm{E}+01,0.8355397 \mathrm{E}-02$ $0.8000000 E+01,0.7840881 E-02$ $0.8250000 \mathrm{E}+01,0.7255260 \mathrm{E}-02$ $0.8500000 \mathrm{E}+01,0.6714201 \mathrm{E}-02$ $0.8750000 \mathrm{E}+01,0.6235197 \mathrm{E}-02$ $0.9000000 \mathrm{E}+01,0.5782876 \mathrm{E}-02$ $0.9250000 \mathrm{E}+01,0.5418809 \mathrm{E}-02$ $0.9500000 \mathrm{E}+01,0.5086483 \mathrm{E}-02$ $0.9750000 \mathrm{E}+01,0.4756637 \mathrm{E}-02$ $0.1000000 \mathrm{E}+02,0.4432298 \mathrm{E}-02$ $0.1330000 E+02,0.1716932 E-02$ $0.1500000 E+02,0.1068773 E-02$ $0.1600000 E+02,0.7913224 E-03$ $0.1800000 \mathrm{E}+02,0.4602075 \mathrm{E}-03$ $0.2300000 \mathrm{E}+02,0.1144893 \mathrm{E}-03$ $0.2700000 \mathrm{E}+02,0.4291907 \mathrm{E}-04,2$ RETURN

MEDIAN*

$\operatorname{LINE}(0.0000000 \mathrm{E}+00,0.1000000 \mathrm{E}+01,1$

$0.5000000 \mathrm{E}-01,0.7463541 \mathrm{E}+00$

$0.1000000 \mathrm{E}+00,0.6327068 \mathrm{E}+00$

$0.1500000 \mathrm{E}+\infty, 0.5513938 \mathrm{E}+\infty 0$

$0.2000000 \mathrm{E}+00,0.4899929 \mathrm{E}+00$

$0.2500000 \mathrm{E}+00,0.4406971 \mathrm{E}+00$

$0.3000000 \mathrm{E}+00,0.4001229 \mathrm{E}+00$

$0.3500000 \mathrm{E}+00,0.3628054 \mathrm{E}+00$

$0.4000000 \mathrm{E}+00,0.3333218 \mathrm{E}+00$

$0.4500000 \mathrm{E}+00,0.3073997 \mathrm{E}+00$

$0.5000000 \mathrm{E}+00,0.2850477 \mathrm{E}+\infty 0$

$0.5500000 \mathrm{E}+00,0.2652728 \mathrm{E}+00$

$0.6000000 \mathrm{E}+00,0.2483225 \mathrm{E}+00$

$0.6500000 \mathrm{E}+00,0.2333687 \mathrm{E}+00$

$0.7000000 \mathrm{E}+00,0.2203711 \mathrm{E}+00$

$0.7500000 \mathrm{E}+\infty, 0.2097112 \mathrm{E}+\infty$ 
$0.8000000 \mathrm{E}+\infty 0,0.1992576 \mathrm{E}+\infty 0$ $0.8500000 \mathrm{E}+00,0.1902534 \mathrm{E}+00$ $0.9000000 \mathrm{E}+00,0.1825861 \mathrm{E}+00$ $0.9500000 \mathrm{E}+00,0.1743934 \mathrm{E}+00$ $0.1000000 \mathrm{E}+01,0.1675142 \mathrm{E}+00$ $0.1050000 \mathrm{E}+01,0.1616396 \mathrm{E}+\infty 0$ $0.1100000 E+01,0.1559624 E+\infty 0$ $0.1133000 \mathrm{E}+01,0.1521893 \mathrm{E}+\infty 0$ $0.1200000 \mathrm{E}+01,0.1468149 \mathrm{E}+00$ $0.1250000 \mathrm{E}+01,0.1425016 \mathrm{E}+00$ $0.1283000 \mathrm{E}+01,0.1393100 \mathrm{E}+\infty$ $0.1333000 \mathrm{E}+01,0.1357623 \mathrm{E}+00$ $0.1400000 \mathrm{E}+01,0.1306901 \mathrm{E}+\infty 0$ $0.1450000 \mathrm{E}+01,0.1270454 \mathrm{E}+\infty 0$ $0.1500000 \mathrm{E}+01,0.1232989 \mathrm{E}+00$ $0.1550000 \mathrm{E}+01,0.1200562 \mathrm{E}+00$ $0.1600000 \mathrm{E}+01,0.1172448 \mathrm{E}+\infty 0$ $0.1650000 \mathrm{E}+01,0.1145043 \mathrm{E}+00$ $0.1700000 \mathrm{E}+01,0.1116334 \mathrm{E}+00$ $0.1750000 \mathrm{E}+01,0.1090089 \mathrm{E}+00$ $0.1800000 \mathrm{E}+01,0.1066669 \mathrm{E}+00$ $0.1850000 \mathrm{E}+01,0.1041265 \mathrm{E}+00$ $0.1900000 \mathrm{E}+01,0.1020300 \mathrm{E}+00$ $0.1950000 \mathrm{E}+01,0.9953812 \mathrm{E}-01$ $0.2000000 \mathrm{E}+01,0.9761813 \mathrm{E}-01$ $0.2050000 \mathrm{E}+01,0.9561905 \mathrm{E}-01$ $0.2100000 \mathrm{E}+01,0.9363572 \mathrm{E}-01$ $0.2150000 \mathrm{E}+01,0.9173092 \mathrm{E}-01$ $0.2200000 \mathrm{E}+01,0.8988579 \mathrm{E}-01$ $0.2250000 \mathrm{E}+01,0.8837061 \mathrm{E}-01$ $0.2300000 \mathrm{E}+01,0.8693677 \mathrm{E}-01$ $0.2350000 \mathrm{E}+01,0.8543687 \mathrm{E}-01$ $0.2400000 \mathrm{E}+01,0.8396951 \mathrm{E}-01$ $0.2450000 \mathrm{E}+01,0.8256046 \mathrm{E}-01$ $0.2500000 \mathrm{E}+01,0.8126954 \mathrm{E}-01$ $0.2750000 \mathrm{E}+01,0.7452092 \mathrm{E}-01$ $0.3000000 \mathrm{E}+01,0.6894428 \mathrm{E}-01$ $0.3167000 \mathrm{E}+01,0.6517889 \mathrm{E}-01$ $0.3500000 \mathrm{E}+01,0.5970375 \mathrm{E}-01$ $0.3750000 \mathrm{E}+01,0.5649908 \mathrm{E}-01$ $0.4000000 \mathrm{E}+01,0.5294258 \mathrm{E}-01$ $0.4250000 \mathrm{E}+01,0.4993482 \mathrm{E}-01$ $0.4500000 \mathrm{E}+01,0.4706598 \mathrm{E}-01$ $0.4750000 \mathrm{E}+01,0.4466926 \mathrm{E}-01$ $0.5000000 \mathrm{E}+01,0.4245387 \mathrm{E}-01$ $0.5250000 \mathrm{E}+01,0.4051010 \mathrm{E}-01$ $0.5500000 \mathrm{E}+01,0.3881580 \mathrm{E}-01$ $0.5750000 \mathrm{E}+01,0.3692094 \mathrm{E}-01$ $0.6000000 \mathrm{E}+01,0.3515644 \mathrm{E}-01$ $0.6250000 \mathrm{E}+01,0.3354414 \mathrm{E}-01$ $0.6500000 \mathrm{E}+01,0.3214720 \mathrm{E}-01$ $0.6750000 \mathrm{E}+01,0.3076831 \mathrm{E}-01$ $0.7000000 \mathrm{E}+01,0.2945143 \mathrm{E}-01$

$0.7250000 \mathrm{E}+01,0.2812898 \mathrm{E}-01$

$0.7500000 \mathrm{E}+01,0.2681594 \mathrm{E}-01$ 
LOSP Frequency

$0.7750000 E+01,0.2568585 E-01$

$0.800000 \mathrm{OE}+01,0.2471176 \mathrm{E}-01$

$0.8250000 \mathrm{E}+01,0.2344669 \mathrm{E}-01$

$0.8500000 \mathrm{E}+01,0.2230225 \mathrm{E}-01$

$0.8750000 \mathrm{E}+01,0.2121469 \mathrm{E}-01$

$0.9000000 \mathrm{E}+01,0.2026050 \mathrm{E}-01$

$0.9250000 \mathrm{E}+01,0.1950373 \mathrm{E}-01$

$0.9500000 \mathrm{E}+01,0.1871312 \mathrm{E}-01$

$0.9750000 \mathrm{E}+01,0.1803369 \mathrm{E}-01$

$0.1000000 \mathrm{E}+02,0.1727138 \mathrm{E}-01$

$0.1330000 \mathrm{E}+02,0.1065451 \mathrm{E}-01$

$0.1500000 \mathrm{E}+02,0.8241972 \mathrm{E}-02$

$0.1600000 \mathrm{E}+02,0.7000074 \mathrm{E}-02$

$0.1800000 \mathrm{E}+02,0.5302712 \mathrm{E}-02$

$0.2300000 \mathrm{E}+02,0.2524897 \mathrm{E}-02$

$0.2700000 \mathrm{E}+02,0.1405742 \mathrm{E}-02,2$

ETURN

UPPER*

LINE( $0.000000 \mathrm{E}+00,0.1000000 \mathrm{E}+01,1$

$0.5000000 \mathrm{E}-01,0.8269160 \mathrm{E}+00$

$0.1000000 \mathrm{E}+00,0.7265984 \mathrm{E}+00$

$0.1500000 \mathrm{E}+00,0.6552023 \mathrm{E}+00$

$0.2000000 \mathrm{E}+00,0.6002278 \mathrm{E}+00$

$0.2500000 \mathrm{E}+00,0.5536128 \mathrm{E}+00$

$0.3000000 \mathrm{E}+00,0.5119509 \mathrm{E}+00$

$0.3500000 \mathrm{E}+00,0.4762957 \mathrm{E}+00$

$0.4000000 E+00,0.4432515 E+00$

$0.4500000 \mathrm{E}+00,0.4168997 \mathrm{E}+00$

$0.5000000 \mathrm{E}+00,0.3915053 \mathrm{E}+00$

$0.5500000 \mathrm{E}+00,0.3703218 \mathrm{E}+\infty 0$

$0.6000000 \mathrm{E}+00,0.3497718 \mathrm{E}+\infty$

$0.6500000 \mathrm{E}+00,0.3339318 \mathrm{E}+00$

$0.7000000 E+00,0.3173733 E+00$

$0.7500000 \mathrm{E}+00,0.3034671 \mathrm{E}+00$

$0.8000000 \mathrm{E}+00,0.2909432 \mathrm{E}+00$

$0.8500000 \mathrm{E}+00,0.2791729 \mathrm{E}+00$

$0.9000000 \mathrm{E}+00,0.2671401 \mathrm{E}+00$

$0.9500000 \mathrm{E}+00,0.2573200 \mathrm{E}+00$

$0.1000000 \mathrm{E}+01,0.2478499 \mathrm{E}+00$

$0.1050000 E+01,0.2388053 E+00$

$0.1100000 \mathrm{E}+01,0.2307131 \mathrm{E}+00$

$0.1133000 \mathrm{E}+01,0.2259223 \mathrm{E}+00$

$0.1200000 \mathrm{E}+01,0.2174941 \mathrm{E}+00$

$0.1250000 \mathrm{E}+01,0.2112151 \mathrm{E}+\infty 0$

$0.1283000 \mathrm{E}+01,0.2075935 \mathrm{E}+00$

$0.1333000 \mathrm{E}+01,0.2024275 \mathrm{E}+00$

$0.1400000 E+01,0.1960352 E+00$

$0.1450000 \mathrm{E}+01,0.1915764 \mathrm{E}+00$

$0.1500000 \mathrm{E}+01,0.1879017 \mathrm{E}+00$

$0.1550000 \mathrm{E}+01,0.1843548 \mathrm{E}+00$

$0.1600000 \mathrm{E}+01,0.1809978 \mathrm{E}+00$

$0.1650000 \mathrm{E}+01,0.1770544 \mathrm{E}+00$

$0.1700000 \mathrm{E}+01,0.1745154 \mathrm{E}+00$

$0.1750000 E+01,0.1718642 E+00$

$0.1800000 \mathrm{E}+01,0.1693036 \mathrm{E}+00$ 
$0.1850000 \mathrm{E}+01,0.1652479 \mathrm{E}+00$ $0.1900000 E+01,0.1621052 E+00$ $0.1950000 \mathrm{E}+01,0.1594075 \mathrm{E}+00$ $0.2000000 \mathrm{E}+01,0.1562051 \mathrm{E}+\infty 0$ $0.2050000 \mathrm{E}+01,0.1529781 \mathrm{E}+00$ $0.2100000 \mathrm{E}+01,0.1505008 \mathrm{E}+00$ $0.2150000 \mathrm{E}+01,0.1481019 \mathrm{E}+00$ $0.2200000 \mathrm{E}+01,0.1457740 \mathrm{E}+\infty 0$ $0.2250000 \mathrm{E}+01,0.1435089 \mathrm{E}+00$ $0.2300000 \mathrm{E}+01,0.1412663 \mathrm{E}+00$ $0.2350000 \mathrm{E}+01,0.1389527 \mathrm{E}+\infty 0$ $0.2400000 E+01,0.1368531 E+00$ $0.2450000 \mathrm{E}+01,0.1348111 \mathrm{E}+\infty 0$ $0.2500000 \mathrm{E}+01,0.1328239 \mathrm{E}+00$ $0.2750000 \mathrm{E}+01,0.1253677 \mathrm{E}+\infty 0$ $0.3000000 \mathrm{E}+01,0.1184479 \mathrm{E}+00$ $0.3167000 \mathrm{E}+01,0.1137395 \mathrm{E}+00$ $0.3500000 \mathrm{E}+01,0.1056090 \mathrm{E}+00$ $0.3750000 \mathrm{E}+01,0.9968156 \mathrm{E}-01$ $0.4000000 \mathrm{E}+01,0.9447845 \mathrm{E}-01$ $0.4250000 \mathrm{E}+01,0.9048945 \mathrm{E}-01$ $0.4500000 \mathrm{E}+01,0.8682710 \mathrm{E}-01$ $0.4750000 \mathrm{E}+01,0.8340991 \mathrm{E}-01$ $0.5000000 \mathrm{E}+01,0.8040784 \mathrm{E}-01$ $0.5250000 \mathrm{E}+01,0.7825368 \mathrm{E}-01$ $0.5500000 \mathrm{E}+01,0.7641406 \mathrm{E}-01$ $0.5750000 \mathrm{E}+01,0.7468758 \mathrm{E}-01$ $0.6000000 \mathrm{E}+01,0.7307281 \mathrm{E}-01$ $0.6250000 \mathrm{E}+01,0.7154985 \mathrm{E}-01$ $0.6500000 \mathrm{E}+01,0.7011337 \mathrm{E}-01$ $0.6750000 \mathrm{E}+01,0.6821700 \mathrm{E}-01$ $0.7000000 \mathrm{E}+01,0.6626640 \mathrm{E}-01$ $0.7250000 \mathrm{E}+01,0.6491457 \mathrm{E}-01$ $0.7500000 \mathrm{E}+01,0.6326144 \mathrm{E}-01$ $0.7750000 \mathrm{E}+01,0.6150336 \mathrm{E}-01$ $0.8000000 \mathrm{E}+01,0.5973991 \mathrm{E}-01$ $0.8250000 \mathrm{E}+01,0.5795457 \mathrm{E}-01$ $0.8500000 \mathrm{E}+01,0.5645822 \mathrm{E}-01$ $0.8750000 \mathrm{E}+01,0.5527582 \mathrm{E}-01$ $0.9000000 \mathrm{E}+01,0.5412262 \mathrm{E}-01$ $0.9250000 \mathrm{E}+01,0.5270466 \mathrm{E}-01$ $0.9500000 \mathrm{E}+01,0.5174899 \mathrm{E}-01$ $0.9750000 E+01,0.5086838 E-01$ $0.1000000 \mathrm{E}+02,0.4984432 \mathrm{E}-01$ $0.1330000 \mathrm{E}+02,0.3822363 \mathrm{E}-01$ $0.1500000 \mathrm{E}+02,0.3366899 \mathrm{E}-01$ $0.1600000 \mathrm{E}+02,0.3180100 \mathrm{E}-01$ $0.1800000 \mathrm{E}+02,0.2834608 \mathrm{E}-01$ $0.2300000 \mathrm{E}+02,0.2041070 \mathrm{E}-01$ $0.2700000 \mathrm{E}+02,0.1534511 \mathrm{E}-01,2$ RETURN 
Attachment G-42

COMMEAN.FOR 
PROGRAM COMMEAN

C COMPUTE MEAN FOR EACH TIME STEP PRODUCED BY 'MODEL'.

C 'MODEL' NAMES THE PLOT FILE 'plant name'.DAT. THAT NAME IS

C CHANGED TO MAP.DAT SO THAT RMAPPER CAN BE USED WITHOUT CHANGE.

C THIS PROGRAM PRODUCES A PLOT FILE, 'MEAN.DAT', THAT IS USED

C IN THE CONTROL STREAM IN 'UPPER.DAT'.

C TO GET A,PLOT:

C MAPPER device name

C The response to ENTER OPTIONS is

C I=UPPER.DAT

PARAMETER(NOT $=88$ )

DIMENSION XVAL(NOT,3),XMEAN(NOT),TIM(NOT),EF(NOT)

CHARACTER LINE*80

OPEN (10,FILE = 'MAP.DAT',READONLY,STATUS=' OLD')

OPEN (12,FILE ='LOGNORMAL.DAT',STATUS='NEW')

OPEN $(13$, FILE = 'MEAN.DAT',STATUS ='NEW')

$1 \quad X M E A N(I)=0$.

DO $2 M=1,5$

READ(10,'(A)')LINE

2

WRITE(13,'(A)')LINE

2 CONTINUE

$\mathrm{DO} 50 \mathrm{~J}=1,3$

$\operatorname{READ}(10,11)$ TIM(1),XVAL(1,J)

11 FORMAT(6X,E14.3,1X,E14.3)

DO $10 \mathrm{I}=2$, NOT

READ $(10, *)$ TIM(I),XVAL(I,J)

TYPE*,TIM(I),XVAL(I,J)

10 CONTINUE

READ(10,'(A)')LINE

READ(10,'(A)',END=99)

50 CONTINUE

C COMPUTE ERROR FACTOR

60 DO $100 \mathrm{I}=1, \mathrm{NOT}$

IF(XVAL(I,l).EQ.0)THEN

TYPE *,I

ENDIF

$\mathrm{EF}(\mathrm{I})=\mathrm{XVAL}(\mathrm{I}, 2) / \mathrm{XVAL}(\mathrm{I}, \mathrm{l})$

100 CONTINUE

WRITE $(12,110)$

110 FORMAT('TIME ',' EF ',' MEAN ')

DO $120 \mathrm{I}=1$,NOT

WRITE(12,111)TIM(I),EF(I),XMEAN(I)

111 FORMAT(F8.2,4X,4X,F4.1,4X,IPE12.3)

112 FORMAT('SLINE(',E14.3,',',E14.3,',1')

113 FORMAT(E14.7,', E14.7)

114 FORMAT(E14.3,';'E14.3,',2')

IF(I.EQ.1)WRITE(13,112)TIM(I),XMEAN(I)

IF(I.EQ.NOT)THEN

WRITE(13,114)TIM(I),XMEAN(I)

GO TO 120

ENDIF

WRITE(13,113)TIM(I),XMFAN(I)

120 CONTINUE

WRITE $(13,115)$

115 FORMAT('RETURN')

STOP

99 GO TO 60

END 
Attachment G-43

LOGNORMAL.DAT 


\begin{tabular}{lcc} 
TIME & EF & MEAN \\
0.00 & 1.0 & $1.000 \mathrm{E}+00$ \\
0.05 & 1.2 & $7.501 \mathrm{E}-01$ \\
0.10 & 1.2 & $6.370 \mathrm{E}-01$ \\
0.15 & 1.2 & $5.564 \mathrm{E}-01$ \\
0.20 & 1.3 & $4.958 \mathrm{E}-01$ \\
0.25 & 1.3 & $4.472 \mathrm{E}-01$ \\
0.30 & 1.4 & $4.069 \mathrm{E}-01$ \\
0.35 & 1.4 & $3.697 \mathrm{E}-01$ \\
0.40 & 1.4 & $3.404 \mathrm{E}-01$ \\
0.45 & 1.4 & $3.146 \mathrm{E}-01$ \\
0.50 & 1.4 & $2.921 \mathrm{E}-01$ \\
0.55 & 1.4 & $2.720 \mathrm{E}-01$ \\
0.60 & 1.5 & $2.548 \mathrm{E}-01$ \\
0.65 & 1.5 & $2.396 \mathrm{E}-01$ \\
0.70 & 1.5 & $2.266 \mathrm{E}-01$ \\
0.75 & 1.5 & $2.160 \mathrm{E}-01$ \\
0.80 & 1.5 & $2.053 \mathrm{E}-01$ \\
0.85 & 1.5 & $1.962 \mathrm{E}-01$ \\
0.90 & 1.5 & $1.885 \mathrm{E}-01$ \\
0.95 & 1.5 & $1.801 \mathrm{E}-01$ \\
1.00 & 1.5 & $1.730 \mathrm{E}-01$ \\
1.05 & 1.5 & $1.671 \mathrm{E}-01$ \\
1.10 & 1.5 & $1.614 \mathrm{E}-01$ \\
1.13 & 1.5 & $1.575 \mathrm{E}-01$ \\
1.20 & 1.6 & $1.523 \mathrm{E}-01$ \\
1.25 & 1.6 & $1.483 \mathrm{E}-01$ \\
1.28 & 1.6 & $1.451 \mathrm{E}-01$ \\
1.33 & 1.6 & $1.416 \mathrm{E}-01$ \\
1.40 & 1.6 & $1.365 \mathrm{E}-01$ \\
1.45 & 1.6 & $1.329 \mathrm{E}-01$ \\
1.50 & 1.6 & $1.290 \mathrm{E}-01$ \\
1.55 & 1.6 & $1.257 \mathrm{E}-01$ \\
1.60 & 1.7 & $1.230 \mathrm{E}-01$ \\
1.65 & 1.7 & $1.203 \mathrm{E}-01$ \\
1.70 & 1.7 & $1.173 \mathrm{E}-01$ \\
1.75 & 1.7 & $1.147 \mathrm{E}-01$ \\
1.80 & 1.7 & $1.124 \mathrm{E}-01$ \\
1.85 & 1.7 & $1.098 \mathrm{E}-01$ \\
1.90 & 1.7 & $1.077 \mathrm{E}-01$ \\
1.95 & 1.7 & $1.051 \mathrm{E}-01$ \\
2.00 & 1.7 & $1.032 \mathrm{E}-01$ \\
2.05 & 1.7 & $1.011 \mathrm{E}-01$ \\
2.10 & 1.8 & $9.923 \mathrm{E}-02$ \\
2.15 & 1.8 & $9.724 \mathrm{E}-02$ \\
2.20 & 1.8 & $9.540 \mathrm{E}-02$ \\
2.25 & 1.8 & $9.410 \mathrm{E}-02$ \\
2.30 & 1.8 & $9.273 \mathrm{E}-02$ \\
2.75 & 1.8 & $9.120 \mathrm{E}-02$ \\
& 1.8 & $8.973 \mathrm{E}-02$ \\
& 1.8 & $8.832 \mathrm{E}-02$ \\
$8.706 \mathrm{E}-02$ \\
8.9 & $8.010 \mathrm{E}-02$ \\
\hline
\end{tabular}

$\begin{array}{llc}\text { TIME } & \text { EF } & \text { MEAN } \\ 3.00 & 1.9 & 7.453 \mathrm{E}-02 \\ 3.17 & 1.9 & 7.066 \mathrm{E}-02 \\ 3.50 & 2.0 & 6.528 \mathrm{E}-02 \\ 3.75 & 2.1 & 6.247 \mathrm{E}-02 \\ 4.00 & 2.1 & 5.898 \mathrm{E}-02 \\ 4.25 & 2.2 & 5.575 \mathrm{E}-02 \\ 4.50 & 2.2 & 5.284 \mathrm{E}-02 \\ 4.75 & 2.3 & 5.054 \mathrm{E}-02 \\ 5.00 & 2.3 & 4.828 \mathrm{E}-02 \\ 5.25 & 2.4 & 4.652 \mathrm{E}-02 \\ 5.50 & 2.5 & 4.526 \mathrm{E}-02 \\ 5.75 & 2.5 & 4.336 \mathrm{E}-02 \\ 6.00 & 2.6 & 4.141 \mathrm{E}-02 \\ 6.25 & 2.6 & 3.970 \mathrm{E}-02 \\ 6.50 & 2.7 & 3.840 \mathrm{E}-02 \\ 6.75 & 2.8 & 3.725 \mathrm{E}-02 \\ 7.00 & 2.8 & 3.603 \mathrm{E}-02 \\ 7.25 & 2.9 & 3.474 \mathrm{E}-02 \\ 7.50 & 3.0 & 3.346 \mathrm{E}-02 \\ 7.75 & 3.1 & 3.242 \mathrm{E}-02 \\ 8.00 & 3.2 & 3.151 \mathrm{E}-02 \\ 8.25 & 3.2 & 3.022 \mathrm{E}-02 \\ 8.50 & 3.3 & 2.910 \mathrm{E}-02 \\ 8.75 & 3.4 & 2.798 \mathrm{E}-02 \\ 9.00 & 3.5 & 2.708 \mathrm{E}-02 \\ 9.25 & 3.6 & 2.640 \mathrm{E}-02 \\ 9.50 & 3.7 & 2.559 \mathrm{E}-02 \\ 9.75 & 3.8 & 2.503 \mathrm{E}-02 \\ 10.00 & 3.9 & 2.430 \mathrm{E}-02 \\ 13.30 & 6.2 & 1.970 \mathrm{E}-02 \\ 15.00 & 7.7 & 1.780 \mathrm{E}-02 \\ 16.00 & 8.8 & 1.682 \mathrm{E}-02 \\ 18.00 & 11.5 & 1.597 \mathrm{E}-02 \\ 23.00 & 22.1 & 1.476 \mathrm{E}-02 \\ 27.00 & 32.8 & 1.328 \mathrm{E}-02\end{array}$

G-197
NUREG/CR-6143 
LOSP Frequency

Attachment G-44

LHS Input File: LOSP.EKI 
$\$$ Developed 9/8/93

$\$$ LHS and LHSPOST Keywords for LOSP CF

$\$$

LHSTITL RLOSP SAMPLE FOR LEVEL I

LHJOBS 500

LHSPEED 1

LHSPVAL 1

LHSMSG C:ILPSIPOSSILOSP.LMO

LHSOUT C:ILPSIPOSSILOSP.LSP

LHSPOST C:ILPSIPOS5ILOSP.MSP

$\$$

DATASET:

RNLOSP 250 UNIFORM 1.0 500.9999

PNTLOSP $250=$ INT( RNLOSP )

LAMDG 2.OE-3 LOGNORMAL 2.OE-3 10

LAM-DG 2.OE-3 = LAMDG

PNRDGDG2 0.87 MAXIMUM ENTROPY O.087 0.87 1.0

PNR-DG2 $0.87=$ PNRDG2

PNRDG3 0.80 MAXIMUM ENTROPY 0.080 .801 .0

PNR-DG3 $0.80=$ PNRDG3

PNRDG35 0.9 MAXIMUM ENTROPY 0.0775 0.7751 .0

PNR-DG35 $0.775=$ PNRDG35

PNRDG5 0.7 MAXIMUM ENTROPY 0.07 0.7 1.0

PNR-DG5 $0.7=$ PNRDG5

PNRDG6 0.65 MAXIMUM ENTROPY 0.0650 .651 .0

PNR-DG6 $0.65=$ PNRDG6

PNRDGII 0.48 MAXIMUM ENTROPY 0.0480 .481 .0

PNR-DGII $0.48=$ PNRDGII

PNRDG14 0.41 MAXIMUM ENTROPY 0.0410 .411 .0

PNR-DG14 0.41 = PNRDG14

$\$$

PNRCMDG2 0.77 MAXIMUM ENTROPY 0.077 0.77 1.0

PNRCM-DG2 0.77 = PNRCMDG2

PNRCMDG3 0.70 MAXIMUM ENTROPY 0.07 0.70 1.0

PNRCM-DG3 $0.70=$ PNRCMDG3

PNRCMDG35 0.675 MAXIMUM ENTROPY 0.06750 .6751 .0

PNRCM-DG35 0.675 = PNRCMDG35

PNRCMDG5 0.6 MAXIMUM ENTROPY 0.060 .61 .0

PNRCM-DG5 0.6 = PNRCMDG5

PNRCMDG6 0.55 MAXIMUM ENTROPY 0.0550 .551 .0

PNRCM-DG6 0.55 = PNRCMDG6

PNRCMDGII 0.29 MAXIMUM ENTROPY 0.029 0.29 1.0

PNRCM-DGll 0.29 = PNRCMDGll

PNRCMDG14 0.24 MAXIMUM ENTROPY 0.024 0.24 1.0

PNRCM-DG14 0.24 = PNRCMDG14 
LOSP Frequency

Attachment G-45

FORTRAN Program: RLOSP 
C

PROGRAM RLOSP

PARAMETER (NPT $=86$, NOBS $=500$, NLHS $=500$, NTIME $=7$, NVAR $1=7$, NVAR2 $=7$ )

CHARACTER*10 NAME

INTEGER IN, OUT, OUT1, OUT2,OUT3,OUT4

EXTERNAL EQ2

DOUBLE PRECISION TSTRI,TM,TCD,LAMDG,TCDVEC(NTIME),TEND

DOUBLE PRECISION H,HMIN,HMAX,EMIN,EMAX,TPRCV(NPT), XINTRP

DOUBLE PRECISION VPDGI(NVAR1), VPDG2(NVAR2), LDGPTE

DOUBLE PRECISION CFI(NTIME),CF2(NTIME),CF3(NTIME),CF4(NTIME)

DOUBLE PRECISION PNRMN(NPT),PNRDAT(NOBS,NPT), PRCV(NPT,2)

DOUBLE PRECISION X, XCTCD(NTIME), XMNTCD(NTIME)

DOUBLE PRECISION T, TCTCD(NTIME), TMNTCD(NTIME)

COMMON /VSETI/ TCD, LAMDG

COMMON /PRDATA/ PRCV, NTIMPT

COMMON /INOUT/IN, OUT

DATA IN2,IN3/8,9/

DATA OUT1,OUT2,OUT3,OUT4/11,12,13,14/

DATA TCDVEC/2.0, 3.0, 3.5, 5.0, 6.0, 11.0, 14.0/

NTIMPT $=$ NPT

$\mathrm{IN}=7$

C

OUT $=10$

C INPUT FILES

C

C

OPEN(UNIT $=$ IN2, STATUS $=$ 'OLD', FILE $=$ 'C:IF77L3ILPSFORILOSP.MSP')

OPEN(UNIT =IN3, STATUS='OLD', FILE='C:IF77L3ILPSFORIRLOSPCUR.LPS')

C OUTPUT FILES

C

OPEN(UNIT = OUT, FILE = 'C:IF77L3ILPSFORIRLOSP.OUT')

OPEN(UNIT = OUT1,FILE $=$ 'C: $:$ F77L3ILPSFOR ICF1.OUT')

OPEN(UNIT $=$ OUT2,FILE ='C:IF77L3\LPSFORICF2.OUT')

OPEN(UNIT =OUT3,FILE $=$ 'C:IF77L3ILPSFORICF3.OUT')

OPEN(UNIT = OUT4,FILE='C:IF77L3ILPSFORICF4.OUT')

C INITIALIZE VARIABLES

TSTR1 $=0.0$

TEND $=24.0$

LAMDG $=2.0 \mathrm{D}-03$

LDGPTE $=$ LAMDG

C TOLERANCES FOR INTEGRATION

.

HMIN $=3 \mathrm{D}-7$

HMAX $=20.0$

EMIN $=0.0$

EMAX $=1 \mathrm{D}-4$

ITMAX $=1000000$

C= 


\section{READ INPUT FILE}

READ(IN3,*)NCURVE,IMAX

C CHECK TO MAKE SURE DIMENSIONS ARE CORRECT IF(NPT .NE. IMAX + 1)THEN WRITE(OUT,920)

920. FORMAT(IX, 'ERROR: NUMBER OF POINTS (IMAX) EXCEEDS DIMENSION') STOP ELSEIF(NOBS .NE. NCURVE)THEN WRITE(OUT,921)

921. FORMAT(IX,'ERROR: NUMBER OF POWER CURVES EXCEEDS DIMENSION') STOP ENDIF

READ(IN3,*)(TPRCV(J+1),J=1,IMAX)

$\operatorname{TPRCV}(1)=0.0$

READ(IN3,*)(PNRMN(J+1),J=1,IMAX)

PNRMN(1) $=1.0$

DO $65 \mathrm{I}=1$, NCURVE

READ(IN3,*)(PNRDAT(I,J+1),J =1,IMAX)

$\operatorname{PNRDAT}(\mathrm{I}, \mathrm{l})=1.0$

CONTINUE

C READ LHS FILE

C ICHK $=1$

1 IF(ICHK.EQ. 1)THEN

READ(IN2,801,END=999)NAME

801 FORMAT(LX,A10)

IF(NAME.EQ.'SAMPLEDATA')ICHK $=0$ GOTO 1

C ENDIF

C SELECT MEAN POWER NON-RECOVERY CURVE

C

DO $70 \mathrm{I}=1$,NPT

$\operatorname{PRCV}(1,1)=$ TPRCV(I)

PRCV(I,2) $=$ PNRMN(I)

70

CONTINUE

DO 85 L2 $=1$,NTIME

TM $=$ TEND

c

$\mathrm{TCD}=\mathrm{TCDVEC}(\mathrm{L} 2)$

C CALL INTEGRATION SUBROUTINE

C

C IFLAG $=0$; SUCCESSFUL PROCEDURE

C IFLAG $=1 ;$ H OUT OF RANGE

C IFLAG $=2$; H OUT OF RANGE AT ENDPOINT

C IFLAG = 3; MAXIMUM NUMBER OF ITERATIONS REACHED

C

C INITIAL CONDITIONS FOR INTEGRATION 
$X=0.0$

$\mathrm{T}=\mathrm{TSTR} 1$

$\mathrm{H}=0.1$

CALL RK45AD(EQ2,T,X,H,TM,ITMAX,EMIN,EMAX,HMIN,HMAX,IFLAG) XMNTCD(L2) = X

TMNTCD(L2) $=$ T 85 CONTINUE

WRITE(OUT,940)

940 FORMAT(IX, 'CF2 WITHOUT DENOMINATOR FOR MEAN CURVE')

WRITE(OUT,950)(TCDVEC(I), I=1,NTIME)

950 FORMAT(IX,7(1X,'TIME-',F4.1,1X),/1X)

WRITE(OUT,951)(XMNTCD(I),I=1,NTIME)

951 FORMAT(IX,7(IX,IPE10.3))

C

C WRITE OUTPUT FILE HEADER c WRITE(OUT1,942)

942 FORMAT(IX,'CFl: POWER NON-RECOVERY CURVES') WRITE(OUT1,950)(TCDVEC(I),I=1,NTIME) WRITE(OUT2,944)

944 FORMAT(IX,'CF2: LOSP AS I.E: D FAILS TO RUN') WRITE(OUT2,950)(TCDVEC(I),I=1,NTIME) WRITE(OUT3,946)

946 FORMAT(IX,'CF3: LOSP AS I.E: DG FAILS TO START') WRITE(OUT3,950)(TCDVEC(I),I=1,NTIME) WRITE(OUT4,948)

948 FORMAT(IX,'CF4: LOSP AS I.E: DG FAILS TO START COMMON MODE')

WRITE(OUT4,950)(TCDVEC(I),I=1,NTIME)

C LHS LOOP

C

DO $30 \mathrm{Ll}=1, \mathrm{NLHS}$

READ(IN2,*)DUM1,DUM2,LHSPNT,LAMDG,(VPDGI(I),I=1,NVARl),

C

$+\quad$ (VPDG2(I),I=1,NVAR2)

C SELECT APPROPRIATE POWER NON-RECOVERY CURVE

C

DO $75 \mathrm{I}=1, \mathrm{NPT}$

$\operatorname{PRCV}(\mathrm{I}, 1)=\operatorname{TPRCV}(\mathrm{I})$

PRCV $(1,2)=$ PNRDAT $($ LHSPNT, 1$)$

75 CONTINUE

C PERFORM CALCULATIONS FOR EACH CORE DAMAGE TIME

C

DO 80 L2 $=1$, NTIME

TM $=$ TEND

TCD = TCDVEC(L2)

C CASE 1: CF = NON-RECOVERY CURVES

CFl(L2) $=$ XINTRP(TCD,PRCV,NPT)

C

C CASE 2: CF = LOSS OF OFFSITE POWER AS I.E.: DG FAILS TO RUN

C

C CALL INTEGRATION SUBROUTINE

C INITIAL CONDITIONS FOR INTEGRATION

C

$\mathrm{X}=\mathbf{0 . 0}$

$\mathrm{T}=\mathrm{TSTR} \mathbf{I}$

$\mathrm{H}=0.1$

CALL RK45AD(EQ2,T,X,H,TM,ITMAX,EMIN,EMAX,HMIN,HMAX,IFLAG)

$\mathrm{XCTCD}(\mathrm{L} 2)=\mathrm{X}$ 


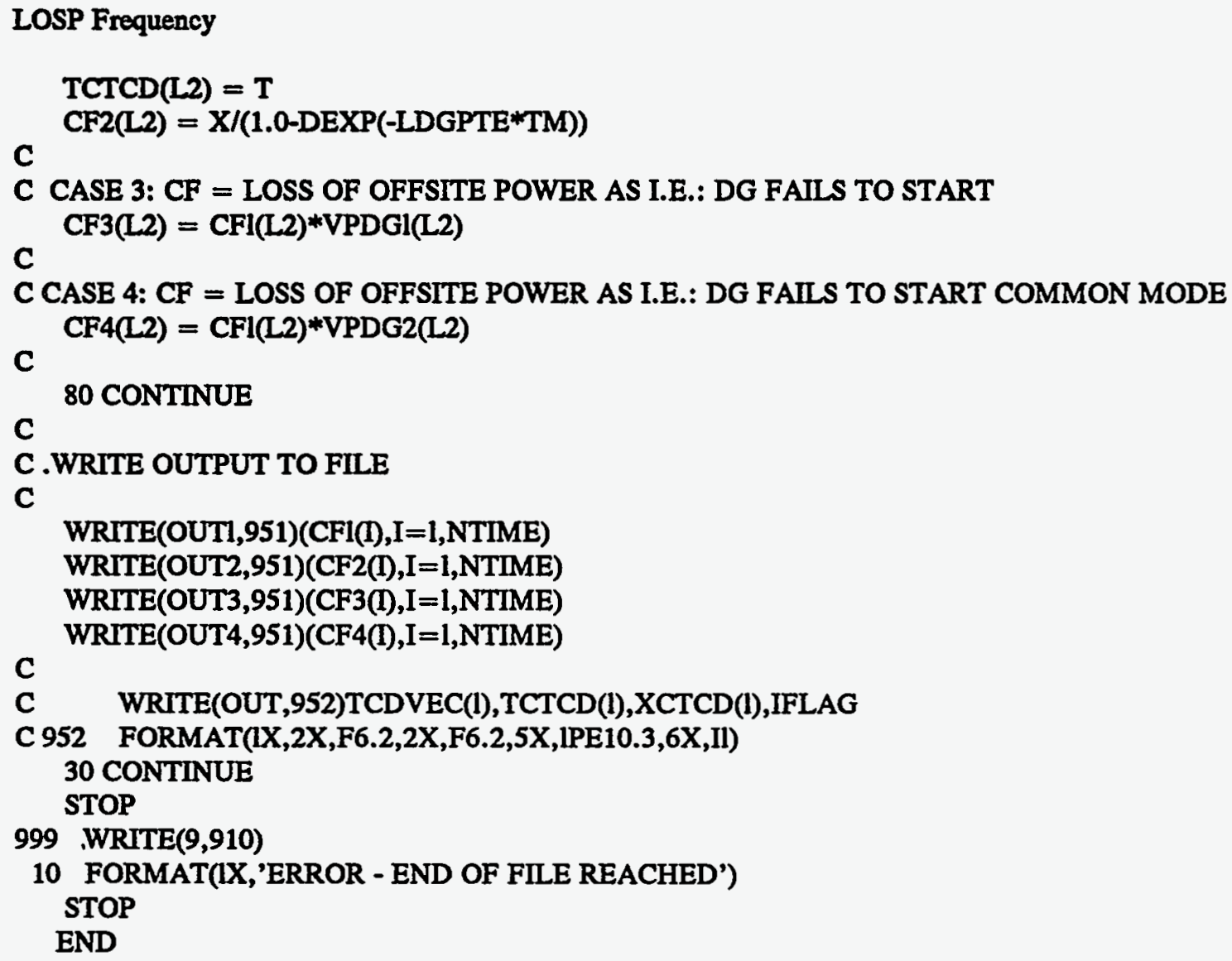

C FUNCTION USED TO EVALUATE CASE 2: LOSP I.E \& DG FAILS TO RUN

DOUBLE PRECISION FUNCTION EQ2(T,X)

DOUBLE PRECISION T, $X, X I N T R P$

DOUBLE PRECISION TCD, LAMDG

DOUBLE PRECISION TRCV, PRCV, PNR

COMMON /VSETI/ TCD, LAMDG

COMMON /PRDATA/ PRCV(86,2),NTIMPT

$\mathrm{TRCV}=\mathrm{T}+\mathrm{TCD}$

PNR $=$ XINTRP(TRCV, PRCV,NTIMPT)

$\mathrm{EQ} 2=\mathrm{LAMDG} * \mathrm{DEXP}(-\mathrm{LAMDG} * \mathrm{~T}) * \mathrm{PNR}$

RETURN

END

C ADAPTATIVE STEPPING ROUTINE FOR RUNGE-KUTTA

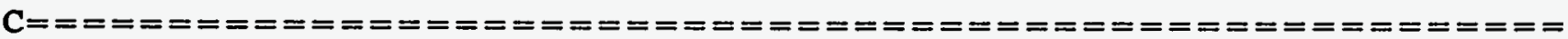
SUBROUTINE RK45AD(F,T,X,H,TB,ITMAX,EMIN,EMAX,HMIN,HMAX,IFLAG)

EXTERNAL F

DOUBLE PRECISION F,T,X,H,TB,EMIN,EMAX,HMIN,HMAX

DOUBLE PRECISION EPSI,DT,XSAVE,TSAVE,EST

INTEGER IN, OUT

COMMON /INOUT/ IN, OUT 
DATA EPSI/0.5D-10/

IFLAG $=3$

NSTEP $=0$

$2 \quad \mathrm{DT}=\mathrm{DABS}(\mathrm{TB}-\mathrm{T})$

IF(DT .GT. DABS(H)) GOTO 3

IFLAG $=0$

IF(DT .LE. EPSI*DMAXI(DABS(TB),DABS(T))) RETURN

$\mathbf{H}=\mathrm{DSIGN}(\mathrm{DT}, \mathrm{H})$

IF(HMIN .LE. DABS(H) .AND. DABS(H) .LE. HMAX) GOTO 3

IFLAG $=2$

RETURN

3 XSAVE $=X$

TSAVE $=\mathrm{T}$

CALL RK45(F,T,X,H,EST)

NSTEP $=$ NSTEP +1

IF(NSTEP .GT. ITMAX .OR. IFLAG .EQ. 0) RETURN

IF(EST .LT. EMIN) GOTO 4

IF(EST .LE. EMAX) GOTO 2

$\mathrm{H}=0.5 * \mathrm{H}$

GOTO 5

$4 \mathrm{H}=2.0 * \mathrm{H}$

$5 \mathrm{X}=\mathrm{XSAVE}$

$T=$ TSAVE

IF(HMIN .LE. DABS(H) .AND. DABS(H) .LE. HMAX) GOTO 2

IFLAG $=1$

RETURN

END

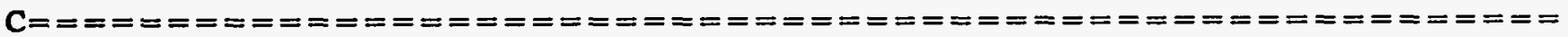
C RUNGE-KUTTA INTEGRATION ROUTINE

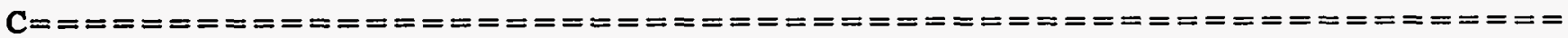

C

SUBROUTINE RK45(F, T,X,H,EST)

EXTERNAL F

DOUBLE PRECISION F,T,X,H,EST

DOUBLE PRECISION C21,C31,C32,C41,C42,C43,C51,C52,C53,C54

DOUBLE PRECISION C61,C62,C63,C64,C65,Al,A3,A4,A5

DOUBLE PRECISION BI,B3, B4,B5,B6, C40,Fl,F2,F3,F4,F5, F6, X5

DATA C21,C31,C32,C41,C42,C43,C51,C52,C53,C54,

$+\mathrm{C} 61, \mathrm{C} 62, \mathrm{C} 63, \mathrm{C} 64, \mathrm{C} 65, \mathrm{Al}, \mathrm{A} 3, \mathrm{~A} 4, \mathrm{~A} 5, \mathrm{Bl}, \mathrm{B} 3, \mathrm{~B} 4, \mathrm{~B} 5, \mathrm{~B} 6, \mathrm{C} 40$

$+10.25,0.09375,0.28125$,

$+0.87938097405553,-3.27719617660446,3.32089212562585$,

$+2.0324074074074,-8.0,7.17348927875244,-0.20589668615984$,

$+-0.2962962962963,2.0,-1.38167641325536,0.45297270955166,-0.275$

$+0.11574074074074,0.54892787524366,0.5353313840156,-0.2$,

$+0.11851851851852,0.51898635477583,0.50613149034201,-0.18$,

$+0.0363636363636364,0.923076923076921$

$\mathrm{Fl}=\mathrm{H} * \mathrm{~F}(\mathrm{~T}, \mathrm{X}) \mathrm{F} 2=\mathrm{H} * \mathrm{~F}(\mathrm{~T}+0.25 * \mathrm{H}, \mathrm{X}+\mathrm{C} 21 * \mathrm{~F} 1)$

$\mathrm{F} 3=\mathrm{H} * \mathrm{~F}(\mathrm{~T}+0.375 * \mathrm{H}, \mathrm{X}+\mathrm{C} 31 * \mathrm{Fl}+\mathrm{C} 32 * \mathrm{~F} 2)$

$\mathrm{F} 4=\mathrm{H} * \mathrm{~F}(\mathrm{~T}+\mathrm{C} 40 * \mathrm{H}, \mathrm{X}+\mathrm{C} 41 * \mathrm{~F} 1+\mathrm{C} 42 * \mathrm{~F} 2+\mathrm{C} 43 * \mathrm{~F} 3)$

Vol. 2, Part 2 
$\mathrm{F} 5=\mathrm{H} * \mathrm{~F}(\mathrm{~T}+\mathrm{H}, \quad \mathrm{X}+\mathrm{C5} 1 * \mathrm{~F} 1+\mathrm{C} 52 * \mathrm{~F} 2+\mathrm{C} 53 * \mathrm{~F} 3+\mathrm{C} 54 * \mathrm{~F} 4)$

$\mathrm{F} 6=\mathrm{H} * \mathrm{~F}(\mathrm{~T}+0.5 * \mathrm{H}, \mathrm{X}+\mathrm{C} 61 * \mathrm{~F} 1+\mathrm{C} 62 * \mathrm{~F} 2+\mathrm{C} 63 * \mathrm{~F} 3+\mathrm{C} 64 * \mathrm{~F} 4+\mathrm{C} 65 * \mathrm{~F} 5)$

$\mathrm{X} 5=\dot{\mathrm{X}}+\mathrm{B} 1 * \mathrm{~F} 1+\mathrm{B} 3 * \mathrm{~F} 3+\mathrm{B} 4 * \mathrm{~F} 4+\mathrm{B} 5 * \mathrm{~F} 5+\mathrm{B} 6 * \mathrm{~F} 6$

$\mathrm{X}=\mathrm{X}+\mathrm{Al} * \mathrm{Fl}+\mathrm{A} 3 * \mathrm{~F} 3+\mathrm{A} 4 * \mathrm{~F} 4+\mathrm{A} 5 * \mathrm{~F} 5 \mathrm{~T}=\mathrm{T}+\mathrm{H}$

EST $=$ DABS $(X-X 5)$ RETURN END

C LINEAR INTERPOLATION ROUTINE

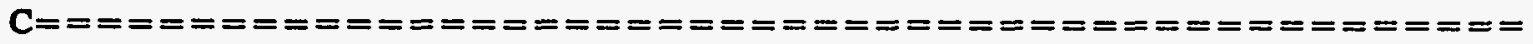

C THIS FUNCTION PERFORMS A LINEAR INTERPOLATION

C T(MMAX,2) $=2$ DIMENSIONAL ARRAY

C T $(I, 1)=X$ DATA

$\mathrm{C} T(\mathrm{I}, 2)=\mathrm{Y}$ DATA

C IMAX = TOTAL NUMBER OF X VALUES (AND ALSO $Y$ VALUES)

C X $\quad X$ VALUE FOR WHICH A Y VALUE WILL BE CALCULATED

DOUBLE PRECISION FUNCTION XINTRP(X,T,IMAX)

DOUBLE PRECISION T(IMAX,2), X, XLO, XHI, YLO, YHI

C IF THE VALUE OF $X$ IS GREATER THAN THE LAST VALUE IN T, SET Y TO THE

C LAST VALUE IN T

IF(X .GT. T(IMAX,1))THEN

XINTRP $=$ T(IMAX,2)

ELSEIF(X .LT. T(1,1))THEN

$\mathrm{XINTRP}=\mathrm{T}(1,2)$

ELSE

$I=1$

10 IF(X .GT. T(I,1))THEN

$I=I+1$

GOTO 10

ELSE IF(I .EQ. 1)

$\mathrm{I}=\mathbf{2}$

$\mathrm{XLO}=\mathrm{T}(\mathrm{I}-1,1)$

$\mathrm{YLO}=\mathrm{T}(\mathrm{I}-1,2)$

$\mathrm{XHI}=\mathrm{T}(\mathrm{I}, 1)$

$\mathrm{YHI}=\mathrm{T}(\mathrm{I}, 2)$

$\mathrm{XINTRP}=(\mathrm{X}-\mathrm{XLO}) /(\mathrm{XHI}-\mathrm{XLO}) *(\mathrm{YHI}-\mathrm{YLO})+\mathrm{YLO}$

ENDIF

ENDIF

RETURN

END 


\section{Attachment G-46}

IRRAS Histogram Development Spread Sheet Input 
LOSP Frequency

\begin{tabular}{|c|c|c|c|c|c|c|c|}
\hline Point & LOSP-2H & LOSP-3H & LOSP-3.5H & LOSP-5H & LOSP-6H & LOSP-11H & LOSP-14H \\
\hline 1 & 0.09264 & 0.0658 & 0.05742 & 0.03928 & 0.03137 & 0.01291 & 0.007832 \\
\hline 2 & 0.08686 & 0.06034 & 0.05324 & 0.03491 & 0.0286 & 0.01133 & 0.006642 \\
\hline 3 & 0.06559 & 0.04222 & 0.03629 & 0.02212 & 0.01718 & 0.00505 & 0.002583 \\
\hline 4 & 0.08587 & 0.05961 & 0.05215 & 0.03465 & 0.02782 & 0.01087 & 0.00651 \\
\hline 5 & 0.1197 & 0.08889 & 0.07911 & 0.05563 & 0.04664 & 0.02354 & 0.01611 \\
\hline 6 & 0.08475 & 0.05921 & 0.05158 & 0.03443 & 0.02743 & 0.01057 & 0.006332 \\
\hline 7 & 0.08327 & 0.05792 & 0.05068 & 0.03383 & 0.02648 & 0.01008 & 0.005758 \\
\hline 8 & 0.1082 & 0.07709 & 0.06884 & 0.04924 & 0.04043 & 0.01874 & 0.01217 \\
\hline 9 & 0.07628 & 0.05248 & 0.04552 & 0.02988 & 0.02296 & 0.00756 & 0.004266 \\
\hline 10 & 0.1174 & 0.08649 & 0.07679 & 0.05394 & 0.04525 & 0.02254 & 0.01555 \\
\hline 11 & 0.09791 & 0.06905 & $\quad 0.06116$ & 0.04258 & 0.03531 & 0.01511 & 0.009755 \\
\hline 12 & 0.1506 & 0.1116 & 0.1013 & 0.07769 & 0.06876 & 0.04103 & 0.03315 \\
\hline 13 & 0.06128 & 0.03966 & 0.03366 & 0.02091 & 0.0152 & 0.00395 & 0.001831 \\
\hline 14 & 0.0705 & 0.047 & 0.04061 & 0.02574 & 0.01992 & 0.00612 & 0.003154 \\
\hline 15 & 0.1119 & 0.08114 & 0.07204 & 0.05108 & 0.04205 & 0.01987 & 0.0132 \\
\hline 16 & 0.1018 & 0.07257 & 0.06418 & 0.04537 & 0.0373 & 0.01669 & 0.01076 \\
\hline 17 & 0.07839 & 0.05388 & 0.04693 & 0.03049 & 0.02373 & 0.00768 & 0.004419 \\
\hline 18 & 0.1328 & 0.1004 & 0.09019 & 0.06652 & 0.05691 & 0.02973 & 0.02186 \\
\hline 19 & 0.09006 & 0.06254 & 0.05492 & 0.03659 & 0.02968 & 0.01207 & 0.007246 \\
\hline 20 & 0.1506 & 0.1115 & 0.1012 & 0.07764 & 0.06817 & 0.04096 & 0.03284 \\
\hline 21 & 0.1623 & 0.1249 & 0.114 & 0.0912 & 0.07934 & 0.04995 & 0.04132 \\
\hline 22 & 0.1417 & 0.1062 & 0.09609 & 0.07146 & 0.06149 & 0.03465 & 0.02548 \\
\hline 23 & 0.05871 & 0.03852 & 0.03255 & 0.01916 & 0.01442 & 0.00365 & 0.001635 \\
\hline 24 & 0.1445 & 0.107 & 0.09706 & 0.07427 & 0.06396 & 0.03722 & 0.02707 \\
\hline 25 & 0.09323 & 0.06588 & 0.05752 & 0.03939 & 0.03149 & 0.01301 & 0.007935 \\
\hline 26 & 0.07097 & 0.04759 & 0.04116 & 0.02583 & 0.02021 & 0.00613 & 0.003204 \\
\hline 27 & 0.07595 & 0.05207 & 0.04526 & 0.02962 & 0.02292 & 0.00755 & 0.004259 \\
\hline 28 & 0.1348 & 0.101 & 0.09085 & 0.06738 & 0.05731 & 0.03018 & 0.02256 \\
\hline 29 & 0.07988 & 0.05518 & 0.04816 & 0.03195 & 0.02474 & 0.00869 & 0.004903 \\
\hline 30 & 0.04782 & 0.02948 & 0.02451 & 0.01327 & 0.00882 & 0.00193 & 0.0007853 \\
\hline 31 & 0.04742 & 0.02849 & 0.02361 & 0.0126 & 0.00871 & 0.00164 & 0.0005726 \\
\hline 32 & 0.1563 & 0.1187 & 0.1073 & 0.08054 & 0.07374 & 0.0455 & 0.03725 \\
\hline 33 & 0.1107 & 0.07858 & 0.06993 & 0.05001 & 0.04141 & 0.01933 & 0.01276 \\
\hline
\end{tabular}


LOSP Frequency

\begin{tabular}{|c|c|c|c|c|c|c|c|}
\hline Point & LOSP-2H & LOSP-3H & LOSP-3.5H & LOSP-5H & LOSP-6H & LOSP-11H & LOSP-14H \\
\hline 34 & 0.06524 & 0.04204 & 0.03607 & 0.02193 & 0.01683 & 0.00504 & 0.002508 \\
\hline 35 & 0.09456 & 0.06662 & 0.0583 & 0.03996 & 0.03239 & 0.01333 & 0.008309 \\
\hline 36 & 0.0555 & 0.03453 & 0.0294 & 0.01735 & 0.01321 & 0.00317 & 0.001309 \\
\hline 37 & 0.08316 & 0.05787 & 0.05053 & 0.03373 & 0.02629 & 0.01005 & 0.00574 \\
\hline 38 & 0.06521 & 0.0419 & 0.03586 & 0.02184 & 0.01682 & 0.00503 & 0.00248 \\
\hline 39 & 0.1234 & 0.09091 & 0.08109 & 0.05838 & 0.04871 & 0.02464 & 0.017 \\
\hline 40 & 0.1201 & 0.08925 & i 0.07932 & 0.0558 & 0.04704 & 0.0237 & 0.01621 \\
\hline 41 & 0.1383 & 0.1025 & 0.09352 & 0.06942 & 0.0589 & 0.03261 & 0.02401 \\
\hline 42 & 0.1221 & 0.09009 & 0.08018 & 0.05627 & 0.04782 & 0.02416 & 0.01629 \\
\hline 43 & 0.0808 & 0.05594 & 0.04889 & 0.03227 & 0.0251 & 0.00904 & 0.005035 \\
\hline 44 & 0.07962 & 0.05502 & 0.04795 & 0.03155 & 0.0247 & 0.00851 & 0.004757 \\
\hline 45 & 0.2028 & 0.183 & 0.1792 & 0.1691 & 0.1636 & 0.1454 & 0.1391 \\
\hline 46 & 0.08213 & 0.0568 & 0.04972 & 0.03319 & 0.02597 & 0.00969 & 0.005408 \\
\hline 47 & 0.09475 & 0.06665 & 0.05838 & 0.04003 & 0.03246 & 0.01335 & 0.00833 \\
\hline 48 & 0.108 & 0.07688 & 0.06866 & 0.0489 & 0.04028 & 0.0187 & 0.01205 \\
\hline 49 & 0.05899 & 0.03862 & 0.03271 & 0.01959 & 0.01459 & 0.00369 & 0.001714 \\
\hline 50 & 0.1409 & 0.1043 & 0.09455 & 0.07018 & 0.06026 & 0.03358 & 0.02442 \\
\hline 51 & 0.1468 & 0.1082 & 0.09804 & 0.07465 & 0.06452 & 0.03803 & 0.0293 \\
\hline 52 & 0.1317 & 0.09866 & 0.08864 & 0.0653 & 0.05562 & 0.02852 & 0.0205 \\
\hline 53 & 0.1206 & 0.08941 & 0.07961 & 0.05586 & 0.04714 & 0.02394 & 0.01624 \\
\hline 54 & 0.1413 & 0.1048 & 0.09509 & 0.07092 & 0.06062 & 0.03433 & 0.0249 \\
\hline 55 & 0.04487 & 0.02696 & 0.02183 & 0.01226 & 0.00847 & 0.00118 & 0.0004245 \\
\hline 56 & 0.09804 & 0.0694 & 0.06138 & 0.04276 & 0.03539 & 0.01535 & 0.009771 \\
\hline 57 & 0.1149 & 0.0832 & 0.07376 & 0.05236 & 0.04328 & 0.02046 & 0.01403 \\
\hline 58 & 0.1249 & 0.09146 & 0.08172 & 0.05988 & 0.05007 & 0.02507 & 0.0173 \\
\hline 59 & 0.06699 & 0.04462 & 0.03829 & 0.02376 & 0.01809 & 0.00556 & 0.002774 \\
\hline 60 & 0.0942 & 0.06649 & 0.058 & 0.0397 & 0.03222 & 0.01331 & 0.008271 \\
\hline 61 & 0.1002 & 0.07147 & 0.06301 & 0.04388 & 0.03674 & 0.01603 & 0.01025 \\
\hline 62 & 0.09155 & 0.06487 & 0.05645 & 0.03837 & 0.03102 & 0.01243 & 0.007448 \\
\hline 63 & 0.1266 & 0.09322 & 0.0835 & 0.06082 & 0.05137 & 0.02566 & 0.01787 \\
\hline 64 & 0.07582 & 0.05196 & 0.04516 & 0.02951 & 0.02287 & 0.00752 & 0.004182 \\
\hline 65 & 0.09516 & 0.06703 & 0.05864 & 0.04036 & 0.03314 & 0.01368 & 0.0085 \\
\hline 66 & 0.08381 & 0.05854 & 0.0511 & 0.03399 & 0.02701 & 0.01027 & 0.006071 \\
\hline
\end{tabular}


LOSP Frequency

\begin{tabular}{|c|c|c|c|c|c|c|c|}
\hline Point & LOSP-2H & LOSP-3H & LOSP-3.5H & LOSP-5H & LOSP-6H & LOSP-11H & LOSP-14H \\
\hline 67 & 0.1033 & 0.07291 & 0.06456 & 0.04556 & 0.03748 & 0.01681 & 0.01123 \\
\hline 68 & 0.07098 & 0.04776 & 0.04126 & 0.02608 & 0.02026 & 0.00619 & 0.003241 \\
\hline 69 & 0.1647 & 0.1324 & 0.1213 & 0.09333 & 0.08578 & 0.05293 & 0.04275 \\
\hline 70 & 0.07543 & 0.05173 & 0.04486 & 0.02927 & 0.02272 & 0.00737 & 0.004142 \\
\hline 71 & 0.06044 & 0.03911 & 0.03322 & 0.02061 & 0.0149 & 0.00385 & 0.001783 \\
\hline 72 & 0.08194 & 0.05655 & 0.0494 & 0.03297 & 0.02564 & 0.00952 & 0.005281 \\
\hline 73 & 0.07448 & 0.0505 & 0.04394 & 0.02866 & 0.02218 & 0.00714 & 0.003934 \\
\hline 74 & 0.09409 & 0.06631 & 0.05789 & 0.03967 & 0.03211 & 0.01326 & 0.00819 \\
\hline 75 & 0.1132 & 0.08196 & 0.07274 & 0.05169 & 0.04234 & 0.02002 & 0.01362 \\
\hline 76 & 0.09131 & 0.06459 & 0.05631 & 0.03816 & 0.03083 & 0.01239 & 0.007341 \\
\hline 77 & 0.07757 & 0.05384 & 0.04659 & 0.03029 & 0.02343 & 0.00767 & 0.004413 \\
\hline 78 & 0.06569 & 0.04262 & 0.03668 & 0.0225 & 0.01734 & 0.0052 & 0.002644 \\
\hline 79 & 0.1198 & 0.08894 & 0.07915 & 0.05575 & 0.04687 & 0.02355 & 0.0162 \\
\hline 80 & 0.1075 & 0.07646 & 0.06827 & 0.04858 & 0.03995 & 0.01838 & 0.01182 \\
\hline 81 & 0.05214 & 0.03142 & 0.02622 & 0.01512 & 0.01151 & 0.00249 & 0.001023 \\
\hline 82 & 0.1951 & 0.1586 & 0.145 & 0.1158 & 0.1071 & 0.07912 & 0.06775 \\
\hline 83 & 0.162 & 0.1195 & 0.1109 & 0.09118 & 0.07721 & 0.04979 & 0.03954 \\
\hline 84 & 0.08853 & 0.06185 & 0.0543 & 0.03576 & 0.02942 & 0.01182 & 0.007001 \\
\hline 85 & 0.1923 & 0.1576 & 0.1441 & 0.1119 & 0.1006 & 0.06848 & 0.05719 \\
\hline 86 & 0.07056 & 0.04709 & 0.04087 & 0.0258 & 0.02021 & 0.00612 & 0.003163 \\
\hline 87 & 0.06002 & 0.03908 & 0.03319 & 0.01989 & 0.01464 & 0.00377 & 0.001771 \\
\hline 88 & 0.0959 & 0.06752 & 0.05933 & 0.04109 & 0.03405 & 0.01402 & 0.008765 \\
\hline 89 & 0.07457 & 0.05125 & 0.04444 & 0.02893 & 0.02246 & 0.00719 & 0.004009 \\
\hline 90 & 0.09767 & 0.06895 & 0.06096 & 0.04249 & 0.03517 & 0.01503 & 0.009647 \\
\hline 91 & 0.1252 & 0.09161 & 0.08216 & 0.06008 & 0.05048 & 0.02534 & 0.0174 \\
\hline 92 & 0.1523 & 0.1149 & 0.1031 & 0.07866 & 0.06919 & 0.04315 & 0.03324 \\
\hline 93 & 0.1084 & 0.0771 & 0.06892 & 0.04942 & 0.04054 & 0.01876 & 0.01227 \\
\hline 94 & 0.08642 & 0.05981 & 0.05248 & 0.0348 & 0.02834 & 0.011 & 0.006555 \\
\hline 95 & 0.06565 & 0.04228 & 0.0365 & 0.02243 & 0.01731 & 0.00519 & 0.002634 \\
\hline 96 & 0.07904 & 0.05482 & 0.04775 & 0.03146 & 0.02463 & 0.00841 & 0.004707 \\
\hline 97 & 0.1153 & 0.08342 & 0.07388 & 0.05238 & 0.04334 & 0.02061 & 0.01413 \\
\hline 98 & 0.1641 & 0.1321 & 0.1208 & 0.09311 & 0.08362 & 0.05272 & 0.04241 \\
\hline 99 & 0.06473 & 0.04119 & 0.03519 & 0.02141 & 0.01646 & 0.0049 & 0.002326 \\
\hline
\end{tabular}




\begin{tabular}{|c|c|c|c|c|c|c|c|}
\hline I $\angle S Z 0^{\circ} 0$ & Z๑SEO 0 & $8 E Z 90^{\circ} 0$ & ZEZLO०0 & $\varepsilon \angle 960^{\circ} 0$ & $990 I^{\circ} 0$ & $I E+I^{\circ} 0$ & EEI \\
\hline $29 S 900^{\circ} 0$ & $8 \mathrm{IIIO} 0^{\circ} 0$ & $67820^{\circ} 0$ & $S 8 † E 0^{\circ} 0$ & $98250^{\circ} 0$ & $\varepsilon I 090^{\circ} 0$ & $Z 9980^{\circ} 0$ & ZEI \\
\hline $\mathcal{E} 66900^{\circ} 0$ & LLIIOOO & $2+620^{\circ} 0$ & I $\angle S E 0^{\circ} 0$ & $\triangleright \tau \triangleright S 0^{\circ} 0$ & LLI90 0 & $91880^{\circ} 0$ & IEI \\
\hline $89 \$ E 0^{\circ} 0$ & IZS\$0 0 & $\mathcal{E} 6 \mathrm{I} \angle 0^{\circ} 0$ & $61080^{\circ} 0$ & $2 S 0 I^{\circ} 0$ & $\nabla L I I^{\circ} O$ & SSI 0 & OEI \\
\hline$\$ 9 S 00^{\circ} 0$ & $86600^{\circ} 0$ & $91920^{\circ} 0$ & S†EEO०O & $\operatorname{EOS} 0^{\circ} 0$ & $S \leftarrow \angle S 0^{\circ} 0$ & $28280^{\circ} 0$ & $6 Z I$ \\
\hline $86 t 20^{\circ} 0$ & I & $90190^{\circ} 0$ & $\nabla 60 \angle 0^{\circ} 0$ & SES60 0 & $6+0 I^{\circ} 0$ & $\varepsilon I t I^{\circ} 0$ & $8 Z I$ \\
\hline I9ZI0॰0 & $\varepsilon Z 610^{\circ} 0$ & $180+0^{\circ} 0$ & $S \angle 6+0^{\circ} 0$ & $\angle L 690^{\circ} 0$ & $\varepsilon \nrightarrow 8 \angle 0^{\circ} 0$ & $660 I^{\circ} 0$ & $\angle Z I$ \\
\hline $9 \angle 8 Z 00^{\circ} 0$ & {$\left[8500^{\circ} 0\right.$} & $87810^{\circ} 0$ & $6 \operatorname{It} 20^{\circ} 0$ & $6 \varepsilon 6 \varepsilon 0^{\circ} 0$ & $819+0^{\circ} 0$ & I9890 0 & $9 Z I$ \\
\hline $9 S 020^{\circ} 0$ & $t \$ 820^{\circ} 0$ & $69 S S 0^{\circ} 0$ & ZES90 0 & $\succcurlyeq \angle 880^{\circ} 0$ & $\angle L 860^{\circ} 0$ & 6IEIㅇ & SZI \\
\hline $828800^{\circ} 0$ & $S I t I 0^{\circ} 0$ & $9 I \sqcup E 0^{\circ} 0$ & $\angle Z I+0^{\circ} 0$ & $\nleftarrow \subseteq 6 \varsigma 0^{\circ} 0$ & $8 S \angle 90^{\circ} 0$ & SE960 0 & $t \tau I$ \\
\hline $90 \varepsilon 800^{\circ} 0$ & IEEI0०0 & $9 Z Z E 0^{\circ} 0$ & $66 E 0^{\circ} 0$ & $20850^{\circ} 0$ & $6 \$ 990^{\circ} 0$ & $\downarrow S t 60^{\circ} 0$ & $\mathcal{E Z I}$ \\
\hline SEOt $000^{\circ} 0$ & I $100^{\circ} 0$ & $I+900^{\circ} 0$ & $8 \angle 600^{\circ} 0$ & $\angle 810^{\circ} 0$ & $\triangleright \angle I Z O^{\circ} 0$ & ZIItO0 0 & $Z Z I$ \\
\hline $8 I S I 0^{\circ} 0$ & $66120^{\circ} 0$ & $\varepsilon 8 t+0^{\circ} 0$ & IEESO 0 & $S 8 S \angle 0^{\circ} 0$ & $\angle t S 80^{\circ} 0$ & $89 I^{\circ} 0$ & IZI \\
\hline ELIO०O & $\$ 20^{\circ} 0$ & $6+6+0^{\circ} 0$ & $89650^{\circ} 0$ & $69180^{\circ} 0$ & $t b 160^{\circ} 0$ & $E \pitchfork Z I^{\circ} 0$ & OZI \\
\hline$I \angle t I 00^{\circ} 0$ & $\tau \succsim \varepsilon 00^{\circ} 0$ & $6 I D I 0.0$ & $98810^{\circ} 0$ & $\angle D I E O^{\circ} 0$ & EI LEO 0 & I $6 \angle S 0^{\circ} 0$ & $6 \mathrm{II}$ \\
\hline $625500^{\circ} 0$ & $28600^{\circ} 0$ & $Z\left[920^{\circ} 0\right.$ & $6 E E E 0^{\circ} 0$ & ELOSO 0 & $\angle Z \angle S 0^{\circ} 0$ & $69280^{\circ} 0$ & $8 I I$ \\
\hline$Z 8 \angle+00^{\circ} 0$ & $9 \$ 800^{\circ} 0$ & $I \angle D Z 0^{\circ} 0$ & $28 \mathrm{IEO}^{\circ} 0$ & $608+0^{\circ} 0$ & ZISSO 0 & $6 \angle 6 \angle 0^{\circ} 0$ & LII \\
\hline ZSII0.0 & SLLIO'0 & S98E0 0 & $S 69+0^{\circ} 0$ & $26990^{\circ} 0$ & SOSLO 0 & SSOI 0 & 9 II \\
\hline$\angle S S 600^{\circ} 0$ & $6 \angle t 10^{\circ} 0$ & DISEO 0 & $\tau \nrightarrow \tau+0^{\circ} 0$ & $26090^{\circ} 0$ & $\$ 6890^{\circ} 0$ & $\angle S \angle 60^{\circ} 0$ & SII \\
\hline E9ZI00॰0 & $6200^{\circ} 0$ & $\vdash 8 Z 10^{\circ} 0$ & SOLIOOO & $16820^{\circ} 0$ & $60 † \varepsilon 0^{\circ} 0$ & $S Z S S 0^{\circ} 0$ & $t I I$ \\
\hline$\angle 0 \angle 900^{\circ} 0$ & $8 \varepsilon I I 0^{\circ} 0$ & $I \angle 8 Z 0^{\circ} 0$ & I ISEO 0 & $\varepsilon \nrightarrow \varepsilon S 0^{\circ} 0$ & $85090^{\circ} 0$ & $6980^{\circ} 0$ & EII \\
\hline$\$ 98600^{\circ} 0$ & ESSI0 0 & S6SEO 0 & $I t \varepsilon+0^{\circ} 0$ & $\varepsilon 0 Z 90^{\circ} 0$ & $\angle 6690^{\circ} 0$ & St $660^{\circ} 0$ & ZII \\
\hline$\varepsilon 0^{\circ} 0$ & $\angle I 6 E 0^{\circ} 0$ & $6 \$ 90^{\circ} 0$ & $98 S \angle 0^{\circ} 0$ & $9 \$ 860^{\circ} 0$ & $880 I^{\circ} 0$ & $\forall \angle D I^{\circ} 0$ & III \\
\hline$\$ 9110^{\circ} 0$ & S8LIO 0 & $Z I 6 E 0^{\circ} 0$ & $8 \varepsilon \angle t 0^{\circ} 0$ & $\tau+\angle 90^{\circ} 0$ & $\$ 9 S \angle 0^{\circ} 0$ & $\angle 90 I^{\circ} 0$ & OI I \\
\hline SZII $0^{\circ} 0$ & $68910^{\circ} 0$ & $9 S \angle E 0^{\circ} 0$ & $\angle L S+0^{\circ} 0$ & $\angle 9 \$ 90^{\circ} 0$ & $\angle 6 Z \angle 0^{\circ} 0$ & $9 \varepsilon 0 I^{\circ} 0$ & $60 I$ \\
\hline$\angle S I Z 00^{\circ} 0$ & $29+00^{\circ} 0$ & 乙E9โ0०0 & $92 I Z 0^{\circ} 0$ & $\angle \mapsto E 0^{\circ} 0$ & 950 to.0 & $9 \$ \varepsilon 90^{\circ} 0$ & $80 I$ \\
\hline StEZO०0 & $290 \varepsilon 0^{\circ} 0$ & $I S 8 S 0^{\circ} 0$ & $\mathcal{E Z 8 9 0 ^ { \circ } 0}$ & $10260^{\circ} 0$ & IZOI 0 & $\varepsilon 9 \varepsilon I^{\circ} 0$ & LOI \\
\hline EI $\varepsilon 0^{\circ} 0$ & $96 E 0^{\circ} 0$ & $\forall \not \$ 90^{\circ} 0$ & $\tau S 9 \angle 0^{\circ} 0$ & IZ660 0 & $860 I^{\circ} 0$ & $6 \angle D I^{\circ} 0$ & $90 I$ \\
\hline $98 S+00^{\circ} 0$ & $20800^{\circ} 0$ & $9 \varepsilon \triangleright Z 0^{\circ} 0$ & Z60£0 0 & $9 S \angle+00^{\circ} 0$ & $\$ 9 t S 0^{\circ} 0$ & $\$ 88 \angle 0^{\circ} 0$ & SOI \\
\hline $99+0^{\circ} 0$ & SSSSO 0 & $6060^{\circ} 0$ & 9I0I*0 & †9ZI'0 & $99 \varepsilon I^{\circ} 0$ & $99 I^{\circ} 0$ & tOI \\
\hline ZLLZOOOO & $2 t S 00^{\circ} 0$ & SLLIO'O & $\angle E E Z 0^{\circ} 0$ & $\square \angle \angle E O^{\circ} 0$ & I9EtO०O & $S 6990^{\circ} 0$ & EOI \\
\hline $85620^{\circ} 0$ & tI6E0.0 & $E \angle t 90^{\circ} 0$ & $6 \angle b \angle 0^{\circ} 0$ & $81860^{\circ} 0$ & $\$ 80 I^{\circ} 0$ & $\varepsilon \angle I^{\circ} 0$ & $20 I$ \\
\hline$\varepsilon \mapsto t z 0^{\circ} 0$ & 乙6ЕЕ००० & $E 090^{\circ} 0$ & $S+0 \angle 0^{\circ} 0$ & $S \angle \nabla 60^{\circ} 0$ & $S+O I^{\circ} 0$ & $I I t I^{\circ} 0$ & IOI \\
\hline$\$ 2610^{\circ} 0$ & $9+920^{\circ} 0$ & E8ZSO 0 & $6290^{\circ} 0$ & $t Z S 80^{\circ} 0$ & $88 t 60^{\circ} 0$ & $6 \angle Z I^{\circ} 0$ & $00 I$ \\
\hline $\mathrm{H} t \mathrm{I}-\mathrm{dSO}$ & HII-dSOT & H9-dSOT & HS-dSOT & $H S^{\bullet} \varepsilon-d S O T$ & HE-dSOT & Hz-dSOT & pụod \\
\hline
\end{tabular}


LOSP Frequency

\begin{tabular}{|c|c|c|c|c|c|c|c|}
\hline Point & LOSP-2H & LOSP-3H & LOSP-3.5H & LOSP-5H & LOSP-6H & LOSP-11H & LOSP-14H \\
\hline 134 & 0.07479 & 0.05169 & 0.04477 & 0.02912 & 0.02267 & 0.00733 & 0.004141 \\
\hline 135 & 0.07557 & 0.05194 & 0.04513 & 0.02943 & 0.02275 & 0.00748 & 0.004181 \\
\hline 136 & 0.1393 & 0.1034 & 0.09403 & 0.06951 & 0.05891 & 0.03299 & 0.0241 \\
\hline 137 & 0.08674 & 0.06016 & 0.05291 & 0.03491 & 0.02858 & 0.01119 & 0.006582 \\
\hline 138 & 0.05782 & 0.03706 & 0.03125 & 0.01868 & 0.01406 & 0.00338 & 0.001466 \\
\hline 139 & 0.09981 & 0.07092 & 0.06266 & 0.04367 & 0.03637 & 0.01598 & 0.01008 \\
\hline 140 & 0.1003 & 0.07157 & 0.06307 & 0.04389 & 0.0368 & 0.01613 & 0.01029 \\
\hline 141 & 0.06852 & 0.04578 & 0.03902 & 0.02405 & 0.01843 & 0.00565 & 0.002853 \\
\hline 142 & 0.1364 & 0.1022 & 0.09226 & 0.06826 & 0.05865 & 0.03065 & 0.02363 \\
\hline 143 & 0.1011 & 0.07191 & 0.0635 & 0.04468 & 0.03694 & 0.01631 & 0.01045 \\
\hline 144 & 0.07851 & 0.05405 & 0.04708 & 0.03052 & 0.0238 & 0.00777 & 0.004448 \\
\hline 145 & 0.06816 & 0.04515 & 0.03865 & 0.02403 & 0.01837 & 0.00563 & 0.002834 \\
\hline 146 & 0.07637 & 0.05301 & 0.04602 & 0.03015 & 0.02318 & 0.00761 & 0.004278 \\
\hline 147 & 0.1294 & 0.09661 & 0.0867 & 0.06396 & 0.05396 & 0.02727 & 0.01988 \\
\hline 148 & 0.1088 & 0.07742 & 0.06912 & 0.04943 & 0.04064 & 0.01881 & 0.01228 \\
\hline 149 & 0.08544 & 0.05958 & 0.05205 & 0.03463 & 0.02773 & 0.01076 & 0.006397 \\
\hline 150 & 0.07435 & 0.05024 & 0.0438 & 0.02854 & 0.02217 & 0.0071 & 0.00383 \\
\hline 151 & 0.09529 & 0.06704 & 0.05869 & 0.04047 & 0.03327 & 0.01369 & 0.008582 \\
\hline 152 & 0.09555 & 0.06723 & 0.05884 & 0.04088 & 0.03353 & 0.01374 & 0.008626 \\
\hline 153 & 0.08278 & 0.05737 & 0.05021 & 0.03341 & 0.02614 & 0.00988 & 0.005539 \\
\hline 154 & 0.06676 & 0.04377 & 0.03771 & 0.02339 & 0.01785 & 0.00543 & 0.002772 \\
\hline 155 & 0.06444 & 0.04108 & 0.035 & 0.0214 & 0.01641 & 0.00489 & 0.002289 \\
\hline 156 & 0.07631 & 0.05249 & 0.04566 & 0.02992 & 0.02312 & 0.00757 & 0.004271 \\
\hline 157 & 0.1282 & 0.09514 & 0.08568 & 0.06329 & 0.05367 & 0.02668 & 0.01952 \\
\hline 158 & 0.08343 & 0.05811 & 0.05083 & 0.03389 & 0.02683 & 0.01021 & 0.005879 \\
\hline 159 & 0.1114 & 0.08023 & 0.07144 & 0.0506 & 0.04199 & 0.01975 & 0.013 \\
\hline 160 & 0.07396 & 0.0496 & 0.04331 & 0.02794 & 0.0216 & 0.00694 & 0.003734 \\
\hline 161 & 0.1167 & 0.08511 & 0.07565 & 0.0533 & 0.04481 & 0.02183 & 0.01513 \\
\hline 162 & 0.08732 & 0.06136 & 0.05394 & 0.03531 & 0.02897 & 0.01144 & 0.006834 \\
\hline 163 & 0.08854 & 0.06186 & 0.05432 & 0.03585 & 0.02944 & 0.0119 & 0.007016 \\
\hline 164 & 0.1015 & 0.07229 & 0.06384 & 0.04484 & 0.03715 & 0.01648 & 0.01063 \\
\hline 165 & 0.09374 & 0.0661 & 0.0577 & 0.03954 & 0.03164 & 0.01308 & 0.008125 \\
\hline 166 & 0.1518 & 0.1126 & 0.1019 & 0.07842 & 0.06886 & 0.04107 & 0.0332 \\
\hline 167 & 0.06504 & 0.04135 & 0.03547 & 0.02162 & 0.01673 & 0.00497 & 0.002469 \\
\hline
\end{tabular}


LOSP Frequency

\begin{tabular}{|c|c|c|c|c|c|c|c|}
\hline Point & LOSP-2H & LOSP-3H & LOSP-3.5H & LOSP-5H & LOSP-6H & LOSP-11H & LOSP-14H \\
\hline 168 & 0.104 & 0.07395 & 0.06554 & 0.04601 & 0.03804 & 0.01704 & 0.01138 \\
\hline 169 & 0.05901 & 0.03905 & 0.033 & 0.01961 & 0.01461 & 0.00373 & 0.001737 \\
\hline 170 & 0.1133 & 0.082 & 0.07279 & 0.05175 & 0.04254 & 0.02011 & 0.01368 \\
\hline 171 & 0.1316 & 0.09856 & 0.08853 & 0.06506 & 0.0554 & 0.02824 & 0.02047 \\
\hline 172 & 0.09183 & 0.06521 & 0.05678 & 0.03868 & 0.03119 & 0.0128 & 0.007574 \\
\hline 173 & 0.1399 & 0.1039 & 0.09426 & 0.0698 & 0.05962 & 0.033 & 0.02414 \\
\hline 174 & 0.07851 & 0.05425 & 0.04719 & 0.03056 & 0.02389 & 0.00778 & 0.004486 \\
\hline 175 & 0.09709 & 0.06789 & 0.0602 & 0.04213 & 0.03493 & 0.01458 & 0.009229 \\
\hline 176 & 0.1174 & 0.0866 & 0.07687 & 0.05399 & 0.04527 & 0.02265 & 0.01563 \\
\hline 177 & 0.09113 & 0.06395 & 0.05585 & 0.03752 & 0.03077 & 0.0123 & 0.007315 \\
\hline 178 & 0.1138 & 0.08234 & 0.07304 & 0.05195 & 0.04258 & 0.02027 & 0.01382 \\
\hline 179 & 0.09802 & 0.06913 & 0.06122 & 0.04262 & 0.03538 & 0.01529 & 0.009766 \\
\hline 180 & 0.1274 & 0.09382 & 0.08403 & 0.06239 & 0.05235 & 0.02633 & 0.01876 \\
\hline 181 & 0.06617 & 0.04341 & 0.03725 & 0.02311 & 0.01758 & 0.00536 & 0.002711 \\
\hline 182 & 0.08893 & 0.06196 & 0.05447 & 0.03611 & 0.0295 & 0.01194 & 0.007116 \\
\hline 183 & 0.08323 & 0.0579 & 0.05064 & 0.03377 & 0.02646 & 0.01008 & 0.005758 \\
\hline 184 & 0.07426 & 0.05024 & 0.0437 & 0.02834 & 0.02206 & 0.00698 & 0.003828 \\
\hline 185 & 0.08199 & 0.05666 & 0.0496 & 0.03315 & 0.02565 & 0.00968 & 0.005398 \\
\hline 186 & 0.1561 & 0.1181 & 0.1056 & 0.08027 & 0.0724 & 0.04543 & 0.03476 \\
\hline 187 & 0.1055 & 0.07502 & 0.06684 & 0.04667 & 0.03835 & 0.01766 & 0.0115 \\
\hline 188 & 0.1157 & 0.08435 & 0.07506 & 0.05276 & 0.04381 & 0.0211 & 0.01464 \\
\hline 189 & 0.08339 & 0.05808 & 0.05077 & 0.03386 & 0.02673 & 0.0102 & 0.005809 \\
\hline 190 & 0.1322 & 0.0992 & 0.0891 & 0.06589 & 0.056 & 0.02874 & 0.02107 \\
\hline 191 & 0.1407 & 0.1042 & 0.09447 & 0.07008 & 0.06004 & 0.03348 & 0.02424 \\
\hline 192 & 0.09654 & 0.06776 & 0.06003 & 0.04139 & 0.03445 & 0.01432 & 0.008983 \\
\hline 193 & 0.05488 & 0.03407 & 0.0286 & 0.01689 & 0.01233 & 0.00289 & 0.001217 \\
\hline 194 & 0.07653 & 0.05334 & 0.0462 & 0.03017 & 0.02323 & 0.00764 & 0.00429 \\
\hline 195 & 0.09682 & 0.06779 & 0.06011 & 0.042 & 0.03486 & 0.01446 & 0.009215 \\
\hline 196 & 0.07456 & 0.05067 & 0.04413 & 0.02885 & 0.0222 & 0.00718 & 0.003935 \\
\hline 197 & 0.1221 & 0.09035 & 0.08032 & 0.05677 & 0.04794 & 0.02428 & 0.01629 \\
\hline 198 & 0.1411 & 0.1046 & 0.09489 & 0.07083 & 0.06061 & 0.03406 & 0.02459 \\
\hline 199 & 0.09716 & 0.06883 & 0.06084 & 0.04239 & 0.03504 & 0.01471 & 0.009463 \\
\hline 200 & 0.1069 & 0.07585 & 0.06764 & 0.04773 & 0.03922 & 0.01796 & 0.01167 \\
\hline 201 & 0.1154 & 0.08371 & 0.07451 & 0.05254 & 0.04342 & 0.02075 & 0.01425 \\
\hline
\end{tabular}

Vol. 2, Part 2

G-213

NUREG/CR-6143 
LOSP Frequency

\begin{tabular}{|c|c|c|c|c|c|c|c|}
\hline Point & LOSP-2H & LOSP-3H & LOSP-3.5H & LOSP-5H & LOSP-6H & LOSP-11H & LOSP-14H \\
\hline 202 & 0.1345 & 0.1008 & 0.0906 & 0.0671 & 0.05718 & 0.03011 & 0.0225 \\
\hline 203 & 0.09009 & 0.06258 & 0.05497 & 0.0366 & 0.0301 & 0.01215 & 0.00725 \\
\hline 204 & 0.05274 & 0.03245 & 0.02713 & 0.01556 & 0.01178 & 0.00275 & 0.001087 \\
\hline 205 & 0.09174 & 0.0652 & 0.05677 & 0.03864 & 0.03113 & 0.01261 & 0.007528 \\
\hline 206 & 0.1116 & 0.0804 & 0.07161 & 0.05067 & 0.042 & 0.01979 & 0.01305 \\
\hline 207 & 0.1433 & 0.1066 & 0.09681 & 0.07297 & 0.06333 & 0.03619 & 0.02594 \\
\hline 208 & 0.09677 & 0.06778 & 0.0601 & 0.04189 & 0.03474 & 0.01444 & 0.009135 \\
\hline 209 & 0.08151 & 0.05643 & 0.04933 & 0.03296 & 0.0256 & 0.00945 & 0.005219 \\
\hline 210 & 0.1673 & 0.1397 & 0.1292 & 0.1029 & 0.0911 & 0.05991 & 0.04855 \\
\hline 211 & 0.1311 & 0.09848 & 0.0885 & 0.06498 & 0.05493 & 0.02785 & 0.02043 \\
\hline 212 & 0.09909 & 0.06968 & 0.06168 & 0.04305 & 0.03562 & 0.01543 & 0.009817 \\
\hline 213 & 0.06898 & 0.04658 & 0.03996 & 0.02505 & 0.01901 & 0.00603 & 0.003001 \\
\hline 214 & 0.0803 & 0.05593 & 0.04878 & 0.03226 & 0.02509 & 0.00892 & 0.005018 \\
\hline 215 & 0.08597 & 0.05965 & 0.0522 & 0.03467 & 0.02788 & 0.01096 & 0.006514 \\
\hline 216 & 0.02701 & 0.01349 & 0.01095 & 0.00582 & 0.00422 & 0.00085 & 0.0003165 \\
\hline 217 & 0.07168 & 0.04823 & 0.0415 & 0.02672 & 0.02043 & 0.00625 & 0.003256 \\
\hline 218 & 0.1618 & 0.1193 & 0.1094 & 0.08589 & 0.07561 & 0.04842 & 0.03919 \\
\hline 219 & 0.0739 & 0.04934 & 0.04314 & 0.02783 & 0.02159 & 0.00693 & 0.003698 \\
\hline 220 & 0.1154 & 0.08412 & 0.07488 & 0.05272 & 0.04361 & 0.02105 & 0.01433 \\
\hline 221 & 0.05413 & 0.03346 & 0.02793 & 0.01625 & 0.01231 & 0.00288 & 0.001196 \\
\hline 222 & 0.08361 & 0.05833 & 0.05097 & 0.03392 & 0.02691 & 0.01021 & 0.005942 \\
\hline 223 & 0.1126 & 0.0816 & 0.07248 & 0.0514 & 0.0423 & 0.01995 & 0.01333 \\
\hline 224 & 0.07174 & 0.04829 & 0.04157 & 0.02673 & 0.02056 & 0.00627 & 0.003294 \\
\hline 225 & 0.138 & 0.1024 & 0.09332 & 0.0691 & 0.05889 & 0.03211 & 0.02392 \\
\hline 226 & 0.1416 & 0.1051 & 0.09554 & 0.07122 & 0.06108 & 0.03453 & 0.02548 \\
\hline 227 & 0.1349 & 0.1013 & 0.09134 & 0.06741 & 0.05776 & 0.03038 & 0.0227 \\
\hline 228 & 0.1278 & 0.09466 & 0.08504 & 0.06261 & 0.05271 & 0.02644 & 0.01921 \\
\hline 229 & 0.06344 & 0.04013 & 0.03431 & 0.02124 & 0.01625 & 0.00458 & 0.002118 \\
\hline 230 & 0.1164 & 0.0847 & 0.07533 & 0.05296 & 0.04426 & 0.02167 & 0.01499 \\
\hline 231 & 0.1492 & 0.1111 & 0.101 & 0.07737 & 0.06626 & 0.04034 & 0.03238 \\
\hline 232 & 0.0849 & 0.05925 & 0.0516 & 0.0345 & 0.02753 & 0.01063 & 0.006358 \\
\hline 233 & 0.09984 & 0.07137 & 0.06291 & 0.04378 & 0.03639 & 0.01601 & 0.01017 \\
\hline 234 & 0.1324 & 0.1001 & 0.08975 & 0.06642 & 0.05662 & 0.02969 & 0.02142 \\
\hline 235 & 0.07402 & 0.04993 & 0.04354 & 0.02829 & 0.02201 & 0.00698 & 0.003745 \\
\hline
\end{tabular}




\begin{tabular}{|c|c|c|c|c|c|c|c|}
\hline $8 E E \angle 00^{\circ} 0$ & $8 \mathcal{E L I 0} 0^{\circ} 0$ & $\angle \angle O E O^{\circ} 0$ & $9 \angle \varepsilon O^{\circ} 0$ & $\mathrm{~S} 09 \mathrm{SO}^{\circ} 0$ & $t I t 90^{\circ} 0$ & $\angle Z I 60^{\circ} 0$ & 692 \\
\hline $8 E \angle 8000^{\circ} 0$ & $\angle 0 Z 00^{\circ} 0$ & $\varepsilon \supset 600^{\circ} 0$ & 99EI0.0 & $68+20^{\circ} 0$ & I $\angle 6 Z 0^{\circ} 0$ & $8 S I S 0^{\circ} 0$ & 892 \\
\hline II $9100^{\circ} 0$ & $29 \varepsilon 00^{\circ} 0$ & $8 Z \triangleright 10^{\circ} 0$ & II6I0 0 & ZIZEO०० & $\dashv 6 \angle E 0^{\circ} 0$ & $\mathrm{SESSO}^{\circ} 0$ & $\angle 9 Z$ \\
\hline$\$ 2 z 00^{\circ} 0$ & $8+00^{\circ} 0$ & SE9I0 0 & EEIZO 0 & $68 t \varepsilon 0^{\circ} 0$ & $880 t 0^{\circ} 0$ & Ett90.0 & 992 \\
\hline $6 \varepsilon 610^{\circ} 0$ & $\tau \varsigma 9 Z 0^{\circ} 0$ & I9\&SO $0^{\circ}$ & 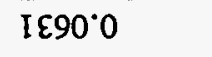 & $t t \varsigma 80^{\circ} 0$ & $\operatorname{toS} 60^{\circ} 0$ & $28 \mathrm{II}^{\circ} 0$ & $\$ 92$ \\
\hline $89110^{\circ} 0$ & $82810^{\circ} 0$ & $9 \& 6 \& 0^{\circ} 0$ & $6 \varepsilon 8+0^{\circ} 0$ & $\angle 6 \angle 90^{\circ} 0$ & $29 \angle 0^{\circ} 0$ & ZLOI'O & $t 92$ \\
\hline $928800^{\circ} 0$ & tot $10^{\circ} 0$ & $80 t E 0^{\circ} 0$ & ZIIt0 0 & tt650 0 & $9 S \angle 90^{\circ} 0$ & $97960^{\circ} 0$ & E9Z \\
\hline $69 \varepsilon Z 0^{\circ} 0$ & $8 Z I E 0^{\circ} 0$ & $8 \angle 8 S 0^{\circ} 0$ & $\varepsilon S 890^{\circ} 0$ & $2 S Z 60^{\circ} 0$ & $\mathcal{E Z O I ^ { \circ } 0}$ & $69 \varepsilon I^{\circ} 0$ & 292 \\
\hline SSEEOO 0 & $5900^{\circ} 0$ & $6 \angle O Z 0^{\circ} 0$ & $20 \angle 20^{\circ} 0$ & $6 Z 2+0^{\circ} 0$ & $298+0^{\circ} 0$ & $6 Z 2 \angle 0^{\circ} 0$ & I9Z \\
\hline ZItE0 0 & ESE† $00^{\circ}$ & $76690^{\circ} 0$ & $\angle I 6 \angle 0^{\circ} O$ & $8501^{\circ} 0$ & $99 I^{\circ} 0$ & $9 \varepsilon S I^{\circ} 0$ & 092 \\
\hline$+8210^{\circ} 0$ & $8 E 6 \mathrm{IO}^{\circ} 0$ & $9 S I t 0^{\circ} 0$ & SIOSO $0^{\circ} 0$ & $\$ 90 \angle 0^{\circ} 0$ & $996 \angle 0^{\circ} 0$ & III 0 & $6 S Z$ \\
\hline $288200^{\circ} 0$ & $88500^{\circ} 0$ & $\varepsilon \angle 810^{\circ} 0$ & $\varepsilon S \pitchfork Z 0^{\circ} 0$ & $\$ 96 \varepsilon 0^{\circ} 0$ & $\angle Z 9+0^{\circ} 0$ & $\angle 8890^{\circ} 0$ & $8 S Z$ \\
\hline$t 80 \varepsilon 00^{\circ} 0$ & $\$ 0900^{\circ} 0$ & $7610^{\circ} 0$ & $Z E S Z 0^{\circ} 0$ & $\varepsilon \varepsilon 0$ † $0^{\circ} 0$ & $899+0^{\circ} 0$ & $\angle b 690^{\circ} 0$ & LSZ \\
\hline $6+210^{\circ} 0$ & II $610^{\circ} 0$ & $80+0^{\circ} 0$ & $\varepsilon 96 \neq 0^{\circ} 0$ & $69690^{\circ} 0$ & $\nabla E \& L 0^{\circ} 0$ & I60I'0 & $9 S Z$ \\
\hline $\operatorname{ESSEO0^{\circ }0}$ & $\angle 900^{\circ} 0$ & $60120^{\circ} 0$ & $2 \$ \angle Z 0^{\circ} 0$ & $s+Z t 0^{\circ} 0$ & $8 \angle 8+0^{\circ} 0$ & S6ZLO $0^{\circ} 0$ & SSZ \\
\hline$\angle O E \angle O 0^{\circ} 0$ & $92210^{\circ} 0$ & I $\angle O E O^{\circ} O$ & $\varepsilon \varepsilon \angle \varepsilon 0^{\circ} 0$ & $8 \angle S S 0^{\circ} 0$ & $28 \varepsilon 90^{\circ} 0$ & $2 \operatorname{LI} 60^{\circ} 0$ & $t S Z$ \\
\hline $66 \angle E O^{\circ} 0$ & $96 \angle t 0^{\circ} 0$ & $\nabla Z S \angle 0^{\circ} 0$ & $98280^{\circ} 0$ & $S 80 I^{\circ} 0$ & E6I I $I^{\circ} 0$ & t09. 0 & ESZ \\
\hline$\varepsilon 8 \$ 800^{\circ} 0$ & $\mathcal{E} \angle E I 0^{\circ} 0$ & 9દE£ $0^{\circ} 0$ & $8+0 \not 0^{\circ} 0$ & $9 \angle 8 S 0^{\circ} 0$ & $21 \angle 90^{\circ} 0$ & $\varepsilon S 60^{\circ} 0$ & ZSZ \\
\hline E8SI0 & DIEZO 0 & $99 S t 0^{\circ} 0$ & $\angle 9 t S 0^{\circ} 0$ & $Ð 8 \angle \angle 0^{\circ} 0$ & $90880^{\circ} 0$ & $88 I^{\circ} 0$ & ISZ \\
\hline$I Z \angle S O 0^{\circ} 0$ & $66600^{\circ} 0$ & $81920^{\circ} 0$ & S9EE $0^{\circ} 0$ & SOSO 0 & $Z 8 \angle S 0^{\circ} 0$ & $86280^{\circ} 0$ & $0 S \mathcal{L}$ \\
\hline $2 t S 10^{\circ} 0$ & $12 Z 20^{\circ} 0$ & $\varepsilon \tau S+0^{\circ} 0$ & SLESO $0^{\circ}$ & It $9 \angle 0^{\circ} 0$ & $50980^{\circ} 0$ & ILII'O & $6+\tau$ \\
\hline 2 tolo $0^{\circ} 0$ & $\nabla 2910^{\circ} 0$ & $\varepsilon 69 \varepsilon 0^{\circ} 0$ & $t S t+0^{\circ} 0$ & $\neg Z \varepsilon 90^{\circ} 0$ & $\varepsilon L I L 0^{\circ} 0$ & $5001^{\circ} 0$ & $8 \circ 2$ \\
\hline $108 \mathrm{IO}^{\circ} 0$ & $\angle S Z 0^{\circ} 0$ & $t S I S 0^{\circ} 0$ & $68190^{\circ} 0$ & $\angle 9 £ 80^{\circ} 0$ & $6 \tau \varepsilon 60^{\circ} 0$ & $\angle 9 Z I^{\circ} 0$ & $\angle D Z$ \\
\hline $28 \angle \angle 00^{\circ} 0$ & $28210^{\circ} 0$ & $t 乙 I \varepsilon 0^{\circ} 0$ & II $6 £ 0^{\circ} 0$ & 9ILSO 0 & $6+S 90^{\circ} 0$ & $\nabla 1260^{\circ} 0$ & $9 b 2$ \\
\hline$\angle I 6100^{\circ} 0$ & $81500^{\circ} 0$ & $t 9 S 10^{\circ} 0$ & $120^{\circ} 0$ & $\angle \sigma \varepsilon E 0^{\circ} 0$ & $t 86 \varepsilon 0^{\circ} 0$ & $16190^{\circ} 0$ & $s \leftarrow \tau$ \\
\hline $8 \angle 610^{\circ} 0$ & $\nabla \angle 9 Z 0^{\circ} 0$ & $t \angle E S 0^{\circ} 0$ & $8 S \varepsilon 90^{\circ} 0$ & $8 \angle S 80^{\circ} 0$ & $92560^{\circ} 0$ & $98 Z I^{\circ} 0$ & 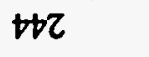 \\
\hline$\varepsilon Z 910^{\circ} 0$ & $68 \varepsilon Z 0^{\circ} 0$ & $I \angle t 0^{\circ} 0$ & $18 S S 0^{\circ} 0$ & $9 S 6 \angle 0^{\circ} 0$ & $\nabla E 680^{\circ} 0$ & $\mathrm{EOZI}^{\circ} 0$ & $\varepsilon \not \tau$ \\
\hline $66 € 10^{\circ} 0$ & t020 0 & $8 z \varepsilon+0^{\circ} 0$ & IZZSऽ $0^{\circ} 0$ & SELO & $69280^{\circ} 0$ & $6 \mathrm{tII} 0$ & $\tau \not \tau$ \\
\hline $89 £ 900^{\circ} 0$ & $69010^{\circ} 0$ & $89 \angle 20^{\circ} 0$ & $\varepsilon 9+\varepsilon 0^{\circ} 0$ & S8ISO 0 & $9 E 6 S^{\circ} 0$ & $27 S 80^{\circ} 0$ & $I \forall Z$ \\
\hline $8 S S Z 00^{\circ} 0$ & $+0 S 00^{\circ} 0$ & $60 \angle I 0^{\circ} 0$ & $90220^{\circ} 0$ & $9 Z 980^{\circ} 0$ & $2 z+0^{\circ} 0$ & $6 t S 90^{\circ} 0$ & 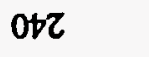 \\
\hline S6LLOOOO & E8ZI $0^{\circ} 0$ & SZIEO 0 & $\angle I 6 E 0^{\circ} 0$ & $\angle Z L S 0^{\circ} 0$ & ISS90 0 & $Z \varepsilon Z 60^{\circ} 0$ & $6 \varepsilon Z$ \\
\hline$t I I 0^{\circ} 0$ & $\angle E L I 0^{\circ} 0$ & $\angle 08 E 0^{\circ} 0$ & $S 09+0^{\circ} 0$ & $9590^{\circ} 0$ & $\varepsilon 0 t \angle 0^{\circ} 0$ & $2+0 I^{\circ} 0$ & $8 \varepsilon Z$ \\
\hline$\angle O E I 0^{\circ} 0$ & $18610^{\circ} 0$ & $10 z+0^{\circ} 0$ & $\angle O S O^{\circ} O$ & $\$ 8 I \angle 0^{\circ} 0$ & $8080^{\circ} 0$ & $\angle I I I^{\circ} O$ & $\angle \varepsilon Z$ \\
\hline ZEIIO०O & $26910^{\circ} 0$ & $108 \varepsilon 0^{\circ} 0$ & $t 6 S t 0^{\circ} 0$ & tIS90.0 & $9 E \angle 0^{\circ} 0$ & $8 \mathrm{EOI} 0$ & $9 \varepsilon Z$ \\
\hline $\mathrm{H} \gg \mathrm{I}-\mathrm{dSO}$ & HII-dSOT & H9-dSOT & HS-dSOT & HS'E-dSOT & HE-dSOT & HZ-dSOT & jụod \\
\hline
\end{tabular}


LOSP Frequency

\begin{tabular}{|c|c|c|c|c|c|c|c|}
\hline Point & LOSP-2H & LOSP-3H & LOSP-3.5H & LOSP-5H & LOSP-6H & LOSP-11H & LOSP-14H \\
\hline 270 & 0.05656 & 0.03616 & 0.03043 & 0.01846 & 0.01372 & 0.00331 & 0.001417 \\
\hline 271 & 0.1529 & 0.1155 & 0.1041 & 0.07911 & 0.06946 & 0.04332 & 0.03393 \\
\hline 272 & 0.1465 & 0.1078 & 0.09776 & 0.07455 & 0.06437 & 0.03755 & 0.02864 \\
\hline 273 & 0.07349 & 0.04897 & 0.04257 & 0.02751 & 0.02118 & 0.00678 & 0.003593 \\
\hline 274 & 0.1797 & 0.142 & 0.1336 & 0.1109 & 0.09598 & 0.06402 & 0.05498 \\
\hline 275 & 0.1448 & 0.1077 & 0.09757 & 0.07435 & 0.06419 & 0.03742 & 0.02828 \\
\hline 276 & 0.08431 & 0.05862 & 0.05117 & 0.03402 & 0.0271 & 0.01035 & 0.006095 \\
\hline 277 & 0.06973 & 0.04693 & 0.04056 & 0.02563 & 0.01974 & 0.0061 & 0.003134 \\
\hline 278 & 0.1112 & 0.08009 & 0.07127 & 0.05053 & 0.04187 & 0.01962 & 0.013 \\
\hline 279 & 0.09374 & 0.06607 & 0.05763 & 0.03941 & 0.03157 & 0.01304 & 0.008047 \\
\hline 280 & 0.04613 & 0.02728 & 0.02257 & 0.01229 & 0.00858 & 0.00118 & 0.0004862 \\
\hline 281 & 0.1207 & 0.0896 & 0.0798 & 0.05587 & 0.0472 & 0.02403 & 0.01626 \\
\hline 282 & 0.08601 & 0.05968 & 0.05239 & 0.03478 & 0.02799 & 0.01097 & 0.006549 \\
\hline 283 & 0.09481 & 0.06666 & 0.05839 & 0.04008 & 0.03261 & 0.01349 & 0.008363 \\
\hline 284 & 0.09583 & 0.06735 & 0.05909 & 0.04108 & 0.03399 & 0.01396 & 0.008757 \\
\hline 285 & 0.119 & 0.08819 & 0.07807 & 0.05478 & 0.04596 & 0.02317 & 0.01583 \\
\hline 286 & 0.06559 & 0.04226 & 0.03633 & 0.02218 & 0.01726 & 0.00516 & 0.002604 \\
\hline 287 & 0.07366 & 0.04903 & 0.04291 & 0.02755 & 0.02137 & 0.00682 & 0.003661 \\
\hline 288 & 0.09652 & 0.0677 & 0.05997 & 0.04132 & 0.03438 & 0.01426 & 0.008921 \\
\hline 289 & 0.1826 & 0.1448 & 0.1359 & 0.1115 & 0.1005 & 0.06492 & 0.05624 \\
\hline 290 & 0.1263 & 0.09307 & 0.08338 & 0.06069 & 0.05132 & 0.02565 & 0.0177 \\
\hline 291 & 0.1144 & 0.08257 & 0.0734 & 0.05206 & 0.04314 & 0.02038 & 0.01397 \\
\hline 292 & 0.1154 & 0.08351 & 0.07404 & 0.05252 & 0.04335 & 0.02074 & 0.01419 \\
\hline 293 & 0.08948 & 0.06238 & 0.05475 & 0.03638 & 0.02962 & 0.01206 & 0.00715 \\
\hline 294 & 0.09877 & 0.0696 & 0.0616 & 0.04289 & 0.03548 & 0.01541 & 0.009816 \\
\hline 295 & 0.1054 & 0.07441 & 0.06593 & 0.0465 & 0.03811 & 0.01758 & 0.01146 \\
\hline 296 & 0.09264 & 0.06583 & 0.05745 & 0.0393 & 0.03145 & 0.01291 & 0.007913 \\
\hline 297 & 0.07731 & 0.05373 & 0.04649 & 0.03023 & 0.02336 & 0.00766 & 0.004375 \\
\hline 298 & 0.04772 & 0.0292 & 0.02404 & 0.01312 & 0.00878 & 0.00189 & 0.0007708 \\
\hline 299 & 0.08689 & 0.06051 & 0.05333 & 0.035 & 0.02864 & 0.01134 & 0.006696 \\
\hline 300 & 0.08859 & 0.06192 & 0.05443 & 0.03607 & 0.02948 & 0.01193 & 0.007099 \\
\hline 301 & 0.05179 & 0.03062 & 0.02555 & 0.01408 & 0.01039 & 0.00212 & 0.0008958 \\
\hline 302 & 0.1647 & 0.1331 & 0.1235 & 0.1002 & 0.08815 & 0.05499 & 0.0435 \\
\hline 303 & 0.1079 & 0.07657 & 0.06845 & 0.04875 & 0.04023 & 0.01855 & 0.01192 \\
\hline
\end{tabular}


LOSP Frequency

\begin{tabular}{|c|c|c|c|c|c|c|c|}
\hline Point & LOSP-2H & LOSP-3H & LOSP-3.5H & LOSP-5H & LOSP-6H & LOSP-11H & LOSP-14H \\
\hline 304 & 0.1487 & 0.1107 & 0.1008 & 0.07712 & 0.06599 & 0.04016 & 0.03228 \\
\hline 305 & 0.1309 & 0.09743 & 0.08778 & 0.06468 & 0.05426 & 0.02751 & 0.02022 \\
\hline 306 & 0.09167 & 0.06498 & 0.05665 & 0.03862 & 0.03112 & 0.01255 & 0.00752 \\
\hline 307 & 0.06617 & 0.04351 & 0.03735 & 0.02318 & 0.01766 & 0.00538 & 0.002726 \\
\hline 308 & 0.1294 & 0.09681 & 0.08693 & 0.06418 & 0.054 & 0.02731 & 0.01998 \\
\hline 309 & 0.1639 & 0.1291 & 0.1184 & 0.09277 & 0.08286 & 0.0527 & 0.04215 \\
\hline 310 & 0.1295 & 0.09686 & 0.08732 & 0.0643 & 0.05411 & 0.02732 & 0.02 \\
\hline 311 & 0.1225 & 0.09035 & 0.08036 & 0.05685 & 0.04833 & 0.02428 & 0.01661 \\
\hline 312 & 0.0802 & 0.05535 & 0.04841 & 0.03198 & 0.02494 & 0.0087 & 0.004947 \\
\hline 313 & 0.1478 & 0.1096 & 0.09909 & 0.07639 & 0.06541 & 0.03919 & 0.03017 \\
\hline 314 & 0.1075 & 0.07648 & 0.06834 & 0.04862 & 0.04001 & 0.01846 & 0.01191 \\
\hline 315 & 0.1089 & 0.07829 & 0.06963 & 0.04961 & 0.04078 & 0.0189 & 0.01233 \\
\hline 316 & 0.07374 & 0.04931 & 0.04308 & 0.02762 & 0.02157 & 0.00692 & 0.003689 \\
\hline 317 & 0.08753 & 0.06142 & 0.05402 & 0.03539 & 0.02899 & 0.01146 & 0.006853 \\
\hline 318 & 0.07861 & 0.05436 & 0.04729 & 0.03071 & 0.02397 & 0.0079 & 0.004493 \\
\hline 319 & 0.0668 & 0.04416 & 0.03796 & 0.02366 & 0.01793 & 0.00554 & 0.002773 \\
\hline 320 & 0.09909 & 0.06974 & 0.06173 & 0.04313 & 0.03567 & 0.01544 & 0.009835 \\
\hline 321 & 0.1258 & 0.09268 & 0.08292 & 0.06039 & 0.05094 & 0.02546 & 0.01753 \\
\hline 322 & 0.1089 & 0.07752 & 0.06922 & 0.0495 & 0.04076 & 0.01888 & 0.01232 \\
\hline 323 & 0.08141 & 0.05635 & 0.04927 & 0.03294 & 0.02557 & 0.00931 & 0.005196 \\
\hline 324 & 0.09514 & 0.06688 & 0.05855 & 0.04027 & 0.03285 & 0.01364 & 0.008498 \\
\hline 325 & 0.09786 & 0.06901 & 0.0611 & 0.04251 & 0.0353 & 0.01507 & 0.009733 \\
\hline 326 & 0.1033 & 0.07286 & 0.06441 & 0.04555 & 0.03747 & 0.01674 & 0.01108 \\
\hline 327 & 0.06927 & 0.04665 & 0.04015 & 0.02516 & 0.01928 & 0.00604 & 0.003068 \\
\hline 328 & 0.09714 & 0.06879 & 0.06081 & 0.04236 & 0.03502 & 0.01467 & 0.009388 \\
\hline 329 & 0.08755 & 0.06149 & 0.05406 & 0.03542 & 0.02913 & 0.01159 & 0.006893 \\
\hline 330 & 0.08647 & 0.05991 & 0.05253 & 0.03484 & 0.02838 & 0.01112 & 0.006557 \\
\hline 331 & 0.09936 & 0.06984 & 0.06193 & 0.04318 & 0.03569 & 0.01545 & 0.009837 \\
\hline 332 & 0.08024 & 0.05563 & 0.04857 & 0.03205 & 0.02495 & 0.00874 & 0.004958 \\
\hline 333 & 0.07435 & 0.05024 & 0.0438 & 0.02854 & 0.02217 & 0.0071 & 0.00383 \\
\hline 334 & 0.06574 & 0.04296 & 0.03685 & 0.02287 & 0.01734 & 0.0053 & 0.002658 \\
\hline 335 & 0.1251 & 0.09158 & 0.08195 & 0.05995 & 0.05029 & 0.0253 & 0.01736 \\
\hline 336 & 0.1074 & 0.07629 & 0.06812 & 0.0485 & 0.03973 & 0.01828 & 0.01169 \\
\hline 337 & 0.118 & 0.08718 & 0.07726 & 0.0543 & 0.04538 & 0.02282 & 0.01573 \\
\hline
\end{tabular}


LOSP Frequency

\begin{tabular}{|c|c|c|c|c|c|c|c|}
\hline Point & LOSP-2H & LOSP-3H & LOSP-3.5H & LOSP-5H & LOSP-6H & LOSP-11H & LOSP-14H \\
\hline 338 & 0.1129 & 0.08172 & 0.07255 & 0.05164 & 0.0423 & 0.01998 & 0.01351 \\
\hline 339 & 0.1052 & 0.07431 & 0.06574 & 0.0463 & 0.03811 & 0.01745 & 0.01144 \\
\hline 340 & 0.09105 & 0.06374 & 0.05569 & 0.03728 & 0.03046 & 0.01226 & 0.0073 \\
\hline 341 & 0.08541 & 0.0593 & 0.05165 & 0.03453 & 0.02759 & 0.01067 & 0.006359 \\
\hline 342 & 0.07883 & 0.05464 & 0.0475 & 0.03083 & 0.02418 & 0.00799 & 0.004503 \\
\hline 343 & 0.05592 & 0.03542 & 0.0299 & 0.0174 & 0.01349 & 0.00318 & 0.001396 \\
\hline 344 & 0.1232 & 0.09073 & 0.08095 & 0.05782 & 0.04853 & 0.02456 & 0.01692 \\
\hline 345 & 0.0299 & 0.02082 & 0.01676 & 0.00802 & 0.00528 & 0.00106 & 0.0003858 \\
\hline 346 & 0.1277 & 0.0941 & 0.08435 & 0.06246 & 0.05244 & 0.02636 & 0.01884 \\
\hline 347 & 0.1158 & 0.08436 & 0.07509 & 0.0528 & 0.04389 & 0.02129 & 0.01474 \\
\hline 348 & 0.07188 & 0.04835 & 0.04181 & 0.02682 & 0.0206 & 0.00628 & 0.003294 \\
\hline 349 & 0.1164 & 0.08453 & 0.0752 & 0.05287 & 0.04402 & 0.02167 & 0.01484 \\
\hline 350 & 0.1194 & 0.08854 & 0.07894 & 0.05511 & 0.04661 & 0.02348 & 0.01605 \\
\hline 351 & 0.1016 & 0.07241 & 0.06396 & 0.04485 & 0.03715 & 0.01652 & 0.01063 \\
\hline 352 & 0.1169 & 0.08573 & 0.07618 & 0.05362 & 0.04521 & 0.02218 & 0.0154 \\
\hline 353 & 0.106 & 0.07512 & 0.06699 & 0.04698 & 0.03869 & 0.01779 & 0.01156 \\
\hline 354 & 0.1293 & 0.09603 & 0.08633 & 0.06396 & 0.05382 & 0.02684 & 0.01986 \\
\hline 355 & 0.06278 & 0.04013 & 0.03426 & 0.02118 & 0.01588 & 0.00456 & 0.002064 \\
\hline 356 & 0.07842 & 0.05394 & 0.047 & 0.0305 & 0.0238 & 0.00773 & 0.004441 \\
\hline 357 & 0.1487 & 0.1101 & 0.1 & 0.07655 & 0.06594 & 0.03995 & 0.03174 \\
\hline 358 & 0.06973 & 0.0468 & 0.04046 & 0.02545 & 0.01945 & 0.0061 & 0.003102 \\
\hline 359 & 0.07301 & 0.04886 & 0.04251 & 0.02749 & 0.02114 & 0.00673 & 0.003571 \\
\hline 360 & 0.0938 & 0.06621 & 0.05782 & 0.03967 & 0.03197 & 0.01311 & 0.008137 \\
\hline 361 & 0.09968 & 0.07053 & 0.06245 & 0.04364 & 0.03619 & 0.01596 & 0.009976 \\
\hline 362 & 0.1423 & 0.1063 & 0.09629 & 0.07215 & 0.06228 & 0.03481 & 0.02563 \\
\hline 363 & 0.1096 & 0.07856 & 0.06985 & 0.04987 & 0.04099 & 0.0193 & 0.01261 \\
\hline 364 & 0.09712 & 0.06872 & 0.06068 & 0.0422 & 0.03498 & 0.01463 & 0.009236 \\
\hline 365 & 0.1191 & 0.0882 & 0.07813 & 0.05491 & 0.0461 & 0.02319 & 0.01588 \\
\hline 366 & 0.1307 & 0.09723 & 0.08763 & 0.06465 & 0.05416 & 0.02738 & 0.02019 \\
\hline 367 & 0.1038 & 0.07347 & 0.06497 & 0.0458 & 0.03778 & 0.01689 & 0.01128 \\
\hline 368 & 0.08245 & 0.05686 & 0.04985 & 0.03328 & 0.02601 & 0.00975 & 0.005501 \\
\hline 369 & 0.09955 & 0.07018 & 0.06227 & 0.04345 & 0.03606 & 0.01564 & 0.009965 \\
\hline 370 & 0.0949 & 0.06679 & 0.05848 & 0.04019 & 0.03267 & 0.01351 & 0.008381 \\
\hline 371 & 0.08094 & 0.05604 & 0.04895 & 0.03232 & 0.02519 & 0.00914 & 0.005038 \\
\hline
\end{tabular}


LOSP Frequency

\begin{tabular}{|c|c|c|c|c|c|c|c|}
\hline Point & LOSP-2H & LOSP-3H & LOSP-3.5H & LOSP-5H & LOSP-6H & LOSP-11H & LOSP-14H \\
\hline 372 & 0.1017 & 0.07245 & 0.06405 & 0.04529 & 0.03715 & 0.01654 & 0.01071 \\
\hline 373 & 0.1375 & 0.1023 & 0.09279 & 0.06858 & 0.05887 & 0.03198 & 0.02389 \\
\hline 374 & 0.07212 & 0.04846 & 0.04187 & 0.027 & 0.02061 & 0.00643 & 0.003296 \\
\hline 375 & 0.079 & 0.05475 & 0.04768 & 0.03145 & 0.02441 & 0.00836 & 0.004606 \\
\hline 376 & 0.1066 & 0.07523 & 0.06706 & 0.04701 & 0.03884 & 0.0178 & 0.01162 \\
\hline 377 & 0.1126 & 0.08142 & 0.07237 & 0.05136 & 0.04222 & 0.01995 & 0.01326 \\
\hline 378 & 0.1322 & 0.1 & 0.08958 & 0.06614 & 0.05612 & 0.02929 & 0.02131 \\
\hline 379 & 0.08025 & 0.0559 & 0.04875 & 0.03216 & 0.02505 & 0.00889 & 0.005017 \\
\hline 380 & 0.07546 & 0.0519 & 0.04507 & 0.02928 & 0.02272 & 0.00743 & 0.004147 \\
\hline 381 & 0.1191 & 0.08832 & 0.07856 & 0.05508 & 0.04626 & 0.02328 & 0.01592 \\
\hline 382 & 0.0794 & 0.05486 & 0.04785 & 0.03149 & 0.02465 & 0.00848 & 0.00472 \\
\hline 383 & 0.08973 & 0.06249 & 0.05484 & 0.03652 & 0.02965 & 0.01207 & 0.007163 \\
\hline 384 & 0.1706 & 0.1419 & 0.1333 & 0.109 & 0.09349 & 0.0618 & 0,0507 \\
\hline 385 & 0.1401 & 0.104 & 0.09434 & 0.07008 & 0.05977 & 0.03325 & 0.02416 \\
\hline 386 & 0.1137 & 0.08214 & 0.07291 & 0.05186 & 0.04257 & 0.02019 & 0.01375 \\
\hline 387 & 0.1235 & 0.09093 & 0.08122 & 0.05853 & 0.04873 & 0.02468 & 0.01701 \\
\hline 388 & 0.08433 & 0.05905 & 0.05141 & 0.03436 & 0.02726 & 0.01041 & 0.006207 \\
\hline 389 & 0.1066 & 0.07554 & 0.06735 & 0.04714 & 0.03889 & 0.01781 & 0.01164 \\
\hline 390 & 0.08443 & 0.0591 & 0.05144 & 0.03441 & 0.0273 & 0.01043 & 0.006287 \\
\hline 391 & 0.06578 & 0.04312 & 0.03697 & 0.02296 & 0.01758 & 0.00532 & 0.002693 \\
\hline 392 & 0.09258 & 0.06562 & 0.05732 & 0.03926 & 0.03135 & 0.01285 & 0.007815 \\
\hline 393 & 0.1023 & 0.07261 & 0.06421 & 0.04543 & 0.03734 & 0.0167 & 0.01081 \\
\hline 394 & 0.1295 & 0.09718 & 0.0876 & 0.06464 & 0.05412 & 0.02737 & 0.02014 \\
\hline 395 & 0.1421 & 0.1062 & 0.09622 & 0.07187 & 0.06151 & 0.03476 & 0.02551 \\
\hline 396 & 0.1184 & 0.08768 & 0.07758 & 0.0546 & 0.04554 & 0.02305 & 0.01575 \\
\hline 397 & 0.1627 & 0.125 & 0.1152 & 0.09261 & 0.08215 & 0.05149 & 0.04136 \\
\hline 398 & 0.07852 & 0.05434 & 0.04726 & 0.03068 & 0.02394 & 0.00789 & 0.004487 \\
\hline 399 & 0.1071 & 0.07598 & 0.06781 & 0.04773 & 0.03935 & 0.01798 & 0.01168 \\
\hline 400 & 0.124 & 0.09137 & 0.08165 & 0.05941 & 0.04943 & 0.02479 & 0.01704 \\
\hline 401 & 0.1005 & 0.07172 & 0.06316 & 0.04443 & 0.03684 & 0.01614 & 0.01032 \\
\hline 402 & 0.1096 & 0.07857 & 0.06988 & 0.04988 & 0.04136 & 0.01932 & 0.01263 \\
\hline 403 & 0.1668 & 0.1368 & 0.1272 & 0.102 & 0.09099 & 0.05834 & 0.0468 \\
\hline 404 & 0.07235 & 0.04867 & 0.04239 & 0.02704 & 0.02085 & 0.00663 & 0.003361 \\
\hline 405 & 0.1006 & 0.07182 & 0.06343 & 0.04462 & 0.03693 & 0.01626 & 0.01043 \\
\hline
\end{tabular}


LOSP Frequency

\begin{tabular}{|c|c|c|c|c|c|c|c|}
\hline Point & LOSP-2H & LOSP-3H & LOSP-3.5H & LOSP-5H & LOSP-6H & LOSP-11H & LOSP-14H \\
\hline 406 & 0.08107 & 0.05624 & 0.04909 & 0.03257 & 0.02523 & 0.00915 & 0.005063 \\
\hline 407 & 0.131 & 0.09837 & 0.08832 & 0.06494 & 0.05441 & 0.02783 & 0.02035 \\
\hline 408 & 0.05247 & 0.03233 & 0.02703 & 0.0153 & 0.01169 & 0.00275 & 0.001074 \\
\hline 409 & 0.134 & 0.1007 & 0.09049 & 0.06693 & 0.05717 & 0.03004 & 0.02245 \\
\hline 410 & 0.1187 & 0.08793 & 0.07771 & 0.05465 & 0.04563 & 0.02312 & 0.01582 \\
\hline 411 & 0.06911 & 0.04663 & 0.04004 & 0.02516 & 0.01927 & 0.00603 & 0.003052 \\
\hline 412 & 0.1154 & 0.08343 & 0.07399 & 0.05247 & 0.04334 & 0.02062 & 0.01417 \\
\hline 413 & 0.09156 & 0.06496 & 0.05652 & 0.03856 & 0.03108 & 0.01244 & 0.007488 \\
\hline 414 & 0.1214 & 0.09003 & 0.08008 & 0.05603 & 0.04758 & 0.02405 & 0.01627 \\
\hline 415 & 0.1109 & 0.07876 & 0.07018 & 0.05009 & 0.04152 & 0.01936 & 0.01283 \\
\hline 416 & 0.06478 & 0.04131 & 0.03526 & 0.02158 & 0.01658 & 0.00496 & 0.002466 \\
\hline 417 & 0.1692 & 0.1399 & 0.1299 & 0.1051 & 0.09146 & 0.0618 & 0.0486 \\
\hline 418 & 0.1264 & 0.09317 & 0.08347 & 0.06079 & 0.05132 & 0.02565 & 0.01771 \\
\hline 419 & 0.06815 & 0.04466 & 0.03837 & 0.02386 & 0.01812 & 0.00562 & 0.002816 \\
\hline 420 & 0.09961 & 0.07037 & 0.06237 & 0.04362 & 0.03619 & 0.01585 & 0.009972 \\
\hline 421 & 0.07988 & 0.05513 & 0.0481 & 0.03193 & 0.02473 & 0.00862 & 0.004802 \\
\hline 422 & 0.07764 & 0.05384 & 0.04679 & 0.0304 & 0.02372 & 0.00768 & 0.004416 \\
\hline 423 & 0.08253 & 0.05714 & 0.05001 & 0.03338 & 0.02603 & 0.00976 & 0.005505 \\
\hline 424 & 0.1128 & 0.08161 & 0.07249 & 0.05164 & 0.0423 & 0.01997 & 0.01349 \\
\hline 425 & 0.07373 & 0.04929 & 0.04306 & 0.02756 & 0.02153 & 0.00682 & 0.003669 \\
\hline 426 & 0.1144 & 0.08257 & 0.0734 & 0.05206 & 0.04314 & 0.02038 & 0.01397 \\
\hline 427 & 0.08139 & 0.05634 & 0.04923 & 0.03283 & 0.02555 & 0.00921 & 0.005171 \\
\hline 428 & 0.1267 & 0.09322 & 0.08355 & 0.06122 & 0.05138 & 0.02567 & 0.01792 \\
\hline 429 & 0.1575 & 0.1191 & 0.1079 & 0.08187 & 0.07472 & 0.04654 & 0.03759 \\
\hline 430 & 0.1293 & 0.09564 & 0.08599 & 0.06363 & 0.05379 & 0.02681 & 0.01978 \\
\hline 431 & 0.1118 & 0.08104 & 0.07198 & 0.05093 & 0.04202 & 0.01985 & 0.01315 \\
\hline 432 & 0.1631 & 0.1263 & 0.116 & 0.09261 & 0.08272 & 0.05204 & 0.04182 \\
\hline 433 & 0.09572 & 0.0673 & 0.05904 & 0.04098 & 0.03391 & 0.01394 & 0.008709 \\
\hline 434 & 0.1255 & 0.09239 & 0.08273 & 0.0602 & 0.0508 & 0.02535 & 0.01744 \\
\hline 435 & 0.1329 & 0.1004 & 0.09026 & 0.06655 & 0.05698 & 0.02999 & 0.02197 \\
\hline 436 & 0.1154 & 0.08396 & 0.07466 & 0.05256 & 0.04345 & 0.02075 & 0.01431 \\
\hline 437 & 0.06196 & 0.04008 & 0.03421 & 0.02117 & 0.01572 & 0.00433 & 0.001971 \\
\hline 438 & 0.1166 & 0.08504 & 0.07556 & 0.05306 & 0.04454 & 0.02178 & 0.01512 \\
\hline 439 & 0.2393 & 0.2101 & 0.203 & 0.1873 & 0.1817 & 0.171 & 0.169 \\
\hline
\end{tabular}


LOSP Frequency

\begin{tabular}{|c|c|c|c|c|c|c|c|}
\hline Point & LOSP-2H & LOSP-3H & LOSP-3.5H & LOSP-5H & LOSP-6H & LOSP-11H & LOSP-14H \\
\hline 440 & 0.08694 & 0.06106 & 0.05367 & 0.03525 & 0.02872 & 0.01139 & 0.00673 \\
\hline 441 & 0.1015 & 0.07196 & 0.06363 & 0.04474 & 0.0371 & 0.01638 & 0.01062 \\
\hline 442 & 0.1054 & 0.07497 & 0.06658 & 0.04664 & 0.03811 & 0.0176 & 0.01147 \\
\hline 443 & 0.09684 & 0.0678 & 0.06011 & 0.04209 & 0.03486 & 0.01456 & 0.009222 \\
\hline 444 & 0.1267 & 0.09328 & 0.08363 & 0.06185 & 0.05149 & 0.02568 & 0.01798 \\
\hline 445 & 0.09668 & 0.06777 & 0.06008 & 0.04164 & 0.03473 & 0.0144 & 0.009131 \\
\hline 446 & 0.09558 & 0.06729 & 0.05895 & 0.04089 & 0.03369 & 0.01384 & 0.008627 \\
\hline 447 & 0.08791 & 0.06168 & 0.05418 & 0.03543 & 0.02936 & 0.01174 & 0.006938 \\
\hline 448 & 0.1226 & 0.09072 & 0.08065 & 0.05753 & 0.04841 & 0.02431 & 0.01681 \\
\hline 449 & 0.1272 & 0.09355 & 0.08389 & 0.0623 & 0.05163 & 0.02607 & 0.01834 \\
\hline 450 & 0.09079 & 0.06339 & 0.05548 & 0.03727 & 0.0304 & 0.01223 & 0.00729 \\
\hline 451 & 0.05801 & 0.03747 & 0.03186 & 0.01904 & 0.01421 & 0.00362 & 0.001475 \\
\hline 452 & 0.1362 & 0.102 & 0.09182 & 0.06799 & 0.0584 & 0.03061 & 0.02288 \\
\hline 453 & 0.1111 & 0.07971 & 0.07083 & 0.05019 & 0.04176 & 0.01947 & 0.01291 \\
\hline 454 & 0.1326 & 0.1003 & 0.09004 & 0.0665 & 0.05677 & 0.02971 & 0.02183 \\
\hline 455 & 0.07474 & 0.05135 & 0.04453 & 0.02896 & 0.0225 & 0.00728 & 0.004088 \\
\hline 456 & 0.1168 & 0.0857 & 0.07615 & 0.0534 & 0.04503 & 0.02214 & 0.01538 \\
\hline 457 & 0.08919 & 0.06229 & 0.05469 & 0.03629 & 0.02954 & 0.01201 & 0.00714 \\
\hline 458 & 0.08024 & 0.05573 & 0.04863 & 0.03213 & 0.02496 & 0.00888 & 0.004962 \\
\hline 459 & 0.08721 & 0.06111 & 0.05371 & 0.03528 & 0.02885 & 0.01139 & 0.006734 \\
\hline 460 & 0.135 & 0.1017 & 0.09151 & 0.0675 & 0.05781 & 0.03048 & 0.02273 \\
\hline 461 & 0.1026 & 0.07281 & 0.06439 & 0.04555 & 0.03741 & 0.01673 & 0.0109 \\
\hline 462 & 0.05544 & 0.03442 & 0.02919 & 0.01723 & 0.01298 & 0.00315 & 0.001276 \\
\hline 463 & 0.05181 & 0.03068 & 0.02561 & 0.01504 & 0.01131 & 0.00243 & 0.001017 \\
\hline 464 & 0.07478 & 0.05155 & 0.04464 & 0.02904 & 0.02251 & 0.00731 & 0.004099 \\
\hline 465 & 0.1319 & 0.09902 & 0.089 & 0.06551 & 0.05576 & 0.02856 & 0.02087 \\
\hline 466 & 0.1261 & 0.09285 & 0.08305 & 0.06068 & 0.05126 & 0.02555 & 0.01768 \\
\hline 467 & 0.05603 & 0.03583 & 0.03021 & 0.01838 & 0.01368 & 0.00328 & 0.001406 \\
\hline 468 & 0.1438 & 0.107 & 0.09701 & 0.07366 & 0.0639 & 0.03708 & 0.02622 \\
\hline 469 & 0.1192 & 0.0885 & 0.07865 & 0.0551 & 0.04645 & 0.02334 & 0.01602 \\
\hline 470 & 0.08432 & 0.05884 & 0.0513 & 0.03423 & 0.02716 & 0.01038 & 0.006187 \\
\hline 471 & 0.07874 & 0.05441 & 0.04736 & 0.03071 & 0.02416 & 0.00798 & 0.004494 \\
\hline 472 & 0.09196 & 0.06523 & 0.05689 & 0.03881 & 0.03119 & 0.01282 & 0.007616 \\
\hline 473 & 0.05722 & 0.03618 & 0.03076 & 0.01854 & 0.01402 & 0.00338 & 0.001426 \\
\hline
\end{tabular}

Vol. 2, Part 2 
LOSP Frequency

\begin{tabular}{|c|c|c|c|c|c|c|c|}
\hline Point & LOSP-2H & LOSP-3H & LOSP-3.5H & LOSP-5H & LOSP-6H & LOSP-11H & LOSP-14H \\
\hline 474 & 0.1081 & 0.07704 & 0.0688 & 0.04919 & 0.04037 & 0.01873 & 0.01206 \\
\hline 475 & 0.1111 & 0.08007 & 0.07117 & 0.05021 & 0.04177 & 0.01954 & 0.01297 \\
\hline 476 & 0.1356 & 0.1017 & 0.09165 & 0.06756 & 0.05834 & 0.03061 & 0.02283 \\
\hline 477 & 0.05234 & 0.03201 & 0.02656 & 0.01514 & 0.01155 & 0.0026 & 0.001023 \\
\hline 478 & 0.08443 & 0.0591 & 0.05144 & 0.03441 & 0.0273 & 0.01043 & 0.006287 \\
\hline 479 & 0.1236 & 0.09136 & 0.08144 & 0.05873 & 0.04927 & 0.02476 & 0.01704 \\
\hline 480 & 0.05319 & 0.03263 & 0.0273 & 0.01604 & 0.01178 & 0.0028 & 0.001158 \\
\hline 481 & 0.07672 & 0.05349 & 0.04632 & 0.03022 & 0.02324 & 0.00766 & 0.004302 \\
\hline 482 & 0.04476 & 0.02668 & 0.02154 & 0.01076 & 0.00724 & 0.00113 & 0.0004241 \\
\hline 483 & 0.08367 & 0.05846 & 0.05104 & 0.03393 & 0.02691 & 0.01026 & 0.006028 \\
\hline 484 & 0.1141 & 0.08245 & 0.07322 & 0.05204 & 0.0431 & 0.02027 & 0.01392 \\
\hline 485 & 0.04638 & 0.02785 & 0.02302 & 0.01246 & 0.00859 & 0.00154 & 0.0005338 \\
\hline 486 & 0.1277 & 0.09438 & 0.08455 & 0.0625 & 0.05256 & 0.02636 & 0.01894 \\
\hline 487 & 0.09043 & 0.0631 & 0.05525 & 0.03675 & 0.03026 & 0.01218 & 0.007259 \\
\hline 488 & 0.1164 & 0.08487 & 0.07543 & 0.05297 & 0.04436 & 0.02168 & 0.01503 \\
\hline 489 & 0.06889 & 0.04652 & 0.03982 & 0.02488 & 0.01884 & 0.00593 & 0.002986 \\
\hline 490 & 0.06114 & 0.03945 & 0.03345 & 0.02083 & 0.01491 & 0.00392 & 0.001823 \\
\hline 491 & 0.07285 & 0.04877 & 0.04245 & 0.02738 & 0.02093 & 0.00666 & 0.003438 \\
\hline 492 & 0.09639 & 0.0676 & 0.05979 & 0.04129 & 0.03435 & 0.01421 & 0.008897 \\
\hline 493 & 0.06172 & 0.03971 & 0.03369 & 0.02097 & 0.01534 & 0.00411 & 0.001914 \\
\hline 494 & 0.1156 & 0.08432 & 0.07502 & 0.05274 & 0.04374 & 0.02106 & 0.0146 \\
\hline 495 & 0.1332 & 0.1005 & 0.09042 & 0.06692 & 0.05712 & 0.03 & 0.02212 \\
\hline 496 & 0.1175 & 0.08676 & 0.077 & 0.05421 & 0.04534 & 0.02275 & 0.0157 \\
\hline 497 & 0.1168 & 0.08549 & 0.07601 & 0.05331 & 0.04484 & 0.02201 & 0.01531 \\
\hline 498 & 0.1654 & 0.1361 & 0.125 & 0.1007 & 0.08931 & 0.05512 & 0.04512 \\
\hline 499 & 0.06889 & 0.04654 & 0.03994 & 0.02503 & 0.01895 & 0.00598 & 0.002998 \\
\hline 500 & 0.1323 & 0.1001 & 0.08963 & 0.06641 & 0.05647 & 0.02936 & 0.02142 \\
\hline
\end{tabular}


LOSP Frequency

\section{Attachment G-47}

IRRAS Histogram Development Spread Sheet 
LOSP Frequency

\begin{tabular}{|c|c|c|c|c|c|c|}
\hline Step & LOSP-2H & Bin Bound & Frequency & Bin Mdpt & Prob Density $(\%)$ & Running Tot \\
\hline 0.00 & 0.00 & 0.0252 & 0.00 & 0.00 & & 0.00 \\
\hline 0.002 & $2.7010 e-02$ & 0.0504 & 10 & 0.04 & 2.00 & 0.02 \\
\hline 0.004 & $2.9900 e-02$ & 0.0599 & 24 & 0.06 & 4.80 & 0.07 \\
\hline 0.006 & $4.1120 e-02$ & 0.0693 & 40 & 0.06 & 8.00 & 0.15 \\
\hline 0.008 & $4.4760 \mathrm{e}-02$ & 0.0756 & 35 & 0.07 & 7.00 & 0.22 \\
\hline 0.01 & $4.4870 e-02$ & 0.0819 & 37 & 0.08 & 7.40 & 0.29 \\
\hline 0.012 & $4.6130 e-02$ & 0.0845 & 22 & 0.08 & 4.40 & 0.34 \\
\hline 0.014 & $4.6380 \mathrm{e}-02$ & 0.0882 & 22 & 0.09 & 4.40 & 0.38 \\
\hline 0.016 & $4.7420 e-02$ & 0.0945 & 33 & 0.09 & 6.60 & 0.45 \\
\hline 0.018 & $4.7720 \mathrm{e}-02$ & 0.1008 & 48 & 0.10 & 9.60 & 0.54 \\
\hline 0.02 & $4.7820 e-02$ & 0.1071 & 26 & 0.10 & 5.20 & 0.59 \\
\hline 0.022 & $5.1580 e-02$ & 0.1134 & 33 & 0.11 & 6.60 & 0.66 \\
\hline 0.024 & $5.1790 e-02$ & 0.1197 & 39 & 0.12 & 7.80 & 0.74 \\
\hline 0.026 & $5.1810 e-02$ & 0.126 & 21 & 0.12 & 4.20 & 0.78 \\
\hline 0.028 & $5.2140 e-02$ & 0.1323 & 33 & 0.13 & 6.60 & 0.85 \\
\hline 0.03 & $5.2340 \mathrm{e}-02$ & 0.1386 & 18 & 0.14 & 3.60 & 0.88 \\
\hline 0.032 & $5.2470 \mathrm{e}-02$ & 0.1512 & 29 & 0.14 & 5.80 & 0.94 \\
\hline 0.034 & $5.2740 \mathrm{e}-02$ & 0.1638 & 14 & 0.16 & 2.80 & 0.97 \\
\hline 0.036 & $5.3190 \mathrm{e}-02$ & 0.1764 & 10 & 0.17 & 2.00 & 0.99 \\
\hline 0.038 & $5.4130 e-02$ & 0.2016 & 4 & 0.19 & 0.80 & 1.00 \\
\hline 0.04 & $5.4880 e-02$ & 0.2394 & 2 & 0.22 & 0.40 & 1.00 \\
\hline 0.042 & $5.5250 \mathrm{e}-02$ & & 0.00 & & & \\
\hline 0.044 & $5.5440 \mathrm{e}-02$ & & 500 & & 100 & \\
\hline
\end{tabular}

\begin{tabular}{|r|r|}
\hline Step & LOSP-2H \\
\hline 0.046 & $5.5500 \mathrm{e}-02$ \\
\hline 0.048 & $5.5920 \mathrm{e}-02$ \\
\hline 0.05 & $5.6030 \mathrm{e}-02$ \\
\hline 0.052 & $5.6560 \mathrm{e}-02$ \\
\hline 0.054 & $5.7220 \mathrm{e}-02$ \\
\hline 0.056 & $5.7820 \mathrm{e}-02$ \\
\hline 0.058 & $5.7910 \mathrm{e}-02$ \\
\hline 0.06 & $5.8010 \mathrm{e}-02$ \\
\hline
\end{tabular}




\begin{tabular}{|r|r|}
\hline Step & LOSP-2H \\
\hline 0.062 & $5.8350 \mathrm{e}-02$ \\
\hline 0.064 & $5.8710 \mathrm{e}-02$ \\
\hline 0.066 & $5.8990 \mathrm{e}-02$ \\
\hline 0.068 & $5.9010 \mathrm{e}-02$ \\
\hline 0.07 & $6.0020 \mathrm{e}-02$ \\
\hline 0.072 & $6.0440 \mathrm{e}-02$ \\
\hline 0.074 & $6.1140 \mathrm{e}-02$ \\
\hline 0.076 & $6.1280 \mathrm{e}-02$ \\
\hline 0.078 & $6.1720 \mathrm{e}-02$ \\
\hline 0.08 & $6.1910 \mathrm{e}-02$ \\
\hline 0.082 & $6.1960 \mathrm{e}-02$ \\
\hline 0.084 & $6.2780 \mathrm{e}-02$ \\
\hline 0.086 & $6.3440 \mathrm{e}-02$ \\
\hline 0.088 & $6.3460 \mathrm{e}-02$ \\
\hline 0.09 & $6.4430 \mathrm{e}-02$ \\
\hline 0.092 & $6.4440 \mathrm{e}-02$ \\
\hline 0.094 & $6.4730 \mathrm{e}-02$ \\
\hline 0.096 & $6.4780 \mathrm{e}-02$ \\
\hline 0.098 & $6.5040 \mathrm{e}-02$ \\
\hline 0.1 & $6.5210 \mathrm{e}-02$ \\
\hline 0.102 & $6.5240 \mathrm{e}-02$ \\
\hline 0.104 & $6.5490 \mathrm{e}-02$ \\
\hline 0.106 & $6.5590 \mathrm{e}-02$ \\
\hline 0.108 & $6.5590 \mathrm{e}-02$ \\
\hline 0.11 & $6.5650 \mathrm{e}-02$ \\
\hline 0.112 & $6.5690 \mathrm{e}-02$ \\
\hline 0.114 & $6.5740 \mathrm{e}-02$ \\
\hline 0.116 & $6.5780 \mathrm{e}-02$ \\
\hline 0.118 & $6.6170 \mathrm{e}-02$ \\
\hline 0.12 & $6.6170 \mathrm{e}-02$ \\
\hline 0.122 & $6.6450 \mathrm{e}-02$ \\
\hline 0.124 & $6.6760 \mathrm{e}-02$ \\
\hline 0.126 & $6.6800 \mathrm{e}-02$ \\
\hline & $6.6990 \mathrm{e}-02$ \\
\hline
\end{tabular}

Vol. 2, Part 2 
LOSP Frequency

\begin{tabular}{|r|r|}
\hline Step & LOSP-2H \\
\hline 0.13 & $6.8150 \mathrm{e}-02$ \\
\hline 0.132 & $6.8160 \mathrm{e}-02$ \\
\hline 0.134 & $6.8520 \mathrm{e}-02$ \\
\hline 0.136 & $6.8610 \mathrm{e}-02$ \\
\hline 0.138 & $6.8870 \mathrm{e}-02$ \\
\hline 0.14 & $6.8890 \mathrm{e}-02$ \\
\hline 0.142 & $6.8890 \mathrm{e}-02$ \\
\hline 0.144 & $6.8980 \mathrm{e}-02$ \\
\hline 0.146 & $6.9110 \mathrm{e}-02$ \\
\hline 0.148 & $6.9270 \mathrm{e}-02$ \\
\hline 0.15 & $6.9470 \mathrm{e}-02$ \\
\hline 0.152 & $6.9730 \mathrm{e}-02$ \\
\hline 0.154 & $6.9730 \mathrm{e}-02$ \\
\hline 0.156 & $7.0500 \mathrm{e}-02$ \\
\hline 0.158 & $7.0560 \mathrm{e}-02$ \\
\hline 0.16 & $7.0970 \mathrm{e}-02$ \\
\hline 0.162 & $7.0980 \mathrm{e}-02$ \\
\hline 0.164 & $7.1680 \mathrm{e}-02$ \\
\hline 0.166 & $7.1740 \mathrm{e}-02$ \\
\hline 0.168 & $7.1880 \mathrm{e}-02$ \\
\hline 0.17 & $7.2120 \mathrm{e}-02$ \\
\hline 0.172 & $7.2290 \mathrm{e}-02$ \\
\hline 0.174 & $7.2350 \mathrm{e}-02$ \\
\hline 0.176 & $7.2850 \mathrm{e}-02$ \\
\hline 0.178 & $7.2950 \mathrm{e}-02$ \\
\hline 0.18 & $7.3010 \mathrm{e}-02$ \\
\hline 0.182 & $7.3490 \mathrm{e}-02$ \\
\hline 0.184 & $7.3660 \mathrm{e}-02$ \\
\hline 0.186 & $7.3730 \mathrm{e}-02$ \\
\hline 0.188 & $7.3740 \mathrm{e}-02$ \\
\hline 0.19 & $7.3900 \mathrm{e}-02$ \\
\hline 0.192 & $7.3960 \mathrm{e}-02$ \\
\hline $7.4020 \mathrm{e}-02$ \\
\hline $7.4260 \mathrm{e}-02$ \\
\hline
\end{tabular}




\begin{tabular}{|r|r|}
\hline Step & LOSP-2H \\
\hline 0.198 & $7.4350 \mathrm{e}-02$ \\
\hline 0.2 & $7.4350 \mathrm{e}-02$ \\
\hline 0.202 & $7.4480 \mathrm{e}-02$ \\
\hline 0.204 & $7.4560 \mathrm{e}-02$ \\
\hline 0.206 & $7.4570 \mathrm{e}-02$ \\
\hline 0.208 & $7.4740 \mathrm{e}-02$ \\
\hline 0.21 & $7.4780 \mathrm{e}-02$ \\
\hline 0.212 & $7.4790 \mathrm{e}-02$ \\
\hline 0.214 & $7.5430 \mathrm{e}-02$ \\
\hline 0.216 & $7.5460 \mathrm{e}-02$ \\
\hline 0.218 & $7.5570 \mathrm{e}-02$ \\
\hline 0.22 & $7.5820 \mathrm{e}-02$ \\
\hline 0.222 & $7.5950 \mathrm{e}-02$ \\
\hline 0.224 & $7.6280 \mathrm{e}-02$ \\
\hline 0.226 & $7.6310 \mathrm{e}-02$ \\
\hline 0.228 & $7.6370 \mathrm{e}-02$ \\
\hline 0.23 & $7.6530 \mathrm{e}-02$ \\
\hline 0.232 & $7.6720 \mathrm{e}-02$ \\
\hline 0.234 & $7.7310 \mathrm{e}-02$ \\
\hline 0.236 & $7.7570 \mathrm{e}-02$ \\
\hline 0.238 & $7.7640 \mathrm{e}-02$ \\
\hline 0.24 & $7.8390 \mathrm{e}-02$ \\
\hline 0.242 & $7.8420 \mathrm{e}-02$ \\
\hline 0.244 & $7.8510 \mathrm{e}-02$ \\
\hline 0.246 & $7.8510 \mathrm{e}-02$ \\
\hline 0.248 & $7.8520 \mathrm{e}-02$ \\
\hline 0.25 & $7.8610 \mathrm{e}-02$ \\
\hline 0.252 & $7.8740 \mathrm{e}-02$ \\
\hline 0.254 & $7.8830 \mathrm{e}-02$ \\
\hline 0.256 & $7.8840 \mathrm{e}-02$ \\
\hline 0.258 & $7.9000 \mathrm{e}-02$ \\
\hline 0.26 & $7.9040 \mathrm{e}-02$ \\
\hline 0.262 & $7.9400 \mathrm{e}-02$ \\
\hline & $7.9620 \mathrm{e}-02$ \\
\hline
\end{tabular}

Vol. 2, Part 2 
LOSP Frequency

\begin{tabular}{|r|r|}
\hline Step & LOSP-2H \\
\hline 0.266 & $7.9790 \mathrm{e}-02$ \\
\hline 0.268 & $7.9880 \mathrm{e}-02$ \\
\hline 0.27 & $7.9880 \mathrm{e}-02$ \\
\hline 0.272 & $8.0200 \mathrm{e}-02$ \\
\hline 0.274 & $8.0240 \mathrm{e}-02$ \\
\hline 0.276 & $8.0240 \mathrm{e}-02$ \\
\hline 0.278 & $8.0250 \mathrm{e}-02$ \\
\hline 0.28 & $8.0300 \mathrm{e}-02$ \\
\hline 0.282 & $8.0800 \mathrm{e}-02$ \\
\hline 0.284 & $8.0940 \mathrm{e}-02$ \\
\hline 0.286 & $8.1070 \mathrm{e}-02$ \\
\hline 0.288 & $8.1390 \mathrm{e}-02$ \\
\hline 0.29 & $8.1410 \mathrm{e}-02$ \\
\hline 0.292 & $8.1510 \mathrm{e}-02$ \\
\hline 0.294 & $8.1940 \mathrm{e}-02$ \\
\hline 0.296 & $8.1990 \mathrm{e}-02$ \\
\hline 0.298 & $8.2130 \mathrm{e}-02$ \\
\hline 0.3 & $8.2450 \mathrm{e}-02$ \\
\hline 0.302 & $8.2530 \mathrm{e}-02$ \\
\hline 0.304 & $8.2690 \mathrm{e}-02$ \\
\hline 0.306 & $8.2780 \mathrm{e}-02$ \\
\hline 0.308 & $8.2820 \mathrm{e}-02$ \\
\hline 0.31 & $8.2980 \mathrm{e}-02$ \\
\hline 0.312 & $8.3160 \mathrm{e}-02$ \\
\hline 0.314 & $8.3230 \mathrm{e}-02$ \\
\hline 0.316 & $8.3270 \mathrm{e}-02$ \\
\hline 0.318 & $8.3390 \mathrm{e}-02$ \\
\hline 0.32 & $8.3430 \mathrm{e}-02$ \\
\hline 0.322 & $8.3610 \mathrm{e}-02$ \\
\hline 0.324 & $8.3670 \mathrm{e}-02$ \\
\hline 0.326 & $8.3810 \mathrm{e}-02$ \\
\hline 0.328 & $8.4310 \mathrm{e}-02$ \\
\hline 0.33 & $8.4320 \mathrm{e}-02$ \\
\hline & $8.4330 \mathrm{e}-02$ \\
\hline
\end{tabular}




\begin{tabular}{|r|r|}
\hline Step & LOSP-2H \\
\hline 0.334 & $8.4430 \mathrm{e}-02$ \\
\hline 0.336 & $8.4430 \mathrm{e}-02$ \\
\hline 0.338 & $8.4750 \mathrm{e}-02$ \\
\hline 0.34 & $8.4900 \mathrm{e}-02$ \\
\hline 0.342 & $8.5410 \mathrm{e}-02$ \\
\hline 0.344 & $8.5420 \mathrm{e}-02$ \\
\hline 0.346 & $8.5440 \mathrm{e}-02$ \\
\hline 0.348 & $8.5870 \mathrm{e}-02$ \\
\hline 0.35 & $8.5970 \mathrm{e}-02$ \\
\hline 0.352 & $8.6010 \mathrm{e}-02$ \\
\hline 0.354 & $8.6420 \mathrm{e}-02$ \\
\hline 0.356 & $8.6470 \mathrm{e}-02$ \\
\hline 0.358 & $8.6620 \mathrm{e}-02$ \\
\hline 0.36 & $8.6740 \mathrm{e}-02$ \\
\hline 0.362 & $8.6860 \mathrm{e}-02$ \\
\hline 0.364 & $8.6890 \mathrm{e}-02$ \\
\hline 0.366 & $8.6900 \mathrm{e}-02$ \\
\hline 0.368 & $8.6940 \mathrm{e}-02$ \\
\hline 0.37 & $8.7210 \mathrm{e}-02$ \\
\hline 0.372 & $8.7320 \mathrm{e}-02$ \\
\hline 0.374 & $8.7530 \mathrm{e}-02$ \\
\hline 0.376 & $8.7550 \mathrm{e}-02$ \\
\hline 0.378 & $8.7910 \mathrm{e}-02$ \\
\hline 0.38 & $8.8160 \mathrm{e}-02$ \\
\hline 0.382 & $8.8530 \mathrm{e}-02$ \\
\hline 0.384 & $8.8540 \mathrm{e}-02$ \\
\hline 0.386 & $8.8590 \mathrm{e}-02$ \\
\hline 0.388 & $8.8930 \mathrm{e}-02$ \\
\hline 0.39 & $8.9190 \mathrm{e}-02$ \\
\hline 0.392 & $8.9480 \mathrm{e}-02$ \\
\hline 0.394 & $8.9730 \mathrm{e}-02$ \\
\hline 0.396 & $9.0060 \mathrm{e}-02$ \\
\hline 0.398 & $9.0090 \mathrm{e}-02$ \\
\hline & $9.0430 \mathrm{e}-02$ \\
\hline
\end{tabular}

Vol. 2, Part 2 
LOSP Frequency

\begin{tabular}{|r|r|}
\hline Step & LOSP-2H \\
\hline 0.402 & $9.0790 \mathrm{e}-02$ \\
\hline 0.404 & $9.1050 \mathrm{e}-02$ \\
\hline 0.406 & $9.1120 \mathrm{e}-02$ \\
\hline 0.408 & $9.1130 \mathrm{e}-02$ \\
\hline 0.41 & $9.1270 \mathrm{e}-02$ \\
\hline 0.412 & $9.1310 \mathrm{e}-02$ \\
\hline 0.414 & $9.1550 \mathrm{e}-02$ \\
\hline 0.416 & $9.1560 \mathrm{e}-02$ \\
\hline 0.418 & $9.1670 \mathrm{e}-02$ \\
\hline 0.42 & $9.1740 \mathrm{e}-02$ \\
\hline 0.422 & $9.1830 \mathrm{e}-02$ \\
\hline 0.424 & $9.1960 \mathrm{e}-02$ \\
\hline 0.426 & $9.2140 \mathrm{e}-02$ \\
\hline 0.428 & $9.2320 \mathrm{e}-02$ \\
\hline 0.43 & $9.2580 \mathrm{e}-02$ \\
\hline 0.432 & $9.2640 \mathrm{e}-02$ \\
\hline 0.434 & $9.2640 \mathrm{e}-02$ \\
\hline 0.436 & $9.3230 \mathrm{e}-02$ \\
\hline 0.438 & $9.3740 \mathrm{e}-02$ \\
\hline 0.44 & $9.3740 \mathrm{e}-02$ \\
\hline 0.442 & $9.3800 \mathrm{e}-02$ \\
\hline 0.444 & $9.4090 \mathrm{e}-02$ \\
\hline 0.446 & $9.4200 \mathrm{e}-02$ \\
\hline 0.448 & $9.4540 \mathrm{e}-02$ \\
\hline 0.45 & $9.4560 \mathrm{e}-02$ \\
\hline 0.452 & $9.4750 \mathrm{e}-02$ \\
\hline 0.454 & $9.4810 \mathrm{e}-02$ \\
\hline 0.456 & $9.4900 \mathrm{e}-02$ \\
\hline 0.458 & $9.5140 \mathrm{e}-02$ \\
\hline 0.46 & $9.5160 \mathrm{e}-02$ \\
\hline 0.462 & $9.5290 \mathrm{e}-02$ \\
\hline 0.464 & $9.5300 \mathrm{e}-02$ \\
\hline 0.466 & $9.5550 \mathrm{e}-02$ \\
\hline & $9.5580 \mathrm{e}-02$ \\
\hline
\end{tabular}




\begin{tabular}{|r|r|}
\hline Step & LOSP-2H \\
\hline 0.47 & $9.5720 \mathrm{e}-02$ \\
\hline 0.472 & $9.5830 \mathrm{e}-02$ \\
\hline 0.474 & $9.5900 \mathrm{e}-02$ \\
\hline 0.476 & $9.6260 \mathrm{e}-02$ \\
\hline 0.478 & $9.6350 \mathrm{e}-02$ \\
\hline 0.48 & $9.6390 \mathrm{e}-02$ \\
\hline 0.482 & $9.6520 \mathrm{e}-02$ \\
\hline 0.484 & $9.6540 \mathrm{e}-02$ \\
\hline 0.486 & $9.6680 \mathrm{e}-02$ \\
\hline 0.488 & $9.6770 \mathrm{e}-02$ \\
\hline 0.49 & $9.6820 \mathrm{e}-02$ \\
\hline 0.492 & $9.6840 \mathrm{e}-02$ \\
\hline 0.494 & $9.7090 \mathrm{e}-02$ \\
\hline 0.496 & $9.7120 \mathrm{e}-02$ \\
\hline 0.498 & $9.7140 \mathrm{e}-02$ \\
\hline 0.5 & $9.7160 \mathrm{e}-02$ \\
\hline 0.502 & $9.7570 \mathrm{e}-02$ \\
\hline 0.504 & $9.7670 \mathrm{e}-02$ \\
\hline 0.506 & $9.7860 \mathrm{e}-02$ \\
\hline 0.508 & $9.7910 \mathrm{e}-02$ \\
\hline 0.51 & $9.8020 \mathrm{e}-02$ \\
\hline 0.512 & $9.8040 \mathrm{e}-02$ \\
\hline 0.514 & $9.8770 \mathrm{e}-02$ \\
\hline 0.516 & $9.9090 \mathrm{e}-02$ \\
\hline 0.518 & $9.9090 \mathrm{e}-02$ \\
\hline 0.52 & $9.9360 \mathrm{e}-02$ \\
\hline 0.522 & $9.9450 \mathrm{e}-02$ \\
\hline 0.524 & $9.9550 \mathrm{e}-02$ \\
\hline 0.526 & $9.9610 \mathrm{e}-02$ \\
\hline 0.528 & $9.9680 \mathrm{e}-02$ \\
\hline 0.53 & $9.9810 \mathrm{e}-02$ \\
\hline 0.532 & $9.9840 \mathrm{e}-02$ \\
\hline 0.534 & $1.0020 \mathrm{e}-01$ \\
\hline & $1.0030 \mathrm{e}-01$ \\
\hline
\end{tabular}

Vol. 2, Part 2 
LOSP Frequency

\begin{tabular}{|r|r|}
\hline Step & LOSP-2H \\
\hline 0.538 & $1.0050 \mathrm{e}-01$ \\
\hline 0.54 & $1.0050 \mathrm{e}-01$ \\
\hline 0.542 & $1.0060 \mathrm{e}-01$ \\
\hline 0.544 & $1.0110 \mathrm{e}-01$ \\
\hline 0.546 & $1.0150 \mathrm{e}-01$ \\
\hline 0.548 & $1.0150 \mathrm{e}-01$ \\
\hline 0.55 & $1.0160 \mathrm{e}-01$ \\
\hline 0.552 & $1.0170 \mathrm{e}-01$ \\
\hline 0.554 & $1.0180 \mathrm{e}-01$ \\
\hline 0.556 & $1.0230 \mathrm{e}-01$ \\
\hline 0.558 & $1.0260 \mathrm{e}-01$ \\
\hline 0.56 & $1.0330 \mathrm{e}-01$ \\
\hline 0.562 & $1.0330 \mathrm{e}-01$ \\
\hline 0.564 & $1.0360 \mathrm{e}-01$ \\
\hline 0.566 & $1.0380 \mathrm{e}-01$ \\
\hline 0.568 & $1.0380 \mathrm{e}-01$ \\
\hline 0.57 & $1.0400 \mathrm{e}-01$ \\
\hline 0.572 & $1.0420 \mathrm{e}-01$ \\
\hline 0.574 & $1.0520 \mathrm{e}-01$ \\
\hline 0.576 & $1.0540 \mathrm{e}-01$ \\
\hline 0.578 & $1.0540 \mathrm{e}-01$ \\
\hline 0.58 & $1.0550 \mathrm{e}-01$ \\
\hline 0.582 & $1.0550 \mathrm{e}-01$ \\
\hline 0.584 & $1.0600 \mathrm{e}-01$ \\
\hline 0.586 & $1.0660 \mathrm{e}-01$ \\
\hline 0.588 & $1.0660 \mathrm{e}-01$ \\
\hline 0.59 & $1.0670 \mathrm{e}-01$ \\
\hline 0.592 & $1.0690 \mathrm{e}-01$ \\
\hline 0.594 & $1.0710 \mathrm{e}-01$ \\
\hline 0.596 & $1.0720 \mathrm{e}-01$ \\
\hline 0.598 & $1.0740 \mathrm{e}-01$ \\
\hline 0.6 & $1.0750 \mathrm{e}-01$ \\
\hline 0.602 & $1.0750 \mathrm{e}-01$ \\
\hline 0.604 & $1.0790 \mathrm{e}-01$ \\
\hline
\end{tabular}




\begin{tabular}{|c|c|}
\hline Step & LOSP-2H \\
\hline 0.606 & $1.0800 \mathrm{e}-01$ \\
\hline 0.608 & $1.0810 \mathrm{e}-01$ \\
\hline 0.61 & $1.0820 \mathrm{e}-01$ \\
\hline 0.612 & $1.0840 \mathrm{e}-01$ \\
\hline 0.614 & $1.0880 \mathrm{e}-01$ \\
\hline 0.616 & $1.0890 \mathrm{e}-01$ \\
\hline 0.618 & $1.0890 \mathrm{e}-01$ \\
\hline 0.62 & $1.0910 \mathrm{e}-01$ \\
\hline 0.622 & $1.0940 \mathrm{e}-01$ \\
\hline 0.624 & $1.0960 \mathrm{e}-01$ \\
\hline 0.626 & $1.0960 e-01$ \\
\hline 0.628 & $1.1070 e-01$ \\
\hline 0.63 & $1.1090 \mathrm{e}-01$ \\
\hline 0.632 & $1.1100 \mathrm{e}-01$ \\
\hline 0.634 & $1.1110 \mathrm{e}-01$ \\
\hline 0.636 & $1.1110 e-01$ \\
\hline 0.638 & $1.1120 \mathrm{e}-01$ \\
\hline 0.64 & $1.1140 \mathrm{e}-01$ \\
\hline 0.642 & $1.1160 \mathrm{e}-01$ \\
\hline 0.644 & $1.1170 \mathrm{e}-01$ \\
\hline 0.646 & $1.1180 \mathrm{e}-01$ \\
\hline 0.648 & $1.1190 \mathrm{e}-01$ \\
\hline 0.65 & $1.1260 \mathrm{e}-01$ \\
\hline 0.652 & $1.1260 \mathrm{e}-01$ \\
\hline 0.654 & $1.1280 e-01$ \\
\hline 0.656 & $1.1290 \mathrm{e}-01$ \\
\hline 0.658 & $1.1320 \mathrm{e}-01$ \\
\hline 0.66 & $1.1330 \mathrm{e}-01$ \\
\hline 0.662 & $1.1370 \mathrm{e}-01$ \\
\hline 0.664 & $1.1380 e-01$ \\
\hline 0.666 & $1.1410 \mathrm{e}-01$ \\
\hline 0.668 & $1.1440 \mathrm{e}-01$ \\
\hline 0.67 & $1.1440 \mathrm{e}-01$ \\
\hline 0.672 & $1.1490 \mathrm{e}-01$ \\
\hline
\end{tabular}

Vol. 2, Part 2 


\section{LOSP Frequency}

\begin{tabular}{|c|c|}
\hline Step & LOSP-2H \\
\hline 0.674 & $1.1490 \mathrm{e}-01$ \\
\hline 0.676 & $1.1530 e-01$ \\
\hline 0.678 & $1.1540 e-01$ \\
\hline 0.68 & $1.1540 e-01$ \\
\hline 0.682 & $1.1540 \mathrm{e}-01$ \\
\hline 0.684 & $1.1540 e-01$ \\
\hline 0.686 & $1.1540 \mathrm{e}-01$ \\
\hline 0.688 & $1.1560 e-01$ \\
\hline 0.69 & $1.1570 e-01$ \\
\hline 0.692 & $1.1580 \mathrm{e}-01$ \\
\hline 0.694 & $1.1640 \mathrm{e}-01$ \\
\hline 0.696 & $1.1640 \mathrm{e}-01$ \\
\hline 0.698 & $1.1640 \mathrm{e}-01$ \\
\hline 0.7 & $1.1660 \mathrm{e}-01$ \\
\hline 0.702 & $1.1670 \mathrm{e}-01$ \\
\hline 0.704 & $1.1680 \mathrm{e}-01$ \\
\hline 0.706 & $1.1680 \mathrm{e}-01$ \\
\hline 0.708 & $1.1680 \mathrm{e}-01$ \\
\hline 0.71 & $1.1690 \mathrm{e}-01$ \\
\hline 0.712 & $1.1710 \mathrm{e}-01$ \\
\hline 0.714 & $1.1740 \mathrm{e}-01$ \\
\hline 0.716 & $1.1740 \mathrm{e}-01$ \\
\hline 0.718 & $1.1750 \mathrm{e}-01$ \\
\hline 0.72 & $1.1800 \mathrm{e}-01$ \\
\hline 0.722 & $1.1840 \mathrm{e}-01$ \\
\hline 0.724 & $1.1870 \mathrm{e}-01$ \\
\hline 0.726 & $1.1880 \mathrm{e}-01$ \\
\hline 0.728 & $1.1900 \mathrm{e}-01$ \\
\hline 0.73 & $1.1910 \mathrm{e}-01$ \\
\hline 0.732 & $1.1910 \mathrm{e}-01$ \\
\hline 0.734 & $1.1920 \mathrm{e}-01$ \\
\hline 0.736 & $1.1940 \mathrm{e}-01$ \\
\hline 0.738 & $1.1970 \mathrm{e}-01$ \\
\hline 0.74 & $1.1980 \mathrm{e}-01$ \\
\hline
\end{tabular}




\begin{tabular}{|r|r|}
\hline Step & LOSP-2H \\
\hline 0.742 & $1.2010 \mathrm{e}-01$ \\
\hline 0.744 & $1.2030 \mathrm{e}-01$ \\
\hline 0.746 & $1.2060 \mathrm{e}-01$ \\
\hline 0.748 & $1.2070 \mathrm{e}-01$ \\
\hline 0.75 & $1.2140 \mathrm{e}-01$ \\
\hline 0.752 & $1.2210 \mathrm{e}-01$ \\
\hline 0.754 & $1.2210 \mathrm{e}-01$ \\
\hline 0.756 & $1.2250 \mathrm{e}-01$ \\
\hline 0.758 & $1.2260 \mathrm{e}-01$ \\
\hline 0.76 & $1.2320 \mathrm{e}-01$ \\
\hline 0.762 & $1.2340 \mathrm{e}-01$ \\
\hline 0.764 & $1.2350 \mathrm{e}-01$ \\
\hline 0.766 & $1.2360 \mathrm{e}-01$ \\
\hline 0.768 & $1.2400 \mathrm{e}-01$ \\
\hline 0.77 & $1.2430 \mathrm{e}-01$ \\
\hline 0.772 & $1.2490 \mathrm{e}-01$ \\
\hline 0.774 & $1.2510 \mathrm{e}-01$ \\
\hline 0.776 & $1.2520 \mathrm{e}-01$ \\
\hline 0.778 & $1.2550 \mathrm{e}-01$ \\
\hline 0.78 & $1.2580 \mathrm{e}-01$ \\
\hline 0.782 & $1.2610 \mathrm{e}-01$ \\
\hline 0.784 & $1.2630 \mathrm{e}-01$ \\
\hline 0.786 & $1.2640 \mathrm{e}-01$ \\
\hline 0.788 & $1.2660 \mathrm{e}-01$ \\
\hline 0.79 & $1.2670 \mathrm{e}-01$ \\
\hline 0.792 & $1.2670 \mathrm{e}-01$ \\
\hline 0.794 & $1.2670 \mathrm{e}-01$ \\
\hline 0.796 & $1.2720 \mathrm{e}-01$ \\
\hline 0.798 & $1.2740 \mathrm{e}-01$ \\
\hline 0.8 & $1.2770 \mathrm{e}-01$ \\
\hline 0.802 & $1.2770 \mathrm{e}-01$ \\
\hline 0.804 & $1.2780 \mathrm{e}-01$ \\
\hline & $1.2790 \mathrm{e}-01$ \\
\hline & $1.2820 \mathrm{e}-01$ \\
\hline
\end{tabular}




\section{LOSP Frequency}

\begin{tabular}{|r|r|}
\hline Step & LOSP-2H \\
\hline 0.81 & $1.2820 \mathrm{e}-01$ \\
\hline 0.812 & $1.2860 \mathrm{e}-01$ \\
\hline 0.814 & $1.2930 \mathrm{e}-01$ \\
\hline 0.816 & $1.2930 \mathrm{e}-01$ \\
\hline 0.818 & $1.2940 \mathrm{e}-01$ \\
\hline 0.82 & $1.2940 \mathrm{e}-01$ \\
\hline 0.822 & $1.2950 \mathrm{e}-01$ \\
\hline 0.824 & $1.2950 \mathrm{e}-01$ \\
\hline 0.826 & $1.3070 \mathrm{e}-01$ \\
\hline 0.828 & $1.3090 \mathrm{e}-01$ \\
\hline 0.83 & $1.3100 \mathrm{e}-01$ \\
\hline 0.832 & $1.3110 \mathrm{e}-01$ \\
\hline 0.834 & $1.3160 \mathrm{e}-01$ \\
\hline 0.836 & $1.3170 \mathrm{e}-01$ \\
\hline 0.838 & $1.3190 \mathrm{e}-01$ \\
\hline 0.84 & $1.3190 \mathrm{e}-01$ \\
\hline 0.842 & $1.3220 \mathrm{e}-01$ \\
\hline 0.844 & $1.3220 \mathrm{e}-01$ \\
\hline 0.846 & $1.3230 \mathrm{e}-01$ \\
\hline 0.848 & $1.3240 \mathrm{e}-01$ \\
\hline 0.85 & $1.3260 \mathrm{e}-01$ \\
\hline 0.852 & $1.3280 \mathrm{e}-01$ \\
\hline 0.854 & $1.3290 \mathrm{e}-01$ \\
\hline 0.856 & $1.3320 \mathrm{e}-01$ \\
\hline 0.858 & $1.3400 \mathrm{e}-01$ \\
\hline 0.86 & $1.3450 \mathrm{e}-01$ \\
\hline 0.862 & $1.3480 \mathrm{e}-01$ \\
\hline 0.864 & $1.3490 \mathrm{e}-01$ \\
\hline 0.866 & $1.3500 \mathrm{e}-01$ \\
\hline 0.868 & $1.3560 \mathrm{e}-01$ \\
\hline 0.87 & $1.3620 \mathrm{e}-01$ \\
\hline 0.872 & $1.3630 \mathrm{e}-01$ \\
\hline & $1.3640 \mathrm{e}-01$ \\
\hline & $1.3690 \mathrm{e}-01$ \\
\hline
\end{tabular}




\begin{tabular}{|r|r|}
\hline Step & LOSP-2H \\
\hline 0.878 & $1.3750 \mathrm{e}-01$ \\
\hline 0.88 & $1.3800 \mathrm{e}-01$ \\
\hline 0.882 & $1.3830 \mathrm{e}-01$ \\
\hline 0.884 & $1.3930 \mathrm{e}-01$ \\
\hline 0.886 & $1.3990 \mathrm{e}-01$ \\
\hline 0.888 & $1.4010 \mathrm{e}-01$ \\
\hline 0.89 & $1.4070 \mathrm{e}-01$ \\
\hline 0.892 & $1.4090 \mathrm{e}-01$ \\
\hline 0.894 & $1.4110 \mathrm{e}-01$ \\
\hline 0.896 & $1.4110 \mathrm{e}-01$ \\
\hline 0.898 & $1.4130 \mathrm{e}-01$ \\
\hline 0.9 & $1.4130 \mathrm{e}-01$ \\
\hline 0.902 & $1.4160 \mathrm{e}-01$ \\
\hline 0.904 & $1.4170 \mathrm{e}-01$ \\
\hline 0.906 & $1.4210 \mathrm{e}-01$ \\
\hline 0.908 & $1.4230 \mathrm{e}-01$ \\
\hline 0.91 & $1.4310 \mathrm{e}-01$ \\
\hline 0.912 & $1.4330 \mathrm{e}-01$ \\
\hline 0.914 & $1.4380 \mathrm{e}-01$ \\
\hline 0.916 & $1.4450 \mathrm{e}-01$ \\
\hline 0.918 & $1.4480 \mathrm{e}-01$ \\
\hline 0.92 & $1.4650 \mathrm{e}-01$ \\
\hline 0.922 & $1.4680 \mathrm{e}-01$ \\
\hline 0.924 & $1.4730 \mathrm{e}-01$ \\
\hline 0.926 & $1.4740 \mathrm{e}-01$ \\
\hline 0.928 & $1.4780 \mathrm{e}-01$ \\
\hline 0.93 & $1.4790 \mathrm{e}-01$ \\
\hline 0.932 & $1.4870 \mathrm{e}-01$ \\
\hline 0.934 & $1.4870 \mathrm{e}-01$ \\
\hline 0.936 & $1.4920 \mathrm{e}-01$ \\
\hline 0.938 & $1.5060 \mathrm{e}-01$ \\
\hline 0.94 & $1.5060 \mathrm{e}-01$ \\
\hline & $1.5180 \mathrm{e}-01$ \\
\hline
\end{tabular}

Vol. 2, Part 2 
LOSP Frequency

\begin{tabular}{|r|r|}
\hline Step & LOSP-2H \\
\hline 0.946 & $1.5290 \mathrm{e}-01$ \\
\hline 0.948 & $1.5360 \mathrm{e}-01$ \\
\hline 0.95 & $1.5500 \mathrm{e}-01$ \\
\hline 0.952 & $1.5610 \mathrm{e}-01$ \\
\hline 0.954 & $1.5630 \mathrm{e}-01$ \\
\hline 0.956 & $1.5750 \mathrm{e}-01$ \\
\hline 0.958 & $1.6040 \mathrm{e}-01$ \\
\hline 0.96 & $1.6180 \mathrm{e}-01$ \\
\hline 0.962 & $1.6200 \mathrm{e}-01$ \\
\hline 0.964 & $1.6230 \mathrm{e}-01$ \\
\hline 0.966 & $1.6270 \mathrm{e}-01$ \\
\hline 0.968 & $1.6310 \mathrm{e}-01$ \\
\hline 0.97 & $1.6390 \mathrm{e}-01$ \\
\hline 0.972 & $1.6410 \mathrm{e}-01$ \\
\hline 0.974 & $1.6470 \mathrm{e}-01$ \\
\hline 0.976 & $1.6470 \mathrm{e}-01$ \\
\hline 0.978 & $1.6540 \mathrm{e}-01$ \\
\hline 0.98 & $1.6600 \mathrm{e}-01$ \\
\hline 0.982 & $1.6680 \mathrm{e}-01$ \\
\hline 0.984 & $1.6730 \mathrm{e}-01$ \\
\hline 0.986 & $1.6920 \mathrm{e}-01$ \\
\hline 0.988 & $1.7060 \mathrm{e}-01$ \\
\hline 0.99 & $1.7970 \mathrm{e}-01$ \\
\hline 0.992 & $1.8260 \mathrm{e}-01$ \\
\hline 0.994 & $1.9230 \mathrm{e}-01$ \\
\hline 0.996 & $1.9510 \mathrm{e}-01$ \\
\hline 0.998 & $2.0280 \mathrm{e}-01$ \\
\hline 1 & $2.3930 \mathrm{e}-01$ \\
\hline
\end{tabular}




\section{RA-LOSP-2H}

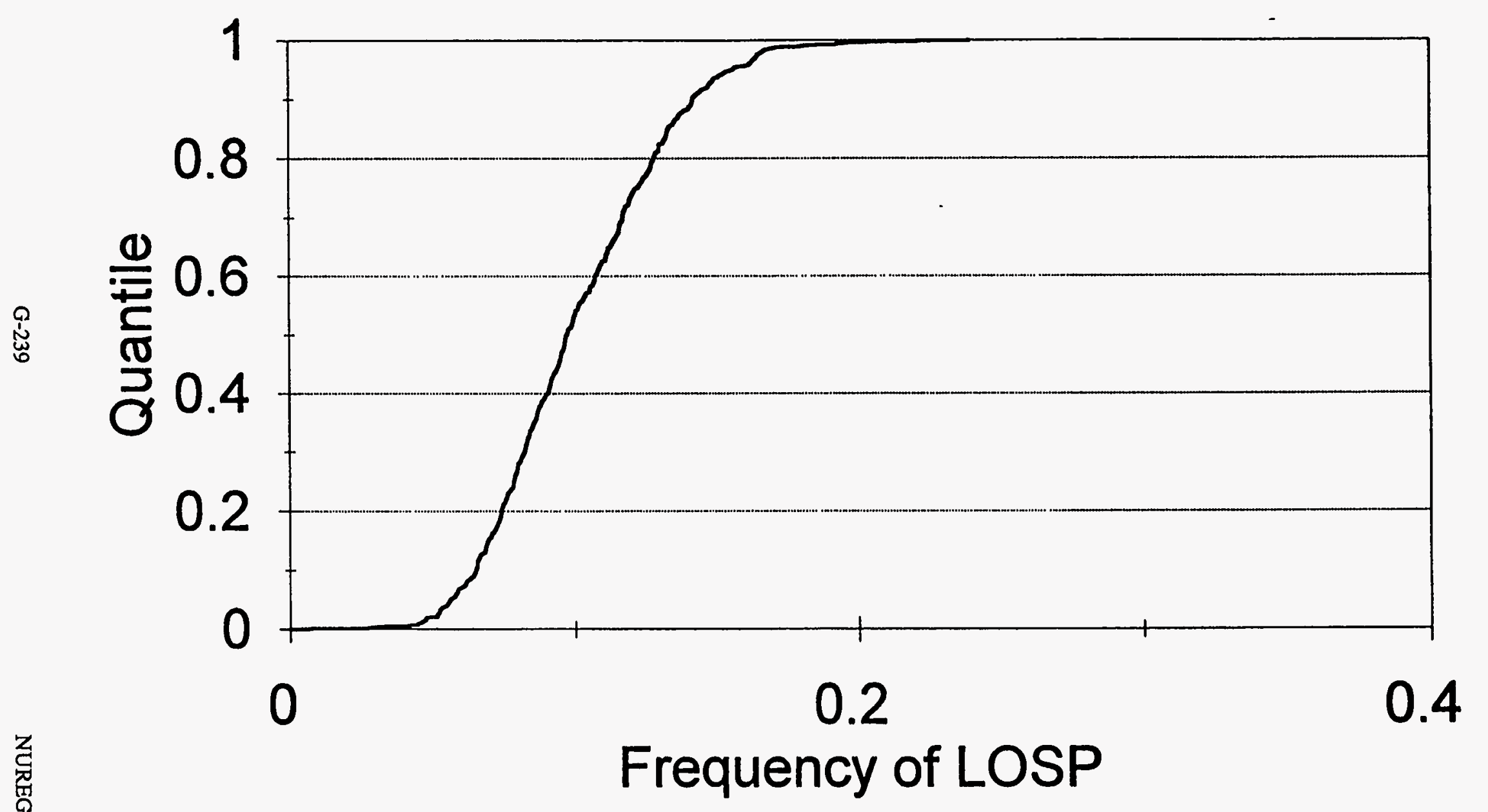

Figure Attachment G-47-1 Example Plot of Cummulative Distribution Function 

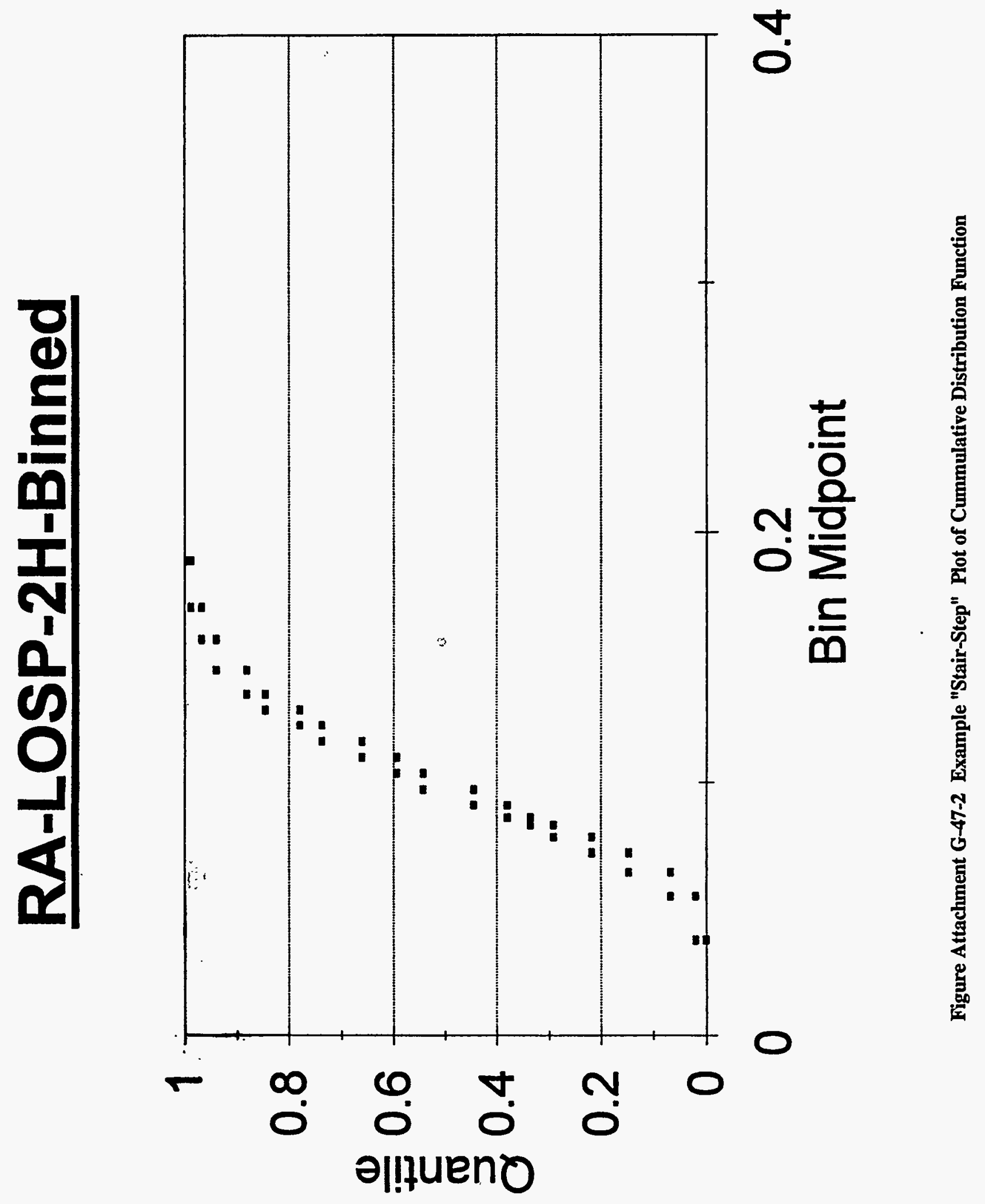


\section{Appendix H. Event Trees}

This Appendix contains various event trees that are not in Section 6 of this report.

\section{H.1 Generic System-Level Event Trees}

The generic, system-level event trees for transients are included in Figure H.1-1 through H.1-93. The purpose of each tree is described in Section 6.1, and the acronyms used in the trees are defined in Section 6.4 .

\section{H.2 Transfer Event Trees}

Sections 6.2 and 6.3 provide the top level event trees for each initiating event. Section 6.2 provides them for specific transient initiating events, and Section 6.3 provides them for each LOCA initiating event. These top level trees transfer to numerous other event trees. Some of the event trees transferred to are the generic, system-level event trees of Section H.1; other special event trees transferred to are included in Figure H.2-1 through H.2-84. The acronyms used in the trees are defined in Section 6.4. 


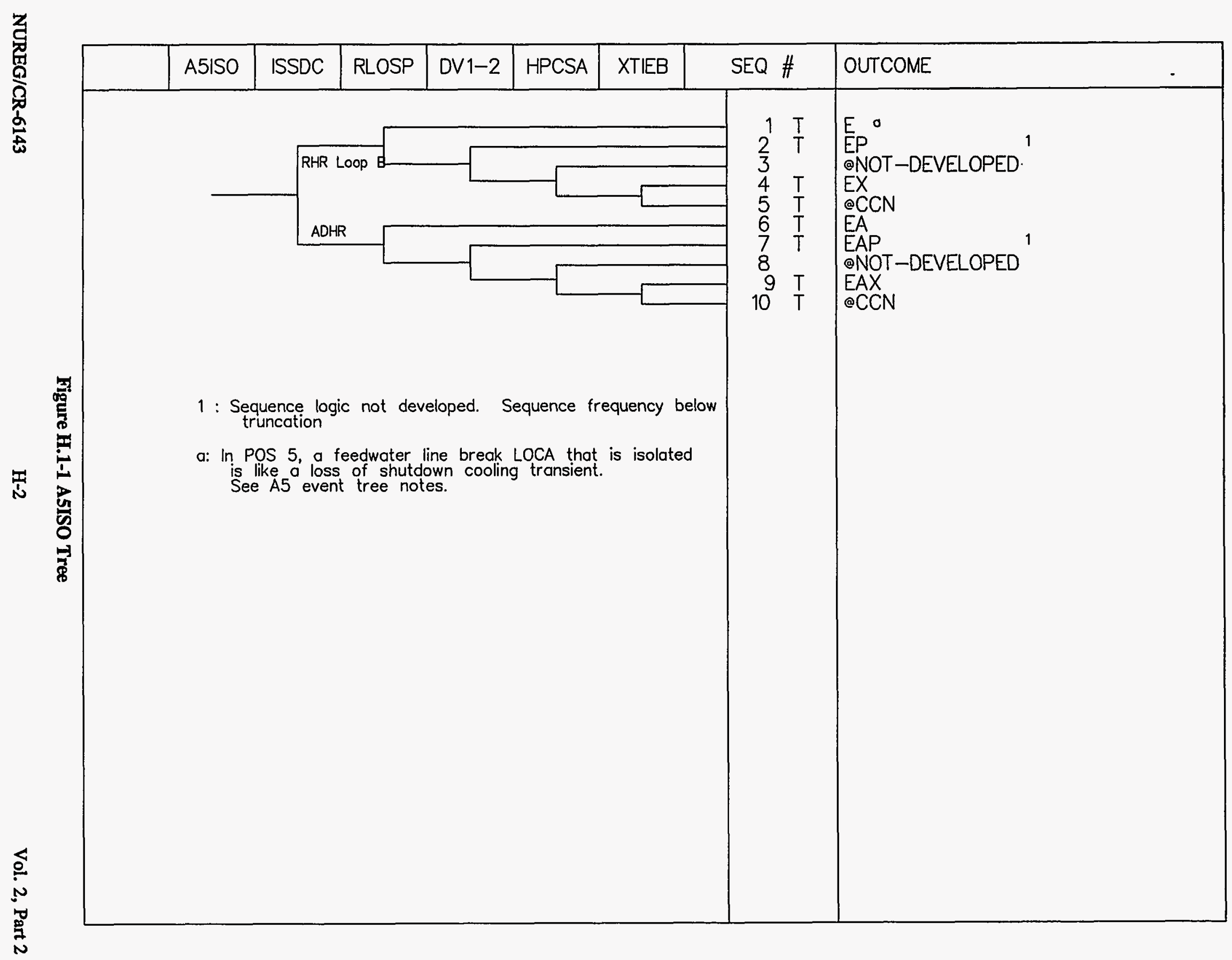


Event Trees

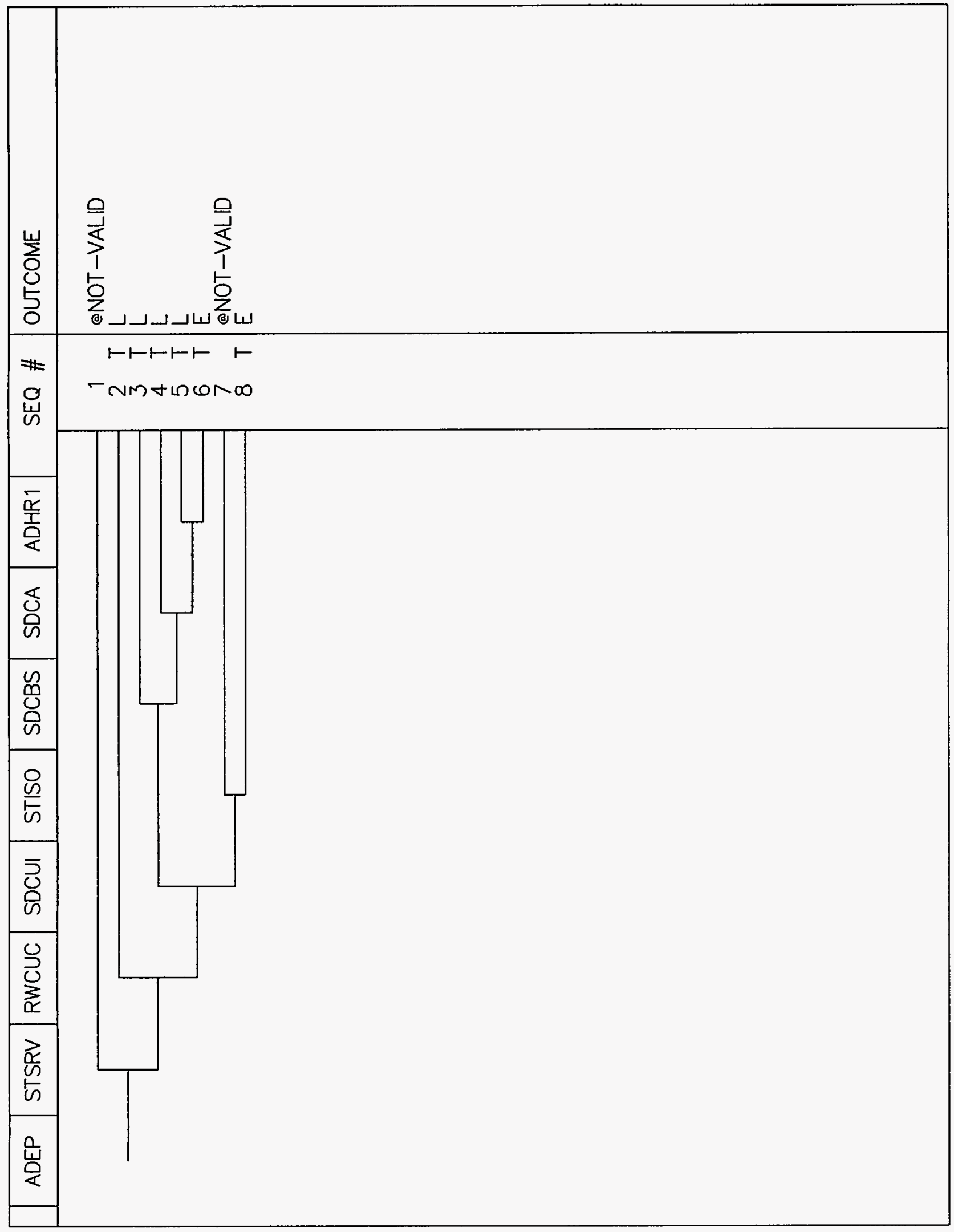

Figure H.1-2 ADEP Tree

Vol. 2, Part 2

H-3

NUREG/CR-6143 


\section{Event Trees}

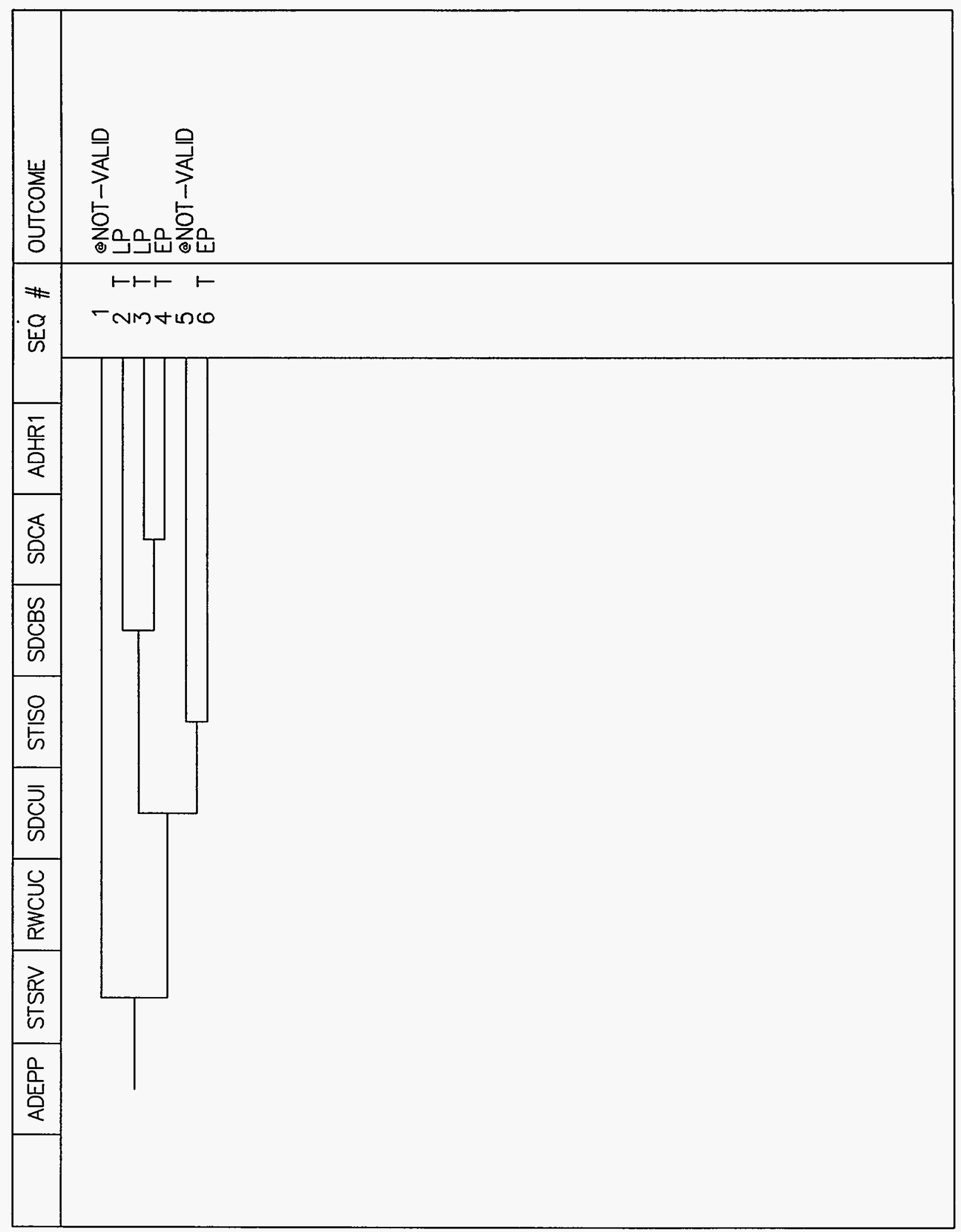

Figure H.1-3 ADEPP Tree 
Event Trees

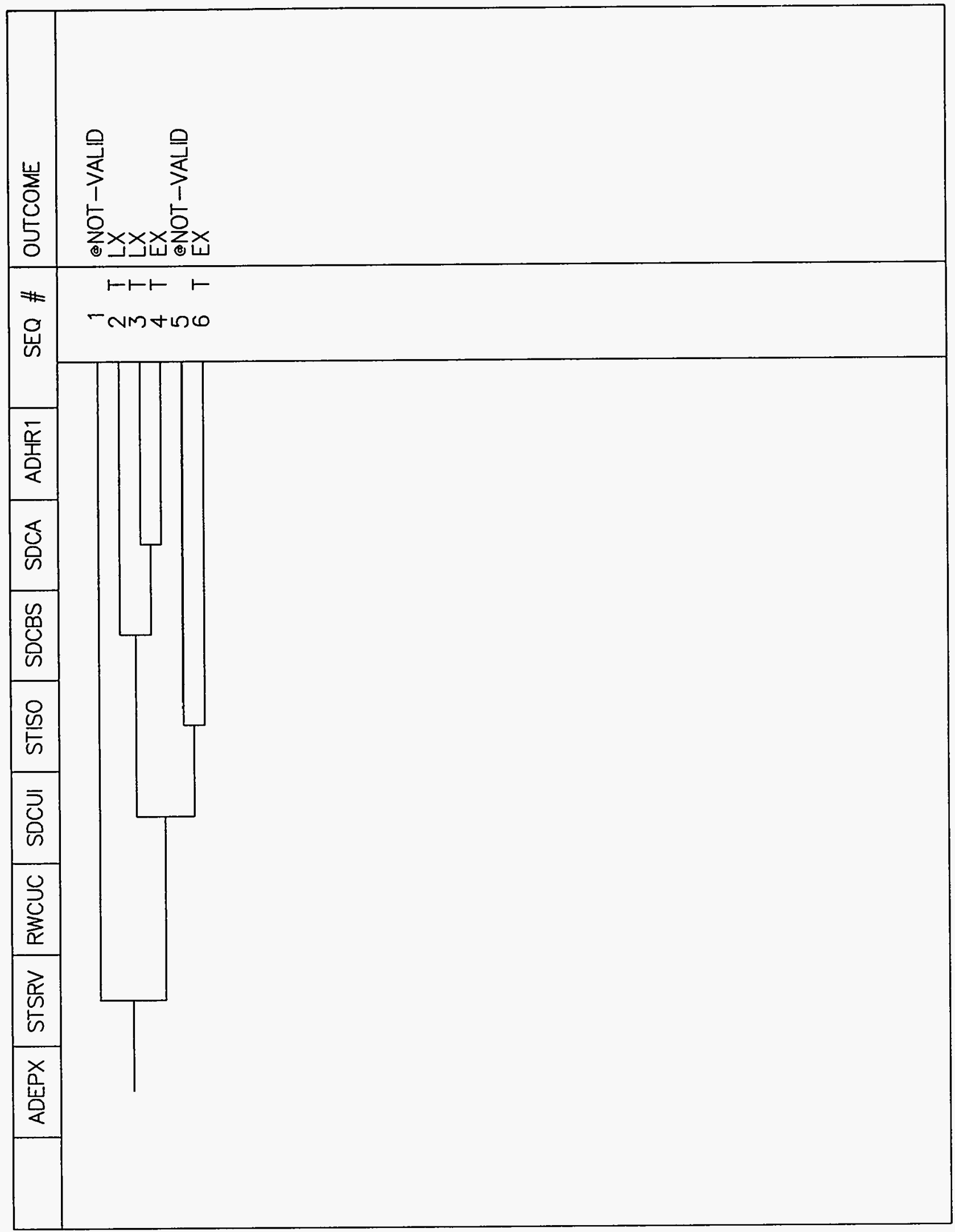

Figure H.1-4 ADEPX Tree

Vol. 2, Part 2

H-5

NUREG/CR-6143 


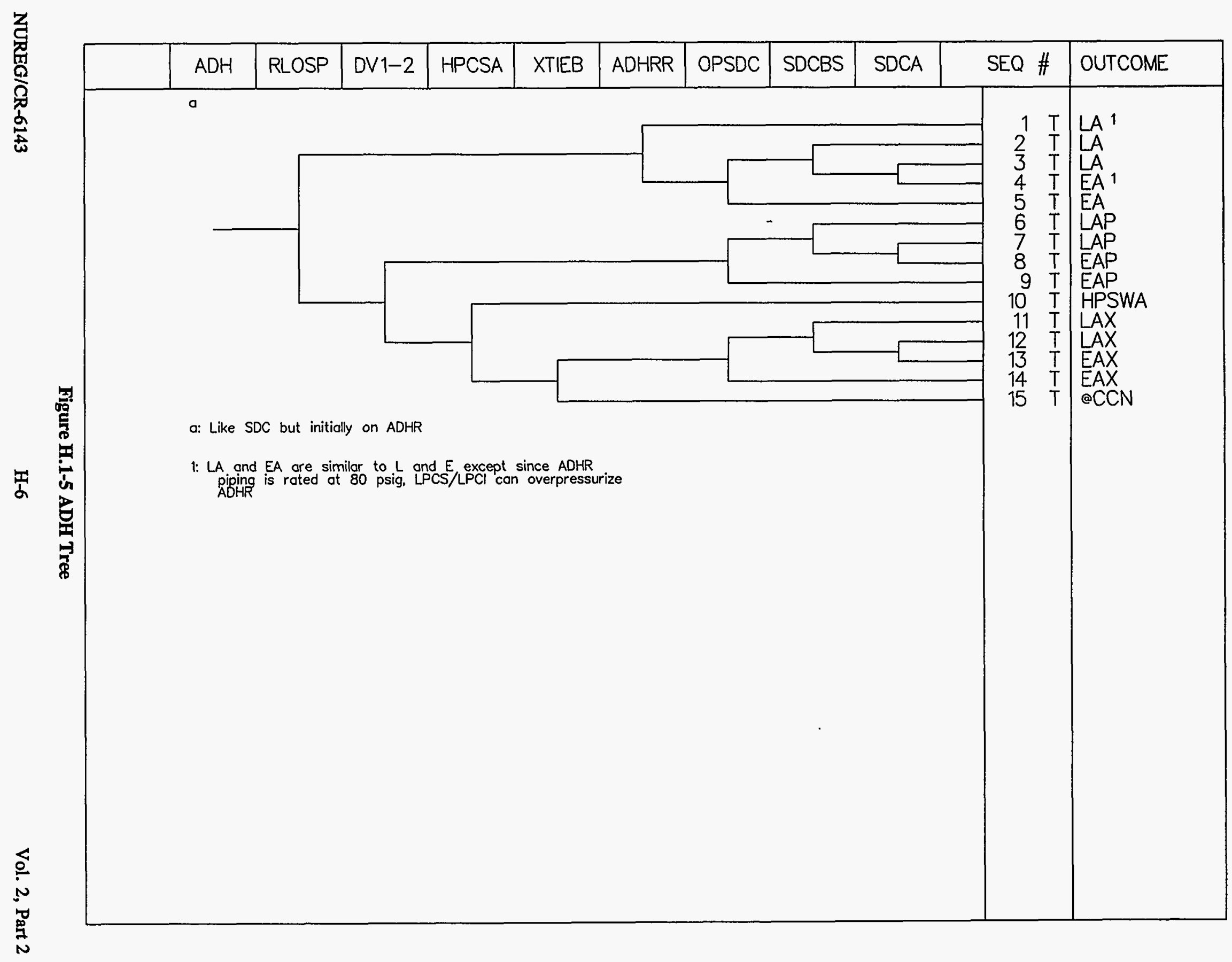




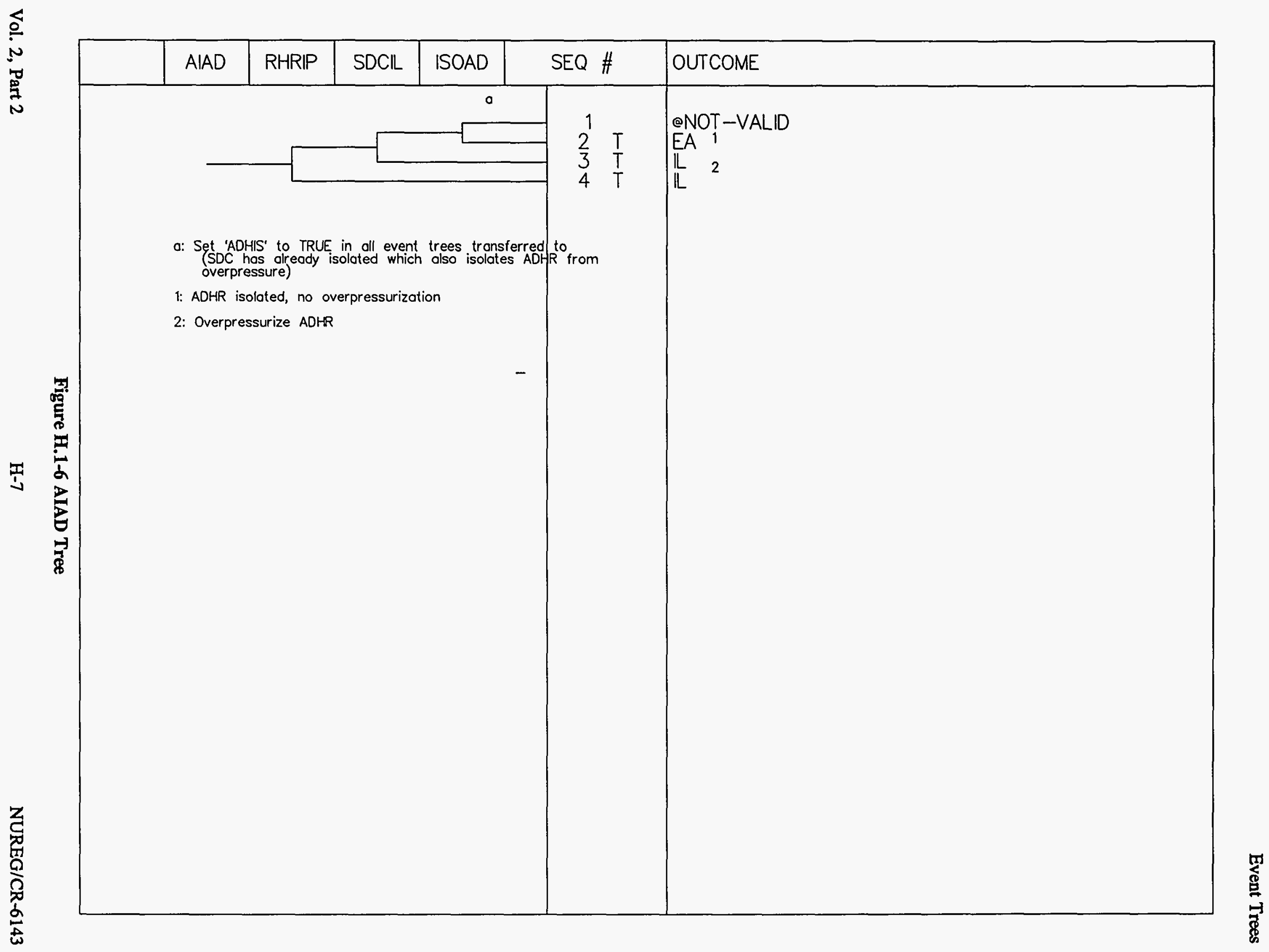




\section{Event Trees}

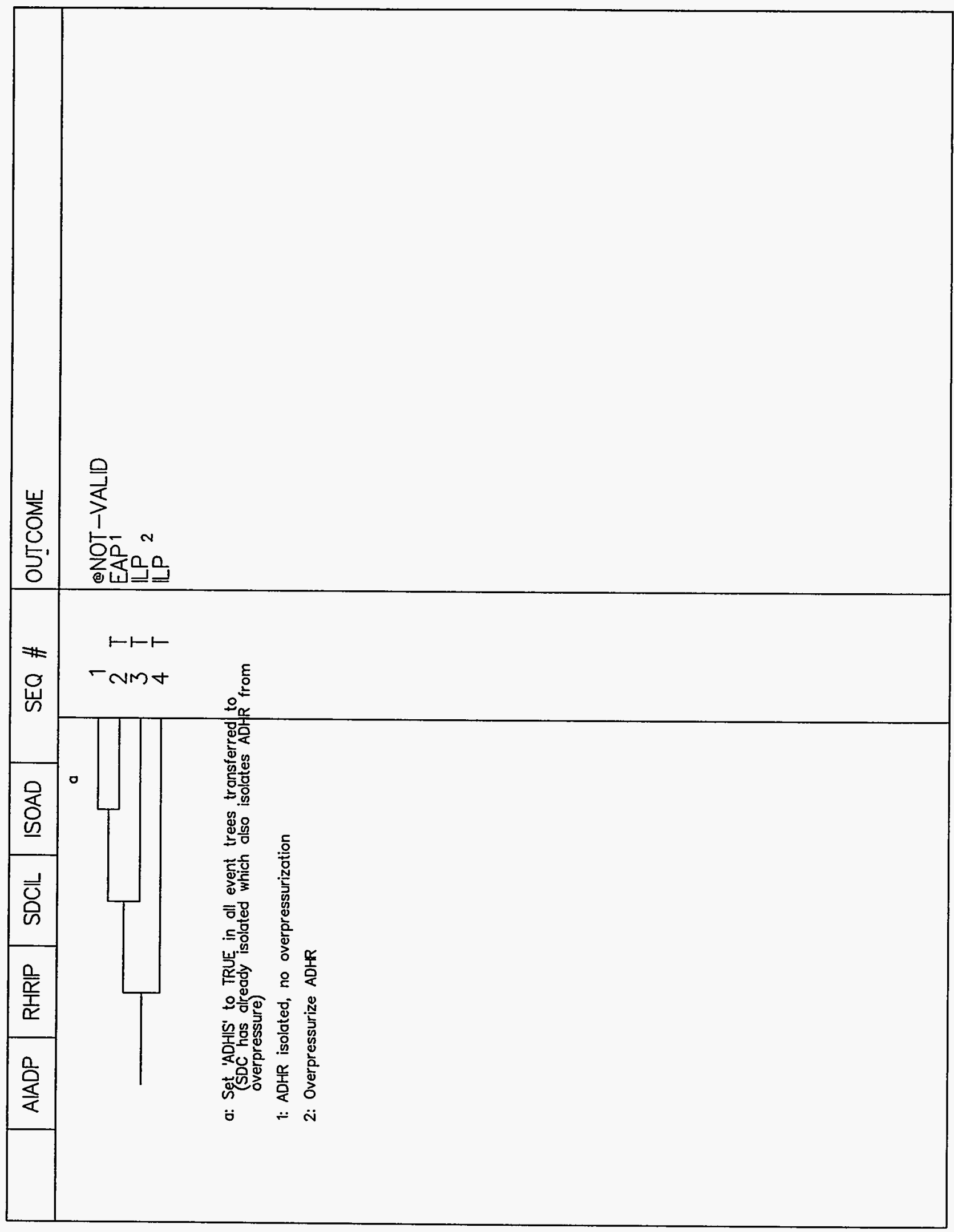

Figure H.1-7 AIADP Tree 


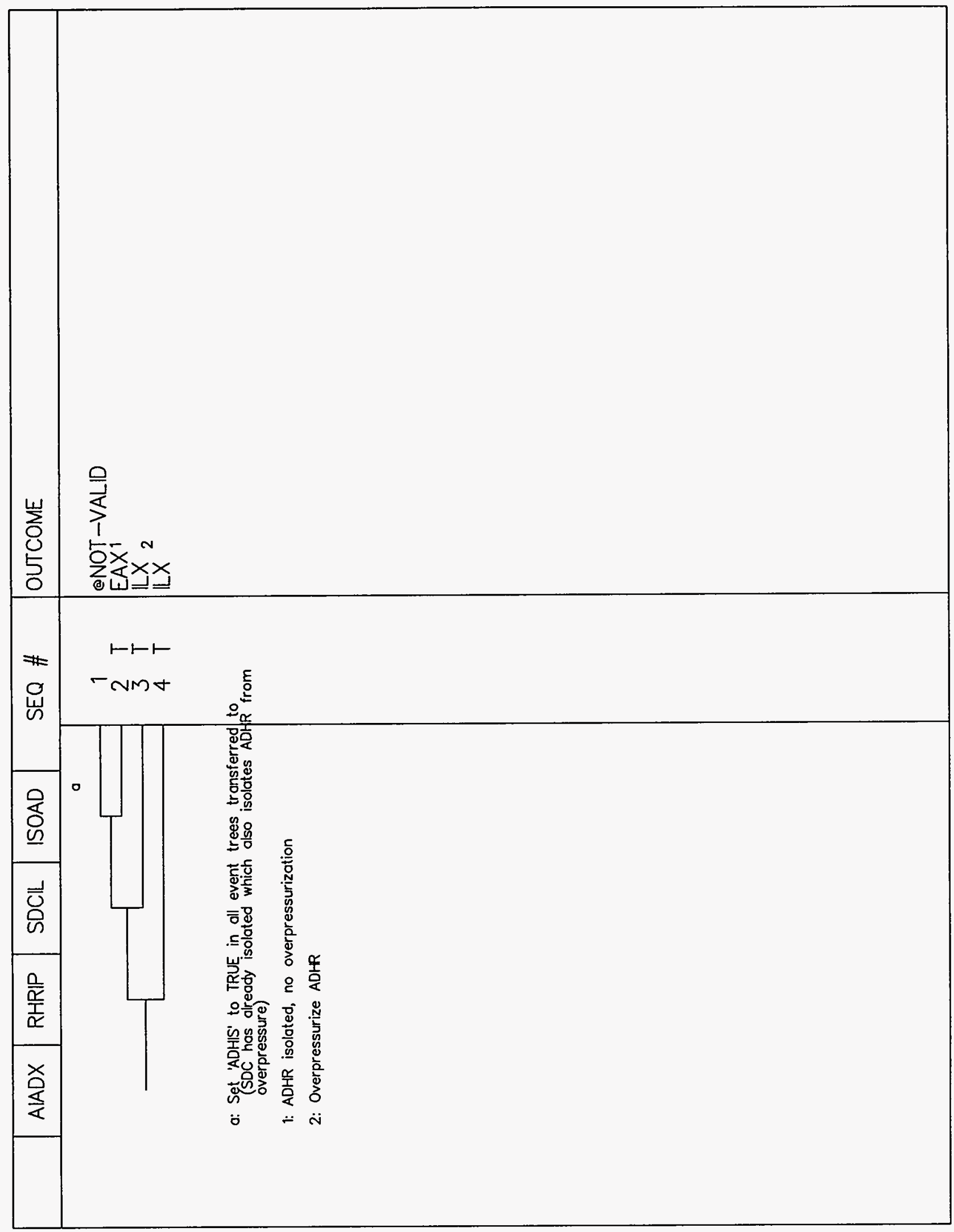

Figure H.1-8 AIADX Tree 


\section{Event Trees}

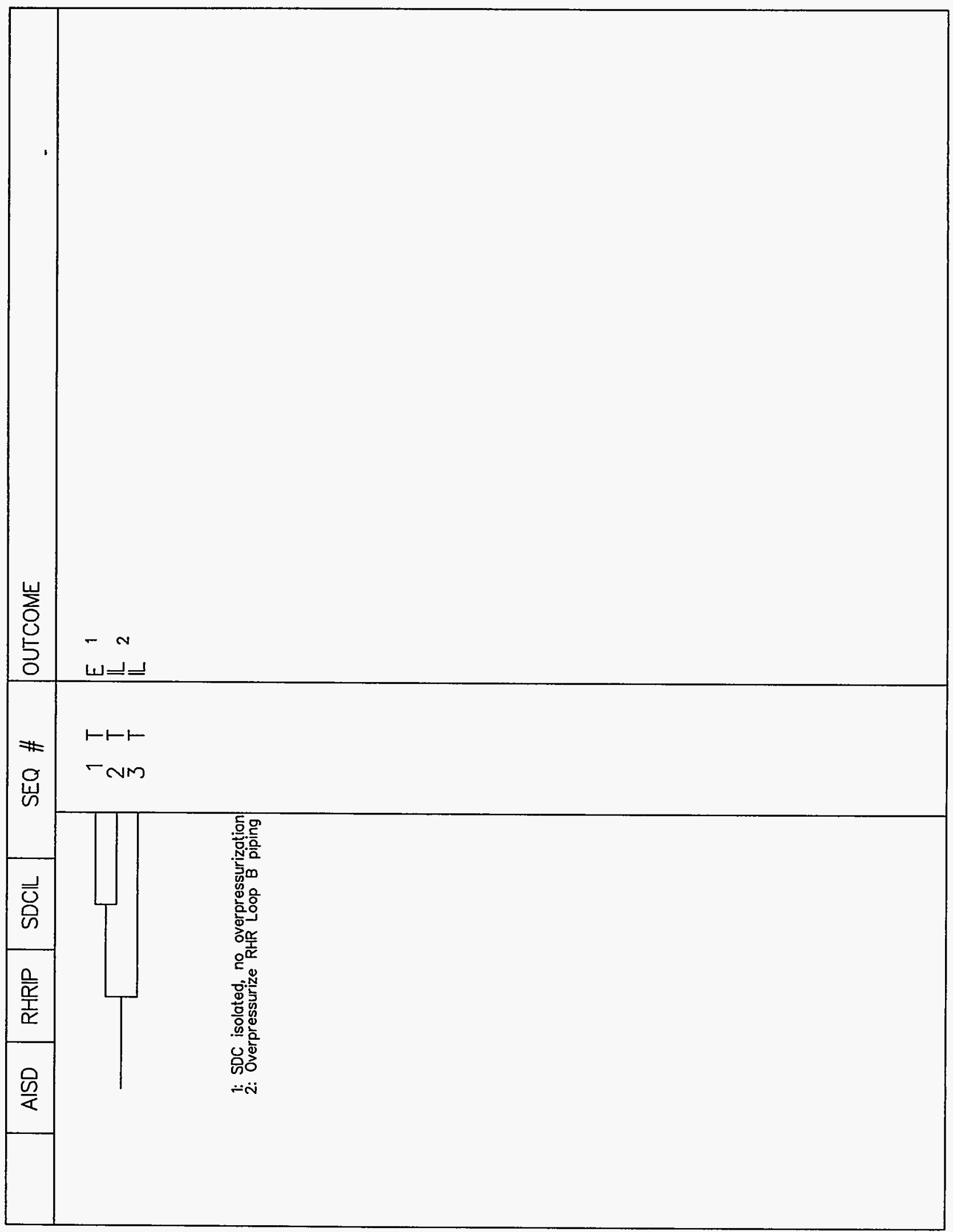

Figure H.1-9 AISD Tree 


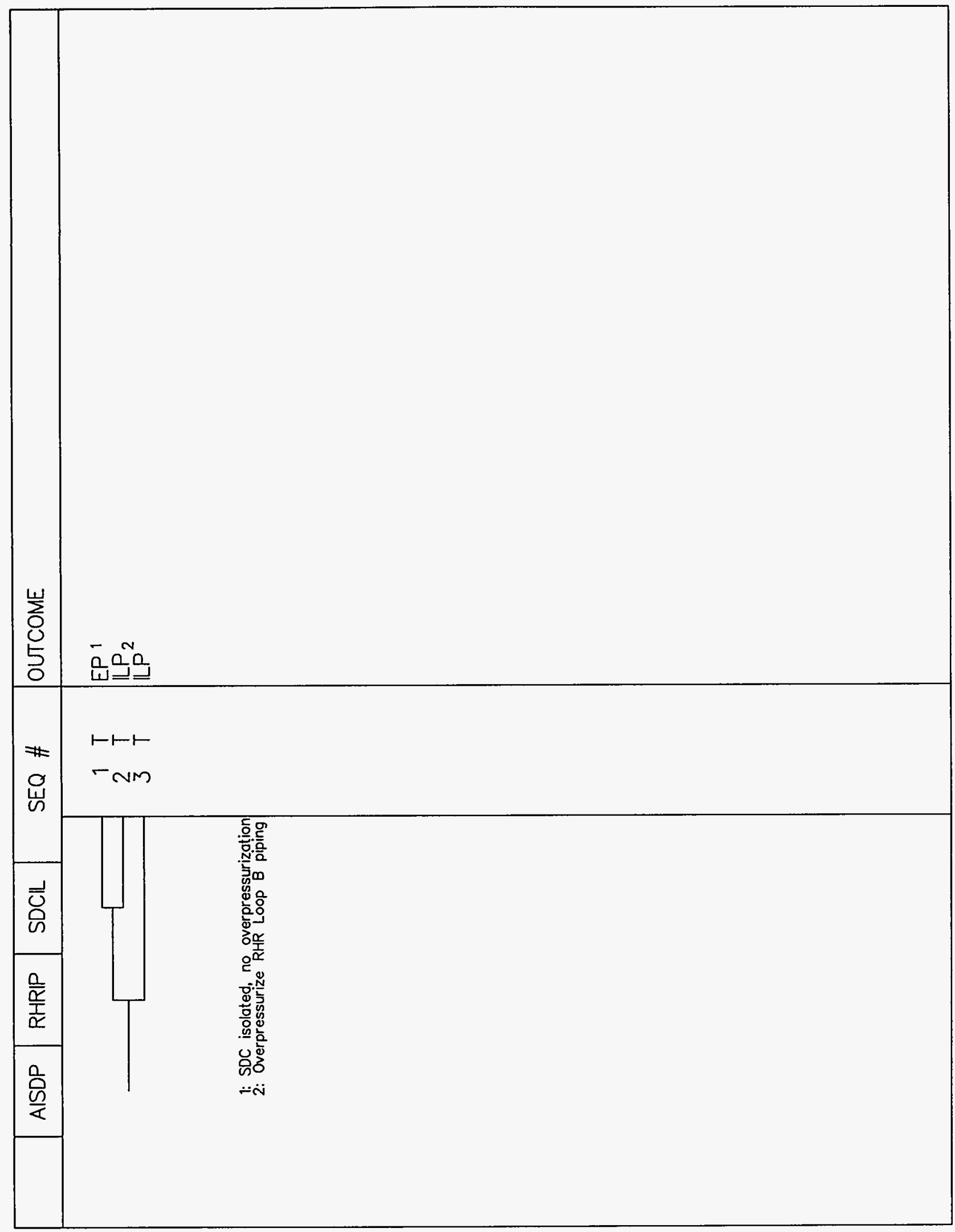

Figure H.1-10 AISDP Tree

Vol. 2, Part 2 


\section{Event Trees}

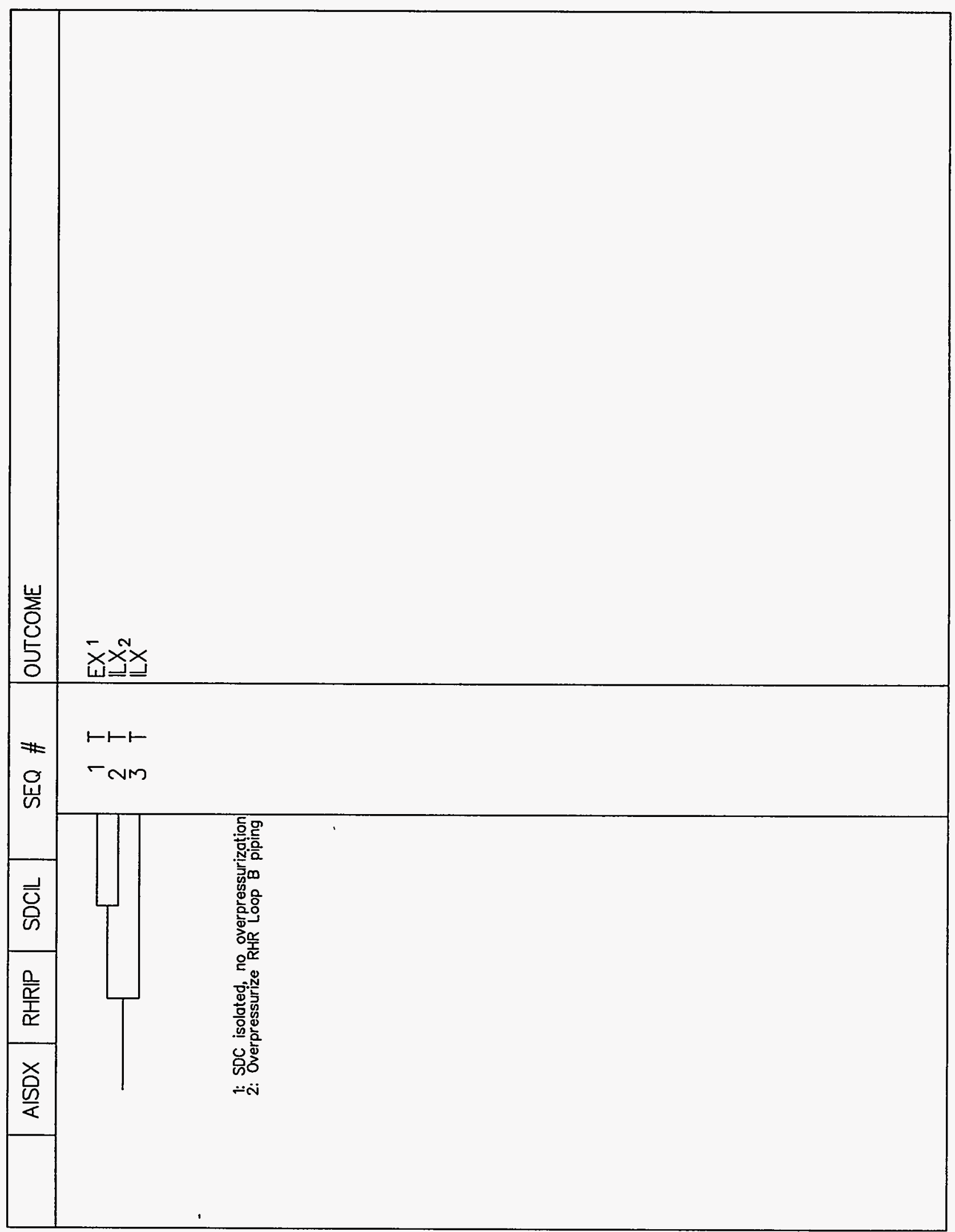

Figure H.1-11 AISDX Tree 


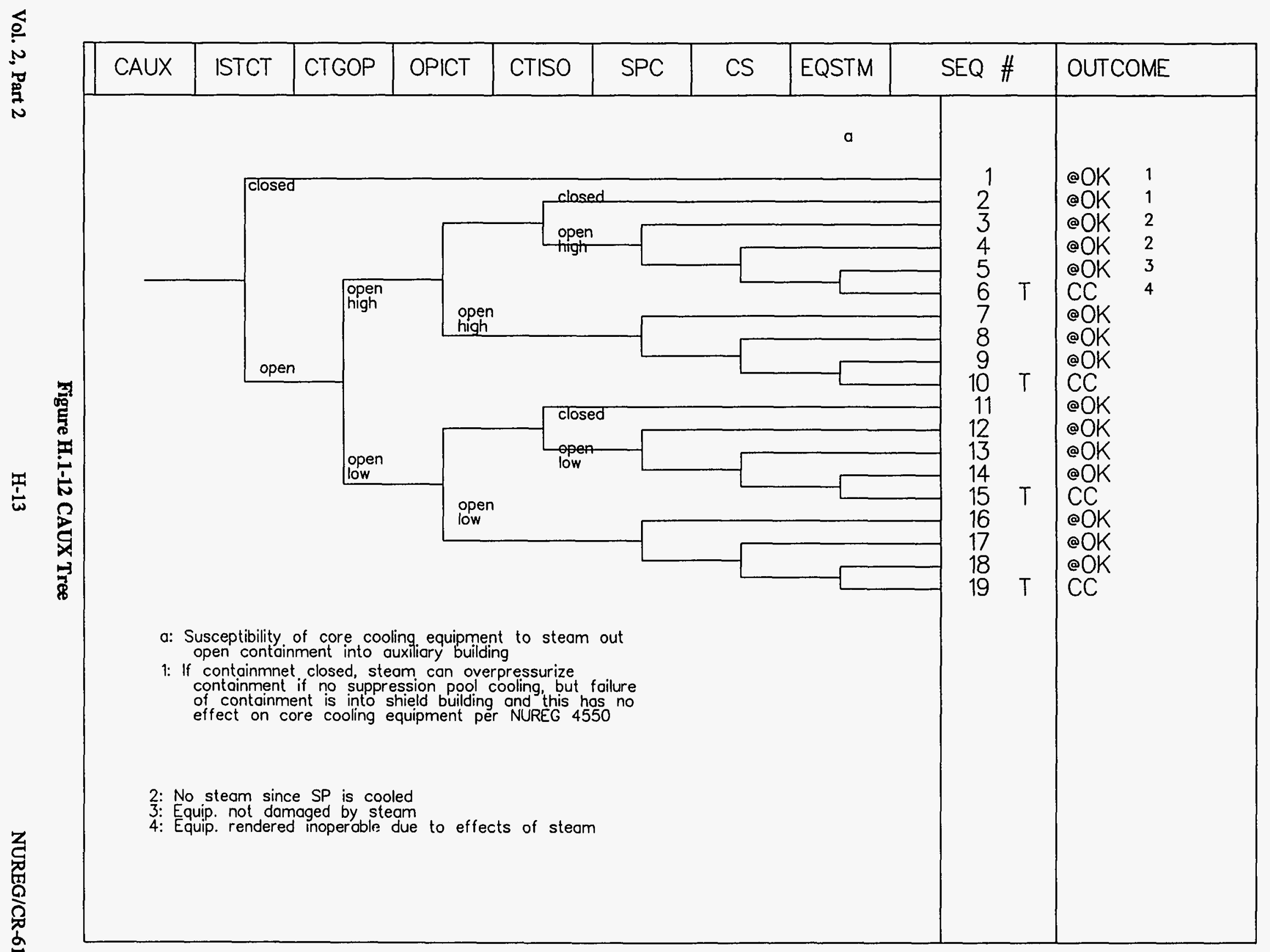


Event Trees

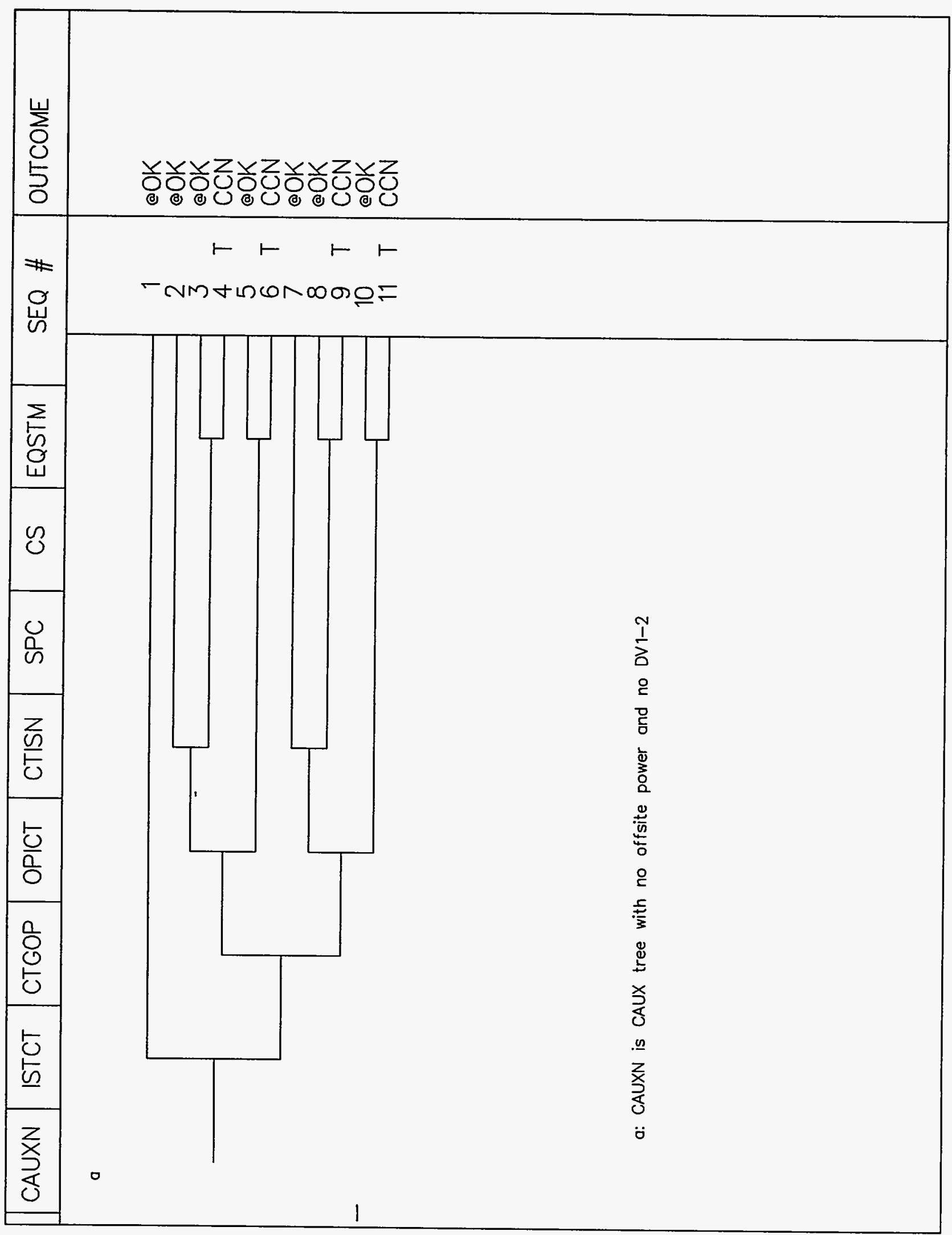

Figure H.1-13 CAUXN Tree 


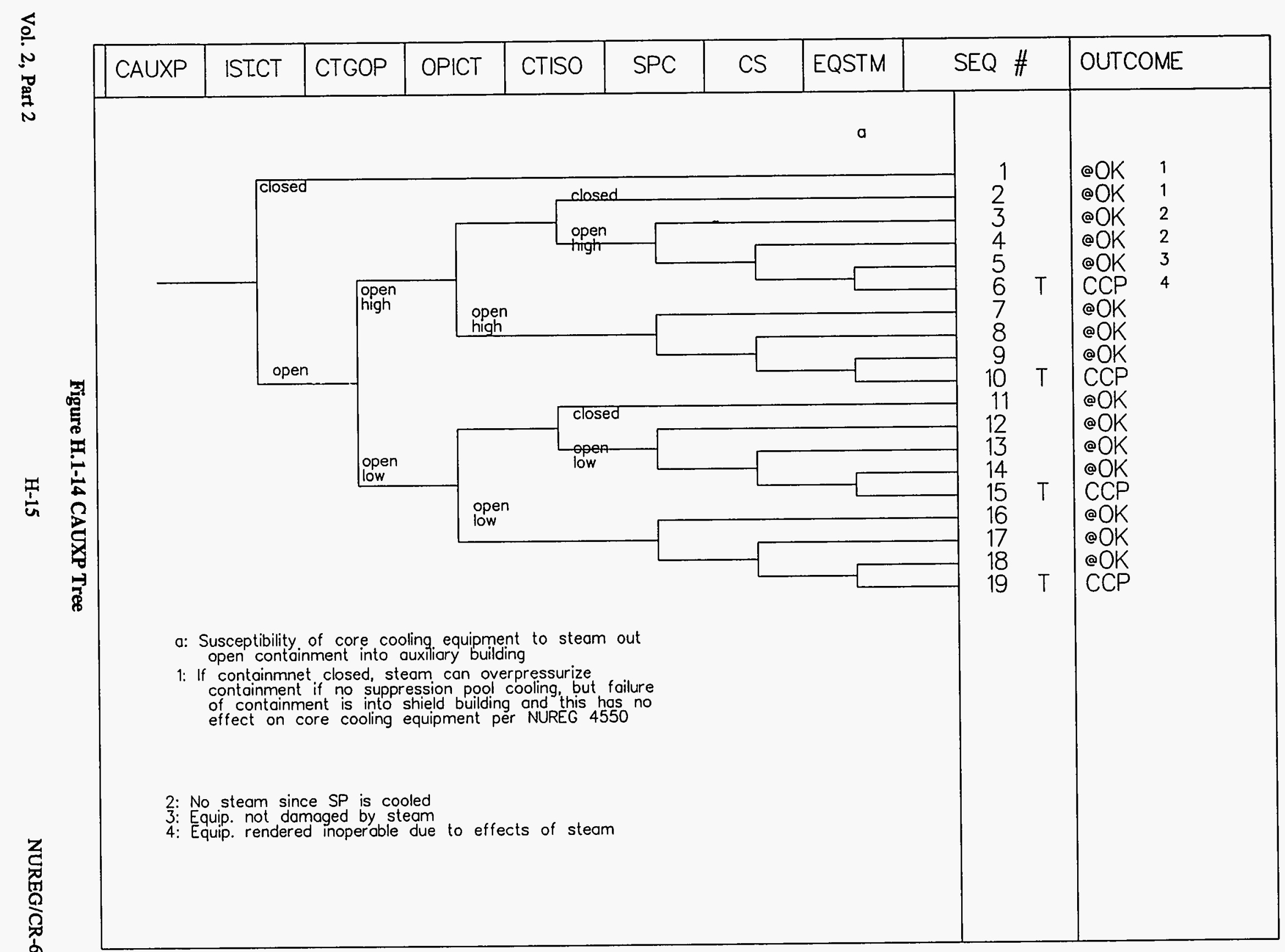




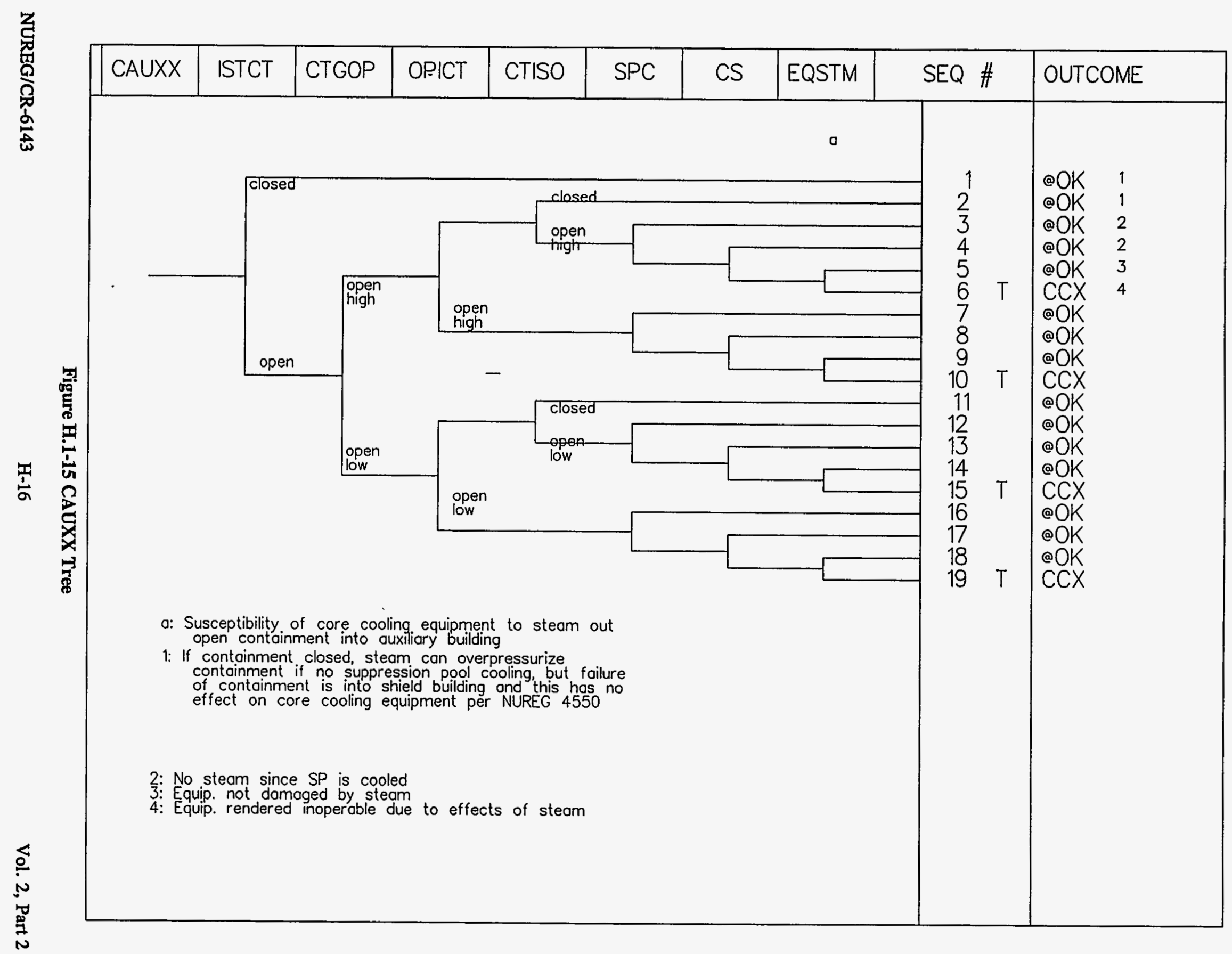




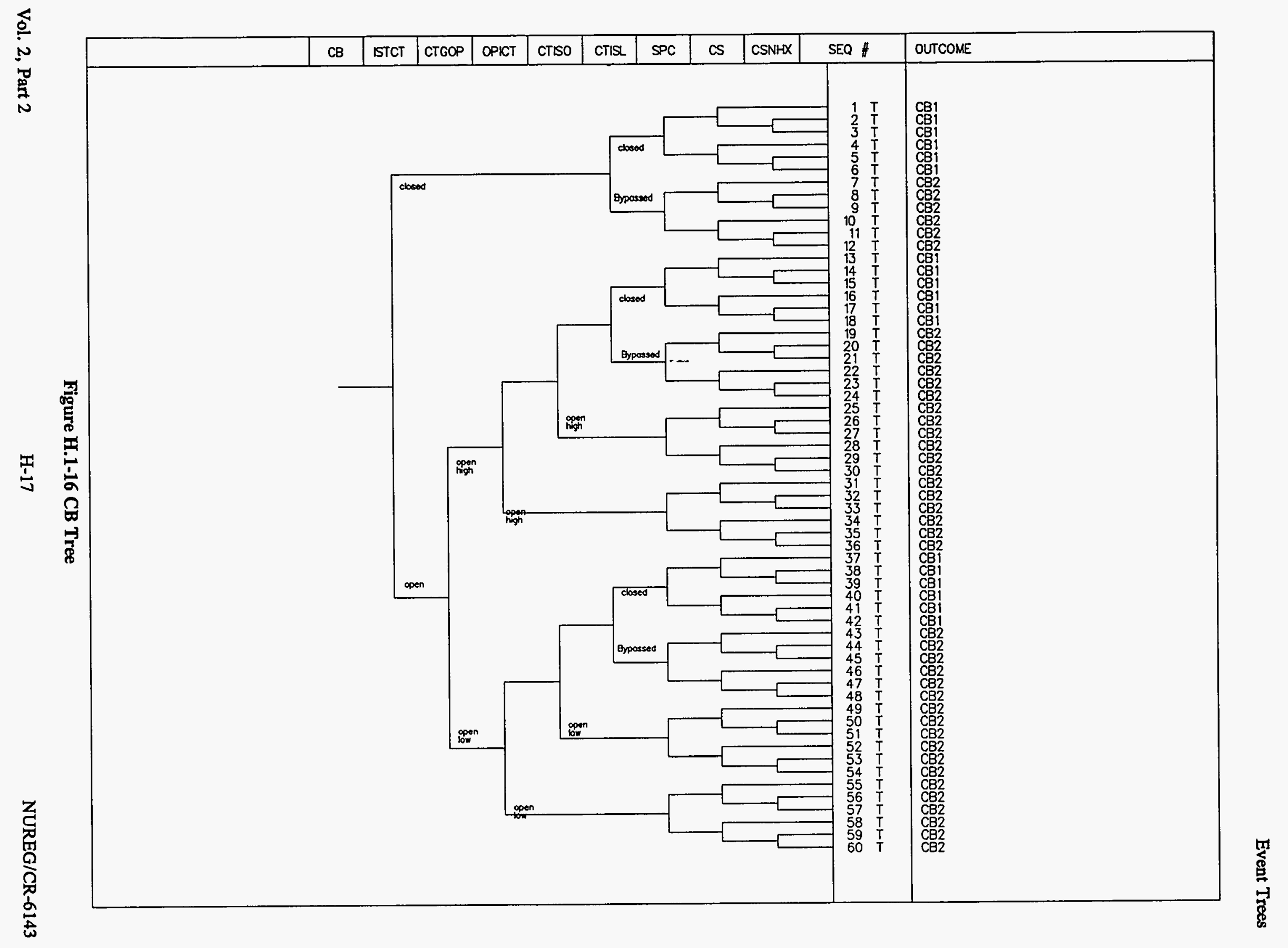




\section{Event Trees}

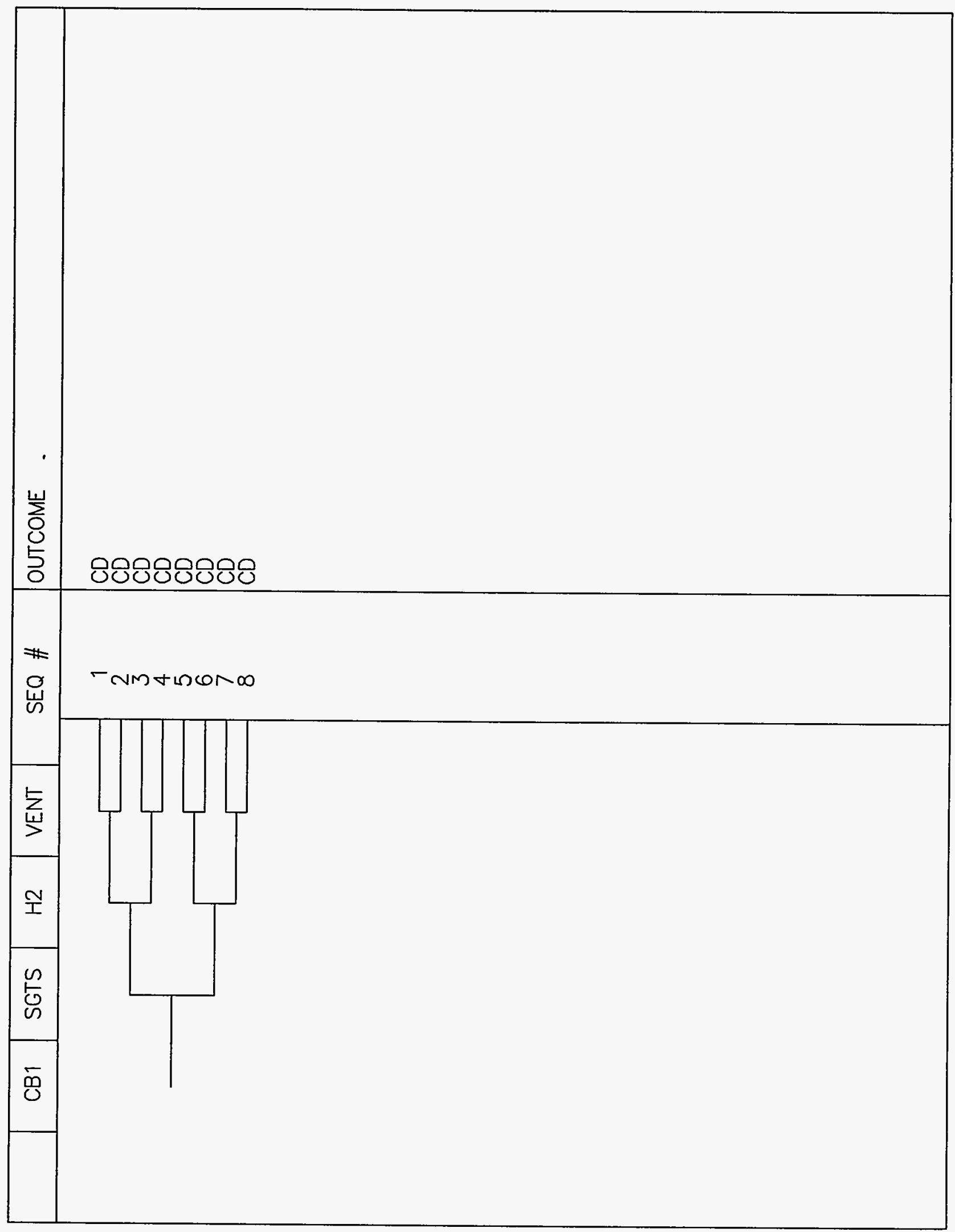

Figure H.1-17 CB1 Tree 
Event Trees

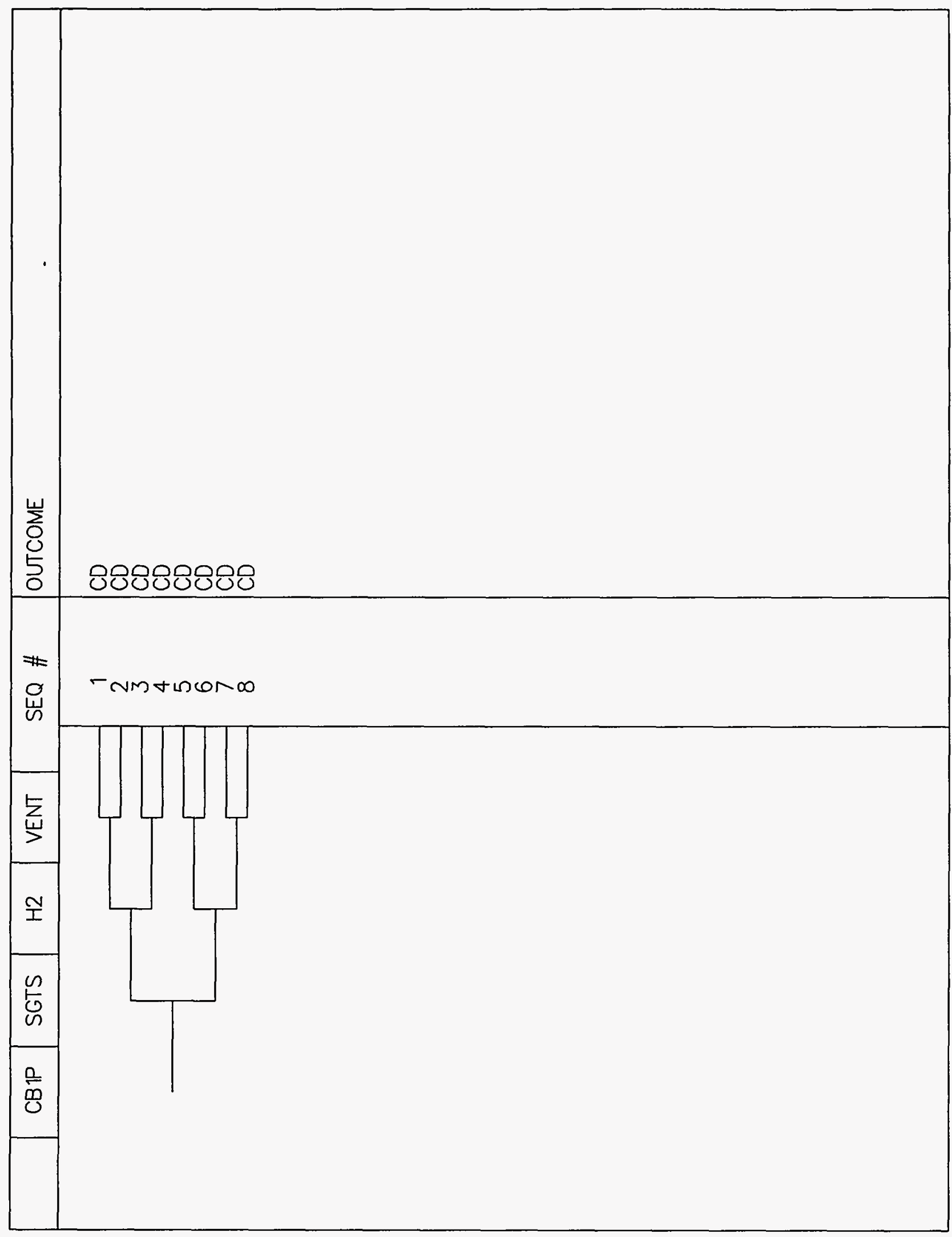

Figure H.1-18 CB1P Tree

Vol. 2, Part 2

H-19

NUREG/CR-6143 
Event Trees

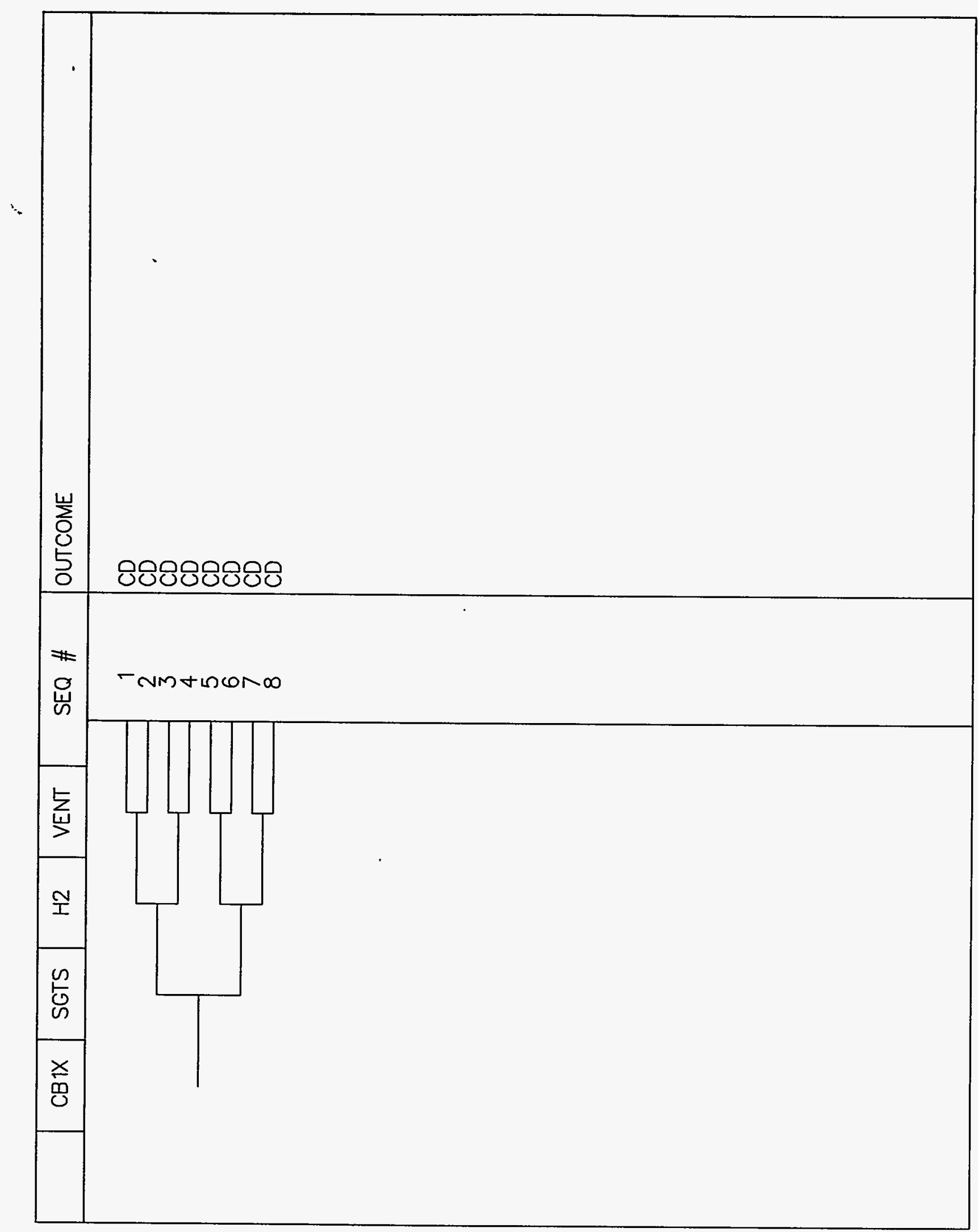

Figure H.1-19 CB1X Tree 


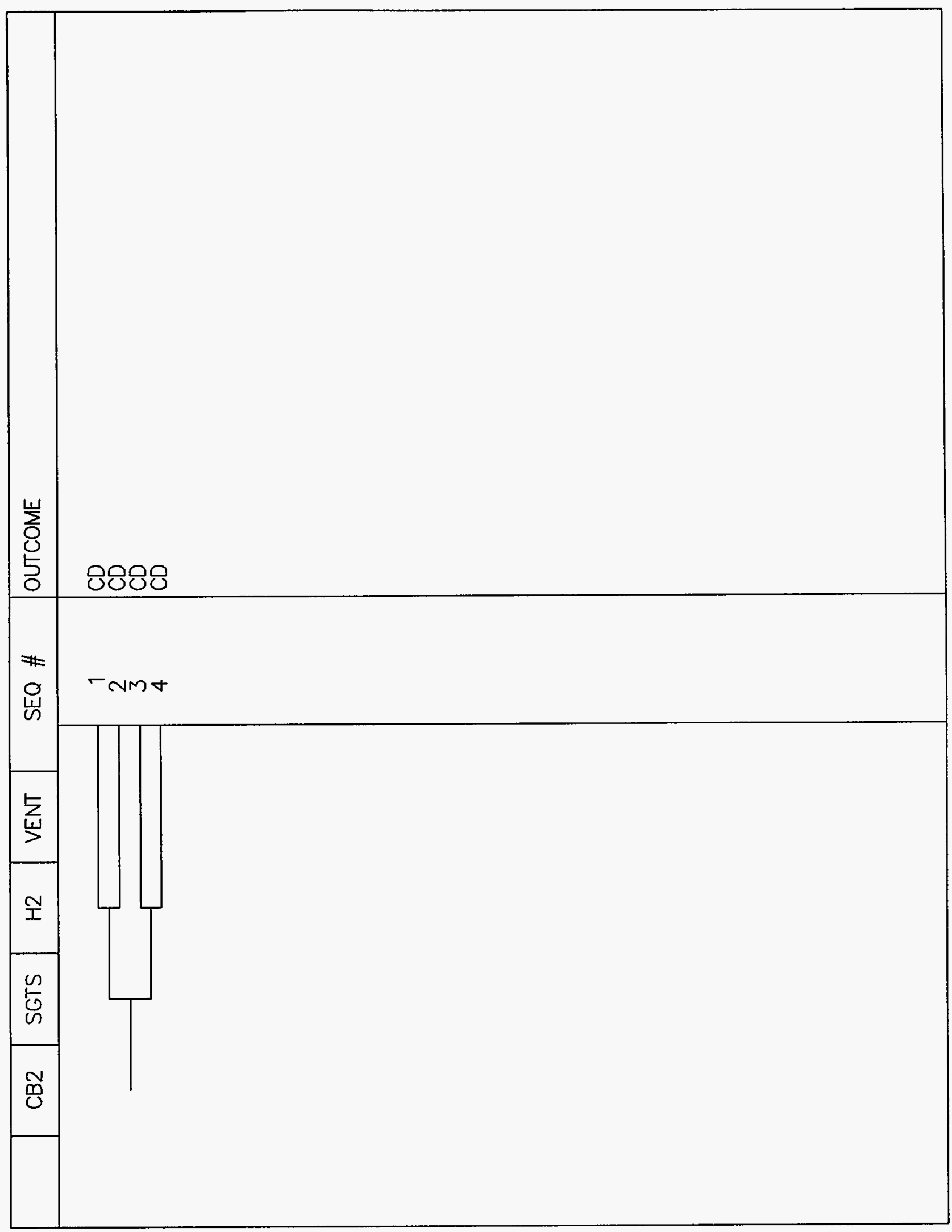

Figure H.1-20 CB2 Tree

Vol. 2, Part 2

H-21 


\section{Event Trees}

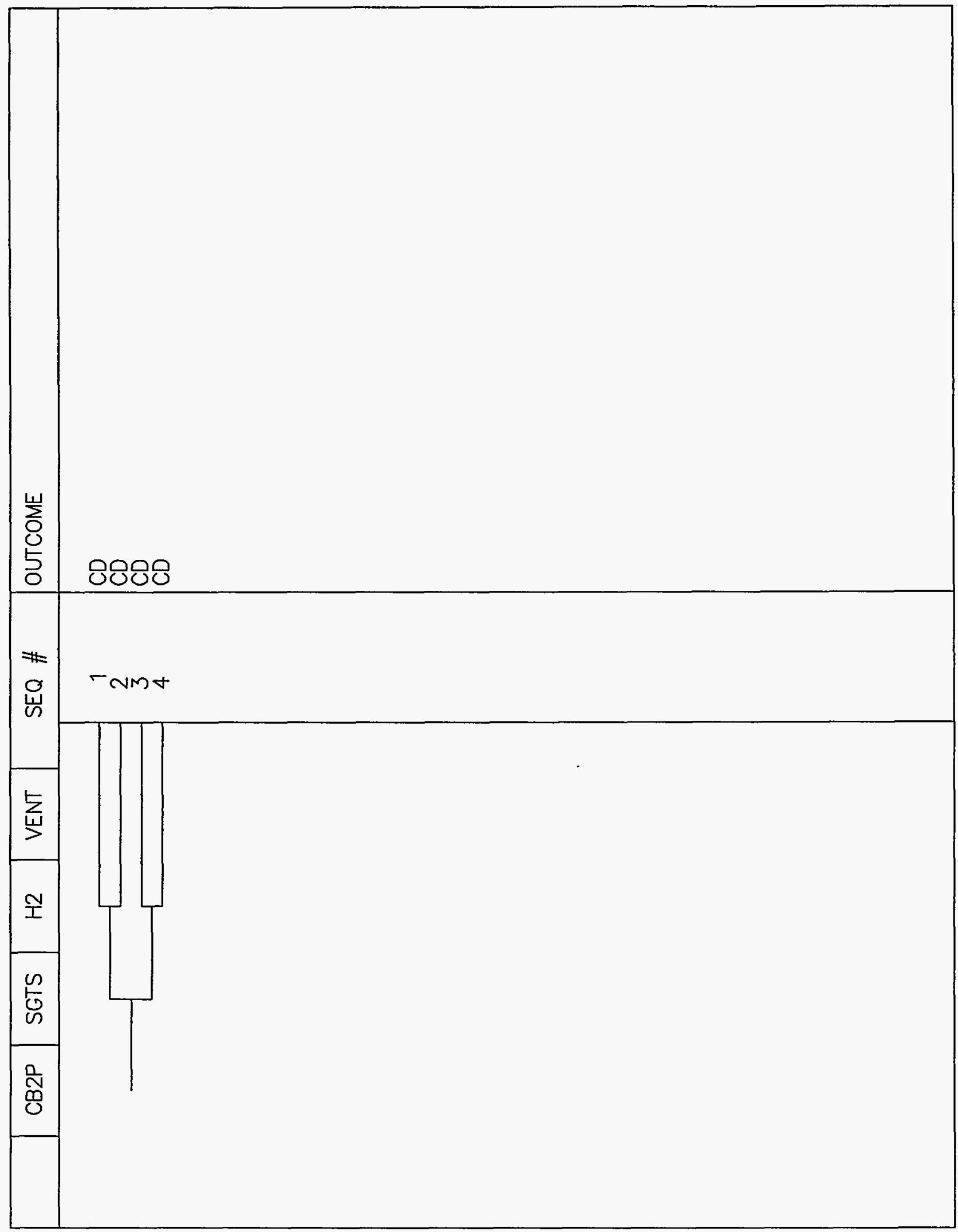

Figure H.1-21 CB2P Tree

Vol. 2, Part 2 
Event Trees

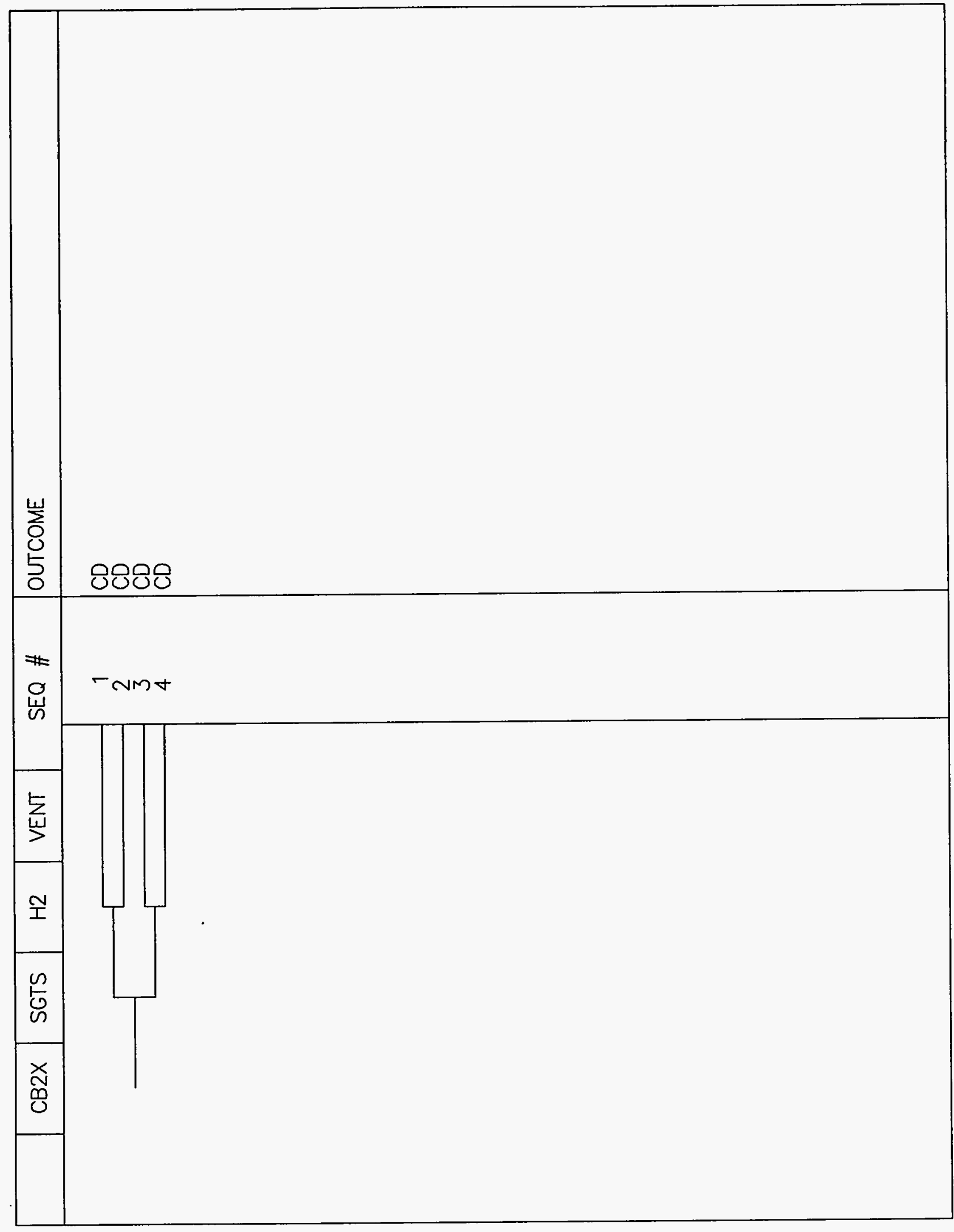

Figure H.1-22 CB2X Tree

Vol. 2, Part 2 
Event Trees

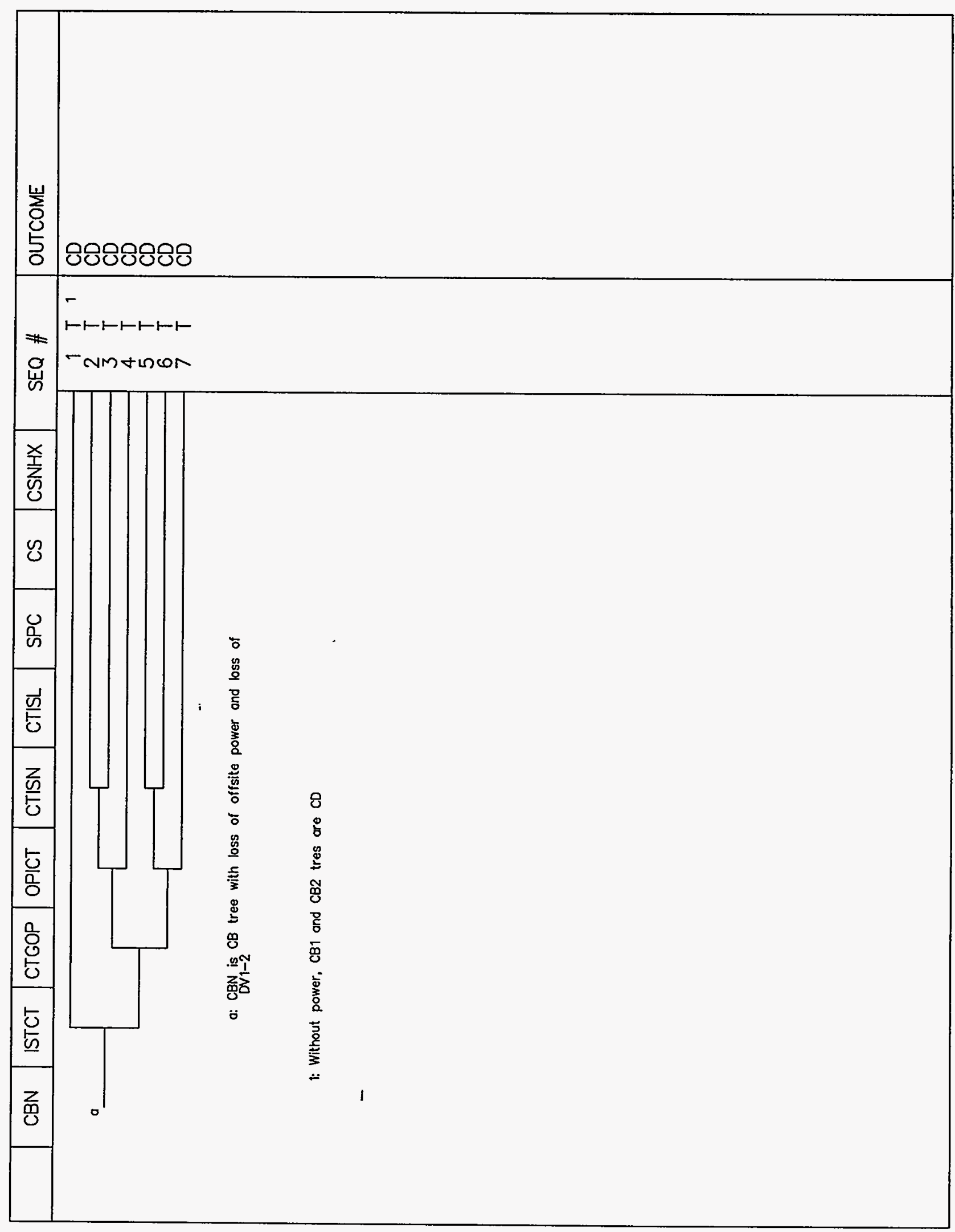

Figure H.1-23 CBN Tree 


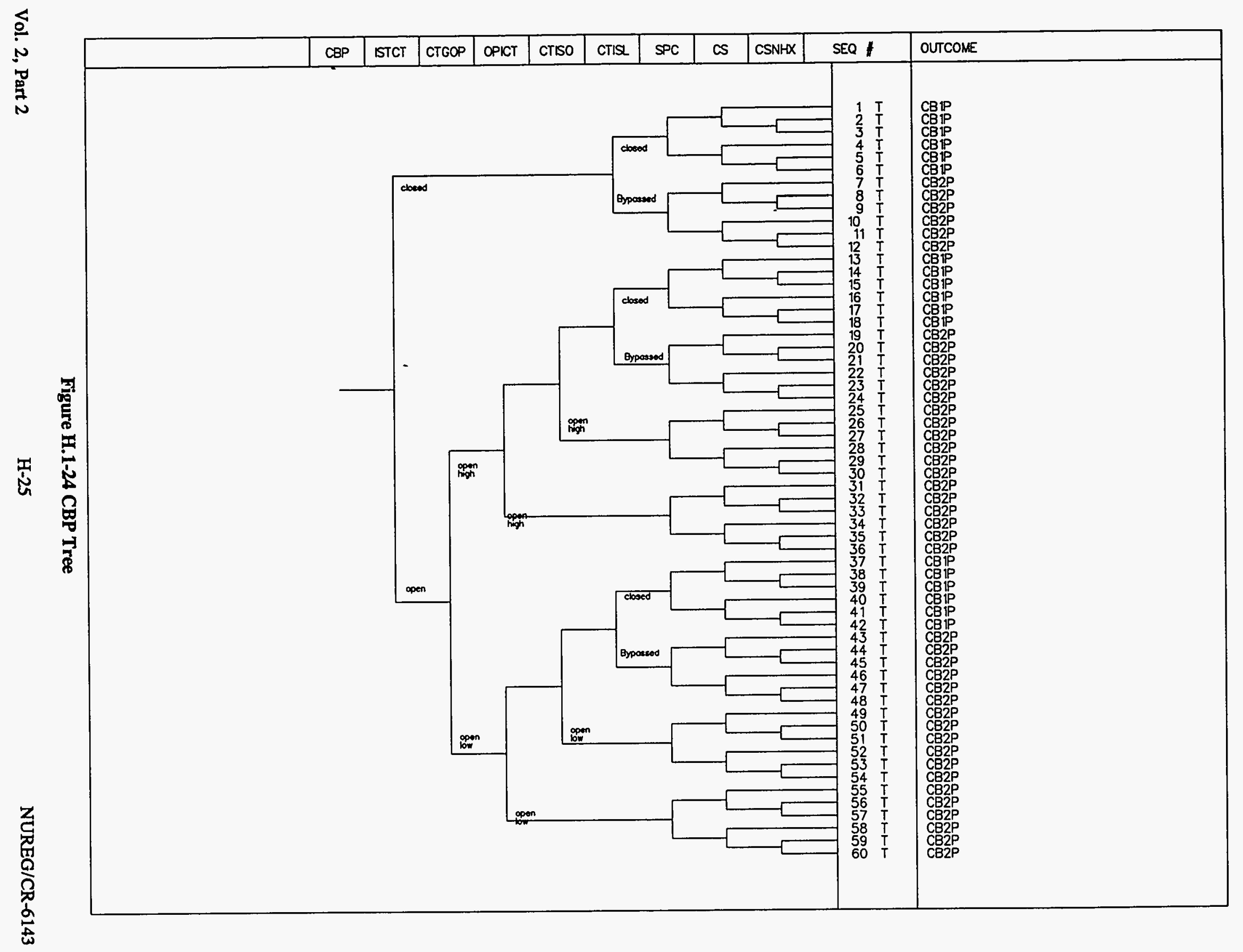

四 


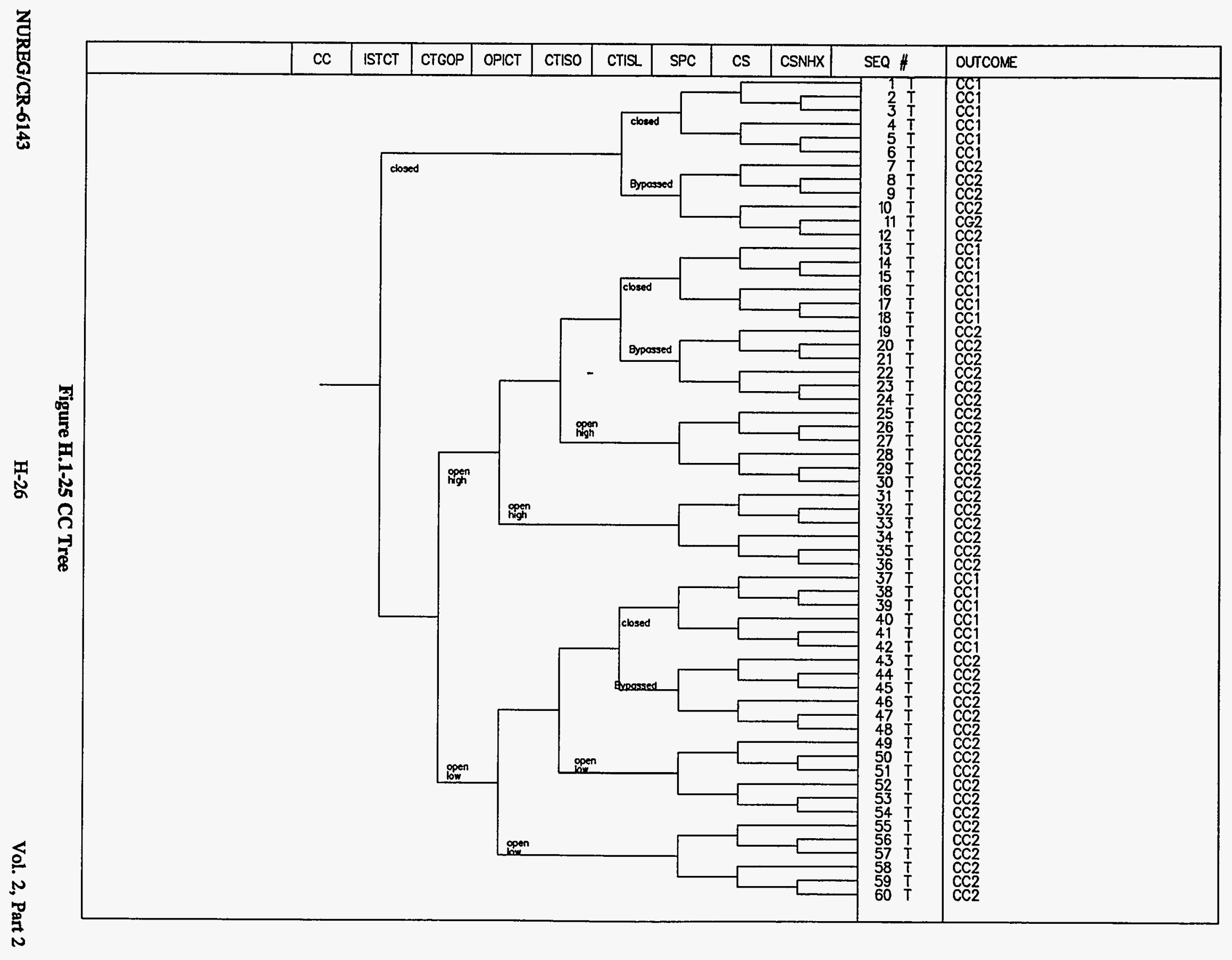




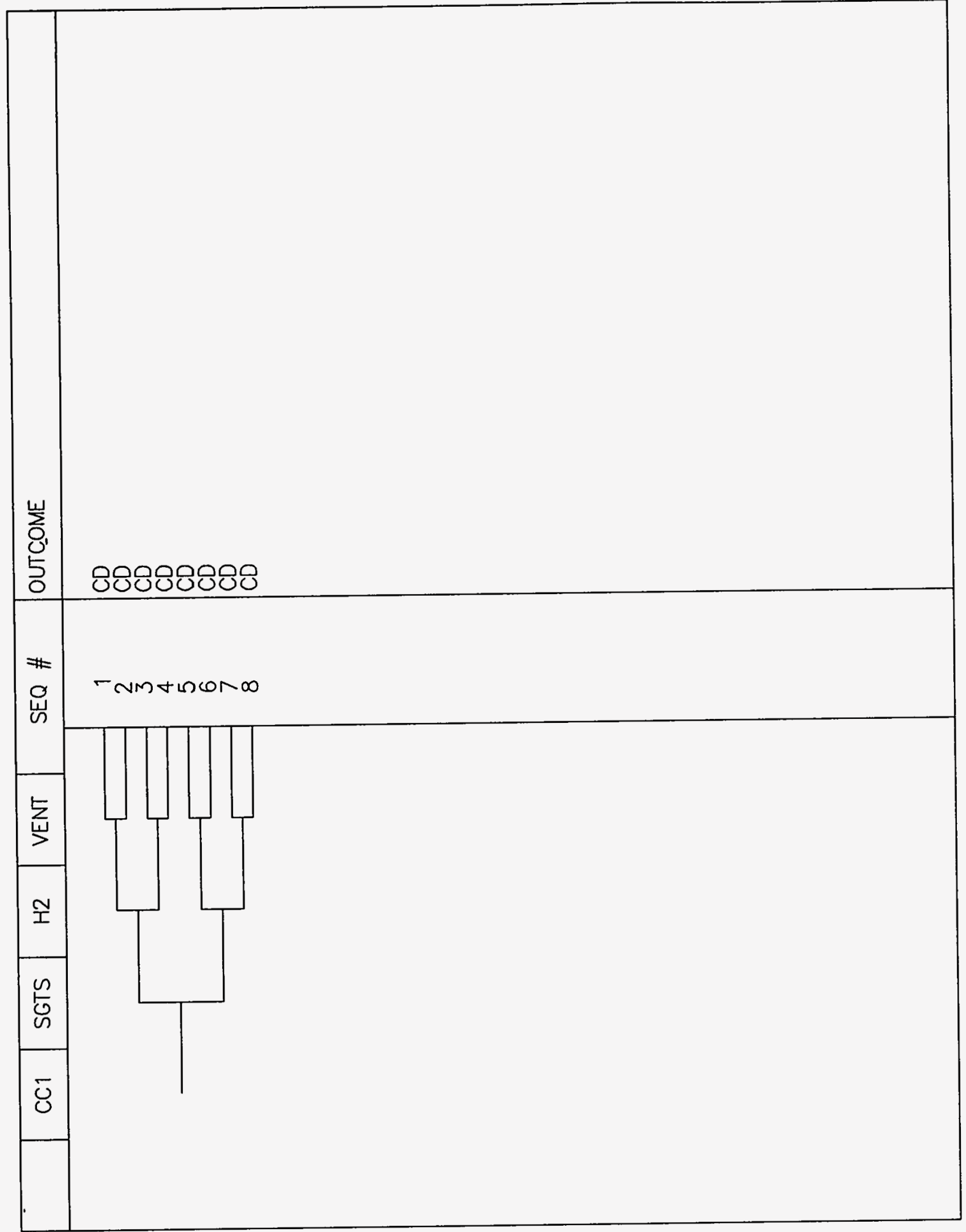

Figure H.1-26 CC1 Tree

Vol. 2, Part 2 
Event Trees

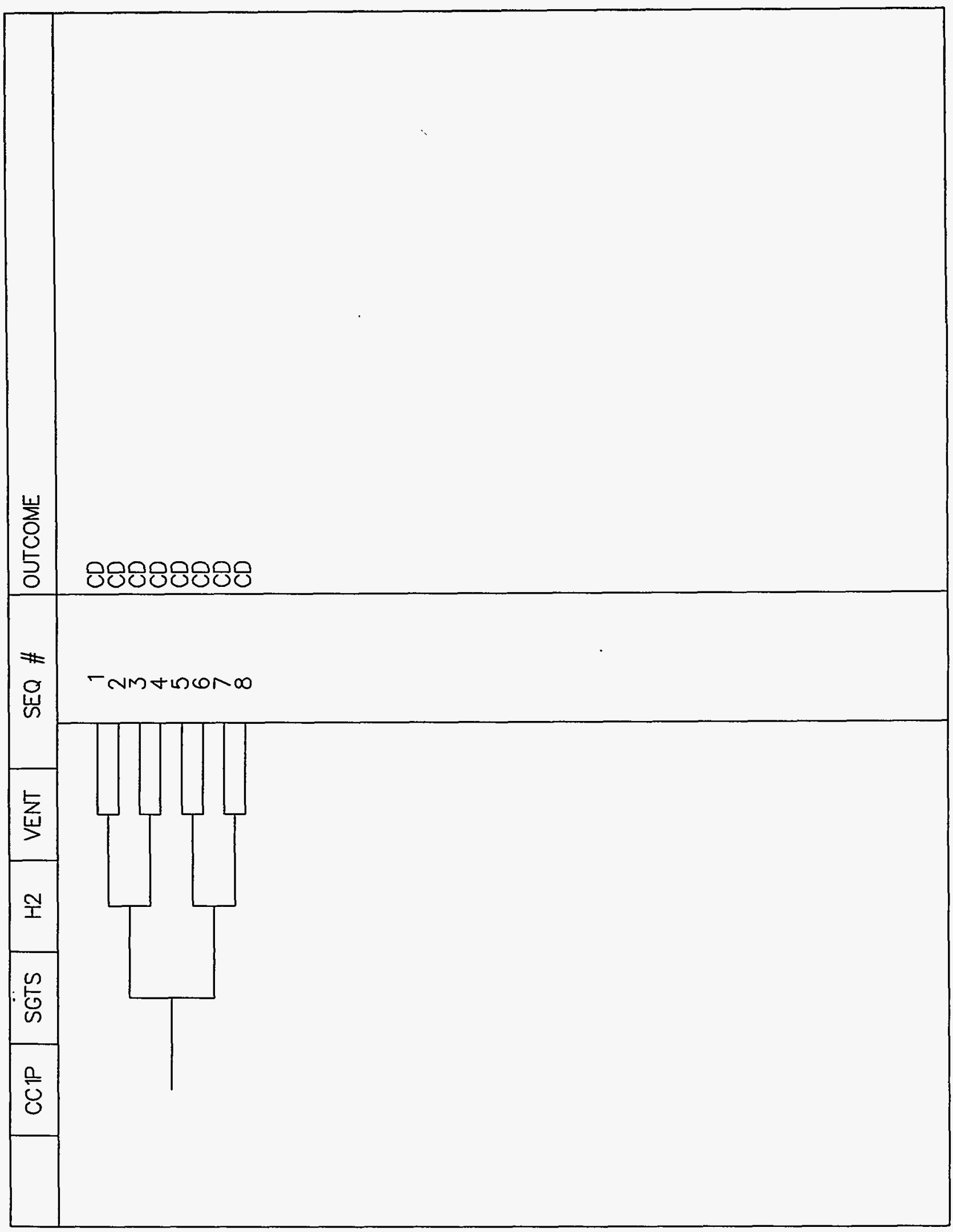

Figure H.1-27 CC1P Tree 
Event Trees

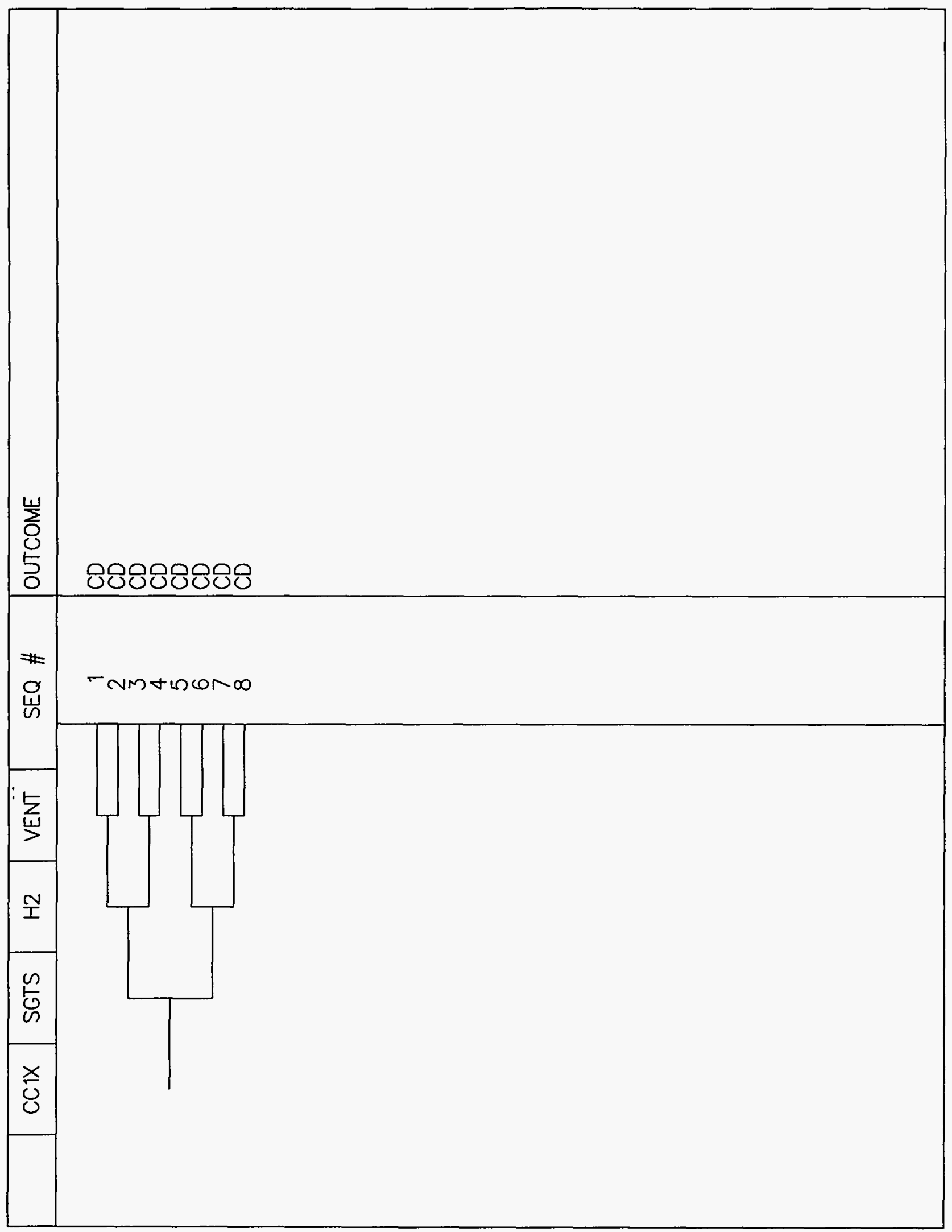

Figure H.1-28 CC1X Tree

Vol. 2, Part 2

H-29

NUREG/CR-6143

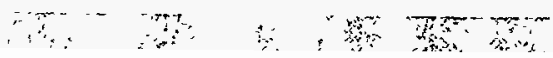




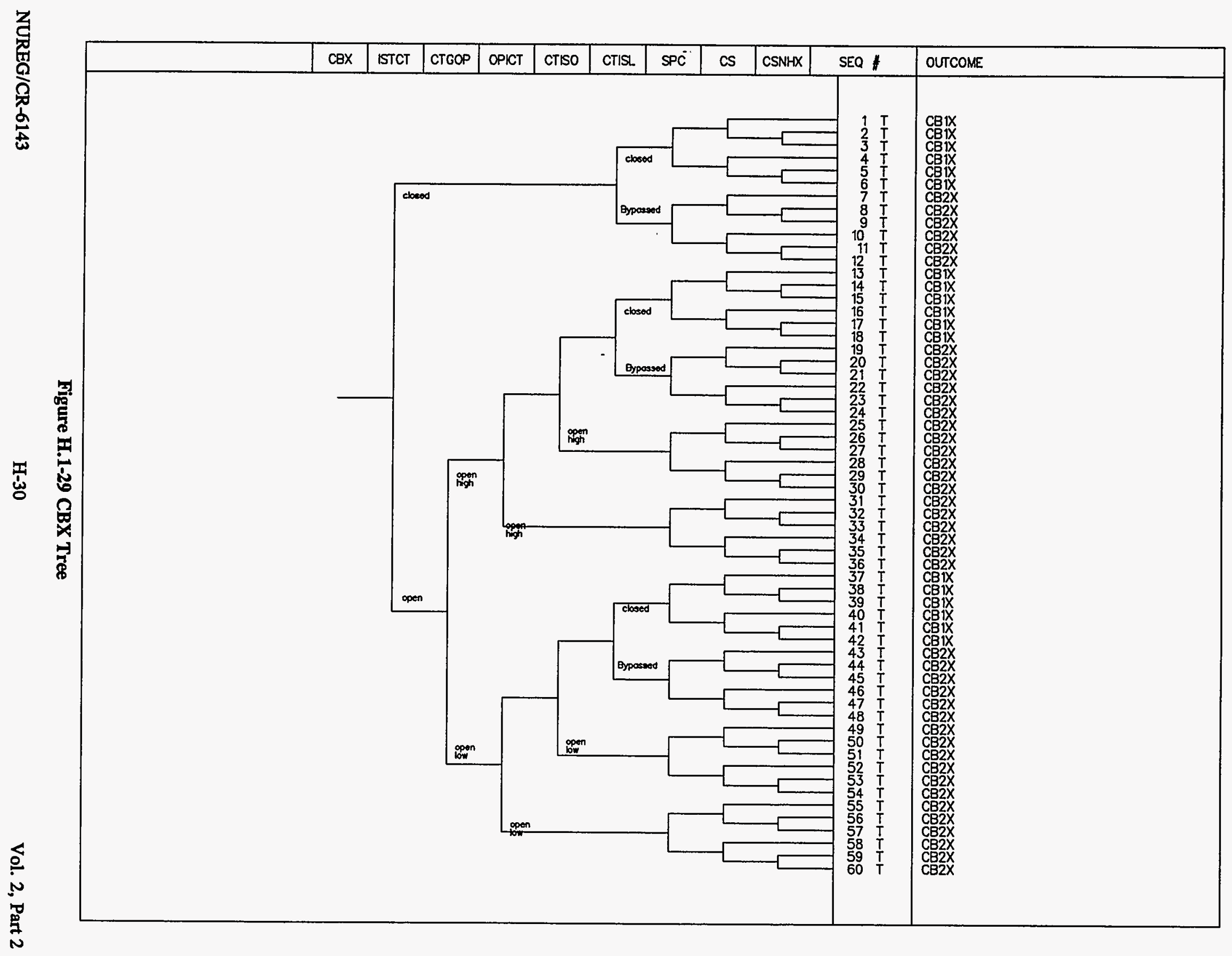




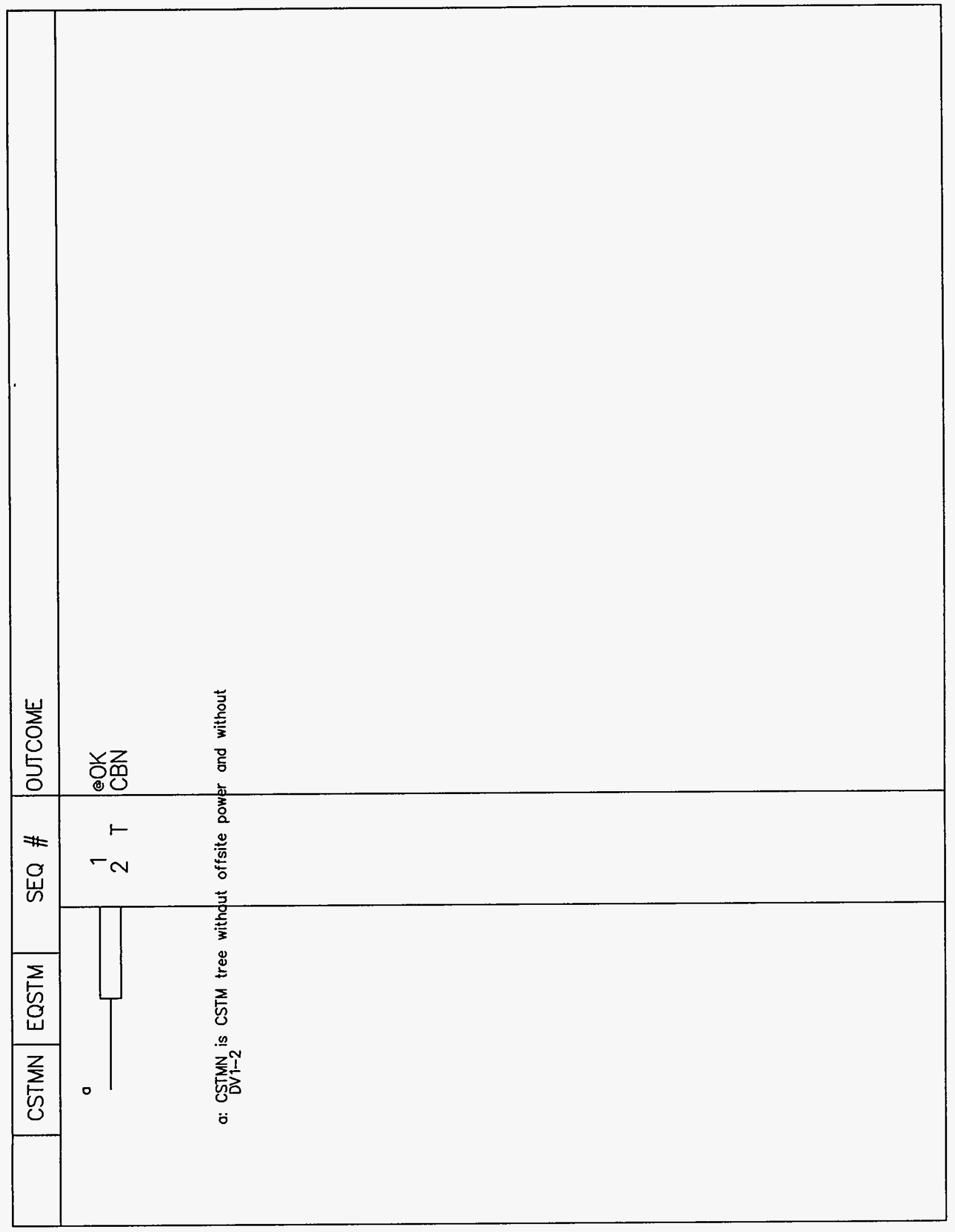

Figure H.1-30 CSTMN Tree

Vol. 2, Part 2

H-31

NUREG/CR-6143

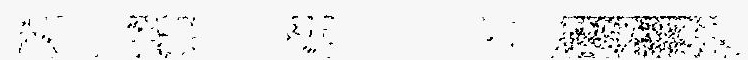




\section{Bvent Trees}

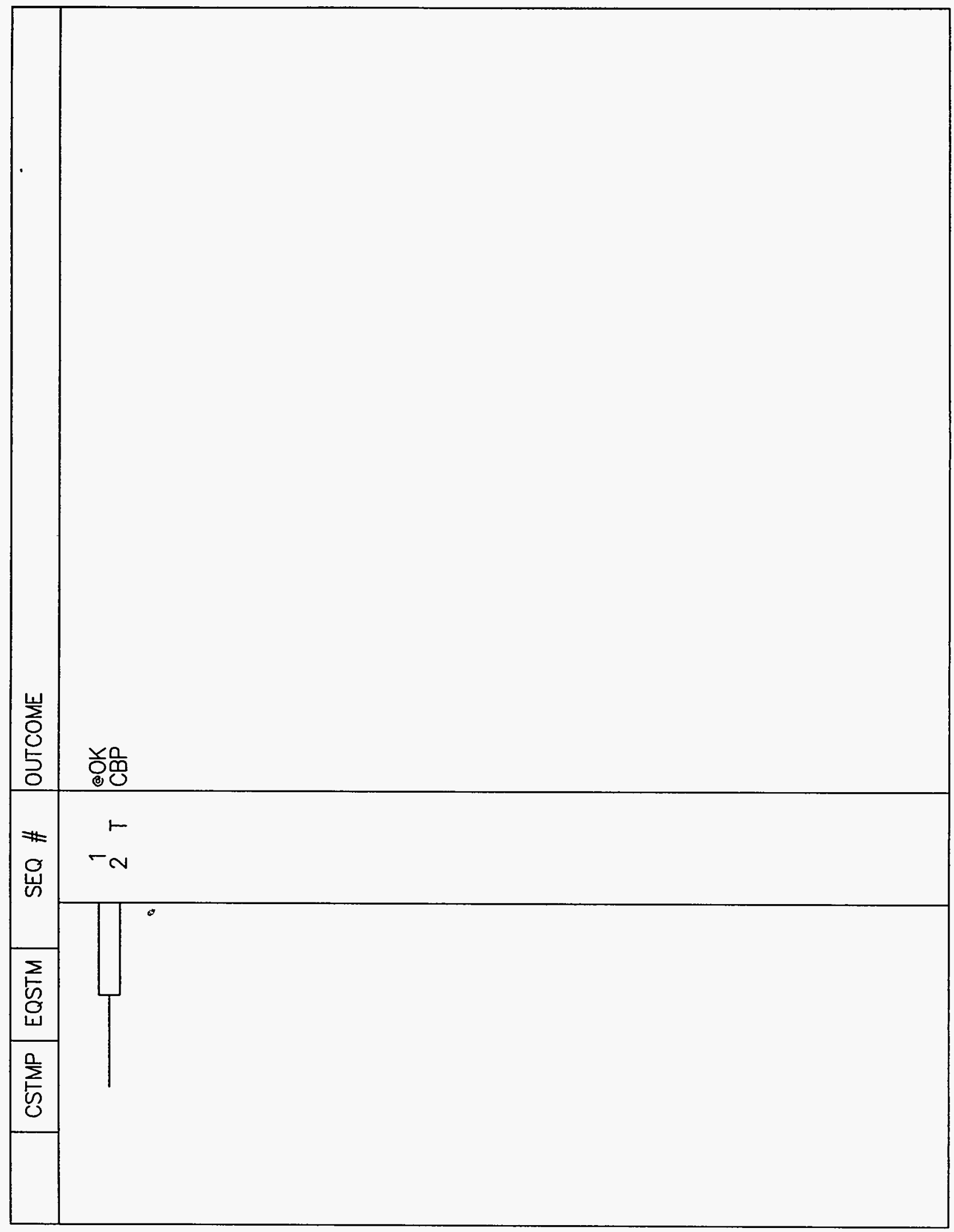

Figure H.1-31 CSTMP Tree 


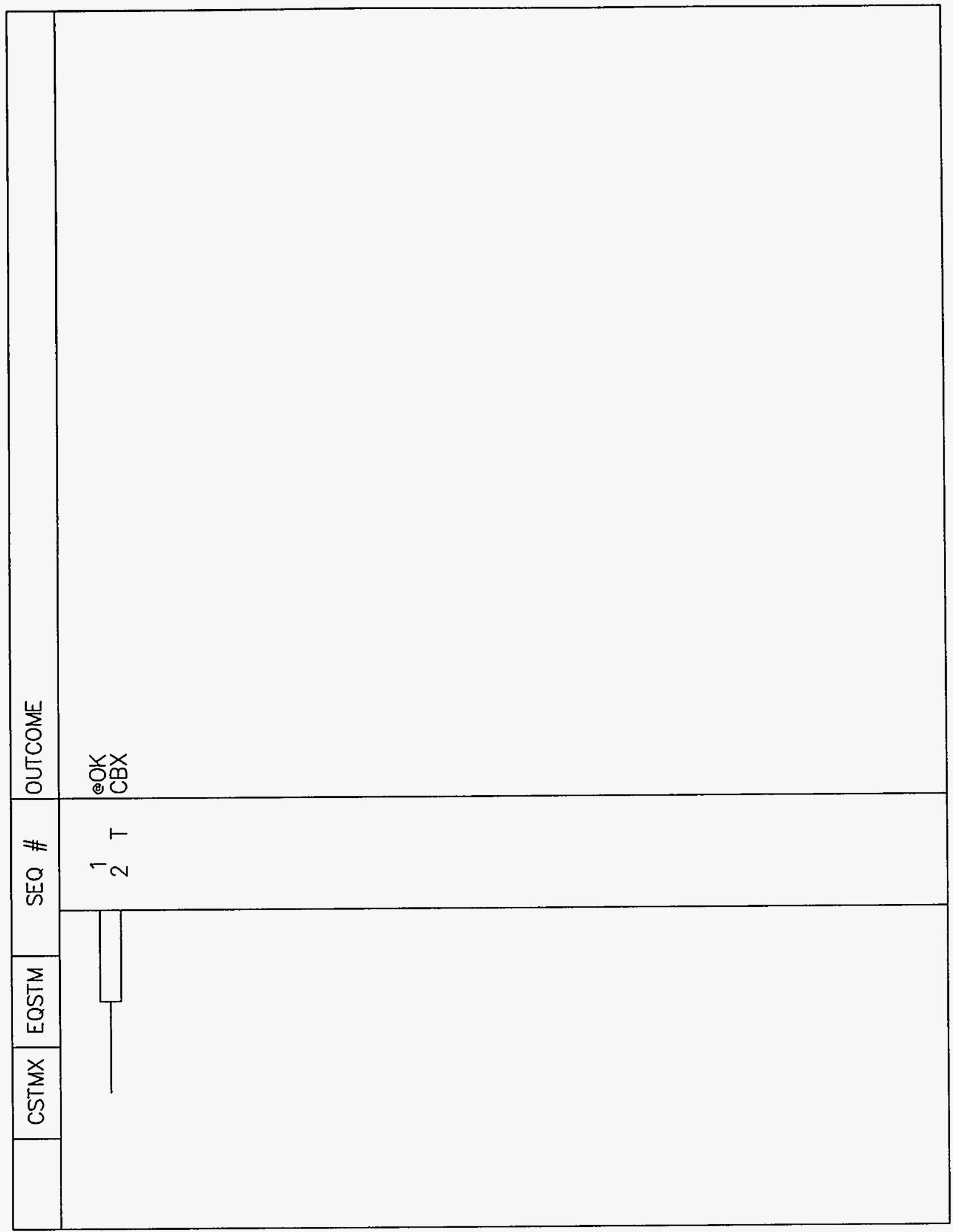

Figure H.1-32 CSTMX Tree 
Event Trees

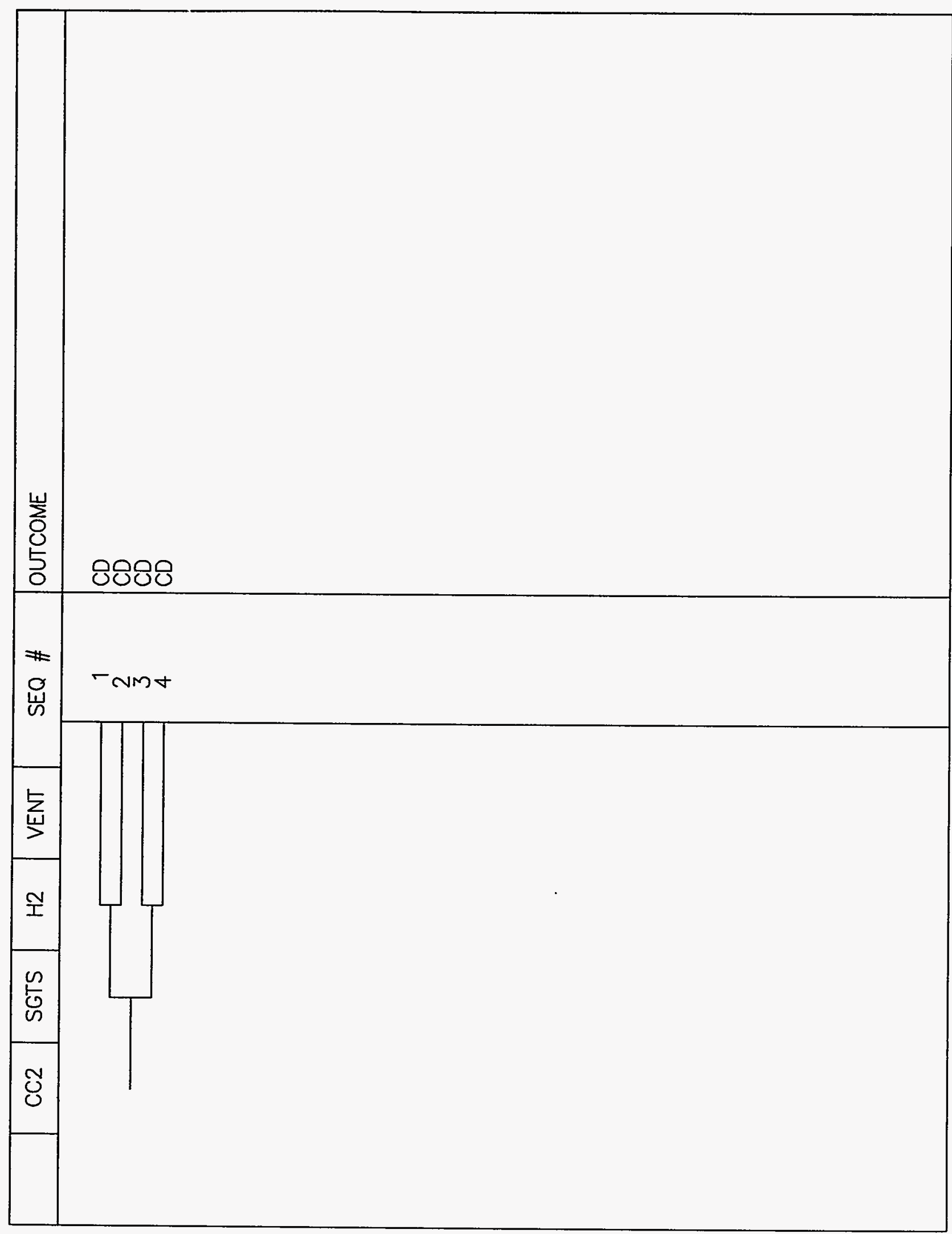

Figure H.1-33 CC2 Tree 
Event Trees

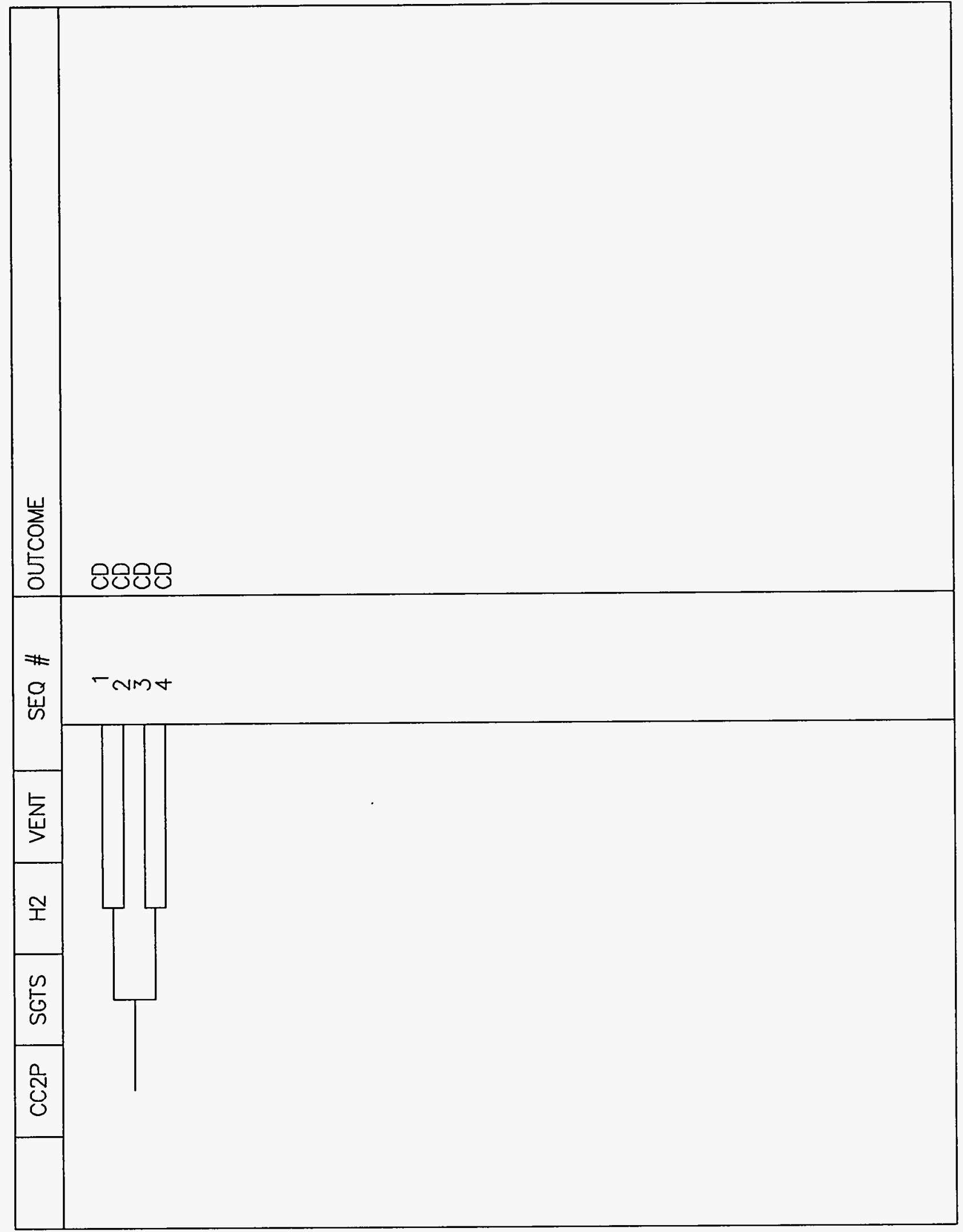

Figure H.1-34 CC2P Tree

Vol. 2, Part 2

H-35

NUREG/CR-6143 
Event Trees

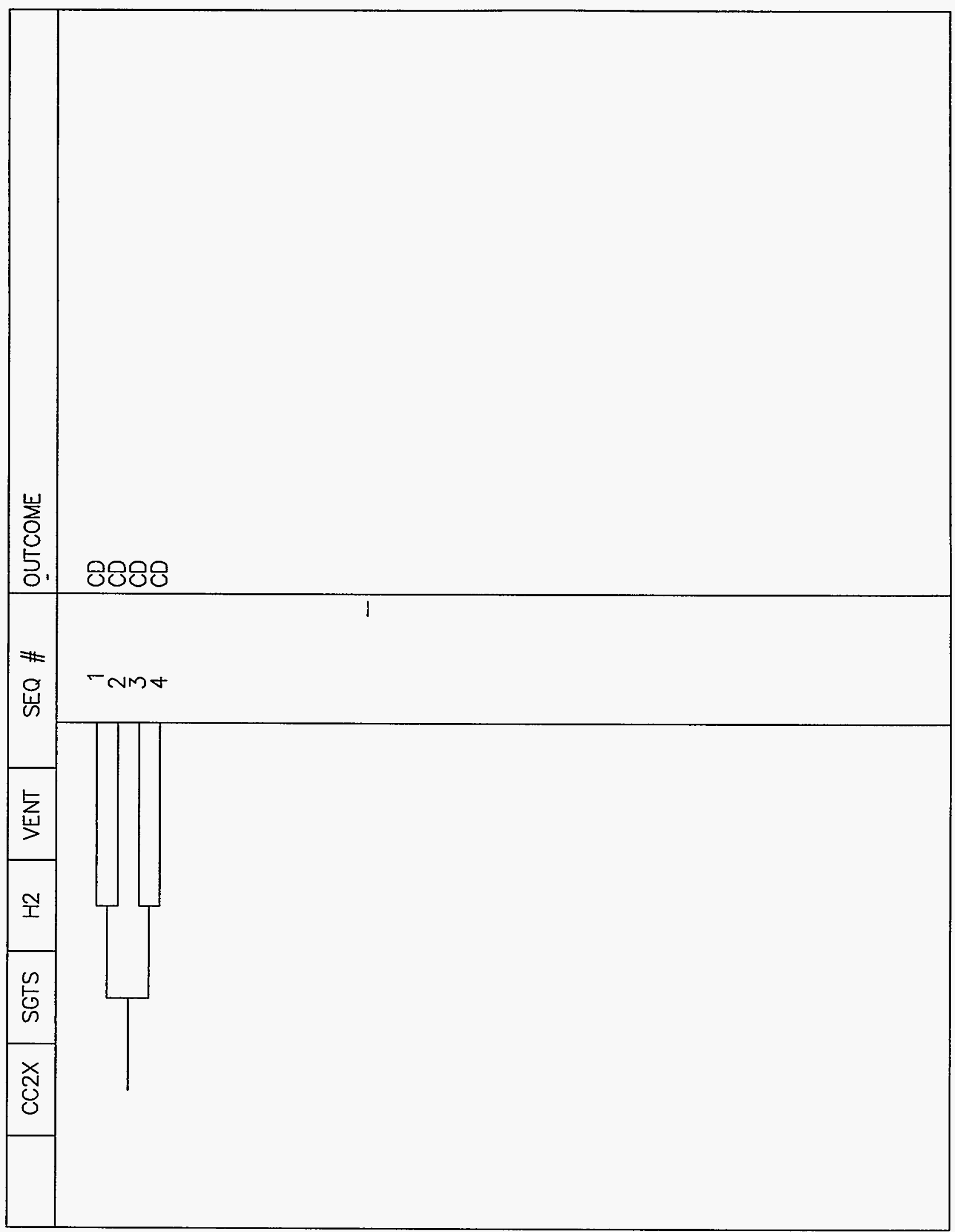

Figure H.1-35 CC2X Tree 


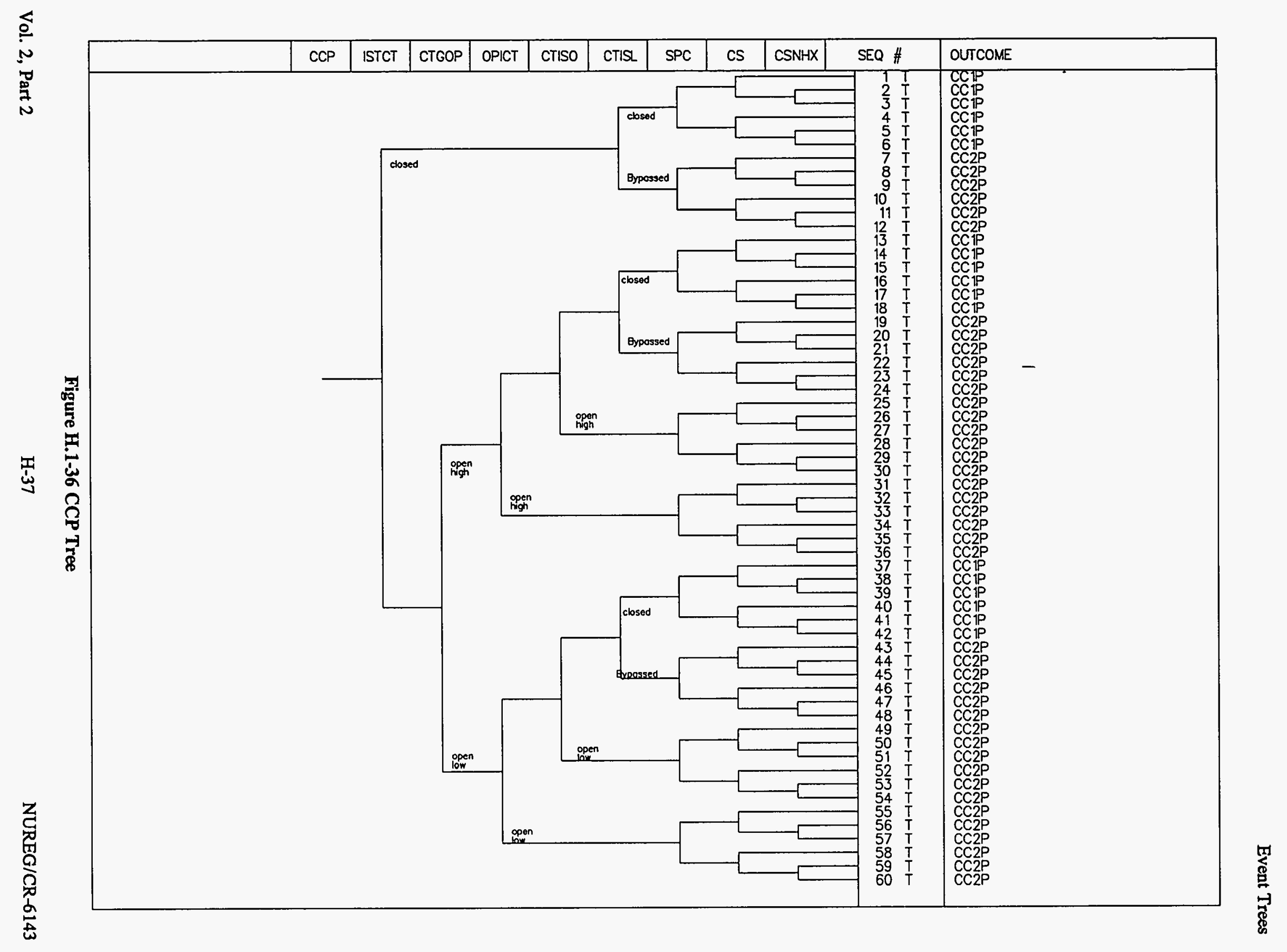




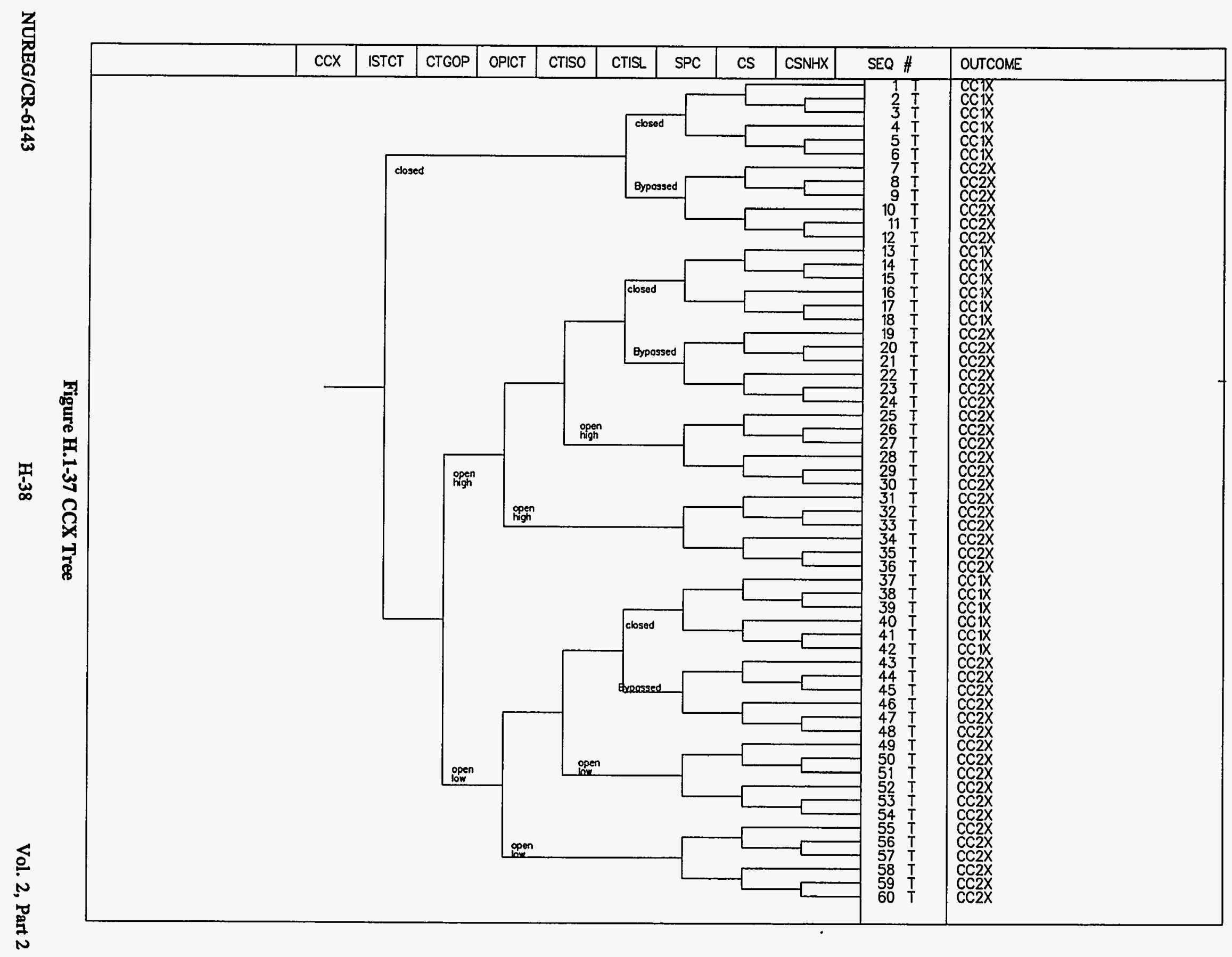

氭 


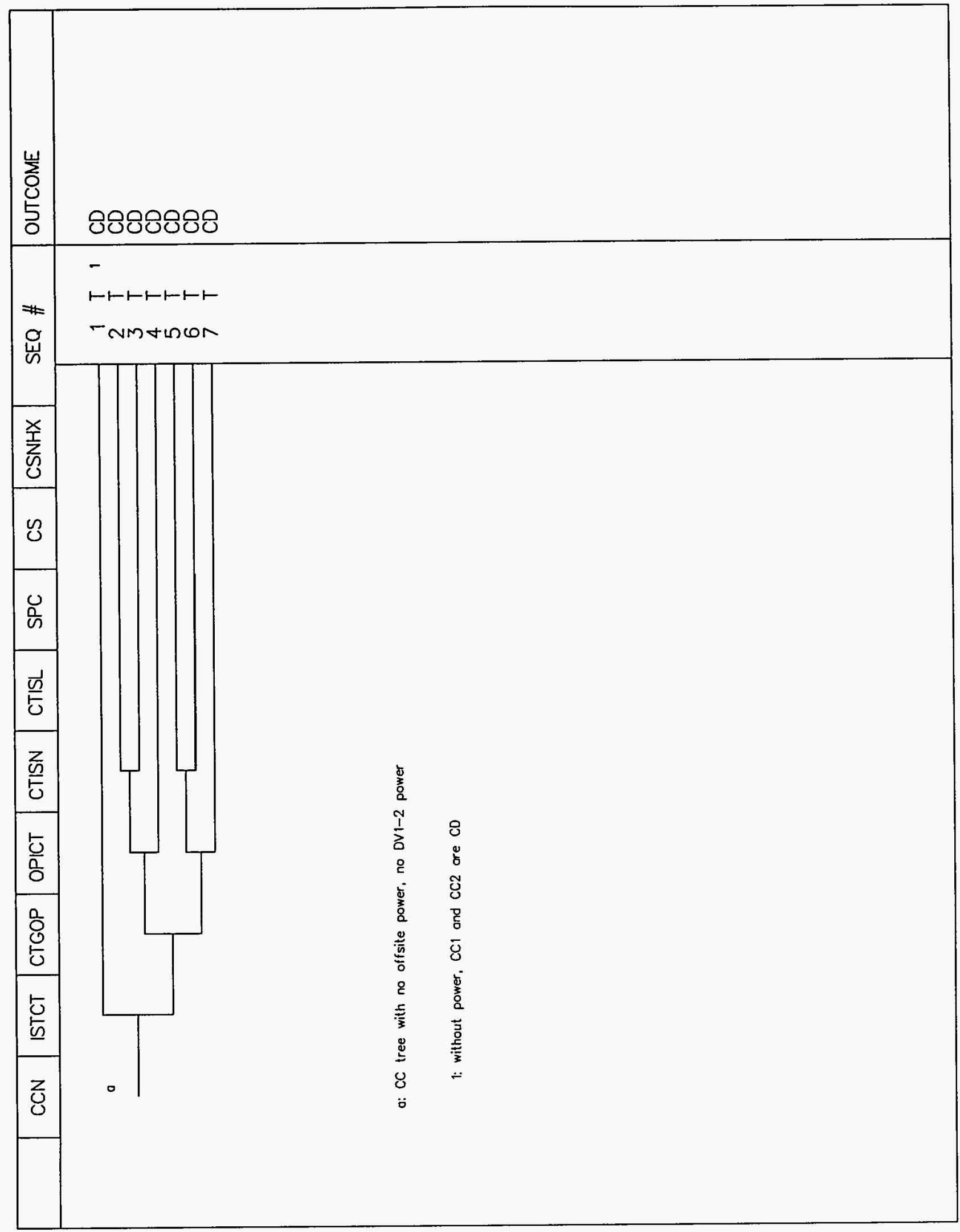

Figure H.1-38 CCN Tree

Vol. 2, Part 2 


\section{Event Trees}

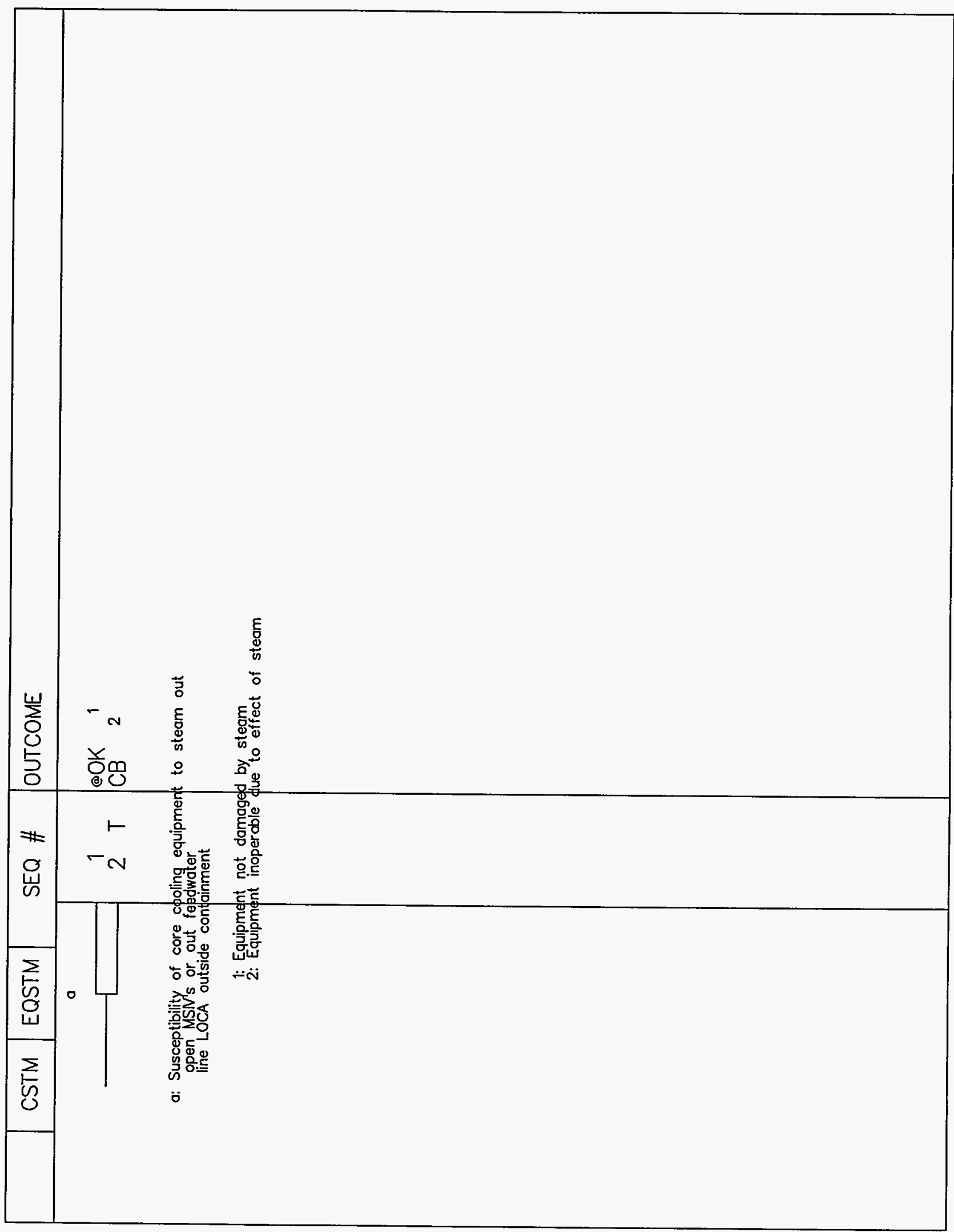

Figure H.1-39 CSTM Tree 


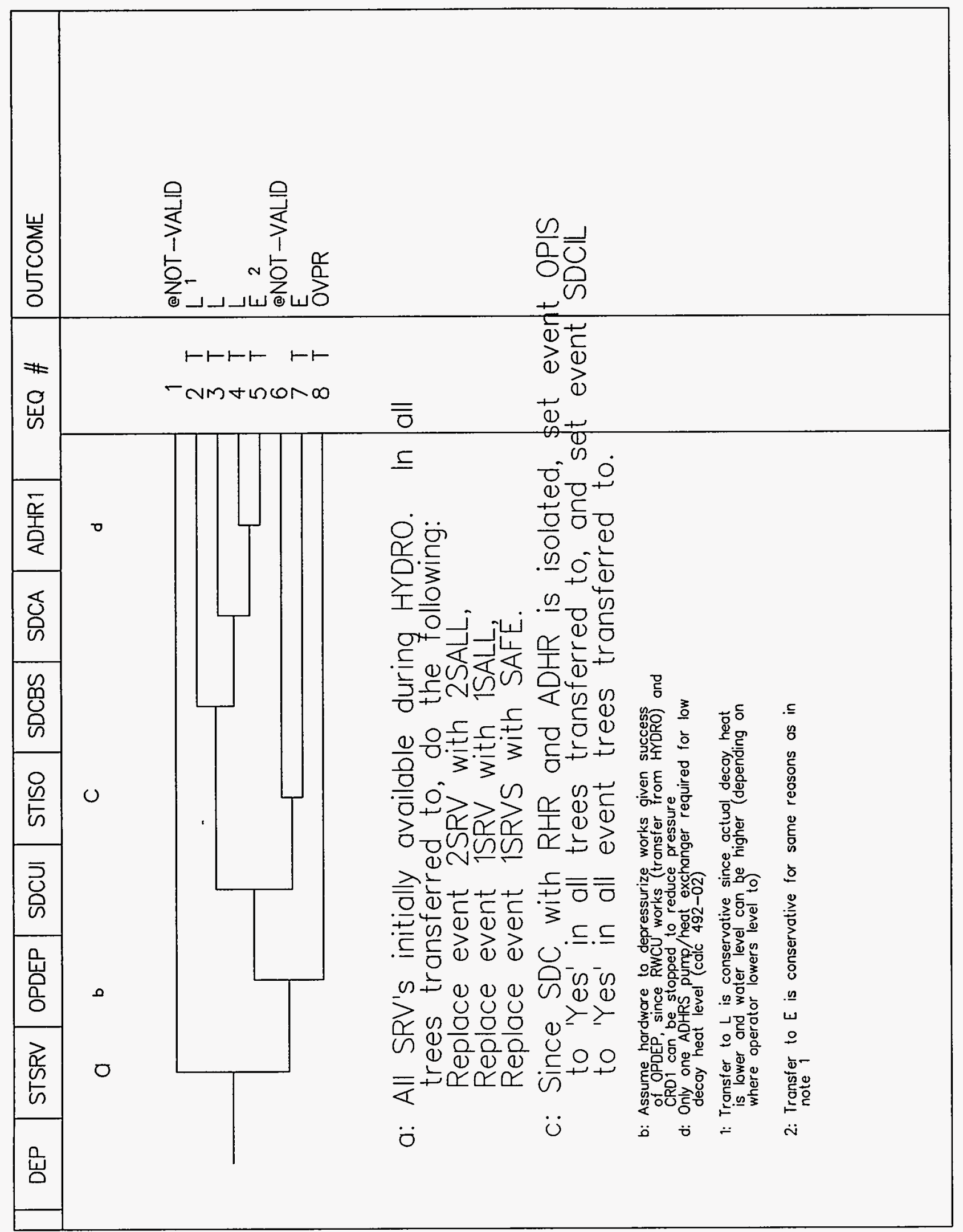

Figure H.1-40 DEP Tree 


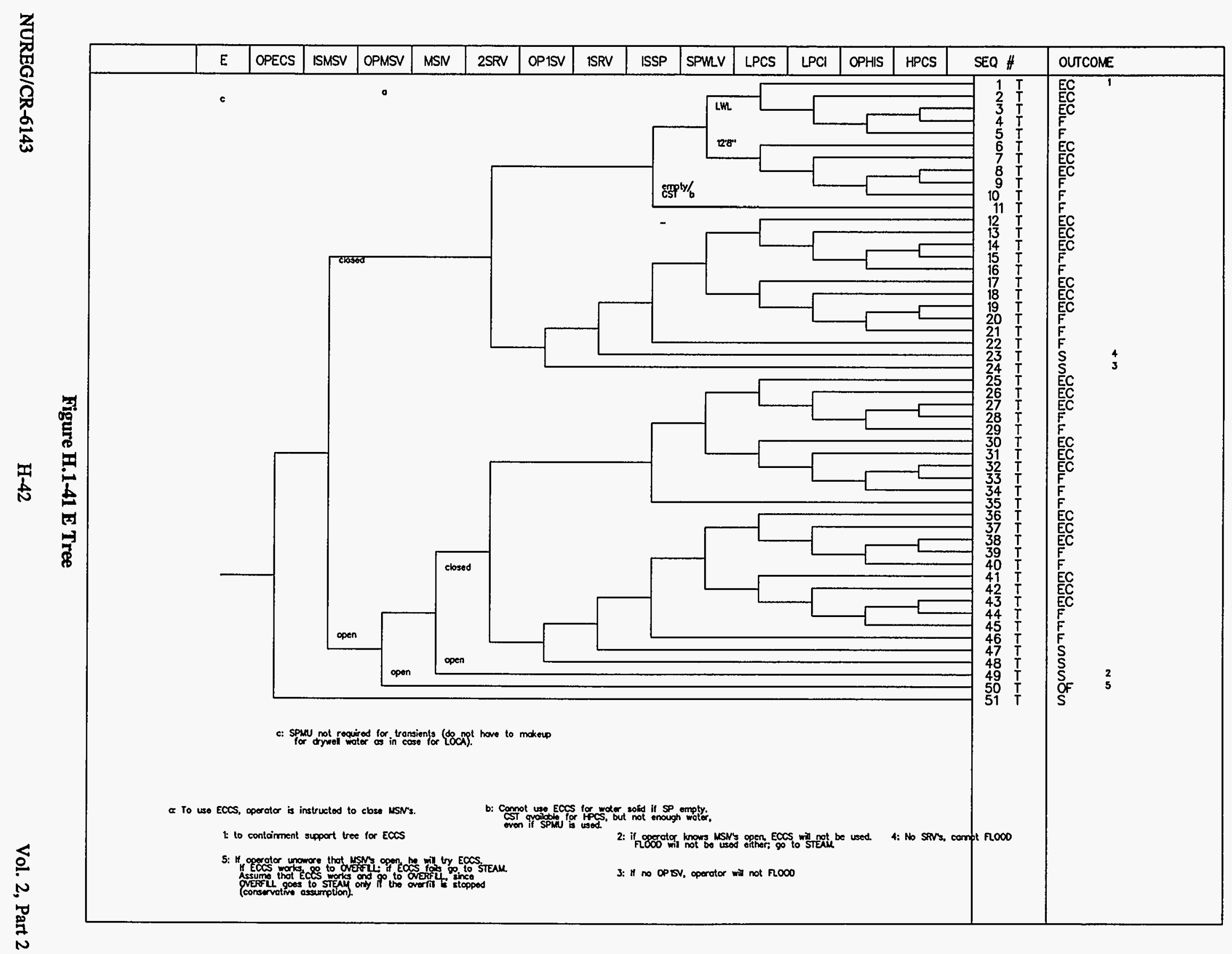


Event Trees

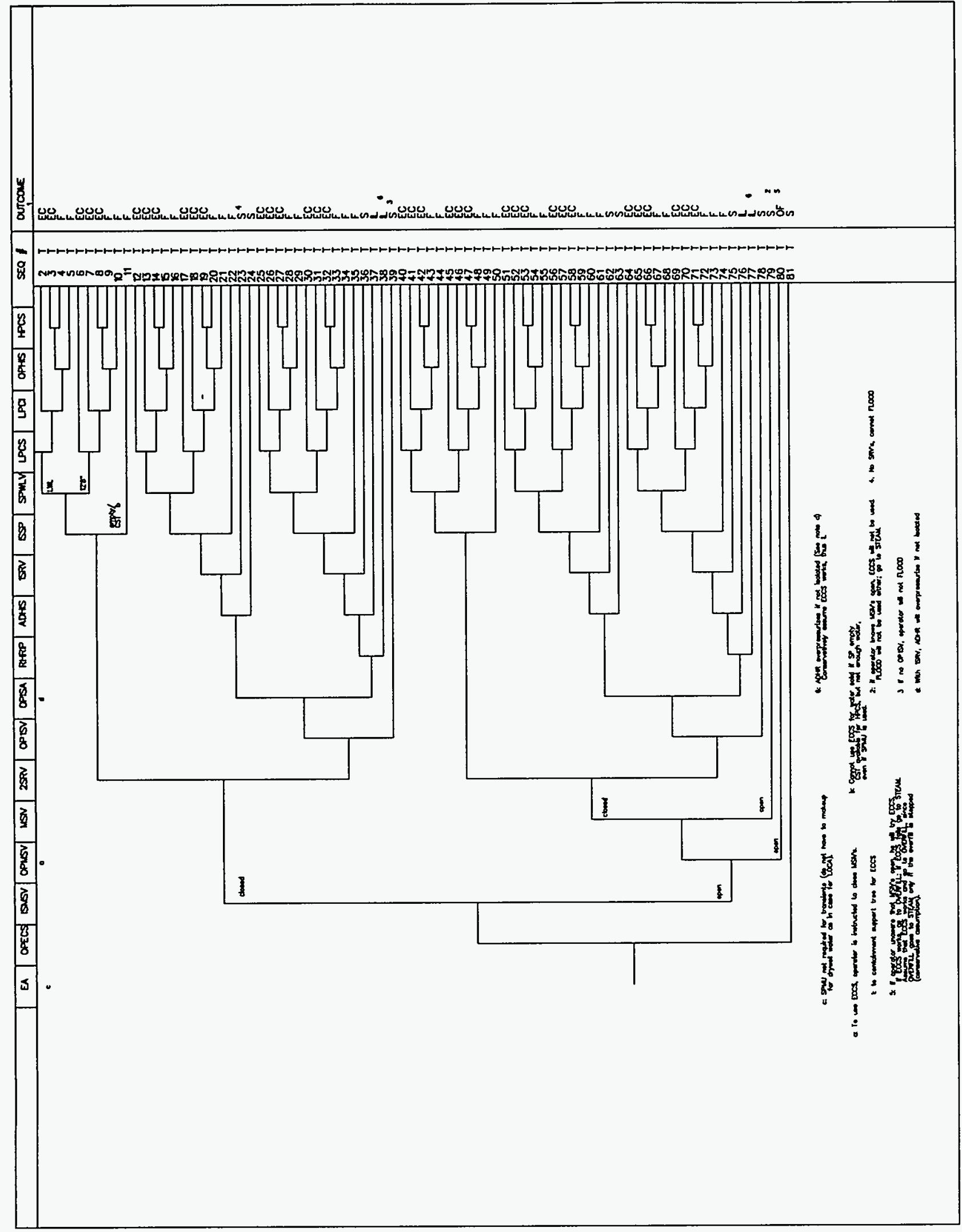

Figure H.1-42 EA Tree 


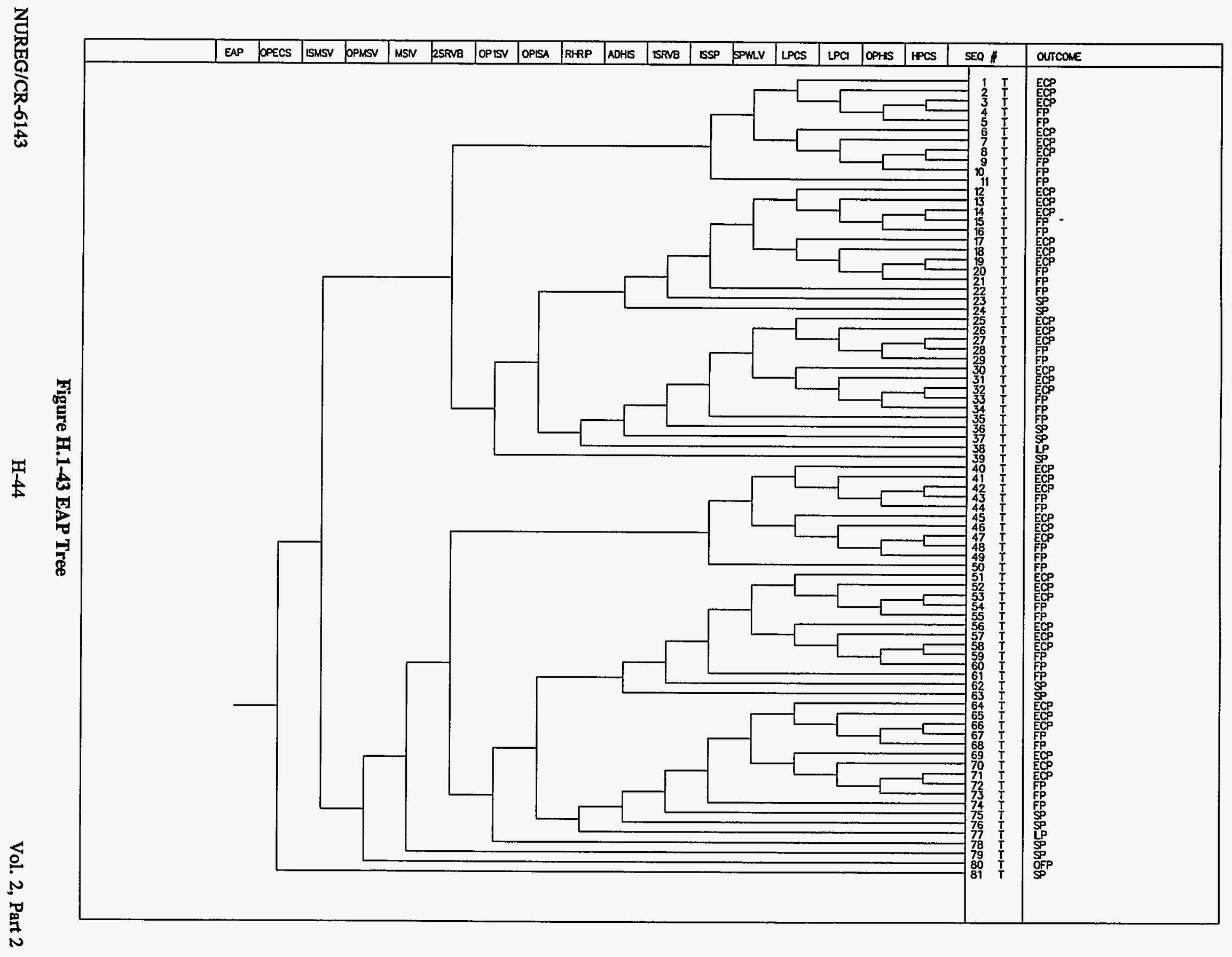


Event Trees

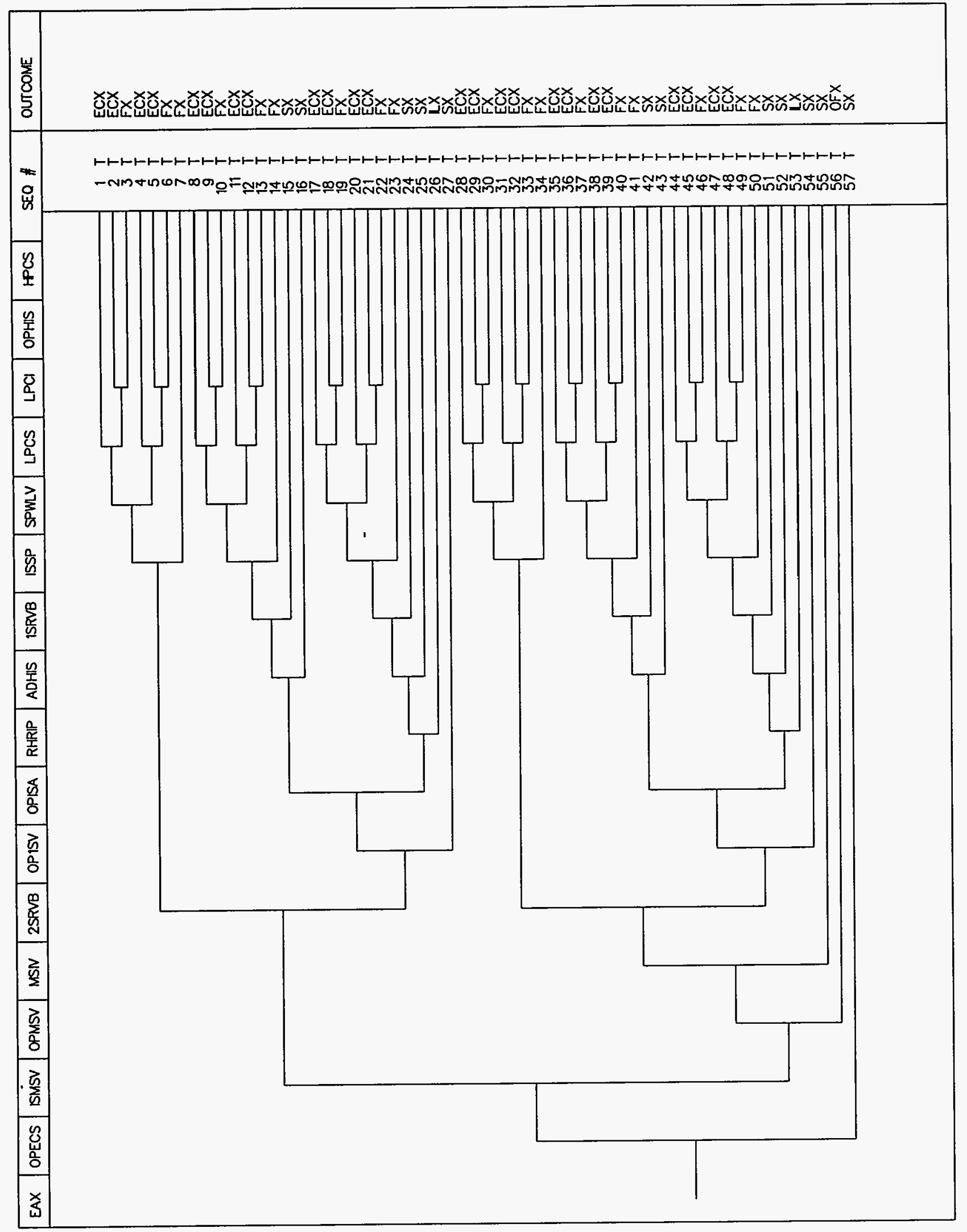

Figure H.1-44 EAX Tree

Vol. 2, Part 2

$\mathrm{H}-45$

NUREG/CR-6143 
Event Trees

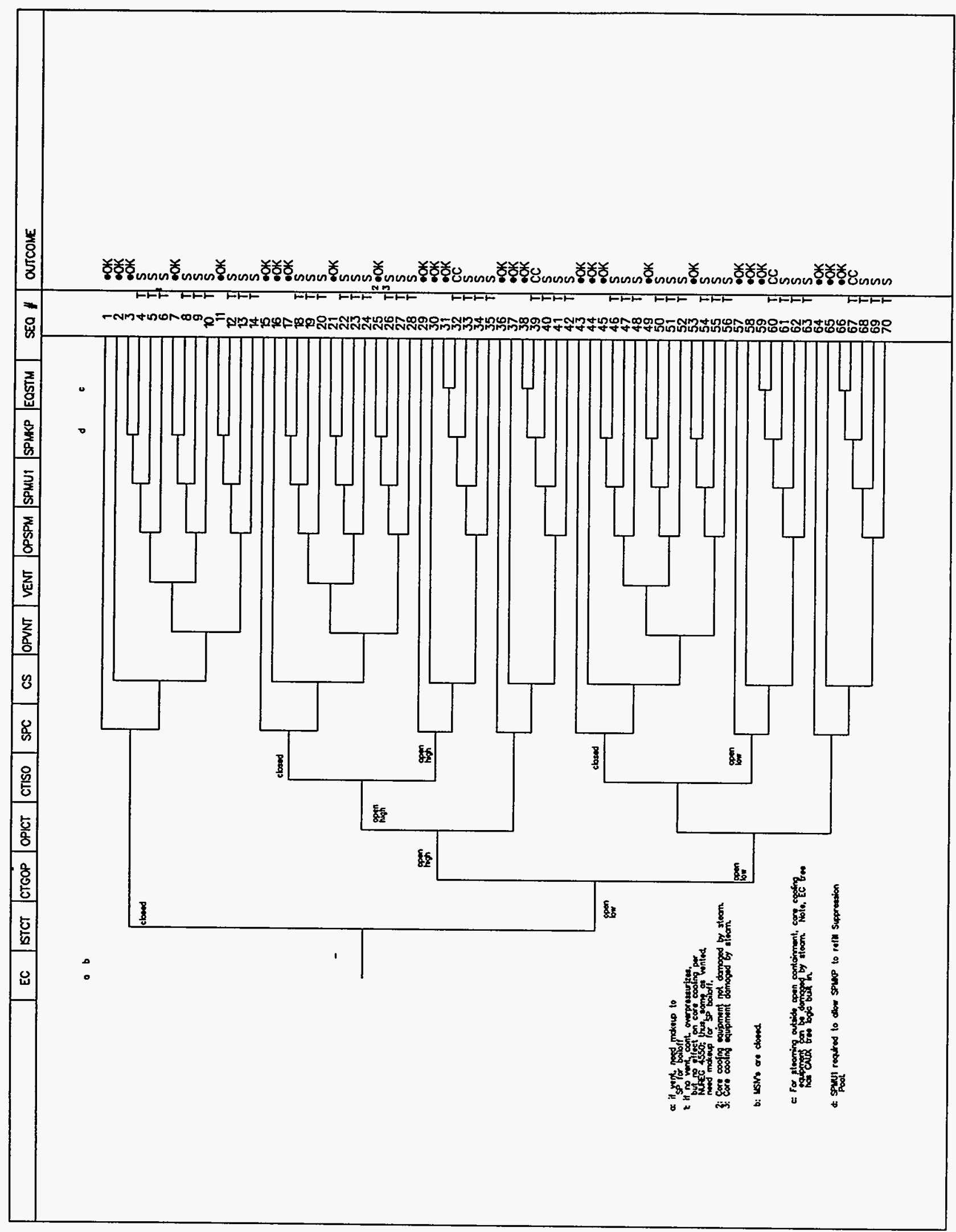

Figure H.1-45 EC Tree 


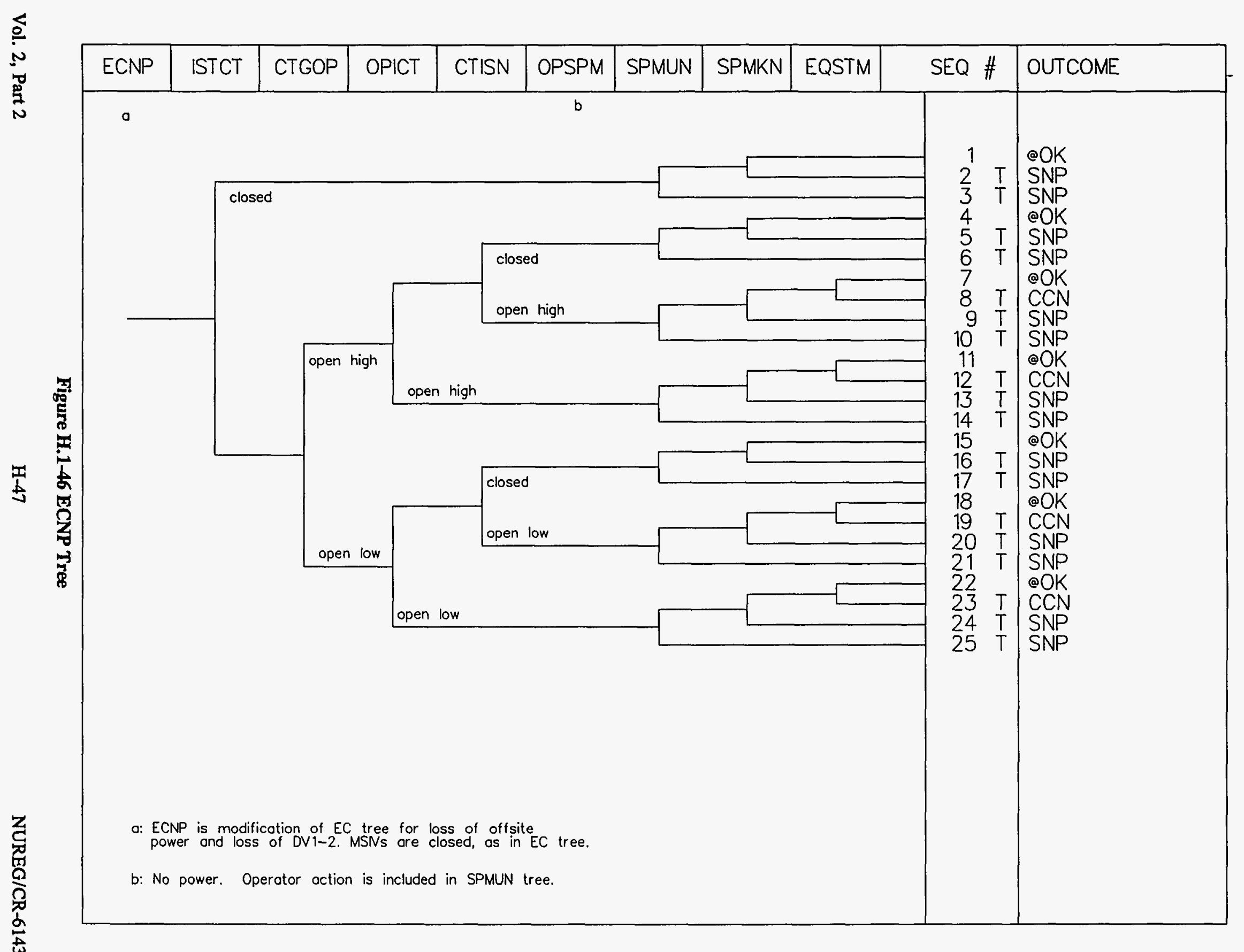




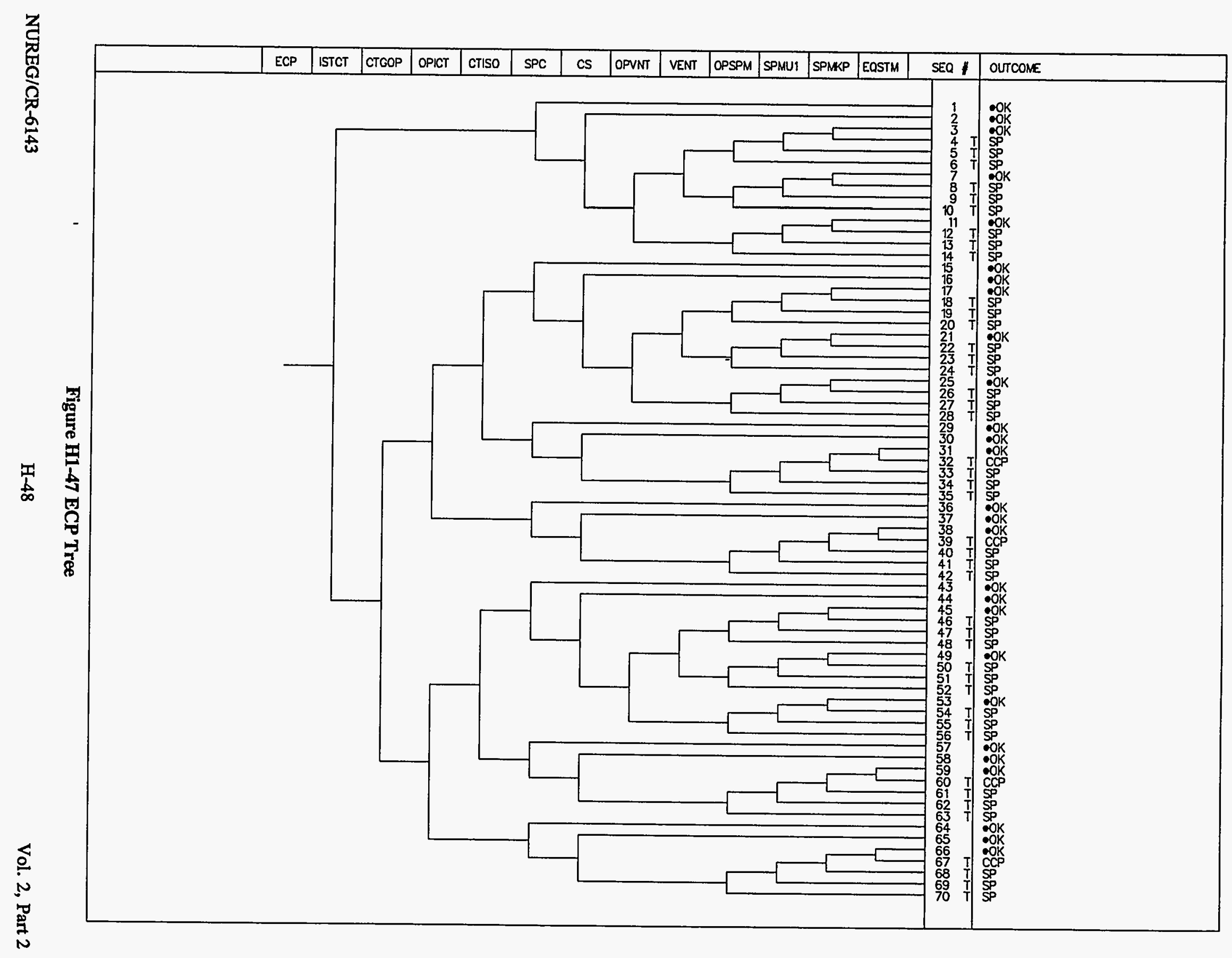


Event Trees

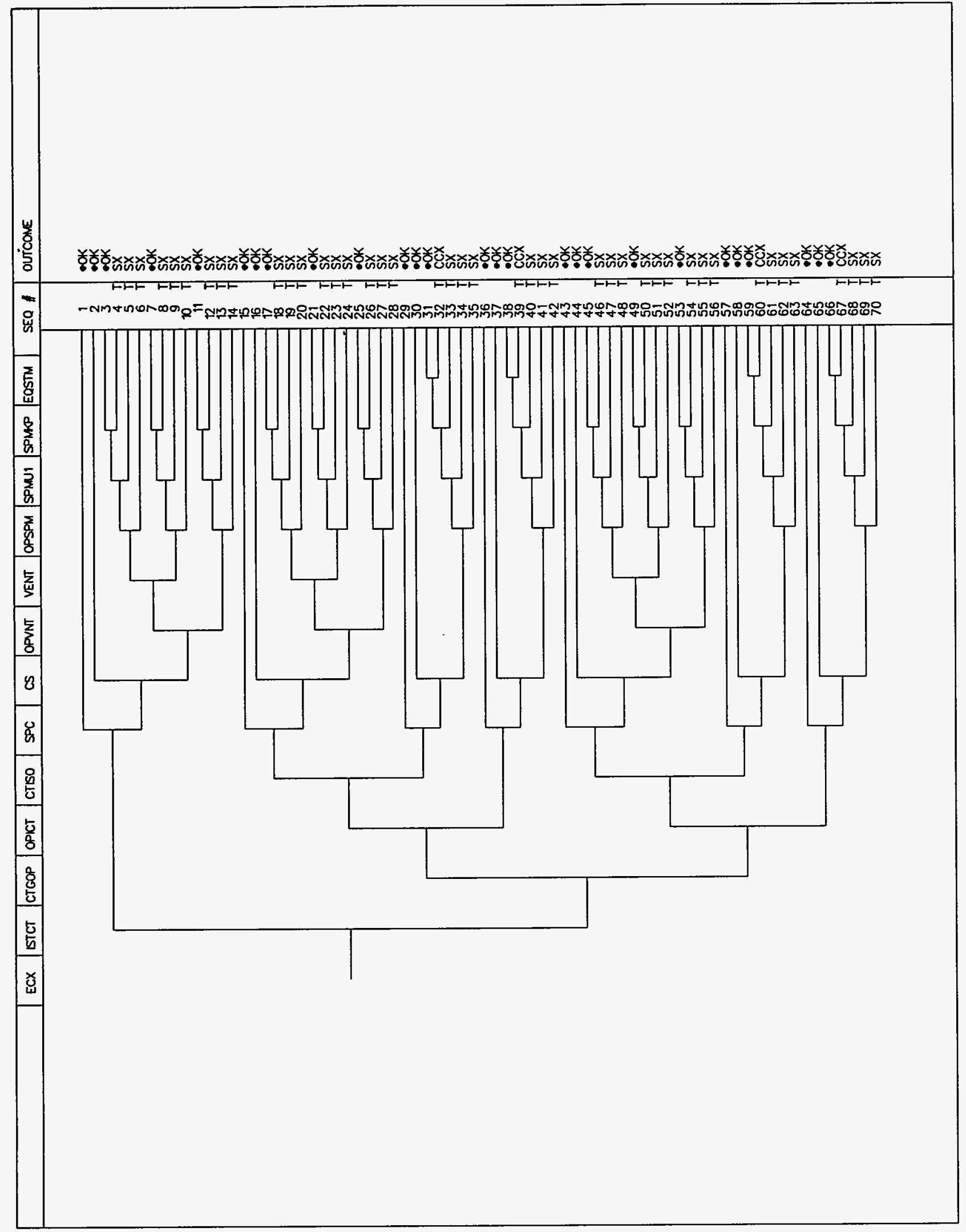

Figure H.1-48 ECX Tree

Vol. 2, Part 2 


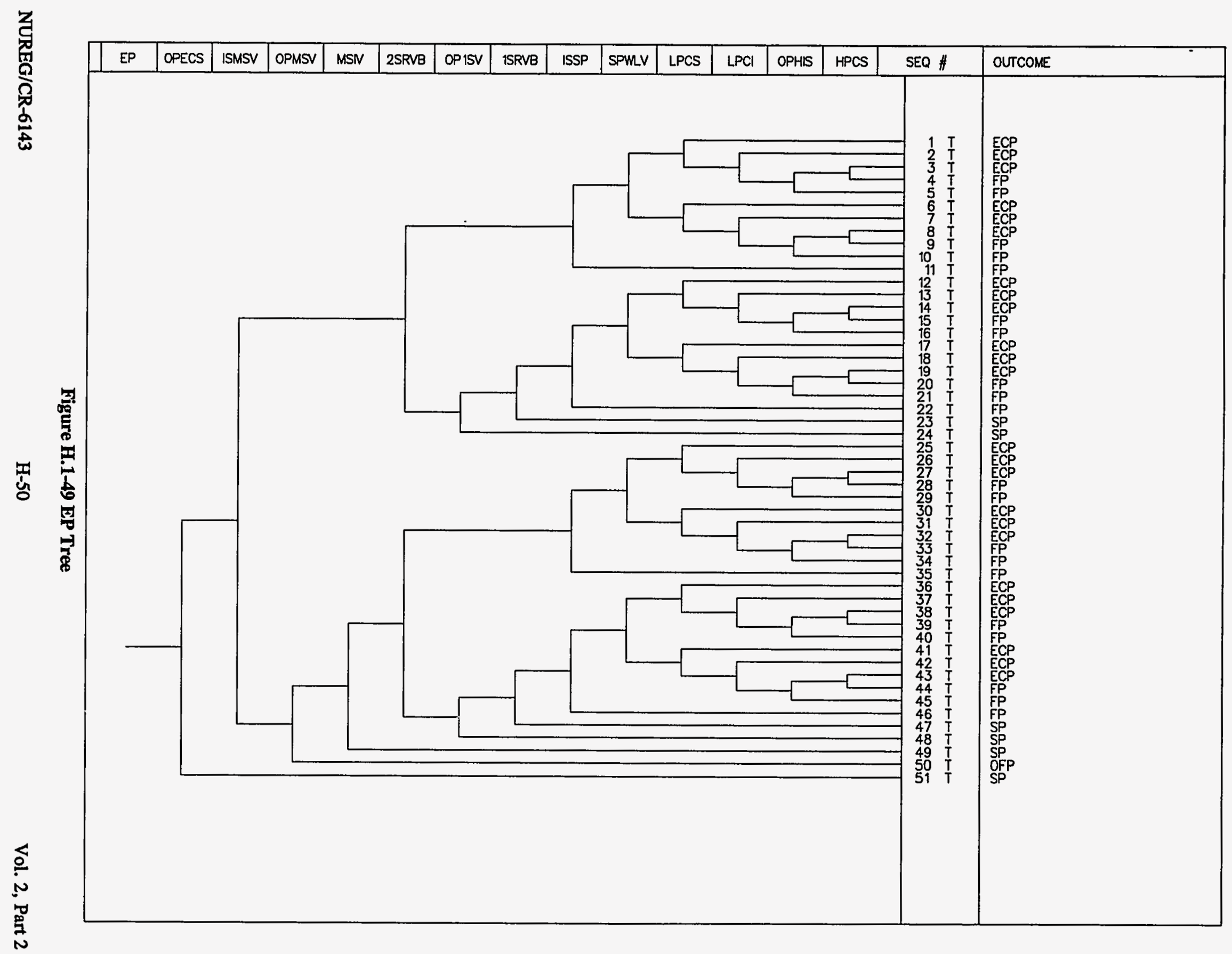




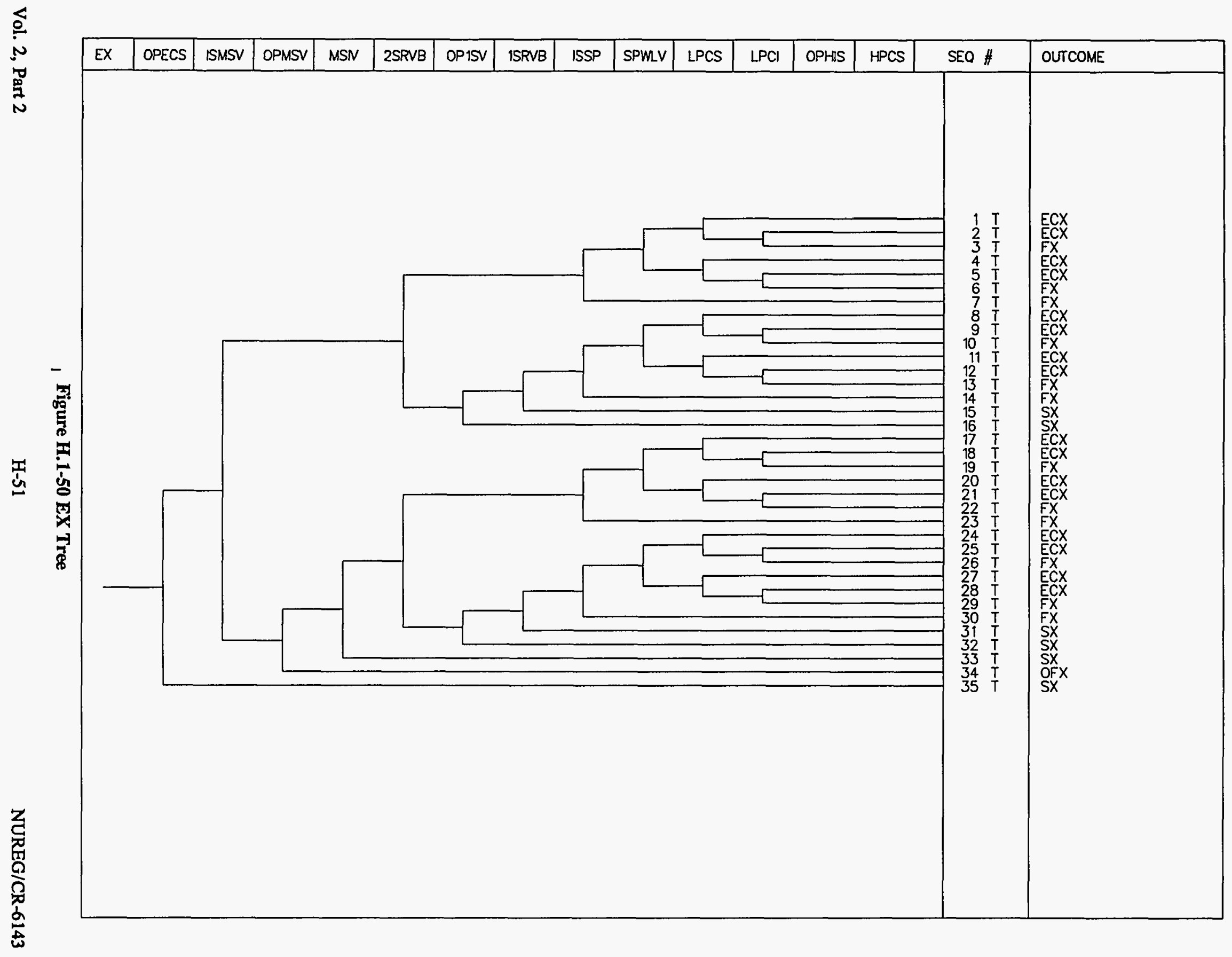




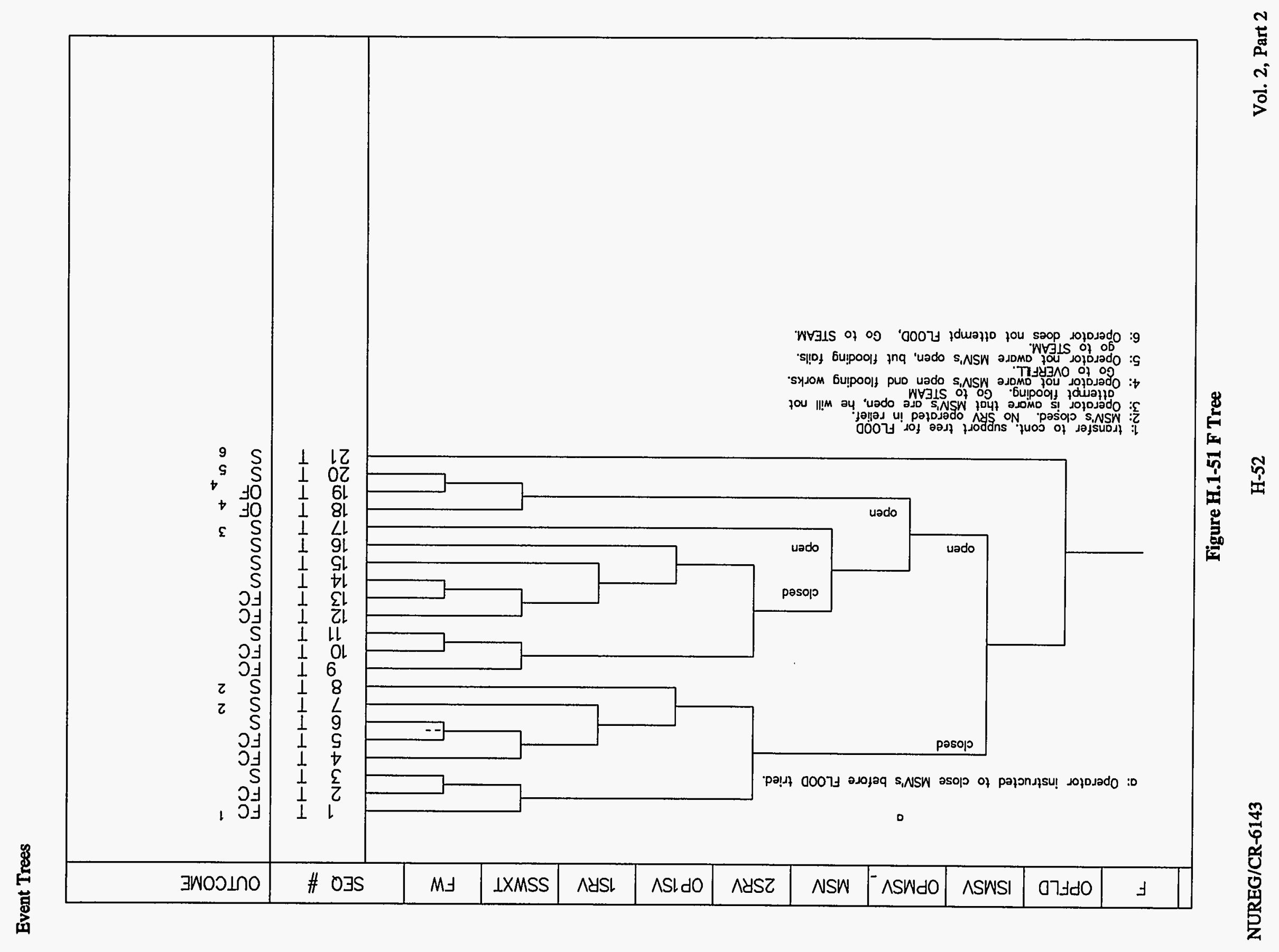




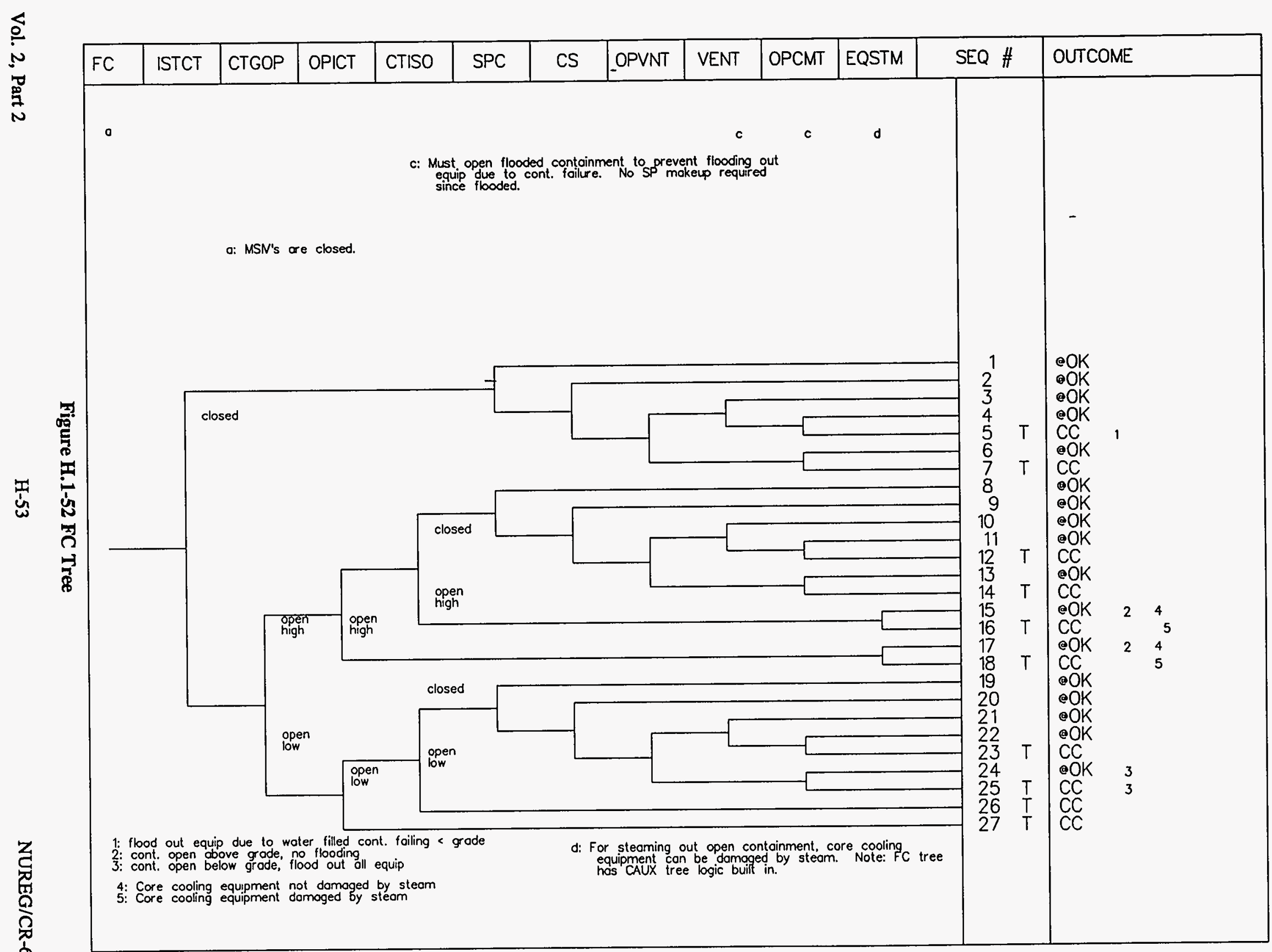




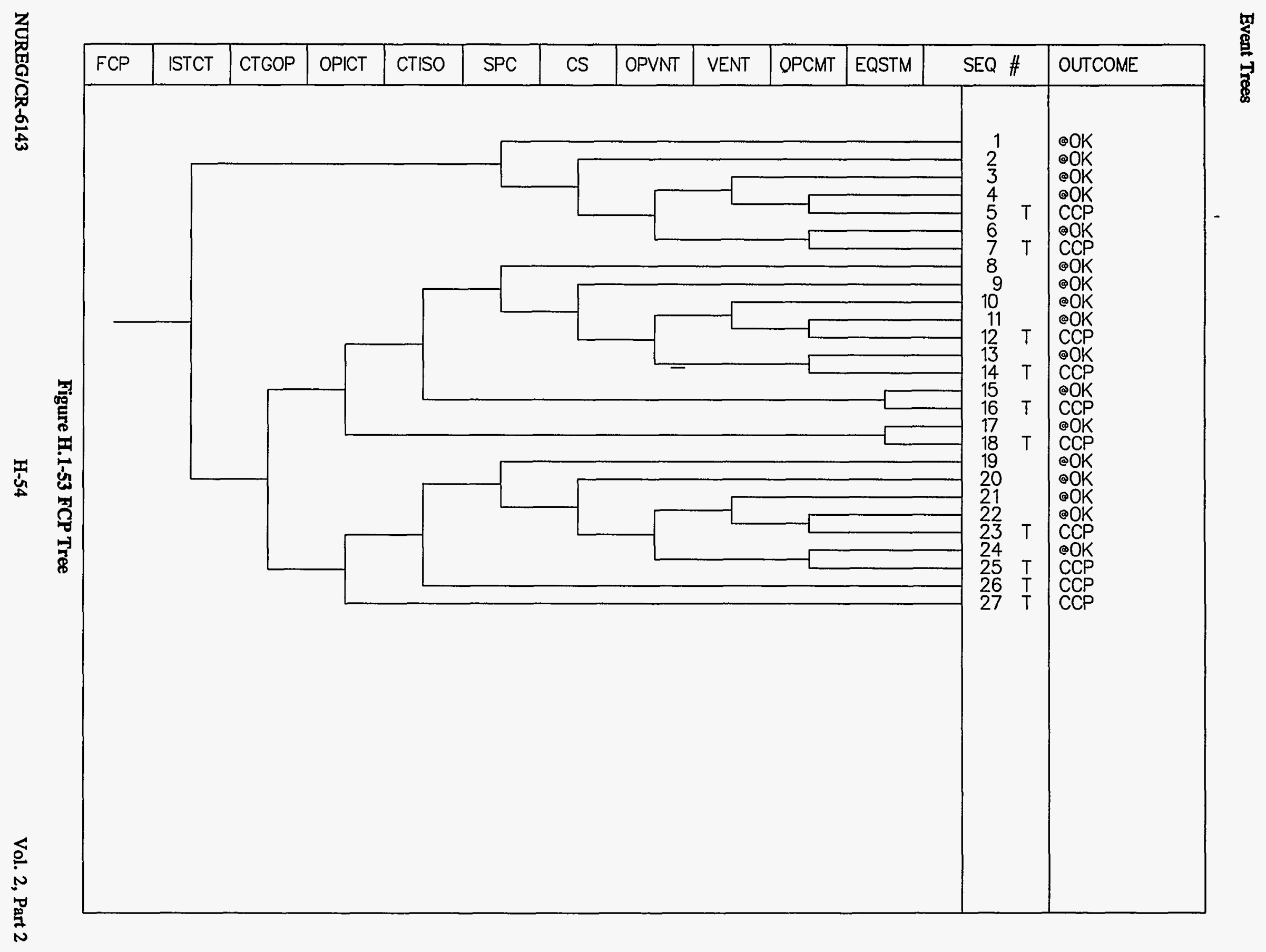


总

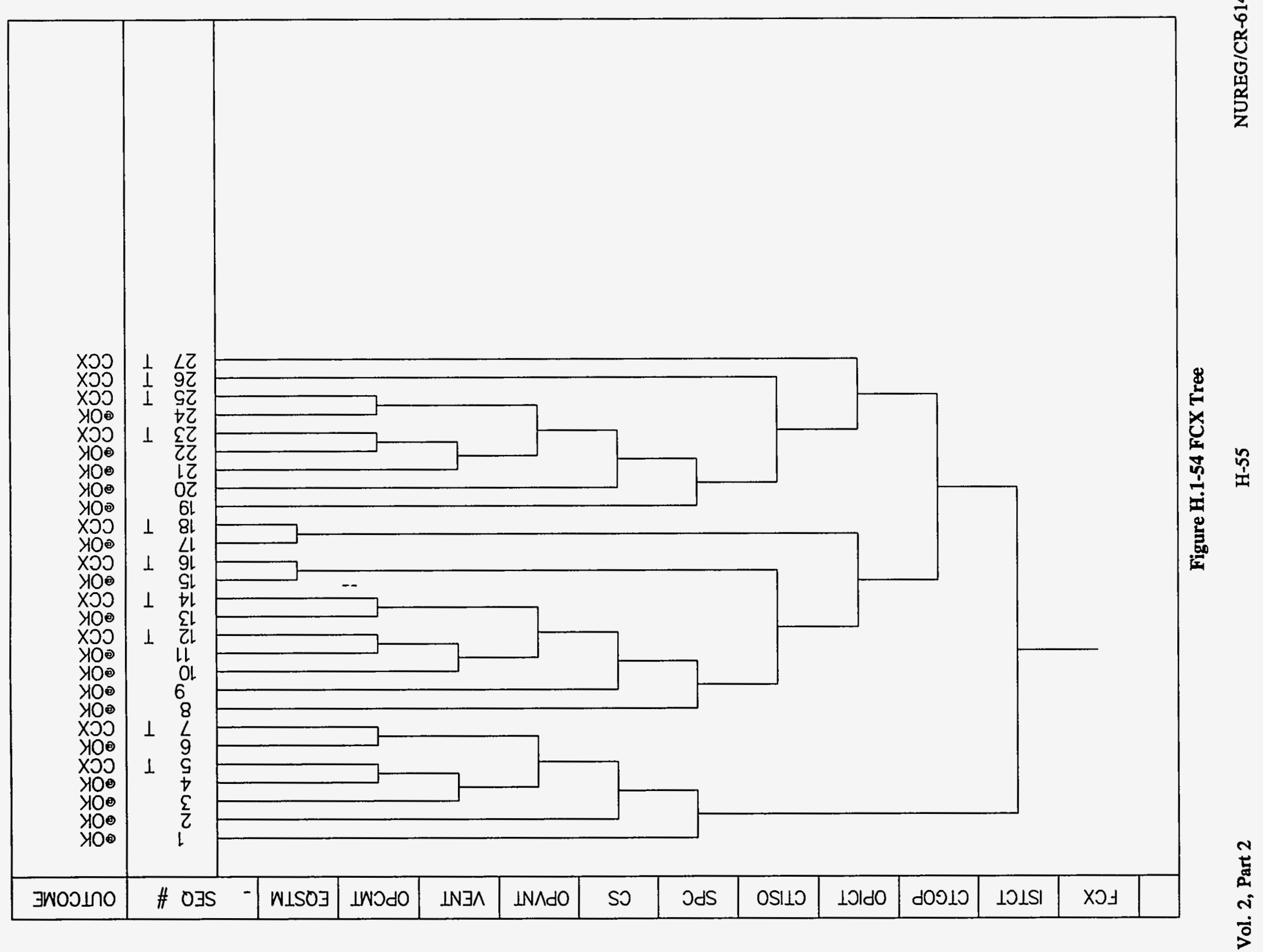




\section{Event Trees}

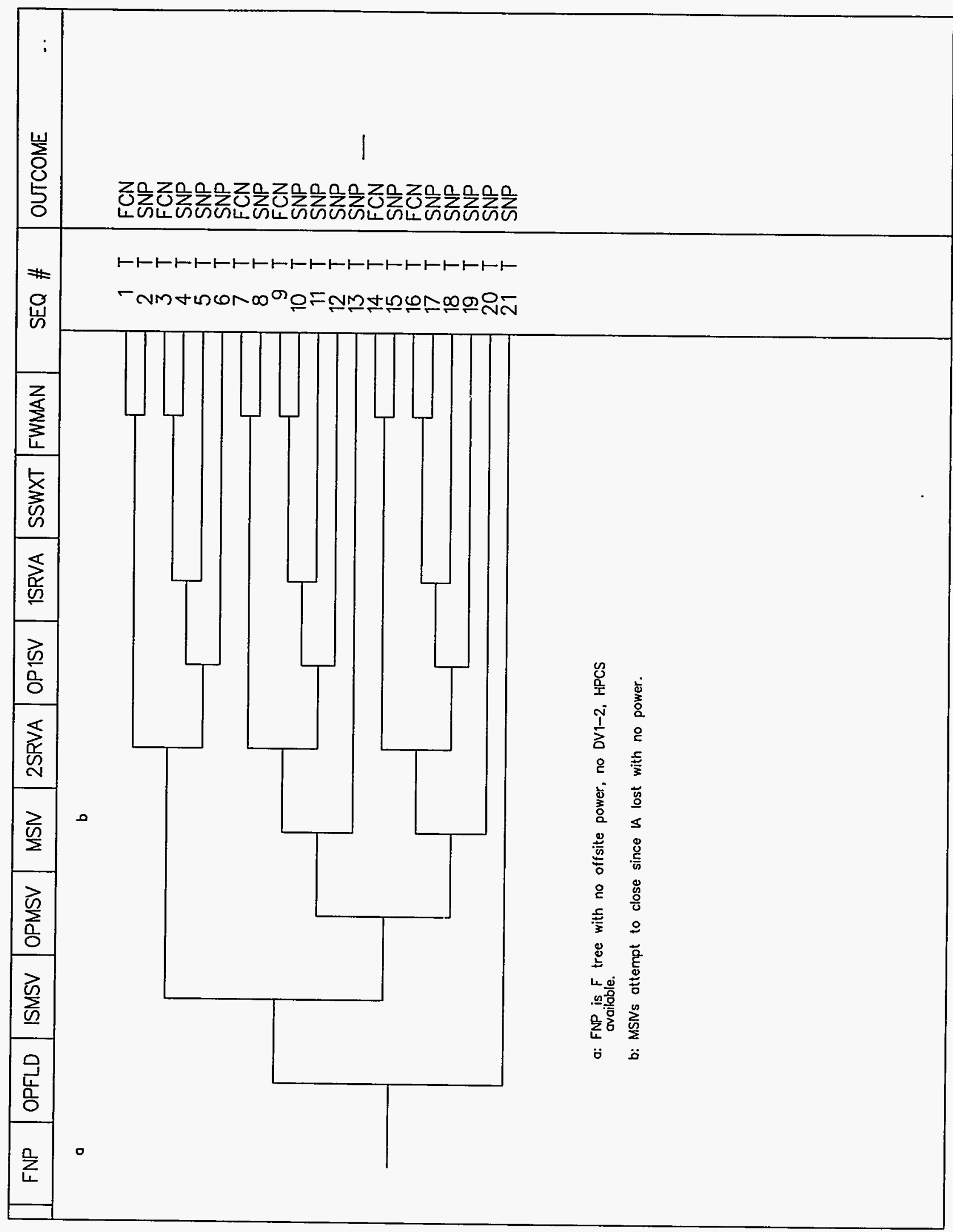

Figure H.1-55 FNP Tree 


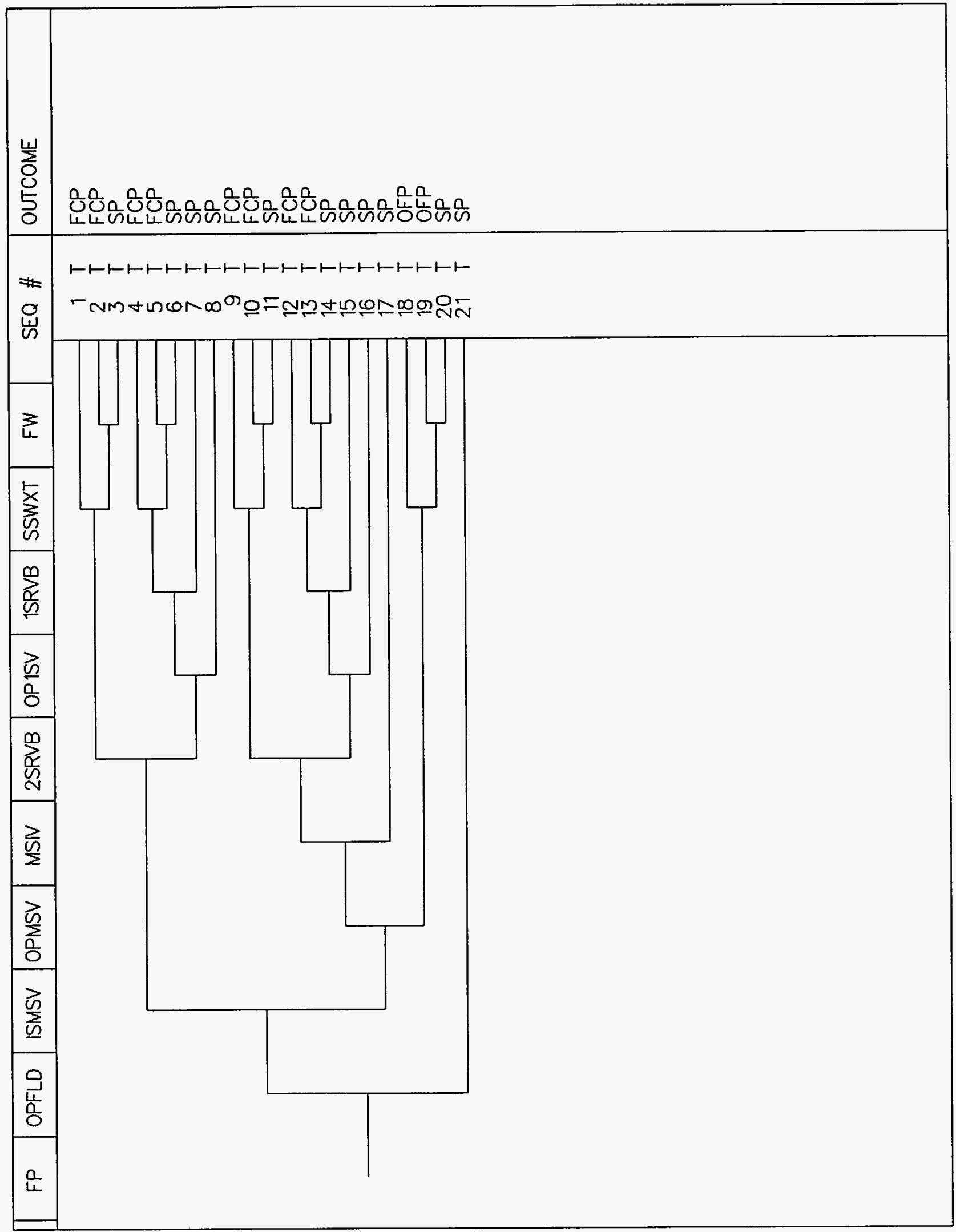

Figure H.1-56 FP Tree 


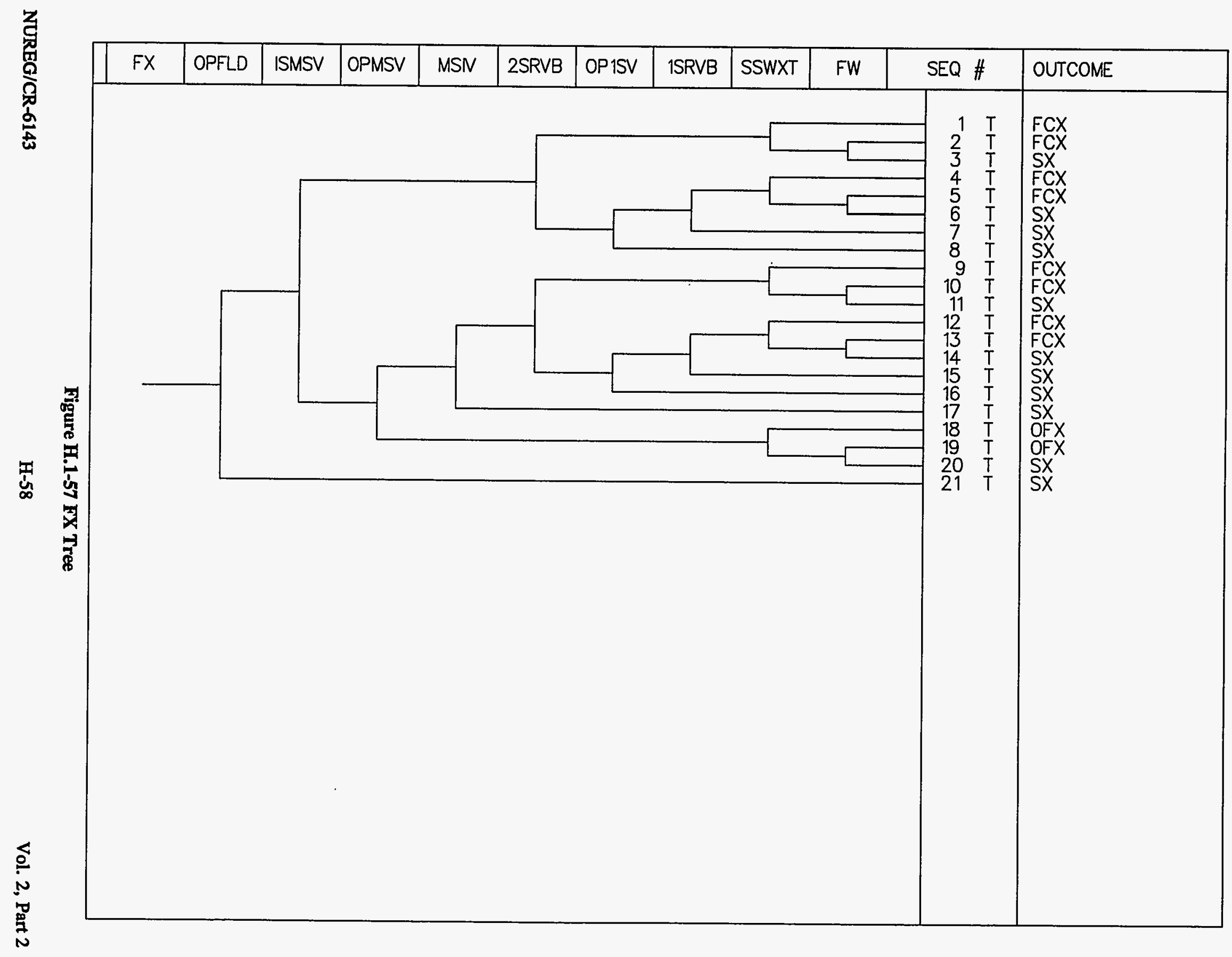




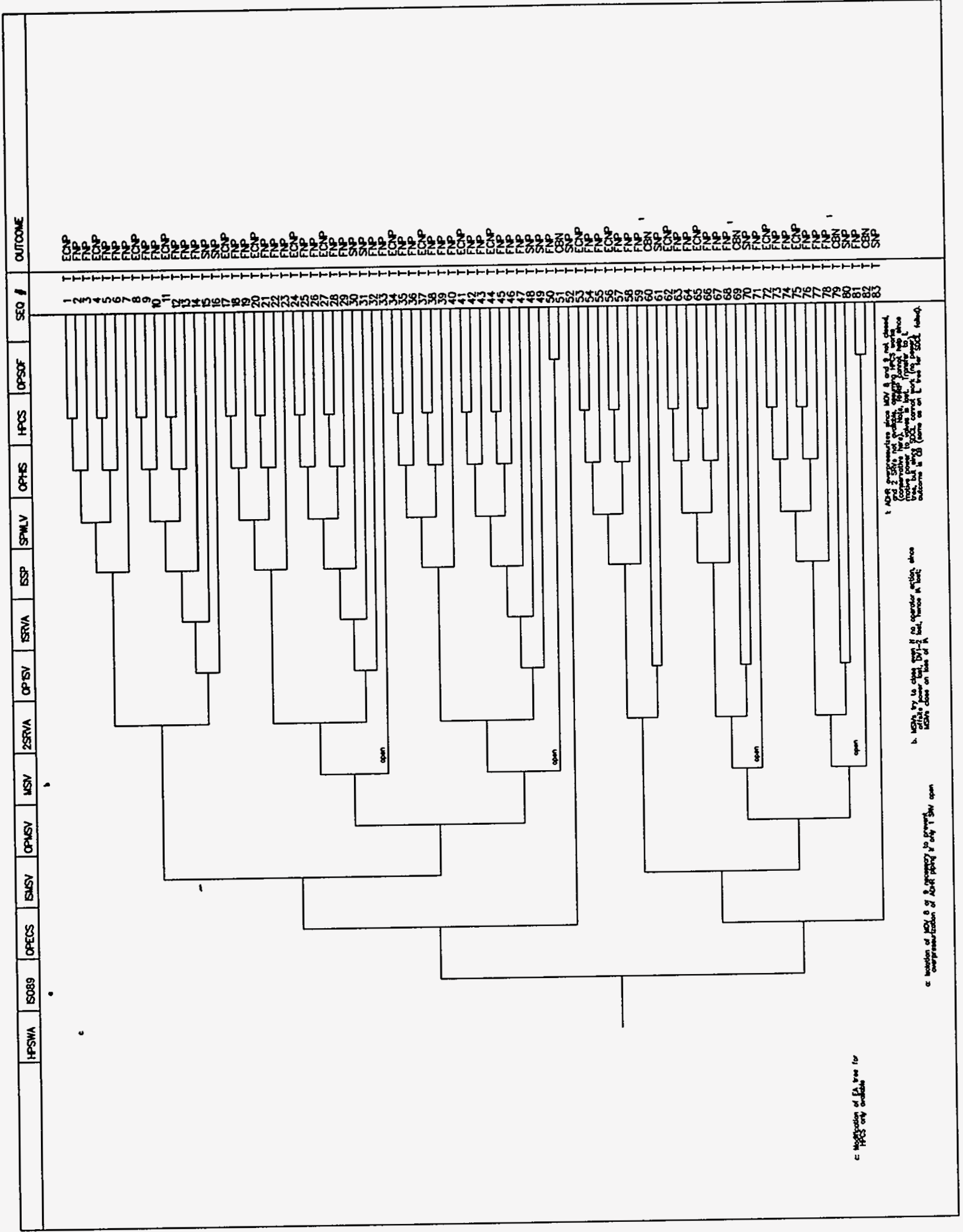

Figure H.1-58 HPSWA Tree 


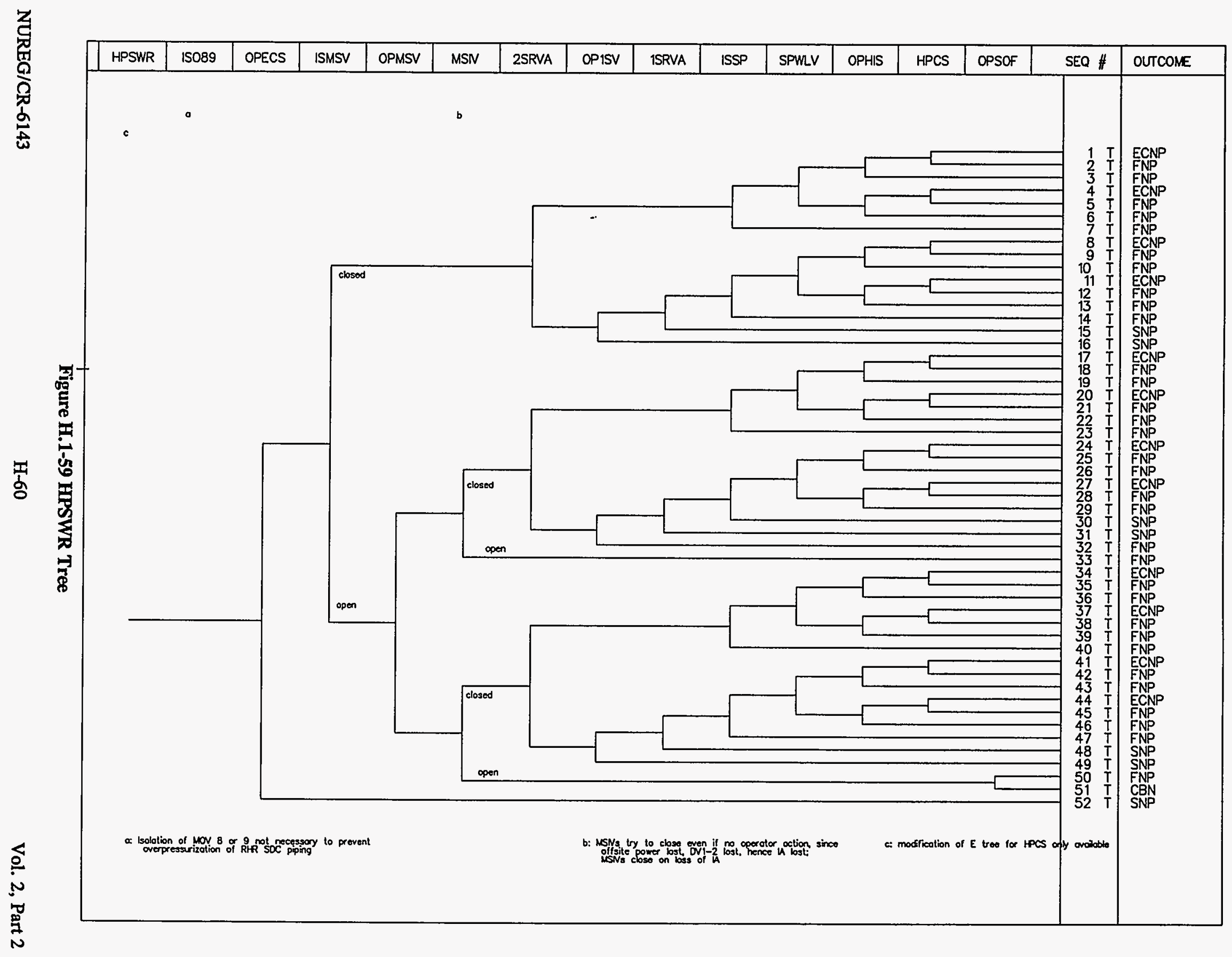




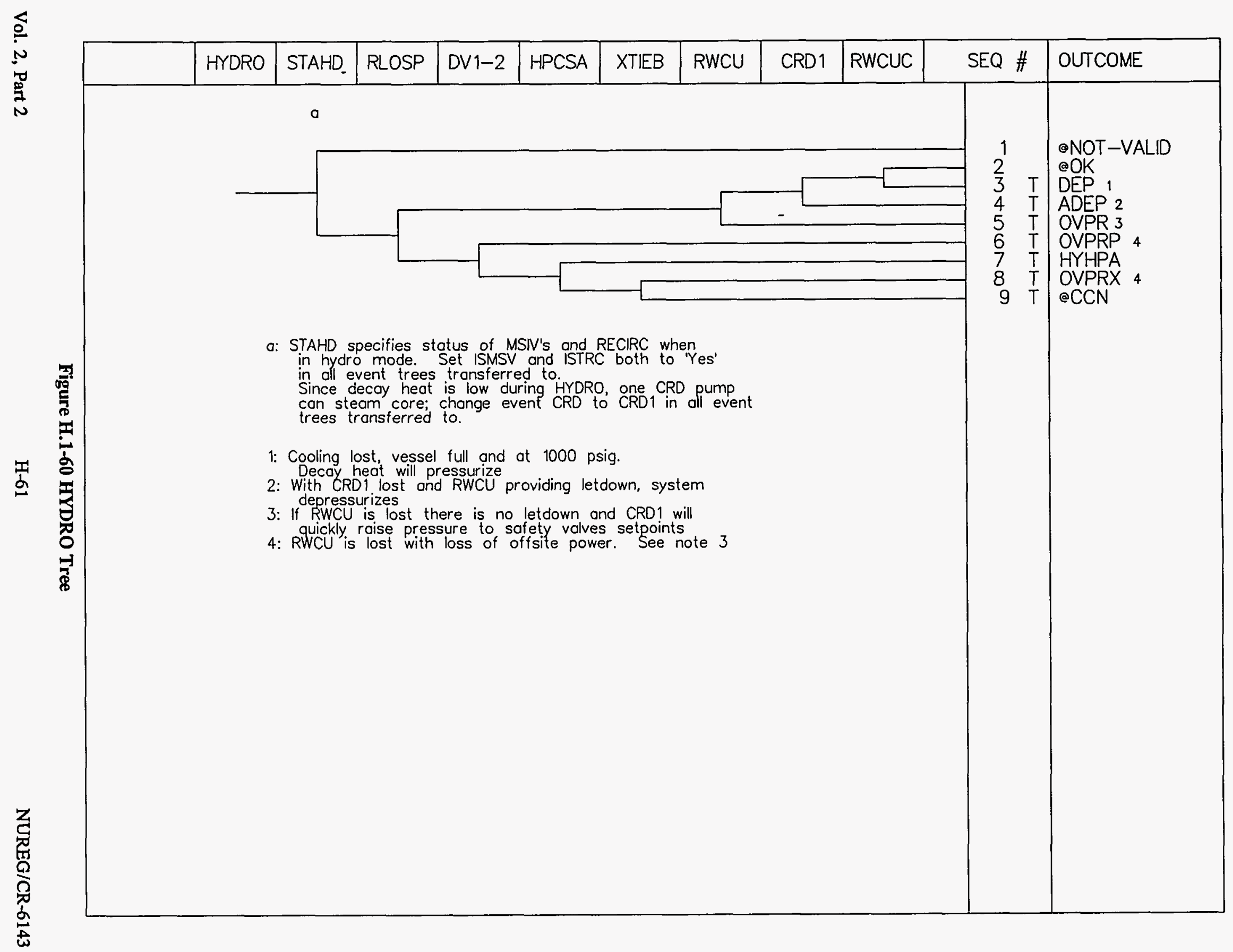




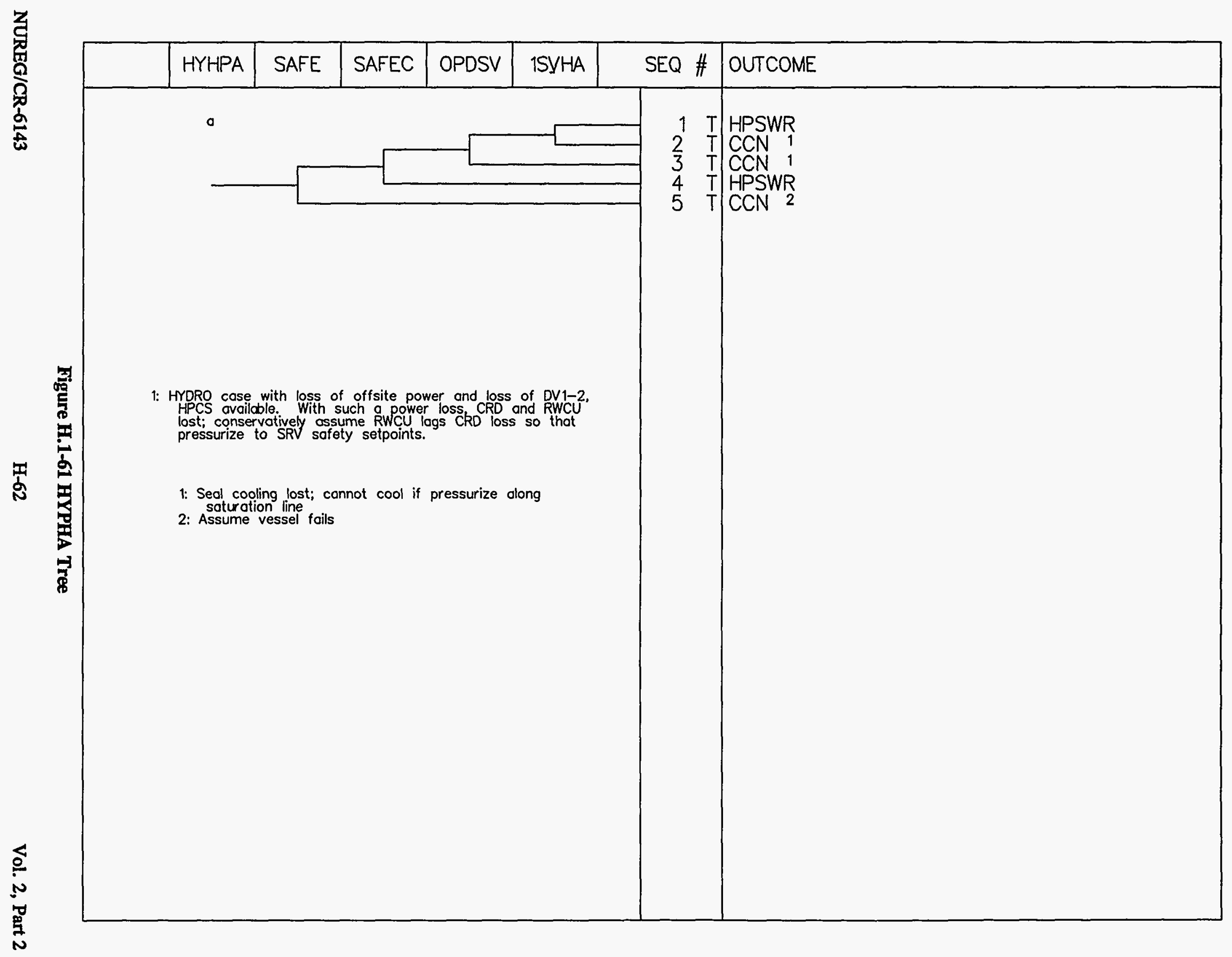




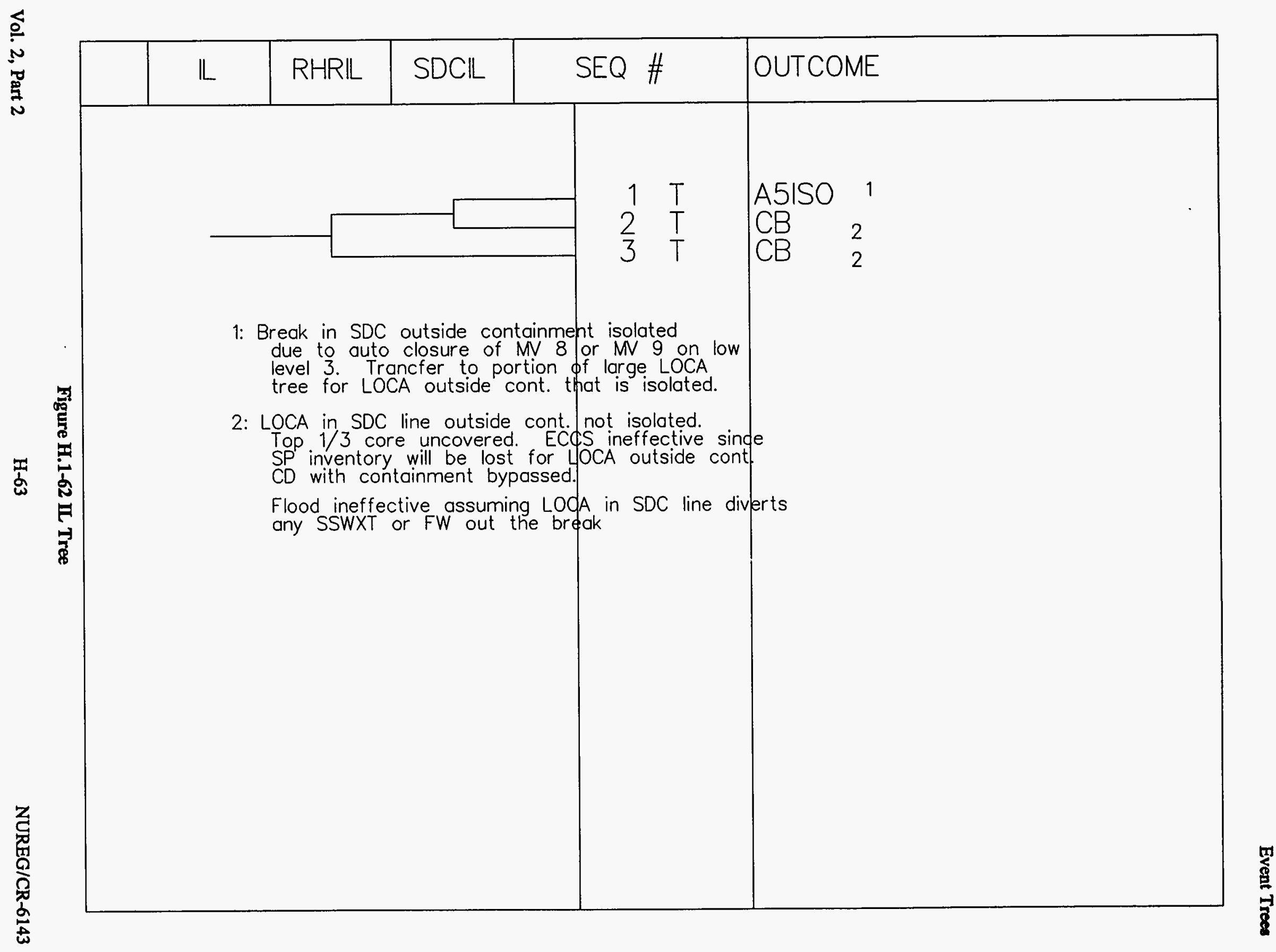


Event Trees

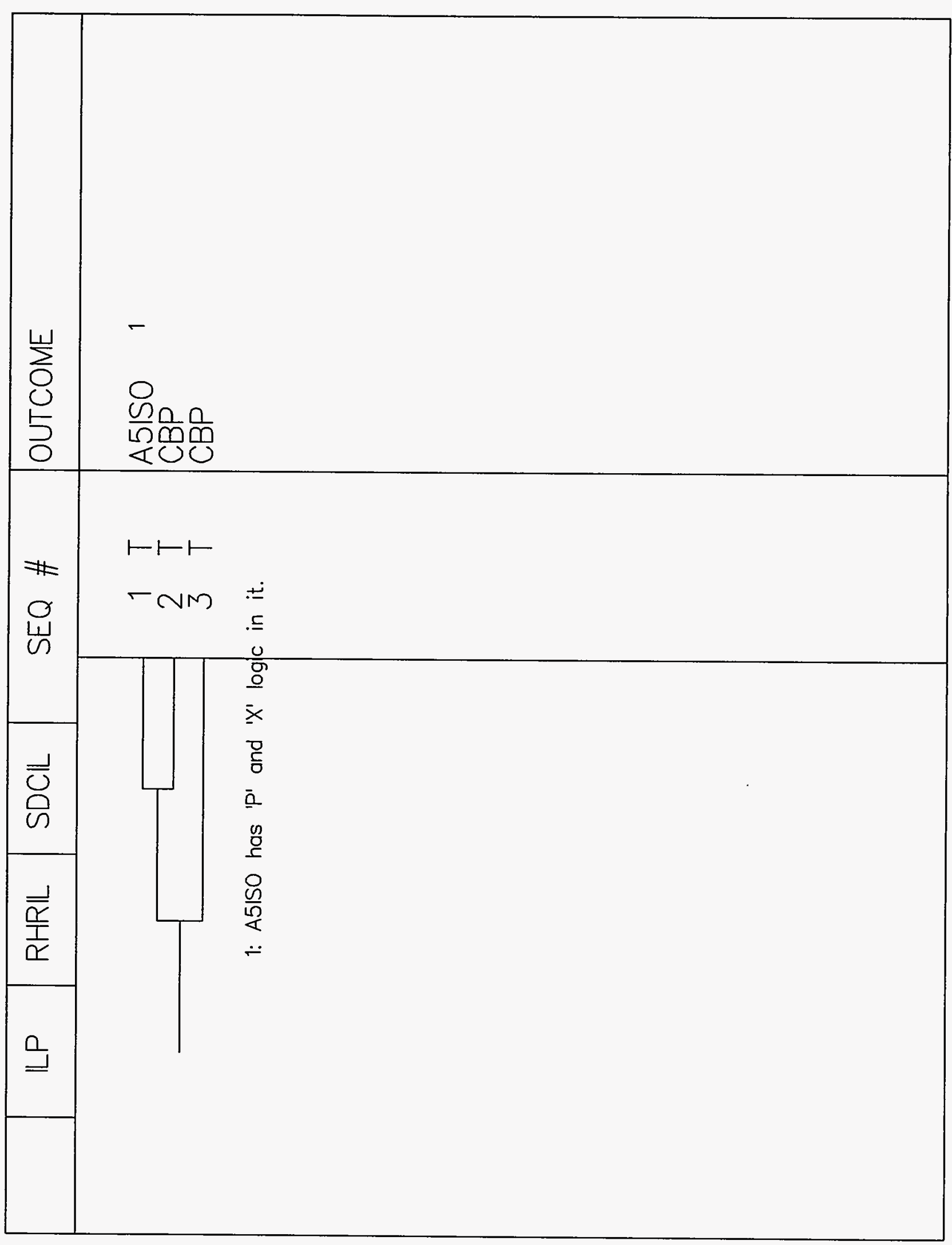

Figure H.1-63 ILP Tree 


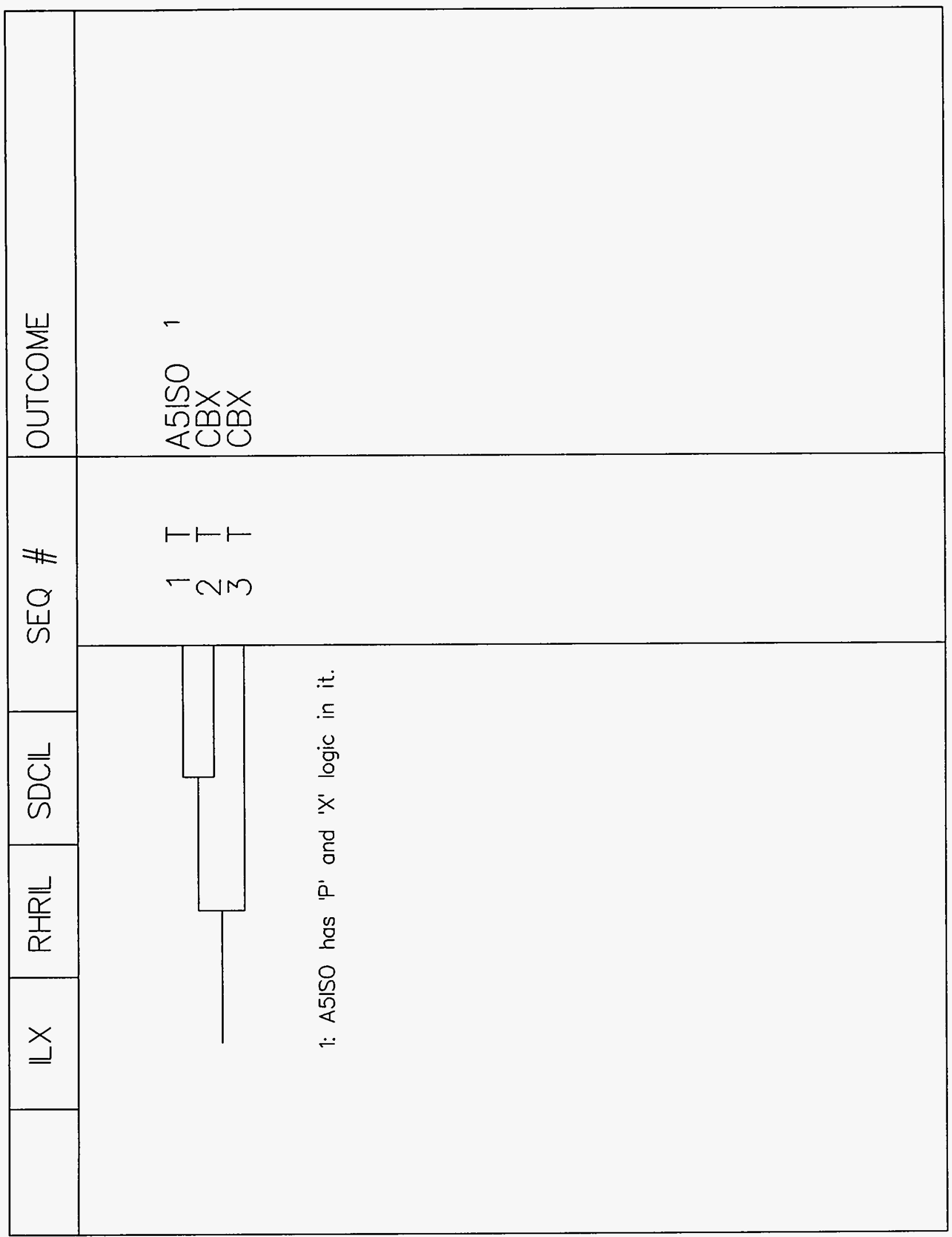

Figure H.1-64 ILX Tree

Vol. 2, Part 2

H-65

NUREG/CR-6143 


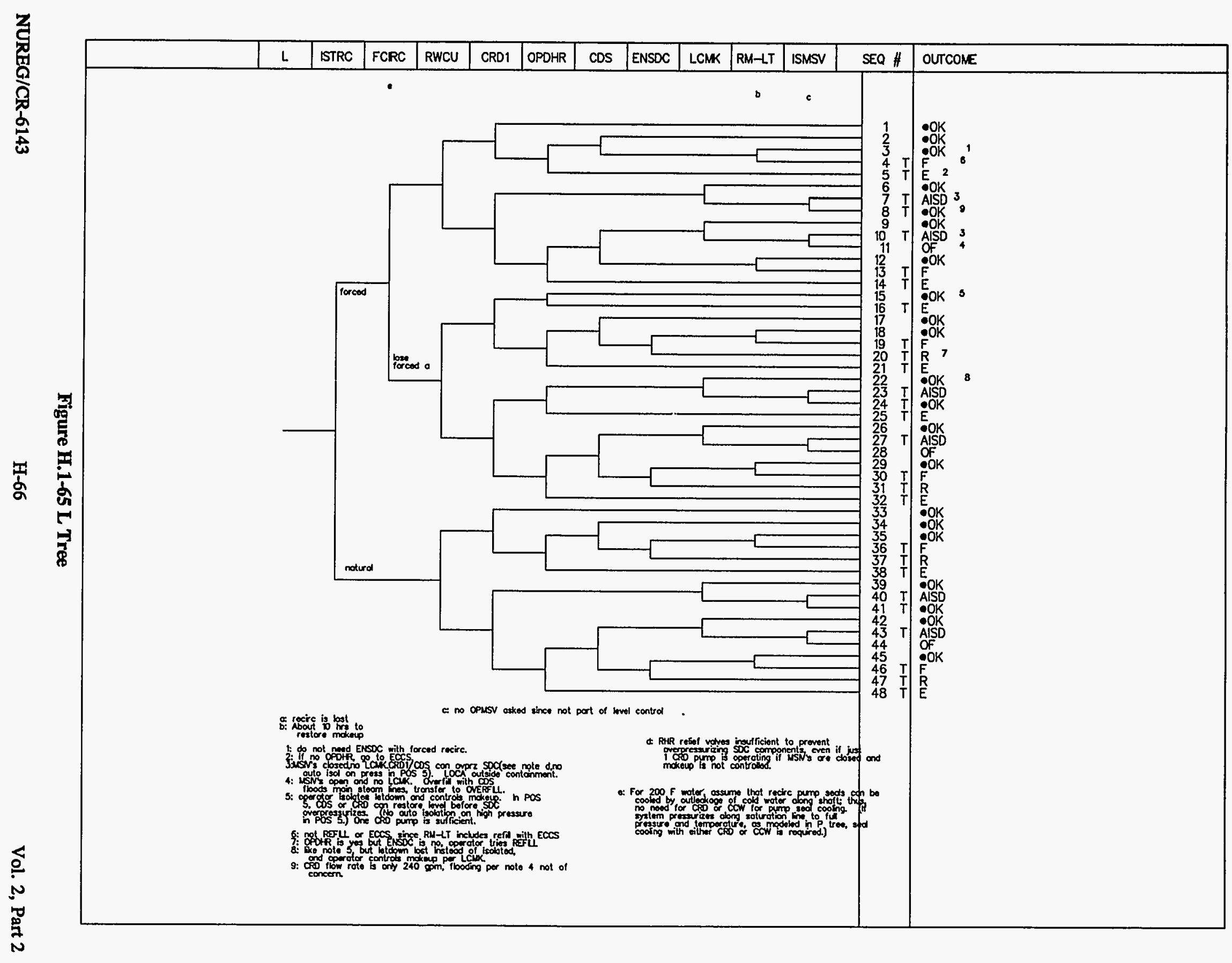




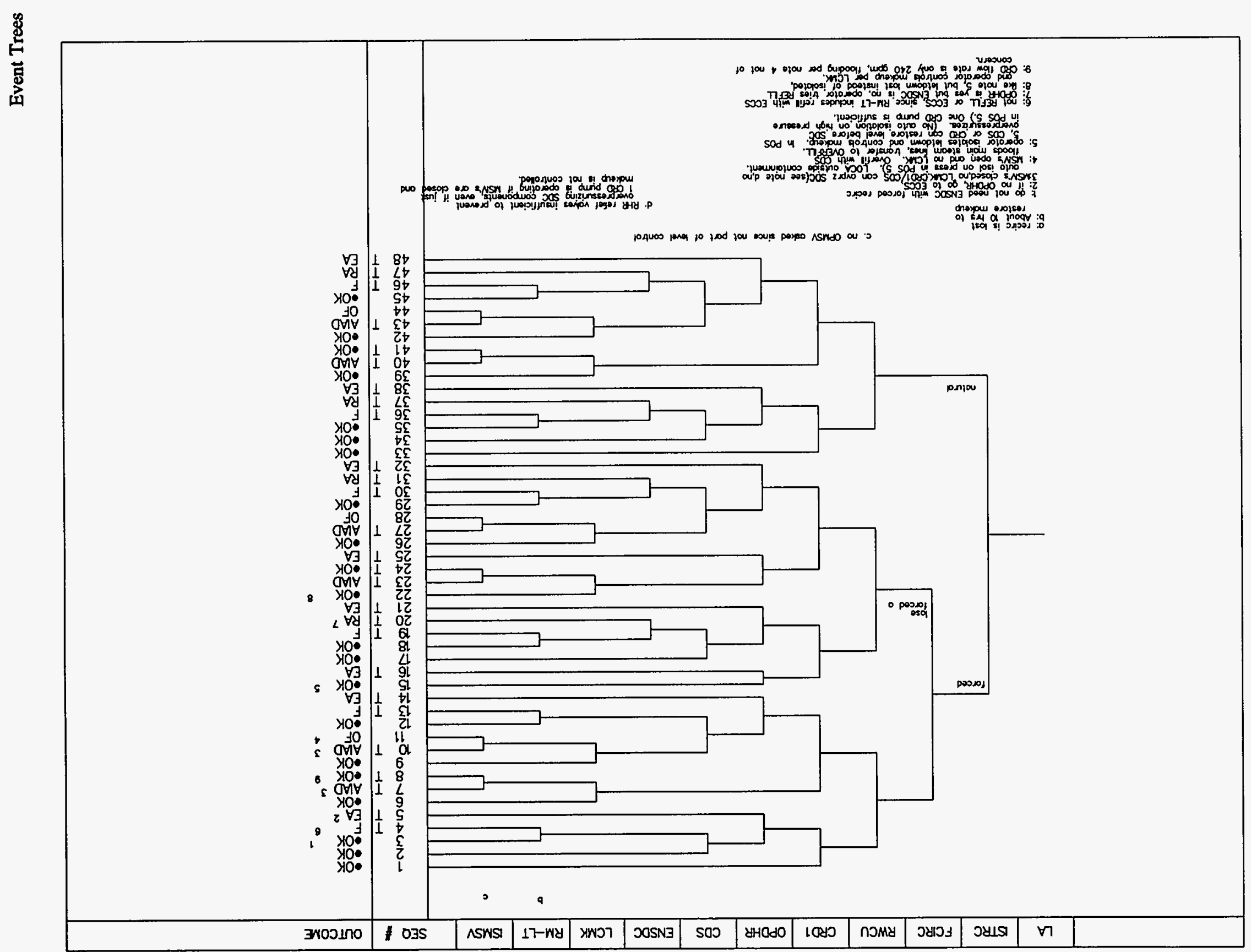




\section{Event Trees}

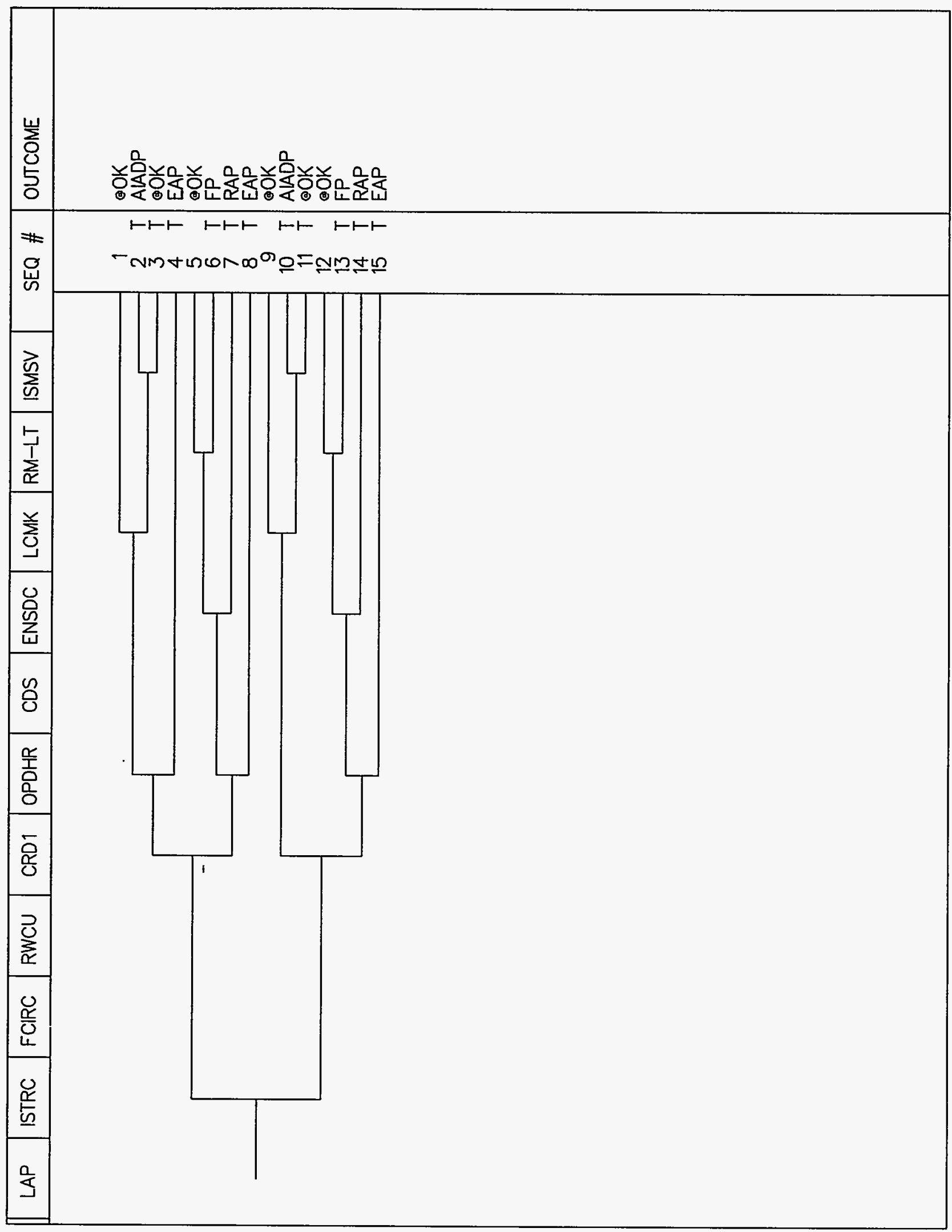

Figure H.1-67 LAP Tree 


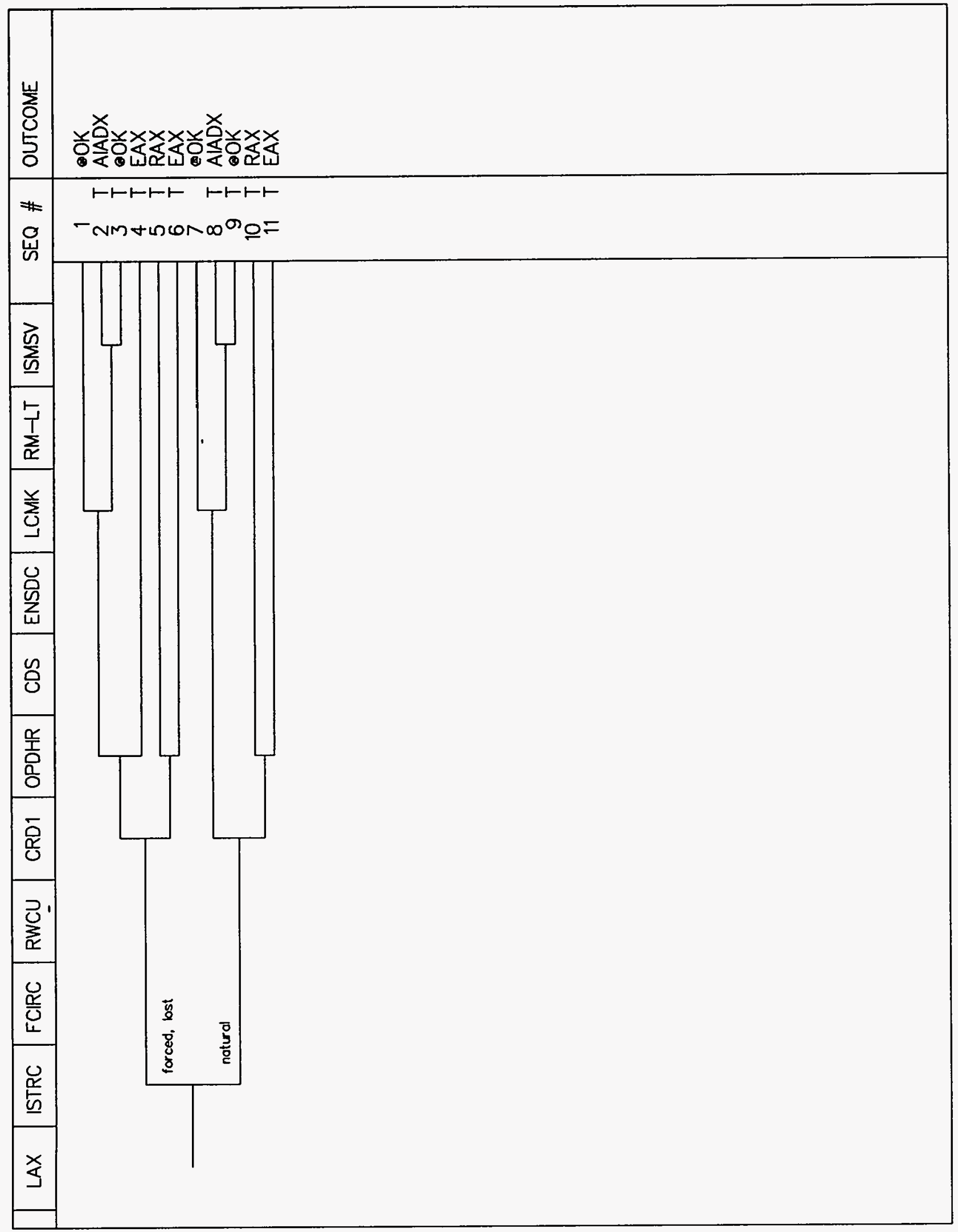

Figure H.1-68 LAX Tree

Vol. 2, Part 2

H-69

NUREG/CR-6143 
Event Trees

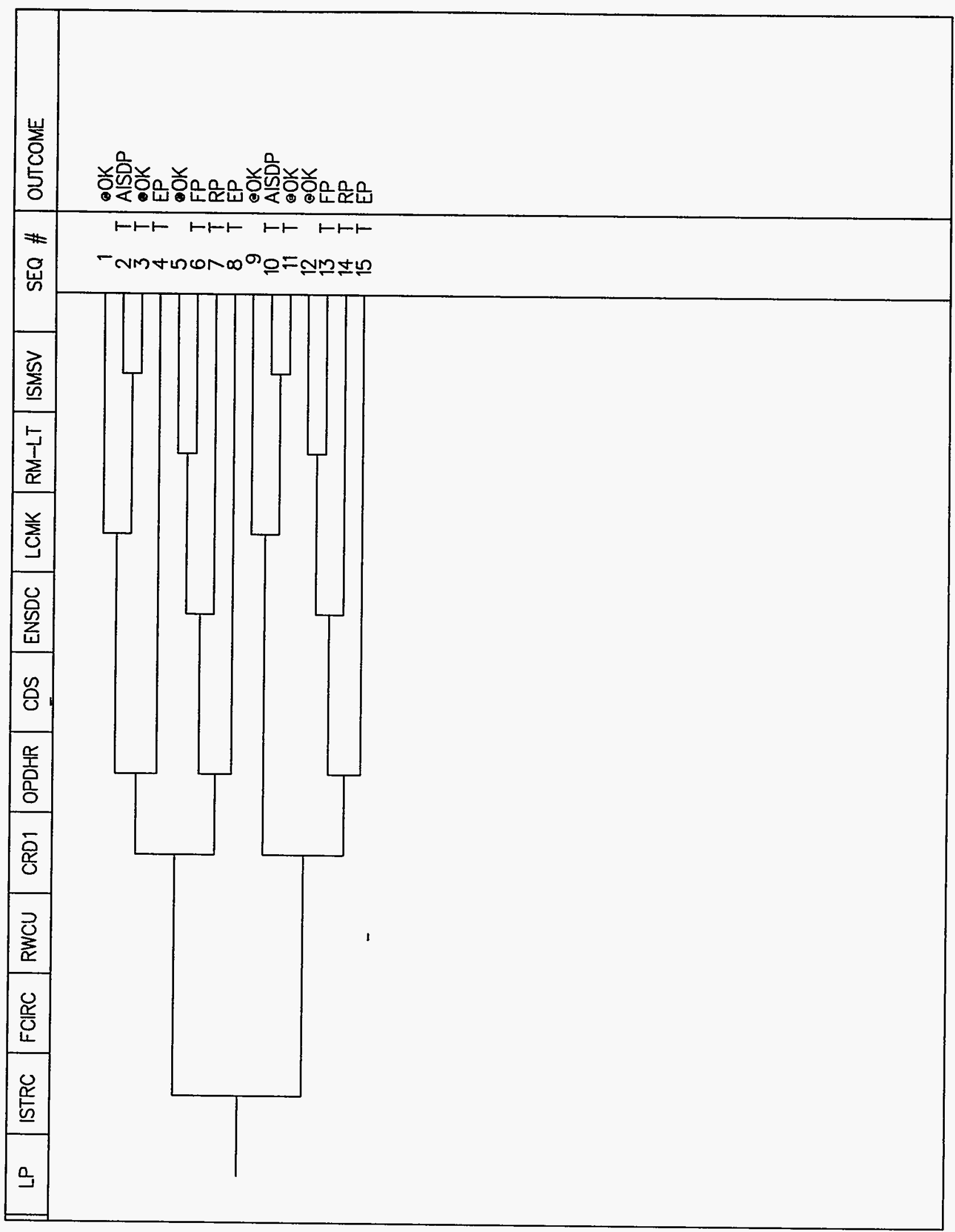

Figure H.1-69 LP Tree 


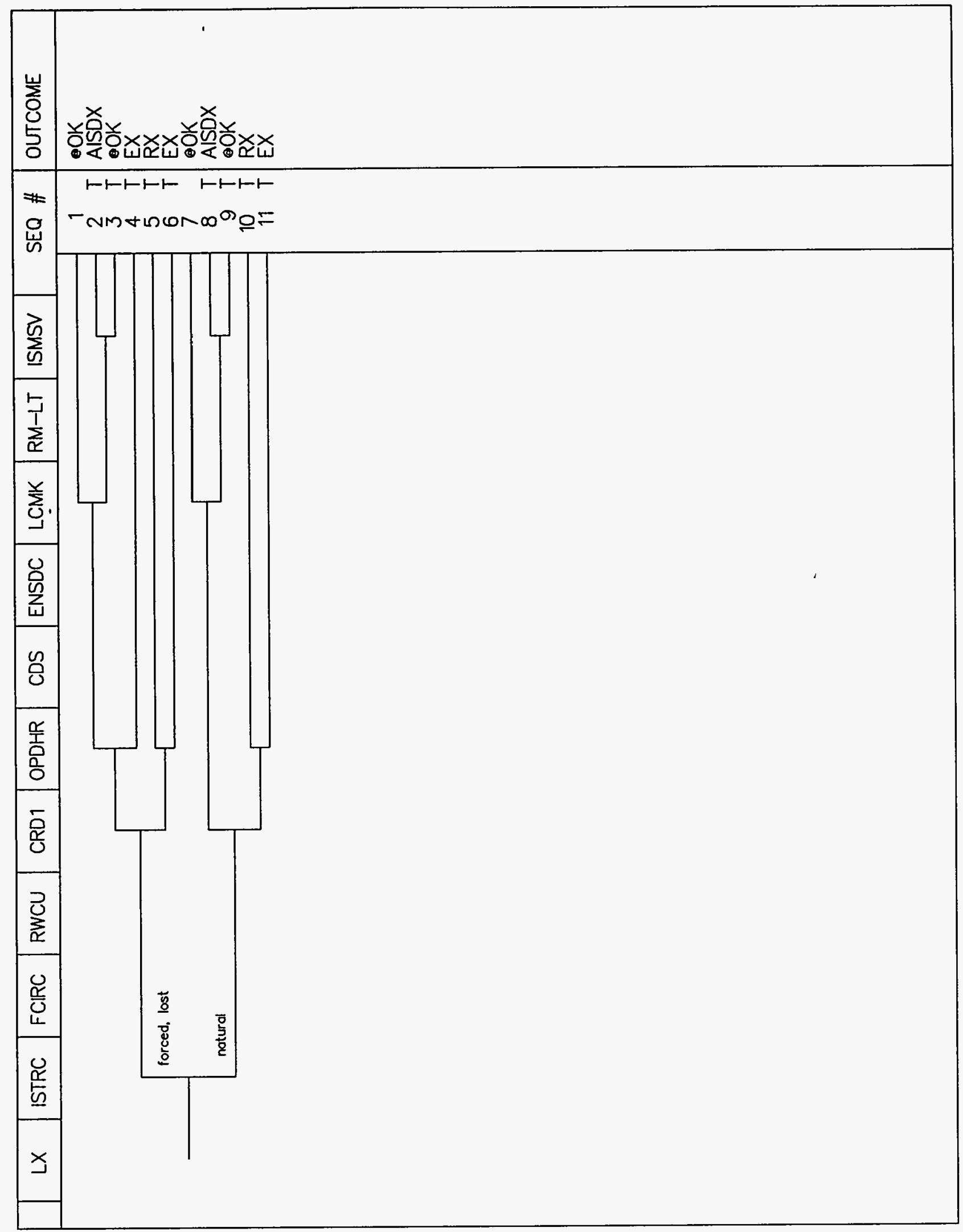

Figure H.1-70 LX Tree 


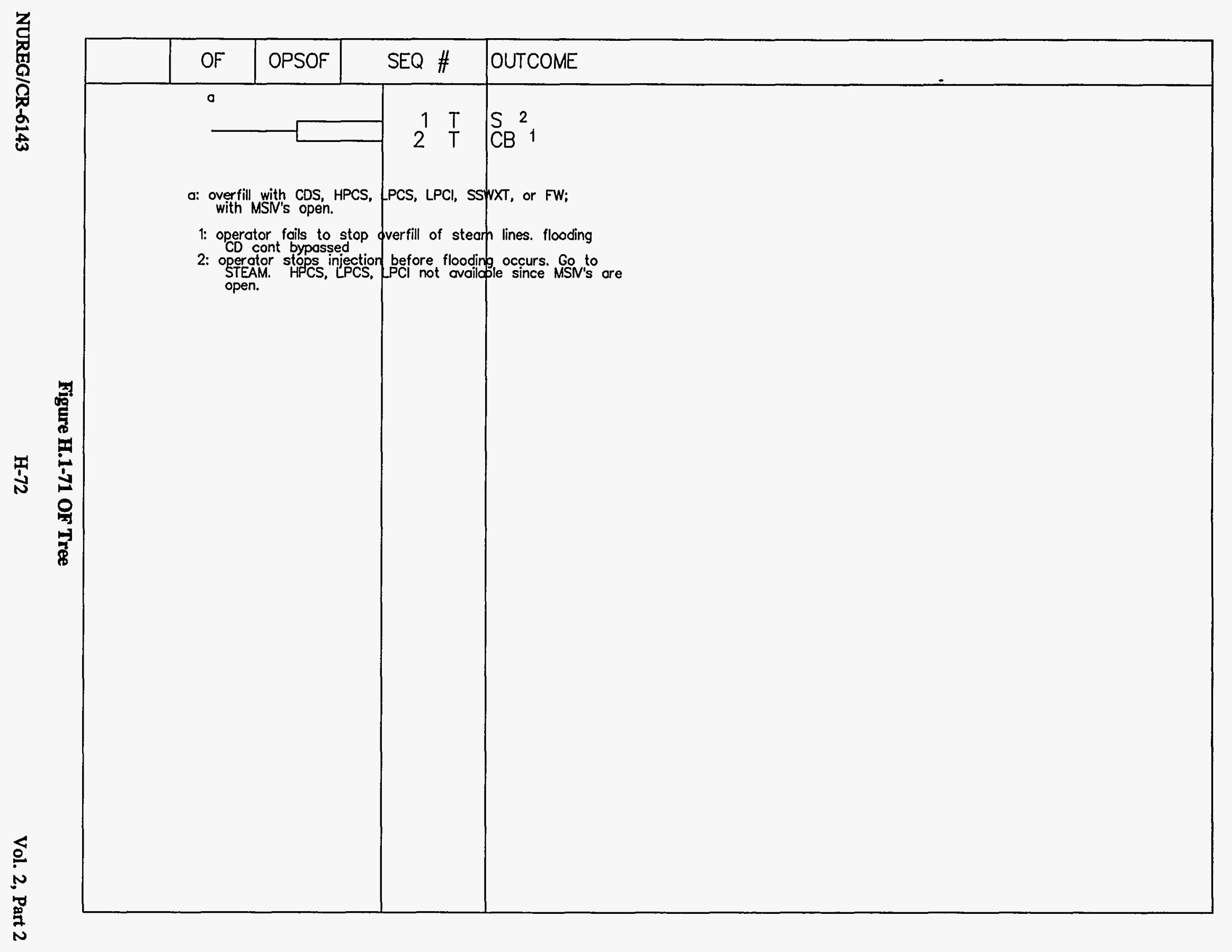




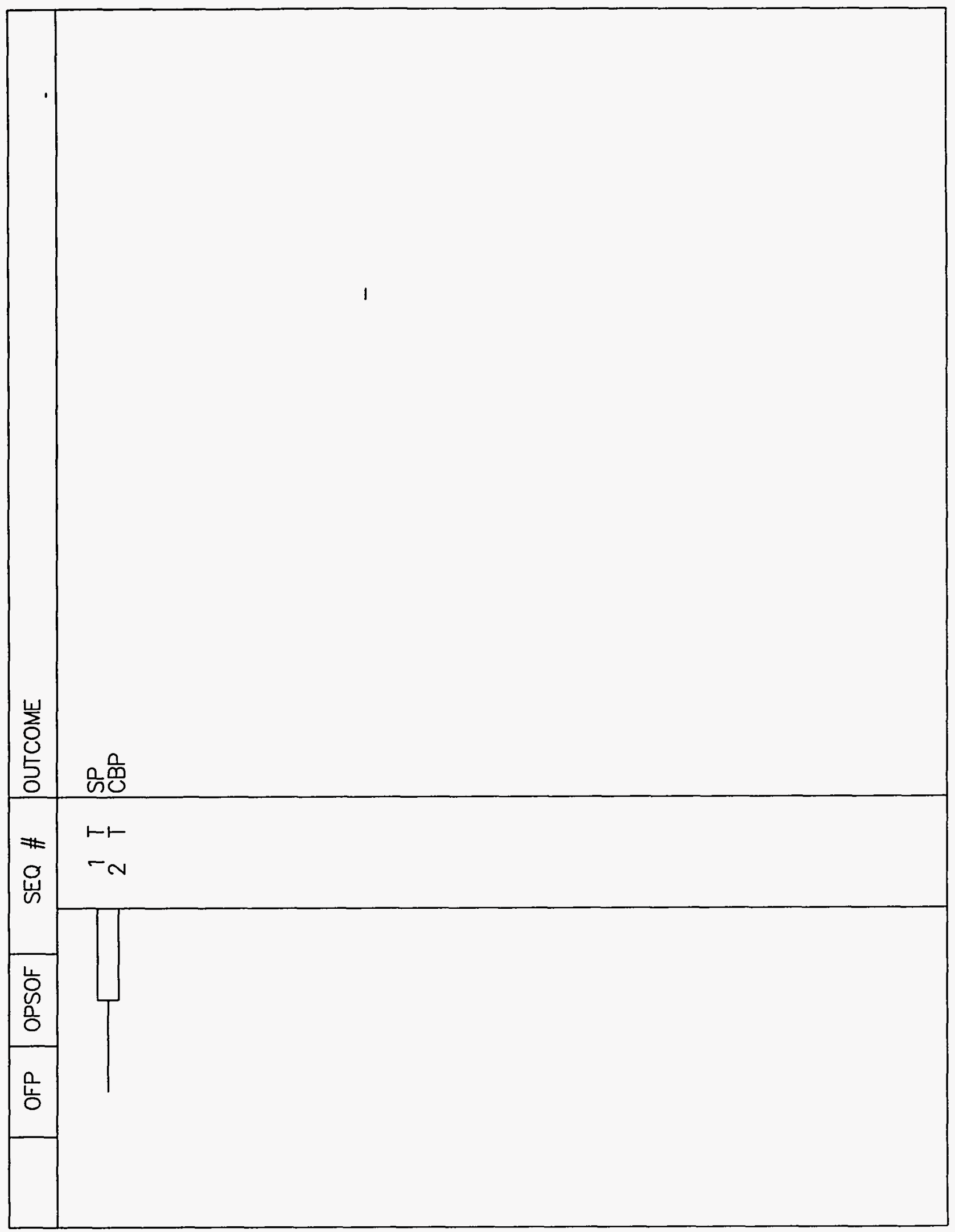

Figure H.1-72 OFP Tree

Vol. 2, Part 2

H-73

NUREG/CR-6143 


\section{Event Trees}

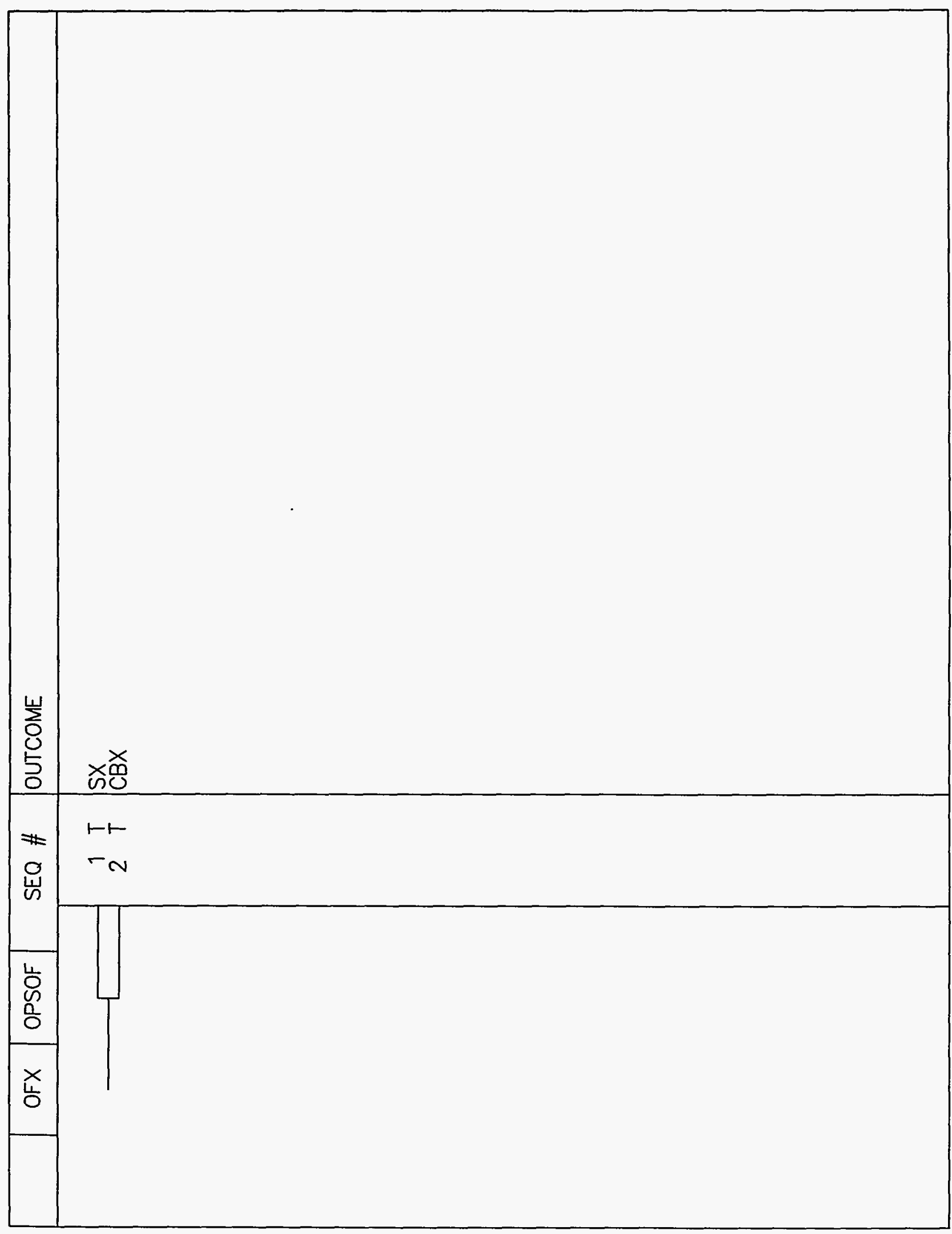

Figure H.1-73 OFX Tree 


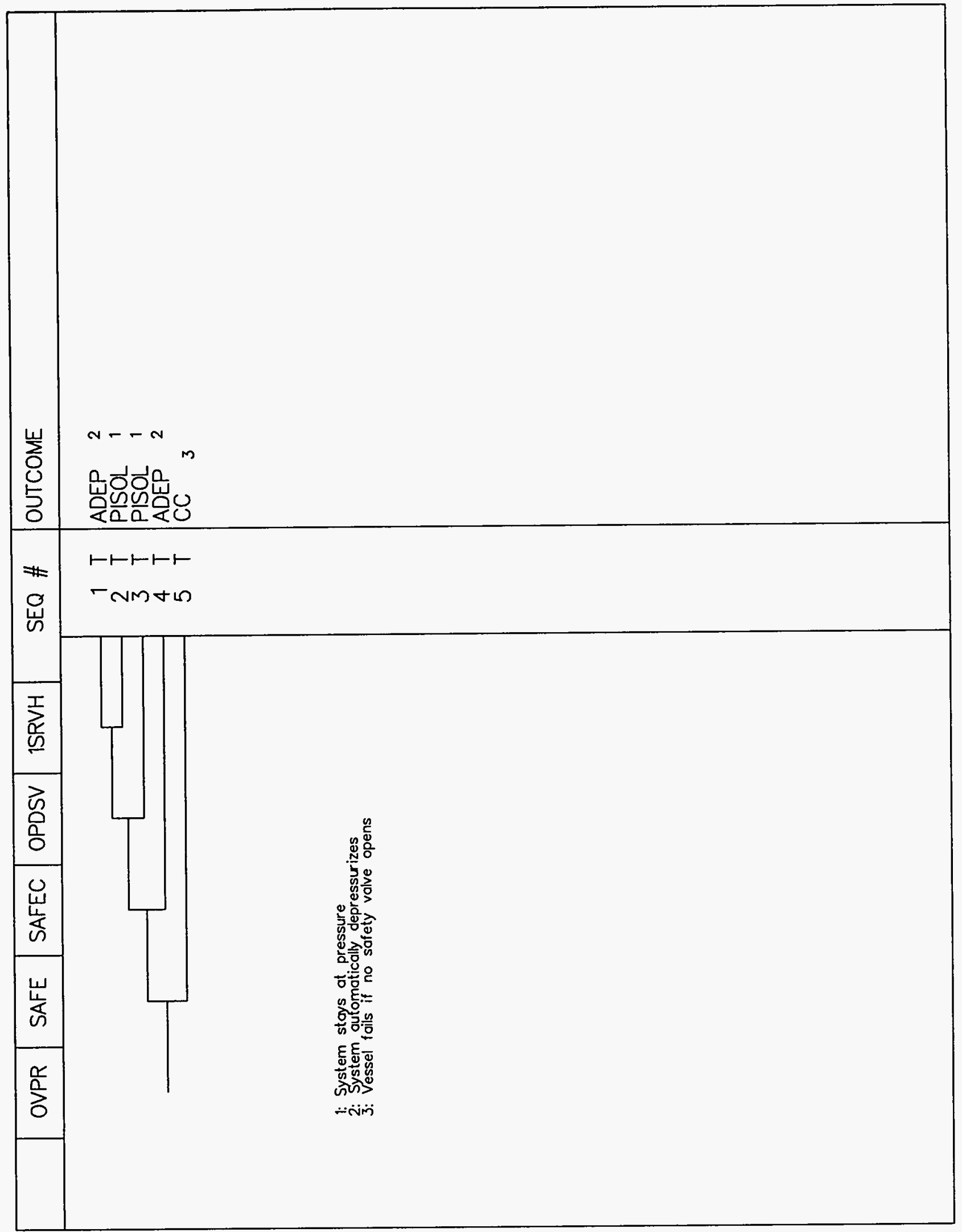

Figure H.1-74 OVPR Tree 


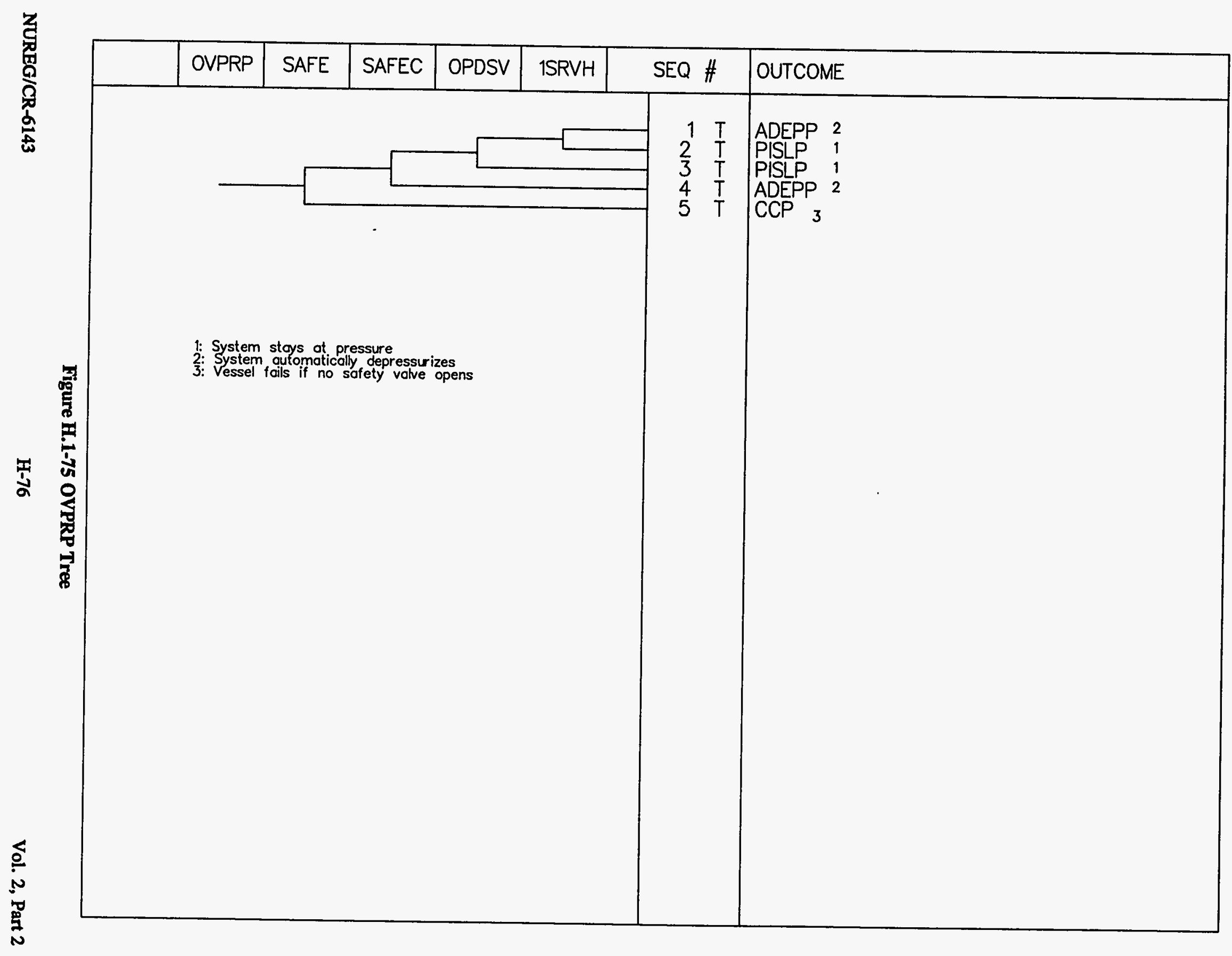




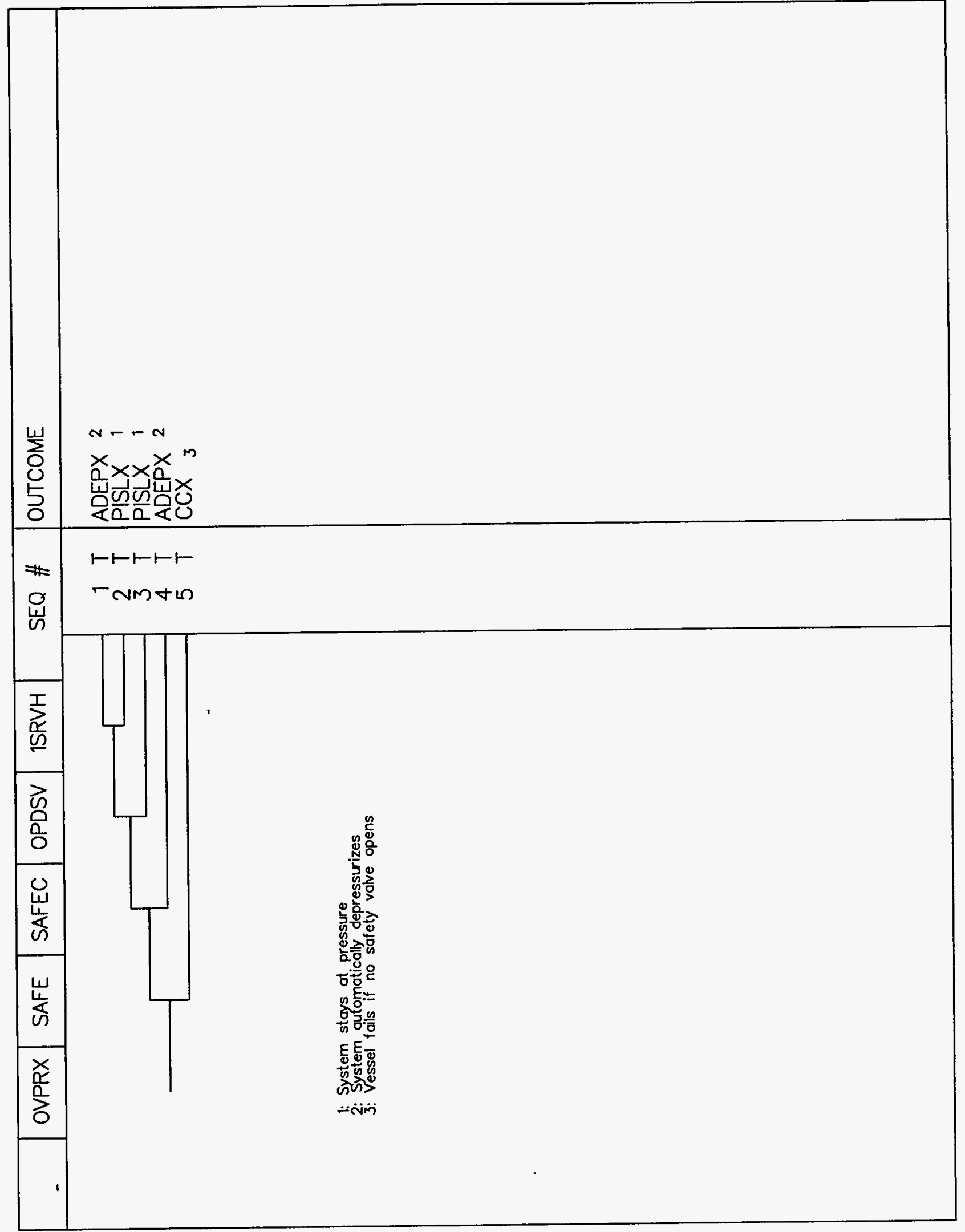

Figure H.1-76 OVPRX Tree 


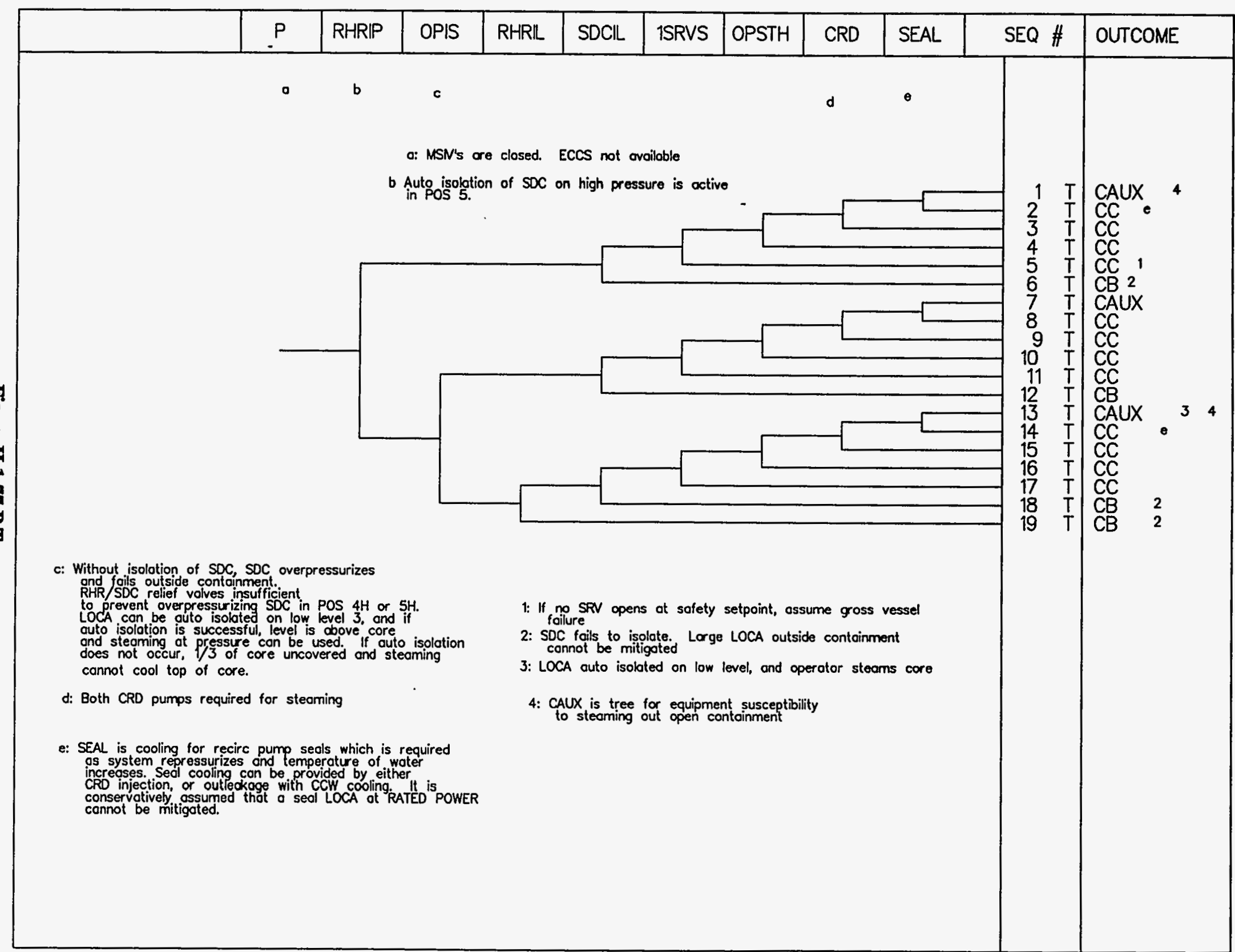

Without isolotion of SDC, SOC overpressurizes

ond goils outside contoinment.

Lo prevent overpressurizing SDC in POS $4 \mathrm{H}$ or $5 \mathrm{H}$ and steoming ot pressure con be used if outo isolation

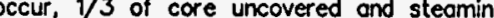

If no SRV opens at sofety setpoint, ossume gross vess

2: SOC foils to isolate. Lorge LOCA outside contoinment

3: LOCA cuto isoloted on low level, and operator stearns core

CAUX is tree for equipment susceptibility
to steaming out open containment

SEAL is cooling for recire pump seels which is required

increoses seol cooines on be provided by either

injection, or outledecoge with CCW cooling. It is

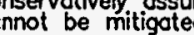


Event Trees

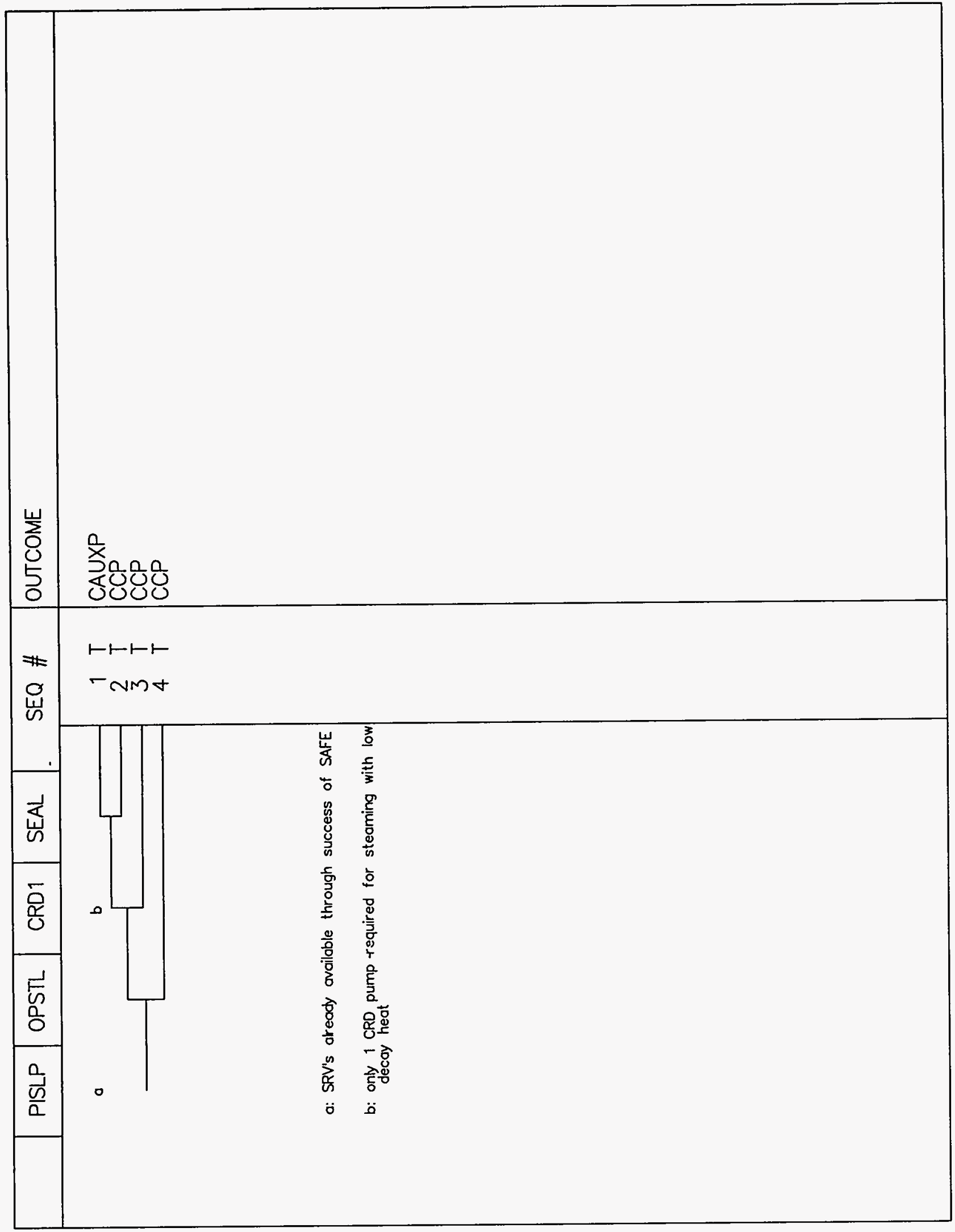

Figure H.1-78 PISLP Tree

Vol. 2, Part 2

H-79

NUREG/CR-6143

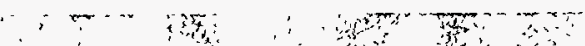




\section{Event Trees}

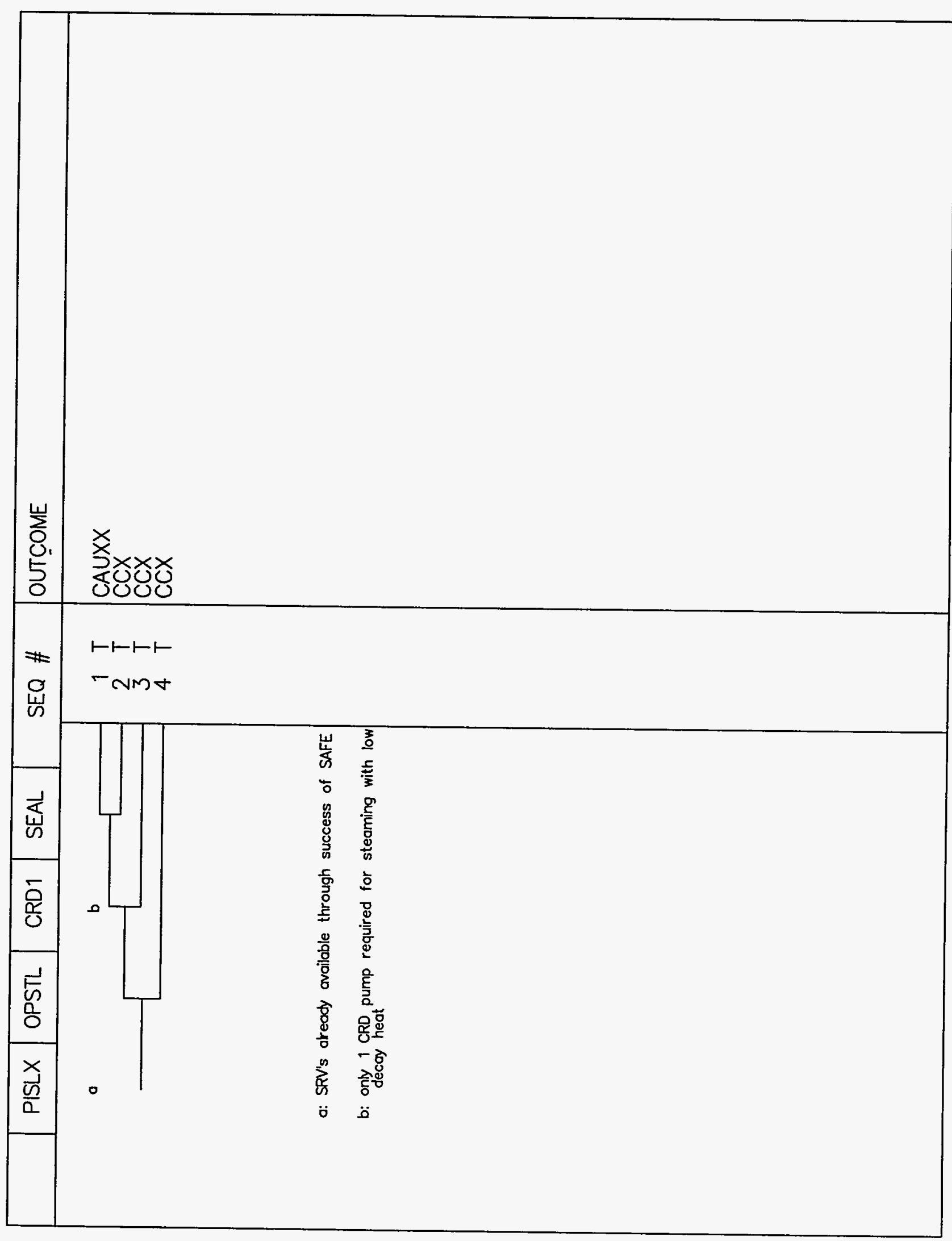

Figure H.1-79 PISLX Tree 
Event Trees

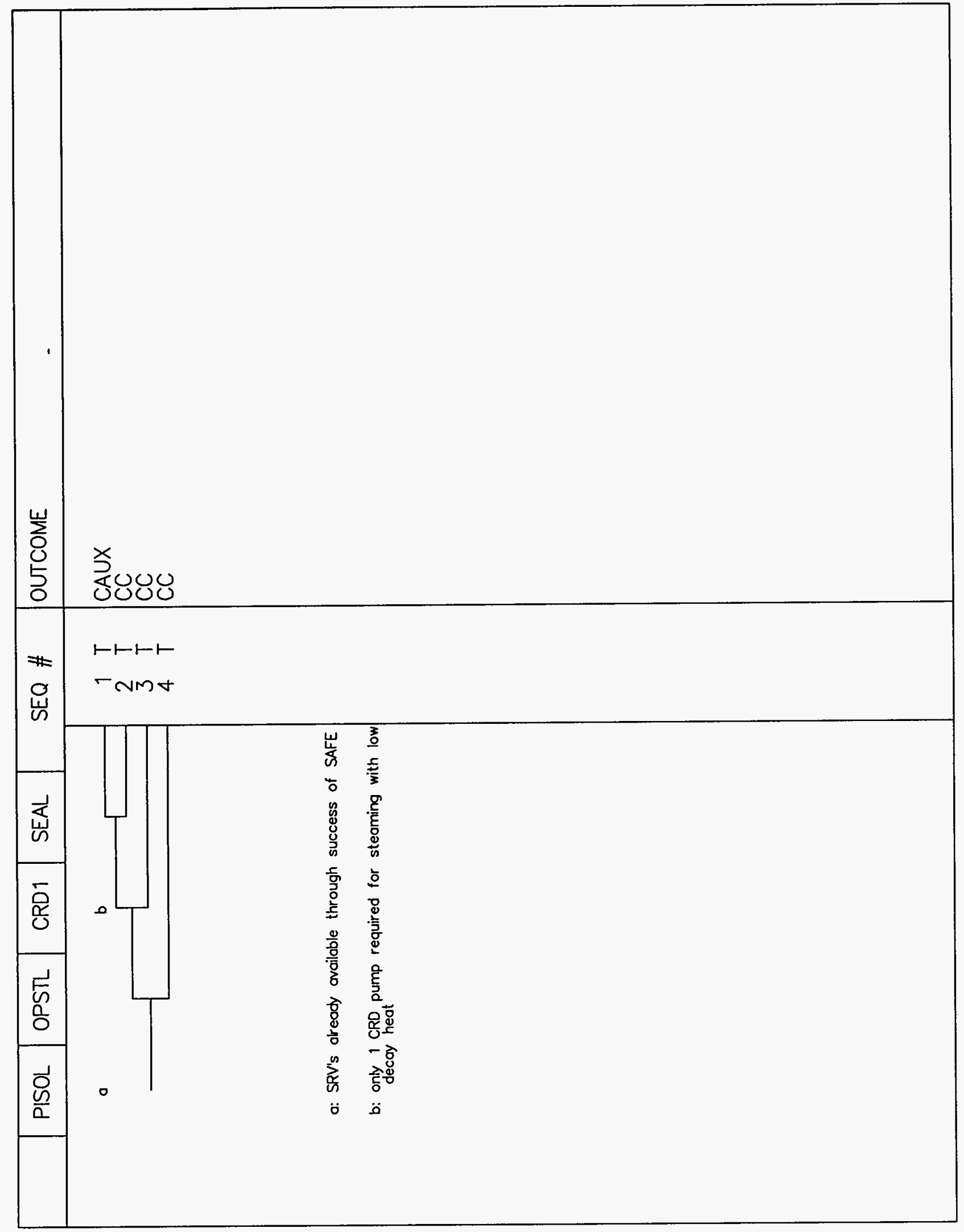

Figure H.1-80 PISOL Tree

Vol. 2, Part 2

H-81

NUREG/CR-6143 


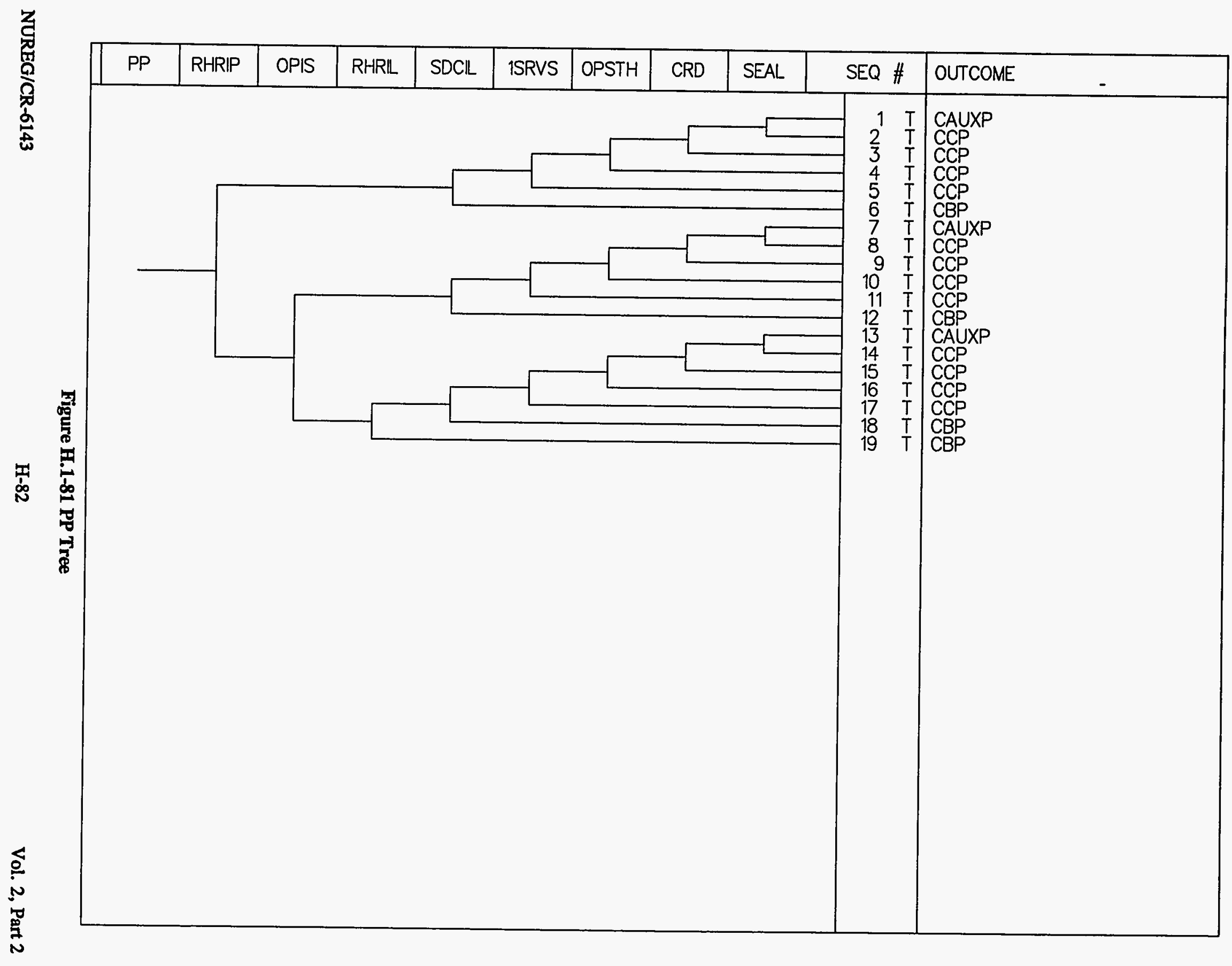

晏 


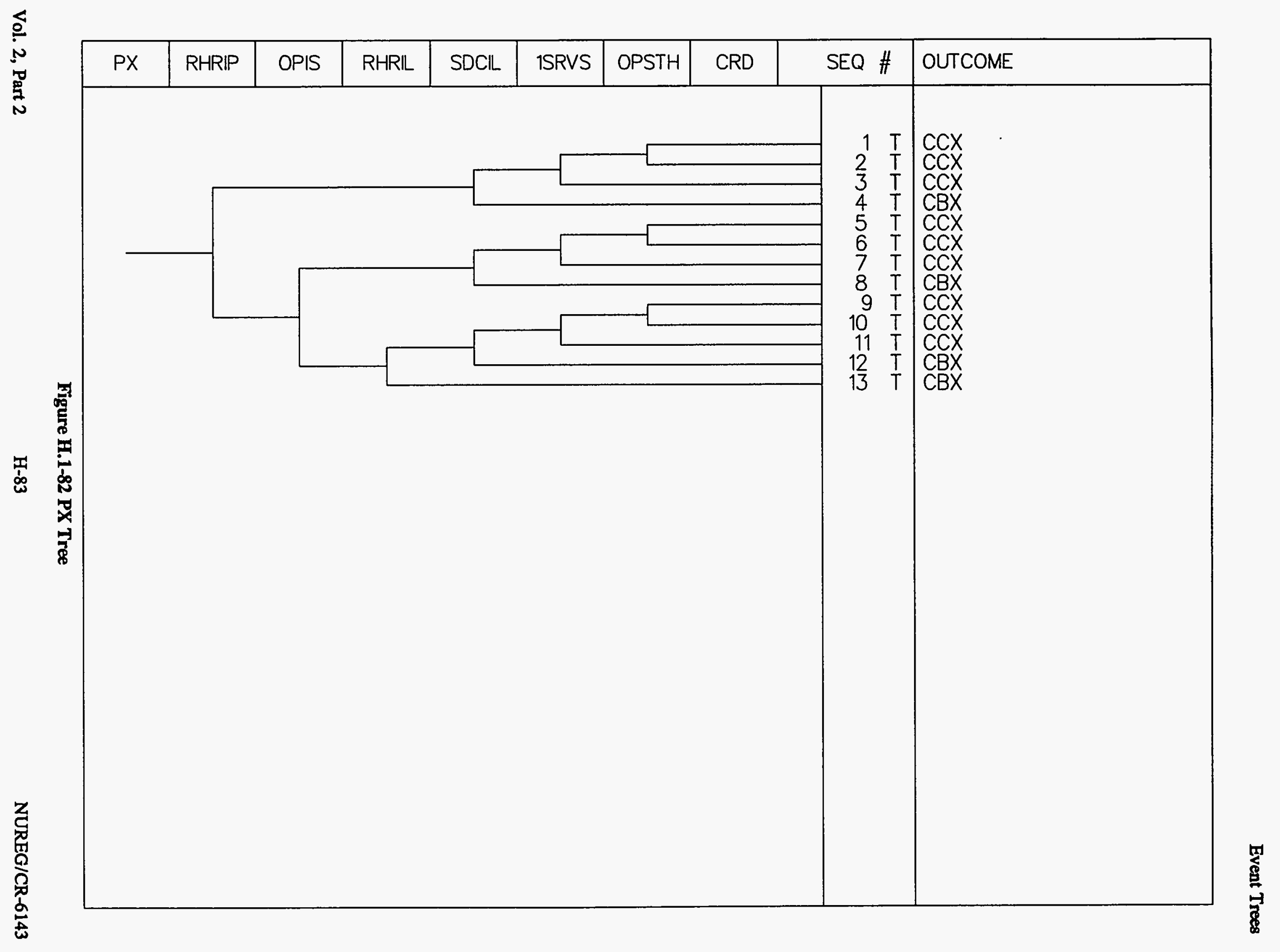




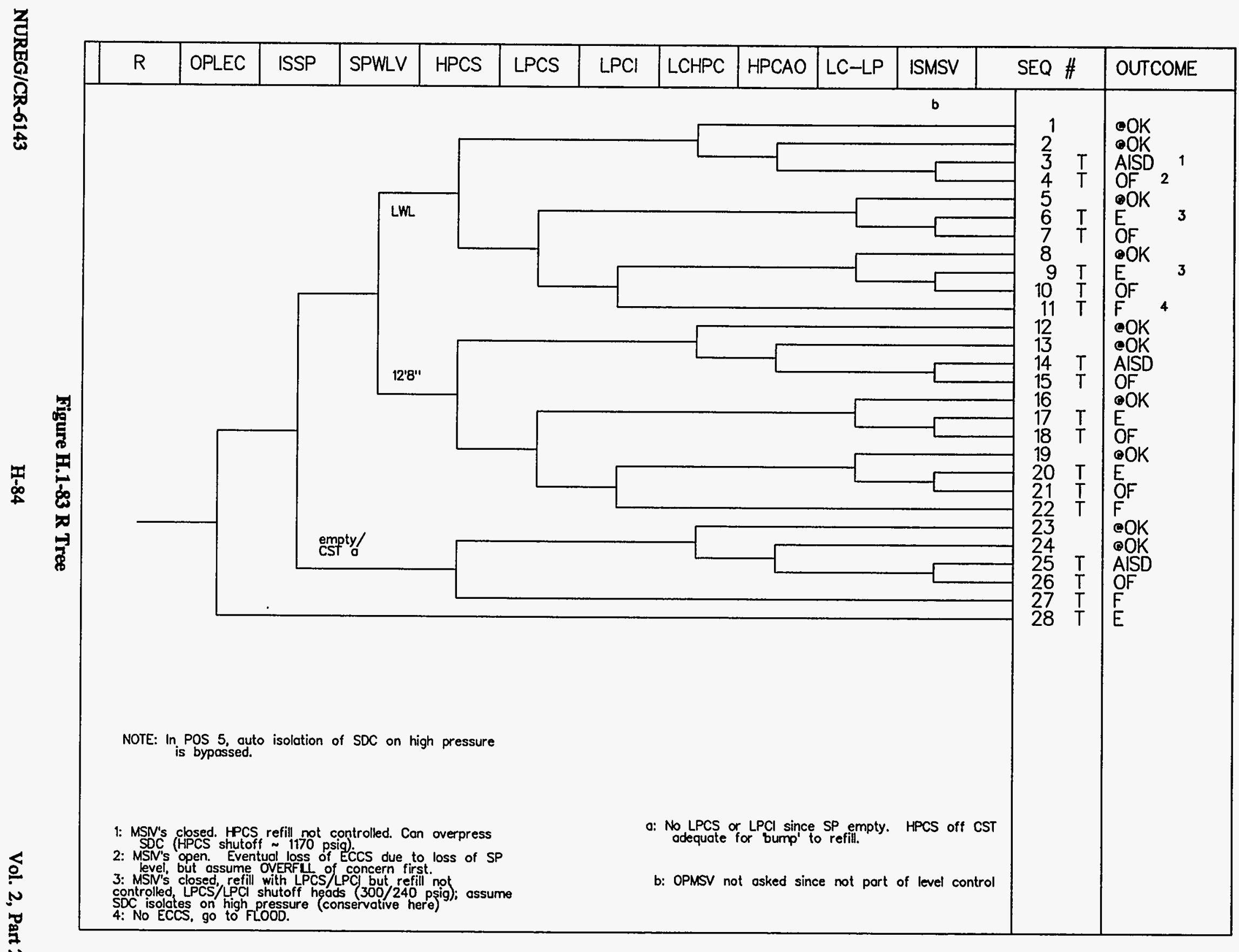




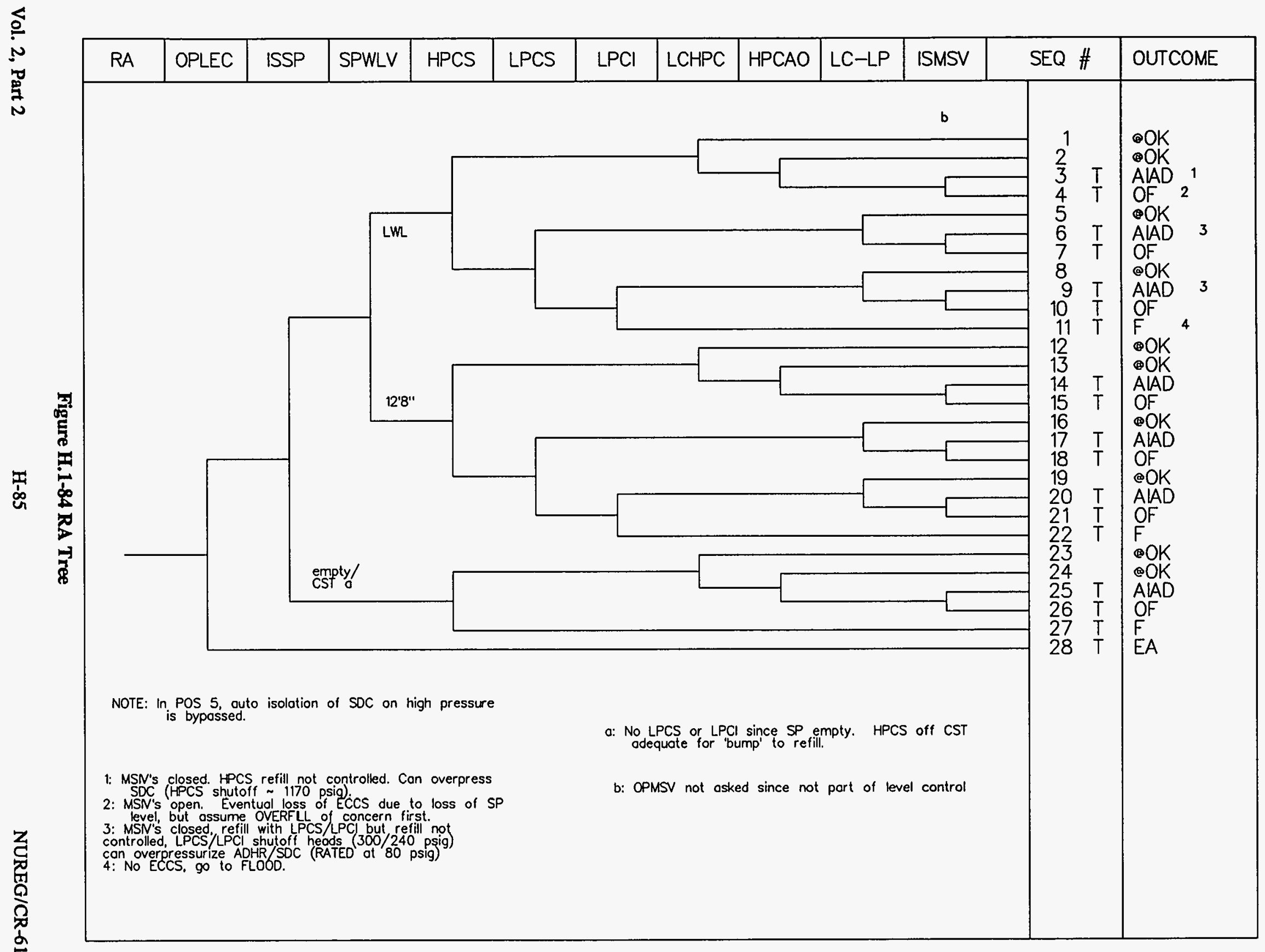


Everit Trees

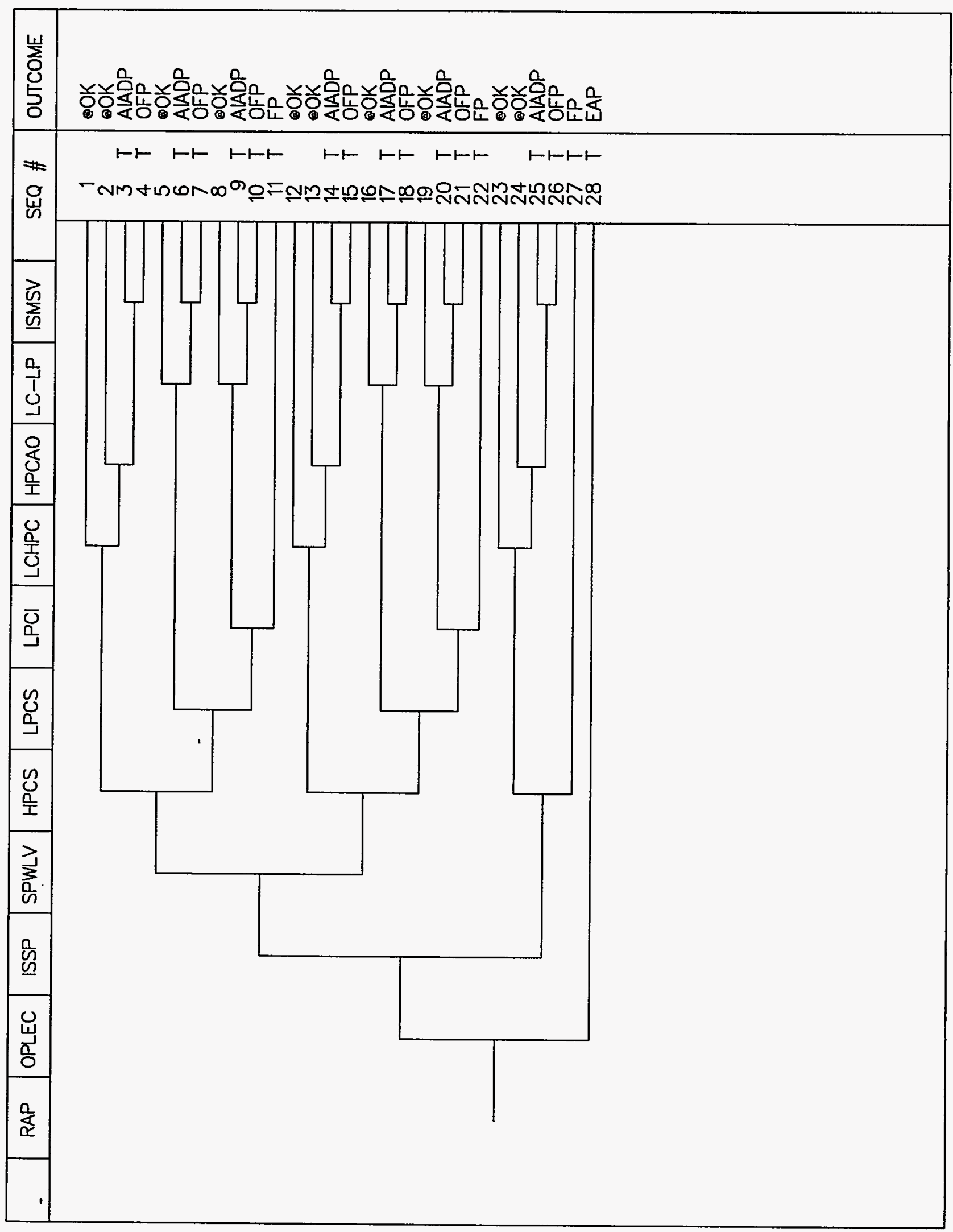

Figure H.1-85 RAP Tree 


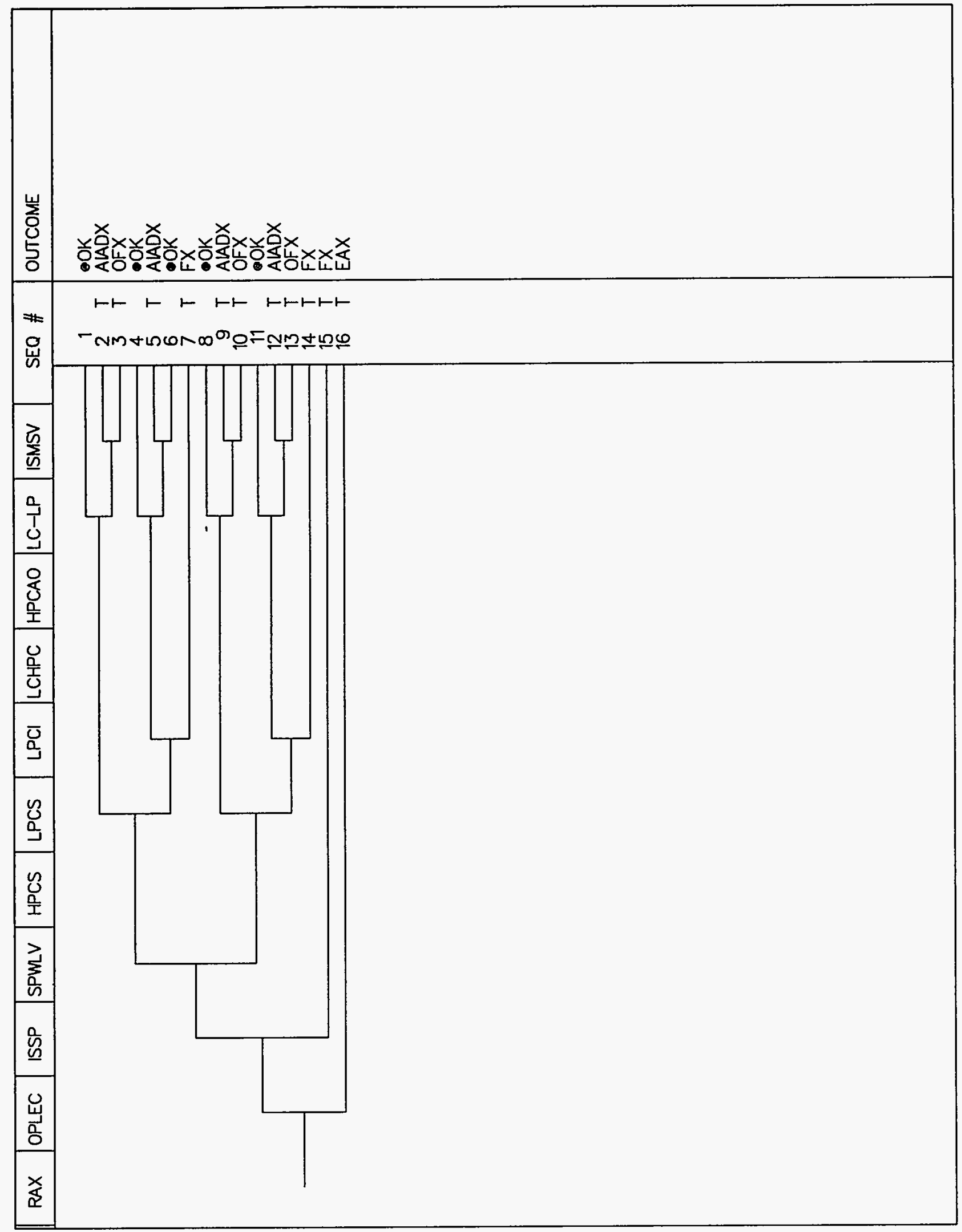

Figure H.1-86 RAX Tree 


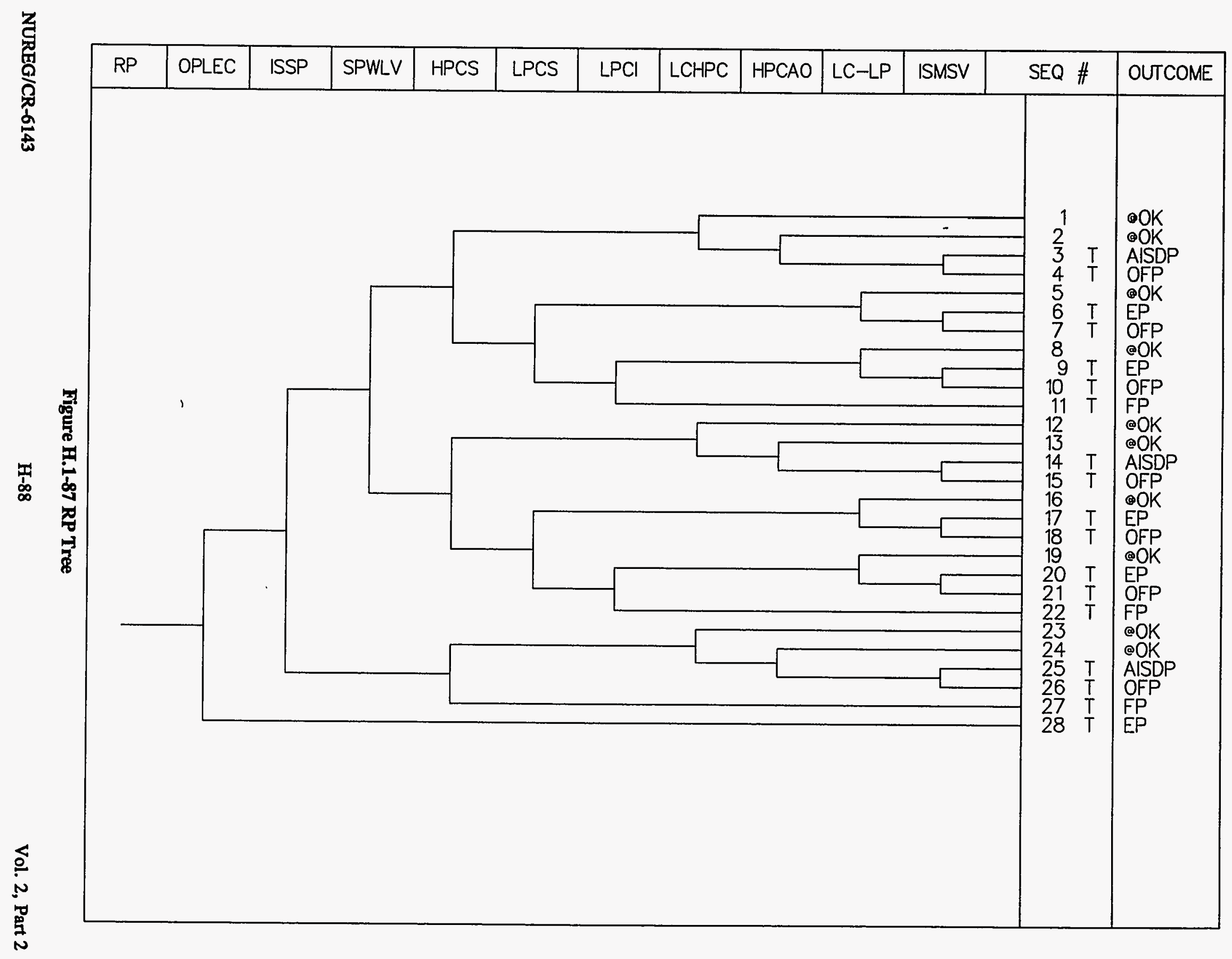




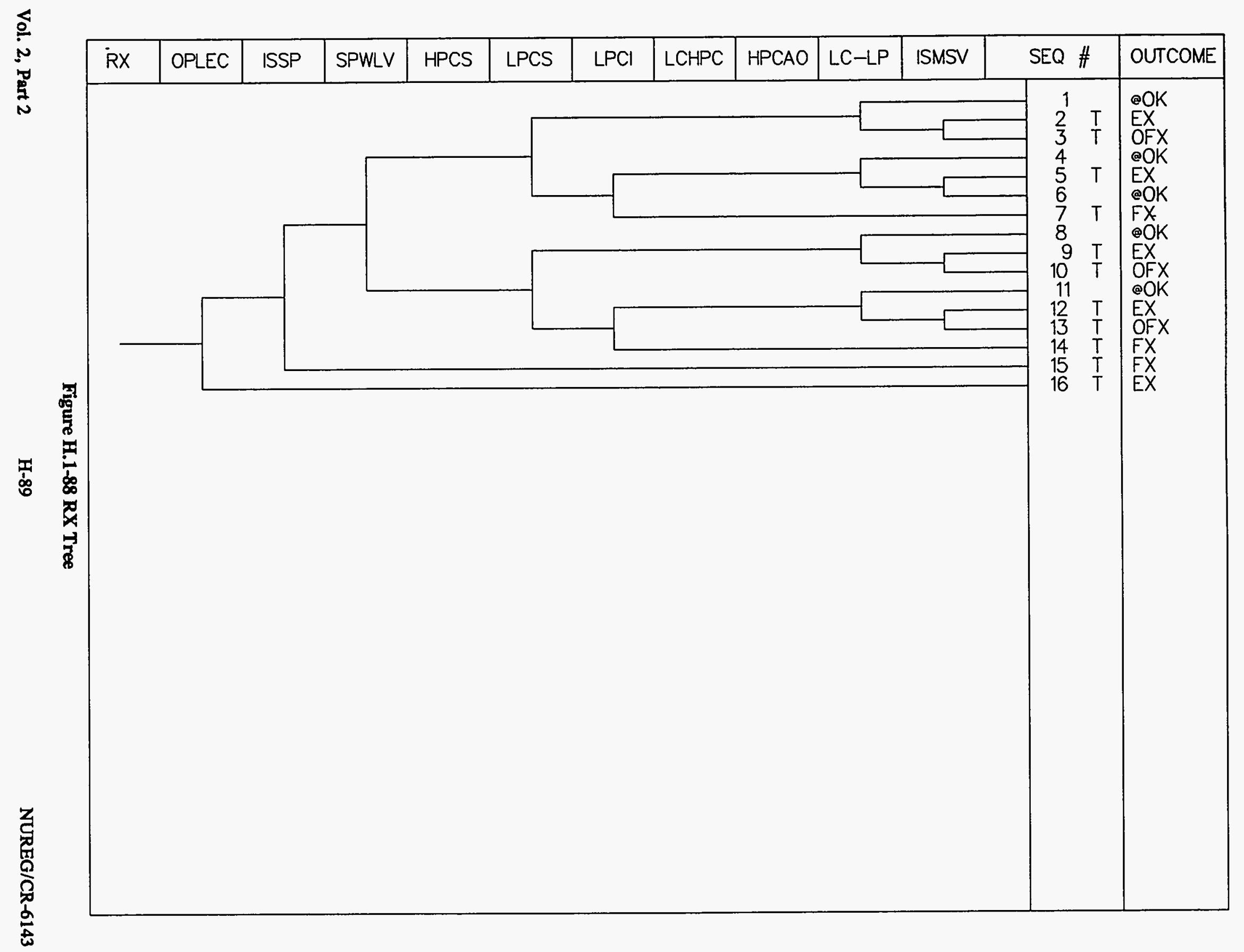




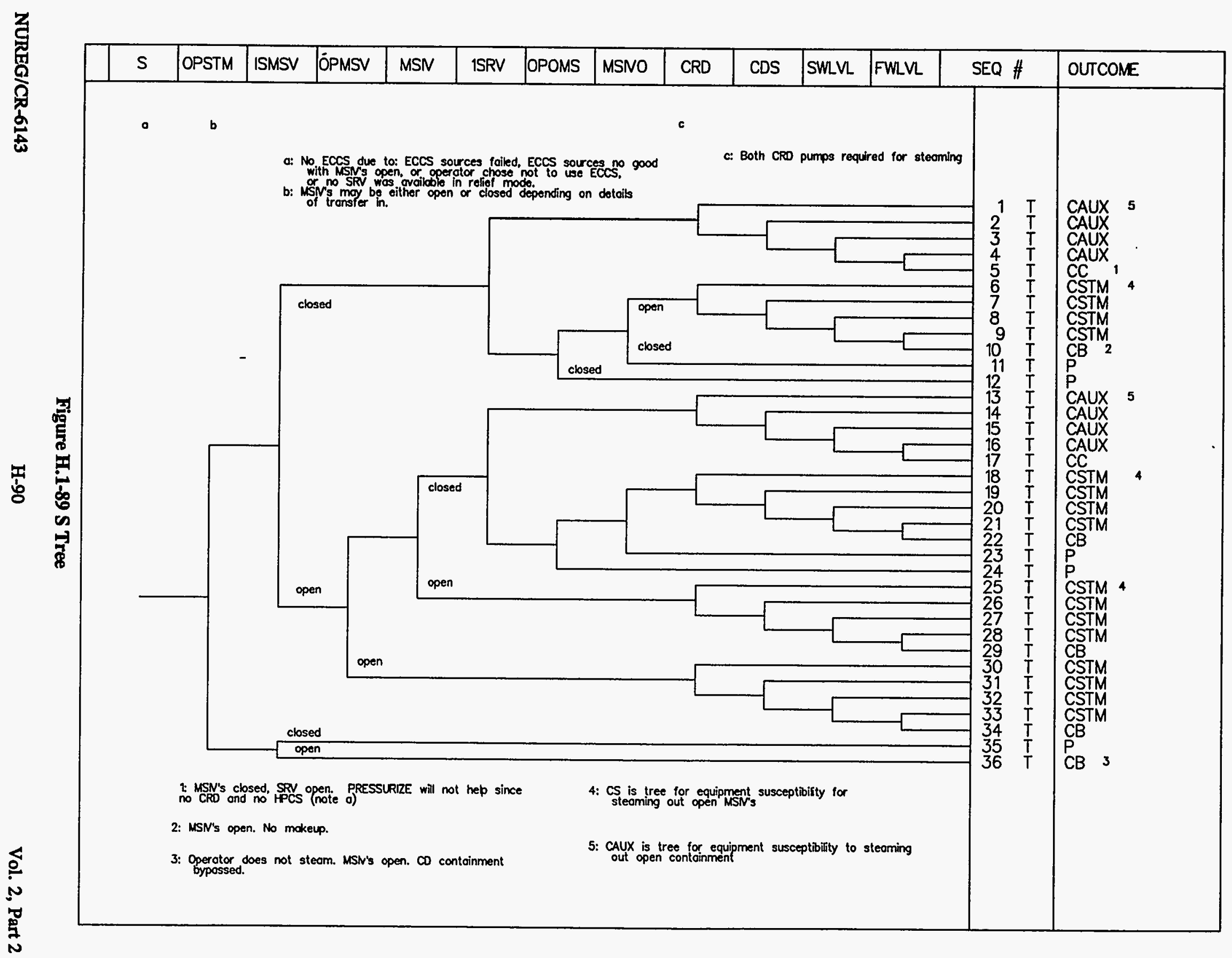




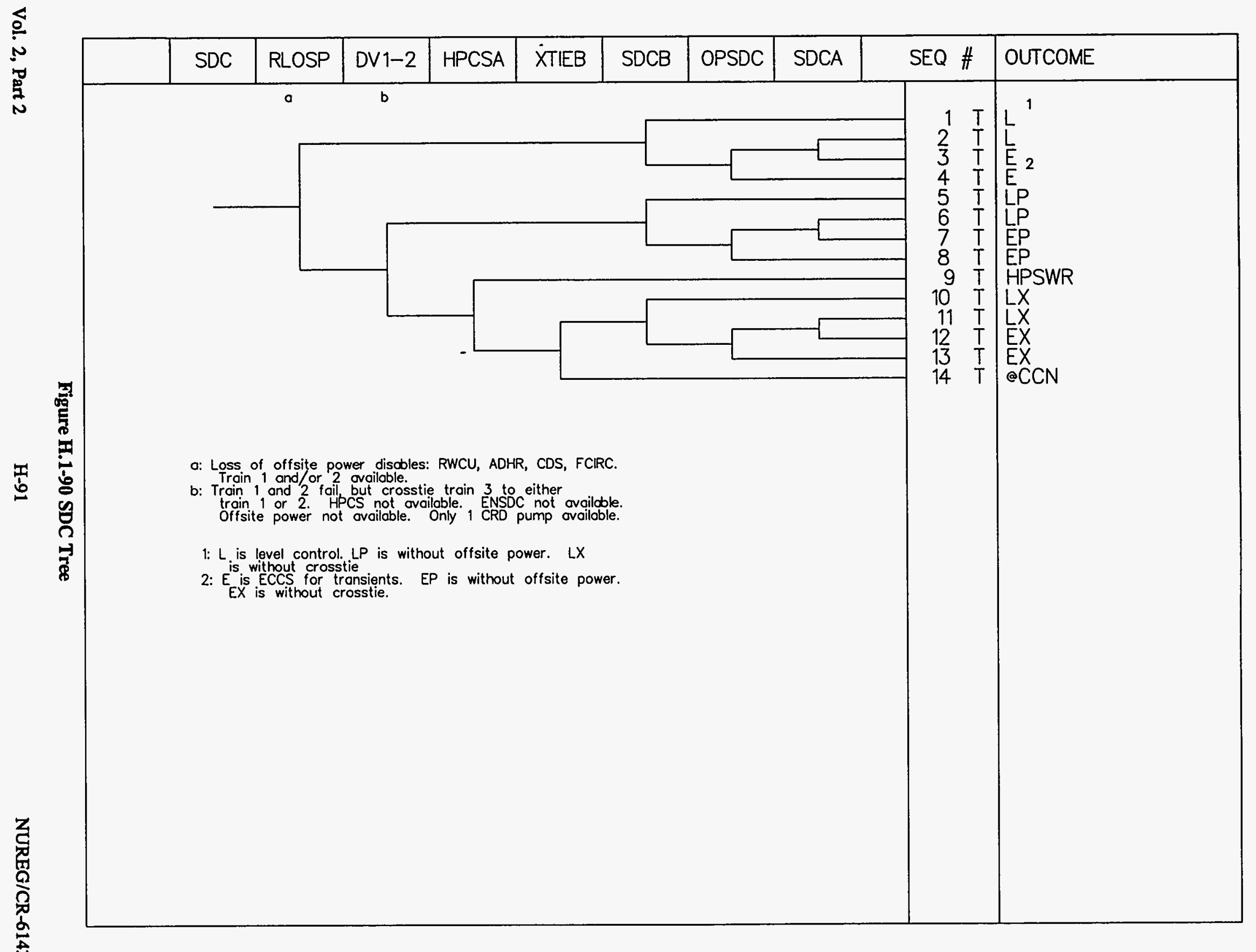




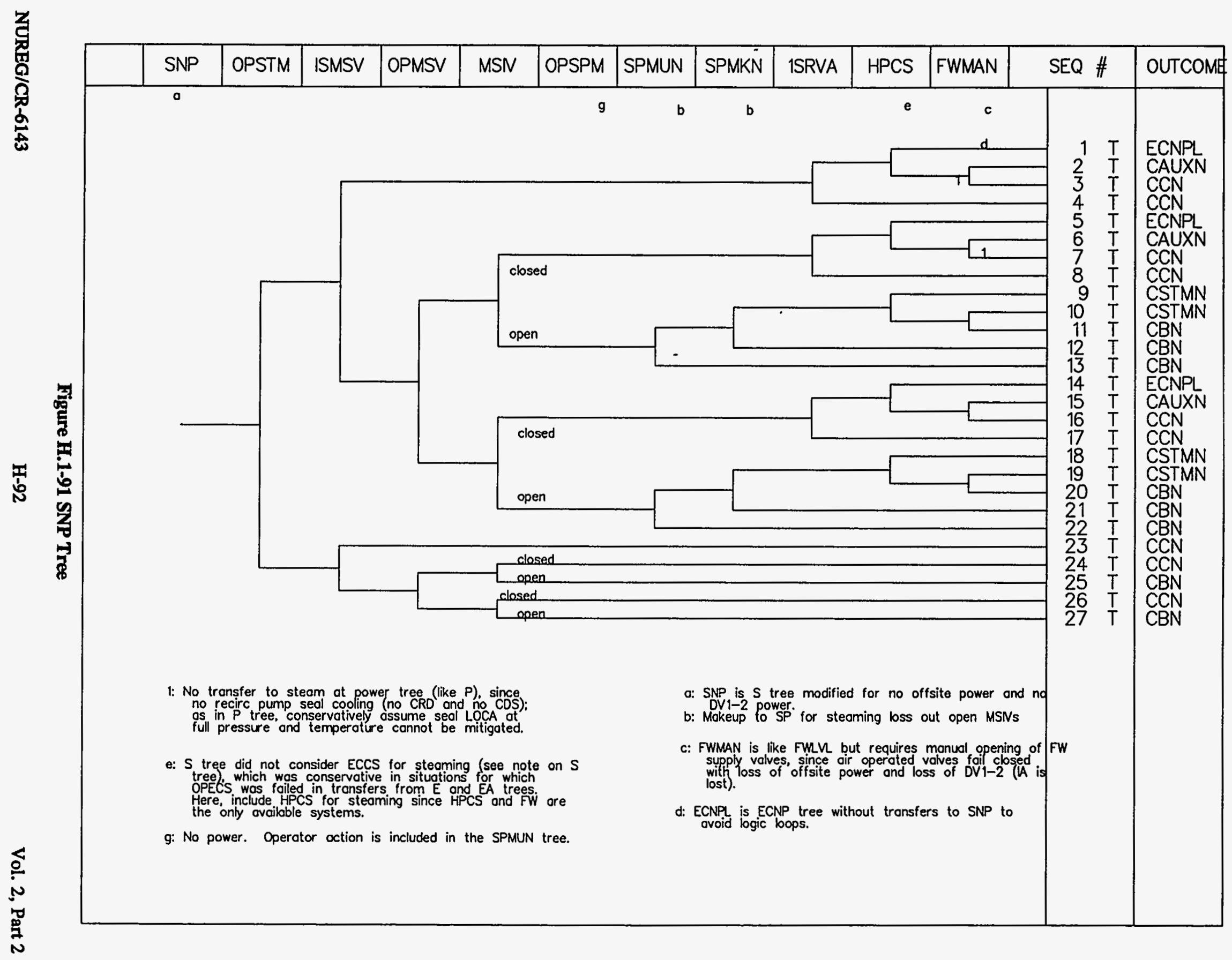




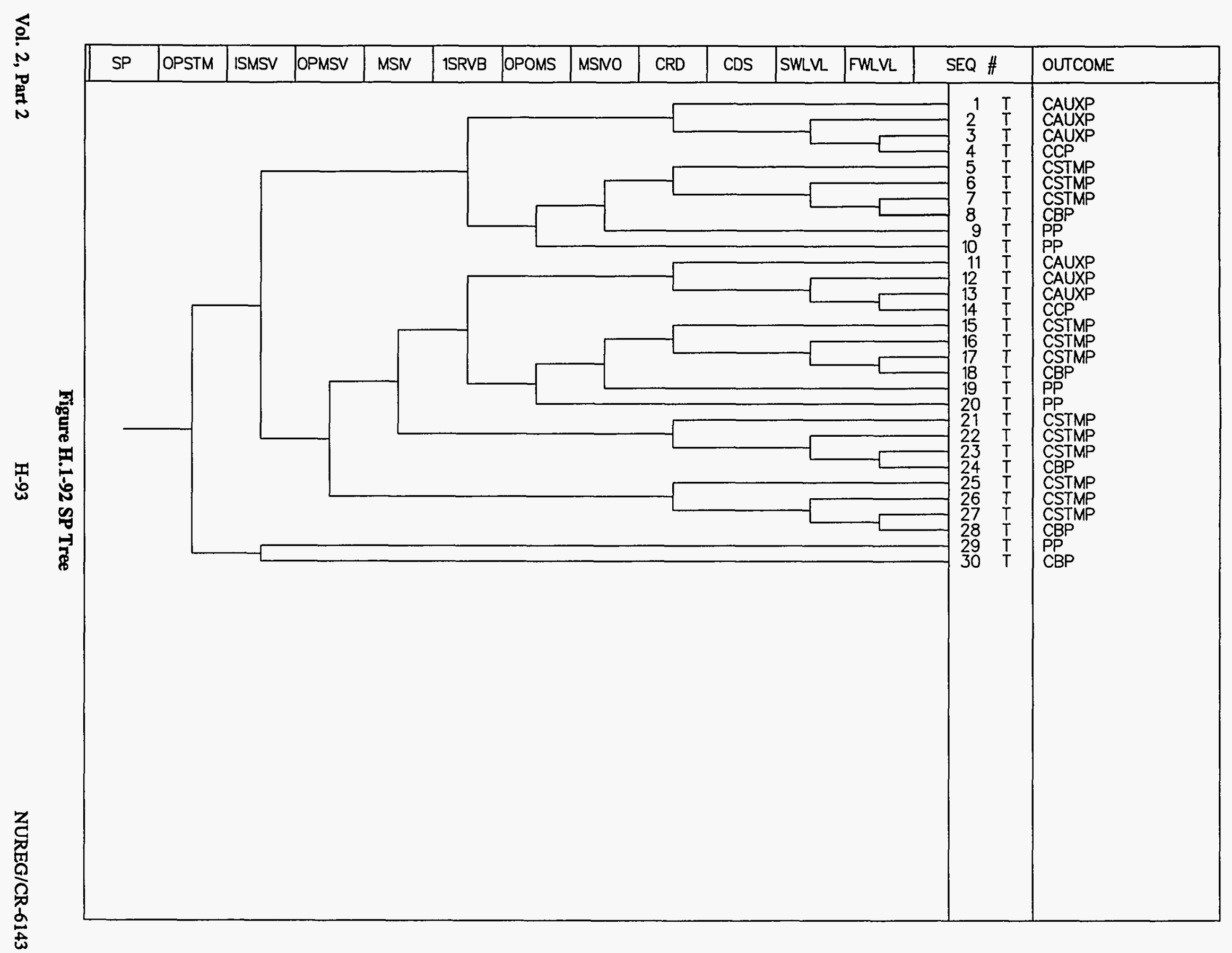




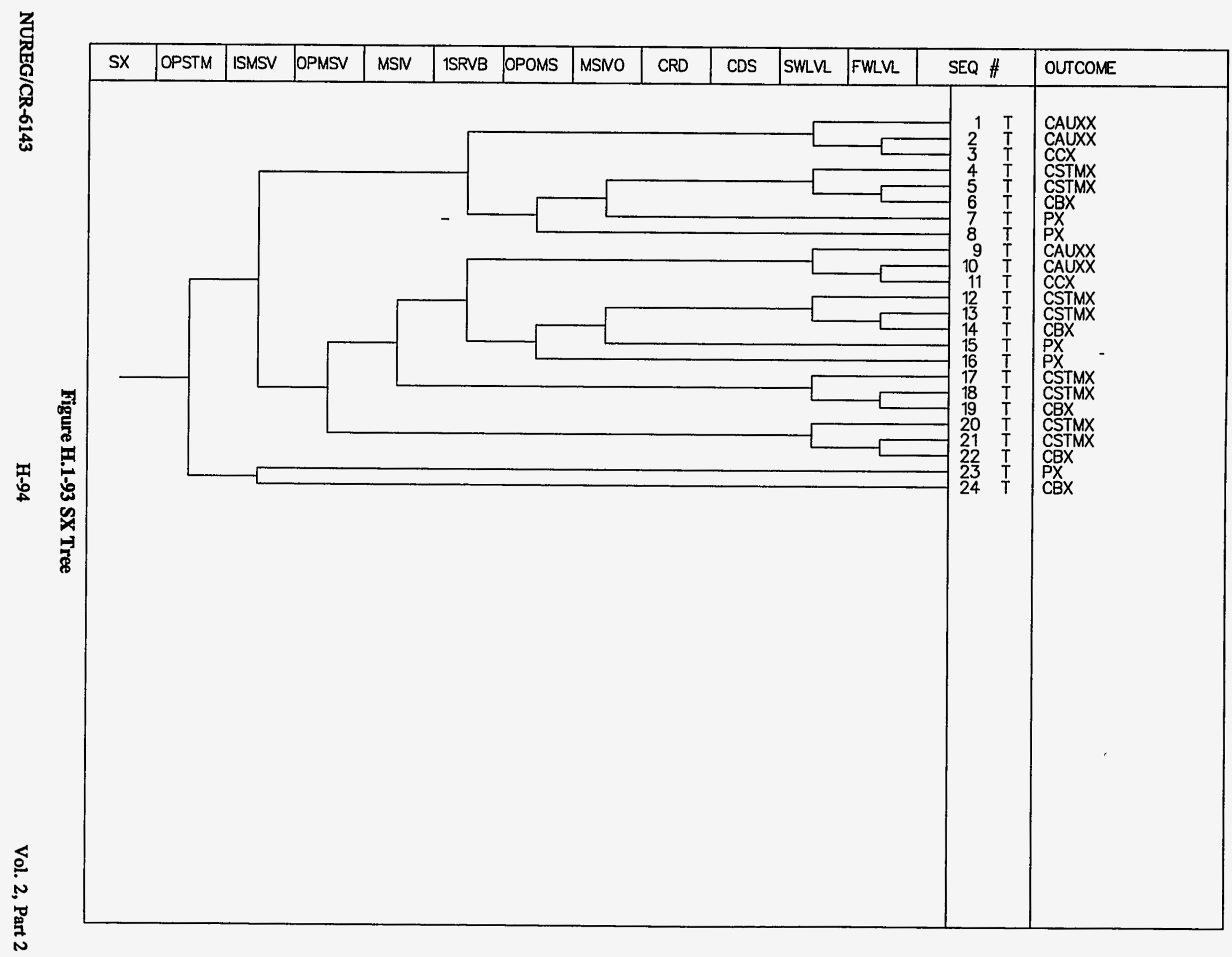




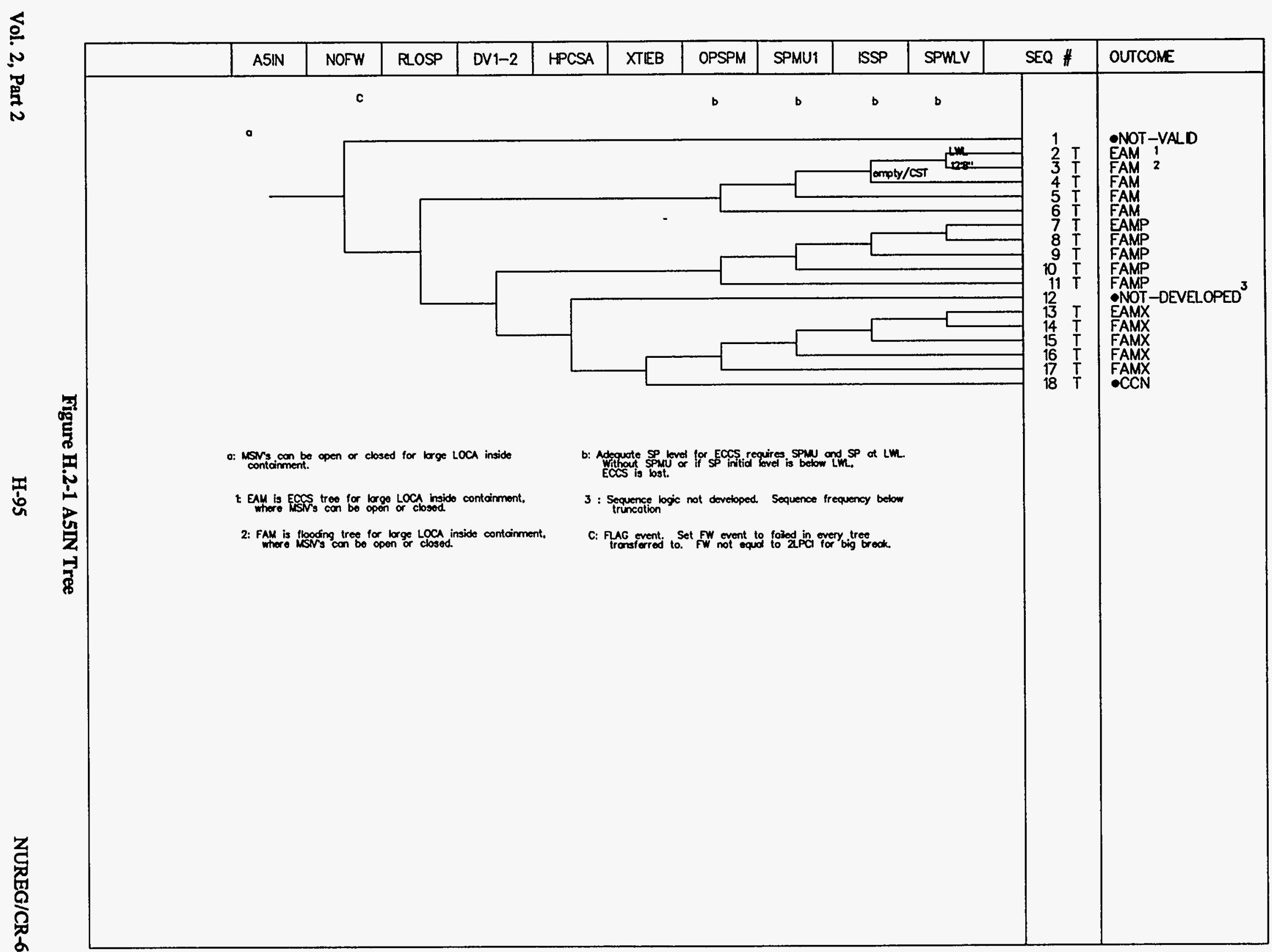




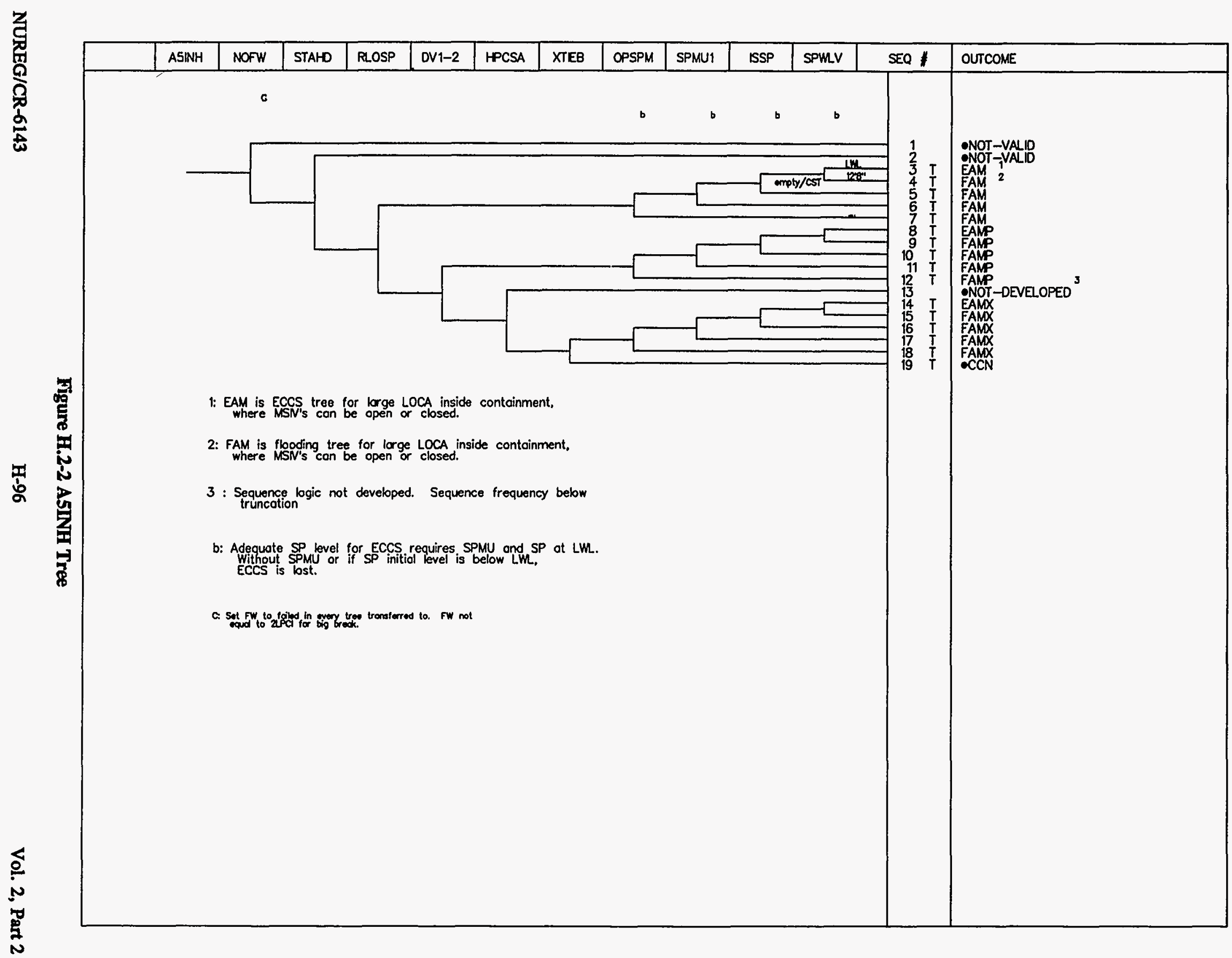




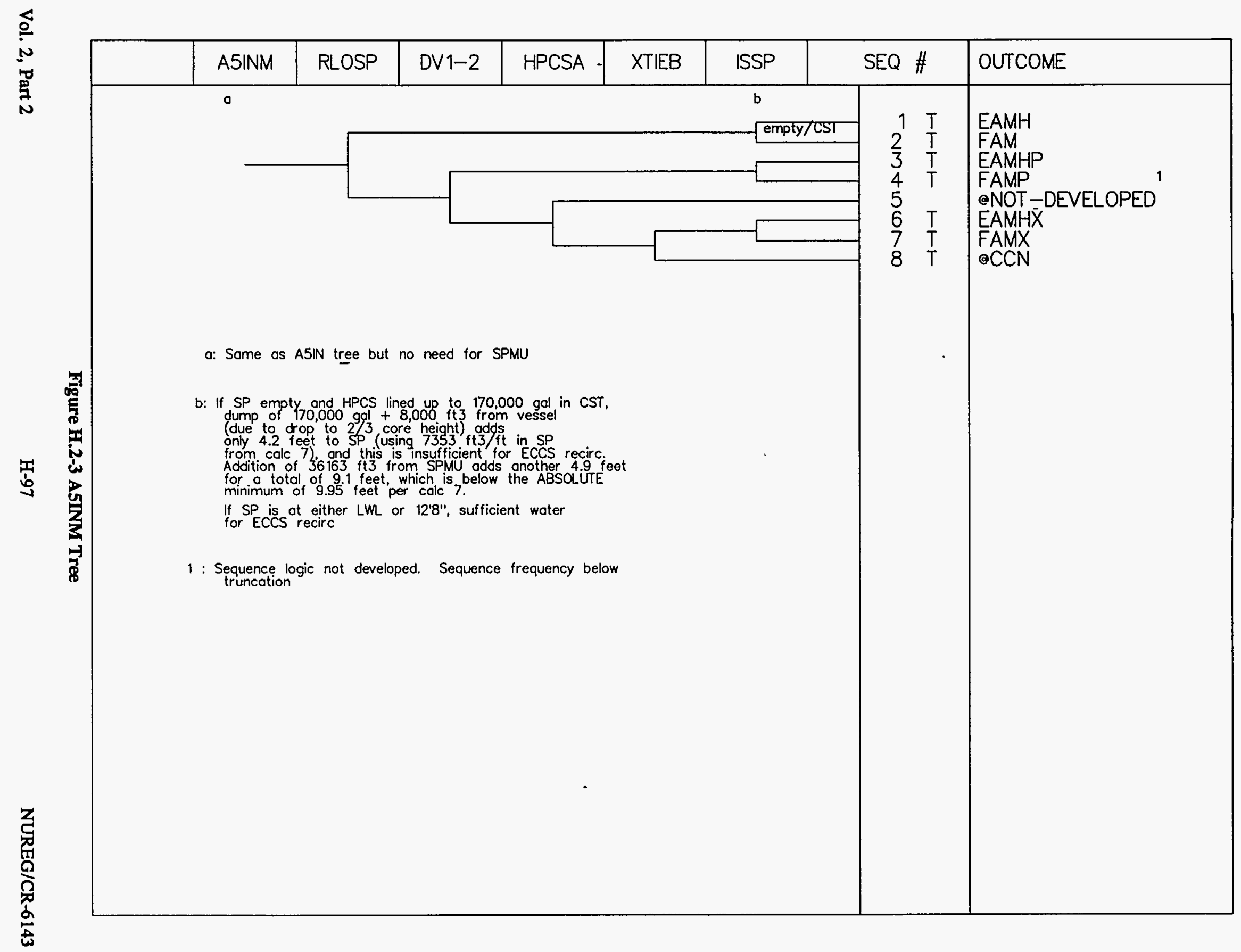




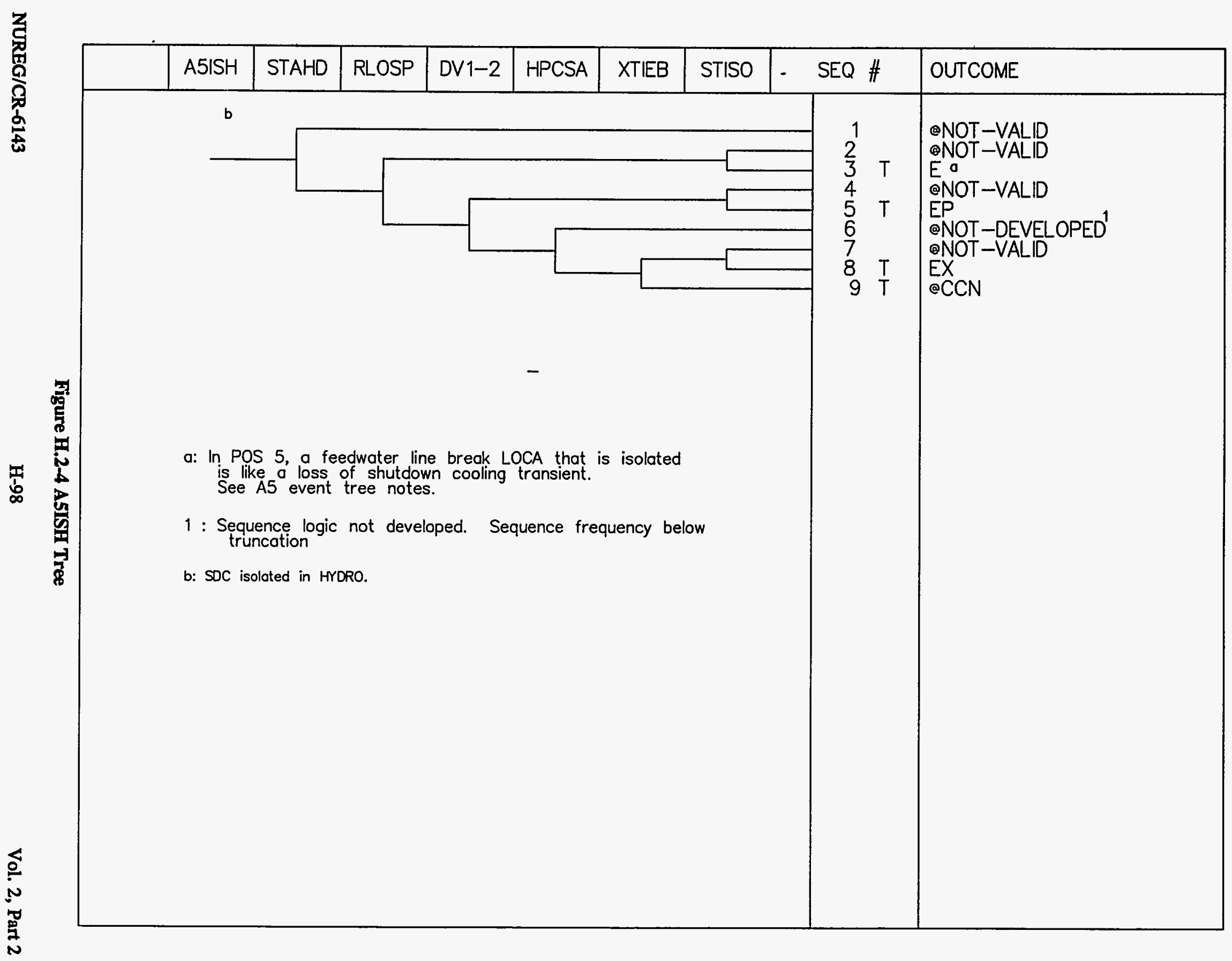




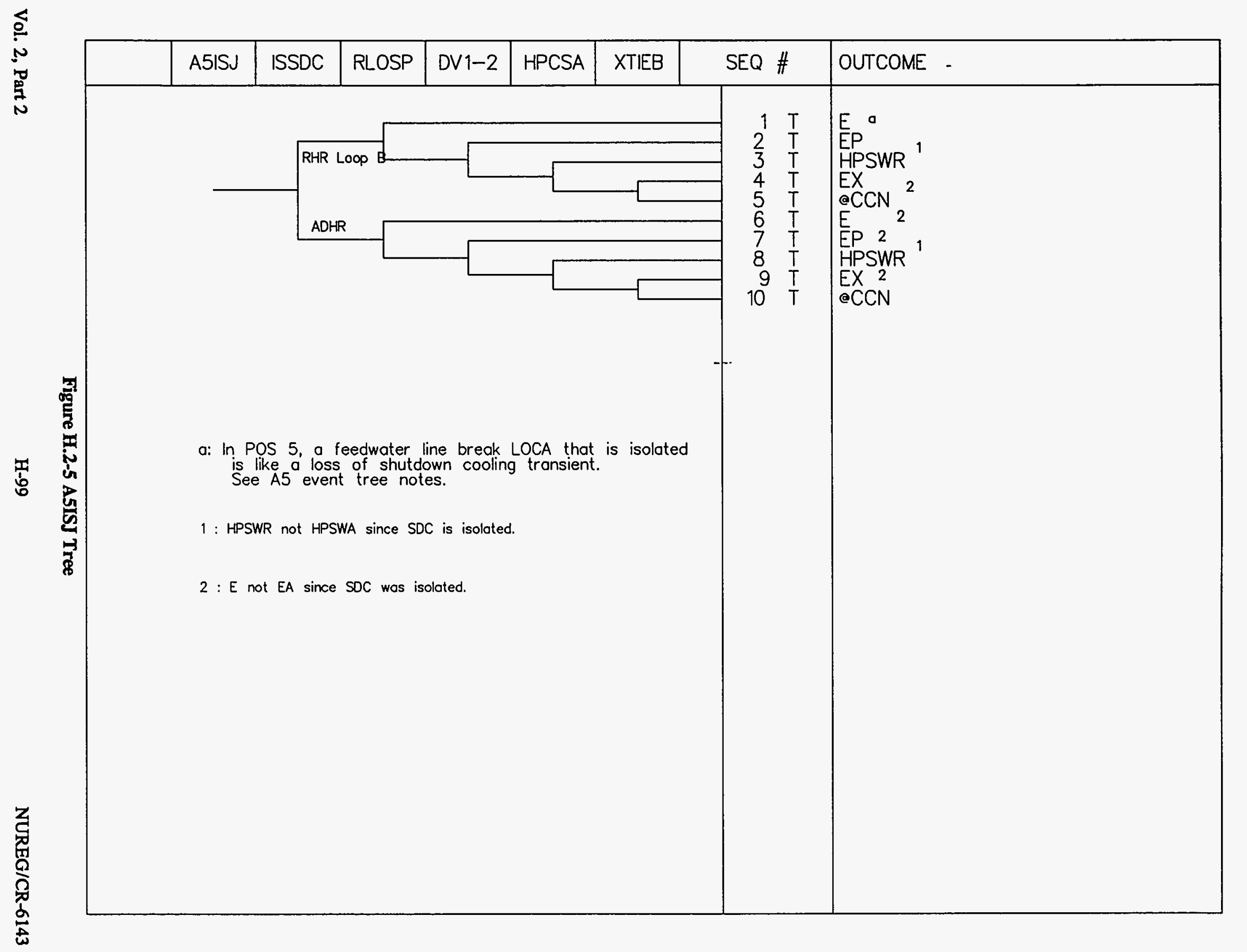

腕 


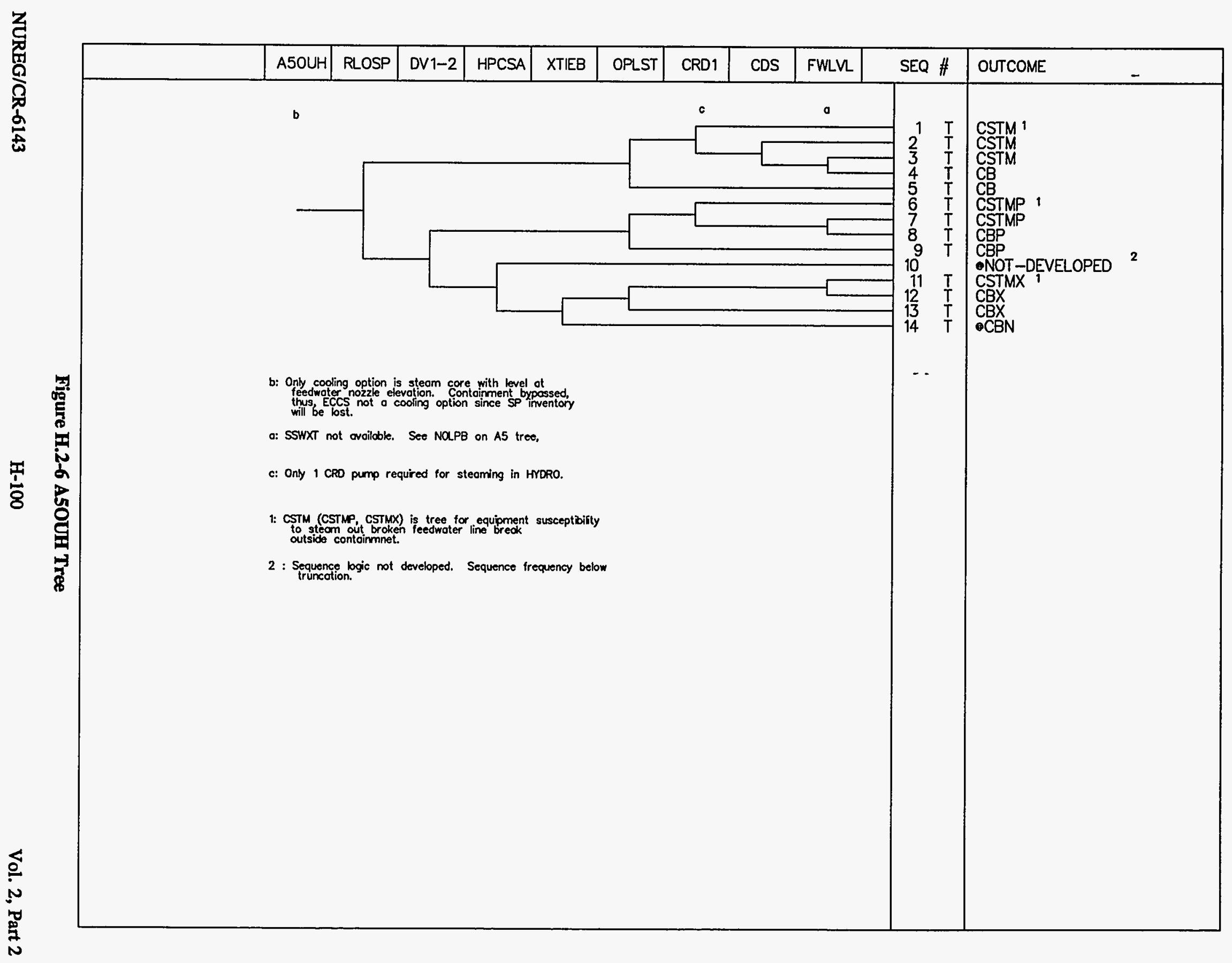




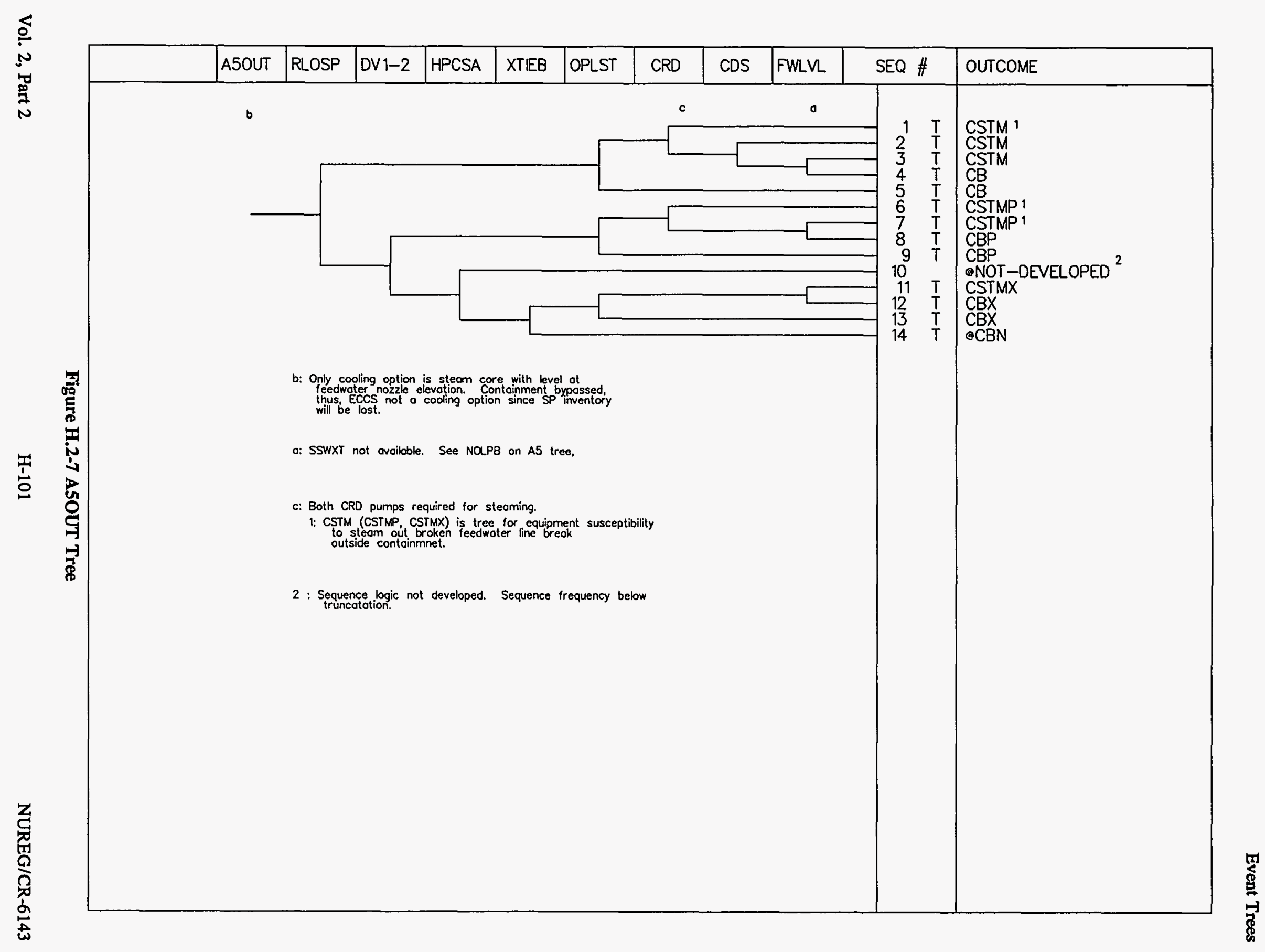




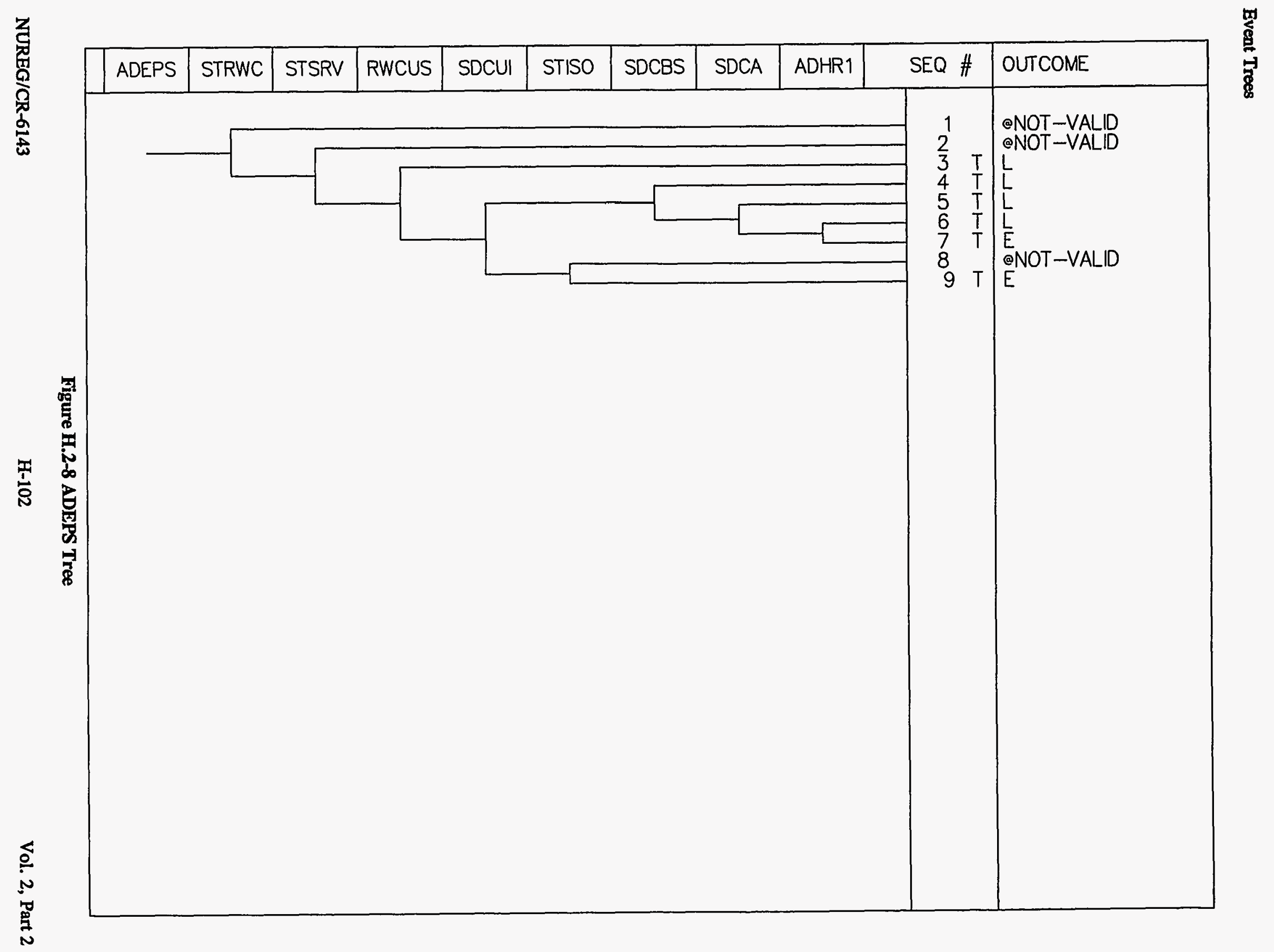




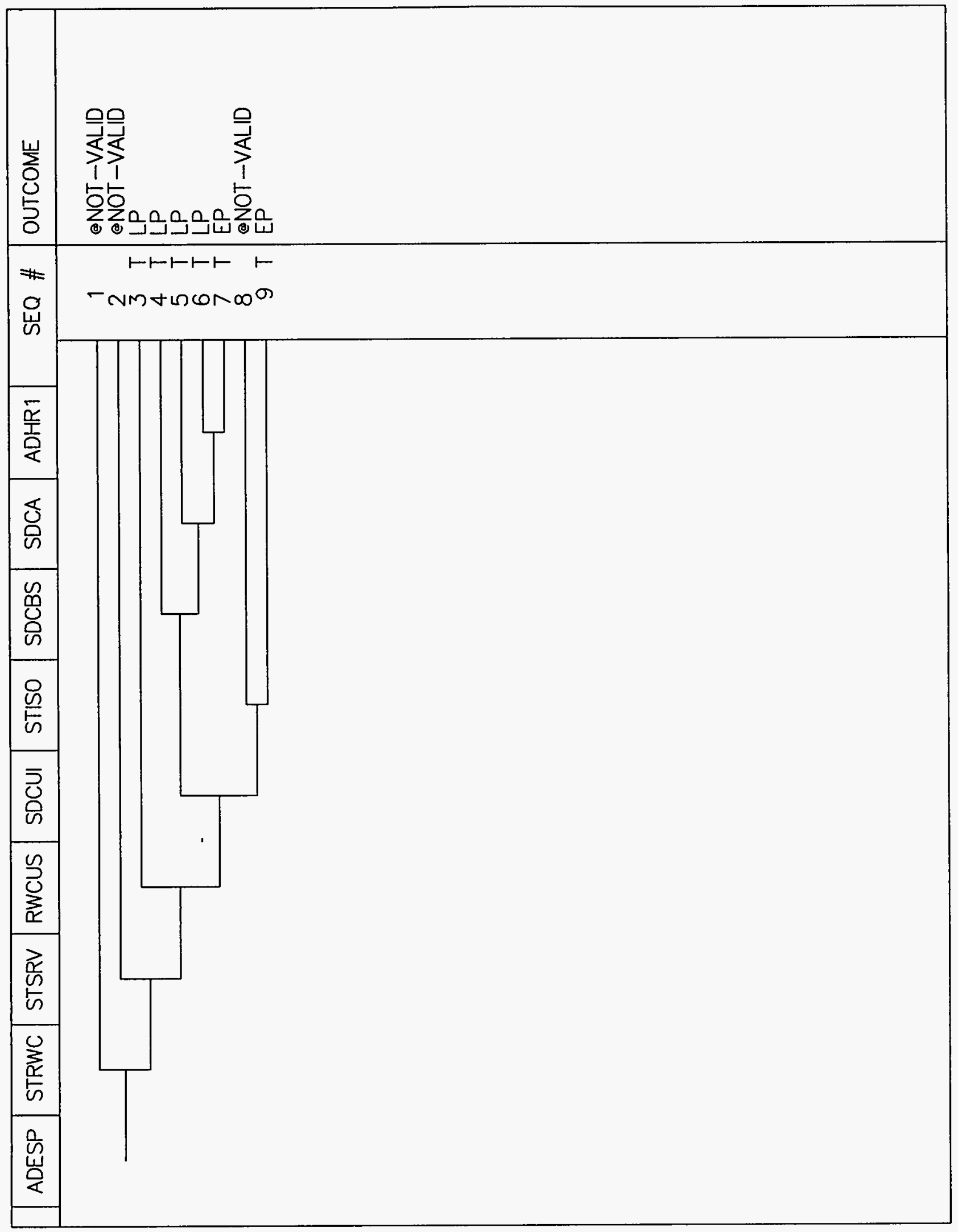

Figure H.2-9 ADESP Tree

Vol. 2, Part 2

H-103 


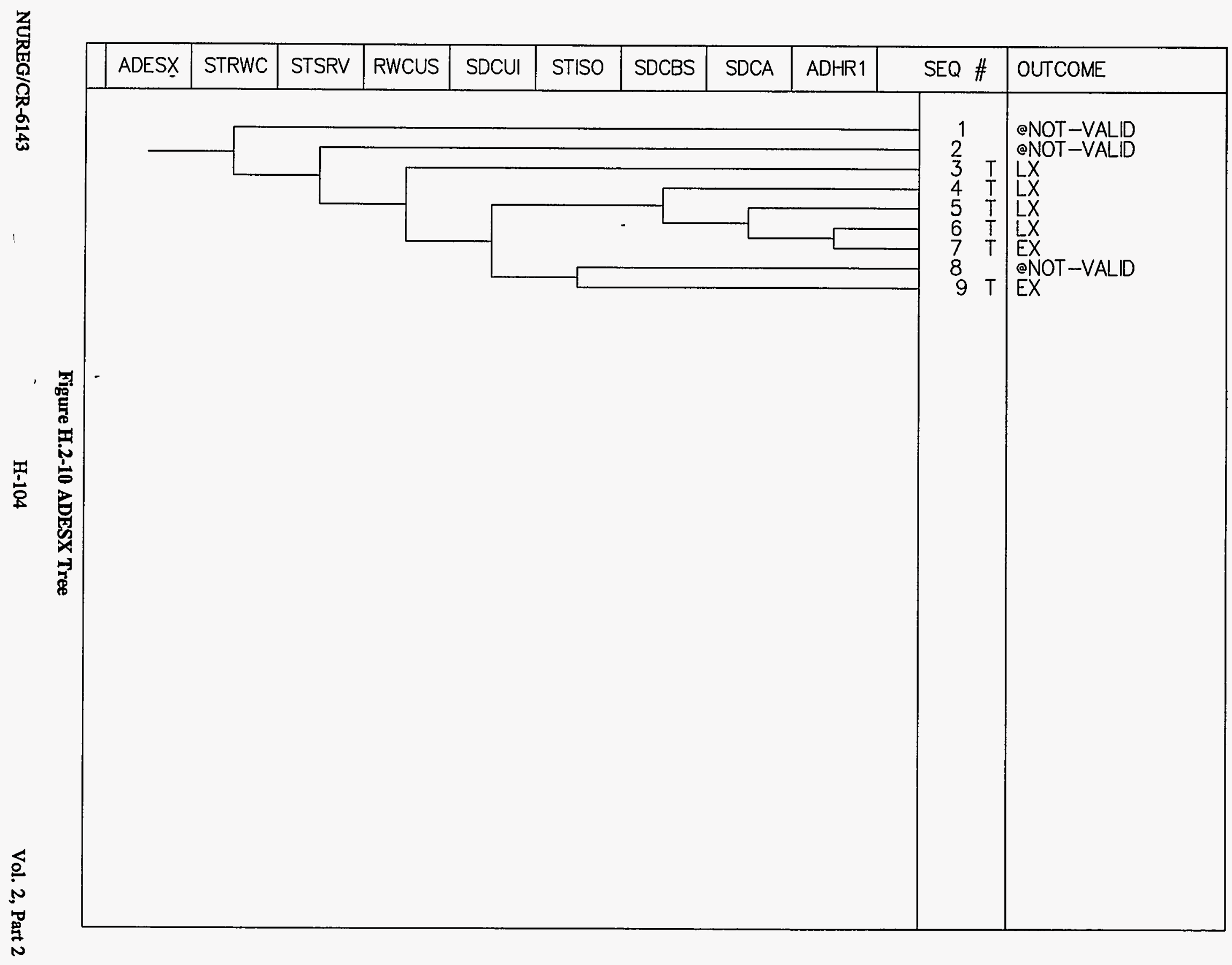




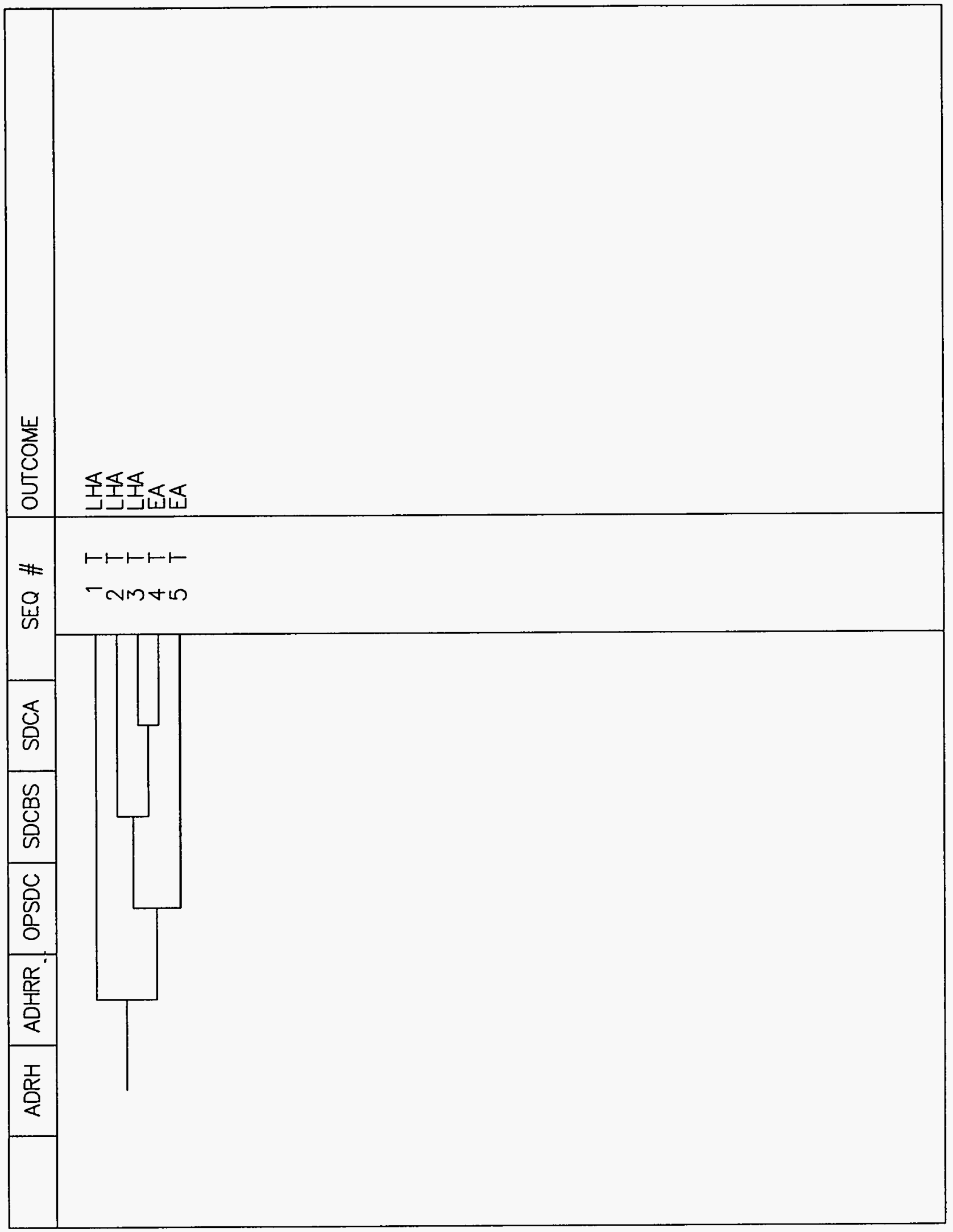

Figure H.2-11 ADRH Tree 


\section{Event Trees}

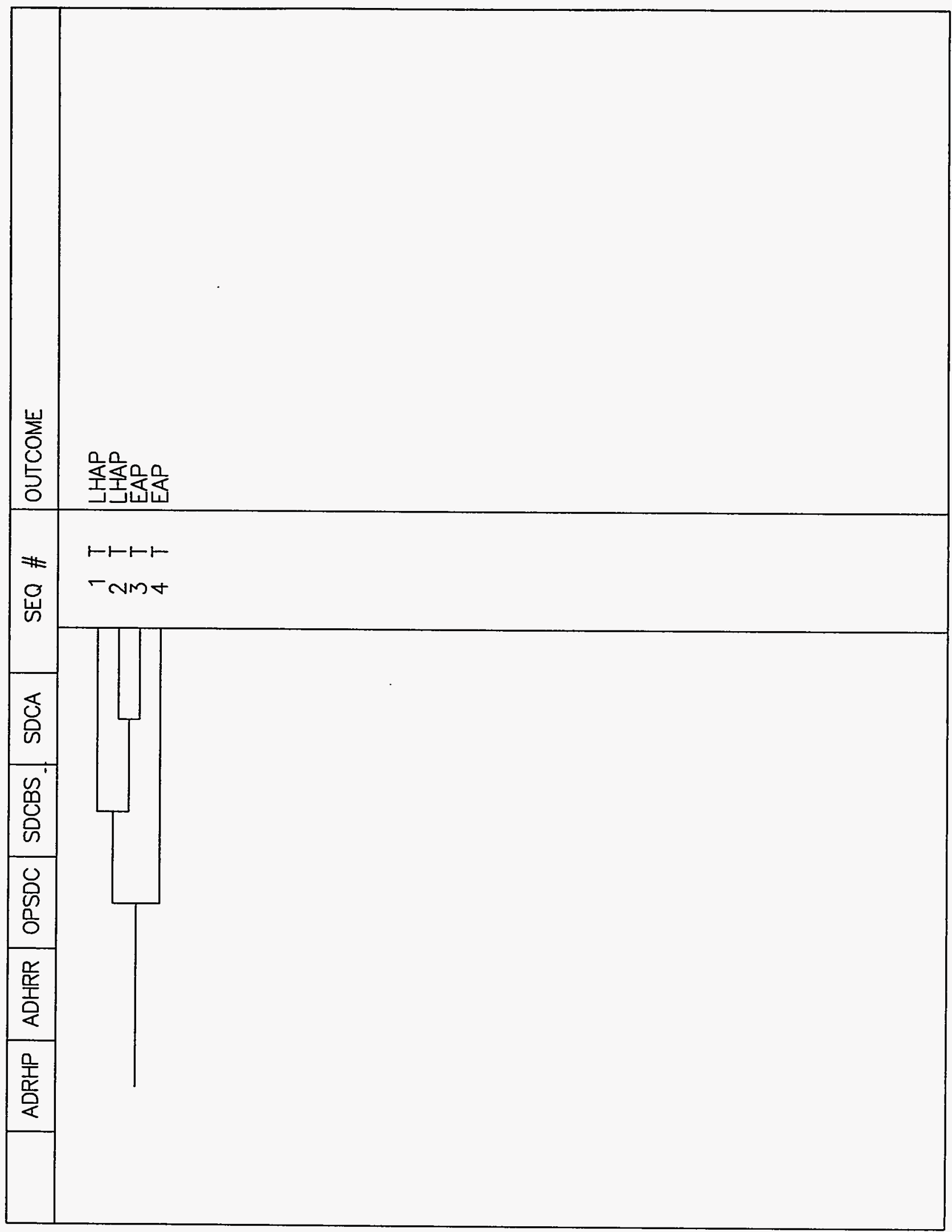

Figure H.2-12 ADRHP Tree 


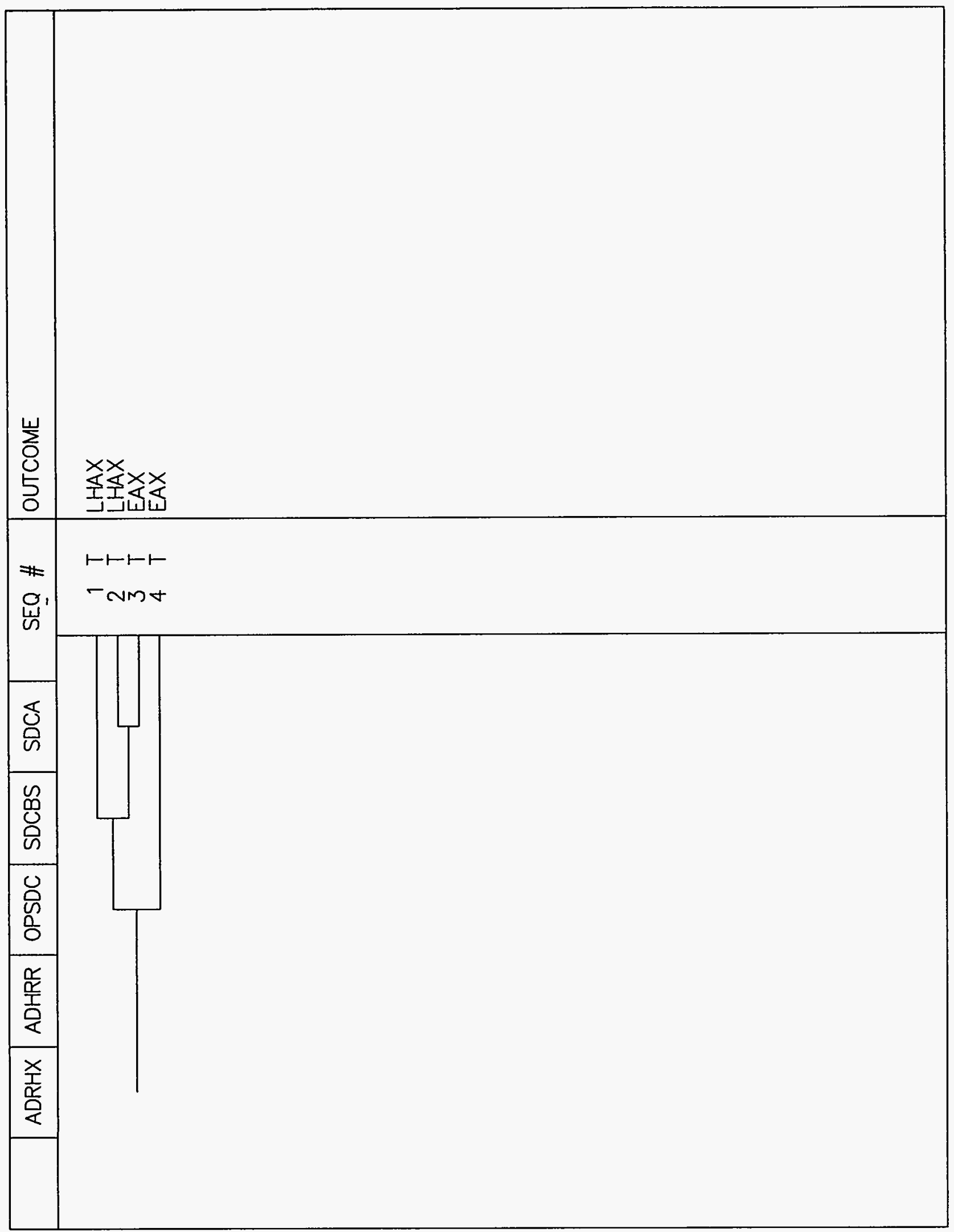

Figure H.2-13 ADRHX Tree

Vol. 2, Part 2

H-107

NUREG/CR-6143 


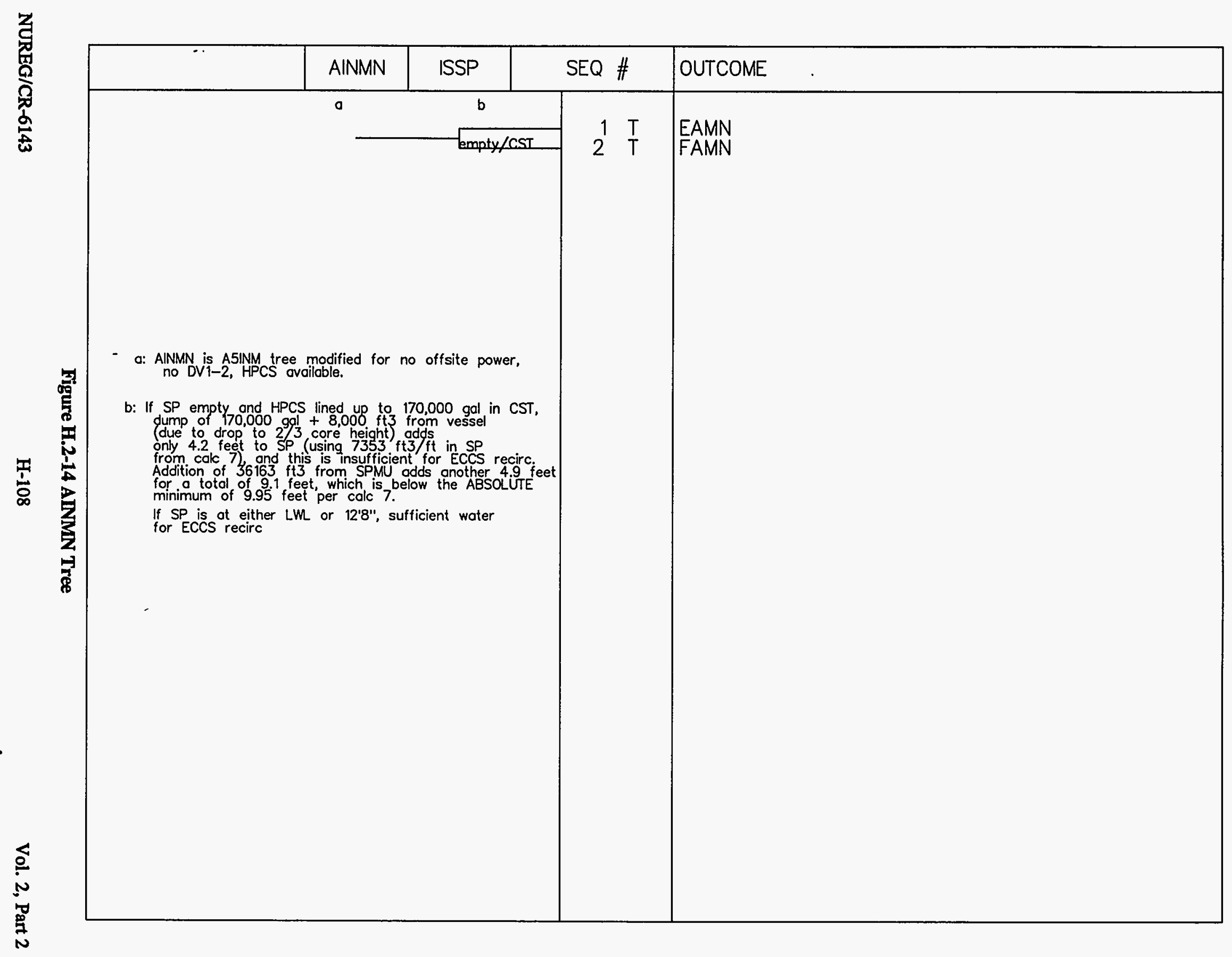




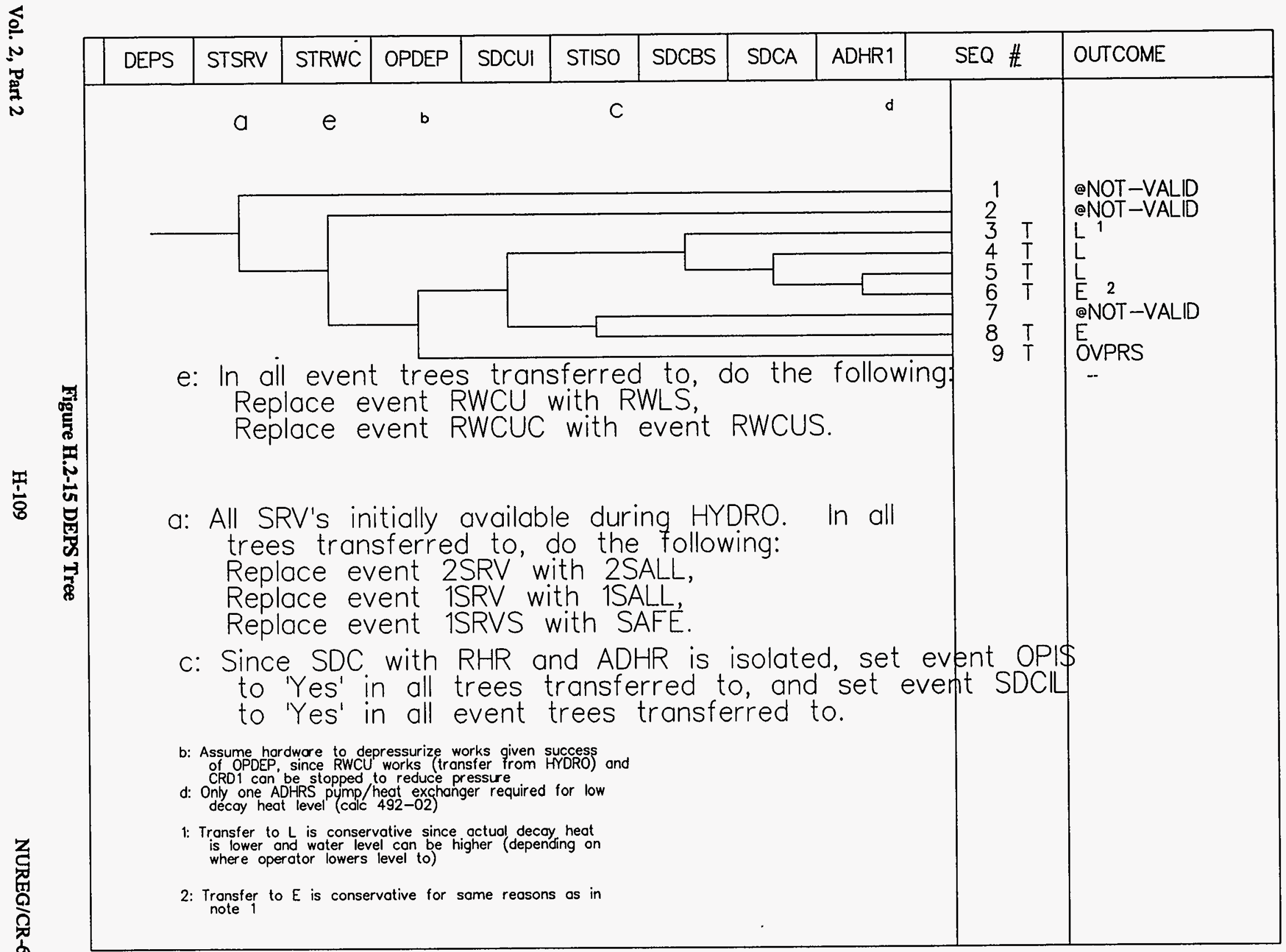




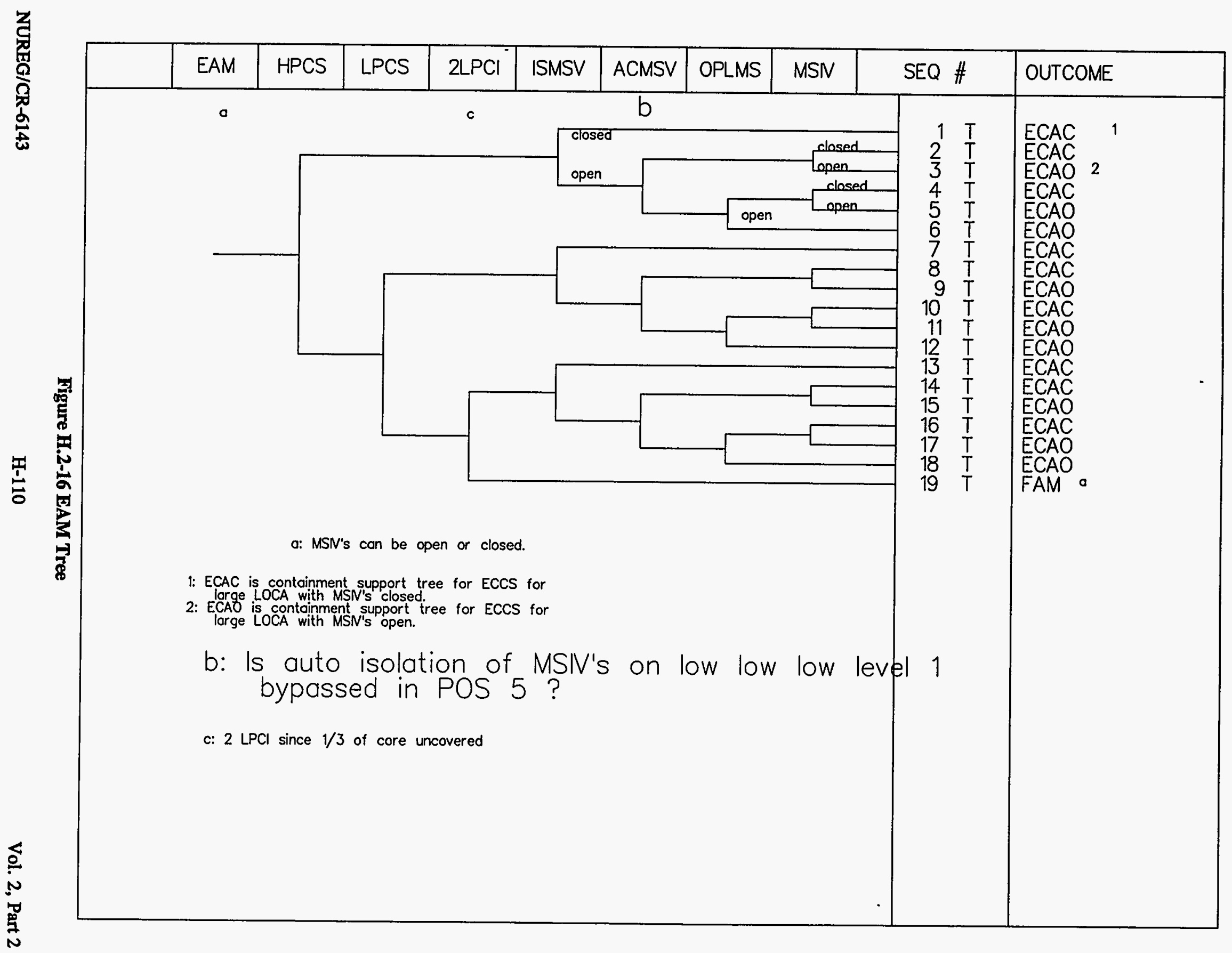




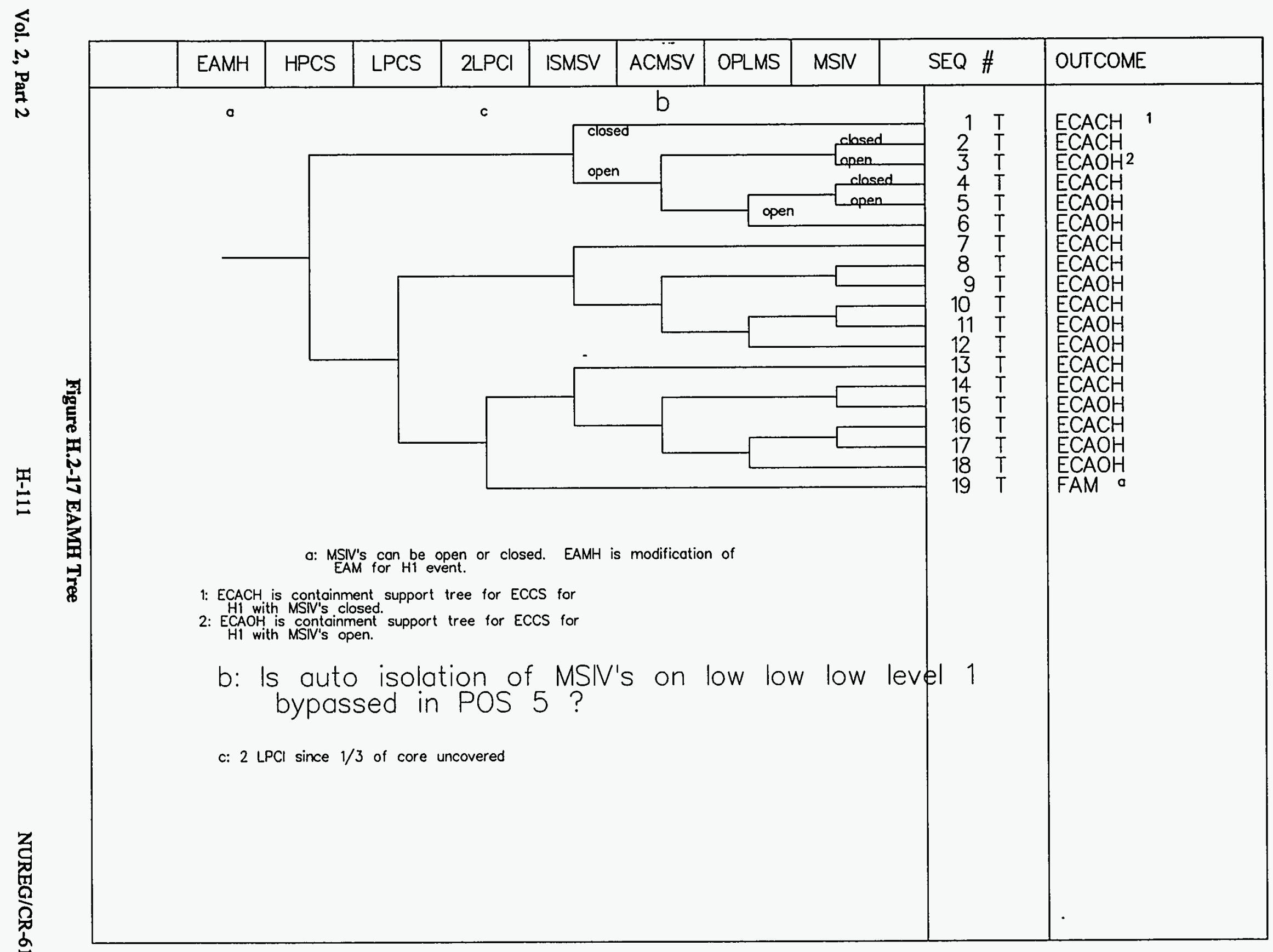




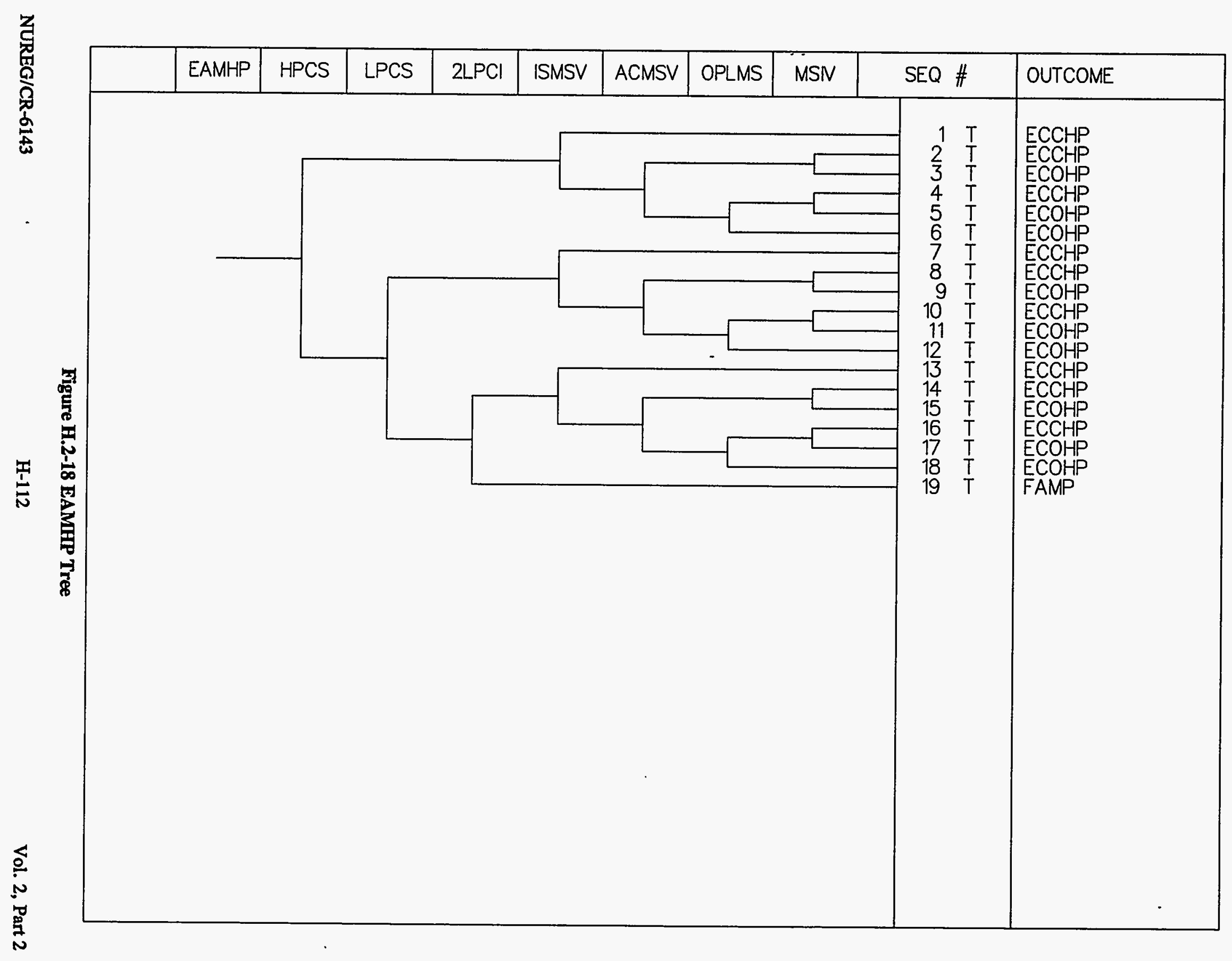




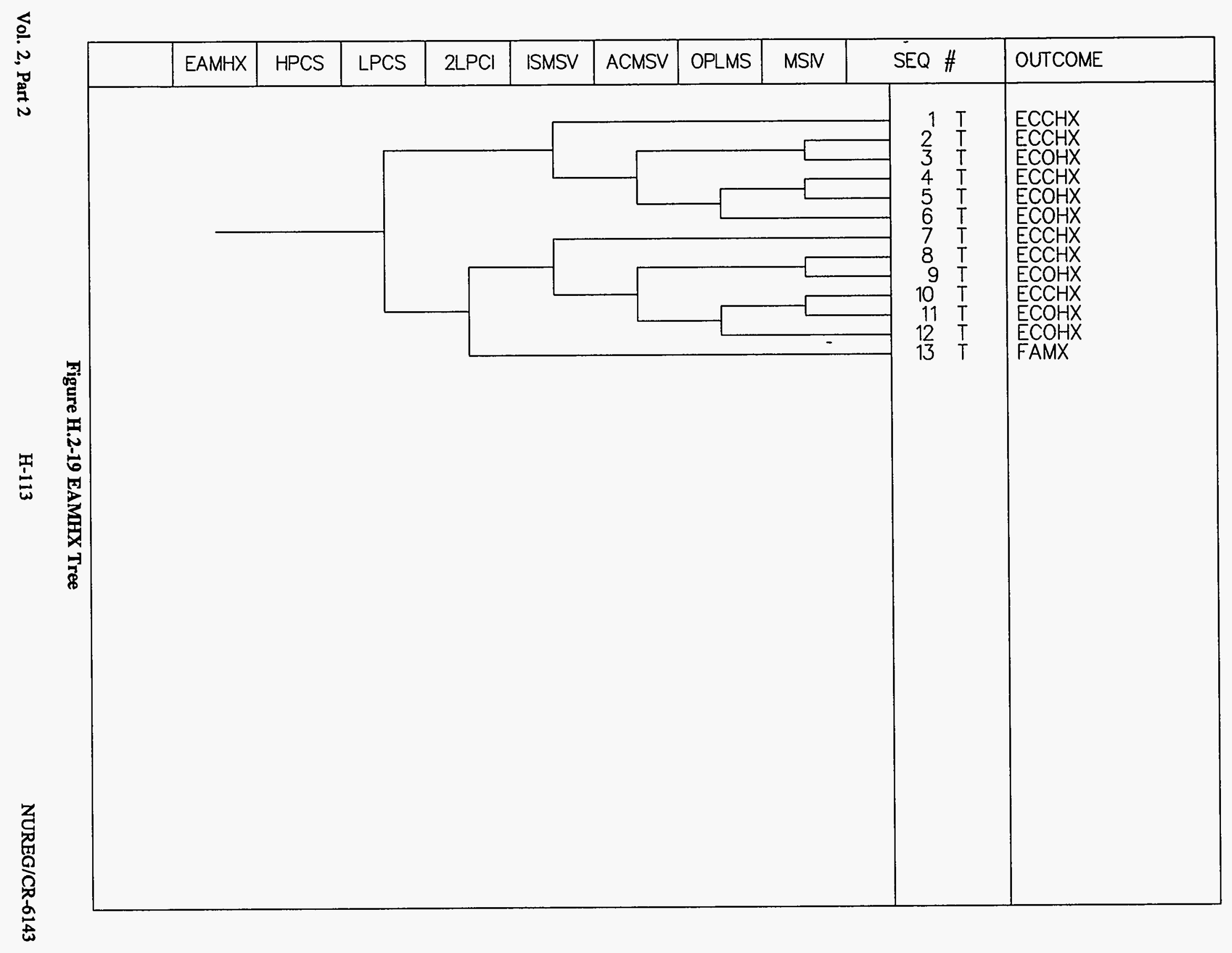




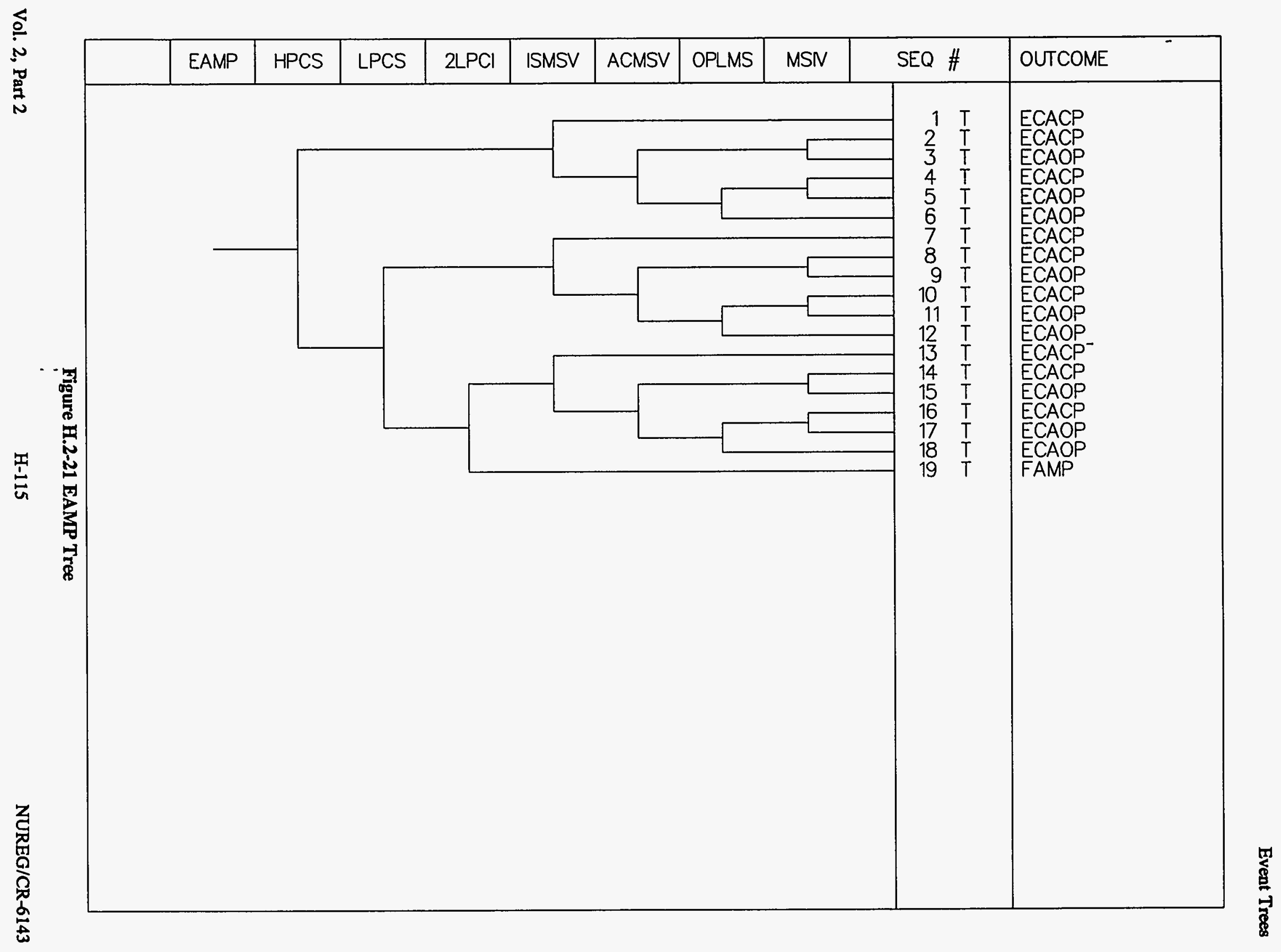




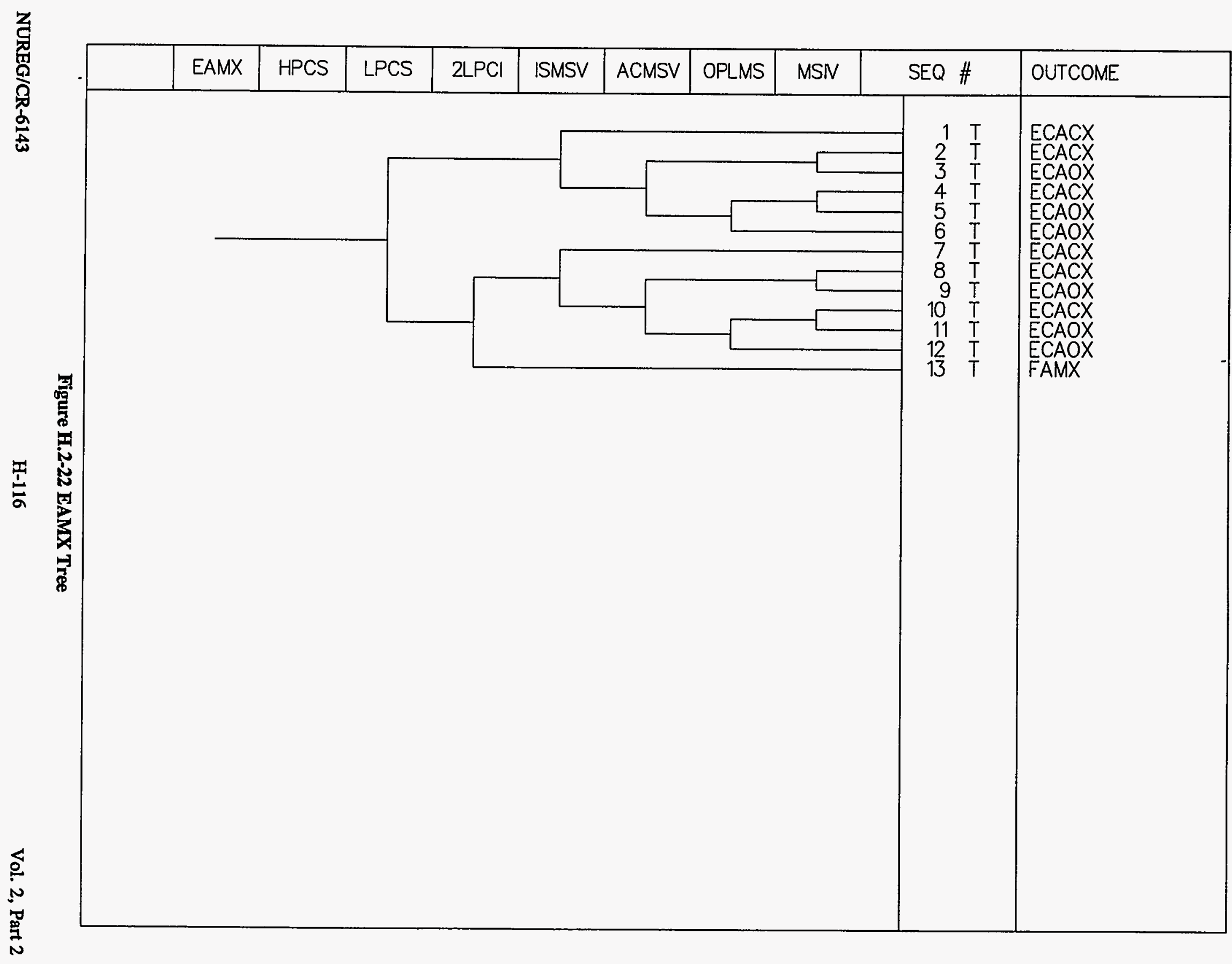




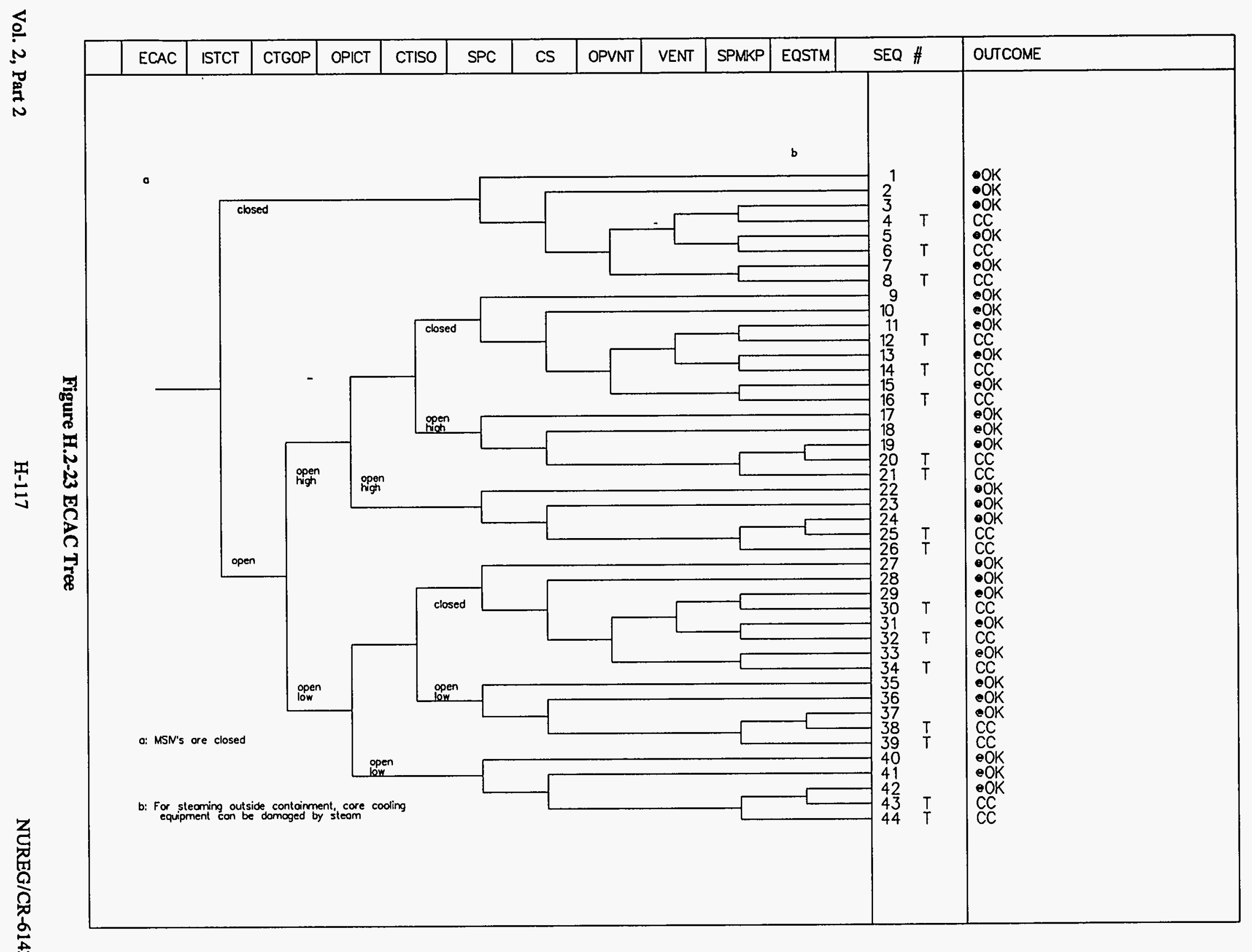

$\stackrel{9}{8}$
$\stackrel{9}{9}$
$\stackrel{7}{8}$ 


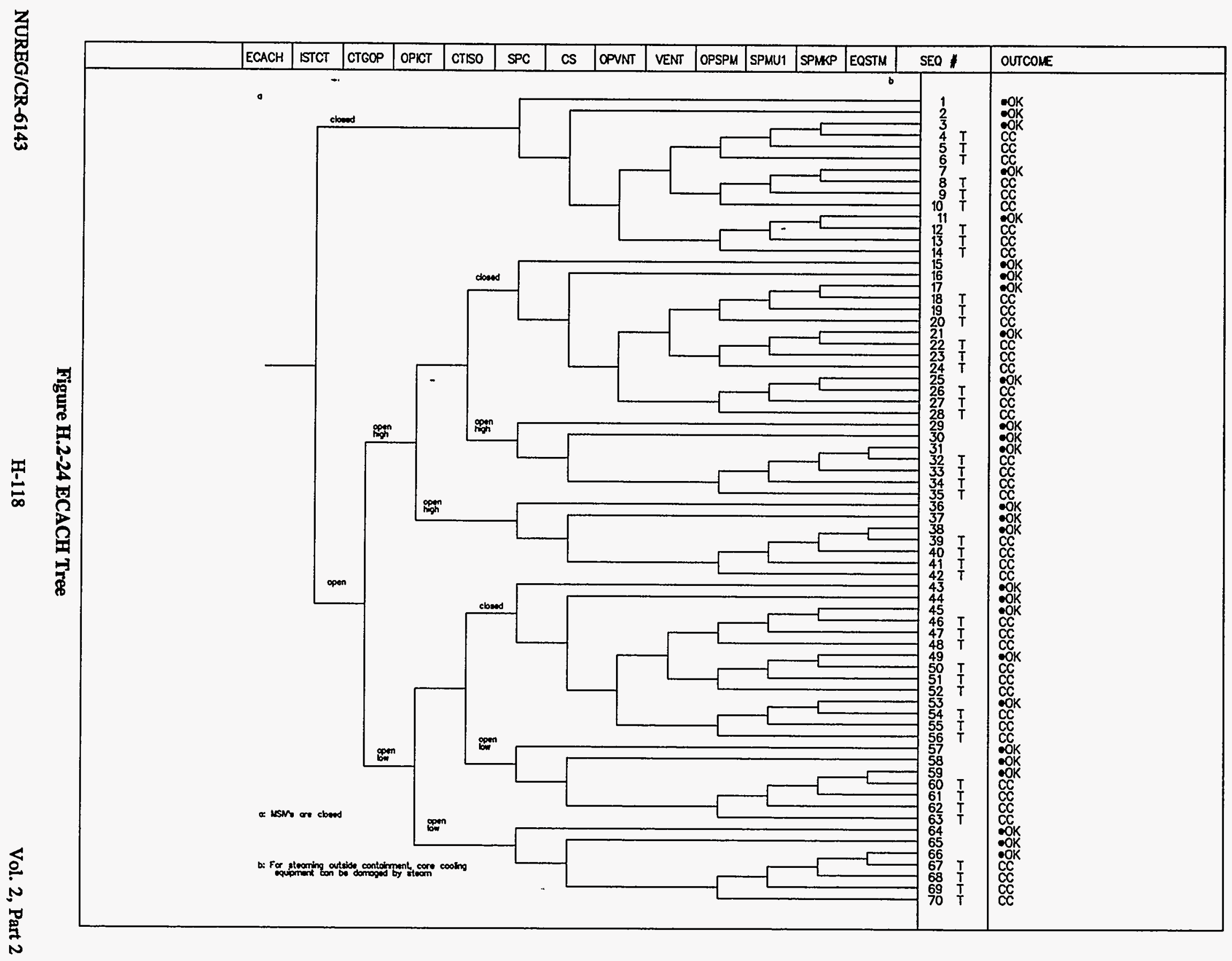




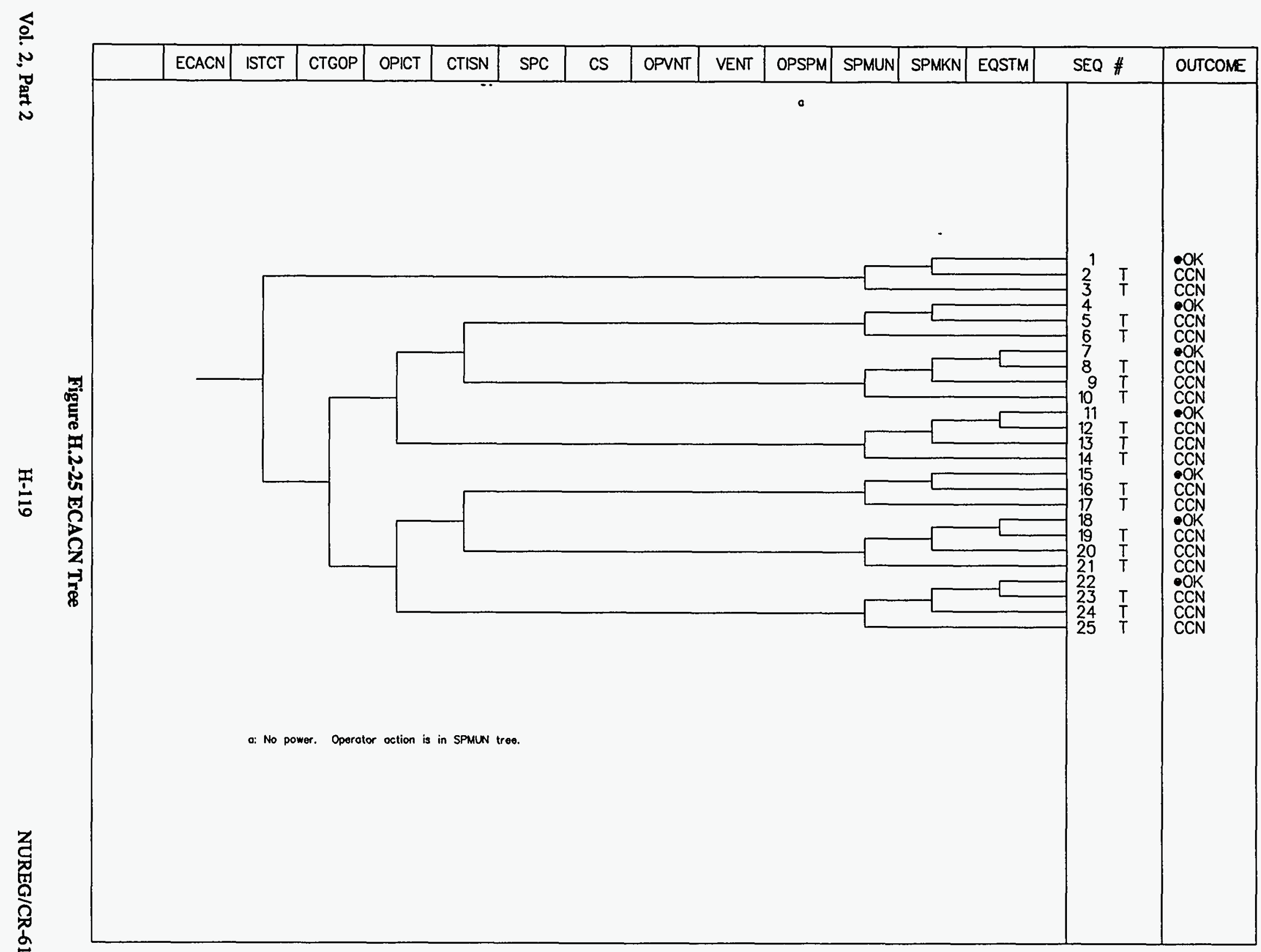




\section{Event Trees}

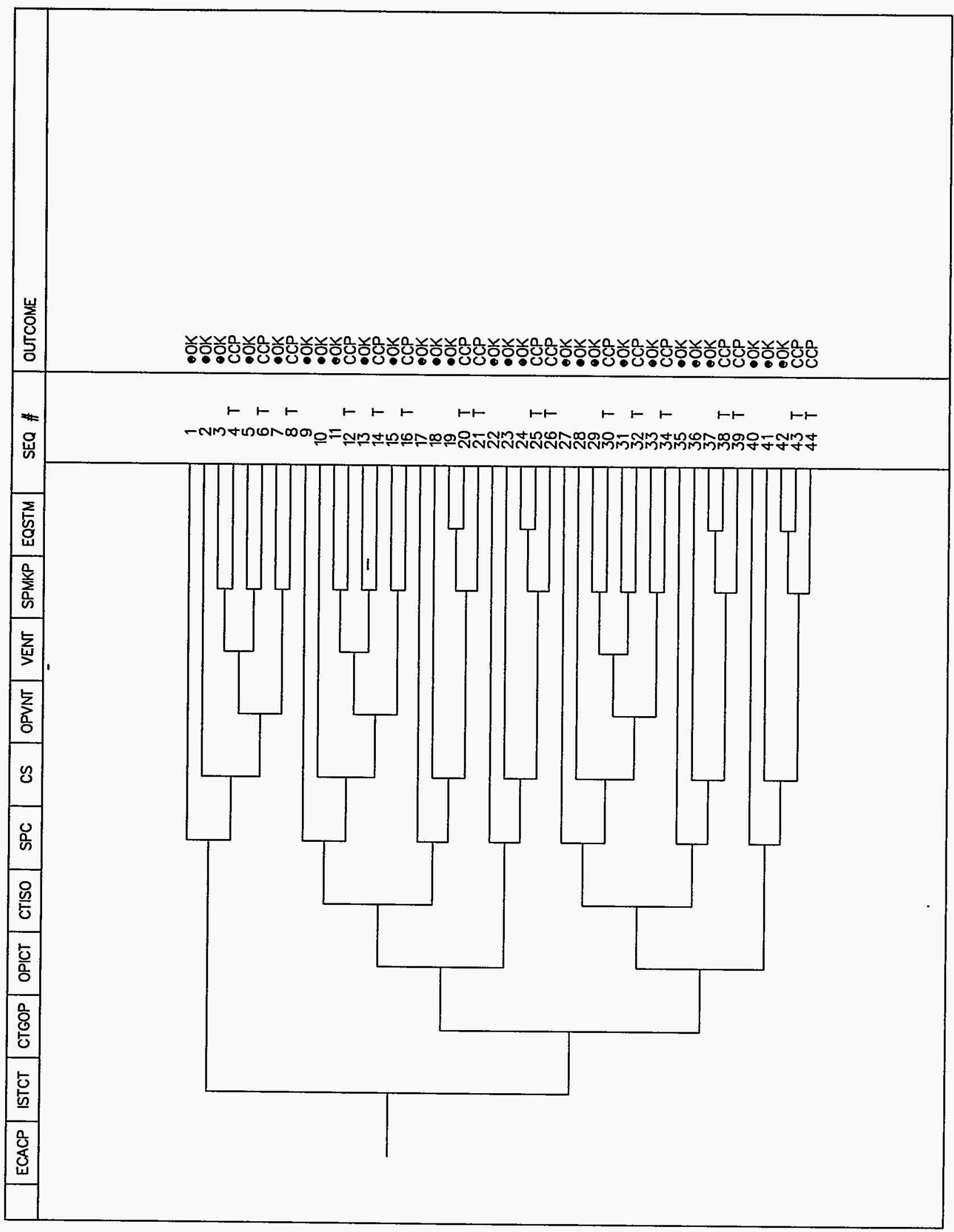

Figure H.2-26 ECACP Tree 


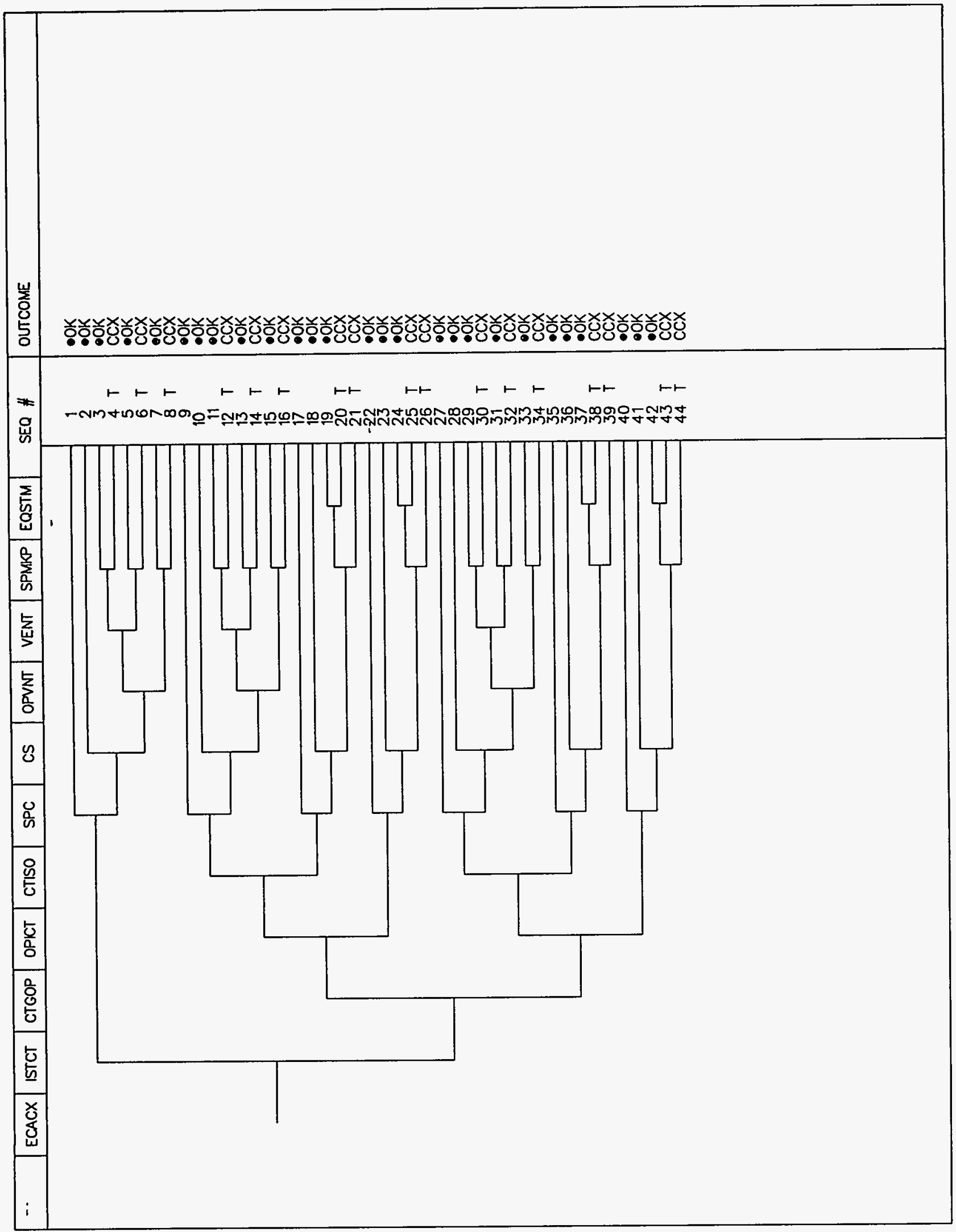

Figure H.2-27 ECACX Tree 


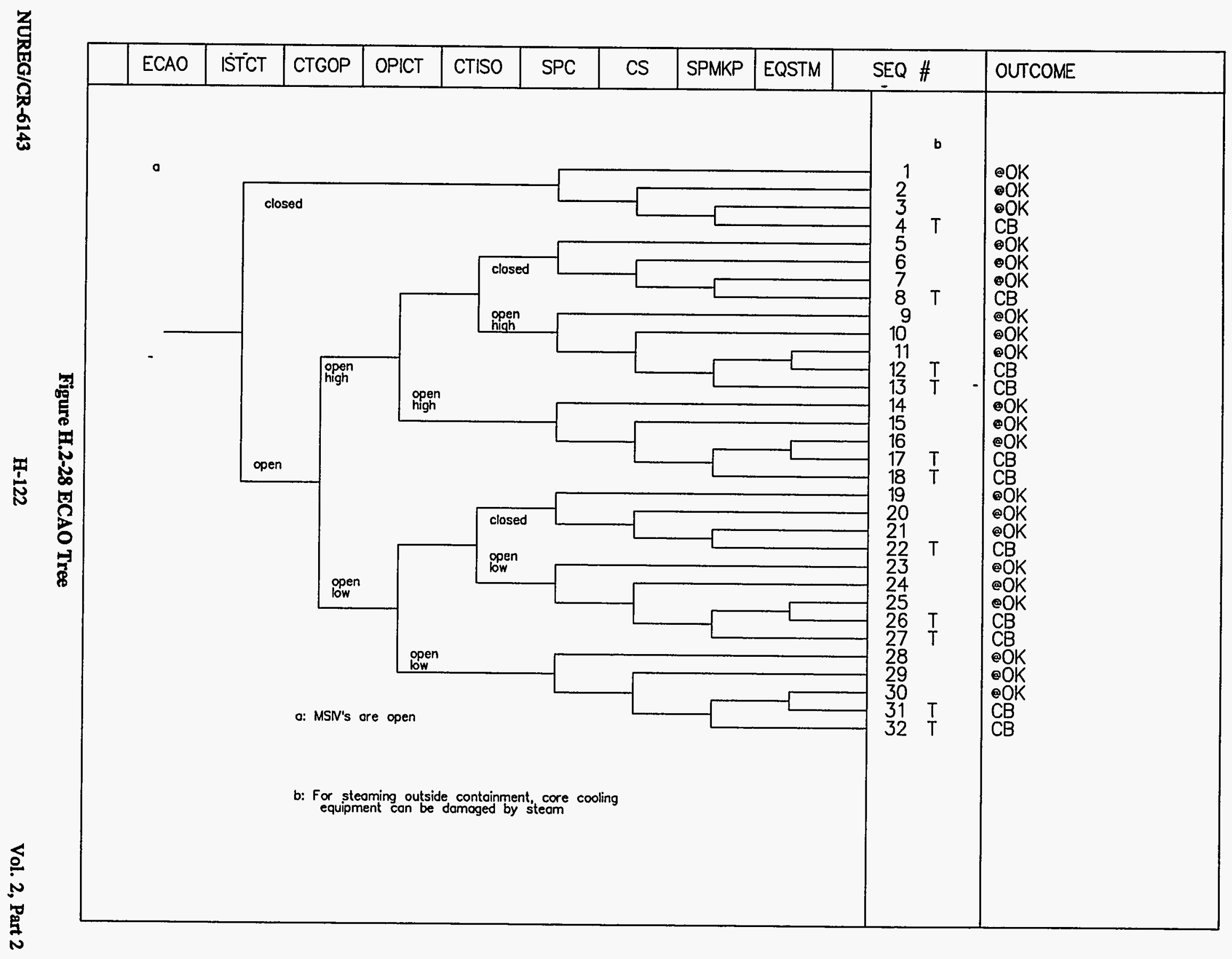




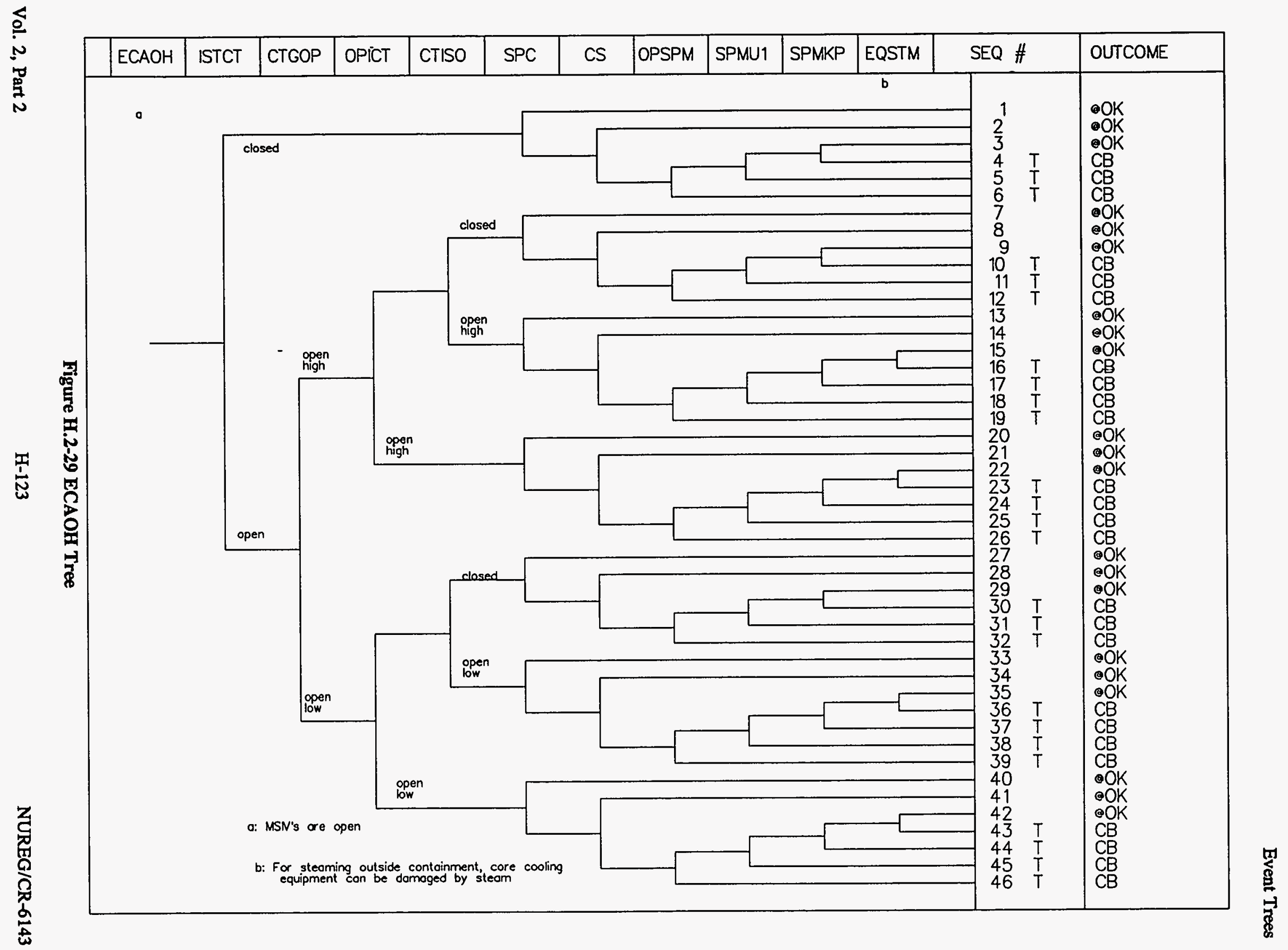




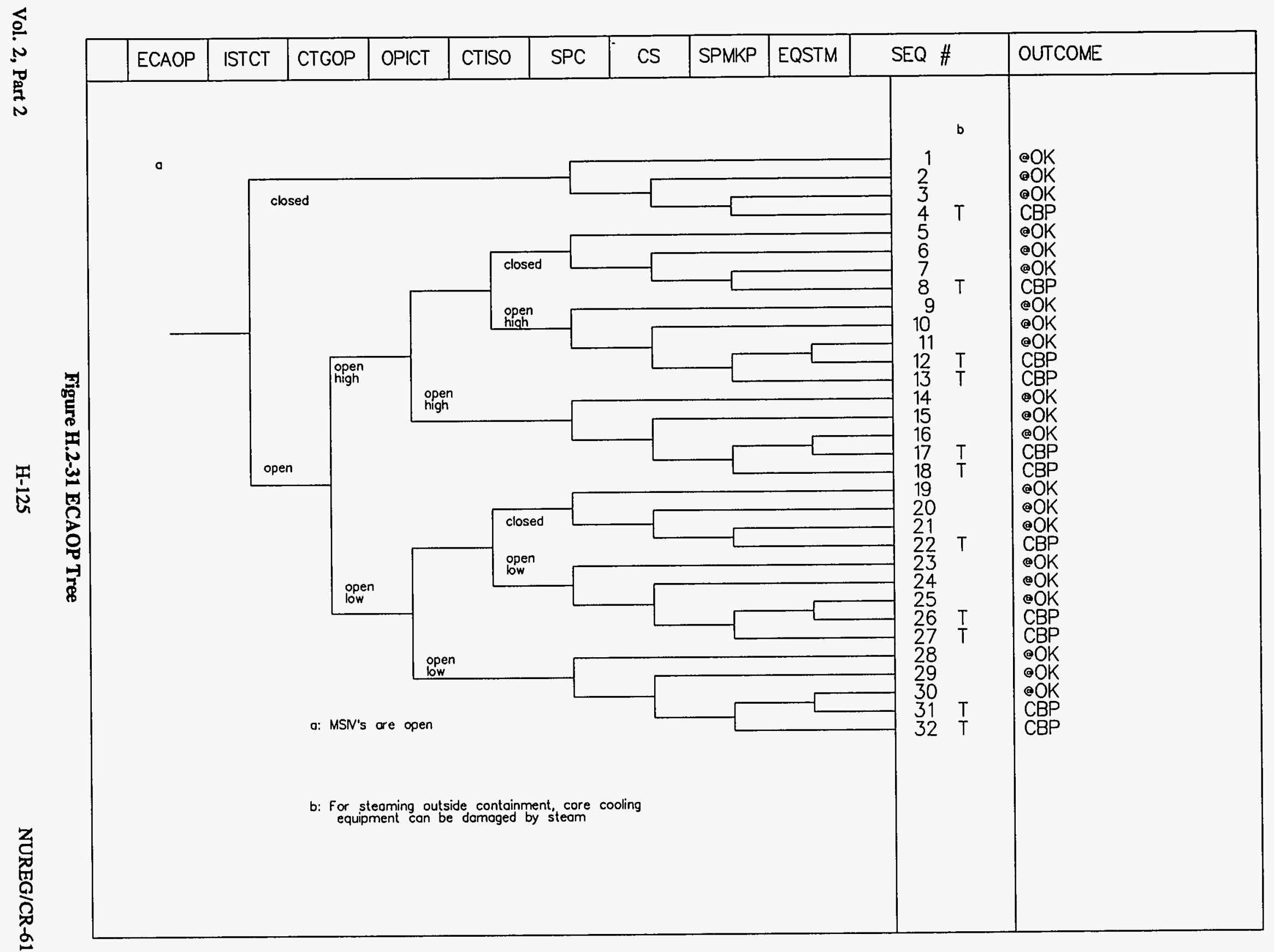




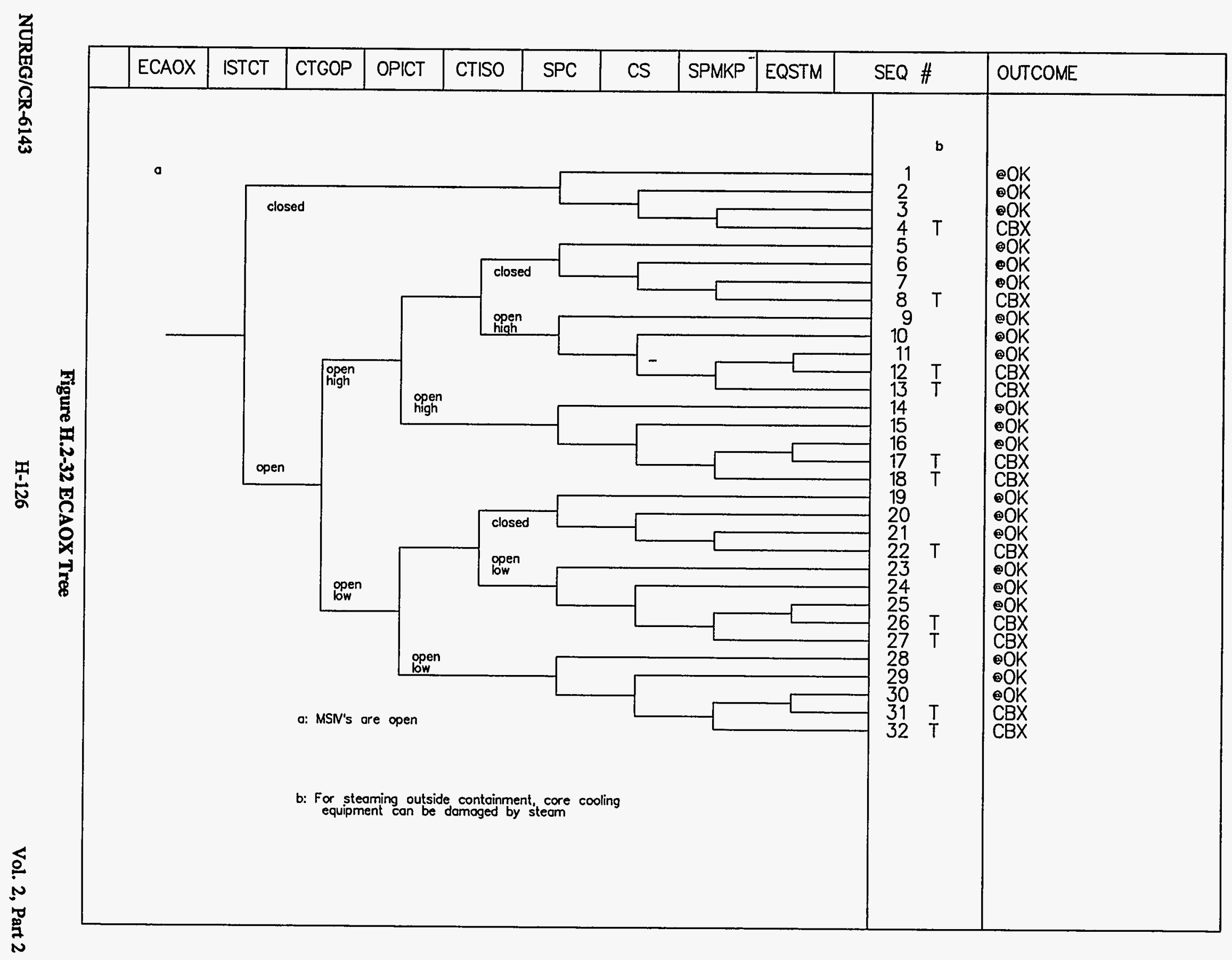




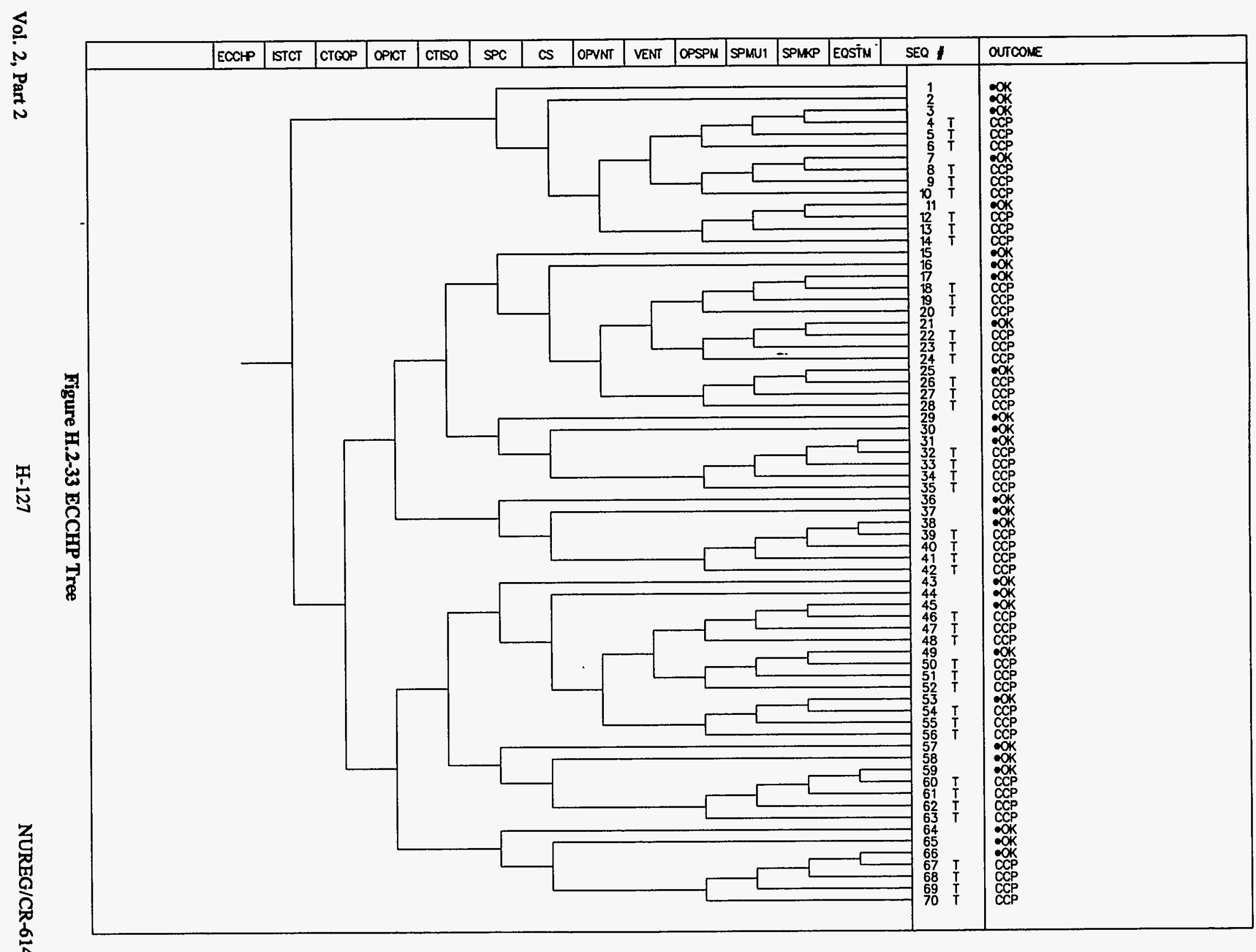

营 


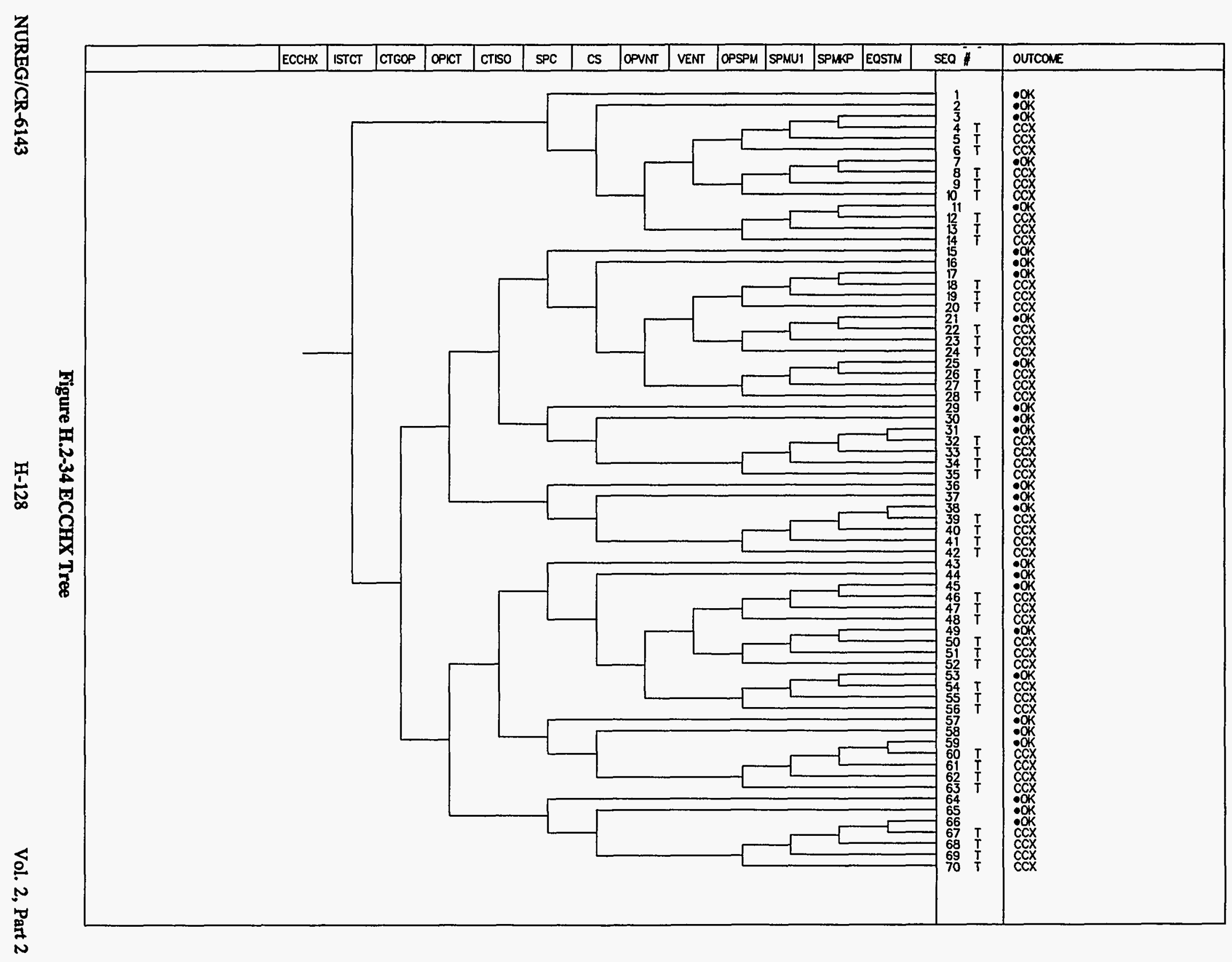


Event Trees

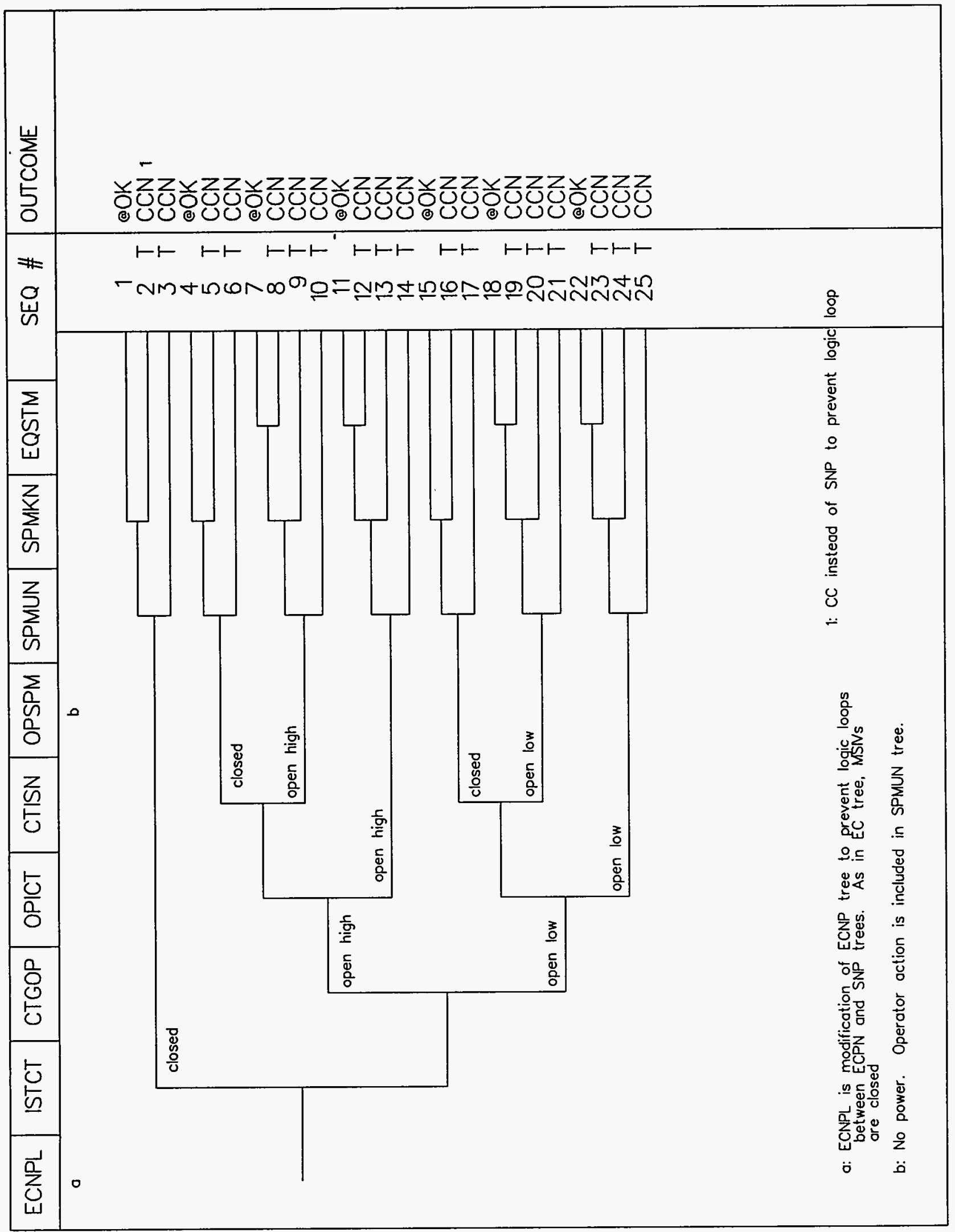

Figure H.2-35 ECNPL Tree 


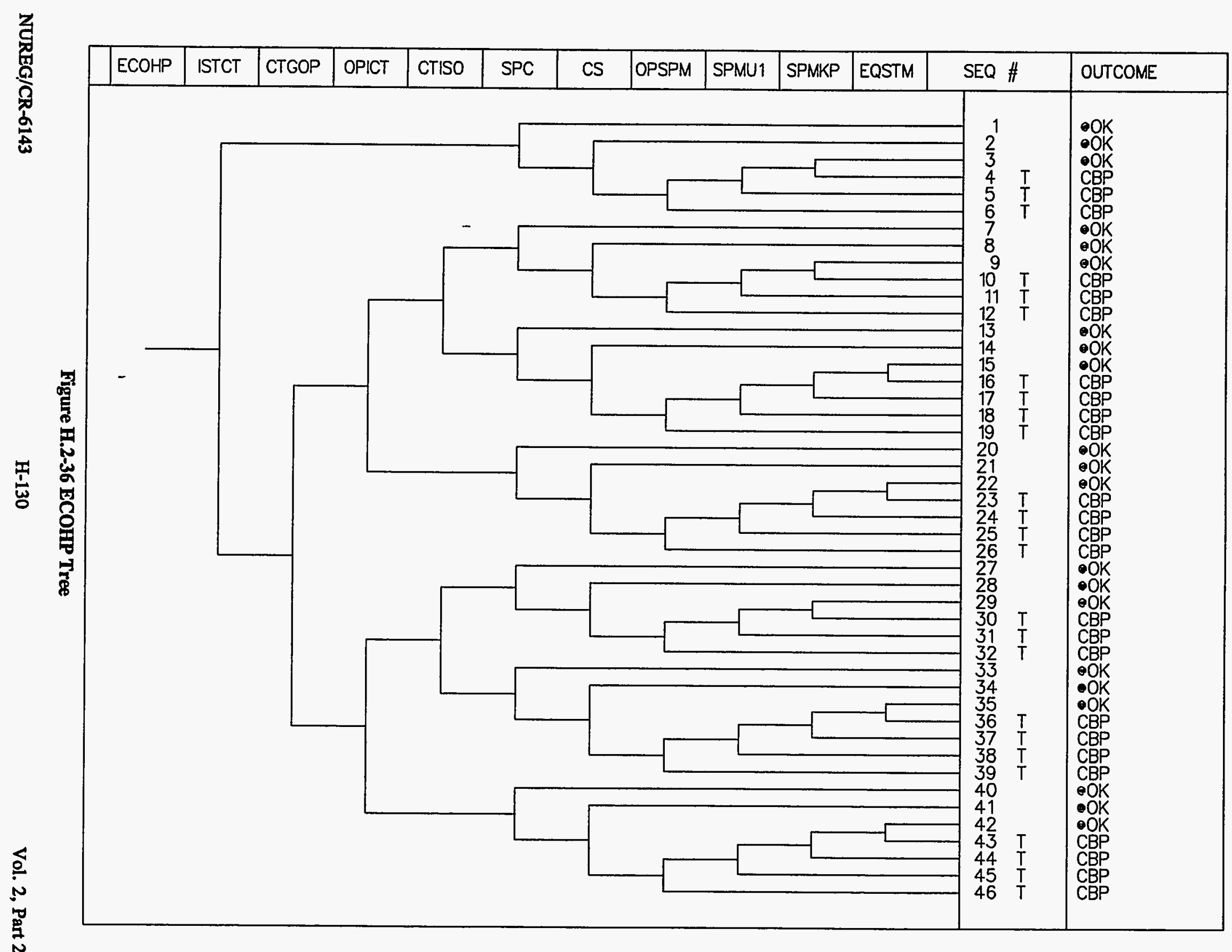




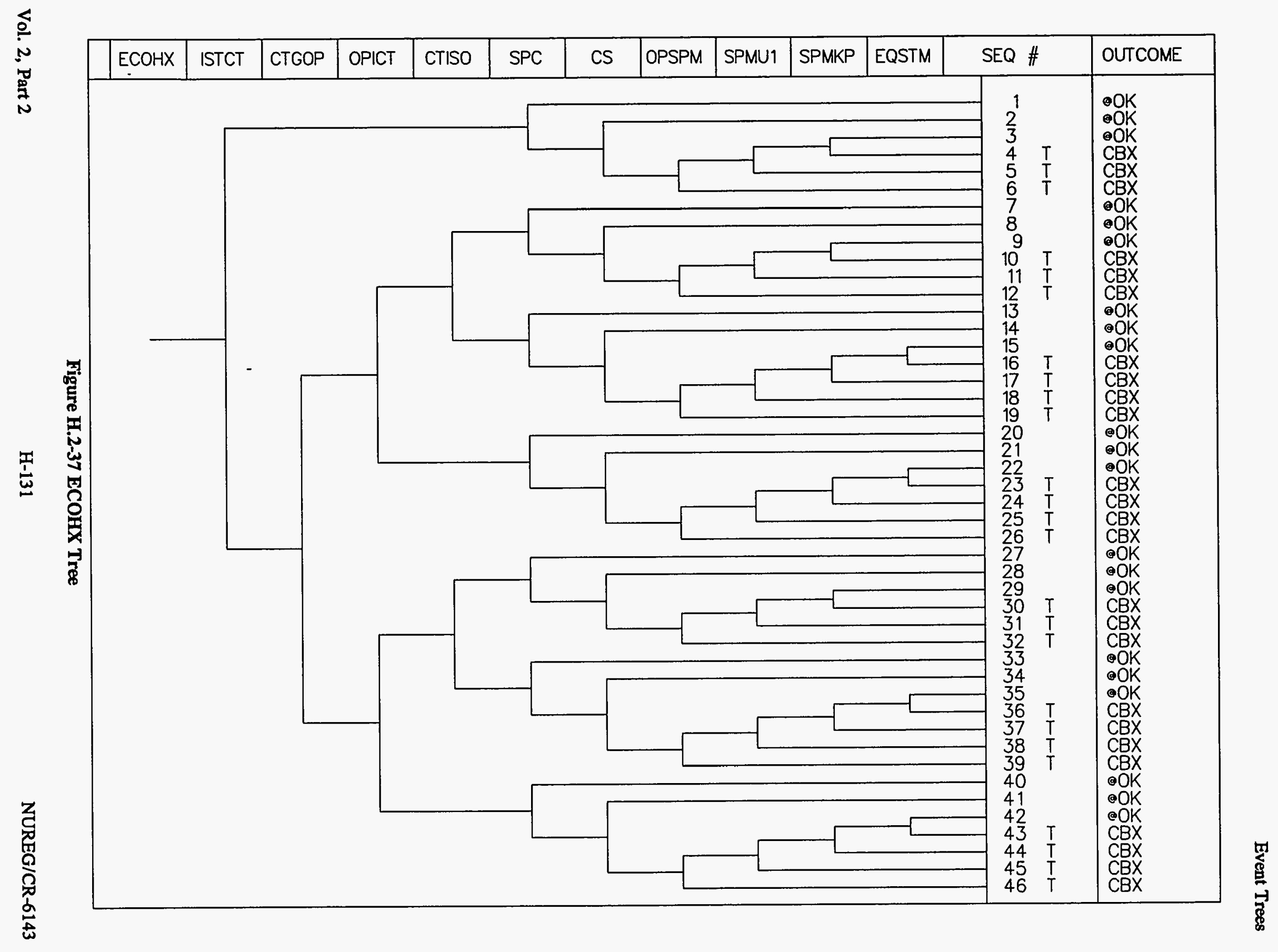




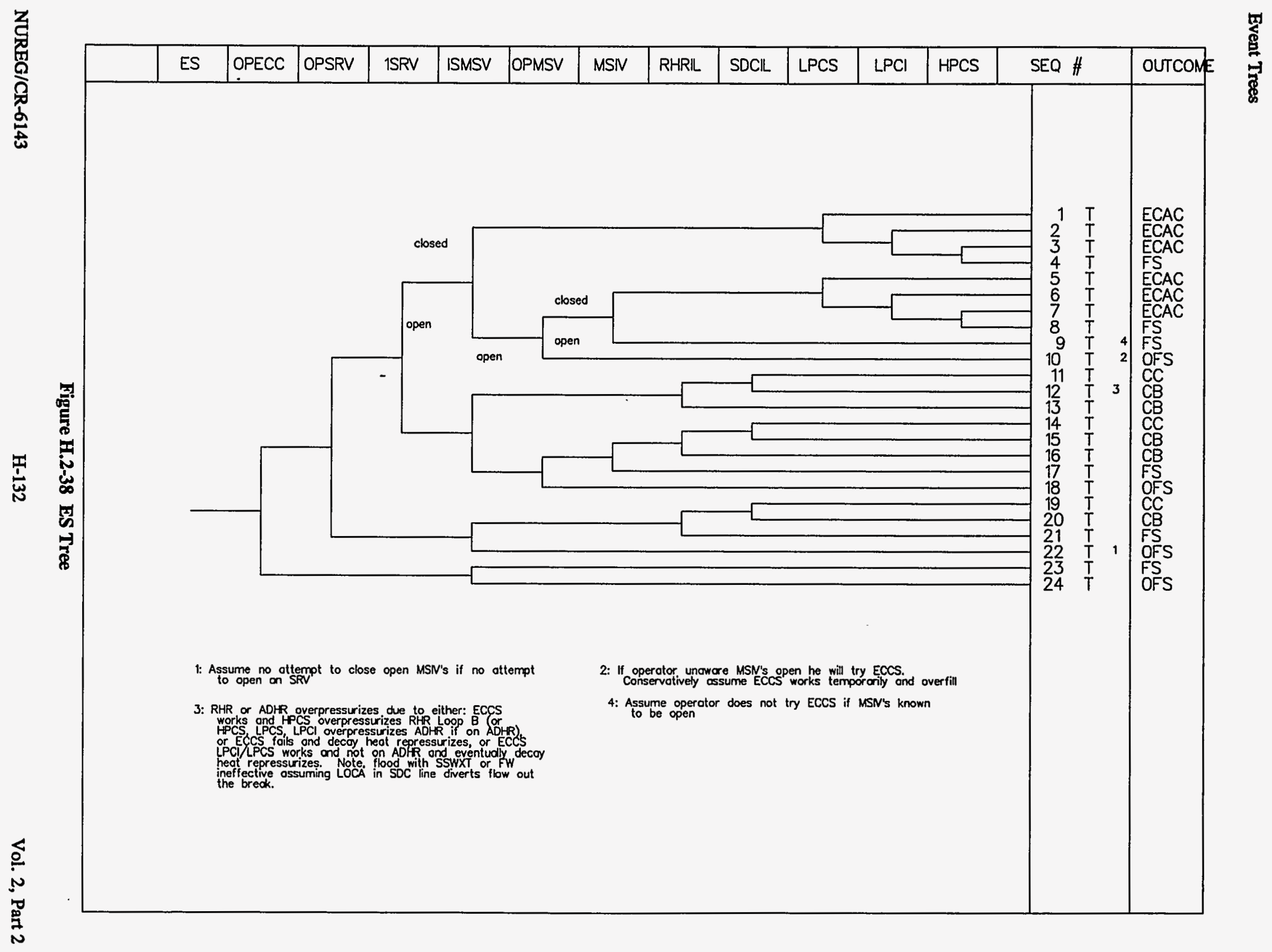


Event Trees

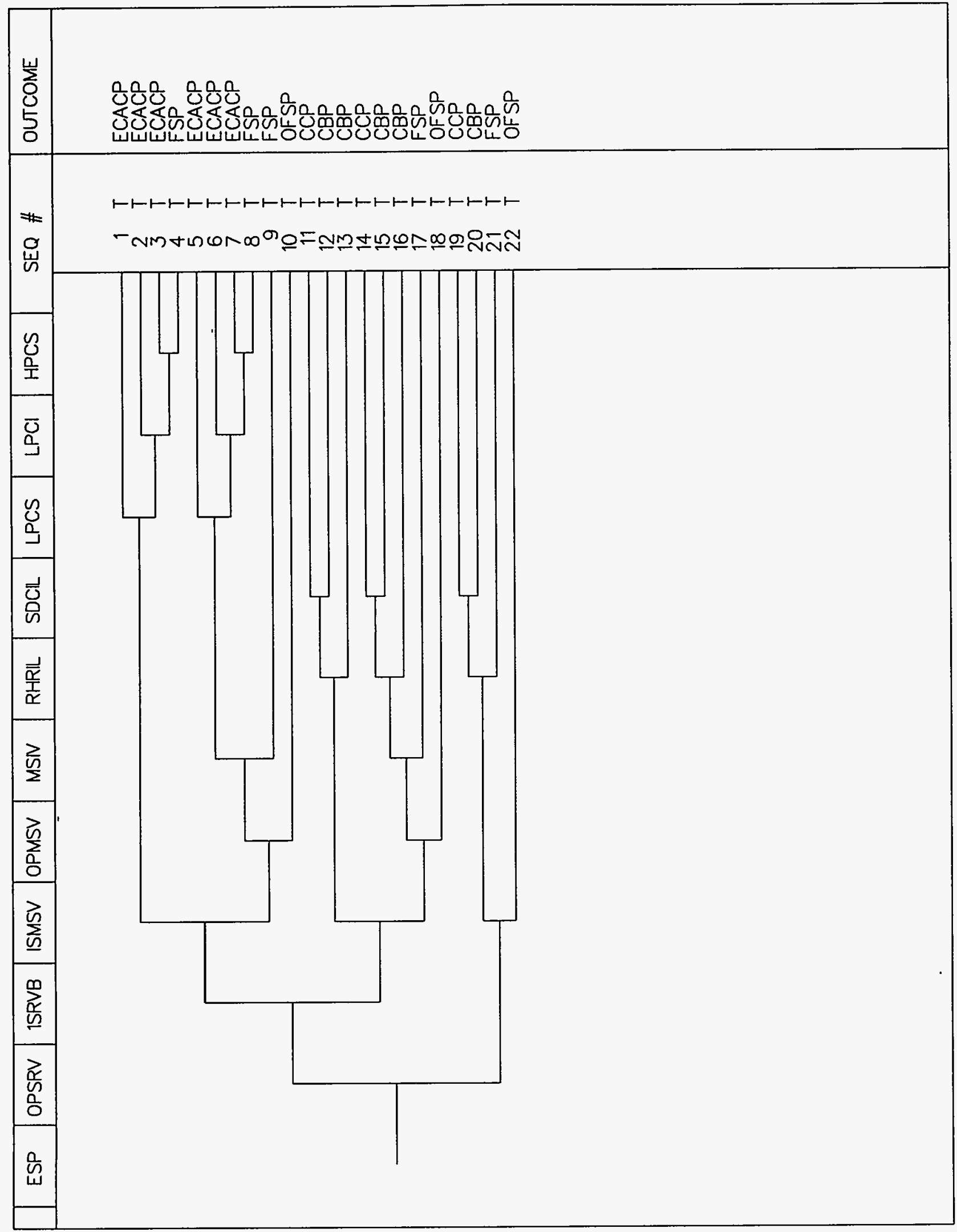

Figure H.2-39 ESP Tree

Vol. 2, Part 2

H-133

NUREG/CR-6143 
Event Trees

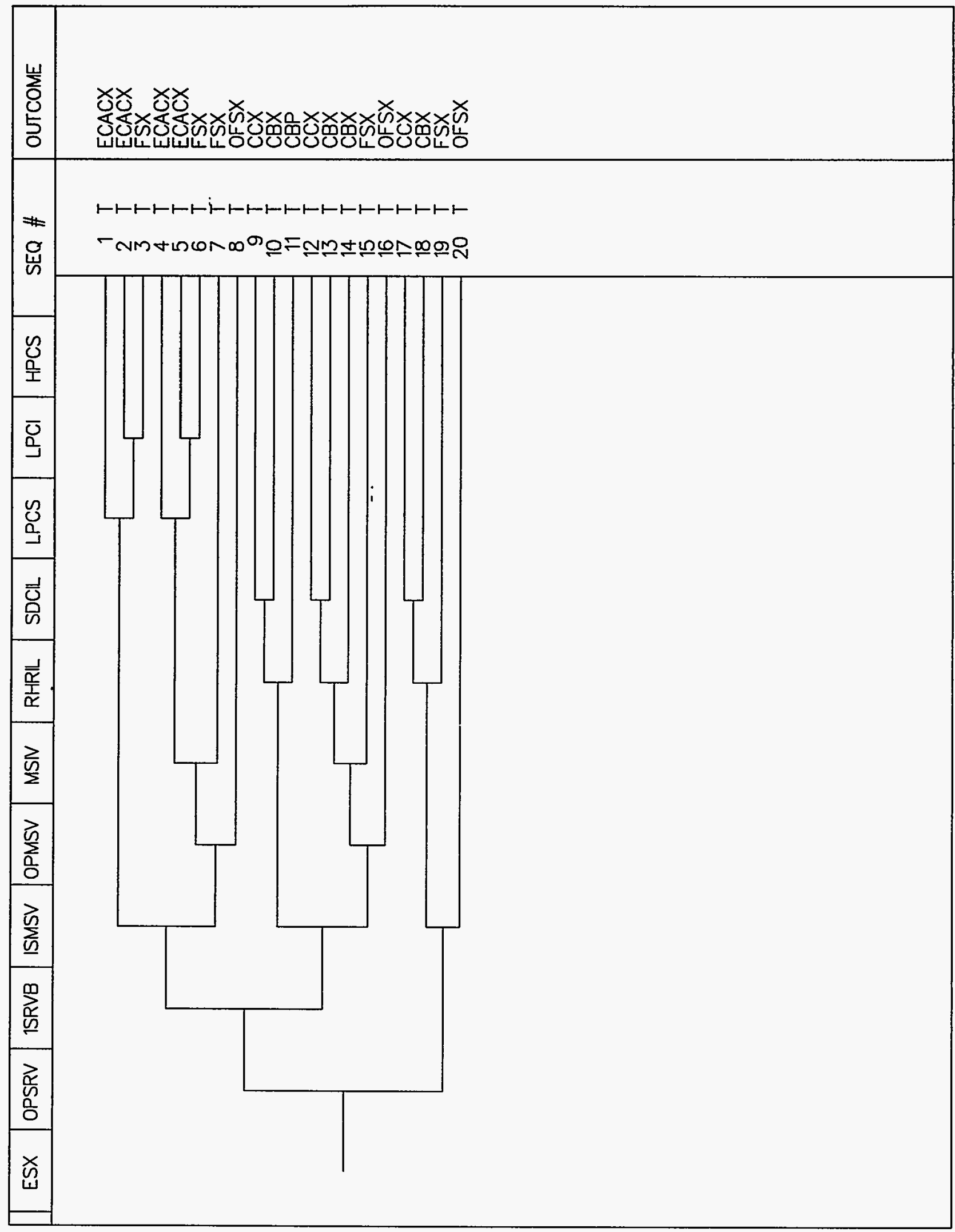

Figure H.2-40 ESX Tree 


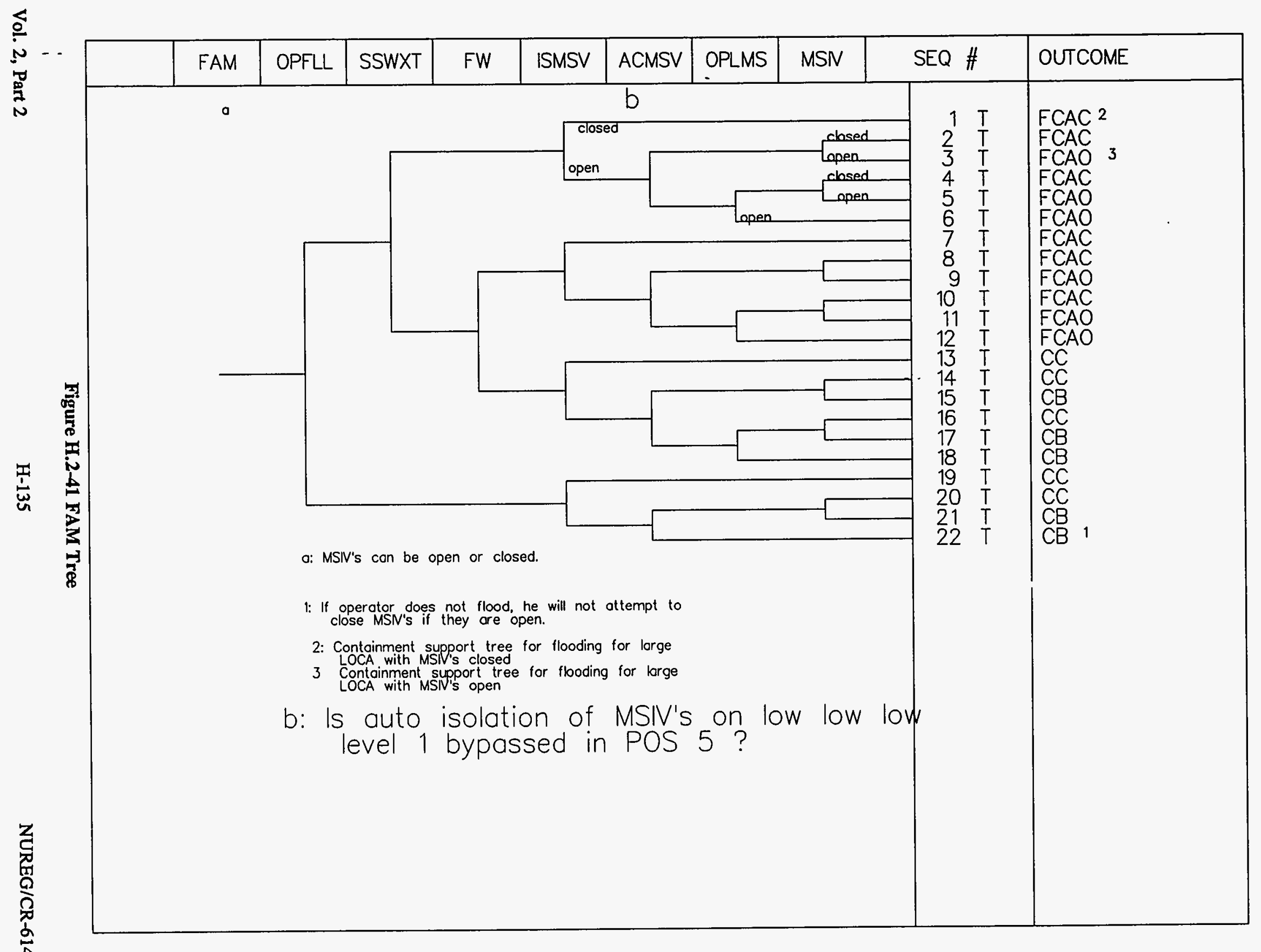




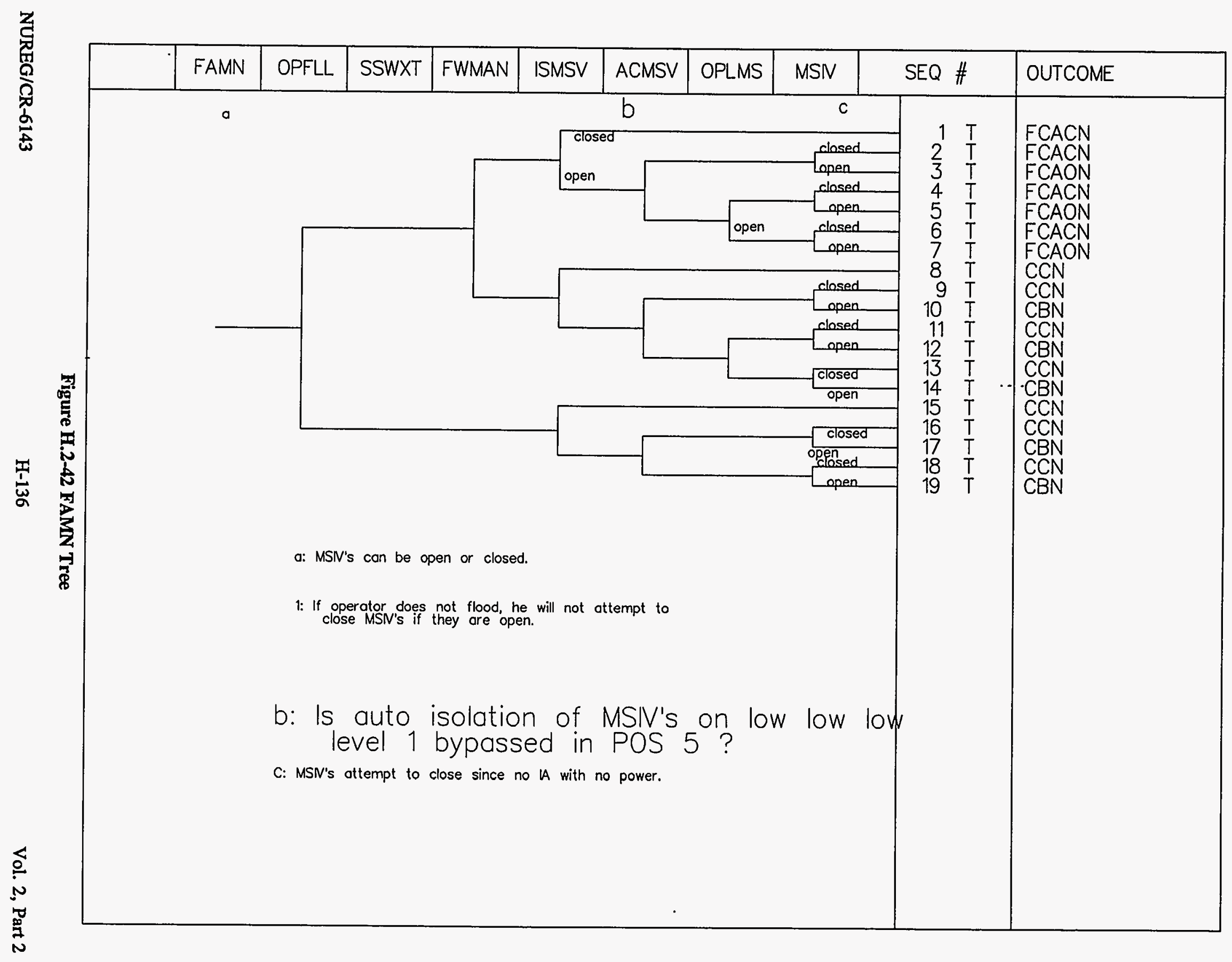




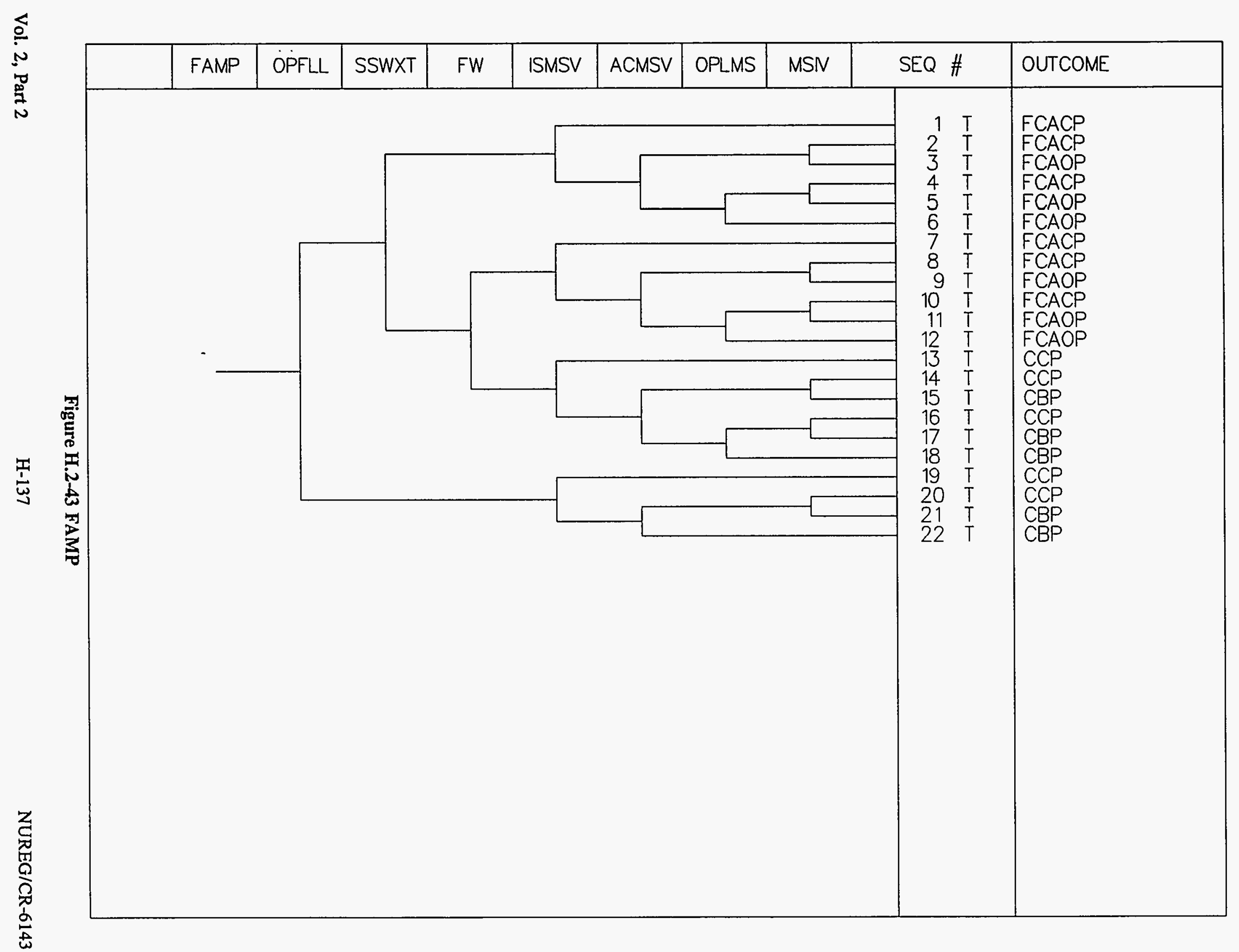

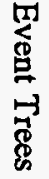




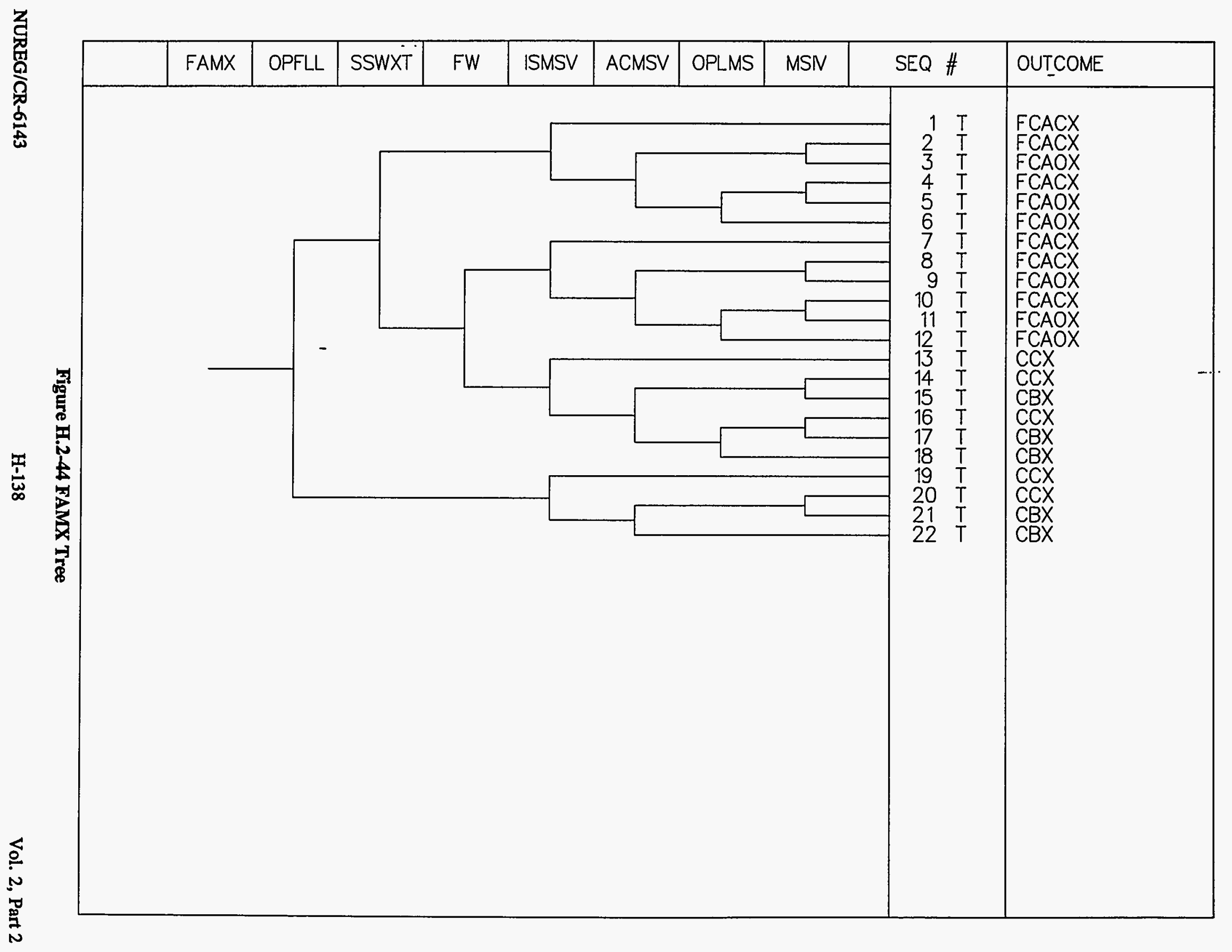




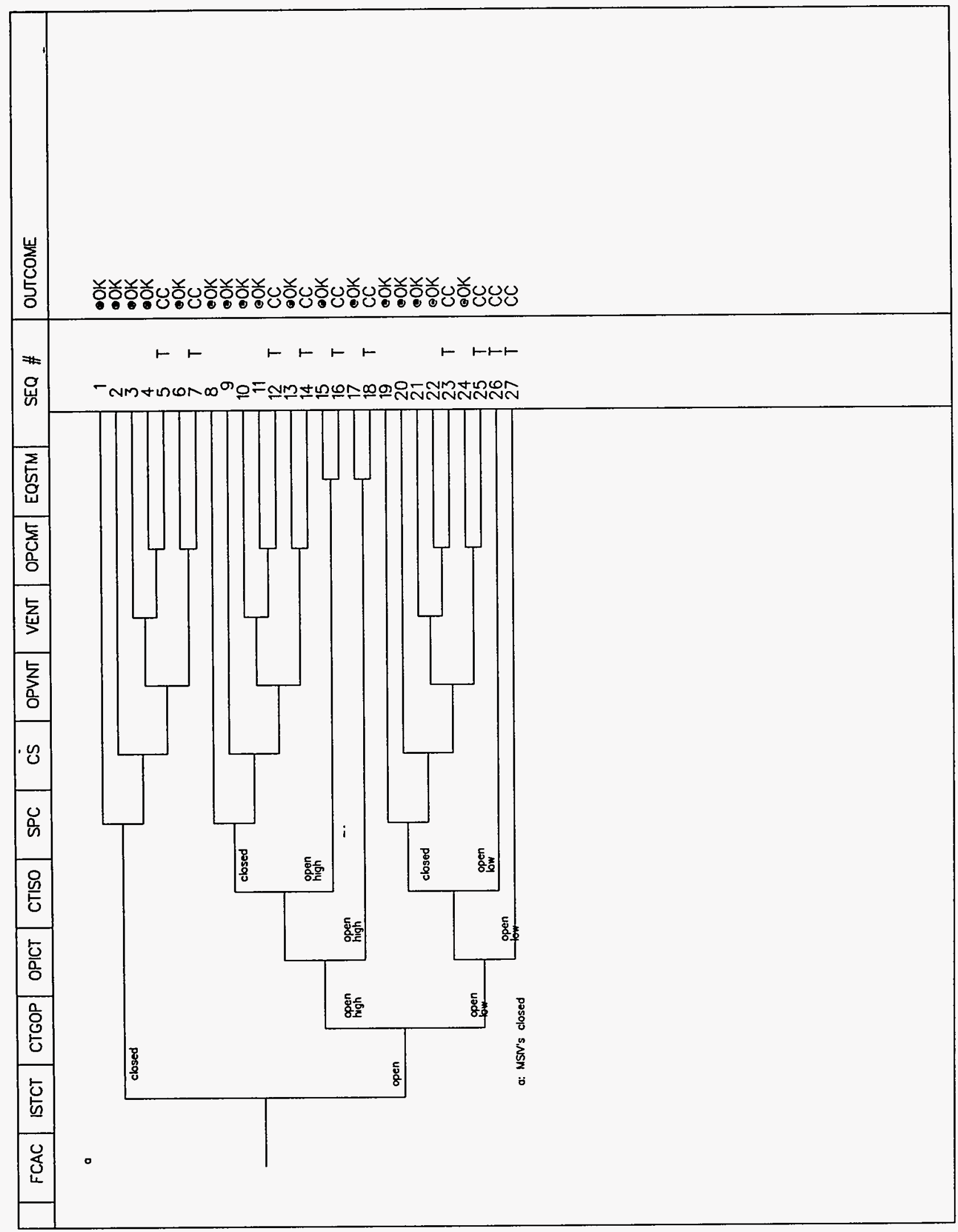

Figure H.2-45 FCAC Tree 
Event Trees

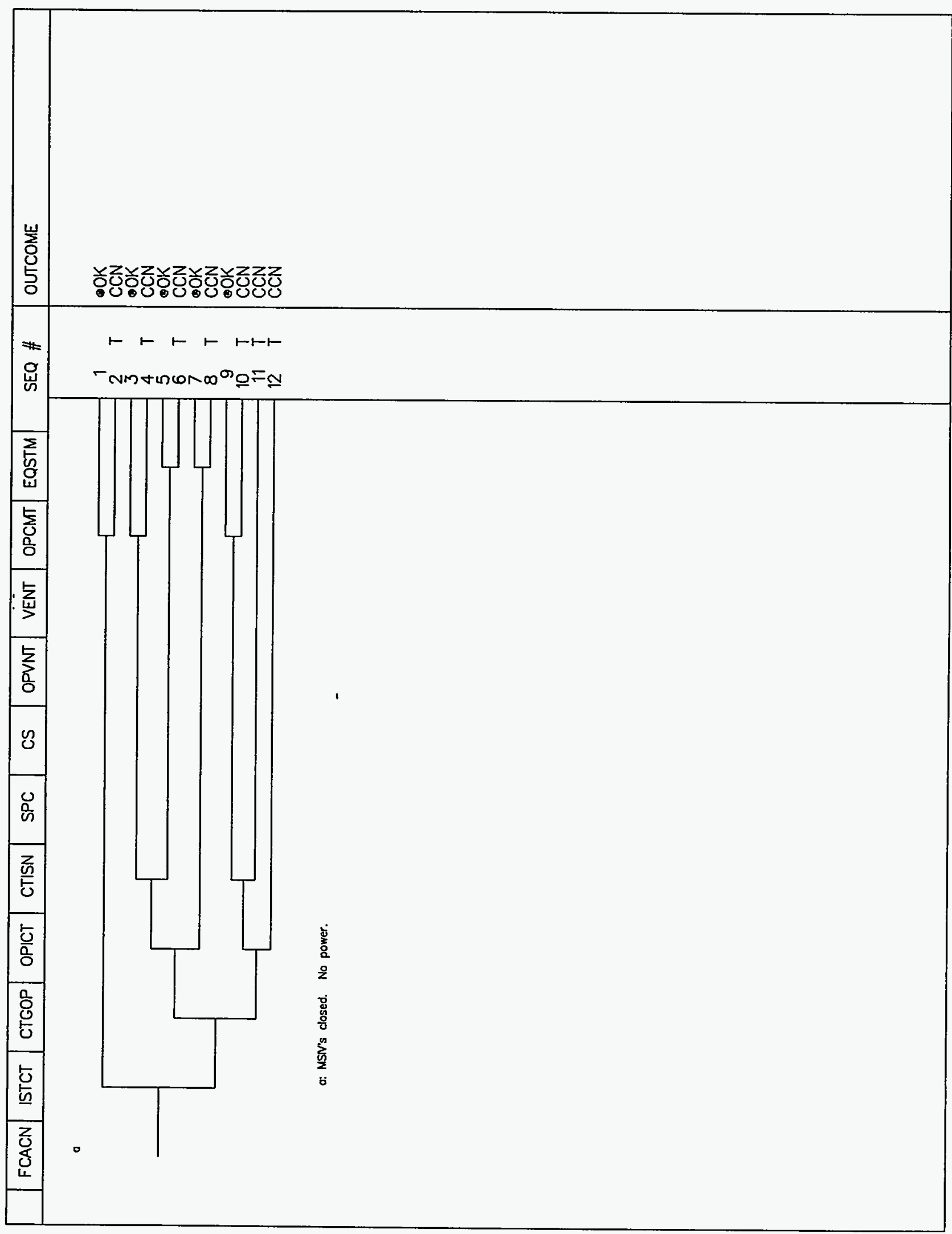

Figure H.2-46 FCACN Tree 


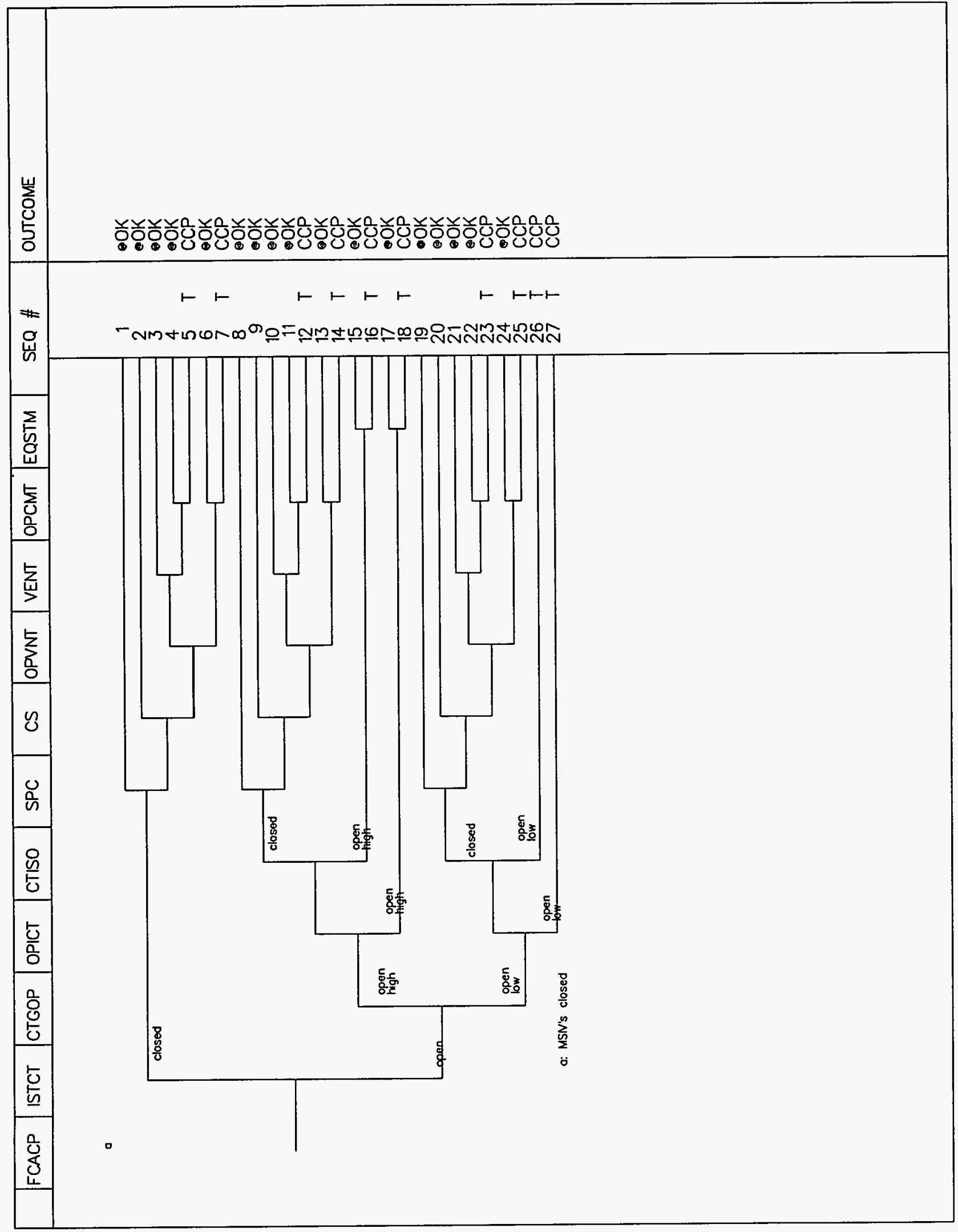

Figure H.2-47 FCACP Tree 


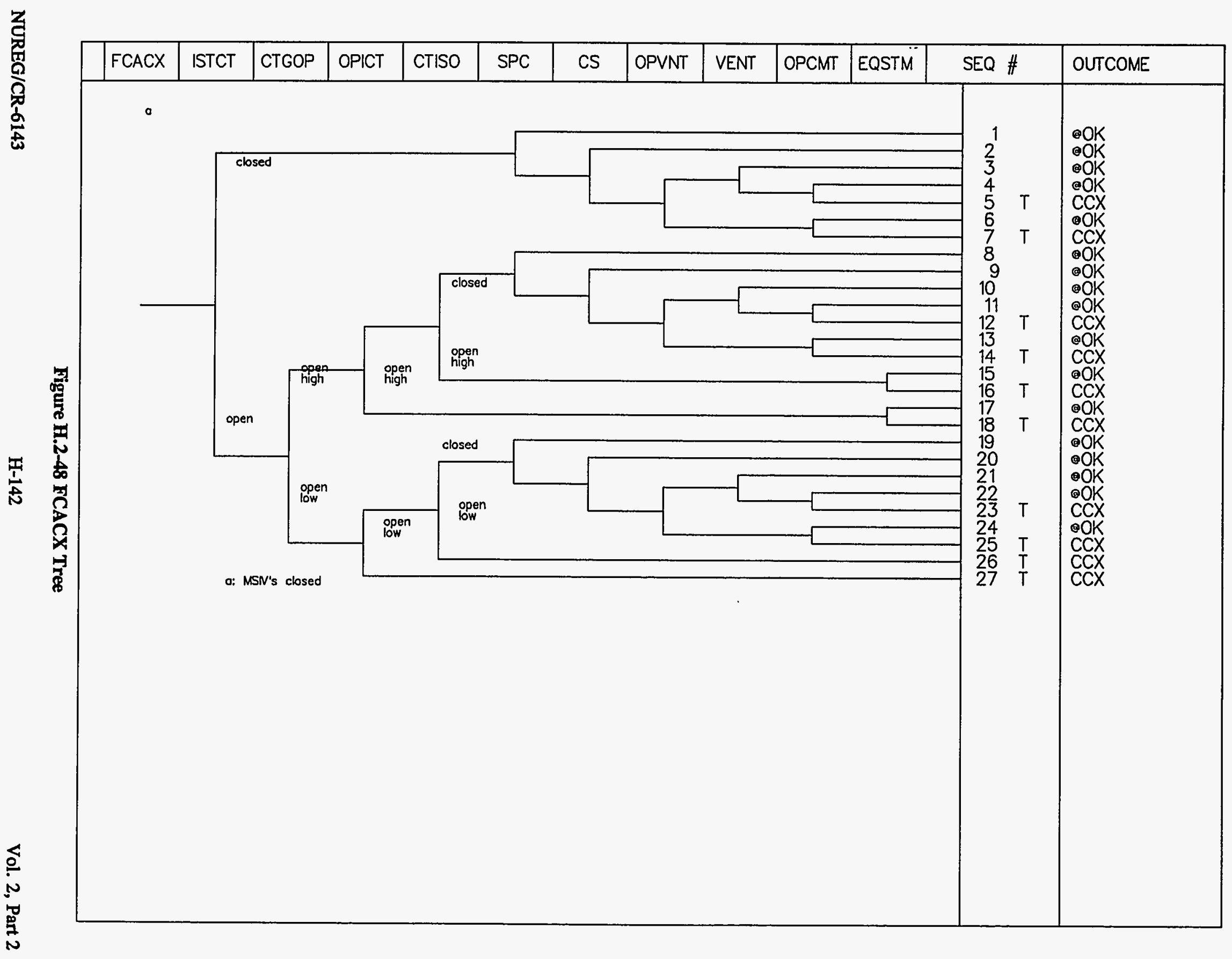




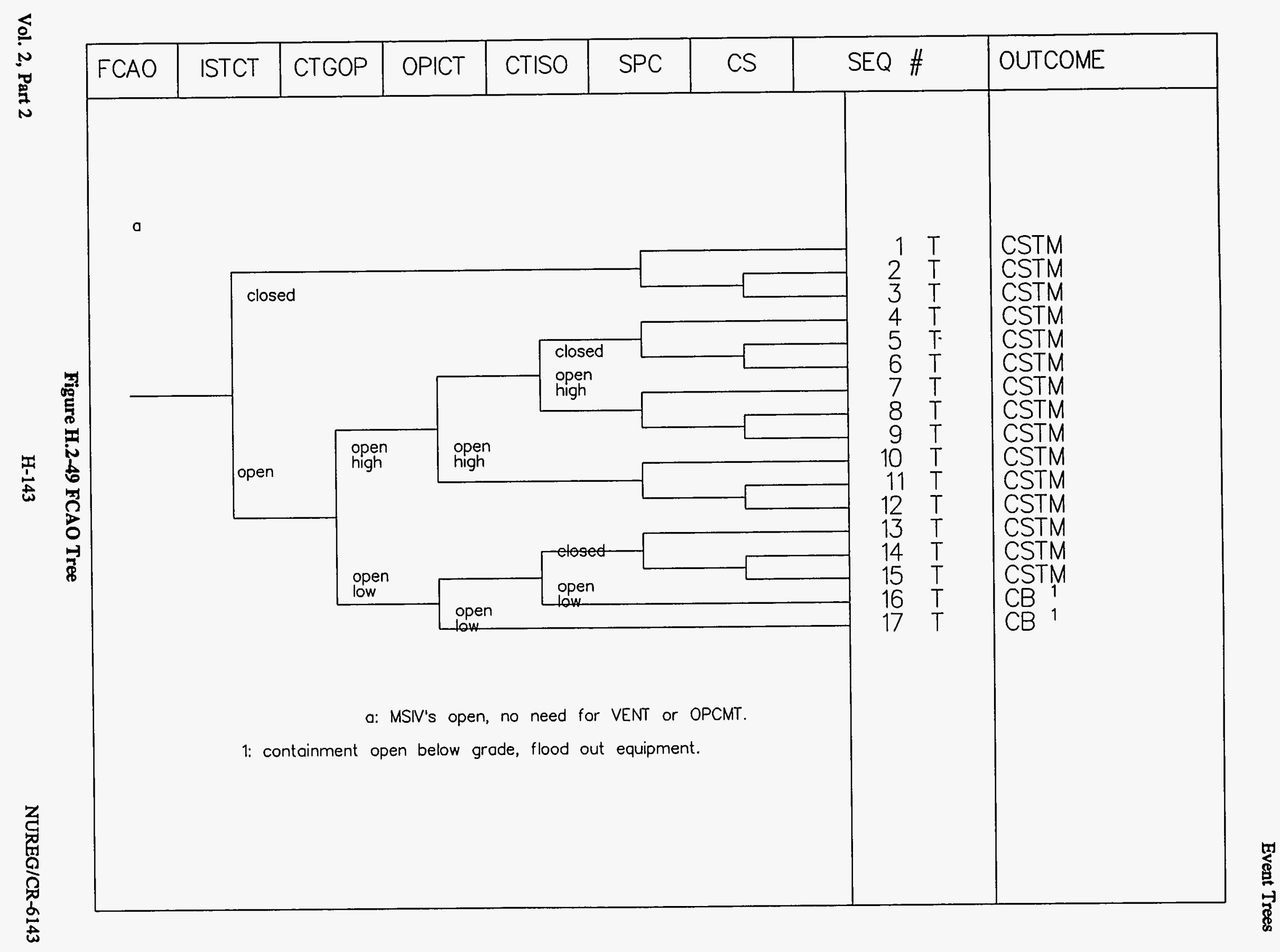




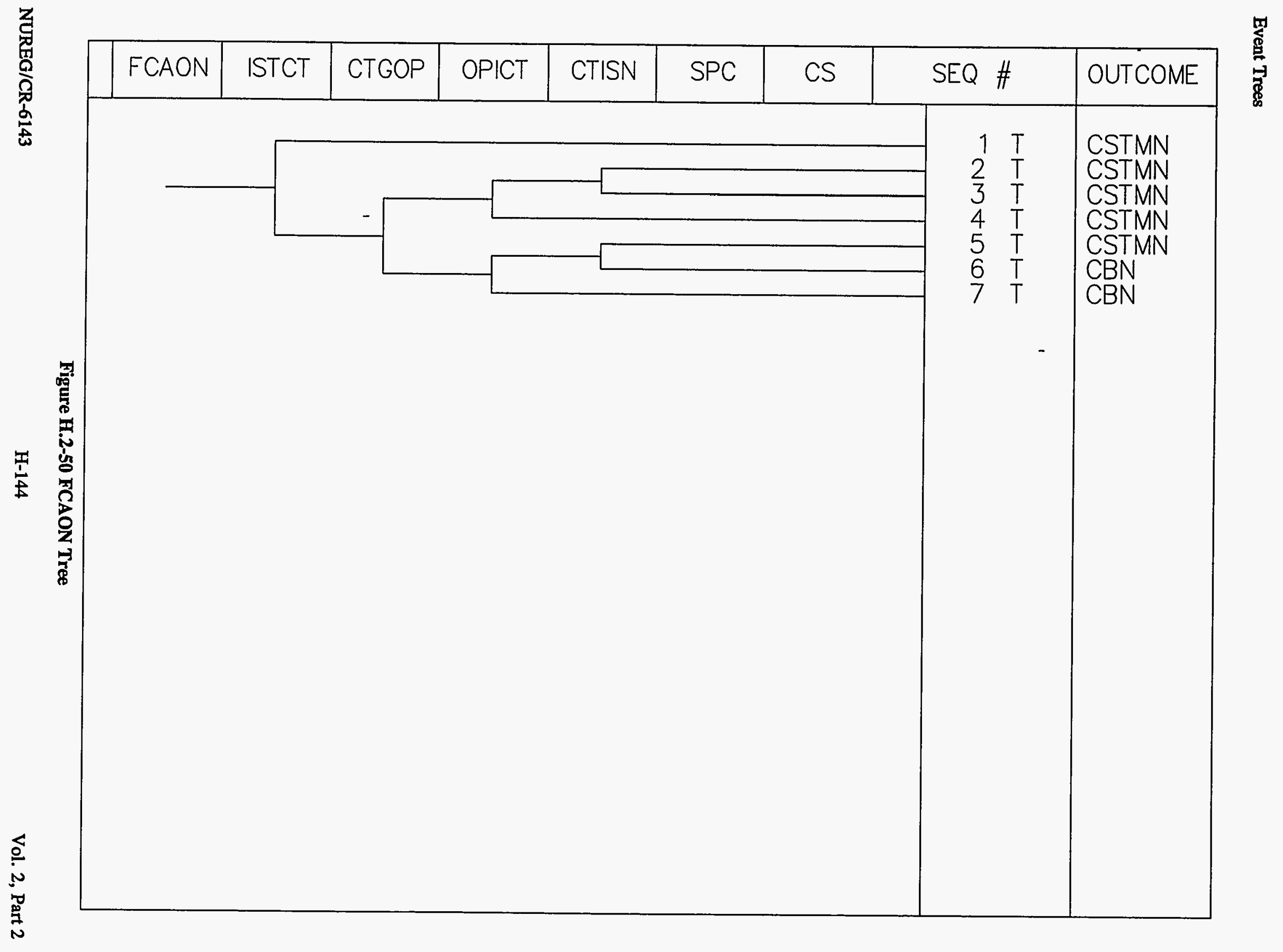




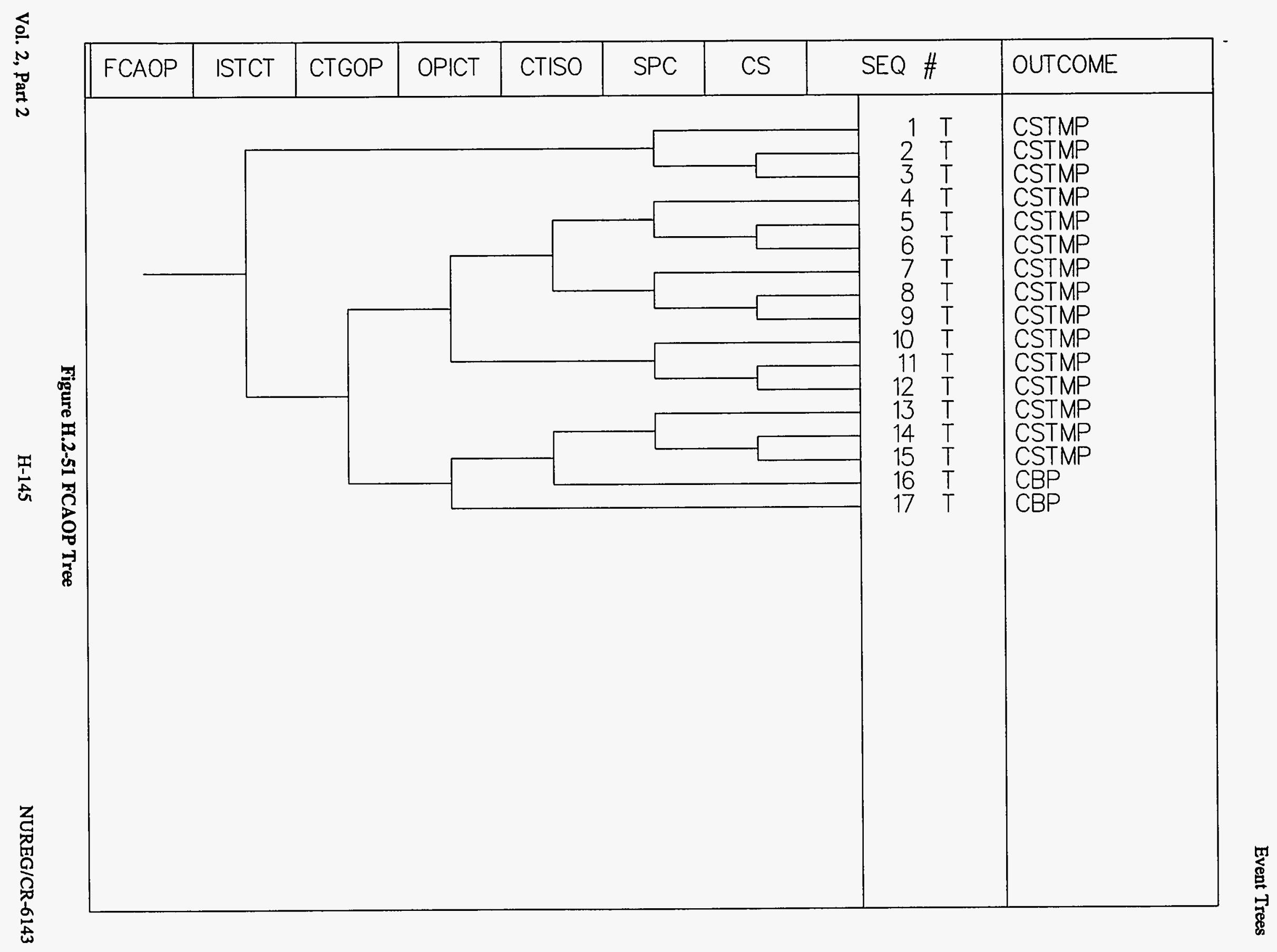




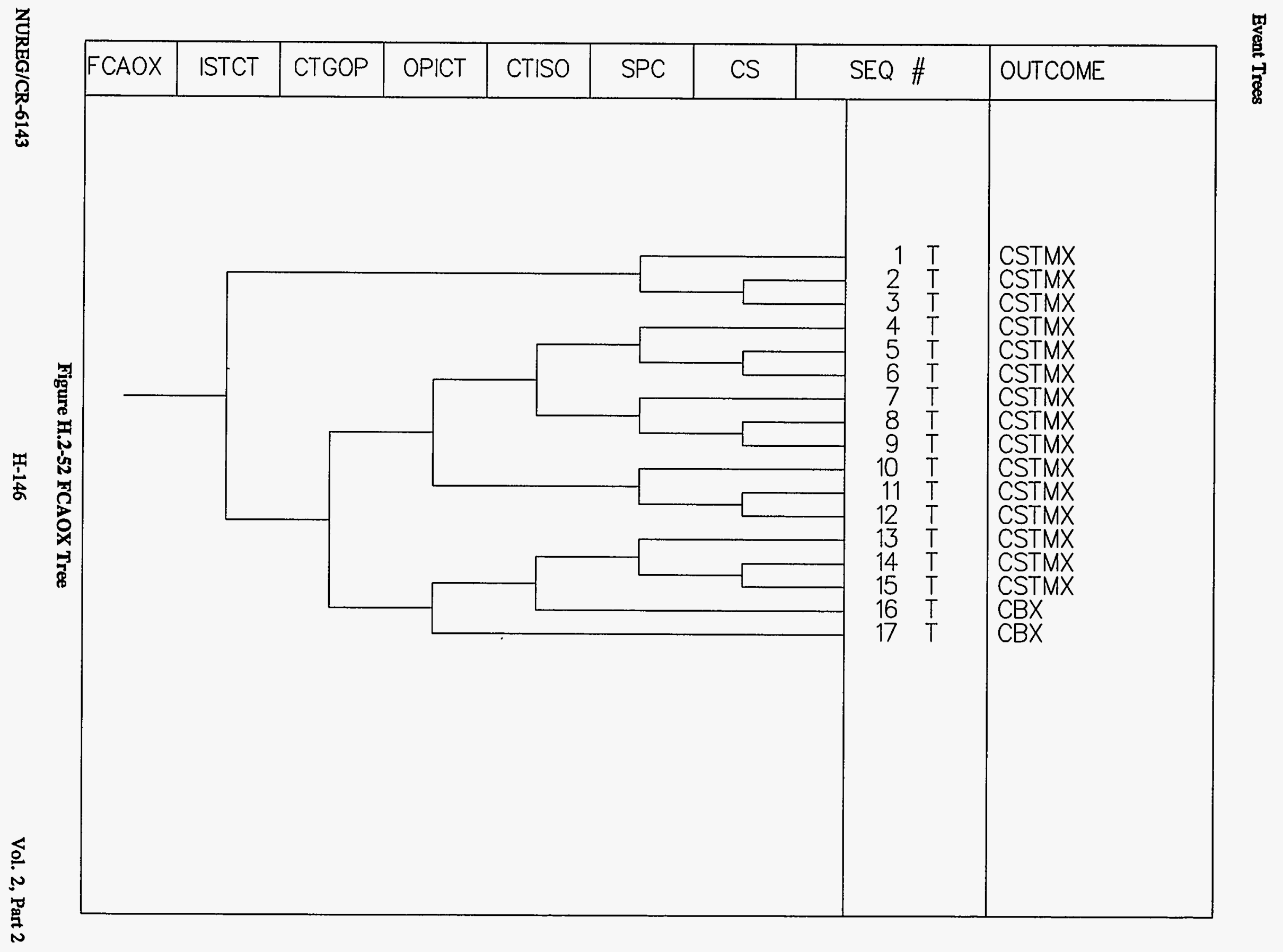


Event Trees

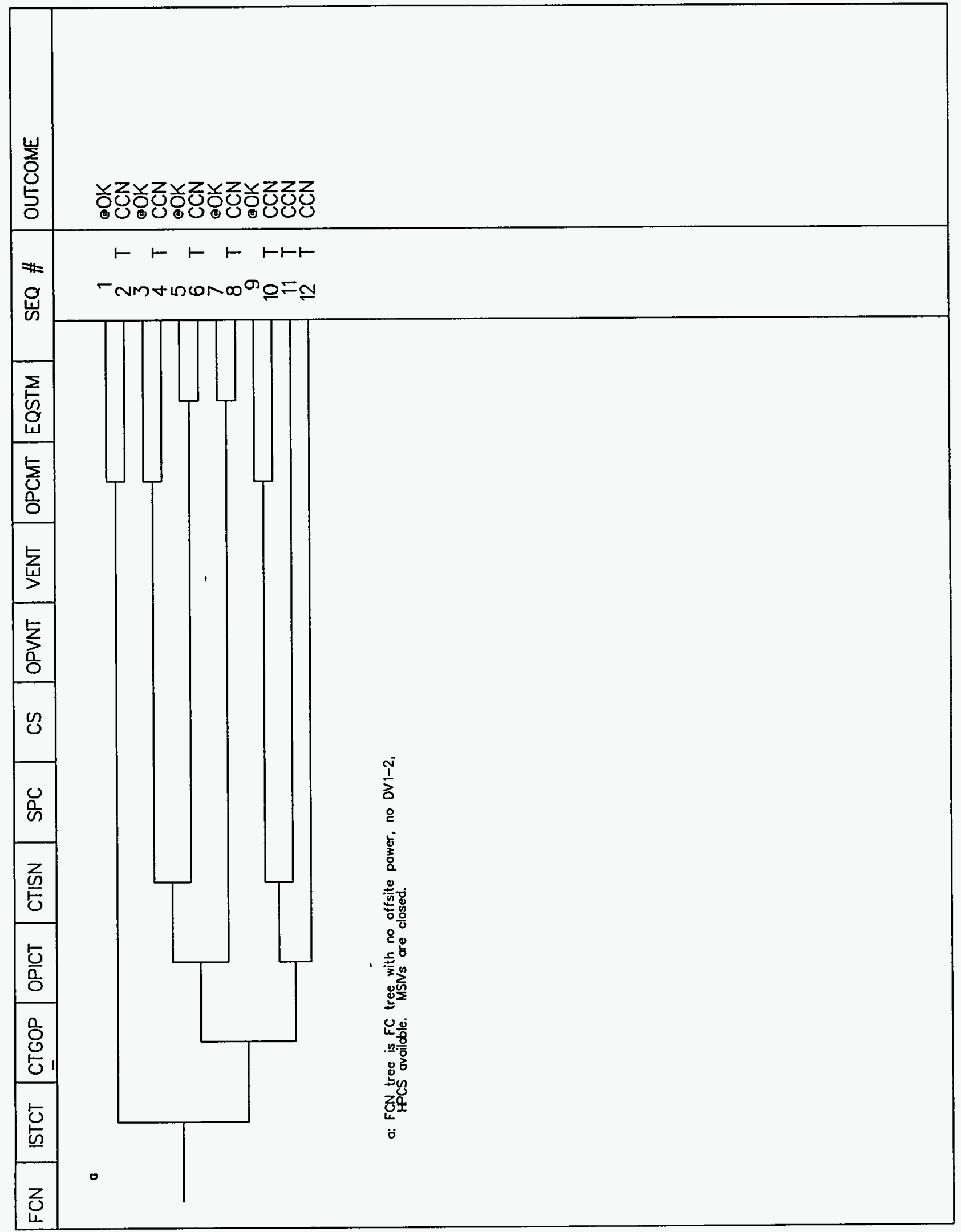

Figure H.2-53 FCN Tree

Vol. 2, Part 2

H-147

NUREG/CR-6143 


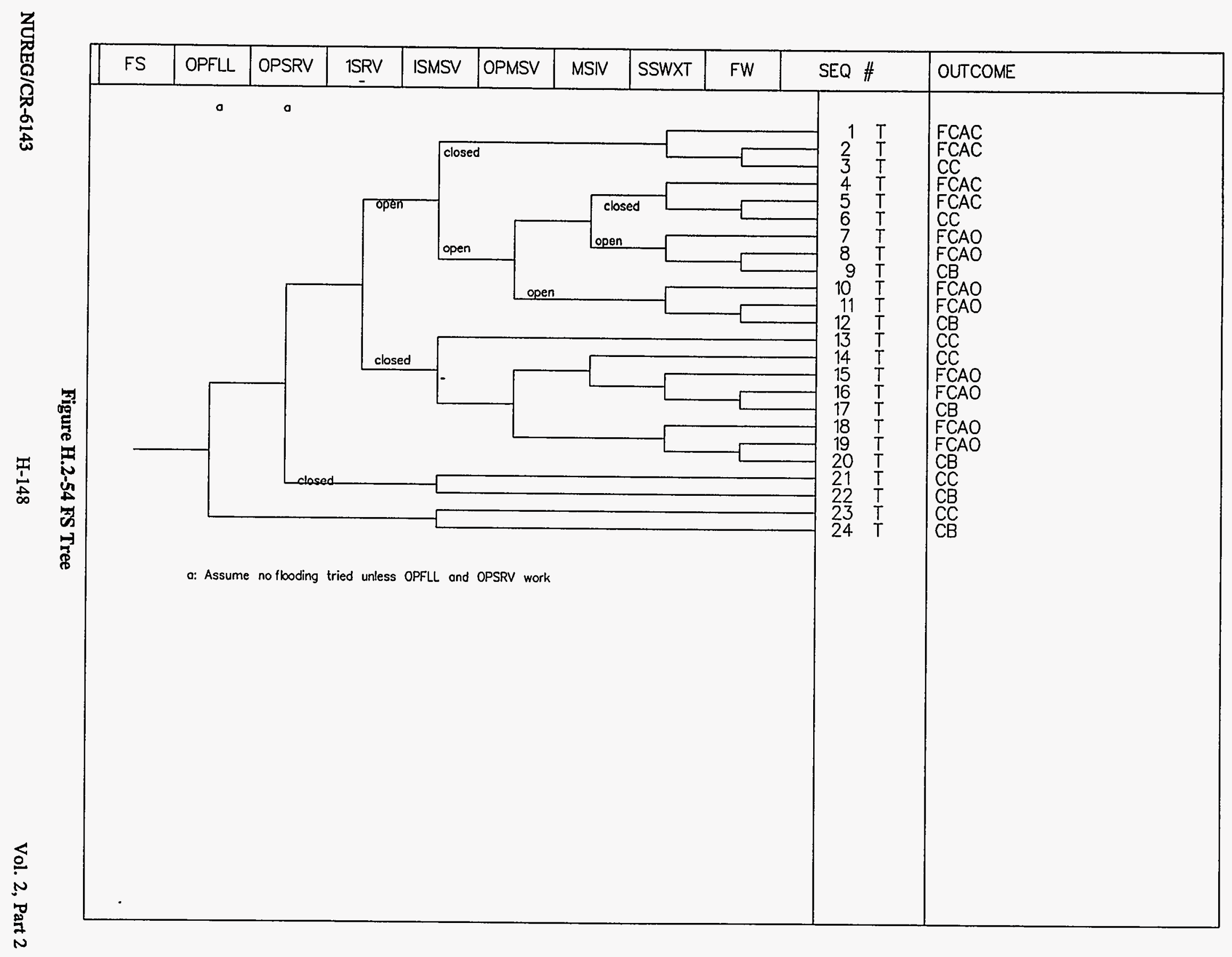




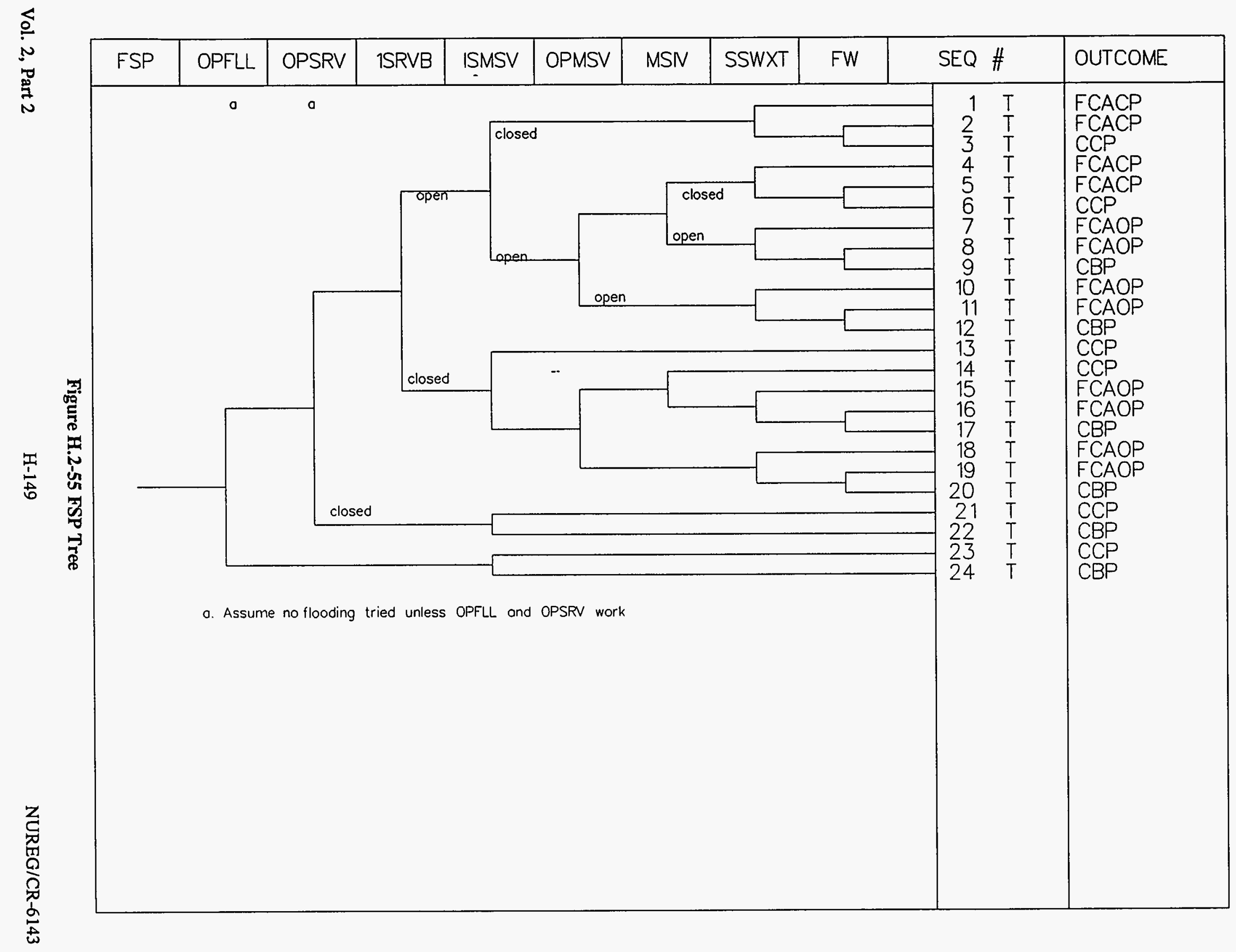




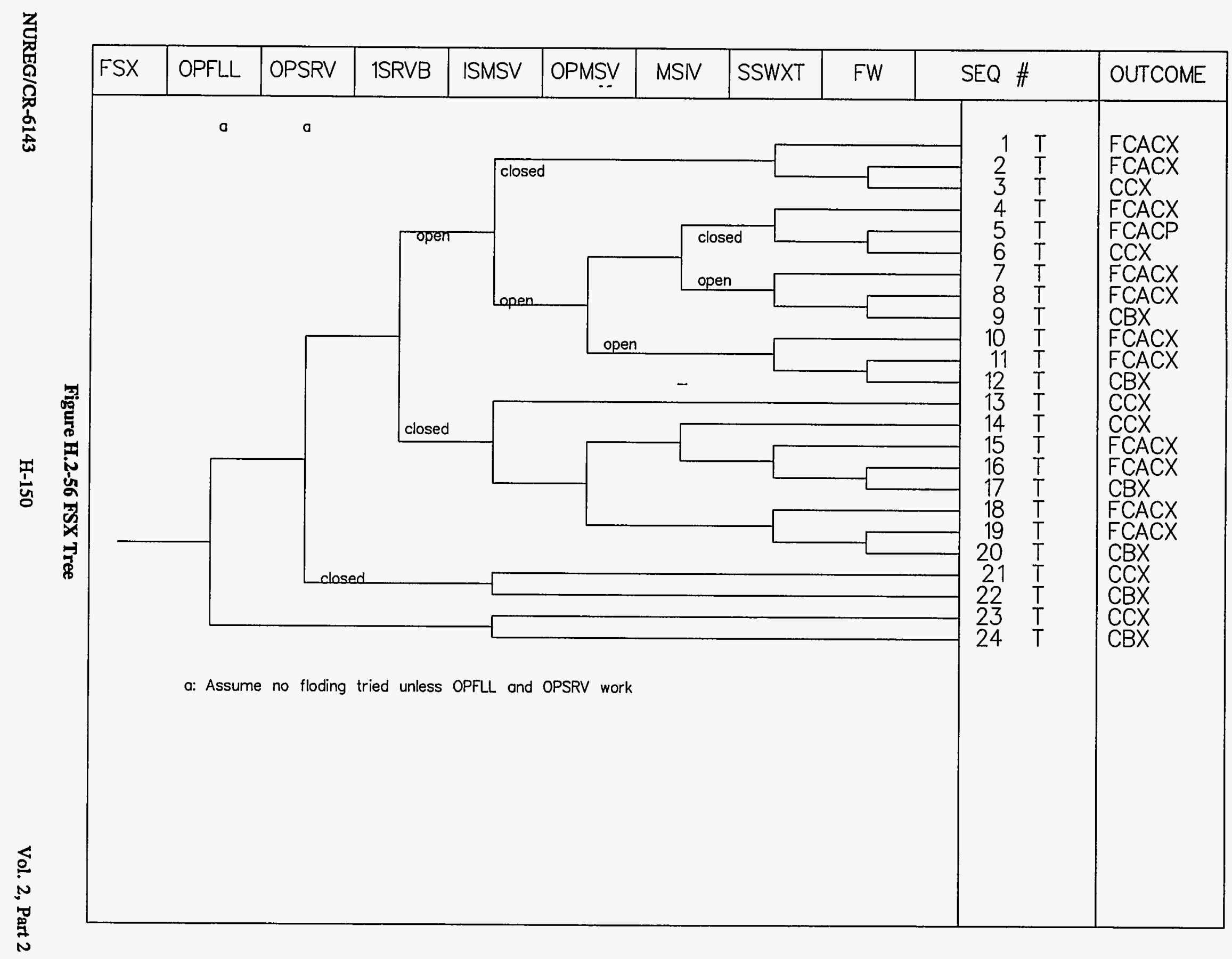




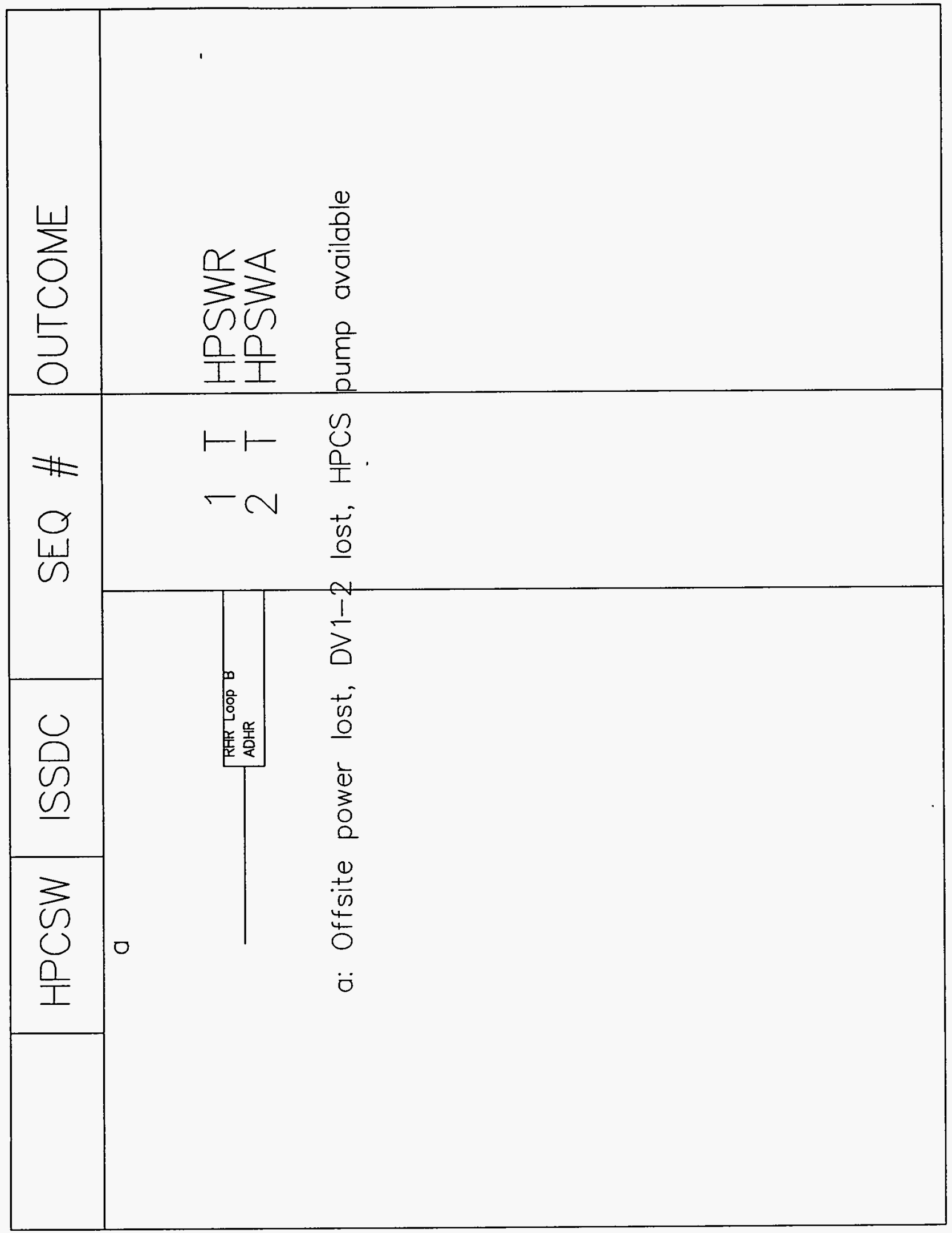

Figure H.2-57 HPCSW Tree

Vol. 2, Part 2

H-151

NUREG/CR-6143 


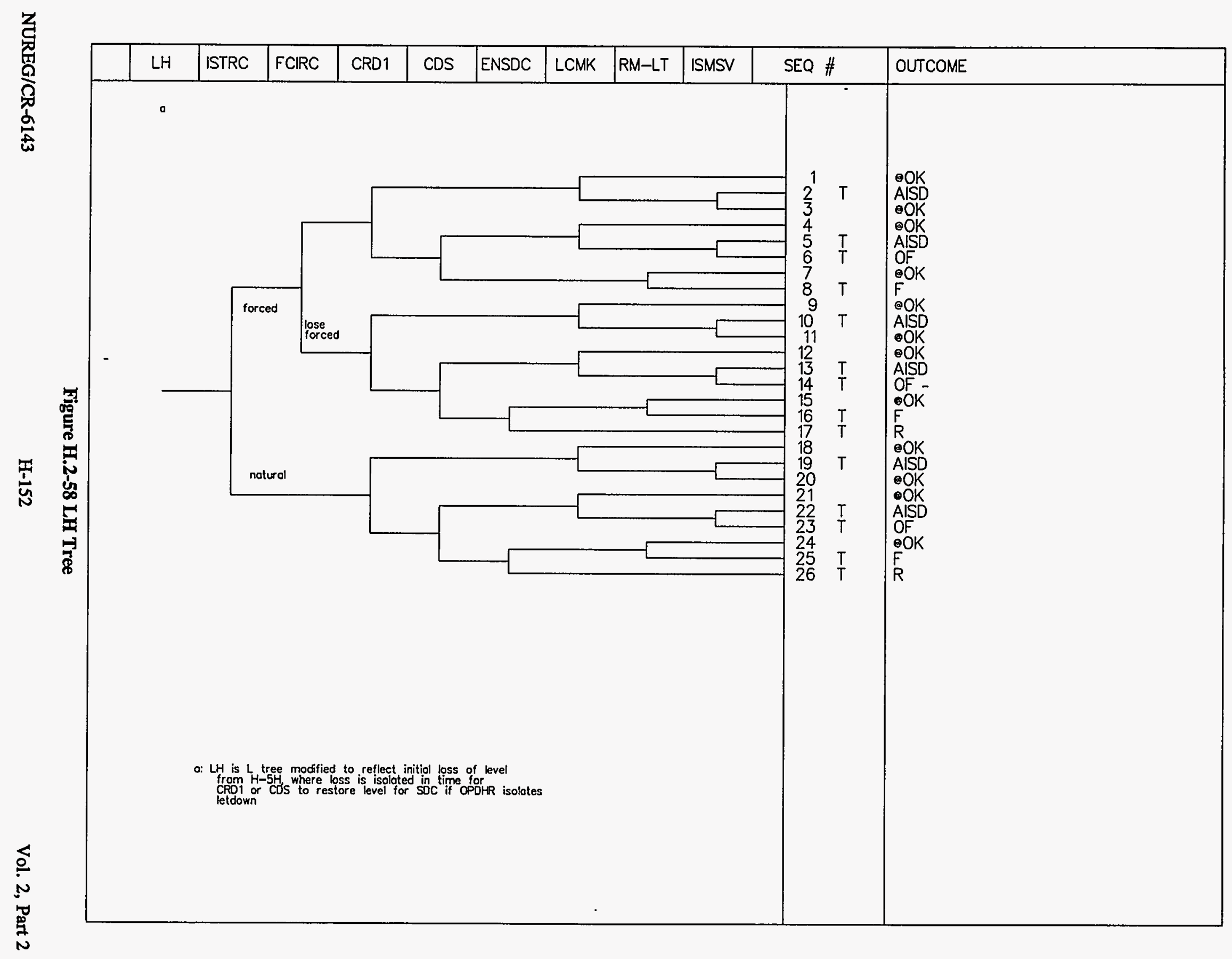




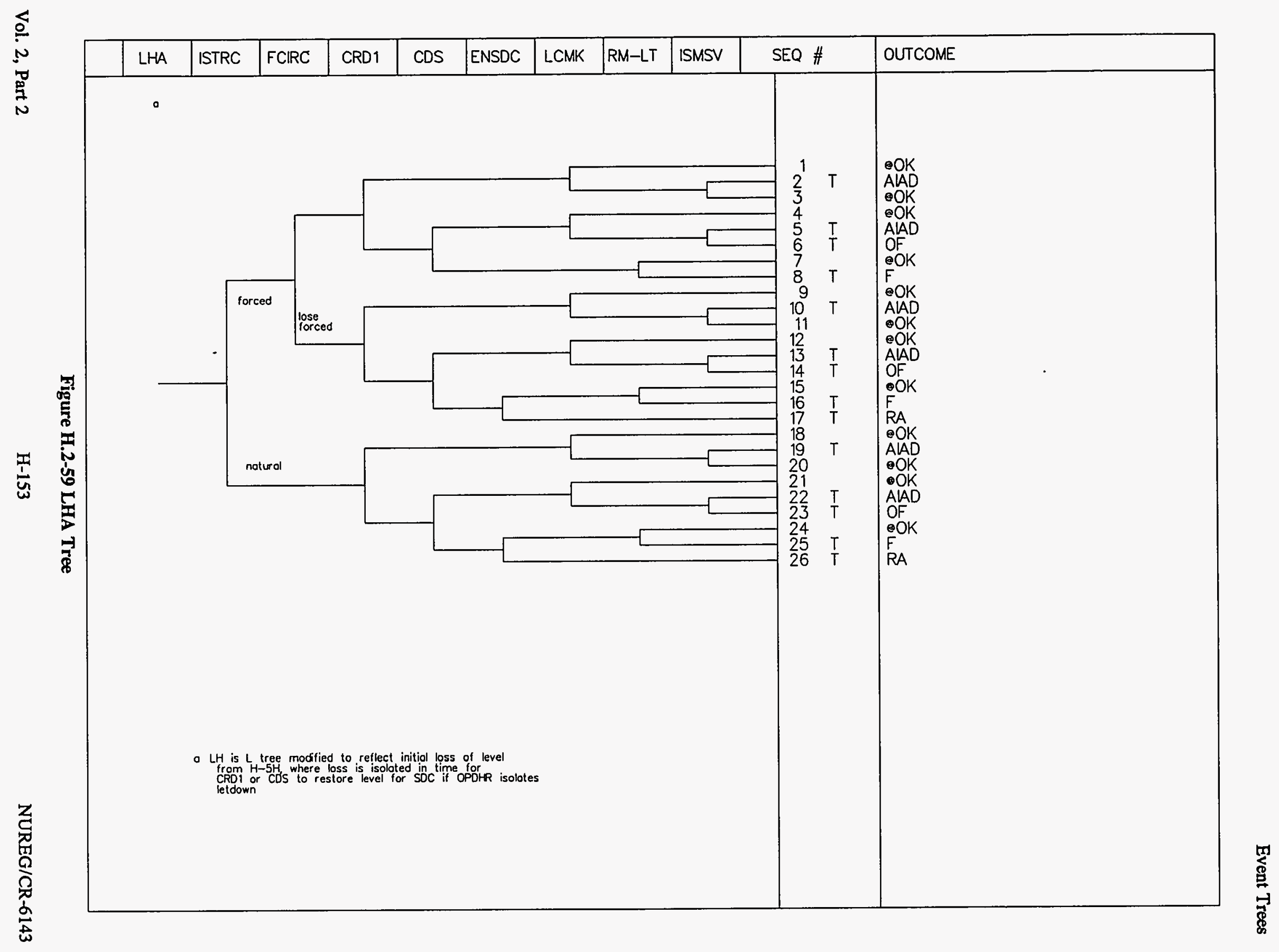




\section{Event Trees}

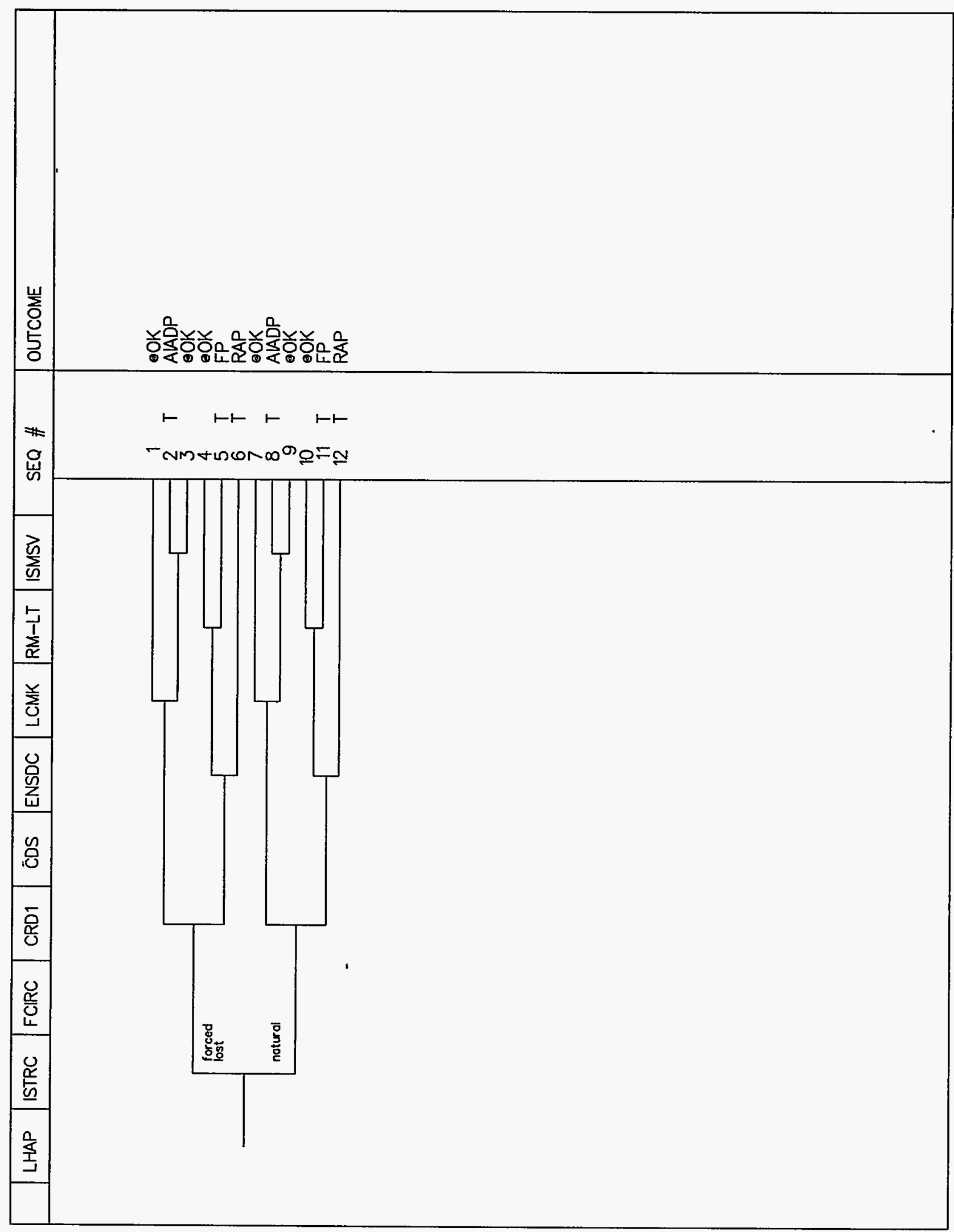

Figure H.2-60 LHAP Tree 
Event Trees

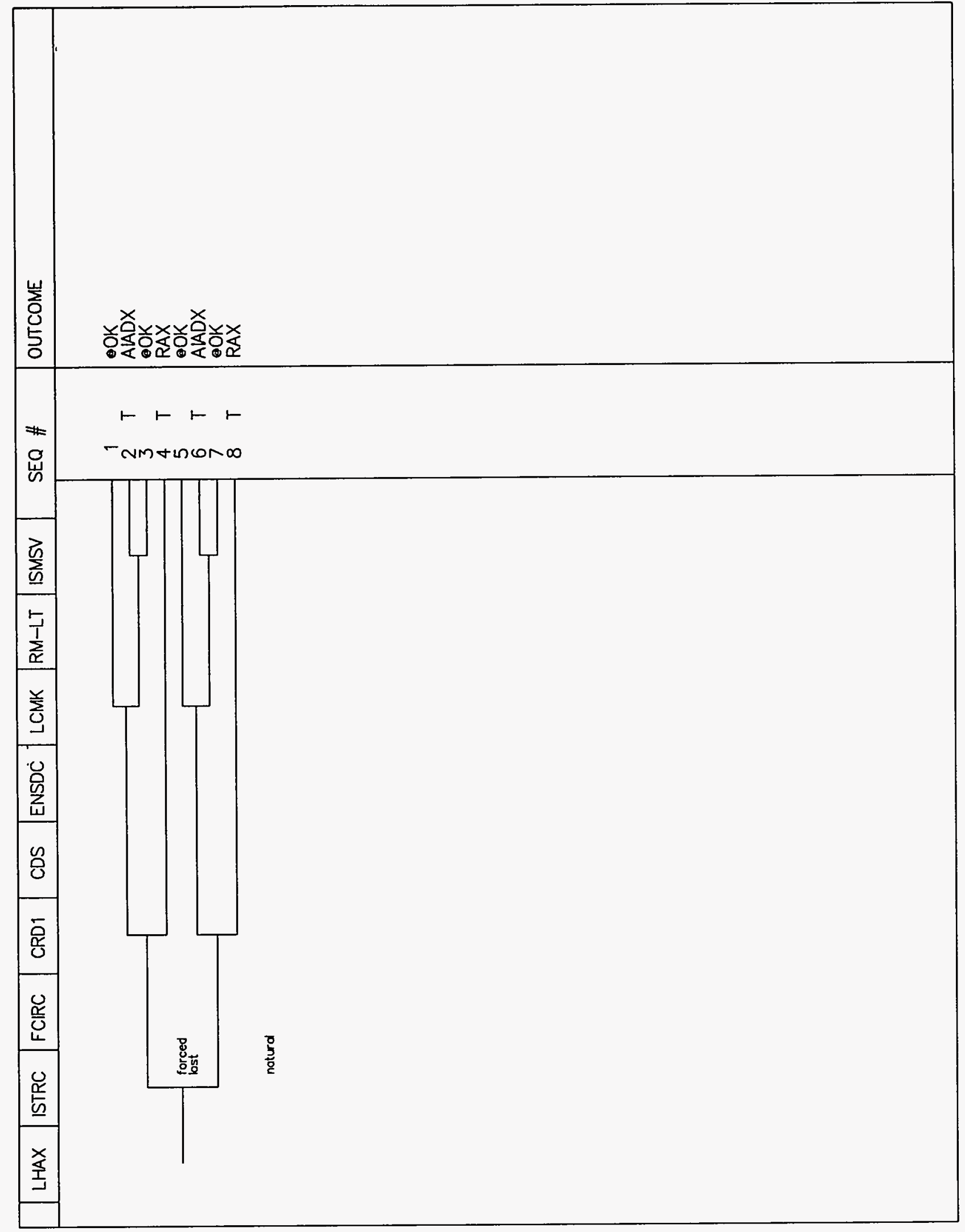

Figure H.2-61 LHAX Tree

Vol. 2, Part 2

H-155

NUREG/CR-6143 
Event Trees

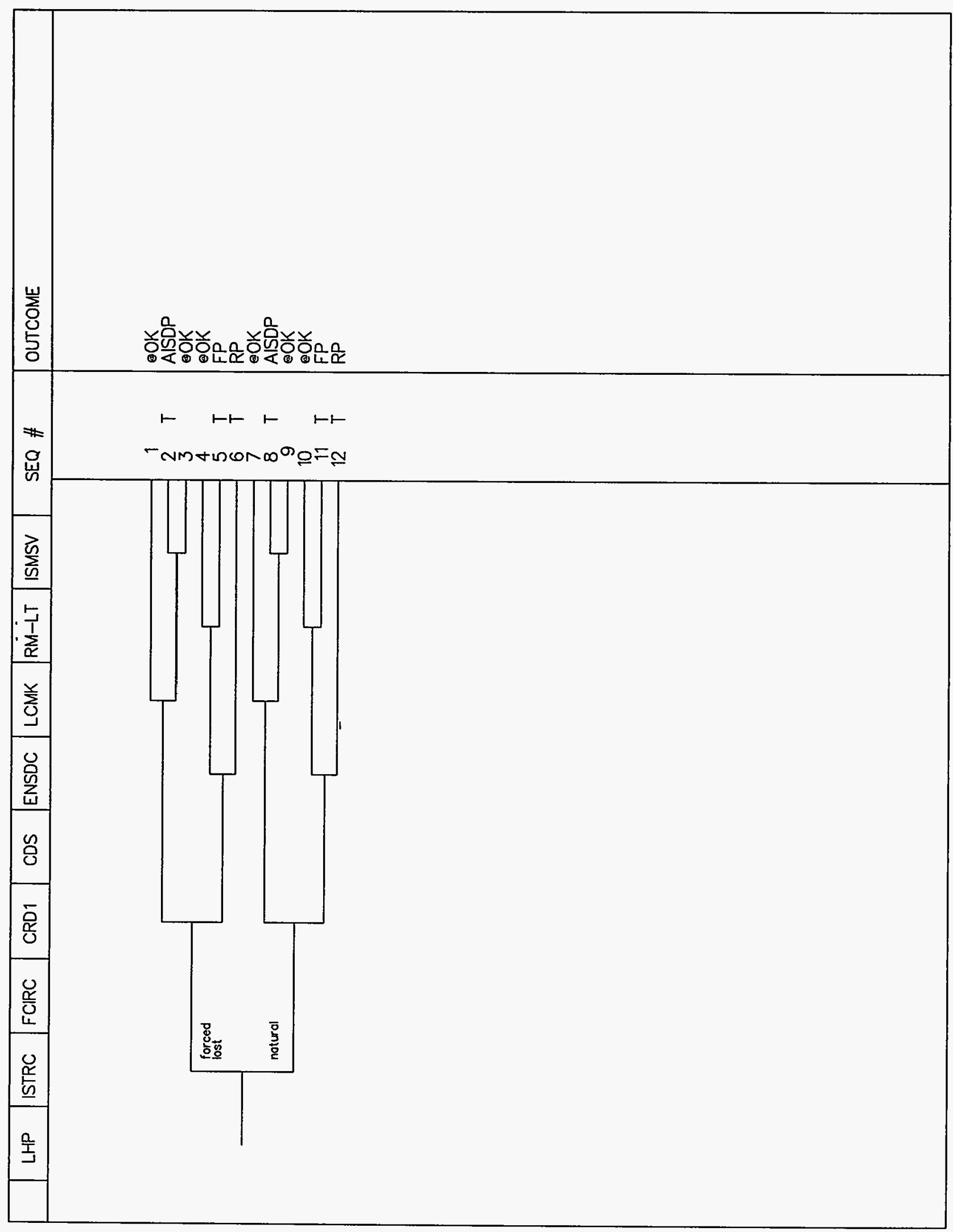

Figure H.2-62 LHP Tree 
Event Trees

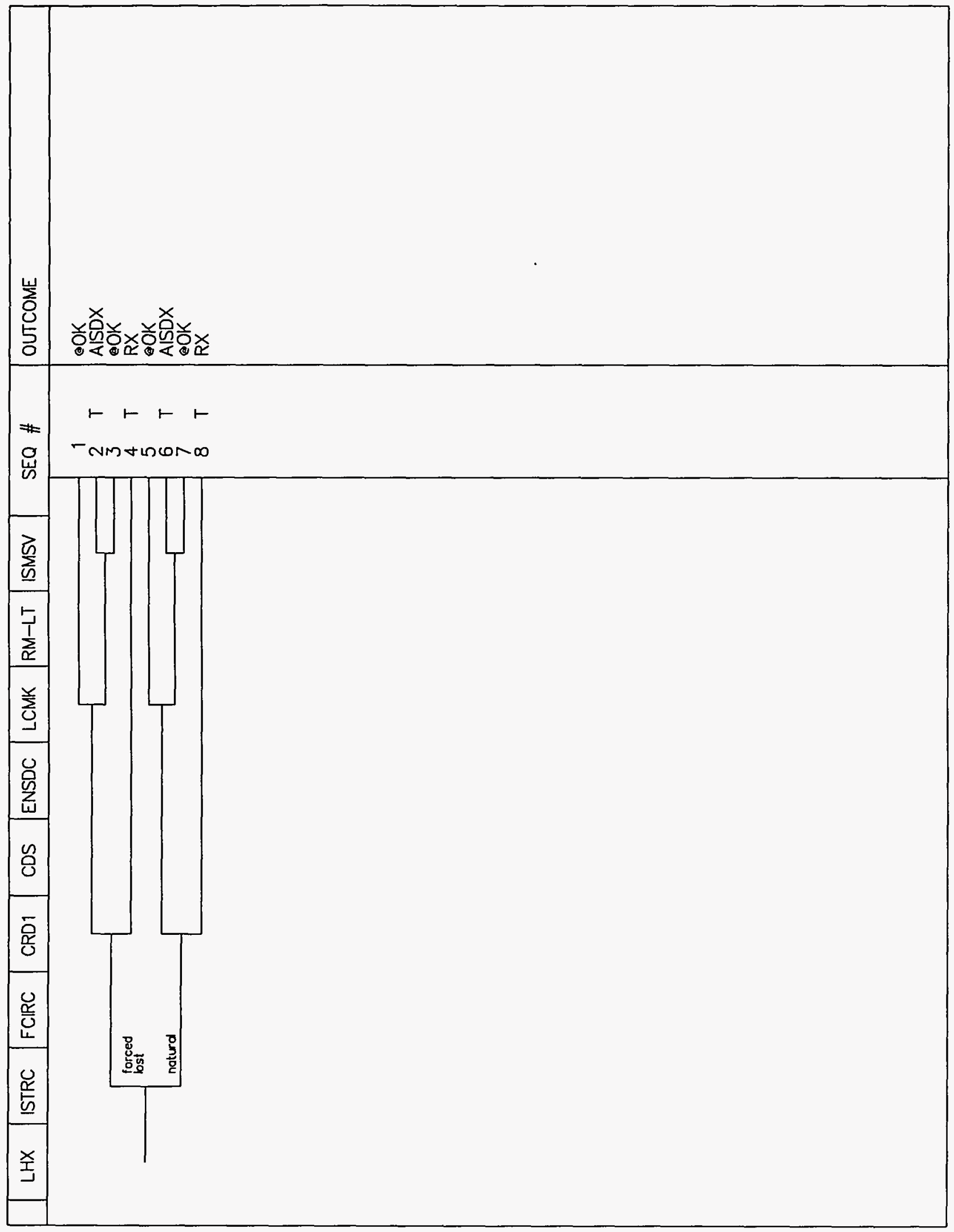

Figure H.2-63 LHX Tree 
Event Trees

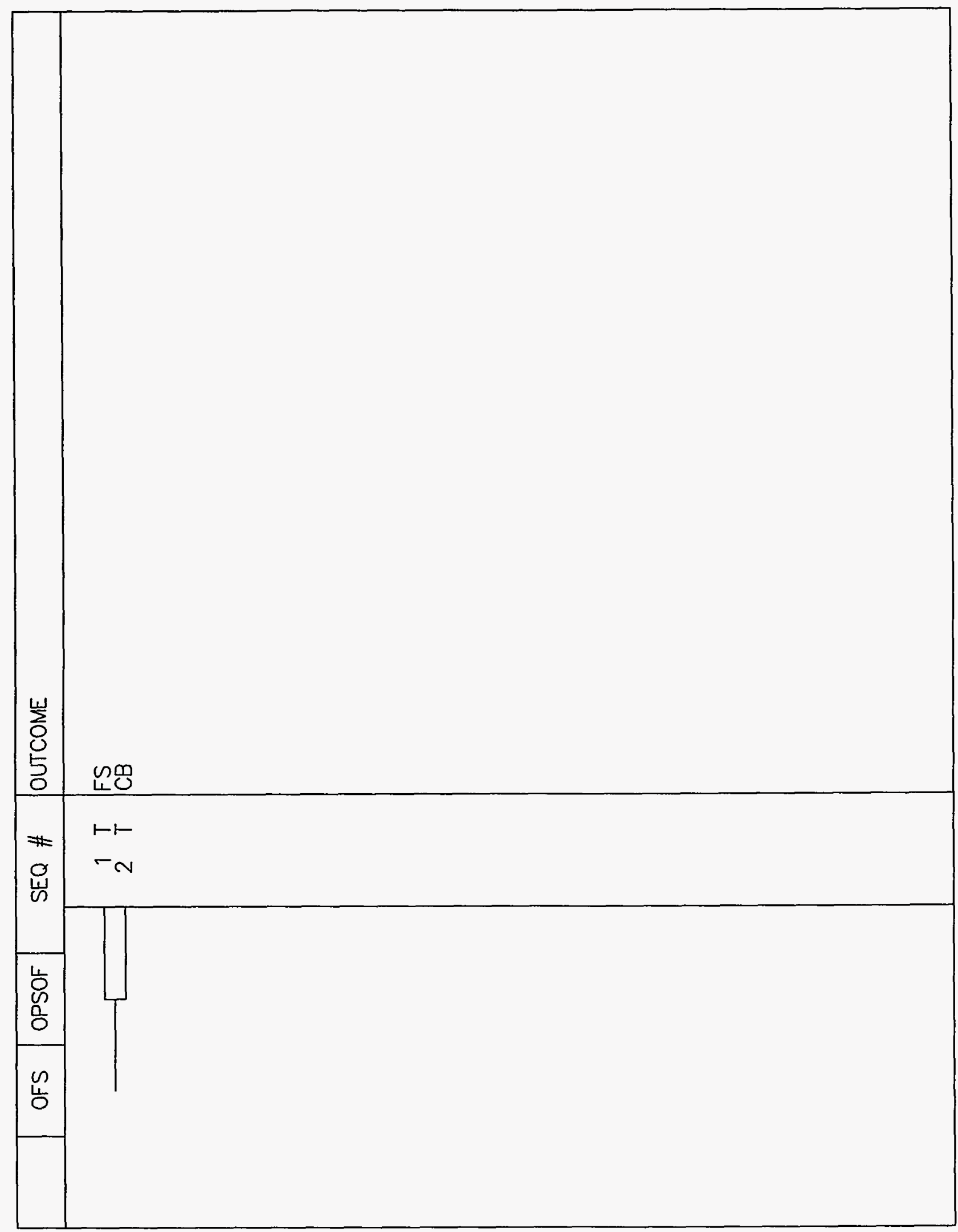

Figure H.2-64 OFS Tree 


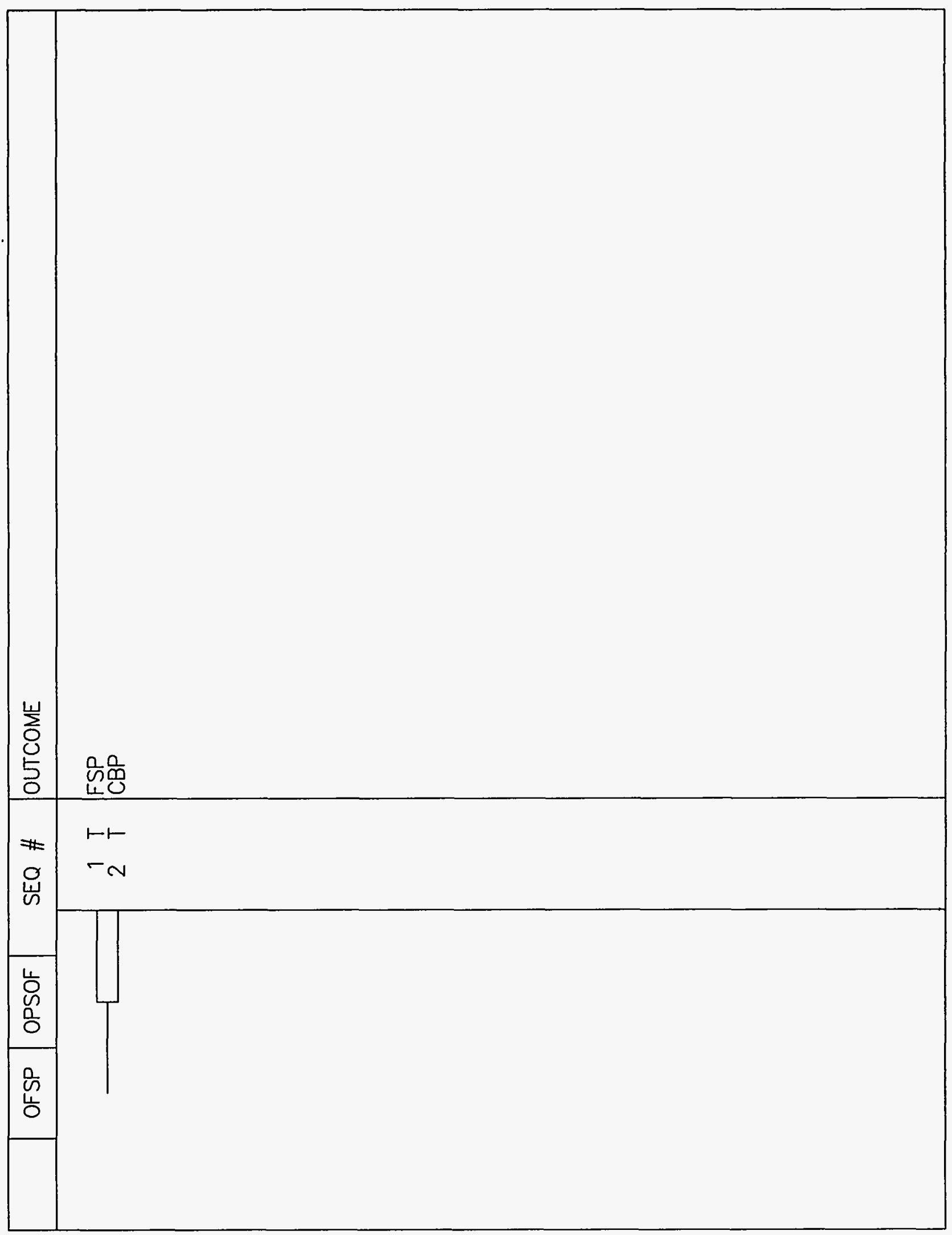

Figure H.2-65 OFSP Tree

Vol. 2, Part 2

H-159

NUREG/CR-6143 
Event Trees

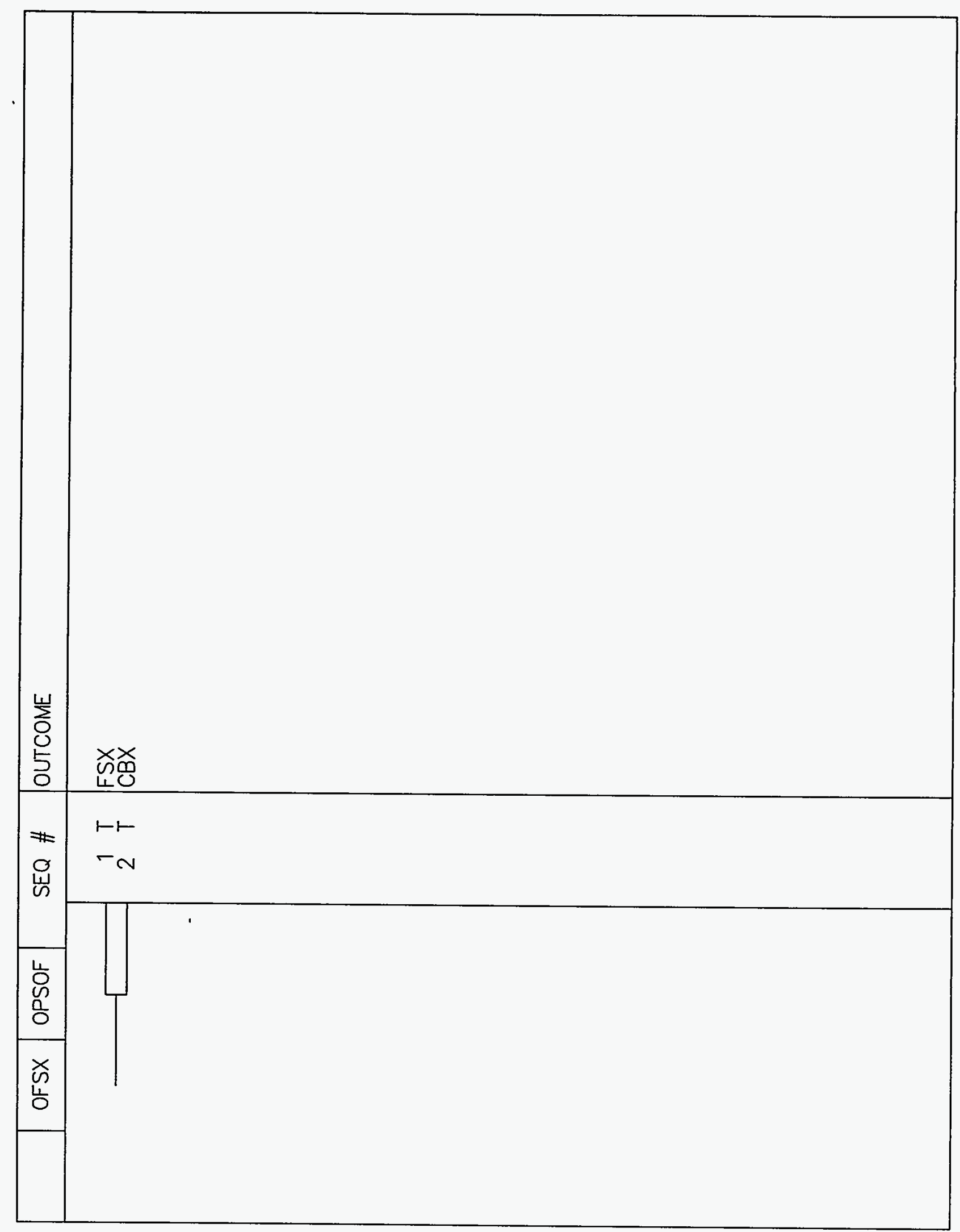

Figure H.2-66 OFSX Tree 


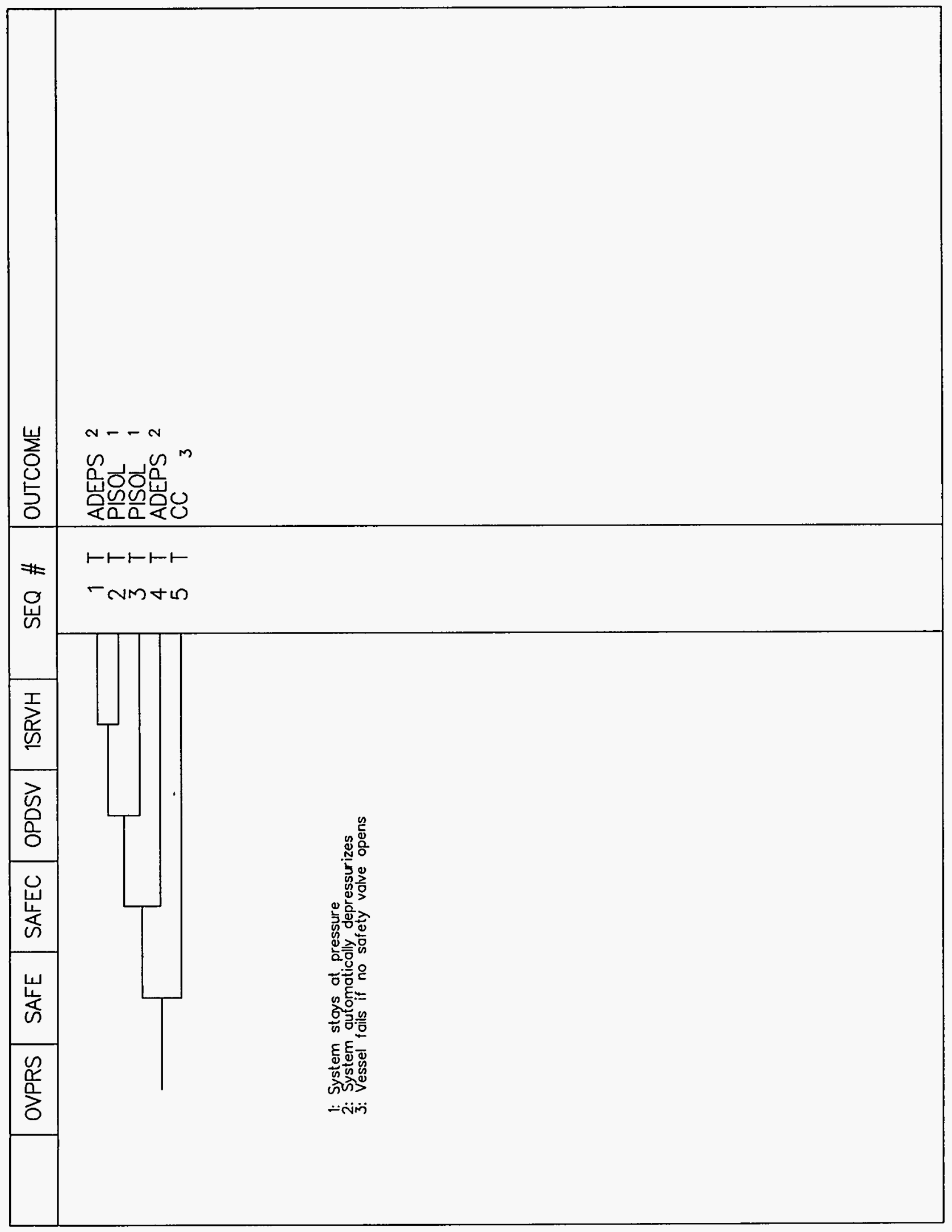

Figure H.2-67 OVPRS Tree 


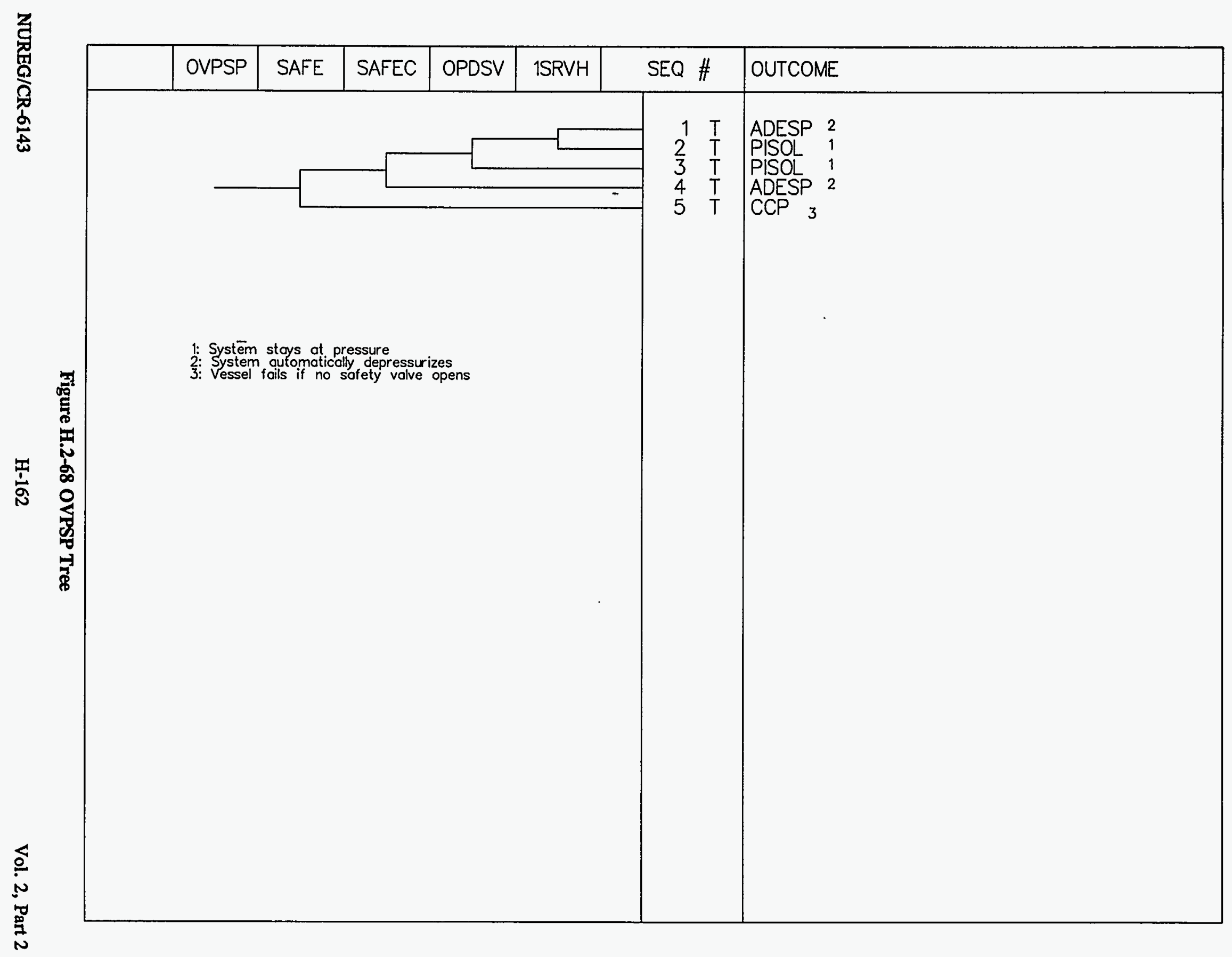


Event Trees

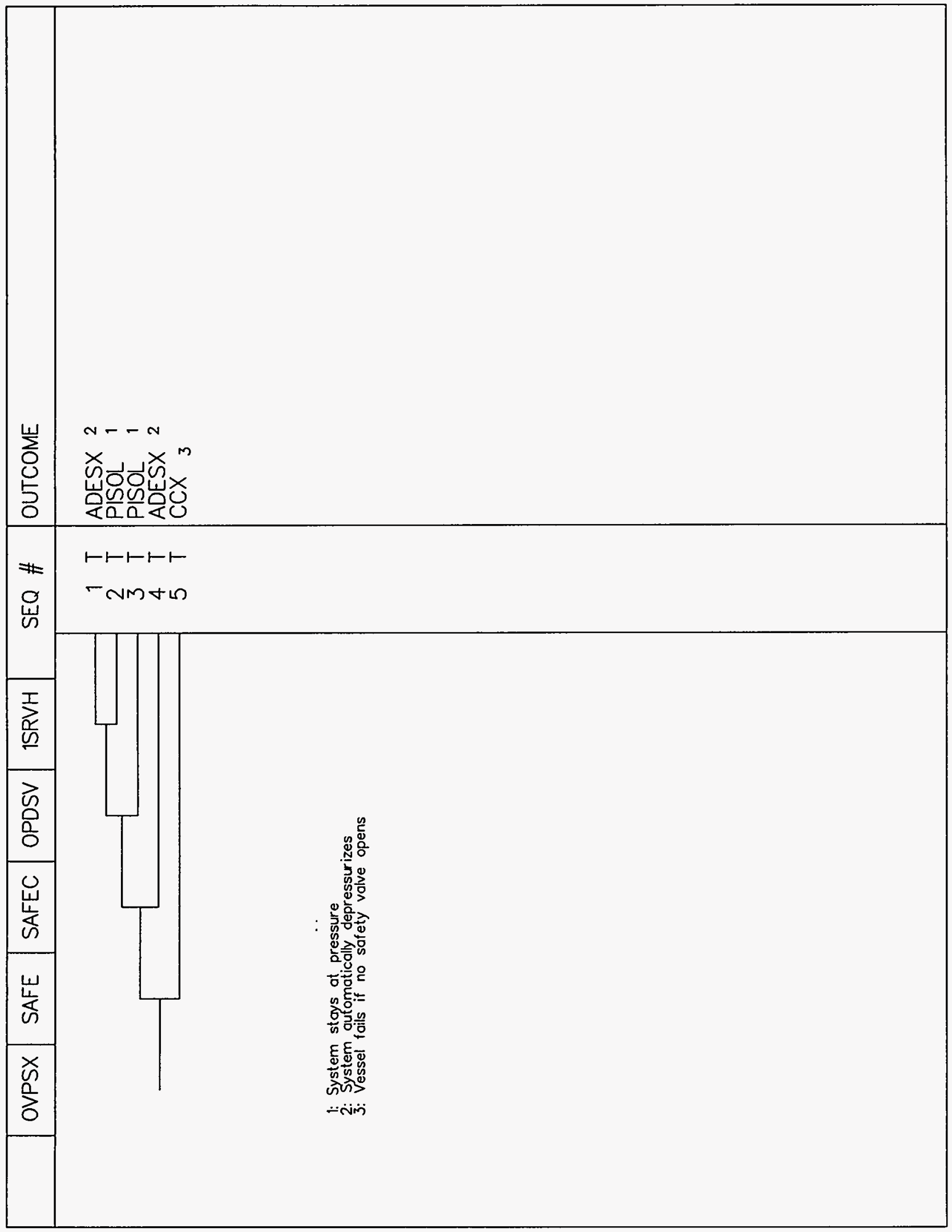

Figure H.2-69 OVPSX Tree

Vol. 2, Part 2

H-163

NUREG/CR-6143

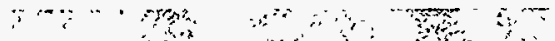


Event Trees

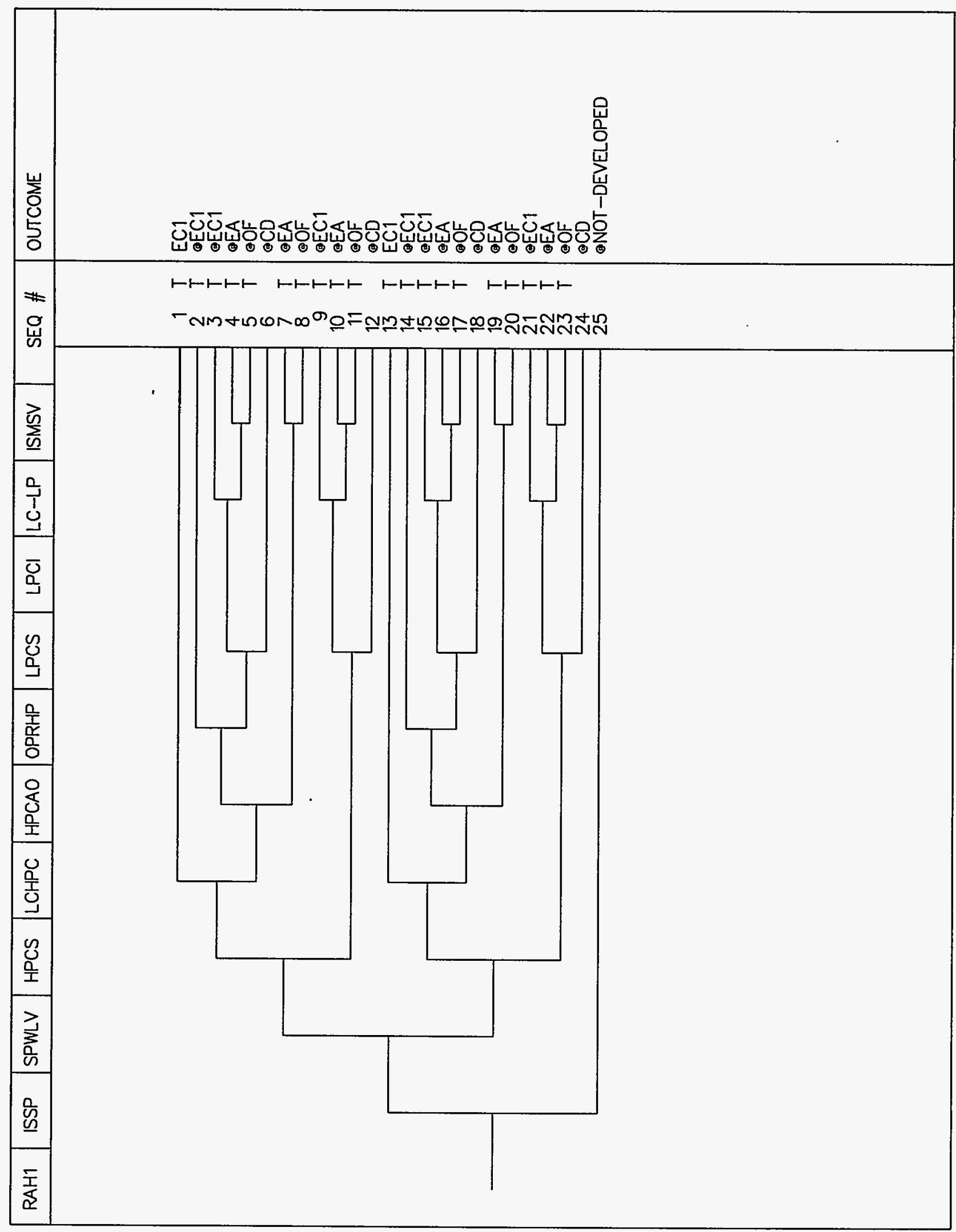

Figure H.2-70 RAH1 Tree 


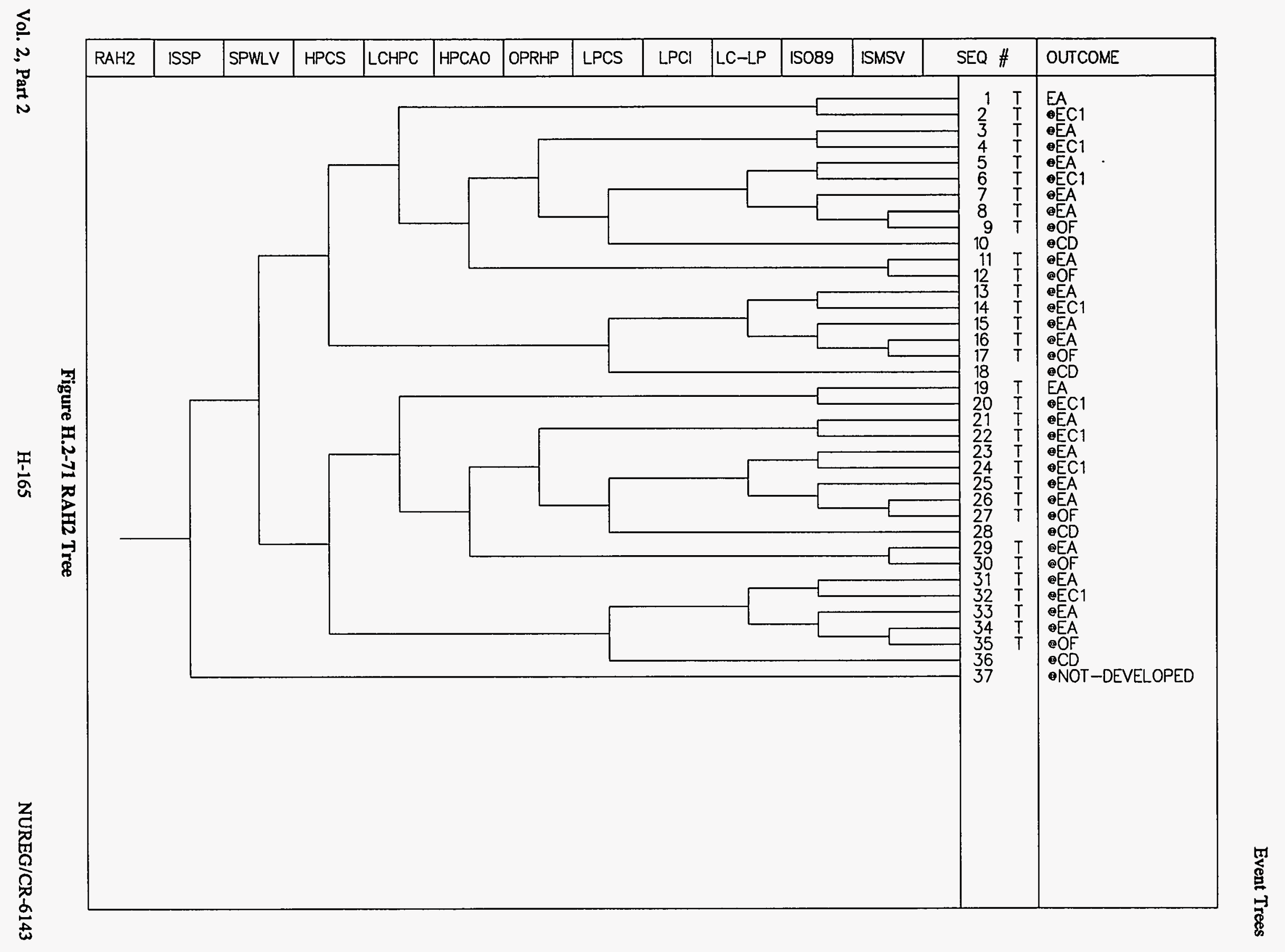




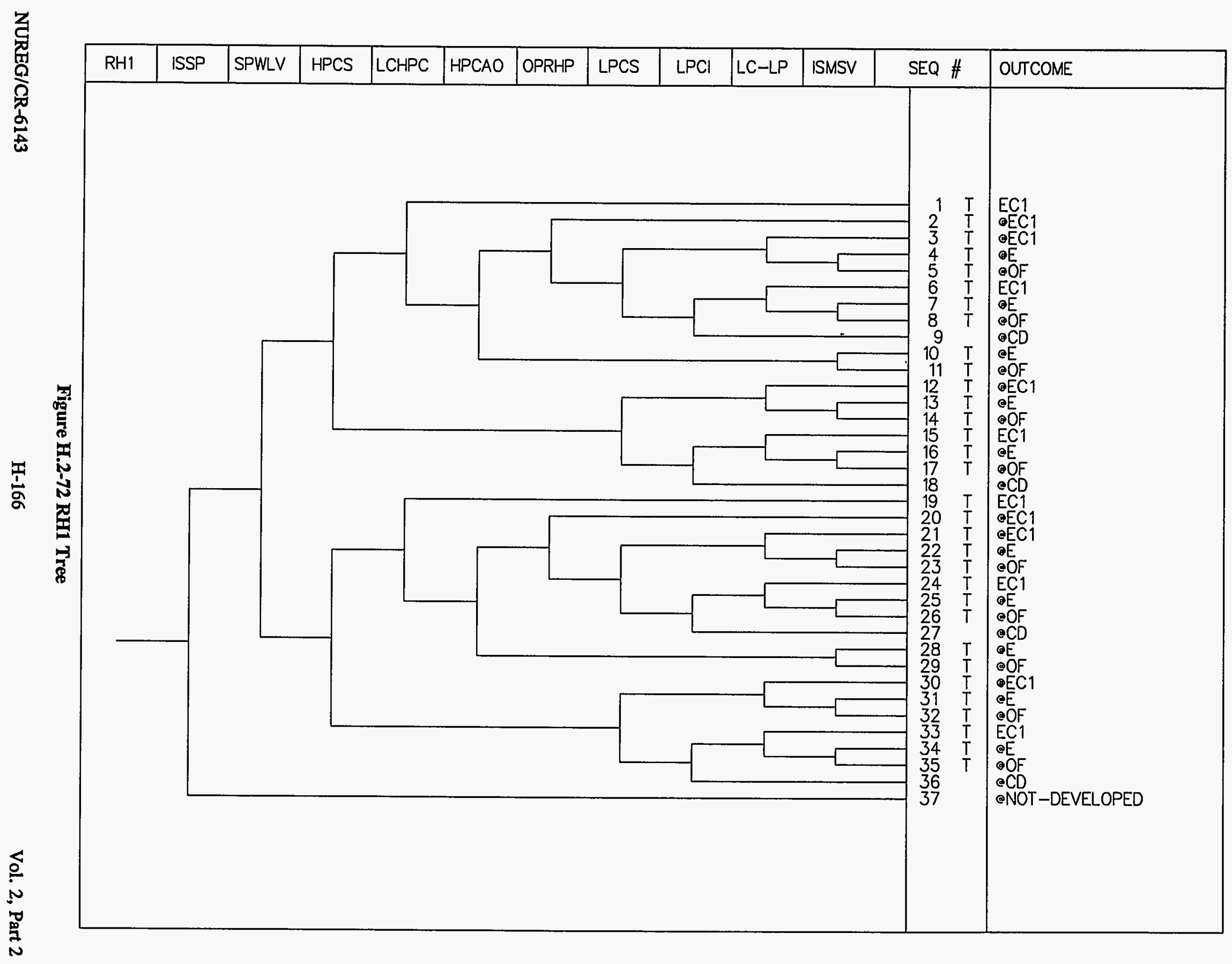




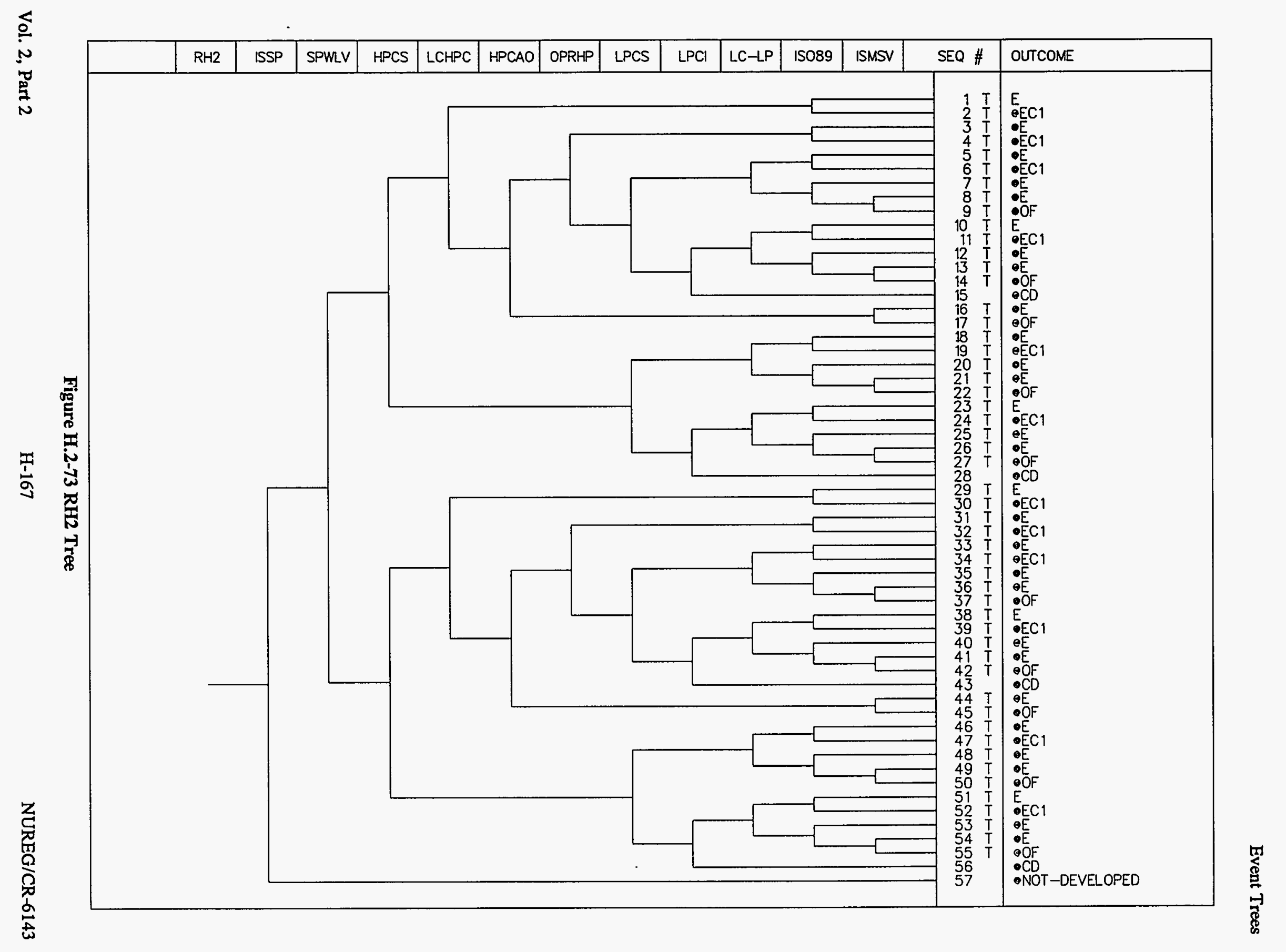




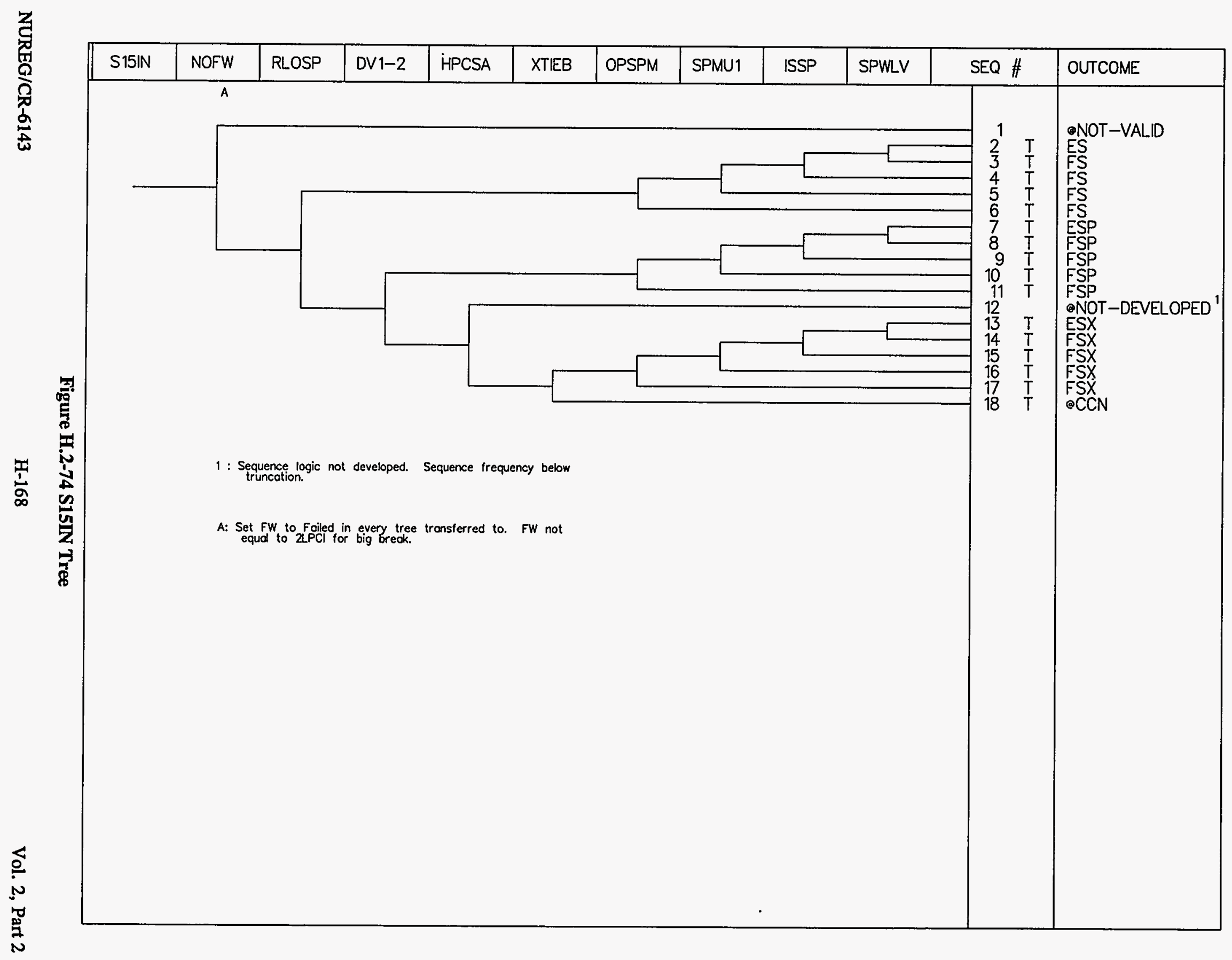




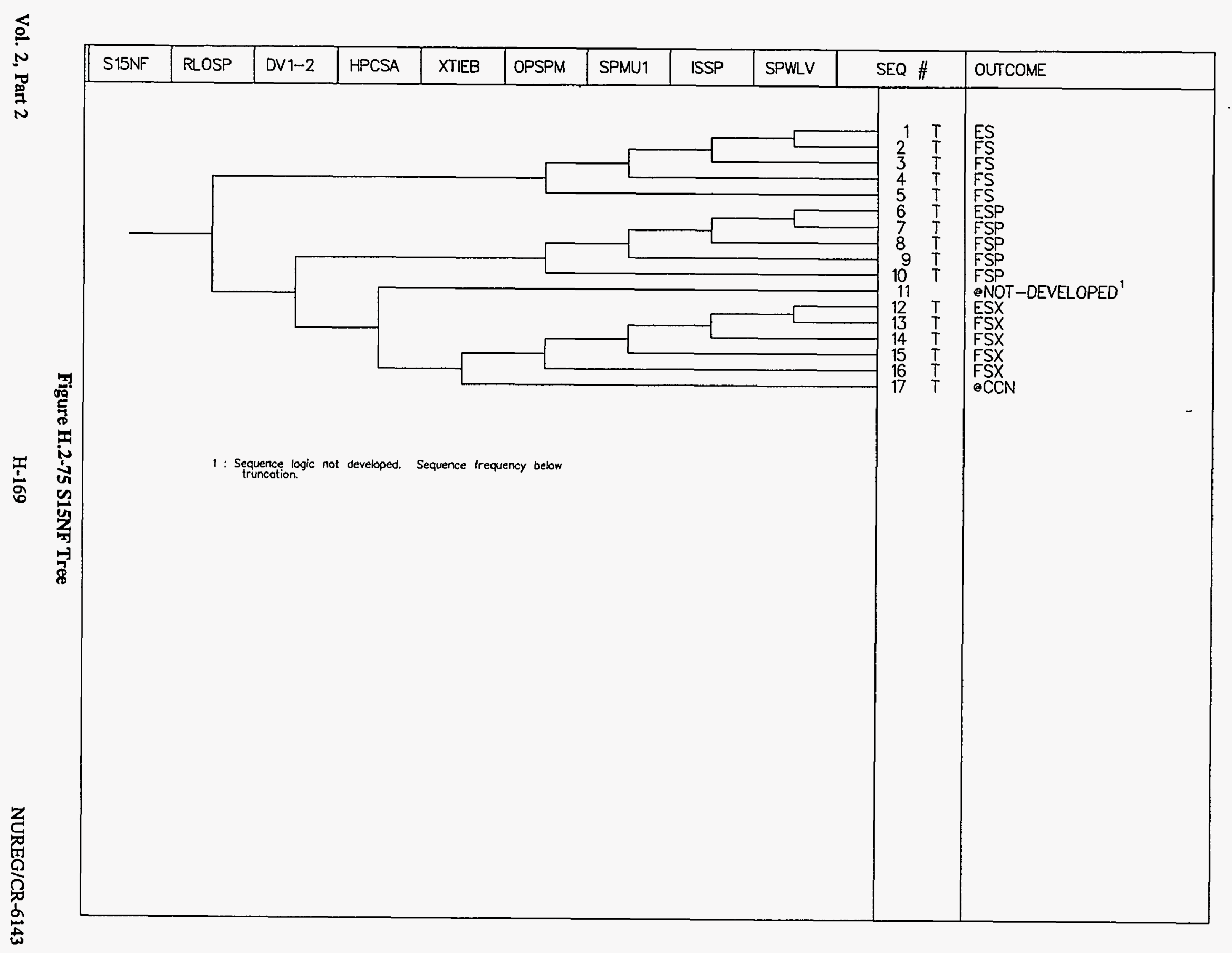




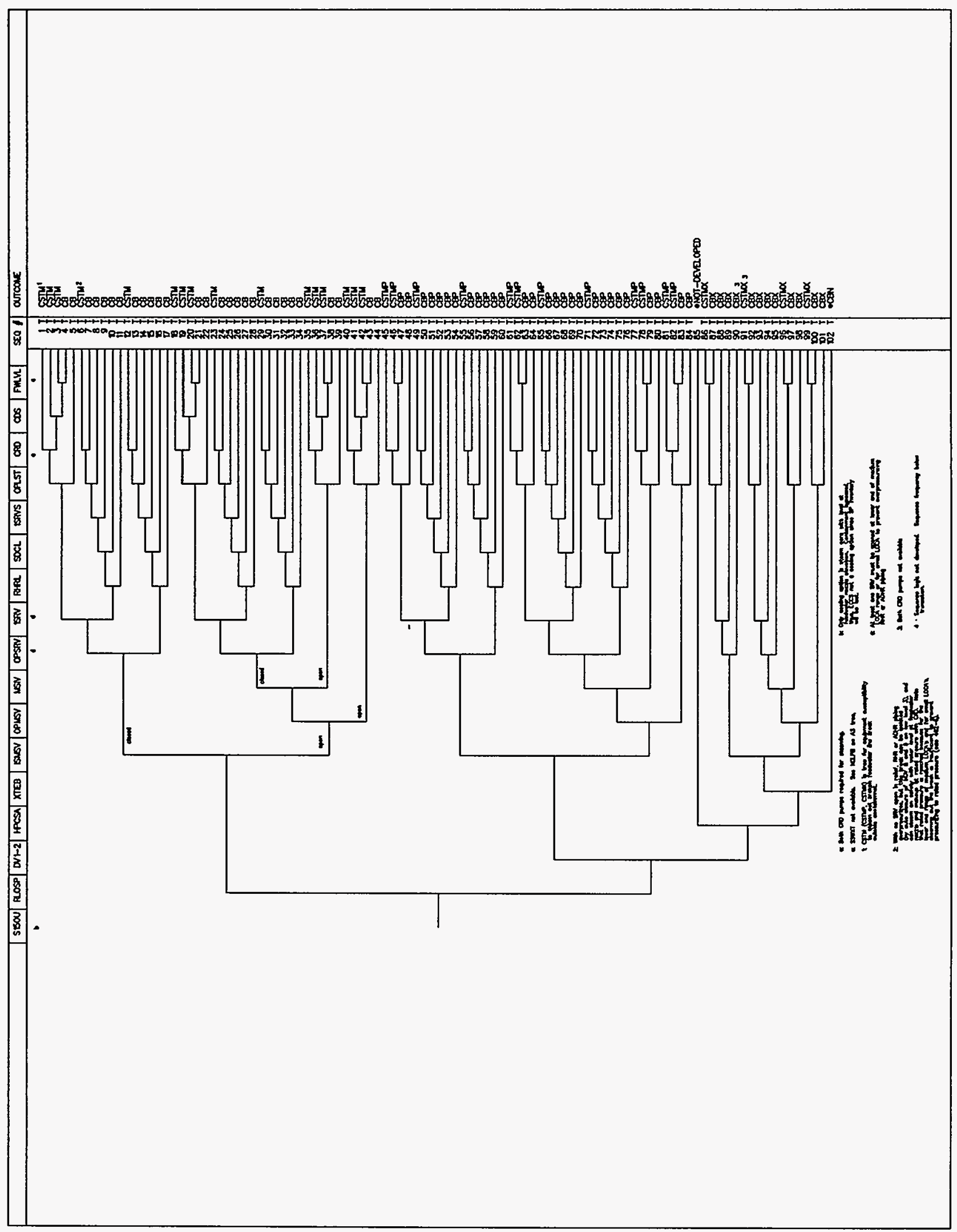

Figure H.2-76 S15OU Tree 
Event Trees

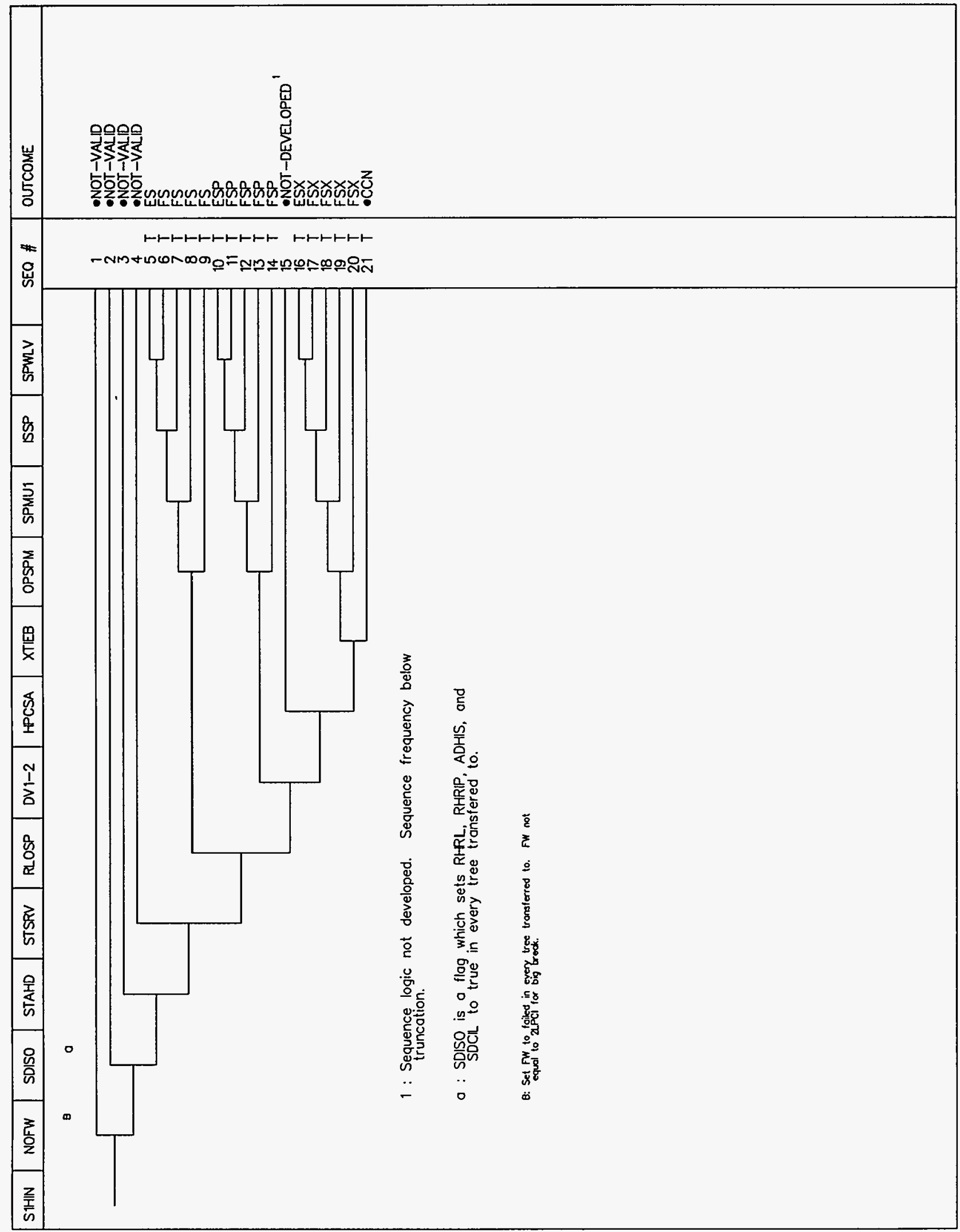

Figure H.2-77 S1HIN Tree

Vol. 2, Part 2

H-171

NUREG/CR-6143 


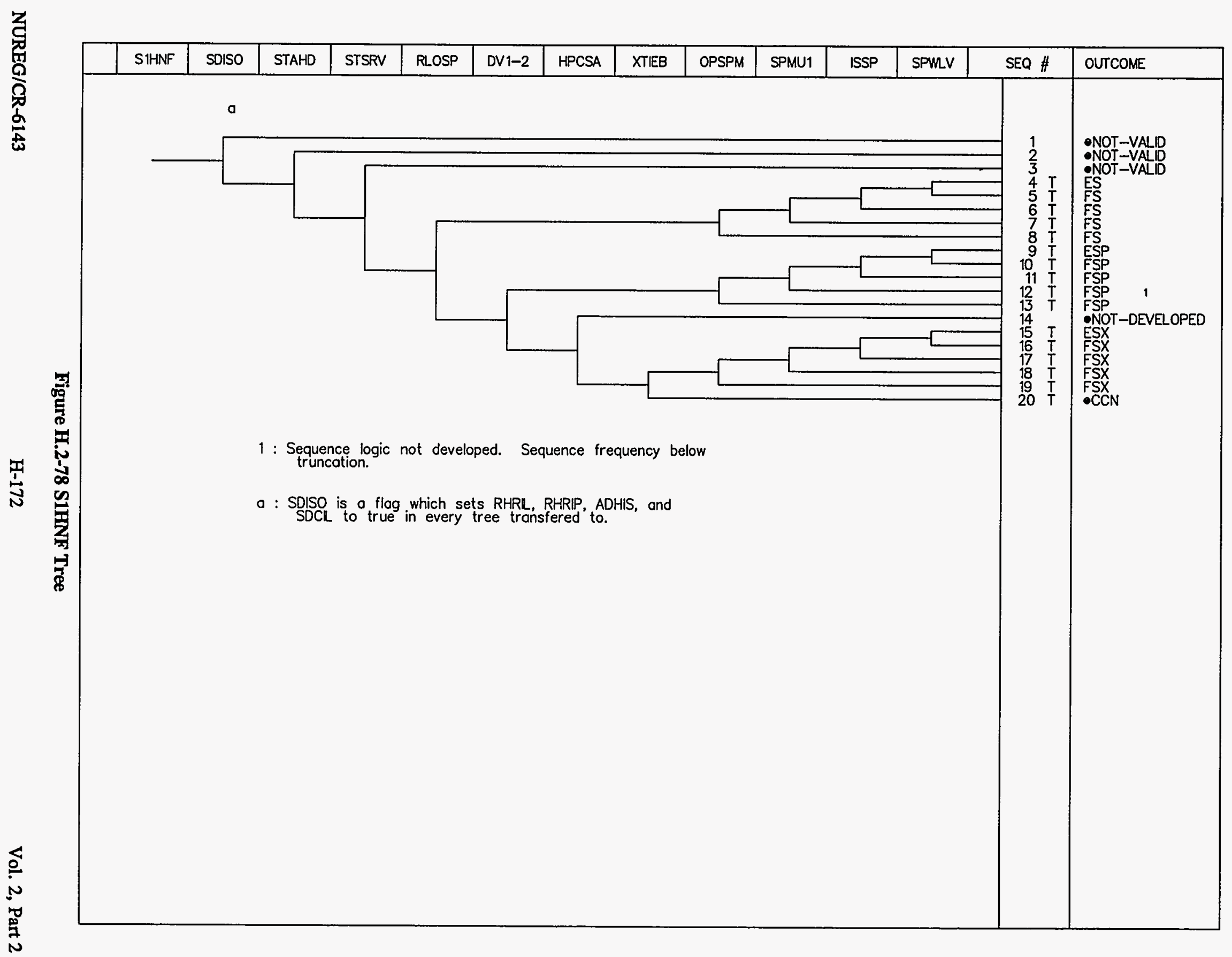




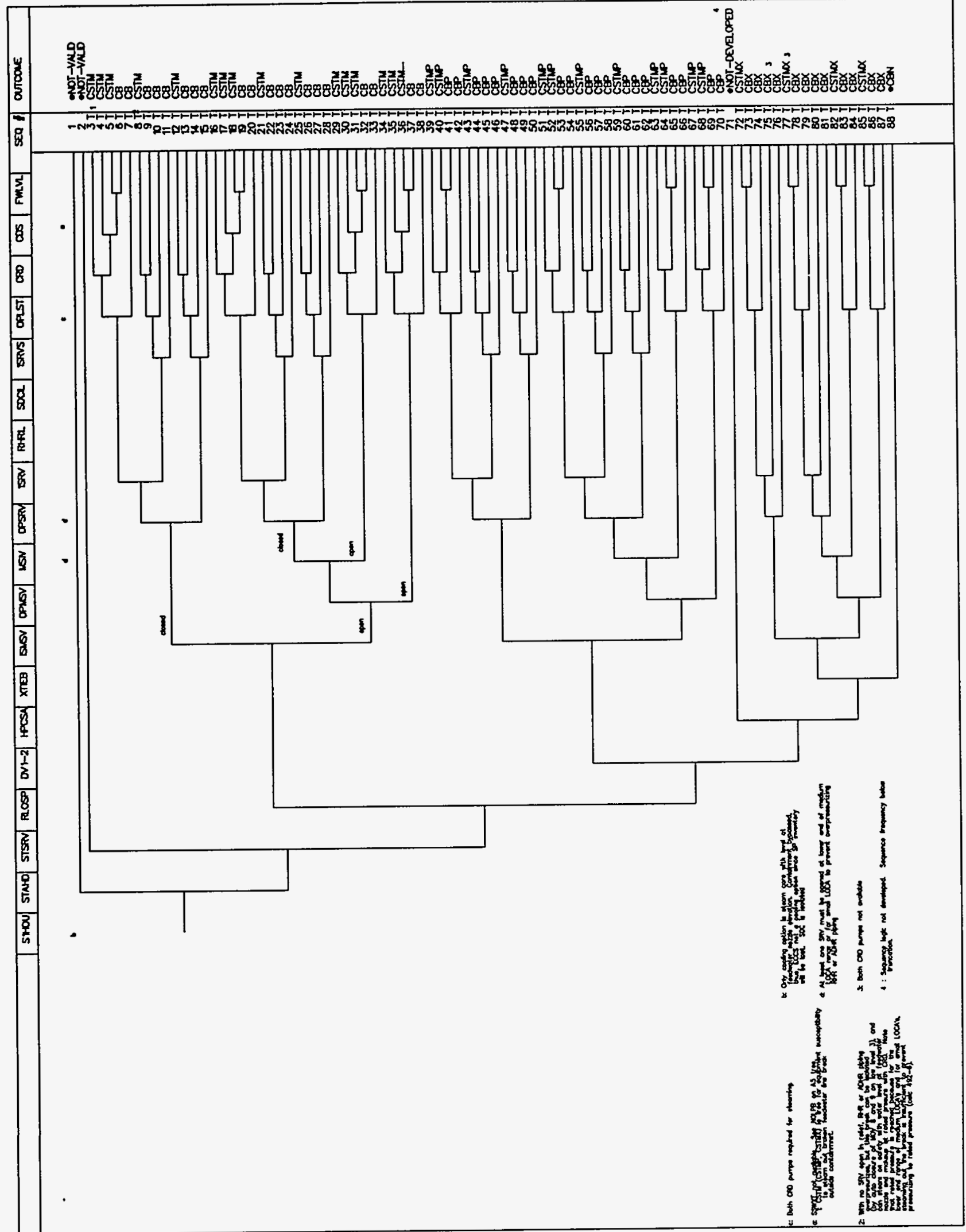

Figure H.2-79 S1HOU Tree 


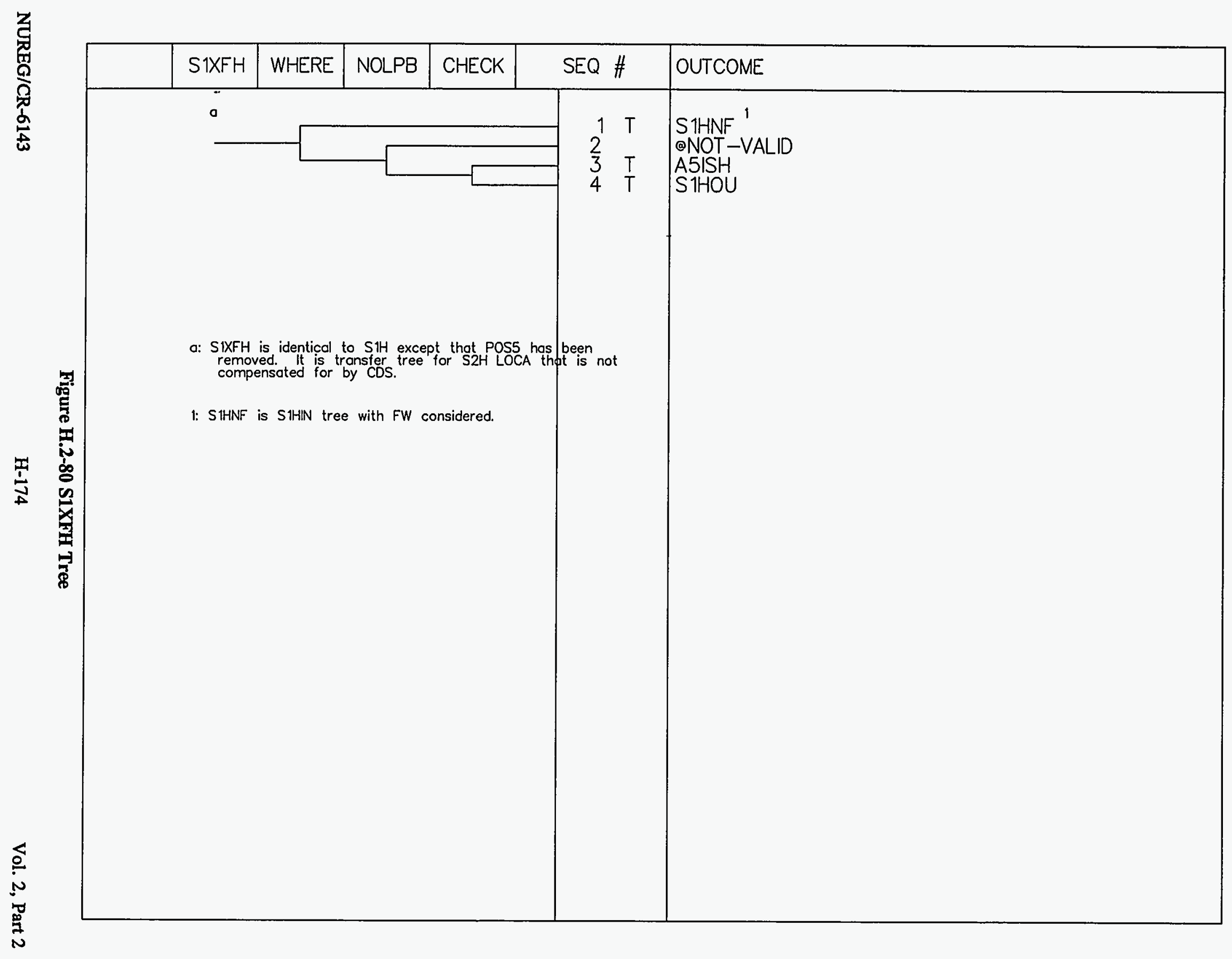




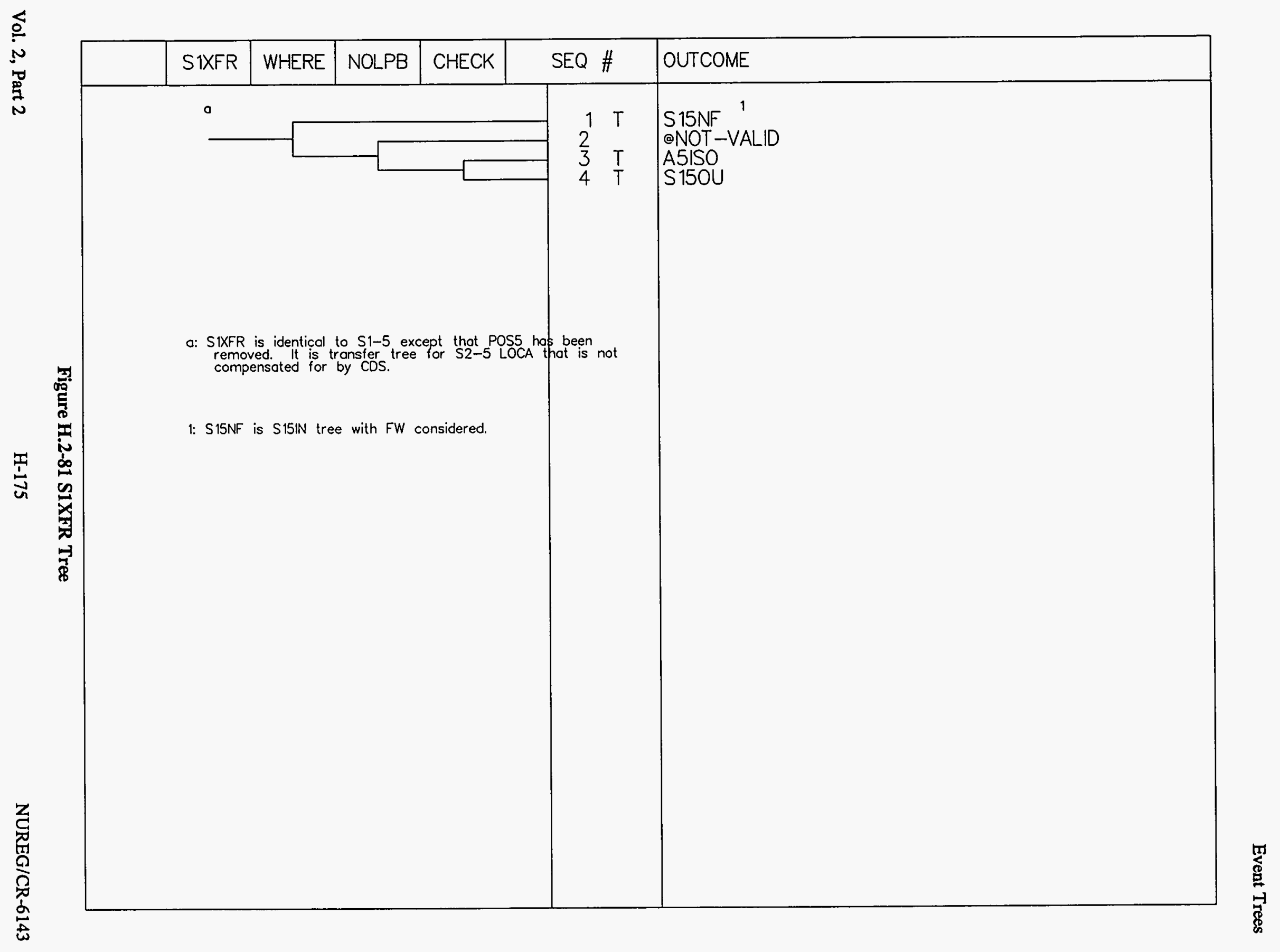


$\cdots$

\section{Event Trees}

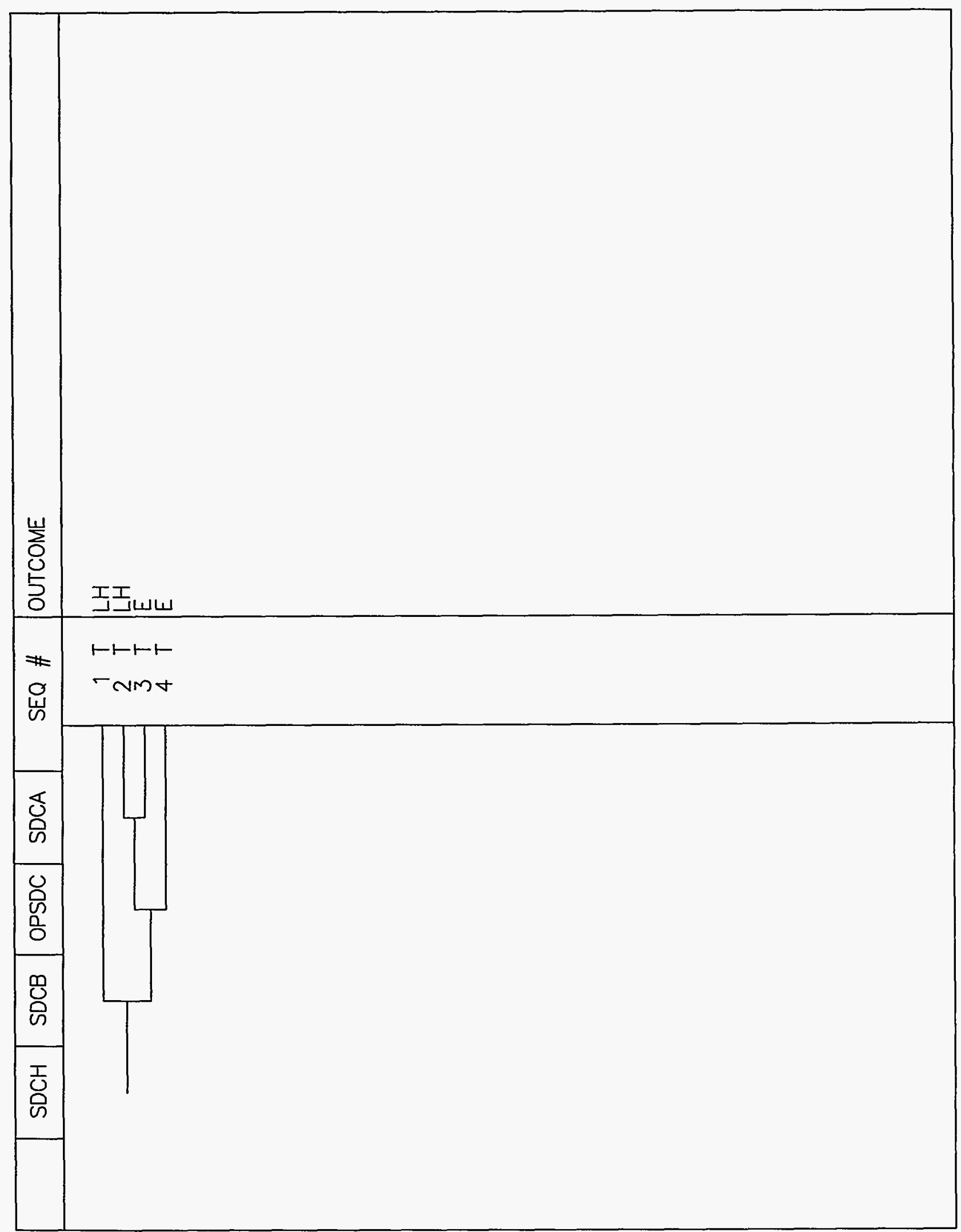

Figure H.2-82 SDCH Tree 


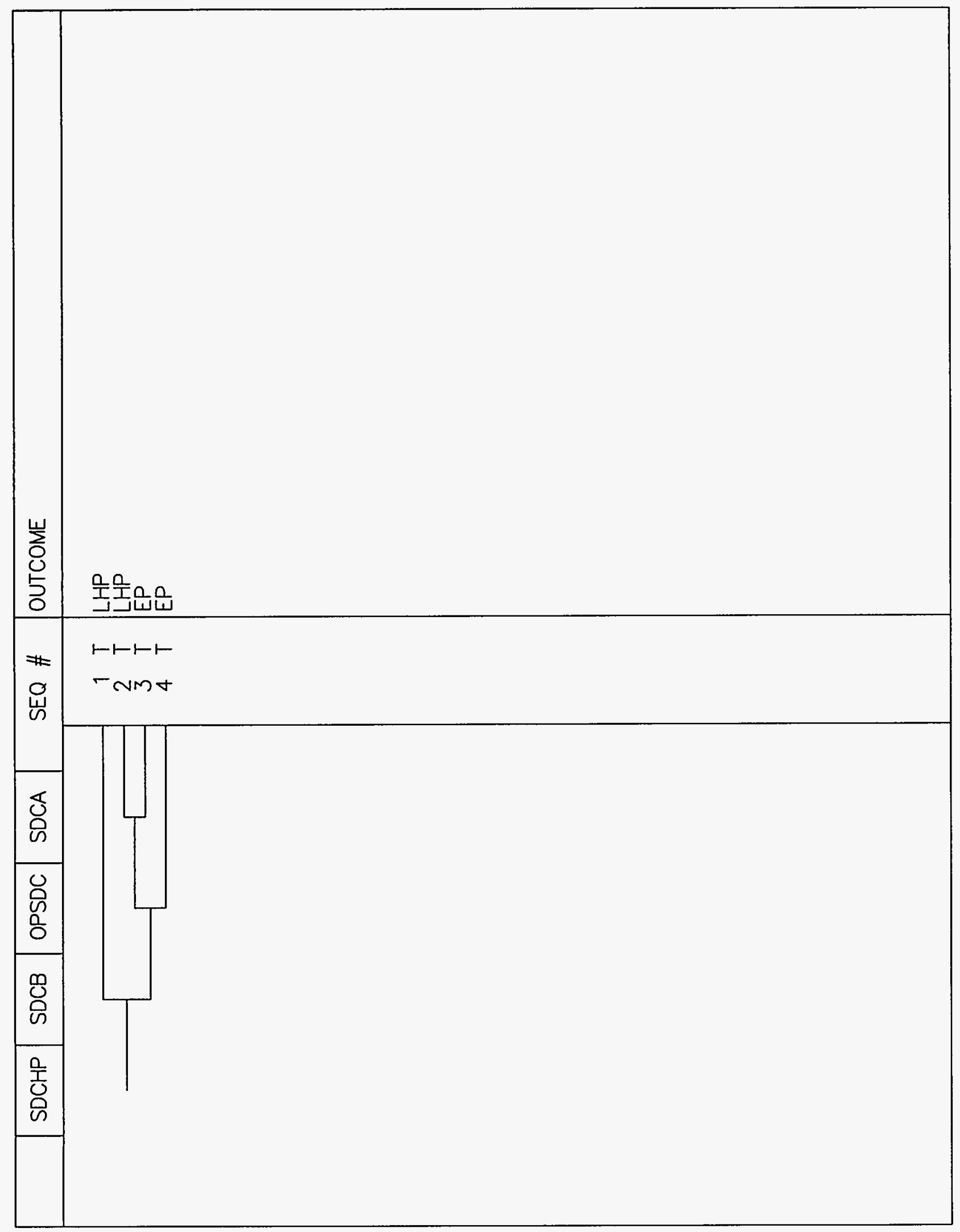

Figure H.2-83 SDCHP Tree

Vol. 2, Part 2 


\section{Event Trees}

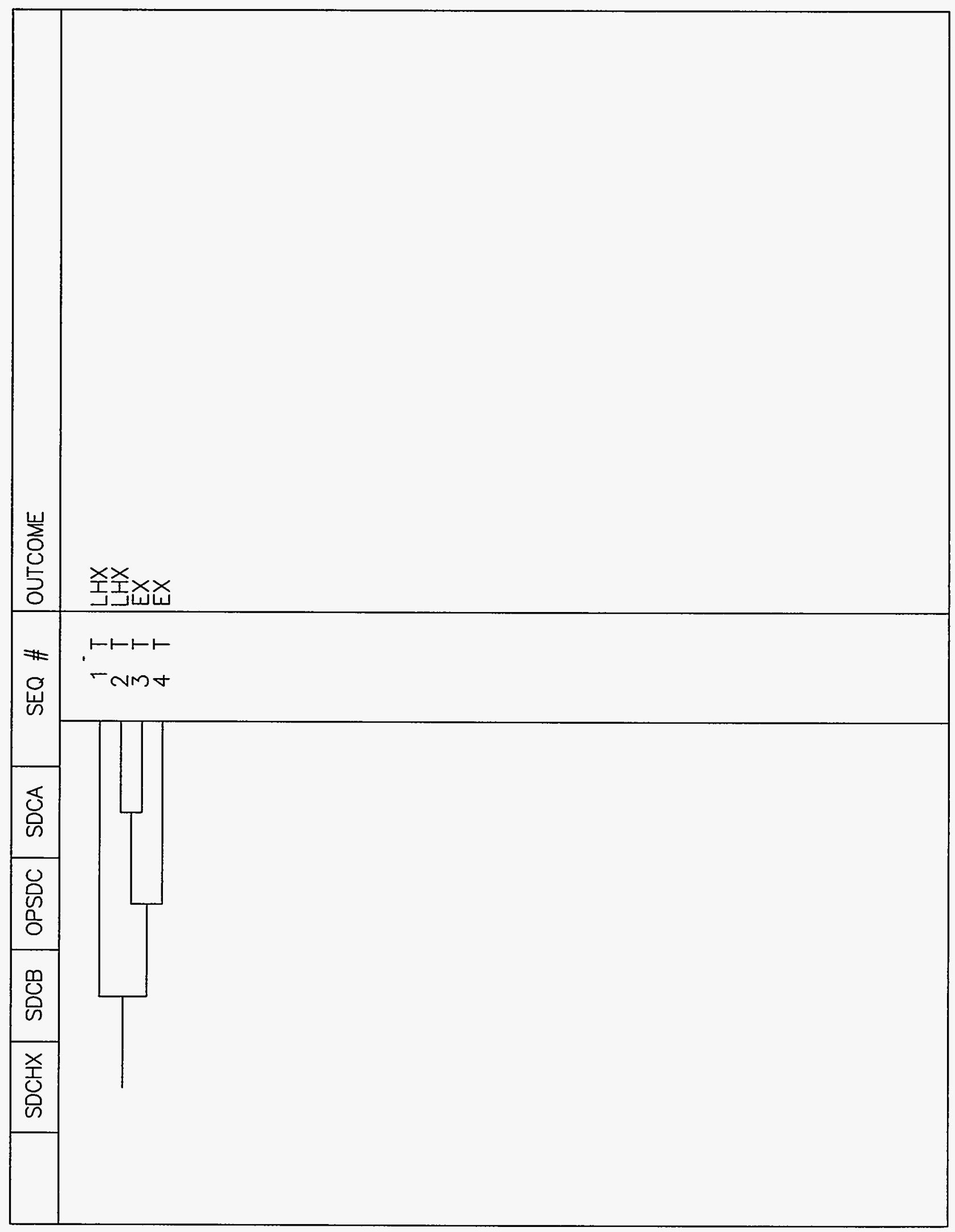

Figure H.2-84 SDCHX Tree 
Kiyoharu Abe

Dept. of Reactor Safety Research Nuclear Safety Research Center

Tokai Research Establishment

JAERI

Tokai-mura, Naga-gun

Ibaraki-ken,

JAPAN

Sarbes Acharya

Department of Energy

NS- 1 / FORS

Washington, DC 20585

Dr. Ulvi Adalioglu

Cekmece Nukleer Arastraima ve Egitim Merekezi

P.K. 1

Havaalani/ISTANBUL

TURKEY

Dr. Eng. Kiyoto Aizawa

Senior Engineer

Reactor Eng. Dev. Department

PNC

9-13, Chome, Akasaka

Minato-K, Tokyo

JAPAN

Harry Alter

Manager Applied Tech

Nuclear Systems Tech

NE - 46

US DOE

Washington, DC 20585

\section{R.M. Andrews}

Nuclear Installations Insp.

St. Peters House

Balliol Raod, Bootle

Merseyside L20 312

UNITED KINGDOM

\section{George Apostolakis}

UCIA

Boelter Hall, Room 5532

LOS Angeles, CA 90024-1597

Director of Reactor Engineering Argonne National Laboratory

9700 S Cass Ave

Bldg 208

Argonne, IL 60439
Ephraim Asculai

Division of Nuclear Safety

Wagramestrasse, 5

P.O. Box 100

A-1400 wien

AUSTRIA

Vladimar Asmolov

Head, Nuclear Safety Department

I. V. Kurchatov Institute of Atomic Enegry

Moscow, 123181

RUSSIA

J. de Assuncao

Cabinete de Proteccao è Seguranca Nuclear

Ministerio da Indusstria

Ave. de Republica 45-6

1000 Lisbon

PORTUGAL

H.P. Balfanz, Head

Institute of Probabilistic Safety Analysis

TUV Nord

Grosse Bahnstrasse 31

D-22525 Hamburg 54

GERMANY

Pat Baranowsky

USNRC - AEOD/TPAB

MS : $T-4 A 9$

Robert A. Bari, Deputy Chairman Dept of Nuclear Energy

Bldg 197C

Brookhaven National Laboratory

Upton, NY 11973

Iibrarian

Technical Information Section Battelle Pacific Northwest Lab P. O. Box 999

Richland, WA 99352

Dr. John Baum

Dept of Nuclear Energy

Radiological Sciences Div Bldg $703 \mathrm{M}$

Brookhaven National Laboratory Upton, NY 11973 
Eric Beckjord

USNRC-RES/DO

MS: T-10FI2

Robert Bernero

USNRC-NMSS/DO

MS : T-8A23

Andrea Besi

Institute for Systems Engineering and Informatics

CEC Joint Research Centre

CP $N 1$

1-21020 Ispra (Varese)

ITALY

John Bickel

Idaho National Engineering Lab.

EG\&G MS : 3850

P.O. Box 1625

Idaho Falls, ID 83415

Vicki Bier

Dept. of Industrial Engineering

University of Wisconsin-Madison

1513 University Avenue, Room 389

Wisconsin, WI 53706

Scott Bigelow

S-CUBED

2501 Yale SE, Suite 300

Albuquerque, NM 87106

Prof. Dr. Dr.-Ing. E. H. Adolf

Birkhofer

Gesellschaft für Anlagen und

Reaktorsicherheit (GRS) $\mathrm{mbH}$

Forschungsgelănde

D-8046 Garching

Federal Republic of Germany

David Black

American Electric Power

1 Riverside Plaza

Columbus, OH 43215

Harold Blackman

Idaho National Engineering Lab.

EG\&G MS : 3850

P.o. Box 1625

Idaho FaIls, ID 83415-3850
Dennis Bley

Buttonwood Consulting

17291 Buttonwood St.

Fountain Valley, CA 92708

Roger Blond

Booz-Allen \& Hamilton

4330 East West Highway

Bethesda, MD 20814

M. P. Bohn

Division 6449

Sandia National Laboratories

Albuquerque, NM 87185

Dr. Mario Bonaca

Manager, Reactor Engineering

Northeast Utilities

P.O. Box 270

Hartford, Conn. 06141

Robert B. Borsum

Nuclear Power Division

$B$ \& W Nuclear Tech

1700 Rockville Pike

Suite 525

Rockville, MD 20852

Stephen Boult

Electrowatt Engineering Services (JK) Ltd.

Grandford House

16 Carfax, Horsham

West. Sussex RH12 IUP

ENGLAND

Gary Boyd

Safety \& Reliability Optimization Services

9724 Kingston Pike, Suite 102

Knoxville, TN 37922

Brookhaven National Laboratory

Attn: Lev Neymotin

Building 130

Arthur Tingle

Upton, NY 11973

David M. Brown

Paul C. Rizzo Associates, Inc. 300 Oxford Drive

Monroeville, PA 15146-2347 
Tom D. Brown

Sandia National Laboratories

Dept. 6413

P.O. Box 5800

Albuquerque, NM 87185

Robert J. Budnitz

Future Resources Associates, Inc. 2039 Shattuck Avenue, Suite 402

Berkeley, CA 94704

Gary Burdick

USNRC-RES/SAIB

MS: IT-10F13

Arthur Buslik

USNRC-RES/PRAB

MS : T-9F31

Edward Butcher

USNRC-NRR/SPSB

MS : O-10E4

Technical Library

$B \& W$ Nuclear Service Co

P. O. Box 10935

Lynchburg, VA 24506

Stefaan Caeymaex

Safety \& Systems section

Nuclear Generation Dept.

TRACTEBEL

Avenue Ariane 7

B-1200 Bruxelles

BELGIUM

Leonard Callan, Administrator U.S. Nuclear Regulatory Commission Harris Tower and Pavilion

611 Ryan Plaza Drive, Suite 400

Arlington, TX 76011-8064

J. Calvo

Division of PSA \& Human Factors

Consejo de Seguridad Nuclear

Calle Justo Dorado, 11

28040 Madrid

SPAIN

\author{
A. I. Camp \\ Division 6412 \\ MS : 0748 \\ Sandia National Laboratories \\ Albuquerque, NM 87185-0748
}

John Forbes Campbel

HM Superintending Inspector

Health \& Safety Executive

St. Peter's House

Balliol Road

Bootle L20 312

UNITED KINGDOM

Leonel Canelas

New University of Lisbon

Quinta de Torre

2825 Monte de Caparica

PORTUGAL

Harold Careway

General Electric Co., M/C 754

175 Curtner Ave.

San Jose, CA 95129

D. D. Carlson

Division 6411

Sandia National Laboratories

Albuquerque, NM 87185

Jose E. De Carlos

CSN International Coordinator

Consejo de Seguridad Nuclear

Calle Justo Dorado 11

28040 Madrid

SPAIN

Annick Carnino

International Atomic Energy Agency

Wagramerstrasse 5, P.O. BOX 100

A-1400 Vienna

AUSTRIA

S. Chakraborty

Swiss Federal Nuclear Safety Inspectorate

Hauptabteilung für die Sicherheit der Kernanlagen

$\mathrm{CH}-5232$ Villigen-HSK

SWITZERIAAND

Erulappa Chelliah

USNRC-RES/PRAB

MS : T-9F31

Dist -3 
G. Diederick

Commonwealth Bdison Co.

Lasalle County Station

RR1, Box 220

2601 North 21at Rd.

Marsielles, IL 61341

Chuck Dobbe

Idaho National Bngineering Lab.

EG\&G MS: 3840

P.O. Box 1625

Idaho Falls, ID 83415

Mary Drouin

USNRC-RBS \SAIB

MS : T-10F13

Duke Power Co. (2)

Attn: Duncan Brewer Steve Deskevich

422 South Church Street

Charlotte, NC 28242

\section{Bill Eakin}

Northeast 0tilities

Box 270

Hartford, CT 06141

Stewart D. Bbneter

OSNRC

101 Marietta St., Suite 2900

Atlanta, GA 30323-0199

Adel A. Bl-Bagsioni

USNRC - NRR/PRAB

MS : O-10B4

BNBA/DISP (2)

Attn: Alvaro Valeri Alfredo Bottino

Via Vitaliano Brancati, 48

00144 Roma BUR

ITALY

Walter P. Engel

PRAG MGR Analysis \& Reg Matter $\mathrm{NE}-60$

CRYCITY

US DOE

Washington, DC 20585
John Flack

USNRC-RBS/SAIB

MS : $T-10 \mathrm{~F} 13$

Karl Fleming

Pickard, Lowe \& Garrick

2260 University Drive

Newport Beach, CA 92660

Terry Foppe

Safety Analysis Engineering

Rocky Flats Plant

Bnergy Systems Group

Rockwell International Corp

P.O. Box 464

Golden, CO 80401

R H. Gauger

Manager-Reliability Bngr

A/B Div

Holmes \& Narver Inc.

$R$ Roanne Circle

Irvine, CA 92714

Robert Gobel

Clark University

Center for Technology, Environment and Development

950 Main St.

Worcester, MA 01610-1477

Paul Govaerts

Studiecentrum voor Kernenergie

(SCK/CEN)

Boeretang, 200

B-2400 $\mathrm{MOl}$

BELGIUM

Mr. Gubler

Internationai Atomic Bnergy Agency NBNS / SAD BO842

Wagramerstrasse 5, P.0. Box 100

A-1140 Vienna

AUSTRIA

Paul M. Haas, President

Concord Associates, Inc.

725 Pellissippi Parkway

Suite 101, Box 6

Knoxville, TN 37933 


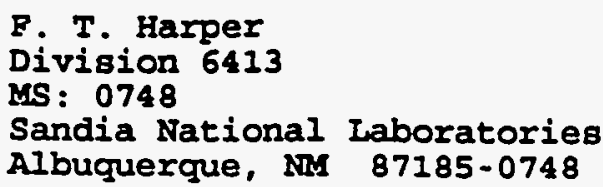

Dr. U. Hauptmanns

Gesellschaft Fùr Anlagen und Reaktorsicherheit (GRS) mgH Schwertnergasse 1

D-5000 Koln 1

GERMANY

Sharif Heger

ONM Chemical and Nuclear Bngineering Department

Farris Engineering, Roon 209

Albuquerque, NM 87131

Jon C. Helton

Dept. of Mathematica

Arizona State University

Tempa, AZ 85287

Dr. P. M. Herttrich

Gesellschaft für Anlagen und

Reaktorsicherheit (GRS) $\mathrm{mbH}$

Schwertnergasse 1

5000 Koln 1

GERMANY

Dr. D.J. Higson

Radiological Safety Bureau

Australian Nuclear Science \& Technology Organisation P.O. Box 153

Roseberry, NSW 2018

AUSTRAIIA

Dr. Mitsumasa Hirano

Deputy General Manager Institute of Nuclear Safety NUPBC

3-6-2, Toranomon, Minato-ku Tokyo 108

JAPAN

Dr. S. Hirschberg

Paul Scherrer Institute

Vurenlingen and villigen

CH-5232 Villigen PSI

SWITZERIAND
Steven Hodge

Oak Ridge National Laboratories

P. O. BOX $Y$

Oak Ridge, TN 37831

Gary Holahan

USNRC-AEOD/OSP

MS : $T-4 A 9$

N.J. Holloway

A72.1

Atomic Weapons Bstablishment

Ademaston

Reading RG7 4PR

UNITED KINGDOM

Griff Holmes

Westinghouse Blectric Co.

Bnergy Center Bast

Bldg. 371

P.O. BOX 355

Pittsburgh, PA 15230

William Hopkins

Bechtel Power Corporation

15740 Shady Grove Road

Gaithersburg, MD 20877

Dean Houston

USNRC-ACRS

MS : $\mathrm{P}-315$

Der-Yu Hsia

Institute of Nuclear Bnergy Research

Lung-Tan 325

TAIKAN

Alejandro Huerta-Bahena

National Commission on Nuclear Safety and Safeguards (CNSNS)

Insurgentes Sur N. 1776

C. P. 04230 Mexico, D. F. MRXICO

Peter Humphreys

US Atomic Bnergy Authority

Wigshaw Lane, Culcheth

Warrington, Cheshire

UNITED KINGDOK, WA3 4NE 
w. Huntington

Commonwealth Edison Co.

Lasalle County Station

RR1, BOx 220

2601 North 21st Rd.

Marsielles, IL 61341

J.S. Hyslop

USNRC-RES/PRAB

MS : T-9F31

Idaho National Engineering Lab.

Attn: Doug Brownson

Darrel Knudson

EG\&G MS: 3840

P.O. Box 1625

Idaho Falls, ID 83415

Idaho National Engineering Lab. (2)

Attn: Art Rood

Mike Abbott

EG\&G MS : 2110

P.O. Box 1625

Idaho Falls, ID 83415

Hanspeter Isaak

Abteilung Strahlenschutz

Hauptabteilung für die Sicherheit der Kernanlagen (HSK)

$\mathrm{CH}-5303$ Wurenlingen

SWITZERLAND

Brian Ives

UNC Nuclear Industries

P. O. Box 490

Richland, WA 99352

Kamiar Jamili

DP-62/FTN

Department of Energy

Washington, D.C. 20585

Robert Jones

USNRC-NRR/DSSA

MS : $0-8 \mathrm{E} 1$

Edward Jordan

USNRC - AEOD/DO

MS : $T-4 D 18$
Dr. H. Kalfsbeek

$\mathrm{DG} / \mathrm{XII/D/I}$

Commission of the European

Communities

Rue de la Loi, 200

B-1049 Brussels

BELGIUM

Yoshio Kano

General Mngr. \& Sr. Engineer

Systems Analysis Section

O-arai Engineer. Centr, PNC

Higashi - Ibaraki-gun

Ibaraki-Ken, 133-13

JAPAN

William Kastenberg

UCLA

Boelter Hall, Room 5532

Los Angeles, CA 90024

Barry Kaufer

$\mathrm{OECD} / \mathrm{NEA}$

"Le Seine St. Germain" 12

Boulevard des Iles

92130 Issy-les-Moulineaux

FRANCE

Paul Kayser

Division de la Radioprotection

Avenue des Archiducs, 1

L-1135 Luxembourg-Belair

LUXEMBOURG

Ken Keith

TVA

W 20 D 201

400 West Surmnit Hill

Knoxville, TN 37092

G. Neale Kelly

Commission of the Buropean Communities

Joint Research Centre

Rue de la Loi 200

B-1049 Brussels

BELGIUM

John Kelly

Sandia National Laboratories

P. O. Box 5800

MS 0742

Albuquerque, NM 87185 
Knolls Atomic Power Laboratory (2)

Attn: Ken McDonough Dominic Sciaudone

Box 1072

Schenectady, NY 12301

Dr. K. Koberlein

Gesellschaft für

Reaktorsicherheit $\mathrm{mbH}$

Forschungsgelände

D-8046 Garching

GERMANY

Alan Kolaczkowski

Science Applications International Corporation

2109 Air Park Rd. S. E.

Albuquerque, NM 87106

Jim Kolanowski

Commonwealth Edison Co.

35 1st National West

Chicago, IL 60690

John G. Kollas

Institute of Nuclear Technology and

Radiation Protection

N.R.C.P.S. "Demokritos"

P.O. Box 60228

GR-153 10 Aghia Paraskevi

Attiki

GREECE

S. Kondo

Department of Nuclear Engineering

Facility of Engineering

University of Tokyo

3-1, Hongo 7, Bunkyo-ku

Tokyo

JAPAN

D. Lamy

CEN/SCK

Dept. Scientific Irradiation

Experiment \& Study BR2

Boeretang, 200

B-2400 Mol

BELGIUM

\author{
Dr. J.M. Lanore \\ CEA/IPSN/DAS \\ Centre d'Etudes Nucléaires de \\ Fontenay-aux-Roses \\ B.P. $n^{\circ} 6$ \\ 92265 Fontenay-aux-Roses CEDEX \\ FRANCE
}

Jose A. Lantaron

Consejo de Seguridad Nuclear

Sub. Analisis y Evaluaciones

Calle Justo Dorado, 11

28040 Madrid

SPAIN

Josette Iarchier-Boulanger

Electricte de France

Direction des Etudes Et Recherches

30, Rue de Conde

75006 Paris

FRANCE

H. Larsen

Head of Department

Riso National Laboratory

P.O. Box 49

DK-4000 Roskilde

DENMARK

Lawrence Livermore Nat'I Lab. (4)

Attn: George Greenly

Marvin Dickerson

Rolf Lange

Sandra Brereton

Livermore, CA 94550

Shengdar Lee

Yankee Atomic Electric Company

580 Main St.

Boston, MA 17407

B.T.F. Liwaang

Dept. of Plant Safety Assessment

Swedish Nuclear Power Inspec.

P.O. Box 27106

S-10252 Stockholm

SWEDEN

Peter Lohnberg

Expresswork International, Inc.

1740 Technology Drive

San Jose, CA 95110 
Steven $M$. Long

USNRC-NRR/SPSB

MS : $0-10 E 4$

D. Eugenio Gil Lopez

Consejo de Seguridad Nuclear

Calle Justo Dorado, 11

28040 Madrid

SPAIN

Los Alamos National Laboratory (2)

Attn: Kent Sasser

$\mathrm{N}-6, \mathrm{~K}-557$

Los Alamos, NM 87545

Christiana $H$. Lui

USNRC-RES/PRAB

MS : $T-9 F 31$

John Iuke

Florida Power \& Light

P.O. Box 14000

Juno Beach, FL 33408

\section{Daniel Manesse}

ISPN

Boite Postale $n^{0} 6$

92265 Fontenay-aux-Roses CEDEX

FRANCE

Fred Mann

Westinghouse Hanford Co.

WIA - 53

P.O. Box 1970

Richland, WA 99352

Nadia Soido Falcao Martins

Comissao Nacional de Energia Nuclear

$R$ General Severianao 90 S/408-1

Rio de Janeiro

BRAZIL

Harry F. Martz

Analysis and Assessment Division

Los Alamos National Laboratory

Los Alamos, NM 87545

Herbert Massin

Commonweal.th Edison Co.

35 Ist National West

Chicago, IL 60690
Hideo Matsuzuru

Tokai Research Establishment

Tokai - mur

Maka-gun

Ibaraki-ken, 319-11

JAPAN

Jim Mayberry

Ebasco Services

60 Chubb Ave.

Iyndhurst, NJ 07071

Andrew S. MCClymont IT-Delian Corporation

1340 Saratoga-Sunnyvale Rd.

Suite 206

San Jose, CA 95129

Michael Mckay

Los Alamos National Laboratory

A-1, MS F600 Services

P.O. Box 1663

Los Alamos, NM87545

Zen Mendoza

SAIC

5150 El Camino Real

Suite C3 1

Los Altos, CA 94022

Dr. J. Mertens

Division of Risk Analysis \& Reactor Technology

Institute of Safety Research

Research Centre Julich (KFA)

D-52425 Julich

GERMANY

Jim Meyer

Scientech

11821 Parklawn Dr.

Suite 100

Rockville, MD 20852

Joe Minarick

Science Applications Int'l Corp.

301 Laboratory Road

P.O. Box 2501

Oak Ridge, TN 37830

Dist-9 
Jose I. Calvo Molins, Head

Division of P.S.A. and Human Factors

Consejo de Seguridad Nuclear

Calle Justo Dorado, 11

28040 Madrid

SPAIN

Ken Muramatsu

Risk Analysis Laboratory

Japan Atomic Energy Research

Institute

Tokai-mura, Naka-gun

Ibaraki-ken, 319-11, Tokyo

JAPAN

Joseph A. Murphy

Division of Safety Issue Resolution

U.S. Nuclear Regulatory Commission MS : T-10E50

Washington, DC 20555

Kenneth G. Murphy, Jr.

US Department of Energy

19901 Germantown Rd.

Germantown, MD 20545

Shankaran Nair

Central Electricity

Generating Board

Berkeley Nuclear Laboratories

Berkeley

Gloucestrshire CI13 9PB

UNITED KINGDOM

Ray Ng

NEI

1776 Eye St. N

Suite 300

Washington, DC 20006-2496

G. Niederauer

Los Alamos National Laboratory

P. O. Box 1663

MSK 575

Los Alamos, NM 87545

Oak Ridge National Laboratory

(2)

Attn: Steve Fisher

Sherrel Greene

MS - 8057

P.O. Box 2009

Oak Ridge, TN 37831
Ken O'Brien

University of Wisconsin

Nuclear Engineering Dept.

153 Engineering Research Blvd.

Madison, WI 53706

Theresa Oh

INEL Tech Iibrary

EG\&G MS : 2300

P. O. Box 1625

Idaho Falls, ID 83415-2300

N. R. Ortiz, Director

Nuclear Energy Technology

Division 6400

Sandia National Laboratories

Albuquerque, NM 87185

Robert Ostmeyer

U.S. Department of Energy

Rocky Flats Area office

P. O. Box 928

Golden, CO 80402

Robert Palla

USNRC - NRR/SPSB

MS : 0-10E4

Gareth Parry

NUS Corporation

910 Clopper Rd.

Gaithersburg, MD 20878

Vern Peterson

Building T886B

EG\&G Rocky Flats

P.O. Box 464

Golden, CO 80402

G. Petrangeli

ENEA Nuclear Energy ALT Disp

Via V. Brancati, 48

00144 Rome

ITALY

Ing. Jose Antonio Becerra Perez

Comision Nacional De Seguridad

Nuclear $Y$ Salvaguardias

Insurgentes Sur 1806

01030 Mexico, D. F.

MEXICO 
William T. Pratt

Brookhaven National Laboratory

Building 130

Upton, NY 11973

Urho Pulkkinen

Technical Research Centre of Finland

Laboratory of Electrical \& Automation Engineeering Otakaari 7B, 02150 Espoo 15 FINLAND

Blake Putney

Science Applications

International Corporation

5150 El Camino Real, Suite C31

LOs Altos, Ca 94022

Dr. V. M. Raina

Project Manager-Risk Assessment

Ontario Hydro $\mathrm{HII}$ GI

700 University Ave.

Toronto, Ontario MSG $1 \times 6$

CANADA

William Raisin

NEI

1726 M. St. NW

Suite 904

Washington, DC 20036

Ann Ramey-Smith

USNRC-RES/PRAB

MS : T-9F3I

Dale Rasmuson

USNRC-AEOD/TPAB

MS : T-4A9

John Ridgely

USNRC-RES/SAIB

MS : $\mathrm{T}-10 \mathrm{~F} 13$

Richard Robinson (2)

USNRC - RES / PRAB

MS : T-9F31
M. Roch

Manager of Design, Nuclear

Department

TRACTEBEL

Avenue Ariane 7

B-1200 Bruxelles

BELGIUM

A.E. Rogers

General Electric Co

175 Curtner Ave

MC -489

San Jose, CA 95125

Judy Rollstin

GRAM InC

8500 Menual Blvd. NE

Albuquerque, NM 87112

Marc Rothschild

Halliburton NUS

$1303 \mathrm{~S}$. Central Ave.

Suite 202

Kent, WA 98032

Christopher Ryder

USNRC-RES/PRAB

MS : $\mathrm{T}-9 \mathrm{~F} 31$

Takashi Sato, Deputy Manager

Nuclear Safety Engineering Section

Reactor Design Engineering Dept.

Nuclear Energy Group, Toshiba Corp.

Isogo Engineering Center

8, Shinsugita-cho, Isogo-ku,

Yokohama 235, JAPAN

Martin Sattison

Idaho National Engineering Lab.

P. O. Box 1625

Idaho Falls, ID 83415

Dr. U. Schmocker

Hauptabteilung für die

Sicherheit der Kernanlagen

$\mathrm{CH}-5232$ Villigen HSK

SWITZERLAND

A.J. Seebregts

ECN Nuclear Energy

Westerduinweg, 3

Postbus 1

NL-1755 Petten ZG

THE NETHERI.ANDS 
Dr. S. Serra

Ente Naxionale per I'Energia

Electtrica (ENEI)

via G.B. Martini 3

I-00198 Rome

ITALY

H. Shapiro

Licensing \& Risk Branch

Atomic Energy of Canada Ltd.

Sheridan Park Research Comm.

Mississauga, Ontario L5K 1B2

CANADA

Nathan 0. Siu

Center for Reliability and Risk Assessment

Idaho National Engineering Lab. EG\&G MS : 3850

P.O. Box 1625

Idaho Falls, ID 83415-3855

E. Soederman

ES-Konsult $A B$

Energy and Safety

P.O. Box 3096

S-16103 Bromma

SWEDEN

Desmond Stack

Los Alamos National Laboratory

Group Q-6, Mail Stop K556

Los Alamos, NM 87545

Jao Van de Steen

KEMA Laboratories

Utrechtseweg, 310

Postbus 9035

NL 800 ET Arnhem

THE NETHERLANDS

Eli Stern

Israel AEC Licensing Div.

P.O. Box 7061

Tel-Aviv 61070

ISRAEI

Dr. Egil Stokke

Advisory Group

OECD Halden Reactor Project

P.O. Box 173

N-1751 Halden

NORWAY
Stone \& Webster Engineering Corp

Technical Information Center

A. Hosford

245 Summer Street

245/01

Boston, MA 02210

\section{Dennis Strenge}

Pacific Northwest Laboratory

RTO/ 125

P.O. Box 999

Richland, WA 99352

Technadyne Engineer. Consultants (3)

Attn: David Chanin Jeffery Foster

Suite A225 Walt Murfin

8500 Menual Blvd. N

Albuquerque, NM 87112

Ashok Thadani

USNRC-NRR/ADT

MS : $0-12 \mathrm{G} 18$

T. G. Theofanous

University of California, S. B.

Department of Chemical and Nuclear Engineering

Santa Barbara, CA 93106

Catherine Thompson

USNRC-RES/SAIB

MS : T-10F13

Soren Thykier-Nielsen

Riso National Laboratory

Postbox 49

DK4000 Roskile

DENMARK

R. Toossi

Physical Research, Inc.

25500 Hawthorn Blvd.

Torrance, CA 90505

Ennio Traine

ENEL

Via Vialiano, 48

00144 Rome

ITALY 
Ulf Tveten

Environmental Physics Section Institutt for Energiteknikk , Postboks 40

N-2007 Kjeller

NORWAY

US Department of Energy

Energy Library

Room G $034 / G T N$

$A D-622.1$

Washington, DC 20585

US Department of Energy

NS -50 (GTN)

NS -10.1

S- 161

Washington, DC 20585

U.S. Environmental Protection Agency (2)

Attn: Allen Richardson Joe Logidon

Office of Radiation Programs

Environmental Analysis Division Washington, DC 20460

Harold VanderMolen

USNRC - RES / PRAB

MS : $\quad \mathrm{T}-9 \mathrm{~F} 31$

Dr. A. Valeri

A.N.P.A.

Via Vitaliano Brancati, 48

I-00144 Rome

ITALY

Magiel F. Versteeg

Ministry of Social Affairs and Employment

P.O. Box 90804

2509 LV Den Haag

THE NETHERLANDS

Martin Virgilio

USNRC - NRR/DSSA

MS : $0-8 \mathrm{E2}$

R. Virolainen, (Chairman PWG5)

Systems Integ. Off. (STUK)

P.O. Box 268

Kumpulanite 7

SF-60101 Helsinki

FINLAND
Seppo Vuori

Technical Research Centre of Finland Nuclear Engineering Laboratory

Lonnrotinkatu 37

P.O. Box 169

Sf-00181 Helsinki 18

FINLAND

Dr. Ian B. Wall

81 Irving Avenue

Atherton, CA 94027

Edward Warman

Stone \& Webster Engineering Corp.

P.O. BOX 2325

Boston, MA 02107

J.E. Werner

Reactor Research \& Techn Division US DOE Idaho Operations

MS : 1219

850 Energy Drive

Idaho Falls, ID 83401-1563

Dr. Wolfgang Werner

Safety Assessment Consulting $\mathrm{GmbH}$ Veilchenweg 8

D 83254 Breitbrunn GERMANY

Westinghouse Electric Corp

Technical Library

P. O. Box 355

East 209

Pittsburgh, PA 15230

Westinghouse Electric Corp

NTD

Central File Nuclear Safety

P. O. Box 355

408 1-A

Pittsburgh, PA 15230

Westinghouse Electric Company (3)

Attn: John Lacovin

Burt Morris

Griff Holmes

Energy Center East, Bldg. 371

P.O. Box 355

pittsburgh, DA 15230

Dist -13 


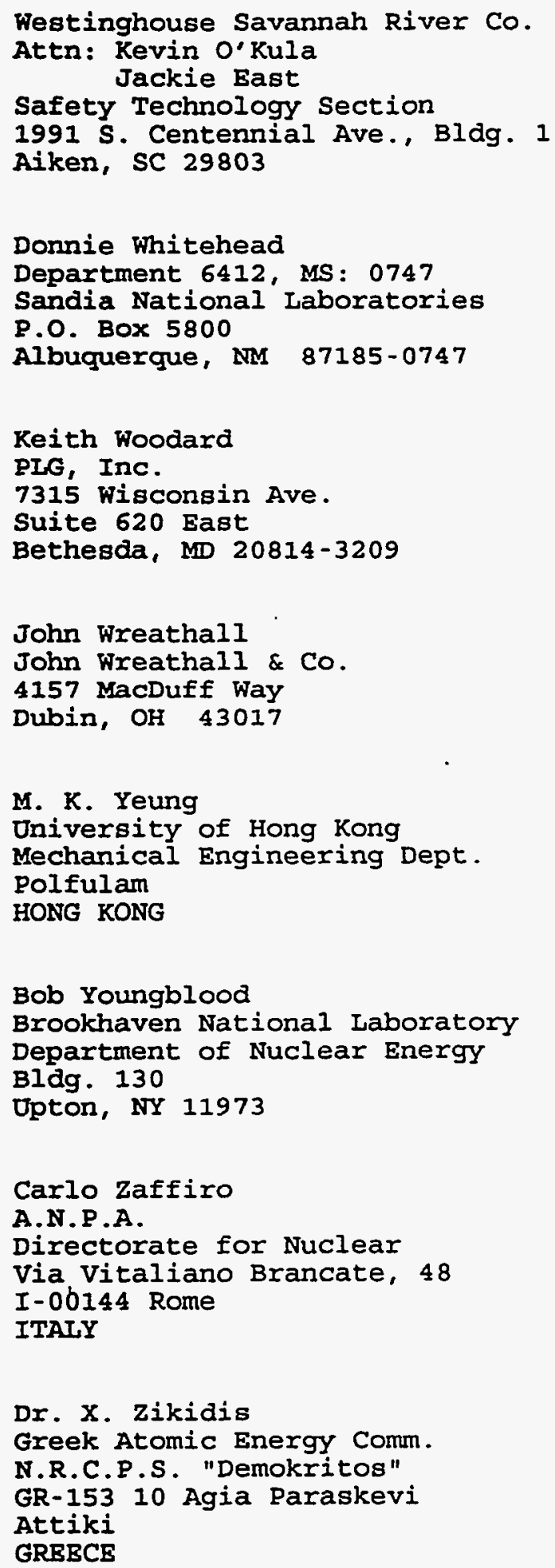

(2)

MS0747

MS0747

MS0747

MS0747

MS0747

MS0747

MS0747

MS0747

MS0747

MS0747

MS0747

MS0747

MS0747

MS0748

MS0748

MS0737

MS0737

MS0742

MS0736

MS9018

MS0899

MS0619
A. L. Camp, 6412

G. L. Benavides, 6412

V. J. Dandini, 6412

S. L. Daniel, 6412

S. E. Dingman, 6412

J. A. Forester, 6412

K. M. Hays, 6412

H. K. Kirk, 6412

D. B. Mitchell, 6412

J. Pfarner, 6412

B. D. Staple, 6412

D. W. Whitehead, 6412 (20)

G. D. Wyss, 6412

F. T. Harper, 6413

T. D. Brown, 6413

M. P. Bohn, 6449

J. A. Lambright, 6449

J. E. Kelly, 6414

N. R. Ortiz, 6400

Central Technical Files, 8523-2

Technical Library, 7141 (5)

Technical Publications, 7151 